\title{
Long View (41RB112): Data Recovery of Two Plains Village Period Components in Roberts County, Texas, Volume 1
}

\author{
J. Michael Quigg \\ Paul M. Matchen \\ Charles D. Frederick \\ Robert A. Ricklis \\ Brittney Gregory
}

See next page for additional authors

Follow this and additional works at: https://scholarworks.sfasu.edu/ita

Part of the American Material Culture Commons, Archaeological Anthropology Commons, Environmental Studies Commons, Other American Studies Commons, Other Arts and Humanities Commons, Other History of Art, Architecture, and Archaeology Commons, and the United States History Commons

Tell us how this article helped you.

This Article is brought to you for free and open access by the Center for Regional Heritage Research at SFA ScholarWorks. It has been accepted for inclusion in Index of Texas Archaeology: Open Access Gray Literature from the Lone Star State by an authorized editor of SFA ScholarWorks. For more information, please contact cdsscholarworks@sfasu.edu. 


\title{
Long View (41RB112): Data Recovery of Two Plains Village Period Components in Roberts County, Texas, Volume 1
}

\author{
Authors \\ J. Michael Quigg, Paul M. Matchen, Charles D. Frederick, Robert A. Ricklis, Brittney Gregory, David Maki, \\ and Mark Bateman

\section{Licensing Statement} \\ This is a work for hire produced for the Texas Department of Transportation (TxDOT), which owns all \\ rights, title, and interest in and to all data and other information developed for this project under its \\ contract with the report producer. The report may be cited and brief passages from this publication may \\ be reproduced without permission provided that credit is given to TxDOT and the firm that produced it. \\ Permission to reprint an entire chapter, section, figures or tables must be obtained in advance from the \\ Supervisor of the Archeological Studies Branch, Environmental Affairs Division, Texas Department of \\ Transportation, 125 East 11th Street, Austin, Texas, 78701
}




\section{Long View (41RB112): Data Recovery of Two Plains Village Period Components in Roberts County, Texas Volume I}

By:

J. Michael Quigg, Paul M. Matchen, Charles D. Frederick, Robert A. Ricklis, Brittney Gregory, David Maki, and Mark Bateman

with contributions by Steven Bozarth, J. Phil Dering, Jeffrey Ferguson, Michael Glascock, Michelle D. Hamilton, Bruce L. Hardy, Linda Perry, David G. Robinson, M. Steven Shack-

ley, Grant Smith, M. Kate Spradley, J. Byron Sudbury, Daniel J. Wescott, and Barbara Winsborough

Prepared for:

Texas Department of Transportation

Environmental Affairs Division

Archaeological Studies Program

Report No. 147

118 East Riverside Drive

Austin, Texas 78704

Prepared by:

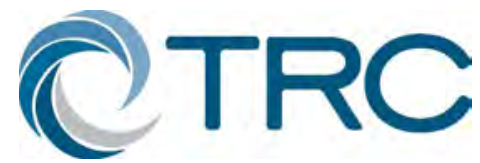

TRC Environmental Corporation

505 East Huntland Drive, Suite 250

Austin, Texas 78752

J. Michael Quigg, Principal Investigator

TRC Technical Report No. 174542 and 46557

TxDOT Scientific Services Contract No. 57906SA003

Texas Antiquities Committee Permit No. 3721

January 2013 
Copyright (C) 2013

Texas Department of Transportation (TxDOT)

This is a work for hire produced for the Texas Department of Transportation (TxDOT), which owns all rights, title, and interest in and to all data and other information developed for this project under Contract 579XXSA003. Brief passages from this publication may be reproduced without permission provided that credit is given to TxDOT and TRC Environmental Corporation. Permission to reprint an entire chapter, section, figures or tables must be obtained in advance from the Supervisor of the Archeological Studies Program, Environmental Affairs Division, Texas Department of Transportation, 125 East 11th Street, Austin, Texas, 78701. Copies of this publication have been deposited with the Texas State Library in compliance with the State Depository Requirement.

\author{
Printed by: \\ Ginny’s Printing \\ Austin, Texas \\ Printed on acid-free, $60 \mathrm{lb}$. paper
}

January 2013

Jointly published by:

Texas Department of Transportation

Environmental Affairs Division

Archeological Studies Program

Scott Pletka, Ph.D., Supervisor

Archeological Studies Program Report No. 147

and

TRC Environmental Corporation

Technical Report No. 174542 and 46557

Austin, Texas

ISBN \# 978-1-935545-14-9 


\section{MANAGEMENT SUMMARY}

This archeological data recovery investigation in Roberts County in the northeastern panhandle of Texas was necessitated by the proposed widening of State Highway 70 (CSJ: 0490-04-037) by the Texas Department of Transportation (TxDOT), Amarillo District. This proposed highway rehabilitation program will directly impact a roughly 10 meter (m, $30 \mathrm{ft}$.) wide north-south section of prehistoric site 41RB112, the Long View site. This site consists of two horizontally distinct Plains Village period occupations shallowly buried along a linear interfluvial ridge between two small tributary creeks to the Canadian River in the midslope of this broad, dissected valley.

This site was initially discovered by TxDOT archeologist, Dennis Price in June 2004 during an archeological inventory of the proposed 9.7 kilometer (6 mile) section north of the Canadian River in response to the planned highway rehabilitation program. Based on Mr. Price's discovery of multiple artifact classes in buried context he recommended this site be assessed for its eligibility for listing on the National Register of Historic Places under criterion $\mathrm{d}$ and possible designation as a State Archeological Landmark (SAL) per the requirements of Section 106 of the National Historic Preservation Act (NHPA) and other related legislation.

Following the Texas Historical Commissions concurrence with that recommendation, TxDOT through the Environmental (ENV) Affairs Division, contracted to TRC Environmental Corporation (TRC) under an existing Scientific Services Contract No. 57XXSA006 and issued a Work Authorization to TRC of Austin to conduct the site eligibility assessment. During a site visit by TxDOT geoarcheologist James Abbott and TRC archeologist Mike Quigg in February 2005, the site boundaries were expanded to nearly 300 meters (m) along the proposed area of potential effect (APE). Investigative strategies were devised to assess the Long View site.

In May 2005, TRC's archeologists from Austin conducted archeological testing for a NRHP and SAL eligibility assessment investigation at 41RB112. The assessment along the 10 -m-wide by 300 -m-long APE was accomplished by hand-excavating 28 1-by-1 m units (totaling $16.8 \mathrm{~m}^{3}$ ), hand-excavating four narrow ca. 30 centimeter $(\mathrm{cm})$ wide trenches (two in each area totaling nearly 32 linear meters), as well as cleaning and inspecting $28 \mathrm{~m}$ of existing road cut exposures. These investigations determined that cultural materials clustered at the northern and southern ends (Areas A and C respectively) of the site with nearly $120 \mathrm{~m}$ of noncultural bearing deposits (Area B) between the two concentrations. A 4-m-wide mechanically bladed fireguard paralleled the existing fenceline throughout the length of the APE and disturbed much of the near surface materials in that zone. The opposite, eastern side of the highway was investigated through the excavation of six 50-by-50 cm shovel tests, surface, and road cut inspection.

Based on the results from the hand-excavations and various collections conducted during the site assessment, it became apparent that the two ends (Areas A and C) of the Long View site in TxDOT's proposed APE contained well-defined cultural components in the top $50 \mathrm{cmbs}$. Each end appeared to represent habitation remains from single occupation episodes with potential structures, restricted to a narrow time period of less than 100 years between uncalibrated 630 and 710 B.P. of the Plains Village period. Rodent and natural disturbances had vertically displaced some small cultural objects within the sandy deposits, but the restricted period of occupation to roughly a 100 year period reduces this impact. TRC recommended the site was eligible for listing on the National Register and as a State Landmark.

The Texas Historical Commissions concurred with that recommendation, and subsequently the ENV Affairs Division of TxDOT, again contracted to TRC under an existing Scientific Services Contract No. 575XXSA008 and issued a Work Authorization to TRC Austin to perform the mitigation of the proposed impacts.

Data recovery investigations were conducted during August through November 2006 along the western side of the existing highway. The previously 
identified northern-Area A and southern-Area C areas with high concentrations of cultural materials were targeted. These investigations began with a thorough geophysical survey that employed three noninvasive electrical detective instruments across Areas $\mathrm{A}$ and $\mathrm{C}$ anticipating to detect the locations of subsurface cultural features to target by handexcavations. Some excavations targeted the detected anomalies, whereas others targeted previously identified features. In the end, hand-excavated blocks were completed in Areas A and C. The excavations totaled $128 \mathrm{~m}^{2}$ in Area A and $93 \mathrm{~m}^{2}$ in Area C for a grand total of $221 \mathrm{~m}^{2}$ or $103.4 \mathrm{~m}^{3}$.

In conjunction with the archeological excavations, geoarcheological investigations focused on defining the age and development of the natural Holocene sediments that contained the cultural materials. The geoarcheological assessment included detailed stratigraphic documentation of site and near site deposits, sediment texture characterization, soil thin sections, magnetic susceptibility, multiple chemical analyses (organic, calcium, and phosphorus). Detailed stratigraphic data was also collected at two rare pithouse structures to pursue construction and filling episodes.

The excavations yielded significant and diverse cultural assemblages from the two occupations assigned Component $\mathrm{A}$ and $\mathrm{C}$. Both components are attributed to the Plains Village period with two discrete occupations dating to uncalibrated 460 to 535 B.P. (cal A.D. 1398 to 1447) in Component A and 530 to 700 B.P. (cal A.D. 1280 to 1437) in Component $\mathrm{C}$. The two assemblages are significant not only in their diversity and quality of materials but also in the information they yielded. This report represents one of the first complete documents to present the entire cultural assemblage from a single site for this time period and region. The total recovered assemblage includes 157 formal chipped and ground stone tools, 226 informal tools, 3,414 pieces of lithic debitage, over 6,400 faunal fragments $(1.4 \mathrm{~kg})$, some 1,541 ceramic sherds, 1,790 burned rocks, at least 116 macrobotanical samples that includes 16 maize cobs, two human burials, and remains of a third, juvenile scattered along a previously bladed fireguard, 32 intact cultural features that include two rare pithouses, and other cultural debris related to these two campsites. The human remains and associated artifacts will be repatriated in accord with the requirements of the Native American Graves Protection and Repatriation Act (NAGPRA). A suite of 10 technical analyses directed at mostly the cultural assemblages included; use-wear, phytolith, diatom, petrography, macrobotanical, starch grain, instrumental neutron activation, bison bone isotopes, obsidian sourcing, radiocarbon and optical stimulated dating. This data was used to address 11 specific research questions concerning these Plains Village period occupations.

Not only does the cultural debris contribute to our understanding of the time period but the geoarcheological information obtained explains the conditions and how the materials were preserved, and inform us concerning the past depositional environment in this immediate area. The combined information contributes to a significant understanding to a specific part of the Plains Village cultures in the Texas panhandle.

Following the acceptance of the final report by the TxDOT and the Texas Historical Commission these cultural materials and all the documentation from the combined investigations will be permanently curated at Texas State University in San Marcos, Texas. The curated materials will provide important data that can be researched by interested parties in the future. 
Table of Contents of Volume I

Page

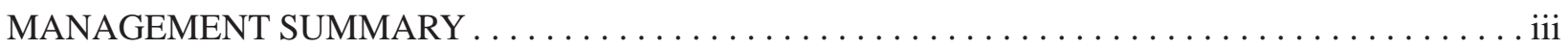

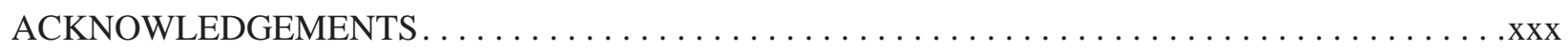

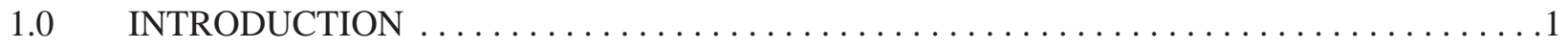

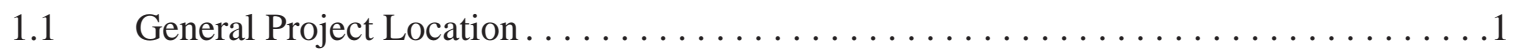

1.2 Texas Department of Transportation Proposed Development. . . . . . . . . . . . . 2

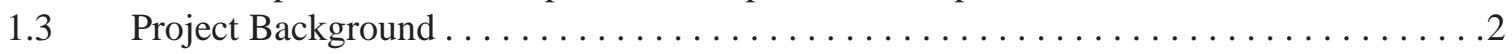

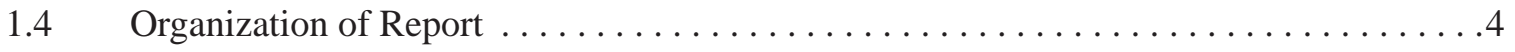

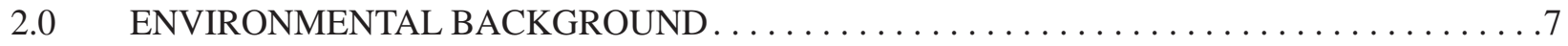

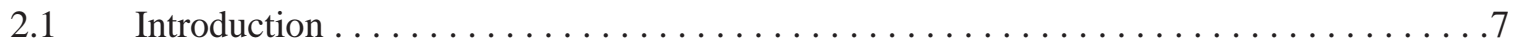

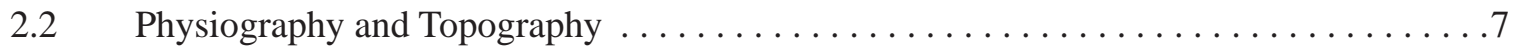

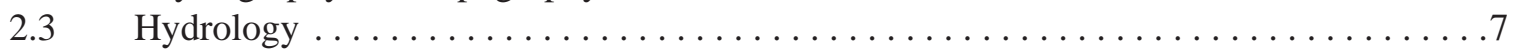

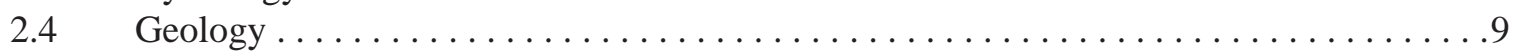

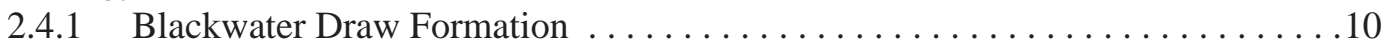

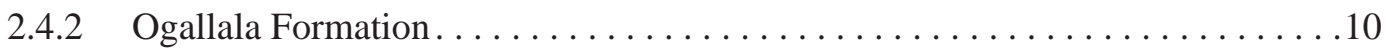

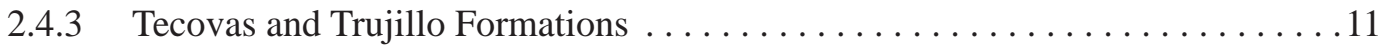

2.4.4 Quartermaster Formation .............................. 11

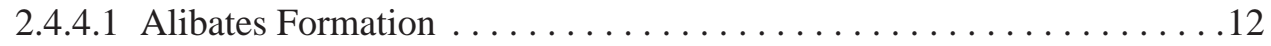

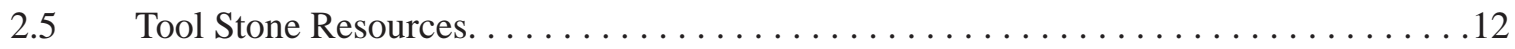

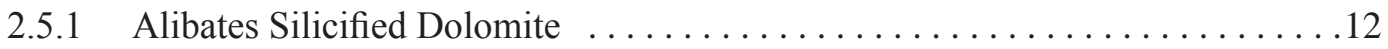

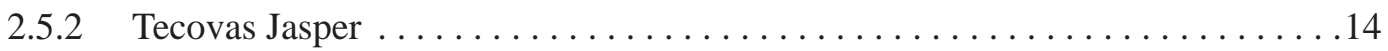

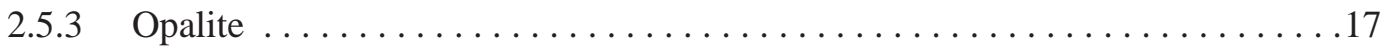

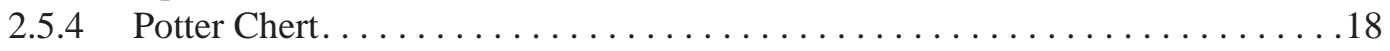

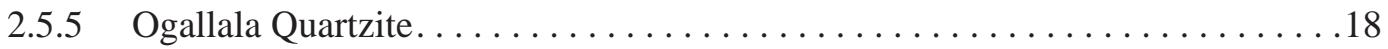

2.5.6 Silicified (Petrified) Wood ............................... 18

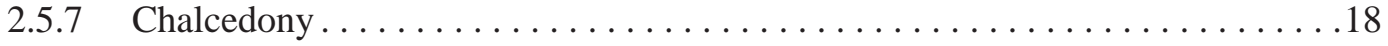

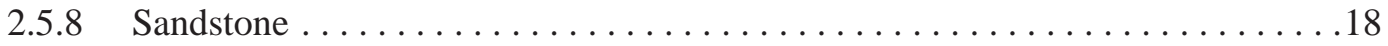

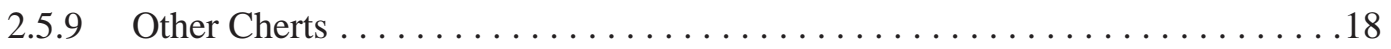

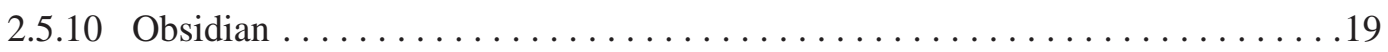

2.5.11 Oklahoma Cherts . . . . . . . . . . . . . . . . . . . . . . . 19

2.5 .12 Kansas Cherts . . . . . . . . . . . . . . . . . . . . . . . . . . 20

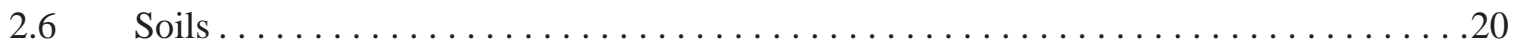

2.6.1 Arable Soils Near the Project Area. . . . . . . . . . . . . . . . . . . . 20

2.6.2 Soils that are Less Desirable for Cultivation Adjacent Long View Site. . . . . . .21

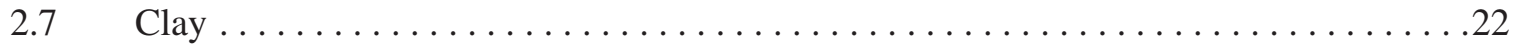

$2.8 \quad$ Climate. . . . . . . . . . . . . . .

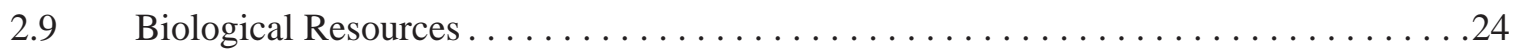

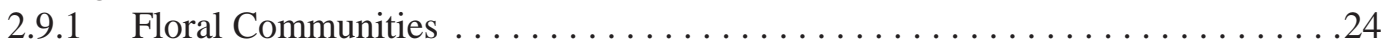

2.9.1.1 Potential Food and Health Resources . . . . . . . . . . . . . . . 27

2.9.1.2 Geophytes (Bulbs and Roots) . . . . . . . . . . . . . . . . . . 29

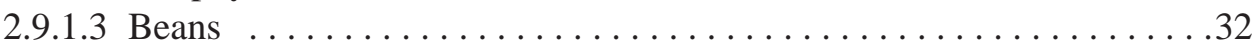

2.9.1.4 Other Resources............................... 34

2.9.2 Faunal Communities................................. 35 


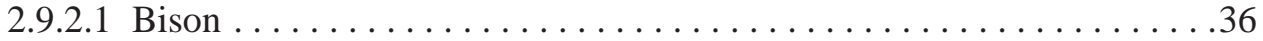

2.9.2.2 Other Game Resources . . . . . . . . . . . . . . . . . . . . 40

2.10 Paleoenvironmental Summary. . . . . . . . . . . . . . . . . . . . . . . .42

3.0 OVERVIEW OF PLAINS VILLAGE CULTURE IN THE TEXAS PANHANDLE $\ldots \ldots \ldots . .47$

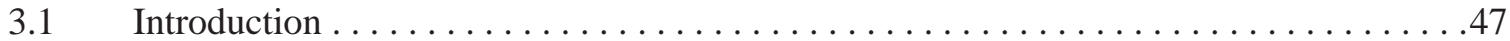

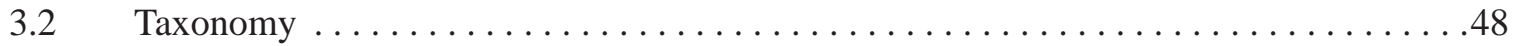

3.3 The Antelope Creek Phase. . . . . . . . . . . . . . . . . . . . . . . .

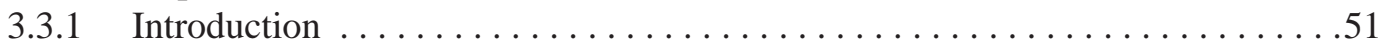

3.3.2 The Antelope Creek Phase Cultural Material Remains . . . . . . . . . . . . . . . 55

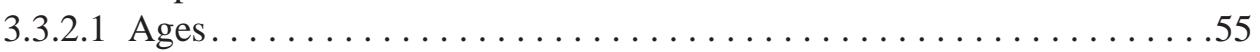

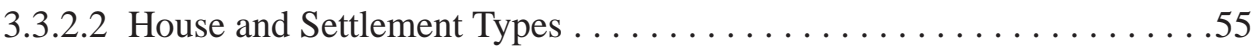

3.3.2.3 Tool Assemblages . . . . . . . . . . . . . . . . . . . . 60

3.3.2.4 Ceramic Assemblages . . . . . . . . . . . . . . . . . . . 60

3.3.2.5 Subsistence Activities . . . . . . . . . . . . . . . . . . . . 665

3.3.2.6 Burial Customs and Biological Characteristics.................68

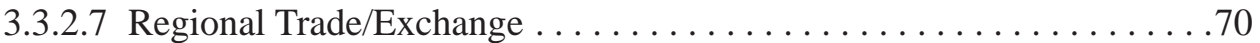

3.4 The Buried City Complex . . . . . . . . . . . . . . . . . . . . . . . . . . . . . . . . .72

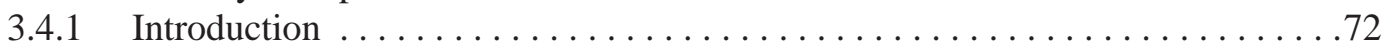

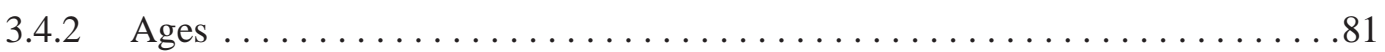

3.4.3 House Patterns and Settlement Types. . . . . . . . . . . . . . . 82

3.4.4 Artifact Assemblages . . . . . . . . . . . . . . . . . . . . . . . 85

3.4 .5 Tool Assemblages. . . . . . . . . . . . . . . . . . . . . . . . 85

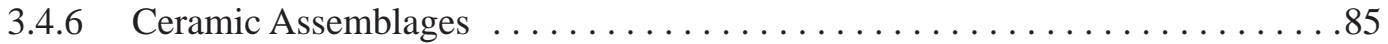

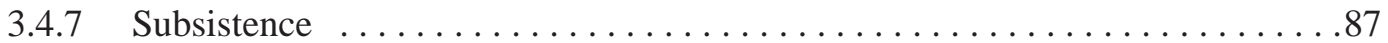

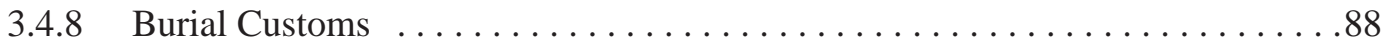

3.4.9 Trade/Exchange . . . . . . . . . . . . . . . . . . . . . . 89

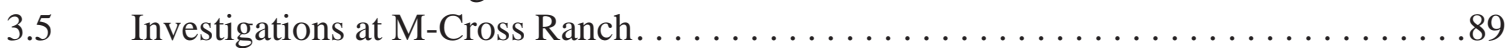

3.6 Investigations at the Courson Property $\ldots \ldots \ldots \ldots \ldots \ldots \ldots \ldots \ldots \ldots \ldots \ldots \ldots \ldots . \ldots \ldots$

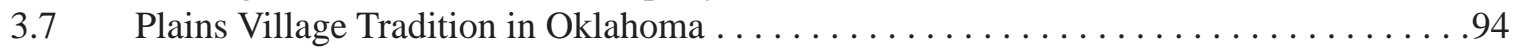

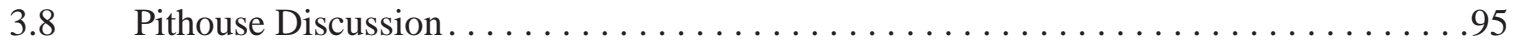

3.8.1 Antelope Creek Phase Occurrences . . . . . . . . . . . . . . . . . . . . . .96

3.8.2 Wolf Creek/Buried City Complex Occurrences . . . . . . . . . . . . . . . . . . 101

3.8.3 M-Cross Ranch Occurrences . . . . . . . . . . . . . . . . . . . . . . . . 102

3.8.4 Other Occurrences . . . . . . . . . . . . . . . . . . . . . . . . . . . . . . . . . . . . . 102

4.0 FINAL RESEARCH DESIGN: RESEARCH QUESTIONS FOR THE LONG VIEW SITE

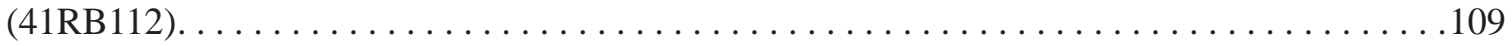

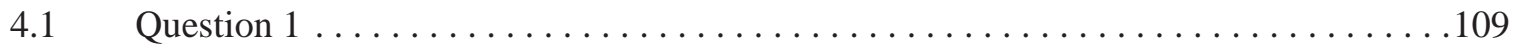

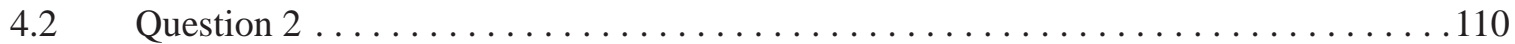

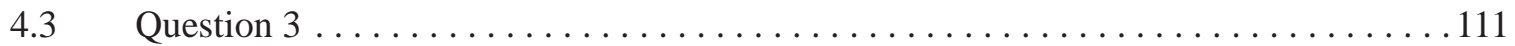

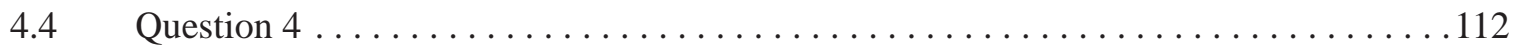

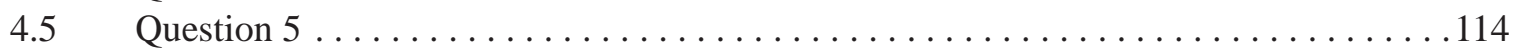

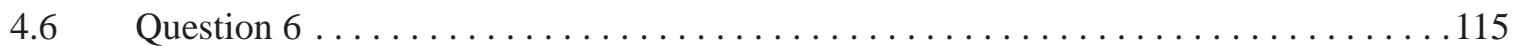

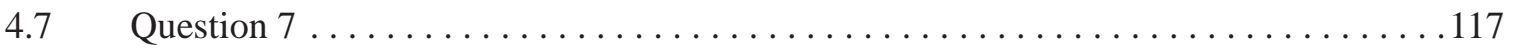

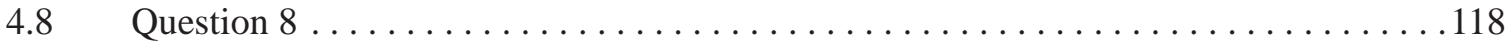




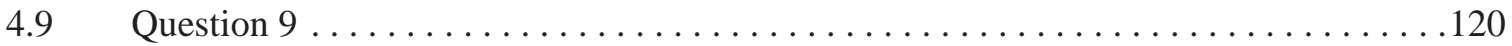

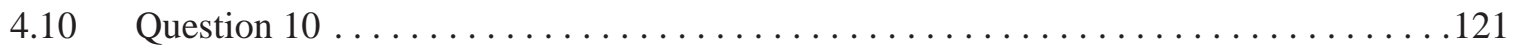

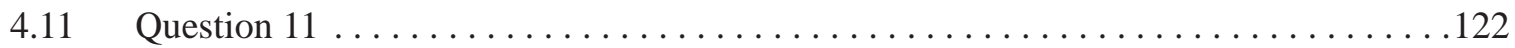

5.0 APPROACH AND METHODS TO ARCHEOLOGICAL ELIGIBILITY ASSESSMENT

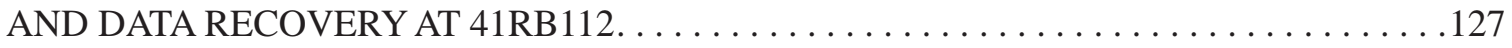

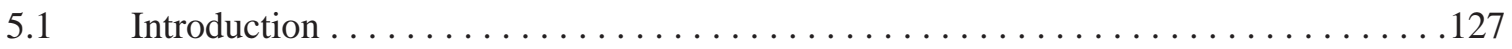

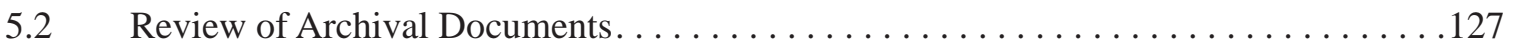

$5.3 \quad$ TRC Field Methods During Site Assessment $\ldots \ldots \ldots \ldots \ldots \ldots \ldots \ldots \ldots \ldots \ldots \ldots \ldots \ldots \ldots$

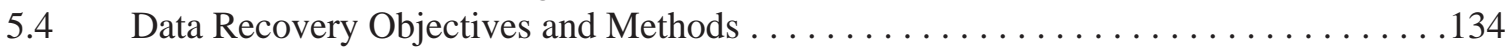

5.4 .1 Data Recovery Field Methods . . . . . . . . . . . . . . . . . . . . . 134

5.4.1.1 Post-Excavation Machine Stripping . . . . . . . . . . . . . 142

5.4.2 Geophysical Methods: Survey Design, Methodology, and Technical

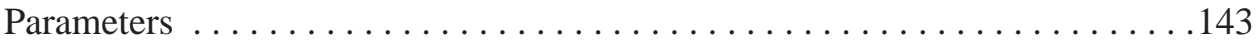

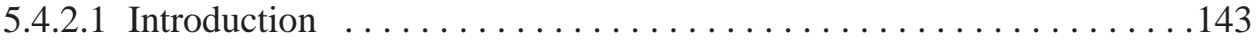

5.4.2.2 Magnetic Field Gradient Survey . . . . . . . . . . . . . . . . . . . . . 143

5.4.2.3 Electrical Resistance Survey . . . . . . . . . . . . . . . . . . . . 145

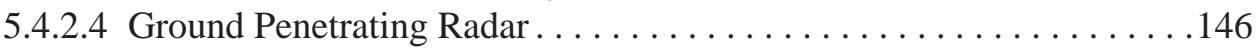

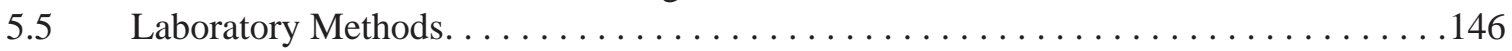

5.5.1 Treatment of Cultural Materials . . . . . . . . . . . . . . . . . . 147

5.5 .2 Flotation Methods. . . . . . . . . . . . . . . . . . . . . . . 148

5.5 .3 Analytical Methods. .............................. 148

5.5.3.1 Chipped Stone Artifact Analysis . . . . . . . . . . . . . . . . . . . 148

5.5 .3 .2 Tools, Bifacial . . . . . . . . . . . . . . . . . . . . . . . 150

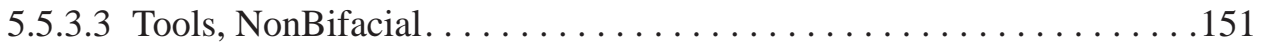

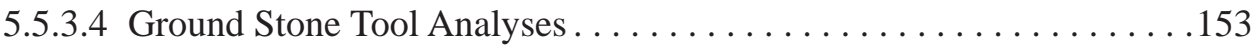

5.5.3.5 Lithic Debitage Analyses. . . . . . . . . . . . . . . . . . . . . 154

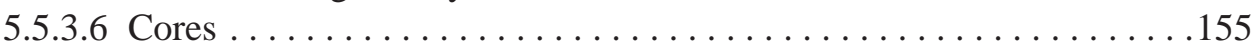

5.5.3.7 Ceramic Artifact Analysis . . . . . . . . . . . . . . . . . . . . . . 155

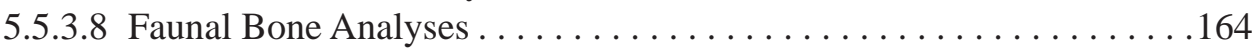

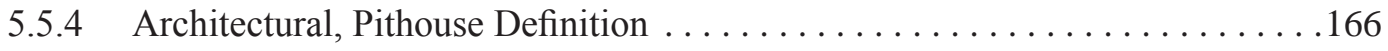

5.5 .5 Analytical Techniques . . . . . . . . . . . . . . . . . . . . . . 167

5.5 .5 .1 Radiocarbon Analysis . . . . . . . . . . . . . . . . . . . . . . . . 167

5.5.5.2 Optical Stimulate Luminescence (OSL) Dating . . . . . . . . . . . . 168

5.5.5.3 Use-Wear Analyses . . . . . . . . . . . . . . . . . . . . . . . 169

5.5.5.4 Starch Grain Analysis . . . . . . . . . . . . . . . . . . . . . . . 169

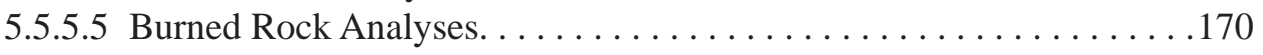

5.5.5.6 Macrobotanical Analyses. . . . . . . . . . . . . . . . . . . . 170

5.5.5.7 Charcoal Analysis . . . . . . . . . . . . . . . . . . . . . 171

5.5.5.8 Ceramic Petrographic Analyses. . . . . . . . . . . . . . . . . . . . 171

5.5 .5 .9 Obsidian Sourcing . . . . . . . . . . . . . . . . . . . . . . 172

5.5 .5 .10 Phytolith Analysis . . . . . . . . . . . . . . . . . . . . . . . . . . . 172

5.5.5.11 Instrumental Neutron Activation Analysis . . . . . . . . . . . . . . 173

5.5.5.12Diatom Analysis . . . . . . . . . . . . . . . . . . . . . 175

5.5.5.13Stable Carbon and Nitrogen Isotope Analyses on Bison Bones . . . . . . 175

5.5.5.14X-Ray Analysis on Ceramic Sherds . . . . . . . . . . . . . 176 
5.5.5.15Mussel Shell Analysis . . . . . . . . . . . . . . . . . . . . . 176

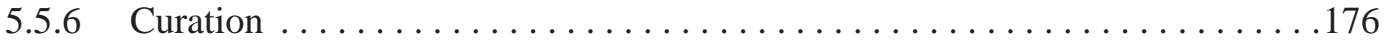

6.0 NATURAL STRATIGRAPHY AT THE LONG VIEW SITE $\ldots \ldots \ldots \ldots \ldots \ldots \ldots \ldots \ldots \ldots 17$

$6.1 \quad$ Methods . . . . . . . . . . . . . . . . . . . . . . . . . . . . . . . . . . . .177

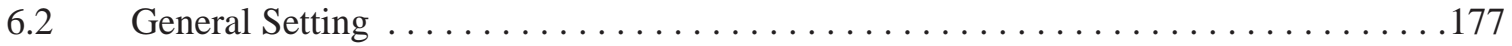

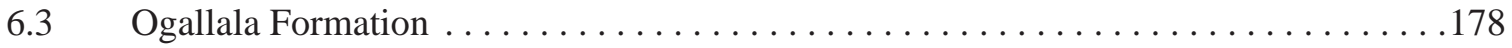

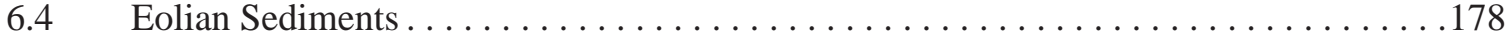

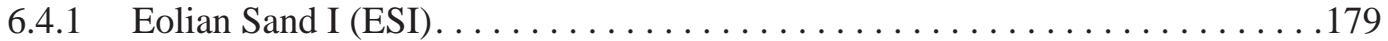

6.4 .2 Eolian Sand II (ESII) . . . . . . . . . . . . . . . . . . . . . . . 186

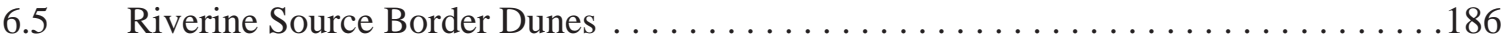

$6.6 \quad$ Upland Dune Field. . . . . . . . . . . . . . . . . . . . . . . . . . . . . . . . . . . 188

$6.7 \quad$ Upland Sand Sheet. . . . . . . . . . . . . . . . . . . . . . . . . . . . . . . . . . . . . . 189

6.8 Patterns of Deposition . . . . . . . . . . . . . . . . . . . . . . . . . . . . . . . . . . 189

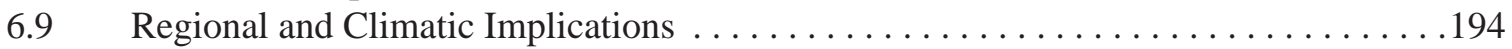

6.10 Archeological Implications . . . . . . . . . . . . . . . . . . . . . . . 195

7.0 CULTURAL STRATIGRAPHY AND CONTEXT $\ldots \ldots \ldots \ldots \ldots \ldots \ldots \ldots \ldots \ldots \ldots \ldots \ldots$

$7.1 \quad$ Analytical Units . . . . . . . . . . . . . . . . . . . . . . . . . . . . . . . . . 197

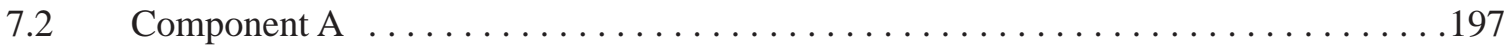

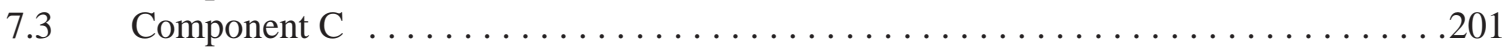

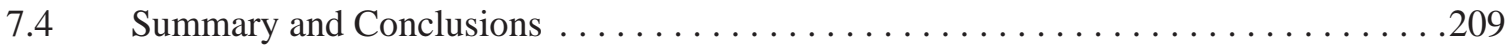

8.0 COMPONENT A - NORTHERN END $\ldots \ldots \ldots \ldots \ldots \ldots \ldots \ldots \ldots \ldots \ldots \ldots \ldots \ldots \ldots \ldots \ldots \ldots \ldots$

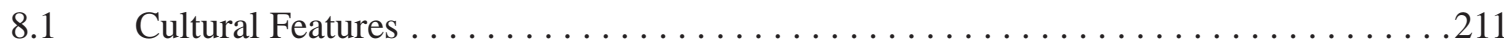

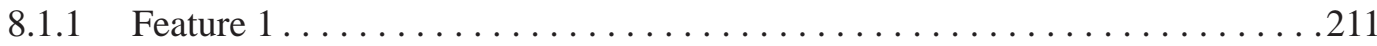

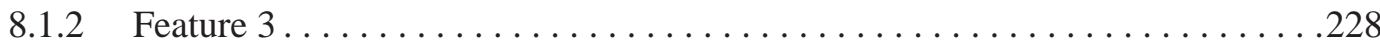

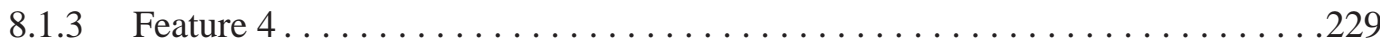

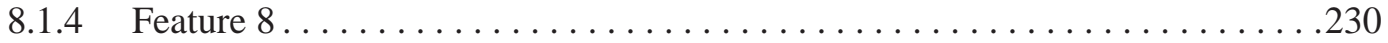

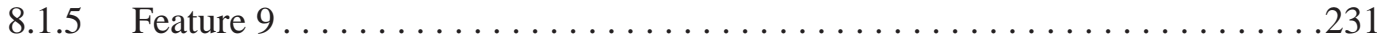

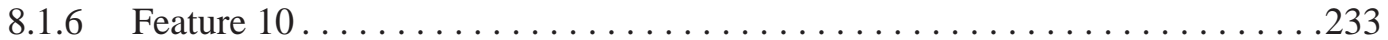

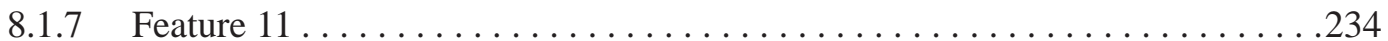

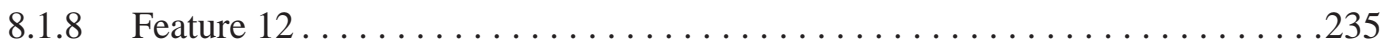

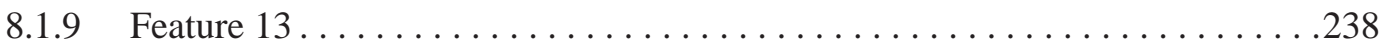

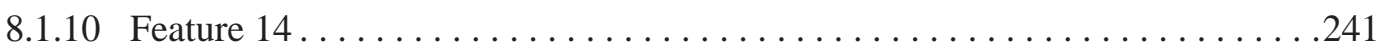

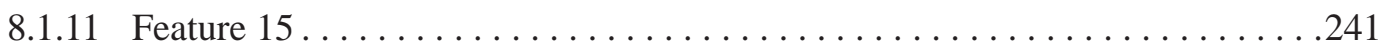

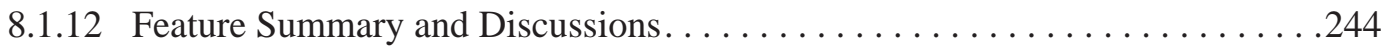

$8.2 \quad$ Chipped Stone Tool Analyses . . . . . . . . . . . . . . . . . . . . . . . . 247

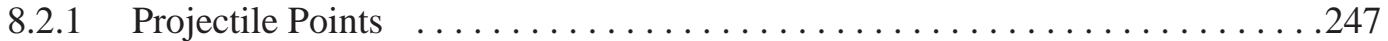

8.2.1.1 Descriptions of Complete Tools . . . . . . . . . . . . . . . . . . . . . . . . .248

8.2.1.2 Findings from Use-wear Analysis . . . . . . . . . . . . . . . . . . . . . .250

8.2 .2 Bifaces . . . . . . . . . . . . . . . . . . . . . . . . . . . . . . . 250

8.2.2.1 Width-to-Thickness Ratios, Reduction Stage and Tool Use-life. . . . . . 250

8.2.2.2 Metric Attributes of Biface Assemblage . . . . . . . . . . . . . . . . . 252

8.2.2.3 Beveled Bifaces. . . . . . . . . . . . . . . . . . . . . . . .252 
Page

8.2.2.4 Data from Bifaces Sent for Use-wear Analysis. . . . . . . . . . . . . . 254

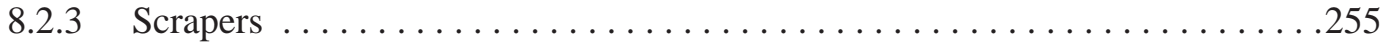

8.2.3.1 Data from Scrapers Sent for Use-wear Analysis . . . . . . . . . . . . . 257

8.2 .4 Drills. . . . . . . . . . . . . . . . . . . . . . . . . . 257

8.2.5 Edge-Modified Flakes. . . . . . . . . . . . . . . . . . . . . . 257

8.2.5.1 Use-wear Analysis of Edge-modified Flakes. . . . . . . . . . . . . 260

8.2.6 Unifacial Tools . . . . . . . . . . . . . . . . . . . . . . 260

8.2.7 Spatial Distribution of Stone Tools in Component A . . . . . . . . . . . . . . 260

$8.3 \quad$ Lithic Debitage Analyses. . . . . . . . . . . . . . . . . . . . . . . 261

8.3.1 Summary of Lithic Debitage Analyses. . . . . . . . . . . . . . . . . . . . 269

$8.4 \quad$ Ceramic Analyses . . . . . . . . . . . . . . . . . . . . . . . . . . . . . . .

$8.4 .1 \quad$ Vessel A. . . . . . . . . . . . . . . . . . . . . . . . . . . . 272

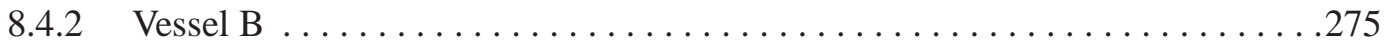

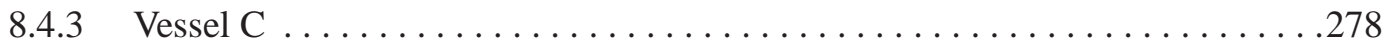

8.4 .4 Vessel D . . . . . . . . . . . . . . . . . . . . . . . . . . . . 279

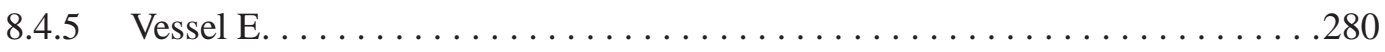

$8.4 .6 \quad$ Vessel F. . . . . . . . . . . . . . . . . . . . . . . . . . . . . . . . .

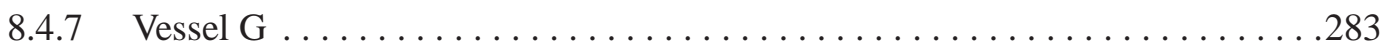

8.4 .8 Vessel H . . . . . . . . . . . . . . . . . . . . . . . . . . .

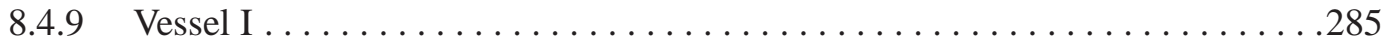

8.4 .10 Vessel J . . . . . . . . . . . . . . . . . . . . . . . . . . . 287

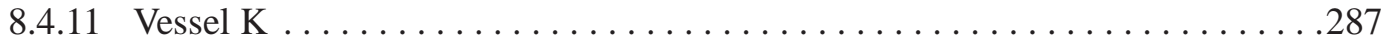

8.4 .12 Vessel L. . . . . . . . . . . . . . . . . . . . . . . . . . 288

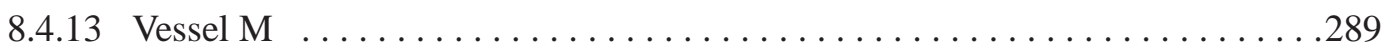

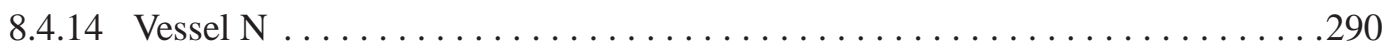

8.4.15 The Unassigned Sherd Assemblage . . . . . . . . . . . . . . . . . . . . 291

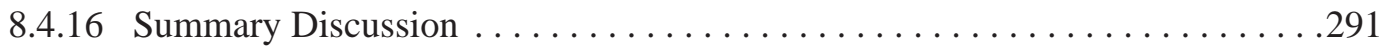

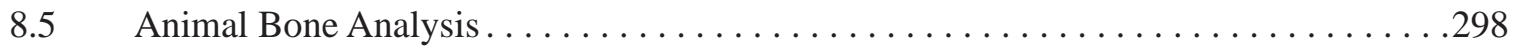

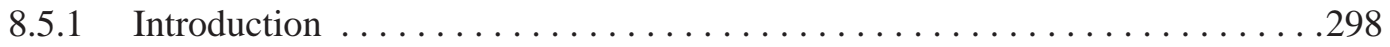

8.5 .2 Nonbison Remains . . . . . . . . . . . . . . . . . . . . . . . 302

8.5.3 Bison Remains . . . . . . . . . . . . . . . . . . . . . . . . . 302

8.5.3.1 Bison Age Groups and Gender Identification . . . . . . . . . . . . 303

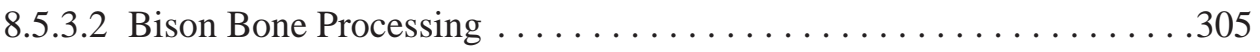

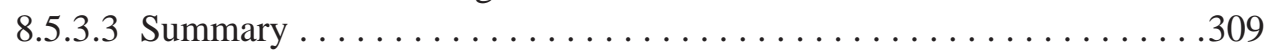

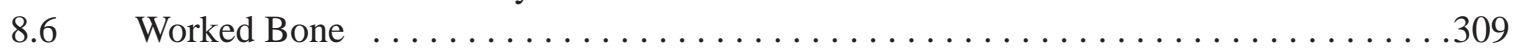

$8.7 \quad$ Burned Rock Analyses. . . . . . . . . . . . . . . . . . . . . . . . . .

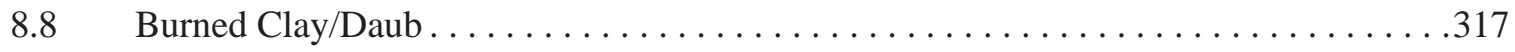

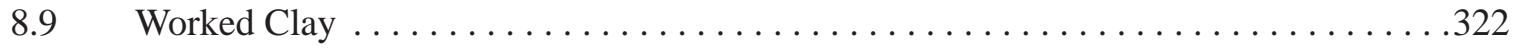

8.9 .1 "Spindle Whorls" . . . . . . . . . . . . . . . . . . . . . . . . . 322

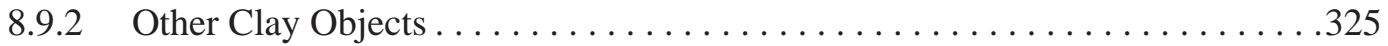

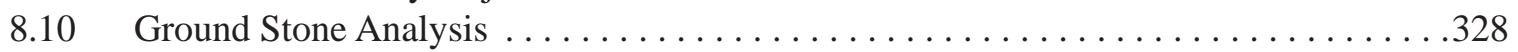

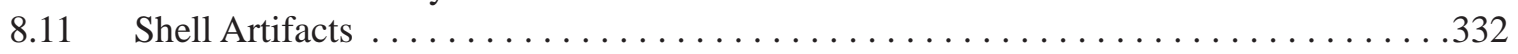

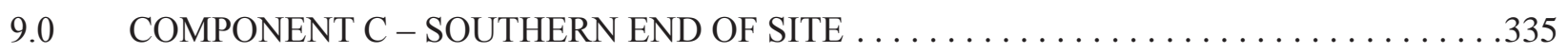

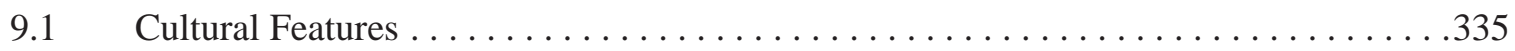

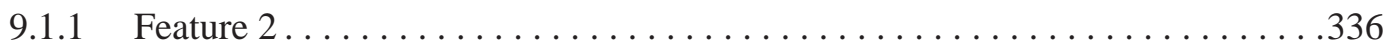




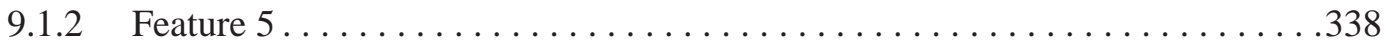

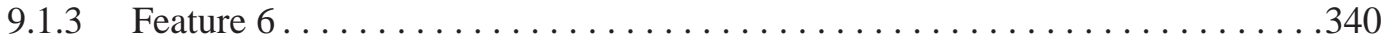

9.1.3.1 Stratigraphy by Charles D. Frederick and Brittney Gregory. . . . . . . . .350

9.1.3.2 Cultural Materials in Feature $6 \ldots \ldots \ldots \ldots$. . . . . . . . . . . . 367

9.1.4 Feature 7 (Cairn Burial) . . . . . . . . . . . . . . . . . . . . . . . . . . . . . . . 374

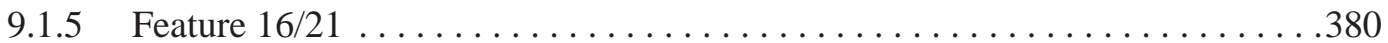

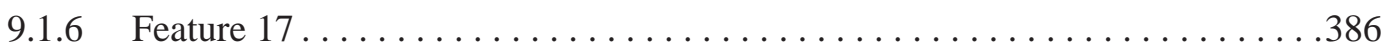

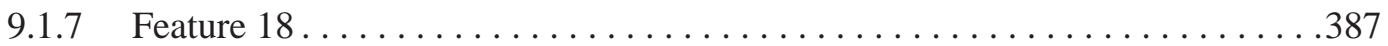

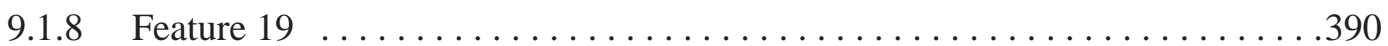

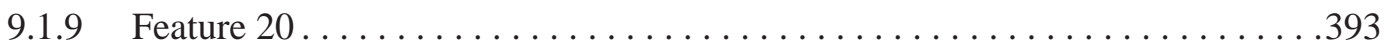

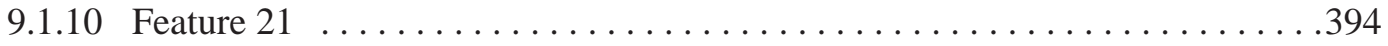

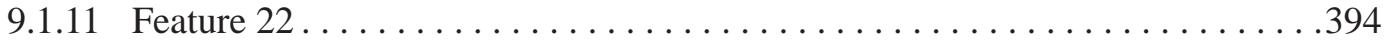

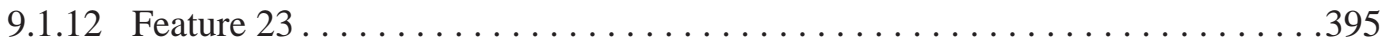

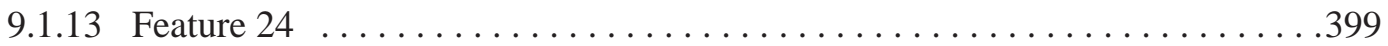

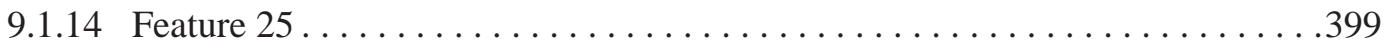

9.1 .15 Feature $26 \ldots \ldots \ldots \ldots \ldots$. . . . . . . . . . . . . . . . . . . . . . . . . 399

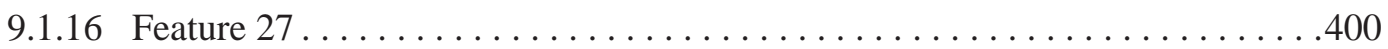

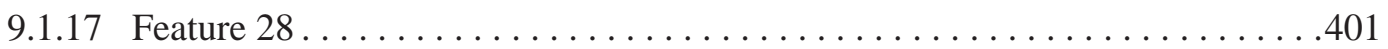

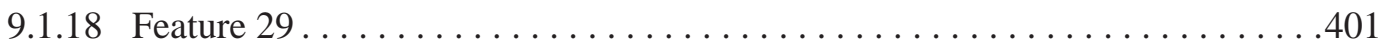

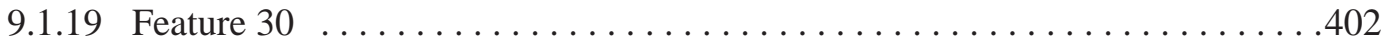

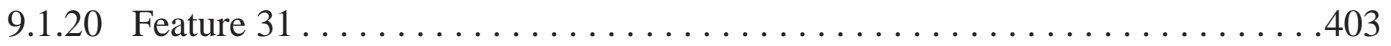

9.1 .21 Rock/Stone Alignment . . . . . . . . . . . . . . . . . . . . . . 404

9.1.22 Summary of Component C Features . . . . . . . . . . . . . . . . .408

$9.2 \quad$ Chipped Stone Tools . . . . . . . . . . . . . . . . . . . . . . . . . . . . . . . . . . 412

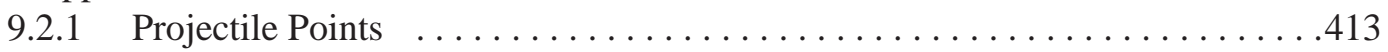

9.2.1.1 Discussion of Complete Projectile Points . . . . . . . . . . . . . . .414

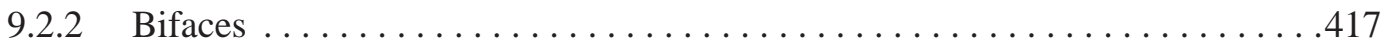

9.2.2.1 Width-to-Thickness Ratios, Reduction Stages and Tool Use-Life . . . .417

9.2.2.2 Metric Attributes of the Biface Assemblage . . . . . . . . . . . . . . .418

9.2.2.3 Beveled Bifaces. . . . . . . . . . . . . . . . . . . . . . . . . . . . . . .418

9.2.2.4 Use-wear Results . . . . . . . . . . . . . . . . . . . . . . . . . . . . . . . .420

9.2 .3 Scrapers .................................. 420

9.2.3.1 Use-wear Results. . . . . . . . . . . . . . . . . . . . . . . . . . . . . . . . . 420

9.2 .4 Drills. . . . . . . . . . . . . . . . . . . . . . . . . . . . 420

9.2.5 Edge-Modified Flakes. . . . . . . . . . . . . . . . . . . . . . . . . . .420

9.2.5.1 Use-Wear Results. . . . . . . . . . . . . . . . . . . . . . . . .421

9.2.6 Unifacial Tools (Non-Scrapers) and Other Specialized Informal Tools. . . . . . .421

9.2.6.1 Use-wear Results . . . . . . . . . . . . . . . . . . . . . . . . . .423

9.2.7 Horizontal Distribution of Formal and Selected Informal Tools . . . . . . . . . 423

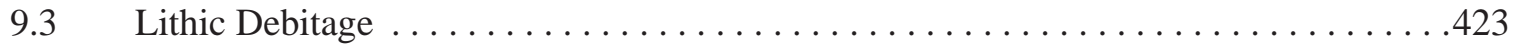

9.3.1 Horizontal Distribution of Lithic Debitage. . . . . . . . . . . . . . . . . . . 425

9.3.2 Summary of Lithic Debitage Analysis . . . . . . . . . . . . . . . . . . .425

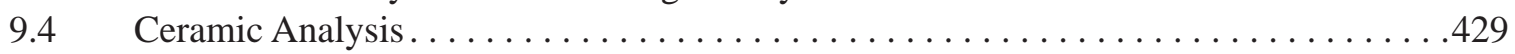

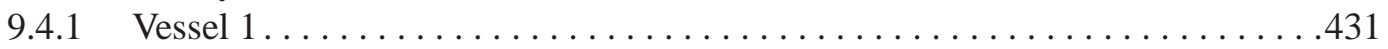

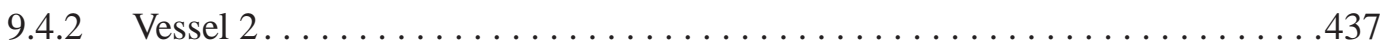

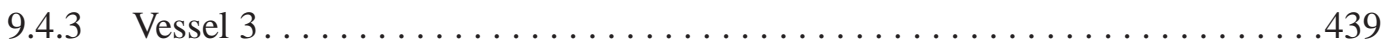

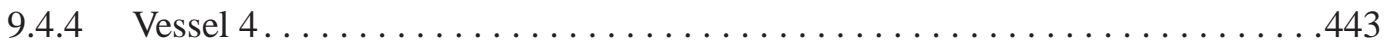


Page

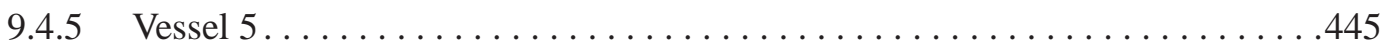

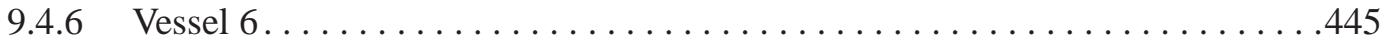

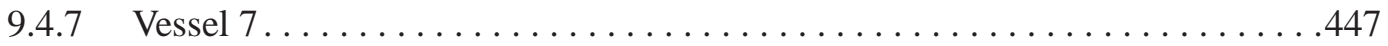

9.4.8 The Unassigned Sherd Assemblage . . . . . . . . . . . . . . . . . . .448

9.4.9 Summary of the Vessel Assemblage . . . . . . . . . . . . . . . . . . 449

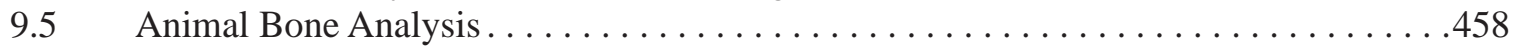

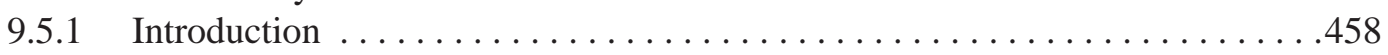

9.5.2 Nonbison Remains from the Pithouse . . . . . . . . . . . . . . . . . . 449

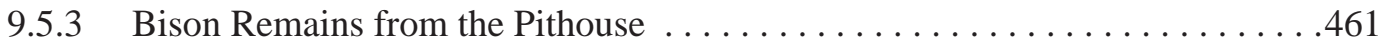

9.5.3.1 Bison Age Groups and Gender Identification . . . . . . . . . . . . . .461

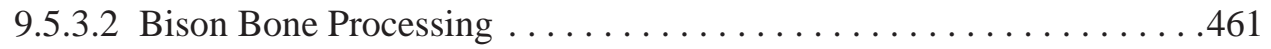

9.5.3.3 Bison Bone Distribution . . . . . . . . . . . . . . . . . . .464

9.5.4 Faunal Remains from Beyond the Pithouse ...................464

9.5.4.1 NonBison Remains . . . . . . . . . . . . . . . . . . . . . . . . .464

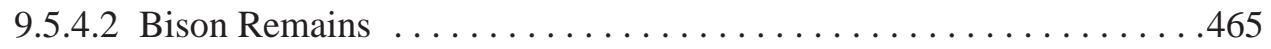

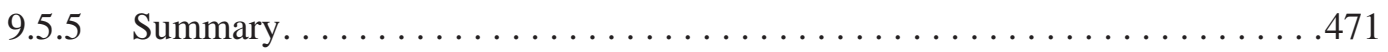

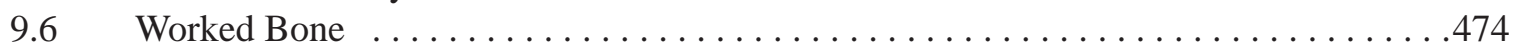

9.7 Burned Rock Analyses . . . . . . . . . . . . . . . . . . . . . . .479

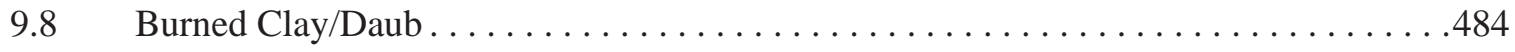

$9.9 \quad$ Worked Clay . . . . . . . . . . . . . . . . . . . . . . . . . . . .

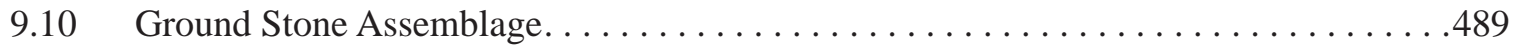

9.11 Shell Artifacts . . . . . . . . . . . . . . . . . . . . . . . . . . . 491

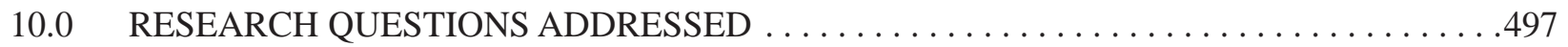

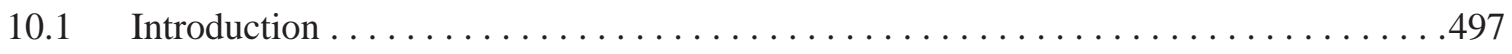

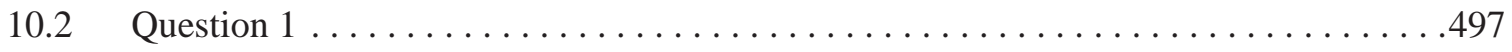

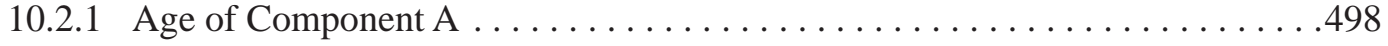

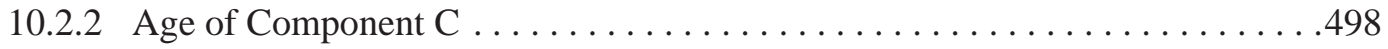

10.2.3 Age Comparison between Component A and C . . . . . . . . . . . . . . . 498

10.2.4 Dating Organic Residues In and On Ceramic Sherds. . . . . . . . . . . . . . . . 500

10.2.5 Summary and Discussion of Age of Thick-Walled Vessels/Sherds . . . . . . . . . 504

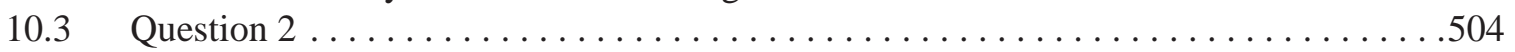

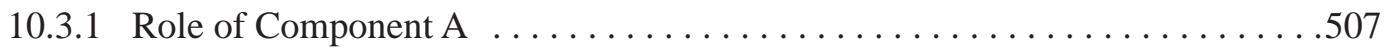

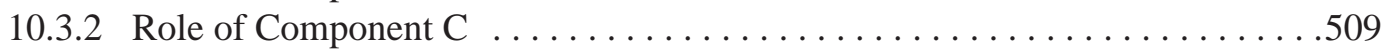

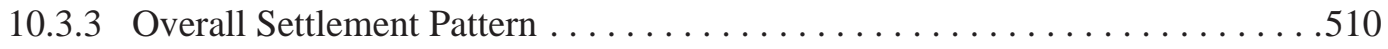

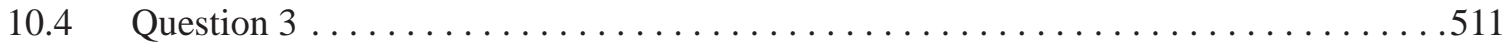

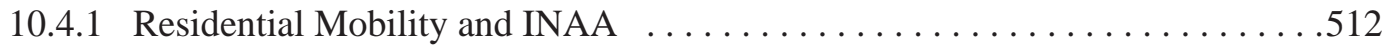

10.4.2 Chipped Stone Tool Assemblage Formation at the Long View Site. . . . . . . . .514

10.4.3 Stone Tool Manufacture and Use in Component A . . . . . . . . . . . . . . 514

10.4.4 Stone Tool Manufacture and Use in Component C . . . . . . . . . . . . 516

10.4 .5 Regional Comparisons . . . . . . . . . . . . . . . . . . . . . . . 516

10.4.6 Discussion of Occupation Span at Long View . . . . . . . . . . . . . . . 518

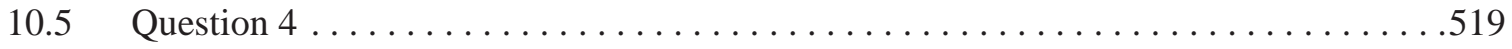

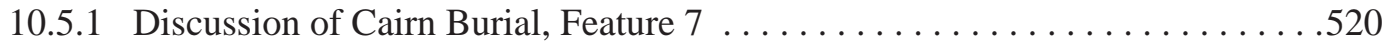

10.5.2 Discussion of Human Cremation, Feature 22 . . . . . . . . . . . . . . 520

10.5.3 Discussion of Scattered Human Remains from Component C. . . . . . . . . . . 521 
10.5.4 Discussion of Human Burial Practices . . . . . . . . . . . . . . . . . . . . . . .521

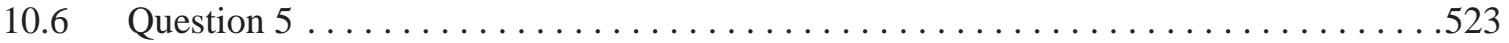

10.6.1 Discussion of Structures in the Region. . . . . . . . . . . . . . . . 526

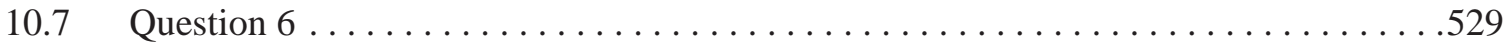

10.7.1 Discussion of Component A Ceramic Assemblage . . . . . . . . . . . . . . . 529

10.7.2 Discussion of Component C Ceramic Assemblage . . . . . . . . . . . . . . . . . . 530

10.7.3 Technical Analyses . . . . . . . . . . . . . . . . . . . . . . . 530

10.7.3.1 Instrumental Neutron Activation Analysis . . . . . . . . . . . . . . . 531

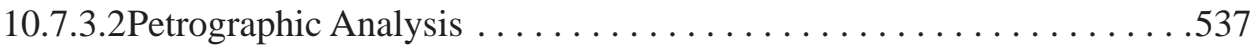

10.7.4 Long View Ceramic Component Discussions . . . . . . . . . . . . . . . . . 542

10.7.5 Other Petrographic Analysis and Further Discussions . . . . . . . . . . . . . 543

10.7.6 Summary of Ceramic Sherd Analyses from Long View . . . . . . . . . . . . 545

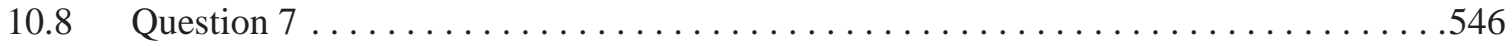

10.8.1 Discussion of Horticulture . . . . . . . . . . . . . . . . . . . . .547

10.8.2 Discussion of Hunting . . . . . . . . . . . . . . . . . . . . . . . . . . . 549

10.8.3 Discussion of Gathering . . . . . . . . . . . . . . . . . . . . . . 549

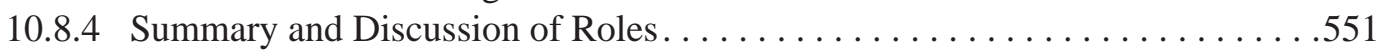

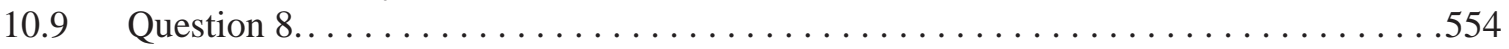

10.9.1 Discussion of Bone Tools in Component A . . . . . . . . . . . . . . . . 555

10.9.2 Discussion of Bone Tools in Component C . . . . . . . . . . . . . . . . . 555

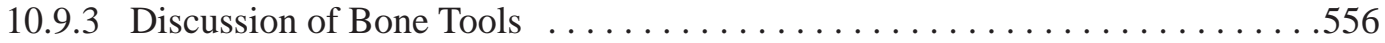

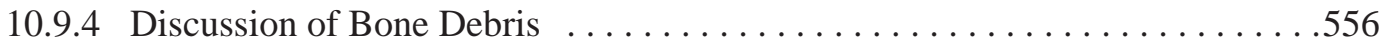

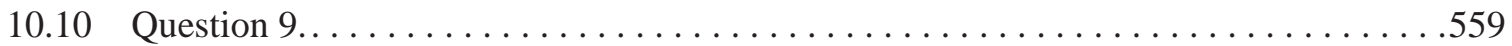

10.10.1 Component A Discussions . . . . . . . . . . . . . . . . . . . . 559

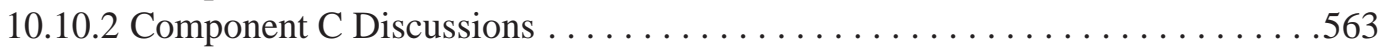

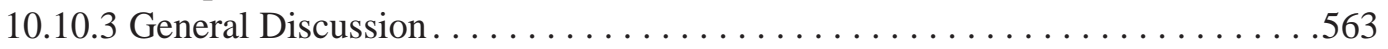

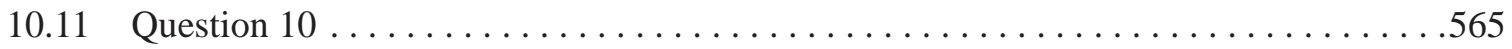

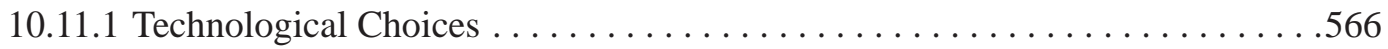

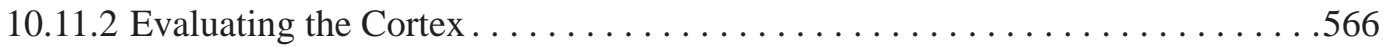

10.11.3 Size of Alibates Tools . . . . . . . . . . . . . . . . . . . . . . 568

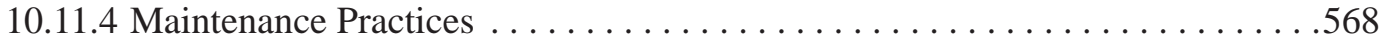

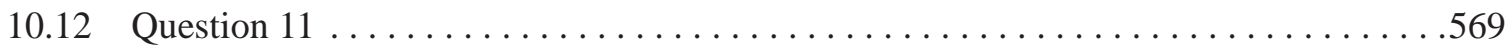

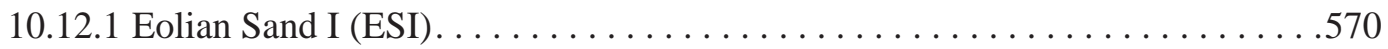

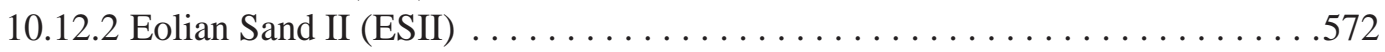

10.12.3 Riverine Source Border Dunes. . . . . . . . . . . . . . . . . . . . . 572

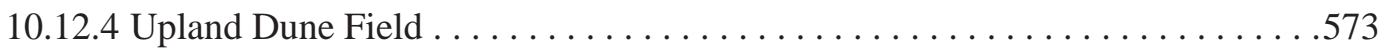

10.12.5 Upland Sand Sheet . . . . . . . . . . . . . . . . . . . . . . . . . 577

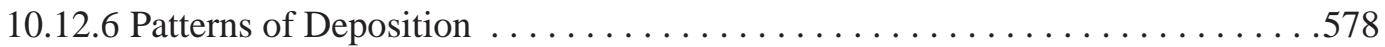

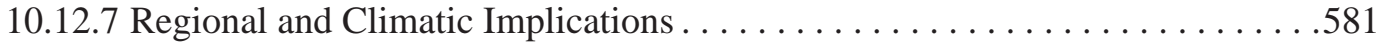

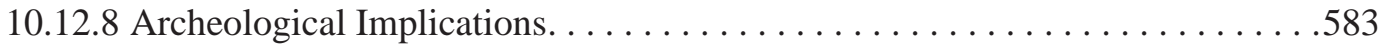

11.0 SUMMARY, CONCLUSIONS, CRITIQUE OF METHODS AND RECOMMENDATIONS. .585

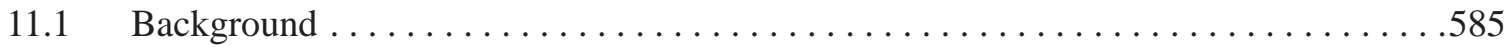

$11.2 \quad$ Site Summary. . . . . . . . . . . .

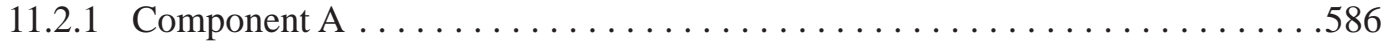

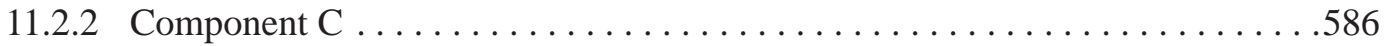




\section{Page}

11.2.3 Comparing Archeological Assemblages. . . . . . . . . . . . . . . . . . . . . 589

11.3 Contributions and Critique of the Technical Analyses . . . . . . . . . . . . . . . 590

11.3.1 Geoarcheological Contributions............................591

11.3.2 Radiocarbon Dating . . . . . . . . . . . . . . . . . . . . . . . . . . 591

11.3.3 Use-Wear and Residue Analysis. . . . . . . . . . . . . . . . . . . . . 592

11.3.4 Phytolith Analysis . . . . . . . . . . . . . . . . . . . . . . . . . . . . 592

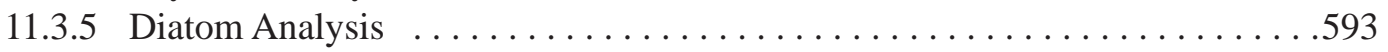

11.3.6 Macrobotanical Analysis . . . . . . . . . . . . . . . . . . . . . . . . . . . 594

11.3.7 Starch Grain Analysis . . . . . . . . . . . . . . . . . . . . . . . . . . . . 594

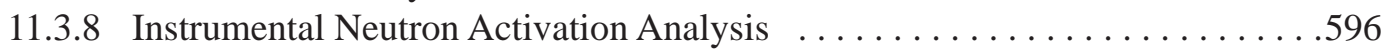

11.3.9 Petrographic Analysis . . . . . . . . . . . . . . . . . . . . . . . 599

11.3.10 Stable Isotope Analyses on Bison Bones . . . . . . . . . . . . . . . 600

11.3.11 XRF Analysis . . . . . . . . . . . . . . . . . . . . . . . 600

11.3.12 Optical Stimulated Luminescence Dating . . . . . . . . . . . . . . . . 601

11.3.13 Physical Anthropological Analyses . . . . . . . . . . . . . . . . .601

11.3.14 Summary of Technical Analyses. . . . . . . . . . . . . . . . . . 601

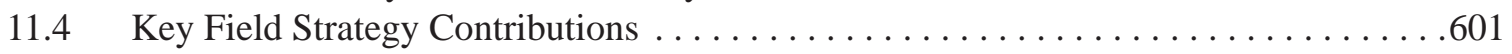

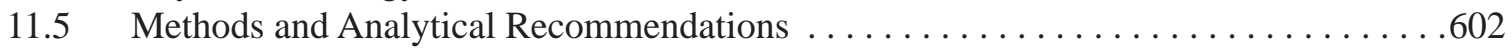

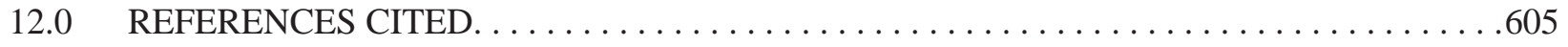

13.0 GLOSSARY OF TECHNICAL TERMS $\ldots \ldots \ldots \ldots \ldots \ldots \ldots \ldots \ldots \ldots \ldots \ldots \ldots \ldots \ldots \ldots \ldots$ 
Figure 2-1. General project location map showing major relief (map from Raisz 1957) . . . . . . . . .8

Figure 2-2. Northern edge of the Canadian River Valley in background with topographic relief within the valley (photograph by M. Quigg) . . . . . . . . . . . . . . . . .

Figure 2-3. Overview of Dugout Creek Valley west of the Long View site $\ldots \ldots \ldots \ldots \ldots \ldots \ldots$

Figure 2-4. Schematic drawing of geologic stratigraphy across panhandle of Texas. . . . . . . . . 10

Figure 2-5. Large prehistoric quarry pit at Alibates Flint Quarries National Monument (41PT1)

(photograph by Paul Katz). . . . . . . . . . . . . . . . . . . . . .

Figure 2-6. Multiple quarry pits exposed following fire at Alibates Flint Quarries National Monument (41PT1) (photograph by Paul Katz). . . . . . . . . . . . . . . . . . . . . 13

Figure 2-7. Boulder with Alibates exposed at Alibates Flint Quarries National Monument (41PT1)

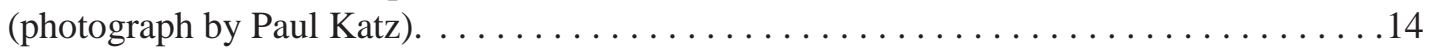

Figure 2-8. Samples of Alibates from Alibates Flint Quarries National Monument (41PT1).. . . . . . . 15

Figure 2-9. Examples of Tecovas from South Basin quarries (41OL284).. . . . . . . . . . . . . 16

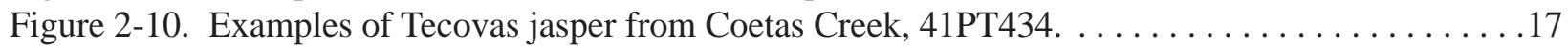

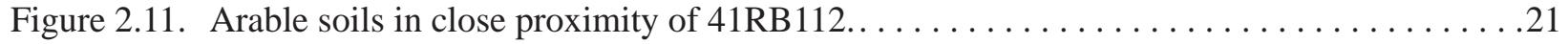

Figure 2-12. Average temperatures in Miami, Texas as recorded from 1951 to 1975 (Source: Roberts

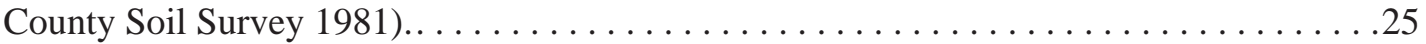

Figure 2-13. Average precipitation measurements as recorded in Miami, Texas from 1951 to 1975 (Source: Roberts County Soil Survey) . . . . . . . . . . . . . . . . . . . . . 25

Figure 2-14. Average wind speed as measured from Miami, Roberts County, Texas. . . . . . . . . . .26

Figure 2-15. Monthly average percentage of sunshine in Roberts County, Texas... . . . . . . . . . 26

Figure 2-16. Maturing amaranth plant with seed spikes (photograph by M. Quigg). . . . . . . . . . .28

Figure 2-17. Modern amaranth seeds (scale in cm) (photograph by M. Quigg). . . . . . . . . . . . . .28

Figure 2-18. Close up of wildrye (Elymus canadensis) grass seed head and loose seeds (photograph

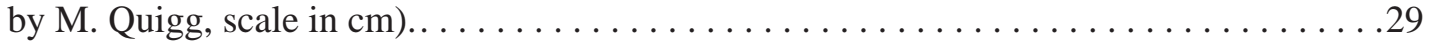

Figure 2-19. Little barley (Hordeum pusillum) grass seed head and loose seeds

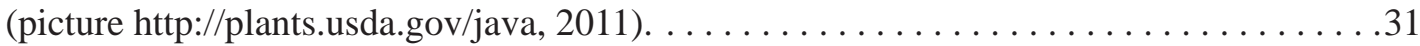

Figure 2-20. Bulbs (rain lily, false garlic, prairie pleatleaf) that represent potential food resources (photograph by M. Quigg, scale in $\mathrm{cm}$ ). . . . . . . . . . . . . . . . 31

Figure 2-21. Dense patch of false garlic, showing blooms (light color) that would facilitate collection

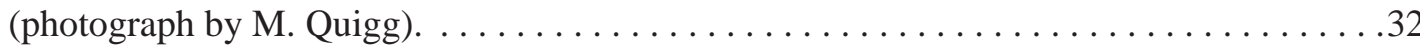

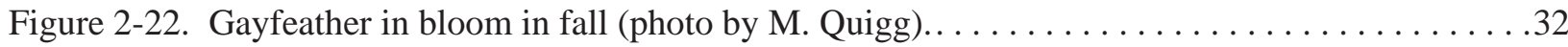

Figure 2-23. Buffalo gourd tuber (Cucurbita sp.) in profile measured at least 40-by-20 cm. . . . . . .33

Figure 2-24. Mesquite tree with seed pods still on tree (photo by M. Quigg).. . . . . . . . . . . .33

Figure 2-25. A single small wild plum tree without fruit (photo by M. Quigg).................34

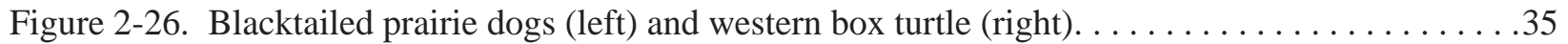

Figure 2-27. Young bison shedding their winter coats (photograph by M. Quigg)... . . . . . . . . 36

Figure 2-28. Pronghorn along the breaks of the Canadian River (photograph by M. Quigg).. . . . . . .41

Figure 2-29. Mule deer on the open plains (photograph by M. Quigg).. . . . . . . . . . . . . . 41

Figure $2-30$. Generalize climatic proxy data using various data sets. $\ldots \ldots \ldots \ldots \ldots \ldots \ldots \ldots \ldots$

Figure 3-1. Reconstructed plains woodland vessels in the Panhandle-Plains Historical Museum (left) with close up of exterior cordmarking (right, photograph provided by PPHM, Accession

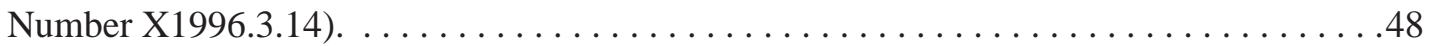

Figure 3-2. Typical Shapes of Plains Village Period cordmarked vessels with vertical rims (left, from Suhm and Jelks 1962, Plate 8) and close up of exterior cordmarks (right). . . . . . . . 49

Figure 3-3. Long View Site in relation to Antelope Creek Phase Core Area, Buried City and M-Cross 


\section{Page}

Ranch localities........................................51

Figure 3-4. Variations in architectural unit types identified in Antelope Creek Phase sites (from Lintz

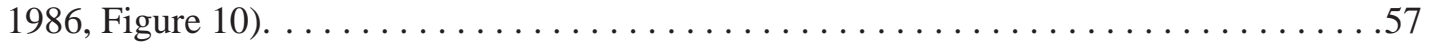

Figure 3-5. Generalized structure of Unit type I showing location of key characteristics (from Lintz

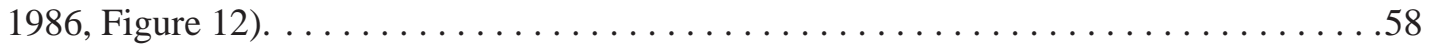

Figure 3-6. Stylized layout of possible and actual aggregate type ii structures (after Lintz 1986,

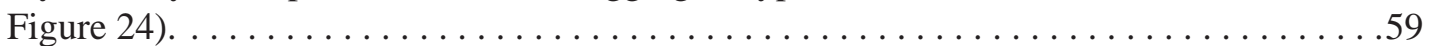

Figure 3-7. Example of cordmarked vessel with flaring rim and weak shoulder from Buried City. . . .66

Figure 3-8. Reconstructed vessel from Two Sisters (34TX32) . . . . . . . . . . . . . . . . .64

Figure 3-9. General map of the main cluster of sites in vicinity of Buried City along Wolf Creek (from Brosowske 2005:152, Figure 4.13, scale is $1 \mathrm{~km}$.) . ..................77

Figure 3-10. Typical stone house foundation, 410C43, Kit Courson House 1 in Buried City (graphic

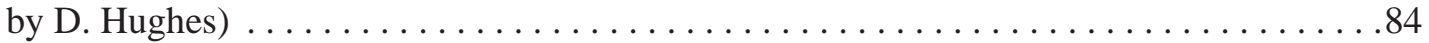

Figure 3-11. Partially reconstructed cordmarked vessel with incised rim and shoulder from Buried City (picture from Texas Beyond History Web Page, Buried City Exhibit, photo by S. Black). ............................................87

Figure 3-12. Two examples of decorated rim sherds from Buried City... . . . . . . . . . . . . 88

Figure 3-13. Closeup of decorated rim on cordmarked vessel from Buried City (picture from Texas Beyond History Web Page, Buried City Exhibit, photo by S. Black) ..............88

Figure 3-14. Plan map of Burned Structure \#1 at Hank’s sites (after Boyd and Wilkens 2001:3,

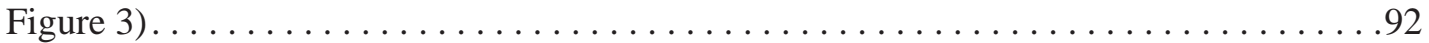

Figure 3-15. Plan map of Structure 4 at Black Dog Village (from Keller 1975:38, Figure 21). . . . . . . 97 Figure 3-16. Plan map of excavations at Greenbelt site (from T. Campbell 1996:42, Map 5). . . . . . . 100 Figure 3-17. Profile drawing of Archie King II habitation structure (from Brosowske 2009c:15,

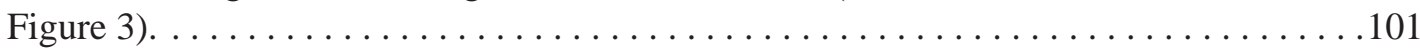

Figure 3-18. Excavated Area A Pithouse in 41OC29, part of the Wolf Creek Complex (Photograph from Texas Beyond History Exhibit on Buried City, photo by S. Brosowske).. . . . . . . .103

Figure 3-19. Overhead view of Structure 4 following complete excavation at Indian Springs (from Cruse 2007:14, Figure 7) ...................................

Figure 3-20. Semisubterranean pithouse (Feature 2000-1) at Odessa Yates (from Brosowske 2005:463, Figure I.7). . . . . . . . . . . . . . . . . . . . . . . . . . . . . . . 104

Figure 3-21. Plan map of pasture house (a pithouse) at Odessa Yates (from Brosowske 2005:455, Figure I.2) .......................................... 105

Figure 3-22. Plan view of excavated pithouse (Feature 268) and associated features at Lundeen Site (from Bevitt 1999:110, Figure 25). ..............................107

Figure 4-1. Graphic display of radiocarbon dates from 41RB112 testing phase... . . . . . . . . . . 110

Figure 4-2. Magne's raw material replacement rate model (1989). . . . . . . . . . . . . . . . . 113

Figure 4-3. A Sample of the highly fragmented bone, possibly representing bone-grease extraction, from the northern portion of Component A, 41RB112.....................120

Figure 4-4. Alternately beveled knives fashioned from alibates recovered from Component A, 41RB112, left to right, exhausted biface (complete), exhausted biface (complete), biface fragment, and biface fragment. . . . . . . . . . . . . . . . . . . . . . . . .

Figure 4-5. Schematic illustration of selected profiles recorded during data recovery geoarcheological investigations within site context, and the location of samples collected. ............................................125

Figure 5-1. Overview of Site 41RB112 setting with Canadian River Valley in background. . . . . . .128 Figure 5-2. Overgrown fireguard with pin flags marking locations of observed artifacts..........129 
Figure 5-3. Plan map of Component A and the northern part of Area B following site assessment. . . 130

Figure 5-4. Plan map of the southern part of Component $C$ following site assessment. . . . . . . . 131

Figure 5-5. Feature 5 exposed in facing the existing road cut in Component C. . . . . . . . . . 132

Figure 5-6. Feature 7, cluster of buried caliche rocks discovered in hand-dug trench C-1 in

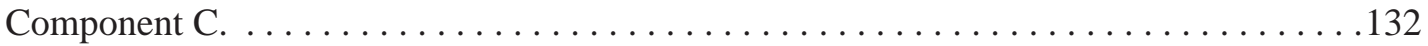

Figure 5-7. Profile of hand-excavated Trench A-2 across fireguard in Component A... . . . . . . . . 133

Figure 5-8. Northern excavation block in Component A, indicating feature locations. . . . . . . . . . 135

Figure 5-9. Southern excavation block in Component A indicating feature locations. . . . . . . . . . .136

Figure 5-10. South westward view of data recovery excavations in Component A in APE. . . . . . . . 137

Figure 5-11. Excavation block in Component $C$ indicating feature locations... . . . . . . . . . . . 139

Figure 5-12. View north of data recovery excavations at Component C.................. 141

Figure 5-13. Mechanical stripping at south end of Component $\mathrm{C}$ following hand-excavations

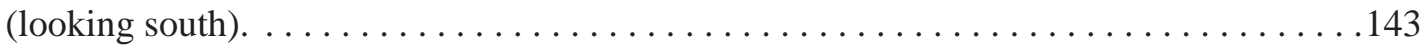

Figure 5-14. Location of the geophysical survey areas (electrical resistance on left, ground penetrating radar in center, and magnetic field gradient on right) along narrow right-of-way across Site 41RB112 . . . . . . . . . . . . . . . . . . 144

Figure 5-15. Flotation of matrix samples using Dousman flotation system. . . . . . . . . . . . . 149

Figure 5-16. Chipped stone artifact analysis flowchart. . . . . . . . . . . . . . . . 149

Figure 5-17. Selected projectile point terms and metric measurement locations. . . . . . . . . . . 151

Figure 5-18. Borger cordmarked vessel with terms and metric measurement locations............ 157

Figure 5-19. Decorations: cordmarked rim of Vessel G (left) and pinched/collared rim of Vessel A

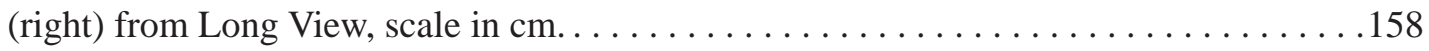

Figure 5-20. Finger puntate on rim of Vessel A from Component A (left) and diagonal cord impressed lip on Vessel G from Component A (right) at Long View Site, scale in cm. . . . . . . . . 158

Figure 5-21. Map depicting the four areas from which pottery sherds and natural clay were selected for petrographic and INA analyses. . . . . . . . . . . . . . . . . . . . 161

Figure 5-22. Decorated ceramic rim (\#1047) with visible organic residues on exterior surface, scale

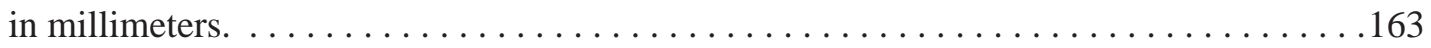

Figure 5-23. Example of a bison fetal long bone that exhibits the platy/flakey exterior surface with missing articular ends. . . . . . . . . . . . . . . . . . . . . . . 165

Figure 5 -24. Beta laboratory, showing the gas extraction process. . . . . . . . . . . . . . 168

Figure 5-25. Instruments used in petrographic analysis (photo furnished by Dr. Robinson). . . . . . . 173

Figure 5-26. MURR laboratory assistant compiling data (photograph furnished by Dr. Glascock)... . .174

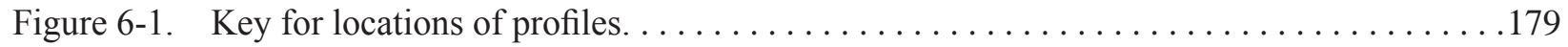

Figure 6-2. Top Panel: A $1.72 \mathrm{~km}^{2}$ false color aerial photograph of the Long View Site and vicinity taken on July 1, 2004, obtained from Terraserver. Lower Panel: Map compiled of selected eolian geomorphic features in vicinity of the Long View Site compiled from the aerial image shown in the upper panel. Stars show the locations of the profiles discussed

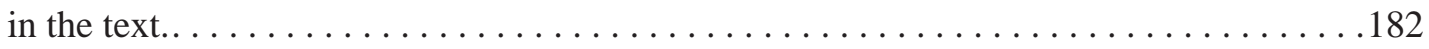

Figure 6-3. Stratigraphy, age, and depth variation in basic physical properties observed at the Lipps Ranch Stream Side Dune (LRSSD) locality. . . . . . . . . . . . . . . . . . 187

Figure 6-4. Stratigraphy, age, and depth variation in basic physical properties observed in Column Profiles C-2 and C-4, within eolian sand sheet depositional environment on south side

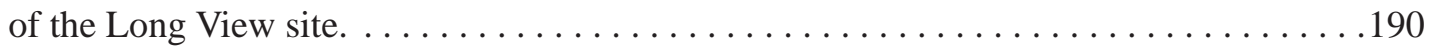

Figure 6-5. Plot of Folk and Ward mean particle size (in phi) versus sorting (standard deviation, in phi) for sediment samples collected from different eolian depositional environments. . . .191

Figure 6-6. A. Change in percent silt with distance from sediment source for each eolian 
depositional environment examined. B. Variation in percent clay in eolian sediments with respect to distance from sediment source. . . . . . . . . . . . . . . . . . 192

Figure 6-7. Plot of sedimentation rates obtained from OSL dates in each eolian environment with respect to distance from sediment source (Dugout Creek). . . . . . . . . . . . . . 193

Figure 6-8. Two sigma radiocarbon ages obtained from Long View Components A and C with respect to one sigma OSL ages obtained from riverine source border dune, upland sand dune, $\quad$ and upland sand sheet. . . . . . . . . . . . . . . . . . . . . . 194

Figure 7-1. Component A, profile south wall of N697 E511 showing rodent disturbance in cultural zone.................................................198

Figure 7-2. Vertical distribution of cultural features in Component A, 41RB112. . . . . . . . . . . 199

Figure 7-3. Example of vertical distributions of artifacts in Units N694 E513, N694 E514, N702 E513, and N701 E514, Component A.. . . . . . . . . . . . . . . . . . . . 199

Figure 7-4. The APE in Component $\mathrm{C}$, with the overgrown fireguard between old fence (right) and new fence (left). . . . . . . . . . . . . . . . . . . . . . . . . . . . . 202

Figure 7-5. View north from Component $C$ along steep road cut on west side of highway. . . . . . .202 Figure 7-6. Vertical distribution of features in northern part of Component C. . . . . . . . . . . .203 Figure 7-7. Example of vertical distributions of artifacts in Units N480 E500, N480 E501,

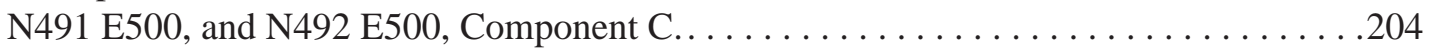

Figure 7-8. General plan map of stone alignment in Component C. . . . . . . . . . . . . . 207 Figure 7-9. Surface exposed caliche rocks that formed the stone alignment in Component C, view

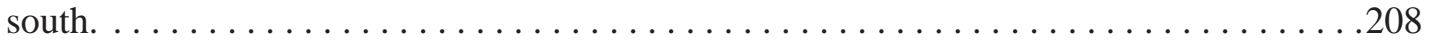

Figure 7-10. An excavated unit that reveals part of the buried stone alignment in Component C. . . . .209

Figure 8-1. Overview of northern part of dense activity area in Component A, 41RB112. . . . . . . 212

Figure 8-2. Deep basin, Feature 1 initially exposed in road cut. . . . . . . . . . . . . . . . .213

Figure 8-3. Profile drawing of Feature 1 exposed in road cut (view west) . . . . . . . . . . . . . 213

Figure 8-4. Eastern edge of pithouse exposed in road-cut following cleaning. . . . . . . . . . . 214

Figure 8-5. Close up of fill in bottom of pithouse and its contact with the underlying Ogallala deposits with patchy calcium carbonate. . . . . . . . . . . . . . . . 214

Figure 8-6. Overhead view of base of pithouse at junction of N700 (left) and N699 (right) showing rodent burrows and post holes (plastic in holes)...................... 215

Figure 8-7. Oblique view of base of pithouse with fill removed at completion. . . . . . . . . . 216

Figure 8-8. Profile and plan view of Pithouse Feature $1 . \ldots \ldots \ldots \ldots \ldots \ldots \ldots \ldots \ldots \ldots \ldots \ldots \ldots \ldots$

Figure 8-9. Profile A-2 particle size distribution for Feature 1 floor deposits compared to Ogallala

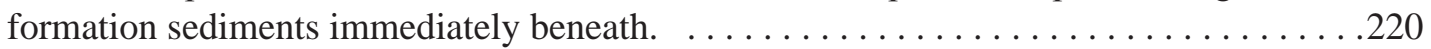

Figure 8-10. Depth variation in bulk soil properties between Profile A-1 (control) and Profile A-2

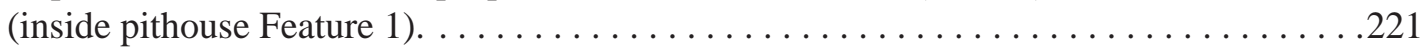

Figure 8-11. Transmitted light scan of micromorphology Block 6, Zone 4, from road cut profile of

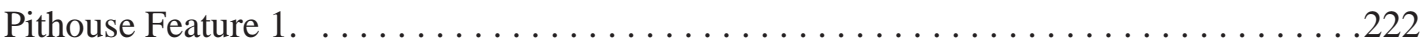

Figure 8-12. Two examples of cleaned out post holes that extended below the floor of pithouse into

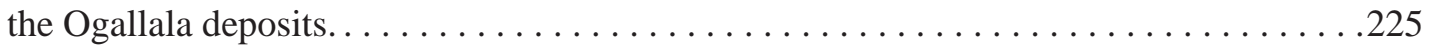

Figure 8-13. Plan view drawing of pithouse floor - Feature 1 in Component A. . . . . . . . . . . 225 Figure 8-14. Plan view and west profile drawing of Feature 3 in Trench A1 . . . . . . . . . . 230 Figure 8-15. Plan view and west profile drawings of Feature 4 in Area A. . . . . . . . . . . . . 231

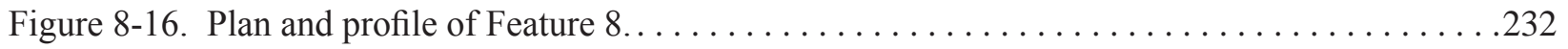
Figure 8-17. Small dark stained sediment of Feature 9 in southeastern corner of unit. . . . . . . . . 234 Figure 8-18. Overview of dark stained sediment of Feature 10 in foreground. . . . . . . . . . .235

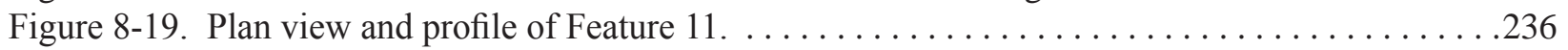


Figure 8-20. Overview of Feature 11, dark stained matrix with scattered charcoal. . . . . . . . . . 237

Figure 8-21. Close-up of half of a circular marine shell bead $(\# 1032-10)$. . . . . . . . . . . . . 237

Figure 8-22. North profile of storage pit - Feature 13 (scale in $10-\mathrm{cm}$ increments)............239

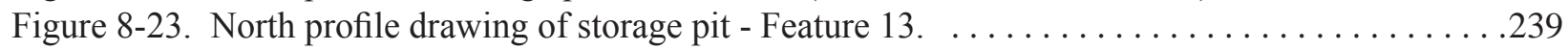

Figure 8-24. Oblique overview of clustered cultural material in darker stained rodent burrow. . . . . . 242

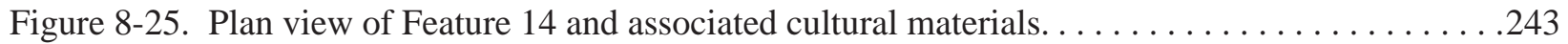

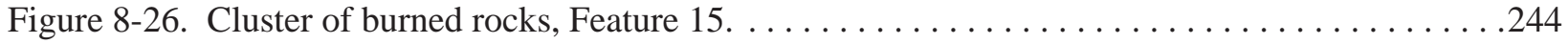

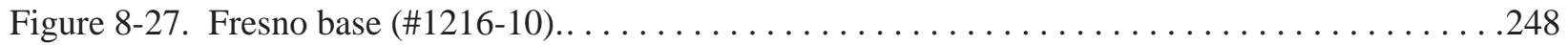

Figure 8-28. Harrell point (\#373-10) from Component A. . . . . . . . . . . . . . . . . . . . 249

Figure 8-29. Complete projectile points (\#23-10, 786-10, \#804-10, and \#822-10) . . . . . . . . . .252

Figure 8-30. Specimen \#1216-10, a Fresno-like point base made from Alibates. . . . . . . . . . . . . . 254

Figure 8-31. Complete unwashed alternately beveled biface (\#768-10) exhausted. . . . . . . . . . 255

Figure 8-32. Complete unwashed exhausted alternately beveled biface (\#768-12). . . . . . . . . 255

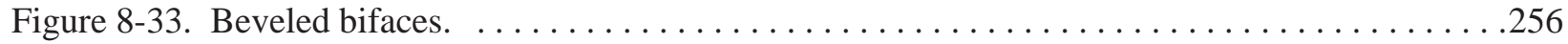

Figure 8-34. Selected scrapers from Component A (left to right, \#1042-10, \#22-10, and \#786-11). . . 258

Figure 8-35. Observations from use-wear analysis scrapers \#22-10 (top) and \#768-14 (bottom). . . . .259

Figure 8-36. Selected drills from Component A. . . . . . . . . . . . . . . . . . . . . . . 259

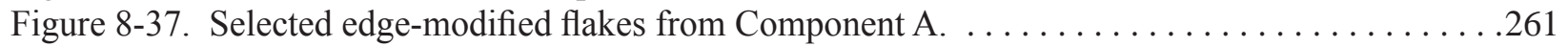

Figure 8-38. Observations from use-wear analysis of selected edge-modified flakes (\#948-10(top; scale in $\mathrm{cm}$ ) and $\# 1270-11$ (bottom; scale in $\mathrm{mm}$ ). . . . . . . . . . . . . . 262

Figure 8-39. Examples of unifacial graver (\#1039-10) and unifacial spokeshave (\#1040-10) from

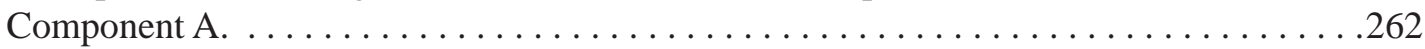

Figure 8-40. Stone tool spatial distribution in Component A. . . . . . . . . . . . . . . . . . .263

Figure 8-41. Depth range and frequency for lithic debitage from Component A. . . . . . . . . . . . 265

Figure 8-42. Example of an opalite chunk (likely tested) recovered from Component A... . . . . . . .265

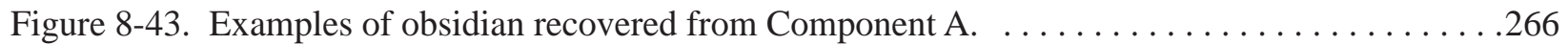

Figure 8-44. Size grade distribution of lithic debitage in Component A. . . . . . . . . . . . . 266

Figure 8-45. Distribution of platform-bearing flakes exhibiting thermal alteration. . . . . . . . . 267

Figure 8-46. Frequency of platform types in Component A debitage assemblage. . . . . . . . . . . 268

Figure 8-47. Cortex presence on platform bearing flakes from Component A. . . . . . . . . . 268

Figure 8-48. Spatial distribution of lithic debitage in Component A.. . . . . . . . . . . . . . . . 270

Figure 8-49. Horizontal distribution of nonlocal material at Component A. . . . . . . . . . . . .271

Figure 8-50. Sample of unwashed body sherds with organic residues adhering to exteriors. . . . . .273

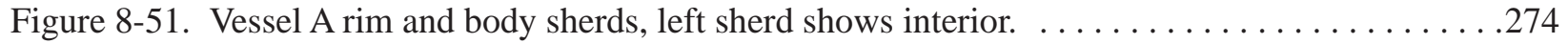

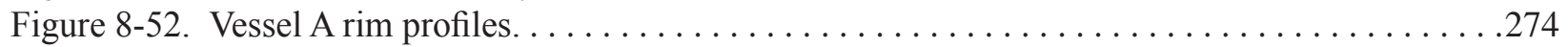

Figure 8-53. Horizontal distribution of sherds representing different vessels in Component A. . . . . .276

Figure 8-54. Vessel B body sherds, interior (left) and exterior (right). . . . . . . . . . . . . 277

Figure 8-55. Vessel C body sherds, exterior (left) and interior (right). . . . . . . . . . . . 278

Figure 8-56. Vessel D rim and neck sherds refit, exterior (left) and interior (right). . . . . . . . . 279

Figure 8-57. Detail of exterior (left) and interior (center) with rim profile (right) of Vessel D rim

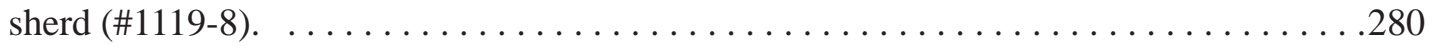

Figure 8-58. Profiles of rim sherds assigned to Vessel E.. . . . . . . . . . . . . . . . . . . 281

Figure 8-59. Vessel E rim and neck sherds, exterior (left) and interior (right) . . . . . . . . . . .281

Figure 8-60. Vessel F conjoined body sherds (\#998-8-1), exterior (left) and interior (right). . . . . . .282

Figure 8-61. Vessel G rim sherd (\#1066-8-1), exterior (left), interior (center) and profile (right). . . . .283

Figure 8-62. Detail of diagonal impressions on decorated lip (\#1066-8-1) of Vessel G. . . . . . . . . . .284

Figure 8-63. Vessel H rim and body sherd (\#1135-8-1), exterior (left), interior (center), and profile

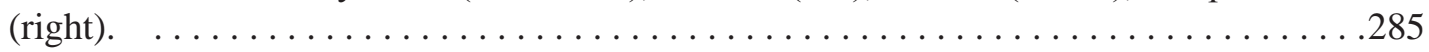


Figure 8-64. Photographs of Vessel I body sherd \#1036-8-1, exterior (left) and interior (center) and \#1072-8-1 (right). . . . . . . . . . . . . . . . . . . . . . . . . . . . 286

Figure 8-65. Vessel J body sherds, interior (left) and exterior (right). . . . . . . . . . . . . . . .287

Figure 8-66. Photograph and profile drawing of Vessel K rim sherds (\#1086-8-1 and \#1019-8-1) showing thick, pinched collar, and slanted lip. . . . . . . . . . . . . . . 288

Figure 8-67. Vessel L rim sherds (\#1058-8 and \#1117-8) showing exterior (left), interior (center), and profile (right). . . . . . . . . . . . . . . . . . . . . . . . . . . . . . 289

Figure 8-68. Exterior of Vessel M rim sherds (\#1047-8-1 and \#1044-8-1) showing cordmarked lip (left) and rim profile (right). . . . . . . . . . . . . . . . . . . . . . . . 290

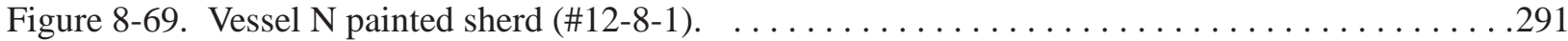

Figure 8-70. Unassigned body sherds (\#940-8-1) used in radiocarbon dating. . . . . . . . . . . . . . .292

Figure 8-71. Body sherds showing exterior cordmarking variations.. . . . . . . . . . . . . . . . 292

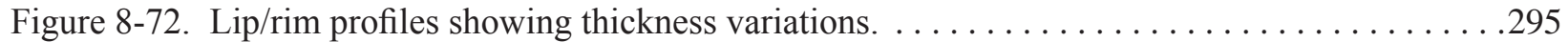

Figure 8-73. Profiles of selected vessels showing rim shapes. . . . . . . . . . . . . . . . . . . 295

Figure 8-74. Pinched rims of vessels K (left) and A (right) with shallow punctates on vessel A. . . . . 296

Figure 8-75. Decorated lips on vessels G (top left), M (top right) and D (bottom).. . . . . . . . . . . 296

Figure 8-76. Horizontal distribution of identified vessel groups in Component A. . . . . . . . . . . 300

Figure 8-77. Horizontal distribution of all ceramic sherds by weight (left) and by quantity (right) in

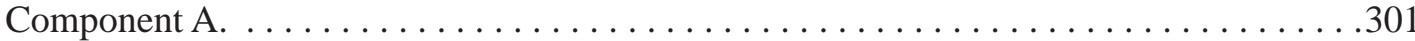

Figure 8-78. Distal deer humerus (\#1057-2-1) showing locations of cut lines. . . . . . . . . . . . 305

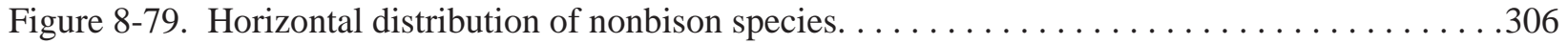

Figure 8-80. Fetal bison femur (\#1107-2-1) partially developed.. . . . . . . . . . . . . . . . . . . . .308

Figure 8-81. A young bison premolar tooth (\#1061-2), showing no wear on facets.. . . . . . . . . . . . 308

Figure 8-82. Horizontal distribution of identified bison elements.. . . . . . . . . . . . . . . . . . .310

Figure 8-83. Horizontal distribution of all faunal material by weight in Component A. . . . . . . . . . 311

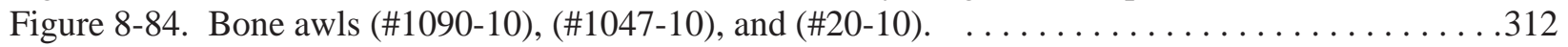

Figure 8-85. Bone tools; a burned pointed tip (\#31-10), a probable punch (\#1192-10), spatula tip

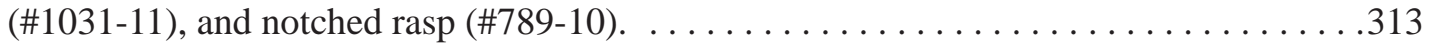

Figure 8-86. Closeup of worn distal end of a bison scapula (\#829-10) showing slight beveling at the

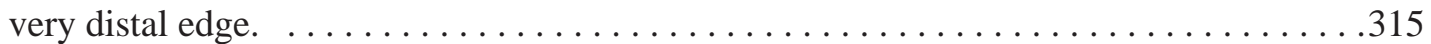

Figure 8-87. Bison scapula (\#829-10) showing manufactured and use areas. . . . . . . . . . . . . .315

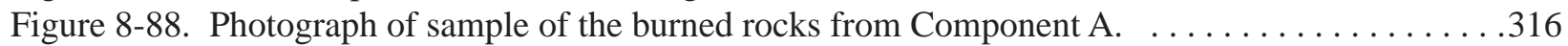

Figure 8-89. Horizontal distribution of burned rocks by count. . . . . . . . . . . . . . . . 318

Figure 8-90. Examples of burned clay/daub (\#1113-5) that exhibit variations in size and shape... . . . 319

Figure 8-91. Burned clay/daub (\#1202-5) with narrow stick impression. . . . . . . . . . . . . 320

Figure 8-92. Burned clay/daub (\#1021-5) with smooth, wide stick impression on one side. . . . . . .321

Figure 8-93. Burned clay/daub (\#1101-5) with multiple narrow impressions on one face............321

Figure 8-94. Burned clay/daub (\#1067-5) with faint and shallow, possible grass impression on left

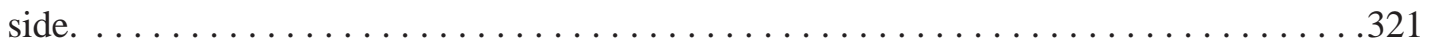

Figure 8-95. Horizontal distribution of daub weight across Component A. . . . . . . . . . . . . . . . . 323

Figure 8-96. Reworked sherds with one complete "spindle whorl" and similar broken pieces. . . . . . .324

Figure 8-97. Reworked ceramic sherds projected on to postulated whole specimens.. . . . . . . . . . 324

Figure 8-98. Interior (left), exterior (center), and profile (right) of red clay object (\#2-8-2). . . . . . 327

Figure 8-99. Interior (left), exterior (center), and profile (right) of red clay object (\#11-8-1). . . . . .327

Figure 8-100.Photographs of small lipped section of probable pipe fragment (\#1151-8-1, exterior on

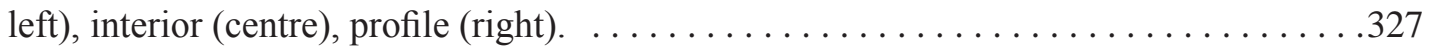

Figure 8-101.Interiors (left) and exteriors (center) of two clay sections (\#1195-8 left and \#1185-8-2

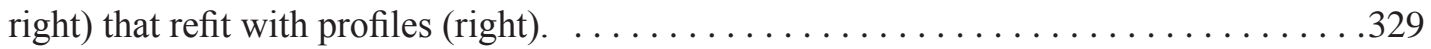


Figure 8-102.Possible figurine or vessel legs (\#1044-10 on left and \#1026-10 on right). . . . . . . .329

Figure 8-103.Photograph of one-half of a sandstone abrader $(\# 1056-10) \ldots \ldots \ldots \ldots \ldots \ldots$

Figure 8-104.One end/edge of a long trough type metate $(\# 783-10) \ldots \ldots \ldots \ldots \ldots \ldots \ldots \ldots \ldots \ldots$

Figure 8-105.Plan view drawings of mano and metate fragments projected onto postulated whole

metates.. . . . . . . . . . . . . . . . . . . . . . . . . . . . . . . . . . . 331

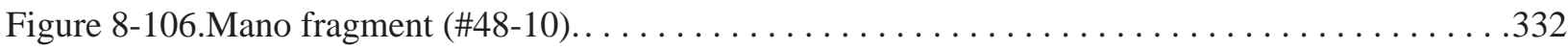

Figure 8-107.Photograph of edge-ground cobble (\#709-10), which yielded 45 lenticular grains of little

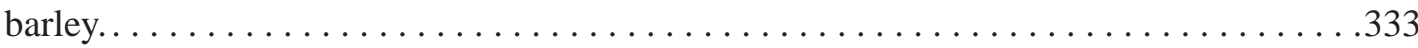

Figure 8-108.Plan and profile of shell bead $(\# 1032-10)$ from Feature $11 . \ldots \ldots \ldots \ldots \ldots \ldots \ldots \ldots 33$

Figure 9-1. Vertical distribution of features in northern part of Component C. . . . . . . . . . . . .335

Figure 9-2. Vertical distribution of features in the deeper southern part of Component C. . . . . . . 336

Figure 9-3. Horizontal distribution of features in Component C.. . . . . . . . . . . . . . . . 337

Figure 9-4. Large burned rock on patch of charcoal, Feature $2 \ldots \ldots \ldots \ldots \ldots \ldots \ldots \ldots \ldots \ldots$

Figure 9-5. Profile drawing of west wall of Feature 5 exposed in road cut.. . . . . . . . . . . . . . 339

Figure 9-6. Picture of profile of western end of Feature 5 basin $20 \mathrm{~cm}$ from road cut. . . . . . . . . 340

Figure 9-7. Profile drawing of three adjoining walls of Unit C-7 that depicts the location, shape, and size of a broad cultural basin (Feature 6). . . . . . . . . . . . . . . . . . 344

Figure 9-8. Photographs of wall profile (left) and bottom edge (right) of deep pit as revealed in Unit

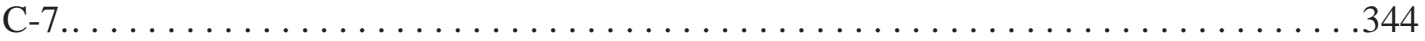

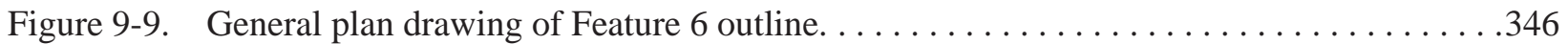

Figure 9-10. Partial profile drawing of entryway at eastern end of pithouse (N498 E497 and E498),

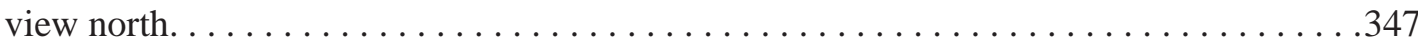

Figure 9-11. Photograph of northern edge of pithouse. $\ldots \ldots \ldots \ldots \ldots \ldots \ldots \ldots \ldots \ldots \ldots \ldots \ldots$

Figure 9-12. Drawing of the large cultural materials and features plotted across the pithouse floor. . . 349

Figure 9-13. West to east profile drawing of $1 \mathrm{~m}$ of the cultural material back plotted in the pithouse

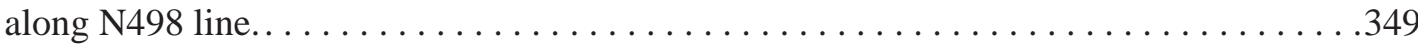

Figure 9-14. Overview of post holes (\#1, \#2 and \#3, right to left) on outside edge, along the northwestern side of pithouse and cultural refuse discarded on sloping floor of pithouse. 350

Figure 9-15. Overall plan view drawing of pithouse structure - Feature $6 \ldots \ldots \ldots \ldots \ldots \ldots \ldots \ldots$

Figure 9-16. Overall photograph of completed pithouse - Feature 6 following excavation, with baulk

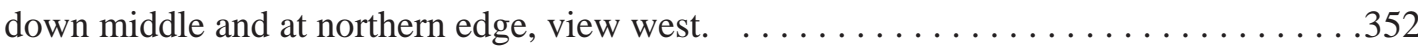

Figure 9-17. Photograph of sloping entryway along south wall of N499 E498. . . . . . . . . . 352

Figure 9-18. Top panel: map of Feature 6 showing the location of the two baulks profiles and column samples. Middle panel: drawing of the stratigraphy revealed by the northern wall of the

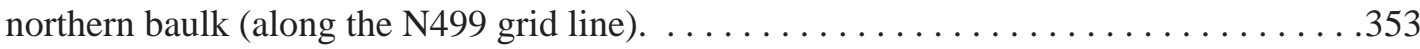

Figure 9-19. Plots of physical properties of sediment samples collected from the four column samples

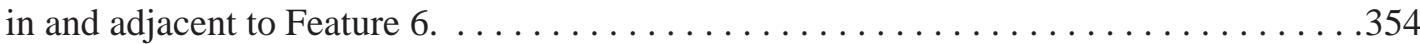

Figure 9-20. Plot of the mean particle size (in phi) versus the sorting (the standard deviation of the mean particle size distribution, also in phi) for different sediment groups associated with

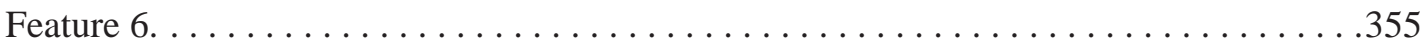

Figure 9-21. Plot of the percentage organic carbon versus the available phosphorous (Mehlich 2

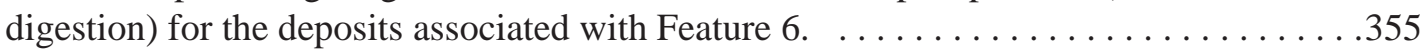

Figure 9-22. Plot of the calcium carbonate content (or calcium carbonate equivalent, in \%) versus the magnetic susceptibility for deposits associated with Feature $6 . \ldots \ldots \ldots \ldots \ldots \ldots \ldots 6$

Figure 9-23. Close-up photograph of baulk profile of interior fill near the middle of the pithouse Feature 6, showing uneven construction fill above floor with eolian fill above (block in

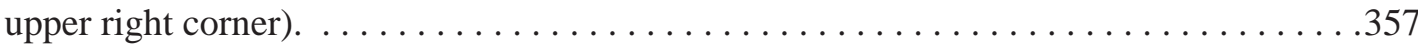


Figure 9-24. Profile drawing that shows the sequence of filling events in pithouse and distribution of

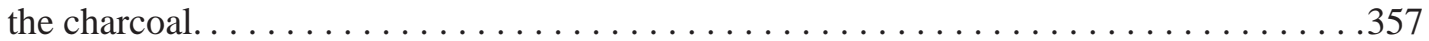

Figure 9-25. Suite of representative low magnification images of the main sediment groups associated with Feature 6: the Ogallala Formation, floor, earthen construction debris, and the Eolian Sand II. . . . . . . . . . . . . . . . . . . . . . . . . . . . 360

Figure 9-26. Plots of the particle size distributions for different deposits associated with Feature 6. . .362

Figure 9-27. Suite of images of the best preserved earthen construction material observed in the polyester embedded blocks collected from Feature 6 (sample MMZ2, immediately east

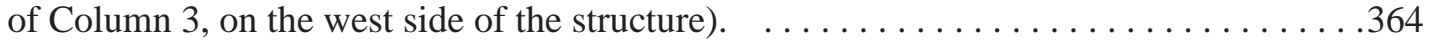

Figure 9-28. Upper panel: map of Feature 6 showing the location of the column samples shown

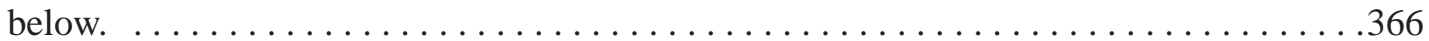

Figure 9-29. Close-up photograph of a whole shell bead from pithouse (scale in millimeters). . . . . .369

Figure 9-30. Overview of clustered rocks in Trench C-1 that was a buried cairn that covered a human

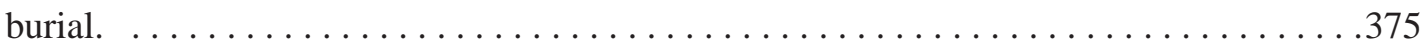

Figure 9-31. Photograph of Feature 7 showing upper caliche rock cairn covering. . . . . . . . . . 376

Figure 9-32. Drawing of the upper layers of the rock cairn and approximate pit outline. . . . . . . . 377

Figure 9-33. Plan View of Feature 7 showing underlying caliche slabs and uppermost reaches of

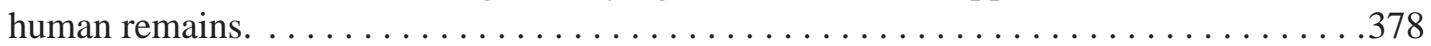

Figure 9-34. Plan view of Feature 7 showing lower reaches of interment. . . . . . . . . . . . . .379

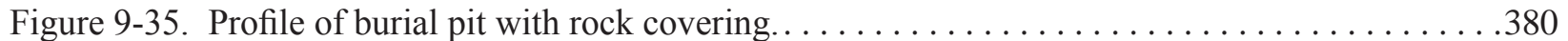

Figure 9-36. Plan view drawing of horizontal positions of Features 2, 5, and $16 / 22 \ldots \ldots \ldots \ldots \ldots 32$

Figure 9-37. Partial profile picture of Feature 16 showing burned rocks in Feature 16 basin above sand lens that filled Feature 21 basin in lower foreground. . . . . . . . . . . . . 383

Figure 9-38. Road-cut profile picture depicting Features 16 (top) and 21 (bottom) separated by sand

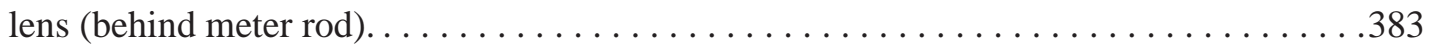

Figure 9-39. Overhead view of Feature 21 basin with burned maize cobs in fire-hardened bottom.....384

Figure 9-40. Profile photograph of road-cut showing Features 5 (left) and 16/21 (right)...........384

Figure 9-41. Profile drawing showing the association of Features 5 and $16 / 21 \ldots \ldots \ldots \ldots \ldots \ldots$

Figure 9-42. Photograph of exterior and interior of plain rim sherd (\#405-8) with decorated lip

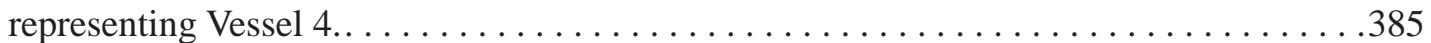

Figure 9-43. Photograph of partially obliterated cordmarked body sherd (\#468-008-4b) that represents Vessel 7. . . . . . . . . . . . . . . . . . . . . . . . . . . 386

Figure 9-44. Charred maize cob fragment (\#453-5-7 left) and charred mesquite beans (\#455-5-10

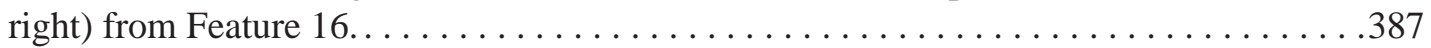

Figure 9-45. Profiles of post hole, Feature $17 \ldots \ldots \ldots \ldots \ldots \ldots \ldots \ldots \ldots \ldots \ldots \ldots \ldots \ldots \ldots \ldots$

Figure 9-46. Overview drawing of the southeast part of Component $C$ that shows a possible margin of Feature 18, in association with Features 19, 20, 23, 26, and 29 and probable post hole. 389

Figure 9-47. Post hole 7 north of Feature 23 in N483 E501 . . . . . . . . . . . . . . . . . . . . . . . 390

Figure 9-48. Sample of rock shapes, sizes, and material types from Feature $18 \ldots \ldots \ldots \ldots \ldots \ldots$. . . . 391

Figure 9-49. Oblique view of thick basal sherd (\#308-8; left) and large rim and neck sherd (\#308-8-3)

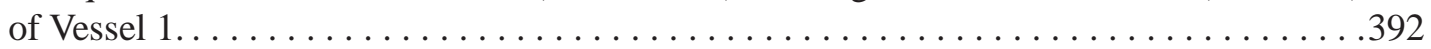

Figure 9-50. View of thick basal sherd (\#118-8-1) from unknown vessel, likely Vessel 3. . . . . . . . .392

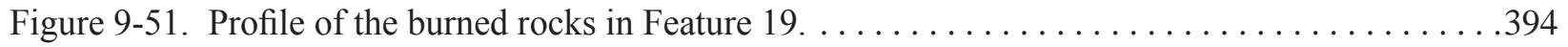

Figure 9-52. Overview of first partially exposed burned rocks in Feature $20 \ldots \ldots \ldots \ldots \ldots$

Figure 9-53. Plan view drawing of burned human remains, Feature 22, in secondary deposits. . . . . . 396

Figure 9-54. Edge rounded freshwater mussel shell associated with Feature 22 . . . . . . . . . . .397

Figure 9-55. Oblique view of storage pit - Feature 23 dug into the Ogallala Formation, post hole \#9 
next to north arrow with possible post hole on left edge. . ...................398

Figure 9-56. Plan view drawing of Feature 26 showing distribution of in situ thick ceramic sherds (Vessel 1) and rounded boiling stones all within Feature 18...............400

Figure 9-57. Profile photograph of charcoal ladened basin shaped heating element, Feature 26 with associated small quartzite boiling stones. . . . . . . . . . . . . . . . . . . 402

Figure 9-58. Profile photograph of Feature 28 at or next to the entryway.................. 403

Figure 9-59. Profile of organic rich basin, heating element, Feature $29 \ldots \ldots \ldots \ldots \ldots \ldots \ldots . . \ldots 404$

Figure 9-60. Plan view drawing of artifacts scattered across in Feature $31 . \ldots \ldots \ldots \ldots \ldots . . . . .405$

Figure 9-61. Profile drawing of deposits and artifacts scattered across Feature $31 \ldots \ldots \ldots \ldots \ldots . .405$

Figure 9-62. Surface and plan view drawing of rock alignment. . . . . . . . . . . . . . . . . 406

Figure 9-63. Hand-excavation exposed rocks along the alignment......................407

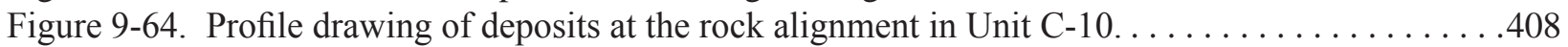

Figure 9-65. Washita (\#368-10), Huffaker (\#510-10), and Washita points (\#510-12). . . . . . . . . .414

Figure 9-66. Reworked Fresno (\#145-10), Huffaker (\#460-10), and Harrell (\#410-11) points from Component C. ........................................ 415

Figure 9-67. Biface fragment \#90-10 made of Niobrara jasper. . . . . . . . . . . . . . . . . . . . . 419

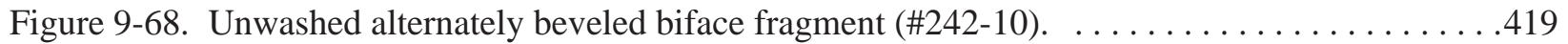

Figure 9-69. Plano-convex scraper from Component C. . . . . . . . . . . . . . . . . . . . . . . 421

Figure 9-70. Plano convex scraper (\#352-10) that exhibits evidence of hafting and use for scraping soft material. . ...................................... 421

Figure 9-71. Drill bit (\#174-10) shows signs of use for boring wood. . . . . . . . . . . . . . . . . 424

Figure 9-72. Edge-modified flake (\#599-10) that exhibits wear that suggests use in wood whittling. . .424

Figure 9-73. Unifacial spokeshave (\#615-10) tool from Component C. . . . . . . . . . . . . . . .424

Figure 9-74. Nondescript uniface (\#589-12) that exhibits signs of hafting and hide scraping. . . . . . .425

Figure 9-75. Stone tool spatial distribution at Component C. ......................426

Figure 9-76. Depth range and frequency for lithic debitage from Component C. . . . . . . . . . . .427

Figure 9-77. Debitage mostly comprised of Alibates from Component C. . . . . . . . . . . . . . . .427

Figure 9-78. Size grade distribution of lithic debitage in Component C.................4. 428

Figure 9-79. Distribution of platform-bearing flakes exhibiting thermal alteration. . . . . . . . . 428

Figure 9-80. Frequency of platforms types in Component $C$ debitage assemblage. . . . . . . . . . . . 428

Figure 9-81. Cortex presence on lithic debitage from Component C. . . . . . . . . . . . . . . . . . . 429

Figure 9-82. Horizontal distribution of flake debris at Component C......................430

Figure 9-83. Profile drawings of rim sherds from Vessel 1 showing slight variations in rim and shoulder shapes.......................................432

Figure 9-84. Photograph of Vessel 1 sherd \#303-8-1 profile showing the curved edge of a coil . . . . .433

Figure 9-85. Detail of poorly welded coils in rim sherd \#303-8-1 of Vessel $1 . \ldots \ldots \ldots \ldots \ldots . .433$

Figure 9-86. Close-up photographs of rim/neck/shoulder sherd (\#308-8-3); exterior (left) and interior

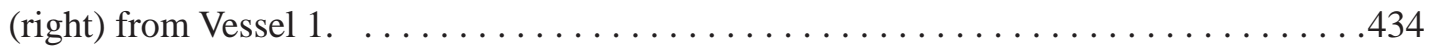

Figure 9-87. Detail of friable edges of thick basal sherds \#153-8-2 (left) and \#303-8-1/\#308-8-2

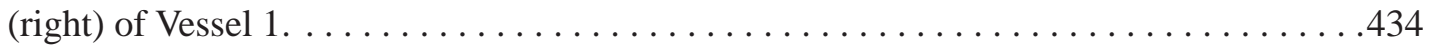

Figure 9-88. Partially reconstructed upper section of Vessel 1, showing detail of exterior lip, rim, neck, and shoulder area markings. . . . . . . . . . . . . . . . . . . . . 435

Figure 9-89. Detail of thick basal sherd (\#303-8-1 and \#303-8-2), exterior (left) and interior (right)

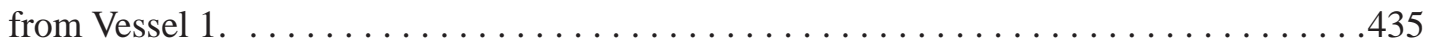

Figure 9-90. Partially reconstructed upper part of Vessel 1, showing detail of interior of lip, rim, and

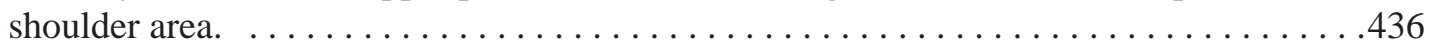

Figure 9-91. Profile photographs showing paste from base (\#303-8-1, left), body (\#335-8-1, middle), 
and rim (\#342-8-1, right) sherds of Vessel 1. . . . . . . . . . . . . . . . . . 436

Figure 9-92. Horizontal distribution of sherds of identified vessel groups across the excavations area. ...............................................

Figure 9-93. Vessel 2 rim sherd \#259-8-1 showing detail of exterior (left), exterior (middle), and

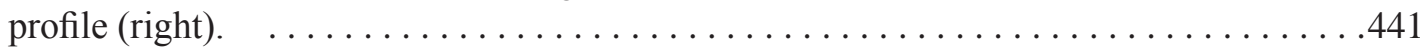

Figure 9-94. Vessel 3 rim refit (\#350-8-1 and \#349-8-1) showing details of exterior (left), interior

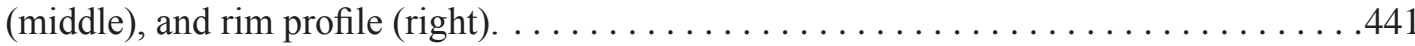

Figure 9-95. Basal sherd (\#118-8-1) of Vessel 3 showing details of exterior (left) and interior (right). .442

Figure 9-96. Vessel 4 showing detail of exterior (left), interior (middle), and profile (right) of rim

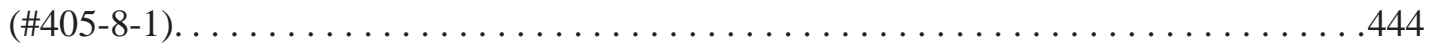

Figure 9-97. Vessel 4 refit body sherds (\#405-8-2) showing obliterated cordmarks on exterior surface...............................................

Figure 9-98. Rim sherds (\#519-8-1) and (\#619-8-1) exterior (left and middle) and interior (right) of

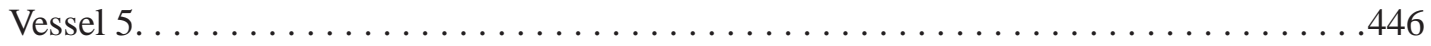

Figure 9-99. Profile drawings of Vessel 5 rim sherds (\#626-8, \#519-8-1, and \#671-8). . . . . . . . . 446

Figure 9-100.Detail of maize cob impressed sherd (\#649-8-4), exterior (left) and interior (right) of

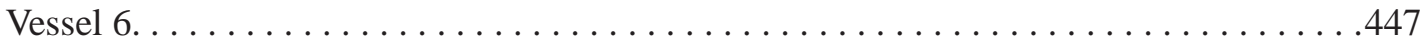

Figure 9-101.Vessel 7 refit sherds; exterior (left) and interior (right) surface treatments. . . . . . . . .448

Figure 9-102.Decorated lip on rim sherd (\#635-8-1) of Vessel 7. . . . . . . . . . . . . . . . . . 449 Figure 9-103.Different surface finishes on Vessels 1 (left, well-defined), Vessel 4 (center, obliterated),

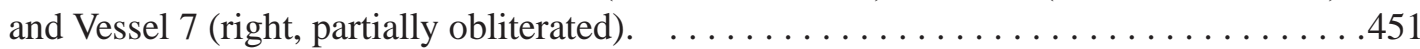

Figure 9-104. Horizontal distributions of ceramic sherds by weight (left) and quantity (right). . . . . . .457 Figure 9-105.Proximal deer femur (\#582-2-2) showing location of cut lines. . . . . . . . . . . . . . 460

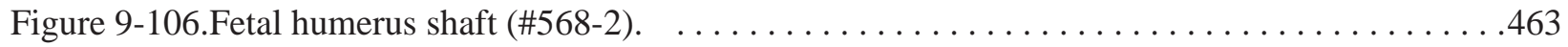
Figure 9-107.Lightly burned midshaft of metatarsal (\#643-2-10, left) and lightly burned distal end of metacarpal (\#643-2-1, right). . . . . . . . . . . . . . . . . . . . . . . . . . . . .465

Figure 9-108.Bison bones and other cultural materials scattered across the pithouse. . . . . . . . . 466 Figure 9-109.Close-up of M3 Showing limited wear on facets (\#413-2-1, left) and M2 with no wear on facets $(\# 349-2-1$, right)... . . . . . . . . . . . . . . . . . . . . . . . . . . 470

Figure 9-110. Horizontal distribution of the identified taxa in Component C.................472

Figure 9-111.Faunal distribution by weight across Component C................... 473

Figure 9-112.Photograph of proximal end of a bison scapula (\#582-2-6) with a deeply incised groove along the inside (to the right) of the removed spine. . . . . . . . . . . . . . . . . 475

Figure 9-113. Drawing of bison scapulas from Component $C$ that exhibit alterations..............476

Figure 9-114.Proximal end of a bison ulna (\#643-16) with flaked and worn coronoid process.. . . . . . 447

Figure 9-115.Two views of bison tibia digging tool (\#671-11), the complete tool (left) and close-up

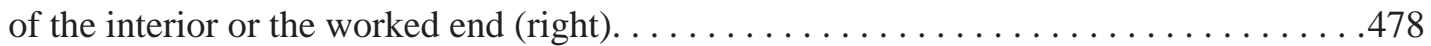

Figure 9-116. Two bone awls, a complete awl on bottom (\#582-11) and a fragment on top (\#582-13). .479

Figure 9-117. Medial section of bison scapula (\#643-2-11) that exhibits extensive, long cut lines next to spine (left), with impact marks on opposite edge, and scattered cut lines on opposite face

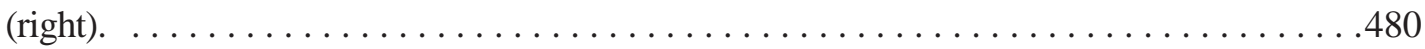

Figure 9-118. Samples of quartzite pebbles from Component C.........................481

Figure 9-119. Sample of burned caliche rocks from Component C. . . . . . . . . . . . . . . . 481

Figure 9-120.Cluster of five small rounded quartzite pebbles next to a basin heating element,

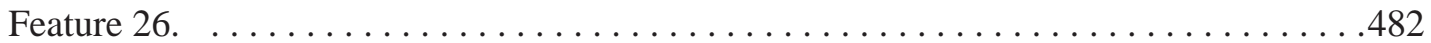

Figure 9-121.Horizontal distribution of burned rocks across Component C, minus data from the

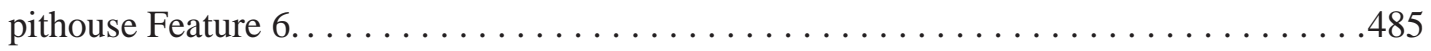


Figure 9-122.Examples of burned clay/daub (\#641-5) that exhibit rounded and curved surfaces and

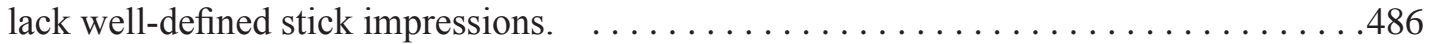

Figure 9-123.Example of burned clay/daub (\#315-5) with a series of three small, narrow stick-like impressions, side view (left) and top view (right). . . . . . . . . . . . . . . 487

Figure 9-124.Example of burned clay/daub (\#629-5) revealing a shallow, narrow stick impression (left) with a smooth convex face on opposite side (right).. . . . . . . . . . . . . 487

Figure 9-125.Burned clay/daub (\#453-5) that exhibits geometric pattern incised into this hard piece. .488 Figure 9-126.Burned clay/daub (\#643-5-1) that exhibits multiple well-defined impressions. . . . . . . .488 Figure 9-127.Burned clay/daub (\#417-5) exhibiting multiple thin, criss-crossing lines on one face.. . . .489 Figure 9-128.Horizontal distribution of daub weight across Component C.. . . . . . . . . . . . . .490

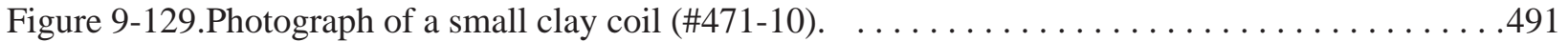

Figure 9-130.Examples of two single grooved abraders (\#643-12 and \#545-10). . . . . . . . . . . .493

Figure 9-131.Two examples of small one handed manos (\#629-10 and \#351-10).. . . . . . . . . . .493

Figure 9-132.Plan and profile drawings of mano and metate fragments projected onto postulated whole metates. . . . . . . . . . . . . . . . . . . . . . . . . . . . . . . . . . . 494

Figure 9-133.Photographs of pieces of deep basin-shaped metates (\#1229-12 and \#671-10). . . . . . . 494

Figure 9-134.Nearly complete one handed sandstone mano (\#191-10) that yielded maize and cheno-am starch grains. . . . . . . . . . . . . . . . . . . . . . 495

Figure 9-135.Plan and profile of shell bead (\#580-10) from 50 to $60 \mathrm{cmbs}$ in Pithouse, Feature 6. . . .495

Figure 10-1. Distribution of age determinations on charred maize (black bars), bison bone (light gray) and wood charcoal (dark gray bars) from Component A and Component C. . . . . . . . 500

Figure 10-2. AMS radiocarbon dated sherds: 41RB112-349-8-1 Vessel 3; 41RB81-291 basal sherd unassigned; and 41OC29-346-4 body sherd from pithouse A-3, exterior and profile. . . . .502

Figure 10-3. Seasonality of occupations at the Long View site, on the basis of different lines of evidence discussed in the text. . . . . . . . . . . . . . . . . . . . 508

Figure 10-4. Magne's assemblage formation model (1989) . . . . . . . . . . . . . . . . . . 515

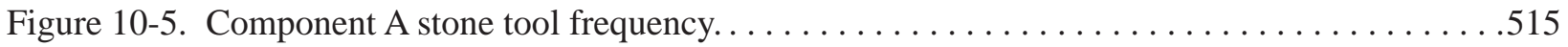

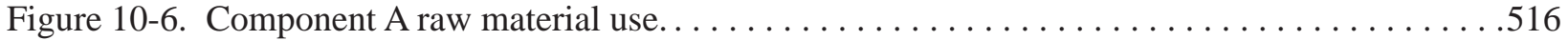

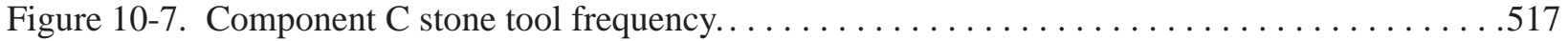

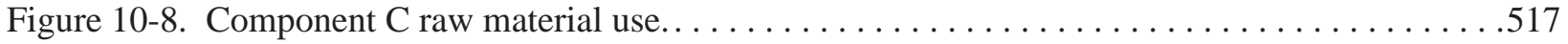

Figure 10-9. Index of tool technology strategy at multiple sites with late prehistoric components. . . .519 Figure 10-10.Radiocarbon age ranges for archeological manifestations in the Texas and Oklahoma

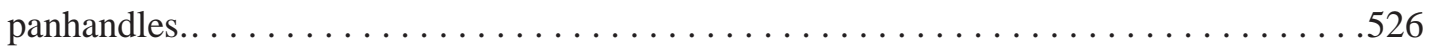

Figure 10-11.Radiocarbon dates before present (B.P.) for archeological manifestations in the Texas

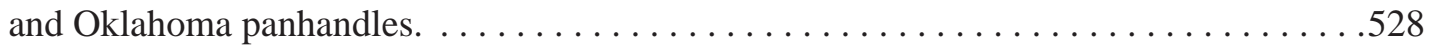

Figure 10-12.Vessel G (\#1066-8-1) from Component A and Vessel 3 (\#350-8-1 and \#349-8-1) from Component $\mathrm{C}$ illustrating difference in exterior cordmarking breadth.. . . . . . . . . 531

Figure 10-13.Map showing location of sites from which selected pottery samples were used in the two technical analyses.. . . . . . . . . . . . . . . . . . . . . . . 533

Figure 10-14.Graph showing the range of temper frequency by Long View component. . . . . . . . . .541 Figure 10-15.Two examples of charred maize cobs (\#453-5-7 left and \#1093-5-7 right). . . . . . . . . . 549 Figure 10-16. Close-up views of beveled outer edge (left) and inner edge (right) of bison tibia digging tool \#671-5-11 from pithouse Feature 6 floor in Component C. . . . . . . . . .556

Figure 10-17.A sample of highly fragmented bone, indicative of bone grease extraction, from the northern part of Component A, 41RB112....................... 558

Figure 10-18.Frequency of formal and informal tool use of non-Alibates materials at Component A. . .567 Figure 10-19.Frequency of formal and informal tool use of non-Alibates materials at Component C. . .567 
Figure 10-20.Line plots comparing maximum dimensions of Alibates tools in Component A to documented cobbles (data from Brosowske 2012) and projected cobble size (data from Ringstaff 2012) . . . . . . . . . . . . . . . . . . . . . . . . . . 569

Figure 10-21.Line plots comparing maximum dimensions of Alibates tools in Component $\mathrm{C}$ to documented cobbles (data from Brosowske 2012) and projected cobble size (data from Ringstaff 2012) . . . . . . . . . . . . . . . . . . . . . . . . . . . . . . . . 570

Figure 10-22.Top panel: A $1.72 \mathrm{~km}^{2}$ false color aerial photograph of the Long View site and vicinity taken on July 1, 2004, obtained from Terraserver. Lower Panel: Map compiled of selected Eolian geomorphic features in vicinity of the Long View Site compiled from the aerial image shown in the upper panel. $\ldots \ldots \ldots \ldots \ldots \ldots \ldots \ldots \ldots \ldots \ldots \ldots \ldots \ldots \ldots \ldots$

Figure 10-23.Stratigraphy, age, and depth variation in basic physical properties observed at the Lipps Ranch Stream Side Dune (LRSSD) locality. . . . . . . . . . . . . . . . . . . . . 574

Figure 10-24.Stratigraphy, age, and depth variation in basic physical properties observed in column profiles C-2 and C-4, within Eolian sand sheet depositional environment on south side

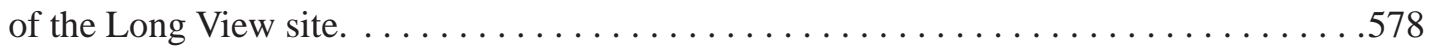

Figure 10-25.Plot of Folk and Ward mean particle size (in phi) versus sorting (standard deviation, in phi) for sediment samples collected from different Eolian depositional environments. . . .580

Figure 10-26.A. Change in percent silt with distance from sediment source for each Eolian depositional environment examined. B. Variation in percent clay in Eolian sediments with respect to distance from sediment source. . . . . . . . . . . . . . . . . 580

Figure 10-27.Plot of sedimentation rates obtained from OSL dates in each Eolian environment with respect to distance from sediment source (Dugout Creek). . . . . . . . . . . . . . . 581

Figure 10-28.Two Sigma radiocarbon ages obtained from Long View Components A and C with respect to one Sigma OSL ages obtained from riverine source border dune, upland sand

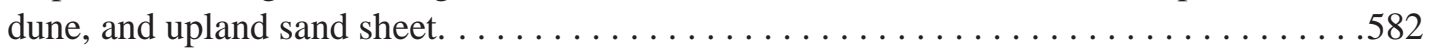

Figure 11-1. Bivariate plot of chromium (Cr) and europium (Eu) showing separation of Components A and $\mathrm{C}$ pottery and tempered natural clay samples from the region. . . . . . . . . . 597 


\section{List of Tables of Volume I}

Table 2-1. Plants that were Potentially Used for Food Resources. . . . . . . . . . . . . . . .30

Table 2-2. Percentage of Fatty Acids, Dry Bone weight, Mean fat Weight, and Mean Weight of Marrow in Bison. . . . . . . . . . . . . . . . . . . . . . . 40

Table 3-1. Overview of the 28 Antelope Creek Phase sites in the "Core Area” Around Lake Meredith (from Lintz 1986) . . . . . . . . . . . . . . . . . . . . . . . . . . .53

Table 3-2. Overview of the Four Excavated Antelope Creek Phase Sites in the Central Oklahoma

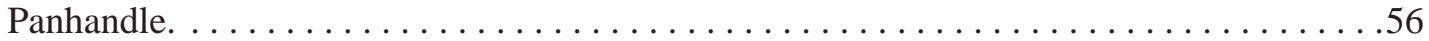

Table 3-3. $\quad$ Summary of Data From the Four Excavated Antelope Creek Phase Sites in the Central Oklahoma Panhandle. .................................... . . . . .

Table 3-4. Explanation of Buried City Sites and Selected Data Per Site. . . . . . . . . . . . . . . .76

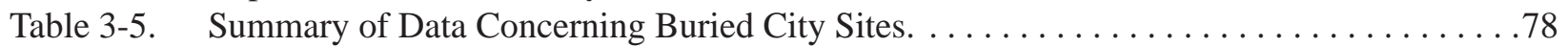

Table 3-6. Radiocarbon Dates Available from Buried City Sites (Brosowske 2005:134). . . . . . . . . 80

Table 3-7. Comparison of Selected Aspects of Antelope Creek Phase and the Buried City Complex. .91

Table 3-8. List of Radiocarbon Dates from Black Dog Village (Brosowske 2005).. . . . . . . . . . . 98

Table 3-9. Radiocarbon Dates from Pithouses at Odessa Yates, Lonker and Lundeen (from

Brosowske 2005:134). . . . . . . . . . . . . . . . . . . . . . . . . . 106

Table 4-1. Samples to be Dated for Study of Eolian Sedimentation at and Near the Long View Site,

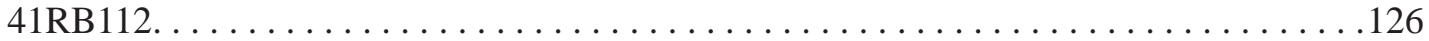

Table 5-1. List of Sites and Sherds from Surrounding Areas Used for Comparisons. . . . . . . . . . . . 162

Table 6-1. Column 2 (C-2) Collected from West Side of Fireguard, Adjacent to TxDOT Right-Of-Way Fence, Where Eolian Mantle Appeared Relatively Thick. . . . . . . . . . . 180

Table 6.2. Column 4 (C-4) Collected from East of Fireguard, Next to the Road Cut at Feature 18. . .181

Table 6-3. $\quad$ Lipps Ranch Stream Side Dune (LRSSD) Profile from Hand-Excavated Stair Step Profile Through 3-to-4-m-Tall Dune Situated Adjacent to the Active Channel of Dugout Creek about $900 \mathrm{~m}$ Southwest of the Southern End of 41RB112.................183

Table 6-4. Profile of Lipps Ranch Upland Dune (LRUD) from Hand-Excavation in a Series of Low Relief Sand Dunes Adjacent to the Site. . . . . . . . . . . . . . . . . . . 185

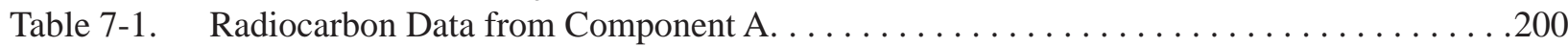

Table 7-2. Radiocarbon Data from Component C. . . . . . . . . . . . . . . . . . 205

Table 7-3. Radiocarbon Dates and Data on Pottery and Residues from Component C.... . . . . . . 206

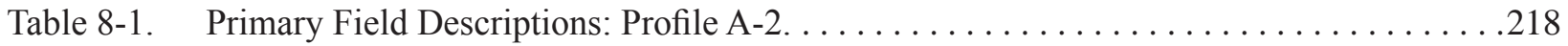

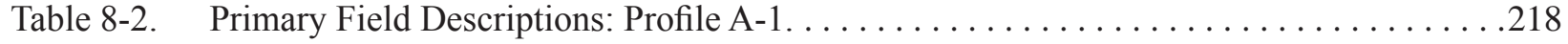

Table 8-3. Metric Data of Identified Post Holes in Associated with Pithouse - Feature 1. . . . . . .224

Table 8-4. Component A, Heavy Fraction Results by Material Class. . . . . . . . . . . . . . . . . . 226

Table 8-5. Summary of Component A Features and Feature Data.. . . . . . . . . . . . . . . . . . 245

Table 8-6. Artifact Class Frequency for Component A. . . . . . . . . . . . . . . . . . . . . . 247

Table 8-7. Selected Quantitative Measurements for Projectile Points. . . . . . . . . . . . . . . . . 251

Table 8-8. Selected Qualitative Observations of Complete Points. . . . . . . . . . . . . . . . . . . . 252

Table 8-9. Selected Attributes on Component A Bifaces. . . . . . . . . . . . . . . . . . . . . 253

Table 8-10. Selected Scraper Attributes... . . . . . . . . . . . . . . . . . . . . . . . .257

Table 8-11. Metric Attributes of Drills from Component A... . . . . . . . . . . . . . . . . . . . 260

Table 8-12. Metric Attributes of Edge-Modified Flakes from Component A. . . . . . . . . . . . . . 260

Table 8-13. Summary of the Assigned Sherds to Vessel Groups and Key Vessel Data............... 293

Table 8-14. Petrographic Identifications and Quantifications of Ceramic Data from Component A... .299 
Table 8-15. List of Species Identified in Component A. . . . . . . . . . . . . . . . . . . . .303

Table 8-16. Type and Number of Deer Elements in Component A. . . . . . . . . . . . . . . . . . . . . .304

Table 8-17. Type and Number of Bison Elements in Component A. . . . . . . . . . . . . . . . . . . . . 307

Table 8-18. Selected Worked Bone Data from Component A. . . . . . . . . . . . . . . . . . . .313

Table 8-19. Attributes of Worked Sherds.. . . . . . . . . . . . . . . . . . . . . . . . . . . . . .326

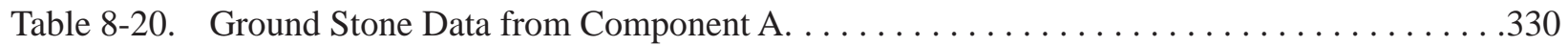

Table 9-1. Heavy and Light Fraction Results from Flotation Analysis of Feature Matrix,

Component C. . . . . . . . . . . . . . . . . . . . . . . . . . . . . . . 341

Table 9-2. $\quad$ Post Hole Data from Pithouse, Feature $6 \ldots \ldots \ldots \ldots \ldots \ldots \ldots \ldots \ldots \ldots \ldots \ldots \ldots \ldots \ldots \ldots$

Table 9-3. Primary Field Descriptions, N498 Grid Line Baulk Profile. . . . . . . . . . . . . . . . 358

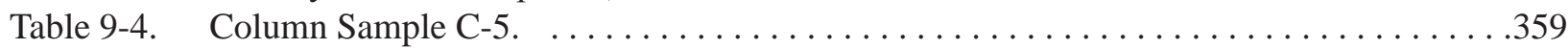

Table 9-5. Heavy Fraction Flotation Results from Pithouse, Feature $6 \ldots \ldots \ldots \ldots \ldots \ldots \ldots \ldots$

Table 9-6. $\quad$ Percentages of Major Short Cell Phytoliths on Floor of the Pithouse. . . . . . . . . . . 373

Table 9-7. Percentages of Major Short Cell Phytoliths in Construction Fill above Pithouse Floor. . . 373

Table 9-8. Summary of Component C Features and Feature Data.. . . . . . . . . . . . . . . . . . . .409

Table 9-9. Artifact Class Frequency for Component C. . . . . . . . . . . . . . . . . . . . .413

Table 9-10. Selected Quantitative Measurements for Projectile Points. . . . . . . . . . . . . . . .416

Table 9-11. Selected Attributes on Component C Bifaces. . . . . . . . . . . . . . . . . . . . . . . . . . . . .418

Table 9-12. Selected Scraper Attributes. . . . . . . . . . . . . . . . . . . . . . . . . . . . . .422

Table 9-13. Metric Attributes of Drills at Component C. . . . . . . . . . . . . . . . . . . . . . .422

Table 9-14. Summary of Metric Measurements on Edge-Modified Flakes. . . . . . . . . . . . . . . . .422

Table 9-15. Metric Attributes of Specialized Informal Tools.. . . . . . . . . . . . . . . . . . . .427

Table 9-16. Petrographic Identifications and Quatifications on Three Different Parts of Vessels 1. . . 438

Table 9-17. Summary of the Assigned Sherds to Vessel Groups and Key Vessel Data from

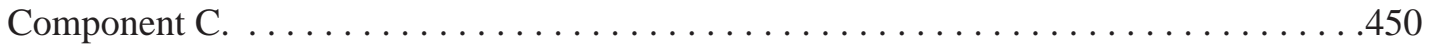

Table 9-18. Petrographic Identifications and Quantifications of Ceramic Data from Component C.. . .454

Table 9-19. List of Taxa Identified and Bone Counts in Feature 6, the Pithouse in Component C. . . .460

Table 9-20. Identified Bison Elements from the Pithouse in Component C . . . . . . . . . . . .462

Table 9-21. List of Taxa Represented and Bone Counts from Outside the Pithouse, Feature 6. . . . . .466

Table 9-22. Identified Bison Elements from Beyond the Pithouse in Component C....... . . . .467

Table 9-23. Measurements on Mature Bison Elements that Indicate Male and Female Elements. . . . 469

Table 9-24. Selected Worked Bone Data from Component C. . . . . . . . . . . . . . . . . . .477

Table 9-25. Component C Ground Stone Data.. . . . . . . . . . . . . . . . . . . . . . . . . . . . .492

Table 10-1. Radiocarbon Dates from Components A and C. . . . . . . . . . . . . . . . . . . .499

Table 10-2. Provenience and Pertinent Data Concerning Radiocarbon Dated Sherds and Organics Scraped from Sherds. . . . . . . . . . . . . . . . . . . . . . . . . 501

Table 10-3. Artifacts and Artifact Classes Recovered from Component A at Long View, Assigned to Preconceived Generalized Activities.. . . . . . . . . . . . . . . . . . . . . . 505

Table 10-4. Artifacts and Artifact Classes Recovered from Component $C$ at Long View, Assigned to Preconceived Generalized Activities.. . . . . . . . . . . . . . . . . . . . . . . 506

Table 10-5. Summary of Artifacts and Classes of Artifacts from Components A and C. . . . . . . . .513

Table 10-6. Debitage-to-Tool Ratios from Selected Late Prehistoric Sites. . . . . . . . . . . . . . . . . . 518

Table 10-7. Antelope Creek Phase Burial Locations and Types in Selected Sites.. . . . . . . . . . . . . 522

Table 10-8. Cultural Manifestations in the Texas and Oklahoma Panhandles with Various Types of Habitation Structures.. . . . . . . . . . . . . . . . . . . . . . . . . . 525

Table 10-9. Sherd and Clay Samples for INAA Analysis from Sites in Regions Adjacent to Long

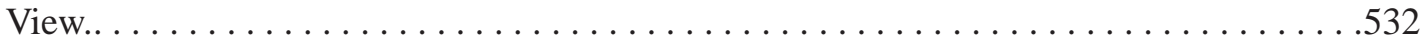


Table 10-10. Chemical Group Assignments by MURR for Multiple Samples from Individual Vessels

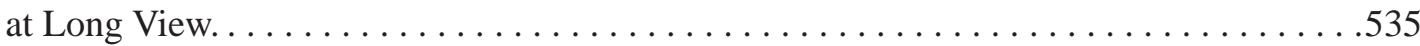

Table 10-11. Sites and Sherd Designation Selected for Petrographic Analysis. . . . . . . . . . . . . 538

Table 10-12. Sherds Assigned to Four Temper Classes by Site. . . . . . . . . . . . . . . . . . . . .539

Table 10-13. Comparison of Temper Classes by Site.. . . . . . . . . . . . . . . . . . . . . . . . . . . .542

Table 10-14. INAA and Petrography Result Comparison for the Two Long View Components. . . . . .544

Table 10-15. Associations of Temper Types with Collared and Uncollared Vessels from the Region. . .546

Table 10-16. Plant and Animal Resources Identified at Long View and other Sites and Cultural Manifestations in the Region. . . . . . . . . . . . . . . . . . . . . . . . . . 548

Table 10-17. Summary of Plants Identified During Starch Grain Analysis and Conditions of the

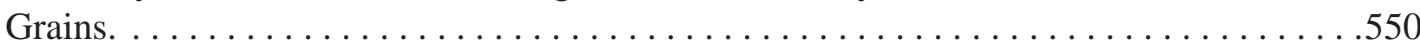

Table 10-18. Overview of Bone Tool Types from Selected Phases and Complexes. . . . . . . . . . . . .557

Table 10-19. Presence/Absence of Nonlocal Goods in Plains Village Sites across the Texas Panhandle Region...................................... 560

Table 10-20. Comparison of Exotic Goods from Sites and Phases/Complexes in the Region. . . . . . . . 564

Table 10-21. Lipps Ranch Stream Side Dune (LRSSD) Profile from Hand-Excavated Stair Step Profile Through 3-to-4-m-Tall Dune Situated Adjacent to the Active Channel of Dugout Creek about 900 m Southwest of the Southern End of 41RB112.. . . . . . . . . . . . . . . . 575

Table 10-22. Column 2 (C-2) Collected from West Side of Fireguard, Adjacent to TxDOT Right-Of-Way Fence, Where Eolian Mantle Appeared Relatively Thick. . . . . . . . . . . 576

Table 10-23. Column 4 (C-4) Collected from East of Fireguard, Next to the Road Cut at Feature 18. .579 Table 11-1. List of Artifacts and Features from Long View (41RB112) . . . . . . . . . . . . . . . . 587 


\section{VOLUME II: APPENDICES}

APPENDIX A RADIOCARBON ASSAY RESULTS. . . . . . . . . . . . . . . . . . . . . 669

APPENDIX B 41RB112 SEDIMENT SAMPLE PHYTOLITH ANALYSIS . . . . . . . . . . . . 707

APPENDIX C PLANT REMAINS FROM THE LONG VIEW SITE: 41RB112 . . . . . . . . . . . 767

APPENDIX D STARCH ANALYSIS OF THE LONG VIEW SITE . . . . . . . . . . . . . . . .793

APPENDIX E SOURCE PROVENANCE OF OBSIDIAN ARTIFACTS AND ELEMENTAL ANALYSIS OF TWO SHELL BEAD ARTIFACTS FROM THE LONG VIEW SITE (41RB112), CANADIAN RIVER VALLEY, NORTH EASTERN TEXAS . . . . . . . 811

APPENDIX F ANALYSIS OF PLAINS VILLAGE SITE CERAMICS FROM THE PANHANDLES

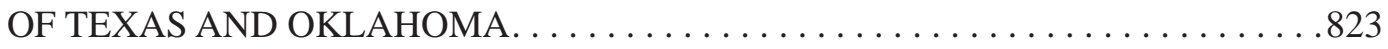

APPENDIX G NEUTRON ACTIVATION ANALYSIS OF CERAMIC AND CLAY SAMPLES FROM SOUTHERN PLAINS VILLAGE SITES IN OKLAHOMA AND TEXAS . . 857

APPENDIX H MICROSCOPIC USE-WEAR AND RESIDUEANALYSES OF STONE TOOLS

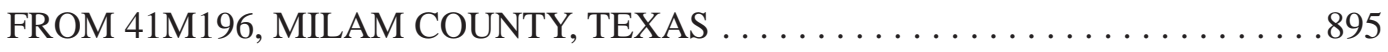

APPENDIX I FUNCTIONAL ANALYSIS OF STONE TOOLS FROM THE PLAINS VILLAGE SITE OF LONG VIEW, ROBERTS COUNTY, TEXAS 41RB112 SEDIMENT

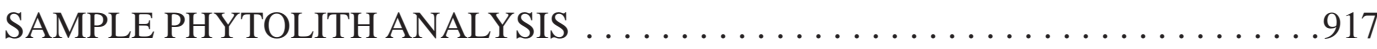

APPENDIX J PALEOENVIRONMENTAL ANALYSIS OF DIATOMS IN DAUB, AND BURNED ROCK SAMPLES FROM THE LONG VIEW ARCHEOLOGICAL SITE (41RB112), ROBERTS COUNTY, TEXAS . . . . . . . . . . . . 943

APPENDIX K NAGPRA INVENTORY FOR SITE 41RB112 (CSJ: 0490-04-037), ROBERTS

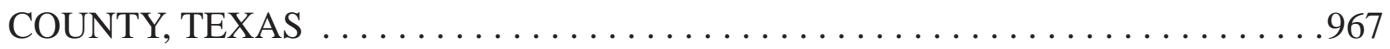

APPENDIX L ASSESSMENT OF 41RB112, ROBERTS COUNTY, TEXAS INTERIM REPORT . .983 APPENDIX M TXDOT CHIPPED STONE PROTOCOL VERSION $2.1 \ldots \ldots \ldots \ldots \ldots \ldots \ldots 1$ APPENDIX N TXDOT CERAMIC PROTOCOL, VERSION $2.0 \ldots \ldots \ldots \ldots \ldots \ldots \ldots \ldots$. . . . . . . . 1097 APPENDIX O METRIC AND NONMETRIC DATA FOR ARTIFACTS FROM LONG VIEW

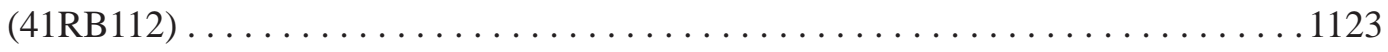

APPENDIX P STABLE ISOTOPE RATIO ANALYSES . . . . . . . . . . . . . . . 1179 APPENDIX Q POTTERY DATA FROM OTHER PLAINS VILLAGE SITES . . . . . . . . . . 1183 APPENDIX R QUARTZ OPTICAL DATING REPORT: LONG VIEW SITE, TEXAS . . . . . . . 1213 APPENDIX S NAGPRA INVENTORY OF TWO INDIVIDUALS RECOVERED FROM 41RB112 - AREA C, ROBERTS COUNTY, TEXAS . . . . . . . . . . . . . . . 1255 


\section{ACKNOWLEDGEMENTS}

The Archeological Studies Program in the Environmental (ENV) Affairs Division of the Texas Department of Transportation (TxDOT) sponsored and oversaw these necessary archeological investigations. We would like to express our gratitude to the many TxDOT personnel for their support and guidance. Initially Dr. Lain Ellis, as Supervisor of the Archeological Studies Program, oversaw this program followed by Dr. Scott Pletka who succeeded Dr. Ellis. Besides Dr. Pletka, Dr. James Abbott and Mr. G. Dennis Price worked closely with TRC Environmental Corporation's (TRC's) archeological staff over the years to facilitate the many individual work authorizations, supplemental agreements, and other paperwork necessary to successfully complete the eligibility assessment followed by the data recovery excavations at $41 \mathrm{RB} 112$.

TRC performed the eligibility assessment of 41RB112 for nomination to the National Register of Historic Places in May 2005. The field crew included D. Batten, Cory Broehm, BobbyJo Coke, Weldon Hammond, Greg LaBudde, C. Mattras, Kerry McGuire, and Ron Rowe. During this testing effort, Marie Archambeault served as Project Archeologist with Mercedes Cody as crew chief. Mr. Quigg served as Principal Investigator.

A team of Dr. Abbott, Dr. Nancy A. Kenmotsu and G. Dennis Price reviewed and commented on the eligibility assessment report. These same individuals then worked with TRC personnel to facilitate the analyses and reporting stages for this final report. Dr. Abbott facilitated the multiple submissions for radiocarbon dating of materials through outside laboratories. He also accompanied Mr. Quigg to the site in February 2005 for an inspection of the site and to discuss the plan for evaluating the deposits. These TxDOT individuals reviewed and commented on interim eligibility assessment, whereas TxDOT archeologists James Abbott, G. Dennis Price, and Waldo Troell reviewed and commented on final draft of the data recovery reports, multiple research designs, and draft documents over the years. These individuals are thanked for their comments, direction, and support over the life of this project. TxDOT also provided TRC with the ceramic, chipped stone tool, and lithic debitage protocols to follow in the analysis of the archeological assemblages.

Individuals from TxDOT district office in Perryton also provided invaluable assistance during the fieldwork. Ms. Cheryl Luther, Enhancement Coordinator of TxDOT's Amarillo District Office. The Perryton office supplied the backhoe and operator used in stripping the south end of Area C at the close of the project to ensure that no cultural resources remained in the right-of-way. Mr. Richard Allan is thanked for the operation of the backhoe.

TRC also thanks Tiffany Osburn of the Texas Historical Commission for her review and comments of the draft final report.

Thanks go to the hard-working archeological field staff from the Cultural Resources Department of TRC's Austin office who helped to complete the data recovery excavations on time through a diverse weather conditions from August through November 2006. Mr. Paul Matchen served as the Project Archeologist with the excellent assistance of Ms. Kendra Luedecke (currently Mrs. DuBois), the crew chief, under the overall guidance and direction of Mr. Mike Quigg the Principal Investigator. Mr. Matchen supervised and directed the day to day operations of archeological technicians, which included Mr. Brennan Bajdec, Mr. Cory Broehm, Mr. Matt Cuba, Mr. Owen Ford, Ms. Lisa Kraus, Mr. Brett Lang, Mr. Kerry McGuire, Ms. Virginia Moore, Jeff Roberson, Mr. Greg Sundborg, and Mr. David Yelacic. Mr. Broehm and Mr. Ford were instrumental in documenting the human remains encountered. Mr. Ford drove the equipment truck loaded of samples from the field to the Austin laboratory. Thanks to all these individuals for their efforts and hard work and meeting the demands of the Principal Investigator. Paul Matchen, Kendra DuBois, and David Yelacic traveled back to the site to monitor and work with the backhoe operator in the final stripping the south end as requested by TxDOT. This stripping was to insure that no other significant cultural features remained within the proposed area of potential effect. 
Dr. Charles Frederick, TRC's geoarcheologist, conducted the in-field stratigraphic sampling and documentation of features and site depositional characteristics, plus the off-site sampling to develop the regional depositional sequence. Dr. Fredrick also worked closely with Mr. Quigg during the analysis and reporting stage to fully document and address key stratigraphic and depositional questions. Dr. Frederick assisted by Brittney Gregory conducted the laboratory analyses on the geoarcheological samples to extract the actual data used to interpret the natural and cultural deposits. Dr. Frederick wrote the section on the natural stratigraphy presented in Chapter 6.0, in addition to the stratigraphic descriptions and conducted analysis on the deposits from both pithouses, discussed in the feature sections of Chapter 8.0 and 9.0. Thank you Charles and Brittney Gregory for another excellent analysis and interpretation of the different deposits.

The geophysical investigations at the beginning of the data recovery program were conducted by David Maki of Archaeo-Physics, LLC- Shallow Subsurface Geophysical Survey from Minneapolis. He used his expert knowledge and multiple instruments to conduct this investigation in the two target areas, A and C. It was anticipated that the geophysical results would help guide the placement of the data recovery units and locate potential unidentified cultural features to target. Unfortunately, a number of mitigating factors, such as temperatures of over 37.8 degrees Celsius (105 degrees Fahrenheit), extremely dry ground, plus the two metal fence lines, metal trash, and overhead power lines reduced the effectiveness of the geophysical investigations. Thank you Mr. Maki for your efforts and technical expertise in employing the multiple pieces of equipment. Mr. Paul Matchen and Ms. Kendra DuBois were on-site during the geophysical investigations to help with the layout of the grid system and conducted the overall mapping of the site, the grid systems employed and other tasks.

Thanks also goes out to the adjacent local landowner Mr. Harold Courson of Perryton who stopped by on different occasions to see our progress, what was being discovered, and show his interest in our work. Mr. Courson expressed positive statements and encouragement to the crew. He also graciously provided a very delicious dinner at his Wolf Creek ranch house along with entertainment for the entire crew. Courson Oil and Gas archeologist, Dr. Scott Brosowske facilitated our visit to the ranch and showed our crew their collections they were processing from various sites. Dr. Brosowske also made numerous visits to the site to see our progress and comment on our findings. He also worked closely with David Maki during the geophysical investigation, in readying the narrow right-of-way by facilitating the removal of the old barbed wire fence, and the fence staples and wire fragments associated with the fence prior to the geophysical investigations. Dr. Brosowske also was kind enough to provide valuable background information and spent time tracking down the requested ceramic and clay samples from the Plains Village sites in Wolf Creek valley used in this analysis. Thank you Scott for your interest and help during our investigations and reporting.

Mr. Doug Wilkens, dedicated Texas Archeological Steward for the panhandle, stopped by a number of times to visit, inspect our fieldwork, and comment on the findings. He also took time off and led the entire crew on a tour of the adjacent M-Cross Ranch sites to show us the excavations at the significant Indian Springs site. Thank you Doug for your time, interest, and exchange of ideas. He also provided Mr. Quigg with a couple of local animal caucuses, and clay and lithic samples thought to be important and contribute to a better understanding our investigations. Doug, your collections made a substantial contribution to the finds of this project.

We also thank Mr. Terry Callihan an independent contractor for his security services in maintaining a watchful eye on the equipment and exposed cultural materials during critical times during the fieldwork. Thankfully nothing was disturbed and no major instances occurred during his late night watch. Thanks Terry for your services.

Many individuals and organizations worked with TRC to make significant contributions to understand the past human behaviors at this Plains Village site and the success of this program. Thanks go out to all of the following for their contributions. 
Once in the Austin laboratory, Ms. DuBois the Laboratory Supervisor, directed and supervised the initial processing of the collections, established the electronic site database, and supported and facilitated the preparation of the interim report by preparing figures and tables. Ms. DuBois was assisted by Ms. Shelly Fischbeck and Mr. David Yelacic, who sorted, washed, labeled, counted, and bagged samples and artifacts. Only a part of the collections were processed under the work authorization for the interim report deliverable. After the work authorization for the analyses and reporting was issued by TxDOT, the rest of the laboratory processing was completed. This latter processing was facilitated by Ms. TrishaAnn Gonzales and Ms. Shannon Gray. Ms. Gonzales sorted, washed, labeled, entered data into the database and helped in many ways with the collections. She conducted all the flotation of the matrix samples, the subsequent picking and sorting the heavy fractions, created data tables, and recorded the data in the database. She searched, assembled, and packaged many of the various samples sent for technical analysis, plus the tracking of the data and adding data to the database. Trisha-Ann Gonzales also conducted some of the initial sorting of the lithic debitage and artifact measurements under the direct supervision of Mr. Paul Matchen. She helped organize and ready the artifacts and data for reporting and conducted a variety of tasks to help Mr. Quigg and Mr. Matchen. Her willingness to perform all the tedious tasks with a smile and her attention to detail was much appreciated.

Ms. Shannon Gray, as laboratory supervisor, directed and oversaw all the activities in the laboratory, conducted the drafting of illustrations used in the data recovery report, managed the database, and generated the many tables used for the writing and those used in the report, and some editing of specific sections. In addition, Shannon conducted artifact measurements for many of the formal and informal chipped stone tools under the direction of Paul Matchen. She also oversaw the curation preparation. Thank you Shannon for your focus on the details.

Paul Matchen served as Project Archeologist and Field Director for the data recovery efforts. He conducted the lithic artifact analysis, wrote the sections on the chipped stone tools and lithic debitage, as well as co-authored sections that addressed project research questions, environmental setting, and methodology chapters. He also took and prepared photomicrograph images for the petrographic analysis section authored by David Robinson. Dr. Robert Ricklis provided his extensive background and knowledge, and contributed to the research design presented in Chapter 4.0. Thank you, Paul! Dr. Ricklis provided peer review for most sections of the draft report, made editorial changes and corrections, added content, and provided many useful comments to improve the overall quality and readability of this report. Thanks Bob for your continued support and expertise.

Ms. Marissa Stewart conducted the formatting of the initial draft, making the corrections and formatting the final report. She also worked with the printing company to facilitate the production of the final report and the distribution of the printed copies. Thank you Marissa for the attention to detail and finalizing this report.

I would like to personally thank two archeological colleagues, Dr. Chris Lintz and Mr. Doug Boyd, for their many hours of exchanging ideas and comments concerning the Plains Village period. Dr. Lintz's extensive research, interest, and considerable knowledge dealing with Plains Village sites, specifically the Antelope Creek phase, has provided me with a wealth of information, background documents, comments, and encouragement. This education has greatly benefited me and this specific project. With permission of the owner Mr. Erickson and with the go ahead from Mr. Brett Cruse of the Texas Historical Commission, I was allowed to see and handle the ceramic sherd collection from the Indian Springs site (41RB81) on the M-Cross Ranch and select specific sherds for use in destructive analyses. Chris also provided guidance in numerous other ways including advice and directions concerning Antelope Creek phase sites and materials, loan of many reference books from his extensive library, unpublished manuscripts dealing with Plains Village sites. Thank you Chris for all your support and ideas.

Mr. Doug Boyd's recent experience and excavations on Plains Village sites in the adjacent property at the 
M-Cross Ranch has also enlightened and provided me with very valuable understanding of the Plains Village variations in this region. Doug shared a table of 14 radiocarbon dates and associations from the M-Cross Ranch. He provided, with the permission of Mr. Erickson, nine sherds and one clay sample from other investigated sites on the M-Cross Ranch that includes Hank's site (41RB109-A, 41RB109-B, and 41RB109-E), Three Toes (41RB110), and Whistling Squaw (41RB108). These samples were also used in our two destructive analyses. Thank you Doug for your time, samples and support in furthering the knowledge of the Plains Village Tradition in Texas panhandle.

Dr. Richard Drass, of the Archeological Survey at the University of Oklahoma, is thanked for his willingness, time and effort to go to the Sam Noble Oklahoma Museum of Natural History and search through the ceramic collections from three excavated Antelope Creek phase sites in the Oklahoma panhandle, specifically Roy Smith (34BV14), Stamper (34Tx1), and McGrath (34Tx4313). He was gracious enough to volunteer to select samples for approval by Dr. Don Wyckoff, Curator, for use in the destructive analyses as part of this project. His valuable time and professional expertise in Plains Village ceramic assemblages significantly contributed in sorting through the ceramic collections and selecting the samples. Richard also provided the legal descriptions of the sites from which the ceramics were recovered. His interest and volunteered efforts are very much appreciated and will result in a major contribution to this project. Without Richards's effort we would not have been able to include the sherds from these three Antelope Creek phase sites. He also photographed the reconstructed vessel from the Two Sisters site and provided that photograph for use in this report. The Museum staff, Ms. Elizabeth Leith and Dr. Wyckoff facilitated the processing of the forms for removal of the artifacts selected. Thank all of you for making these sherds available for this project.

Dr. Marjy Duncan of the Archeological Survey at the University of Oklahoma, also spent time searching through the ceramic collections from the Two Sisters site (34Tx32) held at the Archeological Survey. She selected sherds, a sample of daub and a clay sample for the destructive analysis associated with this project. Thank you Marjy for your selections and cooperation in this endeavor.

We would also like to thank the many private enterprises and professional individuals whose technical expertise towards specific classes of data provided valuable contributions to interpreting different data sets that allowed greater and additional in-depth insights into the prehistory of 41RB112. Their contributions allowed for significant insights into the prehistoric village populations who occupied this site.

The Panhandle-Plains Historical Museum (PPHM) in Canyon, Texas, especially the review board and Dr. Indeck, are thanked for their approval to allow ceramic samples curated at the PPHM to be used in the destructive analysis for our sourcing project. The acquisition of the samples was supported and facilitated under the direction of Dr. Jeff Indeck with the help of Rolla Shaller, and Ms. Mary Moore. Jeff also provided permission from the PPHM to use the picture of the nearly completed Woodland vessel (PPHM specimen X1996.3.14) in this report.

Drs. Michael Glascock and Jeff Ferguson of the Archaeometry Laboratory at the University of Missouri Research Reactor Center (MURR) conducted the instrumental neutron activation analysis (INAA) on cultural pottery and tempered clay samples. Thank you Jeff for answering many of my naive questions and trying to educate me on the analyses, and for your expertise and willingness to structure the analyses to the specific questions at hand.

Dr. David Robinson of Austin, Texas, performed the detailed petrographic analyses of ceramic sherds from these sites and natural clay samples from the surrounding region. Thank you David for your expertise in the tedious job of counting the points, identifying the grains, and the discussions stemming from the results.

Dr. M. Steven Shackley, Director of the Berkeley Archaeological XRF Laboratory, in Berkeley, California conducted the source analysis on the obsidian samples. Thank you Dr. Shackley for your 
quick turnaround time and willingness to work with our samples.

A number of scientists at the University of Georgia (UGA), Center for Applied Isotope Studies, are thanked for providing the necessary and valuable radiocarbon dates. Individual samples were sent to that laboratory through Dr. Abbott at TxDOT who also approved each sample. The staff, led by Dr. Alexander Cherkinsky, are thanked for their professional handling, cleaning, and subsequent results from the diverse samples (wood charcoal, ceramic sherds, corn, and sediments), used in this radiocarbon dating program. Later in the analysis and reporting stage a number of the sediment samples were sent to Beta Analytic Inc. in Florida. Scientists there, such as Darden Hood, Ron Hatfield, Chris Patric and Teresa Zilko are thanked for their continued excellent in processing our samples.

Dr. Phil Dering, of Shumla Consulting Service in Comstock, Texas, provided his extensive expertise in identification of the macrobotanical materials in the light fractions and individual samples. His insightful comments and interpretations continue to add to our understanding of the fuel woods and various food resources used prehistorically, and paleoenvironment conditions which existed.

Dr. Bruce Hardy, Professor in the Department of Anthropology at Kenyon College, is thanked for his identifications of microfossils and excellent highpowered use-wear analyses on the diverse stone artifacts. His insights into tool functions has furthered our understanding of those tools and contributed to identifying human behaviors during the Plains Village period. Dr. Hardy was also kind enough to examine one bison bone digging tool on his own time and his expense to demonstrate the types and kinds of interpretations that could be made on bone tools.

Dr. Linda Perry, Executive Director of The Foundation for Archaeobotanical Research in Microfossils, conducted the starch grain analysis on a broad suite of samples. I want to especially thank Linda for her scientific approach to handling the processing, her attention to detail, indepth identification procedures, and continuous communication and interest in working with us and her willingness to conduct starch analysis on diverse and multiple artifact classes.

Dr. J. Byron Sudbury, at J. S. Enterprises in Oklahoma conducted the detailed phytolith analysis on a suite of sediment samples from across the two components. His precise processing, detailed observations, identifications, and comparison provided significant contributions to understanding the natural deposits and cultural features functions. Thank you Byron for your interest, insights and contributions.

Dr. Barbara Winsborough of Austin conducted diatom analysis on a suite of sediment and burned rock samples. Her insights and expertise in her specialty has advanced our understanding of prehistoric cooking practices undertaken. Thank you Barbara for your dedication to the science and adding to our understanding of human behaviors through your diatom interpretations.

Dr. Mark Bateman at Sheffield Centre for International Dryland Research luminescence laboratory, The University of Sheffield, England provided the optical luminescence dating (OSL) for this project. Thank you Mark for your careful handling of the samples, your continued interest, and laboratory support in providing age estimates for the sandy deposits.

Drs. M. Kate Spradley and Michelle D. Hamilton, forensic anthropologists with the Forensic Anthropology Center at Texas State University (FACTS) performed the inventory of the human remains delivered to them from Features 7 and 22. Their expert identifications and analyses are appreciated, even with the limited parts available. In a subsequent analysis of dispersed human bones, Dr. Daniel J. Wescott, Director of the Forensic Anthropology Center at Texas State University identified a number of elements and provided an addendum to the earlier report. These experts are thanked for their identifications and clear reporting.

Thanks to Dr. Eric Murphy at the FC Spine and Sports Chiropractic in Round Rock for providing the facilities, the x-ray machine, and taking personal time to employ the machine on a number of occasions. Mr. Murphy took the multiple pictures 
and provided the $\mathrm{x}$-ray results used to capture the internal structure of the ceramic sherds to help understand their construction.

The Central Analytical Laboratory at Oregon State University in Corvallis provided the stable carbon and nitrogen isotope data on matrix samples used in the geoarcheological section.

The National Petrographic Institution in Houston prepared the thin section slides to TRC specifications used in the petrographic analyses by Dr. David Robinson. Their precise cutting and grinding allowed this analysis, which has contributed to a better understanding of the matrix in these samples.

Pamela R. Owens, senior paleontology educator of the Texas Natural Science Center at The University of Texas at Austin was kind enough to examine the tiny burned mandible discovered by Dr. Byron Sudbury during the phytoliths analysis. Her comments and identification are much appreciated.
Dan Bach of the High Plains Macrobotanical Services in Cheyenne, Wyoming was kind enough to provide four modern tubers for study and to extract starch grains for comparisons to the archeological starch grains discovered. The tubers included sego lily (Calochortus nuttalli), biscuitroot (Lomatium spp.), prairie onion (Allium textile), and bitterroot (Lewisia rediviva). Thank you Dan for your willingness to part with these samples for our research.

As a group, these highly skilled individuals, professional institutions, and companies contributed significant expertise, information and interpretations on very diverse data sets to this technical report. Their combined efforts allowed greater insight and interpretations of the prehistoric human behaviors. To the above scientists and institutions, we are grateful, and appreciate your expert contributions to this project. Thanks to all for helping preserved part of Texas prehistory. Any problems, omissions, or errors are the responsibility of the project director.

Mike Quigg

Project Manager 
This page intentionally left blank. 


\subsection{INTRODUCTION}

\section{J. Michael Quigg}

This report describes the archeological eligibility assessment and data recovery investigations at the Long View prehistoric site 41RB112 in Roberts County, Texas. These investigations were conducted prior to the proposed widening of a section of State Highway 70 (CSJ: 0490-04-037) by the Texas Department of Transportation (TxDOT), Amarillo District. The proposed widening was for a section 9.7 kilometers (km) or 6 miles (mi.) long that would encompass some 38.7 hectares (ha) or 96 acres (ac.), and extend from the north side of the Canadian River bridge northward to the Ochiltree County line.

These cultural resource investigations were part of TxDOT responsibilities under the National Historic Preservation Act (NHPA) of 1966, as amended through 1992 (PL-89-665; 80 Stat. 915; 16 U.S.C. $\S 470$ et seq.), the Department of Transportation Act of 1966 (PL 89-670), and the Antiquities Code of Texas (as incorporated into Title 98, Chapter 191, of the Natural Resources Code of Texas [1977, as amended]).

TxDOT, through the Environmental (ENV) Affairs Division, contracted TRC Environmental Corporation (TRC) of Austin under existing Scientific Services Contract No. 575XXSA008, and issued a Work Authorization to TRC to conduct the site eligibility assessment investigations. This work was performed to determine if this archeological site contained sufficient and significant data to contribute to the local or regional prehistory, and if so, this site would qualify for listing on the National Register of Historic Places (NRHP) and as a State Archeological Landmark (SAL). The eligibility assessment was completed in May 2005. This field assessment was followed by the completion and submission of an interim report describing methods employed, results of the assessment investigations, recommendations concerning eligibility, and initial research design in October 2005 to ENV at TxDOT (Quigg and Smith 2005; Appendix L, this document). Upon review of the interim report and accompanying recommendations, the State Historic Preservation Of- ficer (SHPO) concurred with the TxDOT eligibility determination that of the Long View site, within the proposed area of potential effect (APE), along the western side of the existing highway right-of-way, was eligible for listing on the NRHP under Criterion $\mathrm{D}$, and warranted designation as a SAL per the requirements of Section 106 and 110 of the NHPA and other related legislation.

TxDOT issued another Work Authorization, under the same Scientific Services Contract, to TRC to conduct data recovery excavations to mitigate the direct impact the proposed highway construction project would have on the prehistoric site. TRC's field investigations were implemented from August through November 2006.

This document describes the fieldwork associated with the data recovery investigations within the APE, which included: three different methods of noninvasive subsurface geophysical survey investigation, broad-area hand-excavations in Areas A and $\mathrm{C}$, site- and area-specific geoarcheological investigations, and mechanical stripping in the extreme southern portion of Area $\mathrm{C}$ to confirm no significant cultural data remained in the APE. This document also presents a comprehensive description of the cultural assemblage from the areas investigated, technical analyses conducted on various aspects of the assemblage, and addresses issues presented in the final research design. It also incorporates and supersedes the archeological results and interpretations reported in the previous interim report concerning the Long View site (Quigg and Smith 2005).

\subsection{General Project Location}

The Long View site (41RB112) is $51 \mathrm{~km}$ (32 miles) north of Pampa, Texas, and about $4.5 \mathrm{~km}$ (2.8 miles) north of the Canadian River in Roberts County, in the Texas panhandle, within the Southern High Plains section of the Great Plains physiographic province (Fenneman 1931). The west-to-east flow of the Canadian River has cut through the Tertiary Ogallala Formation, which caps the underlying Permian Red Beds. The Ogallala Formation composes most of the High Plains across the Texas panhandle (Seni 1980). In the vicinity of the Long View site, the Canadian River valley is very broad, about $37 \mathrm{~km}$ north-south, with a flood plain roughly 2.2 
$\mathrm{km}$ wide. On the northern side of the river, below the valley escarpment, lies gently rolling and undulating topography with north-south trending ridges, intra-valley plateaus, and knolls. These elevated areas lie between numerous shallow creek drainages that trend southward from the base of the escarpment to the Canadian River. In the vicinity of the site, these creeks tend to parallel each other.

The Long View site is buried in sandy loam of Mobeetie-Veal-Potter soil association (Wyrick 1981). The site is near the southern end of a northsouth trending interfluvial ridge, about mid-way between the Canadian River and the high valley rim to the north (Figure 2). Two tributaries, Sourdough Creek, approximately 550 meters (m) to the east, and Dugout Creek, approximately $1,100 \mathrm{~m}$ to the west, lie on either side of this elevated landform. Both creeks have headwaters in the Ogallala Formation caprock along the valley rim to the north, and in the past provided fresh water at least seasonally. Currently, both creek valleys contain quantities of windblown sand, sand sheets, and sand dunes along their margins. The Mobeetie and Veal soils occur throughout the immediate area and consist of deep, well-drained, loamy soils. The Potter series consists of very shallow, loamy soils on uplands, which are more prominent along the southern sloping edge (Wyrick 1981).

\section{$1.2 \quad$ Texas Department of Transportation Proposed Development}

The present highway consists of two general crosssections, a $7.6 \mathrm{~m}$ (30 ft.) wide paved section (two lanes) and a $9.2 \mathrm{~m}$ (41 ft.) wide paved section (two lanes plus a passing lane). The $7.6 \mathrm{~m}$ (30 ft.) wide paved sections would be increased to $13.4 \mathrm{~m}$ (44 $\mathrm{ft}$.) wide, and the $12.5 \mathrm{~m}$ (41 ft.) wide paved sections would be increased to $16.5 \mathrm{~m}$ (54 ft.) wide. Work would generally be confined to the existing 36.6 m (120 ft.) wide right-of-way. However, some areas where deep cuts are present or where curves are tight, minor amounts (7.6 m, or $25 \mathrm{ft}$.) of new right-of-way will be required.

The $7.6 \mathrm{~m}(25 \mathrm{ft}$.) new right-of-way consists of an approximately $3 \mathrm{~m}$ (9 ft.) wide overgrown bladed fireguard between the powerline poles and the existing fence, with undisturbed prairie grassland west of the fireguard. The fireguard measures $30-$ to $50-\mathrm{cm}-$ deep (12 to 19.7 inches), and sediment has potentially slumped and blown into the lower parts.

\subsection{Project Background}

The prehistoric site 41RB112 was recorded on June 17, 2004 by TxDOT archeologist G. Dennis Price, during a linear archeological survey of an about 9.7 km (6 mi.) section (38.7 ha or 96 ac.) proposed for rehabilitation and widening of a state highway from the North Canadian River bridge to the Ochiltree County line. His investigation consisted of surface inspection of the existing right-of-way and various exposures and limited artifact collection. Cultural materials such as cordmarked ceramic sherds, lithic debitage, chipped stone tools, mussel shells, bone fragments, and burned rocks were observed eroding from the upper $0.5 \mathrm{~m}$ deposits of a roughly 4-m-high by 60 -m-long section of road cut into a north-south trending ridge on the western edge of the highway. Cultural materials were also exposed on the natural prairie surface between the edge of the road cut and the existing fence line, and in backdirt from rodent activity.

The cultural materials collected include 1 cordmarked rim and 13 cordmarked body sherds. All sherds appear to be sand-tempered. The rim sherd exhibits a folded over (applied or thickened) lip with two rows of horizontal finger impressions (punctations) forming an 11 millimeter (mm) wide band. Below that band, the sherd is cordmarked. Chipped stone tools consist of one Alibates and one petrified wood biface fragment. Lithic debitage consists of five flakes. Two quartzite burned rocks were also recovered. Bone fragments include a large tooth enamel section from a bison. Fragments of mussel shell were also collected.

Mr. Price hand-excavated and screened two shovel tests at that location, within the northern section, designated Area A in this report. The shovel tests were placed approximately $22 \mathrm{~m}$ apart in the $60-\mathrm{m}$ long by 4-m-wide natural prairie setting between the road cut exposure and the existing right-of-way fence, above the highest density of cultural materials observed eroding from the road cut. Shovel test 
(ST) 1 was 50-by-50 centimeter (cm), and ST 2 was 30-by-30 cm. The fill was dry screened through 6.4 mm (1/4 inch) hardware cloth. Shovel test 1 yielded 22 diverse cultural items that include; 4 fragments of cordmarked pottery, 1 small fragment of daub, 6 small bone fragments, 7 flakes of Alibates, 1 piece of gypsum, flecks of charcoal, and 3 fragments of burned rock. All this material appeared to originate from a single cultural zone between about 17 and 40 cm below surface (cmbs). Shovel test 2, $22 \mathrm{~m}$ south of ST 1, yielded no cultural materials. The sediment profile at that location included sandy loam to about 50 cmbs overlying a calcium carbonate rich C horizon of the Ogallala Formation.

The diverse classes of cultural materials include pottery and small notched arrow points, indicated the presence of a Plains Village occupation. Mr. Price recommended testing this site to determine its eligibility for listing on the NRHP and as a SAL.

In February 2005, Mike Quigg, from the Cultural Resources Department of TRC in Austin, TX, and Dr. James Abbott, of the ENV of TxDOT in Austin, visited the site to discuss and plan the eligibility assessment investigation strategies for 41RB112. The site area identified by Mr. Price on the western side of the highway was walked and inspected, as was the eastern side, opposite the discovered cultural materials. The western road cut was carefully scrutinized and a short 2.5-m-long by roughly 1-m-high section approximately $3 \mathrm{~m}$ east of ST 1 was cleaned and inspected. A broad basin-shaped pit of probable cultural origin was discovered in the top 50 to $60 \mathrm{~cm}$ of the cleaned vertical exposure (subsequently designated Feature 1). Sparse cultural materials including a partially burned bone fragment, a few small tiny chunks of charcoal, a mussel shell fragment, a chert flake, and a burned rock were observed within this dark-stained basin.

Approximately $200 \mathrm{~m}$ south of newly discovered Feature 1, a roughly 10 - to 12-m-long linear arrangement of an estimated 20 to 30 carbonate encrusted cobbles was barely exposed in the prairie grasses inside the existing right-of-way. The rock alignment (see Structure 1 below for description) was about $1 \mathrm{~m}$ west of the 4-m-wide fireguard that parallels the old fence line, and was thought to represent part of a prehistoric Antelope Creek phase structure. Inspection around the rock alignment, specifically the bladed fireguard, revealed more cultural materials that included burned rocks, chert debitage, a hafted drill, and cordmarked pottery sherds, but very few other large cobbles outside the observed linear rock alignment. This cluster of cultural materials was $200+m$ south of the original discovery, and was considered part of the same prehistoric site as the more northern cluster based on similar material remains. Consequently, the original site boundaries were expanded southerly to include the newly discovered cultural materials. A low swale or saddle approximately $2 \mathrm{~m}$ lower than the surrounding areas separates the northern and southern clusters of cultural materials. This low area, Area B, lacked any visible cultural materials in the fireguard or the adjacent exposed road cut.

Between the time of the initial site visit in February 2005 and the start of the TRC fieldwork in May 2005, TxDOT had purchased the new right-of-way and fenced the new section through the site area. The new fence delineated the exact western boundary of the APE. The expanded new right-of-way was not quite as wide as initially thought in February. The cultural materials were within a narrow 8- to $10-\mathrm{m}$ wide horizontal zone between the existing road cut on the east and the newly fenced, western edge of the right-of-way. That APE includes the 4-m-wide previously mechanically bladed fireguard that runs north-south through the entire Long View site.

In May 2005, TRC archeologists conducted an archeological assessment of the nearly 300-m-long, 8to 10 -m-wide strip of site $41 \mathrm{RB} 112$ to be impacted by the proposed highway widening. The assessment was to evaluate the site's eligibility for inclusion in the NRHP and/or for designation as a SAL per the requirements of Sections 106 and 110 of the NHPA and other related legislation. The TRC site assessment was conducted under TxDOT Scientific Services Contract No. 573XXSA006 (Work Authorization No. 57317 SA006) and Texas Antiquities Committee Permit No. 3721 issued to Mike Quigg as Principal Investigator.

Field assessment was followed immediately by initial processing of recovered cultural materials and 
presentation of findings, including geoarcheological evaluations, brief feature and artifact descriptions, along with site-specific recommendations to TxDOT and an initial data recovery plan (Quigg and Smith 2005). The interim assessment report also included two technical assessments, one on phytoliths and the other on macrobotanical remains. The positive results from these two technical assessments provided future direction in the data recovery plan.

The ENV of TxDOT provided recommendations, along with the TRC interim report, to the THC for review and comment. The THC concluded that 41RB112 had the potential to contribute significant information to regional prehistory and was eligible for listing on the NRHP and/or for designation as a SAL. This required the site undergo data recovery prior to TxDOT development.

TXDOT, through the ENV Affairs Division, contracted TRC of Austin under existing Scientific Services Contract No. 575XXSA008, to conduct the necessary data recovery investigations at 41RB112. ENV issued another Work Authorization under the same Scientific Services Contract on August 3, 2006, to mitigate the direct impact of the proposed road construction project on the nonrenewable cultural resource. Subsequent data recovery investigations were conducted from August through November 2006 under original Texas Antiquities Committee Permit No. 3721.

The data recovery investigations included: three different methods of noninvasive subsurface geophysical survey investigation prior to the excavations, broad area hand-excavations in Areas A and C within the APE, geoarcheological investigations of Areas $\mathrm{A}$ and $\mathrm{C}$ within the site and areas immediately surrounding the site. Following the completion of the hand-excavations, mechanical stripping was performed in the southern part of Area $\mathrm{C}$ to confirm no significant cultural data remained within the APE.

\subsection{Organization of Report}

Following this introduction chapter, Chapter 2.0 presents a sweeping overview of the environmental background and includes a wide range of topics such as topography, physiography, hydrology, soils, and natural resources such as flora and fauna of the region and different lithic raw materials available and prehistorically utilized. Chapter 3.0 is an overview and summary of the Plains Village cultural tradition across the Texas panhandle that includes discussions of the Antelope Creek phase, the Buried City complex, recent work at M-Cross Ranch, investigations across Courson properties, and a brief discussion of pithouses in the Texas panhandle and adjacent regions. Chapter 4.0 presents the research questions and design developed for analysis and reporting, finalized in November 2007, and approved by TxDOT, prior to analysis initiation. Chapter 5.0 is an in-depth presentation of the methods to the site assessment and data recovery fieldwork, the subsequent laboratory and technical analyses utilized, and definitions for terminology and metric measurements as applied to artifacts. Chapter 6.0 presents analysis and interpretation of site stratigraphy and context of cultural materials. Cultural stratigraphy is identified and discussed, and the two analytical components, Components A and C, are presented. Documentation of cultural materials is presented individually by component in Chapters 8.0 and 9.0. Chapter 8.0 documents features present within, and cultural materials recovered from, Component A. Chapter 9.0 documents features and cultural materials of Component $\mathrm{C}$. The 11 research questions posed in Chapter 4.0 are discussed in-depth in Chapter 10.0, along with regional information. Chapter 11.0 presents a brief summary, conclusion, critique of the methods employed, and recommendations. Chapter 12.0 contains references cited throughout the body of the report. A glossary of technical terms is provided to help the reader with technical terms.

The main body of this report, Chapters 1.0 through 13.0, is presented in Volume I, while supplemental Volume II presents technical appendices on a wide variety of subjects conducted by outside laboratories and/or professional individuals and supports the statements, conclusions, and interpretations within Volume I. Appendix A presents crucial data from radiocarbon laboratories concerning direct dating of 41RB112. Appendix B provides results of phytolith analysis on 24 sandy sediments from individual features within the both Components A and C. The results of macrobotanical processing of 34 flotation samples and species identification of 114 charcoal 
samples are presented in Appendix C. Starch grain analysis procedures and results from 104 artifacts are presented in Appendix D. Appendix E provides results from sourcing analysis of 49 obsidian items and 2 unknown materials. Appendix F contains the petrographic methods and results conducted on 20 sherds from Long View, plus 10 clay and 67 pottery samples, including pottery from 15 sites in the surrounding region. The instrumental neutron activation analysis (INAA) of the same 20 Long View sherds used in the petrographic analysis, 12 additional sherds from Long View, and 80 additional samples from 15 sites in the surrounding region, is presented in Appendix G. High-powered use-wear and residue identifications on 52 stone tools are presented in Appendix H. Appendix I contains details of geophysical investigations conducted with three different instruments. Appendix J reports methods and diatom analysis of 12 burned rocks and 6 daub samples from Long View. Appendix K contains the Native American Graves Protection and Repatriation Act (NAGPRA) inventory and documentation of the human cremation (Feature 22) and the cairn burial Feature 7) reported to TxDOT by TRC. Appendix L presents the 41RB112 interim assessment report following the site discovery and eligibility investigation fieldwork. The TxDOT protocols for contractor analysis of lithic and ceramic artifacts are presented in Appendices $\mathrm{M}$ and $\mathrm{N}$ respectively. Artifact data specifics not presented in the main body of the text are presented in Appendix O. Stable carbon and nitrogen isotope results from 10 bison bones are presented in Appendix P. Appendix Q provides a descriptive table and pictures of individual sherds from the 15 other sites used in petrographic and INAA studies. Appendix R provides methods and results from 14 optical luminescence dates that targeted sandy eolian sediments. Finally, Appendix S provides the physical anthropological NAGPRA inventory and analysis conducted on human remains recovered from the site. A CD-ROM that contains a tagged PDF version of this report as well as a database file with all of the quantitative data collected during artifact analysis is enclosed in a sleeve on the back cover of Volume I. 
This page intentionally left blank. 


\subsection{ENVIRONMENTAL BACKGROUND}

\author{
J. Michael Quigg and Paul M. Matchen
}

\subsection{Introduction}

This chapter presents the physical and climatic setting of the Texas panhandle region in which the Long View site resides. These attributes are not only considered a part of the Canadian/Cimarron ecoregion, but also a resource for countless numbers of human groups of the past. The availability of diverse resources was paramount in the lives of prehistoric peoples and provided food, shelter, tools, and a way of life in this seemingly harsh environment.

\subsection{Physiography and Topography}

The Long View site lies within the northeastern corner of the Texas panhandle region. The Texas panhandle is part of the Southern High Plains section of the Great Plains physiographic province (Fenneman 1931). The region north of the Canadian River valley is also referred to as part of the Central High Plains that stretches northward along the eastern flank of the Rocky Mountains. The Central High Plains is characterized by a flat, low-relief surface with an average elevation of 976 meters (m, 3,200 ft.). These low-relief surfaces are cut by eastward-flowing rivers such as the Canadian, located in the Texas panhandle and the North Canadian (Beaver) in the Oklahoma panhandle (Figure 2-1). The eastward-flowing Canadian River separates the Central High Plains from the Southern High Plains or Llano Estacado (Spanish for "Staked Plain"). The Canadian River valley creates major topographic relief in contrast to the low relief of the Southern High Plains.

Griffith et al. (2007) refer to the area north of the Canadian River within the Texas panhandle as the Canadian/Cimarron Breaks. The roughened topography of this ecoregion lies below an escarpment marking the edge of the Llano Estacado, although it is generally not as distinct as the escarpment farther south that breaks more precipitously, exposing deeper geological strata and marking the boundary between the Llano Estacado and the Caprock Canyons, Badlands, and Breaks. In this case, the escarpment is visible, but the land surface has more of a terraced aspect as it descends to the Canadian River channel.

Within the Canadian River valley are dissected topography with canyons, buttes, and mesas creating breaks or erosional areas all along the margins of the valley (Figure 2-2). Many spring-fed tributaries exist along both sides of this broad valley, with their waters flowing down to the river. These relatively narrow tributaries often cut through flat and rolling terrain. In Roberts, Ochiltree, and other counties along the Canadian River, the springs flow mainly from the Tertiary Ogallala sand and gravel, whereas some springs originate in the Triassic Dockum or Santa Rosa sandstone below the Ogallala (Brune 1981:365).

\section{$2.3 \quad$ Hydrology}

The creation of the Canadian River trough began during the Pleistocene. This river and other rivers draining the Rocky Mountains at that time carried more water than today because of higher precipitation and glacial melt (Griffith et al. 2007:25). The Canadian River flows generally eastward across the Southern High Plains of the Texas panhandle and then into the Rolling Plains of Texas and Oklahoma and eventually into the Mississippi River. Its headwaters are in northeastern New Mexico near Raton, south of the Trinidad Escarpment. The initial segment of the Canadian River flows southward, paralleling the mountains, then bends sharply to the east and flows across northeastern New Mexico, and finally eastward across the Texas panhandle and into Oklahoma.

The slightly higher ground just south of Amarillo is the drainage divide between the headwaters of the Red River system and the more northern Canadian River systems. The former also flows eastward and eventually forms the boundary between Texas and Oklahoma. The Canadian River valley varies in width from 50 to 56 kilometers $(\mathrm{km}, 31$ to $34.8 \mathrm{mi}$.) and is some $183 \mathrm{~m}$ (600 ft.) deep, with a relatively wide, abraded valley floor with some $2.2 \mathrm{~km}$ wide Holocene alluvium. The Canadian River has a high salt content stream, as the water 


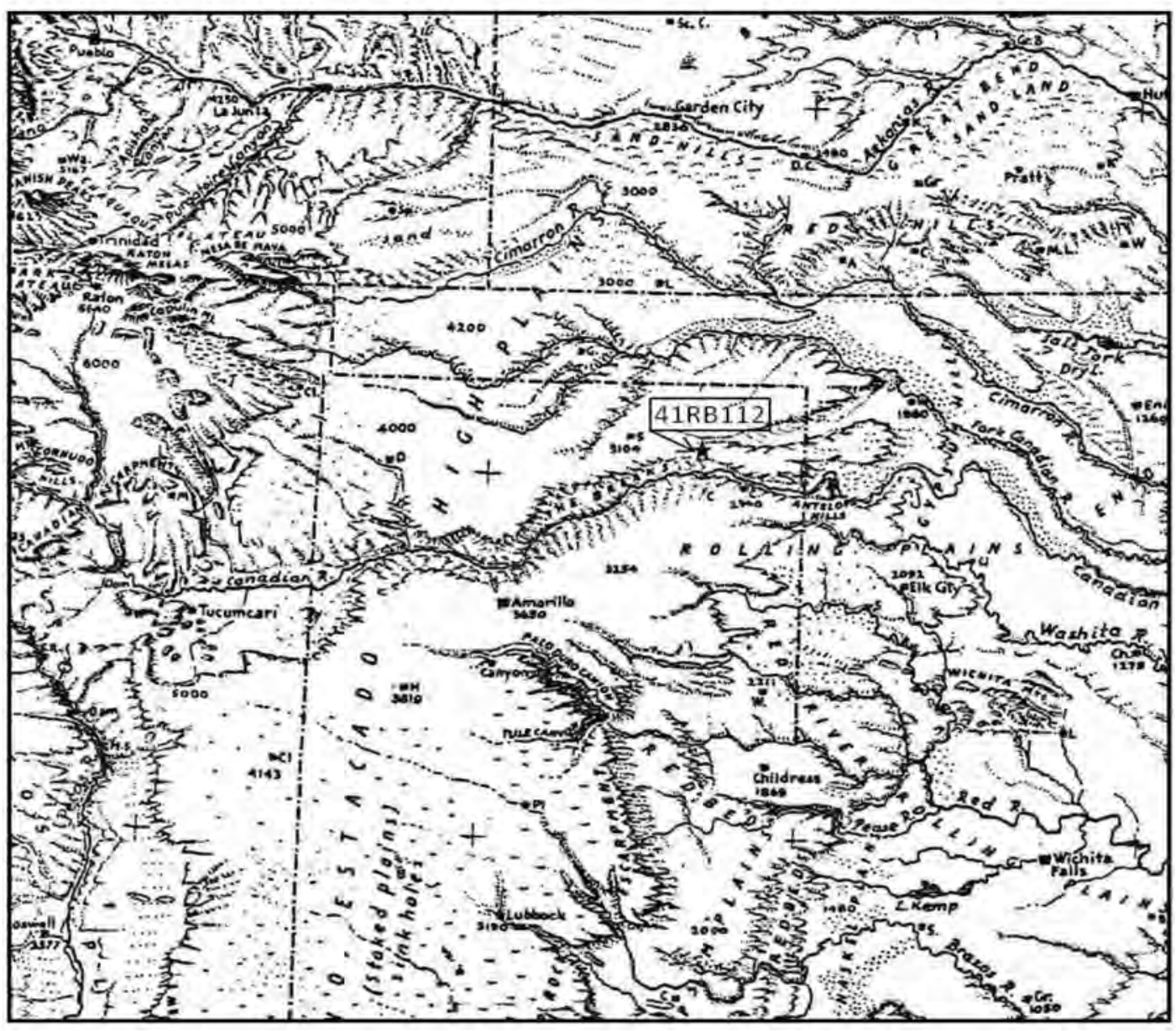

Figure 2-1. General project location map showing major relief (map from Raisz 1957).

flowing in the Canadian River tends to be fairly high in dissolved solids and thus ranges from hard to very hard. Calcium, sodium, magnesium, and bicarbonate are the principal dissolved constituents in most streams (Kunze and Lee 1968 cited in Deal 1975:40). Quaternary-age deposits that are mostly eolian sands fill the stream and river valleys.

The ground water in the Ogallala Formation is generally of good quality in contrast to the water in the underlying Triassic rocks, which is highly variable in quality (Deal 1975). The Ogallala aquifer is recharged by precipitation primarily in eastern New Mexico. In the vicinity of the Long View site, the base of the Ogallala Aquifer ranges from 76 to $457 \mathrm{~m}$ (250 to $1500 \mathrm{ft}$.) below ground surface. Today, the water table has been lowered by anthropogenic processes, altering the original natural flow. Over the last two decades, portions of the Ogallala Aquifer across the Canadian and Cimarron Breaks have been lowered more than 10 m (Center for Geospatial Technology 2007). This has caused the disappearance of many springs, and has reduced the volume of regional streams (Graves 2002).

The flow of the Canadian River varies seasonally, with the many natural springs along the valley wall contributing fresh water through the relatively short tributaries in the valley. Currently, dams upstream in eastern New Mexico, such as Conchas Dam and Ute Dam, regulate the modern flow down river. The Sanford Dam that created Lake Meredith in 1965 lies roughly $70 \mathrm{~km}$ (43.5 mi.) southwest (upstream) from the Long View site. 


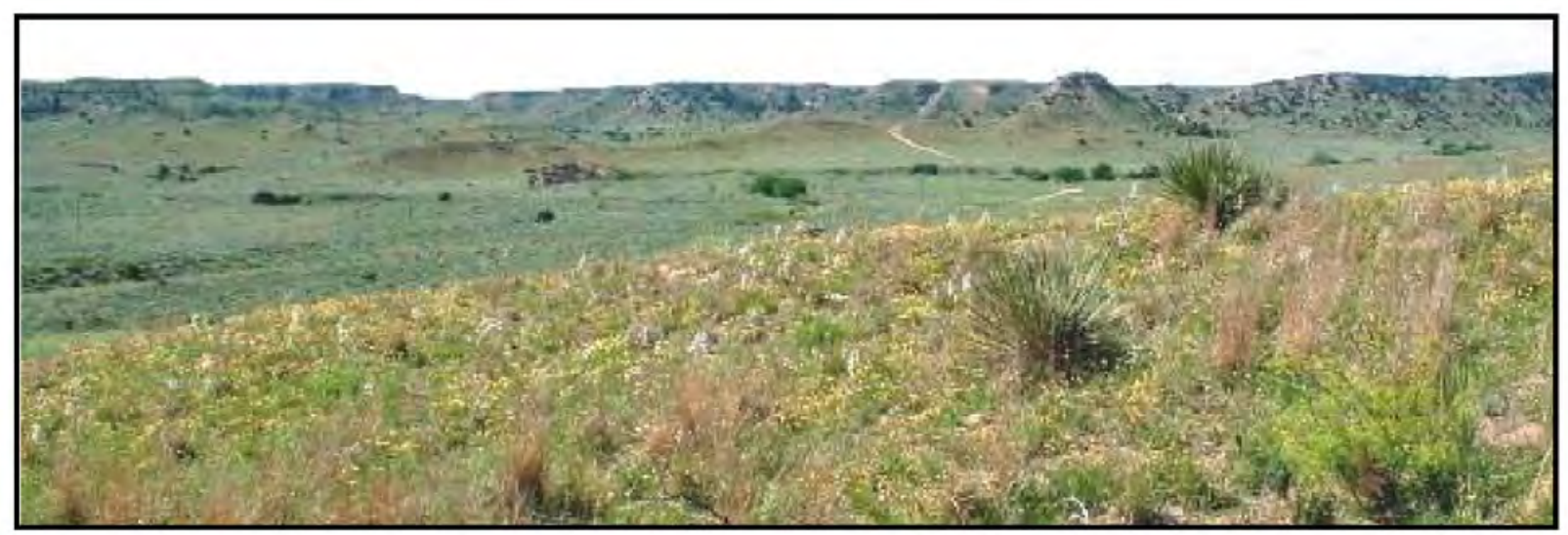

\section{Figure 2-2. Northern edge of the Canadian River Valley in background with topographic relief within the valley (photograph by M. Quigg).}

Immediately west of the Long View site is Dugout Creek, which is roughly $8 \mathrm{~km}(5 \mathrm{mi}$.) long and has its headwaters in the Ogallala Formation at the foot of the northern valley wall of the Canadian River (Figure 2-3). It flows southward in a relatively straight line and is paralleled by Sourdough Creek to the east and Government Canyon Creek to the west.

This tributary valley, as with other tributary valleys of the Canadian River, exhibits sloping or gradual sides, with ill-defined valley walls and in some localities, minor rock outcrops.

The Canadian River valley can be subdivided into physiographic zones such as the valley bottom and the valley slopes, which join the valley rim and the adjoining uplands. The bottom zone includes the creek channel, floodplain, alluvial terraces, and alluvial fans. The break between the valley bottom and slopes is generally not well-defined, as the colluvial deposits continually move sediment down slope, forming the sloping transition between the steep valley walls and the flat alluvial terraces. Areas of exposed gravel deposits exist in some parts of the valley.

\subsection{Geology}

A relatively thin blanket of Blackwater Draw Formation of the recent Quaternary period covers parts of the Ogallala Formation of the Tertiary (Figure 2-4). Below the Ogallala lies the Dockum Group of the Triassic that includes the Tecovas and Trujillo formations, which in turn overlies the Alibates/Quartermaster Formation and other

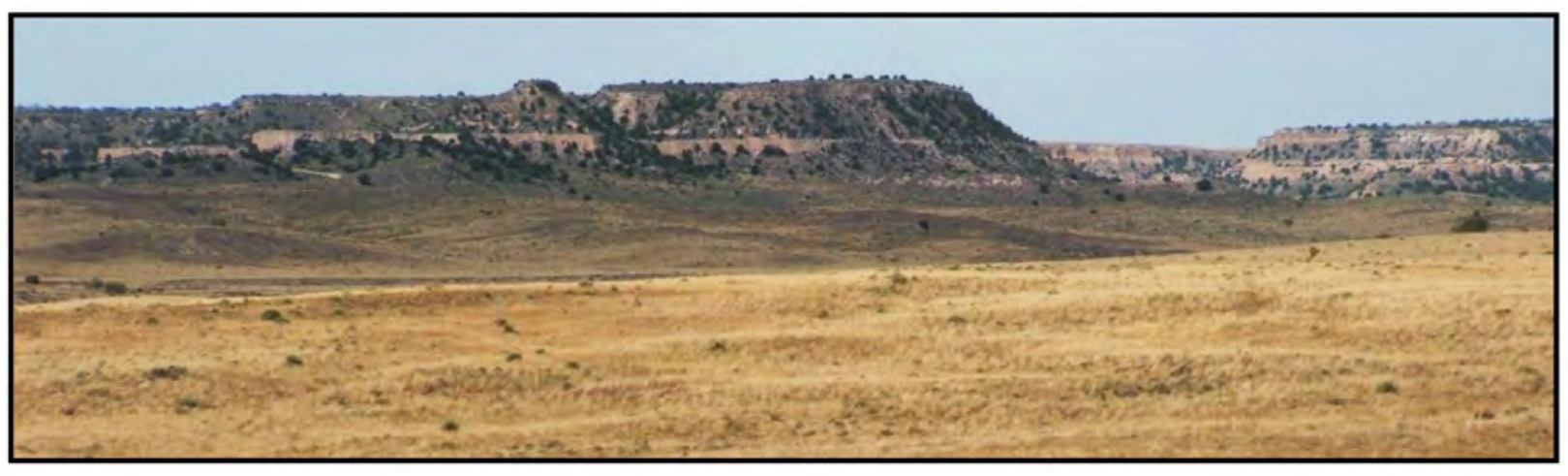

Figure 2-3. Overview of Dugout Creek Valley west of the Long View site. (Photograph by M. Quigg). 
divisions such as the Whitehorse Formation of the upper Permian. Most deposits and formations are not flat, but have considerable vertical changes in elevations below the surface. The overall trend in these formations is a gentle slope to the east where many of these outcrop along the eastern edge of the escarpment. Some thinner formations are not mapped or traceable across broad regions and probably pinch out before they are exposed again. These stratified and distinctive formations are briefly discussed below starting from the surface and going back through time. It is not our intention to go back to the beginning of time, but to inform the reader of the deposits and formations that are pertinent to the project area and to the prehistoric populations that roamed through the region.

\subsubsection{Blackwater Draw Formation}

The Black Water Draw Formation is the major surfacial deposit that consists of eolian and lacustrine sediments of Pleistocene age that occur all across the Llano Estacado (Reeves 1976; Gustavson 1996). Pleistocene lake deposits are interbedded with the eolian deposits. The thousands of playa lakes across the Llano Estacado are cut, collapsed, or formed into this formation. In limited places, the Blanco (late Pliocene) and Tule formations are present below the Blackwater Draw Formation, but these are quite limited in aerial extent and generally buried. The Blackwater Draw Formation covers nearly all of the Llano Estacada and the Central High Plains north of the Canadian River valley (Gustavson 1996). The Blanco Formation is an extensive lacustrine layer of dolomite deposited on the underlying Ogallala Formation.

\subsubsection{Ogallala Formation}

The Ogallala Formation is Pliocene in age and occurs as a broad alluvial apron that covers older formations and extends over much of the High Plains region northward and eastward (Seni 1980; Gustavson 1996). This broad alluvial deposit formed by coalescence of alluvial fans, consists of a thick bed of undifferentiated sand, silt, gravel, conglomerate, and multiple layers of calcareous and siliceous caliche deposited by streams that originated in the mountains to the west. The sandstone contains muscovite and metamorphic rock fragments. The conglomerates contain quartzite, chert, and vein quartz classes. This is the major water bearing, aquifer system (High

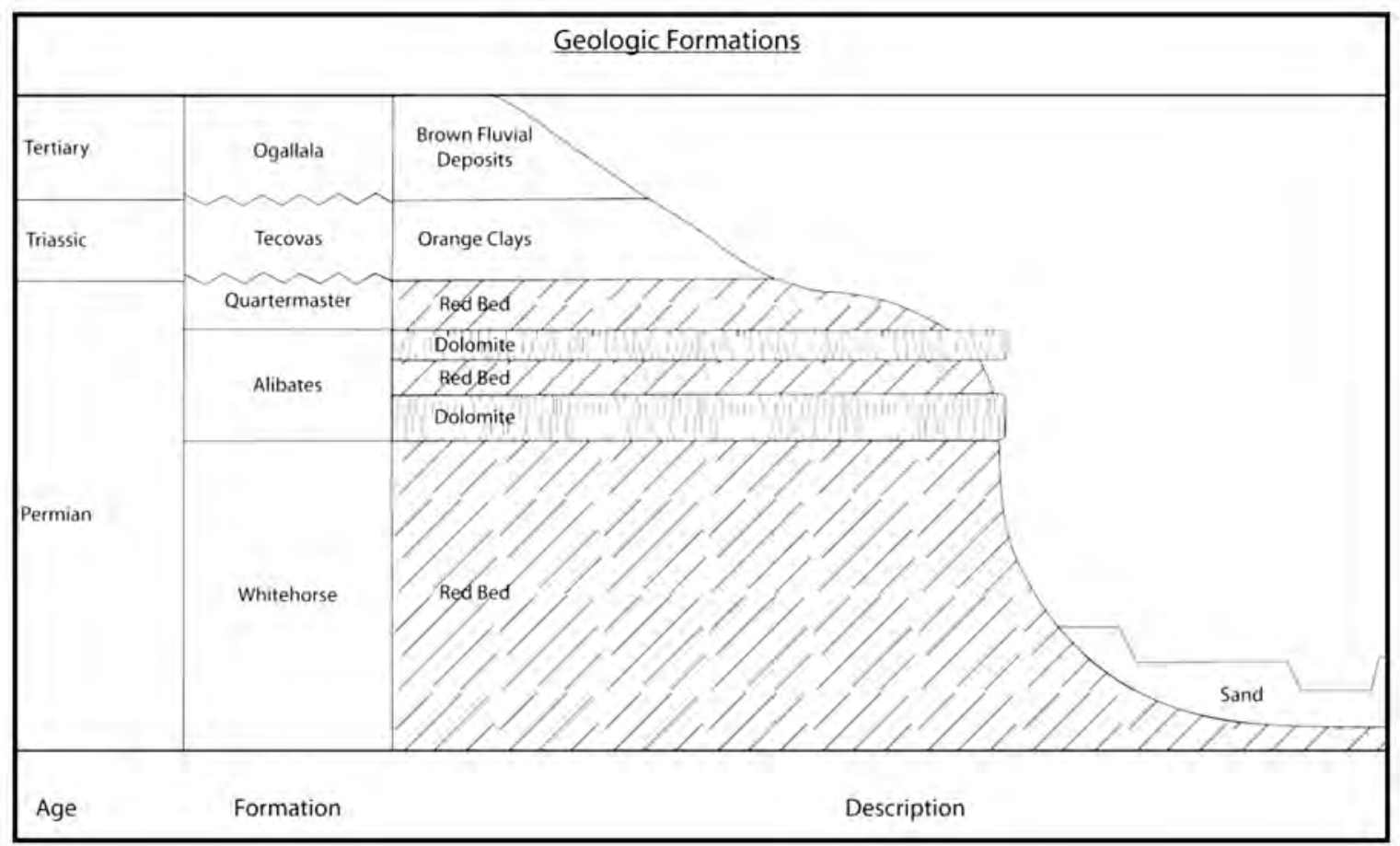

Figure 2-4. Schematic drawing of geologic stratigraphy across panhandle of Texas. 
Plains aquifer) that extends all the way into South Dakota. It consists mainly of deposits derived from the Rocky Mountains to the west in New Mexico. Several calcretes including the indurated "caprock caliche" form a prominent ledge near the top of the escarpments bordering the plateau. This calcrete is believed to be pedogenic and formed in upper Ogallala fine sand and silt (Holliday 1995:11). An unconformity, creating a major time gap of millions of years, occurs between this and the lower Triassic deposits. The lower part is composed of reddishbrown, fine-to-medium grained sandstone that contrasts with the underlying red and green shales of the Trujillo Formation. The Ogallala outcrops throughout much of the Canadian River valley and along the eastern escarpments minimally into eastern Oklahoma and potentially to the eastern side of Oklahoma (Gustavson et al. 1980). In some places, the Ogallala sediments are 250-m-thick (Seni 1980).

\subsubsection{Tecovas and Trujillo Formations}

The following Tecovas and Trujillo formations are part of the Dockum group of the Triassic, which overlie the redbeds of the Quartermaster Formation (Adkins 1958). Members of the Dockum Group outcrop in the Canadian River valley and along the Caprock Escarpment southwards to at least as far as the Double Mountain Fork of the Brazos River, at Post, Texas (Baumgardner 1987). The Dockum Group underlies the entire Llano Estacado south of the Canadian River valley and potentially northward into the Cimarron and North Canadian valleys in the Oklahoma Panhandle (Adkins 1958). Much of the broader region is mapped as undifferentiated Dockum Group, but specific reports address the individual formations. Abundance of water, sands, mica, phosphate, limestone, calcareous shale and sandstone is indicative of the Triassic (Adkins 1958:246). East of the Caprock Escarpment, the Dockum is 150 -m-thick, but buried by the Blackwater Draw and Ogallala formations.

Trujillo Formation: This formation overlies the Tecovas Formation and is the upper member of the Dockum Group. It contains coarse sandstone, cross bedded sandstone, conglomerates, petrified wood, pebbles of quartz, limestone, and interbedded shales (Adkins 1958; Barnes 1969, 1993). It is roughly 30-m-thick in most areas.
Tecovas Formation: This formation lies above the Quartermaster Formation and is some 38-m-thick. It contains shale, siltstone, sandstone, clay, and petrified wood (Barnes 1969). These are generally reddish brown, maroon, gray, greenish gray, yellow, and purple. The sandstone is micaceous and is fineto-medium-fine grained in texture and composed of quartz. Locally, large petrified logs are present. The Tecovas Formation outcrops south of Amarillo in the Palo Duro Canyon and all along the eastern Caprock Escarpment with vast areas along the Canadian River valley west of Amarillo. In places, it is as much as 90-m-thick.

\subsubsection{Quartermaster Formation}

The Quartermaster Formation of Permian age is sedimentary and indicative of marine conditions that extended over most of Texas (Sellers et al. 1932). The term Quartermaster is used in the broad sense for much of the Permian, and some geologists have divided this into smaller members, or more restricted formations, such as the Alibates Formation. The Quartermaster Formation is characterized by the brick red coloration of the sandstones, shales, siltstones, and mudstones. These are often interbedded and appear as lenses. White gypsum veins and dolomite have been observed interbedded in thin discontinuous veins of the mudstones. Uncolored, well rounded frosted quartz grains are common in the Permian (Adkins 1958:245). Often, these deposits reveal folds, arches, troughs, and cross bedding and sometimes ripple marks. One aspect of this formation is the various colors that are present. Some shales contain gray-green, circular spots called reduction halos, which in places give the red shales a distinctive polka dot appearance. These were produced as a result of chemical change of certain minerals in the shales (Matthews 1969:19). In addition to the major outcrop along the Canadian River at Late Meredith, small localized areas of the Quartermaster Formation with Alibates dolomite outcrop in small areas along the Eastern Escarpment. The formation is known to outcrop in limited areas (Baumgardner 1987), but it may not contain any chert that would be suitable for knapping. 


\subsubsection{Alibates Formation}

The Alibates Formation lies above the Whitehorse Formations. It is comprised of two dolomite layers separated by red shale. In comparison to other formations, the Alibates Formation is a quite thin bed that reaches across a broad area of the panhandle. In places, the dolomite becomes agatized and this is referred to as the "Alibates chert." The Alibates chert exhibits a wide range of colors with a diverse range of textures. The usually banded or mottle red blue, purple, brown, cream, and white are common colors (Barnes 1969; Banks 1990; see below for further discussions of Alibates).

\section{$2.5 \quad$ Tool Stone Resources}

The broad Texas panhandle contains many lithic resources and a number of high quality stones suitable for stone tool manufacture. However, much of the flat High Plains are blanketed by sandy soils of the late Quaternary Blackwater Draw Formation (Gustavson 1996). Quantities of local tool stone are still available in specific geological settings and outcrops along the margins of the Canadian River valley and its tributary valleys in the Ogallala Formation that also blanket much of the Southern Plains. The better known materials and source areas are briefly discussed below.

\subsubsection{Alibates Silicified Dolomite}

This is probably the most notable, high quality resource in the Texas panhandle. The famous Alibates Flint Quarries National Monument (AFQNM) is about $100 \mathrm{~km}$ upstream from 41RB112 where this material outcrops at Lake Meredith, along both sides of the valley in Potter County (Figures 2-5 through 2-8). The AFQNM is on the southern side. References to this material in the literature varies and includes Alibates flint, Alibates agate, Alibates agatized dolomite, Alibates chert, and Alibates silicified dolomite (Bowers 1975; Holliday and Welty 1981; Banks 1990; Bowers and Reaser 1996; Holliday and Allen 1987). The principal component is silicon dioxide, with impurities producing the various colors and banding. Alibates dolomite is the upper cap of the Whitehorse Formation of Permian age.
The outcrop in AFQNM is nearly horizontal and is about 1.2-km-long (Katz and Katz 2004 say 2-kmlong) and as much as 100-m-wide in spots and exposed primarily along one ridge between two draws (Shaeffer 1958). The material is both subsurface and in large boulders along the lower slopes. The Alibates Formation consists of two dolomite beds separated by one mudstone bed (Bowers 1975:2122). No more than three percent of the dolomite is chert like. Chert occurs in most outcrops of Alibates, but it is more abundant in the upper member (Bower and Reaser 1996). The massive sheets, 20 to 60 centimeters $(\mathrm{cm})$ thick that cover an area of some 1,000 m, have only been identified at Cactus Flats and the AFQNM. Alibates is a multicolored, fine grained microcrystalline material, which occurs as large lenses and nodules, as a result of silicification of the dolomite (Gould 1907; Bowers and Reaser 1996; Holliday and Welty 1981). It is generally a grayish-blue with light colored banding or veins of grays, blues, reds, purples, and white. Red and white banding is the more common characteristic trait (Figure 2-8). The texture is dense and lacks flaws, with a dull opaque surface (Banks 1990:127-129).

The cortex on Alibates silicified dolomite is usually white and chalky, roughly 1 to 2 millimeters (mm) thick. Bower and Reaser (1996) studied the origin of the chert and their data support a replacement process. In their study, they measured and studied 30 stratigraphic sections, including two on the Salt Fork of the Brazos, and collected samples from each sequence. They then examined more than 100 thin sections with a petrographic microscope. Fifteen samples that included 13 dolomite and 2 chert (one from the upper member and one from the lower member) were analyzed chemically for major and trace elements. They presented the chemical composition for 10 elements on the 2 selected Alibates chert samples and 13 dolomite samples from studies conducted at the Minerals Studies Laboratory, Bureau of Economic Geology, The University of Texas at Austin.

The AFQNM contains minimally 731 prehistoric quarry pits (Katz and Katz 2004, 2005) in four to five clusters along a ca. 1,300-m-long irregular shaped area of one primary ridge. The hundreds of quarry pits testify to the extensive extraction of the 


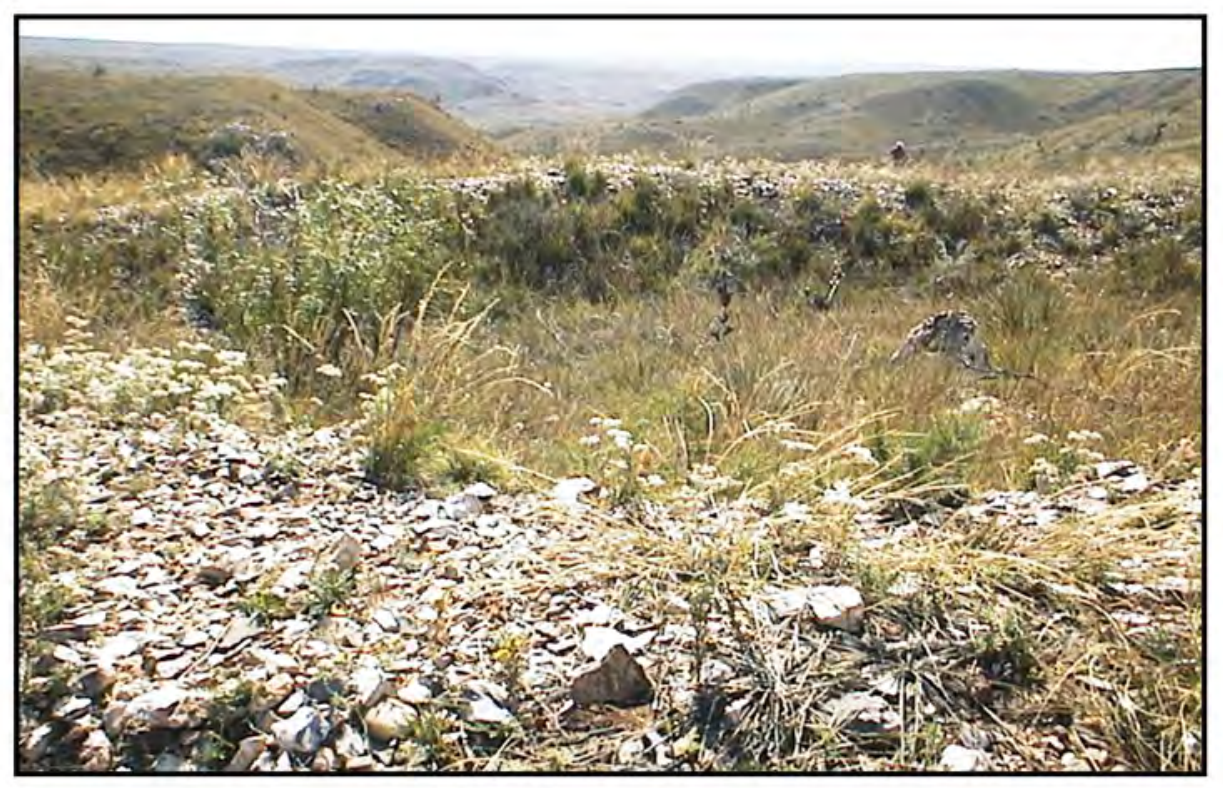

Figure 2-5. Large prehistoric quarry pit at Alibates Flint Quarries National Monument (41PT1) (photograph by Paul Katz).

tool stone from subsurface deposits by prehistoric peoples. Outcrops of Alibates and many more quarry pits are known on the northern side of the Canadian River on private lands. Published information is nearly nonexistent concerning the northern areas and the quantity of Alibates available. Those northern outcrops are reported to extend for 1.6 to $2.0 \mathrm{~km}$ (Shaeffer 1958).
The Canadian River cuts southwest to northeast through the Quartermaster Formation. Over time, the river transported pieces of Alibates downstream ca. $275 \mathrm{~km}$ into western Oklahoma (Wyckoff 1989, 1993). Alibates is definitely present in the various gravel or lag deposits along the Canadian River in western Oklahoma, and in sizes that are suitable for the production of stone tools (Wyckoff 1989, 1993). Alibates transported down river as gravel

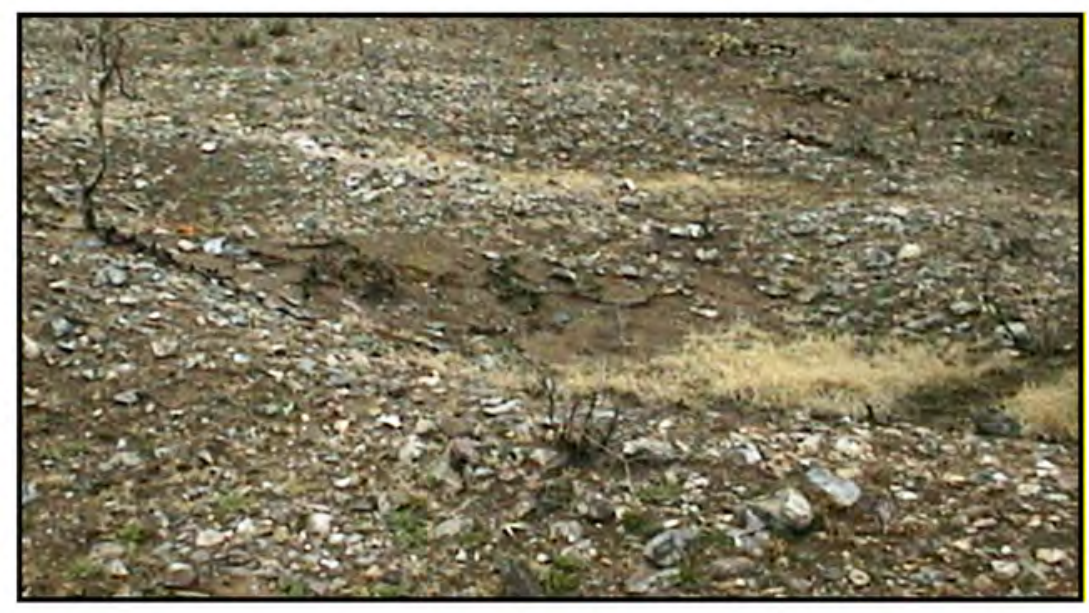

Figure 2-6. Multiple quarry pits exposed following fire at Alibates Flint Quarries National Monument (41PT1) (photograph by Paul Katz). 


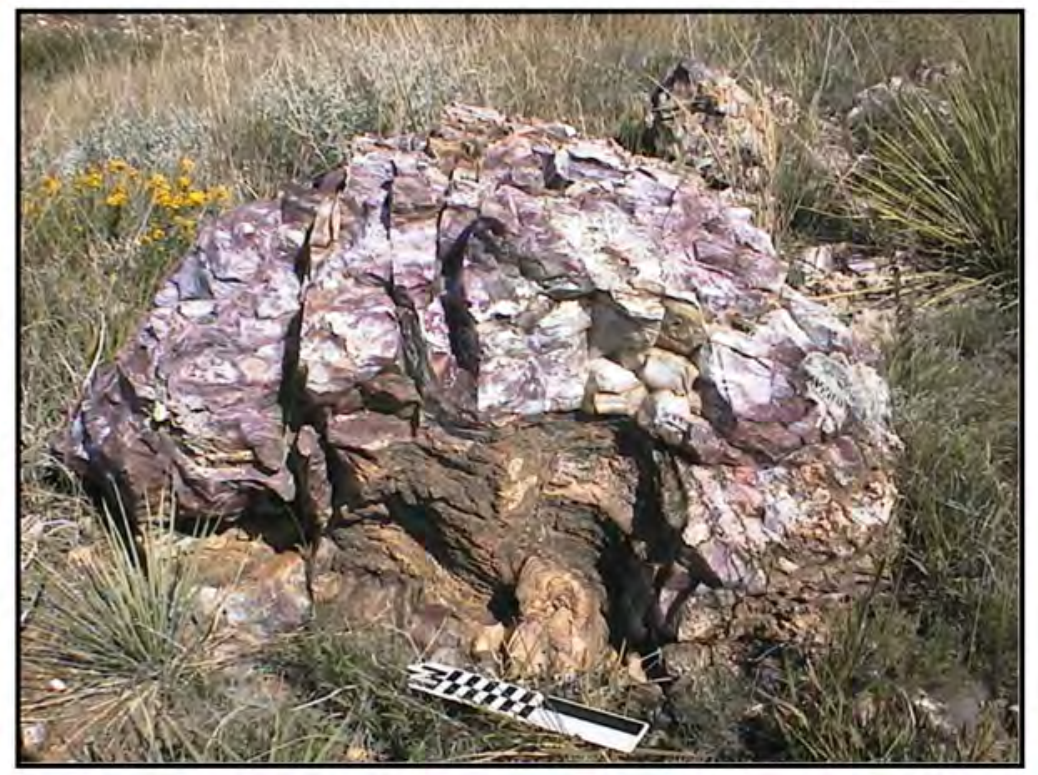

\section{Figure 2-7. Boulder with Alibates exposed at Alibates Flint Quarries National Monument (41PT1) (photograph by Paul Katz).}

or lag pieces will exhibit distinctive water worn and smoothed cortex, with battered corners. The Alibates is often visually distinguishable, but some pieces look similar to Tecovas jasper, another local high quality tool stone (see below).

Instrumental neutron activation (INA) analysis was conducted on 25 pieces of natural Alibates from the Quartermaster Formation (Quigg et al. 2010; Boulanger and Glascock 2010). This limited sample included 8 pieces from private lands opposite the AFQNM (TRC399-404, 441, 442), 1 piece from Quarry pit 1 excavated at 41PT1 (TRC448) and collected by Katz and Katz (2005), 12 more pieces (TRC407-411, 448, 520-526) from the AFQNM in Potter County, and 4 pieces from a single lag source (TRC390-393) exposed on a high terrace on the northern side of the Canadian River in Roberts County just $2 \mathrm{~km}$ south of $41 \mathrm{RB} 112$ and some 90 to $100 \mathrm{~km}$ downstream of the main outcrop at AFQNM. The INA results indicate that the Alibates samples formed a discrete chemical cluster from Tecovas jasper and document that Alibates pieces have definitely moved downstream in the Canadian River valley (Quigg et al. 2010 Boulanger and Glascock 2010; Quigg et al. 2011b). The samples used in this INA analysis sought to represent the full range of colors, stripping, mottling, and diversity, including a rare spotted piece.

\subsubsection{Tecovas Jasper}

This is another high quality natural tool stone source known to outcrop over a much wider region than Alibates with known sources primarily southwest of 41RB112 in the vicinity of Lake Meredith in Potter County, in the Quitaque area of Briscoe County, and west of Amarillo in the Canadian River valley (Shaeffer 1958; Barnes 1968, 1969). Tecovas jasper is widespread along the eastern Caprock Escarpment of the Llano Estacado (Green and Kelley 1960) and in the Canadian River valley west of Amarillo (Barnes 1968, 1969). Small scattered outcrops of Tecovas lie south of Amarillo between Quitaque and Palo Duro Canyon. This is the best known region for Tecovas jasper. In a distribution study of Tecovas jasper, Lynn (1986) recorded 20 locations with Tecovas jasper in a generally north-south line across the Texas panhandle, mostly along the eastern edge of the Llano Estacado, in the Caprock Escarpment. His study was not exhaustive, but he does describe two of the lesser known outcrops including the Blue Creek outcrop in the northern end of his study area just southeast of Dumas, Texas, in Moore County. Other known Tecovas outcrops or source areas are 


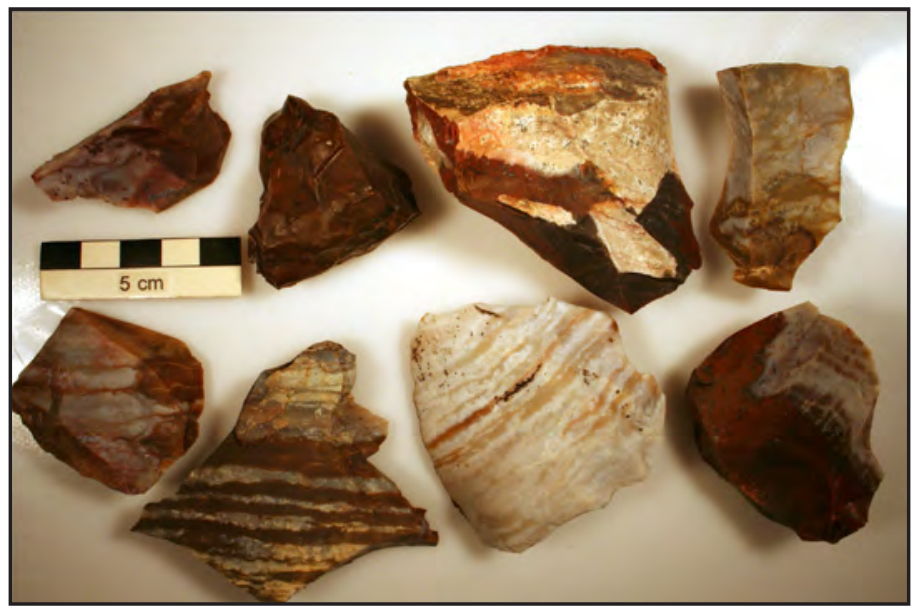

Figure 2-8. Samples of Alibates from Alibates Flint Quarries National Monument (41PT1).

scattered around the Amarillo region and include an outcrop at the South Basin quarries (Rotten Hills, quarries [41OL284 or PPHM-M114, A642/18, Banks 1990:92]) $24 \mathrm{~km}$ south of Landergin Mesa in eastern Oldham County (Figure 2-9, Mallouf 1989), an outcrop at Coetas Creek (41PT434 or PPHM-M151, Etchieson 1979b; Banks 1990; Raab 2005) at the southern end of Lake Meredith, several small outcrops along Blue Creek north of Lake Meredith in Moore County (Figure 2-9, Lynn 1986), and an outcrop in West Amarillo Creek at 41PT276 (J. Hughes 1969; R. Shaller personal communication Dec. 2007). The small outcrops in the Canadian Breaks are less known and have not been systematically investigated or reported in the literature. However, many other Tecovas source areas may be present, but are unrecorded. Multiple source areas are undoubtedly present and exposed within the mapped Tecovas Formation outcrops spread across the Canadian Breaks along the Canadian River valley west of Amarillo. A small Tecovas outcrop is also reported in the Oklahoma Panhandle along some of the small tributaries of the North Canadian River (Figure 2-9) (Banks 1984 citing an Oklahoma Water Resource report). It is important to realize that simply because the Tecovas Formation outcrops in a valley wall setting, this does not mean that Tecovas jasper is necessarily present. This formation also includes silicified wood (Barnes 1968, 1969, 1993).

The best known and most widely cited source area for Tecovas is in the vicinity of Quitaque, Texas, in
Briscoe County. That region provides a vast range of colors of fine grained and variegated materials. The colors range from white through various shades of yellow, red, maroon, and brown, with mottling (Holliday and Welty 1981; Banks 1990).

This material originates in the Tecovas Formation (named by Gould 1907; mapped as part of the Dockum Group, Barnes 1969) of late Triassic age. In general, the Tecovas Formation in Potter County exhibits considerable variation in thickness with an average of about $61 \mathrm{~m}$ (200 ft.) and consists of various colored shales and soft gray unconsolidated, micaceous sandstone (Patton 1923). Banks (1990) provides the best descriptions of the colors and most through discussions of Tecovas. He also provides a color plate of 11 Tecovas samples from 3 localities that include Weymonth Ranch $(N=4)$, Coetas Creek $(N=6)$, and West Amarillo Creek $(N=1)$.

In the southwest end of Lake Meredith is the Coetas Creek outcrop (PPHM-M151, 41PT434, or LAMR 650) at the mouth of Coetas Creek in northeastern Potter County. This site was first discovered by Meeks Etchieson (Etchieson 1979a) and visited again by Jack Hughes, Etchieson, Billy Harrison, and others in 1983 (Harrison 1983; Hughes 1983). More recently, a survey crew from 4G Consulting recorded this relatively large procurement site in detail, documented the materials, mapped and photographed the location (Raab 2005). They recorded the site as extending over some 52,000 


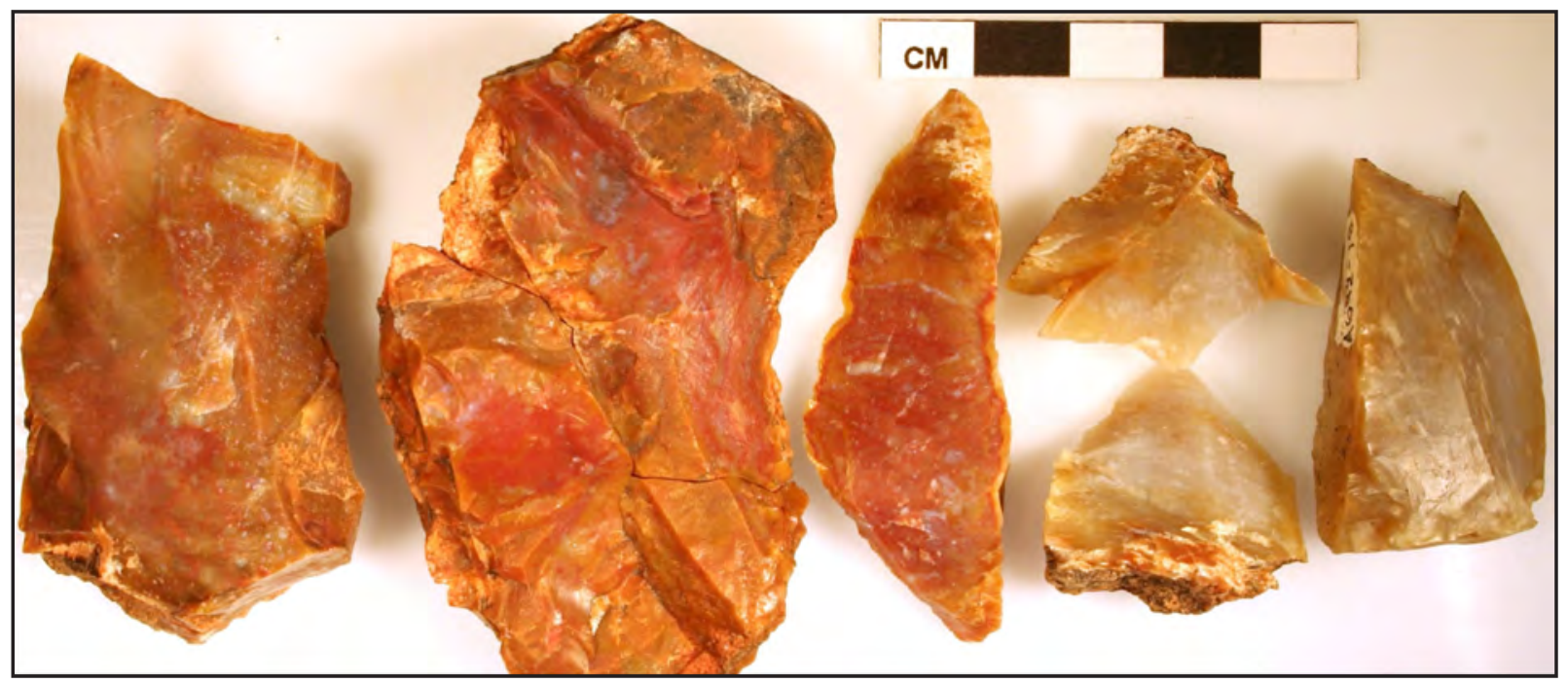

Figure 2-9. Examples of Tecovas from South Basin quarries (410L284).

$\mathrm{m}^{2}$ at an elevation of $952 \mathrm{~m}$ and divided up the site into eight intensive activity areas along the slopes below the Tecovas bedrock outcrops. The outcrop is roughly $10 \mathrm{~m}$ above the Permian age dolomite with large Tecovas jasper boulders below the outcrop. The procurement area includes large boulders that contain Tecovas jasper and shows signs of having been tested and material extracted.

Minimally, six quarry pits, ranging from 70 to 170 $\mathrm{cm}$ in diameter with depths of $30 \mathrm{~cm}$, and associated clusters of artifacts and concentrations of debitage, were observed. Artifacts include tested cobbles, cores, bifaces, end scrapers, edge modified flakes, various stages of reduction flakes within recognized knapping localities, and a possible hearth feature (Raab 2005). Raab (2005) states that most of the bedrock lithic material is cherty, with some residual chalcedony in place on the rim surface. Some jasper specimens grade into orthoquartzite, but this is generally rare. Most of the jasper and chalcedony is heavily weathered and contains many crystal-lined vugs (Figure 2-10). The Tecovas jasper is described as:

\begin{abstract}
"an iron-rich replacement chert with a variegated or randomly mottled appearance replete with lugs and druses filled with botryoidal surfaces, agate, or quartz crystals. Secondary crystal growths are common on frost-fractured surfaces. Flawless masses of Tecovas chert more than 15 $\mathrm{cm}$ in length are very rare. The color range includes: red (10R 5/6, 10R 4/6, 10R 4/8), dark red $10 R 3 / 6)$, dusky red (10R 3/4), yellowish red (5YR 5/6, 5YR 5/8, 5YR 4/6), yellowish brown (10YR 5/6), white, light olive brown (2.5Y 5/4), and olive yellow (2.5Y 6/6) (Raab 2005).”
\end{abstract}

Raab (2005) goes on to describe the Tecovas chalcedonic chert/agate as:

"fine homogenous texture translucent with globular "bubble" features visible at $<0.5 \mathrm{~mm}$ into the material, vitreous luster, in-filled veins of red (2.5YR 4/8) or dark yellowish-brown (10YR 4/6) jasper oriented along internal fracture planes, agate- or quartz-crystal lined cavities, some with botryoidal surfaces. The matrix has a frosted appearance, ranging in color from light greenish gray (Gley 1 7/1) to light bluish gray (Gley 2 7/1) to white." 
The Tecovas orthoquartzite is described as:

"homogeneous fine $(1 / 8$ to $1 / 4 \mathrm{~mm})$ to $\mathrm{me}$ dium $(1 / 4$ to $1 / 2 \mathrm{~mm})$ sand, rounded grain shape, white to colorless cement, opaque, sucrosic luster, jasper overgrowths are common, as are small vugs in-filled with jasper-agate. Color patterning ranges from homogeneous [weak red (2.5YR 4.5/2) or brown (7.5YR 5/4) to mottled weak red and brown with red jasper inclusions (10R 4/8). Tecovas orthoquartzite reported occurs in larger cohesive masses than Tecovas jasper (Banks 1990:93).”

Tecovas jasper is a fine grained material similar to Alibatesin texture and color. It is often distinguishable by its variegated or mottled appearance, with some exceptions. Most pieces are red, brown, cream, white, yellow, or green in colors. It is opaque, often with bluish white quartz vugs. It occurs in massive boulders as much as a meter in diameter that also contains tiny quartz filled vugs (Tunnell 2006). Both Alibates and Tecovas come in red, but the latter has a more even red, and is generally mottled or variegated often with tiny quartz vugs (Holliday and Welty 1981). The Tecovas material is often visually distinguishable, but some pieces may look quite similar to Alibates. Both Alibates and Tecovas reveal very dark or purple/velvet ultraviolet light response (Hofman et al. 1991).

An initial INA analysis was conducted on selected natural Tecovas samples from six different Tecovas
Formation outcrops as part of the mitigation program at the BLM Landis Property (Quigg et al. 2010; Boulanger and Glascock 2010). A limited sample of 25 pieces of unmodified Tecovas were chemically analyzed at MURR, which included 2 pieces from the Blue Creek 1 and 3 localities (TRC439-440), 5 pieces from 41PT434 (TRC510-514), 5 pieces from 41OL284 (TRC515-519), 9 pieces from 41PT276 (TRC384-389, 487-398), 5 pieces from the Quitaque area in Briscoe County (TRC394-398), and 4 pieces from Palo Duro Canyon in Randle County (TRC 444-447). The INA results indicate that the natural Tecovas samples show some similarity to materials from the Quartermaster Formation (Alibates Dolomite), but a biplot of the first canonical discriminant function shows that Alibates and Tecovas can be distinguished chemically from each other (Boulanger and Glascock 2010; Quigg et al. 2011b). More importantly, plots of logged elemental concentrations also demonstrate the possibility of identifying differences between the various outcrops of jasper sources or at least county differences.

\subsubsection{Opalite}

Opalite is another local raw material resource that occurs in the Ogallala Formation. The latter formation was named by Darton (1899) from outcrops near Ogallala, Nebraska. It extends from the Southern High Plains in western Texas northward across the plains east of the Rocky Mountains into western Nebraska and eastern Wyoming (Seni 1980). This generally structurally poor material, a caliche cemented sequence of gravel, sand, silt, and clay, occurs in

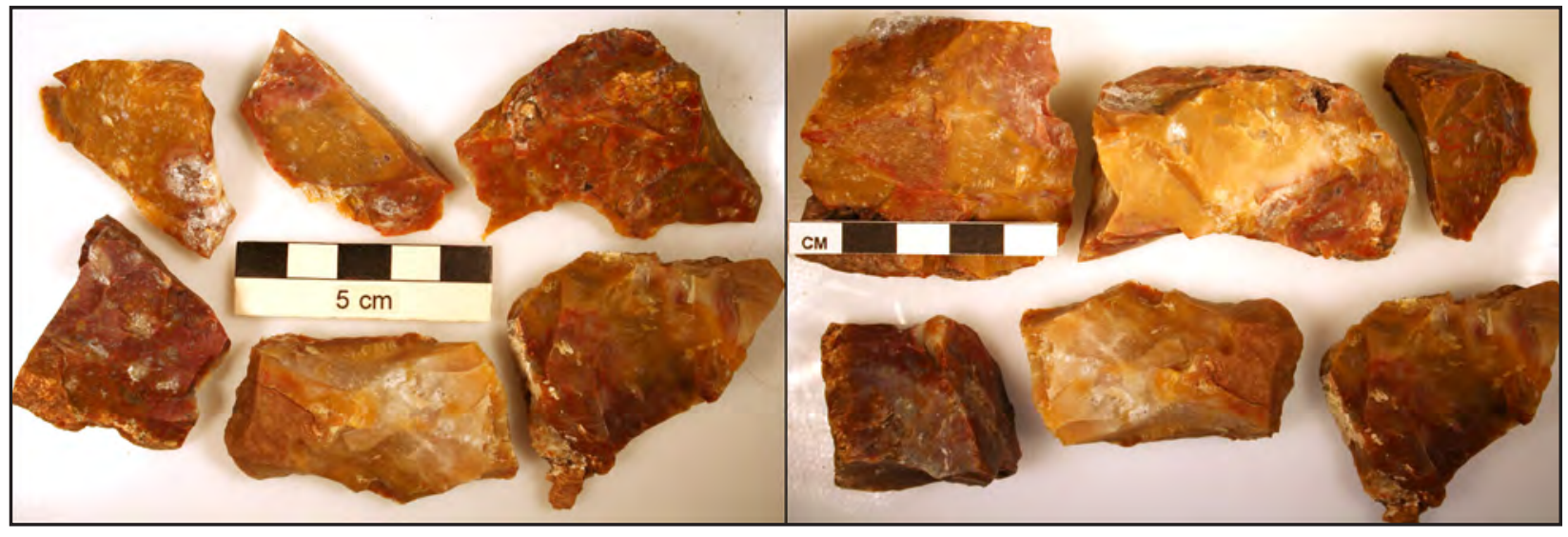

Figure 2-10. Examples of Tecovas jasper from Coetas Creek, 41PT434. 
horizontal beds of various thicknesses within the cemented caliche caprock of the Ogallala Formation, but also in some gravel beds (Gustavson 1996; Lintz 1998). Opalite is opaque cryptocrystalline silica, dull in luster, and formed in clay matrix by a replacement process. The dominant colors are off-white to pinkwhite (5YR 8/1.5), light gray (5YR 7/1), or reddish brown (5YR 6/3). The quality of this material varies tremendously, but most pieces have many internal fractures and weather into blocky chunks. These characteristics create problems in knapping and the usefulness of this material is limited to crafting small tools such as projectile points and scrapers, as Lintz (1998) points out for several assemblages. Some crude chopping and bifacial tools are also made of Opalite, and sometimes it was used as hearth stones.

\subsubsection{Potter Chert}

Potter chert is another knappable material that occurs in the Ogallala Formation. It occurs in outwash Ogallala gravels and appears prominent in the Canadian River valley and across much of the Texas panhandle. Potter chert is the most distinctive material in the gravels, which also includes quartzite, jasper, siltstone, chalcedony, opalite, and silicified wood (Holliday and Welty 1981; Banks 1990). Potter chert is not a true chert, but rather, it is a fine grained silica cemented siltstone (Holliday and Welty 1981). It is primarily green or red; however, heat treating alters its true color. Quality ranges from extremely coarsegrained to very fine-grained. It has been flaked into a variety of objects, mostly larger chopping, cutting, and pounding tools or crude bifaces.

\subsubsection{Ogallala Quartzite}

Ogallala quartzite, also derived from the Ogallala Formation, is very abundant in many places across the Southern Plains, primarily in the Canadian Breaks and along the Caprock Escarpments on each side of the Llano Estacado (Gustavson 1996). It appears throughout the region in dispersed outwash gravels and as isolated occurrences that resulted from tertiary outwash from the Rocky Mountains. Outcrops of Ogallala are found across southeastern Colorado and the Oklahoma panhandle (Banks 1990). Typically Ogallala quartzite occurs as small fist-size cobbles in gravels on ridge tops, colluvial slopes, and high terraces. It is predominately gray to pink and purple in color and ranges from cryptocrystalline to macrocrystalline in texture. This fine to medium grained silicified sandstone or siltstone is quite common and was often employed to make large cutting, chopping, and pounding tools. The Ogallala deposits consist of sand, silt, clay, some weakly developed caliche, and pebble to cobble sized gravels composed of quartz, quartzite, minor amounts of chert, petrified wood, schist, limestone, igneous rocks, metamorphic rocks, and caliche nodules (Barnes 1969).

\subsubsection{Silicified (Petrified) Wood}

Silicified (petrified) wood is present in considerable quantities in both the Tecovas and Trujillo formations (Patton 1923; Barnes 1968, 1969). It is mineralized fossil wood that resembles chert. In some places, large logs have been documented. This is a local resource, but the pieces are not often easily worked into stone tools because linear fracture planes along the growth rings create difficulties during tool manufacturing. Colors vary considerably with reds and browns dominant. It has a dull luster and is opaque to slightly translucent along the edges. It is found in tertiary gravel deposits across a wide area.

\subsubsection{Chalcedony}

Chalcedony is translucent to opaque, fiberous, cryptocrystalline silica with a generally waxier luster than most cherts. Colors are extremely variable with clear and white predominate. Chalcedony often occurs as small pebbles in the local gravels.

\subsubsection{Sandstone}

Sandstone is a cemented or compacted sedimentary rock predominately composed of fine quartz grains. Generally, it is brown to reddish brown in color. Grain size and degree of cementation vary considerably even within a single formation.

\subsubsection{Other Cherts}

Other cherts are often present, but may not fit into our currently known or perceived range for a specific type. Thus, some pieces will fall into this unknown chert category if they cannot be specifically identified in one of the named chert groups. 
Recognizable Nonlocal Stone Tool Resources: Although tool stone is relatively plentiful in the Texas panhandle region, some tools manufactured of nonlocal stone tool have been identified in various cultural assemblages from this region. The more prominent and easily identifiable imported materials are discussed below.

\subsubsection{Obsidian}

All obsidian is considered nonlocal to this region, because the nearest known source areas are northcentral New Mexico. Obsidian is a black volcanic glass that is brittle and easily worked into stone tools. Given the long distance transport involved, it appears most often as small pieces of broken tools and small flakes.

How the obsidian arrived in the Southern Plains is being studied and debated. Baugh and Nelson (1987) present a model of obsidian source use from Paleoindian to Protohistoric times for this region. They suggest sporadic down the line exchange transactions. That is, one group near the source traded obsidian to their neighbor and that group then traded it to their neighbor; distant populations were not going to the source areas and collecting the obsidian firsthand. The trade networks were most likely loosely structured, open systems with a general north to south orientation. This later directional movement was based on some 86 percent of the obsidian artifacts coming from sources in Idaho and Utah, with a much lower percentage originating in the Jemez Mountains in New Mexico (Baugh and Nelson 1987:325). More recent studies by Bement and Brosowske (2001) and Brosowske (2005) indicate that obsidian was from different source areas at different periods of prehistory. The Baugh and Nelson (1987) model was based mainly (92 percent) on obsidian from Protohistoric sites (A.D. 1450 to 1650) that indicate obsidian at that particular time was primarily from Malad, Idaho. Bement and Brosowske (2001) indicate that during the Late Archaic period in the Oklahoma and Texas panhandles, obsidian came from minimally two primary source areas, Obsidian Cliff in northwestern Wyoming, and Valle Grande (i.e., Cerro del Medio) in north-central New Mexico. Quigg et al. (2010) has documented obsidian in Late Archaic campsites just east of Amarillo as early as 2400 B.P.
Brosowske (2005), studying the Plains Village period occupations in western Oklahoma and the Texas panhandle, sourced 130 artifacts from 19 different Middle Ceramic period sites (A.D. 1200 to 1500), and found that nearly all the obsidian came from Cerro Toledo Rhyolite (sometimes call Obsidian Ridge obsidian) in the Jemez Mountains of north-central New Mexico. Brosowske (2005) used the spatial distribution of obsidian to reconstruct the structure of Middle Ceramic period exchange networks on the Southern High Plains. Based on large quantities of obsidian at a few specific sites (i.e., Alibates Ruin 28, Chimney Rock Ruin 51 [A393] in Potter County, and Odessa Yates [34BV100] in Beaver County Oklahoma), Brosowske hypothesized that these communities served as regional trade centers.

\subsubsection{Oklahoma Cherts}

Other nonlocal tool stone is sometimes recovered from archeological sites in the Texas panhandle. Permian age materials are present in southern Kansas and into western Oklahoma. Chert is present in 7 of 16 limestone members and formations within the Council Grove and Chase Groups of the Lower Permian with Day Creek dolomite in the Upper Permian series (Banks 1990; Stein 2006). The most prominent general classes are Wreford and Florence cherts. The Wreford cherts are exposed in the southern Flint Hills of Kansas and north-central Oklahoma and come in a variety of colors including Wreford A, which is gray-buff or tan, dark gray $(2.5 \mathrm{Y} 4 / 1)$, and a dark brown (10YR 4/3) mottled cortex with mottles in color; Wreford B, which is blue-gray to gray in color and mottled; and Wreford C, which is brownish- or bluish-gray in color (Banks 1990; Stien 2006). Four varieties of Florence chert have been identified. Florence A, also known as Kay County chert or Maple City chert, is a buff to yellow-white (10YR 8/1, 8/2) stripped to light gray (10YR 7/1, 7/2) mottled to stripped chert with a white (10YR 8/1) cortex found in the southern Flint Hill that contains large fusilinid fossils appearing as fingerprints ["fingerprints"] with thin parallel lines. When heated, pieces turn a light red $(10 \mathrm{R} 6 / 6)$ to weak red (10R 4/3). Florence A is a fine-grained chert and easily identifiable because of its concentric banding similar to that of woodgrain. Most often Florence A is gray, blueish-gray, or yellow. However, heated, this material becomes pink and waxy in appearance. Florence B is mottled blue-gray 
and contains large fusilinid fragments. Florence $\mathrm{C}$ is uniform gray and contains fragments of unidentifiable fossils (Stein 2006). Florence D is gray to buff with translucent bands.

Quartz crystals are rare, but the Wichita Mountains in Comanche County and the adjacent Kiowa County, specifically Quartz Mountain in Kiowa and Greer counties in southwestern Oklahoma, which are primarily igneous (granite, rhyolite and gabbro) and metamorphic rocks, have yielded crystals (Gilmore 1963). Northcutt (1981) cited in Banks (1990:104) reported a site with considerable quartz crystals. Often, crystals are recovered in ceremonially context and related to Caddoan sites further east. Crystals are generally clear, but flaws may be present. The Wichita Mountains are roughly $250 \mathrm{~km}$ to the southeast.

\subsubsection{Kansas Cherts}

The Niobrara Formation, of Cretaceous age, is in northwestern Kansas. The silicified chalk found in the Smoky Hill chalk member was widely used throughout prehistoric times. It is referred to by a variety of names, including Smoky Hill jasper, Niobrara jasper, and silicified chalk. The material is typically opaque, but may be translucent. Most are dark yellowish brown (10YR 6/8), dark reddish brown (2.5YR 3/4), reddish yellow (5YR 6/6), red (2.5YR 5/6) to week red (10R 4/4), or even dark gray (5YR 4/1) colors, with some banding and infrequent mottling as well. The cortex is most often a pink (7.5YR 8/4) to light red (10R 6/6) or a very pale brown (10YR 8/4). The texture is highly variable and generally lacks fossils (Stein 2006). This jasper is especially prevalent in western Kansas, roughly 380 to $400 \mathrm{~km}$ to the north. Neutron activation analysis has been used to identify the raw material source of Smoky Hill jasper from the bluffs in the Saline River valley in Trego County (Banks 1990 cited in Stein 2006).

\section{$2.6 \quad$ Soils}

\subsubsection{Arable Soils Near the Project Area}

A majority of the soils immediately surrounding 41RB112 are potentially good for agriculture/ horticulture by modern standards (Figure 2-11). These include Likes soils (loamy fine sand designated by Map Units 17 and 18) and Mobeetie soils (fine sand loams designated by Map Units 20, 21, 22, and 23). Others soils (e.g., Lincoln) are present that are not necessarily ideal for farming, but could be used given adequate climatic conditions.

The surface layer of Likes soils is generally brown in color and is classified as rangeland whose vegetation is composed, by weight, of about 80 percent grass, 10 percent forbs, and 10 percent woody plants. Slopes for this soil type can range anywhere from 1 to 8 percent in hilly areas. Likes is excessively drained with moderately rapid permeability resulting in slow surface runoff.

This Prairie setting typically supports tall grasses such as little bluestem (Schizachyrium scoparium var. frequens), sand bluestem (Andropogon glomeratus), indiangrass (Sorghastrum nutans), and sideoats grama (Boutelous curtipendula, Wyrick 1981:20-21). Other grasses that can be found here include Texas bluegrass (poa arachnifera), blue grama (Bouteloua gracilis), hairy grama (Bouteloua hirsuta), switchgrass (Panicum virgatum), silver bluestem (Bothriochloa laguroides), sand dropseed (Sporobolus cryptandrus), and Canada wildrye (Elymus canadensis). Example of forbs that are common include wild alfalfa, Illinois bundleflower (Desmanthus illinoensis), prairie spiderwort (Tradescantia occidnetalis), catclaw mimosa (Mimosa biuncifera), sensitive briar (Schrankia uncinata), and yellow neptunia (Neptunia lutea). Woody plants include shinnery oak (Quercus mohriana), sand plum (Prunus angustifolia), sand sagebrush (Artemisia filifolia), and yucca (Yucca glauca). Wildlife seems to benefit greatly from Likes soil because it propagates the growth of plants that provide both food and groundcover. Animals that might be seen inhabiting areas containing Likes soils are quail (Odontophoridae), deer (Odocoileus sp.), turkey (Meleagris gallopavo), and prairie chicken (Tympanuchus cupido).

Mobeetie soils are fine sand loams that are deep and grayish brown in appearance. This soil is welldrained with rapid permeability and medium degree of runoff (Wyrick 1981:23). Plant root penetration is relatively unfettered. Areas with these soils are classified as rangeland, but they are also moderately 
well-suited to nonirrigated and irrigated crops. The plant community composition is made up of 60 percent tall and midgrasses, 30 percent short grasses, 5 percent forbs, and 5 percent woody plants. Grasses include blue grama, sideoats grama, little bluestem, and sand bluestem, but other grasses such as western wheatgrass (Agropyron smithii), buffalograss (Buchloe dactyloides), black grama (Bouteloua eriododa), and indiangrass are present. Forbs that are presentinclude purple prairie clover(Dalea purpurea), bushsunflower (Helianthus sp.), feather dalea (Dalea formosa), pitchersage (Artemisia sp.), and dotted gayfeather (Liatris punctata). Woody vegetation that is present includes ephedra (Euphorbia sp.), shinnery oak, yucca, and skunkbush sumac (Rhus aromatica). Animal habitats supported by this soil type include those of deer, bobwhite (Colinus virginianus), and blue quail (Coturnix adansonii).
Lincoln fine sand is located in the flat bottomlands of both Sourdough and Dugout Creeks (areas denoted in Figure 2-11 by solid dark gray fill). These areas are frequently flooded within a range of five times a year to once every three years, with a water table at 1.7 to $2.7 \mathrm{~m}$ ( 5 to $8 \mathrm{ft}$.) below surface. This soil is excessively drained. The soil-blowing hazard in this area is severe. Because these are in alluvial settings, they could be considered usable for cultivation practices.

\subsubsection{Soils that are Less Desirable for Cultivation Adjacent Long View Site}

The Berda-Potter association occurs along escarpments and the lower slopes of hills/ridges. These areas contain active examples of natural erosion. Generally, these soils are made up of about 35 percent Berda, 25 percent Potter, and 40 percent

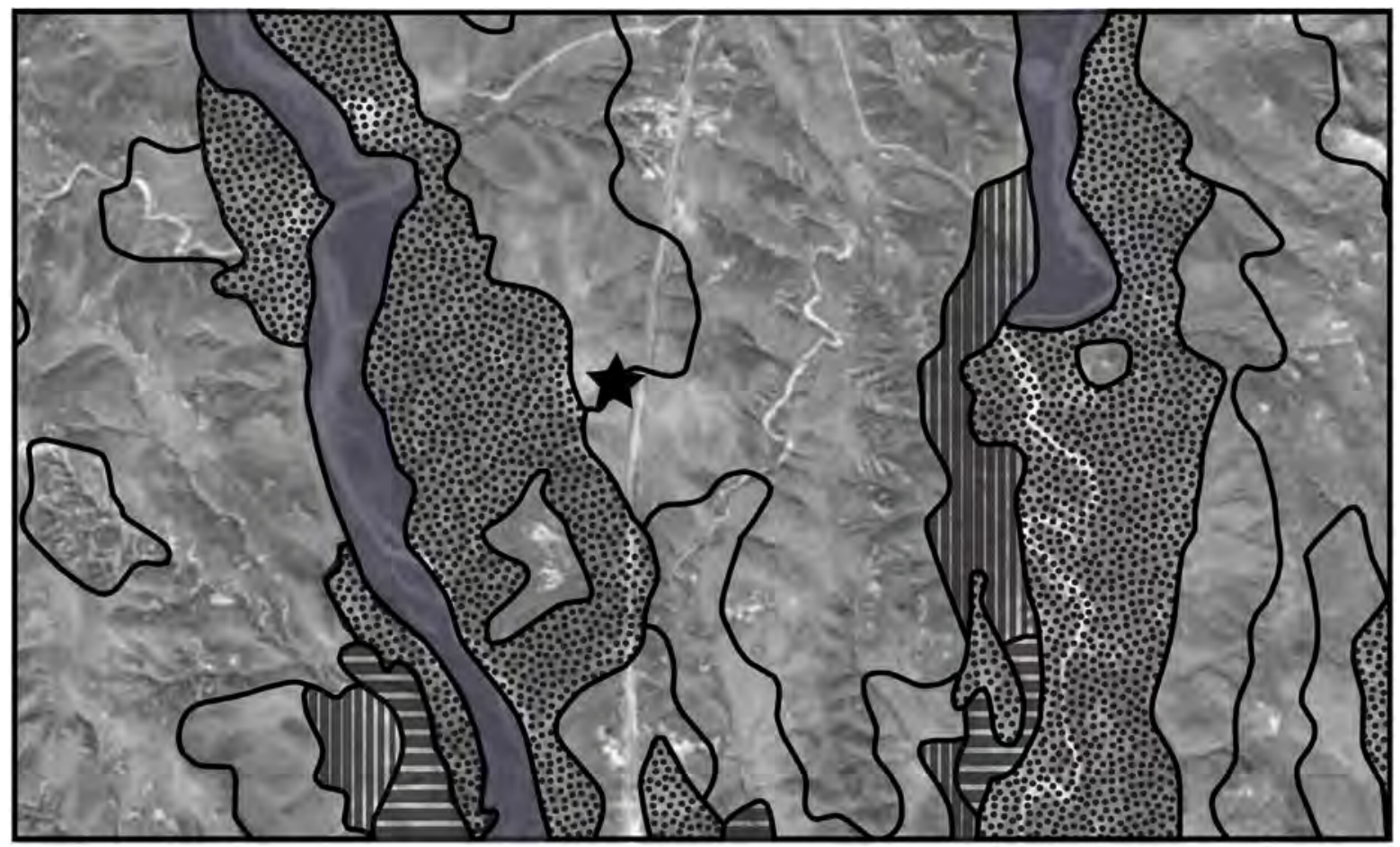

High Productivity: Soil: Type 20 Mobeetie Fine Sandy Loam, 1 to $3 \%$ slope; Type 7 Bippus Fine Sandy Loam, 1 to $3 \%$ slope

Medium Productivity: Soil: Type 21 Mobeetie Fine Sandy Loam, 3 to $5 \%$ slope; Type 28 Paloduro Loam, 3 to $5 \%$ slope

Low Productivity: Soil: Type 19 Lincoln Fine Sand, frequently flooded

Variable Productivity, Dependent upon Slope: Soil: Type 17 Likes Loamy Fine Sand, 1 to $8 \%$ slope

Figure 2.11. Arable soils in close proximity of 41RB112. 
other soils (i.e., Acuff, Bippus, Guadalupe, Likes, Lincoln, Amarillo, Mobeeties, Spur and Veal), but the composition is variable (Wyrick 1981:12). These soils are characterized by high degrees of drainage and runoff. This association is classified as rangeland. Given the steep slopes on which this association is found, these soils are not ideal for crop production.

\subsection{Clay}

Clay resources became important over the last 1,500 years of the Early, Middle, and Late Ceramic period when pottery production was undertaken by various groups. Ceramic vessels were manufactured with clay from selected sources throughout this and adjacent regions. Clay is formed by the mechanical and chemical breakdown and weathering of rocks. The weathering products consist of mineral grains and rock particles of different sizes and different physical and chemical properties (Virta 1992). Clay deposits can be local and residual in nature, deposited in the same location in which they formed. Clays can also be secondary deposits laid down by fluvial processes in valleys or along colluvial slopes. The water transported clays are subject to further alterations and mixing with other minerals (Virta 1992).

In addition to the clay or plastic portion, various granular particles were added to the clay to strengthen the vessel. The additives could include a wide range of materials including, but not limited to, crushed rock fragments generally referred to as temper or grit, which often consists of quartz, micas, feldspar, iron oxides, and other minerals. Crushed sandstone either heated or unheated may have served as an additive to the clay. Even crushed, burned bone was sometimes added as a tempering agent.

The geology of the Texas panhandle region creates a setting that has abundant clay resources. Minimally, three deposits of different ages contain clays that are suitable for pottery manufacture. The oldest, the Permian redbeds, which include many named formations, are exposed at the bottoms of some smaller tributary creeks and most lower margins along the Canadian River with massive exposures further east in the Rolling Plains. These Permian exposures contain clay, sandy shales, fine sandstones, and white gypsum generally underlying a hard cap of Alibates dolomite. Uncolored, well rounded, frosted quartz grains are common in the Permian (Adkins 1958:245). This naturally red clay is suitable for the production of pottery. However, gypsum within the clay is an undesirable ingredient for pottery manufacturing as it tends to cause spalling or pitting in the finished vessel (Lynn 1982).

Stratigraphically overlying the Permian redbeds is the Dockum group of upper Triassic age. The Dockum group is primarily exposed along the Caprock Canyonlands on the eastern margin of the Llano Estacado in eastern Potter and Moore counties. Subdivisions within the Dockum group include a basal shale labeled Tecovas, which is overlaid by sandstone and shale known as the Trujillo Formation (Adkins 1958). Both the Tecovas and Trujillo formations also contain layers of sandstone, mudstones, and shales in a variety of colors including red, maroon, yellow, and variegated. The weathered clay is friable and dull in appearance. When wet, this clay exhibits brilliant colors and is plastic. One known source of this clay is north of the Canadian River near the confluence of Blue Creek (Lynn 1982). This original source of the Triassic clays is assumed to be from around south central Colorado (Adkins 1958:245). The Triassic age material contains silicified wood and abundant mica with colored, subrounded, partially frosted quartz grains (Adkins 1958:245).

The Ogallala Formation of late Tertiary age (Miocene and Pliocene) sits atop the eroded Triassic sediments. This formation is widespread across the southern Plains and contains a series of layered sands, silts, gravels, clays, and caliche in various shades of brown, gray, and pink (Cepeda 1996). The many tributaries of the Canadian River have eroded through the Ogallala Formation exposing brown and buff-colored clay.

Much of the Texas panhandle is covered with the Blackwater Draw Formation. The thousands of shallow playa lakes that dot the panhandle region contain dark gray and blue clay. These playas are cut or collapsed into the Blackwater Draw Formations. Clays from these playas are also suitable for pottery manufacture (Lynn 1982).

Recent or Holocene alluvium from flood deposits is widespread along the bottoms of most creeks and 
rivers across the region. These secondary deposits contain quantities of sand, silt, gravels, and pockets of clay (see Holliday 1995 for details concerning the contents of draws across the Southern High Plains). Consequently, clays and clay mixtures are numerous, with a variety of colors dispersed across the region. The prehistoric population would have had access to these clays for the manufacture of their pottery.

Limited research has focused on the source areas of clay for the production of pottery in the Texas panhandle with no apparent clay distribution maps other than the general geological maps (Barnes 1968, 1969, 1993). This is likely the result of clay being widespread and readily available. Petrographic and INA analyses of clays in association with archeological investigations are extremely rare. Two natural sediment samples from the Palo Duro Reservoir sites, windblown sediment from the top of 41HF5, the other alluvium from the first terrace at 41HF5 were examined during petrographic analysis in conjunction with ceramic sherds (Reese-Taylor 1993a).

Recently, Meier (2007) included 13 modern clay samples from 3 general source areas along the Canadian River valley in the region in her INA analysis of Borger Cordmarked pottery of Antelope Creek phase sites. The 13 natural clay samples came from near the 3 archeological sites sampled in her investigations, which included 3 samples from the Cross Bar Ranch near 41PT109 at the mouth of West Amarillo Creek (HAM88, 89 and 90), 5 samples from further west along Alamosa Creek near Landergin Mesa in Oldham County (HAM8387), and 5 samples from near Alibates Ruin 28 along Alibates Creek in northeastern Potter County (HAM76-79, and 82). The eight samples from Cross Bar Ranch and Alamosa Creek, and most likely all the samples from Alibates Creek, are labeled as alluvial deposits. Alluvial deposits are considered secondary, potentially incorporating minerals from several local geological formations. Following INA analysis, 6 of the 15 clay samples plotted in or near the five INAA ceramic sherd groupings identified by Meier (2007). This data helped to determine where various Antelope Creek phase cordmarked vessels were likely manufactured.
The two phased data recovery effort conducted at the Landis Property in Potter County for the Bureau of Land Management (BLM) also analyzed eight natural clay samples from various sources across the Texas panhandle region during the INA and petrographic investigations (Quigg et al. 2010). Those samples included six mixed alluvial clays from West Amarillo Creek (TRC379, 381, 434437), one natural clay from Blue Creek on the north side of Lake Meredith (TRC380), and one Triassic clay from Wildcat Bluff Nature Center (WBNC) just north of Amarillo (TRC382). Eleven thin sections were created and used to compare with the petrographic analysis conducted on thin sectioned ceramic sherds recovered from the BLM Landis Property investigations.

The INA analysis was conducted to investigate potential source areas for the manufacture of the ceramic vessels. The INA data indicates that the local alluvial clay sources were very similar to the clay used for the manufacture of two or three of the five Antelope Creek phase sherd groups identified by Meier (2007). The Blue Creek clay (TRC380) and an Alvin Lynn replicated ceramic pot using the same Blue Creek clay with additives of sand and ash (TRC383) were quite unlike the local clay sources and unlike any of the cordmarked sherds analyzed. Consequently, the readily available natural sediment and clays across the region were important resources for the manufacture of ceramic vessels for some local ceramic period groups.

\subsection{Climate}

The climate of the northeastern Texas panhandle can be typically characterized as harsh and variable (Figures 2-12 through 2-15). The winter seasons are punctuated by strong fronts that can cause quick and sizeable drops in temperature along with snow and ice storms (Haragan 1978; Wyrick 1981:2). Bomar (1983:235) shows that an average of seven cold fronts move through the panhandle and high plains regions during the months of the most variable weather (January, April, July, and October). This average is higher than any other region in the state. Average temperatures for the winter season range from 2.2 to 5.5 degrees Celsius (C, 36 to 42 degrees Fahrenheit $[\mathrm{F}]$ ). The summers are generally hot with average temperatures around 26.6 degrees C (80 
degrees F), but can quickly change due to the arrival of storm fronts and hot air masses (Figure 2-12).

Annual precipitation is $53.3 \mathrm{~cm}$ (21 in.), with nearly 70 percent coming during the growing season from May through September (Figure 2-13; Wyrick 1981). About 43 percent of the average annual precipitation falls during a three-month period from May through July (Haragan 1978). In general, rainfall increases to the east and decreases to the west (Blair 1950).

The average wind speed for the northern portion of the Texas panhandle is consistently around 13 to 15 miles per hour (mph) throughout the year (Figure 2-14). This is a significant environmental factor for two reasons. First, high winds constrain plant growth and propagation, so that mature plants tend to be relatively small and compact (Beddington 1986). After long exposure to high winds, plants show decreases in leaf area and in the sizes of stem and reproductive parts (Retuerto and Woodward 1992:113). It has been suggested that wind speed has a logarithmic effect on vegetation, with no effect on plants exposed to low wind velocities and great effects on plants exposed to higher velocities. Second, wind amounts can directly affect human settlement patterns. A constant higher wind speed can influence house design and construction, choices regarding outdoor versus indoor activities, lengths of residential occupations, and perhaps most critical, water evaporation, and evapotranspiration.

The sun shines about 80 percent of the time in summer and drops to an average of 67 percent in the winter (Figure 2-15; Wyrick 1981). At least 164 frostfree days occur yearly. Sunshine amounts are directly related to length of the growing season. Growing seasons typically last from the beginning of April to the beginning of November (Wyrick 1981:83).

\section{$2.9 \quad$ Biological Resources}

\subsubsection{Floral Communities}

A study of the native vegetation in the Canadian Breaks along Alamosa Creek in Oldham County provides data to help create an understanding of the past vegetation communities of the Long View site and the surrounding region (Sikes and Smith 1975). In their study, Sikes and Smith identified three major plant communities, conducted transects across different land forms, and provided discussions of major communities represented and the percentage of ground cover occupied by each community. In a transect across a high mesa, they documented a mesquite (Prosopis glandulosa)-Galleta (Hilaria jamesii) association. This is the primary floral community, which extends off the High Plains and into the creek valleys. Vegetation coverage was across 42 percent of the surface. Mesquite is considered an invader species, together with scattered pricklypear (Opuntia sp.) and cholla (Opuntia imbricate).

On an alluvial terrace next to a creek, Sikes and Smith documented a mesquite-bristlegrass (Setaria leucopoila) association (Sikes and Smith 1975) covering about 41 percent of the ground in that locality. Scattered throughout the mesquite grassland, skunkbrush (Rhus aromatica) has replaced mesquite along the steep mesa slopes. Hackberry (Celtis reticulata) is often found with large cottonwood (Populus deltoids) along the streambeds. Near the Canadian River along an alluvial deposit below the crest of a mesa, they encountered 57 percent ground cover dominated by hairy grama (Bouteloua hirsuta) and yucca (Yucca sp.). In one locality, they identified a juniper (Juniperus scopulorum)-hairy grama association. In this one locality, juniper, which is randomly interspersed within the mesquite grassland, composed 85 percent of the total cover. Along the margins of the Canadian River, a concentration of introduced salt cedar was found (Tamarix gallica) with some patches of dropseed (Sporobolus cryptandrus). The overall measured ground cover was 46 percent (Sikes and Smith 1975).

Valley hillsides and slopes support grasses such as little bluestem (Schizachyrium scoparium), sideoats grama, sand bluestem, buffalograss, and blue grama (Griffith et al. 2007: 27). Riparian trees and shrubs include cottonwood (Populus sp.), elm (Ulmus americana), black willow (Chilopsis linearis ssp.), Chickasaw plum, skunkbush sumac, hackberry, sandbar willow (Salix sp.), and sand sagebrush (Griffith et al. 2007:27). These woods would be useful for constructing structures.

The nonarboreal taxa include compositae sagebrush (Artemisia sp.), compositae tribe (Liguliflorae 


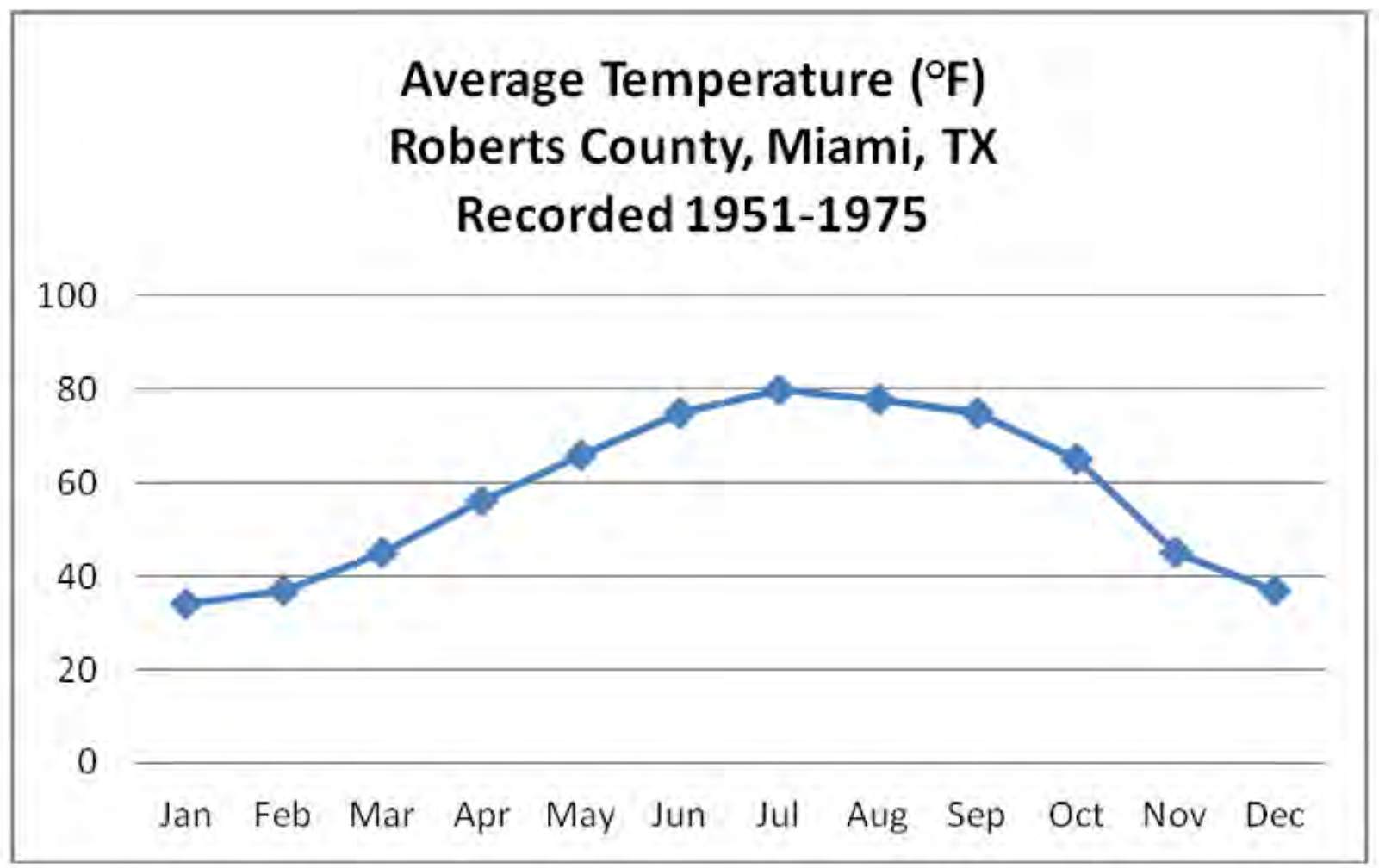

Figure 2-12. Average temperatures in Miami, Texas as recorded from 1951 to 1975 (Source: Roberts County Soil Survey 1981).

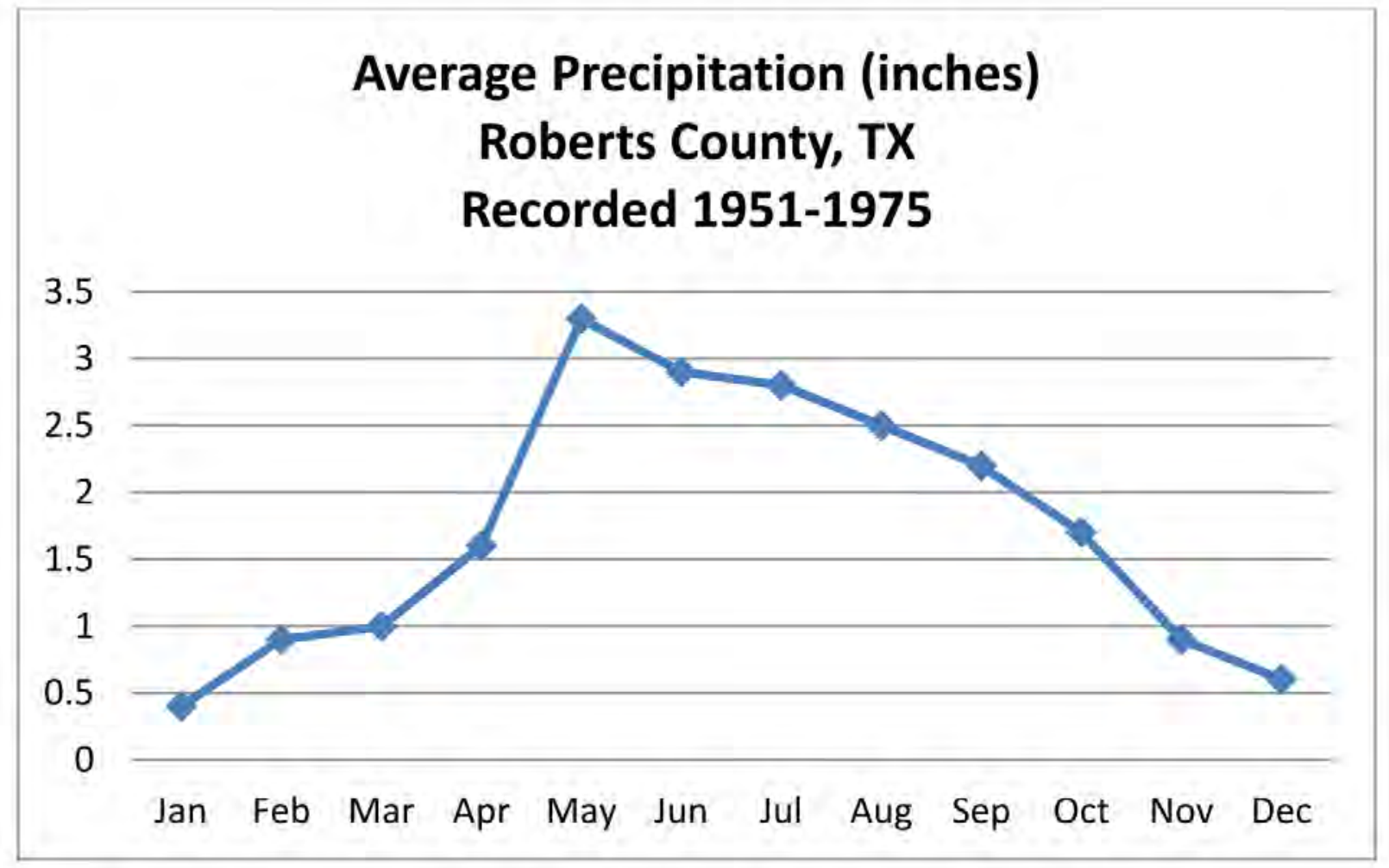

Figure 2-13. Average precipitation measurements as recorded in Miami, Texas from 1951 to 1975 (Source: Roberts County Soil Survey). 


\section{Average Wind speed (MPH) \\ Miami, TX}

20

15

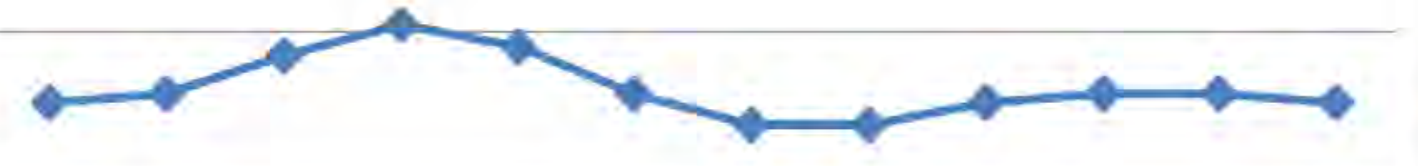

10

5

0

Jan Feb Mar Apr May Jun Jul Aug Sep Oct Nov Dec

Figure 2-14. Average wind speed as measured from Miami, Roberts County, Texas.

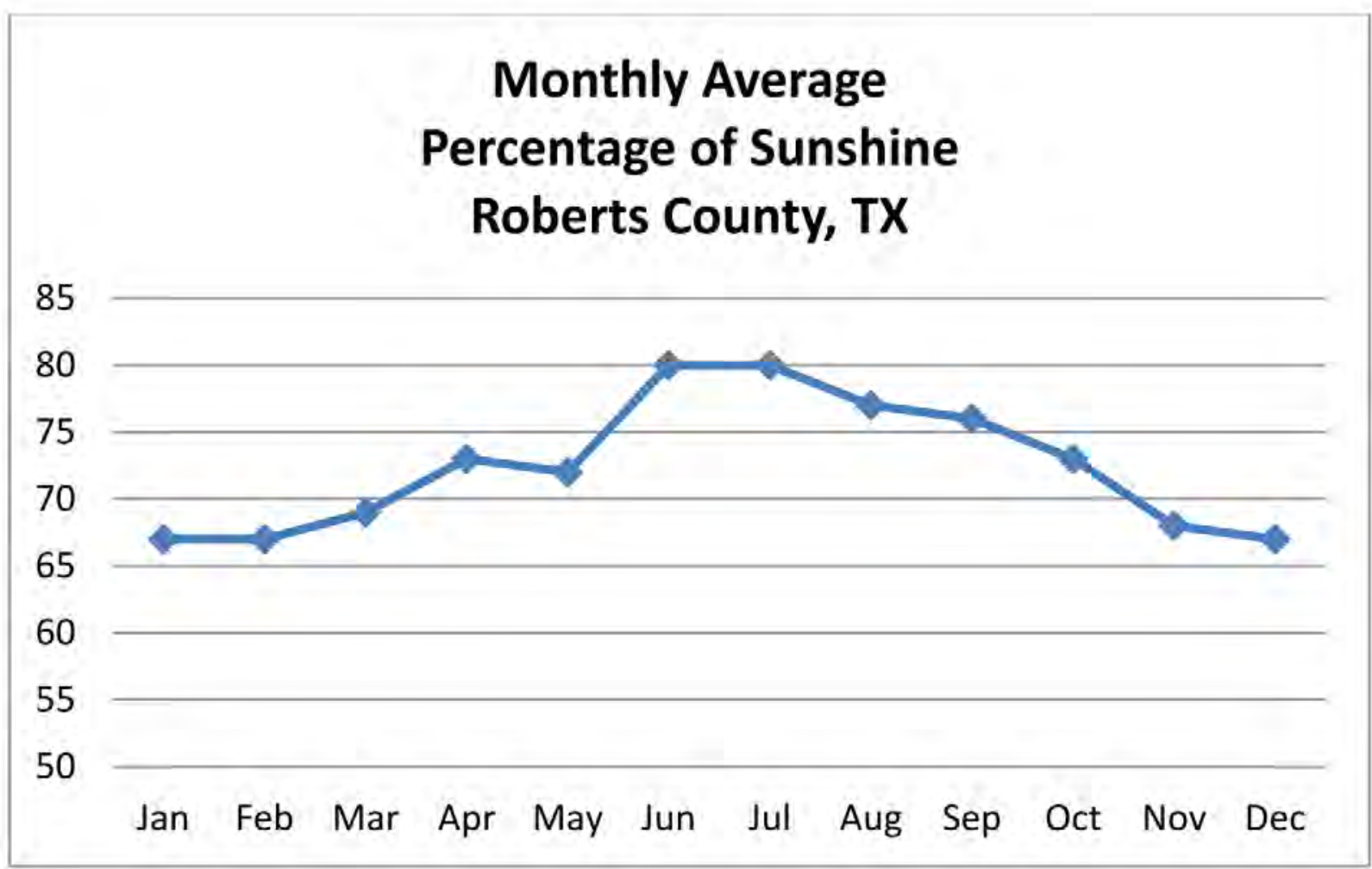

Figure 2-15. Monthly average percentage of sunshine in Roberts County, Texas. 
sp.), goosefoot family, sunflower (Helianthus annuus), marsh elder (Iva xanthifolia) and amaranth (cheno-am); Figures 2-16 and 2-17), grass family (gramineae), mustard family (Brassicaceae), plantain (Plantago), and cattail (Typha). Examples of compositae taxa include ragweed (Ambrosia) and sagebrush (Artemisia sp.).

The current version of the common rangeland plants of the Texas panhandle provided by the Natural Resources Conservation Service (n.d.) lists 75 species of grasses; 75 forbs and legumes; and 50 woody plants, cacti, and vines. Many listed plants have been documented in prehistoric sites across Oklahoma and into Texas. Some of the more important potential food species include, but are not limited to, Canadian wildrye (Elymus sp.), Indiangrass (Sorghastrum nutans), little barley (Hordeum pusillum), Plains lovegrass (Eragrostis intermedia), sand dropseed (Sporobolus cryptandrus), and tobosa (Hilaria mutica).

Of the woody plants that includes trees, the most abundant include the American elm (Ulmus americana), cottonwood (Populus deltoids), desert willow (Chilopsis linearis ssp.), Sand plum (Prunus angustifolia) and possible western soapberry (Spaindus drummondii), which are found along the bottom lands of stream and rivers, with juniper (Juniperus sp.) and mesquite (Popsopis glandulosa) more widely scattered across lower hills and slopes. These woods would be useful for constructing structures.

Various cactus species in the region would also be beneficial plants to the prehistoric populations. Plants such as cholla, (Opuntia imbricate), pricklypear (Opuntia spp.) and Yucca (Yucca glauca) can be useful for many products.

\subsubsection{Potential Food and Health Resources}

The many grass species in the Cimarron and Canadian River Breaks and throughout the surrounding region provide tiny seeds that were probably used as food by humans, and that definitely provided food for the bison on which aboriginal human populations relied. Philips (2000) recorded 16 different grass species for the West Amarillo Creek valley alone, one of the few intensively documented tributaries to the Canadian River valley (Table 2-1). Thirteen (81 percent) of those are warm season $\mathrm{C}_{4}$ species. The regional grassland community is classified as grama-buffalo grass (Bouteloua-Buchloe), reflecting the dominance of those two species (Kuchler 1975). These dominant species are classified within the chloridoid group of grass subfamilies that produce primarily short cell saddle type phytoliths (Fredlund and Tieszen 1994). Other $C_{4}$ grasses recorded for this valley include Big bluestem (Andropogon Gerardii), Little bluestem (Schizachyrium scoparium), Sand bluestem (Andropogon Hallii), Sand Dropseed (Sporobolus cryptandrus), and Indiangrass (Sorghastrum avenaceum), all classified within the Panicoideae subfamily. These grasses produce various phytolith morphotypes including crosses, simple lobates, and panicoid types. In modern phytolith samples to the south in the Lubbock region, the $\mathrm{C}_{4}$ short cell saddle type phytolith generally represents roughly 73 percent of the short cell phytolith assemblage (Fredlund and Tieszen 1994).

The three cool season $\mathrm{C}_{3}$ species identified in the West Amarillo Creek valley include Canadian wildrye (Elymus Canadensis; Figures 2-18), Western wheatgrass (Agropyron Smithii), and crabgrass (Digitaria sanguinalis). The former two species are classified within the Pooideae subfamily and primarily produce short cell phytolith types that include keeled, conical, pryramidal, and crenate forms (Fredlund and Tieszen 1994). In modern phytolith samples from the Lubbock region, the $\mathrm{C}_{3}$ grass phytolith types generally represent roughly 26 percent of the short cell phytolith assemblage (Fredlund and Tieszen 1994).

Another important native grass is little barley (Hordeum pusillum). This is a short, winter annual bunch grass in the Poaceae grass family (Figure 2-19). This has a rapid growth period with a brown seed that develops after spring and is available in the early summer. The seed head consists of flattened spikes. It is considered low in protein and is intolerant to shade. This grass has a low drought tolerance but can grow with only $25 \mathrm{~cm}$ of rain per year. It is considered a $\mathrm{C}_{3}$ grass $(-26.7 \%$; Smith and Brown 1973) adapted to fine and medium soil (http://plants.usda.gov 2011). 


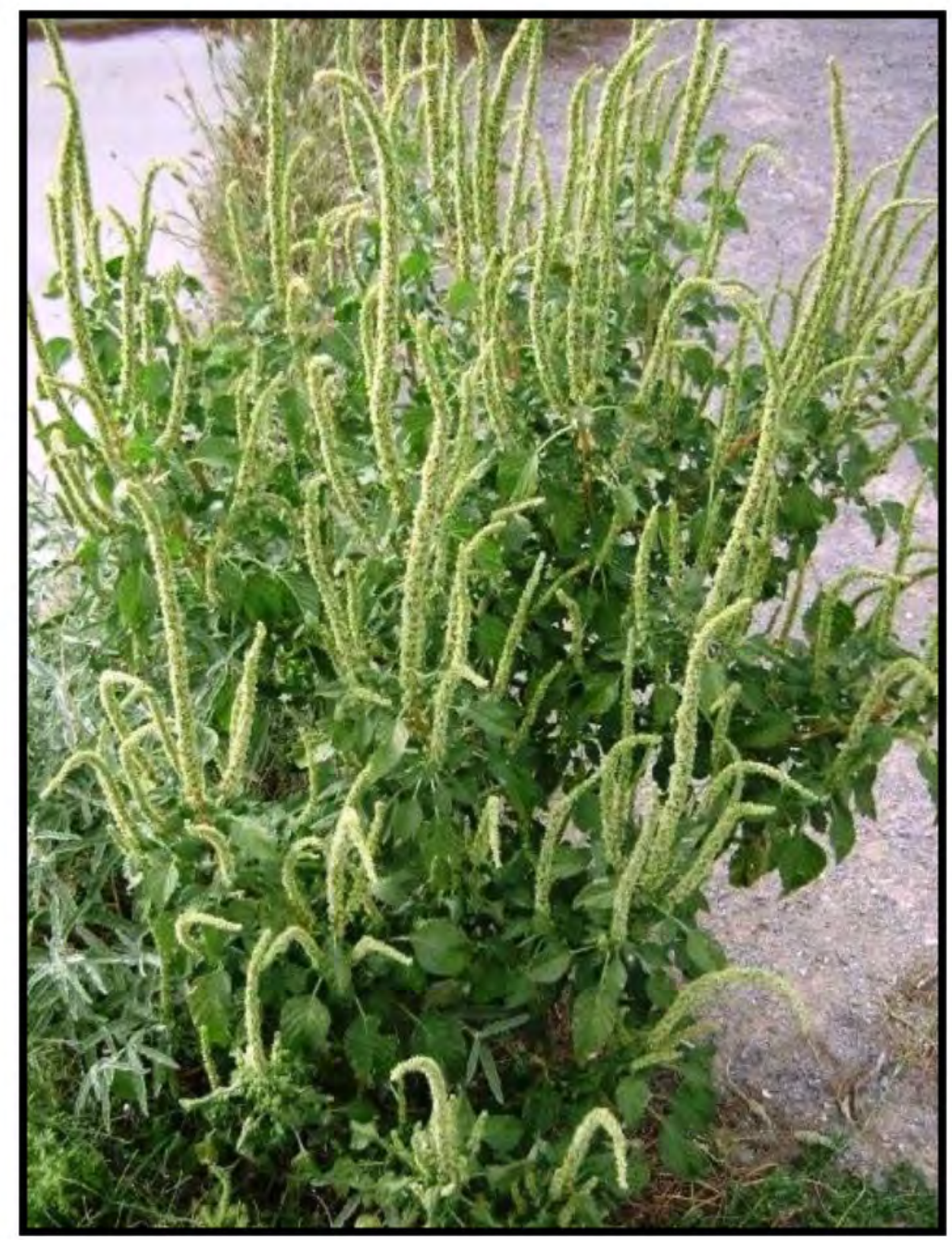

Figure 2-16. Maturing amaranth plant with seed spikes (photograph by M. Quigg).

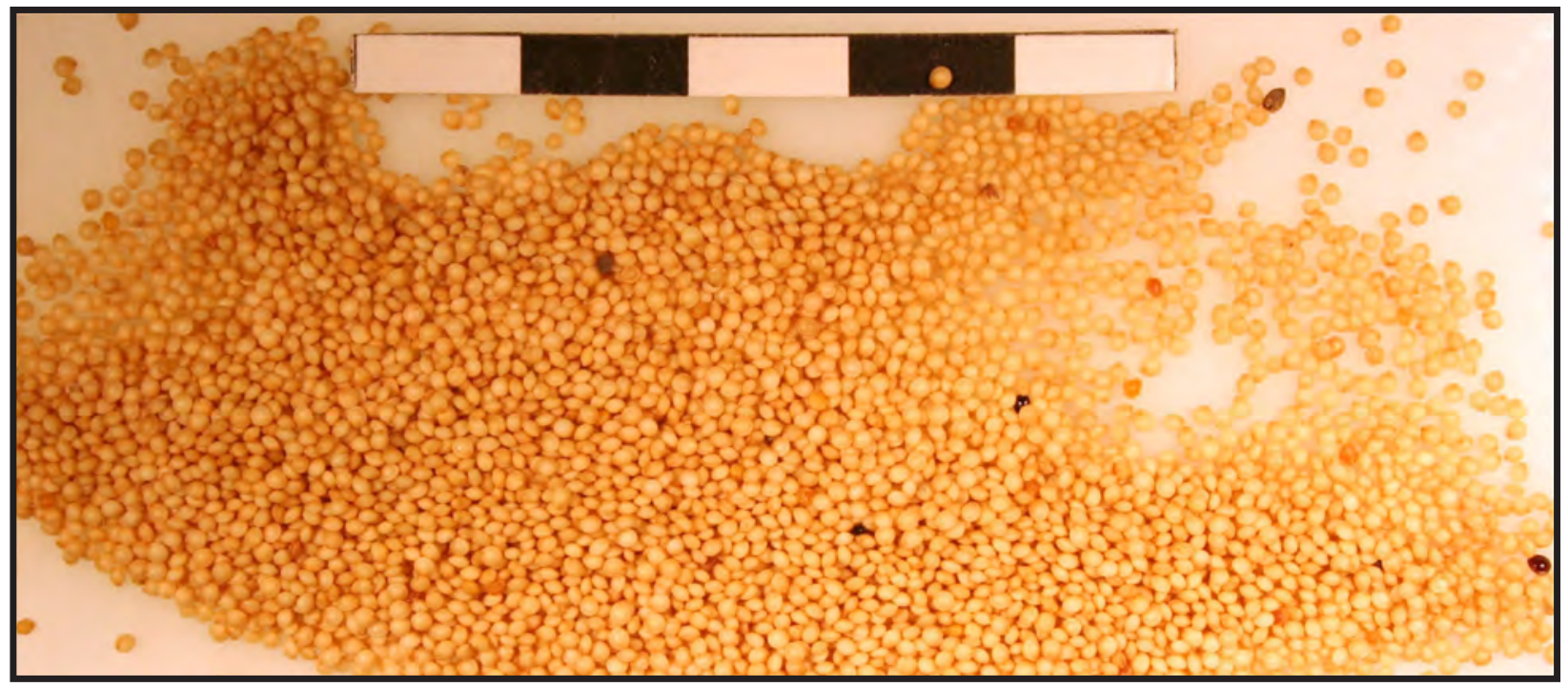

Figure 2-17. Modern amaranth seeds (scale in $\mathrm{cm}$ ) (photograph by M. Quigg). 
Grass seeds require processing by cooking or heating to make them digestible (Stiger 1998). These seeds contain a high percentage of starch. Starch naturally occurs in plant cells in the form of small granules that are water insoluble at room temperature (Arons and Paschall 1975). For the nutrients to become available to humans, the starch granules need to be broken down through cooking. Mechanical grinding or pounding does not rupture the starch granules. Heating as a means of breaking down the structure to release the nutrients is most often achieved through boiling. Upon heating, the granules absorb water and expand, causing the molecules to rupture and thereby making them digestible. Swelling of the starch granules in the heated water is known as gelatinization of the starch grains.

A variety of other plants in the valley were potentially used in diverse ways (i.e., food, medicine) and include Snow-on-the-mountain (Euphorbia marginata), Skunkbush (Rhus aromatica), Mexican hat (Ratibida columnarais), and sunflower (Helianthus annuus). Other plants identified within the region were potentially significant food resources for the early inhabitants. A few of the more important groups of food resources are discussed below.

\subsubsection{Geophytes (Bulbs and Roots)}

Recent archeological investigations in central Texas have identified many carbonized plant bulbs from prehistoric burned rock features. The identified bulbs include, but are not limited to, wild onion (Allium canadense var. canadense, Allium drummondii), false garlic (Nothoscordum bivalve), wild hyacinth (Camassia scilloides), and dog's tooth violet (Erythronium albidum) (Figure 2-20). Bulbs are often found in patches that would make collecting at specific times very easy (Figure 2-21). Farther north in the Wyoming plains, sego lily bulbs (Calochortus nuttalli) have also been linked to prehistoric pit oven baking (Smith and Martin 2001). Each plant has an underground storage organ that stores nutrients, making these perennials an excellent food source (Dering 1998:1610; Smith and Martin 2001). The wild onion or Canadian garlic has been identified in West Amarillo Creek valley (Philips 2000) and visually observed on the Long View site. These wild onions can be eaten raw or cooked. The bulbs have a brown net like (reticulated) fiber covering. The plant also has strong, onion like odor, and the bulbs taste like onion. The narrow, grass like leaves originate near the base of the stem and tend to be flat (not hollow). The stem is topped by a domelike cluster of star shaped, pink or white flowers that grow at the end of a specialized leaf called a scape. The flowers are hermaphroditic (having both male and female organs), and are pollinated by bees and other insects. Flowering typically occurs in the spring and early summer, from May to June. After they are pollinated, the flowers produce seeds.In terms of plant composition, the wild onion contains fructans (inulin form) with sucrose and fructose comprising roughly 55 percent of the dry weight with no starch (Wandsnider 1997, taken from Yanovsky and Kingsbury 1938). The ethnographic literature indicates these bulbs were most often eaten raw or were moist baked. Pit baking of inulin rich foods would have resulted in as much as a 100 percent increase in the energy obtained from these foods (Wandsnider 1997).

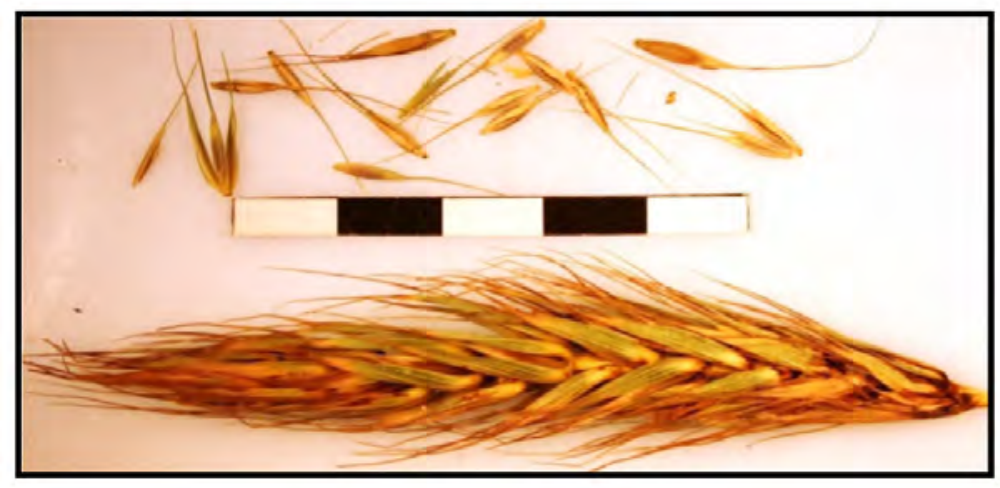

Figure 2-18. Close up of wildrye (Elymus canadensis) grass seed head and loose seeds (photograph by M. Quigg, scale in $\mathrm{cm}$ ). 
Table 2-1. Plants that were Potentially Used for Food Resources.

\begin{tabular}{|c|c|c|c|}
\hline Common Name & Scientific Name & Plant Part for Food & In Season \\
\hline Annual Broomweed & Xanthocephalum sphaerocephalum & greens & summer, fall \\
\hline Big Bluestem & Andropogon Gerardii & seeds & summer, fall \\
\hline Blue grama & Bouteloua gracilis & seeds & summer, fall \\
\hline Buffalo gourd & Cucurbita foetidissima & roots, seeds & summer, fall \\
\hline Buffalo grass & Buchloe dactyloides & seeds & summer, fall \\
\hline Bush Sandlily & Mentzelia strictissima & seeds & summer, fall \\
\hline Canadian wildrye & Elymus canadensis & seeds & summer, fall \\
\hline Cat’s Claw Mimosa & Mimosa biuncifera & seeds & late summer, fall \\
\hline Chicasaw Plum & Prunus angustifolia & fruit & late summer \\
\hline Gayfeather & Liatris puntata & root & spring \\
\hline Hairy Grama & Bouteloua hirsuta & seeds & \\
\hline Honey Mesquite & Prosopis glandulosa & seeds & late summer, fall \\
\hline Indian Rush-pea & Hoffmanseggia glauca & roots & fall \\
\hline Indian Grass & Sorghastrum avenaceum & seeds & summer, fall \\
\hline Little Bluestem & Schizachryium scoparium & seeds & summer, fall \\
\hline Missouri Goldenrod & Solidago missouriensis & leaves & late summer, fall \\
\hline Net-leaved Hackberry & Celtis reticulata & seeds & early fall \\
\hline Panhandle Grape & Vitis acerifolia & fruit & late summer \\
\hline Plains Cottonwood & Populus sargentil & seeds & spring \\
\hline Purple Three-awn & Aristida purpurea & seeds & summer, fall \\
\hline Sand Bluestem & Andropogon hallii & seeds & summer, fall \\
\hline Sandbur & Cenchrus incertus & seeds & summer, fall \\
\hline Sand Dropseed & Sporobolus cryptandrus & seeds & summer, fall \\
\hline Sideoasts Grama & Bouteloua curtipendula & seeds & summer, fall \\
\hline Silver Bluestem & Bothriochloa saccaroides & seeds & summer, fall \\
\hline Silver-leaved Nightshade & Solanum eleagnifolium & roots & summer, fall \\
\hline Small Soapweed Yucca & Yucca augustifolia & fruit, other parts & spring, summer \\
\hline Slimleaf Goosefoot & Chenopodium leptophyllum & seeds & summer, fall \\
\hline Skunkbrush, Fragrant Sumac & Rhus aromatica & fruit, roots & spring, summer, fall \\
\hline Sunflower & Helianthus annuus & \begin{tabular}{|l|} 
seeds \\
\end{tabular} & late summer, fall \\
\hline Wavy-leaved Thistle & Cirsium undulatum & roots & all seasons \\
\hline Western Wheatgrass & Agropyron & roots & summer, fall \\
\hline Wild Onion & Allium drummondii & bulb & spring, fall \\
\hline White Tridens & Tridens albescens & seeds & summer, fall \\
\hline Wrightii Three-awn & Aristida Wrightii & seeds & summer, fall \\
\hline
\end{tabular}



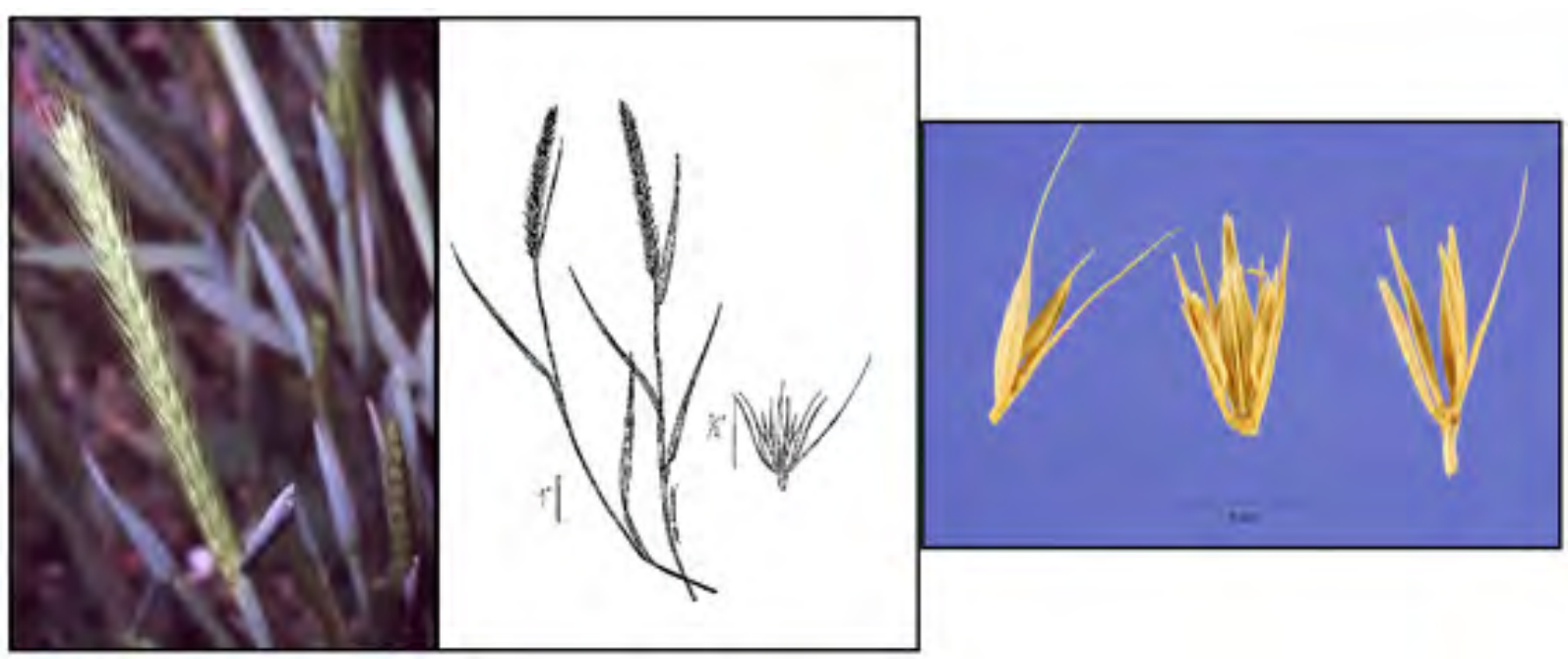

Figure 2-19. Little barley (Hordeum pusillum) grass seed head and loose seeds (picture http://plants.usda.gov/java, 2011).

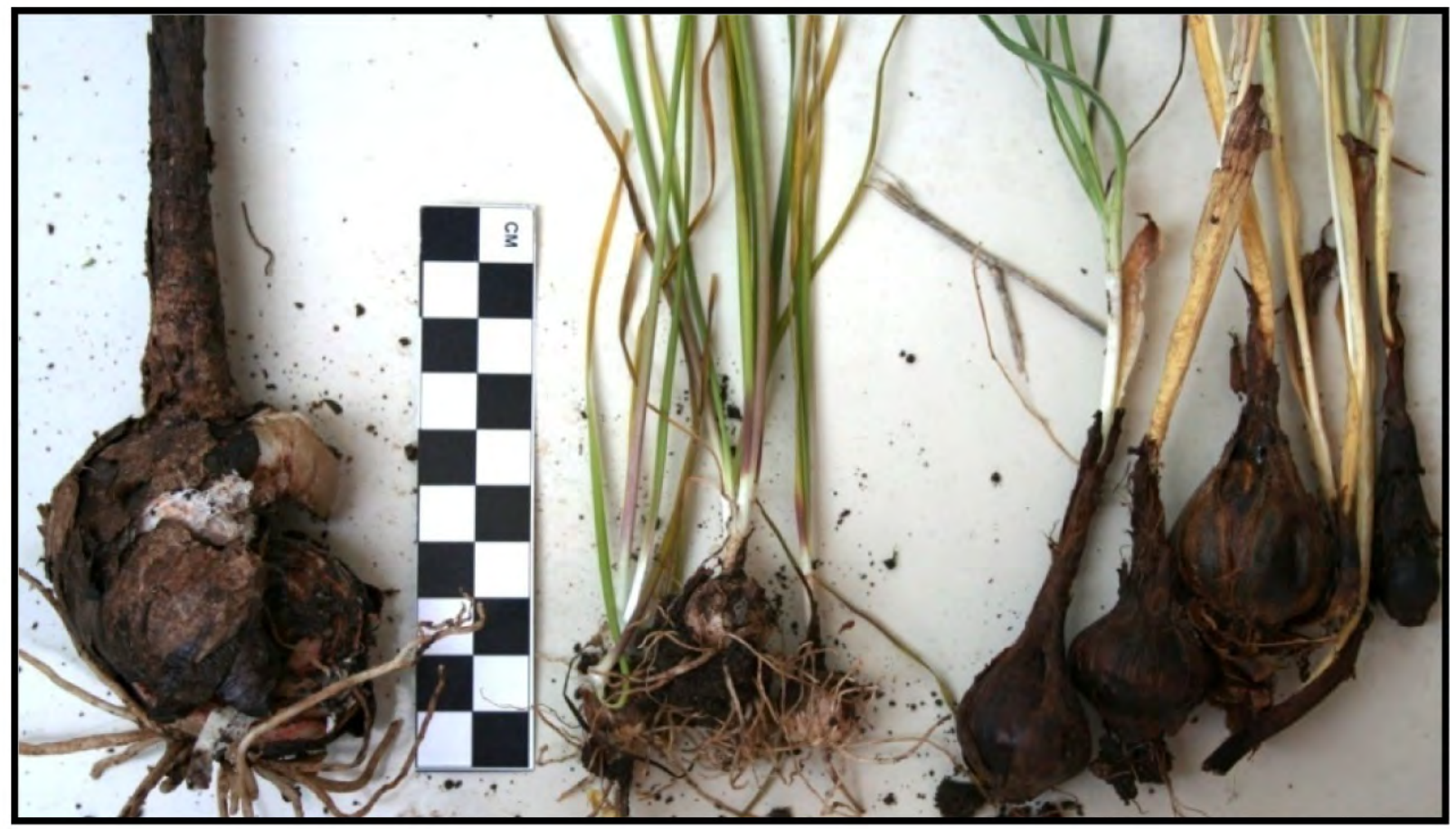

Figure 2-20. Bulbs (rain lily, false garlic, prairie pleatleaf) that represent potential food resources (photograph by $M$. Quigg, scale in $\mathrm{cm}$ ). 


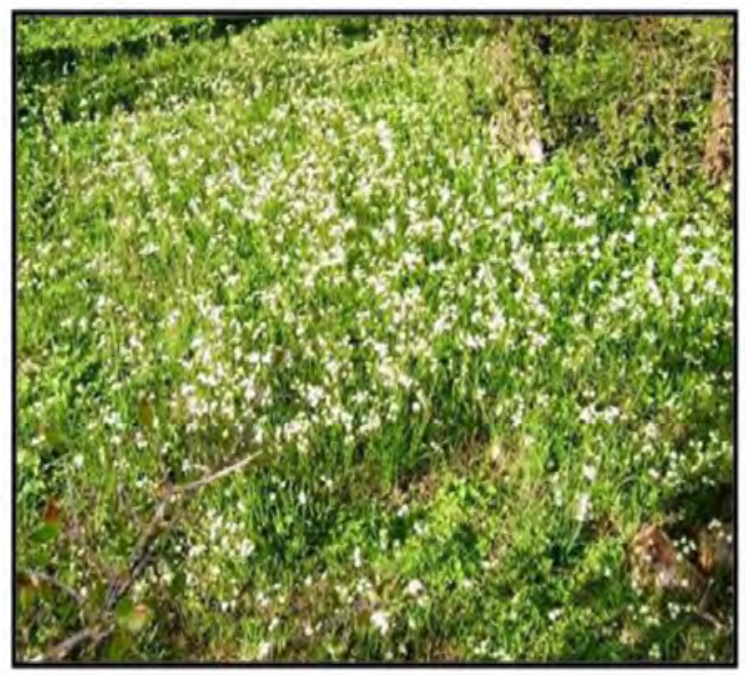

Figure 2-21. Dense patch of false garlic, showing blooms (light color) that would facilitate collection (photograph by M. Quigg).

Gayfeather (Liatris punctata), with purple flowers in August and September, is common in the region (Figure 2-22). This $\mathrm{C}_{3}$ plant produces a taproot that can reach a depth of $5 \mathrm{~m}$. It is this taproot that was sought by native peoples in spring. It was often baked or boiled (Kirk 1970:293).

Another tuber with potential as a food resource is the buffalo gourd (Cucurbita foetidissima, Figure 2-23). The roots had many uses, the fruits were used in a variety ways, and the seeds were also edible. Roots of other plants such as wavy leaved thistle (Cirsium undulatum), common sunflower (Helianthus annuus), and silver leaved nightshade (Solanum eleagnifolium) potentially served in one way or another.

\subsubsection{Beans}

Honey mesquite (Prosopis glandulosa, a $\mathrm{C}_{3}$ legume) is abundant through the region and occurs in many valleys (Philips 2000). These thorny trees produce a long, narrow bean that was extensively used as a major food source in prehistoric times (Figure 2-24). The pods usually occur in late summer, but

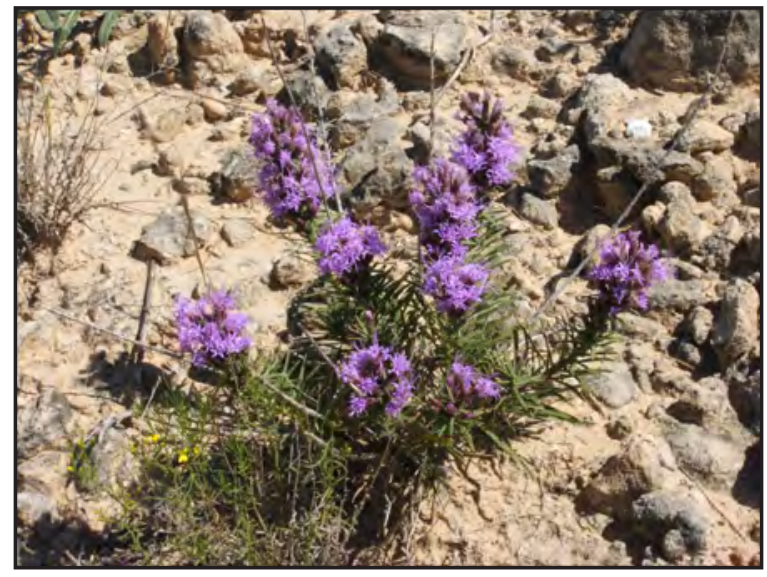

Figure 2-22. Gayfeather in bloom in fall (photo by M. Quigg). 


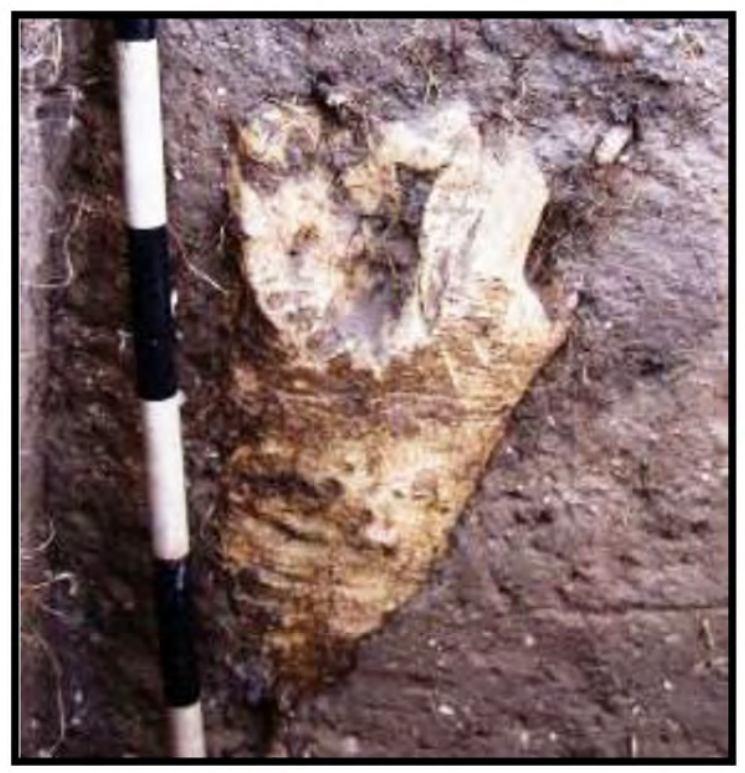

Figure 2-23. Buffalo gourd tuber (Cucurbita sp.) in profile measured at least $40-b y-20 \mathrm{~cm}$.

can persist throughout fall depending on rainfall. Cabeza de Vaca (1961:100) provided a detailed description of the use of mesquite when he camped on the upper Colorado River north of Big Springs, Texas, in the early Sixteenth Century. In prehistoric times, the hard bean pods were processed by pounding in a mortar (wood being superior to stone for this purpose) during which the woody endocarps were often separated from the pod meal and immediately discarded. The seed is edible if ground into meal, but it is very hard and is encased in a woody, inedible endocarp (Dering 2008). The whole pod was ground, or the seeds could be parched by shaking them together in a basket full of live coals. The ground seeds could have been stored as flour, in whole or partially ground dry pods (Bell and Castetter 1937:23-24). In terms of plant composition, mesquite contains high fructans (not inulin) with roughly 11 percent sucrose and fructose, no starch, and 22 percent hemicellulose by

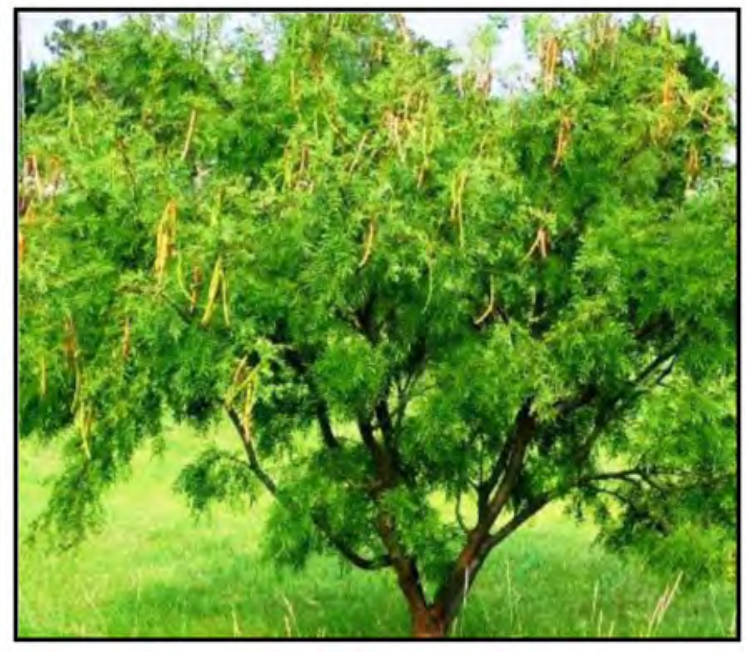

Figure 2-24. Mesquite tree with seed pods still on tree (photo by M. Quigg). 
dry weight (Wandsnider 1997; taken from Yanovsky and Kingsbury 1938).

Catclaw Mimosa (Mimosa biuncifera, a $\mathrm{C}_{3}$ legume) is a perennial shrub typically 1-to 4-m-tall that occurs in valleys (Philips 2000). The stems, branches, and leaves contain prickles or thorns that are slightly bent downwards. The flowers are in heads (puffballs) about 1-cm-wide, with several pink stamens extending outwards. The fruits are small, flattened bean pods, hairy, and arranged in clusters. Individual one seeded sections of the pod break out at maturity, leaving the upper and lower margins intact like a frame. The seeds are gray-brown, about 6-mm-long and 3-mm-wide. The pods are known to have been used by prehistoric populations by drying and grinding into meal (Kirk 1970).

\subsubsection{Other Resources}

Another potential food source in creek valleys is the Chickasaw plum (Prunus angustifolia) (Figure $2-25)$. This shrub grows in clusters or thickets and yields a small, sweet fruit/drupe. Dense stands of plum are currently growing along the creek margins. The fruit ripens in June and July, and is elliptic or round with a large seed. The skin is thin, and the pulp soft and sweet (Medsger 1974).
Specific cactus plants are known to exist in the Canadian River breaks region. Sikes and Smith (1975) list cholla (Opuntia imbricate), tasajillo (Opuntia leptocaulis), pricklypear (Opuntia sp.), and yucca (Yucca sp.) further west in Oldham County along the southern margin of the Canadian River. Pricklypear cacti produce red pear shaped fruits (tunas) 2- to 4-cm-long that are fleshy, juicy, and full of seeds. These fruits generally ripen over a period of weeks and are red in late summer and may be eaten fresh or cooked. Philips (2000) recorded Soapweed Yucca (Yucca angustifolia), which is quite common. Much of this plant provides fibers and food for human use. The relative large fruit can be baked, the seeds eaten roasted (Kirk 1970), and the roots made into soap.

These above mentioned plants, and many others in the region, provide a wide range of potential food and medicinal resources that might have been procured and used by the early inhabitants. However, these organic resources are not well-preserved in many archeological sites, especially open air sites. Better preservation of plant remains is in rock shelters. Plant parts are not often detected at the macroscopic level, as charred beans or seeds in flotation analysis. This fact does not mean these plants were not

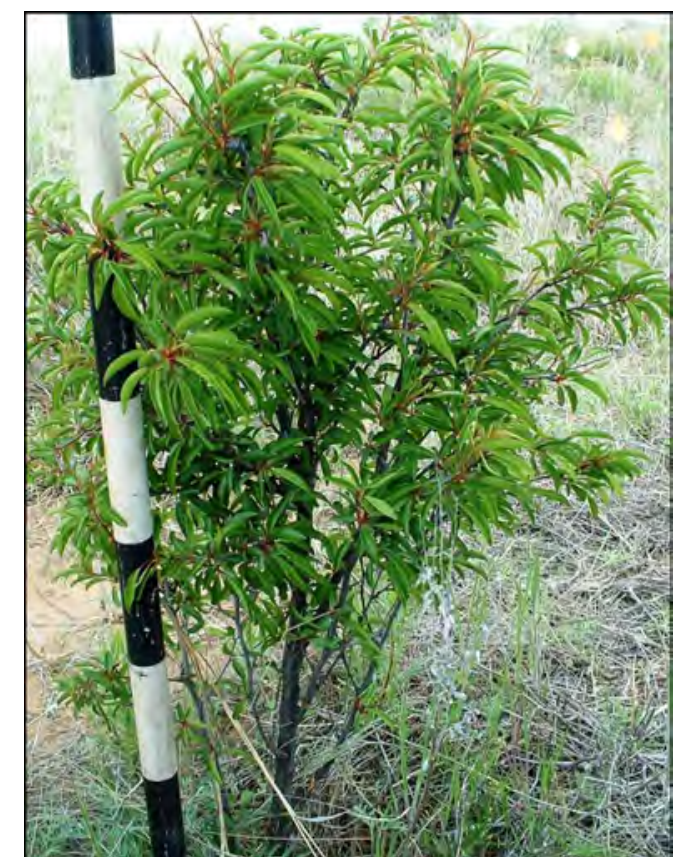

Figure 2-25. A single small wild plum tree without fruit (photo by M. Quigg). 
used by groups in this region or even the people who occupied the Long View site. Charring is generally by accident; therefore, most plants used become invisible in the archeological record at most sites. In many cases, microscopic microfossil remains (i.e., phytoliths, and starch grains) may be preserved in some form or another. The detection and identification of these tiny microfossils requires specific technical analysis of the cultural items and/ or sediments collected from activities areas (see Chapter 5.0 Methods section).

\subsubsection{Faunal Communities}

The Long View site, along with the entire Texas panhandle region, is in the Kansan Biotic Province (Blair 1950). This province reflects the transitional position between the more western Navahonian Province and the Texan Province to the east. Unlike Dice (1943) before him, Blair (1950) places the Permian red plains within the Kansan Province. There is considerable overlap of fauna between these two provinces. The Kansan is subdivided into three biotic districts based on the dominant vegetation and includes the Mixedgrass Plains to the east, the Mesquite Plains to the southeast, and the Shortgrass Plains district across the high plains and Llano Estacado. The Long View site lies within the Shortgrass Plains district.

In general, the mammalian fauna of the Kansan Province in Texas includes minimally 59 species, of which 5 are restricted to this province. The five restricted species include the Swift fox (Vulpes velox), a specific pocket gopher (Geomys lutescens), Plains pocket mouse (Perognathus flavescens), Texas Kangaroo rat (Dipodomys elator), and the Palo Duro mouse (Peromyscus comanche). The characteristic mammals include mink (Mustela nigripes), spotted skunk (Spilogale interrupta), stripped skunk (Mephitis mepbitis), badger (Taxidea tanus), coyote (Canis latrans), blacktailed prairie dog (Cynomys ludovicianus; Figure 2-26), yellow-faced pocket gopher (Cratogeomys leucogaster), jackrabbit (Lepus californicus), cottontail rabbit (Sylvilgus andubonii), and several species of mice (Peromyscus sp.) and rats (neotoma sp.). One land turtle is present, the western or Ornate box turtle (Terrapene ornate; Figure 2-26). Fourteen species of lizards are also known. Thirty one snake species and 14 frog and toad species and toads are found in this province (Blair 1950).

The Canadian River cuts east to west through the high plains region, creating a microenvironment that may not be typical of the broader Kansan Biotic Province. The broad Canadian River valley also creates a corridor allowing mammals to easily move from one region or province to another. West of Amarillo in Oldham County, but in similar Canadian Breaks setting, Scudday and Scudday (1975) conducted a ten day study in June of 1973 of a natural area on the south side of the Canadian River. The species diversity was limited and they listed only four species of amphibians and nine mammalian fauna.
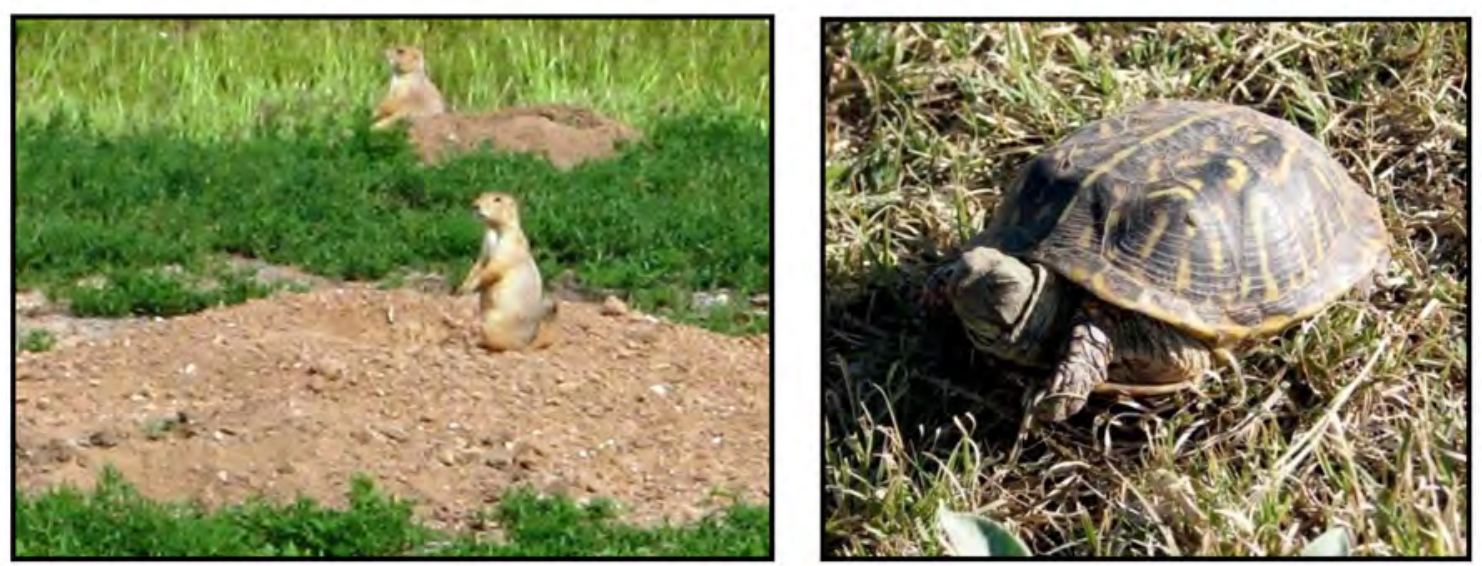

Figure 2-26. Blacktailed prairie dogs (left) and western box turtle (right). 


\subsubsection{Bison}

Bison were once the dominant animal of the Plains and were a significant resource for prehistoric peoples (Figure 2-27). The following is a general discussion that focuses on bison characteristics as a background for understanding this very significant resource. A host of major references, but not an exhaustive list, concerning early observations on bison (buffalo) behavior is cited, from which much of the information presented below has been drawn; these references include Catlin (1851), Allen (1876), Haines (1970), Hornaday (1971), McHugh (1958, 1972), Dary (1974), and Roe (1972). Modern observations on bison handling and processing (Frison 1978a, 1978b), calving patterns (Haugen 1974; Shaw and Carter (1989), bison size (Halloran 1961), bison ecology (Halloran 1968; Penden et al. 1974; Speth 1983;), carcass composition (Brink and Dawe 1989; Emerson 1990), classification and evolution (Wilson 1978; McDonald 1981), and analytical techniques (i.e., Leechman 1951; Frison 1970, 1973, 1974; Frison and Reher 1970; Wheat 1972, 1979; Reher 1970, 1973, 1974; Bedford 1974; von den Driesch 1976; Grayson 1978, 1979, 1984; Wilson 1974, 1978, 1980; Binford 1978, 1981 1984; Reher and Frison 1980; Speth 1983; Lyman 1982, 1984, 1985, 1992; Klein and Cruz-Uribe 1984; Todd 1986, 1987a, 1987b; Todd and Rapson 1988; Morlan 1991). For a comprehensive review of historical records and early ethnographic accounts of communal buffalo hunting in the Northern Plains, the reader is referred to Verbicky-Todd (1984).
Bamforth (1987) provides historical documents concerning bison ecology for the Great Plains.

Bison were quite abundant as the Europeans entered the plains beginning around 400 years ago (A.D. 1542), but the exact numbers are unknown. Estimates on the number of bison around A.D. 1830 range from 20 to 40 million (Roe 1972). In addition to their vast numbers, bison were the largest land mammals in North America during the Holocene. Adult bulls weigh as much as $815 \mathrm{~kg}(1,795 \mathrm{lbs})$. Adult cows are considerably smaller, weighing as much as $490 \mathrm{~kg}$ (1,075 lbs; Halloran 1968). Bulls continue to rapidly gain weight into about their eighth year, whereas cows generally stop gaining weight between 2 and 3 years of age (Halloran 1961). Beyond the age of three, cows and bulls should be distinguishable by weight and bone size. In addition to mass weight, male bison have proportionately larger humps and thicker necks than female bison (Speth 1983:87-88) citing Lott 1974:383). Speths's (1983) metric data on male and female bison bone elements documents a size sexual dimorphism and provides useful comparative information for archeological assemblages. Emerson (1990:76) using measurements on modern bison from Theodore Roosevelt National Park in western North Dakota, shows that some sexual dimorphism is evident in certain attributes as early as 1.5 years of age. The buffalo ranged across a broad array of habitats that exhibit a considerable variation in climate (Roe 1972:69). Despite climatic and topographic variations in habitats, the buffalo species is remarkably uniform.

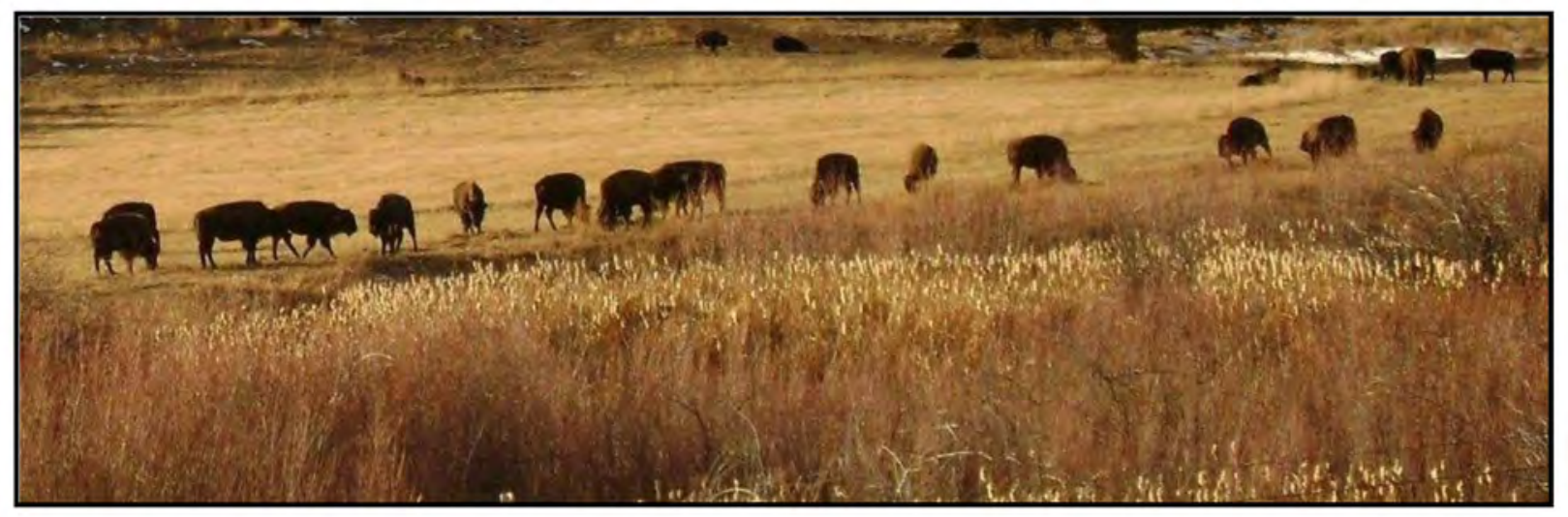

Figure 2-27. Young bison shedding their winter coats (photograph by M. Quigg). 
Bison behavior is briefly discussed here, but McHugh (1958) provides great detail and discussions concerning behavior. Bison have excellent hearing and an acute sense of smell, but poor eyesight. They rely most on the acute sense of smell for detecting danger. They are also very curious and investigate new and strange objects, even investigating other killed animals. Herds can sustain speeds of $48 \mathrm{~km}$ per hour $(\mathrm{km} / \mathrm{hr}, 30 \mathrm{mi} . / \mathrm{hr})$ when chased and can increase speeds going downhill. They have the ability to cross up the face of a steep ridge, climb rocky hills, and go up steep places where they can barely stand (Roe 1972:149). Most observers thought they were stupid animals because they did not run at the noise or smoke of a rifle, falling and struggling animals did not convey a danger signal, they sometimes walk directly into quicksand, they would charge ahead regardless of the obstacles, and they often wondered away from good grazing conditions (Roe 1972:125). Wallowing was one of the most prominent summer activities of the buffalo. Water or rivers were not obstacles, because buffalo are swimmers and can cross rivers such as the mighty Missouri, the Mississippi, and the Yellowstone. Bamforth (1987) states that there are only three reasons that bison move around: to search for food and water, to search for other members of their species, and to escape dangerous or uncomfortable circumstances.

Bison are herd animals and generally move as groups. Norland (1984:46-47) and Marlow et al. (1984:23 cited in Fawcett, 1987) studied modern bison in Theodore Roosevelt National Park and their studies indicate bison move in random directions about 2 to $3 \mathrm{~km}$ per day. They move independently of the location of water resources because they drink water only briefly every few days. No one animal is the sole leader; however, one animal can initiate herd movement in a particular direction, especially if distracted. Cows were generally the leaders (Hornaday 1971). Hornaday observed a single line of some 100 to 200 animals that stretched nearly $0.8 \mathrm{~km}$. Buffalo were known to have made great pathways across the countryside. Some observers have remarked that they have hereditary paths and highways worn deep on the landscape, making for the surest passes over mountains and best fords across rivers (Roe 1972:120). They appeared to choose the easiest routes and most direct course. Feeding and loafing were the principle daily activities, which generally include minimally one trip to water. This contradicts the statement above, that bison "drink water only briefly every few days." However, the early literature provides considerable discrepancy in the drinking habitats. Hornaday (1971) and others thought the buffalo had camel like capacity for enduring long periods without water (Roe 1972:106).

Haines (1970) reports that white buffalo hunters made observations and documented herd sizes. In the A.D. 1870's, one Frank Mayer recorded that a group of more than 60 animals was most unusual and he never saw a herd of over 200 animals. Groups of 15 were the most common. Cows with calves and an occasional 2 to 3 year old bull often formed one or several subgroups with about 25 animals per group within the larger groups. Bull groups, often separated from the cow groups, contain mature males (greater than 4 years of age) in small groups with as many as 12 animals. The cow, calf and bull groups coalesced to form large groups during the rut. As an example, in July of A.D. 1853 in northern North Dakota, a particular herd was estimated at 200,000 (Haines 1970). In A.D. 1541, Coronado, during his trek from east of the Pecos River in northern New Mexico into the Texas panhandle, and then north to the Great Bend of the Arkansas River that lasted three months, stated that not a single day went by that he did not see buffalo, and that there were too many to count (Haines 1970). In general, one can expect a pattern of winter dispersal and summer aggregation (Bamforth 1987).

The life cycle of bison provides a context for interpreting the prehistoric remains. Bison calving and rut are two very important periods in the life cycle. Some variation in the time is noted in these events, generally from north to south across the Plains. In the south, documented behaviors among herds in the Wichita Mountains Wildlife Refuge in southwestern Oklahoma are applicable for the Texas panhandle region (Halloran 1961, 1968). Calves are born in early spring; however, Haugen (1974) indicates a bimodal period of birthing. At the Wichita Mountains Wildlife Refuge, the earliest recorded calves are born between March 10 and 
April 7 after an estimated gestation period of about 270 days (Halloran 1968 citing Mosby 1960); the peak calving period is around April 15. Roe (1972) and others use a 285 day gestation period, but it may last as much as 295 days. This places the initiation of effective breeding around June 5 (Halloran 1968) with peak breeding around July 15. Bulls are generally not effective sires as compared to yearlings, but most become so at two years and all are productive sires by three years of age (Halloran 1968). A bison fetus growth is relatively slow over the first half of the gestation period with rapid growth during the last 40 percent of the period (Robbins and Robbins 1979). Most cows give birth to a single calf and twinning is extremely rare (Halloran 1968). Most cows (73 percent) have their first calves at three years of age, but some breed as yearlings and some (12 percent) give birth at two years of age (Halloran 1968:23; Shaw and Carter 1989). Calves weigh from 13 to $32 \mathrm{~kg}$ (30 to $70 \mathrm{lbs}$.) at birth and are known to nurse into their second year. Newborns normally stand within a few minutes after birth and can walk within 20 minutes. In terms of herd composition, calves constitute about 66 percent of a typical herd. In broad terms, bison live as many as 17 years (Halloran 1968).

Bison are recognized as general grass consumers (opportunists) with intake of the dominant vegetation of the range. That is, bison consume vegetation in proportion to the abundance of grasses and other vegetation while selecting for open expanses of prairie. Bison have greater digestive capabilities than many other ungulate species, which allow them to be less selective in their foraging preferences (Emerson 1990:101). The plains vegetation is composed of mosaics of mostly different types of warm $\left(\mathrm{C}_{4}\right)$ and cool season $\left(\mathrm{C}_{3}\right)$ grasses depending on slope and moisture conditions. Great diversity exists in the grassland communities throughout the plains. As an example, in the Pawnee National Grasslands of northeastern Colorado, the warm season grasses constitute nearly 70 percent of the grass community, whereas cool season grasses constitute 3 to 5 percent of the grasses (Schwartz and Ellis 1981). In the Pawnee National Grasslands, bison showed a greater preference for warm season grasses, specifically grama and buffalo, except in May when new spring growth of cool season grasses had commenced (Penden 1976). Penden (1976) observed that when the shortgrass prairie was heavily grazed, the blue grama grass increased. An exception to the consumption of grass was found in the Arizona region where bison consume mostly salt brush (Atriplex sp.), a $\mathrm{C}_{3}$ species, with minor amounts of grama grass (Martin et al. 1951). Southeast of the Long View sites in the Wichita Mountains Wildlife Refuge of southwestern Oklahoma, bison consume mostly grama (Bouteloua sp.), a $\mathrm{C}_{4}$ species, and dropseed (Sporobolis sp.) grasses, also a $\mathrm{C}_{4}$ species (Martin et al. 1951). Detected dietary patterns of bison display seasonality that relate to the seasonal growth patterns of $\mathrm{C}_{3}$ and $\mathrm{C}_{4}$ photosynthetic systems, and dietary and growth patterns vary across time and space (Penden 1976; Tieszen et al. 1998). The $\mathrm{C}_{3}$ species are dominant in early spring and early summer, whereas the $\mathrm{C}_{4}$ species under go maximum growth in mid to late summer.

Stable carbon and nitrogen isotope data from bison bones across the region provide proxy data to what these animals consumed (Huebner (1991); Quigg 1997; Quigg et al. 2010). The isotope values obtained indicate that bison consumed a very high percentage of $\mathrm{C}_{4}$ grasses (roughly 85 percent) throughout the last 2,500 years. Bison bones sampled from four time periods at the Landis Property outside Amarillo over the last 2,500 years yielded carbon isotope values that indicate less than $1 \%$ differences in their averages. Consequently, this limited change in average carbon isotope value in bison bones over time indicates very limited change in the bison grazing/consumption pattern during that period. By proxy, the carbon isotope results also support very limited change in the regional grassland community during the last 2,500 years. The results also provide proxy data as to the indication of what the regional grassland communities were like, proportional contributions of warm and cool season grasses, and significant changes that occurred to those grasslands communities over time.

The nitrogen values obtained from the same bison bone samples from the Landis Property range from -7.6 to $6.9 \%$. One value of $-7.6 \%$ was rejected as an anomaly. The overall range was from 3.2 to $6.9 \%$ with an overall mean of $4.85 \%$. The difference between the four time periods investigated, which represented 
the last 2,500 years, is $1.24 \%$ with a slight change detected at the ca. 1200 to 1500 B.P. period when the nitrogen values increased to an average of $5.84 \%$ and then decreased to $4.6 \%$ during the 500 to 800 year old period (Quigg et al. 2010).

Catlin (1851) stated that, in winter, buffalo paw through the snow to access the grasses below, and one observer witnessed buffalo using their noses like pigs to plough (root) snow. The distribution and quality of forage in a region are major determinants of migration. Consequently, bison aggregations tend to occur during seasons when forage productivity is highest (Bamforth 1987).

The nutritional status of bison is also assumed to vary largely depending upon the grassland conditions and the seasonal variation in those conditions. Speth (1983, 1991) postulates that by the end of the winter, cows were undergoing a stressful period because they carried fetuses to term and the grass conditions were at their worst. He postulates that males were slightly better off because they lacked the stress of the pregnant cows. Hafez (1969:35), cited in Emerson (1990:94-95), notes that nutritionally, the fetus is privileged because it continues to grow despite some degree of maternal malnutrition. When an animal suffers from malnourishment, fat reserves stored in various parts of the body are mobilized. Male bison were in their best overall condition in late spring or early summer and at their poorest conditions during and immediately following the rut in late summer. Bulls have the toughest meat during rut (Wilson 1924:230). Wilson (1924:221 and 234) also notes the selection of male bison for their hides. Females were in their poorest condition during the calving season and in their best condition in the fall and early winter (Ewers 1958:76; Roe 1972:860-861; Wissler 1910:41). During spring, these animals shed their winter coats, and Roe (1972:116) indicates they go through a "hairless condition" during early summer.

Bison were an excellent source of meat and supplied other nutritional parts and other products for human consumption. A buffalo will dress out about the same as modern cows, with a trimmed carcass nearly 50 percent of the live weight, on average about $363 \mathrm{~kg}$ (800 lbs.) per bull and $180 \mathrm{~kg}$ (400 lbs.) per cow (Haines 1970). However, the native populations consumed more than the just the meat. In addition to quantities of meat protein, their bones supply fatty acids, marrow, and various other nutrients (Table 2-2). Other buffalo parts considered delicacies by the Plains Indians include the fetus, tongue, nose, heart, liver, and hump. Their bones were also used for tools and the hides were used for clothing and shelters (Wissler 1910; Ewers 1955). Nearly every part of the bison was used in some way. In general terms, compilation of data from investigated prehistoric sites in Colorado and Texas provide a broad understanding of when bison were present in eastern Colorado (Butler 1992, 1997) and across Texas (Dillehay 1974). Dillehay’s (1974) Bison Presence period I included the Paleoindian period from ca. 12,000 to 7500 B.P. Paleoindian sites in eastern Colorado support this concept (Butler 1992). Following this was Dillehay's absence period from ca. 7500 to 4550 B.P. This included a major drying period across much of the Plains, the Altithermal, which some assume facilitated a general expansion of the grassland regions. Few sites in eastern Colorado have been investigated, so there is a lack of sites/ data that would document their presence. However, this may be a function of poor preservation more than anything else. Beginning at ca. 4500 to 1450 B.P. is Dillehay's Bison Presence period II. The data from Colorado substantiates that bison were present throughout much of this period and that includes sites dated to the Middle and Late Archaic periods, and the Plains Woodland period (Butler 1992, 1997). It must be said that there are recorded sites during all these periods that also lack bison remains. Roughly 1450 to 750 B.P. was another period in Texas that Dillehay determined lacked bison. Since Dillehay's early work, data from northern Texas, western Oklahoma, and eastern Colorado documents bison were present for most of this period. Four of the six Woodland components (ca. 1650 to 950 B.P.) investigated across Oklahoma yielded evidence of bison and this use pattern increased in the following Late Prehistoric period (S. Baugh 1986). The increased database since Dillehay's work has revealed that bison were present during his most recent absence period. Dillehay's Bison Presence period III includes a period from ca. 750 to 400 B.P. Butler's (1992, 1997) data from eastern Colorado definitely supports the Texas and Oklahoma data that bison were present across most of the region. 
Table 2-2. Percentage of Fatty Acids, Dry Bone weight, Mean fat Weight, and Mean Weight of Marrow in Bison.

\begin{tabular}{|c|c|c|c|c|c|}
\hline Elements & End & $\begin{array}{c}\text { Mean \$ Fatty } \\
\text { Acids } 1 \\
\end{array}$ & $\begin{array}{c}\text { Mean Dry } \\
\text { Bone Wt. (g) }\end{array}$ & $\begin{array}{c}\text { Mean Fat Wt. } \\
(\mathrm{g})^{2}\end{array}$ & $\begin{array}{l}\text { Mean Wt. of } \\
\text { Marrow (g) }\end{array}$ \\
\hline \multicolumn{6}{|l|}{ Front Leg = } \\
\hline \multirow[t]{2}{*}{ Humerus } & proximal & 40.5 & 809 & 324 & \multirow{2}{*}{118} \\
\hline & distal & 22 & 365 & 77 & \\
\hline \multirow[t]{2}{*}{ Radius/Ulna } & proximal & 33.5 & 353 & 116 & \multirow{2}{*}{79} \\
\hline & distal & 25.7 & 270 & 71 & \\
\hline \multirow[t]{2}{*}{ Metacarpal } & proximal & 8.9 & 84 & 7 & \multirow{2}{*}{20} \\
\hline & distal & 15.2 & 172 & 26 & \\
\hline \multicolumn{6}{|l|}{ Hind Leg = } \\
\hline \multirow[t]{2}{*}{ Femur } & proximal & 31.4 & 352 & 111 & \multirow{2}{*}{111} \\
\hline & distal & 35.2 & 739 & 256 & \\
\hline \multirow[t]{2}{*}{ Tibia } & proximal & 33.5 & 376 & 128 & \multirow{2}{*}{124} \\
\hline & distal & 14.1 & 129 & 18 & \\
\hline \multirow[t]{2}{*}{ Metatarsal } & proximal & 12.4 & 73 & 9 & \multirow{2}{*}{22} \\
\hline & distal & 22.7 & 160 & 36 & \\
\hline \multicolumn{6}{|c|}{ 1. Brink and Dawe (1989:91), mean of three Northern Plains bison. } \\
\hline \multicolumn{6}{|c|}{ 2. Brink (1995), mean of three Northern Plains bison. } \\
\hline \multicolumn{6}{|c|}{ 3. Brink (personal communication 1996), mean of Brink (1995) and Emerson (1990) data. } \\
\hline
\end{tabular}

Prehistoric sites across all regions continue to yield bison remains right up to and into historic times. The Protohistoric component at the Corral site (41PT186) in Amarillo Creek valley dated to ca. 250 to 300 B.P. testifies to bison presence through that period (Quigg et al. 2010).

The current information documents bison presence across the Southern Plains on a regular basis for minimally the last ca. 4,550 years and probably sporadically during Dillehay's absence period from ca. 7500 to 4550 B.P. as reflected by bison remains at Lubbock Lake during the middle Holocene/ Middle Archaic (Johnson 1987). This means that the prehistoric populations in the region generally had access to this significant resource on a regular basis up until their near extinction around A.D. 1880 in the panhandle. However, it is not clear what the density of bison was or if all regions had equivalent distributions of bison, year round or seasonally.

\subsubsection{Other Game Resources}

Besides bison, pronghorn antelope (Antilocapra American) is the other relatively large Plains mammal likely to have been targeted prehistorically in the Breaks along the Canadian River valley (Figure 2-28). Male pronghorn weigh between 40 and 60 $\mathrm{kg}$ (90 and $125 \mathrm{lbs}$.) with females slightly smaller (Davis 1978). These are fleet-footed animals that are well adapted to open places and the plains. They have excellent eye sight, tremendous speed, and can endure long periods without water. These animals would have been difficult to hunt, especially in prehorse days. However, they are very curious and may have been taken by crafty hunters. Pronghorn feed entirely upon shrubs and forbs and can feed within the same range as bison, a grazer that consumes mainly grasses. Breeding season is in late summer and early fall (roughly August through the first part of October). The gestation period is between 7 and 7.5 months with birthing from February through March (Davis 1978). The peak calving occurs in 
April and May. On the basis of these known factors, skeletal remains can be aged by examining the lower mandible tooth eruption sequence of animals up to about three years old. After three, most age estimates are based on tooth wear patterns.

A third and another relatively large game animal is the mule deer (Odocoileus hemionus), which ranged throughout the panhandle region (Figure 2-29). In general, mule deer prefer all types of habitat, especially the more arid, open county in which brush dominates. They are equipped with an acute sense of sight and hearing, but rely heavily on their sense of smell in detecting danger (Davis 1978). They feed primarily in the morning before sunrise or in late afternoon and evening. They consume a variety of green leaves, green herbs, weeds, browse, grasses, and even some succulents (Cantu and Richardson 1997). Feeding habit vary depending on the season.
The rut begins in the fall around November or December, but this can vary according to climatic conditions. Conception peaks around mid-December in the Texas panhandle (Cantu and Richardson 1997). The gestation period is about 210 days. Fauns are generally born in June, July, and August. Antlers are generally shed after the breeding season, roughly from mid January to about mid April. Age can be ascertained on skeletal remains with relative accuracy up to about 24 months, based on the sequence of lower mandible eruption and wear. Mature males weigh an average of about $77 \mathrm{~kg}$ (170 lbs.) while doe average around $40 \mathrm{~kg}$ (87 lbs., Cantu and Richardson 1997). Mule deer are not migratory, and have home ranges in the panhandle of roughly $67 \mathrm{~km}$ (26 miles).

Not often mentioned is the bird population, especially the migrating flocks that might have

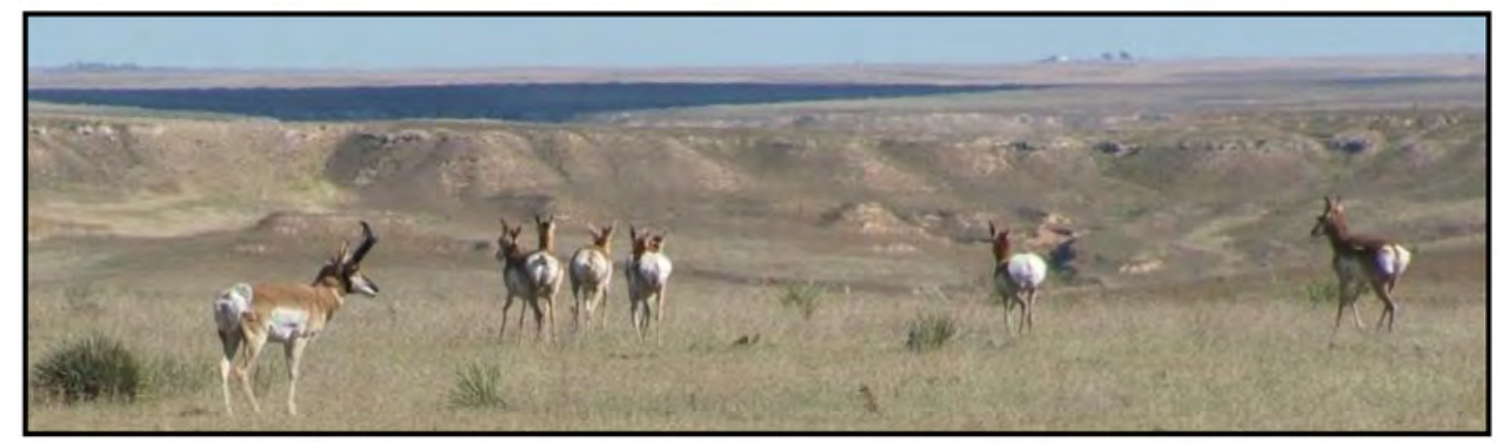

Figure 2-28. Pronghorn along the breaks of the Canadian River (photograph by M. Quigg).

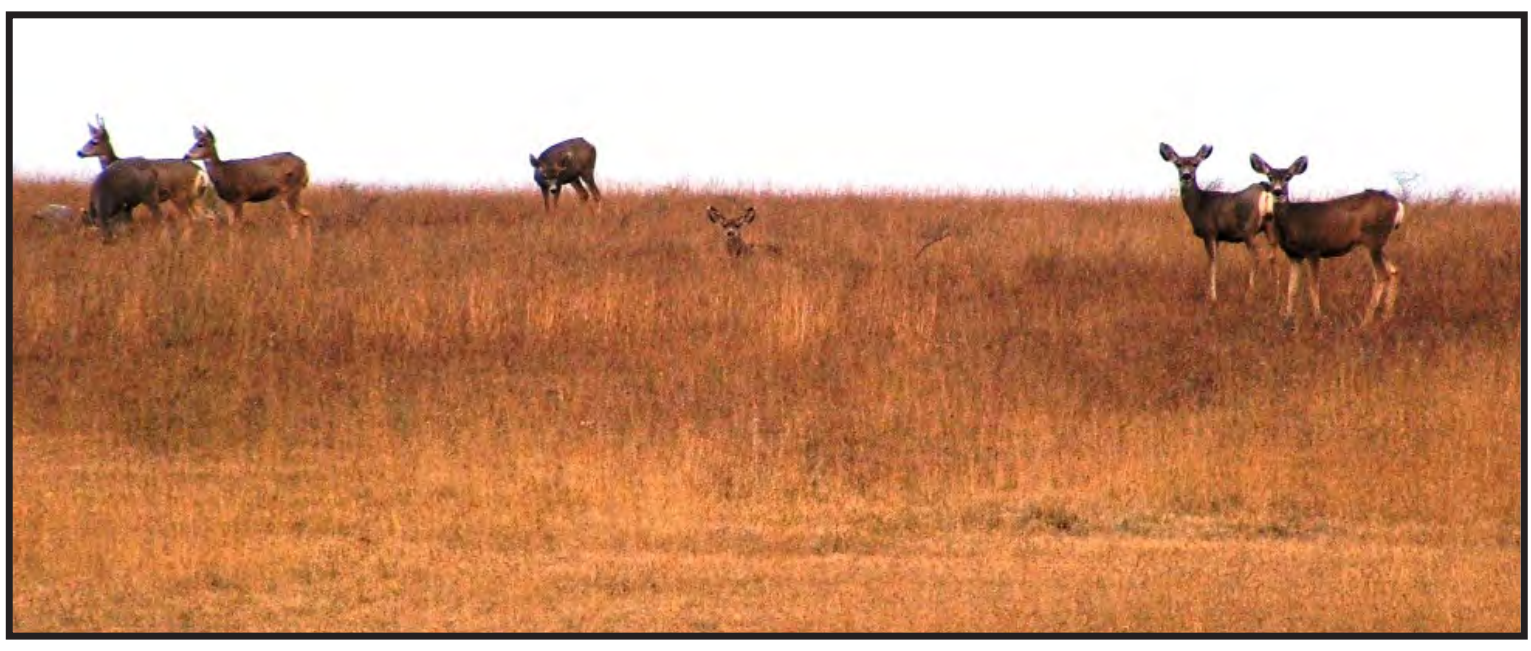

Figure 2-29. Mule deer on the open plains (photograph by M. Quigg). 
provided a significant source of food for prehistoric peoples. In a recent review of the availability and use of birds during the Middle Ceramic period in the Texas panhandle, Lintz (2009) indicates that at least 450 avian species presently frequent the region (Seyffert 2000, 2001). Modern inventories indicate that migrating waterfowl using the Central North American flyways constitute between 4,070 and 9,000 metric tons of meat annually passing through the region. When the meat potential from nonwaterfowl game and other birds using the area is considered, birds clearly have a tremendous economic potential for prehistoric and historic people in the region. Migrating ducks such as mallards (Anas platyrhynchos), canvasback (Aythya valisineria), and redhead (Aythya americana), plus geese and swans, are just a few examples of the species that might have been used seasonally. Lintz (2009) provides a great deal of information from the ethnographic literature on the use and roles of birds, specifically waterfowl, by Plains Indians. Their mere quantity and the importance of birds for uses other than food, make this an important resource.

\subsection{Paleoenvironmental Summary}

The following discussion focuses specifically on the Plains Village period from roughly 550 to 850 B.P. (A.D. 1200 to 1500). However, for a greater understanding of that period, abroader picture leading up to this time is also important. In a similar setting in the Canadian breaks just outside Amarillo about $140 \mathrm{~km}$ to the southeast, extensive multidisciplinary paleoenvironmental investigations in West Amarillo Creek valley revealed that from roughly 2000 to 1500 B.P., the $C_{4}$ plants (grasses that thrive in warm dry climates) contributed only about 40 percent of the organic carbon based on stable carbon isotopic values from the lower half of depositional Unit D (Frederick 2010; Quigg et al. 2010). The sediments associated with the lower part of Unit D are very fine-grained and reflect low magnitude flooding and intermittent ponding on the valley floor, especially in the early stages of deposition when at least one marl bed was deposited. Probably, the earliest expression of the more mesic conditions began towards the end of depositional Unit $\mathrm{C}$ when sedimentation a marl (palustrine carbonate) appeared to prevail on the valley floor. This marl continued and dominated during the deposition of Unit D. In general terms, the West Amarillo Creek channel alternated between periods of ponding, during which dark colored muds and marls were deposited, to periods of increased stream flow and flooding. The combination of phytoliths, temperature, and aridity indices documented are in good, general agreement with the stable carbon isotope record and indicate the region was characterized by a cool and moist climate between 1500 and 2000 B.P.

After 1500 B.P., the alluvial deposits of depositional Unit $\mathrm{D}$ become gradually coarser textured at the same time that carbon isotopic ratio data indicate vegetation was shifting to a more xeric $\left(\mathrm{C}_{4}\right)$ assemblage. A major flood occurred immediately before 1430 B.P., after which the channel of West Amarillo Creek was again dominated by dark muds. After about 1400 B.P., West Amarillo Creek was more often ponded or marshy, resembling a wet meadow. At this time, the proportion of $\mathrm{C}_{4}$ organic matter significantly increased, thereafter oscillating between 60 and 70 percent (roughly $-18 \%$ ). Also around this time, cottonwoods and limited amounts of oak trees replaced willows as the dominant galleria forest. Indeed, the coarsest-textured sediments associated with Unit D were deposited immediately before the channel incised sometime between 850 and 450 B.P., effectively ending Unit $D$ deposition and marking the onset of Unit E sedimentation. The precise timing of the channel incision is not clear at that location. This roughly 1,000 -year period was characterized by a gradual increase in warm, dry conditions until a very subtle trend to cooler and moister conditions may have triggered the incision of the creek channel (Frederick 2010; Quigg et al. 2010). The stable carbon isotope record oscillates on a roughly 500 year cycle, with peaks in more xerophytic vegetation $\left(\mathrm{C}_{4}\right)$ occurring around 1150, 700, and 350 B.P. The combined paleoenvironmental records reveal a contrast in that the valley floor was wet at the same time the regional vegetation was dominated by general arid vegetation. The persistence of the mesic/wet conditions on the valley floor may be attributed to the discharge of emergent groundwater from the High Plains aquifer along the valley floor.

As sedimentation resumed around 430 B.P., the carbon isotopic values indicate that the surrounding vegetation was around 80 percent $\mathrm{C}_{4}$ and shifted 


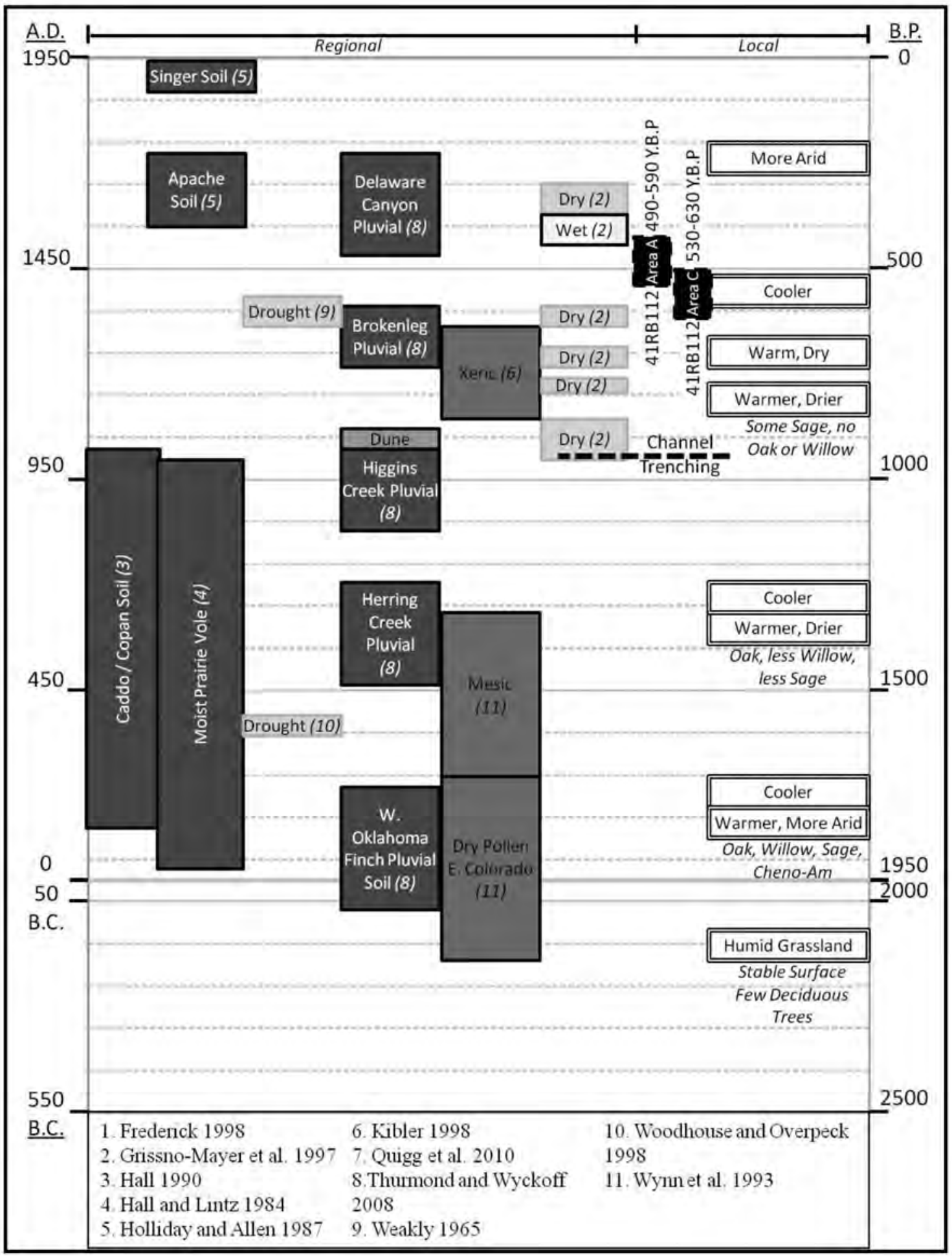

Figure 2-30. Generalize climatic proxy data using various data sets. 
gradually to include a slightly more $\mathrm{C}_{3}$-rich assemblage up to the present day. The coarser sediments associated with depositional Unit E indicate a return to less effective vegetation cover during that period.

The broad pattern of vegetation change in the West Amarillo Creek valley is consistent with previous work performed in the broader region (Figure 2-30). The identification of the Copan, Caddo, and West Fork paleosols across northern Texas and Oklahoma also indicate moist conditions from roughly 1000 to 2000 B.P. (A.D. 1 to 1000; Ferring 1982, 1986; Hall and Lintz 1984; Hall 1982, 1988, 1990). Just to the northwest, in the Palo Duro Creek valley of the North Canadian (Beaver) River valley in Hansford County, a similar record was revealed, which also dated a mesic phase between roughly 3880 B.P. and 1400 B.P. (Caran 1989; Frederick 1993; Quigg et al. 1993). There, a channel incision occurred just after ca. 1440 B.P. followed by more alluvial sedimentation around 1240 B.P. and continuing until sometime around 900 B.P. Further north in eastern Colorado, pollen data from 5EP35 has been interpreted as indicating a much drier episode after ca. 1400 B.P. (Wynn et al. 1993). In southwestern Kansas, soil formations identified by Arbogast (1995) and Olson and Porter (2002) at ca. 1500 B.P. undoubtedly corresponds closely with the named paleosols in Oklahoma and northern Texas.

Across the broad Southern Plains region, a general cycle of wet and dry patterns continued through the Middle Ceramic period and into historic times (e.g., Stratum 5 at Lubbock Lake [Holliday and Allen 1987; Johnson 1987], Dempsey Divide [Thurmond and Wyckoff 1999, 2008], western Oklahoma [S. Hall 1990; Hall and Lintz 1984]). At the extreme southern end of the Plains around Lubbock, Texas, moist conditions appear to have persisted until about 550 to 700 B.P. (A.D. 1250 to 1400; Holliday and Allen 1987:20).

Hall (1990) documented a major channel incision at ca. 1000 B.P. throughout the Southern Great Plains, which is also apparent in the valleys in the extreme southern end of the Great Plains in valleys off the Llano Estacado (Abbott 1990). Abbott speculates that this was potentially caused by more arid conditions. The amount of water strongly influences the above-ground net primary production of grasslands (Sala et al. 1988). Sala et al. (1988) determined that when precipitation is less than 37 $\mathrm{cm}$ per year, sandy soils with low water-holding capacity are more productive than loamy soils with high water-holding capacity, whereas the opposite occurs when precipitation is greater than $37 \mathrm{~cm}$ per year.

The extensive radiocarbon dating $(N=95)$ of some 20 paleosols dating to the last 2,000 years in the Dempsey Divide of Rogers Mills County of western Oklahoma has documented the age of those stable deposits (Thurmond and Wyckoff 1999, 2008). The authors named the six paleosols encountered and believe that these soils developed during periods of higher rainfall and thus refer to them as pluvial events. The paleosols do represent periods of stability and marked changes in deposition, but it is not clear that all represent periods of higher rainfall. Buried soils from 14 exposures were sampled, and the correlations in episodes are interpreted as a cyclical pattern of wet and dry periods lasting an average of 185 years for the pluvials and 213 years for the interpluvials. Thurmond and Wyckoff interpret that data to indicate a roughly-400 year rainfall cycle for the Southern Plains. The Brokenleg Canyon Interpluvial was between 800 to 950 B.P. (A.D. 1000 to 1150) followed by the Brokenleg Canyon Pluvial, radiocarbon dated to between 950 and 650 B.P. (A.D. 1150 to 1300). This was followed by the Delaware Canyon Interpluvial from 650 to 500 B.P. (A.D. 1300 to 1450; Thurmond and Wyckoff 1999, 2008). These data help to identify patterns on a scale that most paleoenvironmental discussions do not normally address.

Woodhouse and Overpeck (1998) provide a comprehensive review of 2,000 years of drought variability in the central United States. They use a wide variety of proxy data to discuss periods and lengths of droughts across the Great Plains and in adjacent regions. Good evidence exists for a major drought during the last quarter of the $13^{\text {th }}$ century (A.D. 1250 to 1300 ), roughly 650 to 675 B.P., based on tree-ring records in the southwestern United States and supported by records from the Great Basin and California. This was a severe 
multidecadal drought that in the U. S. Southwest has been referred to as the "Great Drought," which coincided with the abandonment of the Anasazi settlements and redistribution of those populations. Weakly (1965), cited in Woodhouse and Overpeck (1998), reported a 38-year drought from 637 to 674 B.P. (A.D. 1276 to 1313 ) in southwestern Nebraska, deduced from tree-ring chronology. He sees this as the longest drought in the last 750 years.

In addition to this megadrought, at least four periods of widespread drought have been identified between 2,000 and 700 B.P. (A.D. 1 and 1200) based on a variety of proxy data from the Great Plains and western United States (Woodhouse and Overpeck 1998). The most recent was a drought that began around the mid 12th century (roughly 800 B.P.) although this might have been the start of the megadrought.
Based on changing frequencies in archeological faunal remains from 11 Antelope Creek phase sites, Duffield (1970) concluded that a relatively moist climate existed at the beginning of the period around 750 to 800 B.P. Then, this region gradually became dryer until about 650 B.P. when drought conditions set in.

An important consideration is the relationship between paleoclimatic conditions and communities of plants and animals. For example, the twoyear drought of A.D. 1933 and 1934 in western Kansas caused a threefold increase in the number of blacktailed jackrabbits (Wooster 1935). It also revealed a marked increase in the number of deer mice, in contrast to a significant decrease in meadow mice. Therefore, past changes in plant communities may have caused changes in the small mammals, which potentially affected other populations, including man. 
This page intentionally left blank. 


\subsection{OVERVIEW OF PLAINS VILLAGE CULTURE IN THE TEXAS PANHANDLE}

\author{
J. Michael Quigg
}

\subsection{Introduction}

Archeological investigations of sites and cultural complexes dating to the Plains Village period in the Texas and Oklahoma panhandles and the surrounding regions have been referred to by a number of general terms such as Late Prehistoric II (Boyd 1997), Plains Village period (Lintz 1978, 1986; Brooks and Drass 2005), and Middle Ceramic period (Zier and Kalasz 1999; Brosowske 2005; Brosowske and Bevitt 2006; Lintz 2009). For the most part, the sites being referenced represent the Plains Village Tradition on the Southern Plains. A tremendous number of architectural sites that represent the broad Plains Village manifestation are known and recorded in the Texas panhandle and western Oklahoma, with many having been investigated to some extent.

Chronologically, the Plains Village Tradition (Willey 1966:320) is assumed to have followed the Plains Woodland manifestations, which are poorly known or understood in the Texas panhandle, and represented by only a limited number of known sites. Woodland occupations are thought to be characterized by small corner-notched Scallorn arrow points and large, thick, cordmarked conical pottery vessels (Couzzourt 1985; J. Hughes 1991; Figure 3-1). A number of researchers believe that the Woodland pottery is the most defining artifact for Woodland sites, based on its distinctive characteristics. As Couzzourt (1985:75) points out:

Woodland vessels tend to be large, open-mouthed, unshouldered vessels with conoidal bases. Exteriors are invariably cordmarked with deeply impressed parallel cordwrapped paddles. Manufacture is by the paddle-and-anvil technique. No lugs or handles have yet been found, and exterior decoration, other than cordmarking is rare. Tempering is frequently abundant and ranges from medium- to coarse-grained crushed quartzrose rock to a calcareous aplastic, such as crushed dolomite or limestone or, as in the case of A2060, crushed calcite.

However, buried Woodland sites with good contexts and extensive artifact assemblages have yet to be intensively excavated and fully reported for the Texas panhandle. Couzzourt (1985:118-119) provides thicknesses for Woodland body sherds that vary from 5 to $8 \mathrm{~mm}$, whereas basal sherds vary from 6- to 11 -mm-thick. One atypical basal sherd reveals what Couzzourt sees as edges of individual chunks of prepared clay imperfectly welded together to form the vessel wall. Another has both interior and exterior faces exfoliated, which indicates that a thin veneer of clay was applied to both faces of the base and then paddled into the body (Couzzourt 1985:119).

Plains Village populations appeared in the Southern Plains at about 1150 B.P. and thrived until about 450 B.P. (cal A.D. 800 to 1500; Drass 1997:11), and specifically in the Texas panhandle from about 450 to 750 B.P. (cal A.D. 1200 to 1500: Lintz 1986, 1989; Brooks 1989, 2004:335). This tradition encompasses scattered groups of farmers and hunters that resided in the central and western parts of the Southern Plains, which included much of western Oklahoma, parts of northern Texas, and the Texas panhandle.

Plains Village sites in the Texas panhandle have been investigated since the turn of the twentieth century. These sites in the Texas panhandle have been the subject of numerous and diverse investigations from as early as 1907 (e.g., Eyerly 1907, 1908, 1910, 1912; Holden 1929, 1930, 1932, 1933; Mason 1929; Lowery 1932; Johnston 1939; Hobbs 1941; Duffield 1964; Green 1967; R. Campbell 1969). In fact, most investigations at Plains Village sites in the Texas panhandle occurred prior to 1975. Many early investigations were conducted between 1931 and 1941 by the Federal Emergency Relief Administration (FERA) and the Works Progress Administration (WPA) programs, in which the excavation techniques and reporting, if any, were 


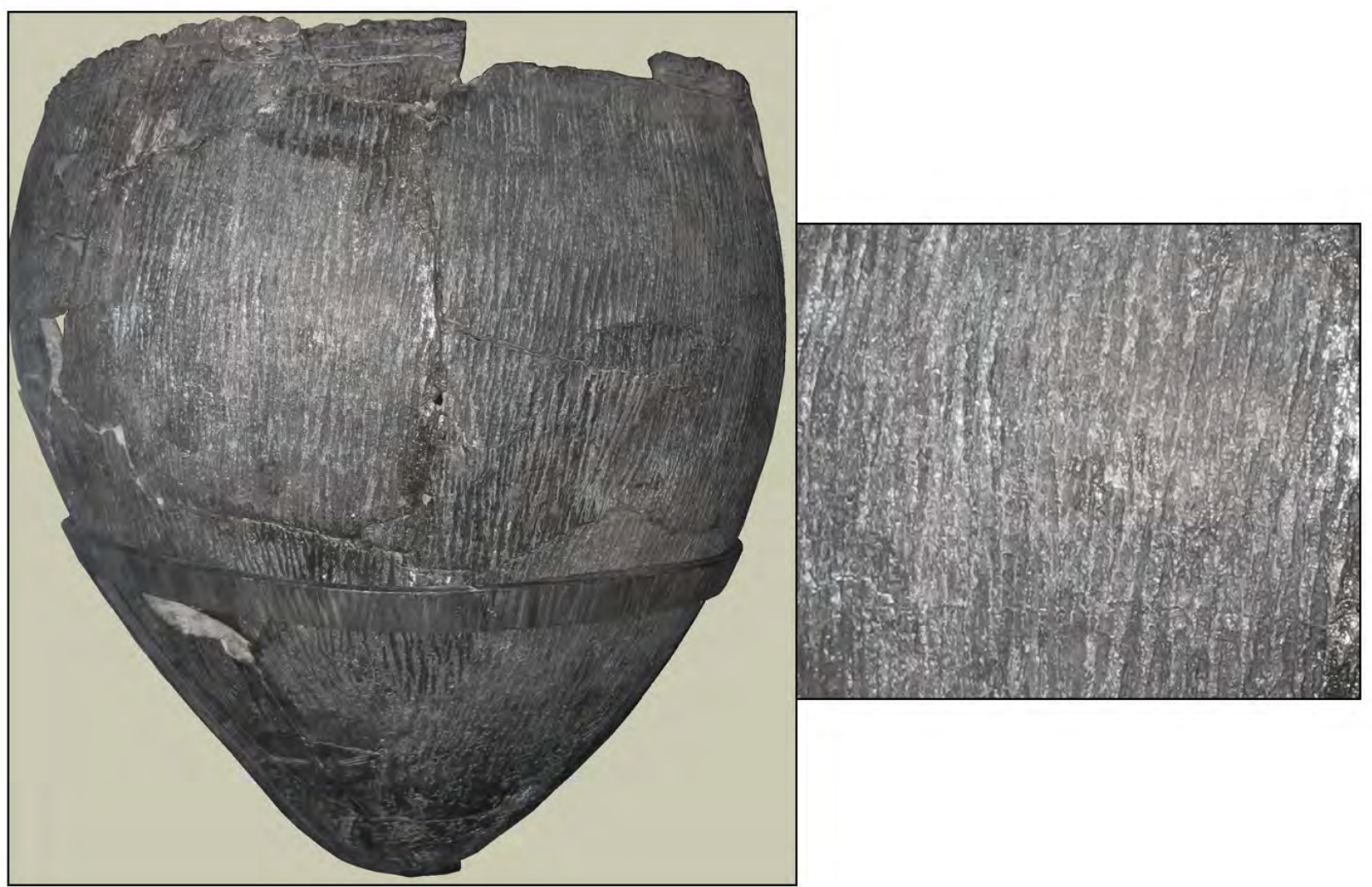

Figure 3-1. Reconstructed plains woodland vessels in the Panhandle-Plains Historical Museum (left) with close up of exterior cordmarking (right, photograph provided by PPHM, Accession Number X1996.3.14).

not as rigorous as today's standards. If reports were published, they were often summaries, or focused on one aspect, such as architecture, and were definitely not comprehensive by today's reporting standards.

Most village sites in the Texas panhandle postdate 750 B.P. (cal A.D. 1200; Lintz 1986; Brooks 1989, 2004:335) with side-notched (Washita), side- and basal-notched (Harrell), and unnotched (Fresno) arrow point forms. Also, the exterior-cordmarked, wide mouth conical pottery vessels of the previous Woodland period were supplanted by more globular, cordmarked jars with constricted orifices during the Plains Village period (Figure 3-2). The continuity of cordmarking on vessel exteriors indicates to some researchers that Middle Ceramic complexes developed from the earlier Plains Woodland cultures. Apparently, no Palo Duro (Mogollon) complex characteristics (Boyd 2004b) carried over into this Late Prehistoric II subperiod, or at least not into the Antelope Creek phase of the upper Texas panhandle, unless one assumes that the occasional presence of pithouses reflects some continuity of that earlier intercultural relationship (D. Hughes 2001; Quigg et al. 2007; Boyd 2008).

\subsection{Taxonomy}

Lintz (1986:5-20) redefined the early work by Willey (1966:320) concerning “The Plains Village Tradition” and proposed the "Upper Canark Variant" of the Plains Village Tradition to encompass Late Prehistoric manifestations between the upper portions of the Canadian River and the southern tributaries of the Upper Arkansas River. The Upper Canark is, therefore, a regional variant of the Plains Village Tradition. It is a taxon under which a portion of Southern Plains Village occupations in the Oklahoma and Texas panhandles, southeastern Colorado, and northeastern New Mexico may be subsumed. This cultural distinction encompasses both the Apishapa (Withers 1954; R. Campbell 1969) and Antelope Creek phases. Geographically, 

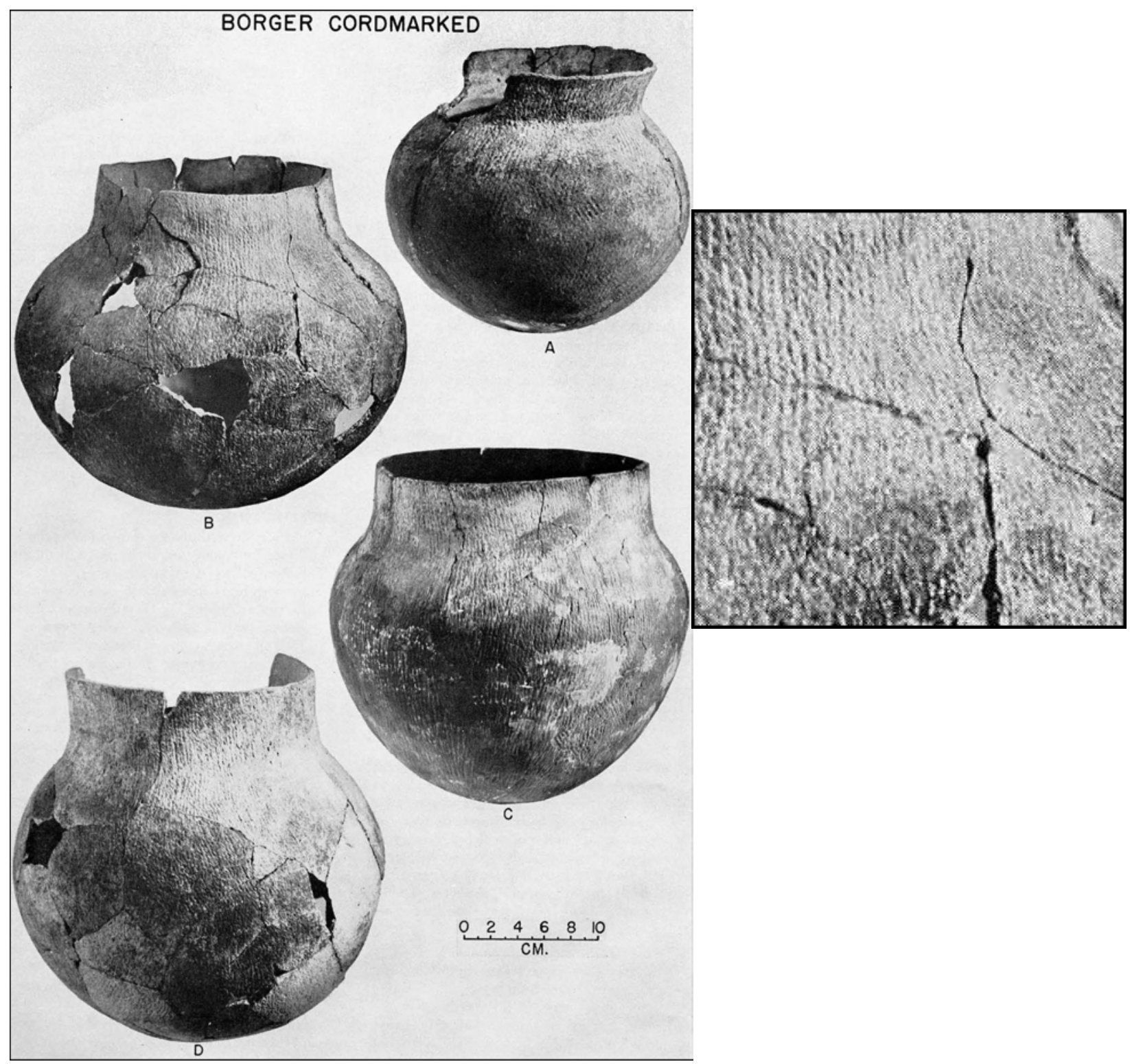

Figure 3-2. Typical Shapes of Plains Village Period cordmarked vessels with vertical rims (left, from Suhm and Jelks 1962, Plate 8) and close up of exterior cordmarks (right).

this Plains Village variant defines an area "between the upper portions of the Canadian River and the southern tributaries of the Upper Arkansas River" (Lintz 1986:25). Apishapa and Antelope Creek phases were identified as roughly contemporaneous western and eastern elements of the Upper Canark variant (Lintz 1986). These two terms are considered synonymous with the Middle Ceramic period as it is often defined for southeastern Colorado (Zier and Kalasz 1999) and adjacent regions (Brosowske 2005; Brosowske and Bevitt 2006; Lintz 2009).
The Apishapa phase is located along the Apishapa Plateau in southeastern Colorado and exhibits stone/ slab enclosures ranging from single-room sites to villages containing close to 60 rooms (Zier and Kalasz 1999). Some Apishapa sites exhibit stoneslab walls that appear as fortification/defensive elements that enclose the small-room or village sites. The chronological placement of the Apishapa phase is best defined by a statement made by Lintz (1989): "chronological information about the Apishapa phase is hindered by the delineation of 
cultural attributes encompassing the phase and, until recently, by relatively few absolute dates." Roughly a dozen sites/components have now yielded some 29 radiocarbon dates that place the timing of this phase roughly between 1000 and 550 B.P. (Zier and Kalasz 1999). The apparent initiation of this phase thus precedes that of the Antelope Creek phase to the southeast; though, for the most part, it is contemporaneous with the Antelope Creek phase. Lintz (1978a) refuted the idea of a sequential, Apishapa-to-Antelope Creek development, and most researchers now see the Apishapa phase as having developed in situ from indigenous hunter gatherer populations (Zier and Kalasz 1999). In southeastern Colorado, the Apishapa phase is documented for this period and is very similar to the Antelope Creek phase in terms of its artifact assemblage and the use of rock foundations for structures (Lintz 1986; Cassells 1997; Zier and Kalasz 1999).

The use of masonry-foundation architecture at Apishapa phase sites in southeastern Colorado, along with cordmarked pottery, resulted in a superficial resemblance to the Antelope Creek phase sites across the Texas panhandle and, potentially, to the Buried City sites (D. Hughes and HughesJones 1987; D. Hughes 1991) in the northeastern Texas panhandle. Buried City is not well-known; much of what constitutes this manifestation has yet to be thoroughly presented in print so as to allow researchers to completely understand the similarities and differences. However, the architecture and intrasite spatial patterning of Upper Canark settlements are principal factors that distinguish them from other Plains Village groups (Lintz 1986:25; Brooks 1989, 2004).

Two Plains Village cultural complexes have been defined in the Texas panhandle: The Buried City complex in the northeastern corner of the Texas panhandle (D. Hughes and Hughes-Jones 1987; D. Hughes 1991), centered along Wolf Creek in Ochiltree County, and the Antelope Creek phase (proposed by Kreiger 1946; redefined by Lintz 1986) centered around Lake Meredith (the Antelope Creek phase "core area") just north of Amarillo (Figure 3-9). The latter phase extends across most of the Texas panhandle during this period, whereas the Buried City complex appears more restricted in area and may only encompass the very northeastern corner of the Texas panhandle. Lintz (1986) originally assigned the stone houses and associated materials in Buried City to the Antelope Creek phase based on general similarities and in the absence of published information concerning the sites. Subsequently, D. Hughes and Hughes-Jones (1987) and D. Hughes (1991) separated the Buried City complex materials from the Antelope Creek phase based on the differences they saw in the stone architecture and more diverse pottery styles (see more discussion below).

It may be too soon to establish a phase assignment for 41RB112, the Long View site. The site may pertain to one of the two currently identified village manifestations, or to an as yet to be named manifestation. Much more work is required at Plains Village sites across this broad region to fully document and better understand the two known manifestations and those in adjacent regions. However, broader regional interactions and settlement patterns may be identified, contributing to our growing knowledge of the various manifestations. The Long View site lies on the north side of the Canadian River in the northeastern part of the Texas panhandle, some 50 to $60 \mathrm{~km}$ northeast of the core Antelope Creek phase area and roughly $80 \mathrm{~km}$ from the main cluster of Antelope Creek phase sites near the Alibates quarries (Figure 3-3). It is some 60 to $70 \mathrm{~km}$ from a cluster of four excavated Antelope Creek phase sites in the central Oklahoma panhandle, and only $25 \mathrm{~km}$ southwest of the Buried City complex along Wolf Creek in Ochiltree County, Texas. The following discussions focus on the Antelope Creek phase and the Buried City complex in order to provide a basis for linkages with either or both manifestations. Although not currently assigned to specific taxonomic positions, a cluster of sites currently under investigation on the M-Cross Ranch, roughly $10 \mathrm{~km}$ to the east of Long View site, will also be briefly discussed.

A number of other Plains Village manifestations are located farther east and northeast of the Long View site. These include the Zimms complex just across the Oklahoma border (Saunders 1973; Flynn 1984; 1986; Brooks 1989; Brooks et al. 1992; Brosowske 2002a); the Custer and Turkey Creek phases father east; and the Paoli and Washita River phases (Brooks 
1989; Drass 1999) that lie in eastern and central Oklahoma respectively, and are now considered part of the Redbed Plains Variant centered along the Canadian and Washita rivers in Oklahoma (Drass 1998, 1999). The Odessa phase, which is roughly 70 to $80 \mathrm{~km}$ to the northeast of Long View (41RB112), may include the Buried City materials, according to Brosowske (2004) and Brosowske and Bevitt (2006).

The discussions that follow focus mainly on Antelope Creek phase sites within the "core” area of the Antelope Creek phase plus four excavated Antelope Creek phase sites in the central Oklahoma panhandle region. This is followed by discussions concerning the Buried City complex sites along Wolf Creek and brief discussions of ongoing studies at M-Cross Ranch and sites on the Courson property that surrounds the Long View site. Investigations in the latter two areas are relatively recent, occurring over the last 10 years, with only limited published information currently available for those two areas. For a discussion concerning the probable climate of this period, see the paleoclimate section at the end of Chapter 2.0, The Environmental Background.

\subsection{The Antelope Creek Phase}

\subsubsection{Introduction}

The Antelope Creek phase is a regional variant of the broader Plains Village Tradition, which existed on the Southern High Plains, including the Texas panhandle, between roughly 750 to 450 B.P. (cal A.D. 1200 to 1500). This regional variation and time period has received the greatest attention in the Texas panhandle region. Many sites thought to represent this period are recorded and discussed in regional survey reports, and some have been targeted

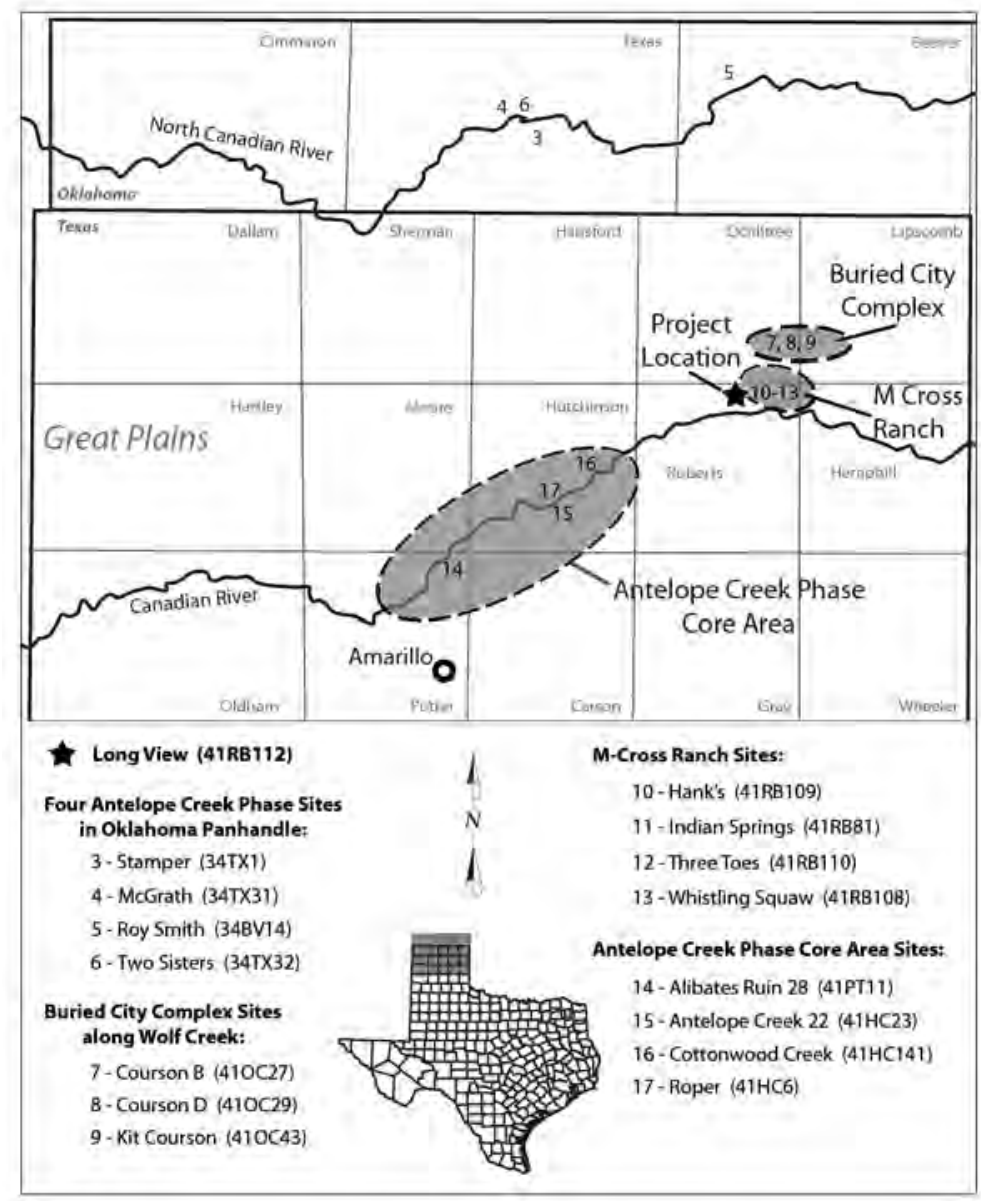

Figure 3-3. Long View Site in relation to Antelope Creek Phase Core Area, Buried City and M-Cross Ranch localities. 
and received limited excavations, while others have been intensively excavated (Table 3-1).

Lintz (1982, 1984, 1986) and, more recently, Brooks (1989, 2004) have characterized the Antelope Creek phase primarily on the basis of analyses of excavated sites in the "Core Area," a limited part of the Canadian River valley near the Alibates quarries at Lake Meredith, and a cluster of four excavated and reported sites (i.e., Roy Smith, Two Sisters, McGrath, and Stamper) along the North Canadian River in Texas and Beaver counties in the central part of the Oklahoma panhandle. Lintz (1986) and subsequently Brooks (1989, 2004) placed the Buried City materials from along Wolf Creek into the Antelope Creek phase.

The Antelope Creek phase is characterized by semisubteranean slab house architecture; small triangular Fresno, Harrell, and Washita arrow points; and Borger Cordmarked pottery, among other traits (see summaries in Lintz 1978a, 1984, 1986; J. Hughes 1991; Boyd 1997; Brooks 1989, 2004). Much of the following information is extrapolated from these summaries and from selected individual site reports.

The Antelope Creek phase was first proposed by Kreiger (1946), primarily on the basis of cultural materials recovered from WPA excavations on sites along Antelope Creek (e.g., Baker and Baker 2000), a southern tributary to the Canadian River near Lake Meredith (Lintz 1986). Lintz defined an apparent core area centered along the Canadian River in the vicinity of Lake Meredith, with some sites farther north along the North Canadian River and its tributaries, and others farther west (see Figure 3-9). Antelope Creek phase sites may exist as far south as the Red River and westward into extreme eastern New Mexico (Lintz 1986). The eastern boundary is not well-defined.

At least 28 major architectural sites attributed to the Antelope Creek phase lie within the "Core Area" along the Canadian River in the Lake Meredith area north of Amarillo (Lintz 1986; see Figure 3-3; Table 3-1). Major excavations in that region have been conducted at many Antelope Creek phase sites (i.e., Duffield 1964, 1970; Keller 1975; Lintz 1986, 1990, 2001; Couzzourt and Schmidt-Couzzourt 1996; Baker and Baker 2000; Brooks 1989, 2004). Most core area sites were excavated early on, prior to 1970 , and more often than not, are partially or poorly reported. Zollers and Ozier, tested in 1980 are the most recent core areas sites excavated.

Although the core area sites are best known, other Antelope Creek phase sites have been investigated to one degree or another, and a few examples are presented here. West of the core area in Oldham County, a major excavation $\left(2,225 \mathrm{~m}^{2}\right)$ was conducted at a large Antelope Creek phase village (41OL2) on top of Landergin Mesa by the Texas Historical Commission (Wulfkuhle 1984; DeMarcay 1986; Dean 1986; Lintz 1990; Robinson 2001). However, no final report has been published on Landergin Mesa.

A single, isolated slab house structure at 41PT109, at the mouth of West Amarillo Creek in Potter County, was partially excavated by students from Texas State University in San Marcos under the direct supervision of Dr. B. Bousman. The Texas State University field school excavated part of one Antelope Creek phase structure on the Bureau of Land Management (BLM) Cross Bar Ranch property in 2004 and 2005 (Weinstein 2005; Meir 2007). Hand-excavations of $31 \mathrm{~m}^{2}$ targeted limited areas both inside and outside the structure walls. The structure's interior yielded few artifacts, which Weinstein (2005) interpreted as reflecting a planned abandonment.

A number of other Antelope Creek phase sites have been investigated to various degrees, some have been briefly reported, but detailed results and findings from many of those sites have never been published (i.e., Chimney Rock Ruins 51 and 51A, Marsh, Jack Allen, Saddleback Ruin, Tarbox Ruin, Lookout Ruin, Alibates 30, Sanford Ruin, Roper, Pickett, and Zollars). Lintz (1986) presents site and structure maps, and briefly describes the excavations and structures at those sites, which targeted verticalslab-wall structures.

Over the last 90 years or so, publications that focused on Antelope Creek phase sites, artifacts, and/or structures in the Texas panhandle are quite limited in number and quality. There have been a few master's theses (i.e., Haynes 1932; Lowery 1932; Lintz 1976; Bandy 1986; DeMarcay 1986; Huhnke 2001; Weinstein 2005; Meier 2007), a few Ph.D. dissertations 
Table 3-1. Overview of the 28 Antelope Creek Phase sites in the "Core Area" Around Lake Meredith (from Lintz 1986)

\begin{tabular}{|c|c|c|c|c|c|c|c|c|c|c|}
\hline $\begin{array}{l}\text { Antelope Creek Core } \\
\text { Area Sites }\end{array}$ & $\begin{array}{c}\text { Site } \\
\text { Trinomial }\end{array}$ & $\begin{array}{c}\text { Number } \\
\text { of } \\
\text { Houses/ } \\
\text { Rooms }\end{array}$ & $\begin{array}{l}\text { Other } \\
\text { Features }\end{array}$ & $\begin{array}{l}\text { Date Tested (area } \\
\text { tested in } \mathbf{m}^{2} \text { ) }\end{array}$ & $\begin{array}{l}\text { Date Excavated } \\
\text { (area dug in } \mathrm{m}^{2} \text { ) }\end{array}$ & $\begin{array}{c}\text { C14 } \\
\text { Dates }\end{array}$ & Cemetery & Burials & $\begin{array}{l}\text { Cairn } \\
\text { Burial }\end{array}$ & References \\
\hline Alibates Ruin 28 & 41PT11 & $56+$ & $124+$ & 1926;1938-39 & $5626 \mathrm{~m}^{2}$ & 5 & & $15+$ & & $\begin{array}{l}\text { Studer 1942; Baker and Baker 2000; Krieger } \\
\text { 1946; Lintz } 1986\end{array}$ \\
\hline Alibates Ruin 28A & & 10 & & $1939-40,381 \mathrm{~m}^{2}$ & $381 \mathrm{~m}^{2}$ & & & & & Baker and Baker 2000; Lintz 1986 \\
\hline Alibates Ruin 30 & 41PT3 & $9+$ & & & $1930-40,225 \mathrm{~m}^{2}$ & & & & & Baker and Baker 2000; Lintz 1986 \\
\hline $\begin{array}{l}\text { Antelope Creek Ruin } \\
22,22 \mathrm{~A}\end{array}$ & 41HC23 & $36+$ & 4 & 1930-32; 1938-39 & $1363 \mathrm{~m}^{2}$ & & & 17 & & $\begin{array}{c}\text { Baker and Baker 2000; Holden 1930; Lowrey } \\
\text { 1932; Krieger 1976; Lintz } 1986\end{array}$ \\
\hline Antelope Creek Ruin 23 & 41HC25 & $1+$ & & $46 \mathrm{~m}^{2}$ & & & & 1 & & Baker 1939a; Lintz 1986 \\
\hline Antelope Creek Ruin 24 & & $19+$ & possible & $1939,45 \mathrm{~m}^{2}$ & са. $200 \mathrm{~m}^{2}$ & & & & & Lintz 1986 \\
\hline Arrowhead Peak & 41HC19 & $12+$ & 1 & & $1963-65,140 \mathrm{~m}^{2}$ & 1 & & & & Green 1967; Lintz 1986 \\
\hline Big Blue Creek & 41MO35 & $11+$ & & & 1969, $36 \mathrm{~m}^{2}$ & & 1 & & 5 & $\begin{array}{l}\text { Lintz 1986; Davis 1986; Couzzourt and } \\
\text { Schmidt-Couzzourt } 1996\end{array}$ \\
\hline Black Dog Village & $41 \mathrm{HC} 30$ & $7+$ & $3+$ & & $1970,180 \mathrm{~m}^{2}$ & 13 & & & & Keller 1975; Lintz 1986 \\
\hline $\begin{array}{l}\text { Canadian River } 1 \text { and } \\
1 \mathrm{~A}\end{array}$ & & & & & & & & & & Lintz 1986 \\
\hline $\begin{array}{l}\text { Chimney Rock Ruin } 51 \\
\text { and 51A }\end{array}$ & & $33+$ & & & $1941,599 \mathrm{~m}^{2}$ & & & & & Studer n.d.; Baker and Baker 2000; Lintz 1986 \\
\hline Coetas Ruin, No. 55 & 41PT25 & $50 ?$ & & & $1934,225 \mathrm{~m}^{2}$ & 6 & & 2 & & Studer 1934; Lintz 1986 \\
\hline Corner & 41HC7 & $2+$ & & & $1961,28 \mathrm{~m}^{2}$ & & & & & Duffield 1964; Lintz 1986 \\
\hline Cottonwood Creek Ruin & $41 \mathrm{HC} 141$ & 19 & & $1958-59,28 \mathrm{~m}^{2}$ & & & & & & Holden 1929; Lintz 1986 \\
\hline Footprint & 41PT25 & 3 & 6 & & $1964,115 \mathrm{~m}^{2}$ & 4 & & 3 & & Green 1967; Lintz 1986 \\
\hline Jack Allen & (A654) & $1+$ & 2 & & $55 \mathrm{~m}^{2}$ & 1 & & & & Harrison 1983; Lintz 1986 \\
\hline Lookout Ruin & & 5 & & & $1931,5.6 \mathrm{~m}^{2}$ & & & & & Lowrey 1932; Lintz 1986 \\
\hline Marsh & & $2+$ & 1 & $1967,40 \mathrm{~m}^{2}$ & & & & & & Lintz 1986 \\
\hline Medford Ranch & 41HC10 & 8 & & & $1961,113 \mathrm{~m}^{2}$ & & & & & Duffield 1964, Lintz 1986 \\
\hline Ozier & 41MO96 & $>1$ & $2+$ & 1979-80,? & & & & & & Lintz 1986 \\
\hline
\end{tabular}


Table 3-1 Overview of the 28 Antelope Creek Phase sites in the "Core Area" Around Lake Meredith (from Lintz 1986) (cont.)

\begin{tabular}{|c|c|c|c|c|c|c|c|c|c|c|}
\hline $\begin{array}{c}\text { Antelope Creek Core } \\
\text { Area Sites }\end{array}$ & $\begin{array}{c}\text { Site } \\
\text { Trinomial }\end{array}$ & $\begin{array}{c}\text { Number } \\
\text { of } \\
\text { Houses/ } \\
\text { Rooms }\end{array}$ & $\begin{array}{l}\text { Other } \\
\text { Features }\end{array}$ & $\begin{array}{l}\text { Date Tested (area } \\
\text { tested in } \mathbf{m}^{2} \text { ) }\end{array}$ & $\begin{array}{l}\text { Date Excavated } \\
\text { (area dug in } \mathrm{m}^{2} \text { ) }\end{array}$ & $\begin{array}{c}\text { C14 } \\
\text { Dates }\end{array}$ & Cemetery & Burials & $\begin{array}{l}\text { Cairn } \\
\text { Burial }\end{array}$ & References \\
\hline Pickett Ruin & & 1 & & 1958, $26 \mathrm{~m}^{2}$ & & 1 & & & & Carter and Carter 1958; Duffield 1970 \\
\hline Roper & 41HC6 & $5^{+}$ & & & $1957,75 \mathrm{~m}^{2}$ & 2 & & & & Lintz 1986 \\
\hline Sanford Ruin & 41HC30 & $9+$ & & $1953,80 \mathrm{~m}^{2}$ & & 1 & & 2 & & Lintz 1986 \\
\hline Spring Canyon & 41HC20 & $5+$ & 2 & & $1961,81 \mathrm{~m}^{2}$ & 1 & & & & Duffield 1964; Lintz 1986 \\
\hline Tarbox & 41HV2 & 19 & 2 & $1964,56 \mathrm{~m}^{2}$ & & & & 2 & & Holden 1929; Lintz 1986 \\
\hline Turkey Creek Ruins & 41PT8 & 3 & & & $1963,44 \mathrm{~m}^{2}$ & & & & & Green 1967; Lintz 1986 \\
\hline Zollers & & 7 & & $1980,35 \mathrm{~m}^{2}$ & & & & & & Smith and Smith 1982; Lintz 1986 \\
\hline $41 \mathrm{MP7}$ & 1 & 2 & & & $1963,109 \mathrm{~m}^{2}$ & & & & & Lintz 1986 \\
\hline Totals & & 66 & & $356 \mathrm{~m}^{2}$ & $9,902 \mathrm{~m}^{2}$ & 30 & 1 & 42 & 5 & \\
\hline
\end{tabular}


(Duffield 1970; Duncan 2002, 2006; Lintz 1986), a few short reports and articles (i.e., Keller 1975; Green 1986; Smith 1989; Boyd and Wilkens 2001), and one major excavation conducted by the TAS field school at Big Blue Creek (41MO35, 41MO36 and 41MO37) in 1969 (Couzzourt and Schmidt-Couzzourt 1996). Also number of unpublished manuscripts have been written on Antelope Creek phase sites or artifacts in Texas (i.e., Green 1967; Wulfkuhle 1984), but these are not well distributed and quality varies considerably.

Along the North Canadian River in the central Oklahoma panhandle, four Antelope Creek phase sites, excavated prior to 1975, have been reported upon. These include the Roy Smith (Schneider 1969), McGrath (Lintz 1976), Stamper (Watson 1950; Lintz 2003a, 2003b, 2003c, 2004), and Two Sisters sites (Lintz 1978a, 1979, 1986; Duncan 2002, 2006; Table 3-2). Nearly a dozen other unexplored Plains Village sites are known throughout the central Oklahoma panhandle region (Bement and Brosowske 2001). In summaries, Lintz (1986) and, subsequently, Brooks (1989, 2004) assigned these four excavated sites to the Antelope Creek phase despite minor differences in the ceramic assemblage (see below for discussions). More recently, since about 1989, Plains Village sites such as Lonker (34BV4; Brooks 1994; Keener 1991; Drass 1997) and Odessa Yates (34BV100, Brosowske 2005), east of Roy Smith in Beaver County, Oklahoma, have been excavated and reported upon. These and other Plains Village sites have been assigned to the Odessa phase (Brosowske 2005; Brosowske and Bevitt 2006).

\subsubsection{The Antelope Creek Phase Cultural Material Remains}

In Texas, the more widely known Antelope Creek phase sites resemble other Southern Plains village manifestations, but are distinguished based on architectural characteristics, specifically the use of vertical stone slabs for foundations associated with sand-tempered cordmarked pottery, dominance of bison remains in the faunal assemblage, and the use of local Alibates chert (Lintz 1978a, 1982, 1984, 1986; Brooks 1989, 2004). The material remains of the Antelope Creek phase are extensive and varied. Below are brief discussions of the various characteristics of the Antelope Creek phase.

\subsubsection{Ages}

Lintz (1986) stated that the Antelope Creek phase is one of the best radiocarbon dated cultural manifestations in the Southern Plains. At that time, at least 58 radiocarbon dates were available. Only a few more dates have been obtained since then. Most radiocarbon dates were derived from wood charcoal and the MASCA tree ring corrections factor (Ralph et al. 1974) narrows the broader range down to roughly 300 years between 750 and 450 B.P. (cal A.D. 1200 to 1500). However, these dates were only derived from about 35 percent of the investigated Antelope Creek phase sites. Most individual dates were obtained from wood charcoal samples with poorly described contexts. Lintz discusses an "Early" and "Late" subphase within this relatively short 300-year period. The "Early" subphase dates to the first half of the broader period, from about 600 to 750 B.P., whereas the "Late" subphase dates roughly from 450 to 600 B.P. Lintz (1986) sees cultural changes occurring through these two subphases and attributes some detected changes to cultural responses and to regional environmental changes.

\subsubsection{House and Settlement Types}

The primary characteristics of the Antelope Creek phase are the vertical stone enclosures. These enclosures are quite varied in size and shape. Lintz (1986) defined 11 architectural units/types with three small pit-type features, plus three other miscellaneous variations (Figure 3-4). Structure types include multifamily hamlets, single family homesteads with clearly defined houses, and a few camp sites without structures. He identified at least 223 architectural units at his 28 core area sites.

The distinctive slab-house architecture exhibits a range of stylistic differences (Lintz 1978, 1982, 1986; J. Hughes 1991; Boyd 1997; Brooks 1989, 2004). The residential structures are often rectangular semisubterranean houses with vertically oriented rock slabs at the base of the walls and a central eastwest depressed floor channel with a fire pit and four major roof support posts (Figure 3-5). An entryway and an altar opposite the entryway are often present. Circular Antelope Creek phase structures of various sizes also exist. On hamlet sites, several residential structures may be contiguously aligned 
Table 3-2. Overview of the Four Excavated Antelope Creek Phase Sites in the Central Oklahoma Panhandle.

\begin{tabular}{|c|c|c|c|c|c|c|c|c|c|c|}
\hline $\begin{array}{c}\text { Excavated } \\
\text { Central } \\
\text { Oklahoma } \\
\text { Panhandle } \\
\text { Sites }\end{array}$ & $\begin{array}{c}\text { Site } \\
\text { Trinomial }\end{array}$ & $\begin{array}{c}\begin{array}{c}\text { Number } \\
\text { of } \\
\text { Houses/ } \\
\text { Rooms }\end{array}\end{array}$ & $\begin{array}{c}\text { Other } \\
\text { Features }\end{array}$ & $\begin{array}{l}\text { Date Tested } \\
\text { (area tested } \\
\quad \text { in } \mathbf{m}^{2} \text { ) }\end{array}$ & $\begin{array}{c}\text { Date } \\
\text { Excavated } \\
\text { (area tested } \\
\left.\text { in } \mathbf{~ m}^{2}\right)\end{array}$ & $\begin{array}{c}\text { C14 } \\
\text { Dates }\end{array}$ & Cemetery & Burials & $\begin{array}{l}\text { Cairn } \\
\text { Burial }\end{array}$ & References \\
\hline Stamper & $34 \mathrm{TX} 1$ & $28+$ & $120+$ & & $\begin{array}{c}\text { 1930s, } 360 \\
\mathrm{~m}^{2} \text { room } \\
\text { interiors }\end{array}$ & 2 & $\begin{array}{c}1=7 \\
\text { bodies }\end{array}$ & 0 & 0 & $\begin{array}{l}\text { Watson 1950; Bareireis and Bryson 1966; } \\
\text { Lintz 2003a; 2003b, 2003c, } 2004\end{array}$ \\
\hline McGrath & 34TX31 & 0 & 8 & $\begin{array}{l}\text { 1972, } \\
\text { exteriors, ca. } \\
25 \mathrm{~m}^{2}\end{array}$ & & 0 & 0 & 0 & 0 & Lintz 1976 \\
\hline $\begin{array}{l}\text { Two } \\
\text { Sisters }\end{array}$ & 34TX32 & $5+$ & & 1972 & 1973, $192 \mathrm{~m}^{2}$ & 8 & 0 & 1 & 0 & Lintz 1979; Duncan 2002, 2006 \\
\hline Roy Smith & 41BV14 & $\begin{array}{c}1 \text { multi- } \\
\text { room }\end{array}$ & 2 & & 1965 & 7 & 0 & 0 & 0 & Schneider 1969 \\
\hline Totals & & 34 & & & & 17 & 1 & 1 & 0 & \\
\hline
\end{tabular}




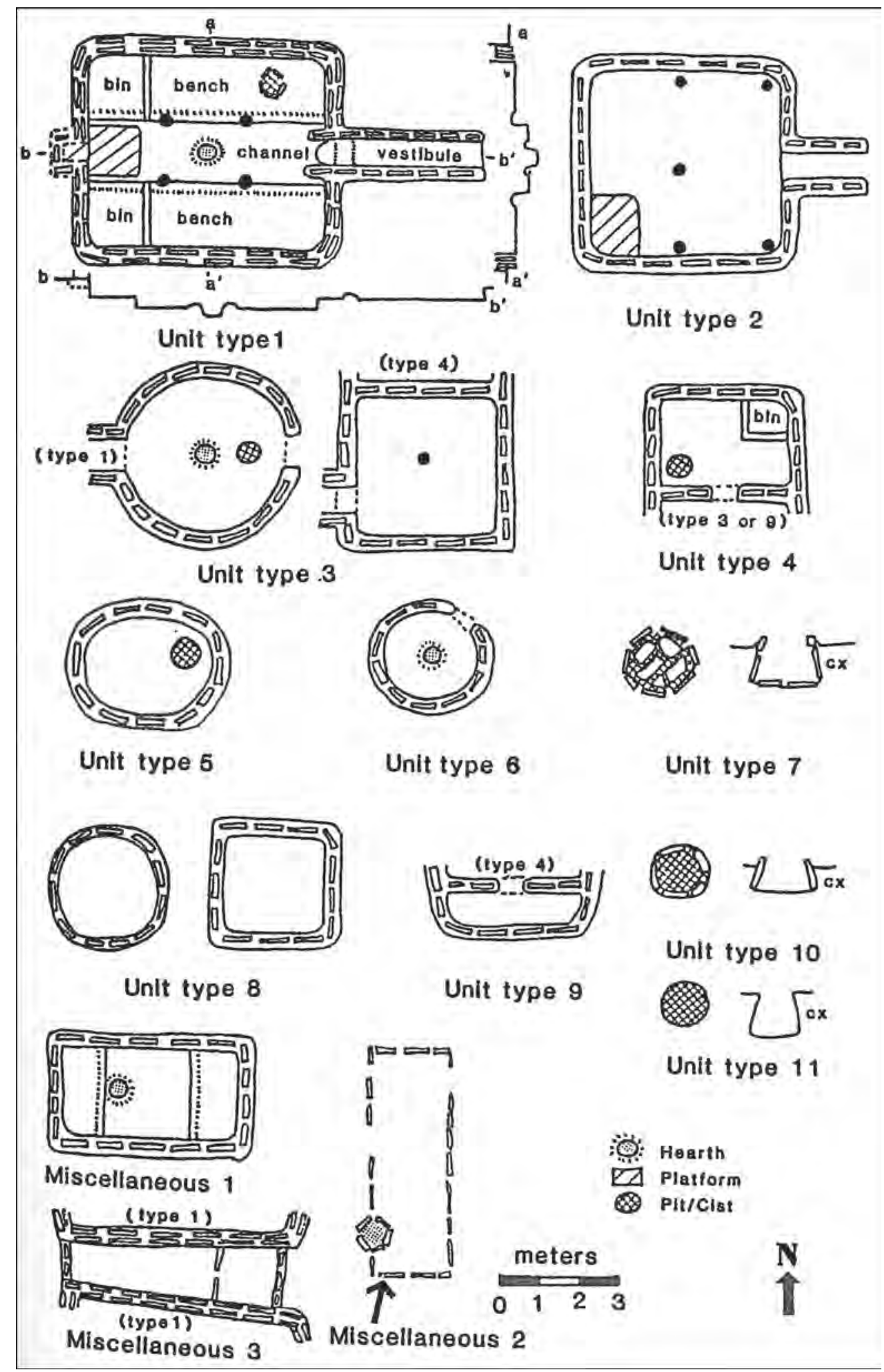

Figure 3-4. Variations in architectural unit types identified in Antelope Creek Phase sites (from Lintz 1986, Figure 10). 


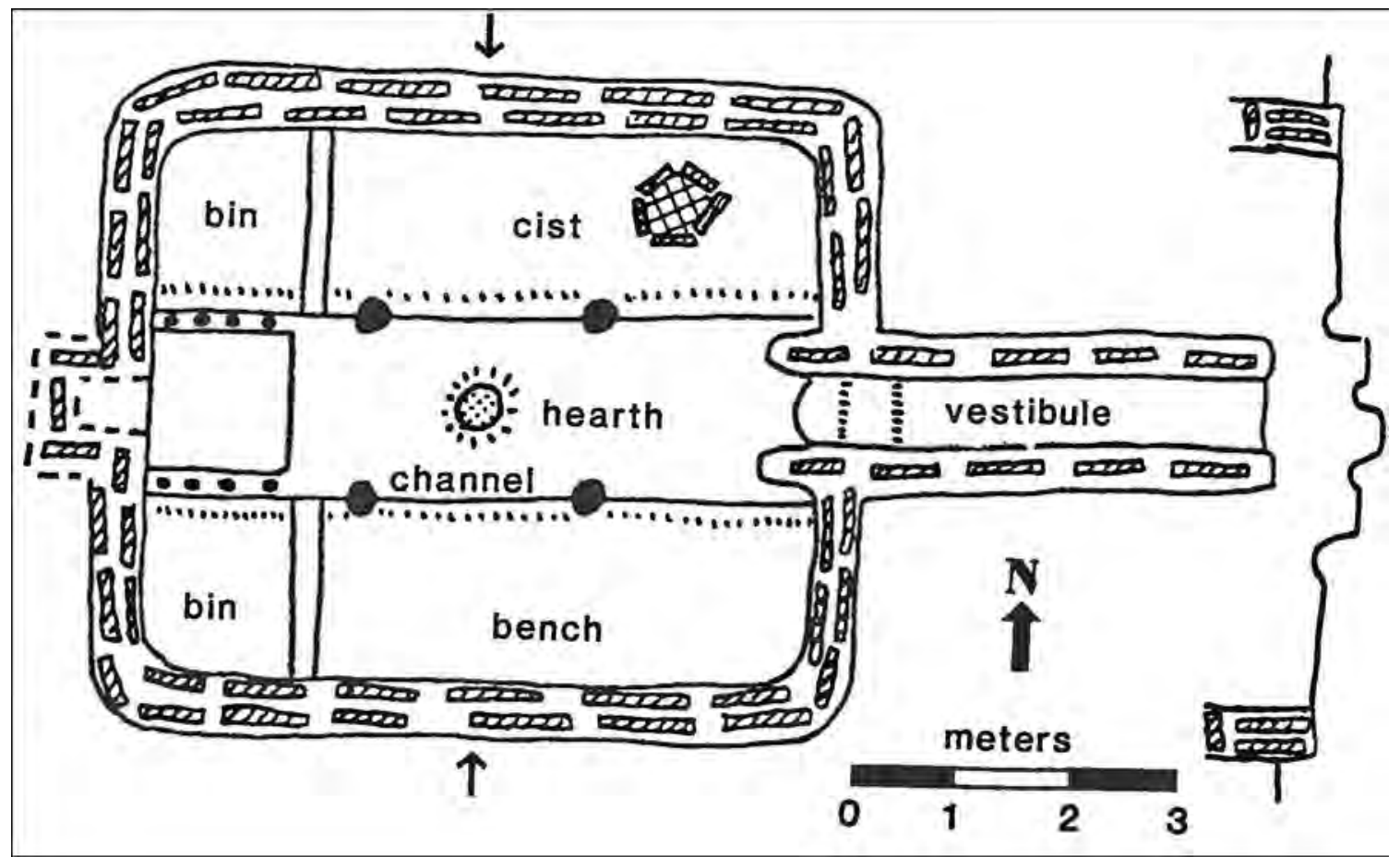

Figure 3-5. Generalized structure of Unit type I showing location of key characteristics (from Lintz 1986, Figure 12).

into apartment style structures, and these forms tend to be earlier (750 to 600 B.P.) than hamlets with isolated residential structures (600 to 450 B.P.).

Reoccupation of individual houses and rooms has been demonstrated. At Antelope Creek Ruin 22, Baker and Baker (2000) often mention refuse deposits underneath the floor and rooms with multiple floors. Watson (1950) also indicates that several rooms at Stamper (34TX1) in the central Oklahoma panhandle have multiple floors, which may be separated from one another. Room 3 at Stamper is cited as an example where there were three floor levels. Caution should be used in interpreting the numbers of floors, as in some instances multiple floors may have been confused with the floor channel. In these contexts, apparently some time had elapsed between occupations. This could indicate that there were instances where rooms and possibly villages were abandoned and then reoccupied.

Settlement types include small to large farming settlements, kill sites (primarily bison, but also other large game animals), temporary processing camps, and isolated settlements (i.e., field houses, homesteads, etc.). Lintz (1986, 1989) points out that substantial variation exists in the size of sites, number of rooms present, and the size and shape of the structures (Figure 3-6). One recognized variation that has come to light over the years is the rectangular structures with picket-post walls and lots of daub (Lintz 2011). These picket-post structures have many characteristics of the Antelope Creek phase houses such as a central depressed floor channel, eastward facing entryway, central roof supports, central hearth, and a raised alter, but lack the more common vertical rock foundation. Village sites are often on high terraces within drainage basins. Primary tributaries have high site densities (Etchieson 1981; J. Hughes 1977). A number of village sites, (i.e., Footprint, Landergin Mesa, Saddleback Ruin, Arrowhead Peak) are on the tops of mesas or on knolls within valleys (Lintz 1986, 1989). Sites are most commonly adjacent to tributary streams, although some occur along major river valleys (i.e., Lintz 1986; Brooks 1989, 2004). Evidence indicates that the subsistence economy was based on hunting, gathering, and farming. Common 


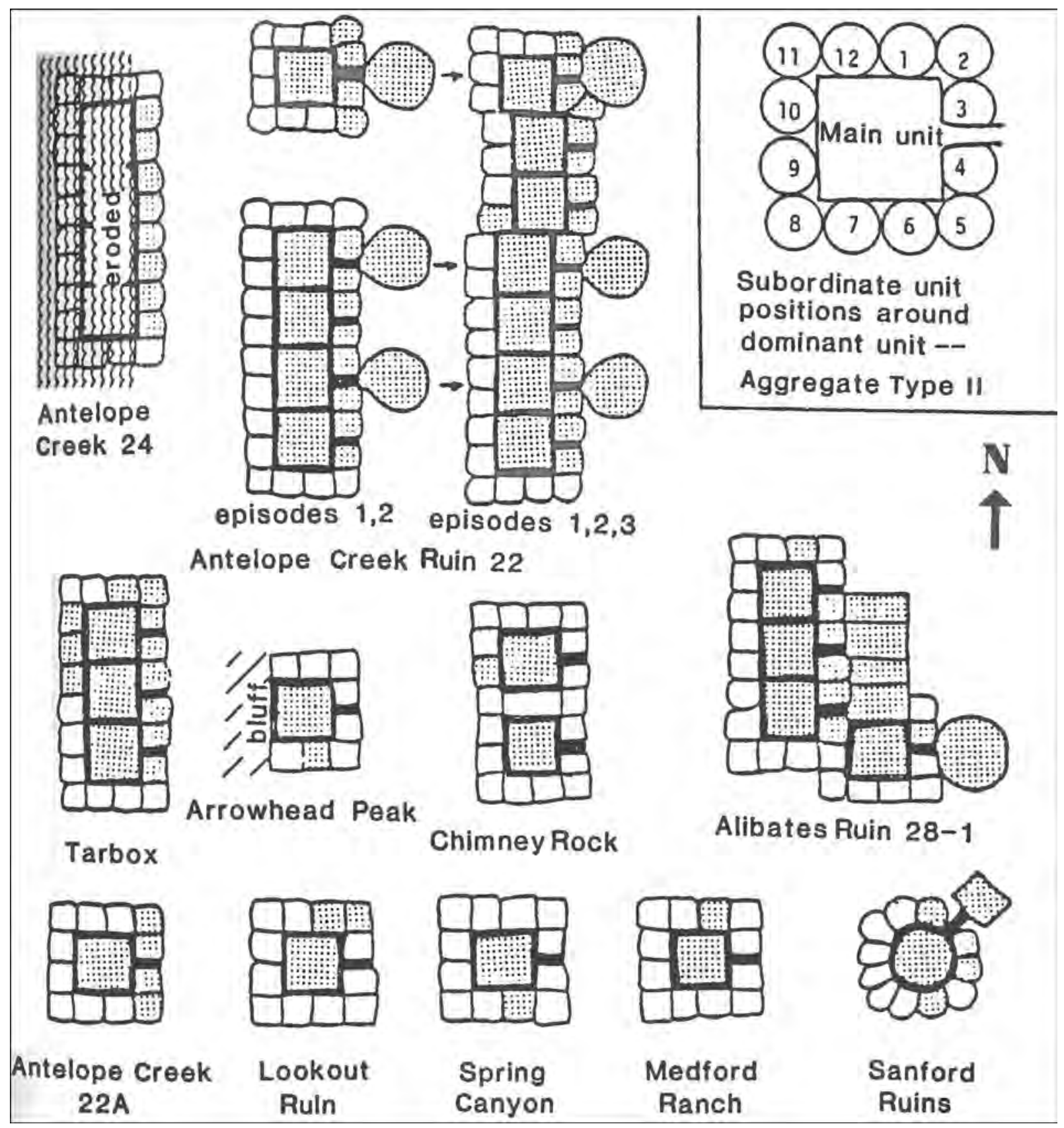

Figure 3-6. Stylized layout of possible and actual aggregate type ii structures (after Lintz 1986, Figure 24). 
cultural material ranges from small, triangular, sidenotched projectile points and grinding implements to cordmarked pottery (Lintz 1986:25; Brooks 1989, 2004).

In addition to the slab-lined semisubterranean houses, slab-lined cists have been recorded at Antelope Creek phase sites (Marmaduke and Witsett 1975; Lintz 1986; Green 1986; Etchieson and Couzzourt 1987; Baker and Baker 2000). These have slight variations in that some have slabs on the floor, others lack this attribute, whereas still others have a central vertical slab (see Figure 3-4). The function of slab cists is still a matter of debate.

\subsubsection{Tool Assemblages}

The Antelope Creek phase tool assemblage is similar in most respects to those of other Plains Village manifestations. It includes triangular, side-notched, and unnotched arrow points; oval or lozenge-shaped bifaces (sometimes alternately beveled); "guitarpick” scrapers or preforms; T-type or pin drills; large, thin end scrapers; flake tools (i.e., edge-modified pieces including gravers); and hammerstones (Watson 1950; Lintz 1978a, 1982, 1986; 2010; J. Hughes 1991; Boyd 1997; Baker and Baker 2000; Brooks 1989, 2004; Duncan 2002, 2006). Ground stone tools include flat grinding slabs and deep ovalbasin metates, small one handed manos, sandstone awl sharpeners, and straight and elbow pipes (i.e., Couzzourt, and Schmidt-Couzzourt 1996:97). Lintz (1986:35) mentions that chipped axes and picks are occasionally present.

Bison bone was fashioned into a range of tools that include tibia and scapula digging implements, squash knives, awls, pegs, beads, rasps, flakers, and bone whistles. Deer antler tines, billets, and metapodial awls have also been recovered (i.e., Lintz 1986; Couzzourt, and Schmidt-Couzzourt 1996; Baker and Baker 2000). Mussel shell scrapers, carved pendants, and shell discs (inlays?) are among the many items reported from Antelope Creek phase sites. Small ceramic discs with holes drilled in them, often referred to as "spindle whorls," have also been recovered (Duffield 1964; Lintz 1986; Couzzourt, and Schmidt-Couzzourt 1996; Brooks 1989, 2004). Almost no detailed analyses have been conducted on these various tools. Most often, tools are referred to by types, sometimes without actual counts, and almost no metric or nonmetric data are presented.

The lithic materials used in the production of the chipped stone tools are dominated by Alibates (Watson 1950; Lintz 1976; Couzzourt and SchmidtCouzzourt 1996; Baker and Baker 2000; Brooks 1989, 2004; Duncan 2002). The core area sites are clustered around the well-known Alibates quarries. Near the Alibates quarry, the tool reduction strategies involve the production of large, flat tabular flake blades, incidental blades and tool performs, or, rarely, prepared bifaces (Bandy 1976; Lintz 1986:33).

\subsubsection{Ceramic Assemblages}

Ceramic assemblages from most excavated Plains Village sites in the Texas panhandle have not, with a few exceptions, been subjected to detailed and/or systematic analyses. The few published exceptions are presented here, to provide a broad understanding of what analyses have been completed and what pottery variation currently exists in the literature. Back in 1978, Lintz (1978a) analyzed a sample of 272 rim sherds from the four excavated sites in the central Oklahoma panhandle: the Two Sisters site, Stamper, Roy Smith, and McGrath, plus the Black Dog Village site in the Texas panhandle towards the eastern end of the core area sites. Only a single rim sherd was from Black Dog Village, so essentially the sample represented the four excavated Oklahoma sites. Lintz discovered that 65 percent had cordmarked or plain rims, 7 percent had diagonal punctuations on the lip, 6.6 percent had a single row of fingernail gouges around the rim, 6.3 percent had pinched lip-rim junctures, and the other 7 percent were represented by dot-punctated lips and rims, diagonal incised lines, lip tabs, or distinctly collared and cambered rims (Lintz 1978a). Although these four northern sites and this ceramic sample reveal a small percentage of decorated rims, it is not clear whether these four sites are representative of the entire Antelope Creek phase.

Ms. Wulfkuhle (1984) conducted an analysis of 210 surface collected ceramic sherds (a 37 percent random sample) from Landergin Mesa. The sample included 21 rim and 173 cordmarked body sherds, 14 tradewares, and 2 miscellaneous. It is the cordmarked sherds that are discussed here. In brief, the rims account for only 12 percent of the sample, and 
were predominantly vertical in stance. Eighty four percent of the sherds are between 40 to $79 \mathrm{~mm}$ in thickness with only 2.6 percent slightly over $10 \mathrm{~mm}$. Based on examination under a binocular microscope at 10 to $20 \mathrm{X}$, the temper was assessed. All sherds contain sand or crushed quartz with ferrous and mica particles in 50 percent. Twenty five percent exhibit pure sand with possible bone in 17 percent. The size of the particles varies from very coarse to fine. Density of temper was assessed at medium to coarse in 80 percent. Eighty five percent were poorly sorted. Color of the interiors and exteriors were assessed. The colors indicate that the composition of the clays and firing conditions were fairly consistent. The cordmarked exterior surface finishes combined with the extensive smoothing of the interiors obliterated any evidence of the method of building the vessels. No coil breaks were identified. Cordmark orientation was vertical in the 16 percent that allowed direction to be determined. Only 1.7 percent show cord impression in two different directions. Another 2.8 percent show signs of decorations with two rims and one body sherd with definite fingernail punctuations, and two other body sherds with possible punctuations or pinching (Wulfkuhle 1984).

Some 13 years later, Lintz (1997) reported the results from the 1959 Norpan Excavations of a common Antelope Creek phase single-room structure at the Cottonwood Creek Ruins (41HC141) in Hutchinson County at the northern end of the core area. In that report, Lintz presented details concerning the limited ceramic assemblages (5.6 percent of the total artifact assemblage). He divided the 80 thin cordmarked sherds (76 body and 4 rims) tempered with sand into various vessel batches (1 through 7) based on the different exterior surface treatments and different rim treatments. The exterior treatments varied from coarse, to indistinct, to fine cordmarked impressions and clear fabric impressions. Many sherds were coated with carbon residue that indicated their use as cooking vessels. Lintz (1997) presented descriptions of the vessel batches, color ranges, macroscopic observations of temper, and cord thicknesses, and some metric attributes. One collared rim was identified and Lintz pointed out that similar specimens have only been reported from the Roper site (41HC6), also in the core area, but collared rims are more common at Buried City along Wolf Creek and further north in Kansas and Nebraska.

Three different rim sherds from the Cottonwood Creek Ruins were previously subjected to petrographic analysis as part of a larger study (Lintz and Reese-Taylor 1994). The three included a rim from coarse cord impression vessels 1 (FS-104.1) and 2 (FS-109.3), and a rare collared rim (FS111.4) from Vessel 4, which bore narrow, shallow cordmarking. The results from the petrographic study indicate that the Cottonwood Creek Ruin collared rim had somewhat higher percentage of clay (75 percent) and pores (5 percent), but lower nonplastic temper content (20 percent) than either of the uncollared rims. All three rims had similar subangular, coarse sand temper. The collared rim had higher quantities of quartz (85 percent) and mica (10 percent) and lower quantities of alkali feldspar (5 percent) than the two other rims (Lintz 1997:60). The temper in the collared rim indicates it was not produced locally, and may have been made in the Buried City region. The uncollared rims show similar texture to sherds from Alibates Ruin (41PT11), Antelope Creek Ruin 22 (41HC23) in the Antelope Creek phase core area, and most sherds from the Kit Courson site (410C43) at Buried City.

Another pottery analyses was conducted on a selected ceramic assemblage from a couple of sites at Buried City (D. Hughes 2001; Lintz and Reese Taylor 1995). The Buried City assemblage will be elaborated upon below.

What is often summarized in the current literature concerning the ceramic assemblages from various Plains Village sites in the Texas panhandle stems from general observations from selected hand samples and broad overviews of assemblages.

Most early work at Plains Village sites in the Texas panhandle yielded what is generally referred to as cordmarked ceramics (i.e., Holden 1932; Studer 1934; Johnston 1939; Krieger 1949; Watson 1950). Besides the large globular jars and infrequent clay beads, miniature pots are mentioned (i.e., Lintz 1986; J. Hughes 1991; Boyd 1997; Brooks 1989, 2004). Suhm and Jelks (1962:15) provide a basic description of Borger Cordmarked pottery as having 
temper of crushed quartz, sand, mica, and crushed bone. The texture is usually quite compact and hard, with sharp broken edges, but thicker vessels may be friable. The colors are mostly dark shades of gray and brown, but some are orange-brown and others nearly black. A light red-wash occasionally occurs on the interior. Sherd cores are dark gray to black. Soot and grease stains are common. The interior surfaces are poorly to fairly well smoothed, but bumpy, while exteriors bear overall cordmarking, which is sometimes smoothed or mostly obliterated. The cordmarkings are generally orientated vertically. In addition to the cordmarkings, incising and fingernail punctuations are present, albeit rarely. Impressions of fine cords cover the entire exterior of vessels, and are almost always placed vertically on the body, neck, and rim. Occasionally, the alignments of cord impressions tend to criss-cross one another. In some instances, cordmarkings on rims are smoothed over and a single deeply incised line or a row of fingernail punctations encircles the vessel at the neck-body juncture. Lips may be deeply notched on the outer edge (Suhm and Jelks 1962:15).

Suhm and Jelks (1962:15) state that vessel walls range from 2 to $12 \mathrm{~mm}$ in thickness, but that many are quite thin, from 2 to $4 \mathrm{~m}$, with a tendency for vessels to be thinner toward the bottom than the top. Lips are rounded or flat and flush with the rim. The base is convex with no distinguishable basal section. Vessel shapes are mostly globular to slightly elongated jars (see Figure 3-2). Rims generally meet the body at a definite angle and are vertical, although some rims slope inward or slightly outward (Figure 3-7). Often the body and rim merge in a gentle curve with the mouth considerably smaller in diameter than the body. Vessel size is on the whole rather uniform, with restored vessels ranging between 20 and $30 \mathrm{~cm}$ in total height with rim sections 3- to 6-cm-high. Bodies range from 23 to $31 \mathrm{~cm}$ in maximum diameter, and vessel mouths have diameters between 14 and $22 \mathrm{~cm}$. Lugs and handles are apparently absent (Suhm and Jelks 1962:15).

Rim treatments are quite variable and include plain, cordmarked, diagonal punctations on the lip, finger pinched lip-rim junctions, a single row of fingernail gouges, diagonal incised lines, and sometimes, collared and cambered rims (Lintz 1978a; Perttula and Lintz 1995). In those sites studied, such as Two Sisters, Stamper, Roy Smith, and McGrath; Black Dog Village; and Cottonwood Creek, decorated rims and necks of cordmarked ceramics are a minority, generally less than 20 percent of the total.

The vessel production sequence involved a series of perceived steps or processes that included collecting the necessary raw materials (clay and temper/ additives), mixing the temper with the wet clay and building the base, constructing the main body, and then adding the rim. In some instances, an extra fillet/rope of clay may have been added to the rim to produce a collared rim.

Once the vessel was constructed and still in the wet stage, decorations could be added, generally, in the broader Plains Village Tradition, on rim and lip areas and seldom below the shoulder. When finished, the completed vessel was allowed to slowly dry and, once dry, it was fired. Firing is most often conducted in an open hearth with wood. Firing was done in either an oxidizing or reducing atmosphere thus influencing the color of the finished vessel. Unevenness in surface color of pottery reflects differences in the length and intensity of firing, plus fluctuations in firing atmosphere that occur with shifting winds, direct contact with flames, and or fuel materials (Shepard 1971:217). Clear light-hued colors such as yellows, bluff, and reds indicate the pottery was fired in an oxygen rich, or oxidizing, atmosphere. Gray colors generally indicate the vessel was fired in a reducing or oxygen-starved atmosphere, but other factors could contribute to the final color (see Shepard 1971 for a lengthy discussion of firing).

Since the original definition provided by Suhm and Jelks (1962), various researchers working in the Texas panhandle have stated that Borger Cordmarked vessels were tempered with sand and grit (undefined by original researchers), with occasional additions of crushed quartz and bone (Duffield 1964:46; Wulfkuhle 1984; Lintz 1997). Crushed quartzose rock with naturally occurring mica, crushed plagioclase feldspar with mica, or quartz and mica are the majority of temper in Borger Cordmarked (J. Hughes et al. 1977; J. Hughes et al. 1978). Perttula and Lintz (1995) indicate the jars 


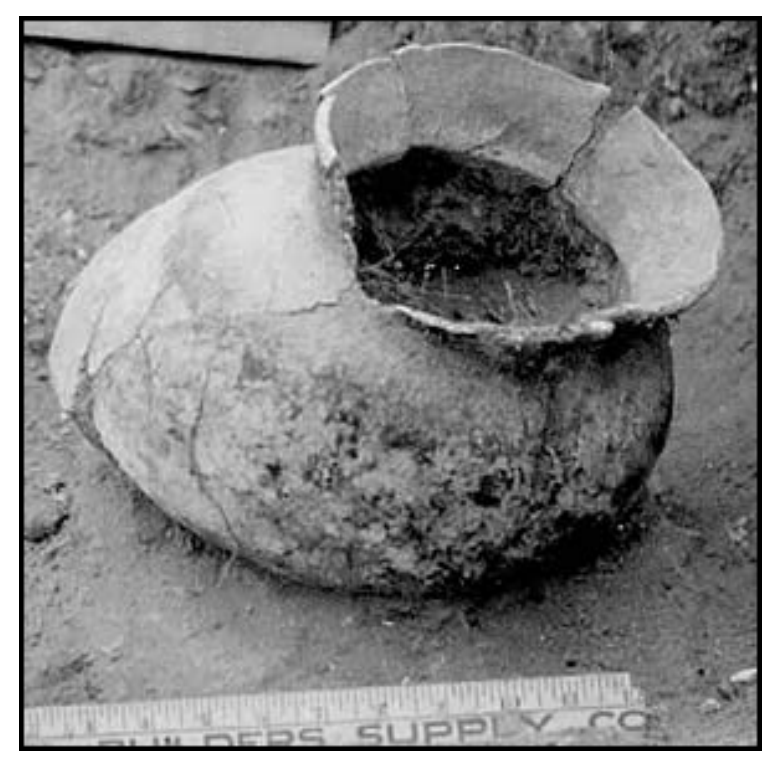

Figure 3-7. Example of cordmarked vessel with flaring rim and weak shoulder from Buried City.

were tempered with crushed rock, sand, and limited amounts of mica, bone, and other materials.

Few restored vessel are available. One restored vessel is from Two Sisters (Figure 3-8; Duncan 2002). Although a number of pictures of complete or restored vessels are presented in the literature, very few details (i.e., metric and nonmetric attributes) are presented concerning those vessels, though they provide impressions of the overall size, shape, and volume of the pots. Most shapes are globular with slight differences in the positionings of the rim and neck. Most volumes are projected at 13 to 19 liters. The volume for the vessel in Figure 3-8 is 17.3 liters (Duncan 2002, 2006).

Lintz and Reese-Taylor (1997) present a detailed and technical analysis conducted on ceramic sherds from Antelope Creek phase sites. Their study was a petrographic analysis of 22 collared and uncollared rim sherds from six sites used to evaluate the relative homogeneity of ceramic technology of the Plains Village populations. For comparative purposes, they included sherds from four sites, namely, Roper (41HC6), Cottonwood Creek (41HC141), Antelope Creek Ruin 22 (41HC23), and Alibates Ruin 28 (41PT11) in the Antelope Creek phase core area; three sherds from the Kit Courson site (41OC43) in Buried City; and four collared sherds from site 25NC29, a central Nebraska Itskari phase site. Two distinctly different ceramic paste technologies were detected.

This finding indicated to Lintz and Reese-Taylor (1997) that the cultural unit intrusion hypothesis into the Texas panhandle is not warranted. The uncollared rim sherds from four Antelope Creek phase sites are typically tempered with igneous (granitic family) materials. Whereas, three collared sherds from the Kit Courson site of the Buried City complex (410C43/64, 188, and 329.6), the collared sherd for Cottonwood Creek (41HC141), and three collared rim sherds from Roper (41HC6-542, 543, and 544) are tempered with sedimentary (sand) materials. Lintz and Reese-Taylor (1997) interpret these data to indicate that the collared sherds from Roper may relate to the Buried City complex. Unfortunately, no comprehensive, detailed ceramic synthesis has been done for the Antelope Creek phase/Middle Ceramic period in the Texas panhandle (Lintz 2010).

Lintz (2005) reported on a small, highly fragmented assemblage of 34 sherds from a single Antelope Creek phase house at 41PT109. He characterized it through macroscopic observations and metric measurements, and provided horizontal distributional data, compared sherd densities at 41PT109 to other Antelope Creek period sites, offered insights into the ceramic manufacturing technology, and interpreted 
the age and cultural affiliation. He then provided comments on the variability of the cordmarked pottery from slab-architecture sites in the Canadian River valley of Texas panhandle. The 41PT109 assemblage only includes 2 rim sherds, 2 neck sherds, 2 basal sherds, and 28 body sherds. All exhibit cordmarked or partially obliterated cordmarked exteriors. Ninetyseven percent are less than 2-by-2 $\mathrm{cm}$ in diameter. A minimum of two vessels are represented. The sherds range in thickness from 3.1 to $8.9 \mathrm{~mm}$ with an average of $4.64 \mathrm{~mm}$. The thicker sherds tend to be at the base (Lintz 2005). A possible basal sherd broke along coil junctures. Lintz (2005) stated that this cordmarked assemblage contains sparse temper, which was a combination of grit and grog. In general, the small assemblage contained no painted, colored, plain, or decorated sherds. This is likely the first time that grog has been mentioned as a tempering agent in the Antelope Creek phase ceramic assemblages.

Although nearly all sherds/vessels generally reported from the Antelope Creek phase assemblages are assigned to the Borger Cordmarked type (Lintz 1976, 1986, 1989, 1997, 2005; Brooks 1989, 2004), other Plains Village assemblages in Texas such as that from Buried City (see discussion below) also include other unnamed wares including plain/ smooth surface vessels and collared-rim vessels reminiscent of the Central Plains Tradition. A few Antelope Creek phase sites such as Cottonwood

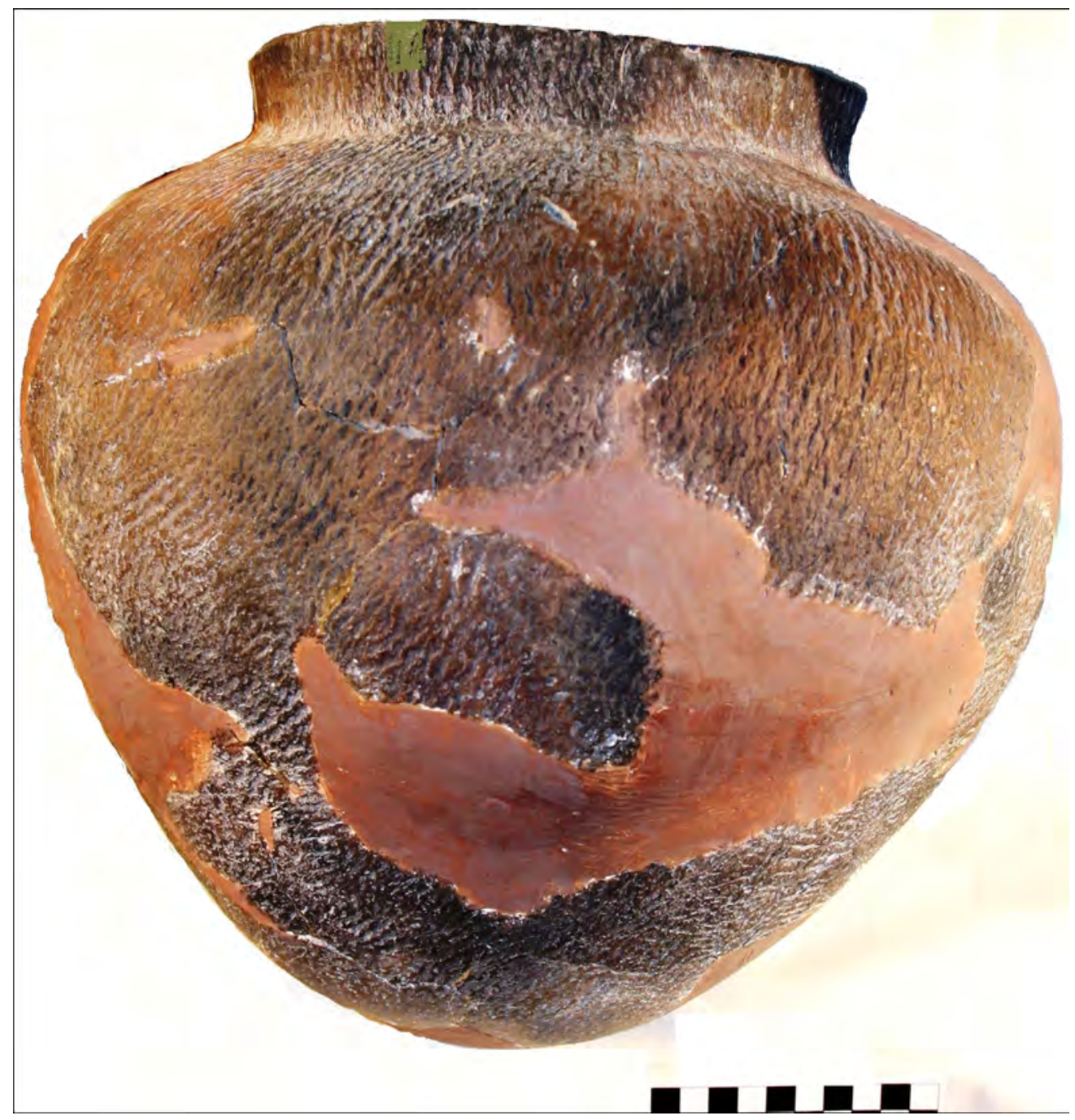

Figure 3-8. Reconstructed vessel from Two Sisters (34TX32). Photograph taken by R. Drass, scale in $\mathrm{cm}$ 
Creek and Roper in the Texas panhandle, and Stamper, Two Sisters, McGrath, and Roy Smith in the central Oklahoma panhandle, are known to have a few decorated and/or collared rim sherds (Lintz 1976, 1997; Lintz and Reese-Taylor 1997), but the lack of ceramic analyses from most Antelope Creek period sites in the region has not defined the frequency of their occurrence or revealed the full range of styles, decorations, or tempering agents.

Instrumental neutron activation (INA) analysis on 75 Antelope Creek phase sherds from three sites (41PT109, Landergin Mesa [41OL2], and Alibates Ruin 28 [41PT11]), plus 15 natural clay samples, has provided intriguing results (Meier 2007). The initial results, based on the Principle Component analysis, indicated that all sherds were chemically very similar. One reason for the general overlap may be the similar nature of the sherd composition, clay, and temper. However, the elemental analysis separated these 75 sherds into five chemical groups (Group 1, 2, 3, 4, and 5, Meier 2007). The groups were generally associated with the natural clay samples analyzed from near the selected archeological sites. Four of the five chemical groups contained sherds from at least two of the three archeological sites sampled. Only chemical Group 3 contained sherds from a single site, Landergin Mesa, which indicate the homogeneity of that group. Apparently, the clay used to manufacture the vessels and/or the actual vessels from these three archeological sites were transported throughout the region.

The INA analysis conducted by Meier (2007) and the petrographic analysis by Lintz and ReeseTaylor (1997) are the only two technical analyses conducted thus far on the many Antelope Creek phase ceramic assemblages. There is a definite lack of detailed information concerning the dozens of Antelope Creek period ceramic assemblages from across the broad region. Lintz (2005) stated that no comprehensive, detailed ceramic synthesis exists for the Antelope Creek phase, or for the preceding period. Although a couple of technical analyses have been conducted (Lintz and ReeseTaylor 1997; Meier 2007), much more in-depth and geographically extensive analyses are needed if cultural patterns and interactions are to be identified.

\subsubsection{Subsistence Activities}

The Antelope Creek phase people had a mixed economy based on hunting, gathering of wild plants, and cultivation (Duffield 1964, 1970; Keller 1975; DeMarcay 1986; Dean 1986; Duncan 2002, 2006; Brooks 1989, 2004; Meissner 2005; Dering 2005b; Lintz 1990, 2004, 2009). However, this is a broad and generalized statement, and there are very limited published data, from very few sites, that provide more in-depth information or details on economic patterns. Unfortunately, small, charred plant remains have only been sporadically targeted for recovery through flotation over the last 30 years or so. Since a high percentage of Antelope Creek phase sites were excavated prior to the 1980's, when flotation became more widely implemented in archeological investigations, specific information concerning the types, frequencies, and roles of plants, both wild and domesticated, in the subsistence strategy is lacking for most Antelope Creek phase sites. One of the few exceptions is a macrofloral assemblage recovered from a large 1-m-wide by 1-m-deep (length unknown) pit/midden immediately south of slab-lined Structure 3 at Black Dog Village (Keller 1975:22). One sample from one feature yielded 11 different wild plant species and two cultigens. Although the report does not clearly state that these species were burned, it is assumed that all reported species were charred, thus indicating human use/processing. The two cultigens identified were specimens of beans (Phaseolus vulgaris, $N=184$ ) and corn (Zea mays, $N=156$ ). The noncultigens include Indian mallow (Abutilon sp), prickly pear (Opuntia sp), plum (Prunus sp), wild buckwheat (Erigogonum sp), grasses (Gramineae), compositae, sedges (Cyperus sp), and Coreopsis sp. (Keller 1975:22). This was one of the first analyses that demonstrate the diversity of plants used during this period.

Recent investigations at village sites in the Texas and Oklahoma panhandles that employed systematic flotation of sediments followed by macrobotanical analyses have yielded more data on plants used by Antelope Creek phase communities (Dean 1986; Duncan 2002). Charred remains of domesticated plants such as corn (Zea maize), beans, and squash (Cucurbita sp) have been found at Antelope Creek phase sites, though the degree of reliance on these 
crops has yet to be determined (Keller 1975; Lintz 1986; J. Hughes 1991; Boyd 1997; Duncan 2002, 2006; Brooks 1989, 2004; Dering 2005b; Boyd 2008). Plains Village sites in western Oklahoma have also yielded similar evidence of cultivated crops, plus little barley (Hordeum pusillum), maygrass (Phalaris caroliniana), knotweed (Polygonum erectus), marshelder (Iva annus), sunflower (Helianthus annuus), and dropseed (Sporobolus sp.; Drass 2008). Extrapolation of macrobotanical data from western Oklahoma, combined with the limited results from a few village sites in the Texas panhandle, reveal considerable potential for detailed macrobotanical studies at village sites. Farming is postulated through the establishment of structures close to fertile soil and reliable water sources, and many village sites along rivers and tributary systems are suspected to represent farming communities (Lintz 1986; Brooks 1989:75; 2005; Brosowske 2005; Brosowske and Bevitt 2006; Drass 2008).

At present, the gathering and use of wild plants is virtually unknown at Texas panhandle village sites, with a few exceptions. Results from the limited flotation of five samples totaling 7.1 liters conducted at 41PT109 revealed no wild plant remains and only one horticultural product: corn/maize (Dering 2005b). In the limited information available, noncultivated plants such as acorns, hackberry, mesquite, plums, prickly pear, mallow, cattail, and persimmons have been identified (Keller 1975; Green 1967; Dean 1986). Unfortunately, small microfossil remains from plants (i.e., pollen, phytolithis, starch grains) have not often been targeted and a great deal of potential information pertaining to the use of wild plants is probably going undetected.

In relation to gathering, mussel shells are mentioned at a number of sites (i.e., Antelope Creek Ruin 22 and Alibates Ruin 28; Baker and Baker 2000); the four central Oklahoma panhandle sites (Duncan 2002). It is not clear if these were collected as a food resource or for use as tools.

Concerning hunting, large mammals found in the grasslands, uplands, and breaks regions, such as bison, deer, and antelope, were procured. The more visible faunal remains from excavated sites have provided information on the various meat resources sought and utilized. However, the early investigations were not consistent or systematic in collecting and analyzing faunal remains, leaving hunting practices at most investigated village sites uninvestigated. Duffield (1970) completed the most in-depth study of faunal remains through comprehensive analysis of fauna from 11 sites (Alibates Ruin 28 [41PT11] and 30 [41PT31], Antelope Creek Ruin 22 [41HC23] and 24, Canyon Club Cave, Conner [41HC7]; Melford Ranch [41HC10]; Picket, Roper, Sanford and Spring Canyon [41HC20]). His analysis involved identifications of skeletal elements and species, study of butchering practices, and paleoecological reconstruction. He identified 38 species of mammals, 29 species of birds, 8 species of reptiles, and 2 species of fish from the 11 sites (Duffield 1970:252). Fish remains $(N=32)$ are also mentioned as present at Black Dog Village (Keller 1975:21), Two Sisters ( $N=7$, Duncan 2002), and Roy Smith (fragments, Schneider 1969). Faunal analyses from Landergin Mesa (DeMarcay 1986), Two Sisters (Duncan 2002), and 41PT109 (Meissner 2005) have also contributed to our understanding of Antelope Creek phase hunting and butchering practices.

Faunal analyses at these few sites indicate that bison was the most important meat resource, although a variety of other game animals including deer and antelope are represented at most sites (Duffield 1964, 1970; Lintz 1986; DeMarcay 1986; Meissner 2005; Duncan 2002, 2006). The evidence indicates that bison were economically exploited not only for meat, but for their bones, grease, hides, and other valuable commodities as well. Bones were broken to retrieve the marrow, then crushed and boiled to obtain the bone grease, both of which can be consumed (Duffield 1970; DeMarcay 1986; Duncan 2002). The faunal remains often appear as small bone splinters reflecting intensive processing. It is not always clear if the splinters reflect cultural activity or natural weathering processes. Hides were made into clothes, components for house construction, and containers. Bison products were immediately consumed, potentially traded to other groups, or stored for later use. The processing of bison was sufficiently important and intensive that their bones tend to dominate the faunal assemblages from village sites in this region (Brooks 1989:75; Drass 1997:43; Duncan 2002, 2006). 
Duffield (1970:241) found that bison were more abundant in the older sites, and antelope were relatively less abundant. According to his data, a major change in bison frequency occurred between 650 and 600 B.P. (unclear if calibrated A.D. 1300 and 1350). During this 50 year period, the percentage of bison at his analyzed sites dropped from 80 percent to 58 percent (Duffield 1970:241). Duffield does not attribute the change to human selection patterns but to climatic change. He sees the gradual increase in the use of antelope over time as an indication the region was undergoing a drying trend. Caution should be used when considering Duffield's data, as it represents only a small number of the total excavated sites.

The presence/absence of specific bison elements at various sites indicates that, in general, the axial skeleton was left at butchering sites (Duffield 1970). Duffield (1970) determined that most long bones and many smaller elements were broken into small fragments and suggested that this represented the production of bone grease. Bison foot elements were present at all sites analyzed, and sometimes these were fragmented and burned.

The central Oklahoma panhandle sites have yielded diversity in game animals, as well. The early report on the Stamper site by Watson (1950) reports bones of bison, deer, jackrabbit, cottontail, turtle, prairie dog, duck, and peccary. The more recent report from Two Sisters reveals a similar diversity of animals being exploited, with bison, white-tailed deer, pronghorn, jackrabbit, cottontail rabbit, prairie dog, and land tortoise all represented (Duncan 2002). Apparently, no one animal species was relied upon to the exclusion of other species.

Lintz (2009) determined that avian remains are also part of the faunal assemblages at many Middle Ceramic sites on the Southern Plains. Sadly, only 25 percent of the 41 Middle Ceramic faunal assemblages Lintz (2009) lists have been thoroughly analyzed. Despite the lack of faunal analysis at most sites, bird bones are mentioned or identified in at least 14 sites including three of the four excavated Antelope Creek phase sites in the central Oklahoma panhandle; Two Sisters, Stamper, and Roy Smith, plus at least five sites in the Antelope Creek phase core area. Hunting and collecting strategies were such that all types of game resources were targeted.

The more abundant and easily observed faunal assemblages are the primary basis for our current understanding of the village subsistence pattern. Despite the lack of detailed faunal and floral analyses from most sites across the region for this time period, a great diversity of faunal and floral species is known to be represented. The diversity reflects a broad-based hunting and collecting economy in which a variety of species from diverse environmental niches were utilized. Lintz (2009) argues that the full range of subsistence resources has yet to be identified. This is presumably the case, considering how few features have been sampled for flotation and macrobotanical analysis, and the general paucity of plant microfossil analyses.

With the lack of detailed faunal and floral analyses, for the most part seasonality of various site occupations has not been defined. In the absence of clear indications of seasonality of structures or sites, it is not clear if relatively large villages and single structure sites represent seasonal variability in site use, or if the larger sites represent year-round occupations. Seasonality data may contribute to a better understanding the differences in faunal and floral assemblages between sites.

Stable carbon and nitrogen isotopes, strontium, and zinc studies were conducted on 29 individual human skeletons from 5 Antelope Creek phase sites (Antelope Creek 22 and 22A and Alibates Ruin 28 I and 28 II) all in the core area. This included at least 8 males and 12 females. The overall results indicate little change in diet over time among Antelope Creek phase populations. However, a significant difference was determined in the mean stable nitrogen isotope ratios between the male and female individuals, which indicates gender-related differences in dietary patterns (Levendosky 1987; Habicht-Mauche et al. 1994). On average, the male remains were more positive in terms of nitrogen, whereas the females revealed a higher coefficient of variation, and indicate a much greater range of variability in individual diets. The $\delta^{15} \mathrm{~N}$ values for both plant and animal foods are roughly equal. The $\delta^{13} \mathrm{C}$ values yielded an overall mean of $-8.0 \%$ with a standard deviation of $1.0 \%$ 
and a coefficient of variation of 12.6 percent. The high coefficient of variation indicates that the diet was varied amongst individuals. The carbon isotope analysis indicates that on average, roughly 90 percent of the Antelope Creek population diet was from $\mathrm{C}_{4}$ resources (i.e., bison, corn, prickly pear cactus, sand dropseed, amaranth). Habicht-Mauche et al. (1994) interpreted the results as indicating no change in the relative ratio of $\mathrm{C}_{4}$ and $\mathrm{C}_{3}$ components in Antelope Creek population diets between Lintz's (1986) early and late subphases.

The analysis of remains of at least 21 individuals from 3 burial pits and a skull pile with at least another 10 individuals from the Footprint site (41PT25) appeared to indicate a nutritionally balanced diet and supports that children consumed a diet of soft, unprocessed foods (Lewis 1998). This was revealed through paleopathological analysis and nutritional inferences. Lewis (1998) interprets the dental pathologies to indicate an overall dietary pattern more typically associated with huntergatherers than horticulturalists. Since these results come from a very limited sample of individuals, it is impossible to determine whether these individuals represent the entire Antelope Creek population or are a local anomaly.

\subsubsection{Burial Customs and Biological Characteristics}

Human burials have not generally been systematically targeted for excavations and most human remains have been discovered by chance during excavations of house/room structures. Burials have been found beneath house floors (i.e., Antelope Creek Ruin 22A, at Footprint), in the fill of house structures (i.e., Antelope Creek Ruin 22, Alibates Ruin 28), or as isolated interments (Baker and Baker 2000; Couzzourt and Schmidt-Couzzourt 1996). The majority of burials reported by Baker and Baker (2000) were in the fill of rooms, which indicate they were interred after abandonment of the houses. At Antelope Creek Ruin No. 22, Room 10 contained a burial within a stone cyst, which had been dug through the floor after the structure had burned. Charred material was found in the matrix surrounding the burial (Baker and Baker 2000:35). Also at Antelope Creek Ruin No. 22, Room 22 yielded six burials, found at various levels, from roughly $45-\mathrm{cm}$-above the last floor to 60 -cm-below the floor (Baker and Baker 2000:58). This might be considered a small cemetery, insofar as the burials were repeatedly interred over time.

At Alibates Ruin 28, most bodies were shallowly buried (less than $60 \mathrm{cmbs}$ ) in pits and often covered with large rocks or cairns (Lintz 1986; Baker and Baker 2000). The bodies were buried individually in primarily flexed or semiflexed positions (Lintz 1986). Roughly 60 percent of the individuals lacked any type of mortuary offering regardless of the individual's age or gender (Baker and Baker 2000). Lintz (1986:41) has noted that associated grave goods are scarce in Antelope Creek phase burials, and moreover, he has tabulated the different ages and sexes and determined that buried individuals were not all accorded the same treatment (Lintz 1986). A few grave goods, made of locally manufactured items, were associated with all ages and both sexes, with a slightly higher frequency with adults as opposed to children. Males tended to be associated with utilitarian objects such as arrow points and ceramic vessels, whereas females tended to be buried with digging sticks (Lintz 1986:171-174). In general, Lintz (1986) determined that prepubescent children were interred with grave goods about 46 percent of the time, whereas adults received grave goods about 53 percent of the time. He interpreted the data to indicate a matrilocal society with ascribed or inherited positions, but little or no major status ranking. He goes on to state that the mortuary offerings show parallels with the patterns recorded ethnographically for the Wichita Indians of western Oklahoma (Lintz 1986).

The excavations at the Footprint site (41PT25) encountered three house structures, with human remains only in the floor of Room 1 (Green 1986), a nearly square structure (6.4-by-6.1 m) with part of the vertical slab foundation still present, a central hearth, and a long, east facing entry way. The majority of human remains were interred in three burial pits (A, $\mathrm{B}$, and $\mathrm{C}$ ) near the outer margin of the room. Each pit held multiple individuals, and there was an isolated pile of 10 skulls and additional human remains scattered across the floor of the structure. Green (1986) interpreted the burial pits as having been created after the floor was plastered; subsequently, the room was reoccupied after the bodies were interred. Looters 
disturbed these pits and removed parts of individual skeletons, so there is some question as to what was in situ and what was not (Green 1986). A complete Borger Cordmarked vessel was in direct association with an adult skeleton in Burial Pit B. Lewis (1998) conducted studies of the commingled remains of at least 21 individuals from the three pits and 10 individual crania from the skull pile. The 10 skulls in the pile may represent decapitated individuals, but it is not clear if these pertained to the population that occupied the site, or were, rather, trophy skulls taken from another group of people. Clearly, some individuals were intentionally buried in the pits inside the original house structure.

An actual cemetery (LMRA242, no trinomial number) with at least six individual interments was discovered at Blue Creek and yielded four intact human burials, plus evidence of two vandalized burials (Couzzourt and Schmidt-Couzzourt 1996). This cemetery is on a tributary on the northern side of the Canadian River and lies between two sites with habitation structures. The human remains represent only young people: an infant, a toddler, and perhaps two adolescents. The individuals were buried in pits that were covered with rock cairns. The actual burial pits were difficult to distinguish, but were generally oval in outline with long axis's between 60 and $90 \mathrm{~cm}$. These small pits accommodated semiflexed bodies placed on their sides. Feature 1, contained the remains of a child less than five years old, was accompanied by some 80 fragments (only 2 rim sherds) of a Borger Cordmarked vessel scattered throughout the pit as intentional grave offering. Similar sherds were also in Burial/Feature 4, an adolescent roughly 13 to 15 years of age. Washita points were recovered from Burial/ Feature 3, another adolescent who was 10 to 12 years of age. Feature 4 also yielded the tip of a bison tibia digging tool. Thus, three of the four burials contained grave goods.

Obviously, the burial pattern or means of disposing of the dead varied, with bodies buried in rooms, outside rooms in midden areas, on or above abandoned rooms, under rock cairns, and in some cases, in small cemeteries (i.e., Blue Creek or Big Blue Creek; Coetas Ruin; Sanford Ruins; Lintz 1986; Couzzourt and Schmidt-Couzzourt 1996; Summers 1997; Baker and Baker 2000). The age and sex of the individuals also varied. A critical aspect of the recovered bodies concerns their affiliation and actual chronological age. Few burials have been directly radiocarbon dated leaving questions as to how old the burials are. Presently, it is not clear if all these individuals represent the same Plains Village group(s), other outside groups, or a mix of populations.

Although very limited data has been published on the individual human skeletons examined thus far, some general biological characteristics for the Antelope Creek populations are discernible. Brooks (2004:335) presents a summary statement of the most recent interpretations of biological data as determined by D. Owsley's analyses (unpublished). The Antelope Creek people were round-headed with a moderate cranial vault. They were of moderate height with few distinguishing characteristics and did not exhibit characteristics of a group under severe nutritional stress (Owsley's comments in Brooks 2004:335). The men exhibited arthritic degeneration in the arm joints. The teeth show very little evidence of dental problems. The biological characteristics studied by D. Owsley indicate little biological continuity between Antelope Creek phase and the earlier Woodland populations or even with other Southern Plains village populations such as the Washita River phase or groups in the Central Plains (Brooks 2004:335). Consequently, the Antelope Creek populations probably represent a distinctive biological group. Their origin is unknown and much additional research is required to answer this important question. The current data indicates that Southern Plains societies and the Central Plains societies were contemporaneous (Brooks 2004).

The Antelope Creek phase is generally thought to have developed from the earlier Lake Creek/ Woodland complex (J. Hughes 1991) and to represent the southwestern most extent of the Plains Village Tradition. However, evidence for a direct development from the Woodland period is currently lacking, and is not supported by the available biological data. Very few well-documented and chronometrically dated Woodland occupations are represented in the current literature. Therefore, the specific characteristics of Woodland manifestations supported by solid radiocarbon dates have yet to be clearly defined. Lintz (1986) pointed out flaws in each of the origin 
theories of immigration and acculturation processes of cultural transmission. Previous suggestions of immigration of groups is not supported by the timing of adjacent events and/or the constellation of traits form the purported source areas do not match the Antelope Creek phase traits. The distinctive Antelope Creek phase architectural and material assemblage has been attributed to the adoption of Southwestern ideas by an indigenous group at the time of its transformation from the Plains Woodland to the Plains Village stage. A limited and preliminary petrographic study of collared and uncollared rim sherds from six Plains Village sites indicates at least two separate ceramic paste technologies (Lintz and Reese-Taylor 1997). This indicates to those authors that the cultural unit intrusion hypothesis into the Texas panhandle is not warranted (Lintz and Reese-Taylor 1997). That is, the presence of two technologies in the region do not support that groups from adjacent areas moved in and settled this region. The Antelope Creek phase populations were relatively unique in their use of contiguous masonry structures, and this may reflect local attempts to copy Puebloan architecture (Lintz 1986). No single southwestern district can be identified as the source of the inspiration for the architecture, although some Pueblo II period sites may have had influences (Lintz 1986:253). Intertribal marriages may be one mechanism responsible for the introduction of Southwestern ideas and goods. Until detailed skeletal morphology and chemical analyses and comparisons are completed, the cultural exogamy as a mechanism of diffusion cannot be supported.

\subsubsection{Regional Trade/Exchange}

In general, trade in the Southern Plains Village Tradition sites centered around the procurement and/or production of bison, corn, and lithic materials (e.g., Alibates silicified dolomite, Edwards chert, Florence-A, Frisco, Niobrara jasper/Smoky Hill silicified chalk, Tecovas jasper) and trading surpluses to neighboring groups. In exchange for these items, outside groups, such as the Southwestern Puebloans and eastern Caddoans, would offer ornaments made from bone, marine shell, exotic stone, as well as ceramic wares, pipes, turquoise, and obsidian, among other items (Vehik and Baugh 1994).

Trade relations, especially with Southwestern groups, appear extensive in some sites, especially in the latter half of the phase when Lintz $(1986,1991)$ suggests that climatic conditions had severely deteriorated. Exotic trade materials from the Anasazi populations in central New Mexico include painted pottery, obsidian, stone pipes and possibly tobacco, marine shells, and turquoise jewelry that most likely accompanied food from trading partners in wider regions (Lintz 1986; J. Hughes 1991; Boyd 1997; Brooks 1989, 2004; Brosowske 2005). Olivella shell beads are sometimes recovered (Couzzourt and Schmidt-Couzzourt 1996:101: Baker and Baker 2000). The majority of goods exported by the Antelope Creek phase people are thought to have included Alibates agate, bison hides and meat, pemmican, and perhaps tobacco (Lintz 1990; Boyd 1997; Brosowske 2005). Baker and Baker (2000) report that a number of the excavated rooms contained caches of "Amarillo" (Alibates) flint tools, including scrapers, and flakes. Baker and Baker (2000) report that 24 percent of the chipped stone implements recovered from the excavations of Antelope Creek Ruin No 22 were snub-nose end scrapers. At Alibates Ruin No. 28, 48 percent of the chipped stone implements from excavated rooms were scrapers. Also, excavated refuse Areas 2, 3, 6, 7, and 8 yielded 1,486 snub-nose scrapers (Baker and Baker 2000:145, 306-312). These high percentages and large numbers seem far too excessive for only on-site tasks, implying that scrapers may have been produced as a trade item, as well as tools for local use. Most prehistoric quarry pits at the Alibates Flint Quarries National Monument in the Antelope Creek phase core area, are assumed to have been used during this period (Brosowske 2005), though conclusive supporting evidence is lacking.

Lintz (1986:335; citing Baker and Baker 2000) reports significant variability in the occurrences of obsidian between some sites. As an example, at Alibates Ruin 28, only 13 pieces were recovered from the $1,515 \mathrm{~m}^{2}$ area excavated in Unit $\mathrm{I}$, in contrast to the 4,132 pieces from Excavation Unit II. Lintz (1986:341) cites an unpublished report by Studer (n.d.), which indicates that thousands of pieces of obsidian and an abundance of Puebloan pottery, turquoise and Olivella shell beads were recovered from Chimney Rock Ruins 51.

Brosowske (2002a, 2005) investigated the development of the exchange between small scale 
societies in the Southern High Plains from ca. 450 to 1400 B.P. (ca. cal A.D. 500 to 1500). He conducted $\mathrm{X}$-ray fluorescence trace element analysis on obsidian from two large Antelope Creek phase sites, 39 pieces from Alibates Ruin 28 and 6 pieces Chimney Rock Ruin 51. The chemical results indicated that all pieces were Cerro Toledo rhyolite from north-central New Mexico (Brosowske 2002a). In combining these findings with data from other sourcing studies, Brosowske (2005) suggested that trade began with a limited transfer of materials during the Early Ceramic period (A.D. 500 to 1200) and intensified dramatically during the subsequent Middle Ceramic period (or, Plains Village period, ca. A.D. 1200 to 1500$)$.

Brosowske (2002a, 2005) documented extensive use of obsidian during the Plains Village period with most specimens (ca. 80 percent) sourced to Cerro Toledo in the Jemez Mountains of north-central New Mexico. The large quantities of obsidian at a few specific Plains Village sites (i.e., Alibates Ruin 28, Odessa Yates, and Chimney Rock Ruin 51) led him to suggest that regional trade centers had emerged and that obsidian from the Jemez Mountains was one of the commodities that was exploited and redistributed at that time (Brosowske 2002a, 2005). He believes the few sites that have yielded especially large quantities of obsidian are likely candidates for regional trade centers that participated in direct exchange with Puebloan communities (Brosowske 2005:336).

Two Antelope Creek phase sites in the Oklahoma panhandle, Roy Smith and Stamper, yielded a few obsidian pieces. Four pieces from Roy Smith and one from Stamper were chemically sourced to Cerro Toledo rhyolite in New Mexico as were the sourced obsidian from Alibates Ruin 28 and Chimney Rock Ruin (Brosowske 2002a). However, one piece from Roy Smith was sourced to Obsidian Cliff in northwestern Wyoming and one piece from Stamper was sourced to Owyhee in Idaho. These latter two sources reflect interactions with groups to the northwest and a much wider exchange network that was not restricted to populations in the Southwest. These two sites on the northern margin of the currently defined Antelope Creek phase indicate influences form, and/or interactions with, other groups in other directions.
Imported Southwestern ceramics have also been recovered from many Antelope Creek phase sites, including many sites in the core area around Lake Meredith (Lintz 1978, 1986, 1989; Brooks 1989, 2004). These include a variety of wares such as Black-on-White, Jeddito yellow ware, Lincoln Black-on-Red, St John's polychrome, and others (Lintz 1986; Brooks 1989, 2004). These nonlocal wares have often been used to provide general age estimates for various Antelope Creek phase sites, since their temporal ranges are generally clearly defined in the Southwest (see Lintz 1986 for listing of the types and associated ages).

It seems clear, then, that long distance exchange with populations in the eastern Pueblos in northern New Mexico is well-documented on the basis of findings of easily recognizable trade items such as obsidian, Puebloan pottery, and items of turquoise). However, local trading/exchanging with neighbors in the adjacent region is much less easily detected. The presence of a collared rim vessel (A-119/111) with a cordmarked exteriors from Cottonwood Creek and at least three collared rims from Roper (A-62/542, 543, and 544) may indicate some localized and perhaps small-scale exchange (Lintz and Reese-Taylor 1997). Similar collared vessels are more common at sites in Buried City (see below) and even more common farther north in Kansas (i.e., Pratt complex, Odessa complex) and central Nebraska (i.e., Itskari phase). Based on petrographic analysis, Lintz and Reese-Taylor (1997) documented that the collared rim sherd from Cottonwood Creek is closely related to the pastes in ceramics from the Buried City complex. They also see direct interactions between populations in the Canadian River valley and those living along Wolf Creek at Buried City.

Four early excavated sites in the Oklahoma panhandle that Lintz (1986) and Brooks (1989, 2004) included in the Antelope Creek phase are; Roy Smith (Schneider 1969), McGrath (Lintz 1976), Stamper (Watson 1950; Lintz 2003a, 2003b, 2003c, 2004), and Two Sisters sites (Lintz 1978a, 1979, 1986; Duncan 2002, 2006; see Table 3-2). These four sites have similar architecture in that they contained slab-foundation houses (no houses were defined at McGrath) and similar Southern Plains Village artifact assemblages, and evidence 
for similar subsistence strategies (Table 3-3). Corn/ maize was present at Two Sisters and Stamper (Watson 1950; Lintz 2003; Duncan 2002).

However, in addition to the normal and dominant Border Cordmarked sherds, a few decorated sherds were also present. Lintz (1976:93) reported that decorated sherds account for only 1.4 to 2.8 percent of the totals from these four sites, with the rest being plain or cordmarked. The decorated styles are limited to finger punctuations parallel to the lip, diagonally-set notches or punctations on the vessel lip, and incised chevrons or diagonal lines on the rim. Less frequent motifs include a burnished (polished) band on the upper part of the vessel body, incised parallel or hatched lines over the bodies, and a ridge (pseudo-collar) on the vessel rim that is further decorated. These decorative traits indicate associations with the Upper Republican ceramic tradition (Lintz 1976:93), so the presence of these decorated sherds may indicate contact/trade with groups to the north.

The Antelope Creek phase apparently came to a rather abrupt end around 450 B.P. (cal. A.D. 1500), if the younger uncorrected radiocarbon dates from Black Dog village (i.e., 250, 300, 350, and 390 B.P.) are excluded. It has been postulated that pressure from Apache groups (Athabascan speakers) moving into the area from the north, combined with the uncertainty of horticultural production during drought conditions caused the demise of this Plains Village manifestation. Evidence of warfare is only evident at a few Antelope Creek phase sites. Piles of trophy skulls on the floor and human remains in bell shaped pits at the Footprint site, and skulls placed with some burials may indicate conflict (Green 1986; Lintz 1986; Brooks 2004). However, none of the 44 burials studied by Lintz (1986) showed any sign of violent deaths. Some burned structures in the core area around Lake Meredith, and possible fortifications along the western margin of the Antelope Creek phase area (i.e., Landergin Mesa) are other possible indicators of conflict. Lintz (1986) suggested that one possible reason for conflict was the disruption of the well established relationship between the Puebloan societies in north-central New Mexico and the Antelope Creek populations. Brooks (2004) suggests another possible reason was competition for access to the highly prized Alibates chert resources, like those at Alibates Flint Quarries National Monument, located within the core Antelope Creek phase area and surrounded by Antelope Creek phase villages. These various hypotheses have yet to be tested with empirical archeological data from good contexts.

\subsection{The Buried City Complex}

\subsubsection{Introduction}

Buried City, now part of the extensive Courson land holdings and previously owned by Sam Handly, lies along a short section of Wolf Creek in Ochiltree County in the extreme northeastern Texas panhandle. Wolf Creek dissects Ochiltree and Lipscomb counties and flows eastward into the North Canadian (Beaver) River in western Oklahoma. This meandering creek cuts through the Ogallala Formation that created a steep-walled valley for nearly $10 \mathrm{~km}$, and which is roughly 1.6to $3.0-\mathrm{km}$-wide in the vicinity of Buried City. The creek is tree-lined and fed with fresh spring water.

Sporadic archeological investigations occurred in this valley beginning in 1907. Lintz (1986), D. Hughes and Hughes-Jones (1987), D. Hughes (1991), and Brooks (2004), plus an exhibit on the Texas Beyond History web page (www.texasbeyondhistory.com) created in 2003 provide in-depth accounts of the long history and the participants of the various archeological investigations that have been carried out at Buried City. I will not attempt to duplicate those detailed histories and accounts in this space, but will briefly summarize the history of investigations and highlight a few selected sites.

Archeological investigations began with Eyerly in 1907 with subsequent short, similar reports (1907, 1908, 1910, and 1912). What brought researchers to this locality was the mounded accumulation of rock rubble from what appeared to be large house foundations with scattered and diverse associated cultural materials. Some midden areas were more obvious than others and were targeted for excavation. Moorehead visited the area and recorded and excavated sites over the years between roughly 1917 and 1921 and published some of his findings and 
Table 3-3. Summary of Data From the Four Excavated Antelope Creek Phase Sites in the Central Oklahoma Panhandle.

\begin{tabular}{|c|c|c|c|c|c|c|c|}
\hline $\begin{array}{c}\text { Site Number } \\
\text { and Name, Area } \\
\text { Excavated in } \\
\text { M2 }\end{array}$ & Structures & $\begin{array}{l}\text { Projectile } \\
\text { Points }\end{array}$ & $\begin{array}{c}\text { Chipped Stone } \\
\text { Tools }\end{array}$ & Bone/Shell Tools & Ground Stone & Pottery/Ceramics & References \\
\hline $\begin{array}{l}\text { 34TX1, Stamper, } \\
360 \mathrm{~m}^{2}\end{array}$ & $\begin{array}{c}\text { Large village; } \\
\text { multiple-28 rooms; slab } \\
\text { foundations "kiva"- } \\
\text { circular } 6 \mathrm{ft} \text { rectangular, } \\
\text { oblong; no subterranean } \\
\text { post supports identified }\end{array}$ & \begin{tabular}{|c|} 
Washita (48); \\
Fresno (43); \\
Harrell (4); Darts \\
(2); Scallorn (1)
\end{tabular} & $\begin{array}{c}\text { beveled knoves } \\
\text { (28); small scrapers } \\
\text { (45); bifaces } \\
(15+) \text {; drills (18); } \\
\text { hammerstones (2). }\end{array}$ & $\begin{array}{c}\text { awls (32); scapula } \\
\text { hoes (5); tibia } \\
\text { digging sticks (17); } \\
\text { some with holes for } \\
\text { handles; rib rasps } \\
(2+) \text {; antler tines (7) }\end{array}$ & $\begin{array}{l}\text { metates (cicular and } \\
\text { elliptical) (6); manos } \\
\text { (3); abraders (12); }\end{array}$ & \begin{tabular}{|} 
cordmarked (1827)-100\%; elbow \\
pipes, globular, 25 decorated on \\
designs on rims, many design \\
variations: plain (79), cord- \\
marked (37),finger (11), tool \\
impressed (12), punctated (2); \\
bone tempered sherds (3); circular \\
discs w/ holes (4); decorated (30); \\
rims (138-141); Pueblo wares (4)
\end{tabular} & $\begin{array}{c}\text { Watson 1950; } \\
\text { Lintz 2003a, } \\
\text { 2003b, 2003c, } \\
2004\end{array}$ \\
\hline $\begin{array}{l}\text { 34TX32, Two } \\
\text { Sisters }\end{array}$ & $\begin{array}{l}\text { central hearth, } 2 \text { pits, } \\
\text { floor channel, "altar", } \\
\text { B=subterranean, no } \\
\text { stone foundation; } \\
\text { burned charred beans, } \\
\text { daub, no post holes. } \\
\text { Structure A has } 4 \\
\text { contiguous rooms with } \\
\text { single row caliche rock; } \\
2 \text { structure styles; } 2 \\
\text { occupations }\end{array}$ & \begin{tabular}{|} 
Washita (49); \\
Fresno (63); \\
side notched \\
(2); Harrell (4); \\
Scallorn (2); \\
arrow (126); dart \\
(1)
\end{tabular} & \begin{tabular}{|c|} 
beveled knives \\
(29); bifaces (16); \\
End scrapers \\
(46); drills(38); \\
edge-modified \\
flakes (239); \\
hammerastones \\
(12)guitar pick \\
scrapers (49); \\
side scrapers (52). \\
Obisdian (3); 77\% \\
of assemblage \\
composed of \\
Alibates
\end{tabular} & \begin{tabular}{|c|} 
\\
awl (34); scapula \\
hoes (3); tibia \\
digging sticks (13); \\
shaft straightener \\
(2); squash knife \\
(4); notched ribs (5); \\
antler tines (2); shell \\
tools (4)
\end{tabular} & $\begin{array}{c}\text { metates (34); } \\
\text { manos(62); abraders } \\
\text { (31);Pipe (2); } \\
\text { Hammerstones (36); } \\
\text { Choppers (2); Boiling } \\
\text { Stones (688) }\end{array}$ & \begin{tabular}{|c|}
$\underline{\text { Features } 12,13, \text { and } 25 \text { in Room }}$ \\
1A: 47 (2 shell temper) +3]; total \\
sherds (1130); sand tempered \\
(1125), decorated (15\%); \\
cordmarked (34\%); smoothed \\
over cordmarked (39\%); plain \\
$(4 \%)$. Room B (Features 6, 7, 8, \\
$9,10)$ : sand tempered (71); plus \\
17.26 liter jar reconstructed; shell \\
tempered (30[2 rims]); sherds \\
$<2.5$ cm $^{2}(95 \%)$; decorated rims \\
(15\%); daub (260)
\end{tabular} & $\begin{array}{c}\text { Duccan 2002, } \\
2006\end{array}$ \\
\hline 34TX31, McGrath & $\begin{array}{c}\text { No structures; } 8 \\
\text { features: including } \\
\text { hearths (5), storage pit } \\
\text { (1), trash dump (1), and } \\
\text { cobble concentration (1) }\end{array}$ & \begin{tabular}{|c} 
Washita (11); \\
Harrell (4); \\
Fresno (24); darts \\
(3); Scallorn (2)
\end{tabular} & \begin{tabular}{|c|} 
beveled knives \\
(2); Bifaces (47) \\
Scrapes (end and \\
side (125); gravers \\
(10); hammerstones \\
(?); drills (6). \\
Obsidian (9); \\
Alibates (903)
\end{tabular} & $\begin{array}{l}\text { awls (6); tibia } \\
\text { digging stick (1); } \\
\text { shaft wrench (1); } \\
\text { spatula (2); shell } \\
\text { tools (3) }\end{array}$ & $\begin{array}{l}\text { metates (10); } \\
\text { manos(23); abraders } \\
\text { (33) }\end{array}$ & $\begin{array}{c}\text { cord marked (133); plain (37); } \\
\text { engraved (1); black-on-white; } \\
\text { daub (7); pueblo pottery (1). rims } \\
\text { (7) = cordmarked (2), plain (4), } \\
\text { tool impressed (1) }\end{array}$ & Lintz 1976 \\
\hline
\end{tabular}


Table 3-3. Summary of Data From the Four Excavated Antelope Creek Phase Sites in the Central Oklahoma Panhandle (cont.).

\begin{tabular}{|c|c|c|c|c|c|c|c|}
\hline $\begin{array}{c}\text { Site Number } \\
\text { and Name, Area } \\
\text { Excavated in } \\
\text { M2 }\end{array}$ & Structures & $\begin{array}{l}\text { Projectile } \\
\text { Points }\end{array}$ & $\begin{array}{c}\text { Chipped Stone } \\
\text { Tools }\end{array}$ & Bone/Shell Tools & Ground Stone & Pottery/Ceramics & References \\
\hline $\begin{array}{l}\text { 34BV14, Roy } \\
\text { Smith }\end{array}$ & $\begin{array}{l}\text { One contiguously- } \\
\text { roomed rectangular } \\
\text { structure; habitation } \\
\text { rooms (5); storerooms } \\
\text { (3); activity areas on } \\
\text { bedrock (2); Room A } \\
\text { has } 4 \text { roof supports, } \\
\text { entryway. }\end{array}$ & \begin{tabular}{|c|} 
Washita (142); \\
Fresno (209); \\
Harrell (18); darts \\
(38)
\end{tabular} & \begin{tabular}{|} 
beveled knives \\
(27); bifaces (50); \\
scapers (484); drills \\
(39); Mahherstones \\
(11); Mullers \\
(9). Obsidian (9); \\
Alibates (??)
\end{tabular} & $\begin{array}{c}\text { awls (22); tibia } \\
\text { digging sticks (3); } \\
\text { scapula hoes (3); } \\
\text { notched rasps (12); } \\
\text { bone beads (3); shell } \\
\text { scrapers (10) }\end{array}$ & $\begin{array}{l}\text { basins (7); manos } \\
\text { (35); abraders (11); } \\
\text { pipe (1) }\end{array}$ & \begin{tabular}{|} 
cord marked (1237): thick (58); \\
decorated (26); discs (3); ; ; exotic \\
pottery (4); lip tabs (2). Rims \\
(67):cord marked (28), finger \\
impressed (21), plain (11), tool \\
impressed (5), collared (2).
\end{tabular} & Schneider 1969 \\
\hline
\end{tabular}


ideas in 1931. No further archeology occurred at Buried City until 1966 when a local archeologist, T. Ellzey, conducted test excavations at a midden and at the Eyerly ruin house structure (Ellzey 1966).

With the exception of Ellzey's (1966) brief testing, no systematic investigations were conducted at Buried City between 1920 and 1985. In 1985, more intensive excavations occurred following the purchase of the Handly Ranch, which contained the Buried City, by Harold Courson in 1984. Mr. Courson funded a crew under the field direction of Dr. David Hughes. This crew conducted excavations at Courson A (410C26), Courson B (41OC27), and Kit Courson (410C43) during the summers of 1985 and 1986 (D. Hughes and Hughes-Jones 1987, D. Hughes 1991, 2001, 2002). The D. Hughes and Hughes-Jones (1987) report focused on the 1985 excavations and analyses, and discusses the work, the features, the material cultural, settlement patterns, chronology and burial practices as evidenced in the 1986 investigations. In 1987 and 1988, Hughes's crew was joined by a massive crew of over 300 volunteers from Texas Archeological Society (TAS). They conducted excavations at six prehistoric village-period sites, tested two areas of a third site, and performed an archeological survey of several kilometers of the Wolf Creek valley (D. Hughes 1991). The following year (1990) David Hughes led a Wichita State University archeological field school that focused on the Temple site and a few sites in Buried City (D. Hughes 1991:138).

As one might expect, the pre-1965 excavations were not as sophisticated as what is practiced today. In the earlier work, the details of the investigations and specific artifact information were not published and only brief overview articles were written. Most researchers presented their interpretations without the full presentations of the data that led them to their conclusions. Notes and field maps of previous investigations were not always available to the subsequent researchers and site locations and names became confused over time, and sometimes duplicated or renamed. D. Hughes (1991) provides a breakdown of the five major clusters of sites and their contents. Table 3-4 is an attempt to provide the basic names and site numbers for the five major site clusters, which have been identified and investigated to one extent or another at Buried City. Currently, no single report presents the complete findings of the various Buried City investigations, not even for a single site. When reading the early literature it is difficult to know exactly what sites or groups of sites were referred to when the term Buried City was used and the meaning has undoubtedly changed over time according to who is presenting the information. The structures and artifact assemblages are summarized below by major categories in order to provide a general understanding of Buried City and allow broad comparisons with other cultural manifestations. An in-depth understanding of the Buried City must await the publication of considerably more detailed information than is presently available.

The five clusters of named ruins that comprise Buried City are distributed over roughly a 2.5-km-long section of Wolf Creek valley. Within the clusters, individual ruins have been assigned at least 17 different trinomial numbers with more ruins towards the eastern end (Table 3-4; Figure 3-9). Within this area, at least 34 house rubble foundations or mounds of rubble have been identified. Apparently, at least nine house locations have been investigated to one degree or another. Currently, only 19 radiocarbon dates have been obtained on 7 investigated sites (Table 3-4, D. Hughes 1991; Brosowske 2005). The majority of investigations conducted by D. Hughes between 1985 and 1989 focused on the Courson A (41OC26), Courson B (41OC27), plus the Kit Courson House (410C43, Table 3-5). Excavations were directed towards large house rubble areas, as well as limited areas immediately outside the houses. House rubble areas were targeted as they were obvious on the surface. Only the findings from the 1985 Courson archeological projects were presented by D. Hughes and Hughes-Jones (1987). That report presents the background, stratigraphy, features, and artifacts for each site investigated during the 1985 work, as well as information on the earlier investigations and the general findings at each of the other ruins/houses. This is the first document concerning Buried City that presented detailed house and artifact descriptions and counts of artifacts. In their conclusions, the authors state that, based on the 12 radiocarbon ages, combined with the cultural and natural stratigraphy, some discernible time depth is represented at Courson B, and suggest that multiple occupations were represented (D. Hughes 
Table 3-4. Explanation of Buried City Sites and Selected Data Per Site.

\begin{tabular}{|c|c|c|c|c|c|c|c|c|c|c|c|c|c|}
\hline Ruin Complex ${ }^{1}$ & 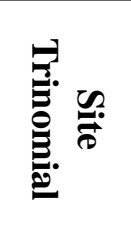 & 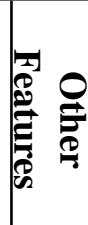 & 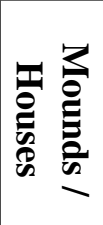 & 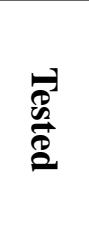 & 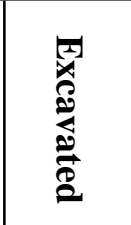 & 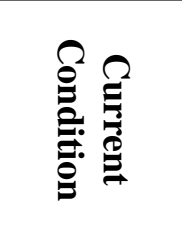 & 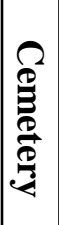 & 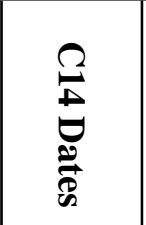 & 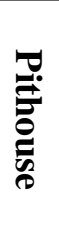 & . & 苞. & 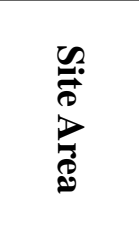 & References \\
\hline Buried City Proper & $410 C 1$ & & 12 & & & & & & & & & 70 acres & Eyerly 1907, 1910, 1912 \\
\hline Handley Ruins & 41OC1 & & & & & & & & & & 1 & & D. Hughes and Hughes-Jones 1987 \\
\hline Temple Ruin/Gould Ruin* & $410 C 1$ & yes & yes & yes & $\begin{array}{l}1986, \\
1990\end{array}$ & destroyed & & $\begin{array}{l}590 \text { B.P. } \\
740 \text { B.P. }\end{array}$ & & & & & Moorehead 1920, 1931 \\
\hline Thorburn Ruin Midden & 41OC1 & & & 1966 & & & & & & & & & Moorehead 1920, 1931; Ellzey 1966 \\
\hline Eyerly Ruin & 41OC4 & & & 1966 & & vandallized & & & & ? & & & Ellzey 1966 \\
\hline Franklin Ruin & 41OC3 & & & & & & & & & & & & \\
\hline Bluff Ruin I & 41OC2 & & & & & & & 740 B.P. & & & & & Moorehead 1931 \\
\hline \multicolumn{14}{|l|}{ Courson Ruins } \\
\hline Courson A/Bluff \#1 & $410 C 26$ & yes & $1+$ & 1985 & $1987-88$ & destroyed & & $\begin{array}{l}520-770 \\
\text { B.P. }\end{array}$ & & & & & $\begin{array}{l}\text { Eyerly 1907; Moorhead 1931, D. } \\
\text { Hughes and Huges-Jones 1987; D. } \\
\text { Hughes 1991; D. Hughes } 2001\end{array}$ \\
\hline Courson B & $410 C 27$ & yes & 3 & & 1985-88 & $\begin{array}{l}\text { partially } \\
\text { damaged }\end{array}$ & & & $1+$ & 1 & 5 & & Same as above \\
\hline Courson C & $410 C 28$ & & 1 & yes & $1987-88$ & $\begin{array}{l}\text { partially } \\
\text { damaged }\end{array}$ & & & & & & & Same as above \\
\hline Courson D & $410 C 29$ & & $5+$ & yes & $1987-88$ & $\begin{array}{l}\text { partially } \\
\text { damaged }\end{array}$ & & & & 1 & & & Same as above \\
\hline Moorehead Ruins & $410 C 46$ & & & & & & & & & & & & D. Hughes 1991 \\
\hline \multirow{2}{*}{ Kirt Courson Ruins } & $410 C 47$ & no & 1 & 1986 & & & & & & & & & D. Hughes 1991 \\
\hline & $410 C 48$ & & $3+$ & & & & ? & 630 B.P. & & & & & D. Hughes 1991 \\
\hline
\end{tabular}


Table 3-4. Explanation of Buried City Sites and Selected Data Per Site (cont.).

\begin{tabular}{|c|c|c|c|c|c|c|c|c|c|c|c|c|c|}
\hline Ruin Complex $^{1}$ & 曷 & 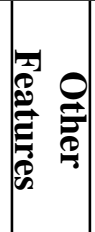 & 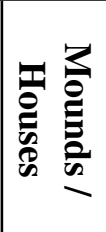 & $\stackrel{\mathscr{8}}{\stackrel{\mathscr{R}}{\mathscr{D}}}$ & 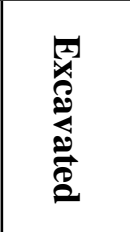 & 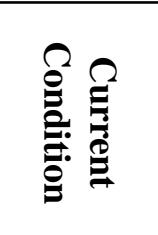 & 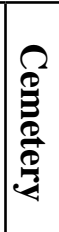 & $\begin{array}{l}\Omega \\
\stackrel{\theta}{\theta} \\
\underset{B}{\mathscr{D}}\end{array}$ & 莺 & 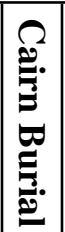 & 四 & 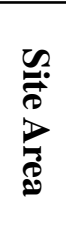 & References \\
\hline \multirow{6}{*}{ Kit Courson Ruins } & $410 C 40$ & & 1 & & & & & & & & & & D. Hughes 1991 \\
\hline & $410 C 41$ & & 1 & & & & & & & & & & D. Hughes 1991 \\
\hline & $410 C 42$ & & 1 & & & & & & & & & & D. Hughes 1991 \\
\hline & $410 C 43$ & & 1 & potted & $1986-88$ & destroyed & & $\begin{array}{l}840 \text { B.P. } \\
580 \text { B.P. }\end{array}$ & ? & & & & $\begin{array}{l}\text { D. Hughes and Huges-Jones 1987; } \\
\text { Hughes 1991; Hughes } 2001\end{array}$ \\
\hline & $410 \mathrm{OC} 51$ & yes & 1 & 1986 & $1976-88$ & & & & & & & & \\
\hline & $410 C 52$ & & & & & & & & & & & & \\
\hline
\end{tabular}

${ }^{1}$ All within 2,100 linear meters, along both sides of Wolf Creek. All locations have earlier occupations (D. Hughes 1991:110). Buried City complex was apparently proposed for entire area by D. Hughes and Hughes-Jones 1987:101 which spanned more than 250 years.

* Two names for same site

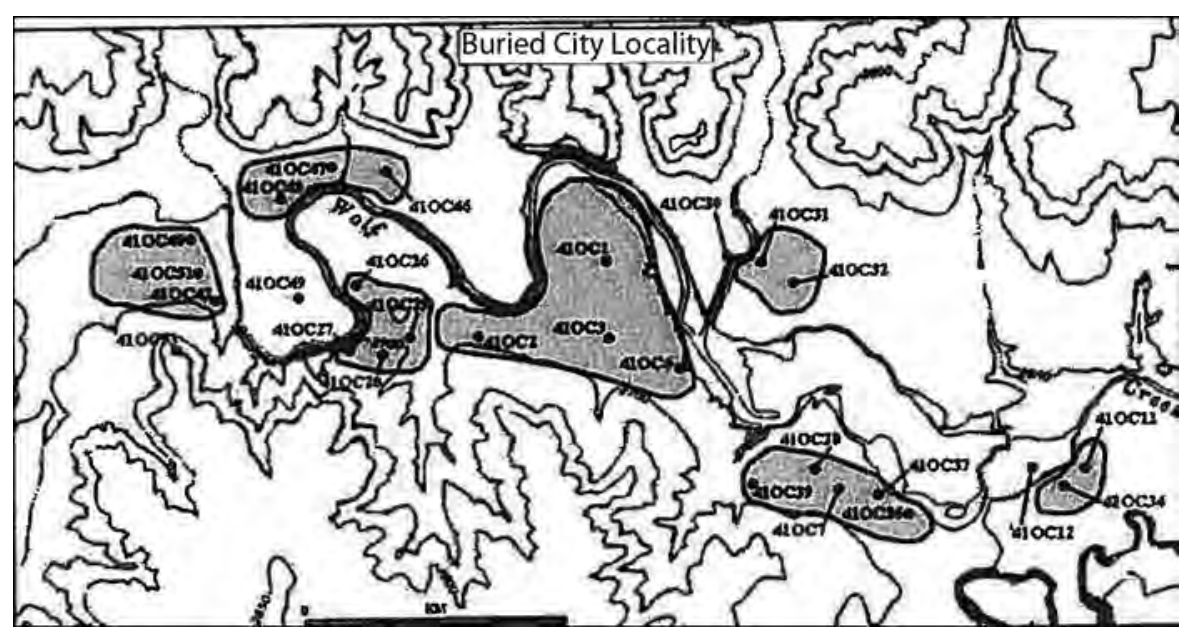

Figure 3-9. General map of the main cluster of sites in vicinity of Buried City along Wolf Creek (from Brosowske 2005:152, Figure 4.13, scale is $1 \mathrm{~km}$.) 
Table 3-5. Summary of Data Concerning Buried City Sites.

\begin{tabular}{|c|c|c|c|c|c|c|c|}
\hline $\begin{array}{l}\text { Site Number } \\
\text { and Name }\end{array}$ & Structures & $\begin{array}{l}\text { Projectile } \\
\text { Points }\end{array}$ & $\begin{array}{c}\text { Chipped Stone } \\
\text { Tools }\end{array}$ & Bone/Shell Tools & Ground Stone & Pottery/Ceramics & References \\
\hline $\begin{array}{c}410 \mathrm{O} 26 \\
\text { (Courson A) }\end{array}$ & $\begin{array}{l}\text { burned house } 3.5 \text { X } 4 \text { m, } \\
\text { burned posts, central hearth, } \\
2 \text { central support posts }\end{array}$ & $\begin{array}{l}\text { Harrell (1) } \\
\text { Fresno (1) } \\
\text { Washita (2) }\end{array}$ & $\begin{array}{c}\text { bifaces (5) } \\
\text { unifaces (3) } \\
\text { edge-modified } \\
\text { flakes (11), } \\
\text { lithic debitage } \\
\text { (204), Alibates } \\
\text { dominates }\end{array}$ & shell (6), bone (0) & $\begin{array}{l}\text { Pestle (2); } \\
\text { Abrader (1); } \\
\text { Mano (2); } \\
\text { Other (10) }\end{array}$ & $\begin{array}{c}\text { cordmarked (13); corncob- } \\
\text { impressed (3), large daub } \\
\text { present }\end{array}$ & $\begin{array}{l}\text { D. Hughes and Hughes-Jones } \\
\text { 1987, D. Hughes 1991; D. } \\
\text { Hughes } 2001\end{array}$ \\
\hline $\begin{array}{c}410 \mathrm{C} 27 \\
\text { (Courson B) }\end{array}$ & $\begin{array}{c}\text { large house- } 80 \mathrm{~m}^{2} \text {, stone } \\
\text { foundation, east entryway, } \\
\text { benches, roof supports; } \\
\text { Features } 2,6,7 \mathrm{~A}=\text { pits } \\
\text { (similar to AC);* pit feature } \\
2.5-3.0 \text { m diameter (dish } \\
\text { bottom, fireplace) filled with } \\
\text { bison bones and trash }\end{array}$ & $\begin{array}{c}\text { Fresno (6), } \\
\text { Harrell (1), } \\
\text { Washita (17), } \\
\text { others (18) }\end{array}$ & $\begin{array}{c}\text { bifaces (16-21), } \\
\text { drills (2), beveled } \\
\text { knives (4), guitar } \\
\text { pick scrapers (1), } \\
\text { edge-modified } \\
\text { flakes (264), flakes } \\
\text { (2980), dominated } \\
\text { by Alibates }\end{array}$ & \begin{tabular}{|} 
bone tools (46): \\
including awls \\
(3), tibia digging \\
stick (1), scapula \\
hoes (3), notched \\
ribs (3); shell \\
tools (43); shell \\
fragments (1324); \\
cutmarks present
\end{tabular} & \begin{tabular}{|} 
ground stone \\
fragments (67); \\
metates (11), \\
manos (19), \\
abraders (14), \\
pipes (1)
\end{tabular} & $\begin{array}{c}\text { total ceramic (902): including } \\
\text { cordmarked (347), plain (181), } \\
\text { decorated (39), smoothed-over } \\
\text { cordmarked, fine grit-tempered, } \\
\text { pipe(1), paint pallet (1), cob- } \\
\text { impressed (2), collared/pinched } \\
\text { (1), check-stamped, cordmarked } \\
\text { rims (5), pinched rim (9), plain } \\
\text { rim (9), incised (1) }\end{array}$ & $\begin{array}{l}\text { D. Hughes and Hughes-Jones } \\
\text { 1987; D. Hughes } 1991\end{array}$ \\
\hline $\begin{array}{l}410 \mathrm{OC} 43 \text { (Kit } \\
\text { Courson) }\end{array}$ & $\begin{array}{c}\text { structures (4), rectangular } \\
\text { 9-x-7 m, } 4 \text { roof supports, clay } \\
\text { lined central hearth, vertical } \\
\text { slab foundation, central floor } \\
\text { channel, } 2 \text { benches }\end{array}$ & ? & ? & ? & $\begin{array}{l}\text { grinding slabs } \\
\text { in structure }\end{array}$ & $\begin{array}{c}\text { not quantified (Lintz and Taylor } \\
\text { 1997, Lintz \#64, \#329.6 }\end{array}$ & $\begin{array}{l}\text { D. Hughes and Hughes-Jones } \\
\text { 1987; D. Hughes } 1991\end{array}$ \\
\hline
\end{tabular}


and Hughes-Jones 1987). They also suggested that the periods of occupation represent the transition from the Woodland period into the full Plains Village period, with the transition from hunting and gathering lifeways to horticulturally supported villages within this area (D. Hughes and Hughes-Jones 1987). They point to the need for intensive geomorphic studies and suggest that the ceramic traditions recognized here are "decidedly unusual for the Texas Panhandle" (D. Hughes and Hughes-Jones 1987:91).

In 1991 D. Hughes presented the general findings and summaries from the 1985 through 1988 investigations, brief artifact discussions for 6 sites, Courson A (41OC26), Courson B (41OC27), Courson C (410C28), Courson D (410C29), Kit Courson (41OC43), and Temple/Gould Ruin (41OC1:A), and listed the same 12 radiocarbon dates from the same 6 sites (Table 3-6). He also pointed out that an extensive archeological survey in 1987 discovered many sites directly upstream from Buried City. However, the main groups of sites did not extend more than a few kilometers upstream from the Courson Ranch (D. Hughes 1991:139). Hughes (1991:142) also briefly discussed site distribution at Buried City. He determined all architectural sites are above the first terrace or activity flood plain, in the Buried City, Moorehead, Kirk Courson, and Kit Courson ruins the houses are more than $200 \mathrm{~m}$ from the base of the bluffs, and houses were often built on terrace margins, or on crests of the terraces. The general patterns is one isolate, single- room houses with about $64 \mathrm{~m}^{2}$ of floor space, situated on low knolls, rises, or ridges adjacent to shallow swales that drain the flanks of the Caprock escarpment (D. Hughes 1991:142).

In March of 2000, a preliminary geophysical survey was conducted on parts of the Courson Ruin sites (specifically 41OC26, 27, 28, and 29) within Buried City (Brosowske and Maki 2002). Specifically, the targeted area was southeast of Courson A and north of Courson D and referred to as Area A. No surface structures were visible in that area. A soil resistance meter, a gradiometer, and ground penetrating radar (GPR) were employed to detect subsurface anomalies that could represent buried cultural features. The geophysical results identified numerous anomalies. Subsequently, in March 2001, a sample of 26 identified anomalies was selected for systematic subsurface testing/ground truthing (Brosowske and Maki 2002). Minimally invasive testing was primarily limited to systematic probing with an Oakfield coring device with a $2.54 \mathrm{~cm}$ (1 inch) open barrel and 50-by-50 cm shovel tests to allow for the recovery of information to determine the source of the anomalies and types and sizes of any features. It was determined that 18 of the 26 anomalies were of cultural origin, most likely associated with the Plains Village period. The sources of eight noncultural anomalies tested were attributable to animal burrows, recent shallow trenches, and local geology. Preliminary interpretations suggested that the cultural features identified during ground truthing included concentrations and scatters of artifacts, bands and lenses of charcoal, small and large basin features, probable pithouses (anomalies 14 and 19), possible trash pits, a possible house (anomaly 18), burned rock clusters, a broken ceramic vessel, a ditch-like depression, and a rock cairn. No obvious rock house foundations were identified during the limited probing. The preliminary results indicate that entirely different feature functions can have nearly identical geophysical signatures (Brosowske and Maki 2002). From this author's point of view, this survey also clearly demonstrated that a considerable range of buried cultural materials exists between the more obvious house ruins that can be seen on or near the surface.

In 2003, an educational exhibit was developed to inform the public on the work conducted at Buried City and is readily accessible online at Texas Beyond History web page (www.texasbeyondhistory.com). That exhibit presents many color photographs and accompanying information concerning the early investigations and backgrounds of the individuals who conducted the early investigations, including PDF files of Eyerly's 1908 and 1912 publications. The exhibit highlights the Buried City architecture, the artifacts recovered, and some work conducted at Courson A and B and the Kit Courson site. It states that four house styles have been recognized at Buried City, including 1) single-post wall structures, 2) pithouse, 3) large single room stone foundations, and 4) multi-room stone based foundations. Unfortunately the pithouse structures are just mentioned with limited detailed information on these rarely identified and poorly known structures. The exhibit does not provide in-depth accounts of 
Table 3-6. Radiocarbon Dates Available from Buried City Sites (Brosowske 2005:134).

\begin{tabular}{|c|c|c|c|c|c|c|c|c|c|}
\hline Site No. & Lab. No. & $\begin{array}{l}\text { Cat. } \\
\text { No. }\end{array}$ & Provenience & Material & $\begin{array}{c}\text { 14C Age } \\
\text { (B.P.) }\end{array}$ & $\begin{array}{c}\mathrm{C} 13 \mathrm{o} / \\
00\end{array}$ & $\begin{array}{c}\text { Corrected } \\
\text { Age }\end{array}$ & Date Range & Reference \\
\hline $410 C 1$ & WIS-90A & NA & midden & charcoal & $740 \pm 80$ & NA & N.A. & A.D. $1280^{*}$ & D. Hughes 1991 \\
\hline “ & DIC-3338 & NA & pit near Franklin Ruin & charcoal & $740 \pm 60$ & NA & N.A. & A.D. $1280^{*}$ & “ \\
\hline “ & WIS-90B & NA & midden & charcoal & $640 \pm 60$ & NA & N.A. & A.D. $1332,1369,1382 *$ & “ \\
\hline “ & DIC-3303 & NA & unknown & charcoal & $590 \pm 60$ & NA & N.A. & A.D. $1329,1343,1993 *$ & “ \\
\hline “" & WIS-97 & NA & Midden & charcoal & $360 \pm 601$ & NA & N.A. & A.D. $1491,1603,1609$ & “ \\
\hline $410 \mathrm{OC} 26$ & DIC-3281 & NA & pithouse, Feature 2 & charcoal & $740 \pm 50$ & NA & N.A. & A.D. $1280^{*}$ & “ \\
\hline $410 \mathrm{OC} 27$ & DIC-3300 & NA & pit NW of house & charcoal & $800 \pm 55$ & NA & NA & A.D. $1256^{*}$ & “" \\
\hline “ & Beta-20276 & $?$ & hearth in pithouse & charcoal & $770 \pm 80$ & & & A.D. $1271^{*}$ & “ \\
\hline “ & DIC-3301 & NA & pit south of house & charcoal & $710 \pm 50$ & NA & NA & A.D. $1287^{*}$ & “ \\
\hline “ & DIC-3228 & NA & pit under house & charcoal & $710 \pm 50$ & NA & NA & A.D. $1287^{*}$ & “ \\
\hline “ & DIC-3227 & NA & stone house-central hearth & charcoal & $620 \pm 50$ & NA & NA & A.D. $1315,1354,1387$ & “ \\
\hline “ & DIC-3280 & NA & human burial \#1 & bone & $240 \pm 651$ & NA & NA & A.D. $1656^{*}$ & “ \\
\hline $410 C 29$ & Beta-185069 & $?$ & burned pithouse & charcoal & $740 \pm 40$ & $?$ & $?$ & A.D. $1280^{*}$ & Brosowske 2005:134 \\
\hline “ & Beta-185071 & $?$ & Area A pithouse & charcoal & $700 \pm 40$ & ? & ? & A.D. $1290^{*}$ & “ \\
\hline “ & Beta-185072 & $?$ & Area A pithouse & charcoal & $660 \pm 40$ & $?$ & $?$ & A.D. $1300^{*}$ & “ \\
\hline “ & Beta-185070 & $?$ & Area B pithouse & charcoal & $630 \pm 40$ & $?$ & $?$ & A.D. $1310,1370,1380 *$ & “ \\
\hline $410 C 43$ & Beta-20277 & $?$ & stone house-central hearth & charcoal & $840 \pm 100$ & $?$ & $?$ & A.D. $1216^{*}$ & D. Hughes 1991 \\
\hline “" & Beta-20871 & ? & stone house-central hearth & charcoal & $580 \pm 60$ & ? & $?$ & A.D. $1332,1340,1398^{*}$ & “ \\
\hline $410 C 48$ & DIC-3302 & NA & unknown & charcoal & $630 \pm 40$ & NA & NA & A.D. $1304,1367,1385^{*}$ & “ \\
\hline
\end{tabular}

* University of Washing Quaternary Isotope Lab, Radiocarbon Calibration Program 4.3

1. rejected by Brosowske 2005:134. 
the various excavations or details concerning the artifacts, since it is not directed at the professional archeologist for research purposes.

Brosowske (2005), in his unpublished dissertation, discusses some old and new findings from the Buried City and summarizes the work at Buried City sites. He presents more information, new radiocarbon dates, and some analysis concerning the Buried City materials and sites. He also presents limited information on his newly named "Odessa phase". Unfortunately, not all the information concerning his type site for the "Odessa phase”, Odessa Yates (34BV100), is presented. In a reversal from Lintz (1986), who assigned all the Buried City materials to the Antelope Creek phase, Brosowske (2005) places all the Buried City materials within his "Odessa phase". His assignment is based on surveys and excavations primarily outside of Texas since 1989. Time does not allow a thorough review of the "Odessa phase" and the sites assigned to it, so reader is referred to Brosowske (2005) for his analysis of the various sites and newly defined/proposed phase dealing with Plains Village sites with distinctive architecture and pithouses. An overview of the "Odessa phase" can also be found in Brosowske and Bevitt (2006). Until detailed descriptions of the excavations, artifacts, features and a complete analysis of the materials from the Odessa Yates site are published, it is difficult to have a complete understanding of this new proposed phase, if that is truly what it is, and to facilitate comparisons of this manifestation to other name manifestations across the region. Lacking that specific data this report treats the Buried City complex separate from Odessa phase.

\subsubsection{Ages}

As expected, no radiocarbon dates were obtained from the early investigations, since they predated the discovery of the technique, but no dates were obtained from the 1966 work by Ellzey (1966). In 1987, D. Hughes and Hughes-Jones (1987, Table 6) presented a set of 12 radiocarbon dates from the Buried city sites, with the same dates published again in 1991, (D. Hughes 1991, Table 1) and again in 2001 (D. Hughes 2001). Although these initial 12 dates have been presented, they were done so with limited sample descriptions or discussions (see Table 3-6). This initial series includes three dates from Beta
Analytic Inc. (Beta) (Miami, Florida) and nine dates from DiCarb (DIC) radiocarbon laboratory (Norman, Oklahoma). The latter laboratory did not correct for $\delta^{13} \mathrm{C}$ on the samples, and it is not clear if the published dates obtained from Beta were $\delta^{13} \mathrm{C}$ corrected or not. A number of discrepancies exist in the dates presented in the tables and the ones referenced in the text (D. Hughes and Hughes-Jones 1987; Table 6), and it is not clear which are the correct values. All dates were apparently on charcoal with one exception (a date of $240 \pm 65$ B.P., DIC-3280), which was on human bone collagen from burial 1 at Courson B (41OC27). D. Hughes (1991:122) interprets this late date and the human remains to represent the final occupation at the Courson B site. This human bone was part of the mass burial of at least five individuals under a large rock cairn. The cairn apparently was built of rubble from a house foundation.

The 11 wood charcoal dates range from 580 to 840 B.P. (A.D. 1110 to 1370), a restricted 260 year period. Two dates were obtained from a single hearth at Kit Courson (41OC43), which yielded considerably divergent ages of $580 \pm 60$ B.P. (Beta20871) and $840 \pm 100$ B.P. (Beta-20277). D. Hughes and Hughes-Jones (1987) provide a brief comment on these two dates and state that the 840 B.P. date was on about $1 \mathrm{~g}$ of charcoal obtained from flotation of the hearth fill. No explanation of the other sample is given and no indication as to whether both dates are accepted. In general, the 260 years represented by the 11 charcoal dates reflect a relatively brief period, perhaps the primary period of occupation. However, the date obtained on the human bone indicates that later events are present as well.

Brosowske (2005:134) presents the original 12 dates and also lists 7 more radiocarbon dates from the Buried City sites that were obtained after about the year 2000 (see Table 3-6). He believes that two dates are clearly in error or, alternatively, represent a later component, and that a third date is inaccurate. The 16 accepted dates for the 6 sites range over a narrow 140 year period from 550 to 690 B.P. (cal A.D. 1260 to 1400). He points out that the vast majority of sites remain undated. Brosowske (2005:146) states that five of the six pithouse dates range between 650 and 680 B.P. (cal A.D. 1270 and 1300). These pithouses are often under the rock house foundations, although 
the dates associated with the pithouse fall within the period represented by the slab houses.

For the most part, the excavations over the years were focused on large, rock house foundations. Therefore, these similar house foundations may reflect the same general use period, leaving us without documentation of the full time range for the occupation of the sites. However, in a number of instances, excavations revealed that cultural materials and some features were stratified and indicate possible multiple occupations. In fact, at least six of the recently presented dates actually are associated with structures identified as pithouses, now recognized at Courson A (410C26), Courson B (41OC27), and Courson C (41OC28). It is likely that these structures/occupations may not have been previously recognized or adequately sampled and radiocarbon dated. Therefore, the full age range of the occupations at the various sites in Buried City may not be represented by the current 16 dates.

Buried City proper (41OC1), the Kent\#1 subdivision, has yielded five radiocarbon dates (see Table 3-6). The date of $360 \pm 60$ B.P. (WIS-97) on charcoal is rejected by Brosowske (2005:134), but may in fact represent a latter occupation. The other four dates fall between 590 and 740 B.P., which would indicate multiple occupations at this site.

Courson A (41OC26) has only one date of $740 \pm 50$ B.P. (DIC-3281) from the pit (Feature 2) exposed in the cutbank (D. Hughes and Hughes-Jones 1987:107, Table 6; D. Hughes 2001). Brosowske (2005:134) refers to this date as coming from a pithouse.

Courson B (41OC27) has yielded six radiocarbon dates (see Table 3-6), including one date of $240 \pm$ 65 B.P. (DIC-3280) on human bone from under the rock cairn, which is mostly above a rock foundation and definitely supports a relatively recent cultural event. The remaining five dates range from 620 to 800 B.P. and likely reflect multiple occupational events, although their association is not clear. If the date of $770 \pm 80$ B.P. (Beta-20276) truly represents a pithouse, its age reflects an occupation slightly earlier than the main rock house (D. Hughes and Hughes-Jones 1987:107, Table 6; D. Hughes 2001).
Courson D (410C29) has been dated more recently and provides solid dates on two different pithouses (see Table 3-6). Pithouses have been recognized at Buried City since roughly 2000. The four pithouse dates range from 630 to 740 B.P. and may reflect a relatively narrow occupation period. These dates appear to overlap with the use of the stone rock foundations that have received most of the archeological attention, especially early on. The range of dates from 630 and 740 B.P. could actually be identical in age or they could represent, combined, as much as 200 years.

Kit Courson Ruins (41OC43) have yielded two radiocarbon dates (see Table 3-6). Both dates are from the same hearth as discussed above. No explanation is given for their difference (D. Hughes and Hughes-Jones 1987). Brosowske (2005:134) rejects the date of 840 as being too old with no justification or explanation.

The single date available from $410 \mathrm{OC} 48$ at Kirt Courson Ruins is acceptable, although its exact association is not clear. This date was on charcoal and recovered from the 1960's (potentially from Ellzey's investigations) with no provenience provided (D. Hughes and Hughes-Jones 1987:107, Table 6; D. Hughes 2001).

Obviously many more radiocarbon dates from clear and unquestionable contexts are necessary from the rock house foundations and pithouses to clearly establish the complete age range of the activities and structures represented at the various sites within Buried City. Currently, it is difficult to see how all the artifacts and the different currently identified features reflect a single cultural manifestation. One possibility is that the material assemblages represent a single culture that developed over time. We must await clear presentation of the stratigraphy and in-depth analysis of the structures, features, and artifact assemblages before general synchronic comparisons can be made.

\subsubsection{House Patterns and Settlement Types}

Buried City is known for its large, stone-based house foundations, at least 34 foundations and counting, made with caliche boulders (Figure 3-10). In general, these are currently perceived to be isolated, 
square to rectangular dwellings with intramural areas of between roughly $64 \mathrm{~m}^{2}$ to $130 \mathrm{~m}^{2}$, that contain central hearths, four major vertical posts for roof support, along with extended entryways that are generally oriented to the east. The distance between the structures averages 98 to $195 \mathrm{~m}$ (D. Hughes 2001). A number of the investigated houses appear to have been reused or perhaps rebuilt multiple times over roughly two centuries based on multiple floors and stacked hearths. As an example, the large boulder-lined house at Courson D was determined to have been rebuilt or at least refloored in the same location at least three time (D. Hughes 2001:3).

Reuse of the same specific location was also apparent at Courson B where at least four separate houses overlapped. D. Hughes comments on the complexity of the cultural sequence at Courson B and states that the small, roughly circular pit (not numbered in the text) may represent a pithouse with a central hearth and may be the earliest structure at this location (D. Hughes 1991). However, in the most recent report, the earliest recognizable dwelling is referred to as a "pit feature approximately 2.5 to $3 \mathrm{~m}$ in diameter with a dished out bottom and a fireplace located just east of the center of the dish" (D. Hughes 2001:3). Wood charcoal from this "pit feature" yielded an uncorrected $\delta^{13} \mathrm{C}$ date of $800 \pm 55$ B.P. (DIC-3300), one of the earliest radiocarbon dates obtained thus far. The "pit feature" was filled with bison bones and trash debris that included pottery that resembles terminal Woodland or initial Plains Village ceramics. D. Hughes states that stratigraphically equivalent to this "pit feature" was a collection of features (not numbered in the text) that represent two additional houses and a series of cache or trash pits (Numbers 2,3 , and 4 on maps). Two trash pits yielded uncorrected $\delta^{13} \mathrm{C}$ dates of $710 \pm 45$ B.P. (DIC3228) and $710 \pm 55$ B.P. (DIC-3301). In addition to the identified trash pits, a series of large, deep, intersecting pits which may predate the main rock house were present. D. Hughes (2001:4) suggests that these pits could represent some external activity which is undefined. He also states that one of the pits had a series of unusual artifact associations and a circle of postholes in its bottom (D. Hughes 2001). The $8 \mathrm{~m}^{2}$ "main Courson B house”, typical of Buried City architecture, was built on top of the "pit feature". Wood charcoal from the hearth in the main Courson B house yielded an uncorrected $\delta^{13} \mathrm{C}$ date of $620 \pm 50$ B.P. (DIC-3227). After the main house was abandoned and fill covered most of it, a small square house (number 6 on the 2001 map and number 8 on the 1991 map) was built that overlapped the southeast corner of the main house (D. Hughes 2001). A mass burial beneath a rock cairn was then added on top of the small square house. A radiocarbon date on the human bone from an individual in the mass burial yielded an uncorrected $\delta^{13} \mathrm{C}$ date of $240 \pm 65$ B.P. (DIC-3280). Thus, the stratigraphy at Courson B and the series of associated radiocarbon dates clearly indicate that multiple occupations occurred over time and not all the structural remains reflect a single, limited time period.

Another structure, which D. Hughes (2001) perceived as similar to the one at Courson $\mathrm{B}$, was also discovered at Courson A. It is not clear which structure he was referring to in the 2001 article, but the 1991 publication may be referencing the same feature. In 1991 Hughes's map of Courson A (Hughes 1991, Figure 5) shows two trash/cache pits, $2+m$ diameter. One was along an eroding bank, and could be similar to the "pit feature" at Courson B. In 2001, Hughes stated that "house" (Feature 2, pit in cutbank) was preserved because it was partially burned, preserving the charred bases of the posts in situ. This structure measured 3.5 to $4 \mathrm{~m}$ in diameter and contained two central support posts that flanked the central firepit (D. Hughes 2001). Charcoal from this house yielded an uncorrected $\delta^{13} \mathrm{C}$ date of 740 \pm 50 B.P. (DIC-3281). This may be associated with another "pit house" that was not recognized as such. In 2001, D. Hughes' concluding remarks note that the previous research has focused on the large stonebased houses, but "smaller, less visible or ephemeral remains are present." The functions of such features are presently unclear.

Moorehead (1931) believed the architectural remains in the area were related to the Cliff Dwellings and Puebloan ruins of New Mexico. Ellzey (1966) suggested the house at Eyerly ruin was more closely linked to the Optima Focus (Watson 1950) in the Oklahoma panhandle than the Panhandle Aspect (now what is known as Antelope Creek phase, Lintz 1986), but it differed somewhat from the 


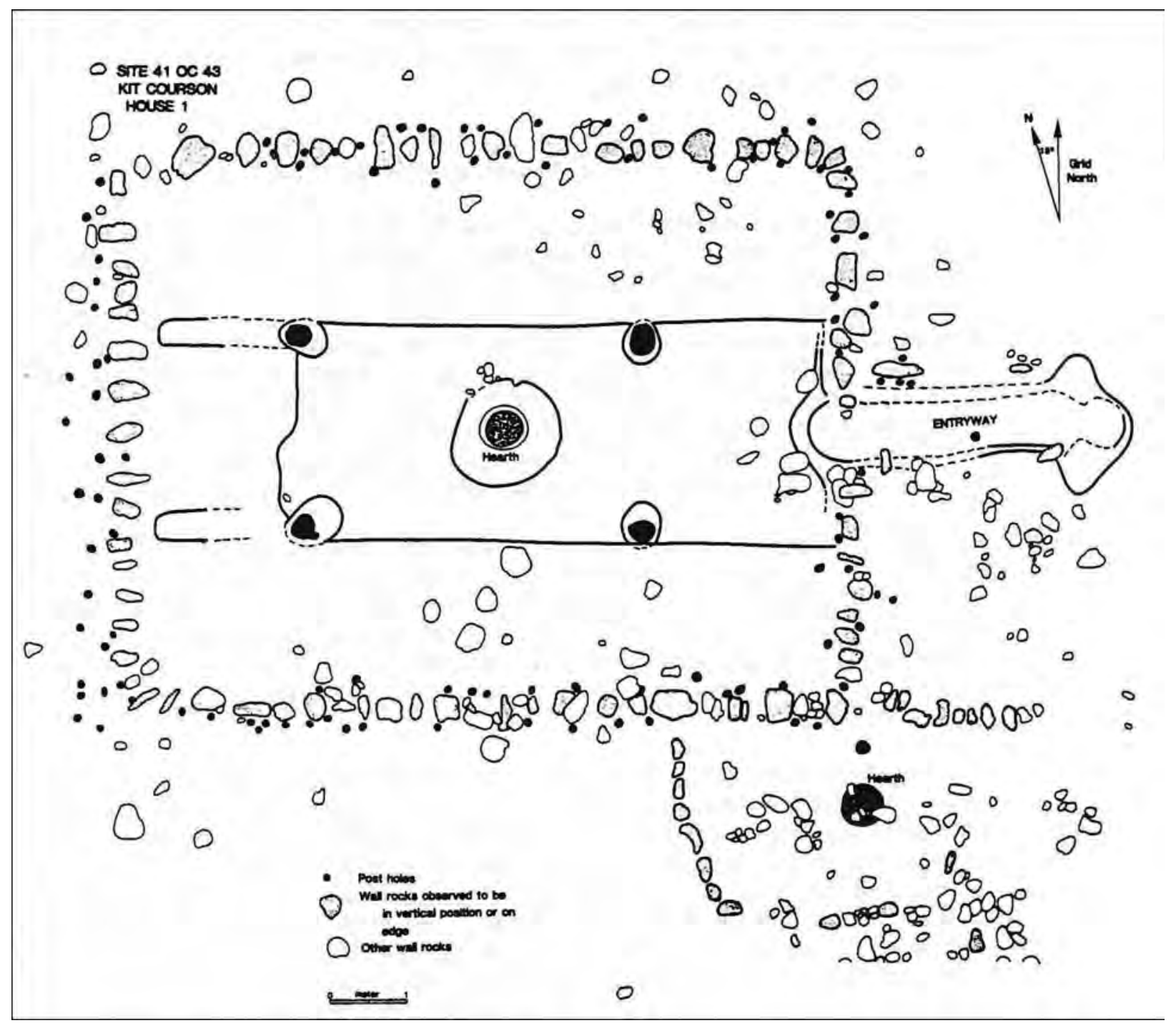

Figure 3-10. Typical stone house foundation, 410C43, Kit Courson House 1 in Buried City (graphic by D. Hughes)

architecture of both. For the most part, the stone foundations in Buried City are very similar to the Antelope Creek phase houses, except that they tend to be larger. Unfortunately, only two radiocarbon dates are acceptable and directly linked to the many stone foundations at Buried City (see Table 3-6).

D. Hughes (1991:142) discusses the broad settlement pattern he observed at Buried City. He points out that all architectural sites are above the first terrace or floodplain. Houses were generally built on the terrace margins or near the margins of the terraces. In general, the houses were situated more than $200 \mathrm{~m}$ from the base of the bluffs. The broad pattern is that of a single isolated structure/ house with around $64 \mathrm{~m}^{2}$ of floor space was situated on a rise or low knoll adjacent to shallow swales. The structures are at least $30 \mathrm{~m}$ apart; many are much further apart. Based on surveys over the years and local informants, it is apparent that the main cluster of structural sites covers roughly an $8 \mathrm{~km}$ (5 mi.) long stretch of terrain adjacent to Wolf Creek (D. Hughes 1991:142). Specifically at Courson D, Brosowske (2005:154) documents a minimum density of residential structures of one house per $1,500 \mathrm{~m}^{2}$, or seven per hectare. 
Over the last 10 years or so, some of the features that D. Hughes referred to as pits are now recognized as the remains of pithouses. Pithouses have now been recognized at Courson A, B, and D. These are small (2.5 to $4.0 \mathrm{~m}$ in diameter), circular to oval in shape, and interior floors roughly $40-$ to $60-\mathrm{cm}-$ below the surface. Shallow basin hearths have been recognized on the eastern half of the interiors, with two pithouses that exhibited central posts and wall supports (Brosowske 2005:143).

\subsubsection{Artifact Assemblages}

A broad suite of materials has been recovered from the various excavations of structures and ancillary features at the various sites. However, individual counts, frequencies, and densities of the classes of materials have not been presented in detail. Generally, only broad descriptions or distribution maps of artifact classes are provided (D. Hughes and Hughes-Jones 1987; D. Hughes 1991). The various classes of materials recovered include freshwater mussel shells, lithic debris, burned rocks, daub, stone and bone tools, pottery, animal bones, shell tools and ornaments, and charred material. Most classes are just briefly mentioned and few details are provided. A few major classes are briefly presented below to give a basic overview of what is known of the material assemblages from the Buried City sites.

\subsubsection{Tool Assemblages}

As noted earlier, most investigations have focused on large house foundations and the reporting of those primary features, and very little information has been published in the way of either detailed descriptions or precise quantifications of artifacts from the various excavations. The work conducted by D. Hughes in 1985 at Courson A and Courson B has produced the only in-depth information publication of data on artifact assemblages (D. Hughes and HughesJones 1987). D. Hughes (1991) also presented some general artifact distribution maps for Courson A, B, D, and Kit Courson sites, but did not include details on the artifact assemblages, although some of the ceramics are highlighted. Nowhere are the volumetrics of excavations presented, so artifact densities cannot be calculated for any of the sites or houses.
Based solely on the reporting of the 1985 investigations (D. Hughes and Hughes-Jones 1987), a broad overview of the stone and bone tool assemblage is possible. The projectile point types represented at Courson A include Harrell, Washita, and Fresno, with corner-notched arrow points and dart points added to these at Courson B. Bifaces from both Courson A and B include diamondshaped beveled knives and ovate knife forms. Other tools include unifaces, "guitar pick" scrapers, " $T$ " shaped drills, and retouched flakes of various shapes and types. Ground stone tools were present at both Courson A and B, and include manos, slab metate fragments, and grooved shaft abraders.

Bone artifacts were not mentioned from Courson A, but Courson B yielded a few. In summary statements throughout the various reports, deer metapodial awls, bison rib "rasp" fragments, double hole bison rib shaft straighteners, antler tine flakers, bison tibia digging sticks, bison horn core scoops, bison scapula shovels or trowels, are all mentioned.

\subsubsection{Ceramic Assemblages}

As noted above, Lintz (1986) incorporated the Buried City materials into his Antelope Creek phase based primarily on the presence of the stone house foundations and comparable artifact assemblages. At that time Lintz had no published information concerning the types and frequencies of the ceramic assemblages from Buried City.

Subsequently, D. Hughes and Hughes-Jones (1987) presented some sherd frequencies and groupings on pottery based on their observations of the exterior surface finishes and tempers present in pottery from the 1985 investigations at Courson A. A possible corn/maize cob impressed "paint pot" was recovered from Courson A. Similar paint pots have been recovered primarily from sites in the Washita River area of western and central Oklahoma (Brooks and Drass 2005).

D. Hughes and Hughes-Jones (1987) also present information on the pottery from Courson B. On the basis of surface treatments, they identified the various frequencies of exterior finishes as 38 percent cordmarked (Figure 3-11), 18 percent with smoothed-over cordmarkings, 16 percent as plain, 
and 28 percent as indeterminate, due to the damaged condition of the sherds.

Importantly, they indicated that the "temper in all pottery is a uniform very fine quartz sand with subangular to subrounded frosted particles in a very dark paste". They discussed six body sherds in greater detail and provided discussions concerning the various rim sherds. The rim sherds from Courson B are more extensively decorated than the unanalyzed pottery from the Antelope Creek phase core area sites. At Courson B, some rims are collared-indented, filleted, shell impressed, indented everted, pinched, and incised (Figures 3-12 and 3-13). A Courson Pinched type with three subtypes (Styles A, B, and C) is introduced as a new type (D. Hughes and Hughes-Jones 1987:78).

D. Hughes (1991:143) stated that ceramic variability is a key characteristic of the Buried City complex. Although limited detailed technical analyses of the pottery are presented, D. Hughes states that most panhandle sites are tempered with crushed rock and are thin, hard, and simply cordmarked (D. Hughes 1991, 2002). Previously, D. Hughes and HughesJones (1987:73), in discussing pottery from Courson B stated that "all the pottery was a uniform very fine quartz sand with subangular to subrounded frosted particles”. Apparently, at least two groups of pottery are represented in the Buried City assemblages. D. Hughes (1991:144) went on to state that the ceramic tradition at the Courson ruins (Courson $\mathrm{D}$ in particular) was thick, poorly fired, rounded globular or subconoidal vessels tempered with fine to very fine quartz sand. The neck, shoulder, and rim sherds show that vessels frequently had high, slightly flaring rims. It has often been proposed that thick cordmarked sherds and vessels were related to the Early Ceramic period or Woodland period in the Texas panhandle. This appears to contradict the statement cited above, so it is unclear how well these two different kinds of pottery described for this ceramic assemblage can be distinguished one from the other, or how they may be interrelated.

On the other hand, body sherds comprise about equal proportions of smoothed ware (including smoothedover cordmarked vessels), and cordmarked ware. Additional surface treatments often are present.
Larger pieces sometimes bear incised chevron motifs, and/or crenelated, filleted, pinched, gouged, incised, punctated, and fluted rims, as well as a variety of other treatments (D. Hughes and HughesJones 1987; D. Hughes 1991; 2002).

Because decorations on the sherds from Buried City sites contrast to those from Antelope Creek phase core area sites, D. Hughes (2001) proposed the term "Buried City complex", believing the ceramic assemblage was significantly different from the Antelope Creek phase materials to justify a separate taxonomic designation. More recently Brosowske (2005) has reassigned all the Buried City materials to the Odessa phase (Brosowske and Bevitt 2006). Brosowske and Bevitt (2006:182) indicate that, based on pedestrian surveys and analysis of site collections, the Odessa phase sites do not extend south of Wolf Creek valley and do not extend west of Palo Duro Creek valley in Hansford County. The Odessa phase extends to the north and east across into western Oklahoma and northward into southern Kansas. Brosowske (2005) linked all the Buried City materials to the Odessa phase, based on similarities of material assemblages, mostly the decorated rim sherds, and the presence of pithouses, which have come to light since 2000. Close reading of the ceramic descriptions presented by D. Hughes (2002) indicates that multiple types of ceramics are present at Buried City sites and combining them all into one specific phase at this time seems premature. This is especially true since so little descriptive detail or technical information are published on the ceramic materials from the Antelope Creek phase, the Buried City complex and the proposed Odessa phase.

Brosowske (2005) states that the now recognized pithouses at Buried City predate the earliest stone foundations there. The pithouse dates are about 520 to 700 B.P. (cal A.D. 1250 to 1430 ) or similar to Lintz's "Early Phase" of Antelope Creek phase, which lacks pithouses. Brosowske (2005) suggests that the pithouses were the original house form at Buried City and that stone foundation structures were a later development. Consequently, the Buried City complex contains materials of various ages, and these may relate to multiple phases or complexes. 


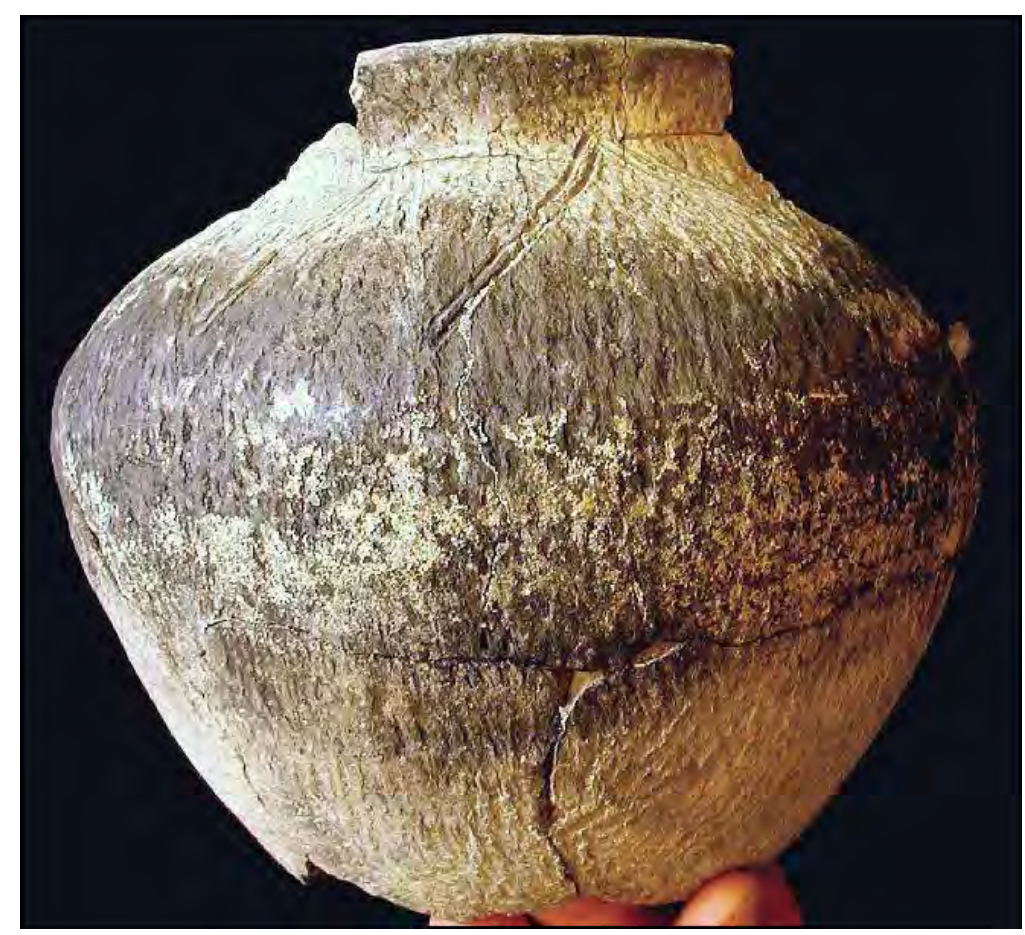

Figure 3-11. Partially reconstructed cordmarked vessel with incised rim and shoulder from Buried City (picture from Texas Beyond History Web Page, Buried City Exhibit, photo by S. Black).

\subsubsection{Subsistence}

In general, faunal analyses have not been conducted or published for any of the Buried City sites. The only information provided is in the form of summary or overview statements, or discussions concerning materials from specific feature. Bones of both bison and deer are mentioned, and tools made from the bones of these two species have been reported. Bones of birds, tortoises, rodents and fish are reported, at least for Courson B. A carnivore, possibly either a dog or coyote, was recovered from Feature 2 at Courson A. Some animal bones revealed cut marks, and the presence of numerous small fragments could indicate either intensive processing or simply deterioration from weathering. Interpreting the findings at Courson A, D. Hughes and Hughes-Jones (1987:55) note that bison bones were of limited occurrence, though they suggest this could be sampling bias.

Charred corn/maize kernels were recovered from trash pits at Courson A and B (D. Hughes 1991), and corn cob impressed pottery is present, so it is apparent corn was present at Buried City sites. One possible charred piñon nut hull and possible charred squash seed were in Feature 2 at Courson B (D. Hughes and Hughes-Jones 1987; D. Hughes 1991).

Freshwater mussel shells are abundant at most sites, but it is not clear if this was a major food resource (D. Hughes 1991). The shells may have selected for other purposes, such as use for tools, and may not be present in sufficient quantities to indicate any significant dietary role for mussels.

Brosowske (2005:138) indicates that cultivated corn parts, squashes, sunflower seeds and beans have been identified at 41OC29, Courson D. Identified remains of wild plants include sunflower, dropseed, hackberry, bulrush, evening primrose, smartweed, grape, knotweed, Johnny jump-up, purslane, poke, prickly poppy, and argemene. This is probably not an exhaustive list of the wild plants that were gathered, as many of the features investigated at Buried City may not have been sampled through flotation, or 
the results are not published. The array of identified plants does indicate that collecting and horticulture were both means of obtaining edible plant foods. A fairly broad subsistence base is indicated, although the proportions of wild verses domesticated plants in the overall diet remains unknown.

\subsubsection{Burial Customs}

Since excavations have focused primarily on the large rock house foundations, the complete range of other cultural patterns, including burial practices, are not be fully understood at present. However, a few individual human remains and one likely mass burial of at least five individuals were excavated during the investigations at Buried City. The mass burial was under a rock cairn above the southeastern corner of the rock foundation house at Courson B. The cairn was apparently constructed from scavenged rock from house foundation. Under this mass of rock were the remains of at least four adults and one juvenile (D. Hughes and Hughes-Jones 1987; D. Hughes 1991). The skeletons were in various orientations and lacked grave goods, except for a stone pendent recovered with the juvenile (D. Hughes and HughesJones 1987; D. Hughes 1991). A second multipleindividual burial may be present at $410 \mathrm{OC} 48$ (Hughes 1991:115). Very limited work has been conducted at these ruins, so only limited information is available. Eyerly (1908:222) stated that "all excavations have yielded remains of human bones”. He interpreted that mounds were created for burials (Eyerly 1908:227). Later, Eyerly (1912:2) noted that an arrowpoint was embedded in a bone of one individual at Buried City. Thus, there is at least one indicator of violent conflict during the relevant time period.

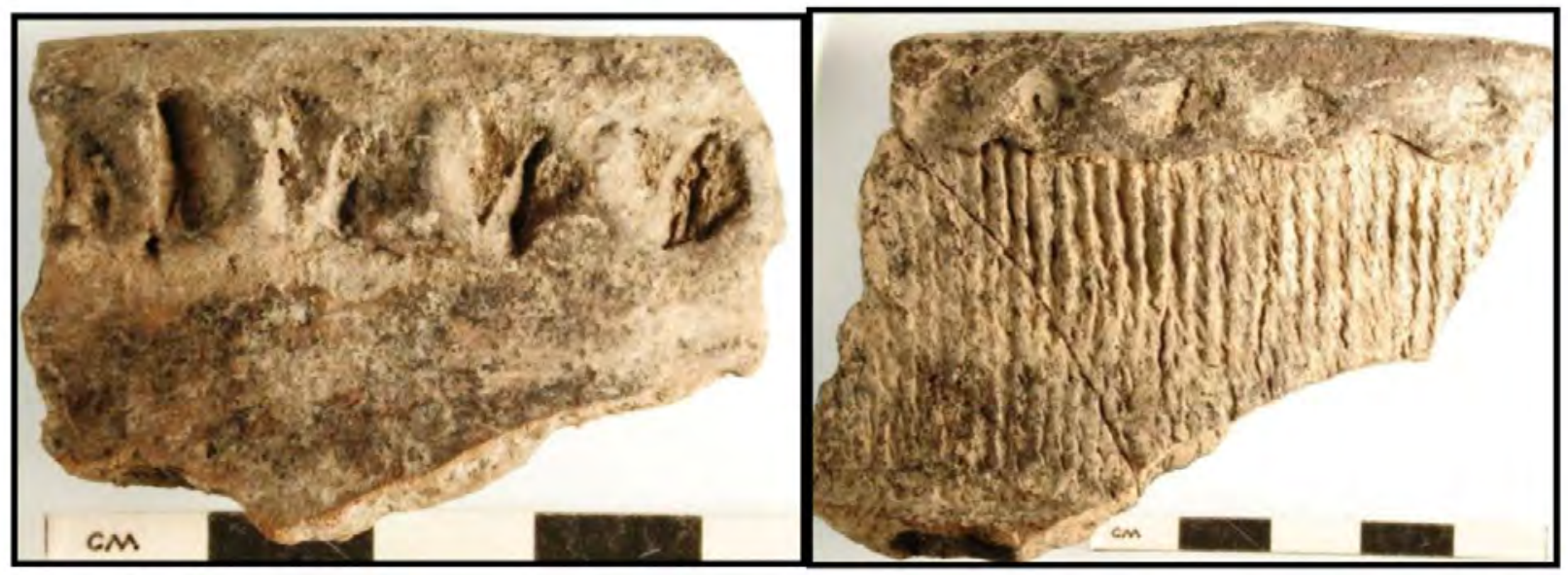

Figure 3-12. Two examples of decorated rim sherds from Buried City.

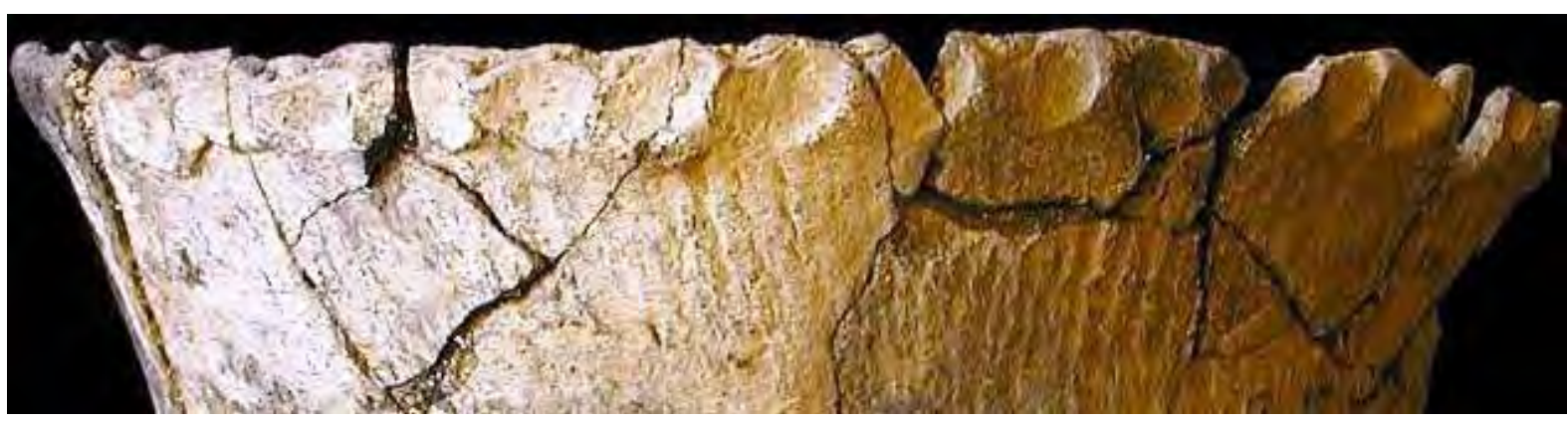

Figure 3-13. Closeup of decorated rim on cordmarked vessel from Buried City (picture from Texas Beyond History Web Page, Buried City Exhibit, photo by S. Black) 
In a subdivision of Buried City proper (410C1), another cairn burial that contained the remains of a single body was excavated. Grave offerings include a few beads (unspecified type) and tools (unspecified type, D. Hughes and Hughes-Jones 1987:104). Another burial without grave goods was discovered at the Handley ruin. The burial was placed face down with head to the northwest, arms flexed, legs flexed at the knees, and was inside a rock wall (Moorehead 1920b; D. Hughes and Hughes-Jones 1987:20). A few remains of a fragmentary skeleton that consisted of a broken femur, some teeth, some ribs, and a broken tibia were recovered from inside the Eyerly ruin (Moorehead 1920; D. Hughes and Hughes-Jones 1987:21). Generally speaking, bodies were normally semiflexed, resting on their sides, backs and stomachs.

Eyerly (1908) refers to numerous Indian graves on the promontories and buttes along Wolf Creek. He also mentions an Indian burial ground downstream from Buried City. Numerous rock cairns are known along Wolf Creek, and many have been vandalized. The lack of well-executed excavations of burials, cemeteries, and cairns, combined with the absence of detailed reporting of the results leaves considerable room for misinterpreting what data do exist. The one dated individual at 240 B.P. documents that that particular individual was not associated with the earlier populations that constructed the large houses that have been excavated.

\subsubsection{Trade/Exchange}

Alibates silicified dolomite appears to have been the most common lithic material used at Buried City sites, although the data represents only one season of fieldwork (D. Hughes and Hughes-Jones 1987; D. Hughes 1991). A few flakes of yellow jasper are mentioned by D. Hughes and Hughes-Jones (1987:103). This potentially is Niobrara jasper from northern Kansas. A few pieces of Kay County chert from western Oklahoma were also identified at Courson B. Confirmation of these sources will have to await INA analyses. Surprisingly, an obvious and easily recognized material, obsidian, is not mentioned in any of the Buried City reports.

D. Hughes and Hughes-Jones (1987) also refer to a few pendants of amazonite, a green potassium feldspar, at Courson B, the Kit Courson house site, and other sites in the area. Marine shell beads, a possible conch columella bead, and other marine shell pieces are only represented at Courson B in burial contexts.

No southwestern trade ceramics are reported from the Buried City sites, in contrast to many findings of such at the Antelope Creek phase sites. On the other hand, the decorated rim sherds (e.g., incised rims, pinched, punctuated, and brushed sherds) have affinities with the Kansas Geneseo types to the north (D. Hughes and Hughes-Jones 1987:106). It is not clear if the plainwares represented by sherds at Buried City were imported or of local origin.

The near absence of Southwestern pottery, obsidian, turquoise and marine shells indicate that there was little, if any, trade/interactions with Southwestern groups. This contrasts with the many Antelope Creek phase sites that have yielded at least some Southwestern pottery and obsidian (Watson 1950; Lintz 1986, 1989, 1991; Wyckoff 1989, 2004). The presence of Niobrara jaspers from northern Kansas and the similarities of the decorated rims to Kansas Geneseo ceramic types may reflect a trade or exchange network that is more northward oriented. Overall, significant data has not yet been presented to adequately address the question of the directions and/or extent of trade relations at Buried City.

Although analyses of most data concerning the Buried City complex has yet to be completed and published, certain aspects of this complex differ from aspects of the somewhat better defined Antelope Creek phase. Table 3-7 presents the better known aspects for each, with currently the more obvious differences between the two manifestations in the actual structures and the ceramic assemblages, although more descriptions and analysis of assemblages are needed to demonstrate the broader characteristics of each.

\subsection{Investigations at M-Cross Ranch}

Background on selected sites at the M-Cross Ranch is pertinent to the Long View project for multiple reasons, as work on that ranch has focused on house structures pertaining to the Woodland/Middle Ceramic and Plains Village periods. Plus, 18 ceramic 
sherds from 4 investigated sites at M-Cross Ranch are used here as part of the 2 technical analyses conducted, to compare with those from the Long View site. A secondary cremation burial (41RB102) from the ranch has been investigated and reported upon, which may represent the Plains Village period (Wilkens et al. 2005).

Archeological investigations at this private ranch are ongoing and are being funded by the local land owner, John Erickson. The M-Cross Ranch is about $10 \mathrm{~km}$ (6.2 mi.) due east of the Long View site and in a similar Canadian breaks setting. The ranch is roughly $8 \mathrm{~km}$ (5 mi.) north of the Canadian River and contains numerous archeological sites, including among others, Indian Springs (41RB81), Erickson Caprock Site (41RB102), Dykema burial (41RB106), Whistling Squaw (41RB108), Hank's site (41RB109), Hank B (41RB109B), and Three Toes (41RB110) (Boyd 2008, personal communication). The archeological investigations at these sites have been, and continue to be, a joint venture of professional and avocational archeologists and volunteers. Investigations began in 2000 and have been ongoing sporadically at the various sites listed above since that time.

Only a few short articles have appeared concerning the archeological work at M-Cross Ranch (Boyd and Wilkens 2001; Wilkens et al. 2005; Maki 2005; Cruse 2007; Boyd 2008). One such article was a short presentation of the initial information on a burned house structure at Hank's site (41RB109) that was excavated. The seven page article primarily addresses the salvage investigations of one-half of a burned house, Hank's House \#1, and six exterior features near the house (Boyd and Wilkens 2001). The nonarchitectural features were described, but detailed analysis has yet to be conducted. The authors presented their initial findings and discussed aspects of house construction. The discovered characteristics of the house are very important, specifically since this house lacked any rock in its construction, unlike the typical slab-lined Antelope Creek phase houses further west or the Buried City rock houses just to the north. Initially the house was thought to be a Woodland period structure (Cruse 2007). A charcoal date on juniper wood from the roof fall yielded a $\delta^{13} \mathrm{C}$ corrected age of $880 \pm 40$ B.P. (Beta-145549).
Very specific construction details came to light from the excavations of Hank's house, because the house had burned, thus preserving many aspects that usually do not remain in the archeological record. Briefly, the specifics of the house include a central hearth lined with a thick layer of well-fired clay, a clay plastered entry ramp with a raised step that opened to the east, a raised channel lip higher than the adjacent benches, a rectangular exterior post hole pattern with 21 post per side and an absence of rock supports, two (and originally, probably four) large interior roof support posts and considerable amounts of clay along the inner wall segments (Figure 3-14; Boyd and Wilkens 2001). Details of the wall construction also came to light, including burned daub with stick and grass impressions that indicate a superstructure with a thatched roof, and a probably clay-lined smoke hole. The overall rectangular shape, size and the east facing entryway are typical of a Type 1 Antelope Creek phase house form (Lintz 1996). However, it did lack the typical Antelope Creek phase vertical rock-slab supports or caliche rock foundations seen at Buried City. Boyd and Wilkens (2001) referred to Hank's house as a pithouse, whereas Lintz (1986) uses the term semisubterranean structures for the main group of Antelope Creek phase houses. This may be a question of interpretation related to the depth of the floor in the bottom of the structure. Boyd and Wilkens (2001) postulate the floor was perhaps 70 to $120-\mathrm{cm}-$ below the original surface. However, sloping earthen walls were not observed.

In 2004 an on-line exhibit written by D. Boyd was released concerning the field investigations of the burned house at Hank's site (www. texasbeyondhistory.net). This well-illustrated exhibit for the general public provides some details concerning the excavations and the burned structure. Much of the information was taken from the earlier Boyd and Wilkens (2001) article.

A second report deals with geophysical investigations at Three Toes (41RB110) in the West Pasture of the ranch (Maki 2005). The geophysical investigations were implemented to help locate buried archeological features, which then could be targeted through excavations. The goal was to identify and prioritize the three most probable archeological anomalies at two locations. At Three Toes proper, some 4,500 
Table 3-7. Comparison of Selected Aspects of Antelope Creek Phase and the Buried City Complex.

\begin{tabular}{|c|c|c|c|c|c|c|c|c|}
\hline $\begin{array}{c}\text { Phase/ } \\
\text { Complex } \\
\text { (Primary } \\
\text { References) }\end{array}$ & House types & Features & Subsistence & Ceramic Artifacts & $\begin{array}{l}\text { Chipped } \\
\text { Stone } \\
\text { Artifacts }\end{array}$ & $\begin{array}{l}\text { Ground } \\
\text { Stone } \\
\text { Artifacts }\end{array}$ & Bone Tools & Burials \\
\hline $\begin{array}{l}\text { Antelope Creek } \\
\text { Phase (Green } \\
\text { 1967; Duffield } \\
\text { 1970, Lintz 1986, } \\
\text { Keller 1975) }\end{array}$ & $\begin{array}{c}\text { diverse architecture; } \\
\text { vertical slab foundations for } \\
\text { most; some picket-post with } \\
\text { no rock, single, multiple; } \\
\text { hamlets, homesteads, } \\
\text { sub-homesteads; round, } \\
\text { square, irregular, } \\
\text { rectangular, House Type } \\
1 \text { has floor channels } \\
\text { with benches on sides, } \\
\text { Type } 1 \text { also sometimes } \\
\text { semisubterranean. }\end{array}$ & \begin{tabular}{|l} 
\\
storage pits, \\
slab cists, \\
rock cairns
\end{tabular} & \begin{tabular}{|} 
diverse: hunting- \\
bison, deer, rabbit, \\
rodents, turtles, \\
fish, mussels, \\
birds-marrow and \\
grease extraction; \\
plants: grasses, \\
cattails, plums, \\
berries, mallow; \\
domesticated crops: \\
corn, squash, beans;
\end{tabular} & \begin{tabular}{|c|} 
globular fine cordmarked, \\
low incidence of collared \\
rims (Roper, Cottonwood \\
Creek) rims: short, vertical, \\
slightly flared, non-collared, \\
tempered with igneous \\
materials; most ceramics \\
not studied; temper mostly \\
sand, crushed rock, mica, \\
bone; decoration is rare; \\
trade wares present from \\
Southwest
\end{tabular} & \begin{tabular}{|c} 
points (Harrell, \\
Fresno, \\
Washita), \\
bifaces, \\
scrapers, \\
retouched \\
flakes, drills, \\
beveled knives, \\
guitar pick \\
scrapers
\end{tabular} & $\begin{array}{c}\text { manos, } \\
\text { metates, } \\
\text { abraders, } \\
\text { hammerstones, } \\
\text { pipes }\end{array}$ & \begin{tabular}{|l} 
bison tibia \\
digging \\
sticks, \\
scapula hoes, \\
rasp, rib \\
tools, beads, \\
awls \\
\end{tabular} & \begin{tabular}{|} 
cairns, simple semi- \\
flexed, primary, \\
placed in middens \\
or cemeteries, at \\
or near homestead \\
and hamlets; \\
ossuary pits-inside \\
structures; grave \\
possessions-rare and \\
in small quantities; \\
individuals represent \\
a cross-section of \\
sex and age (Lintz \\
1986)
\end{tabular} \\
\hline $\begin{array}{l} \\
\text { Buried City } \\
\text { Complex (D. } \\
\text { Hughes \& } \\
\text { Hughes-Jones } \\
\text { 1987; D. Hughes } \\
\text { 1991; 2001) }\end{array}$ & $\begin{array}{c}100+\text { caliche cobbles } \\
\text { forming typical large } \\
\text { rectangular bases enclosing } \\
\text { about } 64 \mathrm{~m}^{2} \text {; oriented east; } \\
\text { mostly isolated from similar } \\
\text { structures; with central } \\
\text { fireplaces; plastered walls, } 4 \\
\text { types: no rock, large single } \\
\text { room with rock, large multi- } \\
\text { room with rock; possible } \\
\text { pithouses; central hearths- } \\
\text { clay-lined; entryways, } \\
\text { house patterns similar to } \\
\text { Antelope Creek types I and } \\
\text { II (square and rectangular) } \\
\text { Hughes and Hughes-Jones } \\
\text { 1987; Hughes 2001 }\end{array}$ & \begin{tabular}{|l} 
\\
central \\
hearths in \\
structures, \\
trash pits, \\
cache pit, \\
burned area, \\
butchering \\
area, rock \\
cairns \\
\end{tabular} & \begin{tabular}{|} 
hunting: bison, \\
deer, fish, rodent, \\
bird; burned and \\
unburned bone, \\
mussel shell; corn \\
and beans; no \\
macrobotanical \\
analysis conducted \\
(Hughes and \\
Hughes-Jones \\
1987)
\end{tabular} & $\begin{array}{c}\text { globular vessels w/rounded } \\
\text { bottoms; high frequency of } \\
\text { collared rims and decorations } \\
\text { (pinched, incised, punctated) } \\
\text { confined to neck and rim; } \\
\text { cordmarked (52\%) and plain } \\
\text { exteriors (16\%), smoothed } \\
\text { over cordmarked (28\%); } \\
\text { collared rims tempered with } \\
\text { sedimentary materials; rims- } \\
\text { straight, lip-flat, paint pallet; } \\
\text { few sub-conical vessels with } \\
\text { direct rims with scoria (?); } \\
\text { metric attributes similar to } \\
\text { Antelope Creek sherd }\end{array}$ & \begin{tabular}{|c} 
points (Harrell, \\
Fresno, \\
Washita), \\
bifaces, \\
scrapers, \\
retouched \\
flakes, drills, \\
beveled knives, \\
guitar pick \\
scrapers \\
\end{tabular} & $\begin{array}{c}\text { manos, } \\
\text { metates, pestle } \\
\text { abraders, } \\
\text { hammerstones, } \\
\text { pipes }\end{array}$ & \begin{tabular}{|} 
bison tibia \\
digging \\
sticks, \\
scapula hoes, \\
rasp, rib \\
tools, beads, \\
awls
\end{tabular} & $\begin{array}{l}\text { cairn above houses; } \\
\text { semiflexed (Courson } \\
\text { B and Kit Courson) }\end{array}$ \\
\hline
\end{tabular}




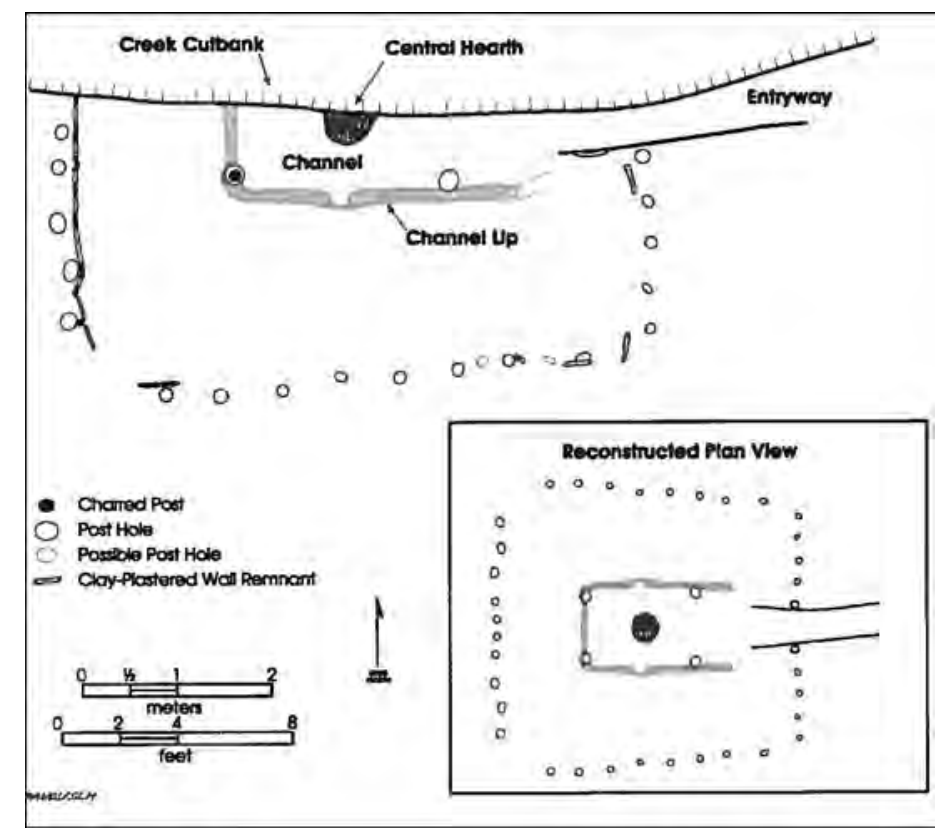
Figure 3-14. Plan map of Burned Structure \#1 at Hank's sites (after Boyd and Wilkens
2001:3, Figure 3)

$\mathrm{m}^{2}$ were geophysically surveyed with another 3,600 $\mathrm{m}^{2}$ surveyed across the lower terrace. The survey employed magnetic field gradiometry using a Geoscan Research FM256 fluxgate gradiometer (Maki 2005). The very preliminary results were presented graphically with specifically identified anomalies to be targeted by archeologists at a later date. At Three Toes proper, anomaly \#1 had an electronic signal that indicated the presence of a storage/refuse pit or hearth. Anomaly \#2 had a signal that reflected a rectilinear pattern, possibly representing a buried house. Anomaly \#3 may have represented a buried cultural feature. Other anomalies were present that could also represent cultural features. In the lower terrace, below Three Toes proper, a larger linear magnetic anomaly, \#1, stood out. This may have represented a ditch filled with a material that differed from the surrounding soil. Anomaly \#2 may have represented a storage/refuse pit or hearth. Anomaly \#3 may have been a stone-lined house feature, although the signal was weak. Several other anomalies were seen but, in general, the rest of the terrace was devoid of possible archeological signals (Maki 2005). Ground truthing was recommended to verify or refute the geophysical findings and interpretations. Unfortunately, it is not clear whether ground truthing has been conducted, and no reports have been presented to date.
A third short article deals with some of the investigations conducted at Indian Springs (41RB81; Cruse 2007) with a brief discussion of M-Cross Ranch and Indian Springs in Boyd (2008). This is a multicomponent site at a spring with a large surface rock alignment that appears to represent a house foundation (structure 1) associated with an extensive midden deposit, surface artifacts, and other cultural features. Based on surface artifacts such as thick parallel-cordmarked ceramics and corner-notched arrow points, this structure was initially thought to represent a Woodland period house. Known Woodland houses are lacking in the Texas panhandle. Over a ten year period since 2000, sporadic excavations have focused on this apparent house foundation as well as four or five adjacent cultural structures and features. A brief description of the reported features is presented below.

Structure 1 is a large, roughly rectangular structure with a floor area of about $86 \mathrm{~m}^{2}$. Hand-excavations have exposed about 60 percent of the structure. The unprepared caliche rocks, which are not slabs like those in the Antelope Creek phase houses are arranged as a single layer, without stacking. The caliche rocks appear to have been placed in a shallow trench. No wall post holes, entryway or 
prepared floor have been recognized thus far (Cruse 2007). The structure appears to be shallowly buried, about 20-cm-below surface, and was constructed in a midden deposit that slopes to the south, away from the spring. Four internal features (Features 4, 5, 6 and 7) have been detected and excavated. At least one post hole, $20 \mathrm{~cm}$ in diameter, is located in the southwestern quadrant. Feature 4 was a cluster of bison bones, $60 \mathrm{~cm}$ in diameter, near the north wall. Feature 5 was a circular, rock-filled basin hearth that measured $50 \mathrm{~cm}$ in diameter and located $4 \mathrm{~m}$ from the south and west walls. Wood charcoal from this hearth yielded a $\delta^{13} \mathrm{C}$ corrected radiocarbon age of $1040 \pm 40$ B.P. (Beta-145549; Boyd 2008). Cruse (2007) interprets the date to indicate a Woodland period chronological position for Structure 1.

Feature 6 is a $1 \mathrm{~m}$ diameter circular pit, 61-cmdeep, which likely functioned as a storage pit. Wood charcoal from this pit yielded a $\delta^{13} \mathrm{C}$ corrected date of $1130 \pm 40$ B.P. (Beta-223739; Boyd 2008). Feature 7 is another pit feature that measured $70 \mathrm{~cm}$ in diameter and was 30-cm-deep. Three manos were in the bottom of this pit.

Two other surface structures (Structures 2 and 3) were marked by small rock rings. Each ring was constructed with unmodified caliche rocks and had a diameter of roughly $4 \mathrm{~m}$. A central hearth that measured 6-cm-deep and contained charcoal flecks was discovered in Structure 2. Wood charcoal from this hearth yielded a $\delta^{13} \mathrm{C}$ corrected radiocarbon age of $320 \pm 40$ B.P. (Beta-167105, Boyd 2008). Structure 3 also contained a shallow, unlined central hearth with charcoal flecking. Wood charcoal from that hearth yielded a $\delta^{13} \mathrm{C}$ corrected age of 490 \pm 40 B.P. (Beta-167106, Boyd 2008). The two radiocarbon dates indicate that these two rock ring structures relate to the terminal Plains Village period or to the early Protohistoric period (Cruse 2007).

Structure 4 was completely excavated and revealed a small circular pithouse that measured $2.3 \mathrm{~m}$ northsouth and 1.8 m east-west, and was about 40 -cm-deep. A sloping ramp-like entrance on the western side was 1.8-m-long and 60-cm-wide. A shallow step or basin was at the outside edge of the entryway. No structural post holes or rocks were detected. A gray clay matrix filled the pithouse and is assumed to represent the collapsed material that originally covered the structure (Cruse 2007:15) or as Boyd (2008:45) states a small earth covered lodge with a west-facing entryway. Three small pit features (Features 2, 8, and 9) were on the floor of the pithouse. All three contained ash, and the central ash pit yielded two charred corn/maize cobs and a piece of cordmarked pottery (41RB81256). Charred wood from the central pit yielded a $\delta^{13} \mathrm{C}$ corrected radiocarbon age of $660 \pm 40$ B.P. (Beta176933, Boyd 2008). Wood charcoal from a second pit yielded a $\delta^{13} \mathrm{C}$ corrected age of $620 \pm 40$ B.P. (Beta176934, Boyd 2008). These two radiocarbon ages place this pithouse in the middle of the Plains Village period. Cruse (2007) suggests this pithouse had either a ceremonial or residential function. Lintz (1986) does not mention small circular pithouses as one of the 11 structural types he identified for the Antelope Creek phase. However, pithouses are characteristic of the Odessa Yates site (34BV100) of the proposed Odessa phase to the north in the Oklahoma panhandle (Brosowske 2005, Brosowske and Bevitt 2006).

A sizable sample of artifacts was recovered from the excavations at Indian Springs, but it must be remembered that multiple occupations are represented that span at least the last 1,100 years. The artifact analysis has not been completed, although the data from the ceramic assemblage has been assembled (Lintz, personal communication 2010). The projectile point assemblage is dominated by corner- and basal- notched arrow points classified as Scallorn and Deadman, which Cruse (2007:15) notes as typical of Woodland period sites in the region. Washita and Reed arrow points are also present, and these types are more typical of Late Prehistoric Plains Village occupations. A few dart points have also been recovered, indicating a long span for the occupations at Indian Springs.

The current ceramic assemblage is characterized by thick-walled, parallel-cordmarked wares thought to represent jars. Most rims are undecorated, but a few show lip decorations in the form of stick or fingernail impressions. Bone, grit, and grog were the favored tempering agents (Cruse 2007; Lintz, personal communication 2010). Cruse suggests that the ceramics are typical of Woodland period pottery of the Southern Plains. 
A fourth and most recent article concerning the M-Cross Ranch sites discusses the role of prehistoric agriculture in the region (Boyd 2008). Until recently, most authors have downplayed the importance of prehistoric farming in the region. Based on new evidence from the M-Cross Ranch, however, Boyd argues that prehistoric agriculture in the eastern Texas panhandle was a significant economic practice, in contrast to the view held by previous researchers (e.g., Habicht-Mauche et al. 1994; Hard et al. 1996; Duncan 2002, 2006; Brosowske 2005). Boyd discusses the role that agricultural might have played and examines multiple lines of direct and indirect evidence to support his argument. He presents brief discussions concerning the current evidence from the M-Cross Ranch sites investigated (Boyd 2008), and concludes with some thoughts about prehistoric agricultural practices at the ranch, suggesting that several crops, such as corn, beans, squash and others were likely planted by these Plains Village farmers. He speculates that the early farmers were probably very knowledgeable about the crops they grew and related techniques of water control. He also notes the importance of comprehensive landscape studies to identify agricultural field areas and farming features, and mentions plans to conduct such studies at M-Cross Ranch.

\subsection{Investigations at the Courson Property}

The 2008 and 2009 Texas Archeological Society (TAS) held its annual field schools on Courson Oil and Gas property and adjacent lands (Brosowske 2008, 2009a, 2009b, 2009c). A number of sites of different types and ages were investigated, including Plains Village sites such as Chill Hill (41RB132), Archie King II (41RB121), Killer (41RB152), Eastview (41RB153), a hunter-gatherer camp site called Bee Jay (41RB113), the Halston (41OC100) historic Indian encampment, and Evan's Military Supply Depot (41RB110). Surveys were also conducted. Work is in progress, and to date, no substantial reports are available to provide descriptions of the specifics results of the excavations.

Of specific interest is Chill Hill (41RB132), which is only $2 \mathrm{~km}$ south of the Long View site. This site represents a large Plains Village with abundant artifacts, numerous rock lined house structures, and ancillary features such as storage pits, middens, and hearths, all indicating intensive occupation (Brosowske 2008). A number of large excavation blocks were opened and various features were found and recorded. A radiocarbon dating program, macrobotanical analysis, and geoarcheological investigations, are all underway (Brosowske 2009b). When the results are published, the information should provide significant insights into the activities associated with Plains village life at this location.

Also of interest is a second Plains Village site just west of Long View in Couch Creek, the Archie King II site (41RB121), an Antelope Creek phase homestead with rock foundation houses. A geophysical survey was conducted over an area of 30-by-90 m. Six subtle, subsurface magnetic anomalies were identified and thought to represent features of cultural origin (Brosowske 2009c:13). The 2009 field school tested a roughly 3-m-wide anomaly through hand-excavation of a number of $1 \mathrm{~m}$ units. Although some units were completed, not all were finished and subsequently Brosowske led the Courson Archeological Research staff in continued testing of this particular anomaly. In the end, the work revealed what was interpreted to be a shallow basin-shaped floor of a habitation structure about $3 \mathrm{~m}$ in diameter and some 60 -cm-deep. Two hard packed floors were identified, separated by a sterile sand layer. A layer of cultural debris about 20 -cm-thick rested on the first floor. The cultural materials recovered are characteristic of Antelope Creek phase and/or Plains Village occupations. The remains are still being processed and analyzed, and only a short summary report is currently available (Brosowske 2009c:16).

\subsection{Plains Village Tradition in Oklahoma}

In redefining the Plains village complexes in Oklahoma, Drass (1999) presented 62 radiocarbon dates and four archeomagnetic dates from 21 village sites in central Oklahoma, with which he defined the time span for his newly designated Paoli and Washita River phases. The Paoli phase dates from between 950 and 1050 B.P. (cal A.D. 900 to 1000) to around 700 to 650 B.P. (cal A.D. 1250 to 1300). The subsequent Washita River phase then lasted until ca. 500 B.P. (cal A.D. 1450). Drass also suggested that some sites are 
multicomponent and thus have yielded dates from both periods. In western Oklahoma, he identifies two phases, Custer and Turkey, phases that are more or less contemporaneous with the two central Oklahoma phases. The Custer phase dates to roughly 950 to 700 B.P. (cal A.D. 900 to 1250) and is followed by the Turkey Creek phase, which dates from 700 to 500 B.P. (cal A.D. 1250 to 1450). These phases appear analogous to Lintz's (1986) early and late subphases of the Antelope Creek phase in the Texas panhandle.

In support of the importance of agriculture by Plains Village populations in the Southern Plains region, Drass (2008) presents hard data for cultivated plants and changing economies by villagers on the Plains of western Oklahoma and northwest Texas. He reviews the paleobotanical data from sites covering the past 1,000 years and examines the role of cultivated and wild plants in these Southern Plains societies. He presents information concerning the importance of various cultivated plants in the wetter eastern tall grass prairies verses the use of these plants in the dryer settings of the western mixed and short grass prairies. Although Drass's sample sizes are small, it is apparent that plants played a key role in the Plains Village diet. Drass (2008) lists corn, beans, and squash as the main cultivated plants with a primary reliance on corn. There is also evidence for the cultivation of marshelder (Iva annua). Tobacco (Nicotiana rustica) was also grown at eastern villages dating back to 705 B.P. Wild plants collected for food include at least seeds from little barley (Hordeum pusillum) and dropseed (Sporobolus heterolepsis; Drass 2008).

\subsection{Pithouse Discussion}

The term "pithouse" is not often mentioned in discussions of the archeological record of the Texas panhandle. It has not been used when discussing Antelope Creek phase (Lintz 1976b, 1978, 1982, 1984, 1986, 1989, 2001, 2003a, 2003b, 2003c, 2004, 2011; Brooks 1989, 2004). The primary structure that characterizes the Antelope Creek phase is considered to be a semisubterranean square to rectangular house with rock slabs placed partly below the original ground surface, and the floors of Antelope Creek phase residential houses were certainly below the surrounding ground surface. However, these were not deep pits and thus researchers may differ over specific terminology and what actually constitutes a pithouse. Although not the dominant structure type in the region, semisubterranean picket-post structures with similar construction details as the vertical slab foundation houses are also scattered throughout the region (Lintz 1986, 2011).

Excavations at the Long View site exposed what appear to be two pithouses, one each in Components $\mathrm{A}$ and $\mathrm{C}$, that lacked rock slab foundations characteristic of house types typical of Antelope Creek phase, and yet the directly associated artifact assemblages from Components A and C are characteristic of Plains Village material culture. Consequently, some general background concerning pithouses is necessary and appropriate.

The term "pithouse" is often associated with the archeological record of prehistoric Southwest populations, specifically with the Basketmaker peoples of the Anasazi region as well as the adjacent Mogollon area, wherein this type of structure has a long history (Cordell 1984; Carmichael 1990; Gilman 1987, 1997). To provide a general overview of typical Southwest pithouses, the following brief discussion is presented.

Pithouses were domestic habitation structures in which the lower parts of the walls were formed by the earthen sides of an excavated pit. Pithouses were generally round to oval in shape, and measured some 4.5 to $5.0 \mathrm{~m}$ in diameter. Floors were usually dug to a depth of about 50-cm-below the ground surface. Unless the pithouse was burned, remains of the walls and roof are rarely preserved. Commonly, the parts of the walls above the ground surface consisted of a framework of poles set vertically around the edge of the pit, then interlaced with small twigs to create a framework that was completely covered with mud on the exterior (Cordell 1984:218). If the floor levels were relatively shallow, the structural walls were made of small logs and branches placed inside the pit's earthen walls. If the floor was relatively deep, the soil into which the structure was excavated formed the lower part or even all of the walls (Gilman 1997). Depth had an influence on the nature of the covering. Different types of pithouses are recognized, and the features of the different kinds of pithouses among residentially mobile groups or in different environmental settings remain unresolved.. 
Elsewhere in North America, pithouses have been archeologically and ethnographically recognized and recorded throughout the Plateau, Southwest, Arctic, Wyoming (Larson 1997), and in parts of the Central Plains (Nabokov and Easton 1990). In some areas, pithouses were used until the mid-eighteenth century (Nabokov and Easton 1990:176). In the Southwest, specifically in the Southern Jornada District of southern New Mexico and western Texas, pithouses appear in the Hueco phase (roughly 3000 to 1800 B.P.) of the Archaic period. Pithouses became more prevalent in the subsequent Mesilla phase (roughly 850 to 1750 B.P.) and the Doña Ana phase (750 to 850 B.P.) of the Formative period, which had deep pithouses as well as contiguous adobe-walled surface structures (Lehmer 1948; MacNeish et al. 1993). The Doña Ana phase is characterized by a transition from pithouses to surface structures and an increased range of ceramic types (Whalen 1981).

The early investigators in the Texas panhandle, specifically at Buried City and in the core Antelope Creek phase area, did not recognize pithouses or mention them in their discussions. The term pithouse does not appear to have been used in reference to archeological sites in the Texas panhandle until 1975. One of the earliest references found was to a structure at Black Dog Village (Keller 1975). Those investigations were performed by the Archaeological Section of the Texas Highway Department in a salvage excavation of a part of a Plains Village site just north of the Canadian River in the Antelope Creek phase core area (see below for details).

In 2001, D. Hughes presented a paper to the Society of American Archaeology in Denver concerning the Buried City architecture and settlement that discussed pit feature(s) (D. Hughes 2001). In that paper Hughes briefly discusses a few large pits, but he did not use the term "pithouse." The brief descriptions of those pits suggest to this author that some may be pithouses, but without adequate descriptions and illustrations of profiles and clear statements concerning context, it is difficult to be certain if these were houses or large storage pits.

Over the last five to seven years, the term pithouse appears in the archeological literature in the Texas panhandle region and a few of these features have been excavated. Researchers have just recently, since around 2003, started to recognize that these types of deep circular to oval pit structures are present in the Texas panhandle. Obviously, it will require time before a number of these pithouse structures are completely excavated, radiocarbon dated, and described in published reports, to enable archeologists working in the region to compare and contrast them to gain clearer understanding of these features. Below, several references and discussions of pit features and possible pithouses in the Texas panhandle are highlighted.

\subsubsection{Antelope Creek Phase Occurrences}

At the Stamper site (34TX1) in Texas County of the central Oklahoma panhandle, excavations by C. Stuart Johnston $(1933,1934)$ and Fred Carter in 1934 uncovered deep circular pits (reference no. 29 on Johnston's 1934 map, provided by Lintz 2003c:26), which was designated a "kiva" (designated A1 by Lintz 2003c:28). This feature was just south of stone slab Structure 11A (Lintz 2004:27). The "kiva" measured about $2.4 \mathrm{~m}$ in diameter, and the depth below surface was given as $1.67 \mathrm{~m}$ (Lintz 2004:28). Almost no information is available concerning this particular circular feature. Although not recognized as a pithouse, the limited measurements and accounts indicate it has the potential to be just that.

Black Dog Village (41HC30) is located along Cottonwood Creek on the north side of the Canadian River towards the eastern end of the Antelope Creek phase core area. Excavations revealed at least five different structures. Structure 4 was a circular depression, located under the slab-lined foundation of Structure 2. The latter structure (2) was referred to as a slab-lined pithouse, which contained a central post and had the appearance of an Antelope Creek phase house (Keller 1975:31). Structure 4, with a

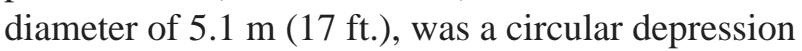
that was not rock-lined, but did contain a large central posthole, a central hearth, and a hard-packed and charred clay floor (Figure 3-15). In cross section, the floor of Structure 4 resemble a shallow basin with the sides of the depression terminating at the walls of the pit. This architectural type-- a large circular pit-had not previously been identified for the Antelope Creek phase (Keller 1975). Keller (1975:33-37) interpreted Structure 4 as a pithouse dwelling rather 


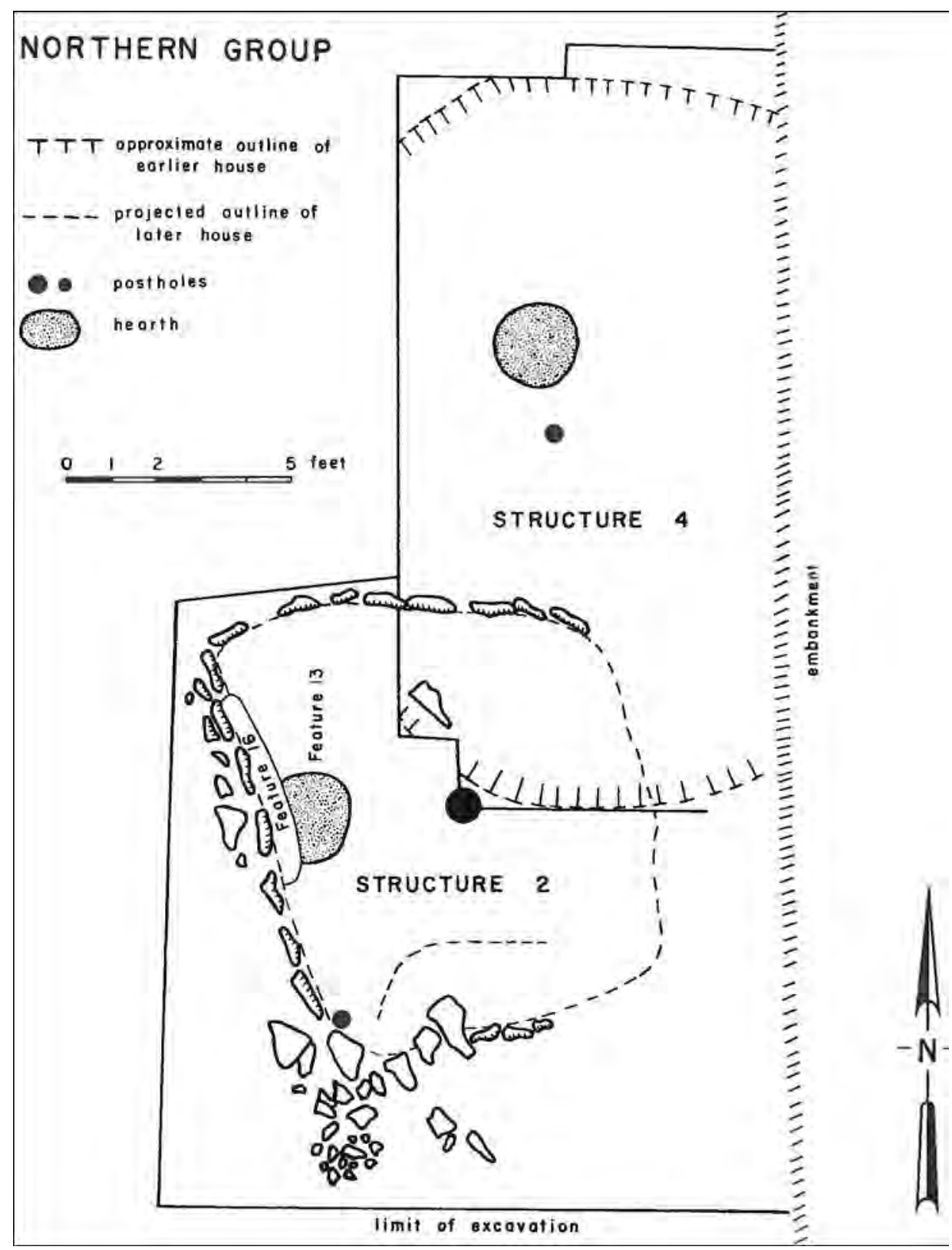

Figure 3-15. Plan map of Structure 4 at Black Dog Village (from Keller 1975:38, Figure 21).

than a storage facility. Charred timbers found within Structure 4 indicate that the superstructure burned, in contrast to the other structures excavated at the site. Four radiocarbon dates (not corrected for the $\delta^{13} \mathrm{C}$ values and uncalibrated) were obtained from the burned timbers (Table 3-8). The four dates range from ca. 390 to 510 B.P. (uncorrected and uncalibrated A.D. 1440 to 1560) with an average of ca. 470 B.P. (uncorrected and uncalibrated A.D. 1480). Structure 4 is radiocarbon dated to later than the then-accepted age range of the Antelope Creek phase. Structure 4 was stratigraphically below Structure 2, which was radiocarbon dated to ca. 300 B.P. (uncorrected and uncalibrated A.D. 1650), so these two structures and the associated radiocarbon dates were in correct stratigraphic and temporal order (Keller 1975:35). It should be pointed out that Brosowske (2005:91) believes that at least five of the radiocarbon dates from Black Dog Village (Tx1493, 1495, 1498B, 1499, and 1512) are probably 
Table 3-8. List of Radiocarbon Dates from Black Dog Village (Brosowske 2005).

\begin{tabular}{|c|c|c|c|c|c|c|c|c|}
\hline Lab. No. & Cat. No. & Structure & Feature & 14C Age (B.P.) & $\begin{array}{c}\text { Uncorrected Date } \\
\text { Range }\end{array}$ & C13 o/oo & Calibrated Date* & Reference \\
\hline Tx-1493 & N.A. & 2 & internal hearth, 13 & $250 \pm 150$ & $1670 \pm 150$ & N.A. & A.D. $1360-1770$ & Valastro et al. 1977 \\
\hline Tx-1513 & N.A. & 3 & pit, 17 & $420 \pm 70$ & $1530 \pm 70$ & N.A. & A.D. $1400-1640$ & “ \\
\hline Tx-1499 & N.A. & 3 & pit, 17 & $350 \pm 90$ & $1600 \pm 90$ & N.A. & A.D. $1400-1640$ & “ \\
\hline Tx-1498A & N.A. & 3 & pit-17, bone apatite & $500 \pm 70$ & $1450 \pm 70$ & N.A. & A.D. $1290-1530$ & “ \\
\hline Tx-1498B & N.A. & 3 & pit-17, bone collagen & $1110 \pm 200$ & $840 \pm 200$ & N.A. & A.D. $550-1300$ & “ \\
\hline Tx-1489 & N.A. & 4 & 6 & $390 \pm 50$ & $1440 \pm 50$ & N.A. & A.D. $1430-1640$ & “ \\
\hline Tx-1490 & N.A. & 4 & 6 , burned timbers & $460 \pm 60$ & $1480 \pm 60$ & N.A. & A.D. $1390-1640$ & “ \\
\hline Tx-1491 & N.A. & 4 & 6 & $470 \pm 60$ & $1490 \pm 60$ & N.A. & A.D. $1380-1640$ & “ \\
\hline Tx-1488 & N.A. & 4 & 6 & $510 \pm 60$ & $1560 \pm 50$ & N.A. & A.D. $1290-1490$ & “ \\
\hline Tx-1512 & N.A. & 5 & north central post & $980 \pm 170$ & $970 \pm 170$ & N.A. & A.D. $650-1300$ & “ \\
\hline Tx-1497 & N.A. & 5 & floor fill next to alter & $610 \pm 50$ & $1340 \pm 50$ & N.A. & A.D. $1290-1420$ & “ \\
\hline Tx-1496 & N.A. & 5 & floor fill in SE corner & $590 \pm 60$ & $1360 \pm 60$ & N.A. & A.D. $1290-1440$ & “ \\
\hline Tx-1495 & N.A. & 5 & floor fill in SE corner & $300 \pm 50$ & $1650 \pm 50$ & N.A. & A.D. $1460-1670$ & “ \\
\hline
\end{tabular}

* Two standard deviation, Stuvier et al. 1998 
erroneous dates for Antelope Creek phase, but the four dates from pit structure 4 are not among the rejected dates.

The Big House (Structure 5 or Feature 21) towards the western side of Black Dog Village revealed many structural characteristics typical of the Antelope Creek phase. These characteristics included vertically positioned slabs set in a wall trench at the base of the structure, six large central support posts along the margins of the central floor channel that was 30-cm-below the two raised benches on the northern and southern sides, a definite curb along the edge of the benches, two hearth features in the floor channel, an east facing entryway, and an altar opposite the entryway. This structure measured 5.5-by-7.9 m (18-by-26 ft) with the long axis east-west. At least two and perhaps three different living surfaces were represented in the channel floor fill. However, the one radiocarbon date of ca. 980 B.P. (uncorrected and uncalibrated A.D. 970) is some 200 years earlier than the beginning of the Antelope Creek phase as defined by Lintz (1986) and Brooks $(1989,2004)$. Based on stratigraphic evidence and the radiocarbon dates, at least three occupation periods were represented in this 28-m-long excavation area, but some dates are suspect (see Brosowske 2005:91). Based on the architectural characteristics, Keller (1975:34) had difficulty assigning these structures to the manifestations known at that time. The Big House apparently represents a typical Antelope Creek phase house. Structure 2 closely resembled houses of the Optima Focus (now part of Lintz's Antelope Creek phase). On the other hand, Structure 4 represented a new and distinct architectural style not previous identified for the Panhandle Aspect and is probably a pithouse.

T. Campbell $(1983,1996)$ reported on the 1966 and 1979 through 1980 excavations at a Southern Plains Village site known as the Greenbelt site (41DY17), located next to Greenbelt Lake in Donley County, south of the Canadian River near the headwaters of the Salt Fork of the Red River, and due east of Amarillo. The site exhibited multiple pit structures, evidence of horticulture, cordmarked ceramic sherds, and small triangular (Washita, Fresno and Harrell) arrow points characteristic of the Plains Village period. The occurrence of a village site this far south gave rise to the question as to what complex or phase was represented. Excavations focused on exposing part of a single structure (Structure \#1) that had no rock slabs to mark the foundation or pit margins. Only the eastern end of an irregular, somewhat rectangular shaped buried structure was exposed, but the wall configurations were not delineated (Figure 3-16), and revealed an irregular, somewhat rectangular, shape. Post holes and cache/trash pits were discovered along the rim of the pit but the house delineation is poor. At the northeastern corner, an L-shaped trench/tunnel/ entrance (Structure \#2) was uncovered. This entryway was $130-\mathrm{cm}$-long and 60- to 90-cm-wide. Four stacked, prepared floors were identified in Structure $\# 1$, which was determined to be a pit with a defined rim in parts of the eastern end. A second structure was probably represented as well. The western end was not excavated and the outline of the north side could only be roughly estimated. No overall pit size could be determined and the actual number of pits and their shapes is not clear (T. Campbell 1996:41, Map 5).

The recovered ceramic assemblage (650 sherds) included cordmarked (58 percent), smoothed cordmarked (31 percent), plainware (7 percent) and tradeware (4 percent) sherds. One partially reconstructed vessel exhibits vertical cordmarkings on the neck and shoulder with overlapping cordmarks on the lower body that exhibits a checkered pattern. The vessel was globular with a rounded base and a vertical to slightly flaring rim. Two sherds exhibit slight depressions along the lip and at least one sherd had a pinched tab appliqué along the shoulderneck juncture. The interior surface was smoothed (T. Campbell 1983, 1996).

Investigations by the TAS field school at the Archie King II ruins (41RB121) in 2009 revealed a geophysical anomaly that was roughly $3 \mathrm{~m}$ in diameter. A 1-by-4 $\mathrm{m}$ test unit dug into that anomaly revealed a basin-shaped depression about 3-m-long (Figure 3-17). The bottom of the depression was about 30-cm-below the ground surface at one end and dipped to about $50 \mathrm{cmbs}$ at the opposite end. A hard-packed, sterile surface at the bottom of the deposit was interpreted to be the floor of a small habitation structure. Continued excavation through that surface encountered a second, lower midden deposit similar to the first, which continued to 90 


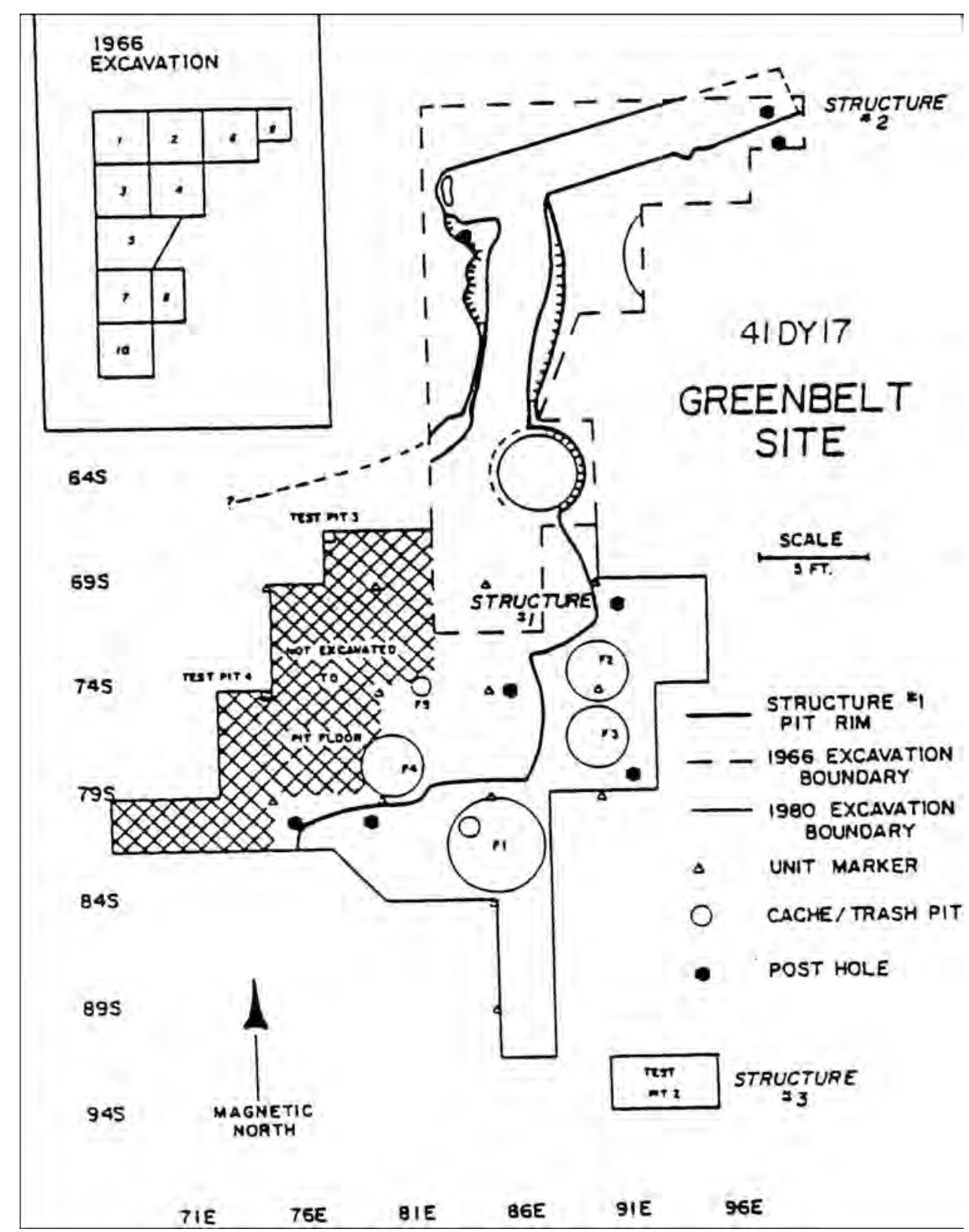

Figure 3-16. Plan map of excavations at Greenbelt site (from T. Campbell 1996:42, Map 5). 
cmbs (Brosowske 2009c:14). In the central part of the depression, a small basin-shaped hearth contained abundant ash and charcoal. Brosowske (2009c:15) interpreted these findings to indicate the presence of a shallow basin-shaped floor of a habitation structure about $3 \mathrm{~m}$ in diameter with a depth of about 60 to $70 \mathrm{~cm}$ below the A horizon. The deposits indicate that this habitation structure was occupied for a short time, followed by deposition of a trash layer about 20-cm-thick and then covered by a natural eolian deposit that consisted of $15 \mathrm{~cm}$ of sterile sand. A second occupation was evidenced by a hard-pack floor on the sterile sand layer. Although the cultural materials from this feature have not yet been completely analyzed, they include butchered bison bones that represent most of the carcass, as well as remains of deer or antelope, turtle, and birds. Parts of maize cobs and kernels were recovered in the flotation samples. Artifacts include three rim sherds from the lower floor, which represent a single vessel with a folded-over lip, bearing circular punctuate impressions. Brosowske (2009c:16) mentions that identical ceramic sherds and a similar small basinshaped habitation structure were found at Chill Hill (41RB132), just $2 \mathrm{~km}$ south of Long View.

\subsubsection{Wolf Creek/Buried City Complex Occurrences}

Courson B (41OC27), one of the 15 recorded hamlet sites along Wolf Creek, is a multicomponent site. A sequence of at least four separate houses overlap stratigraphically and horizontally (D. Hughes 2001). The earliest structure was below Structure 1, a large boulder-foundation house typical of the Buried City complex. This was a pit feature (not referred to as a pithouse in the report) that measured about 2.5by-3.0 $\mathrm{m}$ in diameter with a basin-shaped bottom. Charcoal from a firepit situated just east of the basin's center yielded a $\delta^{13} \mathrm{C}$ corrected date of $770 \pm$ 80 B.P. (report not clear if correct or calibrated A.D. 1180, Beta-20276). This structure contained bison bones and pottery that D. Hughes (2001:4) suggested resembled Woodland or initial "Neoindian" types.

A few meters south of Structure 1 with characteristics similar to those in the Antelope Creek phase, was a series of large, deep, intersecting pits that may represent one or more pithouses (Hughes 2001). A circle of postholes was found in the bottom of at least one of these pits.

At Courson A (410C26) a deep, circular pit that contained burned posts was recognized. This structure (not referred to as a pithouse in the report) measured 3.5 to $4.0 \mathrm{~m}$ with two central post supports, one on each of the two sides of the central firepit (D. Hughes 2001). A radiocarbon date of $740 \pm 50$ B.P. (report not clear if correct or calibrated A.D 1210, DIC-3281) came from pit Feature 2 in the cutbank and may date the circular pit.

Scott Brosowske, archeologist for the Courson Oil and Gas Company, has conducted investigations at several sites on Courson land holdings along Wolf Creek (Brosowske and Maki 2002). These authors located geophysical anomalies, which they suggest

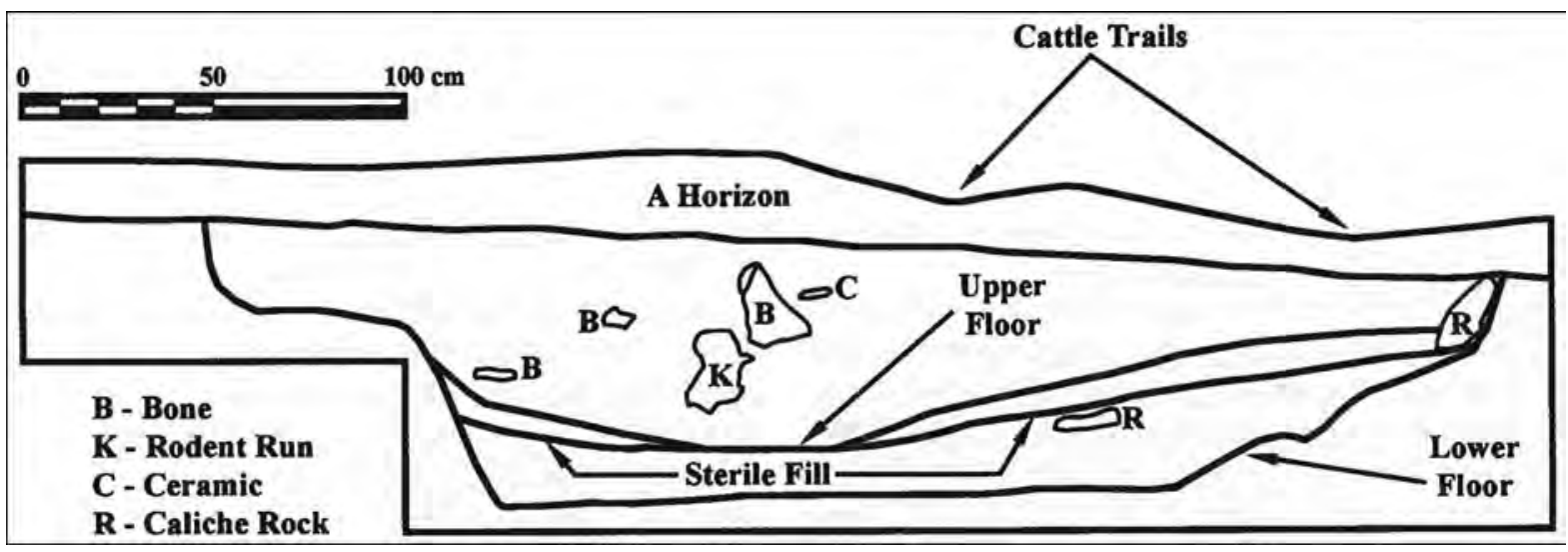

Figure 3-17. Profile drawing of Archie King II habitation structure (from Brosowske 2009c:15, Figure 3). 
represent pithouses, during a geophysical survey of Area 1 at 41OC29. In 2001, they ground-truthed 26 anomalies through soil cores and shovel tests, and obtained positive results from 18 of the 26, including artifacts representing the Plains Village period. They determined that features with entirely different functions can have nearly identical geophysical signatures (Brosowske and Maki 2002:22).

The excavated pithouse shown below in Figure 3-18 was uncovered following the geophysical survey in Area A at 410C29. It has not been thoroughly described in the literature at this time. A variety of cultural materials was recovered from the pit fill and include cordmarked sherds (343-22, 346-04, 33807, and 388-01). However, two radiocarbon dates on corn (Zea mays) have been obtained from this pithouse. One yielded a $\delta^{13} \mathrm{C}$ corrected date of 700 \pm 40 B.P. (Beta-185071; see Table 3-4). A second corn sample yielded a $\delta^{13} \mathrm{C}$ corrected date of $660 \pm$ 40 (Beta-185072; Brosowske 2005; Brosowske and Bevitt 2006). A sherd from this pithouse (\#346-04) was radiocarbon dated as part of the Long View investigations (see discussion of results under Question 1, in Chapter 10.0 below).

Another reference to a pithouse in the region comes in a discussion of a human burial along Red Deer Creek south of the Canadian River near Miami, Texas (Owsley and Mann 1990:93). In discussing the location of human remains, the authors refer to the burial as being next to the badly looted remains of a pithouse. That structure yielded many bones and shell tempered pottery sherds. No discussion was provided of the pithouse. The pottery indicated to Billy Harrison, a likely association with Wolf Creek complex to the north (Owsley and Mann 1990:93).

\subsubsection{M-Cross Ranch Occurrences}

Indian Springs (41RB81) is a localized area roughly $10 \mathrm{~km}$ due east of Long View on the M-Cross Ranch, a private ranch owned by John Erickson. The site is within the Canadian Breaks on the north side of the river in a setting similar to that of Long View. This multicomponent site has revealed artifacts indicative of sporadic occupations dating to at least 1,000 years before present. The site has been periodically excavated since 2002 by Texas Archeological Society memebers led by professional archeologists.
The excavations have primarily targeted various structural features (Cruse 2007).

One of at least four excavated structures was a small, round pithouse (Structure 4) that was completely excavated (Figure 3-19). Structure 4 measured 2.3 $\mathrm{m}$ north-south by $2.2 \mathrm{~m}$ east-west and about $40-\mathrm{cm}-$ deep (Cruse 2007). A sloping ramp-like entrance, 1.8-m-long by 0.6 -m-wide, was on the western side. A shallow step or basin was on the outside edge of the entrance. No structural post holes were observed on the interior floor or along the margins of the pit, and no rocks delineated either the inner or outer edges of the pit. Fill was gray clay that contrasted with the natural sediment matrix. Cruse (2007) interpreted the clay to be fall from the roof of the structure, which covered the entire superstructure.

The pithouse floor contained three small pit features (\#2,8 and 9) filled with ash. Ash pit 2 was in the center, whereas ash pit 8 was on the southern side, and ash pit 9 was on the eastern side. Charcoal, two charred maize cobs, and a cordmarked sherd (41RB81-156) were in ash pit 2. Charred wood yielded a radiocarbon date of $620 \pm 40$ B.P. (report not clear if correct or calibrated A.D. 1330, no laboratory number provided). Charred wood from ash pit 8 yielded a date of $580 \pm 40$ B.P. (report not clear if correct or calibrated A.D. $1370 \pm 40$, no laboratory number provided). The two dates fall within the accepted age range of Plains Village sites and Antelope Creek phase sites (Cruse 2007:15).

As part of the Long View investigations a thick, cordmarked basal sherd (41RB81-291) form this pithouse, Structure 4, was directly AMS dated plus sherd \#156 was subjected to petrography and instrumental neutron activation analyses (see below).

\subsubsection{Other Occurrences}

During archeological testing at the Crowell Reservoir in Foard County in the lower Rolling Plains south of Long View, a "megapit" (Feature 4) was discovered at the Long Ridge site (41FD46/47; Peter et al. 1997). The site is on an elongated ridge that overlooks the Pease River and has yielded archeological evidence for occupations from the Late Archaic through the Late Prehistoric periods. Feature 4 was encountered in backhoe trench 7 and consisted of a dark brown 


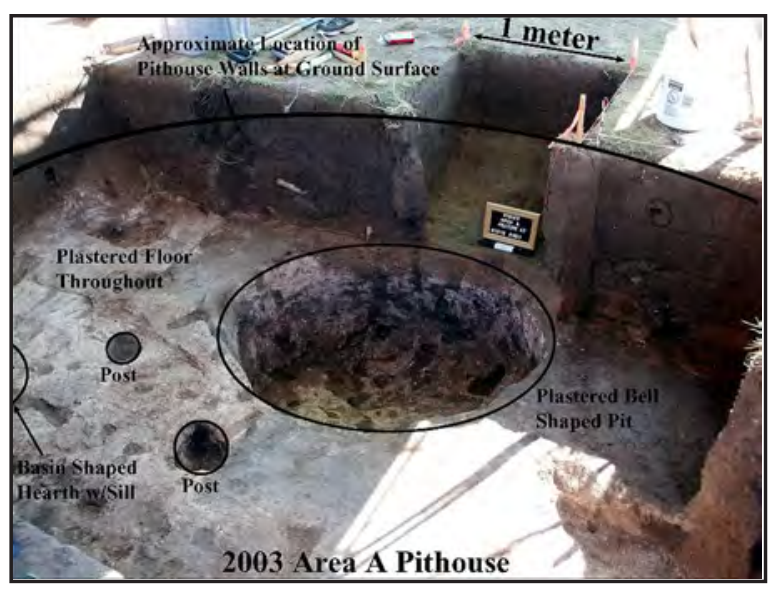

Figure 3-18. Excavated Area A Pithouse in 410C29, part of the Wolf Creek Complex (Photograph from Texas Beyond History Exhibit on Buried City, photo by S. Brosowske).

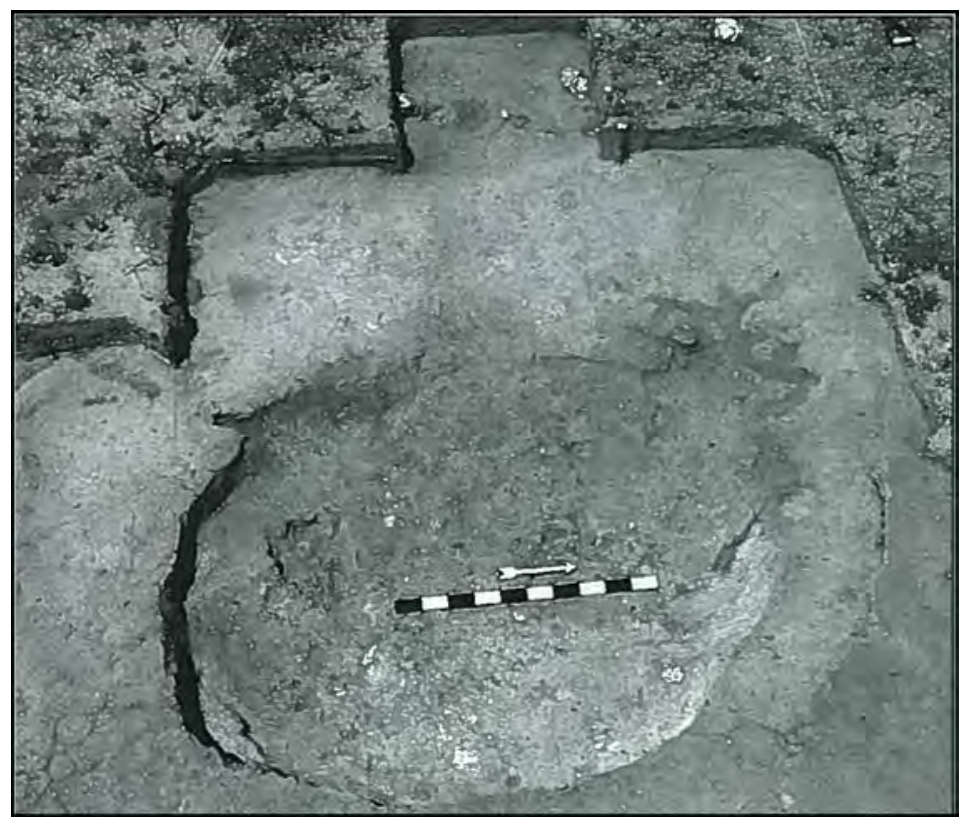

Figure 3-19. Overhead view of Structure 4 following complete excavation at Indian Springs (from Cruse 2007:14, Figure 7). 
midden-like deposit near the surface over a pit that extended to a meter in depth. Three test units (31 through 33) did not define the horizontal limits of the pit and the trench removed the deepest part of the pit, and extended to about 50-cm-below surface. Charcoal flecking was observed throughout the pit. The basal part was at least $85 \mathrm{~cm}$ in diameter, with the projected upper rim estimated at $2 \mathrm{~m}$ in diameter. A sample of charcoal from near the bottom of the pit yielded a $\delta^{13} \mathrm{C}$ corrected age of $730 \pm 60$ B.P. (Beta-81464). A second charcoal sample from near the projected fill interface at the top of the pit yielded a $\delta^{13} \mathrm{C}$ corrected age of $750 \pm 100$ B.P. (Beta-81463). Fresno and Harrell arrow points, a bone awl, ground stone metates fragments, burned rocks, animal bones, and 39 sherds were recovered from the pit. The sherds represent jar forms and a pinch pot or dipper. Cordmarkings, striations, and fingernail punctates comprised the surface treatment and decorative elements. The temper is sand and/or grit. These sherds resemble the Borger Cordmarked pottery of the Antelope Creek phase to the north and west (Peter et al. 1997). Faunal remains were identified as culturally modified deer, antelope, and rabbit bones with turtles, snakes, birds, and rodents also present. Burned macrobotanical remains include wood from mesquite (Prosopis), juniper (Juniperus), and sycamore (Platanus) with a broad range of other plants that include charred Cheno-am seeds, pigweed (Amaranthus), goosefoot (Chenopodium), grass (Poaceae), purslane (Portulaca), corn/maize (Zea mays), cactus (Opuntia) seeds, smartweed (Polygonum), and sunflower (Helianthus) seeds (Peter et al. 1997:132-143). Although not designated a pithouse, the limited description, combined with the recovered materials in a basin shaped pit, leads this author to believe this was potentially a small pithouse. Its location south of the Red River is intriguing and significant as this would be the southernmost pithouse currently known across this broad region.

Farther north in Beaver County, within the central Oklahoma panhandle, is the Odessa Yates site (34BV100) and other sites assigned to the Odessa phase (Brosowske 2005; Brosowske and Bevitt 2006). The most common residential structures at Odessa phase sites are semisubterranean pithouses (Figure 3-20). A minimum of nine pithouses were tested in conjunction with one large bell-shaped cache/storage pit. Brosowske (2005:143) provides a very brief summary of the investigations conducted from 1998 to 2000 and indicates most pithouses were circular to oval in plan, roughly 2.5 to $8 \mathrm{~m}$ in diameter, with floors 80 - to 180 -cm-below the surface. Small posts 5 to $10 \mathrm{~cm}$ in diameter were closely spaced around the perimeters and within the pits (Figure 3-21). Single and paired larger

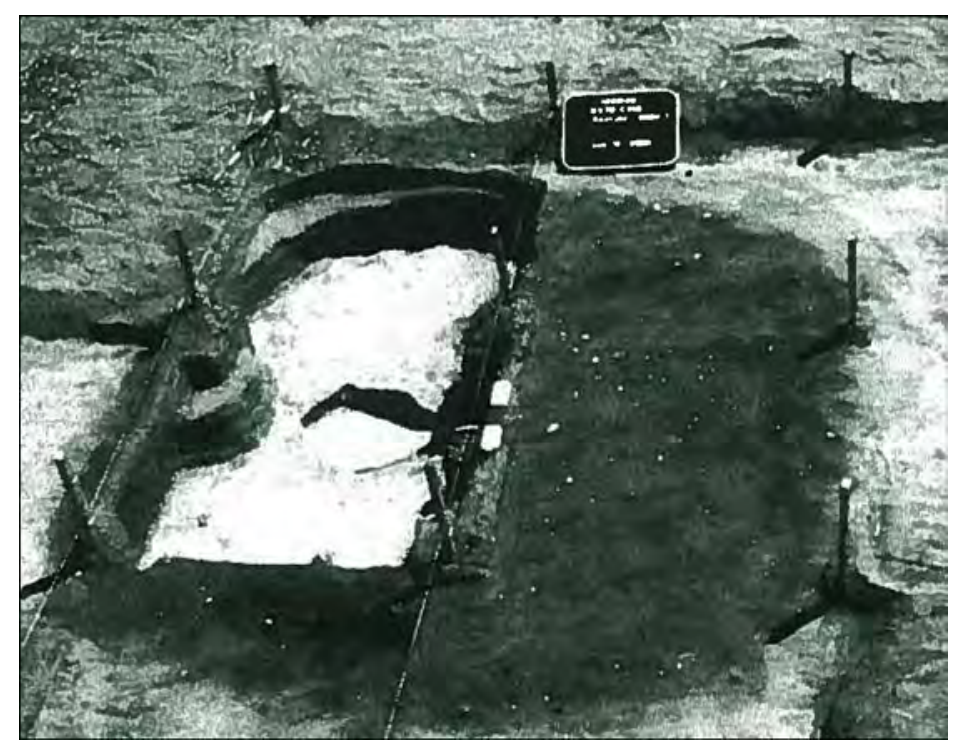

Figure 3-20. Semisubterranean pithouse (Feature 2000-1) at Odessa Yates (from Brosowske 2005:463, Figure I.7). 


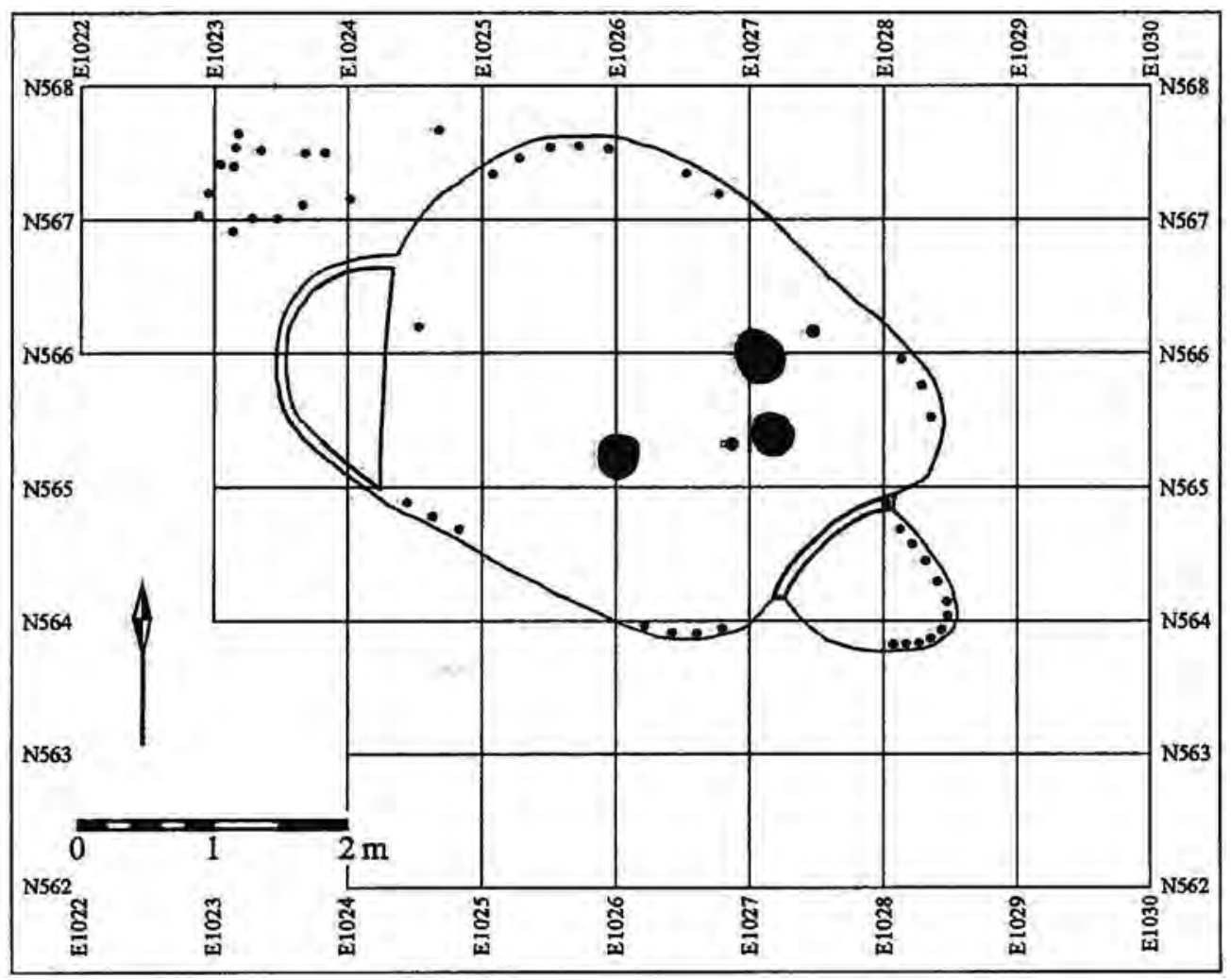

Figure 3-21. Plan map of pasture house (a pithouse) at Odessa Yates (from Brosowske 2005:455, Figure I.2).

central posts were present in the bottoms of the pits. Internal features included shallow basin hearths, small antechamber rooms, and shallow depressions of unknown function. Entryways were undefined. Little is known about the superstructure details. Following abandonment, the pithouses were often filled with prehistoric trash mixed with eolian sediments.

Seven radiocarbon dates are available from Odessa Yates (Table 3-9). Five were on maize and two on wood charcoal. The seven dates range from 390 to 720 B.P. with the two youngest at 390 B.P.; one maize sample yielded the oldest date (Brosowske 2005:465). Charcoal from the floor of the "Pasture House," yielded a $\delta^{13} \mathrm{C}$ corrected radiocarbon date of $680 \pm 60$ B.P. (Beta-133579). Trench 5 exposed a series of four overlapping pithouses, two of which, Structures $\# 1$ and $\# 4$, yielded $\delta^{13} \mathrm{C}$ corrected radiocarbon dates on maize from midden fill. Structure \#1 was dated to $720 \pm 40$ B.P. (Beta145474), and Structure \#4 was dated to $480 \pm$
50 (Beta 153241). Two other semisubterranean pithouses, designated 2000-4 and 2000-5, were also radiocarbon dated. Pithouse 2000-4 yielded a $\delta^{13} \mathrm{C}$ corrected radiocarbon date on carbonized maize of $630 \pm 40$ B.P. (Beta-153242). Pithouse 2000-5 yielded a $\delta^{13} \mathrm{C}$ corrected radiocarbon date on wood charcoal of $670 \pm 40$ B.P. (Beta-153243; Brosowske 2005:465). These pithouses were 4 to $5 \mathrm{~m}$ in diameter and most contained abundant midden debris deposited in the houses after their abandonment.

Bevitt (1999) discusses a pithouse (Feature 268) at the Lundeen site (14MD306) in Meade County in south-central Kansas. At the time of his writing, the site was assigned to the Wilmore complex. The structure (Feature 268) was ovoid in plan, measured 6.6-by- $8.8 \mathrm{~m}$, and had multiple floors with depths of 30 to $160 \mathrm{cmbs}$, and more or less vertical walls that had partially slumped along the northern perimeter. (Figure 3-22). The floor was nearly flat at about 140 cmbs creating a recognized pit about $115 \mathrm{~cm}$ deep. 
Table 3-9. Radiocarbon Dates from Pithouses at Odessa Yates, Lonker and Lundeen (from Brosowske 2005:134).

\begin{tabular}{|c|c|c|c|c|c|c|c|c|c|c|c|}
\hline Site & Area & Unit No. & $\begin{array}{l}\text { Depth } \\
\text { (cmbs) }\end{array}$ & $\begin{array}{l}\text { Feat. } \\
\text { No. }\end{array}$ & $\begin{array}{c}\text { Material } \\
\text { Dated }\end{array}$ & $\begin{array}{l}\text { Wt. } \\
\text { (g) }\end{array}$ & Lab. No. & $\begin{array}{l}\text { Measured } \\
\text { Age }\end{array}$ & $\begin{array}{c}{ }^{13} \mathrm{C} /{ }^{12} \mathrm{C} \text { Ratio } \\
\text { (\%o) }\end{array}$ & $\begin{array}{c}\text { Conventional } \\
\text { Age (B.P.) }\end{array}$ & Calibration Range * \\
\hline $\begin{array}{c}\text { 34BV100 Odessa } \\
\text { Yates }\end{array}$ & $\begin{array}{l}\text { Pithouse } \\
\text { Structure } 1\end{array}$ & Trench 5 & level 6 & & maize & & B-145474 & & -9.7 & $720 \pm 40$ & A.D. 1280 \\
\hline “ & $\begin{array}{c}\text { Pithouse } \\
\text { Structure } 4\end{array}$ & Trench 5 & level 6 & & maize & & B-153241 & & -11.4 & $480 \pm 40$ & \\
\hline “ & Pithouse & $2005-5$ & level 10 & & charcoal & & B-153243 & & -25.7 & $670 \pm 40$ & A.D. 1297 \\
\hline “ & Pithouse & Pasture & level 9 & & charcoal & & B-133579 & & -25.6 & $680 \pm 60$ & A.D. 1300 \\
\hline “ & Pithouse & $2000-4$ & level 12 & & maize & & B-153242 & & -10.1 & $630 \pm 40$ & A.D. $1304,1367,1385$ \\
\hline “ & House & $2000-1$ & level 4 & & maize & & B-169790 & & -10.3 & $390 \pm 40$ & A.D. 1476 \\
\hline “ & Bell Pit & $2000-3$ & level 14 & & maize & & B-169791 & & -10.3 & $390 \pm 40$ & A.D. 1476 \\
\hline 34BV4 Lonker & Trash Pit & na & na & 4 & charcoal & & B-4717 & & & $750 \pm 40$ & A.D. 1278 \\
\hline “ & Trash Pit & na & na & 3 & charcoal & & B-4716 & & & $715 \pm 50$ & A.D. 1285 \\
\hline 14MD306 Lundeen & $\begin{array}{c}\text { Pithouse 90-100 } \\
\text { cmbs }\end{array}$ & & & 268 & charcoal & $3-5$ & ISGS-4006 & & & $670 \pm 70$ & A.D. 1300 \\
\hline “ & $\begin{array}{c}\text { Pithouse } 40-50 \\
\text { cmbs }\end{array}$ & & & 268 & charcoal & $3-5$ & ISGS-4007 & & & $630 \pm 70$ & A.D. $1304,1367,1385$ \\
\hline “ & $\begin{array}{l}\text { Pithouse 140- } \\
150 \mathrm{cmbs}\end{array}$ & & & 268 & charcoal & $3-5$ & ISGS-4009 & & & $600 \pm 70$ & A.D. 1327, 1346, 1393 \\
\hline
\end{tabular}

cmbs = centimeters below surface, g = grams; B = Beta Analytical Inc., ISGS = Illinois State Geological Survey; * University of Washington Quaternary Isotope ; Radiocarbon Calibration Program 4.3, (From Brosowske 2005:134) 


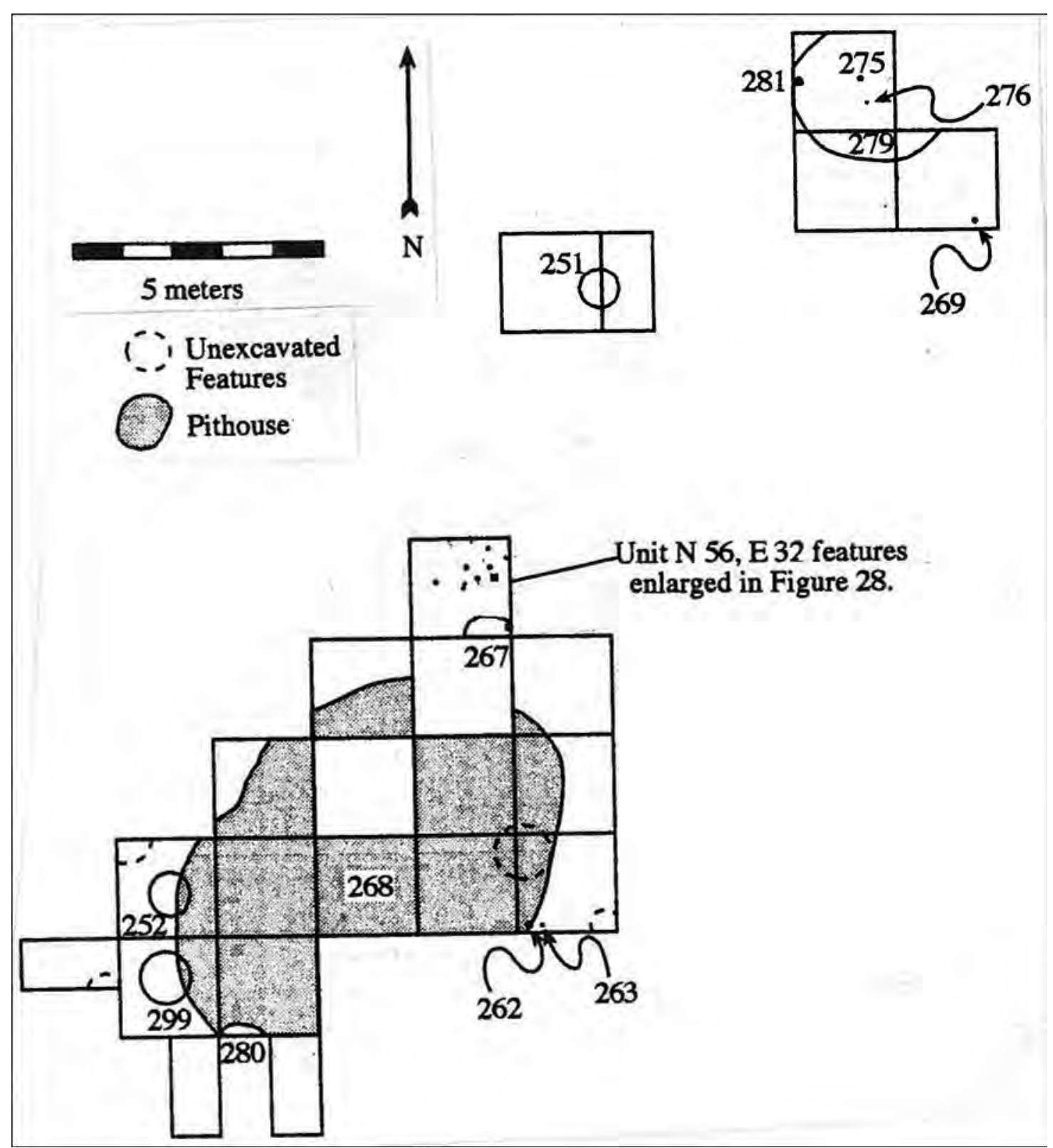

Figure 3-22. Plan view of excavated pithouse (Feature 268) and associated features at Lundeen Site (from Bevitt 1999:110, Figure 25).

Pithouse fill was strongly stratified with various fill episodes. A $30-\mathrm{cm}$-tall bench at the eastern end was roughly perpendicular to the long axis and its relationship with the pithouse is unclear.

A shallow basin (Feature 280) with an irregular bottom and ashy fill was at the southwestern end of the house. A deep basin (Feature 299) was just northwest of the shallow basin. The interior of the structure exhibited strongly stratified fill that reflected several episodes of deposition. The fill was loose, dark grayish brown sediment that contained abundant artifacts. The pithouse (Feature 268) was radiocarbon dated by three charcoal samples from various depths within the house. The dates range in age from 600 to 670 B.P. (ISGS-4006, 4007 and 4009) and are statistically the same at the 95 percent level of confidence (see Table 3-8; Bevitt 1999:120). 
A cluster of small post holes, 5 to $9 \mathrm{~cm}$ in diameter and 4- to 10-cm-deep, was encountered just north of Feature 267. Another megapit (Feature 279) was also identified northeast of the pithouse. This large pit was $3 \mathrm{~m}$ in diameter, round to oval in plan, with relatively straight/vertical walls.

In summary, the Southern Plains region in the Texas and Oklahoma panhandles have yielded scores of semisubterrranean rectangular structures with stone foundations characteristic of the Antelope Creek phase, picket-post structures scattered across the region, and deep pithouses without rock margins, some of which have now been assigned to the Odessa phase (Brosowske 2005; Brosowske and Bevitt 2006). The deep circular to oval pithouses that lack rocks have just been recognized over the last 10 years or so, with the exception of one at Black Dog Village. Very few have been completely excavated, thoroughly described in the literature, or directly radiocarbon dated, making it difficult, if not impossible, to place pithouses within a clearly defined chronological context or assign them to a specific cultural complex or phase. It is not clear whether or not these types of structures are a major or minor component of the archeological record, given that so few have been recognized. Their near absence in the literature may simply reflect a general lack of recognition in the field. A great deal remains to be learned about pithouse structures, and it is not yet possible to offer definitive statements about their temporal positions or their overall significance as domestic habitation structures in the Southern Plains region. 


\subsection{FINAL RESEARCH DESIGN: RESEARCH QUESTIONS FOR THE LONG VIEW SITE (41RB112)}

J. Michael Quigg, Paul M. Matchen, Robert A. Ricklis, and Charles D. Frederick

The following set of basic questions comprises the basis for our proposed analysis and interpretation of archeological and geoarcheological findings at the Long View site as delivered in November 2007. Each of the issues to be addressed comprises a methological linkage between the empirical data recovered from the site and the broader theoretical concerns that we believe can be addressed. Implicit in this research agenda is the underlying assumption that the artifacts, ecofacts and features documented at the site are all residues of past human activities and, as such, reflect technoeconomic, social and demographic dimensions of the culture, as a complex adaptive system (sensu Butzer 1982), that informed and influenced the behavioral patterns of the site's occupants.

All of our findings at the Long View site accord with the basic assumption that it represents a finite window on the lives of people who were participating in a cultural pattern that can be placed within what has been termed the Southern Plains Village Tradition (Lintz 1986). Given this working assumption, the discussions that attend each formulated research question are directed, in varying degrees, to a comparative perspective that draws upon extant literature concerning the relevant defined cultural manifestations in the Texas panhandle and surrounding areas in Oklahoma and New Mexico. The ultimate goals of our analysis are to (a) delineate basic adaptive mechanisms by which Plains Village folk at the Long View site survived and met their basic social and economic needs, and (b) place, to the extent possible within the limits of the data, the defined adaptive patterns within the larger context of Late Prehistoric culture in this sector of the high plains environment.

\subsection{Question 1}

Are Components $A$ and $C$ contemporaneous or do they represent chronologically distinct Plains Village occupations?

Background: One of the major deficiencies in the classification and interpretation of Plains Village Tradition settlements is the paucity of intensively investigated settlements. Recent investigations in the Texas panhandle, although informative, have been narrowly focused on individual structures and/ or burials (Boyd and Wilkens 2001; Boyd 2004a). This has left a gap in information concerning the functional aspects of site occupations at the larger scale of the community. Not only has archeological sampling in the recent past been at too small a scale to clarify community patterning and activities, but those field investigations that were carried out on a larger scale were conducted at least 30 to 40 years ago (McGrath [Lintz 1976], Two Sisters [Duncan 2002, 2006], Stamper [Lintz 2003a, 2003b, 2003c, 2004; Watson 1950], Roy Smith [Schneider 1969]) when contemporary sampling and analytical techniques were unavailable.

More specifically, there is a paucity of detailed chronometric evaluation of Antelope Creek phase sites. The time range for this cultural taxon has been placed between 800 to 500 B.P. (ca. A.D. 1200 and 1500) (Brooks 2005), however, doubts that many of the calibrated dates would surpass 500 B.P. (ca. A.D. 1450), due to observed substantial changes in Southern Plains group adaptive behavior which mark the threshold between Late Prehistoric and Protohistoric periods.

The few radiocarbon dates that were obtained through the testing efforts at 41RB112 do not provide an entirely clear picture of occupation spans at the site. Three radiocarbon samples out of eight yielded dates that were older than $900 \pm 40$ B.P. (Figure 4-1). As a result our interpretation of these values is somewhat problematic. The two clusters of dates that were thought to best represent the occupations observed consisted of two samples dating $710 \pm 40$ B.P. from Component $\mathrm{A}$ and three samples dating $630 \pm 40$ B.P., $650 \pm 40$ B.P. and $700 \pm 40$ B.P from Component C (Quigg and Smith 2005:46). These 


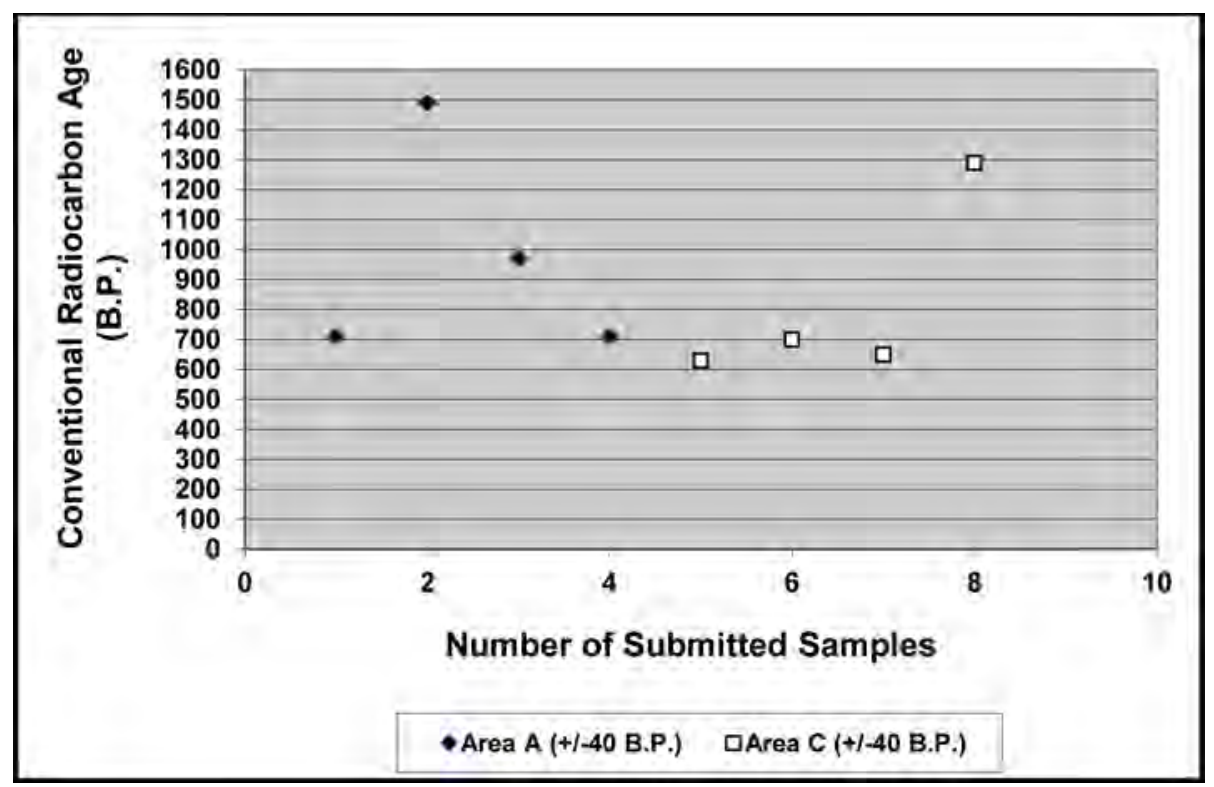

Figure 4-1. Graphic display of radiocarbon dates from 41RB112 testing phase.

values were used as the basis for field interpretation in describing further investigations of these areas during data recovery efforts. Most of the dates were based on charcoal recovered from feature contexts (Quigg and Smith 2005: Table 2).

Methods: There are several samples of wood charcoal from Components $\mathrm{A}$ and $\mathrm{C}$ obtained from feature context at 41RB112. In addition, there are multiple instances of ceramic vessel fragments with soot covered interiors that contain residues which can be sampled to yield radiocarbon dates delineating times of use. Feature 16/17 yielded multiple burned maize cobs and both Feature 1 and Feature 6 (subterranean structures in Components A and C) yielded burned maize kernels that can be dated to establish time of use. Matrix collected from individual features will be floated in anticipation of obtaining more charred macrobotanical remains, such as maize parts and/ or seeds. Also, TRC proposes to run an unspecified number of additional radiocarbon samples to obtain ages for individual features from both Component $\mathrm{A}$ and $\mathrm{C}$.

Discussion/Interpretations: Further dating of materials usingradiocarbon values on macrobotanical remains and charred residues should help determine whether the occupations at Components A and $\mathrm{C}$ are contemporaneous; or if they, like certain characteristics in the material assemblage suggest, are distinct episodes of occupation that occurred in temporal succession. In addition, the dates will help discern whether the various features within each area were used during the same period, or rather that a series of individual episodes of reoccupation are represented.

\subsection{Question 2}

What role did Components $A$ and $C$ at the Long View site play in the settlement pattern of the broader Southern Plains Village community?

Background: Determining site function (i.e., temporary camp, processing area) as well as seasonality will help to define this site's place within a larger pattern of settlement. The site structure and organization relates to the patterning of the activities as represented by the horizontal distribution of features, artifacts and ecofacts. Combining these with the site function will allow interpretations as to what roles Components $\mathrm{A}$ and $\mathrm{C}$ played in the broader range of Plains Village use of the region. The types and quantities of the artifacts and features play a significant role in determining the function of the two areas investigated at the Long View site. 
Methods: We will examine, describe, and document the types and quantities of features represented, the types and quantities of formal and informal tools, the types and quantities of local and nonlocal raw materials, the types and quantities of lithic debitage, the types and quantities of macrobotanical remains, and the types and quantities of faunal remains. Specific data sets, including faunal bones and macrobotanical remains, will be examined for possible clues to seasonality of site use. When these tasks have been accomplished, we will be able to better define the range of activities represented in Components $\mathrm{A}$ and $\mathrm{C}$ and, by logical extension, to identify the adaptive function of each area. This will be combined with comparative discussions based on published data from other sites in the region. Once the function and seasonality of the two areas is determined, then each area can be defined according to its functional role within settlement patterns in the broader region.

Discussion/Interpretations: If each area is interpreted to represent a farmstead involving diverse tasks, then these areas may be inferred to represent small family units who occupied/reoccupied this high ridge on various occasions. More extensive village sites are known in the immediate area, so this site may be linked to one or more of those larger villages if they were occupied at the same time, which is unknown at present. If Components $\mathrm{A}$ and $\mathrm{C}$ did not function as farmsteads or limited seasonal occupations, then these two areas may represent very short-term camps, which reflect multiple activities by small groups who occupied this location on an even more temporary basis. The narrow 8- to 11-m-wide APE through the site, and the correspondingly narrow window afforded by our excavations, will most likely constrain the extent of final interpretations. If seasonality can be established, it will enable us to discuss the possible length of stay and/or how the occupation relates to other longer-term occupations. Because of their storable nature, horticultural products are not good indicators of site seasonality. Wild pants with restricted growing seasons would provide somewhat better indications of a seasonal occupation. Remains of fetal/newborn bison would provide the most reliable indication of a particular season (in this case, spring) of use. While the general lack of published site descriptions, documentation of context, and artifact descriptions from other Southern Plains Village sites in this area will limit comparisons, we believe this to be a worthwhile effort resulting in useful insights into these basic issues.

\subsection{Question 3}

Is there evidence at Components $A$ and $C$ to suggest the length of occupation for represented settlements, and where does this fit into a continuum of residential mobility and sedentism?

Background: Closely related to the previously discussed research question, this issue approaches the overall question of settlement pattern by attempting to place the Long View site components within a hypothetical spectrum of residential patterning, with relatively high mobility at one end of the spectrum, and full sedentism at the other.

Many of the Antelope Creek semipermanent settlements described by Lintz $(1984,1986)$ exhibit stone slab architecture with semisubterranean attributes. There are, however, several sites attributed to the Antelope Creek phase which consist of temporary camps, resource procurement locales, and resource processing areas (Matchen 2002a, 2002b; Brosowske 2005). Given that 41RB112 was delineated within a very narrow window of APE, approximately 10 -m-wide, it is possible that many defining attributes pointing to cultural/ group identity may lay outside of this window. Several factors at Component A and Component $\mathrm{C}$, including feature location and geophysical data, suggest that occupation extended further east and west. The limits of the APE of this project constrain our understanding of the spatial extent of habitation for the occupations (Components A and C) at hand, which may mask more telling attributes such as semipermanent housing and/or activities.

Our goal in addressing this question is to examine attributes among the materials at hand to interpret the trends evident, and then compare these trends to patterns of similar materials of external settlements where there is a clearer understanding length of occupation. The degree of sedentism apparent at Components $\mathrm{A}$ and $\mathrm{C}$ will be interpreted in relation to a continuum of degrees of residential mobility 
and sedentism, in which temporary residential encampments are at one end of the spectrum, and permanent sedentary communities are at the other. Methods: To address this, we will document the diversity and density of materials and features recovered from Components $\mathrm{A}$ and $\mathrm{C}$ in relation to occupation area $\left(\mathrm{m}^{2}\right)$ and compare these values to findings at other Plains Village sites across adjacent areas of Texas, Oklahoma, and New Mexico. To determine archeological material and feature diversity, specimens will be classified by tool, artifact, material, and feature classes based upon qualitative and quantitative attributes. The density of materials will be calculated by documenting material counts within the prescribed areas. For example, the frequency and diversity of lithic reduction sequences as well as tool discard can highlight the role of the location in everyday activities. If a narrow range of tool use and production and material frequency is represented at a location, then one can assume that the locale was not inhabited steadily over a long period of time.

In addition, Magne (1989) has shown that tool to debitage frequency ratios compared with late stage debitage (tertiary flakes) of site assemblages can highlight differences in lithic technological strategies (Figure 4-2). By documenting these strategies across a sample of Plains Village manifestations, and considering this data with raw material availability concerns, patterns of activity can be denoted and can ultimately be used to characterize shorter occupations versus longer ones.

Additionally, densities of other classes of cultural debris (e.g., ceramic sherds, faunal bone fragments) per unit of excavated area can be compared to elicit information on the relative duration of occupation at 41RB112, as compared to other Plains Village sites in the surrounding region. Finally, we propose to compare the evidence for architectural features at the site with comparable data from other Plains Village sites, in order to determine if the pit house features at $41 \mathrm{RB} 112$ can be placed within a hypothetical continuum of size, form, and internal complexity in domestic structures. The working hypothesis here is that the farther a given site is positioned toward sedentism on the above-mentioned mobility-tosedentary scale, the greater will be the likelihood for increase in the variables of size, formal elaboration and internal complexity within domiciliary structures.

Discussion/Interpretations: Obtaining evidence on the degree of sedentism to define approximate length of occupation can help us infer the intensity of activity at 41RB112, and can therefore incorporate or rule out various labor intensive behaviors. This evidence lies in the presence and diversity of early to late stage material reduction, the construction and use of habitation structures, abundance/density of ceramics, horticultural pursuits and food processing (milling activities, faunal exploitation, etc.). By identifying the state of these variables at the locales within 41RB112, inferences can be made about how the site occupation(s) fit into a larger mobilitysedentism continuum, and ultimately the overall settlement and land-use strategy operationalized by Plains Village groups.

\subsection{Question 4}

Were the two occurrences of human remains directly associated with the recognized pithouse occupation at the southern end of the Long View site?

Background: Currently, there is very limited published information on either the ethnicity or biological affiliations of Southern Plains Village populations. A number of Southern Plains Village sites in the region (i.e., Antelope Creek Ruin 22 and 28 [Baker and Baker 2000], Footprint [Lintz 1986], Buried City (D. Hughes and Hughes-Jones 1987; J. Hughes 1991), Big Blue [Couzzourt and Schmidt-Couzzourt 1996; Lintz 1986], and New Smith [Brooks et al. 1992]) have yielded human burials, but few investigations have directly dated the human remains or established clear contexts or cultural associations. Many of the interments on sites occurred in abandoned structures or midden deposits. A number of interments were covered with stones (i.e., cairn burials [Lintz 1986]), and these were often placed on promontories or knolls. Most interments represent single individuals, although cemeteries are known at a few sites. Most interments are semiflexed and are usually not accompanied by grave goods (Baker and Baker 2000; Lintz 1986). 


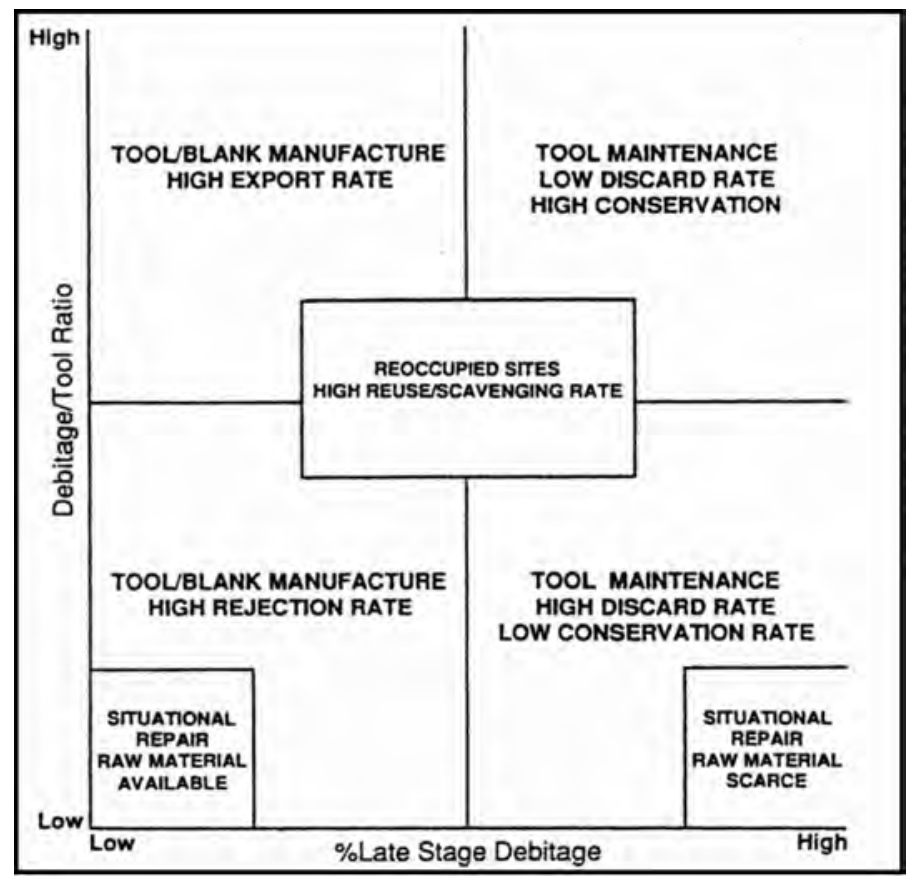

Figure 4-2. Magne's raw material replacement rate model (1989).

Odessa phase mortuary practices are known to have existed, but they are poorly documented (Brosowske 2005). Some bodies were buried in storage pits, and some were cairn burials with ceramic vessels smashed on top of the rocks.

It is quite possible that the human interments in these sites represent groups or populations that postdate the defined occupations. Douglas Owsley's biological investigations of human skeletal materials show that the burials from Buried City differ from those from the ruins in the Antelope Creek phase core area (Brooks 2005). Is either of the human interments at the Long View site similar to burials at either of these two other, just-mentioned, archeological manifestations? The two different treatment types of the dead identified at the Long View site would indicate that two different mortuary patterns/ traditions are represented. Therefore, it is possible that two somewhat different cultural patterns may be represented. Detailed investigations of these two interments will allow us to begin to address these and other related questions regarding connections to other Southern Plains Village cultural variants, as represented by different mortuary patterns. At least one other cremation is known for the immediate region (Wilkens et al. 2005).
Methods: We propose to directly radiocarbon date the human bones represented by each of the Long View site burials, for the purpose of comparison with the radiocarbon ages obtained from the other cultural remains and features from Components $\mathrm{A}$ and $\mathrm{C}$. This will permit assessment of whether the burials and other cultural remains are contemporaneous. We will also conduct metric and nonmetric analyses on the human bones to identify their age, sex, body structure, health conditions, and abnormalities, and then compare these findings with other documented human remains from the region, particularly those from Buried City and sites ascribed to the Antelope Creek phase. Variable treatment of the dead, as represented by the cairn burial and the cremation, will also be compared and contrasted to findings at other Southern Plains Village sites in the region. This will allow comparisons with mortuary practices to one or more of the specific cultural complexes previously identified in adjacent areas. Additionally, we will conduct stable carbon and nitrogen isotope analyses on the human bones to determine dietary patterns and how they compare to the recovered subsistence evidence in occupation Component C, as well as in other regional Southern Plains Village groups. Currently, stable nitrogen isotope data on human skeletal remains from Antelope Creek Ruin 
22 and 28 reveal different dietary patterns between males and females (Habicht-Mauche et al. 1994), and sex identification combined with isotope data from Long View should permit us to assess whether or not a similar pattern is represented at this site.

Discussions/Interpretations: If the interments date later than the occupations in Components $\mathrm{A}$ and $\mathrm{C}$, then we can inquire as to who they may represent by examining other younger complexes/phases in the region with similar burial practices. If they date to a similar time period as the identified occupation in Component $\mathrm{C}$, then we can place the burials within the context of the residential occupation(s) of the site.

\subsection{Question 5}

Do the architectural features (pithouses) identified at the Long View site represent outside groups of Southern Plains Villagers moving into the region, or do these features represent one or more of the previously identified Southern Plains Village complexes/phases in the region?

Background: A number of subgroupings of the Southern Plains Village Tradition are reported for the general region, as represented by the Antelope Creek phase to the west, the Apishapa phase to the northwest in southeastern Colorado, the Buried City complex immediately to the northeast (Hughes and Hughes-Jones 1987; Brosowske 2005), the Odessa phase to the north (mostly in the Oklahoma panhandle; Brosowske 2005; Brosowske and Bevitt 2006), the Zimms complex immediately to the east in Oklahoma (Flynn 1984; Drass et al. 1987; Drass 1989; Brooks 1989; Brosowske 2002b), and the Turkey Creek and Washita River phases also to the east in Oklahoma (Drass 1997). At least the Odessa phase (Brosowske 2005; Brosowske and Bevitt 2006), a few possible Antelope Creek sites (i.e., Two Sisters, Stamper, and probably Alibates Ruin 28 [Lintz personal communication]), and some groups at Buried City (Courson B = 41OC27 and Courson D = 41OC29) appear to have pithouses (D. Hughes 2001; Brosowske 2005). The current literature is not clear as to whether other Southern Plains Village groups utilized these types of houses at this time or earlier. Few good descriptions and dates are available for these pithouse structures. The apparent pithouse in Courson B is dated to 770 B.P. from charcoal found in a fire pit on the floor of the structure (D. Hughes 2001), slightly earlier than the pithouse (tentatively dated to 710 B.P.) in Component $\mathrm{C}$ at the Long View site (though the calibrated ranges overlap and thus the dates could conceivably represent contemporaneity). The current six dates from the five Buried City pithouses are earlier than the large stone-foundation structures, which generally overlie the earlier pithouses (Brosowske 2005). The current dating results from Components $\mathrm{A}$ and $\mathrm{C}$ indicate these areas are roughly similar in age to the pithouses at Buried City.

The Antelope Creek phase is generally characterized by the use of large stone slabs in the lower wall construction of the various architectural structures. The masonry structures are quite variable, and Lintz (1986) has identified at least 11 unit types and 6 different types of residential aggregations. These vary from large single room structures often with complex internal features, internal divisions, and complex floor-plan variations with support posts, to large 30 -room villages. Structures vary in shape from square, to rectangular, to circular with low, narrow entry ways (Lintz 1986). Lintz (1986) attributes the variation in structures to functional differences and engineering constraints. He does not discuss pithouses in association with the Antelope Creek phase. However, the floors of the slabfoundation houses can be considered to be shallow subterranean in character as they are most often roughly 30 -cm-below the ground surface, and have interior channels that are even deeper.

Hank's House, considered to be a pithouse (though not yet assigned to a named archeological phase or complex), is reported to be a rectangular subterranean house with vertical outside posts, interior plastered walls, interior support posts, sloping entry way, an earthen covering, and lacking a stone-slab foundation (Boyd and Wilkens 2001; Boyd 2005). Hank's House is similar to Structure 1 at the Zimms site in western Oklahoma, which is square with outside posts, central posts for supporting wattle-and-daub walls, and semisubterranean construction (Flynn 1984, 1986). The average date for the Zimms structure is slightly later than those currently available for Components A and C. Subterranean structures are 
also reported at the Stamper site (Lintz 2003c). If information on pithouses from other complexes is available, we will document and compare the structural characteristics and ages of such features with what was recovered from Components A and $\mathrm{C}$ at the Long View site. The cultural affiliation, distribution, and age of subterranean structures in the panhandles of Texas and Oklahoma are currently not well known, although just to the south of this area and earlier by a few hundred years, the Palo Duro complex (1450 to 850 B.P.) has pithouses and storage pits (Boyd 1995, 1997, 2004b).

It is critical to mention that a clear definition of pithouse, versus other kinds of subterranean/ semisubterranean structures, has not been formulated. In addition, pithouses were often unrecognized in early excavations. This coupled with the lack of scientific excavations over the last 20 or so years, means we have only very limited knowledge of architectural patterns in the region just prior to the appearance of the subterranean, slab-foundation structures of the Antelope Creek phase and other phases/complexes.

Methods: The pithouses at the Long View site will be thoroughly described and documented through metric and nonmetric observations, including detailed geoarcheological observations. The ages of these structures and associated features will be thoroughly and accurately determined with multiple radiocarbon dates, in order to permit chronologically informed comparisons with other architectural evidence from the region. The different layers of recognized sediments documented in the Long View structures will be analyzed through grain size analysis, micromorphology, and various chemical means. This is in order to identify the types and origins of the fills, and thus to permit definition of superstructures as well as post-abandonment processes of collapse. Sediment from the floor of the structures will be floated, and recovered materials will be identified and quantified to determine the type and quantity of goods represented. This data will be used to more accurately define the function of these pithouses.

Discussions/Interpretations: If these structures are shown to be pithouses and there are no other contemporaneous pithouse features from known complexes/phases in the area, it might be inferred that the Long View pithouses reflect an immigration of intrusive populations into the area, or alternatively, outside influence on domiciliary architectural practices. These pithouses and associated features could potentially represent an influence from the Palo Duro complex (1450 to 850 B.P.) to the south. It might also be inferred that the pithouses represent influence from cultural patterns in other areas, such as the Odessa phase to the north. We intend to examine information from that area for evidence of pithouses and to determine if those pithouses are similar and contemporaneous with the Long View occupation(s) or if, alternatively, there was an identifiable timetransgressive emergence of pithouse architecture across the Southern Plains. If our analyses of these pithouse structures indicate a specific function (e.g., seasonal houses), as opposed to more generalized use of stone-foundation structures, this will be examined and addressed. It is also possible that these structures were not domiciles, but large storage areas for a collection of various plant resources. The recovered data will help with the interpretation of their individual function, and then regional data will be evaluated for spatial and temporal variability.

\subsection{Question 6}

Are the ceramic sherds represented in Components A and C manufactured locally or are they imported from Southern Plains Village complexes/phases in surrounding areas?

Background: Components A and C each yielded samples of ceramic sherds that represent different types of ceramic vessels, with some sherds representing cordmarked vessels like those from Antelope Creek sites (Borger Cordmarked), some resembling vessels from outside the site area (nonlocal), and others are decorated rims similar to those in the Buried City/Odessa phase ceramic samples. One very thick (8 to $18.2 \mathrm{~mm}$ ) cordmarked vessel from Component $C$ (represented by a number of sherds from across Component $\mathrm{C}$ including the fill of the pithouse) is similar in thickness to what some might call Plains Woodland vessels. This specific vessel is potentially significant and will be the focus of intensive study to determine 
its age, composition, form, function and cultural affiliation. Thick-walled vessels have been thought of as indicators of Plains Woodland occupations (e.g., the Lake Creek complex) across the broader region (Couzzourt 1985; J. Hughes 1962). As an example, a Woodland pot in the Panhandle-Plains Historical Museum has walls about 8- to 9-mmthick at the rim and stands about 33-cm-tall, with a conical base, and a cord roughened exterior. Also the floor of the pithouse feature at Courson B is reported to have yielded "some kinds of pottery that indicate terminal Woodland or initial Neoindian in the region” (D. Hughes 2001). Some 58 thickwalled (average thickness of $10 \mathrm{~mm}$ ) sherds were recovered from the Main Structure at the Roy Smith site in the Oklahoma panhandle (Schneider 1969). Therefore, the age, composition, and function of the thick-walled vessel from Component $\mathrm{C}$ are quite significant for understanding not only Component $\mathrm{C}$ and its relationship with the pithouse, but also for understanding the distribution of this type of vessel across the broader region.

Component A yielded a number of rim sherds that are decorated. This, along with other attributes, indicates similarities to ceramics from Buried City/Odessa phase. Such attributes are not very common (less than 10 percent) in the core area of the Antelope Creek phase (Lintz 1978). However, the Antelope Creek sites in the Oklahoma panhandle (i.e., Two Sisters, McGrath, Roy Smith, and Stamper) show a higher percentage of decorated rims in comparison to the sites in the core area. The frequency of occurrence of decorated rim sherds in the surrounding Southern Plains Village complexes will be examined and compared with the findings from Component A. These rim traits may lead us to specific interpretations such as from where these ceramic stylistic influences may have come, and perhaps may indicate corresponding movements of people. Previous petrographic analysis and detailed description are quite limited, although one study on collared rims from Buried City, Antelope Creek sites, and Upper Republican assemblages indicate that the collared-rim vessels from Antelope Creek sites were made locally (Lintz and Reese-Taylor 1997). Collared/decorated rims are most common in the Odessa phase (Brosowske 2005; Brosowske and Bevitt 2006) and at Buried City (D. Hughes 2002).
Methods: The sherds will be metrically and nonmetrically documented, with selected samples from Component $\mathrm{A}$ and $\mathrm{C}$ subjected to petrographic, INAA and lipid residue, and stable isotope analyses on organics absorbed into the clay body. Carefully selected sherds from adjacent sites/complexes (Buried City, Odessa Yates, Antelope Ruin 22, Two Sisters, and Stamper), will also undergo these same analyses so that we can obtain samples to directly compare and contrast to the Long View site. We also plan to conduct INAA on a number of natural clay and alluvial matrix samples from the region to help determine where clays for the manufacturing of vessels were obtained. Part of our INAA sample of sherds will target the exact same sherds that Lintz and Reese-Taylor (1997) used in their petrographic analysis. Through these analyses we anticipate that we can assess relations between the occupants of the Long View site and peoples represented by other complexes/phases, as well as gain insight into food cooking practices. From these multiple lines of inquiry we will hope to be able to make some inferences concerning interactions between regional groups/populations.

The thick-walled vessel from Component C will be directly dated by multiple means (i.e., thermoluminescence and radiocarbon dating of the organic resides extracted from the walls of that vessel) to better define the age of that particular vessel. Lipid residues and stable isotopes will also be extracted to help determine the function of this style of vessel.

Discussions/Interpretations: It appears from the context at Component $\mathrm{C}$ that this thick-walled vessel is associated with the pithouse occupation that dates to roughly 710 B.P. and is also associated with both side-notched and unnotched arrow points. If this is in fact the case, the vessel pertains to the Southern Plains Village period, and not an earlier Plains Woodland period. As a corollary, it would be apparent that this and similar thick-walled vessels can no longer be assumed to represent Plains Woodland occupations in the region. If, on the other hand, this vessel is older than the pithouse, some form of mixing of, and/or interaction between, different populations might be indicated. In addition, interpretation of Component $\mathrm{C}$ will be 
more complex than otherwise thought, and may require reexamination of the overall assemblage in Component $\mathrm{C}$, and how the features and materials relate to each other. It may also signal that multiple groups were operating within the region and that the archeological record is much more complicated than what is now assumed.

\subsection{Question 7}

What proportional roles did the horticulture, hunting, and plant gathering play in the lives of the populations that occupied Components $A$ and $C$ at the Long View site?

Background: Only limited evidence of horticulture has been identified in the preceding Woodland/Lake Creek time period in the Texas panhandle, but is more abundantly represented in the slightly later Southern Plains Village complexes which extend across much of the Southern Plains. Drass (1999) documents maize horticulture in the Paoli phase (ca. 950 to 650 B.P.) of western Oklahoma, and believes these people also cultivated marshelder and, possibly, little barley. He also documents the presence of beans at that time. The peoples of that phase also collected wild plants such as sunflowers, maygrass, dropseed, cheno-ams, and knotweed (Drass 1999). There is direct evidence from the Palo Duro complex (1450 to 850 B.P.) that native plants (e.g., pigweed, goosefoot, and purslane) were used, but indications of cultivated plants like maize or beans are not present, although their presence has been postulated (Boyd 1995, 1997, 2004b). The Palo Duro complex includes use of rectangular and circular pit houses, storage pits, baking pits, ceramics, and a mixed hunting and gathering subsistence economy only a few hundred years earlier than the occupation(s) at the Long View site.

Bison populations were scattered across much of the Southern Plains during the Plains Village period (Butler 1992; Duffield 1970; DeMarcay 1986, Dillehay 1974; S. Baugh 1986; Brooks and Flynn 1988; Quigg et al. 1993) and were hunted at least part-time by most peoples of the region. Bison bones have been recovered from many sites in the Antelope Creek core area (Duffield 1970), at Antelope Creek sites in the Oklahoma panhandle (Duncan 2002, 2006), and from most other Southern
Plains Village sites across the region (Brosowske 2005; Drass, et al. 1990; Lintz 1976, 1984, 1986; Watson 1950). Drass and Flynn (1990) detected a greater dependence on bison, especially after about 700 B.P., and other prairie resources at villages in the western mixed prairie of Oklahoma. They also detected that bison use increased through time in the complexes and phases in western Oklahoma. This finding might contradict a postulated increase of horticultural activities based on bison bone digging tools at Washita River phase sites (Hofman 1978), and might also contradict Duffield's (1970) suggestion that bison populations and use of bison decreased at Texas Antelope Creek phase sites after 650 B.P., based on a sample of five dated sites. Brosowske (2005) sees the Odessa Yates site as evidencing a more specialized bison hunting practice, which yielded a surplus of bison products that were used for exchange.

Horticulture was also being practiced at the same time across this region, as evidenced by the presence of maize and beans on many Southern Plains Village sites (i.e., in the Odessa phase; Brosowske 2005). Antelope Creek sites in the Oklahoma panhandle (Two Sisters and Stamper) have produced evidence of maize and beans; whereas the Roy Smith, Two Sisters, and Stamper sites all yielded bone horticultural tools (Duncan 2002, 2006; Lintz 2003a, 2003b, 2003c, 2004; Schneider 1969; Watson 1950). At the Odessa Yates site maize, beans, sunflower, goosefoot, grass seeds, hackberry, cactus, marshelder, and bulrush were all identified (Brosowske 2005). Apparently, a mixed horticultural-wild resource procurement economy was in place, but the relative input of time and labor on each aspect of economic behavior remains to be determined. Boyd $(2005,2008)$ has initiated an attempt to define the role of horticulture among the peoples who lived in the Canadian River valley and its tributaries in the Texas Panhandle, specifically focusing on study of the M-Cross Ranch sites just $8 \mathrm{~km}$ east of the Long View site. Much of what is in print at the present time consists of postulations, assumptions, and broad unsupported statements, with very limited actual data to provide a clear picture of this dual economy among Southern Plains Village populations. Boyd concludes that horticulture played a major role in regional economies, and 
that this involved primarily dry farming in the extensive sandy soils found throughout the region. Uncertainty stems from the lack of extensive investigations and the imprecise temporal control for Antelope Creek sites investigated prior to the advent of relatively sophisticated investigative techniques within the last 20 to 30 years. The technical reports on most Antelope Creek sites in the core area are very limited, and most do not report on faunal and floral remains. Duffield's work (1970) used faunal remains from sites where they were not systematically collected, and are thus not totally reliable (Lintz 1986), though his work does provide some evidence for the diversity of food resources utilized at those sites. Although contexts and associations may be questionable, Duffield (1970) reports very diverse faunal assemblages. The range of resources includes birds, reptiles, small mammals, turtles, deer, antelope, bison, and even a couple of fish species.

At least three variants of subsistence strategies can be hypothesized: 1) sedentary horticultural-based economies that supplemented food production with local gathering of wild plant resources and part-time hunting, 2) a mixed strategy involving seasonal movement between residential bases and a mix of part-time horticulture and part-time hunting and gathering, and 3) essentially full-time hunting and gathering with only very limited settled village life and a high dependence on wild plants and hunted animals.

Methods: The sediment matrix samples collected from features, including the pithouses, will be floated and the macrobotanical and faunal remains will be identified. The recovered materials will be counted by groups such as cultivated plants, wild plants, large hunted animals, and so on. For the animal remains, the minimum number of specimens and minimum number of individuals will be determined from analysis of the recovered faunal assemblages. The ubiquity of the various plants recovered across the features will be determined. Lipid residue analysis will be conducted on ground stone tools, burned rocks from selected features, and selected ceramic sherds. Pollen, phytolith, and starch grain analyses will be performed on the selected potsherds, ground stone tools, and possibly other tools used in horticultural and processing activities. Following these extractions, use wear analysis will be conducted on formal and informal chipped and ground stone tools to determine the type and amount of wear to support the recovered plant and/or animal residues identified. Horticultural tools (digging sticks, hoes, etc.) will be identified and compared and contrasted to nonhorticultural tools to determine the ratios present. Comparison will be made with similar evidence from other sites (representing defined phases) within the surrounding region. This will aid in approximately defining the relative time and effort directed to horticultural and nonhorticultural subsistence practices.

Discussions/Interpretations: Components A and $\mathrm{C}$ are likely to represent diverse economies with the amount of effort directed towards the different categories of resources (hunted, gathered, or horticultural) yet to be determined. Accumulating the data from diverse lines of evidence (faunal, floral, artifactual, and various technical analyses) will provide a foundation for assessing the roles these different resource strategies may have played at this time and place. Since there are many poorly documented and reported sites for this time period in the region, this makes these analyses of the Long View site even more significant. These broadspectrum foragers appear similar to many groups in the Southern Plains, as reflected by groups representing the Early Ceramic period (ca. 1550 to 750 B.P.) and the Late Ceramic period (after ca. 450 B.P.). The occupations of Components $\mathrm{A}$ and $\mathrm{C}$ may represent a transitional stage from one period to the other. This would be especially true if the populations in question were determined to be an extension of the earlier Palo Duro complex or some other previously identified cultural taxon.

\subsection{Question 8}

Were the modified faunal bones recovered from U1RB112 used primarily for tools (horticulture, awls, needles) or did they serve another function?

Background: This question is closely related to, and contributes to, the immediately preceding research question, since it is relevant to understanding the role of horticulture within the adaptive strategies of the occupants of the Long View site. At Antelope 
Creek phase settlements there seems to be evidence for a dichotomy of faunal bone utilization during the Late Prehistoric period (Brooks 2005). Bison elements were often used to make hoes (scapulae); digging sticks (tibiae); knives, and hide grainers (femurs); and arrowshaft wrenches; and hide fleshers (metapodials). Deer metatarsals and turkey long bones were used for needles, awls, and other piercing implements (Brooks 1989:81-82; Brooks 2005:341). Household items, such as clothing, housing, and day-to-day furniture fashioned from bison hides required the use of numerous tools for product refinement and conditioning. In the wider periphery, bone tools were thought to have been included in designated bison products that were made for exchange along with Alibates lithic material in the latter half of the Antelope Creek phase.These were exchanged for items such as maize, ceramic vessels, obsidian, turquoise, shell pendant, and Olivella shell beads supplied by Southwestern Puebloans of New Mexico (Brooks 1989:83; Vehik and Baugh 1994:257).

Butchering and bone grease production across the Plains has been ethnographically documented by various authors (Catlin 1857; Leechman 1951; Schoolcraft 1854; Wilson 1924; Wissler 1910). This has been said to involve smashing and breaking of faunal bone to expose the marrow and facilitate the extraction of natural oils in the bone. The bones were broken into pieces the size of fingernails (Leechman 1951:355) and then boiled/simmered with water in a pot. The oil/grease rose to the top and was skimmed off and placed in a separate container, usually an animals stomach, for later consumption. Historically, this substance has been used for the production of pemmican in the Yukon, used as a butter, and also could have been added to other foods as a seasoning (Leechman 1950:355; Vehik 1977:171). Findings at the Two Sisters site, a semipermanent Antelope Creek settlement in the Oklahoma panhandle, document the preponderance of seemingly intentional bone breakage around the early and late houses, interpreted as a by-product of bone grease production (Duncan 2002:281). Although bone tools are present $(N=5)$ there, the frequency is low. This indicates, perhaps, a greater emphasis on bone grease production than on plant cultivation for dietary nourishment during the Two Sisters site occupation span.
Methods:To determine whether bones have been used for bone grease production, an analysis of bone size and incidence of bone specimen fracture patterns will ensue. If faunal bones were being utilized for grease manufacturing, a preponderance of green bone breaks (e.g., spiral fractures) would be expected across the resulting bone. To accomplish this, samples of faunal bone from primarily ungulate species will be examined from Components A and $C$ of 41RB112 to determine the frequency of green bone or spiral fractures. Bones will also be examined for the incidence and frequency of modification for other uses, such as farming tools, animal processing tools, lithic reduction tools, and ornamental objects. The distribution of specimen discard across both areas will also be examined to gauge modified specimen concentrations and the resulting occupational significance of bone tooling verses intentional bone breakage.

Discussion/Interpretations: Initial observations at the Long View site highlight the presence of large quantities of small bone fragments in Component A (Figure 4-3). It is likely that these are the result of intentional breakage for bone grease production. Upon further analysis, we should be able to discern if the fractures are caused by impact or by other taphonomic means. Specifically, experimental studies have outlined small percentages of surface assemblages of bone exhibiting green bone breakage due to trampling by free roaming bison and moose, and carnivorous activity among the remains ungulate species (Haynes 1983). The incidence of nonhuman breakage significantly increased among the smaller species in the remains.

There is likely a spatial distinction across Components $\mathrm{A}$ and $\mathrm{C}$ in discard of bone by size, which may reflect processing trajectories. For example, within the southern portion of Component A, a concentration of low-yield elements, possibly representing bone grease production, was encountered. These include scapular and vertebral elements (although vertebral elements are high-utility from a meat perspective; Kehoe and Kehoe 1960). This, together with the fact that low concentrations of accompanying archeological material was recovered from this location, indicates an area of refuse disposal at the margin of the occupation area. 


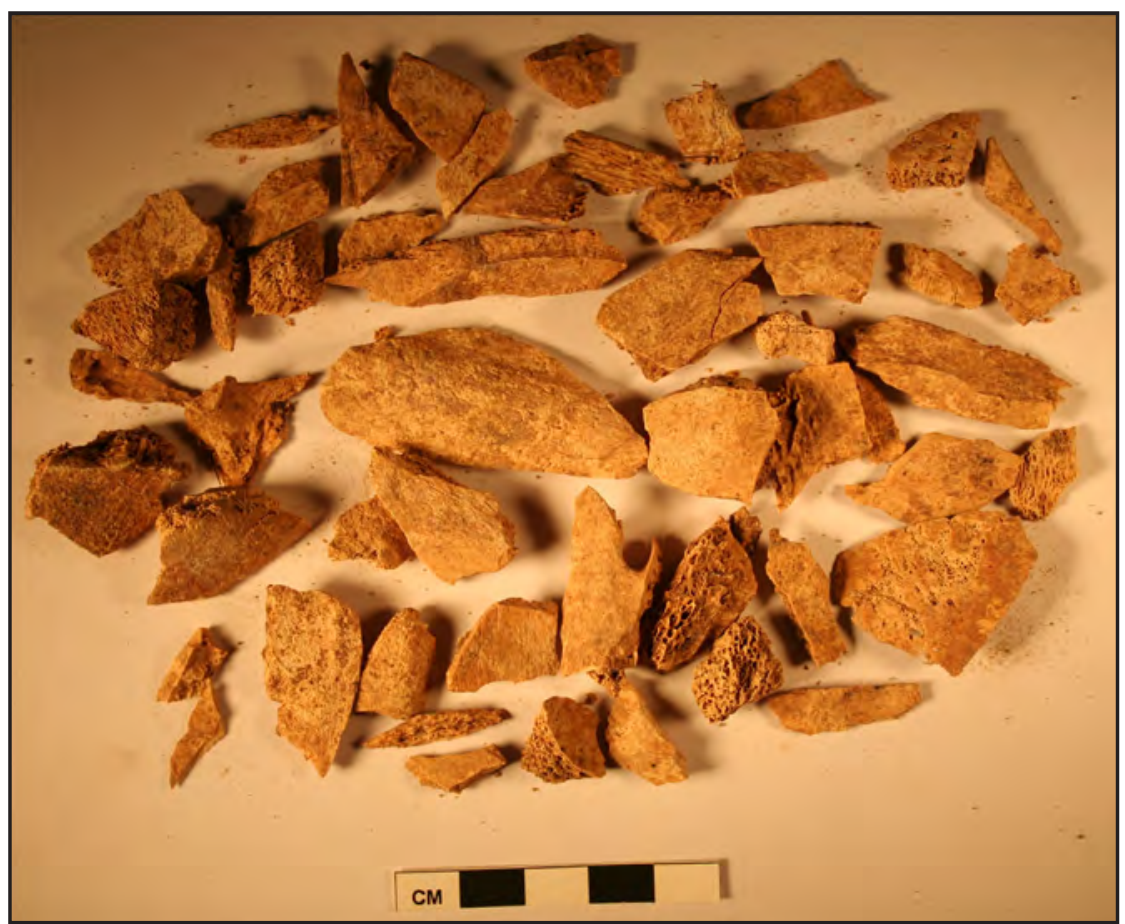

Figure 4-3. A Sample of the highly fragmented bone, possibly representing bone-grease extraction, from the northern portion of Component A, 41RB112.

By documenting the degree to which bone grease processing was conducted at each occupation versus other activities that involved the use of bone elements, we can investigate the potential choices in decision making that faunal skeletal utilization presented to the inhabitants, as discussed by Brooks (2005).

\subsection{Question 9}

What role did exotic goods (i.e., nonlocal obsidian, pottery, and tool stone) play in the lives of the occupants?

Background: A number of Antelope Creek phase sites in the core area have yielded various types of nonlocal goods such as obsidian, marine shells, and Southwestern ceramicpottery andpipes, buttheseitems are rare. The Antelope Creek sites in the Oklahoma panhandle show some differences in representation of trade items. All have yielded obsidian, and Olivella shell beads have been recovered from three sites, while Southwestern pottery was obtained from the McGrath and Stamper sites. Spielmann (1991) has discussed Plains/Pueblo interactions, and suggested mutually beneficial outcomes from such interactions.
It is thought that bison products were traded by Plains Village people to the Pueblos for obsidian and other material items. Since Spielmann's (1991) publication, the Odessa phase has been identified and defined by Brosowske (2005). His work was mostly in northwestern Oklahoma near the Panhandle region north of the Long View site. The sites assigned to the Odessa phase have also yielded nonlocal goods, including obsidian and Southwestern ceramic sherds. Overall Southern Plains villages have yielded durable trade goods that originated from the eastern Pueblos of New Mexico. Therefore, some type of exchange network was in operation in the region during this period.

Brosowske (2005) directed his dissertation towards the economic intensification and emerging social complexity of the Middle Ceramic period, in which we include the Long View site. He sees exchange as embedded in the larger social realm. However, he states that models of technological organization and optimal foraging hold little power for elucidating the acquisition of utilitarian tools manufactured from exotic stone. He believes that we must consider the social value of these utilitarian tools. He suggests 
that these trade items reflect the emergence of social hierarchy in small-scale societies such as represented in the Middle Ceramic period of the Southern High Plains, and that possession/control of the objects obtained through trade enabled leaders to gain prestige and attract followers. He goes on to assert that Chimney Rock Ruin, Alibates Ruins and the Odessa Yates site functioned as regional trade centers that redistributed exotics obtained during long distance trading expeditions.

Methods: The obsidian from the Long View site will be described, photographed and selected pieces will be subjected to X-ray florescence (XRF) source analysis. The nonlocal lithic artifacts and debitage will be identified to their original source where possible, counted, described, and weighed. The nonlocal ceramic sherds will be documented, counted, described, and photographed. Source areas for the nonSouthwestern ceramic vessels and the nonlocal lithic tools (e.g., Florence -A chert, Niobrara/Smoky Hill jasper, etc.) will be determined through INAA. Once compiled, this data will help to determine the various source areas for these materials, and what directions and distances they were transported across the landscape. This will ultimately provide data to interpret/address trade and interaction patterns.

Discussions/Interpretations: The counts of the exotic goods will be compared and contrasted with other Southern Plains village groups. This will allow discussions concerning the importance these items had at the Long View site and their potential role within and/or contribution to the functioning of the larger society. The types and quantities of trade goods present may contribute to understanding the movement of people and goods that occupied the Long View site. It appears that the types of material, except for the obsidian, may be restricted to certain groups over others. All the obsidian appears to have come from one or two New Mexico source areas. However, Smoky Hill jasper and Gray Permian cherts from south-central Kansas currently appear restricted to the Odessa phase. As Brosowske (2005) has tried to demonstrate, a few sites (i.e., the Odessa Yates site [34BV100], Alibates Ruin 28 [41PT11], and Chimney Rock Ruin 51) may have functioned as regional trade centers.

\subsection{Question 10}

Was the Alibates silicified dolomite recovered from the occupations at 41RB112 obtained locally from Canadian river gravels or was it procured from the Alibates quarries, located some $80.5 \mathrm{~km}$ (50 miles) to the west?

Background: This question is closely linked to the previous one, as it also involves the issue of possible movement of nonlocal materials to the Long View site over considerable distances. There has been a good deal of speculation about the nature and origin of Alibates silicified dolomite at sites that are situated at considerable distances from the quarries in the north-central portion of the Texas panhandle. Wyckoff (1989, 1993) and Kraft (1997) have both demonstrated that Alibates cobbles/ clasts of appreciable size could be obtained at great distances from the quarries in the Canadian River and possibly Cimarron River drainages as far east as Lake Eufaula, Oklahoma. Alibates is seen as far away as north-central Oklahoma and south-central Texas (Uncas site, Galm 1979).

Methods: To address material origin, we will examine cortex on early stage debitage within the Alibates lithic assemblage to assess the presence of water-worn verses unaltered cortical surfaces. We will also look at technological choices made by the site occupants in reference to Alibates use in tool production. This will gauge whether certain materials were more highly curated or conserved than others. We will accomplish this by measuring the length and width of tools, but also measuring material thickness, which has been suggested by Brooks (2005) to denote tool durability, a characteristic of extended tool life. In addition, overall tool size can be used to gauge whether pieces are larger than the average clasts observed in previous studies (Wyckoff 1989, 1993), and the average size of local samples. It is generally accepted that grain or clast size of gravels decreases the further the distance from the source. However, factors that could affect this trend include the amount of sediment introduced into the channel, velocity and the consistency of water flow, and subsidence (rate of sediment settlement to the channel floor; Boggs 1987). 
Discussion/Interpretations: If Alibates is determined to originate from local gravels adjacent to 41RB112, this could be used as support for the presence of Alibates gravels as a rationale for site location. In addition, if Alibates materials are determined to result from mainly cobble resources, then the role that Alibates played in intergroup exchange could be addressed.

One of the ways we can explore how materials were obtained is by examining the ways in which materials were treated (Binford 1979; Bleed 1986). Was the material used to make disposable implements as in the case of small, unifacial triangular projectile points and edge modified flakes or was it used to make reusable, sustainable tools, which were kept and maintained for extended periods? A selection of hide working and butchering tools, such as scrapers and alternately beveled knives, have been suggested by Brooks (2005:340) to represent the latter in Antelope Creek phase occupations. This is based on the suggestion that thick bodied implements such as these are designed for durability and long use lives.

Specifically, the production technology behind alternately beveled knives (ABKs) maximized the use-life of the tool. This material saving technology also altered the initial tool shape from ovate to diamond (Sollberger 1971). These tools are commonly recovered in association with Antelope Creek semisedentary village sites, but are also found associated with late prehistoric/Protohistoric groups in western Oklahoma (Custer, Turkey Creek, Washita, and Wheeler phases) and throughout the Southern Plains. Their occurrence in the Southern Plains peaks after 1300 A.D. (Creel 1991).

Four ABKs were recovered from the southern end of Component A (Figure 4-4), while one fragment was recovered from Component $\mathrm{C}$. Based on the information presented above, it would appear that material conservation was of importance at some point. Additional evidence of tool curation at these locations would support the regarded value of this material. The presence of such tools at comparable Plains Village Tradition sites would put Alibates material use at 41RB112 into cultural perspective for the region during this period.

\subsection{Question 11}

What information can the Late Holocene Eolian deposits in the Canadian Breaks provide concerning the patterns and timing of environmental change during the Plains Village Period?

Background: One of the most conspicuous deposits present at the Long View site is the eolian sediment which draped the upland, and either buried and/or bracketed the prehistoric occupations. As noted in the interim report, two different age eolian deposits were tentatively identified within the Component $\mathrm{C}$ block excavation. One of these appeared to predate the Plains Village occupation, and this deposit appeared to be restricted to a structural depression in the southern part of Component $\mathrm{C}$. A younger eolian deposit, within which an A horizon had formed, draped the entire site. This deposit appears to be either contemporaneous with or post-dates, the prehistoric occupation.

Eolian Deposition in the Canadian Breaks: Eolian deposits are common features of the Canadian River Valley, and several dune fields have been mapped in this region by the Bureau of Economic Geology (cf. Barnes 1969). One of these is directly south of the Long View site abutting the southern side of the Canadian River on either side of the highway. Unfortunately, no work has yet been published on the age of eolian deposition in this region; however some work from the M-Cross Ranch is currently in progress (Frederick and Bateman, unpublished data). The best overview of eolian activity in this region is Vance Holliday's $(1995,2001)$ work on the Southern High Plains. Holliday notes that eolian activity is common in this region in the last two millennia. This appears to be a regional phenomenon, most likely a response to cyclical drought. Holliday (2001:88 and 105) identifies 5 periods of eolian activity in this period on the Plains:
1) after 2300 14C years B.P.,
2) ca. 1650-1550 14C years B.P.,
3) around $80014 \mathrm{C}$ years B.P.,
4) between 350 and 400 14C years B.P., and
5 ) in the $19^{\text {th }}$ century. 


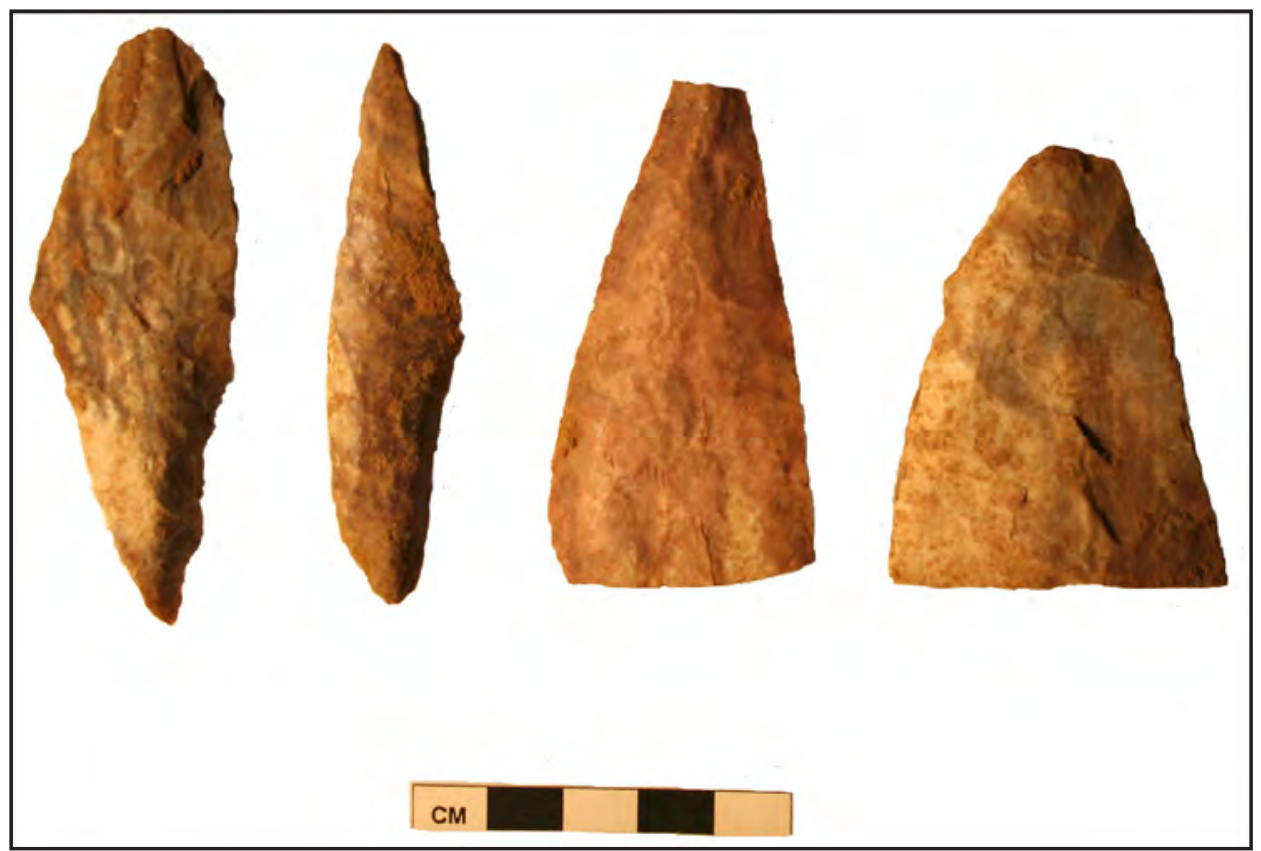

Figure 4-4. Alternately beveled knives fashioned from alibates recovered from Component A, 41RB112, left to right, exhausted biface (complete), exhausted biface (complete), biface fragment, and biface fragment.

In this immediate region, significant eolian deposits are known to bury Plains Village occupations (cf. Boyd and Wilkens 2001; Boyd 2004a, n.d.; Erickson 2004) and it is possible that the conditions responsible for the onset of eolian sedimentation may have affected Plains Village agriculture.

Yet unpublished work on the M-Cross Ranch, (Boyd n.d., Frederick unpublished data), situated within the Canadian Breaks north of the Canadian River about $10 \mathrm{~km}$ east of the Long View site, has speculated that this most recent phase of eolian activity may be attributable to one of two sources: 1) a more arid climate, or 2) down-cutting of local streams. At Hank's House (41RB109) up to $4 \mathrm{~m}$ of eolian deposition buried the Plains Village occupation dating to ca. A.D. 1276 to 1391 . Detailed examination of the geomorphology of the West Pasture on the M-Cross Ranch indicates that most of the recent eolian sand is derived from the now incised channels of the south-flowing streams, which are tributaries to the Canadian River. These streams have removed upwards of 25 percent of the valley floor since they incised in the Late Holocene, and they appear to posses much wider channels than before incision. Near Hank's House one cutbank exposure reveals a channel of West Pasture Creek that was about 5- to 6-m-wide, whereas the modern channel is easily four times that width. The newer, wider channels are quite suited to eolian deflation, and this process is evident in the lower reaches of West Pasture where multiple generations of linear source-border dunes are present on alluvial terraces directly adjacent to the modern or recent channels. As one progresses upstream from the Canadian River, these linear dunes gradually give way to valley floor sand sheets and amorphous dune fields (such as the one that has buried Hank's House). A similar phenomenon is present in the stream valley west of the Long View site. However, unlike the landscape near 41RB112, no upland dunes are known from West Pasture.

The age of these dunes is presently unknown, but in West Pasture, the age of this eolian deposition can be constrained to one or more periods in the last 700 years.

Methods: Fieldwork performed during data recovery at the Long View site collected optical stimulated 
luminescence (OSL) and bulk sediment samples for dating, which may provide information on the period(s) of eolian deposition at the site, and in the overall Canadian Breaks region.

OSL and bulk sediment/soil radiocarbon samples were collected from two off-site dunes (an upland dune and a linear channel fringing dune) as well as from the block excavation (see Figure 4-5). Table 4-1 lists the samples we propose to date, which will provide information on eolian activity in this immediate region, and insight on the deposits present at the Long View site. In general terms, most of the OSL samples from the off-site dunes were collected from laminated eolian deposits, and where bedding was preserved we are suggesting doing standard aliquot OSL dates. A few of the dune deposits lacked bedding, or exhibited some evidence of postdepositional disturbance. The sampling was done with an eye towards avoiding disturbed deposits, but previous experience suggests it would be wise to run these samples as single-grain OSL dates so that the effects of disturbance can be identified and eliminated from the date calculation. Finally, a single bulk sediment/soil sample was collected from the base of each dune in order to provide a maximum age for the eolian deposit.
A total of six OSL samples were collected from the exposures within the block excavations, and given the somewhat compressed nature of the stratigraphy and evidence of postdepositional disturbance, we recommend running all six samples as single-grain OSL dates. Overall, we are recommending nine single-grain OSL, five standard aliquot OSL, and two bulk sediment/soil radiocarbon samples from the off-site dune sections.

In addition to the samples collected for dating, a column of bulk sediment samples was collected from each section. We recommend analyzing the granulometry, organic carbon content and calcium carbonate content of these samples in order to fully comprehend the depositional and pedogenic attributes of the deposits examined. A total of 60 such samples were collected from the off-site dunes (40 from LRSSD; and 20 from LRUD), and another 60 were collected from the profiles where OSL samples were collected within the block excavation (24 from C2, 13 from A1, and 23 from C4). All together we propose characterization of all 120 samples from the measured sections where OSL dates are being run. 


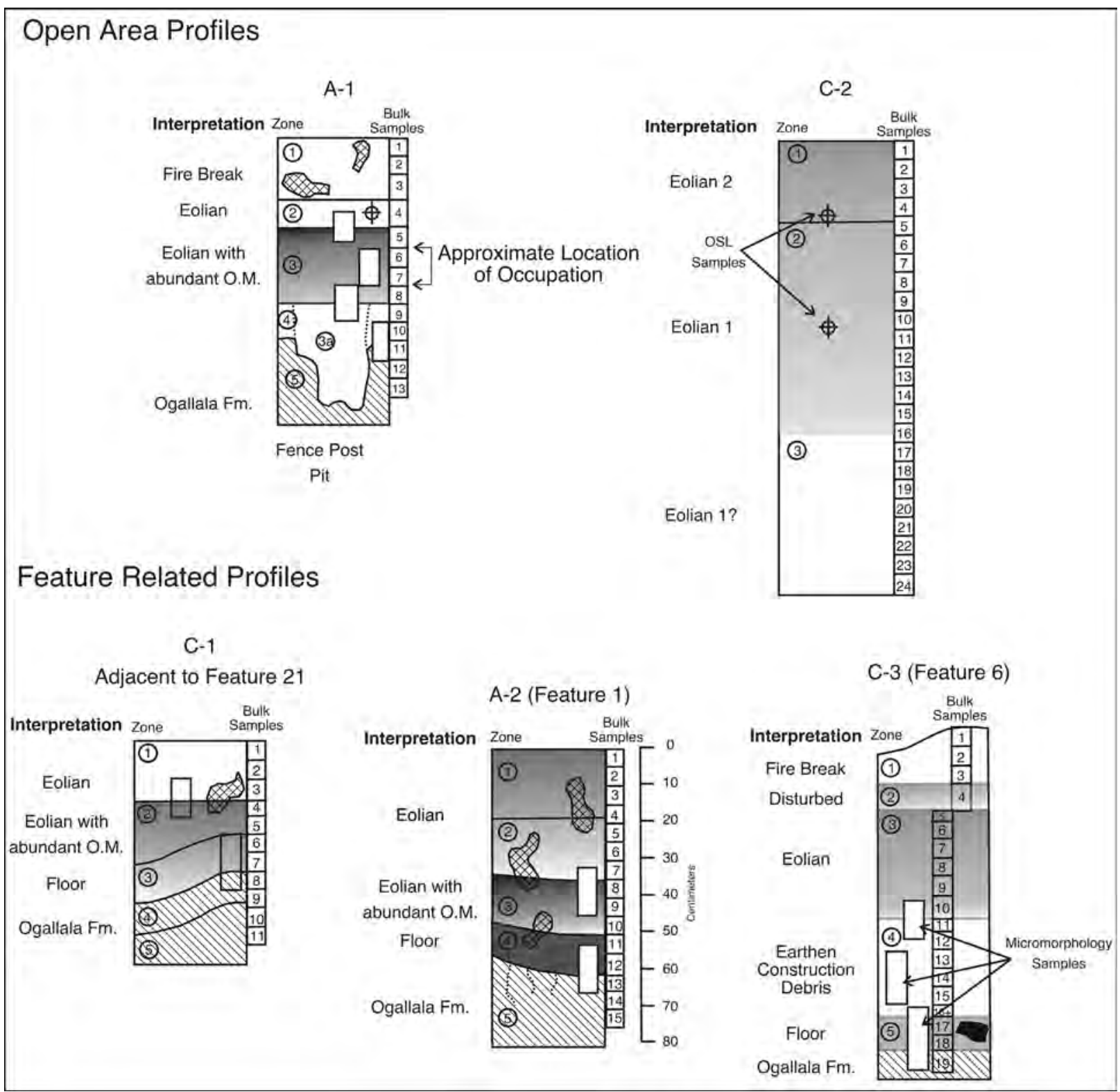

Figure 4-5. Schematic illustration of selected profiles recorded during data recovery geoarcheological investigations within site context, and the location of samples collected. 
Table 4-1. Samples to be Dated for Study of Eolian Sedimentation at and Near the Long View Site, 41RB112.

\begin{tabular}{|c|c|c|c|c|}
\hline Sample Code & Location & Depth & Method & Rationale \\
\hline LRSSD-1 & Stream-side Dune & 60 & Single Grain OSL & Faintly bedded sediment at top of dune. \\
\hline LRSSD-2 & Stream-side Dune & 110 & Standard Aliquot OSL & Well-bedded eolian sediment. \\
\hline LRSSD-3 & Stream-side Dune & 180 & Single Grain OSL & $\begin{array}{l}\text { Middle of dune, but from a deposit lacking } \\
\text { sedimentary stratification. }\end{array}$ \\
\hline LRSSD-4 & Stream-side Dune & 260 & Standard Aliquot OSL & Well-bedded eolian sediment. \\
\hline LRSSD-5 & Stream-side Dune & 310 & Standard Aliquot OSL & Well-bedded eolian sediment. \\
\hline LRSSD- ${ }^{14} \mathrm{C}-1$ & Base of Stream-side Dune & 350 & Radiocarbon & $\begin{array}{l}\text { Bulk sediment sample from alluvial deposits } \\
\text { beneath the dune. }\end{array}$ \\
\hline LRUD-1 & Upland Dune & 30 & Single Grain OSL & $\begin{array}{l}\text { From near the top of the dune but from a deposit } \\
\text { lacking sedimentary stratification. }\end{array}$ \\
\hline LRUD-2 & Upland Dune & 60 & Standard Aliquot OSL & Well-bedded eolian sediment. \\
\hline LRUD-3 & Upland Dune & 120 & Standard Aliquot OSL & Well-bedded eolian sediment. \\
\hline LRUD- ${ }^{14} \mathrm{C}-1$ & Base of Upland Dune & 145 & Radiocarbon & Bulk soil sample from beneath the dune. \\
\hline A1-1 & $\begin{array}{c}\text { Area A, west side of } \\
\text { block, opposite Feature } 1\end{array}$ & 20 & Single Grain OSL & From eolian sand above occupation \\
\hline $\mathrm{C} 2-1$ & $\begin{array}{c}\text { West wall of Area C, } \\
\text { at south end of Stone } \\
\text { Alignment }\end{array}$ & 50 & Single Grain OSL & Will give a maximum age for the stone alignment \\
\hline $\mathrm{C} 2-2$ & $\begin{array}{c}\text { West wall of Area C, } \\
\text { at south end of Stone } \\
\text { Alignment }\end{array}$ & 20 & Single Grain OSL & $\begin{array}{l}\text { Presumed to be an older eolian deposit, beneath the } \\
\text { prehistoric occupation }\end{array}$ \\
\hline $\mathrm{C} 2-3$ & $\begin{array}{c}\text { West wall of Area C, } \\
\text { at south end of Stone } \\
\text { Alignment }\end{array}$ & 100 & Single Grain OSL & $\begin{array}{l}\text { Presumed to be an older eolian deposit, beneath the } \\
\text { prehistoric occupation }\end{array}$ \\
\hline C4-1 & $\begin{array}{l}\text { East wall of Area C, in } \\
\text { vicinity of Feature } 18 .\end{array}$ & 30 & Single Grain OSL & $\begin{array}{l}\text { This appears to be an eolian deposit that post-dates } \\
\text { the Plains Village occupation }\end{array}$ \\
\hline $\mathrm{C} 4-2$ & $\begin{array}{l}\text { East wall of Area C, in } \\
\text { vicinity of Feature } 18 .\end{array}$ & 80 & Single Grain OSL & $\begin{array}{l}\text { This appears to be an older eolian deposit that pre- } \\
\text { dates the Plains Village occupation. }\end{array}$ \\
\hline
\end{tabular}




\subsection{APPROACH AND METHODS TO ARCHEOLOGICAL ELIGIBILITY ASSESSMENT AND DATA RECOVERY AT 41 RB112}

J. Michael Quigg and Paul M. Matchen with contributions by David Maki

\subsection{Introduction}

As a response to TxDOT's proposed widening of a portion of a State Highway to accommodate a passing lane and the addition of new right-of-way and temporary construction easement, Mr. Dennis Price, staff archeologist, from the Environmental (ENV) Affairs Division of the Texas Department of Transportation (TxDOT), conducted a survey in that immediate area (Price 2004) (Figure 5-1). Price acknowledged the presence of pottery, arrow points (Fresno), faunal material, and subsurface features in the highway road cut. The site area was documented as being 125 meters square.

\subsection{Review of Archival Documents}

Prior to TRC entering the field for the site eligibility assessment, TxDOT provided TRC with copies of notes of the archeological survey conducted and the artifacts recovered (e.g., lithic debris, bone, shell, ceramics, finished artifacts, and daub) by Mr. Dennis Price of TxDOT ENV (Price 2004). His survey work included the excavation of two shovel tests at the north end of 41RB112 (now referred to as Component A) and collection of representative and diagnostic artifacts recovered from surface.

In June 2005, prior to conducting the assessment fieldwork, a review of the Texas Historical Commission's (THC's) online Texas Archeological Sites Atlas was preformed to locate existing archeological information on previous cultural resource investigations conducted in the vicinity of this project, and any previously documented cultural resource properties near the area of potential effect (APE). At that time, no archeological sites had been recorded within a 1.6 kilometer $(\mathrm{km}$; 1 mile) radius of the project area. Since that time, three archeological sites (41RB157-a surface lithic scatter, 41RB158 a short-term prehistoric camp, and
41RB160 a prehistoric open campsite) have been documented to the west and southwest of the APE within the $1.6 \mathrm{~km}$ radius. These three sites, as well as several others along the Dugout Creek drainage were recorded by the Texas Archeological Society (TAS) Field School in 2009. The site file review also revealed that relatively few other surveys or excavations had occurred in the area (see Chapter 3.0 for more details on investigations in the region).

A completed THC Antiquities Permit Application was submitted by J. Michael Quigg to the THC on March 7, 2005. The Scope of Work that accompanied the permit application specified the maximum amount and type of work (i.e., surface collecting, cutbank cleaning, hand-excavations, mapping, and shovel testing) and specific tasks for the field assessment program. Also included were the types of initial analyses to follow and the reporting process required by TxDOT. The Scope of Work also included a treatment plan for the discovery of human remains and protocols if and when such remains were encountered. Permit 3721 was granted to Mr. Quigg by the THC on March 29, 2005.

\subsection{TRC Field Methods During Site Assessment}

During the TRC site eligibility assessment at site 41RB112 in May 2005, the following methods were employed for the purpose of assessing National Register of Historic Places (NRHP) and State Archeological Landmark (SAL) eligibility.

Initially, the long narrow north-south APE of site 41RB112 on the western side of the highway varied from about 8 to 10 meters (m) wide by 270-m-long and was subdivided into three sections, Areas A, $\mathrm{B}$, and $\mathrm{C}$, to designate the different topographic settings present and possible cultural variations across the site. Cultural Component A encompassed the northern end (Area A) and covered roughly a 60-m-long section that crossed a low rise at the northern end of the ridge. Component A contained a concentration of cultural materials in the vicinity of a cultural feature (Feature 1) exposed in the road cut. Area B, immediately south of Component A, was slightly lower in elevation, and crossed a low saddle area that lacked significant quantities of cultural material, at least based on the surface observation 


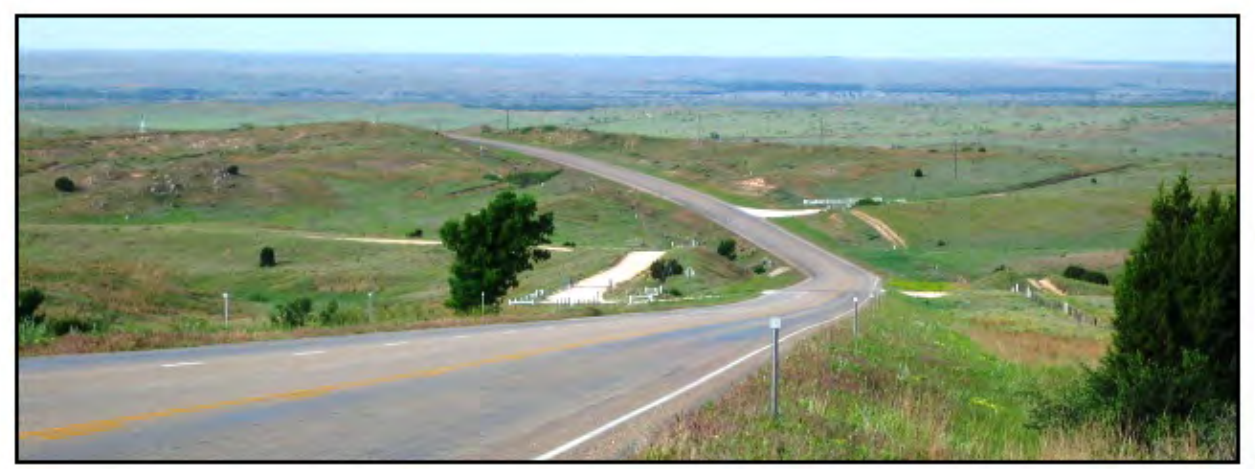

Figure 5-1. Overview of Site 41RB112 setting with Canadian River Valley in background.

during the initial site visit. Area B extended about $120 \mathrm{~m}$ to an arbitrary boundary where the land began to rise. Cultural Component $\mathrm{C}$, immediately south of Area B, was at the southern end of the site and ridge (Area $\mathrm{C}$ ), centered along a low rise that exhibited a linear rock alignment near the surface and clustered cultural materials in the vicinity. Component $\mathrm{C}$ extended about $90 \mathrm{~m}$ southward with the southern end sloped down to the south off the end of the ridge.

The initial step in the assessment was the location of the cultural materials exposed on the previous disturbed surface across the long, narrow APE. The disturbance was a roughly 3.5- to 4.0-m-wide mechanically bladed fireguard that had been repeatedly bladed into the deposits along the property fence line. Six crewmembers lined up eastwest across the narrow APE and walked the entire $270 \mathrm{~m}$ length of the projected site area. Pin flags were used to mark each and every piece of cultural material observed during this inspection (Figure 5-2). This surface collection process included the vertical road cut edge along the eastern edge of the APE. The observed cultural materials were located, identified, and mapped on an overall site map, with the ceramic sherds, stone, and bone tools collected individually. These cultural items were placed in individual plastic bags with individual artifact tags that had provenience information. The more general materials such as lithic debitage, burned rocks, mussel shell fragments, and bone fragments were collected by class by the three different designated areas.
TRC personnel used the existing road cut exposure in an attempt to locate buried cultural features in the most efficient manner without destroying large surface areas. Some $28 \mathrm{~m}$ of exposed Holocene deposits, generally the upper 50 to 60 centimeters (cm) below ground surface (bs) of the road cut, was hand-faced and cleaned in selected positions in Component A and C. In Component A, a nearly 15-m-long section was cleaned that included the area that encompassed the roughly 2-m-wide cultural basin labeled as Feature 1 (Figure 5-3). This linear section was inspected, cultural materials noted and collected, and a profile drawn. In Component C, a nearly 13-m-long section was cleaned and inspected, $6.5 \mathrm{~m}$ directly east of the rock alignment (Figure 5-4). Feature 5 was detected in this area (Figure 5-5), but no large rocks potentially associated with the rock alignment were detected.

Four hand-dug trenches, about 25- to 30-cm-wide, were completed, two each in Components A and C. Two hand-dug trenches, Trench A- 1 and Trench C-1, were completed along the edges of the fireguard to help assess the sediment deposition and depth of the disturbance (Figures 5-3 and 5-4). These two trenches, 9- and 8-m-long respectively in a northsouth direction, were also dug in anticipation of locating buried cultural features. Trench A-1 was dug along the eastern edge of the fireguard about $5 \mathrm{~m}$ due west of Feature 1 observed in the top of the road cut. Cultural materials including Feature 3 were encountered during the trench excavation and observed in the trench walls. Photographs were taken and a profile was drawn of Trench A-1. Trench $\mathrm{C}-1$ was dug on the western edge of the fireguard 


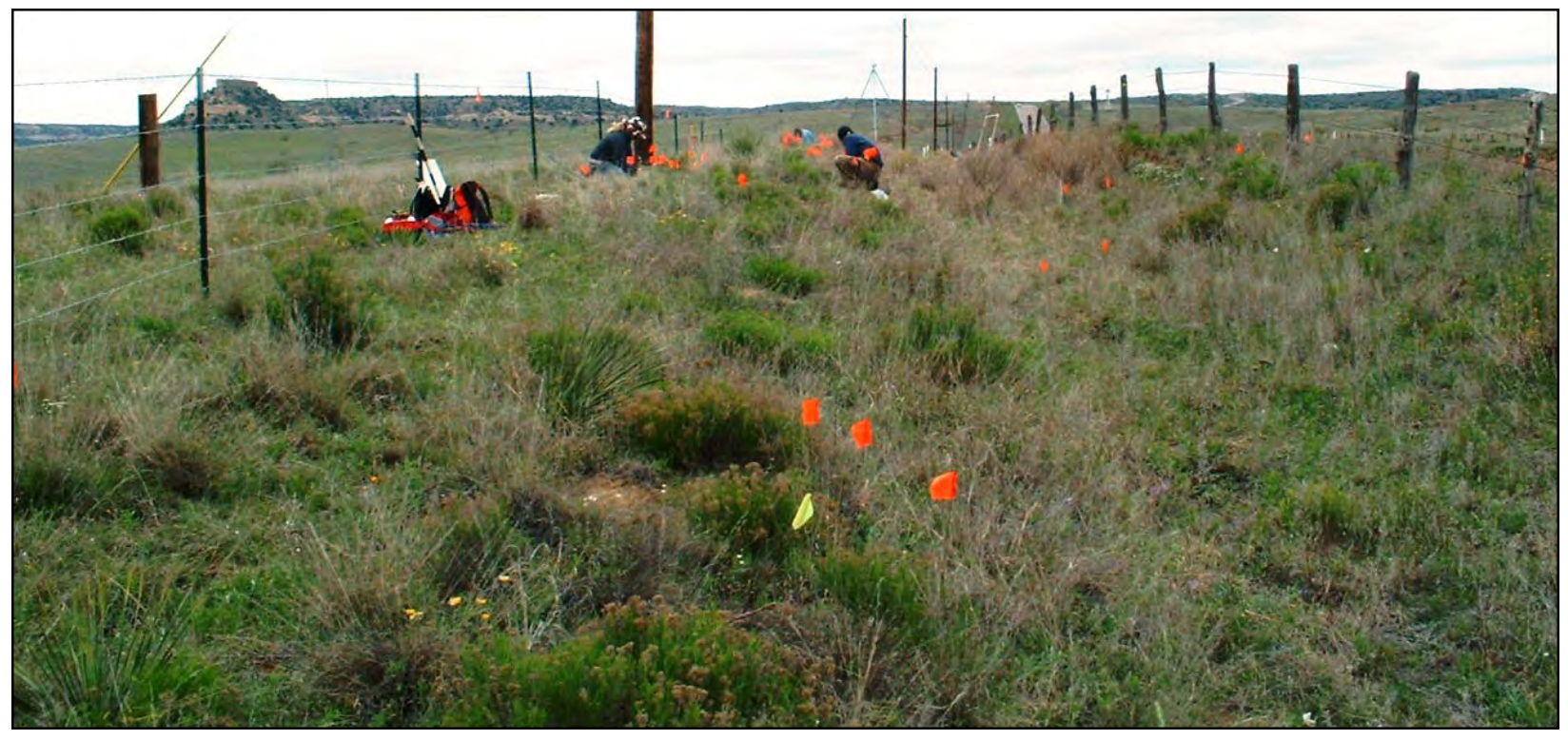

Figure 5-2. Overgrown fireguard with pin flags marking locations of observed artifacts.

about $1.5 \mathrm{~m}$ directly east of the rock alignment in Component C. This trench was the place to explore the possibility of rock alignments perpendicular to the observed surface rock alignment, which might help confirm the presence of a structure. One tight cluster of natural caliche rocks (Feature 7) was encountered during the digging of this trench (Figure 5-6). No sign of any other significant rock alignment was encountered. The trench walls were photographed and the profile drawn.

Two other hand-dug trenches, Trench A-2 and Trench C-2, were completed perpendicular (eastwest) across the fireguard in Areas A and C (Figure 5-7). These two trenches were used to examine the depth of the fireguard disturbance in the two areas where cultural materials were concentrated to determine the potential for cultural materials to remain below the bladed fireguard.

A total of 28 individual 1-by-1 m units, $16.8 \mathrm{~m}^{3}$, were hand-excavated across the APE and the sediments screened through 6.4 millimeters (mm, $1 / 4$ inch) hardware cloth. These test units were widely distributed across all three areas with eight units each in Areas A and B, and 11 units in Component C (see Figures 5-3 and 5-4). Placements were done opportunistically at the judgment of the Principal
Investigator to provide broad coverage and gather information from across the long APE relevant to site structure and content; integrity, feature, and non-feature contexts; and to identify areas for potential mitigation. These units were numbered sequentially for each area and were preceded by the Area designation (i.e., A-1 for the first unit in Area/Component A). Units were excavated in 10 $\mathrm{cm}$ arbitrary levels until calcium carbonate nodules dominated the last level or sterile deposits were encountered. The vertical measurements were recorded from below surface (bs) using a string and line level. The depth of individual units varied from $42 \mathrm{~cm}$ in A-8 to $115 \mathrm{cmbs}$ in B-2. When sizable pieces of cultural material were encountered in situ during the excavations, these items were piece plotted on the excavation level records and the bottom elevation of the object was recorded. An excavation level form was completed for each handexcavated and screened level. Recognized cultural materials were collected and placed in resealable plastic bags by excavation unit and level, class of material, appropriately labeled with field tags in each bag, and returned to the laboratory in Austin for processing and analysis.

When multiple pieces of cultural material were in a cluster, these clusters were designated as 


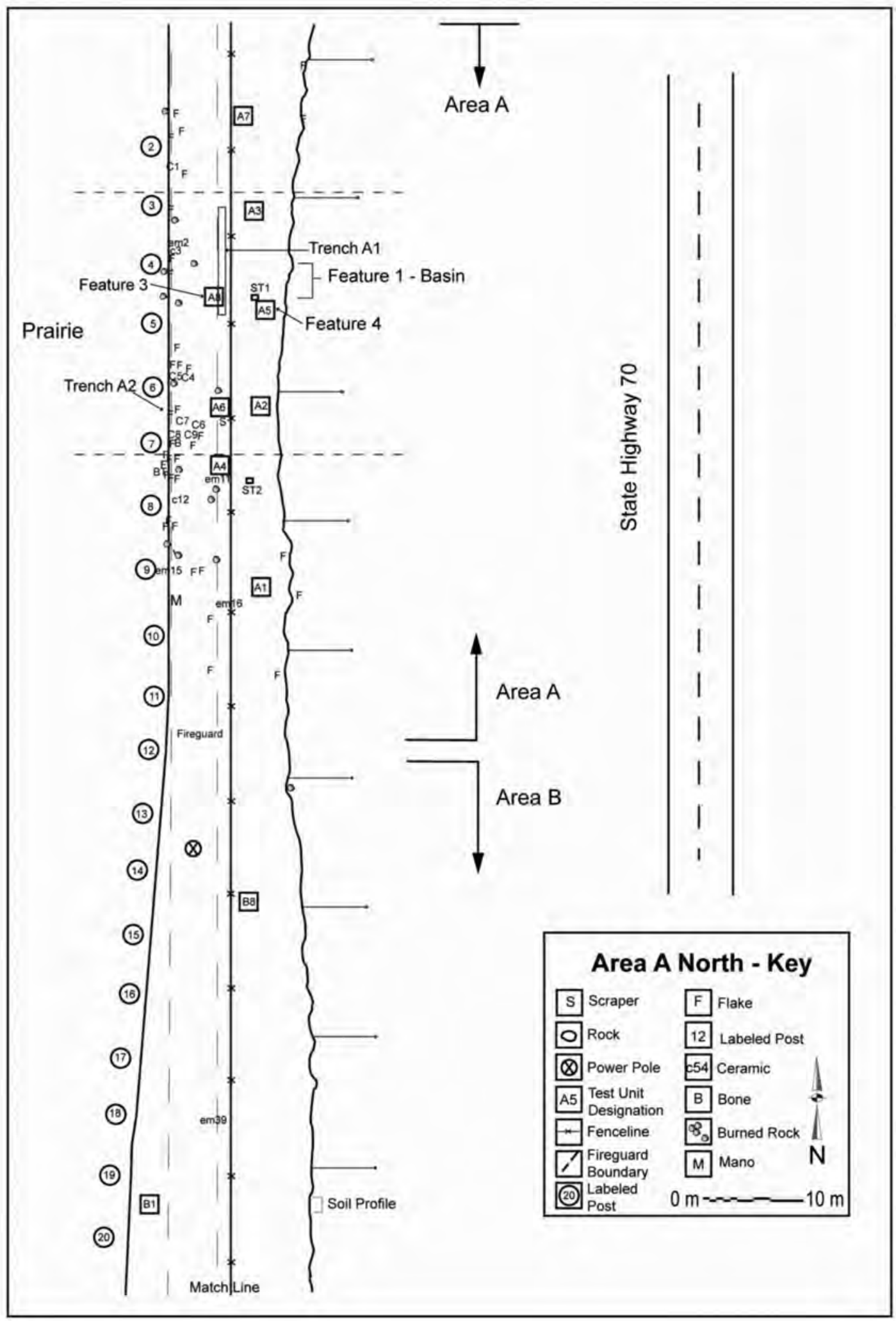

Figure 5-3. Plan map of Component A and the northern part of Area B following site assessment. 


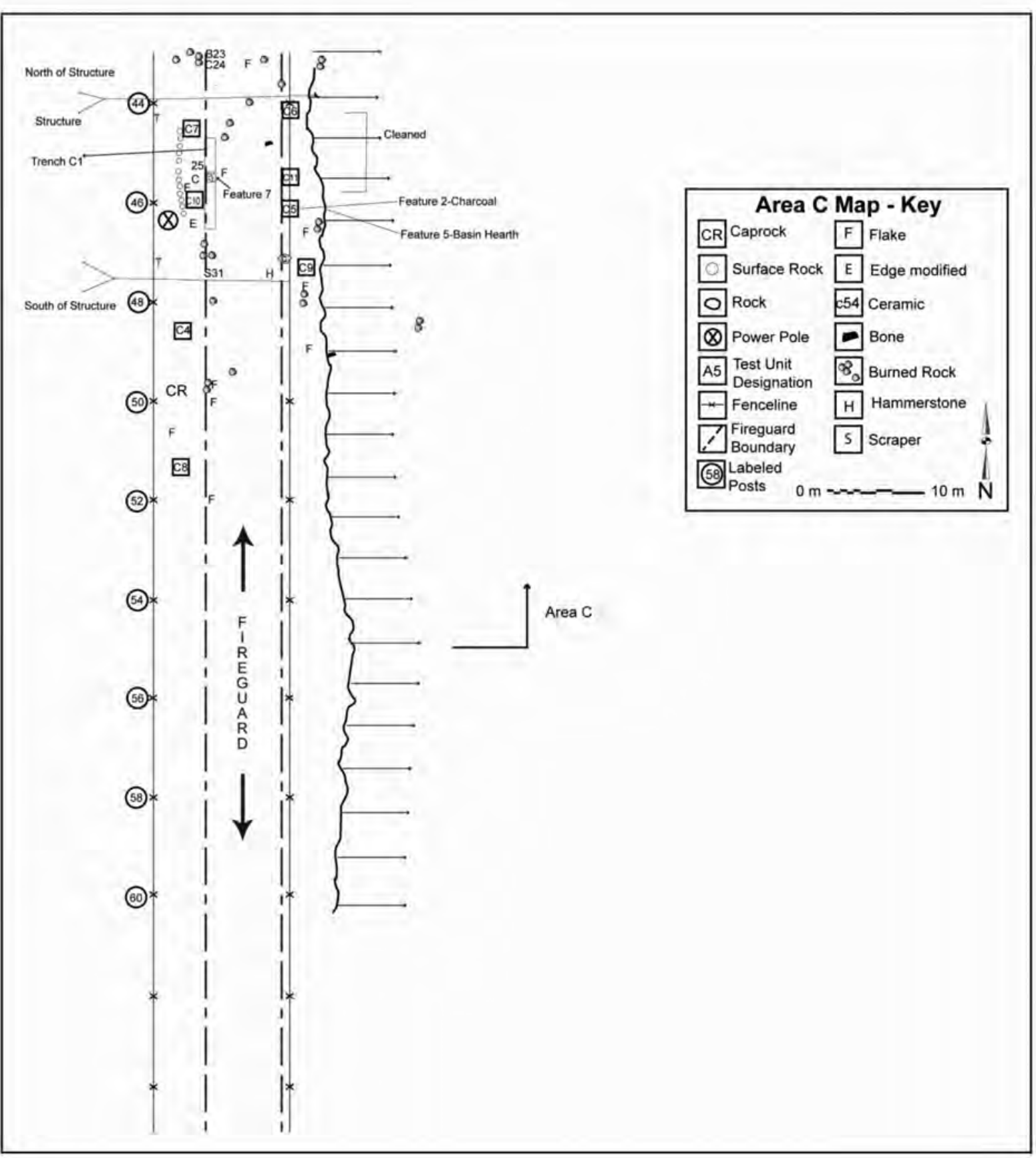

Figure 5-4. Plan map of the southern part of Component $\mathrm{C}$ following site assessment. 


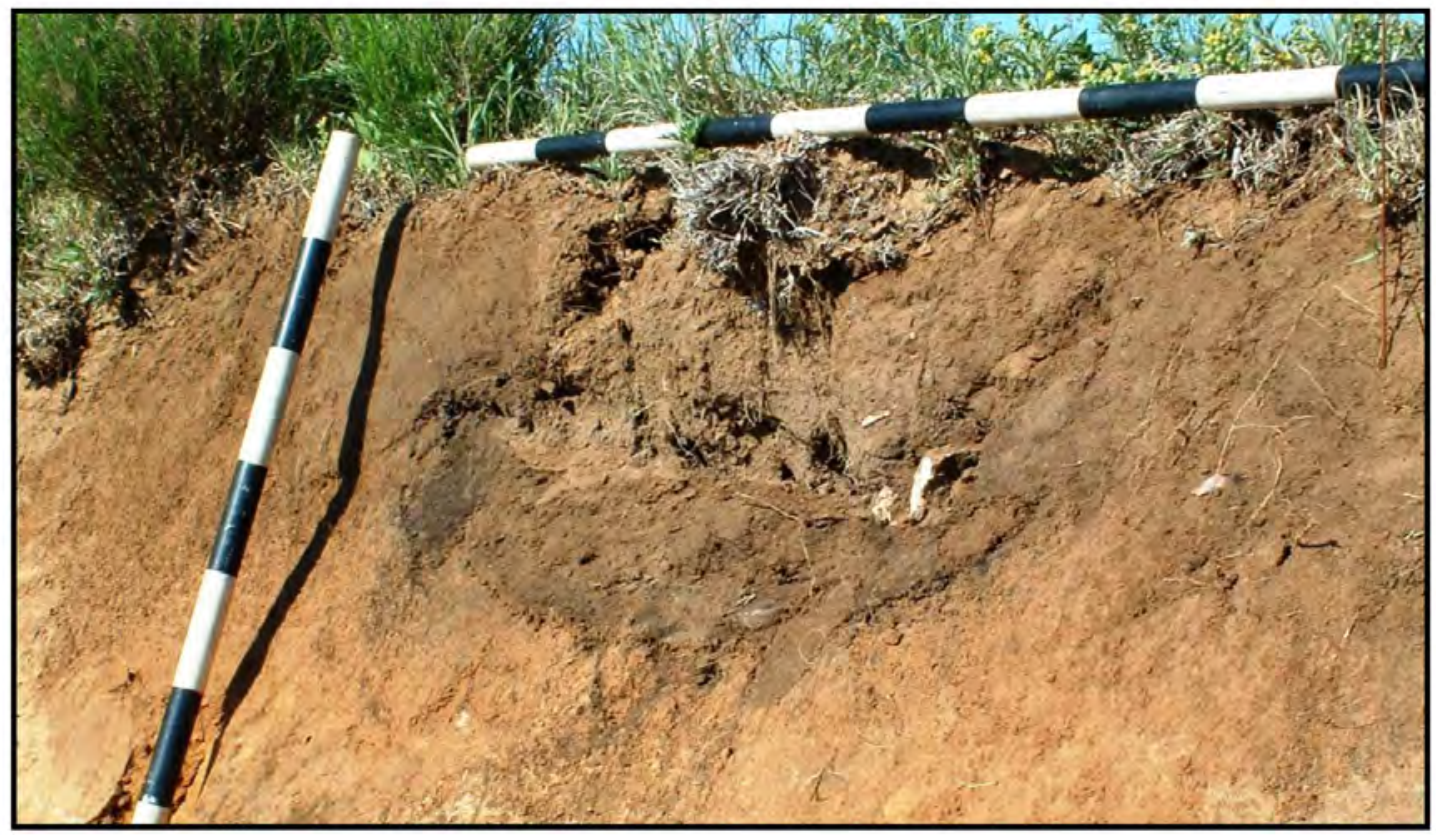

Figure 5-5. Feature 5 exposed in facing the existing road cut in Component $\mathrm{C}$.

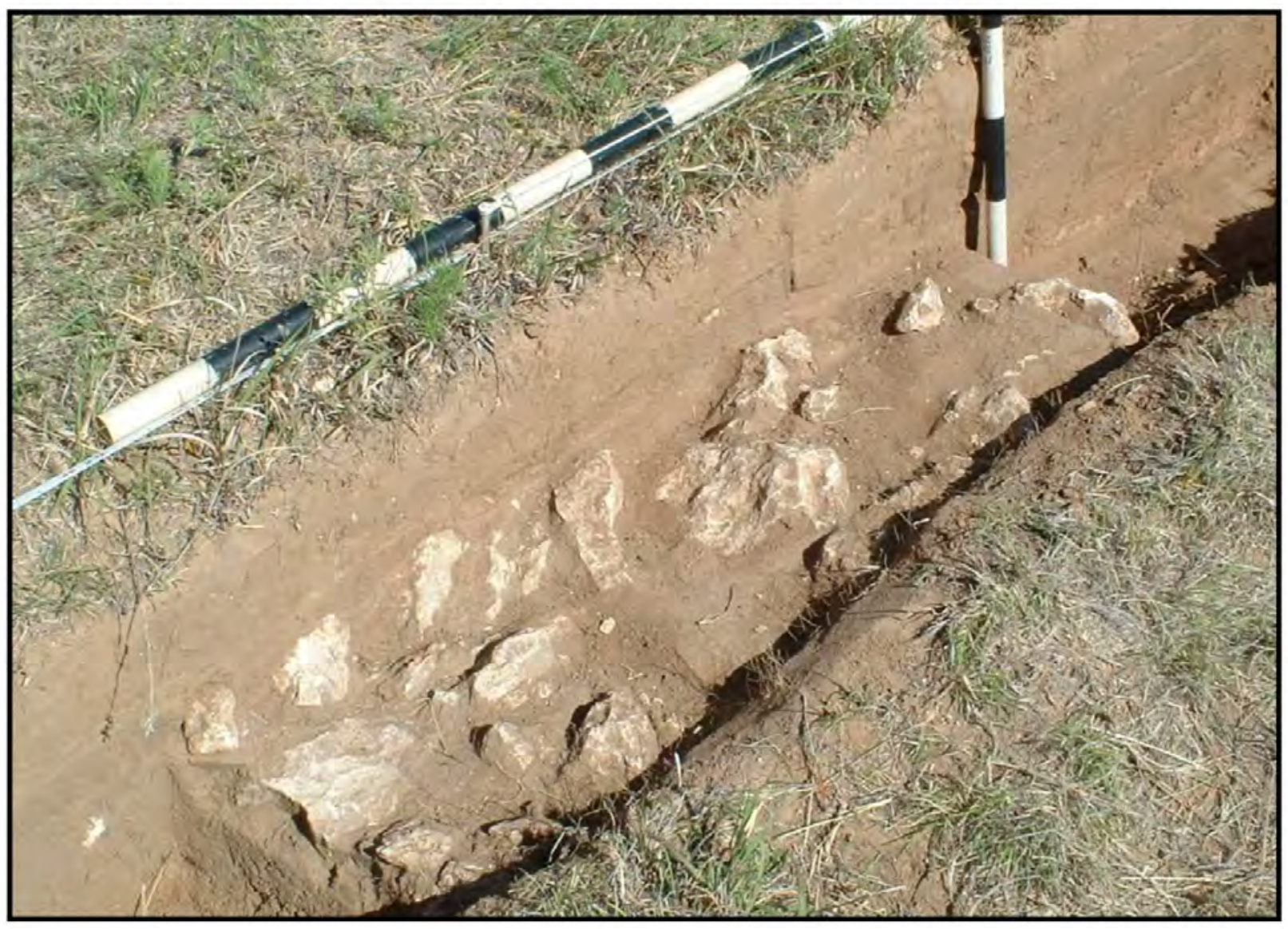

Figure 5-6. Feature 7, cluster of buried caliche rocks discovered in hand-dug trench C-1 in Component $\mathbf{C}$. 


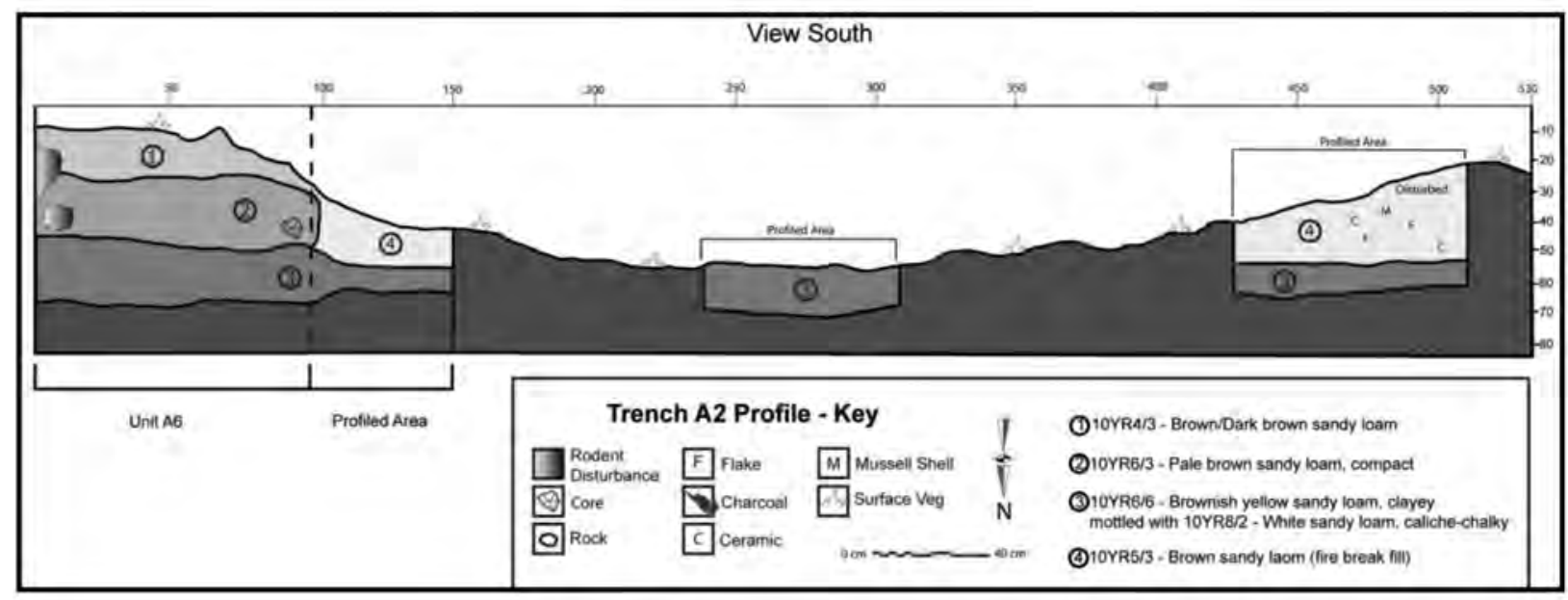

Figure 5-7. Profile of hand-excavated Trench A-2 across fireguard in Component A.

cultural features. Once features were recognized, the excavation and recording methods changed in order to collect more observations and data for interpretation. With small features, the feature was isolated from the rest of the level for more precise excavation and documentation. In most instances, the internal matrix of small features was removed and bagged without screening for more refined screening and/or flotation in the laboratory. The small features were cross sectioned at least once to expose the profile. The feature was drawn in plan view and profile, digital photographs taken, and a feature form was completed. The form documented the size, shape, and various construction elements. The large features, Features 1 and 6 plus Structure 1, were dealt with slightly differently because of their greater size and lack of complete excavation.

A hand-operated Oakfield coring device was used to remove 16 small diameter cores $(2 \mathrm{~cm})$ across a gridded area between the Feature 1 basin in the road cut and Feature 3 in Trench A-2, and next to Unit A-5. This coring apparatus provided a 2-by-24 $\mathrm{cm}$ open core that allowed the sediment recovered to be examined. Coring was implemented to investigate the possible continuation and location of the cultural basin observed in the road cut. As cores were retrieved, the sediment colors were recorded on a form and the presence or absence of cultural materials was noted. The depth of the cores ranged from 14 to 74 cmbs.
A site plan map was drawn. The surface artifacts, 1-by-1 m units, the faced/cleaned sections, the hand-excavated trenches and profiled areas, and other relevant locational data were drawn on the map (see Figures 5-3 and 5-4). A more detailed map of the rock alignment in Component $C$ was recorded on the Component $\mathrm{C}$ map, in addition to the location of the cultural materials collected from the surface, position of the identified features, and other relevant data in that immediate area.

Selected units in each area had at least one wall profiled. In some instances, small sediment samples were collected from these walls. These sediment samples could potentially be used for a variety of analysis including grain size, phytolith, isotope investigations, etc.

Artifacts classified as burned rock were generally counted and weighed in the field by predetermined size classes and recorded on individual level records. Once recorded, most were discarded, but some selected samples from various levels, units, and features were retained and returned to the laboratory for potential analysis and assessment. In a number of localities, small water rounded, unbroken quartzite cobbles were discovered, unlike most burned rocks. Many of these cobbles were retained for closer observations as they could have served as boiling stones without fracturing. 
Bulk sediment samples for fine-screening and/ or flotation in the laboratory were collected from selected features and other context. General sediment samples from selected units in Areas A and C were also collected.

Macrobotanical, charcoal, and other samples were collected from recognized features and other contexts during excavations. Many charcoal pieces outside features were piece plotted, collected, and bagged separately.

The eastern side of the highway, opposite the concentration of cultural materials, was also investigated. Five 50-by-50 cm diameter shovel tests were excavated in the narrow APE. The sediments from those tests were also screened through $6.4 \mathrm{~mm}$ hardware cloth. These shovel tests revealed very limited cultural materials. The lack of substantial cultural materials indicated that no further archeological investigations were justified in that area.

Back in the Austin laboratory, various methods were employed to further assess specific data sets. The collected lithic debitage, mussel shells, and bone were hand-washed, sorted, and counted. Selected stone and bone artifacts and most ceramic sherds were not washed to preserve cultural residues that may still be adhering to their surfaces. Selected sediment samples from across the three areas were sent to different specialists for analyses. Six sediment samples were selected and sent to Dr. Steve Bozarth to determine the presence/absence of phytoliths. Eight samples, seven charcoal pieces, and one maize kernel were selected and submitted to TxDOT for approval, and then forwarded them to Beta Analytic Inc. for radiocarbon dating. About 27 liters of sediment from Features 3, 4, 5, and 6, plus eight individual charcoal chunks, were sent to Dr. Phil Dering for flotation and macrobotanical identifications.

Grant Smith, TRC geoarcheologist, documented and characterized the Holocene deposits from various excavation units, trench walls, and the road cut exposures following the hand-excavations. From his observations in the field, Smith wrote the initial assessment of the geoarcheology of the areas in the APE. The geoarcheological evaluation was included with the archeological methods, results, conclusions, recommendations, and two technical assessments (phytoliths and macrobotanical) plus a data recovery plan in an interim report submitted to TxDOT ENV for review and comment (Quigg and Smith 2005; Appendix L).

\subsection{Data Recovery Objectives and Methods}

\subsubsection{Data Recovery Field Methods}

The field tactics employed during the data recovery phase focused on opening large excavation blocks within in the narrow APE in Component A (north end) and Component $\mathrm{C}$ (southern end), west of the highway. A total of $103.4 \mathrm{~m}^{3}$ of deposits was removed, sampled, and screened through handexcavation. The excavation blocks enabled the exposure of large parts of each occupation zone within the narrow APE to allow investigations of spatial patterning of features and artifacts.

Excavations in Component A were segmented into two major blocks with lines of excavated units between the two blocks (Figures 5-8 and 5-9). During the data recovery in Component A, 121 $\mathrm{m}^{2}$ were hand-excavated not including the $7 \mathrm{~m}^{2}$ excavated during site assessment. In Component A, $77 \mathrm{~m}^{2}$ were excavated in the northern sections and another $51 \mathrm{~m}^{2}$ excavated in the more southern block (Figure 5-10). The previous blading of the fireguard immediately west of the excavation block in Component A removed roughly 30 to 40 $\mathrm{cm}$ of deposits that contained the upper part of the occupation zone, perhaps half of the cultural deposits (see Figure 5-7). Therefore, hand-excavations did not target deposits beneath the mechanically scraped fireguard. Instead, the cultural deposits contained below the intact natural prairie were targeted for the hand-excavations between the fireguard and the highway cut bank.

Hand-excavations in Component $\mathrm{C}$ were conducted in long, narrow segmented blocks because the stripped fireguard was down the middle of the APE (Figure 5-11 map of Component C). Component C was divided into eastern and western parts by the 


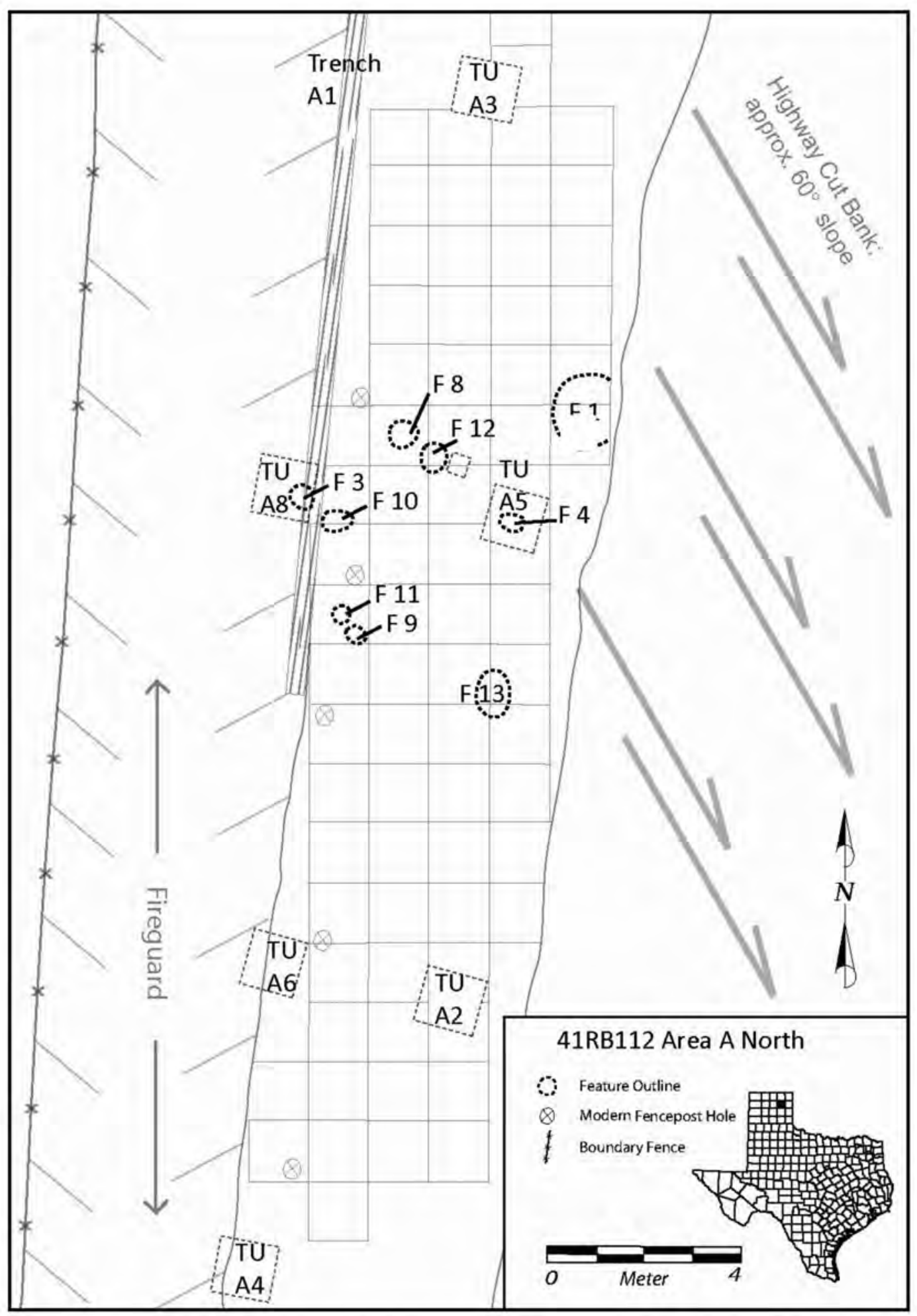

Figure 5-8. Northern excavation block in Component A, indicating feature locations. 


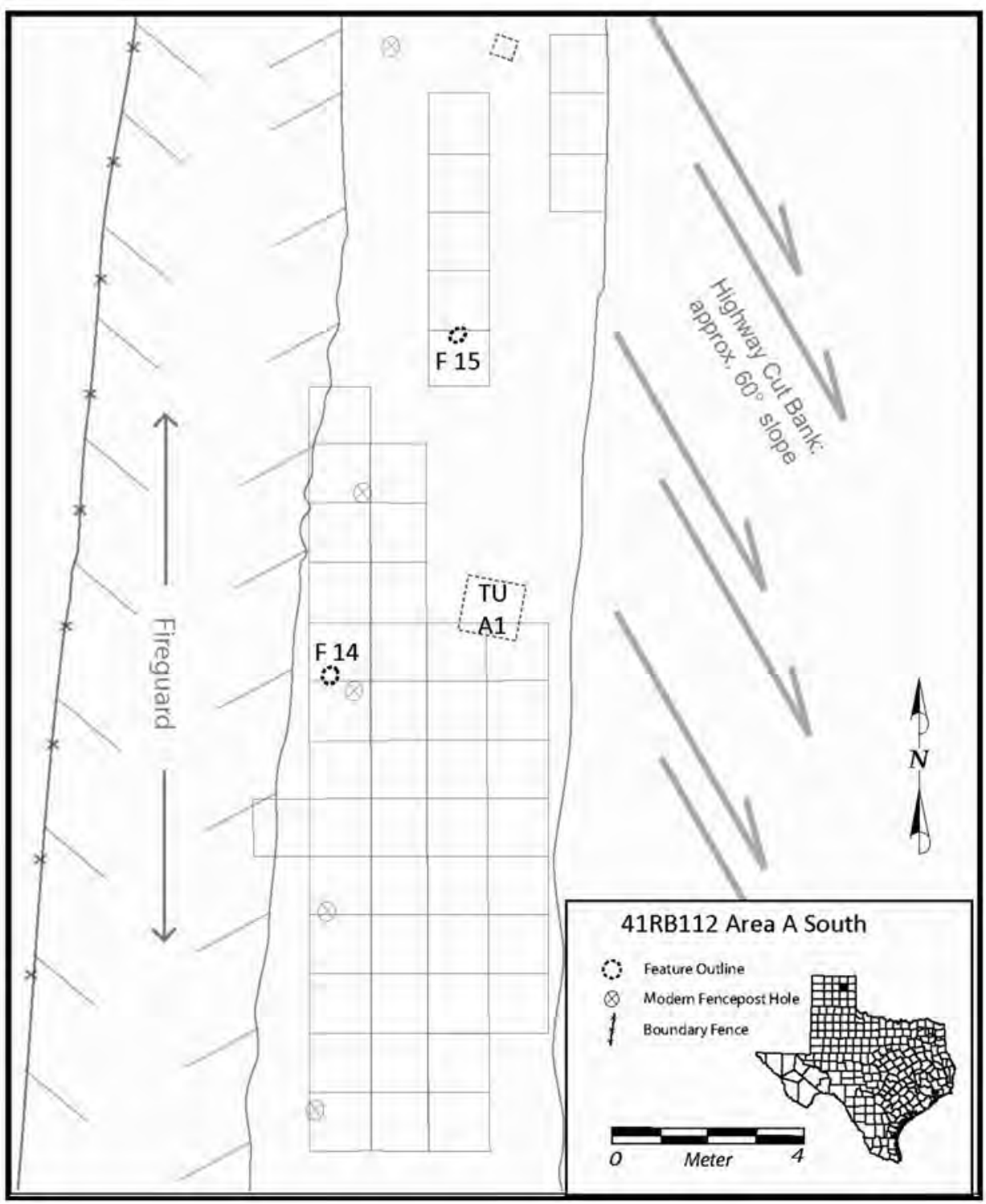

Figure 5-9. Southern excavation block in Component $A$ indicating feature locations. 


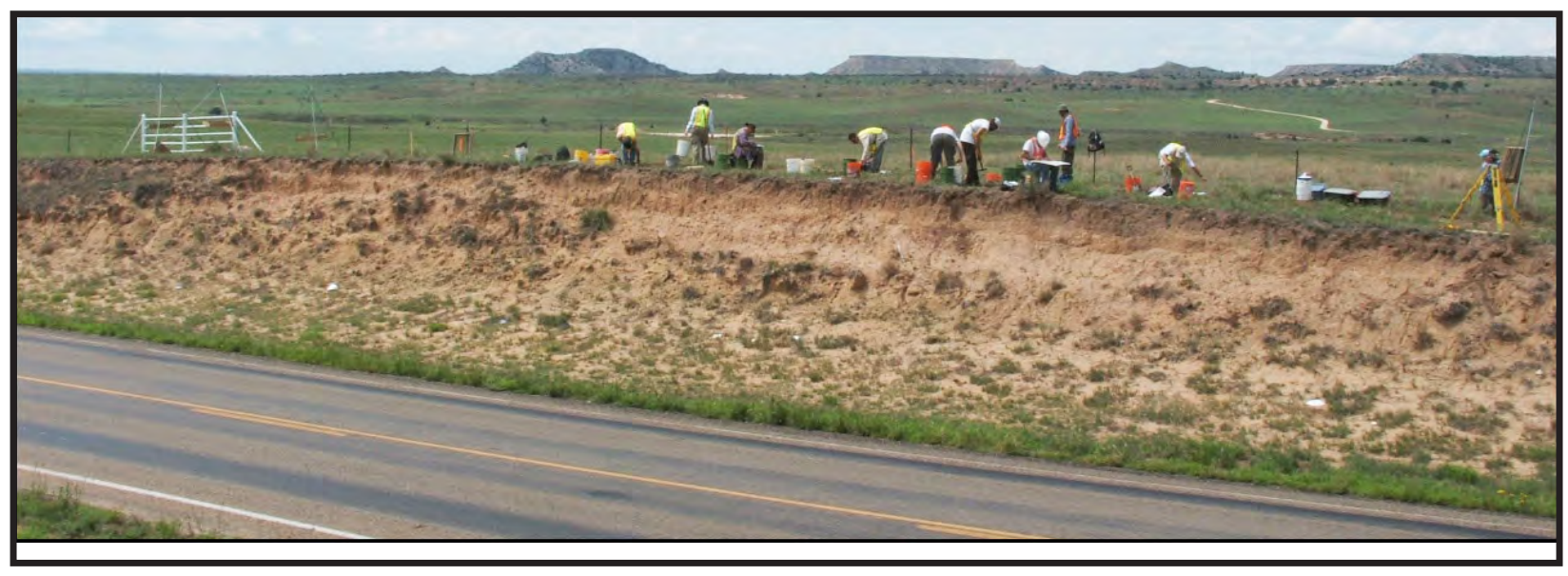

Figure 5-10. South westward view of data recovery excavations in Component A in APE.

roughly 4-m-wide bladed fireguard, which penetrated the upper 30 to $40 \mathrm{~cm}$ of the potential occupation zone. This left a narrow strip of natural prairie on either side of the fireguard within the narrow APE (Figure 5-12). In places it was noted that the fireguard disturbance did not remove the lower part of the brown (10YR 4/3) sandy loam A horizon. During the data recovery efforts, $93 \mathrm{~m}^{2}$ were excavated in an effort to further investigate the cultural features located during the eligibility assessment, as well as to locate new features and further define activity areas. Once it was determined that Feature 6 was a subterranean structure along the western edge of the fireguard and likely extended beneath the disturbed fireguard, hand-excavations were expanded across the fireguard to fully expose this subsurface structure and its immediate surroundings.

During the eligibility assessment/testing, the original highway right-of-way was demarcated by a wooden post and barbwire fence line that extended the entire length of the APE. At the time of the data recovery investigations, the new right-of-way fence was in place along the western boundary of the APE. This was a five strand barbwire fence with metal "T" posts. Just prior to the geophysical investigation, which initiated the start of the data recovery excavations, the old wooden fence line and barbwire was removed by the previous landowner.

Hand-excavations were conducted within an assumed 1-by-1 m grid system across the entire site area with coordinate values used to identify each unit by the northeast corner designation. The vertical target zone was generally between 0 and $50 \mathrm{cmbs}$, but in many instances this varied according to the nature of the deposits. The extreme southern end of Component $\mathrm{C}$ constituted the southern crest of the north-south ridge. As such, a considerable quantity of eolian sand had accumulated over the targeted archeological deposits. As a result, a number of the excavation units in Component $\mathrm{C}$ were excavated to roughly 100 cmbs. Hand-excavations were conducted in $10 \mathrm{~cm}$ arbitrary levels to remove and screen sediments from the individual 1-by-1 m units. In most units, five levels (i.e., $50 \mathrm{~cm}$ ) were excavated. It was not uncommon, however, for Ogallala Formation deposits to be encountered above that depth in much of Component $\mathrm{A}$. When cultural materials and cultural features appeared to decrease in frequency at the margins of either of the blocks, hand-excavations were focused towards concentrations within those blocks.

An excavation level record was completed for each hand-excavated and screened level. The handexcavated matrix was screened through $6.4 \mathrm{~mm}$ hardware cloth. Cultural materials such as lithic debitage, stone tools, faunal bone, mussel shell, charcoal, and burned rock were collected and placed in resealable plastic bags and labeled according to the appropriate provenience. Although the vertical nature of the cultural materials is generally known, vertical depths for many of the larger cultural items were piece-plotted during the hand-excavations. The selective piece-plotting contributed to the 
Chapter 5: Approach and Methods to Archeological Eligibility Assessment and Data Recovery at 41RB112

This page intentionally left blank. 


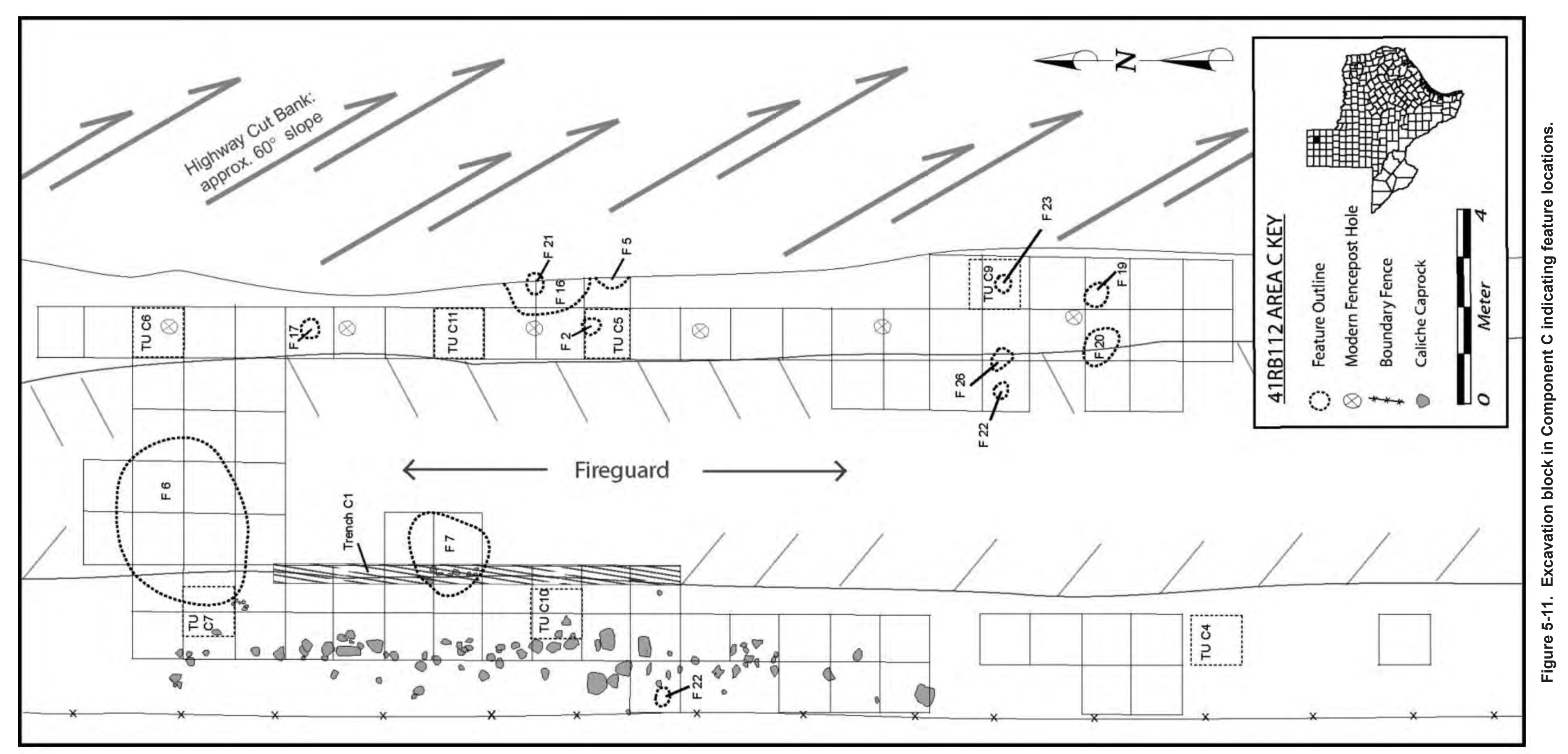




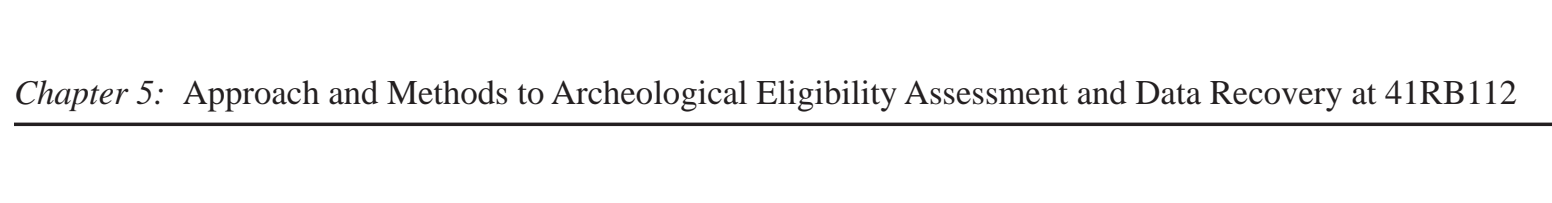




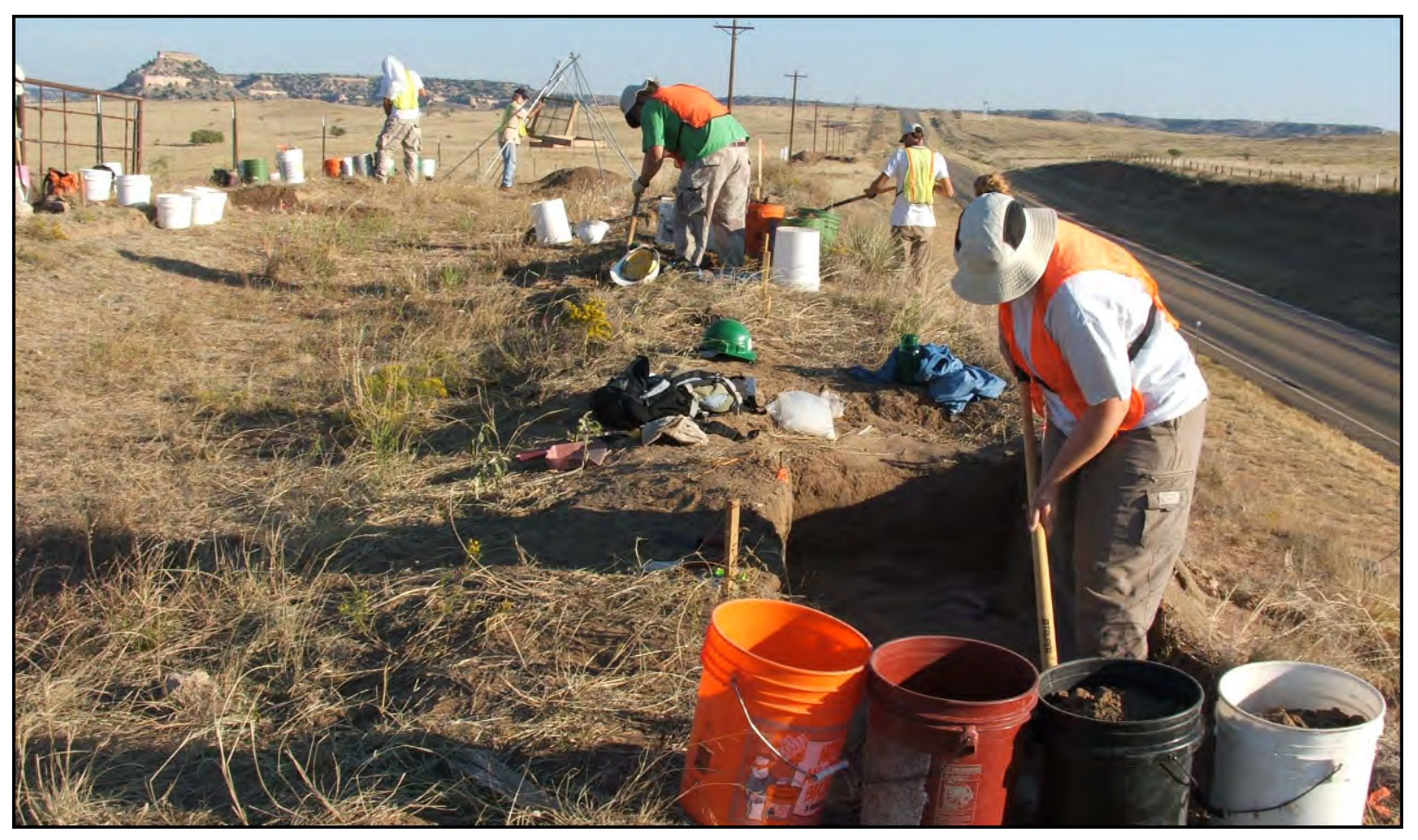

Figure 5-12. View north of data recovery excavations at Component C.

documentation of the vertical depth of the occupation zone or event(s) and helped determine the elevation from which pit features were originally excavated. The horizontal provenience of the larger pieces was also mapped on the level records to allow spatial patterning and associations to be investigated. This type of piece plotting allows horizontal maps to be developed to address site structure, define activity areas, and to address other behavioral patterns.

When clusters of cultural material were encountered, these clusters were again designated as cultural features, hand-excavated, and documented with greater precision. Following careful exposure that employed hand-tools in and around the material concentration, features were photo-documented, mapped in plan and profile views, measured, and observations made on the context, integrity, and associations of cultural materials. Artifacts and samples (i.e., charcoal, burned rocks, and matrix) from within features were collected. Recovered cultural debris from features were bagged and appropriately labeled separately from the materials collected from the general $10 \mathrm{~cm}$ excavation level(s) in which the feature occurred. Burned rocks were most often sorted into four previously identified size categories, counted and weighed by size category, and sometimes typed by material in the field. Some individual samples or entire units of burned rocks were retained for further inspection and/or subsequent detailed analyses. Unscreened feature sediment was also collected, bagged, and appropriately labeled for flotation or fine screening in the laboratory. A feature form was completed for each designated feature to provide primary data concerning the nature of feature construction and content.

A few features that extended beyond a single $1 \mathrm{~m}$ square (i.e., Features 1, 6, and 7) required adjustments to the excavation of those features. At Feature 7, the vertical and horizontal context of that pit feature was recorded and excavated in segments to fully document what was being uncovered. In some instances multiple vertical levels were partially excavated to view and record profiles. In Feature 6,15 - and 20-cm-wide east-west baulks were left along a continuous row of units that crossed through this 3-to 4-m-long feature. These baulks were used to record vertical profiles, facilitate the collection 
of multiple types of sediment samples from very specific vertically identified horizons, and retained for photographing and further scrutiny toward the end of the excavations of Feature 6. Feature 1 was similarly handled, in that a 20 -cm-wide baulk on the eastern side of Feature 1 was retained and used for recording that profile and to sample the contents of Feature 1.

A number of small, circular dark stained areas were carefully examined. Although many were determined to be rodent burrows, others appeared to be small post holes and part of structures (i.e., Features 1, 6 and 18). First, the internal matrix were removed, with the remaining vertical hole lined with cellophane, and then filled with expanding foam. Once dried and hardened, the expanded foam provides a physical record of the probable post hole. These foam "artifacts" were then bagged, in some instances with the sediment removed from the hole, and labeled as any other specimen. The cultural holes were then measured and their lengths and widths recorded as was their horizontal position in relation to other materials.

Multiple sediment columns from the excavated Areas A and C (at least two per Area) were collected by the geoarcheologist and the archeologists for future analyses. These samples were used for such analyses as examining soil texture, stable carbon and nitrogen isotopes, optical stimulated luminescence (OSL) dating, and phytolith content.

A sample of the recognized stone tools discovered were not touched with bare hands or washed upon examination in the laboratory. A number of the unwashed tools were targeted for high-powered usewear and/or residue analyses. Other unwashed tools were curated for possible future analyses.

A sample of natural cobbles, including both chert and nonchert-bearing pieces, were collected from exposed gravel beds in the two creek valleys adjacent to 41RB112, and a gravel ridge/old terrace deposit south of the site overlooking the Canadian River valley. These natural rock samples were used to compare and contrast with the cultural materials collected from the cultural occupations.
Special attention was directed towards finding and collecting macrobotanical remains. Individual charred plant remains encountered during general level excavations, and/or specific features were collected and bagged separately. Cultural sediment was collected from identified features for flotation processing in the anticipations that the resulting fractions would yield macrobotanical remains. In anticipation of mesquite wood structure analysis, dead mesquite wood (branches) in the vicinity of 41RB112 were collected to provide modern comparative samples to establish and document the present moisture condition growth patterns in this area.

\subsubsection{Post-Excavation Machine Stripping}

During the data recovery excavations, archeological staff identified two human interments within the APE at the southern end of Component C. Following completion of planned hand-excavations, TxDOT directed TRC to supervise machine stripping across the southern part of Component C where the interments were discovered to insure that additional human interments were not still present within the APE. If human remains were encountered during the stripping, archeologists were to recover those remains. Archeologists were directed to clean, expose, and document any additional nonarchitectural prehistoric features encountered during machine stripping. Furthermore, if potential human remains were identified, archeologists were to employ hand-excavation methods to expose and confirm the presence of human remains. When the presence of a human interment was established, and upon notice to proceed from TxDOT, TRC would document and remove each burial. In addition, any architectural features identified were to be fully excavated and documented.

An area about $35 \mathrm{~m}^{2}$ in size was mechanically stripped to about 90 cmbs (Figure 5-13). The back dirt was placed within the APE to the south of the machine stripping and at least $3 \mathrm{~m}$ from TxDOT travel lanes. Although prehistoric Features 30 and 31 were identified and documented during this stripping, no human remains were observed. Subsequently, the back dirt was redistributed across the machine stripped area and compacted to an acceptable level by TxDOT personnel. 


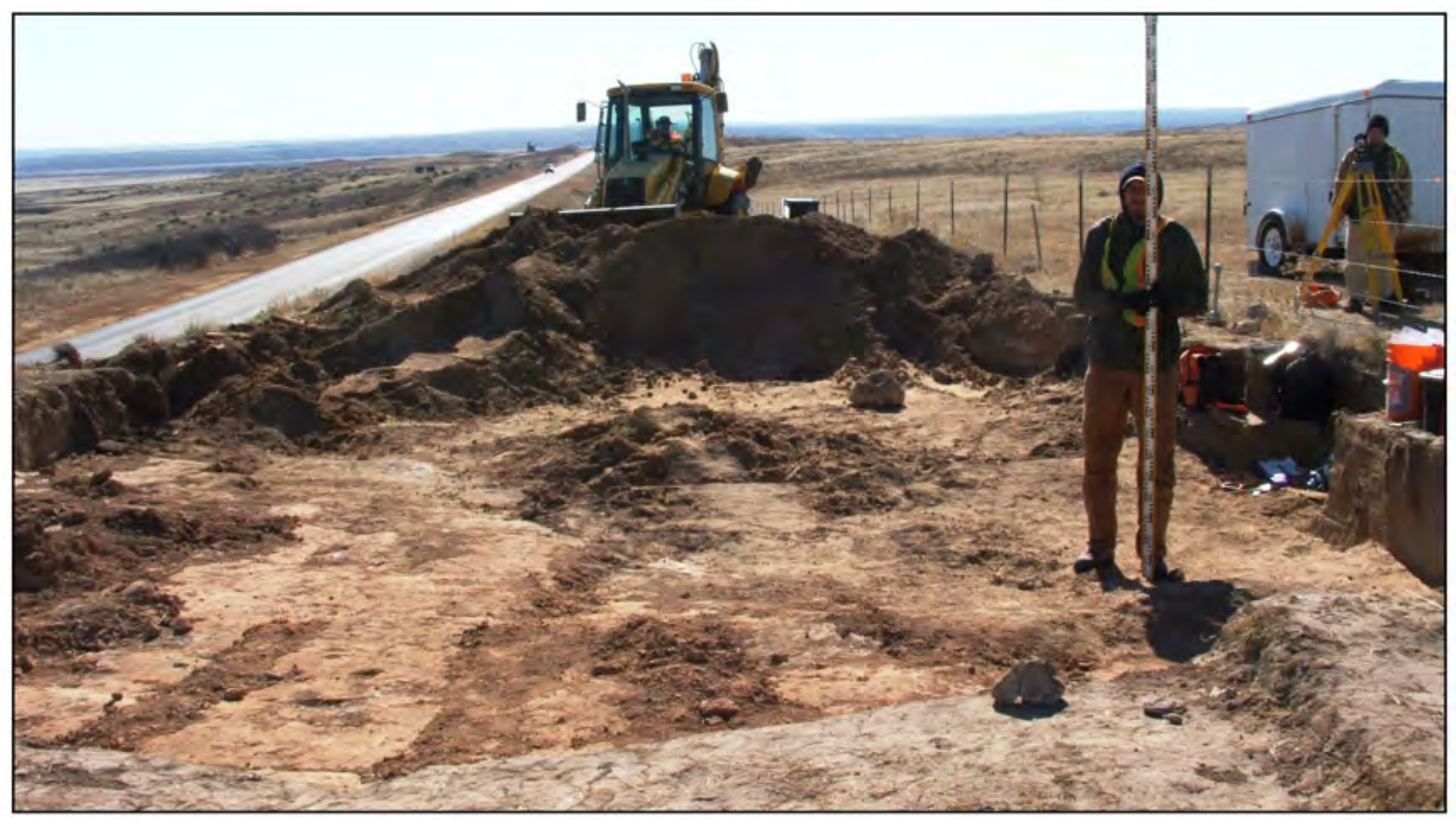

Figure 5-13. Mechanical stripping at south end of Component $\mathrm{C}$ following hand-excavations (looking south).

\subsubsection{Geophysical Methods: Survey Design, Methodology, and Technical Parameters}

By David Maki

\subsubsection{Introduction}

Following the site assessment/testing investigations, the interim report submitted to TxDOT ENV recommended that a geophysical survey be conducted to determine if buried cultural features (house structures, hearths, storage pits, etc.) might be located in the shallow sandy deposits, with specific interest in the bladed fireguard (Quigg and Smith 2005). It was believed that the results would help guide the mitigation efforts. It was anticipated this approach would detect the horizontal position of buried cultural features, which archeologist could then target with hand-excavations. After TxDOT approval, plans were made to implement a series of nondestructive geophysical investigations through Archaeo-physics from Minneapolis under the direction of David Maki. Mr. Maki has a history of working in the region and has conducted work on similar Plains Village sites (i.e. Odessa Yates,
West Pasture, and Buried City). Those previous geophysical investigations provided positive results in identifying buried cultural features (Brosowske and Maki 2002; Brosowske 2005). Mr. Maki and a two person support crew from TRC conducted the various geophysical investigations during a week in August 2006 prior to the data recovery excavations. Because of the electrical sensitivity of the equipment used in the geophysical survey, it should be noted that an overhead transmission line and a five strand barbwire fence with metal "T" posts existed along the western edge of the APE.

\subsubsection{Magnetic Field Gradient Survey}

A Magnetic field gradient survey was conducted over approximately 2,900 $\mathrm{m}^{2}$ across Area A. The magnetic field gradient survey coverage across Area C was slightly smaller, with a total area of 2,700 $\mathrm{m}^{2}$ total having been surveyed. At both Areas, magnetic survey was conducted within the project APE and in areas directly adjacent to, but outside the right-ofway (see Figure 5-14). There are two reasons that magnetic survey was performed outside the rightof-way. 


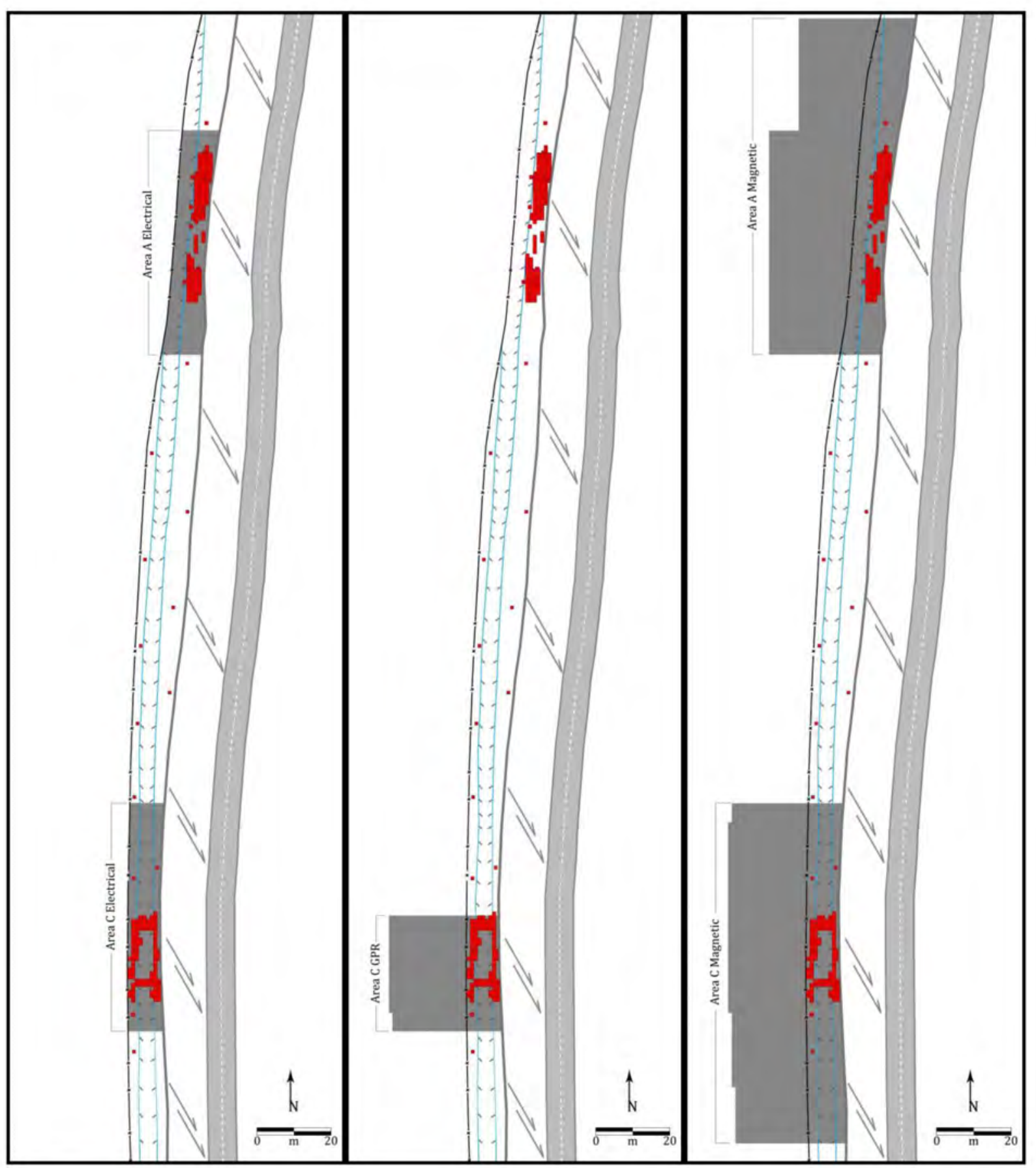

Figure 5-14. Location of the geophysical survey areas (electrical resistance on left, ground penetrating radar in center, and magnetic field gradient on right) along narrow right-of-way across Site 41RB112 
By extending the survey area to relatively undisturbed areas outside of the APE, it was possible to better understand the natural signal response due to heterogeneity in geology or soils at the site, and to better understand and identify nonarcheological signal clutter associated with the metal fence, metal trash, and fireguard within the APE.

Survey of undisturbed areas outside of the rightof-way allowed us to examine the nature and characteristics of magnetic anomalies that are archeological in origin, without the signal clutter associated with the heavy disturbance within the right-of-way.

The magnetic field gradient data were collected using a Geoscan Research FM256 fluxgate gradiometer. The FM256 has two fluxgate sensors, separated by $0.50 \mathrm{~m}$. The recorded data are the difference between the two sensors (the vertical magnetic gradient). The instrument was operated in the $0.1 \mathrm{nT}$ sensitivity range. Data were collected at a relatively high-resolution data sample density in transects spaced at $0.50 \mathrm{~m}$, with eight samples per meter along each transect (16 samples per $\mathrm{m}^{2}$ ). Magnetic data transects were collected in a zigzag manner, meaning the first data transect was collected from south to north, the second data transect was collected north to south, and so on. Magnetic field gradient data are presented in units of nanoTeslas (nT) in this report by convention. Multiplication by two is required to convert to SI units for the magnetic field gradient $(\mathrm{nT} / \mathrm{m})$. Processing of magnetic data included:

- Azero mean traverse filter, which compensates for defects caused by instrument drift and sensor orientation (heading error). Data exceeding a threshold value were excluded from the transect mean value calculation.

- Lowpass filtering to suppress small scale noise and enhance the detectability of cultural patterning.

- Interpolation to a uniform number of data points in both the $\mathrm{x}$ and $\mathrm{y}$ directions.

- Clipping the data range used to construct imagery in a manner that would best display cultural features.

\subsubsection{Electrical Resistance Survey}

Electrical resistance survey was conducted over $520 \mathrm{~m}^{2}$ across Area A, and $460 \mathrm{~m}^{2}$ across Area C (see Figure 5-14). All electrical resistance survey data were collected within the project right-ofway. A Geoscan Research RM15 resistance meter operated in twin electrode configuration was used to perform the resistance survey. Resistance survey was conducted using a mobile probe spacing of $0.5 \mathrm{~m}$ resulting in a nominal depth of investigation of approximately $0.5 \mathrm{~m}$. The resistance survey at Component $\mathrm{C}$ used potential of $40 \mathrm{~V}$, a current of $1 \mathrm{~mA}$, and an integration time set to medium (this is related to the number of data values that are averaged for each recorded value).

These same settings were utilized at Area A, unfortunately the Area A results suffered from a higher signal noise level than the results from Area C. This reduced data quality may have been related to the extremely dry conditions that existed during the resistance survey, although it is not clear why Area C results were acceptable when Area A results were not. In any case - Area A was surveyed a second time in an effort to obtain higher quality data. Much more acceptable electrical resistance results were obtained during this second survey, which used a potential of $100 \mathrm{~V}$, a current of $0.1 \mathrm{~mA}$, and an integration time set to slow (more readings were averaged for each recorded value).

Electrical resistance data at both Areas A and C were collected using a transect spacing of $0.5 \mathrm{~m}$, with two samples per meter along each transect (overall data sample density $=4$ samples per $\mathrm{m}^{2}$ ). Resistance data transects were collected in a zig-zag manner. The resistance survey data in this report are reported in units of relative resistance $(\Omega)$. Resistance survey data processing included:

- Removal of extreme statistical outliers.

- Interpolation to uniform sample densities in the $\mathrm{x}$ and $\mathrm{y}$ directions.

- Lowpass filtering to suppress small scale noise and enhance the detectability of cultural patterning.

- Highpass filtering (10 meter radius) to suppress large-scale geologic variation and to 
enhance the visibility of small low-contrast anomalies.

- Clipping the data range used to construct imagery in a manner that would best display cultural features.

\subsubsection{Ground Penetrating Radar}

After the magnetic field gradient and electrical resistance surveys were completed, a systematic survey by ground penetrating radar (GPR) was undertaken. The GPR survey was to cover the same areas as the electrical resistance survey, but would include areas outside of the APE as well. Regions outside the APE were to be surveyed for the same reasons as the magnetic field gradient survey namely to understand how disturbance within the APE might affect the GPR signal response, which in turn would help identify signal that may be archeological in origin. Unfortunately, the GPR equipment overheated and failed before complete survey coverage was obtained.

A total of $900 \mathrm{~m}^{2}$ of GPR survey coverage was obtained across Area C prior to this failure (see Figure 5-14). These data were collected using a pulse EKKO 1000 GPR operating at a center frequency of $450 \mathrm{MHz}$. The data transect interval was $0.5 \mathrm{~m}$ and the trace interval (stepsize) was 0.05 $\mathrm{m}$ (overall data sample density $=40 \mathrm{GPR}$ traces per $\mathrm{m}^{2}$ ). Each GPR trace consisted of data points within a 100 nanosecond time window; data are recorded every 0.2 nanoseconds within this window, resulting in 500 data points per trace. GPR data transects were collected in a unidirectional manner from south to north.

The radar wave propagation velocity was estimated at $0.1 \mathrm{~m} / \mathrm{ns}$. This is a typical value for sandy loams; however, it should be noted that the velocity is an estimate and was not calculated using commonmidpoint (CMP) analysis. The GPR failed before a common-mid-point velocity analysis could be conducted. The GPR survey was designed to facilitate "time slice" analysis. Time slice analysis calculates the average amplitude of the reflected radar signal within various time windows for display as plan view maps. The approximate depth of these time windows was calculated using the estimated reflected wave propagation velocity of $0.1 \mathrm{~m} / \mathrm{ns}$.
The GPR data are presented in units of microVolts $(\mu \mathrm{V})$. The processing methods applied during the construction of the GPR time slices are as follows:

- Each data transect was cropped to a length of $30 \mathrm{~m}$.

- A constant time gain was applied.

- DEWOW signal saturation correction was used to remove unwanted inductive low frequency components.

- A low pass filter (3 data points) operating in the time domain was used to suppress high frequency noise.

- A highpass background subtraction filter (401 trace window) was used to remove horizontal banding and enhance dipping events.

- Data were converted from wavelets with both positive and negative components to a monopulse wavelet with all positives (average enveloped amplitude).

- An estimated wave velocity of $0.1 \mathrm{~m} / \mathrm{ns}$ was used to construct time slices.

- Time slice data were interpolated down in the $\mathrm{x}$-direction from 20 samples per meter to 16 samples per meter and up in the y-direction to 16 samples per meter.

- A spatial lowpass filter (2 data point radius) was used to suppress small-scale noise and enhance the detectability of cultural patterning.

\subsection{Laboratory Methods}

The collected materials and associated data were transported to and temporarily stored in the TRC Austin laboratory. The laboratory tasks outlined below were performed in three stages over the years since the various excavations were completed.Stage one laboratory tasks were performed following eligibility testing prior to submission of the eligibility interim report. The second stage followed data recovery efforts prior to submission of the data recovery interim report. The third stage was conducted in preparation for this document. An effort has been made to maintain standard and practical methods for processing artifacts throughout the duration of this project (6 years) even though TRC personnel and laboratory procedures have changed as have curation standards. 


\subsubsection{Treatment of Cultural Materials}

In general, artifact processing entailed washing, sorting, and labeling most cultural materials recovered, including lithic debitage, stone tools, bones, and some mussel shell. Washing involved removing the dirt from artifact surfaces with tap water and soft bristled toothbrushes, while arranging wet artifacts to dry on drying racks lined with fine mesh screen. Fragile materials such as daub, charcoal, beads, and pottery, were not washed. Stone tools identified in the field for potential use-wear were bagged without handling and kept unwashed. On unwashed specimens, a portion of one surface was cleaned so that an archivally stable ink label could be placed on the artifact. A subset of these unwashed tools was submitted for use-wear analysis and others were set aside for long-term curation. Nitrile gloves were used when handling these unwashed tools.

Unique provenience numbers (PNUMs) were assigned to individual excavation level records as well as selected material samples and features. The provenience information and pertinent data from the level records were entered into an MS Access database.

TRC's cataloging system assigns strings of numbers to artifacts that encode information on provenience, artifact class, a unique identifier, and samples taken from the artifact or lot for specialized analyses. The PNUMs (e.g., \#1261) were assigned to lithic debitage, stone tools, burned rocks, sediment, burned clay, faunal bones, ceramic sherds, historic artifacts, and mussel shells. PNUMs are sequential integers that designate the overall provenience unit (i.e., excavation unit, backhoe trench, modern ground surface) and level, or depth, within that provenience unit by reference to a master list of PNUMs. Within each PNUM, the various artifact classes were assigned a secondary designation (i.e., lithic debitage [001], faunal bone [002], burned rock [003], soil [004], feature [005], shell [006], macrobotanical remains [007], ceramic sherds [008], and historic material [009]) referred to as the artifact class number. Individual tools and other unique items were assigned individual artifact numbers starting with the number 10 within the same unit and level designated by the PNUM. Thus, individual tools plus other unique objects (e.g., beads, pipe fragments, etc.) were assigned a PNUM and an individual unique number appended to the PNUM (e.g., \#1261-010, \#1261-011, and \#1261012).

In many cases, individual samples were removed from larger bags for specialized analyses (e.g., radiocarbon dating, wood identifications, and starch grain analysis). For example, if a single burned rock was extracted from the collection of burned rocks designated as \#1261-003 for starch grain analysis, then that burned rock would be designated as \#1261003-1 to indicate it constituted the first sample from that burned rock group. In another words, a catalogue number such as \#1261-003-1 would identify that specific burned rock as the first sample (1) taken from the burned rock class of artifacts (003) within a specific provenience unit (\#1261). If burned rock \#1261-003-1 was subdivided into two pieces for different types of analyses, such as lipid residue and starch grain analyses, then lower case letter designations (e.g., a and b) would be added following the last number in the sequence (e.g., \#1261-003-1a and \#1261-003-1b) to signify that two parts (part a and b) were taken from burned rock \#1261-003-1. The complete two or three part number sequence assigned to each object or class of objects constitutes the catalog number. This process allows individual pieces of large collections of various materials to be individually handled and tracked.

About one in ten items (10 percent) occurring in bulk classes (e.g., chert debitage, faunal bones, pottery, and mussel shells) within specific provenience units (e.g., a level) were individually labeled. Object size was also a major consideration for labeling purposes, as many lithic debitage, ceramic sherds, bone fragments, and daub are less than $1 \mathrm{~cm}$ in diameter and were not labeled. Artifact labeling consisted of inscribing the State of Texas Archeological Site Trinomial (41RB112) and the catalog number on designated artifacts using black indelible ink. After the ink was dry, the artifact labels were coated with clear acetone to preserve the inscriptions.

Permanent paper bag tags were included with each individual artifact or class of artifacts collected from 
a single provenience. These tags include the site trinomial, provenience information (unit and depth), the class or type of artifact(s), the date of excavation, the excavator's initials, and the quantity of items in the bag. These permanent tags were printed on acid free, $30.4 \mathrm{~kg}$ (67 lb.) card stock and filled out using No. 2 pencils.

All stone tools, samples of lithic debitage, samples of matrix from features, samples of burned rocks, field records, and photographs from both field phases are to be permanently curated. A small suite of burned rocks from selected burned rock features will also be curated. Individual artifacts and artifact lots, including all stone tools, lithic debitage, burned rocks, faunal bones, and mussel shells, are in clear, seal top plastic bags according to provenience. Small samples of sediment from various proveniences are stored in a similar fashion. Each polyethylene bag contains an archival quality, acid free curation tag that lists the site number, provenience data, date of excavation, excavator(s) name, artifact type, and quantity. Digital photographs printed out on a color printer were placed in curation approved, acid free plastic preservers for curation. All original field records are on acid free paper and placed in acid free reinforced file folders for curation.

\subsubsection{Flotation Methods}

Twenty-seven bulk sediment samples (165 bags/ buckets) that totaled 1,197.25 liters, and included sediment from 22 feature proveniences, and at least five nonfeature proveniences were floated. Flotation was conducted at the TRC Austin facilities in south Austin using the Dousman flotation system (Figure 5-15). The dry sediment was first measured for volume and then poured into the churning water. The light and heavy fractions were collected separately and dried. Selected light fractions that contained various cultural artifact classes such as seeds and charcoal were sent to Dr. Dering of Shumla Consulting Service in Comstock, Texas, for identification where possible. Dr. Dering's analytical procedures, results, and interpretations of the macrobotanical remains are presented in Appendix C.

In the Austin laboratory, each heavy fraction was spread across a clean white paper and the remains were sorted into general artifact classes such as flakes, shells, burned rock fragments, charcoal, bone, etc. The sorting was facilitated with the aid of magnification. The frequencies and weights of the various classes were recorded on forms and results incorporated into appropriate the feature discussions.

\subsubsection{Analytical Methods}

Artifacts were subjected to different metric, nonmetric, typological, and other special analyses, and included use-wear analysis. In some instances, artifact quantities in specific classes were so high that only a sample of the class was subjected to more detailed analyses. A set of predefined attributes for each material class was first encoded on paper, then entered into TRC's electronic database management system based on Microsoft's (MS) Access 2007 software. This MS Access 2007 database constitutes the master database for the eligibility assessment and data recovery investigations at site 41RB112. A copy of this database is provided on the CDROM attached to the back cover of this report. The specific data recorded for each class of artifacts are presented below. Analytical methods pertinent to each data class and the various secondary suites of software used for specialized analyses are discussed in detail in the appropriate parts of this report. The materials and data collected from the eligibility assessment and data recovery were integrated into a single database.

\subsubsection{Chipped Stone Artifact Analysis}

Analysis protocols concerning debitage and chipped stone tools were generated by TxDOT archeological staff in an effort to standardize the ways in which data is collected and presented in analytical and interpretive chapters of archeological reports sponsored by TxDOT (Appendix M). This protocol was incorporated into the research design at the onset of this project. As such, TRC has made an effort to conform to the general structure and goals of this protocol (TxDOT 2010a). When possible, terminological and taxonomic considerations have been made in this presentation that would allow for this assemblage to be comparable to future analyses employing these specific TxDOT protocol guidelines. 


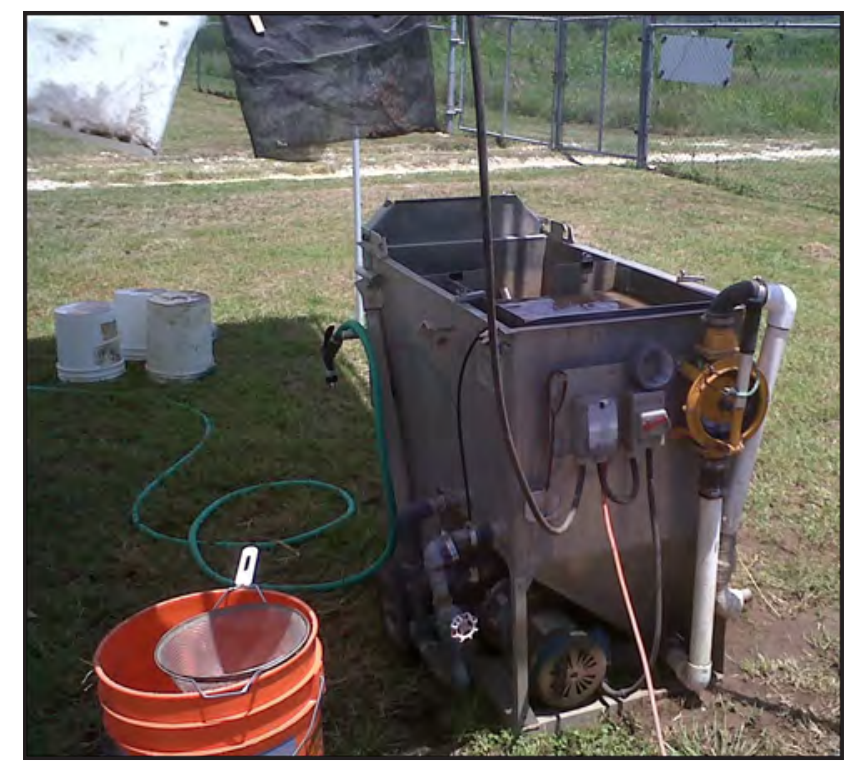

Figure 5-15. Flotation of matrix samples using Dousman flotation system.

Data entry forms werecreated torecord qualitativeand quantitative attributes of chipped stone artifacts for analytical and interpretive insight. A morphological typology (based on Andrefsky and Bender (1988); Andrefsky 1994; and TxDOT ENV 2010a) was used that allowed lithic analysts to classify and sort chipped stone artifacts first into debitage versus tools then into more specific categories (Figure 5-16). The edges and surfaces of each piece of chert were macroscopically examined for signs of use as a tool. If worked areas were identified, the artifact was assigned to a morphological and/or technological category based on general form and inferred function. Sets of observations were recorded for all tool classes recovered. The following subsections provide definitions of major tool classes.

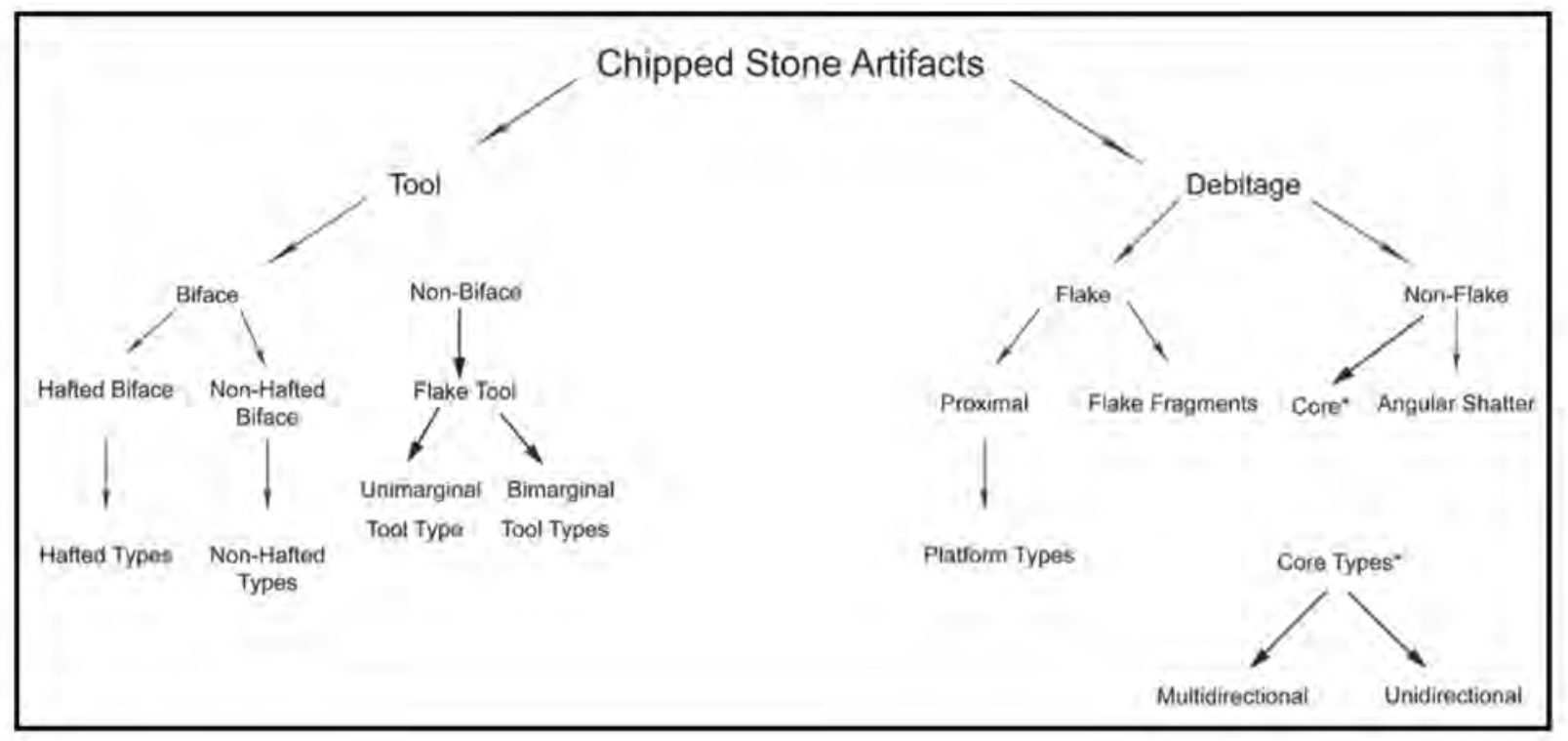

Figure 5-16. Chipped stone artifact analysis flowchart. 


\subsubsection{Tools, Bifacial}

Bifaces: Bifacial tools are those worked pieces, whether finely or crudely produced, in which the manufacturing process has apparently been brought to completion, as evidenced by secondary retouch, edge straightening, hafting preparation, notching, and similar characteristics. Bifaces are defined based predominantly on morphological characteristics, but they may also have functional associations (e.g., cutting, piercing, chopping, drilling). Bifacial tools exhibit purposeful, usually patterned flake removals on both faces of the object. Most or all of each face may be covered with flake scars, and in some cases one face may be completely modified, whereas the opposite face exhibits only partial modification. Bifaces may be fashioned either from large bifacial cores or from flakes. However, if only the margin of a specimen exhibits modification rather than most or all of at least one face, then the tool was classified as an edge-modified flake tool. Included within this overall morphological category are diverse functional groups such as projectile points and drills (see below). The measurements of 25 morphological attributes were recorded for each biface. Attributes included nonmetric observations concerning the completeness of the specimen, overall morphology, manufacturing characteristics, and manufacturing stage based on morphological classes adapted from Callahan (1979). Metric measurements, including edge angle, maximum width, maximum thickness, weight and maximum length, were recorded for complete and incomplete specimens. These attributes were used to evaluate tool stage, use, and circumstances of discard (see Appendix $\mathrm{M}$ for TxDOT chipped stone tool analytical protocol).

Projectile Points: Projectile points are a functional subset of the biface class specifically designed to be hafted to the distal end of a shaft used in stabbing, throwing, or shooting to penetrate animal hides and flesh. Projectile points are bifacial tools formed by fine secondary retouch, usually with basal modification in the form of notching, stemming, or thinning of the proximal end for purposes of hafting. Dart points, arrow points, and indeterminate dart/ arrow points are all classes of projectile points. Dart points are those employed to tip hand held darts or spears, arrow points are used to tip arrows, and indeterminate points are, as the name implies, of uncertain usage. Whereas dart points are usually manufactured from bifacial preforms, arrow points are often manufactured on thin flakes.

Projectile points were assigned to recognized types whenever possible. In traditional archeological literature, projectile points are normally referred to by their typological designation, which are usually based on a set of morphological characteristics (that generally focus on the hafting modification) shared in common by groups of similar points. Point classifications were conducted by TRC's personnel in reference to established point typologies in use in Texas archeology (Suhm et al. 1954; Turner and Hester 1999).

A comprehensive suite of 44 metric and nonmetric observations was recorded for the projectile points recovered. Nonmetric attributes recorded include descriptors of overall morphology and manufacturing characteristics. Some 21 quantitative measurements also were recorded (Figure 5-17). Metric measurements were recorded for complete and incomplete specimens. Tool edge angles were also recorded. These measurements were used to evaluate tool stage, use, and circumstances of discard (see Appendix M for TxDOT chipped stone tool analytical protocol).

Drills: Drills are another function specific subset of the biface class. Drills generally consist of two sections - the distal bit (or working edge) and the stem or proximal end section. Distal bits are typically long, tapered, and bifacially flaked, and reflect a diamond shaped cross section that distinguishes this type of tool. The bit is usually relatively thick and is designed to produce a stable base for rotary motion. Drills are usually presumed to have been used on hard substances, such as wood, shell, or bone, and spun in a rotating fashion to penetrate the material; therefore, drill tips usually exhibit heavy rounding and/or polishing of bit edges. Drills are often subdivided into specific types, such as T-butt, irregular, or notched, but this typology was not employed in this analysis. Twenty-five metric and nonmetric observations were recorded for drills. Metric measurements of length, width, thickness, and weight were recorded for complete and 


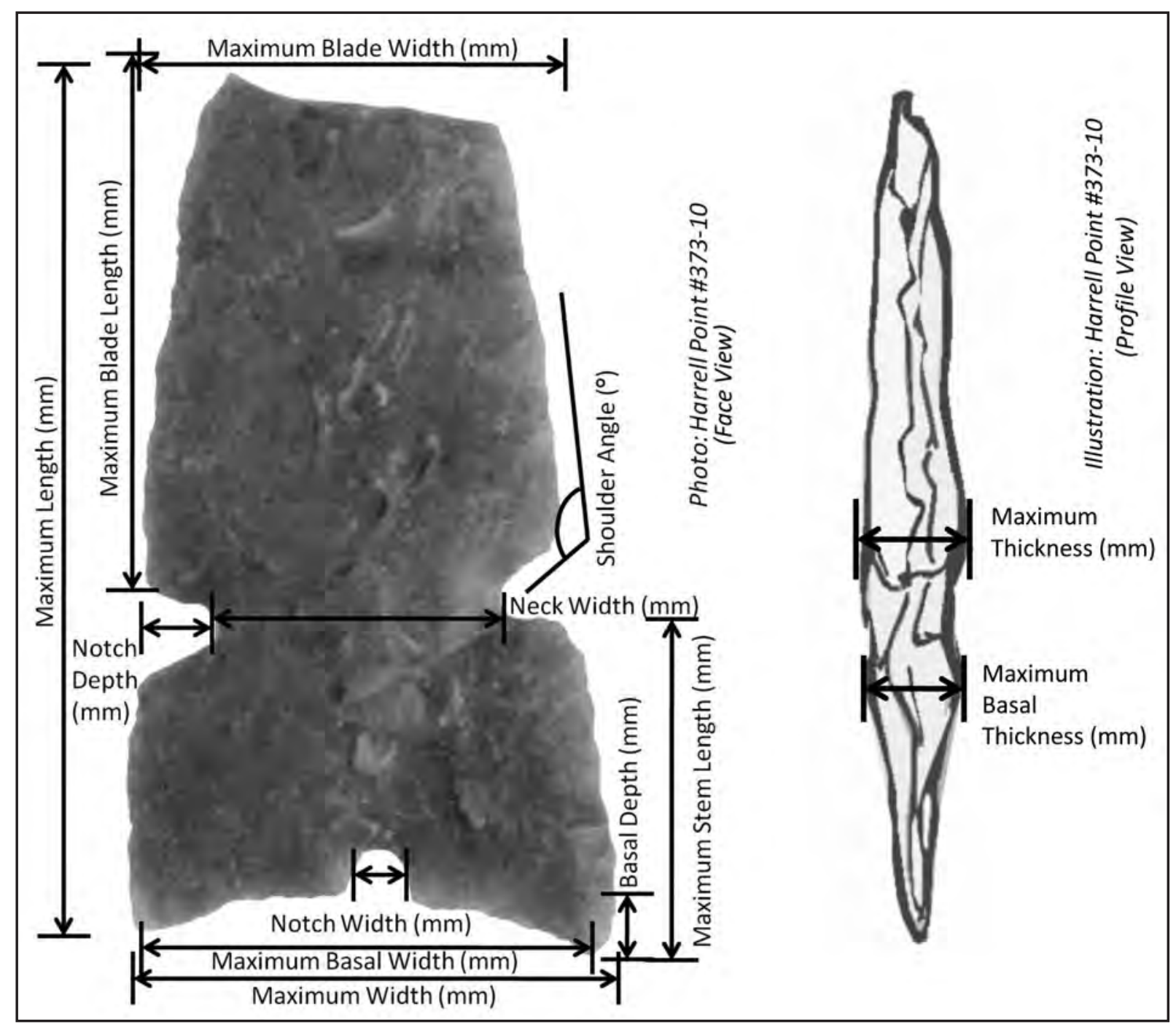

Figure 5-17. Selected projectile point terms and metric measurement locations.

incomplete specimens. These attributes were used to evaluate tool stage, use, and circumstances of discard (see Appendix M for TxDOT chipped stone tool analytical protocol).

\subsubsection{Tools, NonBifacial}

Unifaces: Unifaces are those tools that exhibit flake scars on one face only. Like bifaces, unifaces are defined based predominantly on morphological characteristics, but they also tend to have functional associations (e.g., scraping, planing, cutting, engraving). Unifacial tools exhibit purposeful flaking across most or all of one face, whereas the opposite face most often remains flat and unmodified.
Unifaces may be fashioned from cobbles or flakes. This category includes such functionally diverse groups as scrapers, gouges, edge-modified flakes, gravers, and spokeshaves. One or more edges of a unifacial tool may exhibit manufacture and/or use related flake removals that may be patterned or random. To some degree, unifacial tools form a continuum from formal tools exhibiting intentional, patterned, and manufacture related edge flaking to informal, ephemeral tools that show only use related edge scarring. The former tend to fall within the scraper and gouge categories, whereas the latter are generally classified as edge-modified flakes (see Appendix M for TxDOT chipped stone tool analytical protocol). 
Scrapers: Scrapers are a specific type of unifacial tool that have at least one intentionally modified working edge. In some instances, bifacial modification may be present, but in such cases the intentional retouch tends to be located on the dorsal flake surface whereas the ventral surface tends to exhibit primarily use related flake scars. Based upon the location of the primary working edge, scrapers are subdivided into end, side, or combination types. End scrapers are pieces with retouch, restricted primarily to either the distal or proximal end of the flake blank, generally producing a convex working edge. The opposing end of the piece may bear some minimal retouch, presumably to facilitate hafting. Side scrapers are pieces with retouch present on one or both lateral edges of the flake blank. Working edges may be convex, straight, or concave. On combination scrapers, marginal retouch may appear along the end as well as along one or more lateral edges of the blank. As implied by the name of this tool, the primary function of scrapers is presumed to relate to scraping relatively soft materials such as animal hides or vegetable matter, or slightly harder materials, such as wood or possibly antler or bone.

Twenty-eight metric and nonmetric attributes were recorded for scrapers. Many measurements relate to the number, location, and characteristics of the various working edges on the tool. Metric measurements of length, width, thickness, and weight were recorded for complete and incomplete specimens (see Appendix M for TxDOT chipped stone tool analytical protocol).

Edge-Modified Flakes: Edge-modified flakes are minimally modified flakes, flake fragments, or pieces of angular debris that are characterized by one or more areas of flake scarring along margins. The edge flaking may be patterned or unpatterned, continuous or discontinuous, and may result from intentional pressure retouching to prepare an edge for use or may result exclusively from use related activities. Many edge-modified flake tools exhibit combinations of these characteristics, and most have more than one working edge. The modifications, however, usually are restricted to the edges of the piece and do not significantly alter the original flake form. Edge modifications may be either unifacial or bifacial. Edge-modified flakes are usually considered to be "expedient" tools, or pieces of raw material that are picked up, utilized for a short time with or without first being minimally modified, and subsequently discarded at the location of use, or soon after use. Twenty-one metric and nonmetric attributes were recorded for edge-modified flakes. Metric measurements including length, width, thickness, and weight were recorded for complete and incomplete specimens.

Gravers and Spokeshaves: Various types of specialized working edges are often found on tools otherwise identified as scrapers or edge-modified flakes. While it is possible that only one such specialized bit may exist on a tool, these types of tools are considered to primarily fall within the appropriate scraper or edge-modified flake category, while the specialized working edge would be classified as one of the working edges. Types of specialized working edges that are often recognized include perforators or borers, graver spurs, spokeshaves or notches, and burins. For purposes of this analysis, graver spurs and borers are combined into a single category, as are spokeshaves and notches.

Graver spurs, or gravers, are additional carefully flaked, prominent, sharp protrusions formed on scrapers or edge-modified flake tools by the creation of adjacent shallow concavities or notches. Graver spurs may be quite short, only a millimeter or two in length, or rather prominent, in which case they grade into the category of tools often referred to as borers or perforators. Graver spurs may exhibit alternating edge retouch, but this is usually present only on longer specimens. The function of graver spurs is assumed to be engraving relatively hard substances such as wood, bone, and antler.

Spokeshaves, or notches, are working edges on scrapers or edge-modified flakes formed by the removal of numerous small flakes in a limited area along the lateral edge of a piece to form a single, relatively deep, concave area. Such notches may be relatively small or quite large, and shallow or deep. The function of spokeshaves is assumed to relate to scraping or planing relatively hard substances, such as wood, bone, and antler, that are either tubular in shape or for which a convex outer surface is a desired result (e.g., dart or arrow shafts). 
By definition, graver spurs, spokeshaves, and burins are considered to be specialized tools made on pieces that may otherwise be classified as scrapers or edge-modified flake tools. As such, the metric and nonmetric data encoded regarding that working edge would follow the procedures used for scrapers or edge-modified flakes, as appropriate.

\subsubsection{Ground Stone Tool Analyses}

This broad artifact class includes pieces of natural rock that have been modified by grinding, pecking, or battering, either to intentionally shape an implement or as a by-product of use. Ground stone tools are recognized by the presence of intentional abrasions, grooves, and striations and/or smoothing. Significant rounding, flattening, and/or pitting of utilized surfaces can also be identified. Categories of ground stone tools include hammerstones, manos, metates (milling stones or grinding slabs), abraders/ shaft smoothers, and edge-ground cobbles.

The edges and surfaces of each piece of rock were macroscopically examined for signs of use as a tool. If battered, smoothed, unnaturally flattened, pitted, ground, striated, incised, or pecked areas were identified, then the artifact was assigned to a morphological and/or functional category based on general form and inferred function. Sets of observations were recorded for the tool classes recovered. The following subsections provide definitions of major tool classes.

Manos and Metates: Manos and metates are generally used together to grind friable materials (nuts, seeds, other vegetal matter, and sometimes pigments) into powder. A mano is a hand held grinding stone, generally characterized by a round to ovate shape, usually of hard, dense siliceous rock such as quartzite, dolomite, or sandstone. One or more surfaces exhibit a smooth or polished, and/ or possibly flattened area caused by grinding action against another hard surface (the metate). In some instances, the edges exhibit crushed or pitted areas indicating possible use as hammerstones as well. Sometimes one or both faces may be pitted, which results from the user trying to rough up the smooth surface to facilitate the grinding. Generally, these are water worn cobbles that exhibit no other alterations to the natural cobble.
A metate is often a large slab of a dense siliceous rock such as sandstone, limestone, or dolomite, which has functioned as the base on which the mano is used to grind materials. The grinding action most often wears the natural surface and creates a shallow concave face that is smoothed and/or polished. Extensive and continued use creates a deeper concave basin and in some instances, both faces may have functioned as a base for grinding. The deep, oval, basin like or elliptical grinding surfaces on metates from the Great Basin region, or the long, rectangular trough characteristic of metates of agricultural cultures, are sometimes recovered from the Plains Village sites. Occasionally, the edges of metates are artificially shaped, usually by direct percussion that removed flakes along the margins. Metric and nonmetric observations were recorded for manos and metates. Measurements of dimensions were recorded only when the dimension in question was completely represented and/or could be reasonably estimated.

Hammerstones: A hammerstone is a hard nodule of lithic material, usually dense siliceous rock such as quartzite, used for direct percussion fracturing of tool stone during lithic reduction. These pieces usually exhibit areas of battering, crushing, and/ or pitting on one or more surfaces and along the edges of the natural cobble. In some cases, small flake scars may form as the result of hard hammer percussion, creating an appearance similar to a tested cobble core. Metric and nonmetric observations were recorded for hammerstones. Measurements of dimensions were taken only when the dimension in question was completely represented and/or could be reasonably and actually estimated.

Shaft Abraders/Smoothers: These are generally pieces of course materials such as sandstone and used to abrade softer materials such as bone, wood, or antler. Sometimes the piece may be intentionally shaped or just in a natural state. Most often one or more longitudinal V-shaped or U-shaped grooves are present on the same piece, potentially on different faces. Actual wear is difficult to discern beyond the grove itself as the materials abraded/smoothed are generally softer than the abrading stone.

In some instances, a harder stone like quartzite may function as an abrading stone. This would function 
more as a grinding implement than the more specific shaft smoother. This tool would exhibit leaner striations along the edge of a cobble.

Edge-Ground Cobbles: These are natural cobbles that exhibit mostly rounded, smooth, waterworn exteriors that are generally less than $15 \mathrm{~cm}$ in size with one or more edges that have been abraded, battered, crushed, and/or pitted from use. Occasionally, small flake scars maybe evident along the used margins. Most often the cobbles do not exhibit any preparation before use.

\subsubsection{Lithic Debitage Analyses}

Chipped stone debitage is the unmodified debris that results from lithic reduction activities associated with the manufacture and maintenance of stone tools. Lithic debitage lacks any macroscopic indications of use or modification. Pieces that exhibit any sign of use-wear or intentional modification are placed in the appropriate tool category. The debitage collection from each excavation block was subjected to detailed analyses, with individual pieces sorted into the reduction classes listed below (see Appendix $\mathrm{M}$ for TxDOT debitage sorting protocol).

Besides the total count, the pieces were classified by completeness/type of debitage represented (whole, proximal fragments, distal fragment, shatter/blocky debris); size grade into 6.4, 12.8, 19.2, and $25.6 \mathrm{~mm}$ groups; cortex percentage (0, 1 to 25,26 to 50,51 to 75 , and 76 to 100 percent); platform type (indeterminate, cortical, flat, complex, abraded, faceted, multifaceted, and rejuvenated after Andrefsky [1998:93-96]); observed purposeful thermal alteration; technique used in reduction (indeterminate, hard hammer, soft hammer, indirect, pressure, and bipolar); and raw material type. Counts and weights for debitage were assessed for artifact groupings (analytical assemblages) that were created through the analytical process (see Appendix M for TxDOT debitage analytical protocol). A summary of the debitage typology implemented for this analysis is outline below.

Core Reduction Flakes: This category includes flakes, flake fragments, and pieces of angular debris associated with initial core preparation activities, such as test flakes that were removed to determine the quality of raw material within a cobble as well as to decorticate a cobble for further reduction. Items in this category tend to have cortex covering on more than 50 percent of their dorsal surfaces. By definition, most of these items tend to be relatively large (smaller flakes with dorsal cortex often fall within other categories, such as early and late stage biface flakes or indeterminate flakes, depending on their diagnostic characteristics). Core preparation flakes may or may not exhibit pronounced platforms, bulbs of percussion, or ventral concussion rings, though most do have one or more of these characteristics.

Biface Thinning Flakes: Biface manufacture flakes were classified based on the presence of multifaceted striking platforms, multidirectional dorsal flake scars, parallel to slightly expanding flake margins, and slight to moderate longitudinal curvatures. This category was subdivided into early and late stage biface manufacture flakes. Early stage biface flakes tend to be somewhat larger than late stage biface flakes, have fewer and larger dorsal flake scars, and may retain a considerable amount of cortex on their dorsal surfaces. As employed in this analysis, early stage biface flakes correlate roughly with Callahan's (cf. 1979) revised Stage 1, 2, and 3 bifaces ("blank," "rough out," and "primary preform" stages) while late stage biface flakes correlate with Callahan's revised Stage 4 and 5 bifaces ("secondary preform" and "final preform" stages). In practice, Stage 1 ("blank") flakes are more likely to fall within the core preparation flake category due to the lack of clear diagnostic characteristics on many such specimens. Final percussion thinning, pressure thinning, and retouch flakes that do not clearly exhibit biface manufacture characteristics due to their small size would likely be included in the tertiary thinning/ retouch flakes category. The early and late stage biface flake categories may contain complete flakes, proximal and distal flake fragments, and/ or small pieces of angular debris that exhibit clear characteristics of the biface manufacturing process (in practice, the latter type of debitage-angular debris bearing bifacial traits-is rare in the biface manufacture flake categories).

Tertiary Thinning/Retouch Flakes: This category includes flakes and proximal and dorsal flake fragments resulting from the final stages of tool 
manufacture, including final percussion thinning and any subsequent pressure retouch. By definition, flakes in this category tend to be quite small, and it is difficult to distinguish whether they result from biface manufacture, uniface manufacture, or resharpening.

Angular Debris: Angular debris, or "shatter," includes angular pieces of lithic raw material that break away from the core as flakes are struck. In contrast to flakes, angular debris does not generally retain any diagnostic characteristics of the flint knapping process (i.e., platforms, bulbs of percussion, concussion rings, and definable dorsal or ventral surfaces). In this analysis, those few pieces of angular debris that exhibit characteristics diagnostic of biface manufacture were included in the appropriate biface manufacturing category (i.e., early versus late stage biface flakes).

Indeterminate Flakes: This category includes flakes and flake fragments that lack diagnostic traits that would permit their placement into one of the other categories. Generally, these flakes are small fragments of flakes and/or thin pieces of angular debris that do not display clear evidence of a platform, concussion rings, or flake scar patterning on their dorsal surfaces. This category also includes a small number of potlid flakes and fractured heat spalls resulting from thermal alteration of raw materials.

\subsubsection{Cores}

A core is a cobble, pebble, or other mass of lithic raw material that exhibits one or more platforms and flake scars resulting from the systematic removal of flakes by flint knappers (Parry and Kelly 1987). Technically, any chipped stone tool may properly be classified as a core as it is the object created through the removal of flakes from the exterior surface of the original mass of lithic material. In common terms, however, cores are generally considered to be those masses of material from which one or more flakes were removed. In other words, cores do not exhibit any intentional or use-related flake scarring along any of their edges, though scars resulting from platform preparation may be evident, and a core might be expediently used as a tool (e.g., extensive crushing damage along one or more thick edges of a core would probably result in classification of the object as a chopper).

Various types of cores are recognized according to the degree of knapping and the flake removal strategy. Four basic types of cores are unifacial, bifacial, multidirectional, and blade core. The last named type often has a distinctive conical polyhedral shape, the result of the repeated, parallel removal of long, narrow flakes known as prismatic blades.

A unifacial core is one that exhibits flake scars removed from only one face. The flake removals may be in various directions and exhibit no pattern or structure to the removals. There are usually only one or two platforms.

A bifacial core exhibits flake removals from both faces and again these may be in multiple directions. The parent or objective rock is generally a cobble that exhibits two detectable faces. The flakes were driven from the lateral edges; thus, the platforms are along the edges.

The multidirectional core is generally a chunk of raw material that does not necessarily exhibit two obvious faces. Generally, there are a number of platforms from which flakes were removed. Most often, the flakes are removed in different directions.

Blade cores are chunks of raw material intentionally prepared to facilitate the removal of a specific kind of desired flake. These generally exhibit two or more parallel scars driven from the same platform in the same direction with the same overall shape.

Twenty metric and nonmetric observations were recorded for cores. Metric measurements of length, width, thickness, and weight were recorded for each core specimen even if it was broken.

\subsubsection{Ceramic Artifact Analysis}

In general, the ceramic sherds were not washed, although in some instances the broken edges were lightly brushed to expose the core and interior tempering agents, or lightly washed with tap water to examine the surfaces. Most sherds were left unwashed in hopes of preserving organic residues such as starch grains, pollen, phytoliths, and other 
microfossil remains that may help determined how the vessel was used or what was cooked in the vessel. In many instances, calcium carbonate adheres to one side of the sherd. Occasionally, a black organic residue was observed adhering to the exterior of a sherd and this was left intact on most sherds. In a few instances, that organic residue was carefully scrapped from sherds and placed in a plastic vial for potential analysis. A few sherds were selected and socked in distilled water, then subjected to a brushing with a sonic tooth brush to remove fine organic residues. The recovered residues were captured in small glass petri dishes and allowed to air dry. Once dry, the residues were placed in small plastic vials for potential analyses. A few sherds were selected from vessel groups and latex impressions of the cordmarkings were obtained from exterior surfaces to better reveal the nature and structure of the cordmarkings.

Protocols for ceramic analysis for the Long View site were established by TxDOT (2010b, Version 2.0 in March 11, 2010). TxDOT established the protocols to gain a greater understanding of the ceramic universe in Texas. The specific details of the TxDOT protocols include a purpose statement, general discussions, glossary of seven basic terms, discussion of two analytical techniques, discussions of middle range theory, sampling strategies, recording techniques and forms, plus the INAA protocol are presented in their entirety in Appendix $\mathrm{N}$.

As with all other artifacts, the ceramic pieces were recorded by unit and level with counts and weights provided for each provenience. The ceramic analysis was a combination of visual observations, starting with the identification of the vessel part represented (Figure 5-18), sherd and vessel characteristics, selected metric measurements, and two detailed analytical techniques that focused on sherd composition. The observations and measurement documented are presented below.

Colors were recorded for sherds that represent different element/parts of the individual vessel. This was done with the aid of a Munsell color chart (1988). The interior surface, the exterior surface, and the inner core colors were documented per vessel. The exterior surface treatment of each vessel was recorded. Possible surface treatments include; but are not limited to, cordmarked, smoothed cordmarked, or obliterated cordmarked, maize cob impressed, plain, burnished, or painted.The interior surfaces were also recorded and include smoothed, bumpy, irregular, striated, drag marks, or a combination of these. Rim and neck decorations were also recorded and include, but not limited to figure pinching, tools punctuates, figure punctuates, incising, cordmarks, tool impressions, curved fingernail marks, polished, and other (Figures 5-19 and 5-20). Profiles of the vessels, rims, shoulders and bases were also documented. Sherds were inspected to determine the presence or absence of coils, coil breaks, lipping on the breaks, and other construction and firing attributes. The temper composition was defined primarily by the petrographic analyses conducted on sherds selected from individual vessels. This included observations concerning the paste (clay, temper, and texture), with types, sizes, and frequency of temper documented (see Appendix F for details).

Digital photographs, generally interior and exteriors of sherds in the vessel groups, rims and shoulders, and in a few instances the interior cores were taken per vessel, plus those sherds that were to be destroyed in the petrographic and INAA. Unique and unusual pieces were also photographed.

Metric measurements were recorded in millimeters $(\mathrm{mm})$ for vessel height, vessel width at the shoulder and rim, vessel orifice diameter, range of thickness for individual vessels, lip and rim thickness, and height of rim where possible. Measurements were obtained with digital calipers. Weights were measured in grams (g) with electronic scales.

An initial step in the macroscopic analysis for the Component $\mathrm{C}$ assemblage was to spread the sherds out on a table and examine the basic macroattributes (rim shape and thickness, body thickness, interior and exterior surface finish, decorations, interior finishing characteristics, and general workmanship) and assign similar sherds to vessel groups where possible. This assignment accounted for the variability across what would be the entire vessel, understanding that hand-made vessels would not be perfectly formed with identical thicknesses, consistent finishing techniques around the entire 


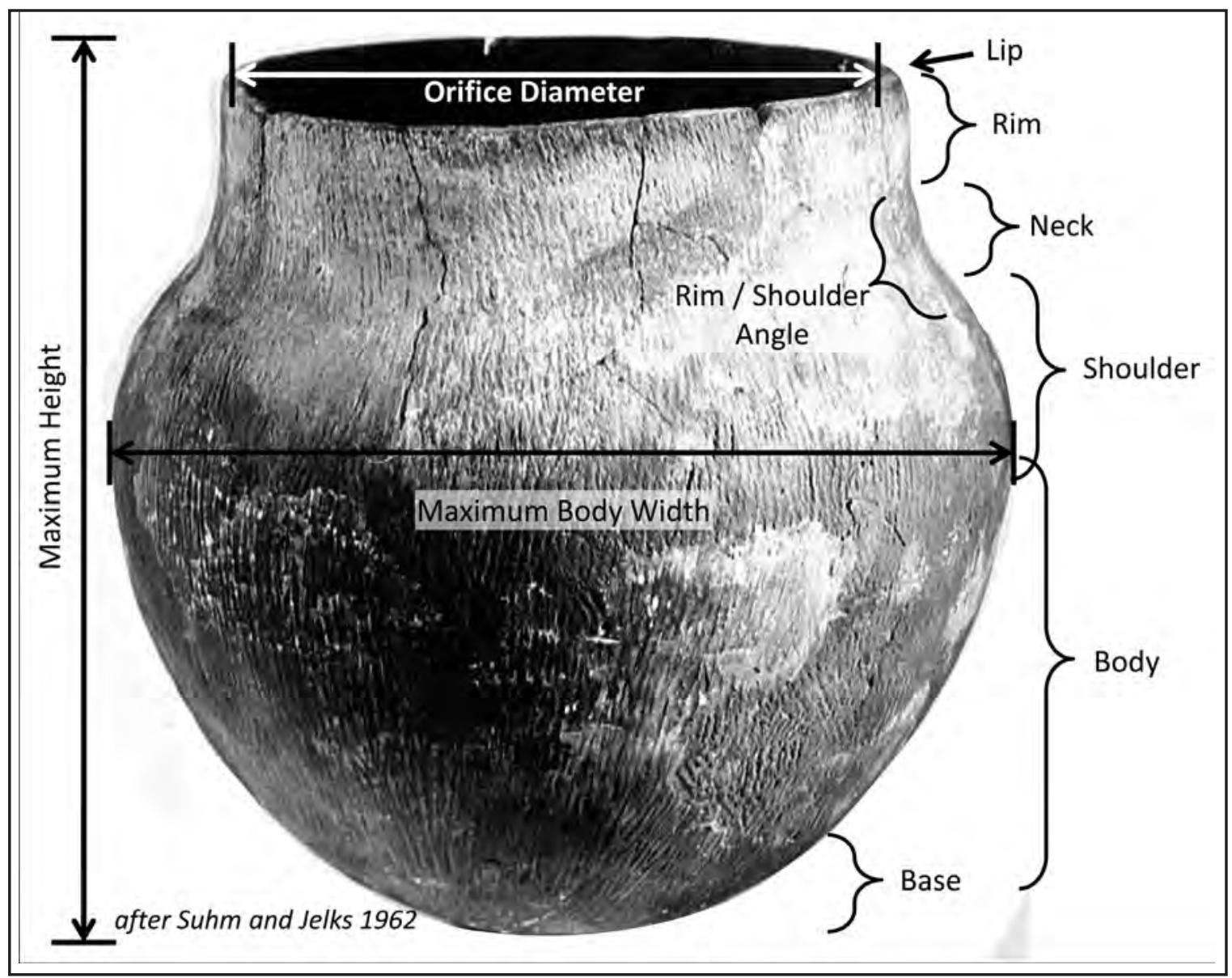

Figure 5-18. Borger cordmarked vessel with terms and metric measurement locations.

vessel, and that variations and deviation around the vessel exist. Therefore, the observed attributes were used as guides and subjective decisions were made as to the vessel assignment. If considerable dought existed in assigning a particular sherd to a vessel group, then sherd was not assigned to that group.

The Component A sherds are generally much smaller than those in Component C. Roughly 100 sherds are larger than 2 to $2.5 \mathrm{~cm}$ in length and those became the focus of trying to assign to vessel groups. The larger sherds were laid out on a table and groups were attempted and formed, based on the macroscopic observations taking into consideration a range of macroscopic characteristics. Once vessel groups were identified, the bags that contained the smaller sherds were again examined to look for small sherds that might be assigned to the existing groups. Very few of the small sherds were assigned to the identified vessel groups.

Next, attempts were made to refit (conjoin) sherds together, both within a vessel group and between vessel groups. This refitting process helped to verify the assignment of sherds to individual groups and verify the homogeneity of each group. Refitting was quite successful in Vessel Group 1, a very thick vessel from Component $\mathrm{C}$, where major sections of this vessel were reconstructed. The overall vessel shape and size became apparent after conjoining sherds in Vessel Group 1. Vessel Group 5 had a number of conjoined sherds. However, most other vessel groups lack many refits, which limits our understanding of overall vessel shapes, sizes, and variations across and within a vessel. The refits were glued together with acryloid B-72 (ethyl 

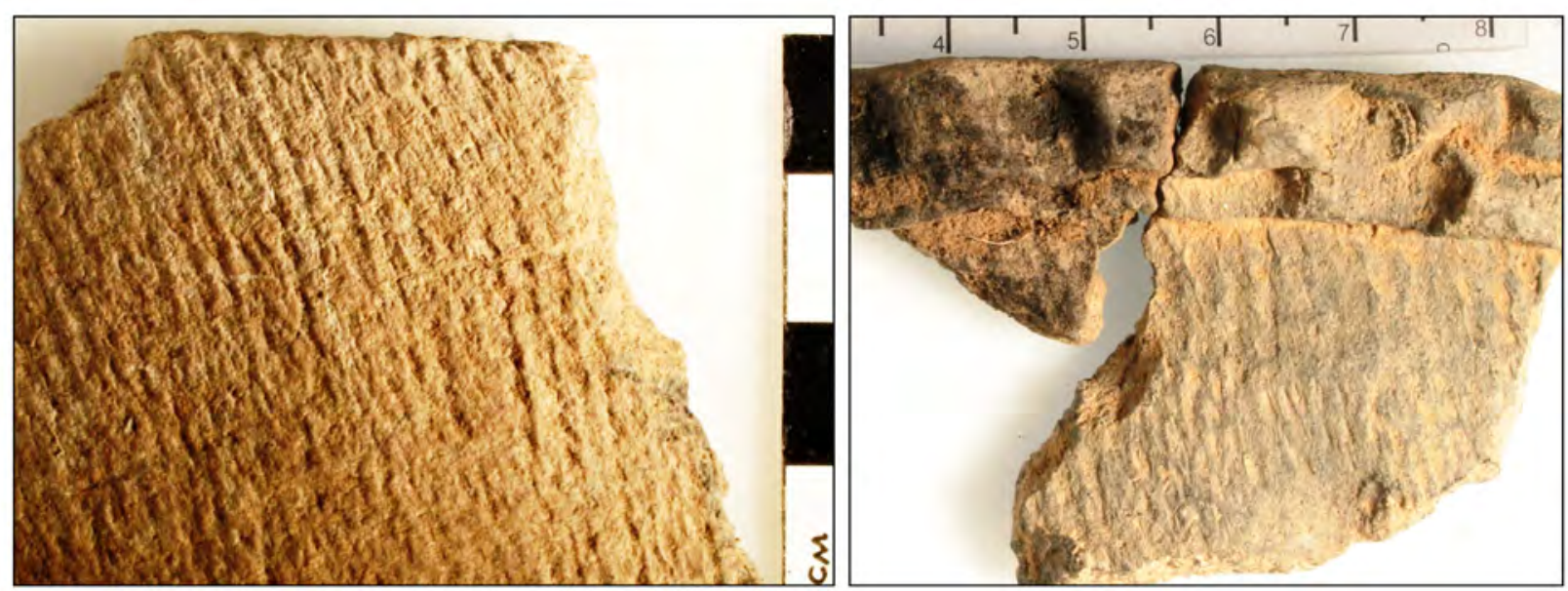

Figure 5-19. Decorations: cordmarked rim of Vessel G (left) and pinched/collared rim of Vessel A (right) from Long View, scale in $\mathrm{cm}$.
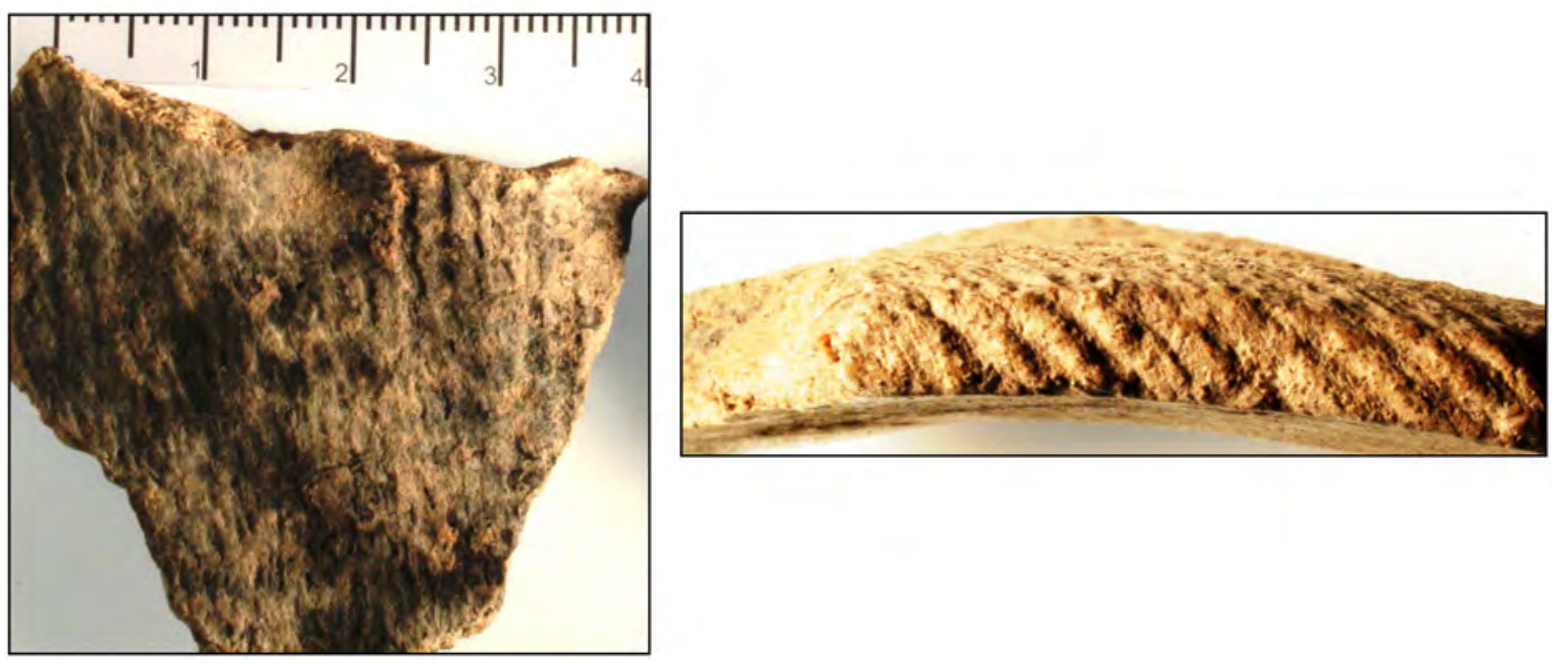

Figure 5-20. Finger puntate on rim of Vessel $A$ from Component $A$ (left) and diagonal cord impressed lip on Vessel G from Component A (right) at Long View Site, scale in cm.

methacrylate copolymer). In most instances the sherds could not be assigned to a particular vessel group, since there were no visually obvious means to do so, with cordmarked body sherds that looked very similar combined with the understanding that cordmarkings vary across the body of the vessel. The vessel groups that were identified contained relatively few sherds, except for the Vessel 1 from Component C.
In a number of instances, individual sherds appeared to represent something beside the basic base, body, and rim of a vessel. These unique individual pieces were grouped by perceived part or function and discussed as a group.

Selection of Sherds for Technical Analyses: TxDOT directed the use of two specific analytical techniques: petrography and INA (see below for further discussions concerning these two techniques). Most selected sherds were subjected to 
both techniques, which documented the variability in plastic and aplastic constituents in order to determine the range of variation and homogeneity of the group(s).

The sampling strategy for the technical analyses (petrography and INA) was done to encompass vessel diversity within and between vessel groups, within the Long View ceramic assemblage, and includes both components (A and C). First, the sherds from the two components (A and C) were sorted into visually similar vessel groups based on a variety of characteristics such as interior and exterior surface treatments, temper, color, and breakage patterns. The visually identified vessel groups were then targeted for sampling. At least one sherd from most identified vessel groups was selected for these destructive analyses. In all instances, the exact same sherd used for petrography was also used for INA. The sherds were selected to represent individual vessels; in some instances this was a section of rim, in other instances the rim and body, and in a couple instances the rim, body, and base were represented.

Because the construction of a vessel may have included one to three stages, such as but not limited to; the formation of the base, development of the body, and creation of the neck/rim areas as three separate parts, the authors believe it necessary to sample and analyze those three distinct vessel areas by the two technical analyses to address possible variations. Lowie (1954:61) stated that "Plains pottery, unlike that of most North American natives, was not coiled, i.e., not build up spirally from little sausages of clay, but hand molded”. He continued and stated that "A noteworthy Pawnee feature is the collar-like rim of the pots with its incised ornamentation largely consisting of isosceles triangles enclosing chevrons or lines parallel to one of the sides" (Lowie 1954:61).

Detailed analysis, both macroscopically and technically, on relatively complete vessels from Woodland/Early Ceramic and Plains Village/Middle Ceramic period contexts in eastern Colorado indicate thickness, firing, and temper differences across most complete vessels (Ellwood 2002). As an example, the complete Early Ceramic period Mee-Parker vessel has wall thicknesses that vary from 9 to 22 $\mathrm{mm}$ from rim to base, documenting a thin rim and a thick base. This vessel exhibits a combination of lump-modeled base and accretion by lumps or coils with different quantities of temper in the walls and interior with more inclusions in the base (Ellwood 2002:10-12). For a Middle Ceramic period vessel, the complete Carlson-Chimney Canyon vessel has wall thicknesses from 6.0 to $3.7 \mathrm{~mm}$ with a base of $4.6 \mathrm{~mm}$. The construction appears to have been patch modeled with the neck and rim made and attached separately after the rest of the vessel was partly dry (Ellwood 2002:34-35). Ethnographic records of the Papago Indian pottery making also document vessels were manufactured in three parts using a molded base with coiled body and separate rim (Fontana et al. 1962).

In Component A, 14 vessel groups were defined and represent the minimum number of vessels in that area and are assigned letter designations A through $\mathrm{N}$. Visually, the ceramic assemblage from Component A is quite different from Component $\mathrm{C}$. The cordmarked sherds from Component A are generally much thinner, the cord impressions are much narrower, a number of the rims reveal decorations, at least one pinched or collared rim vessel is present, a number of plan surface sherds, which are red colored are present, and at least one nonlocal painted sherd is represented. From these 14 vessel groups, 14 sherds were selected for INAA, one from 10 vessel groups (\#2-008-6, \#2-008-4, \#762-008-1, \#973-008-1, \#998008-1, \#1034-008-1, \#1036-008-1, \#1066-008-1, \#1119-008-1, \#1135-008-1, \#1140-008-1, \#1175008-1, \#1206-008-1, and \#1223-008-1) except vessel groups $\mathrm{A}, \mathrm{B}, \mathrm{C}$ and $\mathrm{E}$ that had two sherds, generally one body and one rim.

In Component $\mathrm{C}$, seven vessel groups assigned number designations 1 through 7, were defined and represent at least that many vessels. It is possible that Vessel Group 1 represents more than one vessel that exhibit very similar macroscopic attributes. In the other instances, each vessel group represents a single vessel. From these 7 vessel groups, 18 sherds were selected for the two technical analyses. Seven sherds from Vessel Group 1 were selected, three from the base (\#118-008-1 \#303-008-1 and \#643008-1b), two from the central body (\#308-008-6a and \#362-008-1), and two from the rim (\#308-008-2 
and \#338-008-3) to address the vertical variability within this thick vessel and possible construction differences. Two body sherds from just below the rim were selected from Vessel Group 3 (\#349-0081 and \#350-008-1. Two sherds were selected from Vessel Group 4 and include a decorated lip (\#405008-1) and a lower body sherd (\#405-008-12). Two sherds from Vessel 5, a rim (\#628-008-1b) and a body sherd (\#629-008-1) were selected. A single rim sherd (\#259-008-1) and a single body sherd (\#639008-1), from Vessel Groups 2 and 6 respective, body sherd (\#468-008-1) from vessel 7, along with two unassigned body sherds (\#684-008-1, and \#697008-1) were selected.

Natural clay samples were collected from various areas nearby or on the archeological site where sherds were selected from, plus two local Long View samples (one of alluvium and one from the Ogallala Formation) were selected for petrographic and INA analysis to provide comparisons with the sherds. A buried soil (alluvium) just upstream inside the Dugout Creek valley was selected (\#C-Aa). The soil had windblown sand covering the soil. The Ogallala sample selected (\#OCa) was from deposits below the occupation in Component C. These two and eight other selected clay samples (i.e., from the head of Government Canyon, Blue Creek, West Pasture, Indian Springs, Hank's, Courson D [2 samples] and Two Sisters) were moistened with distilled water, stirred, then a measured amount of ground local sandstone or other sands from the area of 41RB112 were added to the moist clay, mixed, and made into small clay tiles/bricks, about 3-by-2 cm and 1-cm-thick. The tiles/bricks were allowed to air dry at room temperatures for days. Subsequently, the tiles/bricks were fired in a small kiln, one set baked to a temperature of $450^{\circ} \mathrm{C}$ and a second set baked to $650^{\circ} \mathrm{C}$. These were removed and air cooled. The baked tiles/bricks were cut in half long ways and pieces were selected and sent for both INA and thin section preparation followed by petrographic analyses. It was assumed that the baked, sand tempered clay tiles would simulate the pottery sherds recovered here and from the surrounding regions.

In an attempt to determine how the Long View ceramic assemblage is associated with the regional Plains
Village ceramic traditions, TRC decided to examine regional variation in the ceramic production process, identify possible manufacturing regions and sources areas, and gain a greater understanding of Plains Village potters. This research strategy was approved by TxDOT. To address this research question, INA analyses was conducted on 32 ceramic samples, 14 from Component A and 18 from Component C) at the Long View site, plus two natural clay samples from next to the site. Petrographic and INA analyses were also applied to a group of 80 ceramic sherds from 15 selected excavated sites in the surrounding region plus 8 tempered clay samples from the region. The four adjacent regions selected to obtain sherds from include: 1) the Antelope Creek phase core area sites (i.e., Alibates Ruin 28, Antelope Creek Ruin 22, Cottonwood Creek and Roper) around Lake Meredith roughly $85 \mathrm{~km}$ to the southwest; 2) the M-Cross Ranch sites (i.e., Hank's, Indian Springs, Three Toes and Whistling Squaw) about $10 \mathrm{~km}$ to the east; 3) the Buried City complex sites (i.e., Courson B and D, and Kit Courson) in Wolf Creek valley about $35 \mathrm{~km}$ to the northeast; and 4) the four excavated Antelope Creek phase sites (i.e., McGrath, Roy Smith, Stamper and Two Sisters) in the central Oklahoma panhandle roughly $75 \mathrm{~km}$ to the north (Figure 5-21; Table 5-1).

Ceramic assemblages from these four areas were selected to provide a broad regional coverage immediately surrounding the Long View site and provide a variety of vessel finishes and styles from adjacent Plains Village sites. These areas have yielded excavated ceramic assemblages from which to obtain the necessary samples. The individual sites within these areas provide a wide range of conditions and structures that might relate to a broader understanding of the individual potters, groups of populations, and conditions in these regions. A significant factor in selecting these particular sites and the actual individual pieces was that individuals and institutions housing the various ceramic assemblages were willing to part with certain samples for use in these destructive analyses. In the case of the four central Oklahoma sites the rare decorated rim sherds, especially the collared rims were not allowed to be subjected to destructive analyses. Therefore, the samples other than the Long View site samples were biased and judgmentally selected by other archeologists. 


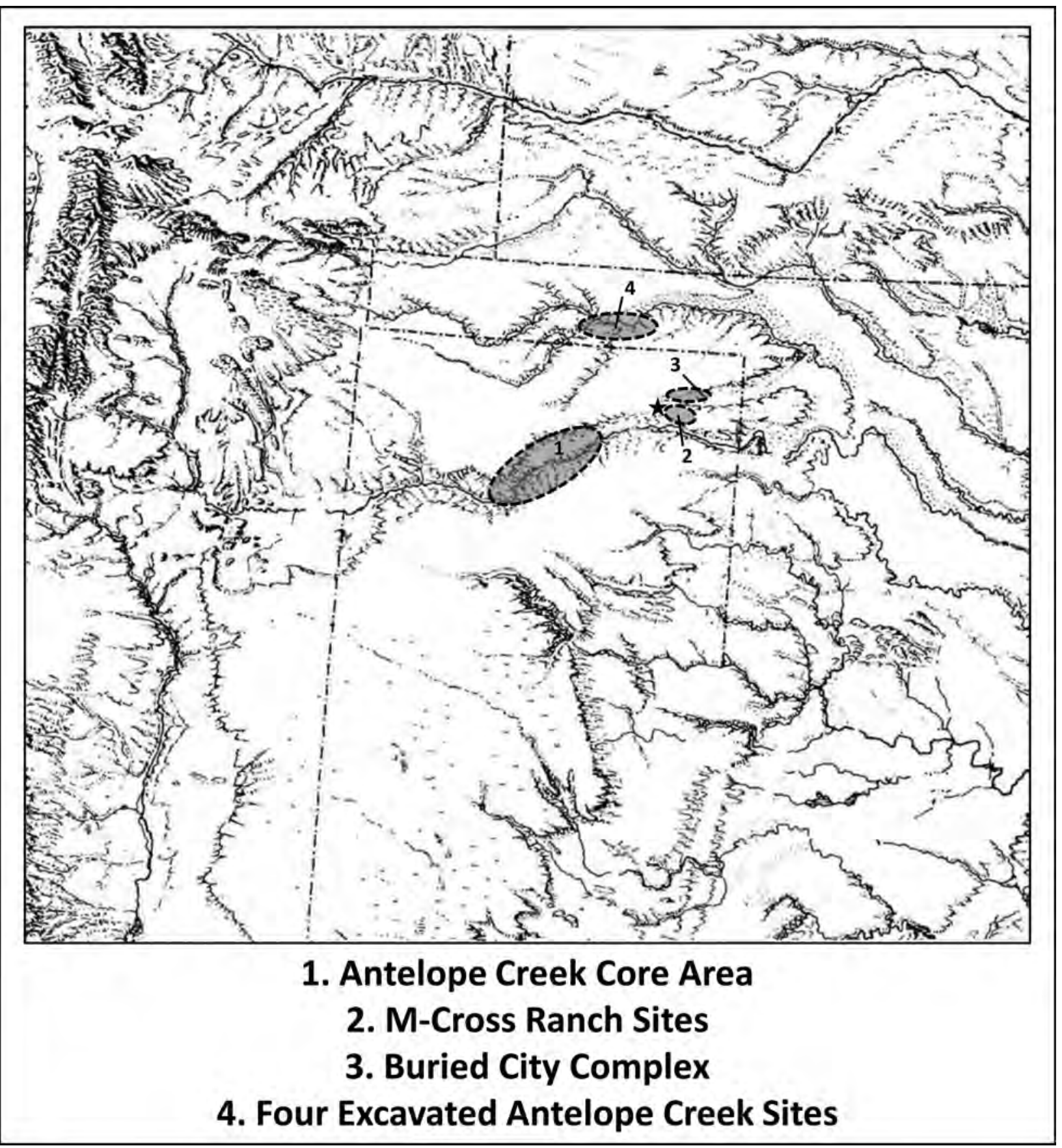

Figure 5-21. Map depicting the four areas from which pottery sherds and natural clay were selected for petrographic and INA analyses. 
Table 5-1. List of Sites and Sherds from Surrounding Areas Used for Comparisons.

\begin{tabular}{|c|c|c|c|}
\hline Site Number & Site Name & $\begin{array}{c}\text { Number of } \\
\text { Sherds }\end{array}$ & Natural Clay \\
\hline \multicolumn{4}{|c|}{ Buried City Sites along Wolf Creek } \\
\hline $410 \mathrm{OC} 27$ & Courson B & 9 & 1 \\
\hline $410 \mathrm{OC} 29$ & Courson D & 4 & 1 \\
\hline $410 \mathrm{OC} 43$ & Kit Courson & 2 & \\
\hline \multicolumn{4}{|c|}{ Four Antelope Creek Phase Sites in Oklahoma Panhandle } \\
\hline 34TX1 & Stamper & 6 & 1 \\
\hline $34 \mathrm{TX} 31$ & McGrath & 3 & \\
\hline 34TX32 & Two Sisters & 7 & \\
\hline 34BV14 & Roy Smith & 7 & \\
\hline \multicolumn{4}{|c|}{ Antelope Creek Phase Core Area Sites } \\
\hline 41HC6 & Roper & 6 & \\
\hline $41 \mathrm{HC} 23$ & Antelope Creek Ruin 22 & 6 & 1 \\
\hline 41HC141 & Cottonwood Creek & 3 & \\
\hline 41PT11 & Alibates Ruin 28 & 9 & \\
\hline \multicolumn{4}{|c|}{ M-Cross Ranch Sites } \\
\hline 41RB81 & Indian Springs & 9 & 1 \\
\hline 41RB108 & Whistling Squaw & 1 & 1 \\
\hline 41RB109 & Hank’s & 5 & 2 \\
\hline 41RB110 & Three Toes & 3 & \\
\hline \multicolumn{2}{|l|}{ Total } & 80 & 8 \\
\hline
\end{tabular}


A third analytical technique applied to a sample of 37 sherds from the Long View site was starch grain analysis (see details on technique below). Sherds selected came from Components A and C. They were selected based on the presence of macroscopic burned residues adhering to their surfaces, plus sherds that were darker stained with what might be food residues (Figure 5-22). Most sherds represented the same vessels analyzed for their chemical content (INAA) and their construction aspects (petrographic analysis) from the two components.

In four instances (sherds \#1233-8-1, \#342-8-9, \#643-8-1, and \#335-8-1) the sherds were placed in a shallow Pyrex dish, socked for up to 20 minutes in distilled water, then the exterior surface with the residues were subjected to a sonic tooth brush cleaning for five minutes with the residues collected in the dish. The water was allowed to evaporate and their remaining residues then placed in plastic vials. In some instances the burned residues were just scraped off the sherd, in other instances the sherds were brushed with a clean tooth brush to remove residues that were collected and placed in vials. In a few instances the entire sherd was sent directly to the analyst to remove the suspected residues (see starch grain analysis in Appendix D for details concerning the methods).
A forth analysis, was the direct radiocarbon dating of seven sherds. Four relatively thick-walled sherds from four separate vessels were targeted to determine if thick sherds reflect Plains Woodland or Plains Village period vessels. This analysis included one thick sherd from Vessel 1 (\#308-008-19) and a thick sherd from Vessel 3 (\#349-008-1d), both representing thick-walled vessels from Component $\mathrm{C}$ at the Long View site, one thick-walled sherd from Indian Springs (41RB81, \#291) at M-Cross Ranch, plus one thick-walled sherd from Courson D (410C29, \#346-4d) at Buried City. These four sherds each lacked interior or exterior organic residues and were sent to the radiocarbon laboratory at the University Georgia for direct dating.

All four sherds vary from 7.4 to 11.3 -mm-thick and represent four different thick-walled vessels. Some researchers would have labeled these thick sherds as Plains Woodland/Early Ceramic period vessels as they exhibit cordmarked exteriors on very thick bodies. It was our intention to establish the precise age of these four vessels. The radiocarbon ages were derived from the crushed and powdered interiors, treated for humic acids and combusted. The details of the procedures and individual results are presented in Appendix A with individual results reported in appropriate places in the text.

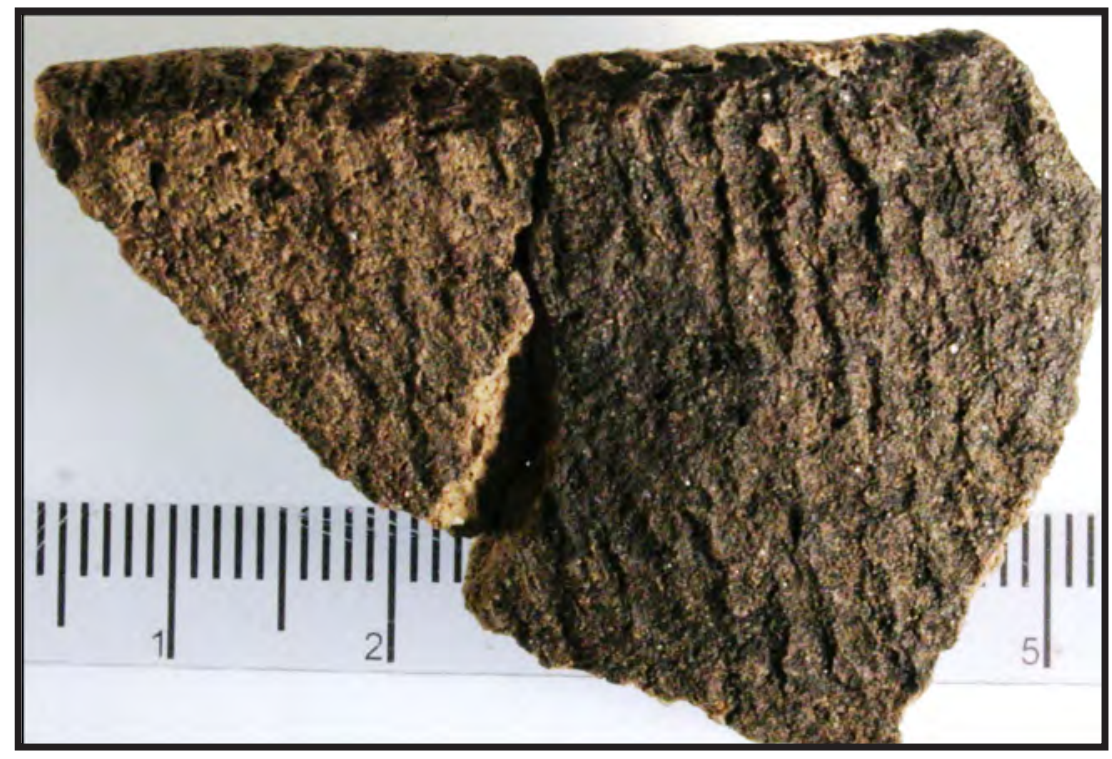

Figure 5-22. Decorated ceramic rim (\#1047) with visible organic residues on exterior surface, scale in millimeters. 
In conjunction with these four thick sherds, three relatively thin sherds from Component A were selected for radiocarbon dating to compare and contrast with the results from the thick sherds. In these instances, all three sherds also had dark organic residues adhering to their exteriors. The organic residues were scraped from the exteriors and retained, and submitted for radiocarbon dating. These three pairs of radiocarbon samples allow direct comparisons of the residues adhering to the bodies and those residues inside the vessel walls. A residue sample from the exterior of Vessel 1 (\#308008-19) was also extracted and sent for dating to compare with the internal residue from Vessel 1.

\subsubsection{Faunal Bone Analyses}

The recovered vertebrate faunal assemblage was mostly quite fragmentary with the exception of some larger elements recovered from Feature 6, the pithouse in Component $\mathrm{C}$. The pieces were examined in an attempt to identify them to specific taxa, anatomical elements, element symmetry, and element part. This information was recorded along with their size, weight, skeletal maturity, presence or absence of burning, and type of human modification (cuts, impacts, and/or use as a tool). If bone tools were identified, the pertinent specimen was set aside for more detailed observation and recorded as an artifact (see below). Such items are discussed in the text under heading, "Bone Tools".

The faunal remains from the two components were divided into major taxon groups based on the size and type of animal represented. The various groups identified include deer (Odocoileus sp.), bison (Bison bison), turtles (Testudines), snakes (Serpentes), small rodents, and fish (Osteichthyes). The assignment of a bone fragment to a specific taxon was based primarily on cortical wall thickness, bone shape and structure, and other specific observed attributes. If the attributes were not sufficient to confidently assign a bone to a specific taxon or general category, the fragment was assigned to an unknown category. Bones were identified as to element and symmetry where possible, but most pieces are small, long bone fragments (LBF) that lack diagnostic attributes and could not be identified to a specific taxon. The counts and weights of each group or taxon were recorded and are listed by taxon.
The bones were also recorded according to predetermined size categories. The categories range from 0 to $3 \mathrm{~cm}, 3.1$ to $6.0 \mathrm{~cm}, 6.1$ to $9.0 \mathrm{~cm}, 9.1$ to 12.0 $\mathrm{cm}$, and greater than $12.1 \mathrm{~cm}$. Knowing the size bone fragments provides an indication of how intensively the bones were processed (e.g., highly fragmented bones may reflect bone grease rendering).

Each bone was inspected for various human alterations, including burning, scrape marks, chop marks, blunt impacts, cut marks and other possible cultural modifications (Fisher 1995). The cut marks include various types such as thin and thick cut lines from stone tools made during skinning, defleshing, and disarticulation. Cut mark morphology reflects the shape of the tool's edge, the angle at which the tools was held, and the force behind the tool. Broad chop marks or percussion pits are often linear depressions that generally have a V-shaped cross section caused by larger and heavier stone tools, often during disarticulation. Impact locations are characterized by conchoidal flake scars and bone flakes, created by heavy hammer stones that indicate the point of impact where the element was struck to break the bone, as in marrow extraction.

Burning may result in a variety of observed colors that are generally related to the temperatures (degrees Celsius $\left.\left[{ }^{\circ} \mathrm{C}\right]\right)$ that the bone was exposed too. This includes bones burned to a solid black, a solid brown, a mixture of brown and black, a calcined white, and a mixture of black and white. Generally speaking, the bones of an ungulate turn to a brown color in the temperature range around $200^{\circ} \mathrm{C}$, black in the $300^{\circ} \mathrm{C}$ range, gray in the 300 to $400^{\circ} \mathrm{C}$ range, and white above about $700^{\circ} \mathrm{C}$ range (Nicholson 1993).

General weathering of bone surfaces were observed, but no details concerning this process were recorded beyond its presence or absence. It should be noted that bone weathering is not just a direct result of time; it also reflects a combination of physical and chemical processes that result in cracking, splitting, exfoliation, disintegration and decomposition.

Root etching is a separate process from weathering that causes narrow, shallow lines and pits etched into the surface of bones by acids associated with plant roots (Fisher 1995). These lines are sinuous or 
wavy, have U-shaped cross sections, and are easily identified. Much of the bone assemblage recovered was weathered and root etched, with the exception of the elements from Feature 6, the pithouse in Component C.

Four broad age categories of bison are recognized, fetal, immature, mature, and unknown. Each category is discussed here. These stages represent maturity and growth patterns and not to the animals ability to produce young. Fetal elements are recognized by their platy/flakey or porous appearing periosteum layers and overall structural morphology that mimics the corresponding mature element. Fetal long bones have periosteal tissue deposited along the shaft in layers separated by thin cancellous interspaces (Figure 5-23). These elements are in their early stage of development of unborn animals and their cortical walls have not been fully developed and are being developed by layers of tissue. These layers become solidified once the new born animal begins to put the weight on the skeletal structure at birth. These are small, light weight bones that lack the proximal and distal ends or epiphyses, which are still soft tissue and unattached to the shaft. Fetal elements are easily recognized, although species identification is often difficult and depending on the size and/or amount of the element present not always identifiable to element. During the developmental stage in the mother, fetal bison elements grow at different rates. The limb elements of most mammals, including Bos taurus with a gestation period of about 284 days, grow most intensively during the second half of uterine development, in contrast to the slight intensity of the axial bone growth during this same period (Vsyakikh 1969:227-233), cited in Wilson 1974:146-147.

Once the bison is born the bones will mature and develop, and the growth is reflected in the overall size and degree of fusion of the proximal and distal epiphyses to the main shaft or body. However, little is known about the exact timing of the bone fusion in American bison and other animals. For bison, most researchers use Koch's (1935) study of European bison to approximate the general trend in the timing of various epiphyseal fusion. Proximal and distal epiphyses of each element fuse at different times during the bison's life. In bison less than 6.5 years old, most epiphyses on long bone elements have fused, but those of the vertebral, pelvis, ribs, sacrum, and scapula have not fused. Therefore, an animal may have some fused elements at the same time it has unfused elements. Mature or immature definitions in this study are based on the fusion of the articular epiphyses following Bement and Basmajian (1996).

The minimum number of individuals (MNI) by species was derived from the maximum number of recognized elements coupled with size, age, and sex estimates also taken into consideration. The faunal identifications and observations were conducted by Mike Quigg using his personal comparative collection. The results are incorporated into the body of the text for each component.

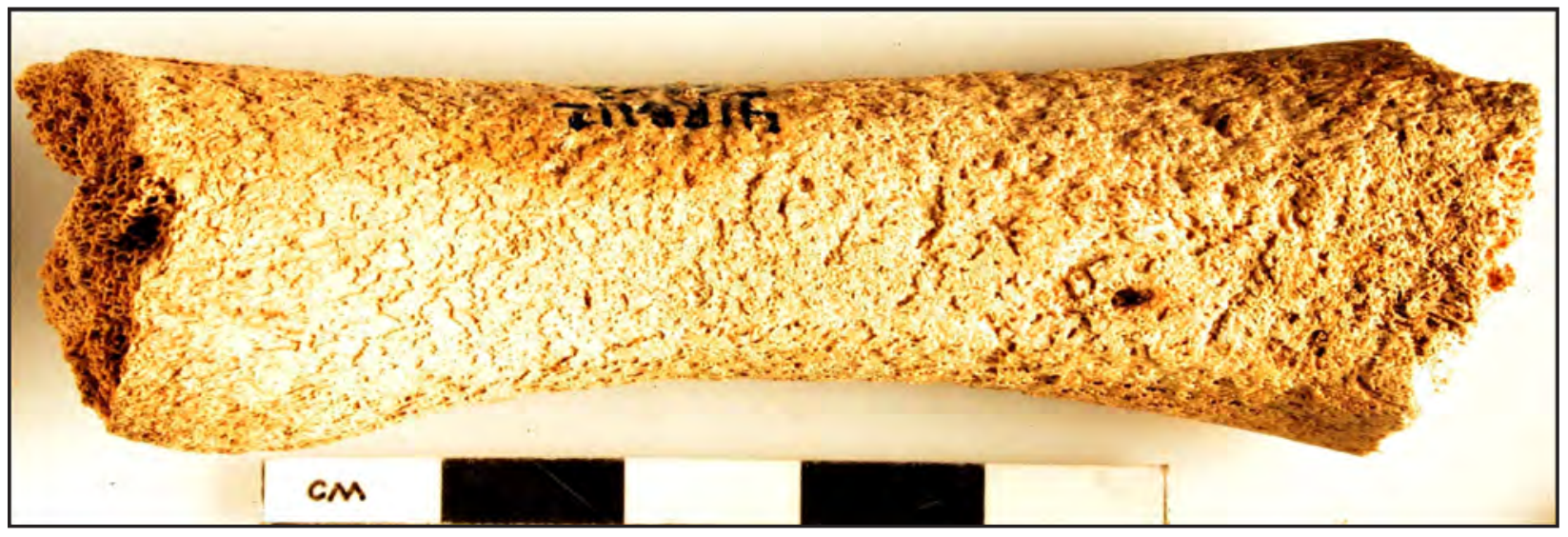

Figure 5-23. Example of a bison fetal long bone that exhibits the platy/flakey exterior surface with missing articular ends. 
When worked/altered areas on a bone were observed macroscopically, that specimen was set aside and considered as a separate category. The worked/altered areas are intentional modifications to the original shape of the bone beyond the cut marks and chop marks that might have been created during deflecting, or impacts created during bone breaking activities. Modification may have resulted from actual use in a chopping or pounding motion, the results of continuous use to create a smooth or rounded edge or through specifically directed alteration to the bone to facilitate a specific function. Classification into categories was based on the overall shape, observed attributes, and inferred function. Sets of observations were recorded for all tool classes recovered. The following subsections provide definitions of major tool classes encountered.

Bone Awls: Bone awls reveal intentional shaping through grinding and abrading to form a long, slender and pointed tool with parallel to contracting sides. Awls are generally formed from a long bone splinters, often deer/pronghorn metapodials. Sometimes striations paralleling the long axis of the bone are present or the very end can be polished. Awls were fashioned to a specific pointed shape, with an assumed function for use in hide working or making clothing. Polish may be present on all of part of the awl and be present across tiny linear striations. If a small diameter hole was intentionally drilled at the proximal end, then it will be classified as a needle. The needle would be used in a sewing function.

Scapula Hoes: Scapula hoes are generally large complete bison scapulas or scapula blade fragments that exhibit rounded, beveled and/or often polished blade edges. Sometimes the spine is removed and that area exhibits wear as well. These limited modifications were developed through use and not from intentional modification. Worn scapulas are thought to have functioned as horticultural tools and used in the horticultural fields, but they may have also functioned as general shovels for digging and/ or shoveling dirt.

Digging Tools: Digging tools are generally bison long bone shaft segments with thick cortical walls that have one articular end still present. The articular end may form the handle or a hole may have been created in the end to insert a wooden handle, which would penetrate the marrow cavity and provide strength. The fragmented end may have been intentionally shaped into a wedge or pointed end either through grinding or use to create a sharp edge. This sharp edge is thought to have facilitated the digging in the earth. Often this tool is thought of as a horticultural item, but again it may have functioned as a pick to dig pits (i.e., storage of house pits).

Cut and/or Incised Bones: Bone elements sometimes have been cut with a sharp object, likely a chert flake or biface to remove the skin, cut tendons, or detach bones. To cut through a bone, a technique referred to as a groove and snap technique was often used. This involved continually cutting/incising in the exact same spot until it was possible to snap the bone into. What is left is the cut/beveled edge or intentional incisions created in an attempt to detach a segment of the bone. This may be conducted to create bone beads or the removal of a flat section of the scapula from the larger blade section.

Bone Rasp: These are generally bison rib sections that exhibit parallel incisions or notches perpendicular to the long axis along one edge or face. The entire piece may reveal slight polish, but no other modifications may present. These have been assumed to have a variety of functions including, but not limited to, counting sticks, a musical instrument, etc.

Other: Some bone pieces reveal intentional flaking and/or rounded edges. These limited modifications are considered signs of intentional use, but the overall form does not reflect a specific functional class. Often these limited work elements lack significant alteration to the original element and may have had limited use as an expedient tool. Most pieces in this category are classified as bone tools without a known function.

\subsubsection{Architectural, Pithouse Definition}

Currently, no clear universal definition for what is called or classified as a pithouse is in use for this or adjacent regions. Here, TRC has chosen to characterize a pithouse as:

- an excavated pit that is at least $2 \mathrm{~m}$ or greater in diameter (or $3.14 \mathrm{~m}^{2}$ in area); 
- having the natural ground form a major part of the side wall.

- a floor is at least $35 \mathrm{~cm}$ below the original ground surface and often much greater in depth

- the association of post molds in or along the immediate margins of the pit

- various attributes associated with pit use and/or the superstructure such as: a central hearth, size and frequency of the framework posts, the positions of those posts, presence or absence of plastered floors or walls, type of coverings, style or position of an entryway, the use of stone linings, can be quite variable and not a defining factor in calling a structure a pithouse.

\subsubsection{Analytical Techniques}

The following analytical techniques were performed on suites of samples selected from various artifact classes to gain greater insights and understanding of specific classes of materials, which will contribute to the interpretations of the human behaviors and towards addressing specific research questions developed in the approved research design (see Chapter 4.0). Selected techniques (e.g., macrobotanical assessment, pollen and phytolith assessments) were implemented on a limited suite of samples following the eligibility assessment program to provide direction to the kinds and quality of data to expect in subsequent analyses (Quigg and Smith 2005).

Following TxDOT approval of the research design, all but one requested technique was approved to go forward, the exception being the lipid residue analysis. Consequently, no lipid residue analyses were permitted by TxDOT on this data set. The various technical analyses were conducted by highly skilled individuals who applied their expertise and knowledge, then offered their interpretations based upon the obtained results. Their individual reports in the appendices provide details concerning their methods, analytical results, and interpretations. The results from these diverse technical studies, combined with analyses of the various artifacts obtained during site assessment and data recovery investigations, are incorporated throughout the body of this report. The combined results are used to address the research questions presented in Chapter 4.0. Each technical analyses employed is briefly discussed below.

\subsubsection{Radiocarbon Analysis}

Charcoal, generally the preferred material for radiocarbon analysis, was plentiful in most features and scattered across other locations. Wood charcoal was initially employed for dating following the data recovery fieldwork to establish the chronological age for the two investigated areas (Areas A and C). Four radiocarbon dates were obtained from Component A. These four dates provided a preliminary age range from 710 to 1490 B.P. for this component. The two oldest dates of 970 and 1490 B.P. are thought to be too old and reflect old wood, as no artifacts recovered fit with those ages. The two dates of 710 B.P. from Features 1 and 4 appear to fit the age of the recovered artifacts. Four radiocarbon dates were obtained from Component $C$. Their ages range from 630 to 1290 B.P. with three dates that cluster around 660 B.P. The oldest date is considered to represent the use of old wood. Therefore, the preliminary age of Component $\mathrm{C}$ is around 660 B.P.

The initial eight radiocarbon dates (7 on wood charcoal and 1 on charred maize) were provided by Beta Analytical Inc., (Beta) in Miami. At Beta, each sample was pretreated prior dating (Figure 5-24). The wood charcoal was washed with acids. Beta dates are reported as radiocarbon years before present (B.P.), with present being A.D. 1950 using the Libby ${ }^{14} \mathrm{C}$ half life of 5,568 years. Each sample was measured for carbon 13 verses carbon 12 ratios $\left({ }^{13} \mathrm{C} /{ }^{12} \mathrm{C}\right)$ expressed as the delta 13 carbon $\left(\delta^{13} \mathrm{C}\right)$ and calculated relative to the internationally standard Cretaceous belemnite formation at Peedee, South Carolina (PDB or VPDB). Beta's individual laboratory reports with specific details concerning each sample are presented in Appendix A. Individual sample results are also presented throughout the text.

A refinement of the initial two age ranges was sought through a suite of 17 charred maize samples and one bison bone. These samples were selected from the many features identified in Areas A and $\mathrm{C}$ to more fully assess their contemporaneity and refine the age of the two occupations.

The subsequent 17 selected macrobotanical (maize parts), 4 ceramic, and 2 sediment samples were submitted to TxDOT for approval and when 


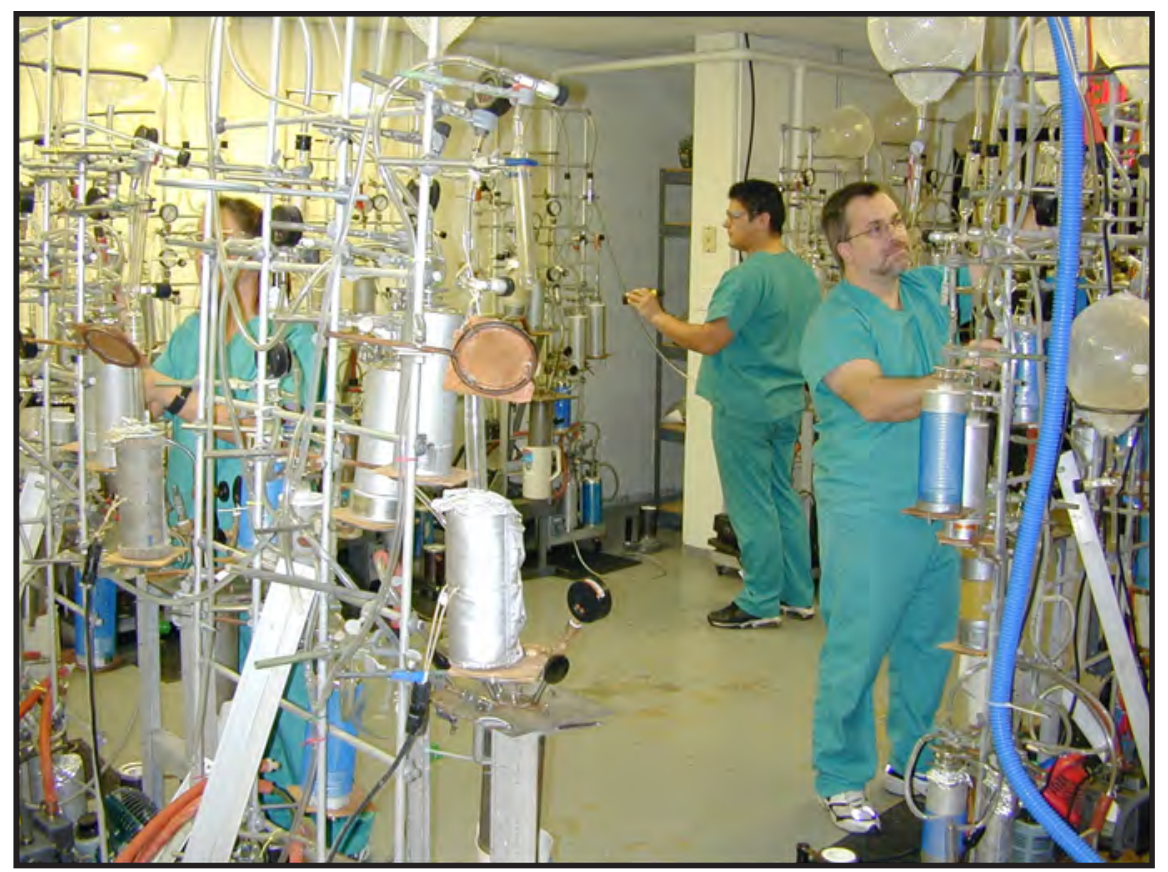

Figure 5-24. Beta laboratory, showing the gas extraction process. (Photograph provided by Beta Analytic Inc.)

approved, sent to University of Georgia (UG) Center for Applied Isotope Studies in Athens for analysis. At the UG laboratory, each sample was pretreated prior to dating. The obtained dates are reported as radiocarbon years before present (B.P.), with present being A.D. 1950 employing the ${ }^{14} \mathrm{C}$ half-life of 5568 years, the same as Beta. The error is quoted as one standard deviation and reflects both statistical and experimental errors. Each sample was also measured and corrected for ${ }^{13} \mathrm{C} /{ }^{12} \mathrm{C}$ ratios, and again calculated relative to the internationally standard Cretaceous belemnite formation at Peedee, South Carolina (PDB or VPDB). The detail laboratory reports concerning each sample are also presented in Appendix A.

Four ceramic sherds were also directly radiocarbon dated and included two from Long View (\#349008-1d [Vessel 1] and \#308-008-19, [Vessel 3]), one from 410C29-\#346-4d (Courson D) at Buried City, and one from Indian Springs (41RB81-291) at M-Cross Ranch. These four thick sherds represent thick-walled vessels that are not ordinarily thought of as representative of Antelope Creek phase ceramic sherds. All four sherds vary from 7.4 to 11.3-mm-thick. Some researches would have labeled these thick sherds as Woodland as they exhibited cordmarked exteriors on very thick bodies. It was our intention to establish the precise age of these four vessels. The four sherds were sent to The University of Georgia laboratory for direct radiocarbon dating. The radiocarbon ages were derived from the crushed and powdered interiors, treated for humic acids and combusted. The details of the procedures and individual results are presented in Appendix A with individual results reported in appropriate places in the body of the text.

\subsubsection{Optical Stimulate Luminescence (OSL) Dating}

Optical dating of late Quaternary quartz sands has been in use for many years. This dating technique was necessary where organic remains were not present, specifically in the eolian sand deposits on and adjacent to the Long View site. Fourteen samples from various stratigraphic proveniences across the Long View site and just off-site in the adjacent Dugout Creek valley (reference LRUD and LRSSD) were collected by Charles Frederick. The samples were collected in $5.1 \mathrm{~cm}$ (2 inch) wide by 15 cm (6 inch) long, thick, opaque PVC tubing with the 
ends capped with plastic caps, to block out any light. The PVC sections were driven into the sediments, dug out and capped immediately, with the caps then duck taped. A soil moisture sample was collected from deep in the hole from which the OSL sample was collected and placed in doubled plastic bags. A vertical column of three OSL samples were collected from N486 E493. These were collected from 30, 60 and $105 \mathrm{cmbs}$ in dark plastic tubes. These samples were sent to Dr. Mark Bateman at Sheffield Center for International Drylands Research (SCIDR) in Sheffield, England, for analysis. Both single aliquot and grain level analysis was applied to coarse quartz grains extracted from submitted samples. The details of the methods, sample preparation, and results are presented in Appendix R.

The relative dating technique was employed to gain an understanding of when the various sand deposits accumulated in this general locality. Individual radiocarbon and OSL dating results are incorporated specifically in Chapter 6.0 which provides an indication of the age of the eolian deposits both onand off-site and help solidify the absolute age of the two components and reveal their age differences. These results also provide an indication of the age of the sediments in which the cultural remains were deposited and later buried by.

\subsubsection{Use-Wear Analyses}

Most stone tools are generally categorized by their overall form with an assumed function. However, to gain a greater understanding of their true function, a suite of tools were selected and submitted for highpowered use-wear analyses. A total of 60 unwashed artifacts, roughly divided equally between Areas A and C, were sent to Dr. Bruce Hardy at Kenyon Collage (Gambier, Ohio) for high-powered usewear analyses. Most tools selected were minimally handled in the field and not washed in the laboratory. In order to track individual specimens, a small spot on one face of each artifact was cleaned and an ink provenience number applied and coated. Diverse chipped stone tool classes represented in the recovered assemblage were sampled and submitted for analysis. Fifty-two items were sent and include 2 Fresno point base, 10 end and side scrapers, 4 bifaces, 5 beveled knives, 5 drill tips and bases, 24 edge-modified flakes, 1 pecked stone, and 1 uniface.
Edge-modified flakes were intensively sampled as they presumably functioned in a variety of tasks and on a variety of materials. Therefore, the greatest functional diversity would be apparent in the edgemodified flake tool class. The edge-modified flake tools included a variety of edge shapes and sizes in anticipation of identifying a wide range of functions such as cutting, graving, shaving, scraping, and whittling. The analytical methods and individual results of Dr. Hardy's findings are presented in Appendix $\mathrm{H}$.

\subsubsection{Starch Grain Analysis}

Starch grain analysis is becoming more widely used in Texas archeology (i.e., Quigg et al. 2010, 2011a; Perry and Quigg 2011a). However, many may not be as familiar with this technique or actually what is being analyzed. A brief introduction is provided here to provide background to this discipline.

Starch grains are microscopic granules that serve as the principal food storage mechanism of plants. These grains are found mainly in roots, tubers (e.g., crow poison, rain lilies, false garlic, wine cup, and spring beauty), seeds of legumes, and grasses, where they are often produced in abundant numbers (Perry personal communication 2008). Starch grains from different plants possess a large variety of forms that have been recognized for some time. Distinctive features of starch grains are genetically controlled and when carefully observed, can be used to identify plant taxa. At least 300 species and varieties of important economic plants from around the world have been described and there is widespread recognition that these materials can be preserved in archeological contexts (Piperno and Holst 1998; Piperno et al. 2000). Researchers around the world (particularly in the neotropics and in Australia) have been using these techniques with excellent results (Perry personal communication 2007). Specifically, starch grain remains have significantly increased the knowledge of plant domestication and crop-plant dispersal in various regions (Perry et al. 2006:76-77).

Researchers have employed starch grain analyses to study diet, plant processing, plant domestication and cultivation, tool use, and uses of ceramic vessels. Starch grains have been extracted from soil samples, ceramics, and chipped and ground stone tools to 
address questions of resource procurement and preparation of foods. Intact starch grains have been extracted from formal and informal chipped stone tools, both washed and unwashed (Perry personal communication 2007). Heat alone does not destroy starches as they are found in vessels, so burned rocks also have the potential to yield starch grains.

A total of 104 samples that include 20 burned rocks from 7 different cultural features, 8 metate pieces, 26 chipped stone tools, 4 abraders, 1 hammerstone, 1 edge-ground pebble, 5 manos, 2 pipe fragments, 35 ceramic sherds, and 2 sediment samples were selected and sent for starch grain analysis. This includes 46 items from Component A and 58 items from Component C. These were submitted to Dr. Linda Perry, executive director of The Foundation for Archeobotanical Research in Microfossils in Virginia to determine the presence/absence, human alterations to the grains present, and if possible the identification of specific taxa recovered. Dr. Perry's extraction methods, results, and interpretations are presented in Appendix D.

\subsubsection{Burned Rock Analyses}

Burned rocks often account for a high percentage of the artifacts recovered from hunter gatherer campsites, although they are often more limited in more semipermanent settlements. These rocks were originally heated and often rapidly cooled in water as the result of use in cooking or other heating activities. While it is occasionally difficult to distinguish burned from unburned rocks in the field, many burned rocks exhibit internal cracks, discoloration, crazing, reddening, graying, and angular fragmented edges to facilitate identification.

During excavation, burned rocks were treated as cultural artifacts. Larger pieces were often mapped in situ and burned rocks from each hand-excavated level were collected and recorded. The collected pieces were sorted into four previously established size categories (i.e., 0 to $4 \mathrm{~cm}, 4.1$ to $9 \mathrm{~cm}, 9.1$ to $15 \mathrm{~cm}$, and greater than $15 \mathrm{~cm}$ ) based on maximum dimensions, and then counted and weighed by size class. This information was recorded on individual level records. Most burned rocks from feature contexts and a sample of burned rocks from nonfeature contexts were collected, bagged, and returned to the laboratory for processing, cataloging, and analysis. Some rocks from features and most from nonfeature contexts were discarded in the field after documentation. The entire volume encountered during hand-excavations was documented; only a limited sample was retained for possible further analysis and even a smaller sample was curated.

Twenty burned rocks were selected for starch analysis. These samples represented seven features, some from each of the two components. These 20 samples were sent to Dr. Linda Perry in Virginia for analyses. Her detailed sample preparation and extraction methods, individual rock analyses, and interpretations of the lipid residues are presented in Appendix D.

Parts of 12 burned rocks used in the starch grain analyses were also sent to Dr. Barbara Winsborough for diatom analysis (see below for details). The fundamental belief is that multiple analyses on the exact same rocks would strengthen the final interpretation of the results and more precisely determine the function of the rocks and/or the foods cooked by these rocks. The diatom sample preparation and extraction methods, individual rock analyses, results, and interpretations are presented in Appendix J.

Pieces of rocks subjected to specific types of analyses such as starch grain or diatom analyses, were curated. Larger pieces from the various individual features and specific context were also selected and curated.

\subsubsection{Macrobotanical Analyses}

Macrobotanical assessment conducted following the eligibility assessment investigations yielded very positive results with wood charcoal and charred food remains (i.e., maize) represented in both components (Dering 2005a). Consequently, during data recovery quantities of sediment were collected from excavated features for flotation and potential analysis.

In the laboratory, bulk matrix samples from 22 features with potential to yield macrobotanical remains were subjected to flotation ( $N=108$ or 1,233.25 liters) at the Austin facilities to retrieve the macrobotanical remains. The samples were floated using a Dousman 
flotation system that allowed for the collection of separate light and heavy fractions. The collected heavy and light fractions were subjected to separate analyses. Twenty-seven of the 108 light fractions were selected for macrobotanical analysis and sent to Dr. Phil Dering of Shumla Archeobotanical Services in Comstock, Texas, for sorting and identification of organic materials. The 27 samples ranged from 2 to 82 liters per sample with the light fractions representing 1,786 $\mathrm{g}$ of extracted material from the 540 liters floated. Dr. Dering's detailed technical report is presented in Appendix C.

Each heavy fraction was carefully examined and sorted into the different classes (e.g., charcoal, burned seeds, bones, lithic debitage, burned rock fragments, and shells) and then recorded on paper forms. These materials were then counted, weighed, and bagged by material class with the results presented in the appropriate feature discussions within the body of the report.

\subsubsection{Charcoal Analysis}

From the hundreds of individual charcoal and macrobotanical samples that were collected during the fieldwork, 100 macrobotanical samples of carbonized materials from inside and outside individual features were selected and submitted to Dr. Phil Dering for identification. The selection of charred samples was done judgmentally, insuring that samples from across wide areas of each component were represented, as well as around features. A high percentage was from pithouse Feature 6 in Component $\mathrm{C}$ to address possible materials used in construction. In anticipation that the vertical stratified charcoal in the fill of the pithouse might yield different types of charred materials used in the construction of that feature, many samples from what was considered construction fill and the floor of the pithouse were submitted. The charred pieces used in radiocarbon analysis were most often identified prior to dating. Dr. Dering presents the detailed methods, macrobotanical identifications, and interpretations in Appendix C.

\subsubsection{Ceramic Petrographic Analyses}

Microscopic thin section analysis has been around for over 50 years and provides a means of quantifying the contents of ceramic sherds through point counts under high-power microscopic analysis. This allows for interpretations concerning the manufacture, production techniques, and cultural differences, which also can be used to address broader research questions. This analytical technique was prescribed by TxDOT. They also established a protocol for TRC to follow in this project and it is attached as Appendix N.

Over 1,500 sherds were recovered from the investigations at the Long View site. A small sample of 32 sherds (2.1 percent), 14 from Component $A$ and 18 from Component $\mathrm{C}$, the two discrete and horizontally separated components, were selected for petrographic and accompanying INA analyses. To address research question 6 (see Chapter 4.0), suites of sherds (roughly 20 sherds per group of sites representing a region) from multiple Plains Village sites clustered in the adjacent regions were also subjected to these same two analyses. Suites of sherds plus natural clay samples from specific Antelope Creek phase sites in the core area centered at Lake Meredith (Alibates Ruin 28 [41PT11], Roper [41HC6], Cottonwood Creek [41HC141], and Antelope Creek Ruin 22 [41HC23]), the M-Cross Ranch (Indian Springs [41RB81], Three Toes [41RB110], Hank's House 1 [41RB109-A], Hank's Feature 1 [41RB109-B], Whistling Squaw [41RB108], and Hank's cairn burial [41RB109-E]) east of Long View, the Buried City complex (Courson B [41OC27] and Courson D [41OC29]) to the northeast, the four excavated Antelope Creek phase sites in the Oklahoma panhandle (Two Sisters [34TX32], McGrath [34TX31], Roy Smith [34BV14], and Stamper [34TX1]) to the north, were used for the comparison to those from Long View (see Figure 5-21 and Table 5-1). Mr. Quigg had some general input into the type and number of sherds and clay samples originally requested from the various institutions and individuals; however, the individuals in charge of each specific collection at the time of the request were the principals involved in the selection of the specific sherds submitted for analyses. Mr. Doug Boyd selected the 9 sherds and 2 clay samples from the M-Cross Ranch sites; the 9 Indian Springs sherds and 1 clay samples were selected by Mr. Quigg. Dr. Scott Brosowske selected the 15 sherds and 2 clay samples from three Buried City complex sites. Dr. Richard Drass with the approval of Dr. 
Don Wyckoff selected the 16 sherd samples from the three Oklahoma sites (Roy Smith, McGrath and Stamper) housed at the Sam Noble Museum of Natural History. Whereas Dr. Marjy Duncan of the Archeological Survey of Oklahoma selected the 8 sherds and 1 clay sample from the Two Sister site (41TX32) housed at the Oklahoma Archeological Survey. Dr. Jeff Indeck, Chief Curator at the Panhandle-Plains Historical Museum in Canyon, Texas was kind enough to provide the sherds from the four Antelope Creek phase sites in their collections.

A total of 97 samples, which included 87 sherds and 11 experimentally tempered clays, were subjected to petrographic analysis. This includes 10 sherds from Component A and 10 from Component $\mathrm{C}$ at the Long View; 13 sherds from four different sites on the M-Cross Ranch; 15 sherds from three different sites from the Buried City complex; 22 sherds from four Antelope Creek phase sites in the Oklahoma panhandle; and 17 sherds from four Antelope Creek phase sites in the core area.

Most sherds selected for petrographic analysis were first split into two and sometimes three parts in order to conduct multiple technical analyses (e.g., instrumental neutron activation analysis [INAA], petrography analysis, and possibly radiocarbon dating) on the exact same sherd. Besides the 87 sherds, 11 tempered sediment and/or clay samples from Long View, other sites, and the surrounding region were also selected for analysis to use for comparison to the sherd pastes. The natural clay samples selected were subsequently tempered with two different ratios, 25 and 50 percent of local sandstone. In most instances the tempered clays were made into two small bricks/tiles. The bricks were roughly 3-by-1 cm by 1 -cm-thick. These bricks were then fired in a small kiln over a period of 1.5 hours to $450{ }^{\circ} \mathrm{C}$ and $650^{\circ} \mathrm{C}$. Once baked, the bricks were allowed to cool at air temperature, then each was cut in half and pieces selected for the two analyses.

The selected sherd and the experimental tempered clay samples were first sent to National Petrographic Service, Inc., in Houston, Texas, to prepare microscopic thin sections and mounting. Slide preparation entailed impregnation with a blue resin, staining for carbonates and feldspars, cutting each sherd, grinding it to a prescribed thickness, mounting on a 27-by-46-mm glass slide with no cover, and etching a reference number on the slide. The thin section slides were submitted to Dr. David Robinson, in Austin, for petrographic analysis of the fabrics (Figure 5-25). The prepared slide was then examined under an Olympus BH-2 sterographic polarizing microscope with a rotating stage at the Texas Archeological Research Laboratory at The University of Texas at Austin. Dr. Robinson's detailed methods, analysis, individual results, and interpretations are presented in Appendix F. In short, he conducted 200 point counts where possible, recorded the types and percentage of materials, recorded the matrix colors, made observations on the pastes, categorized paste texture, created paste groups, and made comparisons. The specific information derived from his analysis is incorporated into the body of this text and used to address specific research questions. The petrographic data combined with the INAA on the exact same sherd or a sherd from the same vessel, provides powerful evidence as to where these vessels may have been manufactured and what materials were used in their manufacture.

\subsubsection{Obsidian Sourcing}

Obsidian is not a local lithic material common to the site or region. Fortunately, this black glass has chemical properties that can be traced back to its original source. Consequently, all 49 pieces identified as obsidian were subjected to a nondestructive, quantitative source analysis. The obsidian was only found in the northern Component A. These pieces were sent to Berkeley Archaeological XRF Lab at the University of California in Berkeley under the direction of Dr. Steven Shackley to determine their sources. Along with the obsidian two tiny white beads (\#500-1 and \#1032-10) were sent for XRF analysis. Dr. Shackley's detailed report is presented in Appendix E. Individual specimen descriptions and sources are discussed within the text.

\subsubsection{Phytolith Analysis}

Opal phytolith studies are important in reconstructing a general profile of grassland flora in this high plains setting and potentially to enable specific identification of the use of various domesticated 


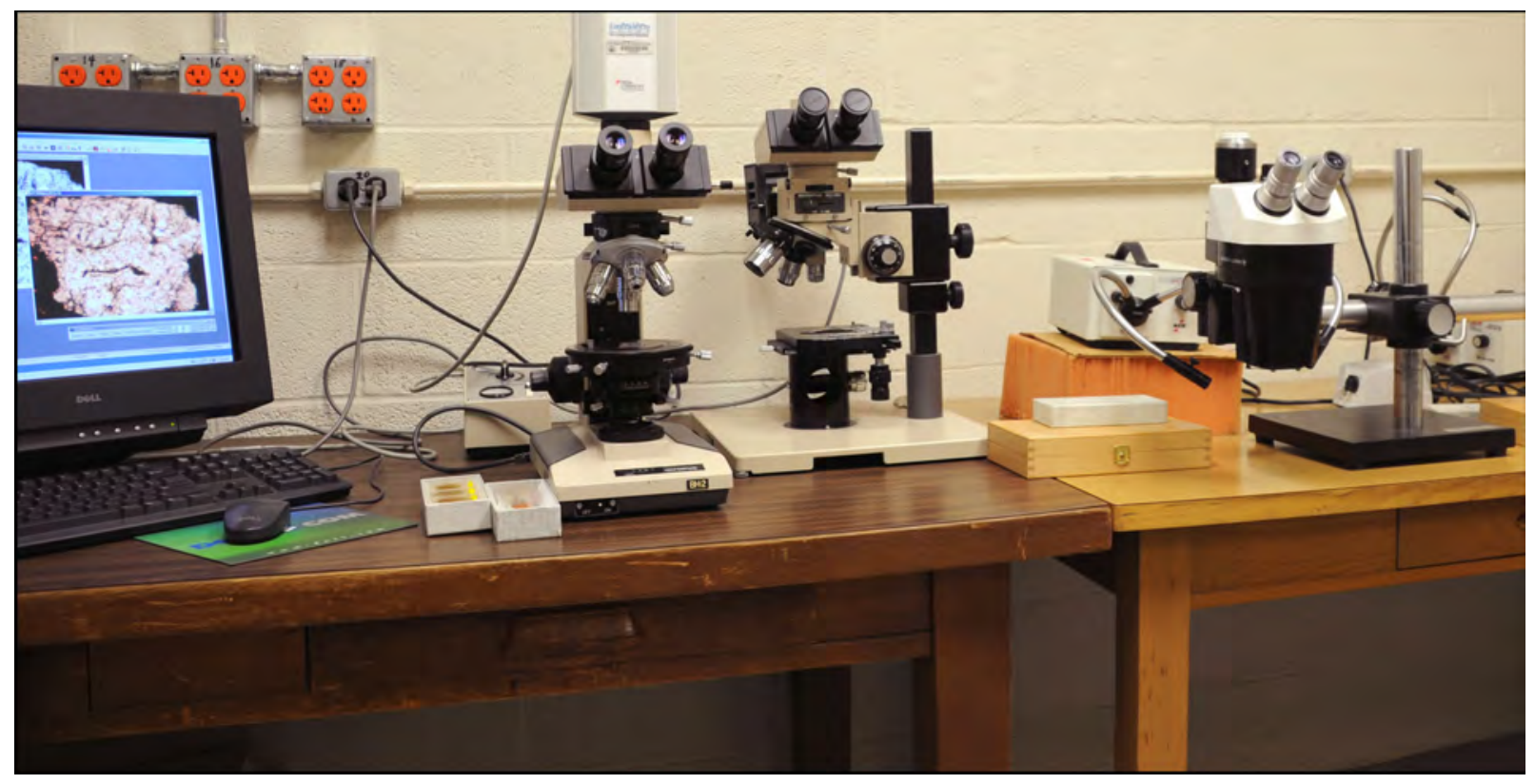

Figure 5-25. Instruments used in petrographic analysis (photo furnished by Dr. Robinson).

such as maize (corn) that have diagnostic phytoliths. Opal silicate bodies are produced in multiple shapes and sizes and comprise the phytoliths entities from within plant cells. The distinctiveness of various types of bodies varies according to cellulose structure. In grasses, phytoliths exhibit diversity and are distinct for grass species. The presence of certain phytoliths (e.g., panicoid, festucoid, and chloridoid) in the paleoenvironmental record provides a record of general vegetative conditions, such as forested versus open grassland prairie, and the grasslands constituents. Nongrass monocots also produce numerous taxonomically valuable phytoliths. Water orientated plants such as bulrush (Scripus pallidus) and sedges (Cyperus) exhibit distinctive types. Phytoliths are also formed in woody and herbaceous dicotyledons. Diagnostic phytoliths are rarely formed in edible fruits and nuts. However, common beans (Phaseolus vulgaris), specific species in the sunflower family (Asteraceae), rinds of selected varieties of squash (Cucurbita species), and maize (Zea maize) all yield recognizable phytoliths (Bozarth and Woodburn 2010).

Following the eligibility assessment, a phytolith assessment on six sediment samples from the Long View site was conducted by Dr. Steven Bozarth from the University of Kansas Palynology
Laboratory. His presence/absence results indicated that phytoliths were adequately preserved in all six samples and that $\mathrm{C}_{3}$ and $\mathrm{C}_{4}$ grass phytoliths, plus arboreal phytoliths, were present. In his professional opinion, the phytolith assemblages would provide interpretable paleoenvironmental and archeological data (Bozarth 2005). Subsequently, 25 sediment samples were selected from various proveniences across both components, primarily feature context, which included a series of 10 samples from pithouse Feature 6, an on-site control sample from a deeply buried (92 to $96 \mathrm{cmbs}$ ) A horizon in a low swale in Area B between the two prehistoric components, and an off-site surface control sample from the upland prairie on the south side of the Canadian River valley adjacent to the highway for comparisons to the cultural samples. These were submitted to Dr. Byron Sudbury in Oklahoma for analysis. Dr. Sudbury's methods of extraction, sample counts, identifications, and interpretations are presented in Appendix B.

\subsubsection{Instrumental Neutron Activation Analysis}

Instrumental neutron activation analysis (INAA) provides a chemical fingerprint for a variety of different materials, such as ceramic sherds, tool stones, and clays (Figure 5-26). The chemical fingerprint aids in tracing that material to a 
general region or sometimes a specific locale. This analytical technique allows inquiry into origins of ceramic manufacture, lithic procurement areas, and movements of these artifacts and populations. It is possible that actual quarry sources used in the manufacturing of artifacts (clay for the production of pottery and tool stone used in tool manufacturing) can be identified. If so, this would significantly contribute to our understanding of resource procurement strategies, and movement of products through trade and/or population movements.

Meier (2007) provides INAA on 19 natural clays, 5 clays from the floor of the structure at 41PT109, and 75 ceramic sherds from three Antelope Creek sites (41PT109, Landergin Mesa - 41OC2, and Alibates Ruin 28 - 41PT11) and source areas along the Canadian River valley west of Long View. Her samples were also run by Dr. Michael Glascock at MURR with the prefix of HAM (Figure 5-26). The 19 natural clay samples were derived from five alluvial sources near 41PT109 at the mouth of West Amarillo Creek north of Amarillo in Potter County, five alluvial sources near Landergin Mesa (41OL2) at the mouth of Alamosa Creek further west in Oldham County, six alluvial source along the Canadian River, and five sources in the Antelope Creek phase core area near Alibates Ruin 28 on the southern side of Lake Meredith. The 75 Antelope Creek phase ceramic sherds (HAM1 through HAM75) were equally divided between these three Plains Village sites. This sample of 99 provides an excellent database, both source areas for clay and ceramic sherds to compare and contrast with other Plains Village samples. Reanalysis of these 99 samples are presented in Appendix G along with the Long View project samples.

TRC expanded upon Meier's clay samples by submitting clays/sediments from nine more natural sources as part of the Landis property investigations near Amarillo (Quigg et al. 2010). The goal was to evaluate and determine the similarities and differences with Meier's (2007) local and regional clays and her Antelope Creek phase sherds. Those results promote identification of clay sources employed in the manufacture of Antelope Creek phase pottery and potentially the movement of those vessels across space. Appendix $G$ provides the INAA on the ceramic sherds and natural clays.

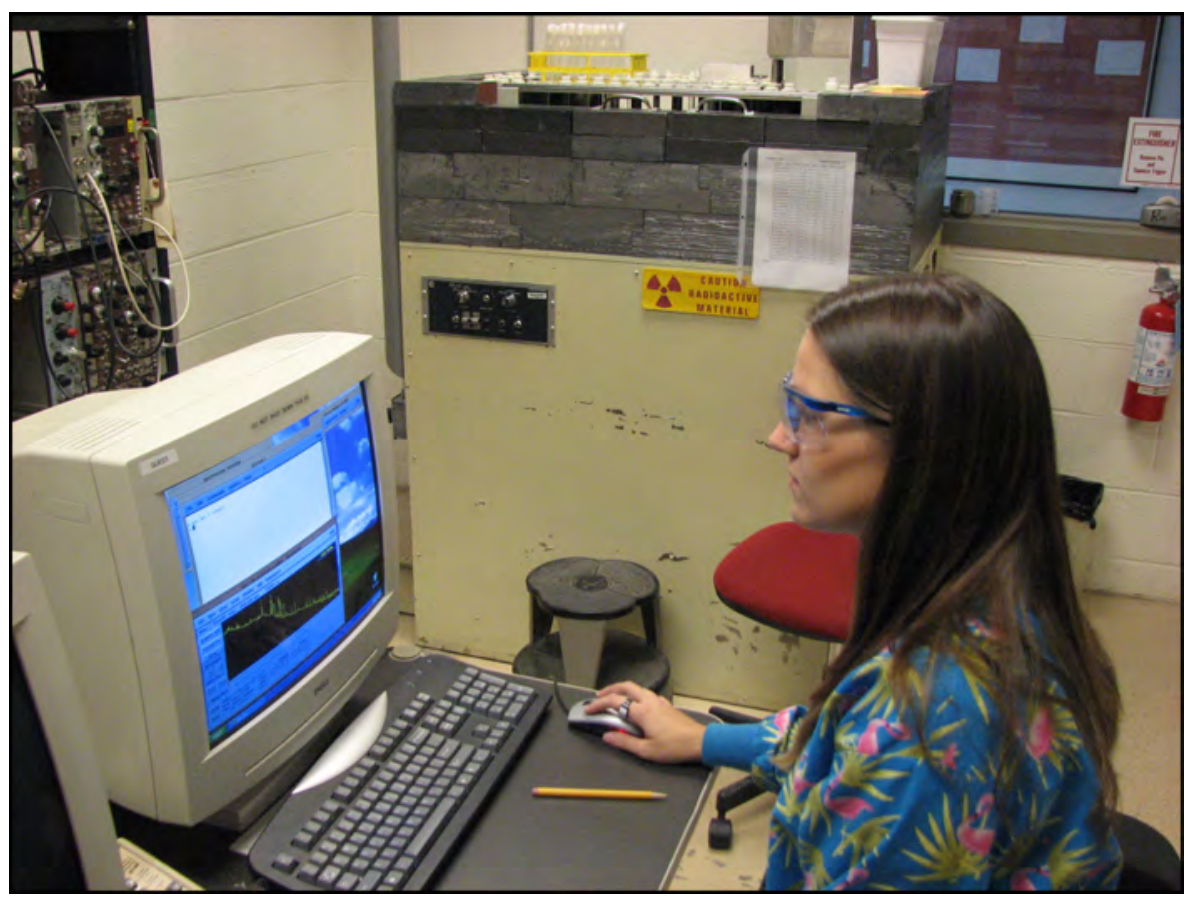

Figure 5-26. MURR laboratory assistant compiling data (photograph furnished by Dr. Glascock). 
INAA have been conducted and published concerning two local prominent tool stone resources, Alibates and Tecovas (Boulanger and Glascock 2010; Quigg et al. 2010; Quigg et al. 2011b). Both are known to outcrop in or adjacent to the Canadian River valley in the Texas panhandle, at least $80 \mathrm{~km}$ southwest of the Long View site. However, both Tecovas and Alibates may be locally available in the Canadian River gravels and Pleistocene gravel terraces in the immediate region of the Long View site. The INAA indicates that Alibates and Tecovas have individual chemical signatures for specific sources/outcrops (Boulanger and Glascock 2010; Quigg et al. 2010; Quigg et al. 2011b). Now that some tool stone source and/or outcrops are known and some chemical fingerprints are established, a limited suite of lithic materials from the Long View site were submitted to compare to the MURR database that currently includes a variety of lithic reference samples. The combined results presented in this document contribute to a broader understanding of tool stone selection processes, the chemical variability in stone from these source locales, and the distances humans have moved material around the region.

With the goal of identifying the specific production localities of the ceramic vessels from the Long View site, and their original source or sources 32 ceramic artifacts were selected for analyses from Components A and C. Two natural clay samples from Long View, and nine from surrounding sites and localities from the broader region, were also selected, experimentally tempered with local materials, and submitted to Dr. Michael Glascock at the Missouri University Research Reactor (MURR). These included 16 sherds and 3 pieces of daub from each Long View component (see Appendix G for details and results). The two natural clay samples from Long View were selected for their diversity. One sample (C-Aa = TRC554) came from an alluvial context and a buried A horizon just upstream from the site along the east margin of Dugout Creek. The second sample $(\mathrm{OCa}=\mathrm{TRC553})$ was of Ogallala Formation sediment from below the rock alignment near the middle of Component $\mathrm{C}$.

\subsubsection{Diatom Analysis}

The study of diatom has generally been linked to water quality and paleoenvironmental conditions. Here, we are hoping to explore the use of water in some of the artifacts, burned rocks, daub, and sediment from features, to better understand the presence of water and type of water used. As an introduction, diatoms are single-celled algae with a siliceous cell wall. They grow in a wide range of aerophilous habitats, including damp soils, wet plants and rocks, marshes, wetlands and mudlands, as well as in all types of aquatic habitats. Their silica cells are often preserved in sedimentary deposits. Because individual taxa have specific requirements and preferences with respect to water chemistry, hydrologic conditions, and substrate characteristics, the presence of diatoms in natural and/ or archeological contexts can provide information about the nature of the local environments. Water orientated diatoms, when present, indicate the use of water and provide a proxy measure of water quality/ degree of pollution and ultimately certain aspects of the paleoenvironment.

Eighteen samples were selected for analysis. This included 2 sediment samples from the construction fill in pithouse Feature 6, 4 pieces of daub, 2 pieces from each component, 2 sediment samples from Feature 6 pithouse in Component C, and 12 burned rocks mostly from cultural features. The samples were sent to Dr. Barbara Winsborough of Winsborough Consulting in Austin, for diatom analysis. Her detailed methods, individual sample results, and interpretations concerning the past environmental conditions and use of water with burned rocks are presented in Appendix J.

\subsubsection{Stable Carbon and Nitrogen Isotope Analyses on Bison Bones}

Stable carbon and nitrogen isotope analyses on collagen were conducted on 10 individual bison bones from Components A and C. The 10 bone samples, five from each component ranged from 8.4 to $26 \mathrm{~g}$ each, each assumed to represent an individual bison. These were submitted to Geochron Laboratories (Geochron) in Massachutes. The reported carbon isotope results, minus the fractionation affect (-5\%), provide an indication of the amount of $\mathrm{C}_{4}$ grass consumed by each individual over its life span. Combined results provide proxy data for interpreting the regional grassland communities that the animals grazed. These isotope data can be compared to other sets of similar data and in diachronic perspective, 
may also reveal changes in the regional grassland conditions over time. Because prehistoric populations relied heavily on bison throughout much of prehistory, the bison bone isotope values will also contribute to interpretations concerning isotopic values obtained from human bones from the same time periods, if such are analyzed in the future. The individual carbon and nitrogen isotope values are presented in Appendix P.

\subsubsection{X-Ray Analysis on Ceramic Sherds}

Selected sections of a number of ceramic vessels and other clay objects were subjected to x-ray analysis, specifically to view the orientation of the temper particles, to gain a greater understanding of the construction technique(s) employed in the vessel construction. Parker (2002), for example, used X-radiographs to investigate the orientation of particles in whole vessels from the Plains. Our analysis was conducted using a standard $\mathrm{x}$-ray machine normally used to view a human skeleton. Thanks to Dr. Eric Murphy at Murphy Family Chiropractic in Round Rock for providing the facilities, taking the time and interest to employ the machine, and taking multiple pictures of the samples.

As previously defined, a circular-spiral orientation is characteristic of coil construction, a randomunpatterned orientation for slab built and lump modeled vessels, and paddle and anvil construction which exhibits characteristic impact factures within the past (Parker 2002). It was anticipated that insights into the construction process would be observed.

\subsubsection{Mussel Shell Analysis}

Freshwater mussel shells and shell fragments were present in low frequencies from the cultural occupation. Most pieces were recovered from the $6.4 \mathrm{~mm}$ screens and consist predominantly of small shell fragments that lack a hinge or tooth sections.
In the laboratory, the shells were separated from other artifacts. Each piece was inspected for use modification such as rounded edges, incisions, burned, or drilled. The larger pieces were labeled in the same manner as the other artifacts. Individual samples were weighed and the weights entered into the database. Those pieces that were potentially identifiable based on the presence of one of more characteristics were compared to shells in TRC's mussel shell comparative collection and reference book on Texas mussels (Howells et al. 1996).

\subsubsection{Curation}

Cultural materials were labeled according to the 2007 curation standards of the Texas Archeological Research Laboratory (TARL) of The University of Texas at Austin. All stone tools, lithic debitage, samples of matrix from features, samples of burned rocks, field records, and photographs from the two phases of investigations are permanently curated at the Center for Archeological studies (CAS) at Texas State University in San Marcos. Two to three burned rocks from selected features and various localities are also curated. Individual artifacts and artifact lots, including all stone tools, sociotechnic items (e.g., bone beads and worked shells), debitage, burned rocks, faunal bones, and mussel shells, are in clear line seal-top plastic bags according to provenience. Upon completion of laboratory processing, cataloging, and analysis, these bags of artifacts were placed in acid-free cardboard boxes with lids for permanent curation. Small samples of sediment from various proveniences are stored in a similar fashion. Each polyethylene bag contains an archival-quality, acid-free curation tag that lists the site number, provenience data, date of excavation, excavator(s) initials, artifact type, and quantity. All original field records are on acid-free paper and placed in sheet protectors and then in acid-free reinforced file folders for curation. 


\subsection{NATURAL STRATIGRAPHY AT THE LONG VIEW SITE}

Charles D. Frederick, Brittney Gregory wand Mark Bateman

\subsection{Methods}

Stratigraphy at the Long View was examined within hand-excavated archeological test units and hand-excavated pits. Deposits were described in general accordance with methods outlined by Schoeneberger et al. (2002). Samples for laboratory analysis were generally continuous column samples that respected major stratigraphic breaks. Analysis included determination of the particle size distribution, calcium carbonate equivalent, organic carbon content, magnetic susceptibility, and both total and Mehlich 2 phosphorous content. The less than 2-mm-diameter texture analysis was performed with a Beckman-Coulter LS 13-320 Lasersizer. Samples were pretreated with 30 percent hydrogen peroxide to remove organic matter and 5 percent sodium hexametaphoshate to disperse the clays. Results of this work report percentages of sand, silt and clay, as well as by means of Folk and Ward (1957) descriptive statistics in phi values (specifically mean, median, sorting, kurtosis, skewness). Calcium carbonate equivalent was determined on a Chittick Apparatus (Dreimanis 1962; Machette 1986) and the soil organic matter content of the deposits was determined by the Walkley-Black method (Walkley and Black 1934; Magdoff et al. 1996). The reversible, low frequency mass corrected magnetic susceptibility was measured on a Bartington MS2 meter using a MS2B sensor (Gale and Hoare 1991:222-226). Two phosphorus extractions were performed, a Mehlich 2 extraction which employs acetic acid, ammonium fluoride and ammonium chloride (Mehlich 1978) and total phosphorus determined by digestion with sulphuric acid, hydrogen peroxide and hydrofluoric acid following the method outlined by Kuo (1996:872-873). Phosphorus concentrations for both methods were measured with Hach DR2700 Spectrophotometer.

The deposits were dated by means of radiocarbon (Appendix A) and optically stimulated luminescence (OSL) dating (Appendix P). Two radiocarbon samples were submitted to Beta Analytic for radiocarbon dating from bulk soil samples collected beneath eolian deposits. Sand samples for OSL dating were collected in black PVC tubes that were driven into vertical excavation walls. Details of OSL dating methods and results can be found in Appendix P, but in general terms, two OSL dating methods were employed: single aliquot and single-grain. Where the deposits exhibited sedimentary structures and there was little evidence of post-depositional pedoturbation, single aliquot dating was employed. Where the deposits were massive, and did not exhibit evidence of bedding, and/or the eolian sediments were thin, single-grain dating was used. Single-grain dating permits a clearer understanding of the age structure of the deposit, especially where post-depositional mixing has occurred. This approach was necessary to obtain useful ages at the Long View site.

\subsection{General Setting}

The Long View site is situated within the deeply incised Canadian River valley, commonly known as Canadian Breaks, in the middle of the Texas panhandle. This deeply incised valley began to form sometime in the early Pleistocene (ca. 1.5 million years ago; cf. Wisniewski and Pazzaglia 2002) or before and this process has in part been aided by karstic dissolution of Permian age bedded salts at depth (Gustavson 1986).

The Long View site occupies a broad, low relief interfluvial ridge that separates two ephemeral streams, which drain the dissected lands of the Canadian River Valley, on the north side of the Canadian River. Dugout Creek drains the lands west and north of the highway, whereas Sourdough Creek drains the lands east of the highway. The highway closely follows the drainage divide between the two streams for most of the route between the Canadian River and the High Plains surface. The southern portion of the site slopes southeastward and drains into Sourdough Creek, and the northern portion slopes north-northwest and drains into Dugout Creek.

The site is on a low relief rise that stands several meters above the roadbed, where the road has been cut into the hill as it passes across the drainage divide in this area. The road surface at the base of the road cut lies about 4- to 6-m-below the surface 
of the site and a steep slope separates the two. The site is on an 8- to 10-m-wide strip of land, between the steep slope leading down to the road cut and the fence that separates private land from the TxDOT right-of-way. A shallow linear concavity or fireguard (about 50-cm-deep and 4- to 6-m-wide) bisects the site locale north-south, and appears to have been formed by through mechanical scraping of the surface.

The natural deposits observed at the site can be divided into two major groups: the Ogallala Formation, and Quaternary eolian sediments. The Ogallala Formation comprises the bedrock of the site. Holocene eolian sediments are found on top of the Ogallala and underlie and overlay parts of the Plains Village occupation surfaces.

\subsection{Ogallala Formation}

The bedrock for the Long View site is the Miocene-Pliocene age Ogallala Formation. The Ogallala is a suite of fluvial and eolian sediments derived from erosion of the eastern slopes of the Rocky Mountains and deposited across the Great Plains. In this region, incision of the Pecos and Canadian rivers in the early Pleistocene terminated Ogallala sedimentation, after which a substantial duricrust formed in the deposits, locally referred to as Caprock Caliche. The Caprock forms the distinctive edge of the Canadian River valley, and lies about $3 \mathrm{~km}$ north of the site and at greater distances to the east and west. Erosion of the Ogallala during the Pleistocene and Holocene, in association with incision of the Canadian River, has resulted in a complex mosaic of eroded Ogallala Formation mantled by slope, fluvial and eolian deposits within the modern canyon.

In general, deposits of the Ogallala Formation range in texture from sand and gravel to clay. The deposits consisted of 7.5YR hued sandy loam to silty clay loam (specifically light brown (7.5YR 6/4, d) to brown (7.5YR 5/3 d), silty clay loam (reddish yellow (7.5YR 6/6, d), sandy loam, and loam (brown (7.5YR 5/4, d). All but the sandiest sediments exhibited well-developed compound soil structure that ranged from prismatic to subangular blocky, and most deposits exhibited a nodular calcic soil horizon containing 3 to 25 percent white irregular shaped calcium carbonate nodules and masses 1 to $5 \mathrm{~cm}$ in diameter. Most exposures of the Ogallala within the site did not exhibit an A horizon, implying that a phase of erosion preceded occupation of the site.

\subsection{Eolian Sediments}

The landscape around the Long View site contains abundant evidence of eolian deposition. This ranges from relatively discrete source border dunes adjacent to the modern and ancient creek channels, to low relief dune fields and sand sheets on the convex interfluvial ridge occupied by the site. The modern eolian deposits appear to originate at the channels of the local creeks, where sand is deflated during the dry season and blown northeastward (Figure 6-1). The eolian deposits observed in the vicinity of the Long View site would most likely be considered by Caran and Baumgardner (1990:783) as part of the Upper Lingos Formation, described as follows:

"extensive, fine-grained eolian deposits. Most of the eolian material probably was winnowed from local stream beds and floodplains during dry seasons and was redeposited on adjacent vegetated surfaces. This process still occurs in the region." (Caran and Baumgardner 1990:783).

The Lingos Formation was originally defined for the western Rolling Plains, but is directly attributable to the retreat of the Ogallala Formation Caprock Escarpment within the Canadian River valley, which forms the northern horizon as viewed from the site. The processes and deposits implicit in the definition of the Lingos Formation are also present within the Canadian Breaks and as such, the application of this formation to these deposits is considered appropriate.

Within the site, eolian sediments appear to have been deposited in a sand sheet environment, primarily after the Late Prehistoric occupation. These deposits are generally quite thin, often less than $0.5 \mathrm{~m}$ (Tables 6-1 and 6-2). Because the deposits were thin, and due to post-depositional pedoturbation, we felt that ascertaining their age would be difficult. To address this issue, we examined two profiles from off-site on private land (with the permission of the land owner). 


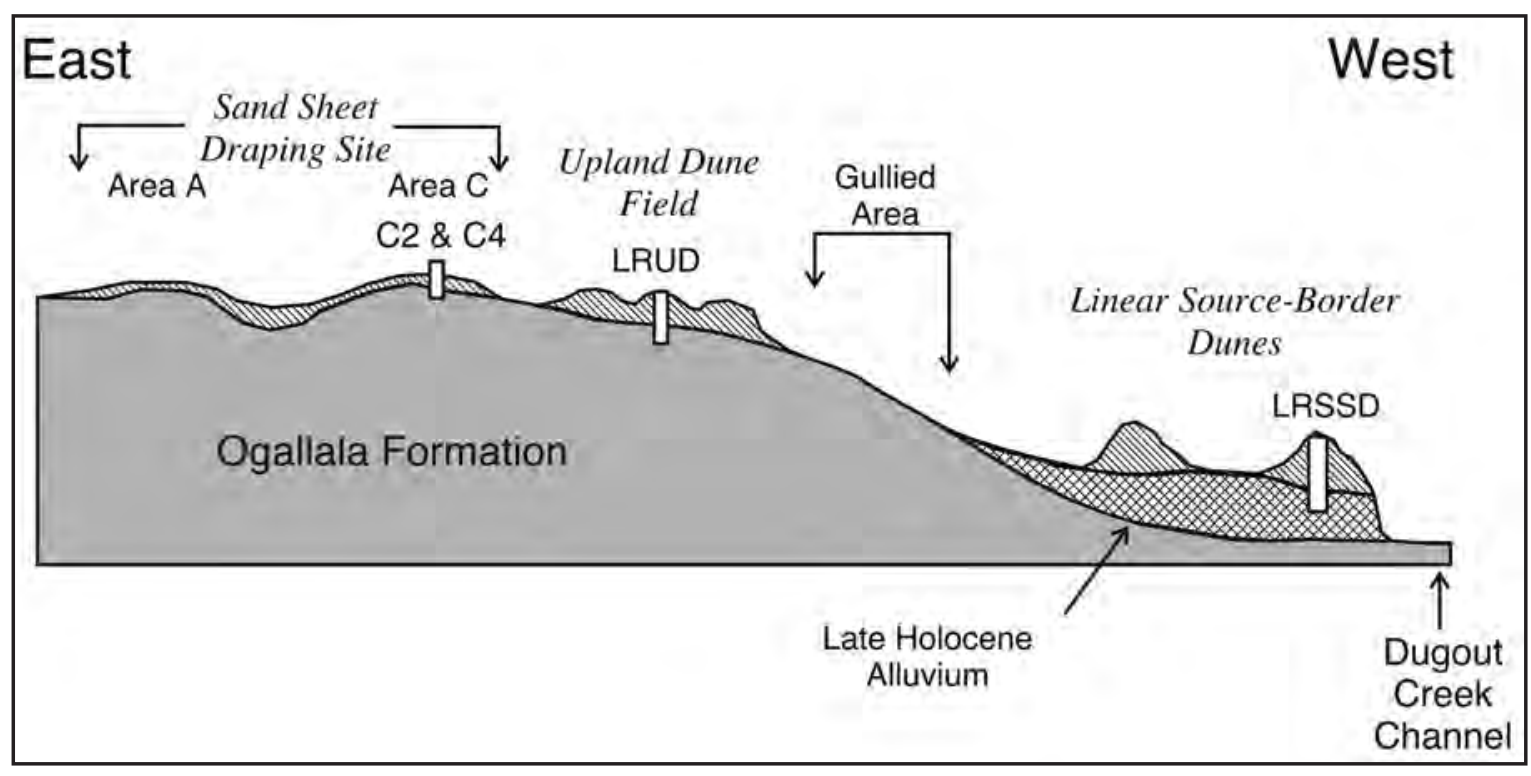

Figure 6-1. Key for locations of profiles.

The off-site profiles encompassed thicker eolian sands, which provided better dating opportunities and a more complete image of recent eolian activity. These two profiles were collected from a linear source border dune immediately adjacent to Dugout Creek (the Lipps Ranch Stream Side Dune, or LRSSD) and a small dune within a dune field that covers the drainage divide south and west of the site (Lipps Ranch Upland Dune, or LRUD; Figure 6-2; Tables 6-3 and 6-4).

Two separate eolian deposits were recognized through examinations of deposits on- and off-site, and were informally termed Eolian Sand I and Eolian Sand II. These two deposits are discussed below.

\subsubsection{Eolian Sand I (ESI)}

The oldest eolian deposit, Eolian Sand I or (ESI), was present only within site context, and comprised the lower eolian deposits where a relatively thick eolian mantle was present. Profiles C-2 and C-4, each examined within the site, revealed an ESI deposit. These two profiles were collected from the southern end of the site where the eolian sands were between 70 and 120-cm-thick. In the field, ESI sediments were light yellowish brown (10YR 6/4, d; 10YR 5/4, m) to very pale brown (10YR 7/4, d; 10YR 6/6, m) loamy sand. In one exposure, these sands were observed directly resting upon the Ogallala Formation (see profile descriptions). Neither of the exposures of ESI in these profiles exhibited significant pedogenic alteration which would normally show that they were much older than the overlying late Holocene eolian sands. One of the exposures contained 1 to 3 percent of widely dispersed calcium carbonate nodules eroded from the Ogallala Formation, implying this deposit experienced a greater amount of post-depositional pedoturbation.

Luminescence dating indicated that ESI was most likely deposited between 37,000 and 64,000 years ago, and has experienced a complex post-depositional history. In Profile C-2, an OSL sample collected at a depth of $90 \mathrm{~cm}$ (Shfd-10175) yielded a single-grain OSL age distribution that was polymodal and had four different age components identified by finite mixture modeling. The majority (59 percent) of dated grains were associated with two components that dated 37,780 \pm 4660 years B.P. (24 percent) and $64,710 \pm 5450$ years B.P. (35 percent). The oldest is thought to represent the depositional age of this portion of the deposit. However, the polymodal age distribution yielded by the OSL single-grain dating clearly demonstrates that this deposit has had a complex post-depositional history and has been adversely affected by pedoturbation. 
Table 6-1. Column 2 (C-2) Collected from West Side of Fireguard, Adjacent to TxDOT RightOf-Way Fence, Where Eolian Mantle Appeared Relatively Thick.

\begin{tabular}{|c|c|c|c|c|}
\hline Zone & Horizon & $\begin{array}{l}\text { Depth } \\
\text { (cmbs) }\end{array}$ & Description & Interpretation \\
\hline 1 & A & $0-22$ & $\begin{array}{l}\text { Very dark grayish brown (10YR 3/2, m) sandy loam, very } \\
\text { friable, weak coarse prismatic parting to weak medium } \\
\text { subangular blocky structure, gradual smooth boundary, } \\
\text { slightly effervescent, many roots; OSL sample from near } \\
\text { base of zone at depth of } 20 \text { cm yielded a single-grain age } \\
\text { distribution that finite mixture modeling identified three } \\
\text { components } 410 \pm 50 \text { years B.P. ( } 63 \% \text { of the grains), } 1600 \\
\pm 210 \text { years B.P. ( } 14 \% \text { of the grains), and } 9750 \pm 710 \text { years } \\
\text { B.P. ( } 24 \% \text { of the grains), youngest thought to represent } \\
\text { depositional age (Shfd-10174). }\end{array}$ & Eolian Sand II \\
\hline 2 & $\mathrm{AC}$ & $22-78$ & $\begin{array}{l}\text { Yellowish brown ( } 10 \text { YR } 5 / 4, d ; 10 Y R \text { R/3, m) sandy loam to } \\
\text { loamy sand, very friable, weak medium subangular blocky } \\
\text { structure, strongly effervescent, few krotovina; OSL sample } \\
\text { from near the middle of zone at depth of } 50 \mathrm{~cm} \text { yielded an } \\
\text { single-grain age distribution that finite mixture modeling } \\
\text { identified three components } 680 \pm 60 \text { years B.P. ( } 70 \% \text { of the } \\
\text { grains), } 1530 \pm 200 \text { years B.P. ( } 19 \% \text { of the grains), and } 6000 \\
\pm 580 \text { years B.P. ( } 11 \% \text { of the grains), youngest thought to } \\
\text { represent depositional age (Shfd-10173). }\end{array}$ & Eolian Sand II \\
\hline 3 & $\mathrm{C}$ & $78-120$ & $\begin{array}{l}\text { Light yellowish brown (10YR 6/4, d; } 10 \text { YR 5/4, m) loamy } \\
\text { sand to sandy loam, very friable, massive to single-grain, } \\
\text { moderately effervescent, few krotovina; OSL sample from } \\
\text { near base of zone at depth of } 90 \mathrm{~cm} \text { yielded a single-grain } \\
\text { age distribution that finite mixture modeling identified four } \\
\text { components } 8190 \pm 1020 \text { years B.P. (11\% of the grains), } \\
15,770 \pm 1550 \text { years B.P. ( } 21 \% \text { of the grains), } 37,780 \pm \\
4660 \text { years B.P. ( } 24 \% \text { of the grains), and } 64,710 \pm 5450 \\
\text { years B.P. ( } 35 \% \text { of the grains), oldest thought to represent } \\
\text { depositional age (Shfd-10175). }\end{array}$ & Eolian Sand I \\
\hline
\end{tabular}

*Note: stone alignment was in the top $20 \mathrm{~cm}$. Single-grain OSL data, with all three ages exhibiting polymodal age distributions, showed this deposit was considerably disturbed at a granular level. Although no break in the profile was visibly obvious, the lower deposit (Zone 3) was older, as confirmed by OSL. 
Table 6.2. Column 4 (C-4) Collected from East of Fireguard, Next to the Road Cut at Feature 18.

\begin{tabular}{|c|c|c|c|c|}
\hline Zone & Horizon & $\begin{array}{l}\text { Depth } \\
\text { (cmbs) }\end{array}$ & Description & Interpretation \\
\hline 1 & C & $0-19$ & $\begin{array}{l}\text { Brown (10YR 5/3, d; } 10 \text { YR 3/2, m) sandy loam, very } \\
\text { friable, moderate medium subangular blocky structure, } \\
\text { abrupt smooth boundary, strongly effervescent, many roots, } \\
\text { many worm casts. }\end{array}$ & $\begin{array}{l}\text { Disturbed fireguard } \\
\text { deposit }\end{array}$ \\
\hline 2 & $\mathrm{C}$ & $19-21$ & $\begin{array}{l}\text { Light yellowish brown (10YR 6/4, d; } 10 \text { YR 4/3, m) sandy } \\
\text { loam, very friable, massive, abrupt discontinuous boundary, } \\
\text { laminated in places. }\end{array}$ & $\begin{array}{l}\text { Sheetwash } \\
\text { associated with } \\
\text { disturbed Fireguard }\end{array}$ \\
\hline 3 & 2Ab1 & $21-42$ & $\begin{array}{l}\text { Brown (10YR 5/3, d; } 10 \text { YR 4/2, m) sandy loam, very } \\
\text { friable, weak extremely coarse prismatic structure, clear } \\
\text { smooth boundary, strongly effervescent, few krotovina, } \\
\text { more massive than Zone } 4 \text {; OSL sample from depth of } 30 \\
\text { cm (Shfd-10176) yielded a single-grain age distribution } \\
\text { from which finite mixture modeling identified three age } \\
\text { components, } 400 \pm 110 \text { years B.P. ( } 64 \% \text { of the grains, } \\
\text { considered the depositional age of the deposit), } 810 \pm 200 \\
\text { years B.P. ( } 25 \% \text { of the grains), and } 2880 \pm 330 \text { years B.P. } \\
\text { (11\% of the grains). }\end{array}$ & Eolian Sand II \\
\hline 4 & $2 \mathrm{Ab} 2$ & $42-71$ & $\begin{array}{l}\text { Brown (10YR 5/3, d; } 10 \text { YR 4/3, m) sandy loam, very } \\
\text { friable, moderate coarse prismatic structure, gradual smooth } \\
\text { boundary, strongly effervescent, many ant/worm passages, } \\
\text { few larger krotovina, few charcoal fragments and sherds in } \\
\text { the top } 10 \mathrm{~cm} \text { of the zone. }\end{array}$ & Eolian Sand II \\
\hline 5 & $3 \mathrm{C}$ & $71-88$ & $\begin{array}{l}\text { Very pale brown (10YR 7/4, d; } 10 Y R \text { } 6 / 6, \mathrm{~m}) \text { loamy sand, } \\
\text { very friable, massive, abrupt smooth to wavy boundary, } \\
\text { strongly effervescent, few krotovina, few }(1-3 \%) \text { coarse } \\
\text { fragments; OSL sample from a depth of } 80 \mathrm{~cm} \text { yielded a } \\
\text { single-grain age distribution that finite mixture modeling } \\
\text { identified two age components, } 38,750 \pm 2400 \text { years B.P. } \\
\text { ( } 81 \% \text { of the grains) and } 530 \text { years B.P. ( } 10 \% \text { of the grains), } \\
\text { older of the two thought to represent the depositional age. }\end{array}$ & Eolian Sand I \\
\hline 6 & $4 \mathrm{Bk}$ & $88-110$ & $\begin{array}{l}\text { Light brown }(7.5 Y R \text { 6/4, d; } 7.5 Y R \text { R/4, m) loam, sandy } \\
\text { loam and silt loam, very friable, weak to moderate } \\
\text { columnar structure, strong to violently effervescent, many } \\
\text { (20-30\%) coarse 3-7 cm white irregular calcium carbonate } \\
\text { nodules. }\end{array}$ & Ogallala Formation \\
\hline
\end{tabular}




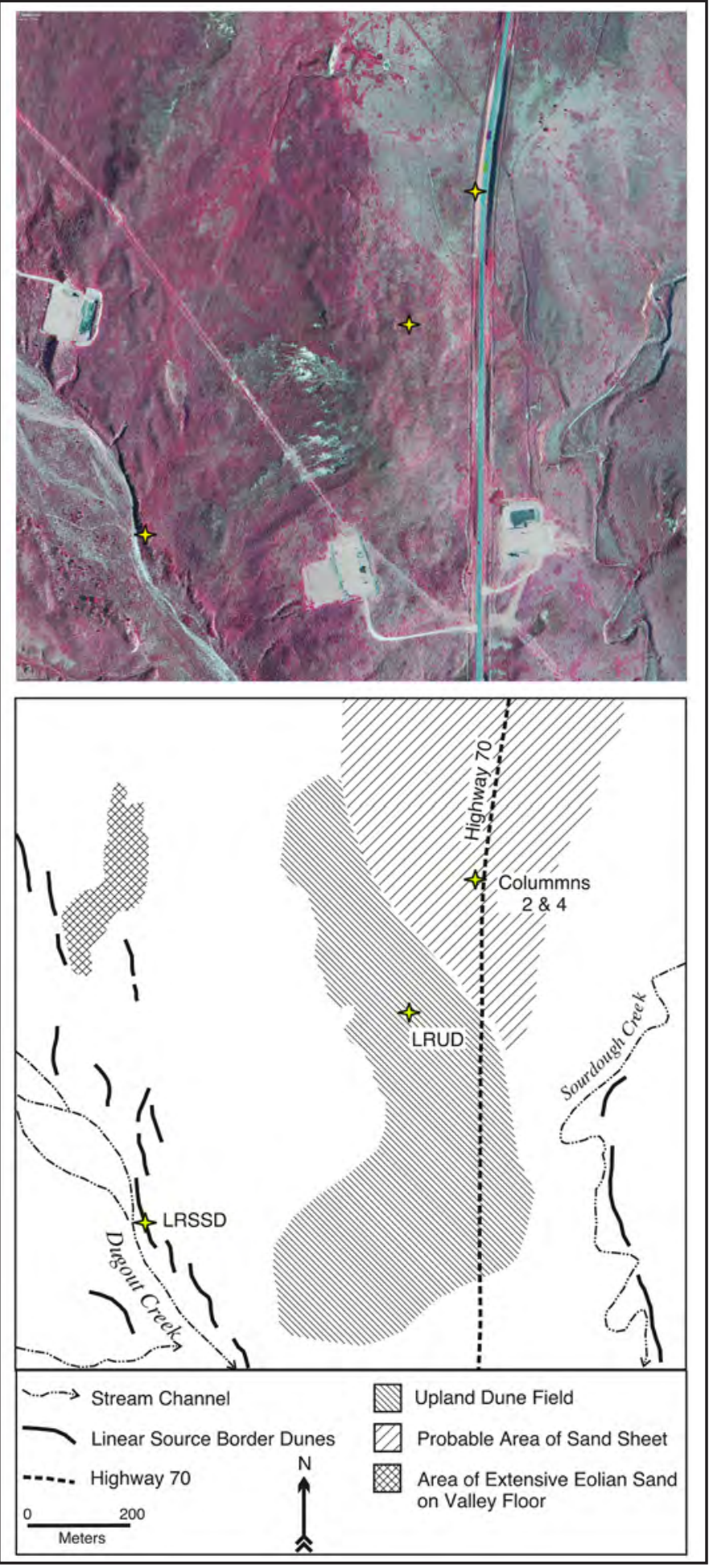

Figure 6-2. Top Panel: A $1.72 \mathrm{~km}^{2}$ false color aerial photograph of the Long View Site and vicinity taken on July 1, 2004, obtained from Terraserver. Lower Panel: Map compiled of selected eolian geomorphic features in vicinity of the Long View Site compiled from the aerial image shown in the upper panel. Stars show the locations of the profiles discussed in the text. 
Table 6-3. Lipps Ranch Stream Side Dune (LRSSD) Profile from Hand-Excavated Stair Step Profile Through 3-to-4-m-Tall Dune Situated Adjacent to the Active Channel of Dugout Creek about $900 \mathrm{~m}$ Southwest of the Southern End of 41RB112.

\begin{tabular}{|c|c|c|c|c|}
\hline Zone & Horizon & $\begin{array}{l}\text { Depth } \\
\text { (cmbs) }\end{array}$ & Description & Interpretation \\
\hline 1 & $\mathrm{C}$ & $0-67$ & $\begin{array}{l}\text { Very pale brown }(10 Y R \text { R } 7 / 4, d) \text { sand, loose, single-grain, } \\
\text { abrupt smooth boundary, many krotovina, few faint } \\
\text { discontinuous horizontal bedding planes; a single-grain OSL } \\
\text { sample collected from } 60 \mathrm{~cm} \text { depth yielded finite mixture } \\
\text { model ages of } 100 \pm 20 \text { years B.P. (20\% of the grains) and } 440 \\
\pm 60 \text { years B.P. ( } 76 \% \text { of the grains). The younger age mode is } \\
\text { considered most likely depositional age (Shfd-10167). }\end{array}$ & \begin{tabular}{|l} 
Eolian Sand II \\
\end{tabular} \\
\hline 2 & $\mathrm{C}$ & $67-92$ & $\begin{array}{l}\text { Light yellowish brown-very pale brown (10YR 6.5/4, d) sand, } \\
\text { loose, single-grain, abrupt smooth boundary, few (1\%) calcium } \\
\text { carbonate filaments, prominent horizontal laminations, few } \\
\text { krotovina. }\end{array}$ & Eolian Sand II \\
\hline 3 & $\mathrm{C}$ & $92-115$ & $\begin{array}{l}\text { Pale brown (10YR } 6 / 3, \mathrm{~d}) \text { sand, loose to slightly hard, } \\
\text { single-grain, abrupt smooth boundary, prominent low angle } \\
\text { foresets dipping } 10^{\circ} \text { to the northeast, few of the laminae are } \\
\text { distinctly darker color (reworked sand from Zone 4); a single } \\
\text { aliquot OSL age of } 100 \pm 20 \text { years B.P. obtained at a depth of } \\
110 \mathrm{~cm} \text { (Shfd-10168). }\end{array}$ & Eolian Sand II \\
\hline 4 & Akb & $115-160$ & $\begin{array}{l}\text { Pale brown (10YR 6/3, d) sand, loose to slightly hard, } \\
\text { single-grain, abrupt smooth boundary, appears slightly darker } \\
\text { than bounding zones, inferred in field to be a weak A-horizon, } \\
\text { lab work confirmed very slight increase in organic matter and } \\
\text { magnetic susceptibility; OSL dates suggest this surface may } \\
\text { have been stable for almost } 200 \text { years. }\end{array}$ & Eolian Sand II \\
\hline 5 & C & $160-240$ & $\begin{array}{l}\text { Very pale brown (10YR 7/4, d) sand, loose, single-grain, } \\
\text { abrupt smooth boundary, appears massive; a single-grain } \\
\text { OSL sample collected from a depth of } 180 \mathrm{~cm} \text { yielded two } \\
\text { finite mixture model ages ( } 270 \pm 40 \text { years B.P. }(80 \% \text { of } \\
\text { grains) and } 740 \pm 210 \text { years B.P. ( } 19 \% \text { of grains), the younger } \\
\text { is considered to represent the age at time of transportation } \\
\text { (Shfd-10169). }\end{array}$ & Eolian Sand II \\
\hline 6 & $\mathrm{C}$ & $240-275$ & $\begin{array}{l}\text { Very pale brown (10YR 7/4, d) sand, loose, single-grain, } \\
\text { abrupt smooth boundary, few (1-3\%) calcium carbonate } \\
\text { filaments, prominent low angle foresets dipping } 1-3^{\circ} \text { to the } \\
\text { east; a single aliquot OSL age of } 350 \pm 20 \text { years B.P. obtained } \\
\text { at a depth of } 260 \mathrm{~cm} \text { (Shfd-10170). }\end{array}$ & Eolian Sand II \\
\hline 6 & $\mathrm{C}$ & $240-275$ & $\begin{array}{l}\text { Very pale brown (10YR 7/4, d) sand, loose, single-grain, } \\
\text { abrupt smooth boundary, few (1-3\%) calcium carbonate } \\
\text { filaments, prominent low angle foresets dipping } 1-3^{\circ} \text { to the } \\
\text { east; a single aliquot OSL age of } 350 \pm 20 \text { years B.P. obtained } \\
\text { from a depth of } 260 \mathrm{~cm} \text { (Shfd-10170). }\end{array}$ & Eolian Sand II \\
\hline
\end{tabular}


Table 6-3 (continued). Lipps Ranch Stream Side Dune (LRSSD) Profile from Hand-Excavated Stair Step Profile Through 3-to-4-m-Tall Dune Situated Adjacent to the Active Channel of Dugout Creek about $900 \mathrm{~m}$ Southwest of the Southern End of 41RB112.

\begin{tabular}{|c|c|c|c|c|}
\hline 7 & $\mathrm{C}$ & $275-324$ & $\begin{array}{l}\text { Very pale brown (10YR } 7 / 4, \mathrm{~d} ; 10 \mathrm{YR} 6 / 4, \mathrm{~m}) \text { sand to loamy } \\
\text { sand, very friable to loose, single-grain, abrupt wavy boundary, } \\
\text { few }(1-3 \%) \text { calcium carbonate filaments, top half of zone is } \\
\text { slightly coarser textured, lower half of zone exhibits several } \\
\text { medium beds; a single aliquot OSL age of } 370 \pm 20 \text { years B.P. } \\
\text { obtained at a depth of } 310 \mathrm{~cm} \text { (Shfd-10171). }\end{array}$ & Eolian Sand II \\
\hline 8 & 2Bk1 & $324-344$ & $\begin{array}{l}\text { Very pale brown (10YR } 7 / 3 \text {, d; } 7.5 Y R 5 / 4, \text { m) silt loam, } \\
\text { friable, moderate medium to coarse subangular blocky } \\
\text { structure, abrupt smooth boundary, common ( } 5-7 \% \text { ) calcium } \\
\text { carbonate filaments, few thin discontinuous coats of calcium } \\
\text { carbonate on ped faces, traces of a thin bed of sand within the } \\
\text { middle of this zone. }\end{array}$ & $\begin{array}{l}\text { Late Holocene } \\
\text { Alluvium }\end{array}$ \\
\hline 9 & 2Bk2 & $344-364$ & $\begin{array}{l}\text { Light yellowish brown (10YR 6/4, d; } 7.5 Y R \text { R/4, m) loam, } \\
\text { very friable, moderate medium prismatic structure parting to } \\
\text { moderate medium subangular blocky structure, abrupt wavy } \\
\text { boundary, common ( } 5 \% \text { ) calcium carbonate filaments, few thin } \\
\text { discontinuous coats of calcium carbonate on ped faces and } \\
\text { lining channels and pores; a bulk sediment sample collected } \\
\text { from } 344-349 \text { cm yielded an age of cal B.P. } 3300-3260 \text { (3110 } \pm \\
30 \text { years B.P., Beta-297506). }\end{array}$ & $\begin{array}{l}\text { Late Holocene } \\
\text { Alluvium }\end{array}$ \\
\hline 10 & BC & $364-367$ & $\begin{array}{l}\text { Reddish yellow }(7.5 Y R \text { R/6, m) silt loam, very friable, } \\
\text { massive, abrupt wavy boundary, few }(1-3 \%) \text { calcium carbonate } \\
\text { filaments, a single very thin wavy bed. }\end{array}$ & $\begin{array}{l}\text { Late Holocene } \\
\text { Alluvium }\end{array}$ \\
\hline 11 & BC & $367-380$ & $\begin{array}{l}\text { Strong brown }(7.5 Y R \text { R/6, m) loam, very friable, moderate } \\
\text { coarse subangular blocky structure, abrupt smooth boundary, } \\
\text { few ( } 3 \% \text { ) calcium carbonate filaments. }\end{array}$ & $\begin{array}{l}\text { Late Holocene } \\
\text { Alluvium }\end{array}$ \\
\hline 12 & BC & $380-400$ & $\begin{array}{l}\text { Strong brown }(7.5 Y R \text { 5/6, m) sandy loam, very friable, } \\
\text { moderate medium prismatic structure parting to moderate } \\
\text { medium subangular blocky structure. }\end{array}$ & $\begin{array}{l}\text { Late Holocene } \\
\text { Alluvium }\end{array}$ \\
\hline
\end{tabular}


Table 6-4. Profile of Lipps Ranch Upland Dune (LRUD) from Hand-Excavation in a Series of Low Relief Sand Dunes Adjacent to the Site.

\begin{tabular}{|c|c|c|l|l|}
\hline Zone & Horizon & $\begin{array}{c}\text { Depth } \\
\text { (cmbs) }\end{array}$ & \multicolumn{1}{|c|}{ Description } & Interpretation \\
\hline 1 & A & $0-24$ & $\begin{array}{l}\text { Brown (10YR 4/3, d) loamy sand, slightly hard, weak } \\
\text { medium to coarse subangular blocky structure, gradual } \\
\text { smooth boundary. }\end{array}$ & Eolian Sand II \\
\hline 2 & C & $24-50$ & $\begin{array}{l}\text { Light yellowish brown (10YR 6/3, d) sand, slightly hard } \\
\text { to loose, weak medium subangular blocky structure to } \\
\text { single-grain, clear smooth boundary, no obvious bedding. }\end{array}$ & Eolian Sand II \\
\hline 3 & C & $50-134$ & $\begin{array}{l}\text { Light yellowish brown (10YR 6/3, d) sand, loose, single- } \\
\text { grain, abrupt wavy boundary, prominent horizontal } \\
\text { laminations, occasional ripple laminations, few (1-3\%) } \\
\text { calcium carbonate filaments in the lower half of the zone. }\end{array}$ & Eolian Sand II \\
\hline 4 & 2 Ab & $134-170$ & $\begin{array}{l}\text { Light yellowish brown (10YR 6/3, d) sandy loam, slightly } \\
\text { hard, moderate coarse subangular blocky structure, clear } \\
\text { smooth boundary, few (3\%) coarse fragments, few (3\%) } \\
\text { calcium carbonate filaments, common continuous coats of } \\
\text { calcium carbonate on ped faces, shaved face looks darker } \\
\text { in color than broken peds, and appeared to have a lower } \\
\text { value than Munsell value indicates. }\end{array}$ & Ogallala Formation \\
\hline 5 & $2 B k$ & $170-200$ & $\begin{array}{l}\text { Brownish yellow (10YR 6/6, d) slightly gravelly sandy } \\
\text { loam, slightly hard, weak coarse subangular blocky } \\
\text { structure, 20-30\% coarse fragments which are primarily } \\
\text { sharp edged calcium carbonate nodules (0.3 to 5 cm in } \\
\text { diameter, irregular shaped, white) which may be reworked } \\
\text { or currently degrading. }\end{array}$ & Ogallala Formation \\
\hline
\end{tabular}


The basal eolian sand in Profile C-4 was sampled for OSL dating at a depth of $80 \mathrm{~cm}$ (Shfd-10177) and the single-grain age distribution of this sample was less complex than in Profile C-2, with finite mixture modeling identifying only two age components: $38,750 \pm 2400$ years B.P. (81 percent of the grains) and 530 years B.P. (10 percent). As in Profile C-2, the old grain age component in this sample (a total of 41 grains) exhibits a wide range of grain ages (4047 to 86,776 years B.P.). The young age component identified in this sample is consistent with the age of the Eolian Sand II (ESII) discussed below.

Although it is tempting to explain these old OSL ages away by citing pedoturbation of the Ogallala Formation, the granulometric attributes of ESI deposits are nearly identical to the late Holocene ESII sediments and are consistent with deposition in a sand sheet environment. In Profile C-4, where ESII was observed resting upon the Ogallala Formation, the deposit exhibits significantly different granulometric attributes from the Ogallala Formation deposits immediately beneath it. The fact that both profiles yielded similar grain age ranges implies that a significant amount of eolian deposition most likely occurred around 38,000 years ago. These broad age distributions could also indicate a long period of very incremental eolian sedimentation during the last glaciation. However, one would expect a significant soil to have formed in such a deposit and that is lacking here, suggesting that such a soil must have completely eroded prior to the deposition of ESII.

\subsubsection{Eolian Sand II (ESII)}

The majority of eolian sand examined and dated is attributable to a phase of deposition that began by A.D. 1500, and perhaps as early as A.D. 1150 and continues to this day. These sands, referred to as Eolian Sand II or ESII, were identified in three different eolian depositional environments, the source border dunes, an upland dune field, and in the sand sheet environment around the site.

\subsection{Riverine Source Border Dunes}

One of the more conspicuous features of the tributaries to the Canadian River in this region is the prominent linear source border dunes adjacent to the present stream channels. Slightly older source border dunes delineate now-abandoned stream channels. Dunes that form adjacent to river channels have been noted as distinct stratigraphic elements for nearly a century (cf. Haltenberger 1913). They are now recognized as a species of dune that forms adjacent to its sediment sources (in contrast to dunes found in lacustrine environments (lunettes) and marginal marine environments (coastal foredunes; cf. Page et al. 2001:187). Figure 6-2 depicts the spatial distribution of several source border dunes adjacent to Dugout Creek and Sourdough Creek. They are generally found on the northeast side of the stream channels. In the field these dunes are generally well-vegetated, less than 4-m-tall, about 10-m-wide and up to 150 -m-long.

A single source border dune (Lipps Ranch Stream Side Dune or LRSSD) located immediately adjacent to Dugout Creek was examined by a series of hand-excavated stair-step exposures cut into the west side of the dune. This excavation revealed about 3.2 $\mathrm{m}$ of eolian sand resting unconformably upon late Holocene alluvium (Figure 6-3). The dune lies about $10 \mathrm{~m}$ from the channel of Dugout Creek and about $900 \mathrm{~m}$ from the Long View site. Another, presumably older (no longer bordering an active stream channel) source border dune was observed immediately to the west of this dune, but this was not sampled.

The alluvium beneath the dune is Late Holocene, based on radiocarbon dating of a bulk sediment sample collected from near the top of the alluvium, within a Bk horizon at a depth of 344 to $349 \mathrm{~cm}$. The sample yielded an age of cal B.P. 3300 to 3260 (3110 \pm 30 years B.P.; Beta-297506). These alluvial deposits were of significantly finer texture (primarily silt loam and loam), and contained greater amounts of calcium carbonate and organic carbon than the overlying eolian sands. The upper portion of the alluvium was a calcic (Bk) horizon, and contained significantly more calcium carbonate than the underlying sediments.

The eolian sediments in this profile appear to have been deposited in two phases. The first phase started around 370 years B.P. and continued until sometime shortly after 270 years B.P., after which the dune briefly stabilized, and a very incipient A horizon formed. About $2 \mathrm{~m}$ of sand was deposited during this 


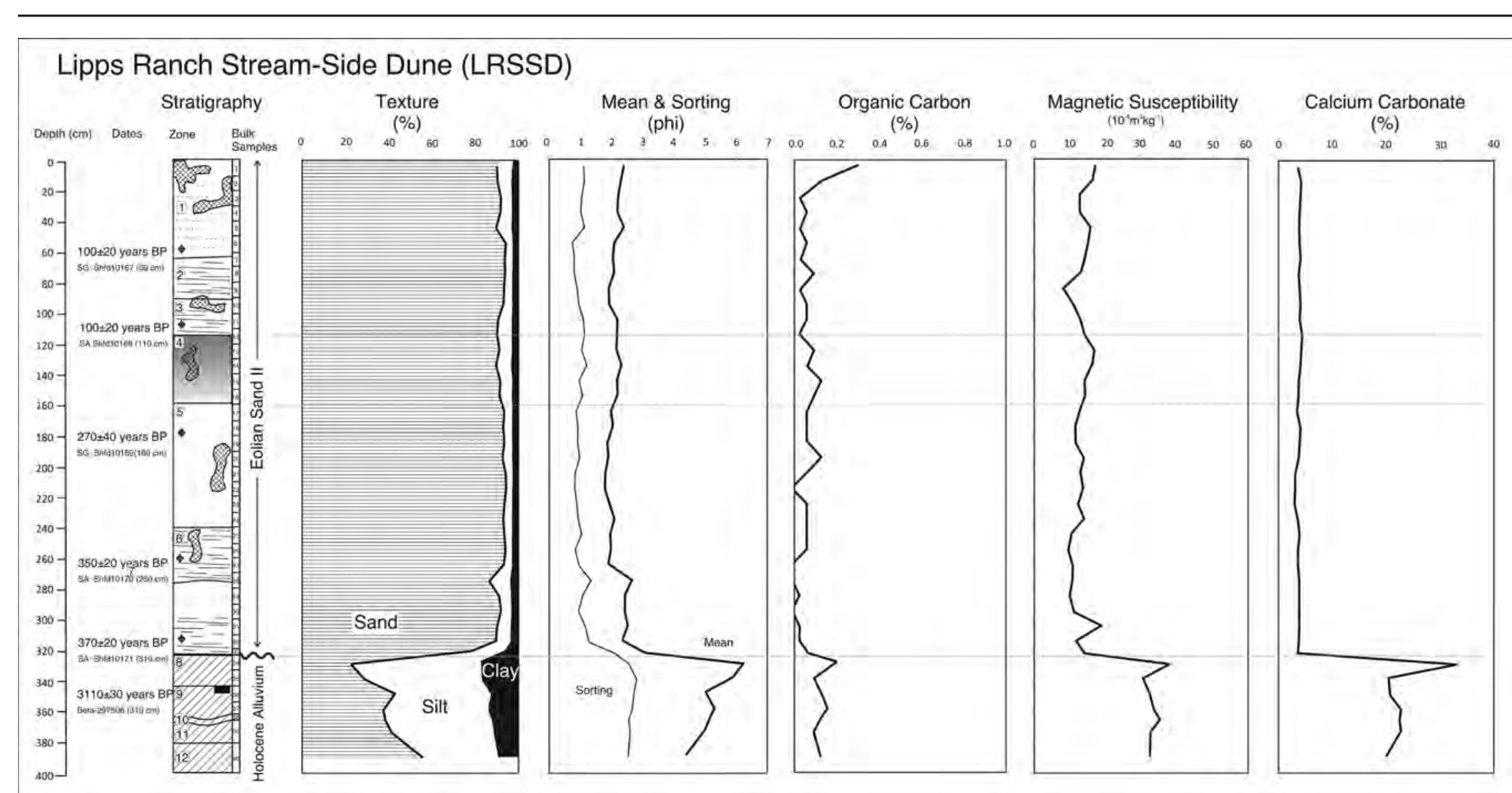

Figure 6-3. Stratigraphy, age, and depth variation in basic physical properties observed at the Lipps Ranch Stream Side Dune (LRSSD) locality. 
period. Sedimentation resumed around 100 years ago and deposition during this phase added about 1.2 $\mathrm{m}$ of sand to the dune crest. The deposits associated with this dune are generally very pale brown (10YR $7 / 4$, d) to pale brown (10YR 6/3, d) sand which is often laminated. The dune sand contains between 3 and 5 percent calcium carbonate, significantly less than the underlying alluvium (20 to 33 percent) and the Ogallala Formation (generally 10 to 20 percent). The paleosol separating the two phases of deposition is very faintly melanized pale brown (10YR 6/3, d, distinctly darker than the bounding deposits), and exhibits slightly greater amounts of organic carbon and a slight magnetic susceptibility enhancement.

\subsection{Upland Dune Field}

The western slopes of the interfluvial ridge do not exhibit any obvious eolian features. The crest of the ridge west and south of the site is occupied by a dune field. On some aerial photos thick stands of sagebrush are apparent, although today no sage is present, as it was burned sometime in the recent past. Charred stems and branches are still readily found throughout this area.

The dunes are generally less than 1.5-m-tall, roughly oriented northwest to southeast, and are separated by relatively broad, irregularly shaped blowout depressions. The dunes are generally rather flat topped and none retain clear slip faces. Today the dunes are densely vegetated by grass, and are not active.

A single pit was hand-excavated into the crest of one dune about $700 \mathrm{~m}$ northeast of the channel of Dugout Creek and about $200 \mathrm{~m}$ southwest of the Long View site. This 2-m-deep pit revealed 1.3 $\mathrm{m}$ of eolian sand that rested unconformably upon the Ogallala Formation (see Figure 6-3). Like the streamside dune (LRSSD), the eolian sands exposed here were generally light yellowish brown (10YR $6 / 3, d)$, and were prominently laminated in most places. An incipient, 24-cm-thick brown (10YR 4/3, d) loamy sand A horizon had formed and exhibited weak subangular blocky structure.

Three OSL samples were collected from this deposit. Two were dated using the single aliquot method and one was dated using the single-grain method. The lowest sample (Shfd-10164), recovered from 1.2 $m$ depth near the base of the eolian sediments, had polymodal single aliquot age distribution, which suggests it has been disturbed since deposition or the grains were inadequately reset during transportation. Finite mixture modeling of the distribution identified five components. The youngest of these, at $800 \pm$ 60 years B.P. (36 percent of the dated aliquots), is representative of the age of transportation.

A sample collected from 60-cm-deep (Shfd-10165) was also dated using the single aliquot method and yielded an age of $390 \pm 20$ years B.P. This sample exhibited a bimodal age structure where 91 percent of the aliquots comprised the dominant, younger age mode. Only two aliquots were rejected from the age calculation, both close in age (885 to 907 years B.P.).

A third OSL sample collected from a depth of $30 \mathrm{~cm}$ (Shfd-10166) was dated by the single-grain method. This sample yielded two modes, one of which represented the transportation of the sand and dated $450 \pm 50$ years B.P. and a second that consisted of 16 percent zero dose grains (grains that have been reset so recently that they have no measureable age). This suggests that there is significant pedoturbation of this deposit. Although this age is older than the sample collected from $60 \mathrm{~cm}$, the two ages overlap at both one and two standard deviations and should be considered statistically similar.

The dune was deposited on the former ground surface formed within the Ogallala Formation and exhibited an A-Bk soil profile. A bulk sample collected from the top of this buried soil yielded an age of $1230 \pm 30$ B.P. (Beta-297507; $\delta^{13} \mathrm{C}=-24.0 \%$; cal B.P. 1300 to 1180 ; cal A.D. 650 to 770 ) that provides a maximum age for dune formation. Surprisingly, the stable carbon isotope composition of this soil suggests that the upland at this time was vegetated by $\mathrm{C}_{3}$ vegetation.

OSL samples from this dune suggest that sedimentation began around 800 years ago (A.D. 1146 to 1266) upon a surface with brush and/or trees, and continued until sometime after 390 years B.P. (A.D. 1596 to 1636). The lack of evidence of soil development within the dune deposits except at the top of the profile suggests that deposition was more or less constant and too rapid for soil development to occur. 


\subsection{Upland Sand Sheet}

An eolian sand sheet abuts the upland dune field on the northeast and is broad, relatively featureless, and lacks evidence of dunal topography normally associated with eolian sand sheets. This eolian depositional environment is represented at the site. Two profiles observed within the southern portion of the site were OSL dated for comparison with off-site profiles. Profile C-2 was collected from the area of the stone alignment adjacent to the fence that bounds the western edge of the TxDOT right-of-way. Profile C-4 was collected on the eastern side, immediately overlooking the highway road cut. The eolian mantle in this portion of the site appeared to thicken to the east. This trend may be due to the ground surface beginning to slope southeastward towards Sourdough Creek.

Unlike the dune sands, which exhibited minimal pedogenic alteration and often displayed bedding, the late Holocene ESII deposits in the sand sheet setting typically exhibited cumulic A horizons. Upon closer examination these A horizons showed decreasing amounts of organic carbon with increased depth, moderate magnetic susceptibility enhancement, and a very minor leaching of calcium carbonate at the very top of the profile (Figure 6-4). Profiles C-2 and C-4 also exhibited a slight fining upward texture defined by a gradual increase in silt throughout the deposition of the ESII. The reason for this shift in texture is unknown.

The A horizon formed at the top of the ESII deposits ranged from a very dark grayish brown (10YR 3/2, m) sandy loam in Profile C-2 to a brown (10YR 5/3, d; 10 YR 4/2, m) sandy loam in Profile C-4. The core of this deposit ranged from a yellowish brown (10YR 5/4, d; 10YR 4/3, m) sandy loam to loamy sand in Profile C-2 to a brown (10YR 5/3, d; 10YR $4 / 3, \mathrm{~m})$ sandy loam in Profile C-4. Neither deposits exhibited evidence of bedding and graded almost imperceptibly to ESI at depth.

Two OSL samples were collected from the ESII in Profile C-2, one at a depth of $20 \mathrm{cmbs}$ (Shfd-10174) and a second at $50 \mathrm{cmbs}$ (Shfd-10173). The sample from 50 cmbs yielded a single-grain age distribution with three different age components, the youngest of which is presumed to represent the age of transportation. These components dated $680 \pm 60$ years B.P. (70 percent of the grains), $1530 \pm 200$ years B.P. (19 percent of grains) and $6000 \pm 580$ years B.P. (11 percent of grains). The sample collected from $20 \mathrm{cmbs}$ also yielded a single-grain age distribution from which finite mixture modeling identified three components: $410 \pm 50$ years B.P. (63 percent of the grains), $1600 \pm 210$ years B.P. (14 percent of grains), and $9750 \pm 710$ years B.P. (24 percent of grains). Like the lower sample, the youngest of these is thought to represent the depositional age of this portion of the deposit. A single OSL sample was collected from the ESII deposits in Profile C-4 from a depth of $30 \mathrm{cmbs}$ (Shfd-10176). Like the other samples within the sand sheet setting, the single-grain age distribution exhibited significant scatter and finite mixture modeling was used to identify different age components within the data. Three such components were identified and the youngest of these, $400 \pm 110$ years B.P. is thought to represent the depositional age of the sediment and is represented by 64 percent of the dated sand grains. The next older component, $810 \pm 200$ years B.P. is represented by 25 percent of the dated grains, and the oldest, $2880 \pm 330$ years B.P. is represented by 11 percent of the dated grains.

Hence, the one sigma OSL data from the sand sheet environment indicates that deposition may have begun as early as A.D. 1260 and continued to aggrade beyond A.D. 1715. Sedimentation rates were much slower than in the dunes. At $0.5 \mathrm{~mm}$ to $1 \mathrm{~mm}$ per year, sedimentation would most likely have been fairly imperceptible unless the actual deposition was episodic.

\subsection{Patterns of Deposition}

The dating and documentation of the eolian deposits at Long View and surrounding area present a relatively clear image of recent eolian activity in the last millennium. These deposits appear to be the result of wind erosion of sand from the channel of Dugout Creek. They were deposited in three distinct eolian facies within the Canadian River valley; 1) riverine source border dunes, 2) upland dunes, and 3) sand sheets. No compositional work was performed to source the sand, but the spatial match between the three eolian suites is relatively direct, and indicates that southwesterly winds erode 


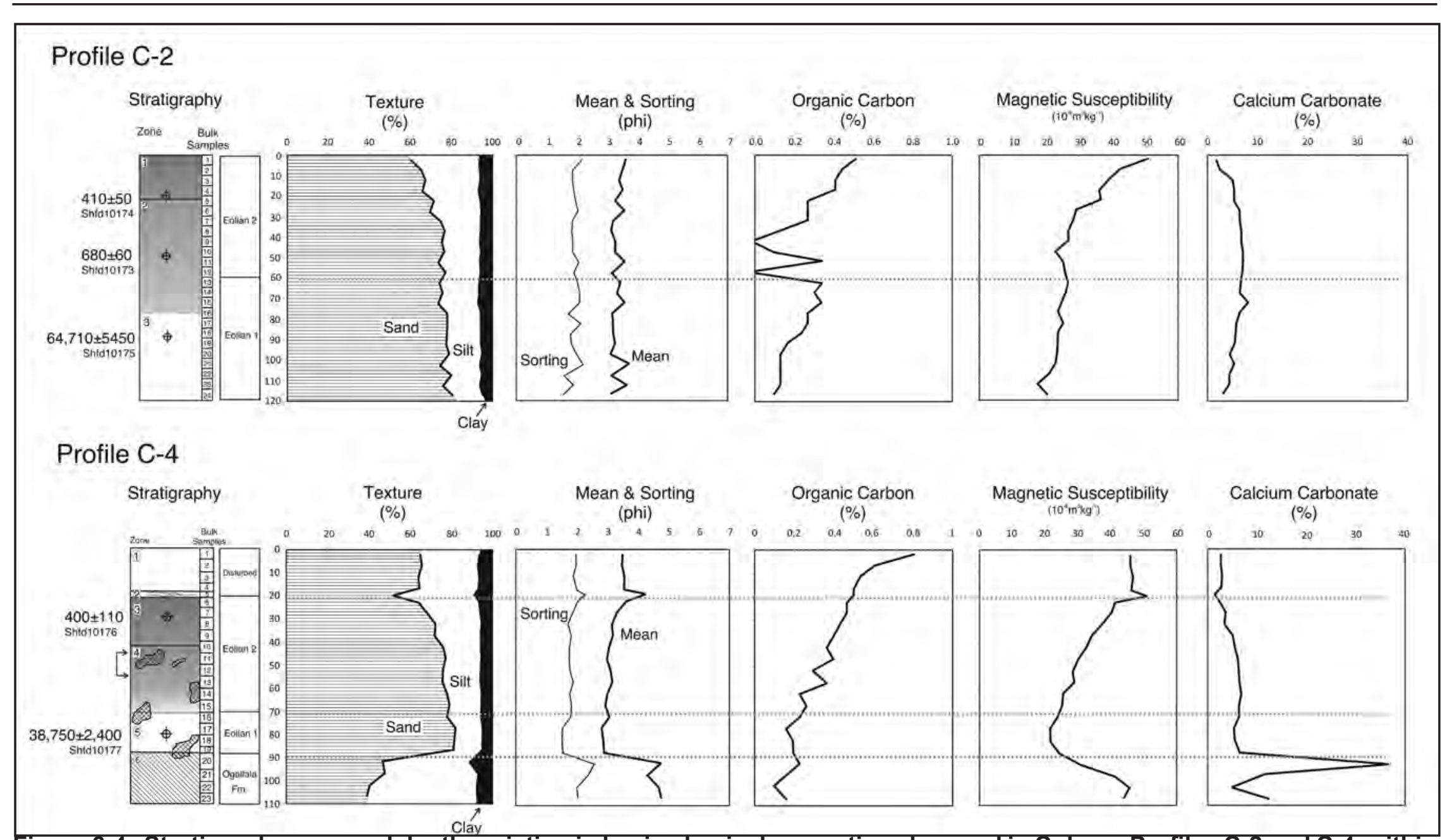

Figure 6-4. Stratigraphy, age, and depth variation in basic physical properties observed in Column Profiles C-2 and C-4, within eolian sand sheet depositional environment on south side of the Long View site. 
sand from the channel and transport it to higher landscapes to the northeast. The distinct tie to wind direction is the riverine source border dunes that lie on the eastern side of the stream channels.

The work performed here revealed trends that reflect the nature of this eolian system in terms of landforms and their textural composition and sedimentation rates. Generally, the eolian landforms become smaller and the deposits thinner away from the source. The riverine source border dunes ranged from less than $1 \mathrm{~m}$ to more than 4-m-tall and were the largest dunal forms in the suite. The upland dunes were generally less than 1.5-m-tall and the deposits examined were about 1.3-m-thick. The sand sheet exhibited no obvious eolian landforms such as dunes and deposits range from less than 0.5 m to slightly less than a meter.

The eolian deposits become progressively finer-grained and less well-sorted with increasing distance from the sediment source, specifically the channel of Dugout Creek. Figure 6-5 shows a bivariate plot of mean particle size versus sorting (standard deviation of particle size distribution) and illustrates how the stream side dune is the coarsest

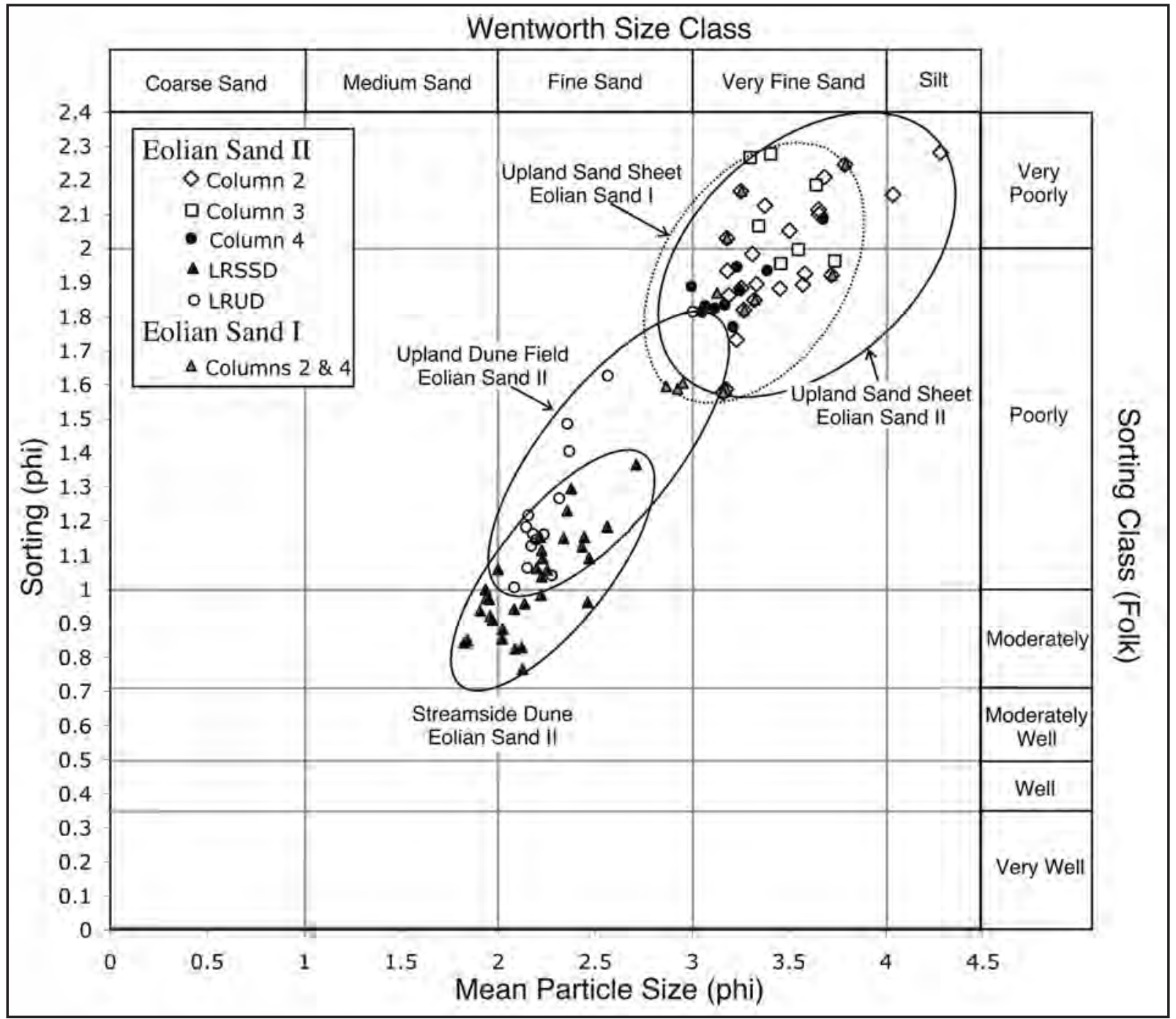

Figure 6-5. Plot of Folk and Ward mean particle size (in phi) versus sorting (standard deviation, in phi) for sediment samples collected from different eolian depositional environments. Note trend toward finer and more poorly sorted sediments as distance from sediment source increases. Ellipses delineate plotted area of samples from each depositional environment. 
and best sorted (moderately sorted medium sand to poorly sorted fine sand) deposit of the three present. These deposits exhibit no overlap with the sand sheet environment on the ridge crest (poorly to very poorly sorted very fine sand to very poorly sorted silt). Upland dune field sediments overlap significantly with streamside dunes, but also include some samples that are texturally similar to the sand sheet (poorly sorted fine sand to poorly sorted very fine sand). Figure 6-6 shows how both silt and clay increased exponentially with increased distance from the sediment source.

The sedimentation rates calculated from the OSL dates show an exponential decrease upslope, away from the sediment source (Figure 6-7). In particular, riverine source border dunes aggraded at rates around $1 \mathrm{~cm}$ per year, whereas upland dunes were deposited at a rate of $0.1 \mathrm{~cm}$ per year, and the sand sheet was deposited even more slowly, at a rate of around 0.05 $\mathrm{cm}$ per year. The slower sedimentation rate in the sand sheet setting resulted in greater opportunities for post-depositional mixing of different age sand grains, illustrated by the single-grain OSL dates.

The chronology of eolian activity obtained from the OSL dates indicates that deposition of ESII may have started as early as A.D. 1250, but the majority of the deposits dated were transported after A.D. 1500. Figure 6-8 shows the two sigma radiocarbon ages obtained from Components $\mathrm{A}$ and $\mathrm{C}$ within the site (excluding four ages on wood charcoal that were unacceptable) compared with the one sigma OSL ages from ESII, in order from oldest to youngest. From these ages it is inferred that the eolian activity occurred in three pulses, the first from A.D. 1250 to 1400, the second (the main phase) from A.D. 1500 to 1800 , and the third from around 1900 to the present.

Field observations support the latter two dates from the streamside dune, where a weak soil separated the two depositional events. There is no soil-geomorphic evidence to support a hiatus between the earliest phase of deposition and the main phase between A.D. 1500 and 1800. The most accurate age for the onset of eolian activity might be found in the base of the riverine source dune most distant from the modern channel, which presumably predates the dune examined immediately adjacent to the channel of Dugout Creek.

The early phase of eolian sedimentation (ESI) is difficult to pinpoint conclusively. In the field, ESI was subtly different from ESII, and OSL dating

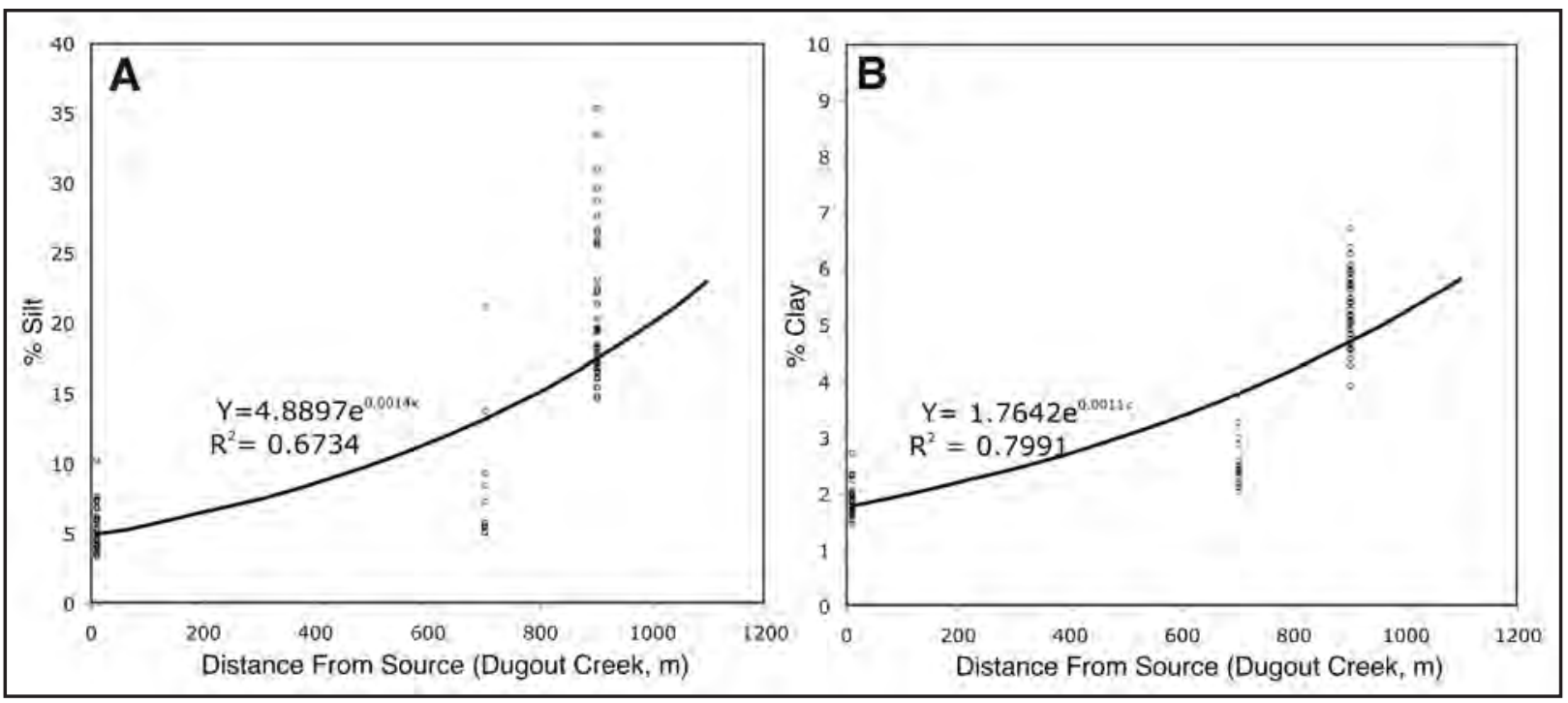

Figure 6-6. A. Change in percent silt with distance from sediment source for each eolian depositional environment examined. B. Variation in percent clay in eolian sediments with respect to distance from sediment source. 


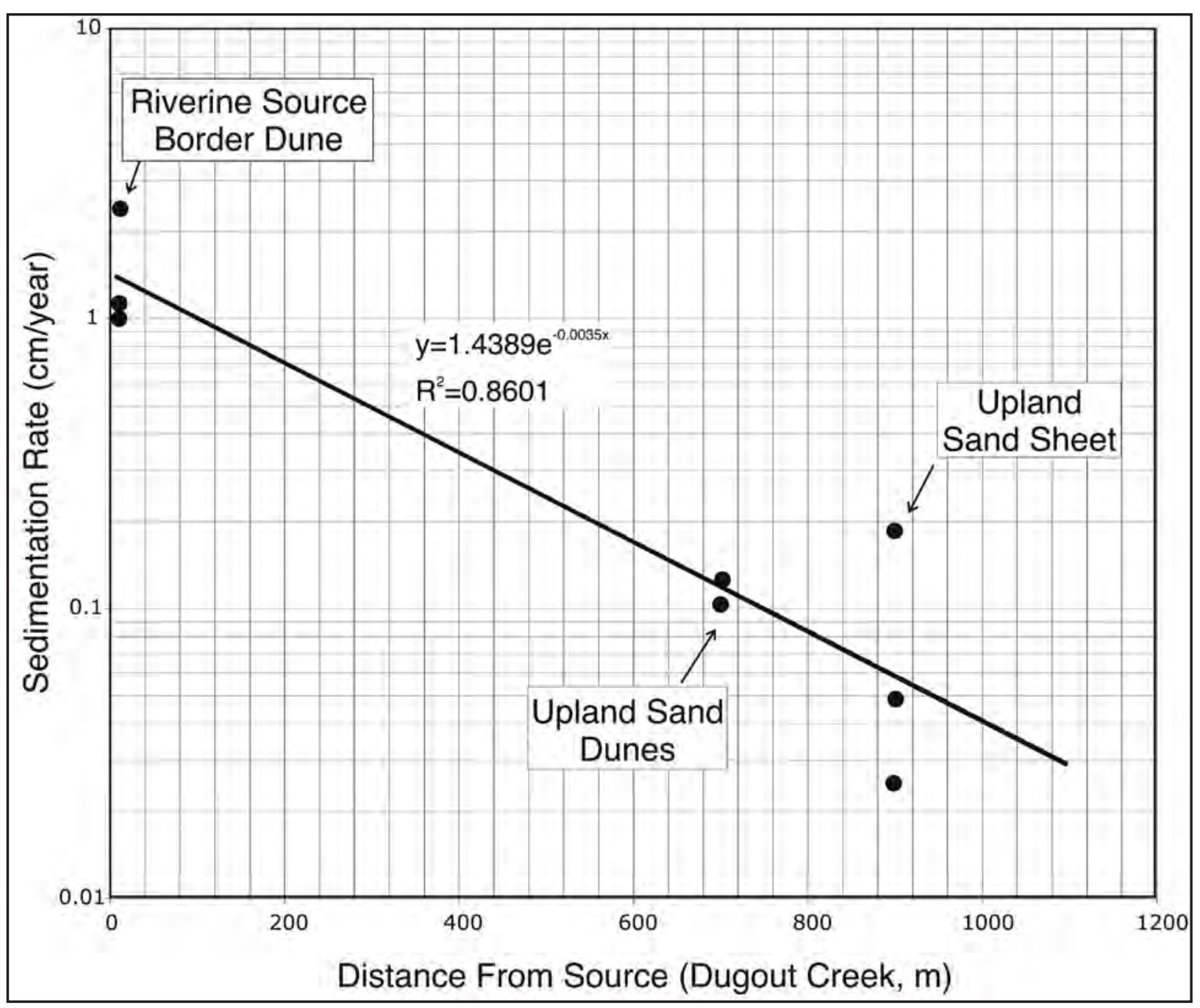

Figure 6-7. Plot of sedimentation rates obtained from OSL dates in each eolian environment
with respect to distance from sediment source (Dugout Creek). Note exponential decrease in sedimentation rate with increasing distance from sediment source.

confirmed the majority of its grains are significantly older. The ages obtained for this deposit are consistent with ages obtained by Rich and Stokes (2011) for the Blackwater Draw Formation on the Southern High Plains. Particle size analysis shows that this sediment is consistent with sand sheet deposits of late Holocene age, and it is interpreted as a much older phase of sand sheet sedimentation. The absence of soil features associated with sediments of such antiquity suggests that the majority of this deposit had been eroded prior to deposition of the latest Holocene sand sheet. A prominent red color is typically associated with deposits of the Blackwater Draw Formation, and is used in the field to discriminate between eolian deposits of different age. The absence of red in ESI is puzzling. Rich and Stokes (2011) dated one section of Blackwater Draw sediment of similar appearance, which was at the base of the eolian deposit, and as is inferred here, was below the level of significant pedogenic alteration.

The fireguard is clearly a modern structure that parallels the modern highway and consists of two convex banks separated by a broad gentle linear swale or depression. Presumably this was created by a road grader or bull dozer. Laboratory 


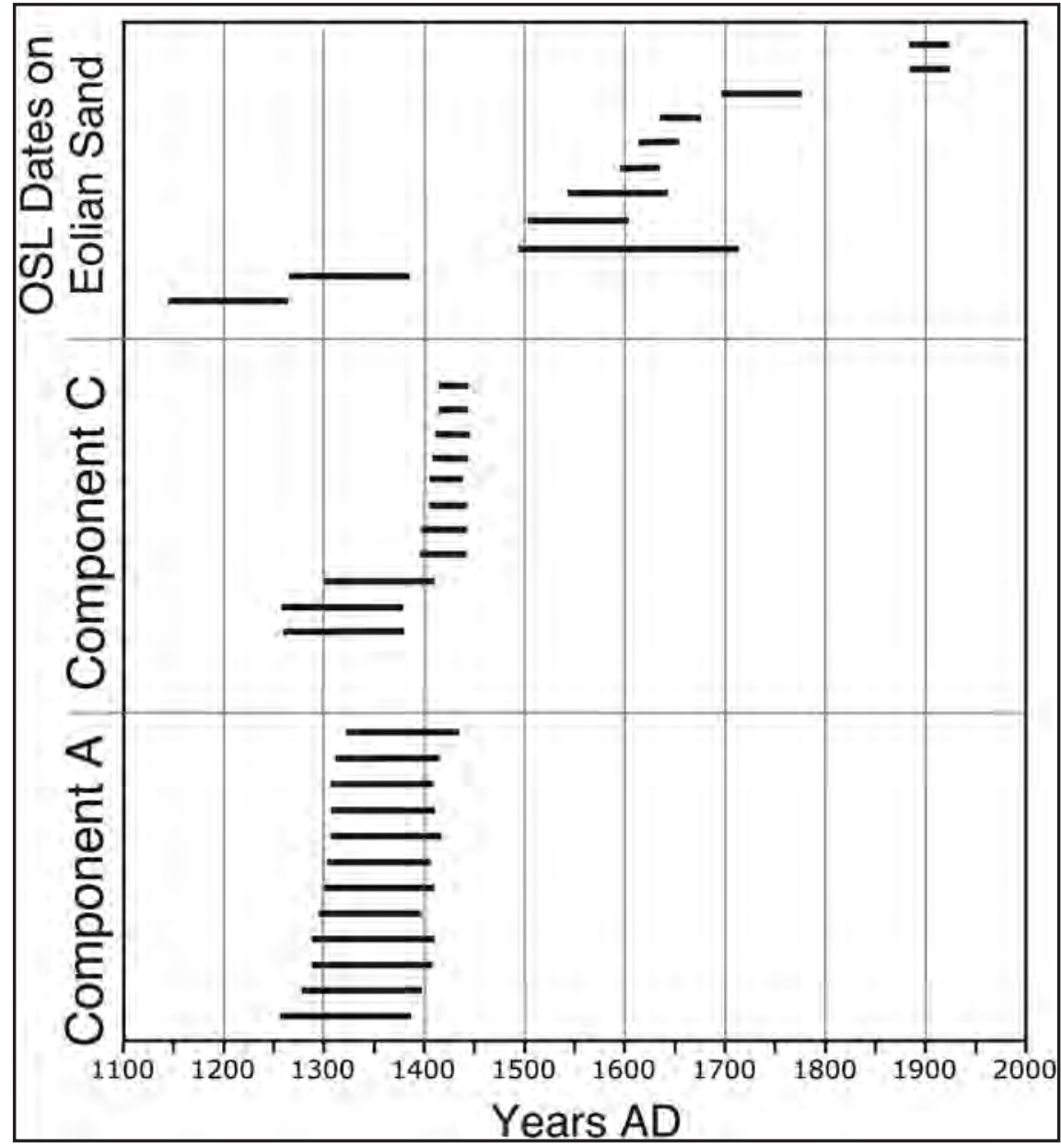

Figure 6-8 Two sigma radiocarbon ages obtained from Long View Components A and C with respect to one sigma OSL ages obtained from riverine source border dune, upland sand dune, and upland sand sheet.

characterization of bulk samples collected from the deposits of the fireguard in and around Feature 6 indicates this deposit was slightly finer grained than the underlying Eolian Sand II, but it shares most attributes with it. The upper part of the fireguard deposits was generally massive and exhibited a minor amount of melanization, and in several exposures the basal part was prominently laminated, most likely due to overland flow soon after it was constructed.

\subsection{Regional and Climatic Implications}

Eolian activity on the Great Plains is often directly correlated with arid or drought conditions (cf. Forman et al. 1995, 2001, 2008; Hanson et al.
2010), but in the case of the system described here, the principal control on eolian sedimentation appears to be sediment supply. Eolian activity requires a sediment source and a wind source, and the lack of either will fail to result in eolian deflation, transport and sedimentation. A variety of factors may influence the availability of sediment for erosion and transport. For instance, Werner et al. (2011) cautions that the relationship between dune activity and climate is often nonlinear and can be influenced by other processes affecting the sediment supply, such as the long-term effect of pedogenesis. They argue that soil formation makes older dunes more resistant to remobilization than recent dunes, primarily through the addition of pedogenic clay to form argillic horizons, which have greater water 
holding capacity that supports more vegetation, leading to a greater resistance to eolian deflation.

In this system, the sediment source is the channel floor of Dugout Creek, which today is a broad, braided sandy plain that ranges from 100 - to 200 -m-wide in the vicinity of the study area. Although it is tempting to assume that present conditions are similar to the past, the sandy sediment load and broad braided channel visible today is not necessarily representative of the nature of this channel during the late Pleistocene and Holocene. For instance, in a study of alluvial stratigraphy, Quigg et al. (2010) demonstrated that for much of the Holocene, West Amarillo Creek, on the south side of the Canadian River Valley, had a relatively fine-grained sediment load, and the coarse sand and gravel seen in the channel today is a recent phenomenon, begun about 800 to 1,000 years ago. The lack of earlier Holocene eolian deposits near the Long View site implies that there was insufficient sediment supply to form eolian deposits during the Holocene. Suggested testing includes examining the alluvial stratigraphy of Dugout Creek. Rolfe Mandel (personal communication, 2011) is conducting such a study.

Regardless of the causal linkage with drought, late Holocene eolian deposits are common in this region (the Southern Great Plains and Southern High Plains). In Texas, two studies summarize the dating results of numerous widely dispersed localities and report several localities with last millennium eolian deposits. Holliday (2001) prepared a compendium of eolian stratigraphy on the Southern High Plains. The majority of his examples were from the southern side of the Llano Estacado, where he identified several localities in the Muleshoe Dunes and a single locality in Terry County that were active in this period (e.g., Clovis, Tabosa Ranch and Plant X). Rich and Stokes (2011) examined eolian activity on the west and south sides of the region, focusing on Muleshoe valley and the Mescalero/ Monahans dunes on the southwestern margin. They confirmed the activity of the Muleshoe dunes in the last millennium.

To the north and east a number of studies, listed below, have documented widespread eolian activity in the last millennium, with sites to the east generally exhibiting a single period of sedimentation between 1100 and 500 years B.P., and sites to the west exhibiting multiple depositional events in this period. Lepper and Scott (2005) used OSL and radiocarbon dating to evaluate the age of a series of linear source-border dunes on the Qt2 terrace of the Cimarron River in Major and Kingfisher counties of Oklahoma. The majority of their dates indicate the last major phase of eolian activity was between A.D. 1100 and 1250. This activity coincides with Woodhouse and Overpeck's (1998) "Thirteenth Century Megadrought," also known as the Medieval Warm Period. Hanson et al. (2010) examined the age of the Abilene dunes in eastern Kansas, and 15 of their 20 OSL ages fell between 1060 and 460 years B.P. In contrast, Forman et al. (2008) examined dunes along the Arkansas River Valley in western Kansas and documented five periods of eolian sedimentation in the last 1,500 years, which they argue correlate well with tree-ring records of continental-scale drought. Werner et al. (2011) examined two dune localities between the Cimarron River in Western Kansas and the Beaver (North Canadian) River in Western Oklahoma. They documented dune activity between 800 and 400 years B.P. at the Albright site, and between 630 and 520 years B.P. at the Banner site. Arbogast (1996) and Arbogast and Johnson (1998) examined the age of dunes and documented four periods of eolian sedimentation over the last 1,000 years in the Great Bend Sand Prairie on the south side of the Great Bend of the Arkansas River in south-central Kansas.

\subsection{Archeological Implications}

The possible onset of eolian sedimentation happening during and after Late Prehistoric occupations of the region hold significant implications for discovery and preservation of archeological sites of this age. If the eolian activity was dependent upon the rejuvenation of the stream network, this event may have adversely affected Late Prehistoric agricultural activities, which likely targeted water gathering slopes and small valley floors for passive irrigation (cf. Boyd 2008). The main phase of eolian activity appears to have completely buried Late Prehistoric period sites from the drainage divide all the way down onto the valley floor. Hank's House (41RB109; Boyd 2004a), a Plains Village house about $10 \mathrm{~km}$ east of Long View, was buried by about $4 \mathrm{~m}$ of eolian sand postabandonment, sometime after A.D. 1283 to 1398 (650 \pm 40 B.P., Beta-168385 radiocarbon age 
from charred maize collected from floor deposit). not be as deeply buried, but will nonetheless have These results are consistent with the dates obtained negligible archeological visibility.

here. Sites like Long View, situated in sand sheet settings on the drainage divide or valley slopes will 


\subsection{CULTURAL STRATIGRAPHY AND CONTEXT}

\section{J. Michael Quigg}

\subsection{Analytical Units}

The archeological materials recovered from the Long View site have been grouped into two "analytical units" (Component A/Area A, in the northern end and Component $\mathrm{C} /$ Area $\mathrm{C}$, in the southern end), as useful heuristic devices that represent individual archeological units, for analysis and interpretation. The terms "analytical unit” and "component" are used interchangeably throughout this report and imply an association of material that represents a very limited time period. A component may represent a single, discrete occupational episode or a number of shortterm events that created a palimpsest of occupations that occurred within a definable time range. These two horizontally defined occupations are each attributed to a single component believed to date at least to a single cultural or chronological period (i.e., Plains Village period). Therefore, the idea of an analytical unit, as used here, refers to an archeological component that possesses recognizable discreteness when compared to surrounding, stratigraphically (and usually archeologically) distinct sediments. At Long View, two distinct components/analytical units are identified on the basis of horizontal separation and corresponding stylistic differences mainly in ceramic artifacts and frequencies within artifact classes. These components do not possess internal microstratigraphic structure because of turbation of the sandy deposits of one kind or another, although they may represent multiple, discrete events within relatively short time intervals. Among the studies proposed for the data assemblage in the Research Design (Chapter 4.0) are strategies that will address definable differences between these two analytical units. The two analytical units/components are horizontally separated by Area B, a stretch of ground roughly $120 \mathrm{~m}$ in length that yielded extremely sparse cultural materials.

\subsection{Component A}

Component $\mathrm{A}$, the northern component, extends eastwest across the entire width of the narrow area of potential effect (APE). The variable 9- to 10-m-wide APE is comprised of only about 4 to $5 \mathrm{~m}$ of natural prairie, plus a 4- to 5-m-wide mechanically bladed fireguard that abuts the western edge of the new right-of-way fence line. This fireguard extends along the entire length of the Long View site and beyond. This northern component extends for nearly $70 \mathrm{~m}$ north-south along the linear APE, parallel to the highway below. The occupational debris in the APE encompassed an estimated $665 \mathrm{~m}^{2}$ with nearly half that area having a surface impacted by the mechanically bladed fireguard. The highway cuts north-south through the north-south ridge and forms the eastern edge of the APE in a steep, nearly vertical exposure above the roadbed. This weathered and eroded exposure revealed sparse cultural material scattered along nearly $70 \mathrm{~m}$, plus one dark-stained basin or pit nearly $2 \mathrm{~m}$ in diameter, designated Feature 1 . The western edge of the APE is demarcated by the new right-of-way fence line, with natural prairie farther to the west. This northern component likely extends farther westward beyond the fence line, but our investigations were restricted to the APE and could not verify that assumption.

In the investigated area, the sandy loamy Holocene deposits were, for the most part, 45- to 55-cm-deep and overlaid the very old Ogallala Formation (or Ogallala-derived sediment). These reddish Ogallala sediments, which contain patchy white caliche spots, are typically significantly siltier and in some cases, clayier than the overlying eolian deposits. The caliche did not form a continuous or hard boundary line that was easily distinguishable, but rather a softer discontinuous patchy zone that varied in elevation.

The cultural materials in the sandy loamy Holocene deposits were somewhat vertically dispersed throughout the 45 to $55 \mathrm{~cm}$ deposits. For example, three pinched rim sherds from the same vessel were recovered from the surface of the fireguard (\#2-0081), from $14 \mathrm{cmbs}$ in Test Unit A-5 (\#58-008-1) and from 30 to $40 \mathrm{cmbs}$ in N697 E515 (\#1074-008-1). The latter two rim sherds were less than a meter apart, but were vertically separated by at least 15 $\mathrm{cm}$. This indicates postdepositional displacement following cultural discard. The top $10 \mathrm{~cm}$ and the bottom $10 \mathrm{~cm}$ through the transition zone between the Holocene and preholocene deposits were often 
culturally sterile. The vertical dispersal of cultural materials is thought to significantly reflect extensive rodent turbation that occurred and was observable as krotovinas in most deposit (Figure 7-1). However, the tops of the larger or darker-stained and more obvious cultural features were concentrated in a restricted vertical zone, mostly between 25 and 35 cmbs (Figure 7-2). Some elevational differences were detected in the materials and the tops of the features due to the uneven surfaces and gently sloping terrain. In some instances, prehistoric features, such as postholes, storage pits, and pithouses, were only detected where their bottom sections penetrated the reddish colored Ogallala sediments. Therefore, these bottom sections of subsurface features document the deepest extension of the cultural materials that often had poorly defined or indistinguishable upper sections. The tops of features were primarily concentrated between 25 and $35 \mathrm{cmbs}$ and reflect the projected vertical position of the prehistoric occupation surface (Figure 7-3).

No cultural features overlapped; all were horizontally separated from one another. The horizontal distribution of broad classes of materials (e.g., bones and features) also reflects horizontally discrete activity areas. Only a single occupation is represented in Component $\mathrm{A}$, judging by these horizontal distributions combined with recovered time-diagnostic artifacts (i.e., projectile points and pottery).

The diagnostic materials recovered consist of Washita and Fresno arrow points, plus cordmarked, plain, and one painted pottery sherds. These diagnostic artifacts reflect a Plains Village occupation dating to the Late Prehistoric period. To refine the temporal placement of this general occupational period, 13 radiocarbon dates from Component A provide an age range of 1,010 years from uncalibrated 480 to 1490 B.P. or cal A.D. 460 to 1447 (Table 7-1).

These dates were derived from four pieces of wood charcoal and nine charred maize pieces from six different features and areas that surrounded those features. This includes three dates for Feature 1, the pithouse, with one of the wood charcoal pithouse date and one wood charcoal date from heating element

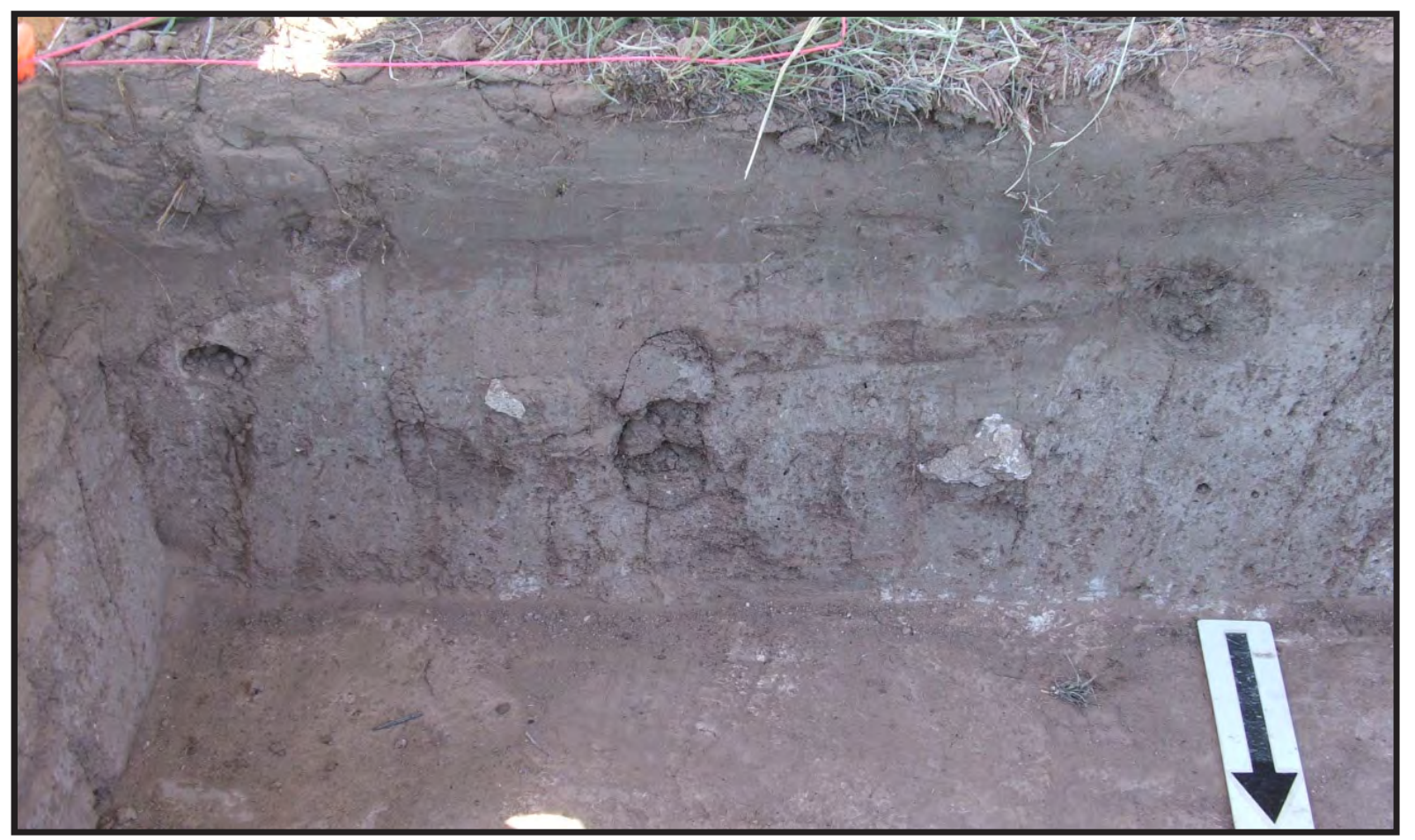

Figure 7-1. Component A, profile south wall of N697 E511 showing rodent disturbance in cultural zone. 
The Long View Site (41RB112): Data Recovery of Two Late Prehistoric Plains Village Period Components in Roberts County, Texas -Texas Department of Transportation

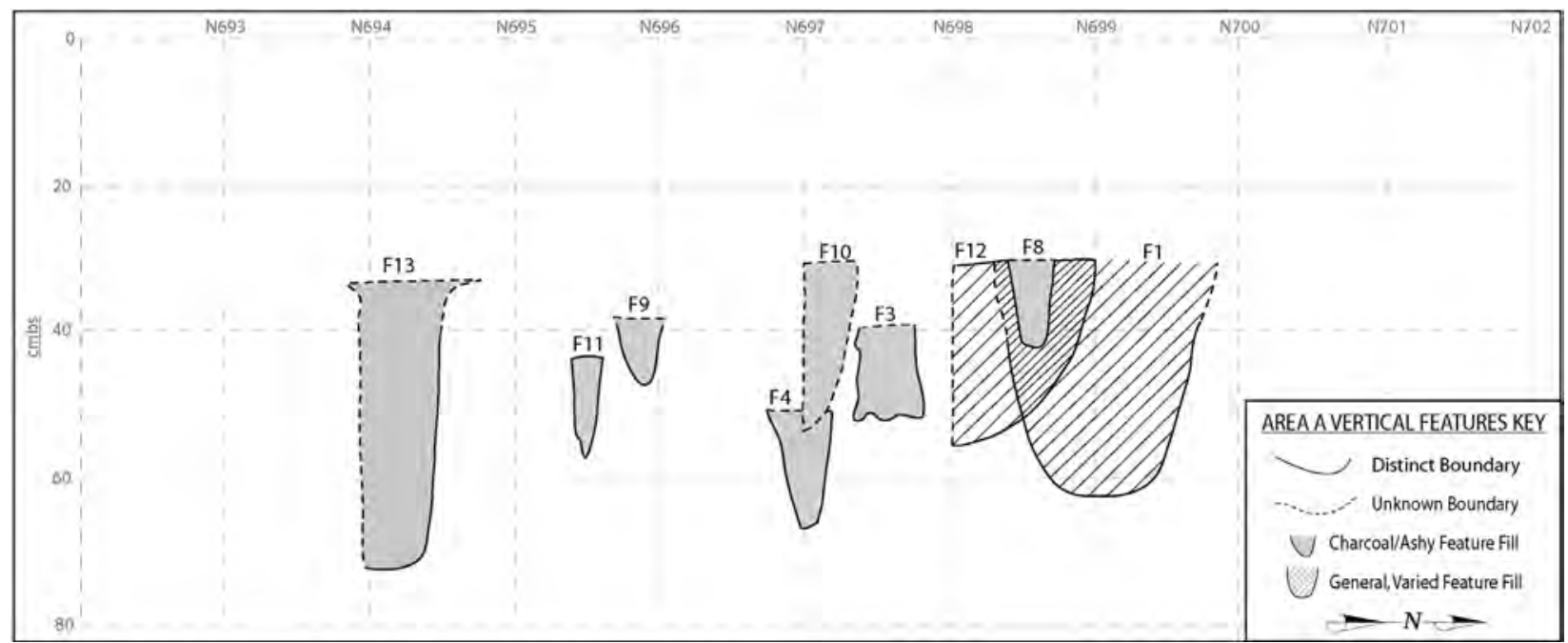

Figure 7-2. Vertical distribution of cultural features in Component A, 41RB112.

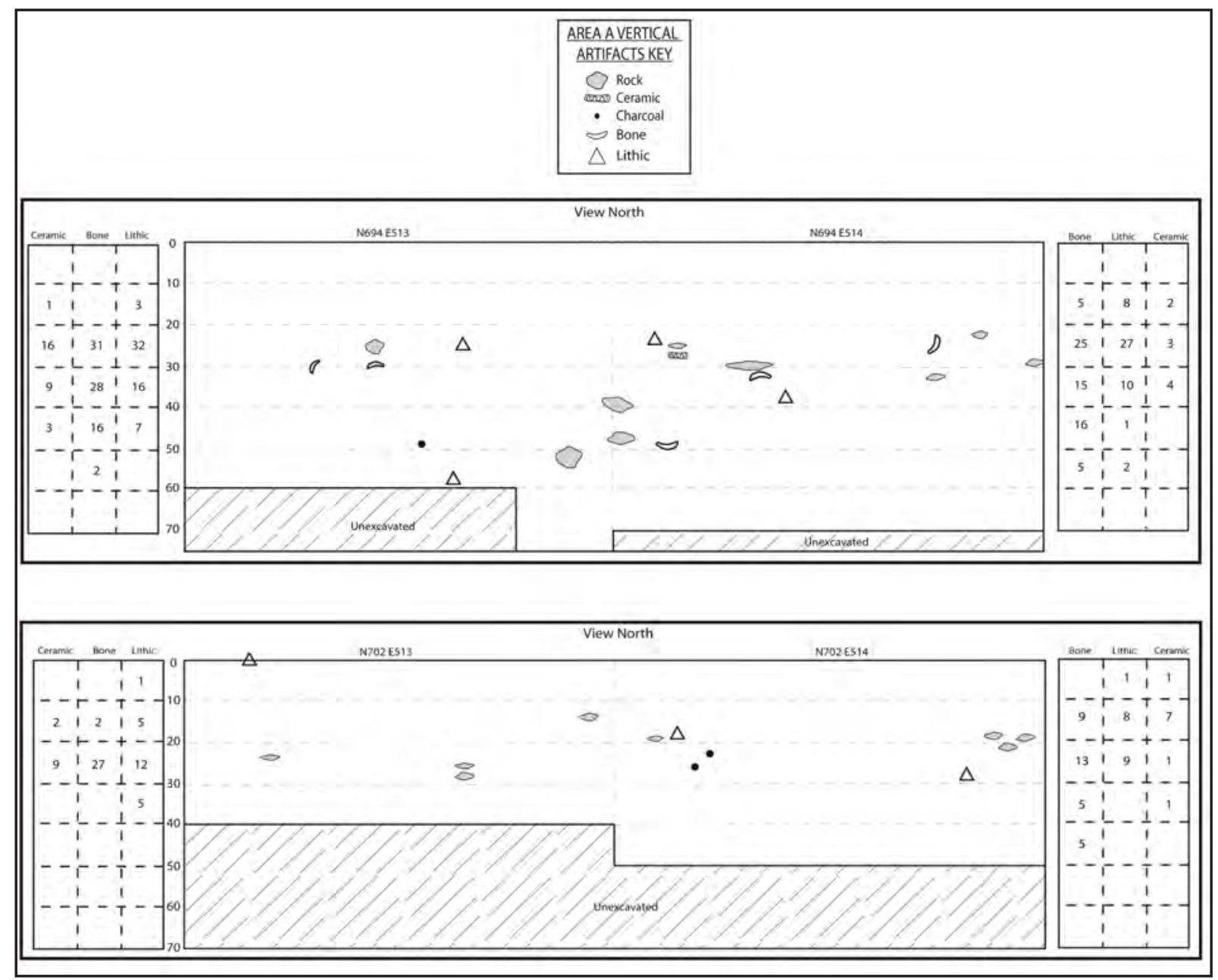

Figure 7-3. Example of vertical distributions of artifacts in Units N694 E513, N694 E514, N702 E513, and N701 E514, Component A. 
Table 7-1. Radiocarbon Data from Component A.

\begin{tabular}{|c|c|c|c|c|c|c|c|c|c|c|c|}
\hline Catalog No. & Component & Unit No. & $\begin{array}{l}\text { Depth } \\
\text { (cmbs) }\end{array}$ & $\begin{array}{c}\text { Feature } \\
\text { No. }\end{array}$ & $\begin{array}{c}\text { Material } \\
\text { Dated }\end{array}$ & Wt. (g) & Lab. No. & $\begin{array}{c}\text { Measured } \\
\text { Age }\end{array}$ & $\begin{array}{c}{ }^{13} \mathrm{C} /{ }^{12} \mathrm{C} \\
\text { Ratio (\%o) }\end{array}$ & $\begin{array}{c}\text { Conventional } \\
\text { Age (B.P.) }\end{array}$ & 2 Sigma Calibration Range \\
\hline $31-4-2 \mathrm{a}$ & A & Cutbank & $62-64$ & 1 & wood charcoal & 0.1 & B-206557 & $680 \pm 40$ & -23.0 & $710 \pm 40$ & AD 1260-1310 AD 1370-1380 \\
\hline $31-7-1$ & A & Cutbank & 52 & 1 & wood charcoal & 0.1 & B-206558 & $1460 \pm 40$ & -23.3 & $1490 \pm 40 *$ & $\mathrm{AD} 460-480, \mathrm{AD} 520-650$ \\
\hline $34-7-2$ & A & Trench A-1 & 36 & 3 & wood charcoal & 0.5 & B-206559 & $940 \pm 40$ & -23.2 & $970 \pm 40 *$ & AD 1000-1170 \\
\hline $62-7 a$ & A & Unit A-5 & $50-60$ & 4 & wood charcoal & 0.1 & B-206560 & $690 \pm 40$ & -24.0 & $710 \pm 40$ & AD 1260-1310 AD 1370-1380 \\
\hline 1032-7-1 & A & N695 E511 & $50-60$ & 11 & 1 maize & 0.1 & U-7831 & & -12.5 & $500 \pm 25$ & AD 1406-1444 \\
\hline $1064-7-1 \mathrm{a}$ & A & N697 E513 & $45-55$ & NA & 1 maize & 0.1 & U-7832 & & -9.9 & $510 \pm 20$ & AD 1406-1439 \\
\hline 1074-7-1a & A & N697 E515 & $30-40$ & NA & 1 maize & 0.1 & U-7833 & & -12.7 & $510 \pm 25$ & AD 1398-1444 \\
\hline $1080-7-1$ & A & N698 E511 & $31-53$ & 10 & 1 maize & 0.1 & U-7834 & & -10.6 & $510 \pm 25$ & AD1398-1444 \\
\hline 1093-7-1a & $\mathrm{A}$ & N698 E513 & $50-60$ & NA & 1 maize & 0.1 & U-7835 & & -11.4 & $480 \pm 20$ & AD 1416-1445 \\
\hline 1116-7-1 & $\mathrm{A}$ & N699 E512 & $40-50$ & 8 & 1 maize & 0.1 & U-7836 & & -9.8 & $480 \pm 25$ & AD 1413-1447 \\
\hline $1128-7-1$ & A & N696 E511 & $40-47$ & 9 & 1 maize & 0.1 & U-7837 & & -11.3 & $480 \pm 20$ & AD1416-1445 \\
\hline $1064-7-2$ & $\mathrm{~A}$ & N697 E513 & $50-60$ & NA & 1 maize & 0.1 & U-7838 & & -11.3 & $490 \pm 25$ & AD 1410-1445 \\
\hline $1164-7-3$ & A & N700 E515 & $50-60$ & 1 & 1 maize & 0.1 & U-7839 & & -9.9 & $590 \pm 25$ & AD 1301-1411 \\
\hline
\end{tabular}

cmbs = centimeters below surface, $\mathrm{g}=$ grams; $\mathrm{B}=$ Beta Analytical Inc., $\mathrm{U}=$ University of Georgia AMS, * date is unacepted, 
Feature 3 rejected as too early for this occupation. These 13 dates document the age of Component A. Based on the relatively tight clustering of nine dates derived from individual pieces of maize combined with the diagnostic materials and horizontal patterning of the cultural materials, Component $\mathrm{A}$ is viewed as a single Plains Village occupation dating between uncalibrated ca. 480 and 535 B.P. or A.D. 1398 and 1447 with a mean of roughly cal A.D. 1423. Two of the four wood charcoal dates at 710 B.P., although consistent with each other, are roughly 120 years older than the cluster of nine maize dates, but overlap at the two sigma range and are generally acceptable. The two unacceptable dates of uncalibrated $790 \pm 40$ B.P. and $1490 \pm 40$ B.P. derived from wood charcoal are thought to be a factor of old, dead wood being used as fuel in their fires (Smiley 1985; Schiffer 1986).

\subsection{Component C}

Component C, the southern component, is $120 \mathrm{~m}$ south of Component A and separated by the nearly sterile Area B. Component C extends east-west across the entire width of the proposed APE that varies from between 9- and 11-m-wide. The APE consisted of a narrow 1- to 3-m-wide strip of natural prairie along the eastern side, with another 2- to 3-m-wide strip of natural prairie on the western side, with a 3- to 5-m-wide bladed fireguard between the two strips of natural prairie. The fireguard runs north-south through the middle of the APE and its surface is 4- to 30-cm-below the adjacent, unbladed ground surface (see Figures 5-4 and 7-4). During our fall investigations, vegetation was less dense within the fireguard and numerous cultural materials were visible across its partially exposed surface. Most cultural materials were found along the western side of the fireguard, which indicates they had been at least horizontally displaced.

The cultural materials extended horizontally in a north-south trajectory for about $90 \mathrm{~m}$. The northern two-thirds of this stretch was relatively level, while the southern one-third sloped gently to the south. The highway cut along the eastern edge (Figure 7-5) exposed sparse cultural artifacts and faint dark stains.

In the relatively level northern part of Component $\mathrm{C}$, the sandy loamy Holocene deposits varied in thickness from 45 to $55 \mathrm{~cm}$. These more recent Holocene deposits again overlaid the much older Ogallala deposit with its mottled grayish clay patches, white caliche chunks, and reddish sands. However, the boundary between the two deposits was not always distinct, often grading from one deposit into the other.

At the very southern end of Component $\mathrm{C}$, the sandy Holocene deposits greatly increased in thickness to about $100+\mathrm{cm}$ along the eastern edge at E501, near the southern end of the north-south ridge. At this point, the Ogallala deposits dip sharply to the south, creating a steeper slope where more recent eolian sediments have accumulated. Consequently, the Holocene deposits were not of uniform thickness across Component $\mathrm{C}$ and thickened considerably at the very southern end of the excavations. As a result, the cultural materials deposited below the surface exhibited a much greater range in depth. Extensive rodent turbation also displaced many small cultural materials. As an example, thick body and rim sherds from a single vessel in the vicinity of Feature 18 along the southeastern margin of the APE varied in depth from near the surface to $70 \mathrm{cmbs}$ in N483 E499. This example of vertical displacement of sherds from this thick-walled vessel illustrates the postdepositional movement of directly related materials. Consequently, even though the small cultural artifacts were vertically displaced in the sandy eolian deposits, especially at the very southern end of Component $C$, the artifacts still can be interpreted to represent a single occupation.

On the other hand, the cultural features were not displaced, but were vertically concentrated in a relatively narrow zone between about 25 and $35 \mathrm{cmbs}$ (Figure 7-6). Because of the increased thickness of the sands towards the southern end, cultural features and artifacts at that end reveal a greater vertical dispersion (Figure 7-7). For instance, Feature 17 was discovered slightly higher (20 cmbs) than many of the other features and therefore, could be slightly younger than the main occupation encountered. Feature 22 was downslope from the other features and the most southerly of the identified features. Its depth below surface may be exaggerated because of the sloping deposits and the thicker accumulation of eolian deposits in that area. 


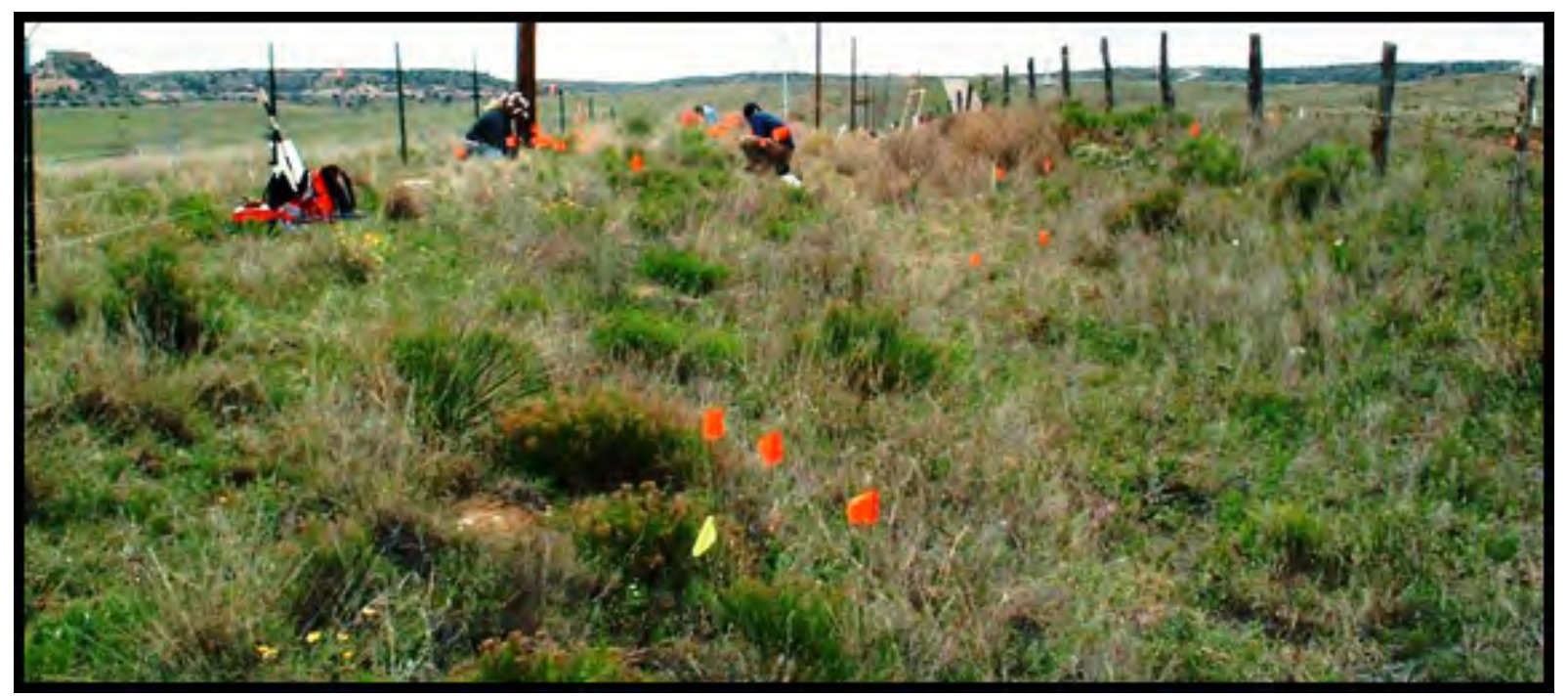

Figure 7-4. The APE in Component C, with the overgrown fireguard between old fence (right) and new fence (left).

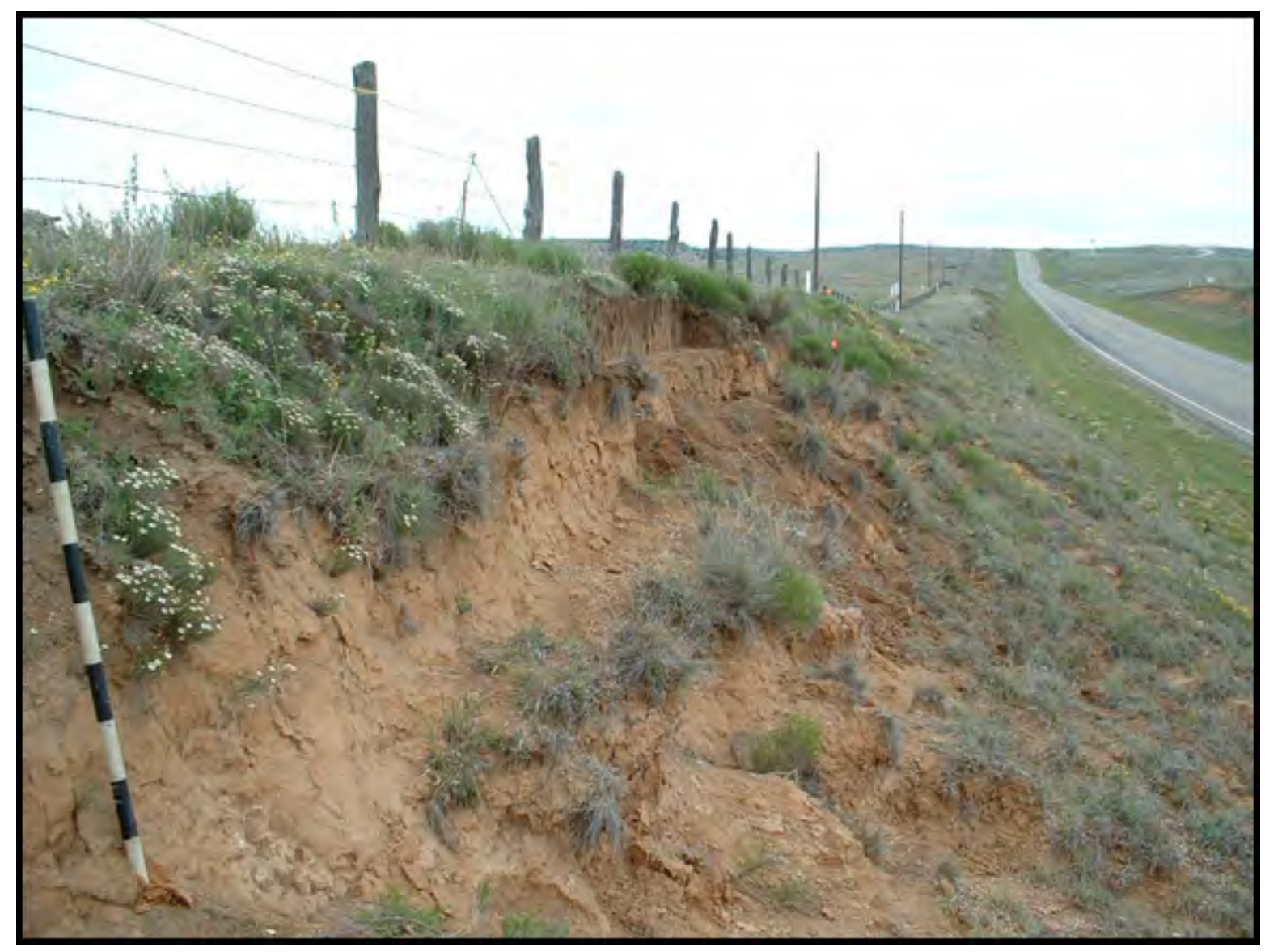

Figure 7-5. View north from Component $C$ along steep road cut on west side of highway. Note: Old Fence Line Visible along Eastern Edge of APE. 


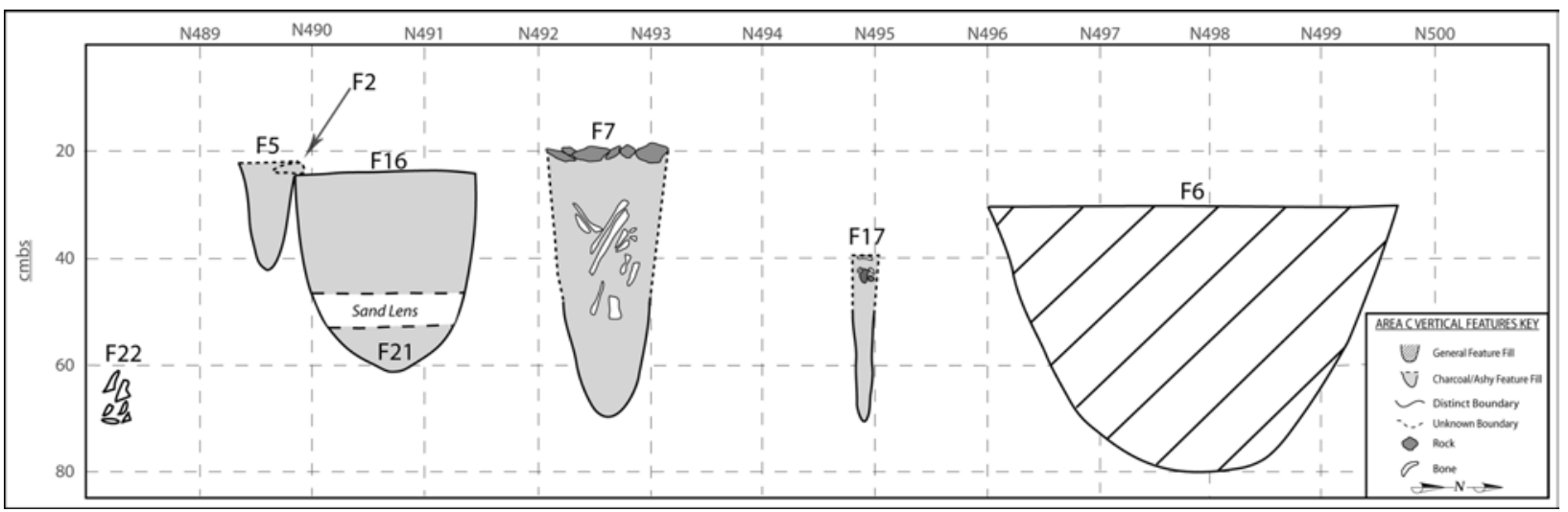

Figure 7-6. Vertical distribution of features in northern part of Component C.

Washita, Harrell, and Fresno arrow points were recovered from this southern area and the rest of the cultural assemblage of stone and bone tools, cordmarked ceramic sherds, bones, etc., combined with the identified cultural features, all represent a Plains Village occupation.

To document the precise age of Component C, three radiocarbon dates on wood charcoal, nine on charred maize fragments, and one on bison bone were obtained (Table 7-2). These 13 dates range from uncalibrated 530 to 1290 B.P. or cal A.D. 660 to 1437 with 12 dates clustering over 170 years between uncalibrated 530 and 700 B.P. or cal A.D. 1280 to 1437 . The oldest date of uncalibrated $1290 \pm 40$ B.P. was obtained on wood charcoal and is considered unacceptable. This wood charcoal probably represents old wood or wood unrelated to this Plains Village occupation. None of the recovered diagnostic artifacts (projectile points or pottery) reflect this earlier period. Component $\mathrm{C}$ is currently viewed as a single occupation with all materials, with the exception of the stone alignment and Features 7 and 22 (see below), reflecting a Plains Village component dated between uncalibrated 530 and 700 B.P. or cal A.D. 1280 and 1437.

The two radiocarbon dates on bulk ceramic sherds and one on exterior residues from one of the dated sherds were obtained in order to determine their precise age (Table 7-3). It was believed that the organic residues remaining in the vessel walls from the cooking activities would yield a AMS date of when the sherds were used. Two thick sherds that represent two different thick cordmarked vessels, Vessel 1 (\#308-8-19) and Vessel 3 (\#349-8-1d) were selected as the thickness of these two vessels created some dought that they represented the Plains Village period. The body sherd of Vessel 1 was 9.7 to 10.2 $\mathrm{mm}$ thick with a core that exhibits two colors with gray (10YR 6/1) at the center, a thin black (7.5YR $2 / 0$ ) line on the interior edge. The $19 \mathrm{~g}$ of this sherd yielded a $\delta^{13} \mathrm{C}$ corrected AMS uncalibrated date of $21,555 \pm 70$ B.P. This extremely early date is not accepted. It is believed that the date was derived from organic resides in the original clay that were not combusted during the original firing and subsequent use.

The very negative $\delta^{13} \mathrm{C}$ value of -29.1\% is indicative of $\mathrm{C}_{3}$ grasses in the subfamily of Arundinoideae, Festucoideae (i.e., wildrye and little barley) and some Panicoideae (Smith and Brown 1973). The negative $\delta^{13} \mathrm{C}$ value indicates 100 percent $\mathrm{C}_{3}$ plant residues remained inside the vessel walls. Significantly, obvious $\mathrm{C}_{4}$ products recovered from this component, such as bison and maize residues, were not represented in the $\delta^{13} \mathrm{C}$ value of this dated sherd.

Organic residue scraped from the exterior of the dated Vessel 1 sherd (\#308-8-19) was also AMS dated to compare with the bulk sherd date. Although the bulk sherd date is very old and unacceptable the residue yielded an uncalibrated date of $510 \pm 30$ B.P. or cal A.D. 1300 to 1420 , is only slightly younger 


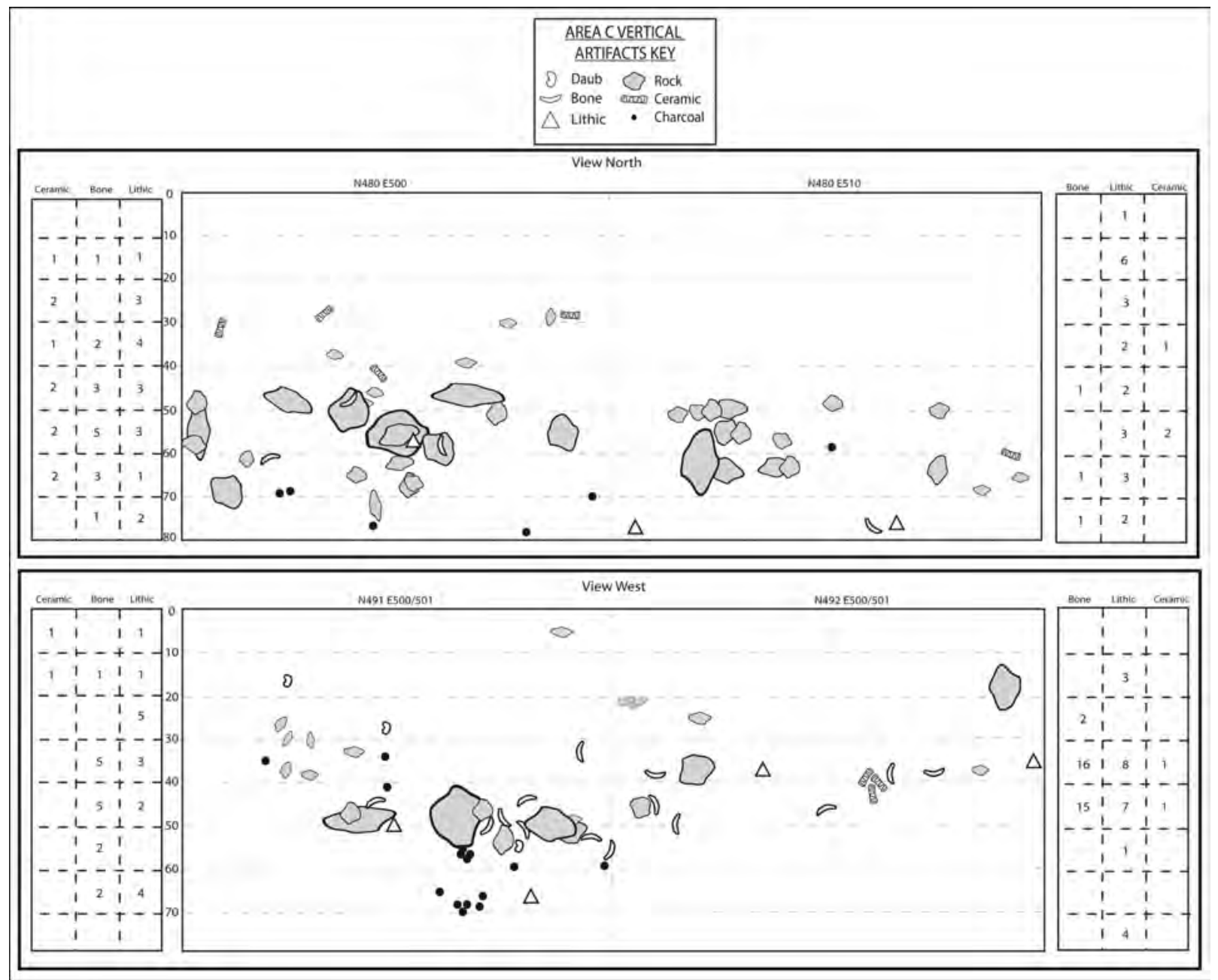

Figure 7-7. Example of vertical distributions of artifacts in Units N480 E500, N480 E501, N491 E500, and N492 E500, Component C.

than the 12 accepted uncorrected AMS dates on a variety of materials. This accepted residue date documents the age of Component $\mathrm{C}$ and the period of use for that sherd. The negative $\delta^{13} \mathrm{C}$ value of $-19.9 \%$ is indicative of a nearly equal mixture of $\mathrm{C}_{3}$ plants and $\mathrm{C}_{4}$ products (e.g., maize, grasses, and bison meat) indicating that multiple products were apparently cooked in this vessel.

The lower rim/body sherd of Vessel 3 was 8.1to-8.8-mm-thick with a mostly reddish yellow (7.5YR 6/6) core. This $11.1 \mathrm{~g}$ sherd yielded a $\delta^{13} \mathrm{C}$ corrected AMS uncalibrated date of $940 \pm 25$ B.P. This date is some 200 to 300 years older than the most acceptable age range of uncalibrated 530 to
700 B.P. for Component $\mathrm{C}$ with which it appeared directly associated. It is again believed that the organic residues inside the vessel walls were dated and it is unclear if these were contaminated or represent the true age of this vessel. If this is the true age of this vessel, then it lasted a lot longer than we normally think of for the life of a vessel. The context of Vessel 3 indicates it belongs with the Plains Village occupation dated here, therefore the residues are presumed to have been contaminated. The context and comparison with the date derived from the organic residue on the Vessel 1 sherd indicate that the uncalibrated date of $940 \pm 25$ B.P. and is too old to reflect the true age of Component C. Consequently, this bulk sherd date is unacceptable. 
The Long View Site (41RB112): Data Recovery of Two Late Prehistoric Plains Village Period Components in Roberts County, Texas -Texas Department of Transportation

Table 7-2. Radiocarbon Data from Component C.

\begin{tabular}{|c|c|c|c|c|c|c|c|c|c|c|c|}
\hline $\begin{array}{c}\text { Catalog } \\
\text { No. }\end{array}$ & Component & Unit No. & $\begin{array}{l}\text { Depth } \\
\text { (cmbs) }\end{array}$ & Feature No. & $\begin{array}{l}\text { Material } \\
\text { Dated }\end{array}$ & Wt. (g) & Lab. No. & $\begin{array}{l}\text { Measured } \\
\text { Age }\end{array}$ & $\begin{array}{c}{ }^{13} \mathrm{C} /{ }^{12} \mathrm{C} \\
\text { Ratio (\%o) }\end{array}$ & $\begin{array}{c}\text { Conventional } \\
\text { Age (B.P.) }\end{array}$ & \begin{tabular}{|c|}
2 Sigma \\
Calibration Range
\end{tabular} \\
\hline 120-4-3a & $\mathrm{C}$ & Cutbank & $30-40$ & 5 & 1 maize & 0.1 & B-206561 & $380 \pm 40$ & -9.7 & $630 \pm 40$ & AD 1290-1410 \\
\hline 131-7-1 & $\mathrm{C}$ & Unit C-7 & $40-50$ & 6 & 1 maize & 0.1 & U-7822 & & -9.4 & $580 \pm 20$ & AD 1309-1412 \\
\hline 133-4-a & $\mathrm{C}$ & Unit C-7 & $60-70$ & 6 & wood charcoal & 0.1 & B-206562 & $690 \pm 40$ & -24.4 & $700 \pm 40$ & $\begin{array}{c}\text { AD 1260-1310 AD } \\
1360-1390\end{array}$ \\
\hline $164-7-1$ & $\mathrm{C}$ & Unit C-10 & 19 & $\begin{array}{c}\text { Below } \\
\text { Structure } 1\end{array}$ & wood charcoal & 0.1 & B-206563 & $630 \pm 40$ & -23.6 & $650 \pm 40$ & AD 1280-1400 \\
\hline $167-7-1$ & $\mathrm{C}$ & Unit C-10 & 34 & $\begin{array}{c}\text { Below } \\
\text { Structure } 1\end{array}$ & wood charcoal & 0.1 & B-206564 & $1260 \pm 40$ & -23.0 & $1290 \pm 40 *$ & AD 660-790 \\
\hline 266-7-1 & $\mathrm{C}$ & N481 E500 & $50-60$ & 18 & 1 maize & 0.1 & U-7823 & & -9.2 & $590 \pm 20$ & AD 1305-1408 \\
\hline $300-7-1$ & $\mathrm{C}$ & N482 E499 & $70-80$ & 29 & 1 maize & 0.1 & U-7824 & & -9.9 & $570 \pm 20$ & AD 1313-1416 \\
\hline 331-7-1 & $\mathrm{C}$ & N482 E501 & $80-90$ & 23 & 1 maize & 0.1 & U-7825 & & -8.6 & $570 \pm 25$ & AD 1308-1419 \\
\hline 455-7-1a & $\mathrm{C}$ & N491 E501 & $60-70$ & 21 & 1 maize & 0.1 & U-7826 & & -11.0 & $530 \pm 25$ & AD 1324-1437 \\
\hline 470-7-1a & $\mathrm{C}$ & N491 E501 & $40-50$ & 16 & 1 maize & 0.1 & U-7827 & & -10.0 & $610 \pm 20$ & AD 1298-1400 \\
\hline $625-7-1$ & $\mathrm{C}$ & N499 E495 & $60-70$ & 6 & 1 maize & 0.1 & U-7828 & & -10.3 & $580 \pm 20$ & AD 1309-1412 \\
\hline 641-2-1a & $\mathrm{C}$ & N499 E495 & $30-40$ & 6 & Bison bone & & U-7829 & & -8.0 & $630 \pm 25$ & AD 1288-1411 \\
\hline 643-7-1a & $\mathrm{C}$ & N499 E497 & $40-50$ & 6 & 1 maize & 0.1 & U-7830 & & -10.0 & $590 \pm 25$ & AD 1301-1411 \\
\hline
\end{tabular}

cmbs = centimeters below surface, $\mathrm{g}=$ grams; $\mathrm{B}=$ Beta Analytical Inc., $\mathrm{U}=$ University of Georgia AMS, * date is not accepted, 
Table 7-3. Radiocarbon Dates and Data on Pottery and Residues from Component C.

\begin{tabular}{|c|c|c|c|c|c|c|c|c|c|}
\hline $\begin{array}{c}\text { Site/Feature/ } \\
\text { Component }\end{array}$ & Cat. No. & $\begin{array}{c}\text { Provenience } \\
\text { (Unit, Depth) }\end{array}$ & $\begin{array}{c}\text { Vessel } \\
\text { No. }\end{array}$ & $\begin{array}{c}\text { Sherd } \\
\text { Characteristics }\end{array}$ & $\begin{array}{l}\text { Lab. No. } \\
\text { (UGAMS) }\end{array}$ & $\begin{array}{c}\text { Measured } \\
\text { Age }\end{array}$ & $\begin{array}{c}{ }^{13} \mathrm{C} /{ }^{12} \mathrm{C} \\
\text { Ratio } \\
(\% \text { o) }\end{array}$ & $\begin{array}{c}\text { Conventional } \\
\text { Age B.P. }\end{array}$ & $\begin{array}{c}2 \text { Sigma } \\
\text { Calibration } \\
\text { Range* }^{*}\end{array}$ \\
\hline $\begin{array}{c}\text { 41RB112/ } \\
\text { Component C }\end{array}$ & $349-8-1$ & $\begin{array}{l}\text { N484 E496, } \\
60-80 \mathrm{cmbs}\end{array}$ & 3 & $\begin{array}{c}\text { Cordmarked } \\
\text { exterior, base }= \\
8.1-8.8 \mathrm{~mm} \text { thick, } \\
\text { sand and scoria } \\
\text { temper, } 11.1 \mathrm{~g}\end{array}$ & 8456 & not reported & -21.7 & $940 \pm 25$ & $\begin{array}{c}\text { cal AD 1029- } \\
1156\end{array}$ \\
\hline $\begin{array}{c}\text { 41RB112/ } \\
\text { Component C }\end{array}$ & $308-8-19$ & $\begin{array}{l}\text { N482 E500 } \\
67-70 \text { cmbs }\end{array}$ & 1 & $\begin{array}{l}\text { Cordmarked } \\
\text { exterior, body } \\
=9.7-10.2 \mathrm{~mm} \\
\text { thick, } 19 \mathrm{~g}\end{array}$ & 8457 & not reported & -29.1 & $21,550 \pm 70$ & $\begin{array}{l}\text { cal 24,230- } \\
23,444 \text { BC }\end{array}$ \\
\hline $\begin{array}{c}\text { 41RB112 } \\
\text { Component C }\end{array}$ & $305-8-1 a$ & $\begin{array}{l}\text { N482 E500, } \\
60-70 \mathrm{cmbs}\end{array}$ & 1 & $\begin{array}{l}\text { Organic } \\
\text { residue scraped } \\
\text { from exterior } \\
\text { cordmarked } \\
\text { Vessel } 1\end{array}$ & B-307381 & $510 \pm 30$ & -19.9 & $590 \pm 30$ & $\begin{array}{c}\text { cal AD 1300- } \\
1410\end{array}$ \\
\hline
\end{tabular}

cmbs = centimeters below surface; $\mathrm{mm}=$ millimeters; $\mathrm{g}$ = grams; UGAMS = University of Georgia AMS date; $\mathrm{B}=\mathrm{Beta}$ Analytic; * = CALIB REV 6.0.0; **

The $\delta^{13} \mathrm{C}$ value of $-21.7 \%$ indicates a roughly 65 percent $\mathrm{C}_{3}$ plant residue within the vessel walls. The two most prominent food resources recovered from this component, bison meat and maize, both $\mathrm{C}_{4}$ products, were apparently not cooked in this vessel, or at least their chemical signatures were not preserved in this sherd. Grasses, flowering plants, and deer/antelope meat are all $\mathrm{C}_{3}$ products and would be major contributors to this negative $\delta^{13} \mathrm{C}$ value.

A relatively straight, nearly buried stone alignment along the western margin of the APE in Component $\mathrm{C}$ is not associated with the buried Plains Village component (Figures 7-8 and 7-9). This line of stones was partially visible on the surface and was partially excavated. It was at least $15 \mathrm{~m}$ long, and extended in a north-south line roughly $1 \mathrm{~m}$ east of the new right-of-way fence along the western boundary of the APE and about $1 \mathrm{~m}$ west of the fireguard. It was in a relatively flat area that gently slopes to the south. Although it resembled some Antelope Creek phase house-wall alignments, close inspection and subsequent excavation revealed no rocks or partial alignments perpendicular to, or connected to, this line, thus, no indication of adjoining walls that would indicate room structures. At least 197 natural chunks caliche rocks were detected in this irregular alignment, which were mostly 20 to $30 \mathrm{~cm}$ in diameter, and partially buried with just their tops exposed (Figure 7-10). One or two rocks were nearly vertical in orientation. A wooden power pole had been inserted towards the southern end, about $25 \mathrm{~cm}$ west of this alignment, and three larger rocks were around the base of the pole. These three rocks were probably removed from the alignment, judging by gaps that appeared in the adjacent portion. A sample of rocks was weighed and their depths measured. About 55 percent of the rocks were buried between 0 and 13 cmbs. Nearly 43 percent were between 15 and 20 cmbs with only 2 percent lower than 20 cmbs. About 61 percent $(N=121)$ were weighed and yielded a total weight of $282 \mathrm{~kg}$. This indicates an average weight of nearly $2.3 \mathrm{~kg}$ per rock. These rocks were definitely higher in the sediment profile than the majority of the prehistoric materials and all prehistoric features identified.

The sediments that buried these rocks were eolian in nature and apparently derived from the adjacent fireguard following blading activities. Some prehistoric artifacts were recovered from near and around the rocks during the hand-excavations. These could have been displaced and their original 


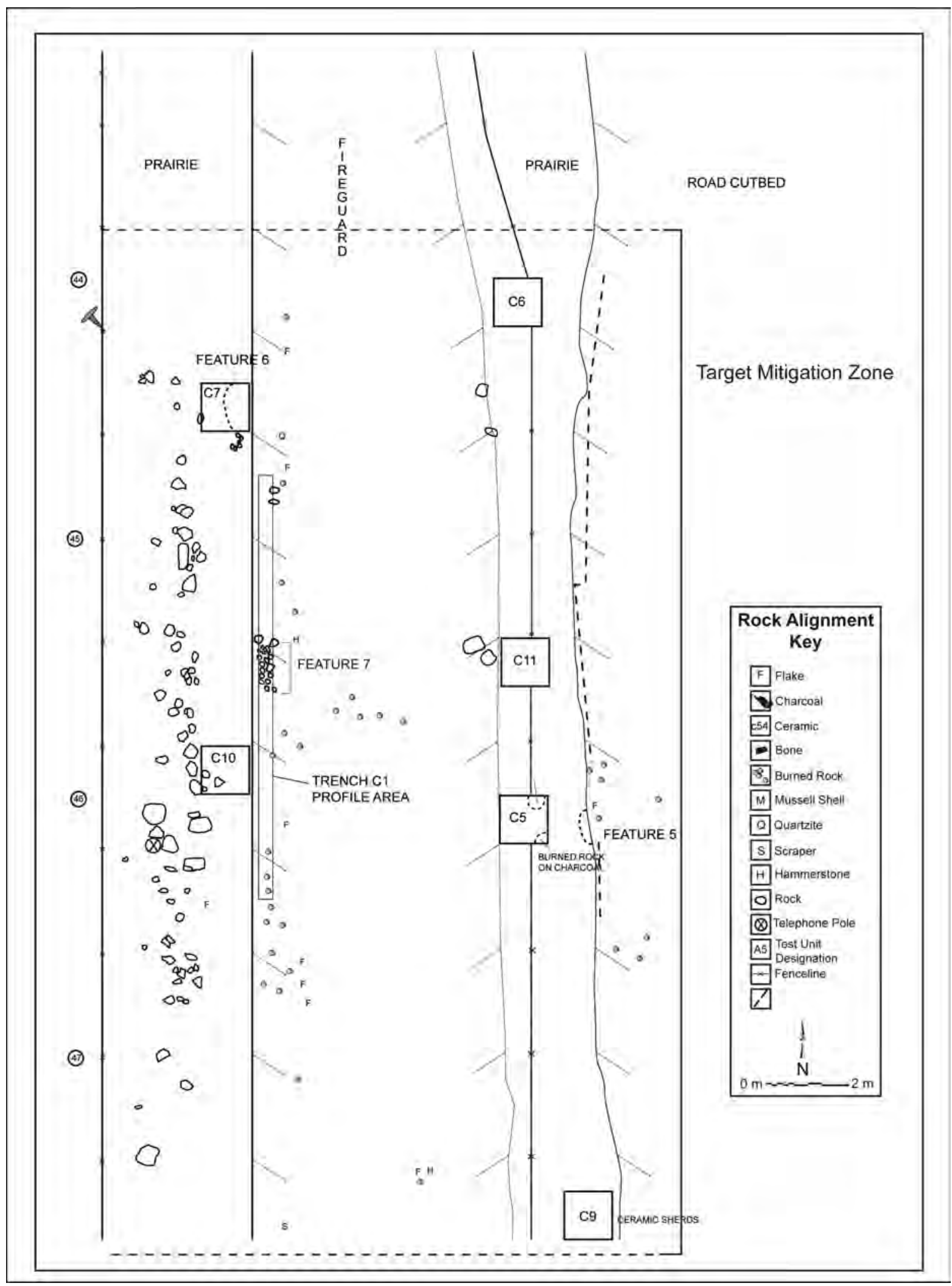

Figure 7-8. General plan map of stone alignment in Component $\mathrm{C}$. 


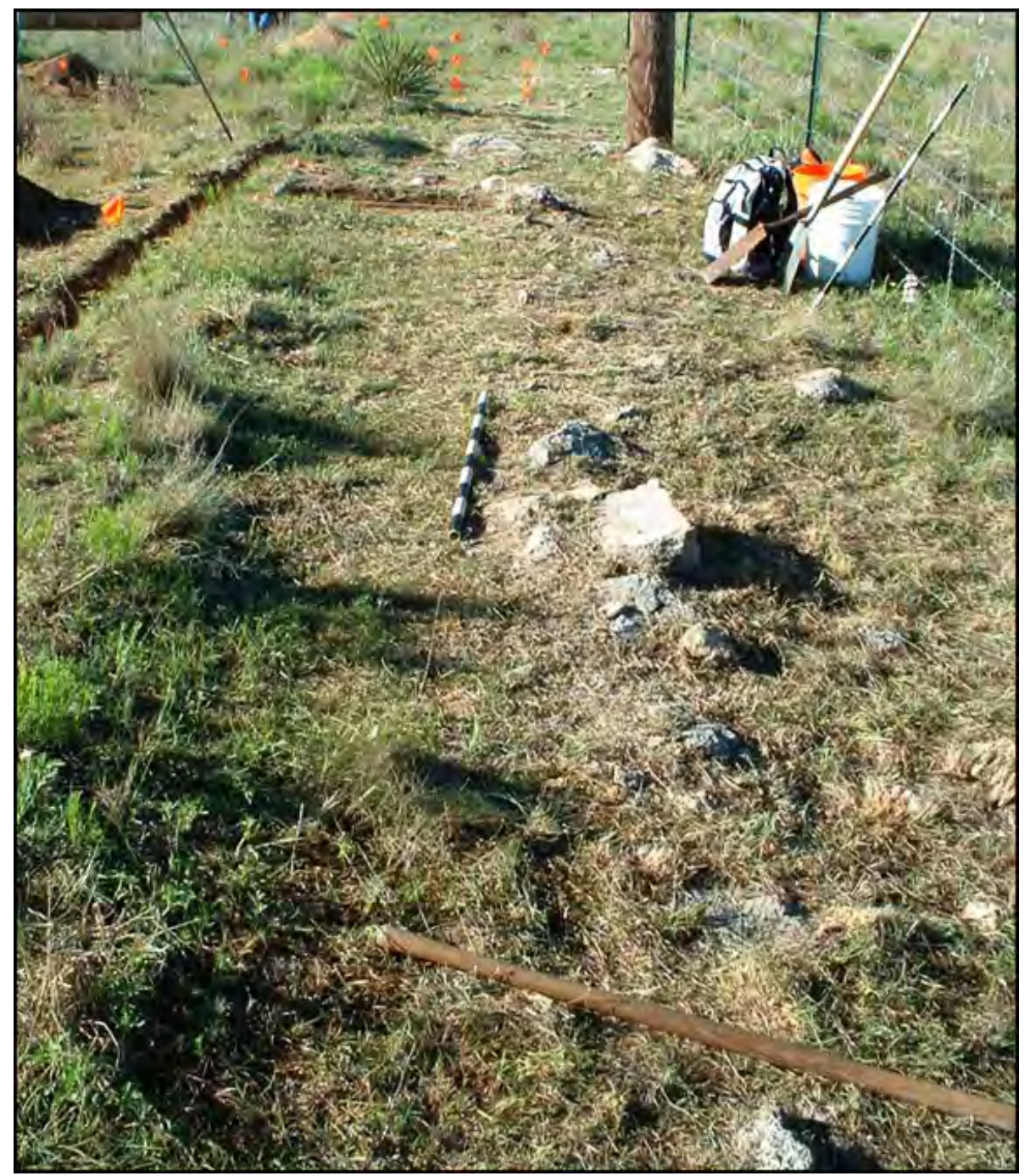

Figure 7-9. Surface exposed caliche rocks that formed the stone alignment in Component C, view south.

association is in question, but most likely they were originally part of the buried Plains Village occupational debris. Based on the depth of the rocks, primarily less than $20 \mathrm{cmbs}$, in comparison to the majority of prehistoric artifacts away from this alignment, primarily below $30 \mathrm{cmbs}$, and the depth of the prehistoric features primarily between 30 and $35 \mathrm{cmbs}$, this rock alignment is considered more recent and not associated with the Plains Village Component C. As such, this stone alignment will not be discussed further. Two apparent prehistoric features, consistent with Native American Graves Protection and Repatrriation Act and the expressed wishes of consulting tribes, Features 7 and 22, both yielded human remains and minimal artifacts. TxDOT informed TRC that, consistent with Native American Graves Protection and Repatriation Act and the expressed wishes of consulting tribes, radiocarbon dating the human bones or associated materials in these two interments was not permissible. Consequently, although there is doubt as to their association with the Plains Village occupation, without directly dating these remains one cannot directly link these human remains to the recovered and analyzed Plains Village materials. Both features were encountered in the excavations, 


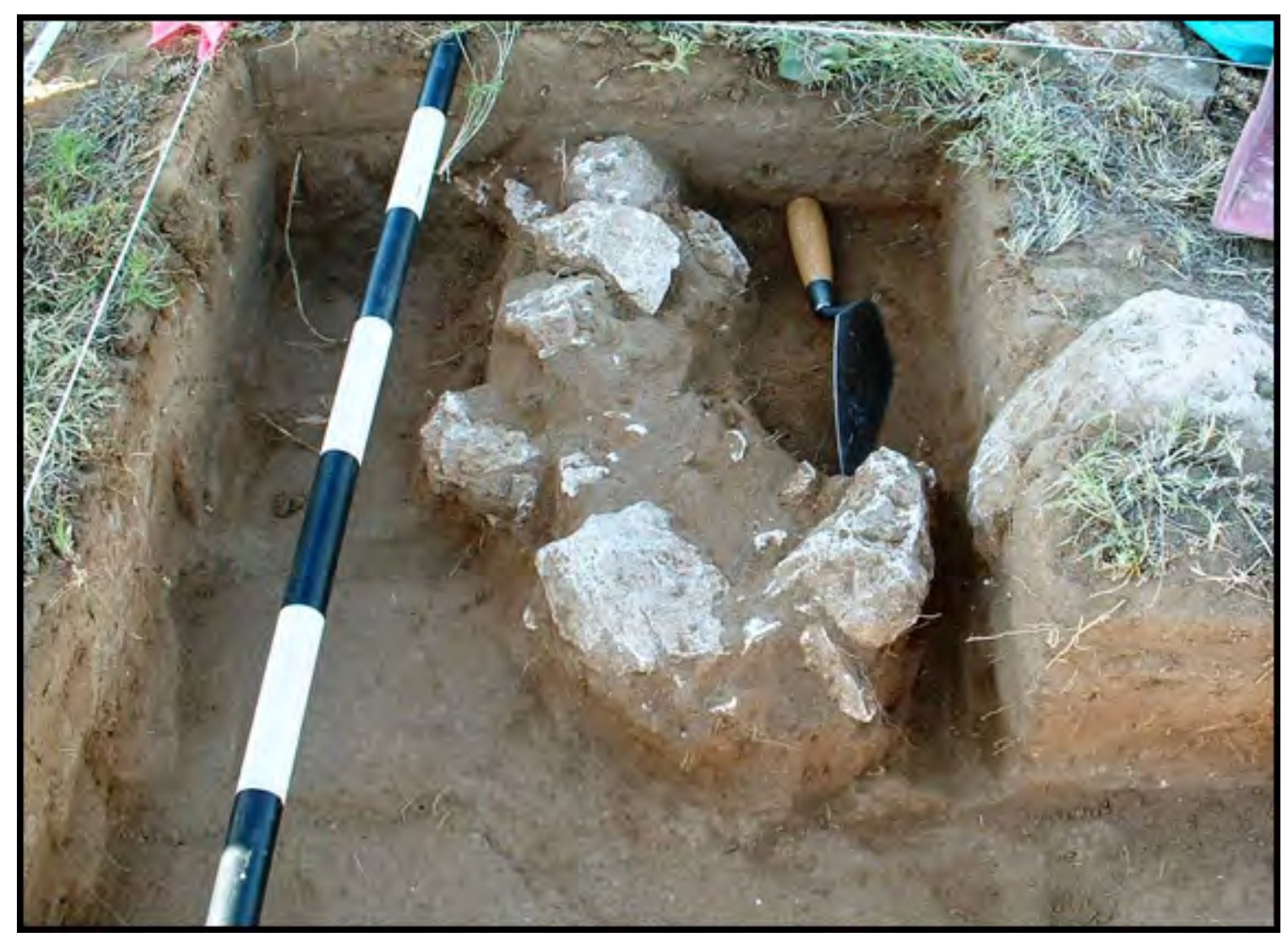

Figure 7-10. An excavated unit that reveals part of the buried stone alignment in Component C.

but they may represent isolated events that were not contemporaneous with the other cultural materials from across the broader area. See further discussions of these under the feature section.

\subsection{Summary and Conclusions}

At Long View two distinct components/analytical units, Components A and C, have been recognized. These two components were horizontally separated by at least a 120-m-long area (Area B) that lacked cultural materials. Each component appears to reflect and represent a single discrete Plains Village period occupation based on horizontal, vertical, artifactual and radiocarbon evidence. Turbation within each component has displaced materials within these sandy deposits at least vertically within the profile. Therefore, no general microstratigraphic structure is present beyond the recognized features. Despite the fact that some cultural materials were vertically disturbed, the broad associations between the artifacts and features are still valid and useful and provide an excellent opportunity to interpret human behaviors within a single camp at a point in time. Broad horizontal structure is still present in each component even with the existence of the previous mechanically bladed fireguard through each of the two components. 
This page intentionally left blank. 


\subsection{Component A - Northern End}

J. Michael Quigg and Paul M. Matchen with contributions by Charles D. Frederick and Brittney Gregory

This component was roughly was at the northern end of the site and separated from Component $C$ by Area B to the south. Component A extends eastwest across the entire width of the APE, which was between 9- and 10-m-wide. This narrow APE contained an approximately 4- to 5-m-wide strip of natural prairie along its eastern margin and a 4to 5-m-wide fireguard running north-south along the very western side along the new right-of-way fence line (see Figure 5-3). Component A extended roughly $70 \mathrm{~m}$ north-south across a nearly level area. The road cut defined the eastern edge with sparse cultural materials and at least Feature 1 eroding out of the Holocene deposits along the exposed cut bank above the road.

The sandy loam Holocene deposits varied from 45to 55-cm-deep and overlay the much older Ogallala Formation with its mottled grayish-clay patches, white caliche chunks, and reddish sands. The bedrock Ogallala deposits were not a continuous well-defined boundary line of hard caliche, but a rather soft ill-defined patchy zone the varied slightly in elevation.

Smaller cultural materials were vertically dispersed within the Holocene deposits as a result of extensive rodent turbation. However, cultural features had not been displaced and were concentrated in a relatively thin vertical zone between about 25 and $35 \mathrm{cmbs}$ (see Figure 7-2). Cultural features and materials were vertically dispersed within the sediment profile (Figure 7-3).

Below, the recognized features are described and functionally interpreted, along with summaries of associated artifacts, and results of their analyses are presented. Following the features discussion, the various artifact classes from Component A are presented to provide the reader with an understanding of the types and frequencies of materials recovered.

\subsection{Cultural Features}

A total of 11 cultural features were identified in Component $\mathrm{A}$, nine in the northern area and two further south in the southern part of Component A (see Figures 2-1 and 8-1). This includes one partial pithouse (Feature 1), at least seven heating elements (Features 3, 4, 8 through 12), a small storage pit (Feature 13).

One questionable cluster (Feature 14), and possibly a second cluster (Feature 15) in which cultural materials may have accumulated in rodent holes. The features were assigned numbers as they were encountered. Missing numbers here are part of Component C (see Chapter 9.0 below). Each Component A feature is presented below with descriptions, results of specific technical analyses, and interpretations. Following individual feature presentations, a summary and discussion of the horizontal distribution of the features is presented.

\subsubsection{Feature 1}

This feature was first recognized in the existing road cut during a site visit prior to initiating site assessment. Feature 1 appeared as a relatively large (roughly 250-cm-wide) basin exposed in the upper $60 \mathrm{~cm}$ of the road cut profile near the middle of Component A (Figures 8-2 and 8-3). Initially, a 4-m-long section of the existing exposure was hand-cleaned, straightened, examined, and then documented. Once cleaned, the bottom part of the broad basin was easily distinguishable from the underlying Ogallala Formation deposits. The basin had been dug to about 65 cmbs into the lower pale yellow (5YR 7/3) calcium carbonate layer. The internal fill of the basin was a yellowish brown (10YR 5/4) sandy loam that contained an occasional piece of cultural material and charcoal towards the bottom. The top of the basin faded into, and became indistinguishable from, the lower part of the A horizon. However, the bottom part of the northern section was above a pale olive (5YR 6/3) matrix. The exposed southern edge was badly disturbed by at least two discernible rodent burrows. South of the rodent burrows, the questionable lower pit boundary gradually angled toward the surface, but again faded into the A horizon. The lower part of the interior basin yielded small, scattered chunks 


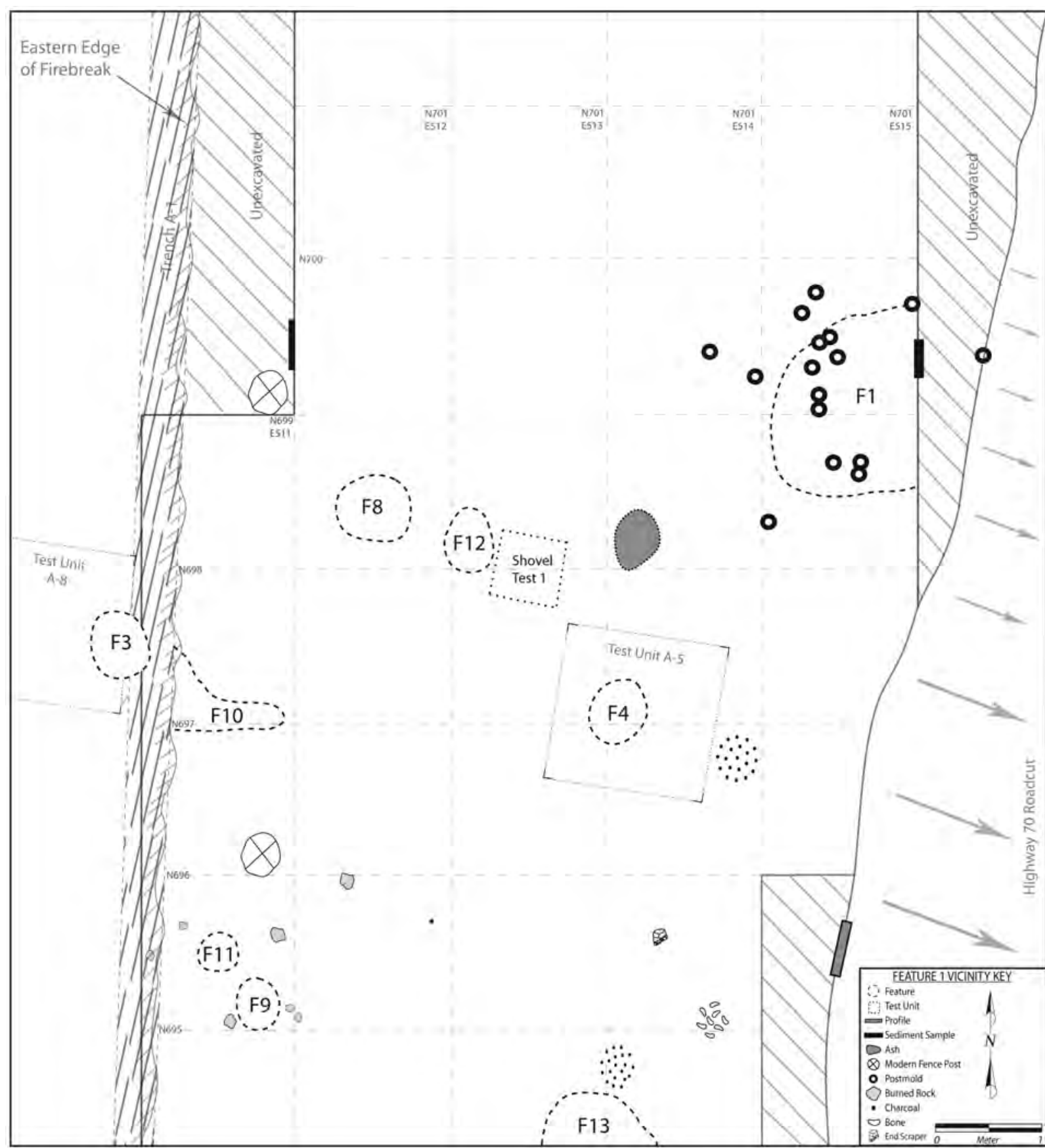

Figure 8-1. Overview of northern part of dense activity area in Component A, 41RB112.

of charcoal, a partially burned and pointed bone fragment, two small mussel shell fragments, and two small burned rock fragments. No oxidation rim, charcoal or ash lens, clay or rock lining, or other visible characteristics that would indicate use as a thermal feature were observed along the bottom edge of this basin (see Figures 8-2 through 8-5).
Feature 1 was not excavated during the eligibility assessment as it was clearly an important and significant feature. The part remaining was completely excavated during data recovery in the eastern margin of a large, linear block of units at the northern end of Component A. Hand-excavations revealed that only about $1+m$ of the basin remained under the natural prairie west of the road-cut exposure. This part of the 


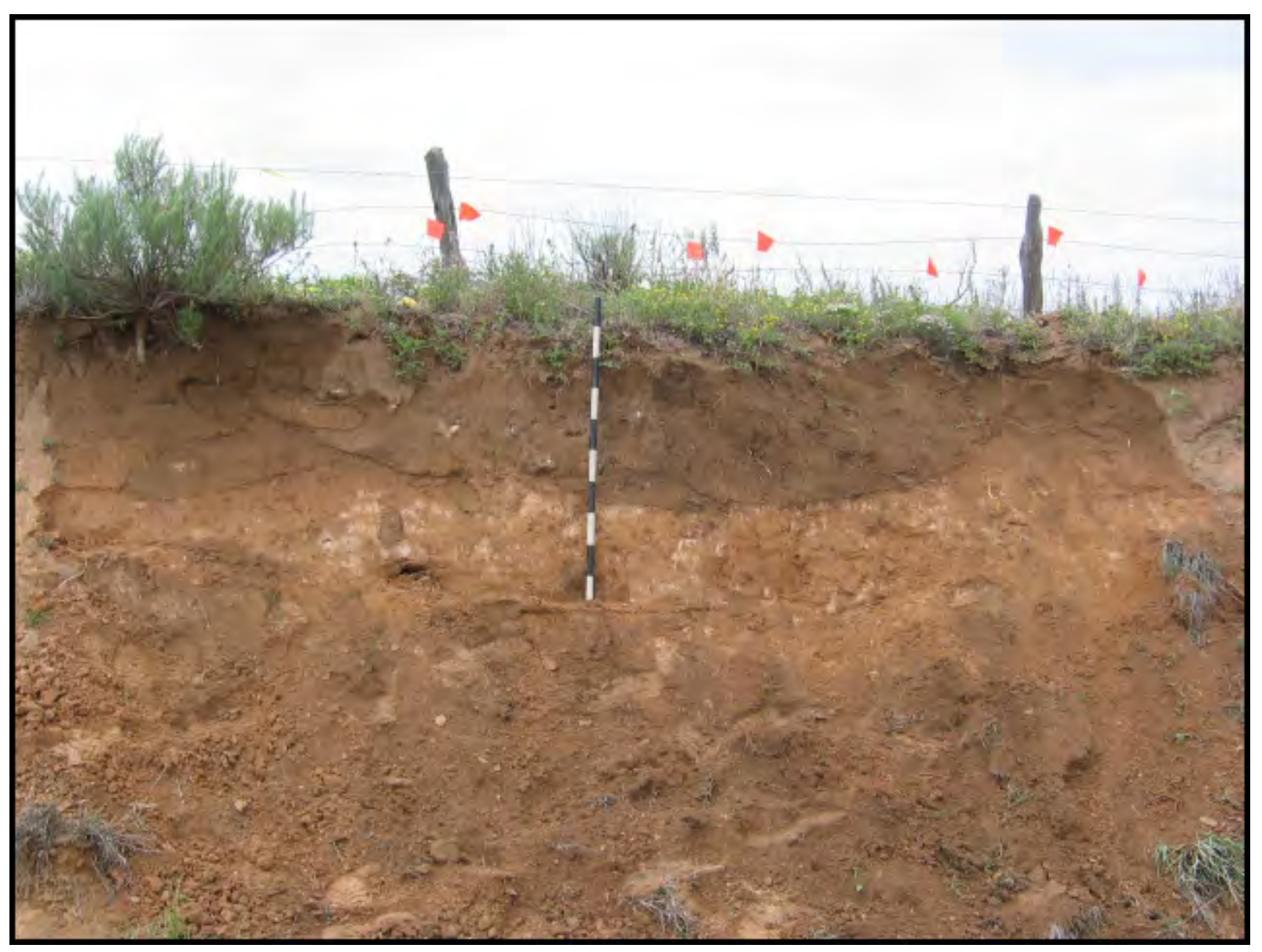

Figure 8-2. Deep basin, Feature 1 initially exposed in road cut.

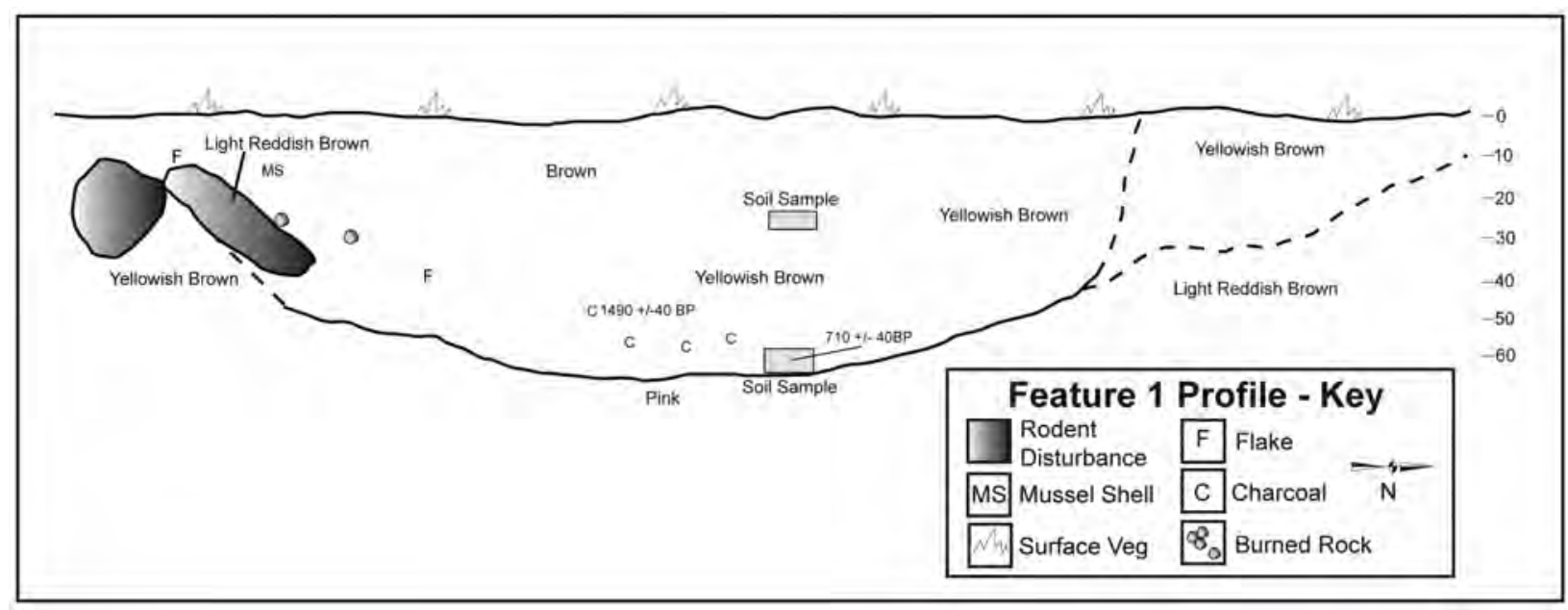

Figure 8-3. Profile drawing of Feature 1 exposed in road cut (view west). 


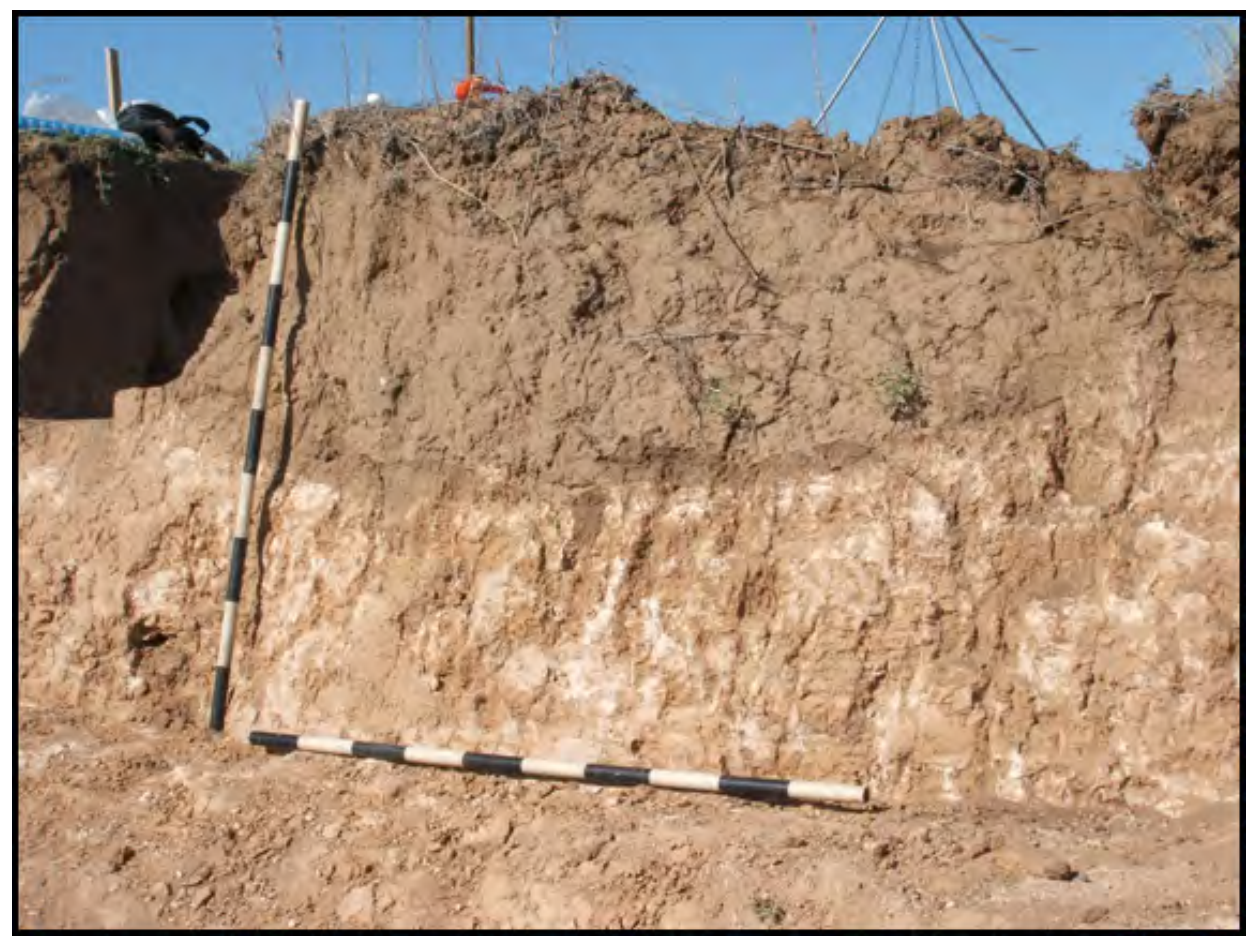

Figure 8-4. Eastern edge of pithouse exposed in road-cut following cleaning. (Note: small post hole in lower middle that penetrates into the underlying Ogallala Formation deposits).

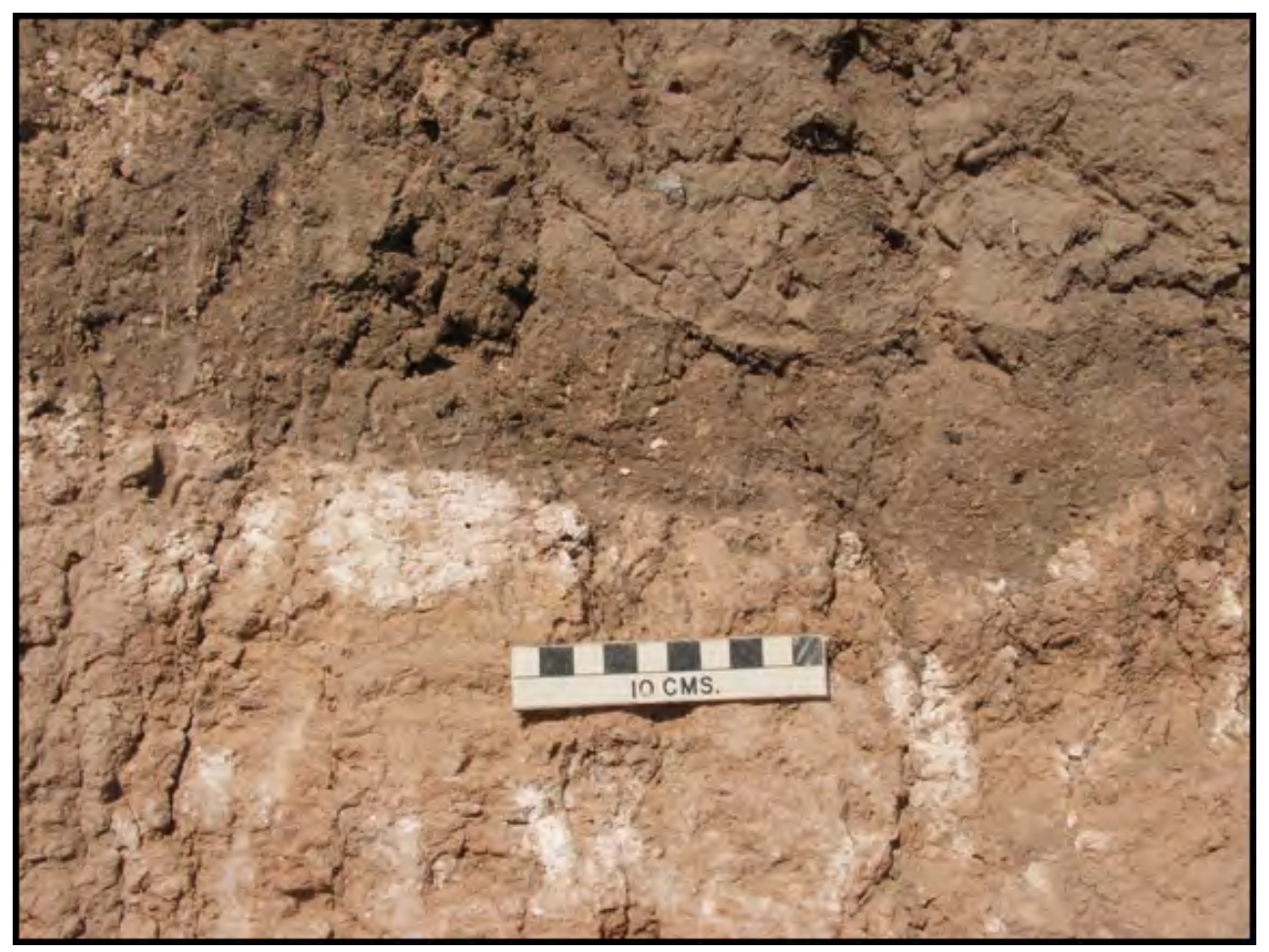

Figure 8-5. Close up of fill in bottom of pithouse and its contact with the underlying Ogallala deposits with patchy calcium carbonate. 
basin was captured within two 1-by-1 m units (N699 E515 and N700 E515). Each unit was excavated and the multiple walls of these units created profiles of the feature for documentation. The northern unit (N700 E515) encompassed the northern half of the basin that reached a depth of 60 cmbs. Excavating from the top down, the side walls of this basin were nearly impossible to distinguish until reaching the visible color change in the soil towards the bottom. As best determined, the poorly visible upper edge of the basin was roughly between 30 and 35 cmbs in the A horizon. That the upper margin of the feature was at this depth is supported by the fact that a sample of floated matrix from 20 to $30 \mathrm{cmbs}$ (\#1134-4) yielded almost no cultural materials. The basin fill was slightly darker than the surrounding sandy matrix and distinguishable by the presence of charcoal flecking and a few charcoal chunks, along with the occasional cultural artifact. Only the last 10 to $15 \mathrm{~cm}$ of the lower part of the basin was clearly distinguishable during excavation, and this became evident at about 45 to 50 cmbs. The very base of the basin was at 65 cmbs. The distinguishable basin in the lower part of the excavations measured about 1.2-by- $1 \mathrm{~m}$ with the upper portions disappearing into the A horizon (see Figures 8-3 and 8-4). Given that the basin angled outward toward the ground surface, it is assumed that the original upper edge would have had greater dimensions than those recorded at the very bottom of the basin. The western extent of this roughly ovate basin angled slightly towards the southwest. In general, the excavations revealed charcoal flecking and small chunks of daub between 20 and 30 cmbs. This was the first indication that the upper part of the pit was at this depth. The charcoal flecking and scattered pieces of diverse cultural materials such as

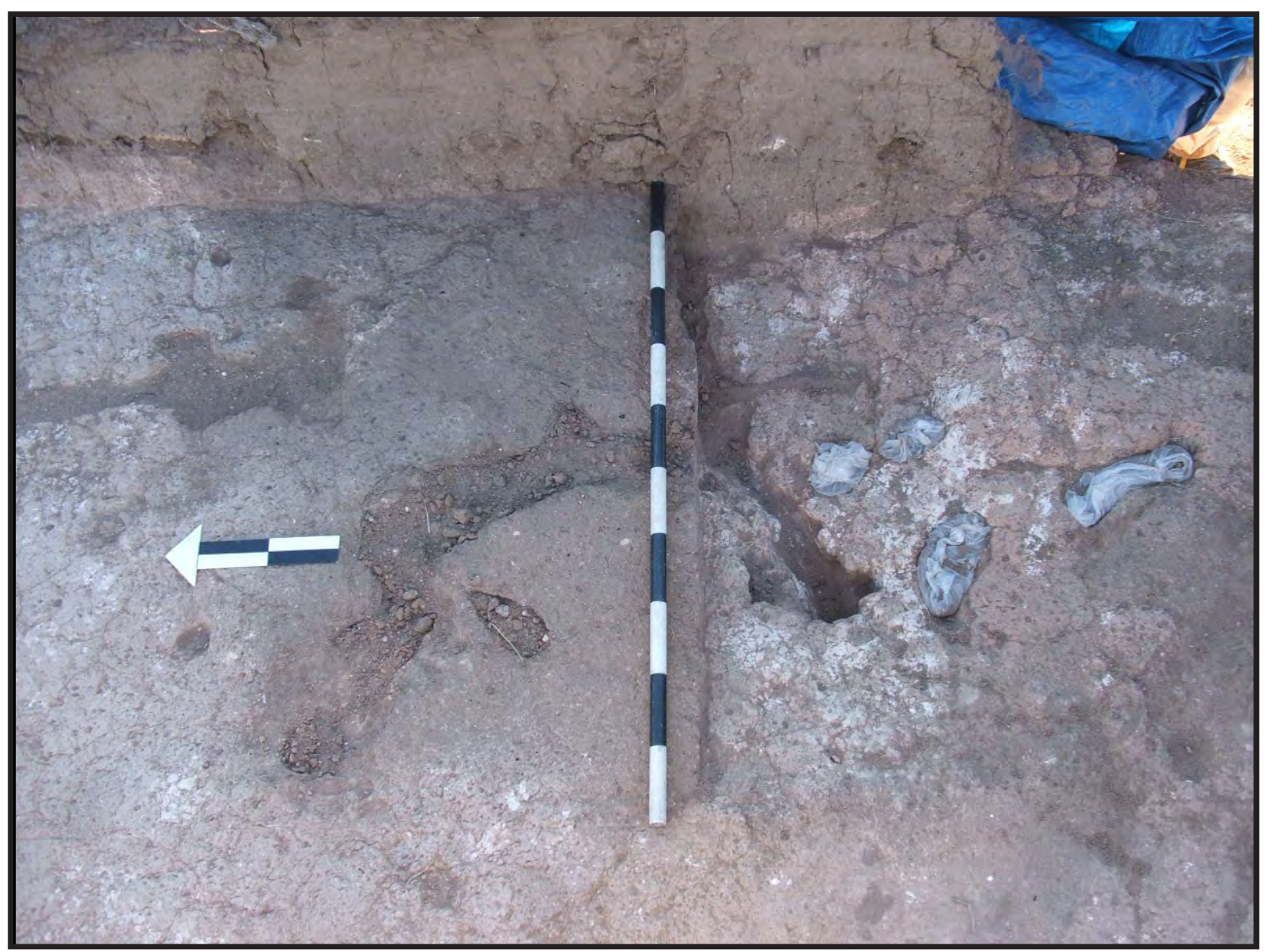

Figure 8-6. Overhead view of base of pithouse at junction of N700 (left) and N699 (right) showing rodent burrows and post holes (plastic in holes). 


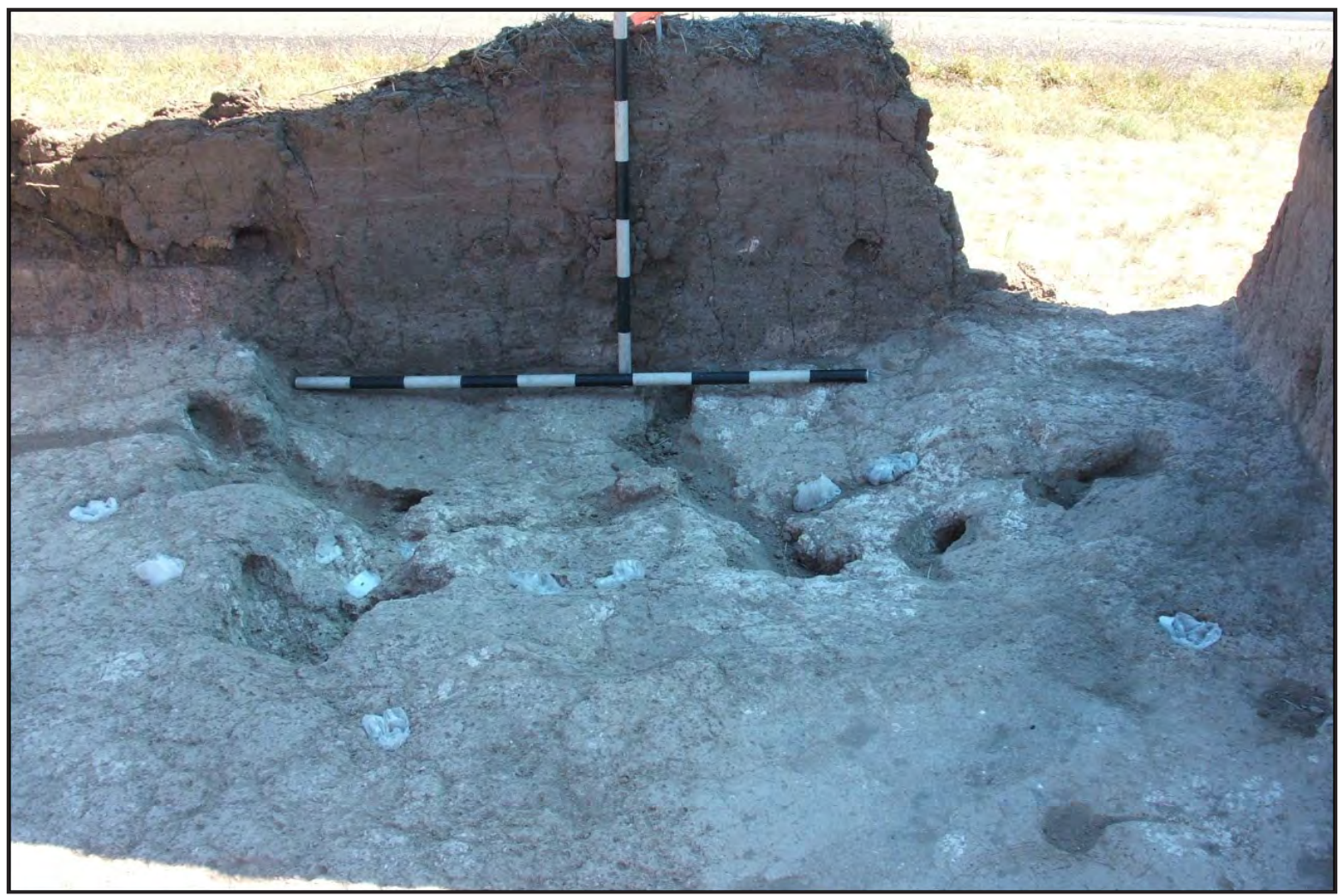

Figure 8-7. Oblique view of base of pithouse with fill removed at completion.

(Note: postholes filled with plastic, view is east).

bone fragments, small chert flakes, small pieces of daub, and the occasional ceramic sherd continued to ca. 65 cmbs.

Rodent holes and tunnels were abundant across and throughout the basin area and even into the Ogallala deposits below the bottom of the basin (Figures 8-6 and 8-7). Multiple unscreened sediment samples were collected for subsequent flotation in a controlled setting. These samples were from specific locations on and across the floor, and from parts of the lowest 10 to $15 \mathrm{~cm}$ of sediment within the basin.

\section{Stratigraphy and Geoarcheological Observations on Feature 1}

Charles D. Frederick and Brittney Gregory

In order to determine the stratigraphy of the Feature 1 pithouse two soil profiles (A-1 and A-2) were examined and recorded in the vicinity of Component A, at the north end of the site. Profile A-2, on the road cut exposure of Feature 1, revealed the cross section of a concave pithouse floor and the sedimentary fill within the structure (Figure 8-8). From this location a column of bulk soil samples and three oriented soil micromorphology blocks were also collected.

The specific observations, descriptions and arbitrary assigned zones of Profile A-2 are presented in Table 8-1 and address the deposits from top to bottom through the cultural pithouse into the Ogallala Formation deposits below. In general, the Ogallala deposits (Zone 5) are extremely old with the pithouse dug into this deposit. The boundary of the pithouse floor and the underling Ogallala is well-defined (see Figure 8-8). Following abandonment of the structure, the pithouse depression filled with windblown sand associated with the sand sheet facies of ESII. Nothing in the deposits that rested on the pithouse floor (Zone 4) indicated this pithouse contained a significant earthen cover or plaster component.

For stratigraphic comparison with the pithouse, a second control profile, A-1, was cleaned, described, and sampled (Table 8-2). This profile was near grid point N700 E511, on the western edge of the TxDOT 


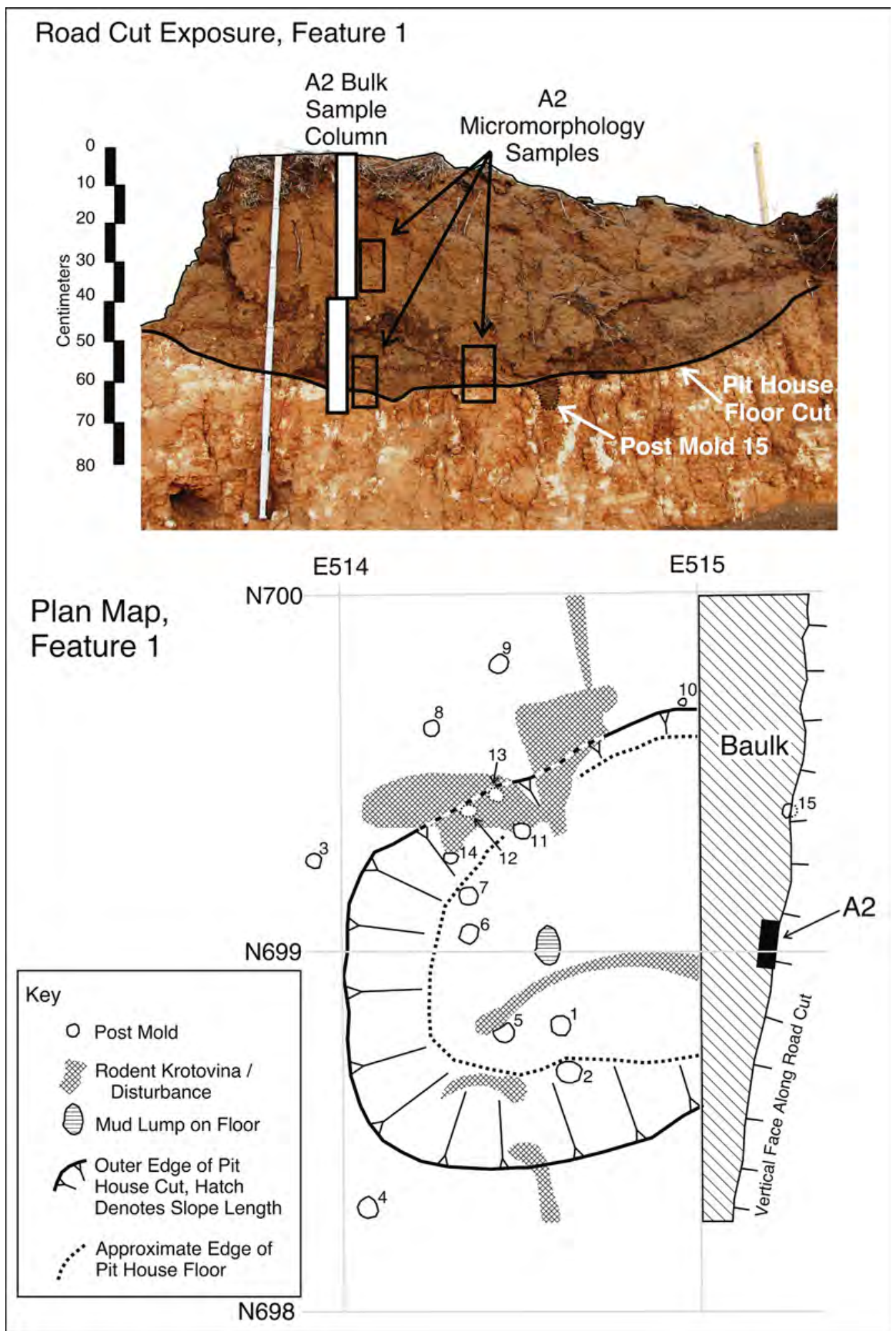

Figure 8-8. Profile and plan view of Pithouse Feature 1.

Upper panel: Baulk at road cut, eastern edge of Feature 1, Profile A-2 column sample and three micromorphological samples. Lower panel: plan view Feature 1 and Profile A-2 column sample. 
Table 8-1. Primary Field Descriptions: Profile A-2.

\begin{tabular}{|c|c|c|c|}
\hline Zone & Horizon & Description & Interpretation \\
\hline 1 & Ap & $\begin{array}{l}\text { Dark grayish brown }(10 \mathrm{YR} 4 / 2, \mathrm{~d} ; 10 \mathrm{YR} 3 / 3, \mathrm{~m}) \text { sandy loam, very friable, moderate } \\
\text { coarse to fine subangular blocky structure, abrupt to clear smooth boundary, few to } \\
\text { common krotovina. }\end{array}$ & $\begin{array}{l}\text { Fireguard Spoil / } \\
\text { Eolian Sand II (ESII) }\end{array}$ \\
\hline 2 & A1 & $\begin{array}{l}\text { Brown (10YR 4.5/3, d; 10YR 3.5/3, m) sandy loam, very friable, weak medium to } \\
\text { fine subangular blocky structure, clear smooth boundary, few to common krotovina. }\end{array}$ & ESII \\
\hline 3 & $\mathrm{~A} 2$ & $\begin{array}{l}\text { Brown }(7.5 \mathrm{YR} 4 / 3, \mathrm{~d} ; 10 \mathrm{YR} 3 / 3, \mathrm{~m}) \text { sandy loam, very friable, weak medium to fine } \\
\text { subangular blocky structure, clear smooth boundary, few to common krotovina. }\end{array}$ & ESII \\
\hline 4 & $2 A p$ & $\begin{array}{l}\text { Brown }(7.5 Y R \text { R/2, d; } 7.5 \text { YR } 3 / 2, \mathrm{~m}) \text { sandy loam, very friable, weak to moderate } \\
\text { medium prismatic structure parting to moderate fine subangular blocky structure, } \\
\text { abrupt smooth to abrupt irregular boundary, many charcoal fragments, few small } \\
\text { bone fragments, many } 1-2 \mathrm{~mm} \text { wide passage features filled with Zone } 5 \text { material. }\end{array}$ & $\begin{array}{l}\text { Pithouse Floor and } \\
\text { ESII }\end{array}$ \\
\hline 5 & $3 \mathrm{Bk}$ & $\begin{array}{l}\text { Yellowish brown }(10 \mathrm{YR} 5 / 4 \text {, d; } 7.5 \mathrm{YR} 5 / 4, \mathrm{~m}) \text { silt loam, friable, strong medium } \\
\text { prismatic structure parting to strong fine angular blocky structure, many }(25 \%) \\
\text { medium to coarse }(1-4 \mathrm{~cm}) \text { white calcium carbonate nodules, common }(7-10 \%) \\
\text { discontinuous patchy coats of calcium carbonate on ped faces, common }(5-7 \%) \\
\text { calcium carbonate filaments, many } 1-2 \mathrm{~mm} \text { wide passage features filled with Zone } 4 \\
\text { material. }\end{array}$ & Ogallala Formation \\
\hline
\end{tabular}

Table 8-2. Primary Field Descriptions: Profile A-1.

\begin{tabular}{|c|c|c|c|}
\hline Zone & Horizon & Description & Interpretation \\
\hline 1 & Ap & $\begin{array}{l}\text { Brown (10YR 5/3, d; } 10 \text { YR 4/3, m) sandy loam, very friable, weak medium subangular } \\
\text { blocky structure, abrupt smooth boundary, many krotovina, traces of lamination in places } \\
\text { similar to fireguard elsewhere on site. }\end{array}$ & Fireguard Spoil \\
\hline 2 & A & $\begin{array}{l}\text { Brown }(10 \mathrm{YR} 4 / 3 \text {, d; } 10 \mathrm{YR} 3 / 3, \mathrm{~m}) \text { sandy loam, very friable, moderate medium subangular } \\
\text { blocky structure, clear smooth boundary, darker in upper } 3 \mathrm{~cm} \text {. OSL sample collected } \\
\text { from this zone at a depth of } 20 \mathrm{~cm} \text { yielded a single grain age distribution from which } \\
\text { finite mixture modeling identified two age components, the majority of the grains }(88 \% \\
\text { of measured grains) yielded an age of } 510 \pm 50 \text { years B.P., whereas a second component } \\
\text { (12\% of grains) yielded an age of } 180 \pm 90 \text { years B.P., the older and dominant component is } \\
\text { considered a reliable age for the transportation of this sand. }\end{array}$ & ES II \\
\hline 3 & $2 \mathrm{~A}$ & $\begin{array}{l}\text { Brown (10YR 5/3, d; } 10 \text { YR 4/3, m) sandy loam, very friable, moderate medium prismatic } \\
\text { structure parting to moderate medium subangular blocky structure, clear smooth boundary, } \\
\text { numerous small charcoal fragments and small quantities of prehistoric cultural items } \\
\text { between } 30-40 \mathrm{~cm} \text {. }\end{array}$ & ES II \\
\hline 3a & $\mathrm{C}$ & Brown (10YR 5/3, d; 10YR 4/3, m) sandy loam, similar to Zone 3; probable fence post fill. & Fence Post Fill \\
\hline 4 & $2 \mathrm{ABb}$ & $\begin{array}{l}\text { Yellowish brown }(10 \mathrm{YR} 5 / 4, \mathrm{~d} ; 7.5 \mathrm{YR} 4 / 3, \mathrm{~m}) \text { loam, very friable, strong medium to fine } \\
\text { subangular blocky structure, abrupt smooth boundary, few }(1-3 \%) \text { calcium carbonate } \\
\text { filaments. }\end{array}$ & $\begin{array}{l}\text { Soil Formed in } \\
\text { Ogallala Formation }\end{array}$ \\
\hline 5 & $3 \mathrm{Bk}$ & $\begin{array}{l}\text { Light brown }(7.5 Y R \text { R/4, d; } 7.5 \text { YR } 5 / 4, \text { m) silt loam, very friable, moderate coarse prismatic } \\
\text { structure parting to strong medium subangular blocky structure, common }(5-10 \%) \text { calcium } \\
\text { carbonate filaments, many }(10-25 \%) \text { medium to coarse }(1-7 \mathrm{~cm}) \text { sharp edged white calcium } \\
\text { carbonate nodules. }\end{array}$ & Ogallala Formation \\
\hline
\end{tabular}


right-of-way about $4 \mathrm{~m}$ west of pithouse Feature 1 and Profile A-2. Observations of Profile A-1 are presented in Table 8-2 for direct comparison with the descriptions in Table 8-1. Below, an in depth discussion is presented of the observed deposits from the two columns beginning with the oldest that predate Feature 1.

Ogallala Formation deposits (Zone 5) directly beneath Feature 1 consisted of yellowish brown (10YR 5/4, d) silt loam with prominent prismatic structure and well-developed stage II calcic soil horizon characterized by large (generally 1 to 4 $\mathrm{cm}$ diameter, a few more than $7 \mathrm{~cm}$ ) white calcium carbonate nodules (see Figure 8-8). The Ogallala Formation in this specific setting had been truncated naturally by erosion, and the upper portion of this deposit was later abruptly truncated by the human excavation of the pithouse, leaving a sharp boundary with wavy to irregular topography at the base of Zone 4. Multiple worm and insect passages perforate the interface between the Ogallala and structure floor deposits. The particle size distribution of the Ogallala sediments beneath the structure is polymodal. The dominant mode (about 4.06 phi), straddles the boundary between very fine sand and coarse silt, with a small mode in the fine sand (about 2.29 phi) and a small, but broad mode in the fine to very fine silt range (centered about on 7.5 phi; Figure 8-9). In thin section, Ogallala sediments exhibit an open to close porphyric related distribution, with the coarse fraction about 10 to 20 percent medium sand and a fine fraction of coarse silt. Typic, impregnative calcium carbonate nodules are common and highly variable in size, generally in excess of $5 \mathrm{~mm}$. The exceptionally large nodules common in the Ogallala beneath the pithouse Feature 1 were not sampled for petrographic examination. Passage features filled with sandy loam Zone 4 sediment were common within the upper portion of the Ogallala Formation beneath the pithouse, but well-defined excrement was uncommon due to the relatively coarse texture of the sand.

\section{Deposits within Feature 1, Pithouse Floor Deposits, Profile A-2}

Sedimentary deposits in Zone 4 believed to be associated with Feature 1 pithouse were dark brown, (7.5YR 4/2, d; 7.5YR 3/2, m) sandy loam, about 10-cm-thick, rested directly upon the structure floor (Zone 4 on Figure 8-10 and see Table 8-1). Consequently, the pithouse floor is generally a blurred line and not a zone. Zone 3 sediment, 15-cm-deep, of slightly lighter color, but still notably melanized (brown 7.5YR 4/3, d; dark brown 10YR 3/3, m) sandy loam rested on top of the pithouse floor. Zone 3 and 4 deposits exhibited elevated levels of organic carbon, magnetic susceptibility and phosphorus, as compared with the overlying and underlying deposits (see Figure 8-10). Given that the deposits in the same stratigraphic position outside the structure in Profile A-1 (specifically Zone 4) do not show the same degree of enrichment, the enhancement within the pithouse is either due to cultural activity within the structure or pedogenic alteration following abandonment of the structure, but associated with the microtopography (specifically the depression) of the abandoned building.

Particle size distribution of Zone 4 sediments and the overlying Zone 3 reveal similar composition as the eolian sands that comprise the upper part of this profile (see Figure 8-9). Zones 3 and 4 sands within the pithouse are distinctly different from the underlying Ogallala Formation.

From the data presented in Figure 8-10 it is deduced that the pithouse lacked a plastered floor, an earthen plaster cover, and was likely only covered with brush. The sediment excavated from the Ogallala Formation to create the pithouse did not end up on the floor of the structure as a possible cover, and was clearly moved elsewhere.

Micromorphological observation of thin sections from the floor deposit (Zone 4) revealed predominantly a coarse fraction of medium to fine sand with a fine fraction in the coarse silt size range. The coarse/fine related distributions present in this deposit range from chitonic to close porphyric, and showed no evidence of trampling-related microlamination or other such microstructure. One dominant micromorphological attribute of Zone 4 was the presence of many generations of excrement pedofeatures and passage structures. Introduction of underlying Ogallala sediments through these passage structures resulted in obvious differences in color, particle size, and texture. These structures 


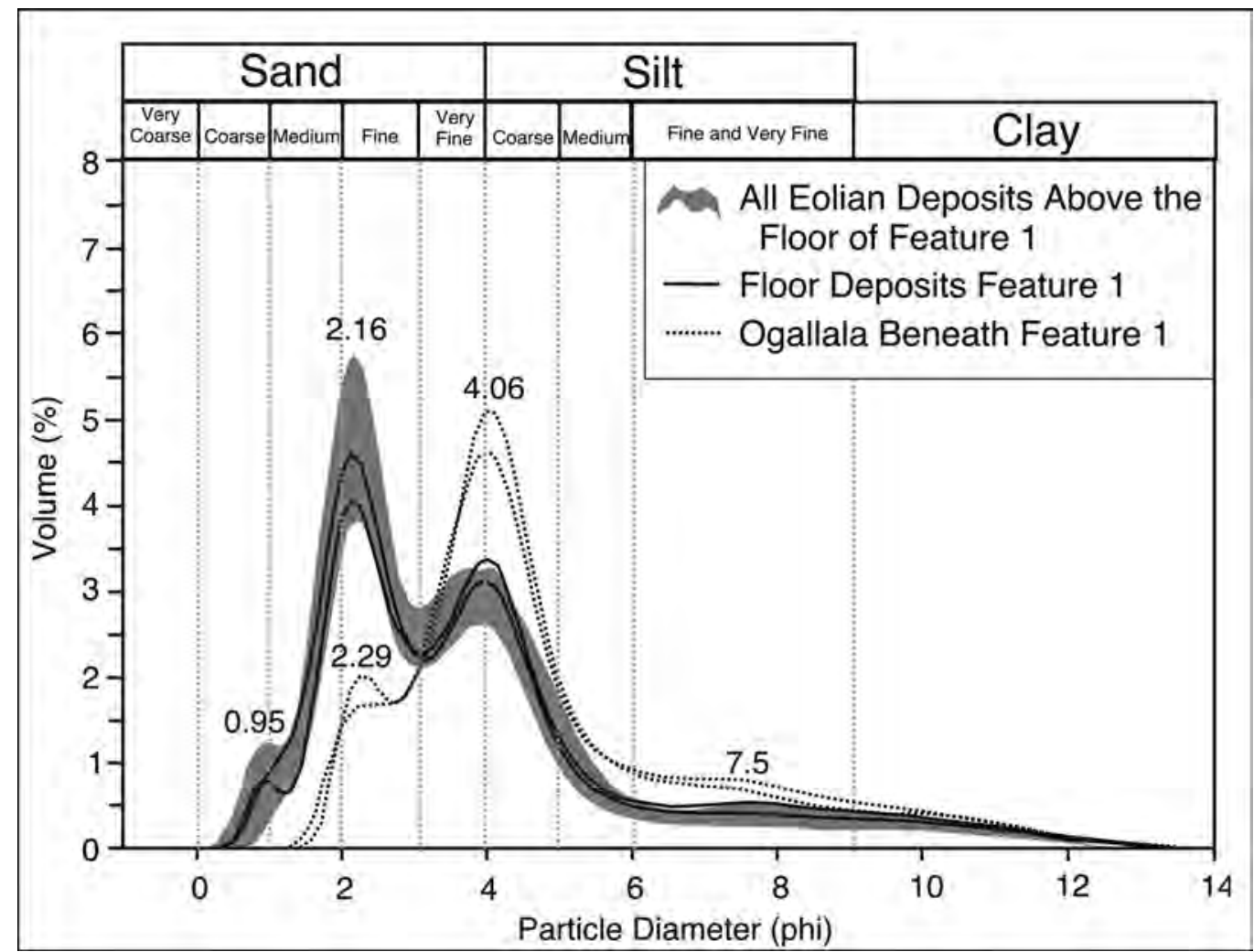

Figure 8-9. Profile A-2 particle size distribution for Feature 1 floor deposits compared to Ogallala formation sediments immediately beneath.

Note similarity of Profile A-2 floor deposits of Feature 1 with overlying ESII sediments, and prominent mismatch to underlying Ogallala Formation.

comprised more than 50 percent of the examined thin sections in the majority of samples.

The slightly organically enriched sandy sediments of Zone 4 inside the pithouse are compositionally similar to ESII. This suggests that either deposition of the sand sheet was ongoing while the structure was in use, or postdepositional processes (specifically pedoturbation and pedogenesis) altered and dispersed artifacts within this structure following abandonment. There is ample evidence of postdepositional bioturbation from the horizontal and vertical burrows of gophers (see krotovina distribution, see Figure 8-8, lower panel) and the large quantity of predominantly vertically oriented passage features of worms and other soil microfauna.

Evidence indicative of a wooden frame with brush cover over the pithouse includes multiple post molds in the floor and margins of the pit depression, and an apparent fragment of mud dauber wasp nest in one of the micromorphological samples collected from Zone 4, near Post Mold 15 (see Figure 8-8). The nest fragment in the thin section is an incomplete oblique cross-section comparable in size to modern mud dauber nests (Figure 8-11, B). Several attributes typical of modern mud dauber nests are visible, such as prominent arcuate voids less than 5-mm-wide, a flat attachment surface, and y-shaped vughs. The composition is finer textured and significantly redder than the floor sediments and similar in texture, but much redder than Ogallala Formation deposits immediately beneath the floor. The microstructure is consistent with mud dauber wasp construction, specifically micro-interlamination of red loam and calcium carbonate-dominated mud (presumably reworked fragments of pedogenic carbonate nodules within the Ogallala Formation). This fragment is consistent with a mud dauber wasp nest constructed from Ogallala Formation sediment, but 


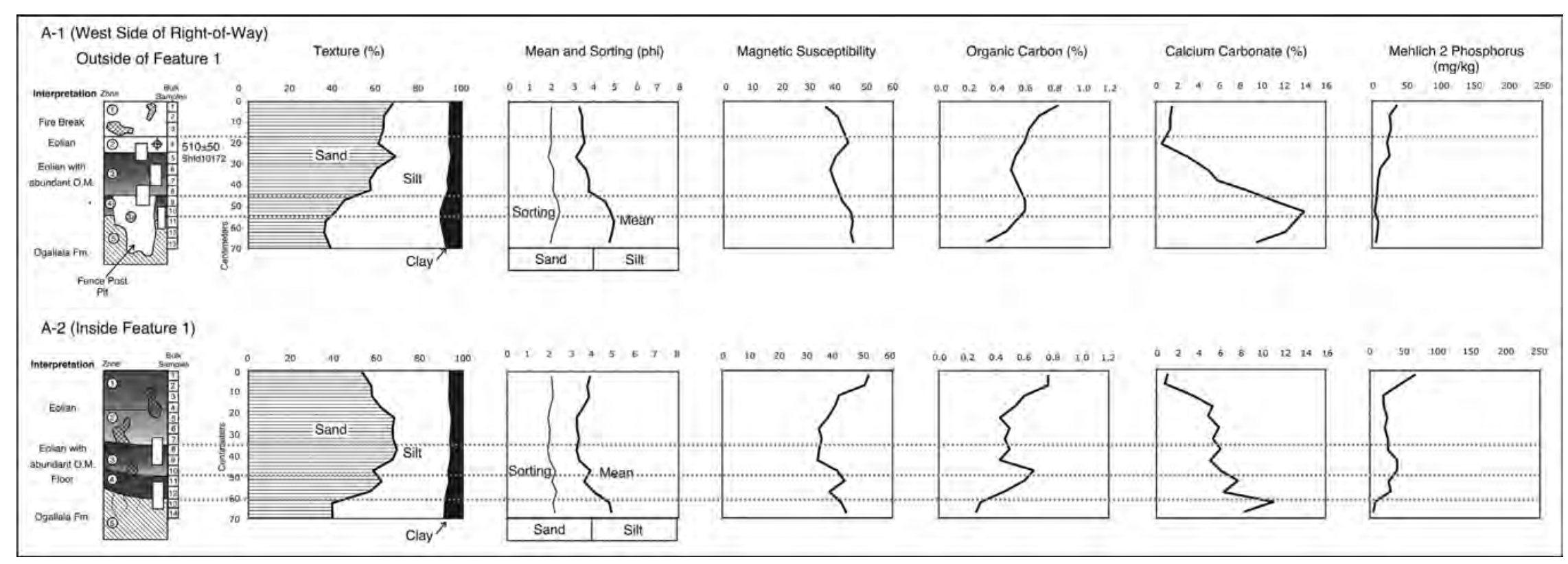

Figure 8-10. Depth variation in bulk soil properties between Profile A-1 (control) and Profile A-2 (inside pithouse Feature 1). 


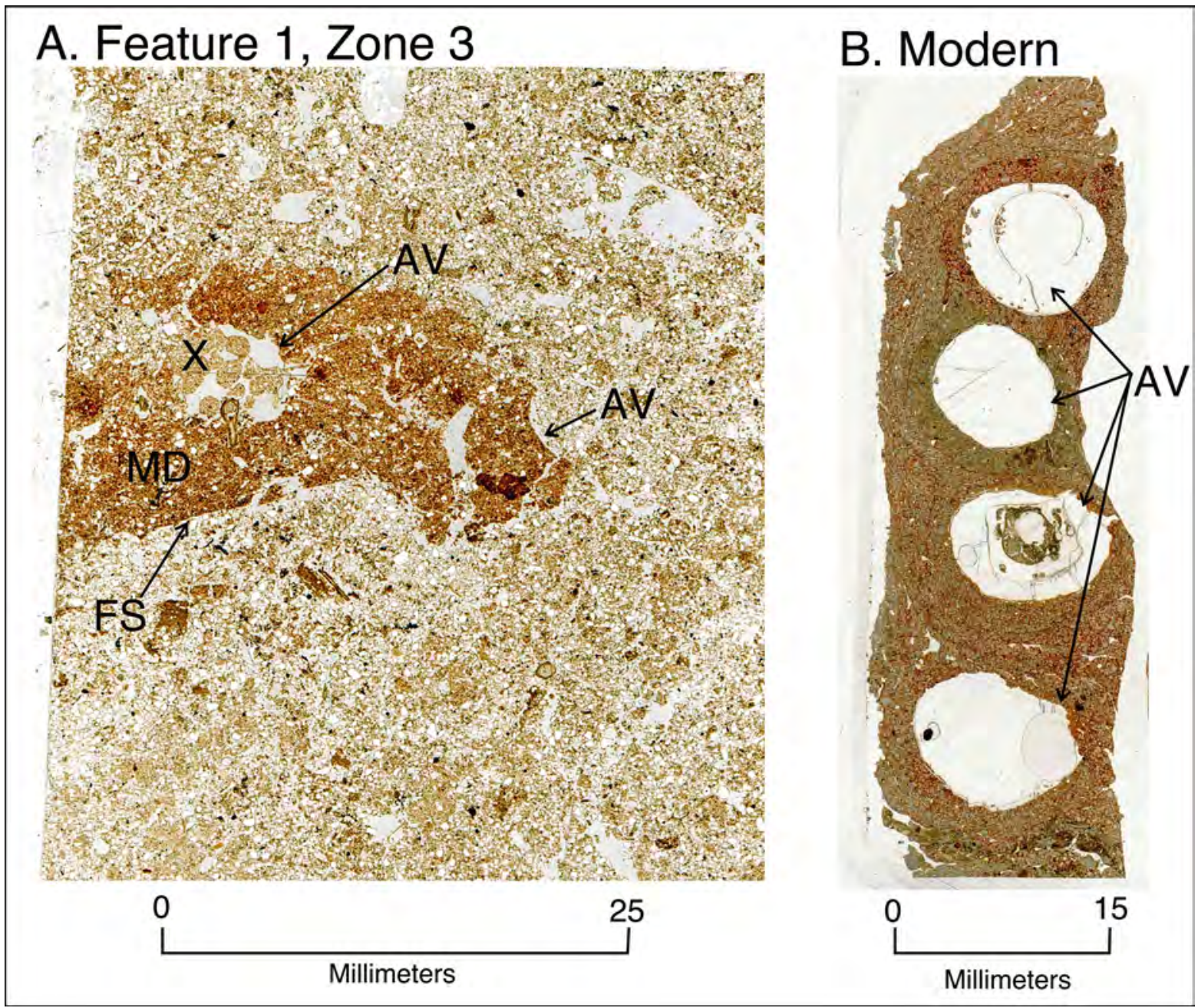

Figure 8-11. Transmitted light scan of micromorphology Block 6, Zone 4, from road cut profile of Pithouse Feature 1.

The dark red sandy loam to silt loam textural pedofeature in the center left is thought to be a fragment of a mud dauber wasp nest (MD).

Note the prominent arcuate voids (AV), one of which contains a loose excremental infill (X). Also, note the nearly flat surface (FS) at the base, consistent with an attachment surface for the nest. B: Transmitted light scan of a thin section of a modern mud dauber wasp nest, made perpendicular to the long axis of the chambers. Arcuate voids (AV) dominate this slide, but the earthen material also displays a vughy microstructure in places, similar to those seen in $A$. 
is not consistent with Ogallala deposits immediately below the pithouse. The presence of such a nest in the current context is highly suggestive of a brush superstructure for this pithouse.

All of the Profile A-2 sediments overlying Zone 5 and postdating the pithouse floor were sandy loams associated with ESII, within which a weak soil had formed. This soil consists of an Ap-A1-A2 profile where the Ap horizon is thought to be fireguard spoil and exhibited increased amounts of silt towards the modern ground surface, presumably from incorporation of Ogallala Formation sediment. However, the opposite was observed in Profile A-1, where fireguard sediments coarsened upward slightly. Evidence of modern soil formation was present in the upper portion of both profiles, as indicated by increases in organic carbon, phosphorus, and magnetic susceptibility, and a decrease in calcium carbonate at the very top of the profile.

In sum, the deposits within and above the pithouse floor are texturally and petrographically consistent with the sand sheet deposits of ESII. There is no evidence of an earthen plaster that might have covered this structure. All sediments within and overlying the pithouse contained significantly more organic carbon than the underlying Ogallala Formation. These sediments were deposited in a very slowly aggrading sand sheet setting conducive to the development of a cumulic A horizon. Organic carbon depth variation suggests somewhat variable sedimentation rate.

Those bottom deposits did not contain any large pieces of obvious construction remnants such as charred posts, large chunks of daub, rocks, or plaster. Cultural materials were extremely sparse across the floor. When artifacts were encountered in situ, they were piece plotted and collected, whereas most small items were recovered from the screen.

Some 16 post holes were identified around the margin and inside the recognized bottom of the basin. It was difficult to distinguish possible cultural posts from the many rodent holes. Each potential post hole was carefully examined, but most were shallow and hard to distinguish from the rodent holes. In seven cases, molds were made using expanding foam to preserve the size and shape of the holes. The identified post holes ranged in size from 2.5 to $7.5 \mathrm{~cm}$ in diameter with an average of $5.9 \mathrm{~cm}$ diameter (Table 8-3). The depths ranged from 2 to $10 \mathrm{~cm}$ with an average of 6 $\mathrm{cm}$. The dark-stained post hole observed exposed in the road cut and toward the middle of the pithouse was the smallest (see Figure 8-4). Eight probable post holes were within the basin, whereas six others were detected outside the distinguishable margins of the basin (Figures 8-6 through 8-8, 8-12, 8-13). The current interpretation is that at least two rows of wooden posts were employed in the construction, with some along the inside margin and some along the outer edge. The recognized post holes represent the bottoms of posts, some of which may not have been driven into the ground as deeply as others. In a couple of instances inside the basin, the holes were quite shallow and not as well-defined as others. The observed pattern may not be representative of the original post pattern. It is not clear if the differences in depth or their locations reflect corresponding differences in post functions. In at least two instances, identified holes inside the basin were in pairs, but this may be a fact of recognition, a small sample, or a skewed perception due to rodent disturbances (Figure 8-13).

For the interim report submitted following the field assessment, a piece of juniper charcoal was radiocarbon dated. The sample came from matrix collected from the side of the road cut, and from inside and near the bottom of the basin, between 62 and 64 cmbs (see Figure 8-3). This charcoal (\#31-4-2a) yielded a $\delta^{13} \mathrm{C}(-23.0 \%$ o) corrected AMS date of $710 \pm$ 40 B.P. (Beta-206557). A second piece-plotted chunk of pine/juniper charcoal (\#31-7-1) from $52 \mathrm{cmbs}$ inside the basin yielded a $\delta^{13} \mathrm{C}(-23.3 \%)$ corrected AMS date of $1490 \pm 40$ B.P. (Beta-206558). The two charcoal dates reflect diverse ages, and it is suggested that the oldest date does not reflect the actual period of pithouse use. Subsequently, a maize kernel (\#1164$7-2)$ from 50 to $60 \mathrm{cmbs}$ in the northern half of the basin was radiocarbon dated, yielding a $\delta^{13} \mathrm{C}(-11.3 \%)$ corrected AMS date of $590 \pm 25$ B.P. (UGAMS-7839). Based on the latter age and other radiocarbon dates obtained from Component A, the 1490 B.P. date is unacceptable. A possible explanation of this early unacceptable date is that the charcoal represents a piece of older dried wood used during the much later occupation (Smiley 1985; Schiffer 1986). 
Two bulk sediment samples from inside the broader basin between 50 and $60 \mathrm{cmbs}$, one of 18 liters from the western half (\#1164-4-2b), and the second of 36 liters from the eastern half (\#1164-4$3 b)$ of N700 E515 were floated. The light fractions were sent to Dr. Phil Dering for macrobotanical analysis. Dering's detailed findings are presented in Appendix C. The light fractions from both sides of the pithouse are comparable and Dering identified juniper or pine family wood type in four of the seven macrobotanical samples, and rose family wood, possibly sand plum in two samples. Each sample contains maize cupules and kernels, but no other evidence of cultigens or other food plants. Juniper and mesquite are the most abundant identifiable wood types. Maize fragment density in the sample from the eastern half is roughly twice that of the western half (Appendix C).

The heavy fractions were systematically sorted. The $59 \mathrm{~g}$ heavy fraction (\#1164-4-3) from the eastern half yielded 1 tiny mussel shell fragment, 16 tiny pieces of lithic debitage (16 g), 1 tiny fleck of charcoal, 1 charred seed, 17 tiny bone fragments $(5.7 \mathrm{~g})$, and 3 tiny pieces of daub ( $0.1 \mathrm{~g}$; Table $8-4)$. The 53.8 g heavy fraction (\#1164-4-2) from the western half yielded 20 tiny pieces of lithic debitage ( $0.3 \mathrm{~g})$, tiny flecks of charcoal, 30+ tiny bone fragments (17.9 g), and 26 tiny pieces of daub (5.8 g). Less than 10 percent of the tiny bone fragments were burned, and these fragments appear primarily in the size range of small rabbit size mammals. Medium-size mammals (i.e., deer/pronghorn) are represented by a few of the unburned fragments. The tiny daub fragments are mostly rounded from the flotation process and show no distinguishing marks or impressions, and may actually be burned clay chunks. The $3.1 \mathrm{~g}$ of heavy fraction (\#1164-4-4) from the western half yielded 1 maize fragment and 3 bone fragments.

Four pieces of charcoal (\#1114-7-1, \#1160-7-1, \#1162-7-1, and \#1164-7-3) were also sent to Dering for wood identification. The results indicate two are juniper (Juniperus sp.), and two are Rosaceae (Appendix C). A ceramic sherd (\#1162-8-1) from $43 \mathrm{cmbs}$ in the basin fill was subjected to starch

Table 8-3. Metric Data of Identified Post Holes in Associated with Pithouse - Feature 1.

\begin{tabular}{|c|c|c|c|c|c|}
\hline $\begin{array}{c}\text { Hole } \\
\text { Number }\end{array}$ & $\begin{array}{c}\text { Hole } \\
\text { Location }\end{array}$ & $\begin{array}{c}\text { Hole } \\
\text { Width }\end{array}$ & $\begin{array}{c}\text { Hole } \\
\text { Depth }\end{array}$ & $\begin{array}{c}\text { Sediment } \\
\text { collected }\end{array}$ & $\begin{array}{c}\text { Post Mold } \\
\text { Made }\end{array}$ \\
\hline 1 & inside & 7.5 & 10 & Yes & Yes \\
\hline 2 & inside & 9 & 5 & Yes & Yes \\
\hline 3 & outside & 6 & 5 & Yes & Yes \\
\hline 4 & outside & 6 & 6 & Yes & Yes \\
\hline 5 & inside & 6 & 9 & Yes & Yes \\
\hline 6 & inside & 6 & 10 & Yes & No \\
\hline 7 & inside & 7 & 7 & Yes & No \\
\hline 8 & outside & 5 & 3.5 & Yes & No \\
\hline 9 & outside & 6.5 & 4 & Yes & Yes \\
\hline 10 & outside & 2.5 & 2.5 & Yes & No \\
\hline 11 & inside & 5.5 & 6 & Yes & Yes \\
\hline 12 & inside & 6 & 4 & Yes & No \\
\hline 13 & inside & 4 & 2 & Yes & No \\
\hline 14 & inside & 5 & 9.5 & Yes & No \\
\hline 15 & inside & 6 & 7 & Yes & No \\
\hline 16 & outside & $?$ & $?$ & No & No \\
\hline
\end{tabular}




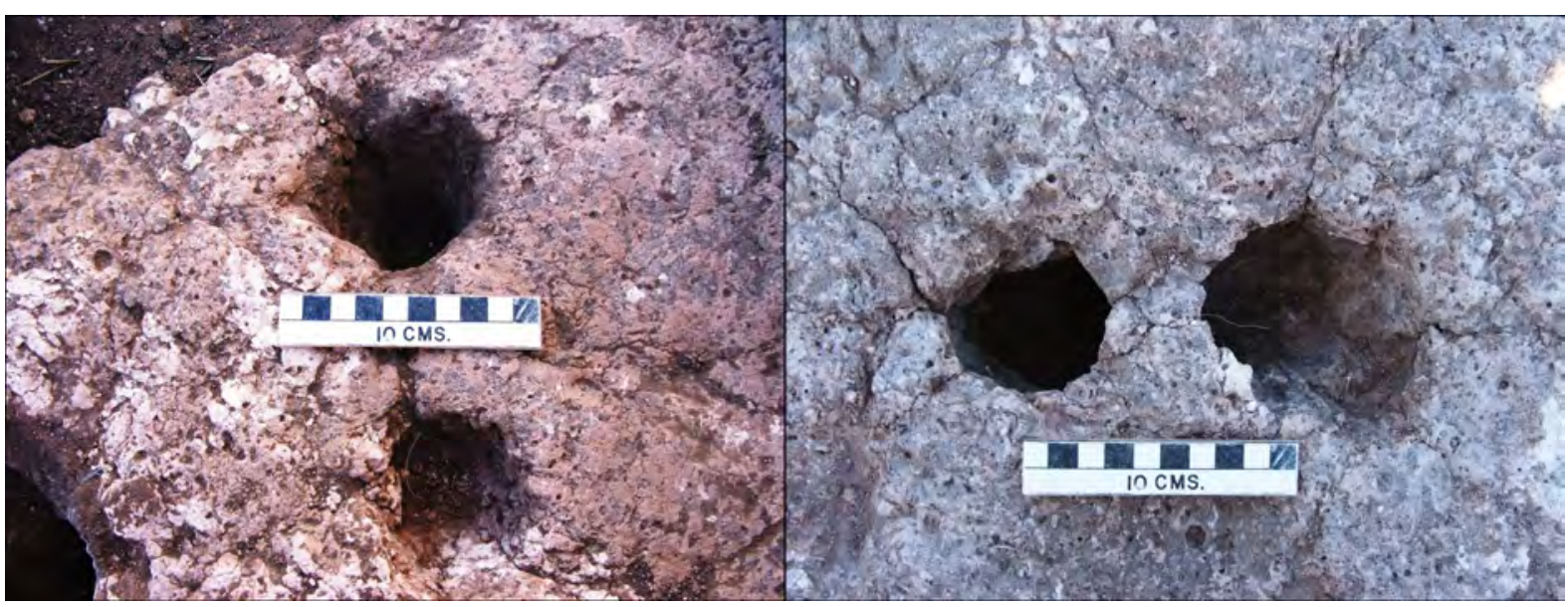

Figure 8-12. Two examples of cleaned out post holes that extended below the floor of pithouse into the Ogallala deposits.

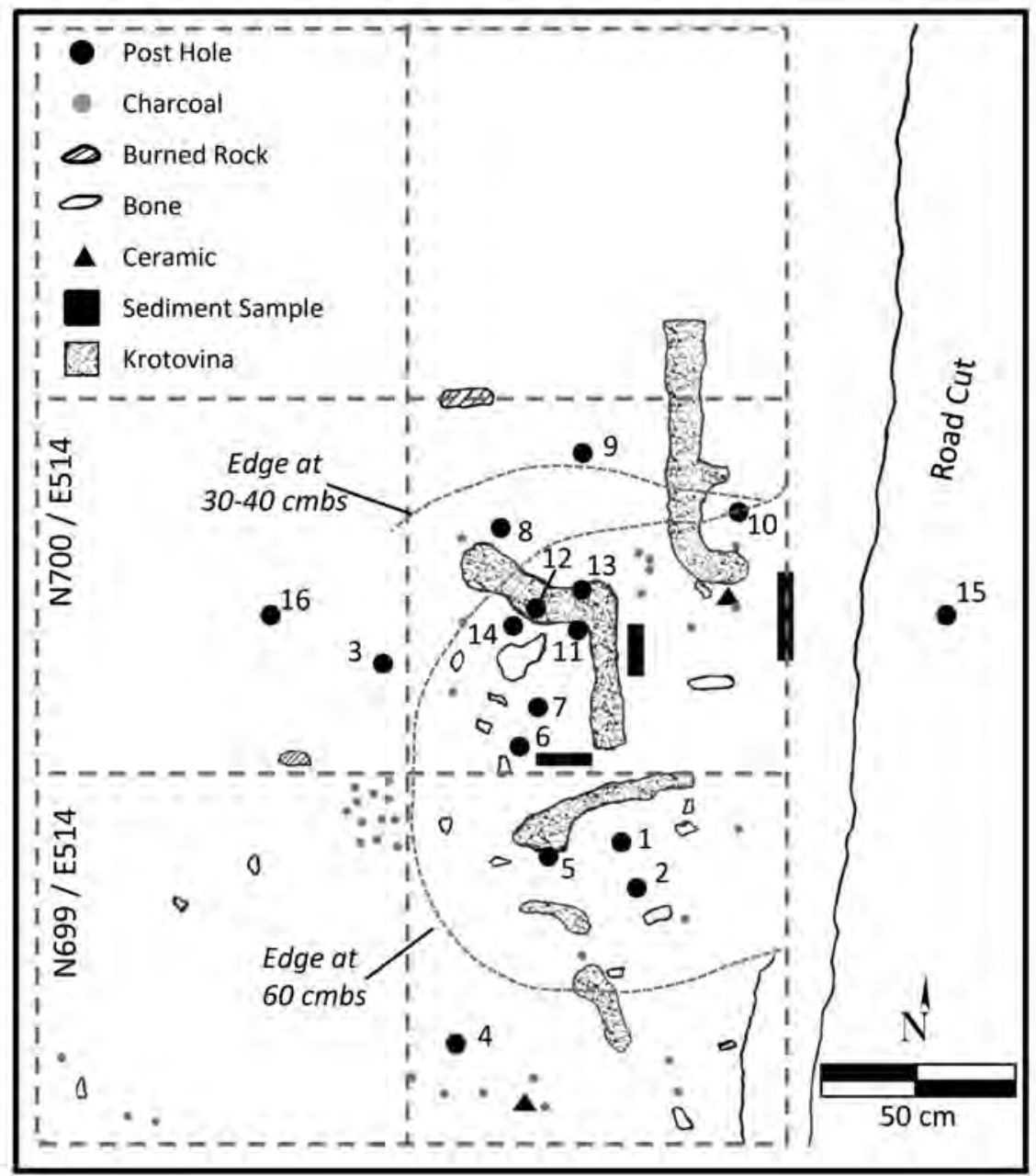

Figure 8-13. Plan view drawing of pithouse floor - Feature 1 in Component $A$. 
Table 8-4. Component A, Heavy Fraction Results by Material Class.

\begin{tabular}{|c|c|c|c|c|c|c|c|c|c|c|c|c|c|c|c|c|c|c|c|c|c|c|}
\hline \multirow[t]{3}{*}{$\begin{array}{c}\text { Cat No./ } \\
\text { No.of Liters }\end{array}$} & \multirow[t]{3}{*}{ Unit } & \multirow[t]{3}{*}{$\begin{array}{l}\text { Depth } \\
\text { (cmbs) }\end{array}$} & \multirow[t]{3}{*}{ Feature No. } & \multirow[t]{3}{*}{$\begin{array}{c}\text { Weight } \\
\text { (g) }\end{array}$} & & \multicolumn{16}{|c|}{ Flotation Recovery } & \multirow{3}{*}{ Comments } \\
\hline & & & & & & \multicolumn{2}{|c|}{ Mussel Shell } & \multicolumn{2}{|c|}{ Burned Rock } & \multicolumn{2}{|c|}{ Debitage } & \multicolumn{2}{|c|}{ Charcoal } & \multicolumn{2}{|c|}{ Macrobotanical } & \multicolumn{2}{|c|}{ Ceramic } & \multicolumn{2}{|c|}{ Bone } & \multicolumn{2}{|c|}{ Daub } & \\
\hline & & & & & & $1 / 4$ & $<1 / 4$ & $1 / 4$ & $<1 / 4$ & $1 / 4$ & $<1 / 4$ & $1 / 4$ & $<1 / 4$ & $1 / 4$ & $<1 / 4$ & $1 / 4$ & $<1 / 4$ & $1 / 4$ & $<1 / 4$ & $1 / 4$ & $<1 / 4$ & \\
\hline 816-004 & N673 & $40-50$ & F14 & 2 & $\mathrm{~N}$ & - & 1 & - & - & - & 3 & - & 1 & - & - & - & - & - & 12 & - & 2 & \\
\hline 3 liters & E509 & - & & - & $\mathrm{Wt}$ & - & $<0.1$ & - & - & - & $<0.1$ & - & $<0.1$ & - & - & - & - & - & 0.1 & - & 0.2 & \\
\hline 979-004-2 & N694 & $40-50$ & Rodent \#2 & 10.4 & $\mathrm{~N}$ & - & - & - & - & - & 5 & - & 1 & - & - & - & - & - & 23 & - & - & \\
\hline 1.5 liters & E512 & - & & - & $\mathrm{Wt}$ & - & - & - & - & - & 0.3 & - & 0.1 & - & - & - & - & - & 0.4 & - & - & \\
\hline 979-004-1 & N694 & $40-50$ & Rodent \#1 & 10.4 & $\mathrm{~N}$ & - & - & - & - & - & 4 & - & 1 & - & - & 1 & - & 1 & 6 & - & - & \\
\hline 1 liters & E512 & - & & - & $\mathrm{Wt}$ & - & - & - & - & - & 0.2 & - & $<0.1$ & - & - & 7.3 & - & 1.9 & $<0.1$ & - & - & \\
\hline 1012-004-1 & N695 & $35-45$ & F13 & 48 & $\mathrm{~N}$ & - & 5 & - & - & - & 47 & - & 1 & - & 1 & - & - & - & $30+$ & - & 15 & \\
\hline 22.5 liters & E513/514 & - & & - & $\mathrm{Wt}$ & - & 0.2 & - & - & - & 1.4 & - & 0.1 & - & $<0.1$ & - & - & - & 10.8 & - & 0.8 & \\
\hline 1014-004-1 & N695 & $45-55$ & F13 & 40.2 & $\mathrm{~N}$ & - & 7 & - & - & - & 66 & - & 2 & - & 2 & 1 & 4 & - & $60+$ & - & 64 & 2-Larvae $<0.1 \mathrm{~g}$ \\
\hline 37 liters & E513 & - & & - & $\mathrm{Wt}$ & - & 0.2 & - & - & - & 6.0 & - & 0.1 & - & 0.1 & 2.1 & 1.4 & - & 12.3 & - & 6.2 & \\
\hline 1014-004-2 & N695 & $55-65$ & F13 & 15.8 & $\mathrm{~N}$ & - & 3 & - & - & - & 54 & - & 1 & - & 10 & 2 & - & - & $30+$ & - & $30+$ & 26-Larvae 0.1g \\
\hline 34 liters & E513/514 & - & & - & $\mathrm{Wt}$ & - & $<0.1$ & - & - & - & 2.4 & - & 0.1 & - & $<0.1$ & 3.3 & - & - & 11.2 & - & 6.2 & Daub w/ impressions \\
\hline 1014-004-3 & N695 & $65-75$ & F13 & 65.8 & $\mathrm{~N}$ & & 1 & & & & 48 & & 1 & & 8 & 1 & 1 & & $30+$ & & 40 & \\
\hline 34 liters & E513/514 & - & & - & $\mathrm{Wt}$ & - & $<0.1$ & - & - & - & 0.4 & - & $<0.1$ & - & $<0.1$ & 10.8 & 0.5 & - & 7.7 & - & 3.4 & \\
\hline 1020-004 & N695 & $40-50$ & stain & 2.4 & $\mathrm{~N}$ & - & - & - & - & - & 3 & - & 1 & - & - & - & - & - & - & - & 7 & \\
\hline 1 liter & E514 & - & & - & $\mathrm{Wt}$ & - & - & - & - & - & 0.5 & - & $<0.1$ & - & - & - & - & - & - & - & 0.3 & \\
\hline 1028-004 & N696 & $40-47$ & F9 & 33.1 & $\mathrm{~N}$ & - & - & - & - & - & 10 & - & 1 & - & 25 & - & - & - & 150 & - & 50 & sent for species ID \\
\hline 3 liters & E511 & - & & - & $\mathrm{Wt}$ & - & - & - & - & - & 0.1 & - & 0.3 & - & $<0.1$ & - & - & - & 19.3 & - & 4.6 & \\
\hline 1032-004 & N696 & $50-60$ & F11 & 24.7 & $\mathrm{~N}$ & 1 & 4 & - & - & - & 22 & - & 1 & - & 1 & - & 5 & - & $50+$ & - & 20 & 1 broken bead $<0.1 \mathrm{~g}$ \\
\hline 5.5liters & E511 & - & & - & $\mathrm{Wt}$ & $<0.1$ & $<0.1$ & - & - & - & 0.8 & - & 0.3 & - & $<0.1$ & - & 1.4 & - & 7.6 & - & 1.0 & \\
\hline $\begin{array}{ll}1079-004 \\
\end{array}$ & N698 & $30-40$ & - & 2.7 & $\mathrm{~N}$ & - & 4 & - & - & - & - & - & 1 & - & - & - & - & - & $20+$ & - & - & \\
\hline 0.5 liters & E511 & - & & - & $\mathrm{Wt}$ & - & $<0.1$ & - & - & - & - & - & 0.2 & - & - & - & - & - & 0.4 & - & - & \\
\hline 1082-004 & N698 & $31-53$ & F10 & 170.9 & $\mathrm{~N}$ & 2 & 16 & - & - & - & 68 & - & 1 & - & 1 & - & - & 5 & $100+$ & - & $100+$ & 1 -ocher $<0.1 \mathrm{~g}$ \\
\hline 16 liters & E511 & - & & - & $\mathrm{Wt}$ & 1 & - & - & - & - & 1.1 & - & 0.5 & - & 0.1 & - & - & 3.6 & 52.1 & - & 38.8 & Daub w/ impressions \\
\hline 1116-004 & N699 & $40-50$ & F8 N1/2 & 14.5 & $\mathrm{~N}$ & - & - & 1 & - & - & 31 & - & 1 & - & 1 & - & - & - & $30+$ & - & 41 & 1 obsidian \\
\hline 20 liters & E512 & - & & - & $\mathrm{Wt}$ & - & - & 65.0 & - & - & 1.1 & - & $<0.1$ & - & $<0.1$ & - & - & - & 11.9 & - & 2.0 & \\
\hline 1121-004 & N699 & $20-30$ & \begin{tabular}{|l|} 
outside F12 \\
\end{tabular} & 8.1 & $\mathrm{~N}$ & - & - & - & - & - & 2 & - & 1 & - & - & - & -- & - & 21 & - & 14 & \\
\hline
\end{tabular}


Table 8-4. Component A, Heavy Fraction Results by Material Class (continued).

\begin{tabular}{|c|c|c|c|c|c|c|c|c|c|c|c|c|c|c|c|c|c|c|c|c|c|c|}
\hline \multirow{3}{*}{$\begin{array}{c}\begin{array}{c}\text { Cat No./ } \\
\text { No.of Liters }\end{array} \\
1.25 \text { liters }\end{array}$} & \multirow{3}{*}{$\begin{array}{l}\text { Unit } \\
\text { E513 }\end{array}$} & \multirow{3}{*}{\begin{tabular}{|c|}
$\begin{array}{l}\text { Depth } \\
\text { (cmbs) }\end{array}$ \\
- \\
\end{tabular}} & \multirow{3}{*}{\begin{tabular}{|l} 
Feature No. \\
\end{tabular}} & \multirow{3}{*}{\begin{tabular}{|c}
$\begin{array}{c}\text { Weight } \\
\text { (g) }\end{array}$ \\
-
\end{tabular}} & \multirow{3}{*}{$\mathrm{Wt}$} & \multicolumn{16}{|c|}{ Flotation Recovery } & \multirow{3}{*}{ Comments } \\
\hline & & & & & & \multicolumn{2}{|c|}{ Mussel Shell } & \multicolumn{2}{|c|}{ Burned Rock } & \multicolumn{2}{|c|}{ Debitage } & \multicolumn{2}{|c|}{ Charcoal } & \multicolumn{2}{|c|}{ Macrobotanical } & \multicolumn{2}{|c|}{ Ceramic } & \multicolumn{2}{|c|}{ Bone } & \multicolumn{2}{|c|}{ Daub } & \\
\hline & & & & & & - & - & - & - & - & 0.6 & - & $<0.1$ & - & - & - & - & - & 0.8 & - & 0.7 & \\
\hline $1125-004$ & N695 & $30-55$ & F12 & 38 & $\mathrm{~N}$ & - & 1 & 1 & - & - & 15 & - & 1 & - & 11 & 3 & - & - & $30+$ & - & 20 & sent for ID, 1-obsidian \\
\hline 23 liters & E513 & - & & - & $\mathrm{Wt}$ & - & $<0.1$ & 157.8 & - & - & 3.8 & - & 0.4 & - & $<0.1$ & 3.7 & - & - & 5.4 & - & 0.9 & \\
\hline $1134-004$ & N699 & $20-30$ & F1 & 3.0 & $\mathrm{~N}$ & - & - & - & - & - & 2 & - & 1 & - & 4 & - & - & - & $20+$ & - & 1 & seeds \\
\hline 2 liters & E515 & - & & - & $\mathrm{Wt}$ & - & - & - & - & - & $<0.1$ & - & $<0.1$ & - & $<0.1$ & - & - & - & 0.1 & - & $<0.1$ & \\
\hline $1140-004$ & N699 & $50-61$ & F1 & 6.0 & $\mathrm{~N}$ & - & - & - & - & - & - & - & 1 & - & - & 1 & 2 & - & 12 & - & - & \\
\hline 2 liters & E515 & - & & - & $\mathrm{Wt}$ & - & - & - & - & - & - & - & $<0.1$ & - & - & 2.3 & 0.3 & - & 0.3 & - & - & \\
\hline 1164-004-3 & N700 & $50-58$ & F1 E 1/2 & 59 & $\mathrm{~N}$ & - & 1 & - & - & - & 16 & - & 1 & - & 1 & - & - & - & 17 & - & 3 & \\
\hline 4.25 liters & E515 & rodent & & - & $\mathrm{Wt}$ & - & $<0.1$ & - & - & - & 1.2 & - & $<0.1$ & - & $<0.1$ & - & - & - & 5.7 & - & 0.1 & \\
\hline 1164-004-4 & N700 & $50-60$ & F1 W1/2 & 3.1 & $\mathrm{~N}$ & - & - & - & - & - & - & - & - & - & 1 & - & - & - & 3 & - & - & corn \\
\hline 1 liter & E515 & rodent & & - & $\mathrm{Wt}$ & - & - & - & - & - & - & - & - & - & $<0.1$ & - & - & - & $<0.1$ & - & - & sent for ID \\
\hline 1164-004-2 & N700 & $50-60$ & $\mathrm{~F} 1 \mathrm{~W} 1 / 2$ & 53.8 & $\mathrm{~N}$ & - & - & - & - & - & 20 & - & 1 & - & 1 & - & - & - & $30+$ & - & 26 & \\
\hline 18 liters & E515 & - & & - & $\mathrm{Wt}$ & - & - & - & - & - & 0.3 & - & 0.2 & - & 0.2 & - & - & - & 17.9 & - & 5.8 & \\
\hline 1164-004-1 & N700 & $50-60$ & F1 E1/2 & 13.1 & $\mathrm{~N}$ & - & - & - & - & - & - & - & 1 & - & 2 & - & 1 & - & 11 & - & 5 & \\
\hline 36 liters & E515 & - & & - & $\mathrm{Wt}$ & - & - & - & - & - & - & - & $<0.1$ & - & $<0.1$ & - & 0.3 & - & 1.2 & - & 1.3 & \\
\hline mixed, 35.5 lit & N699E511 & 31-53 & F10? & 49.9 & $\mathrm{~N}$ & - & - & - & - & - & 4 & - & 1 & - & 7 & - & - & - & $20+$ & - & 3 & \\
\hline 4 liters & N699E515 & $50-60$ & & & $\mathrm{Wt}$ & - & - & - & - & - & 5.5 & - & $<0.1$ & - & $<0.1$ & - & - & - & 4.1 & - & 1.0 & \\
\hline Totals & & & & & & & 43 & 2 & & & 420 & & & & & 9 & 13 & & 705 & & 441 & \\
\hline
\end{tabular}

277 liters total

272.75 liters

in features 
grain analysis. This sherd yielded three maize (Zea mays) grains, three lenticular little barley (Hordeum pusillum) grains and one unidentified and damaged grains (Appendix D). The starch grain results from a single burned rock (\#1135-3-2b) revealed four lenticular grains of little barley (Appendix D). Three sediment samples (\#1164-4-7a, \#1164-4-11a and \#1278-4-1a) from across the floor of the pithouse were selected for phytolith analysis. One (\#1278-41a) was from the profile at very bottom of the pit fill along the road cut, at 57 to $61 \mathrm{cmbs}$. The other two (\#1164-4-11a and \#1164-4-7a) were collected from just above the floor at 56 to $59 \mathrm{cmbs}$, in N700 E515. The phytoliths results indicate a dominance of hot dry chloridoids in the range of 52 to 62 percent, followed by cool pooids in the range of 28 to 30 percent, and warm moist panicoids in the range of 9 to 18 percent (Appendix B). A single positive maize phytolith, with a few other possible maize phytoliths were present, but no beans (Phaseolus sp.) or squash (Cucurbits sp.) phytoliths were identified on the floor of the pithouse. Small burned cross shaped, cool season panicoid phytoliths outnumber the other two major groups by far and may reflect a specific processing activity or plants used in the pithouse construction. These burned cool grasses may have blown into this open basin following the site abandonment. These burned grasses may indicate the season occupation (postulated to be fall).

One small daub piece (\#1160-5) from the basin fill between 30 and $40 \mathrm{cmbs}$ was subjected to diatom analysis. The diatom results indicate a very high frequency of diatoms with 93 percent dominated by Aulacoseira distans, which are aquatic species and characterize clear cold water (Appendix J) and likely reflect the Ogallala deposits. Two pieces of daub were submitted for INAA. One piece (\#11405-4a = TRC641) was from 50 to 61 cmbs within and near the bottom of the pithouse and the second piece (\#1113-5-2 = TRC642) was from the western half of the pithouse. The INAA results document chemical differences between the two daub samples with the latter piece more similar to the pottery samples from this component (Appendix G). The difference in chemical composition may indicate difference sources of constituents were used in the process of making the daub. Neither daub piece was assigned to the pottery compositional groups. Two pottery sherds $(\# 1140-8-1 b=$ TRC555 and \#1135-8-1b = TRC562) that represent Vessels A, a collard pinched vessel, and Vessel $\mathrm{H}$, respectively, were sent for INAA. The chemical results indicate that both are part of Compositional Group 2 and similar to most other vessels in this component (Appendix G).

Feature 1 is interpreted as the western margin of an ovate pithouse with the projected upper margin of the pit at roughly $35 \mathrm{cmbs}$ and the bottom at $65 \mathrm{cmbs}$. The pit revealed a slightly concave floor with steep angled side walls, small diameter post holes, both inside and outside the lower basin that penetrated into the underlying Ogallala, but no evidence of trampling or an earthen plaster/covering. At the time of abandonment, the floor of this habitation structure was nearly devoid of cultural materials. The depression was filled with eolian sand associated with the sand facies of Eolian Sand II. Considerable evidence is present for postdepositional disturbances of the internal deposits. Unfortunately, the majority of this pithouse (the eastern end) was removed during prior road construction activities. The above-ground portions of the walls were apparently supported by small wooden posts less than $10 \mathrm{~cm}$ in diameter. It is not clear from the small excavated part of this pithouse whether or not larger center posts were part of the support system. Aside from the many small post holes, no direct evidence exists with which to infer the nature of the superstructure. Indirectly, the fragment of a mud daubers wasp nest from the floor deposit supports the presence of a wooden structure, which based on the size of the post holes, was fashioned from poles mostly less than $7 \mathrm{~cm}$ in diameter. Found immediately west of the pithouse were artifacts that represent a Plains Village occupation, that include cordmarked potsherds, pinched rim sherds, Alibates flakes and tools, obsidian and opalite flakes, scattered burned rocks, the occasional mussel shell fragment, tiny bone fragments, a reworked Washita point, and various heating elements. Two small charcoal-laden heating elements (Features 3 and 4) were about 1.5 $\mathrm{m}$ and $4.5 \mathrm{~m}$ west of this pithouse. A small storage pit (Feature 13) was about $4 \mathrm{~m}$ to the south.

\subsubsection{Feature 3}

This feature was discovered in the hand-excavation of Trench A-1 during site assessment. Trench A-1 
was $5 \mathrm{~m}$ west of Feature 1 in the northern part of Component $\mathrm{A}$ along the very eastern edge of the north-south firebreak (see Figures 2-1 and 8-1). Trench A-1 was roughly 11-m-long north to south, 25- to 30-cm-wide, and roughly 60-cm-deep. A charcoal concentration was observed during profile cleaning between 40 and 50 cmbs on the eastern wall of the trench. The opposite side of the trench also exhibited a small charcoal stain about 39 cmbs. Unit A-8, a 1-by-1 m unit, was established over this charcoal stain and was hand-excavated through the stain. Most of the western side of Unit A-8 was in the bladed fireguard in which the top 25 to $30 \mathrm{~cm}$ of the original deposits had been removed. The top of the charcoal stain appeared to have been removed by blading the firebreak. Some $30 \mathrm{~cm}$ of the eastern side of the Unit A-8 was removed during Trench A-1 excavation. A bison long bone fragment was found just to the south of the charcoal-stained area, and two bison molars were noted in the trench profile some $250 \mathrm{~cm}$ to the north.

A few small charcoal chunks were visible across the trench at $39 \mathrm{cmbs}$; these were the first indications of the top of Feature 3. The plan view of the western part Feature 3 exhibited irregular margins that were extensively disturbed by rodent activity (Figure 8-14). The stained areas exhibited a gray (5YR 5/1) matrix, whereas the surrounding sediment was a brown (10YR 5/3) sandy loam. In profile, the gray-stained fill was in a shallow basin about 8- to 9-cm-deep with gently sloping sides. The lower boundary exhibited considerable turbation by small insects that had created a 3- to 4-cm-wide band of poorly defined basin margin. No oxidation rim or charcoal concentration was visible in the profile. No burned rocks, flakes, or other cultural materials were observed in the gray feature fill. The bottom was at about $48 \mathrm{cmbs}$ with the turbated matrix extending to about 51 cmbs.

About four liters of dark stained fill within the basin were bagged in anticipation of flotation in the laboratory. A chunk of charcoal was extracted from the basin fill for radiocarbon dating. This juniper wood charcoal (\#34-7-2) yielded a $\delta^{13} \mathrm{C}(-23.2 \%)$ corrected AMS date of $970 \pm 40$ B.P. (Beta-206559).
The nearly four liters of feature fill were sent to Dr. Phil Dering for flotation and identification of the macrobotanical remains. The floated matrix yielded a single maize kernel. Juniper, mesquite, and cottonwood/willow wood were identified (Appendix C).

A plain-exterior potsherd (\#74-8) was recovered from Unit A-8, but it is not clear that it came from inside this feature. Feature 3 was the partial remains of a small circular heating element with a shallow basin filled with dark, organic-rich sediment. Vertically, it was within the detected occupation zone in Component A and is, therefore, associated with diverse occupational materials that included the pithouse and other features.

\subsubsection{Feature 4}

Feature 4 was discovered during site assessment near the middle of Unit A-5 (Figure 4-8). This dark stain was about $1.5 \mathrm{~m}$ southwest of the pithouse, Feature 1 . The top of the stain and other cultural materials were encountered at $49 \mathrm{cmbs}$ (the actual 'top' had probably been disturbed). It first appeared as stained matrix, circular in plan view. A few chunks of charcoal, a small bone fragment, an opalite flake, and small spots of baked/burned clay were present across the top of the dark grayish brown (10YR 4/2) ashy matrix. This circular stain was about $30 \mathrm{~cm}$ in diameter and quite flat across the top (Figure 8-15). The stained margins, except the northern quarter, were a very dark brown (7.5YR 2/2). A few small chunks of caliche were just outside the stained margins. The profile revealed a steep-sided basin that was about 15-cm-deep with no visible oxidation rim or charcoal lens. All sediment from this stained basin was bagged for subsequent flotation in the laboratory.

About four liters of stained fill were sent to Dr. Phil Dering for flotation and identification of macrobotanical remains. The floated matrix yielded considerable evidence of charred food remains that includes a cheno-am seed, a squash rind fragment, 27 maize cupules, 3 maize kernels, and 2 mesquite seeds (Appendix C). A chunk of wood charcoal from 50 to $60 \mathrm{cmbs}$ and removed from the collected matrix, was sent for radiocarbon dating. This wood charcoal piece (\#62-7a) yielded a $\delta^{13} \mathrm{C}(-24.0 \%)$ corrected 


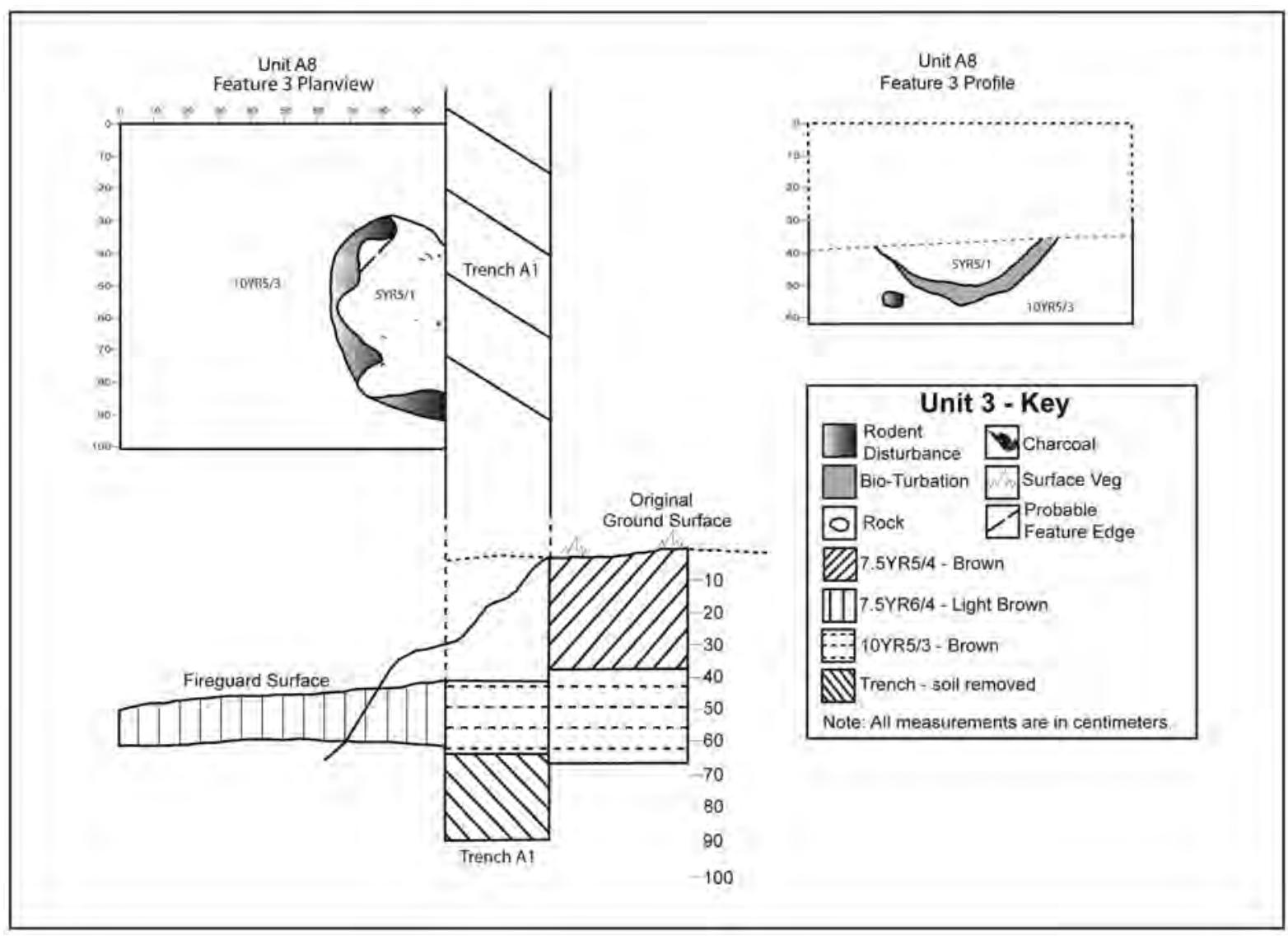

Figure 8-14. Plan view and west profile drawing of Feature 3 in Trench A1.

AMS date of $710 \pm 40$ B.P. (Beta-206560). Feature 4 was roughly $10-\mathrm{cm}$-below the identified surface of Feature 3, but within the same occupation zone. Feature 4 was surrounded by diverse occupational evidence that included other features. Feature 4 was a small circular heating element with a shallow basin filled with dark, organic-rich sediment.

\subsubsection{Feature 8}

This feature was near the center of unit N699 E512 and vertically positioned between 30 and $42 \mathrm{cmbs}$ (see Figure 8-1). It was exposed by trowel, which revealed a circular stain about 30-by-28 cm in diameter with rodent burrows that intersected the feature in several places. The feature fill was yellow brown (10YR 5/4) in slight contrast to the surrounding matrix, which was brown in color (10YR 5/3; Figure 8-16). The minimal color contrast made definition of the feature margins rather difficult. The stain was bisected eastwest, which created a cross-section that exhibited a slightly squared or bucket-shaped basin about 12- to 14-cm-deep with a rodent burrow at the base at 39 cmbs. The sides were steeply sloped, and the bottom was narrower than the top. The northern half of the stain was collected for flotation, whereas the southern half was screened in the field.

About 20 liters of fill (\#1116-4) from the northern half, between 40 and $50 \mathrm{cmbs}$, was floated and yielded heavy and light fractions. The light fraction (\#11164b) was sent for macrobotanical identifications. The heavy fraction was sorted, and yielded 1 piece of obsidian, 1 small burned rock (65 g), 31 tiny pieces of lithic debitage (1.1 g), tiny charcoal fragments, 30 tiny bone fragments (11.9 g), and 41 tiny pieces of daub (2.0 g). One unburned long bone fragment was sufficiently thick to indicate a bison-size animal, whereas another was thin enough to represent a small mammal. Roughly 40 to 50 percent of the bone fragments were burned, resulting in a gray color. Chert and opalite are represented in the lithic debitage. 


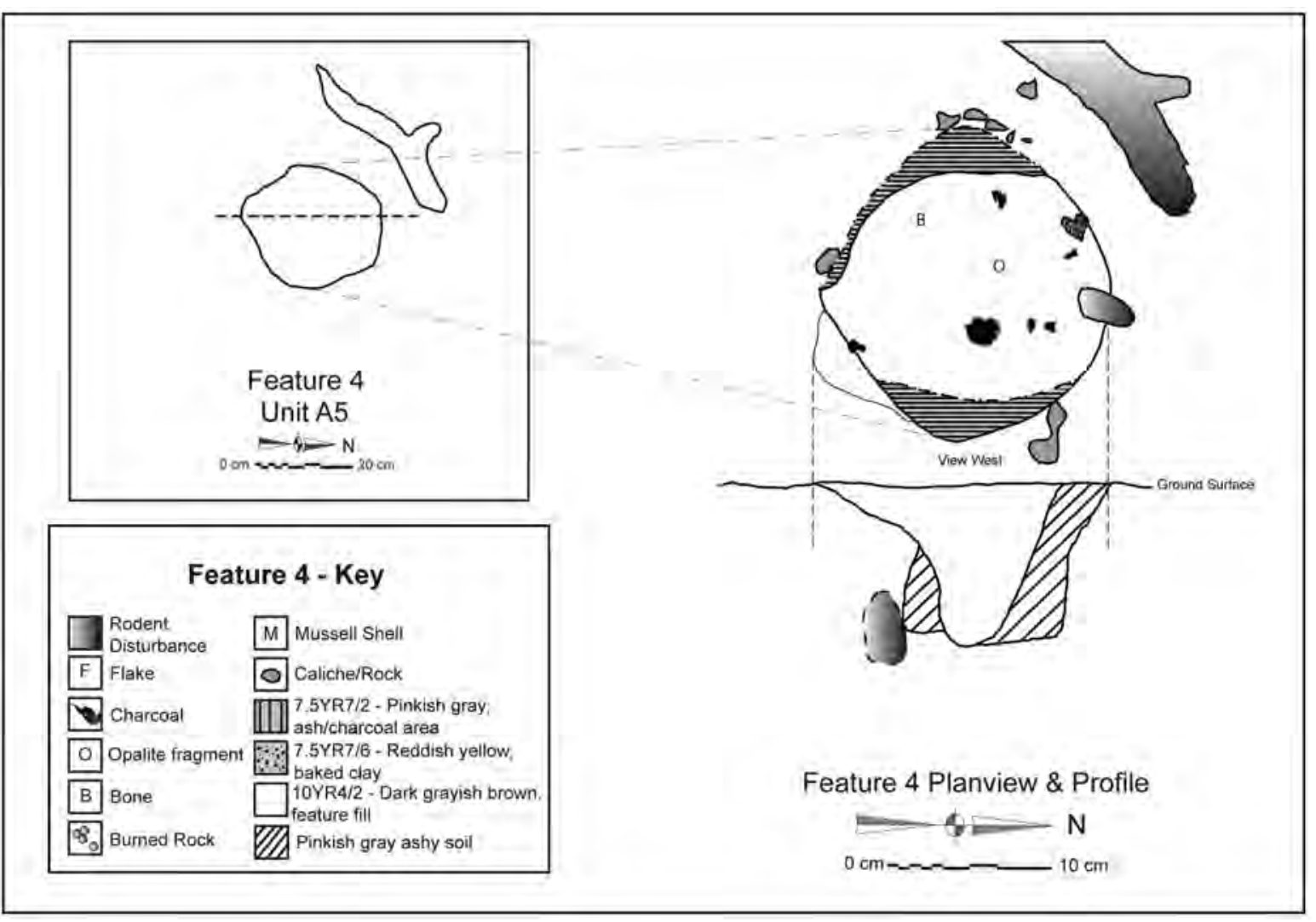

Figure 8-15. Plan view and west profile drawings of Feature 4 in Area A.

The light fraction yielded only six maize cupules and rose-family wood (Appendix C). A single sample of charcoal (\#1116-7-1) from 40 to $50 \mathrm{cmbs}$ was sent for identification. Dering identified the charcoal as juniper (Appendix C).

A charred maize kernel from the collected feature fill between 40 and 50 cmbs was sent for radiocarbon dating. This kernel (\#1116-7-1-7a) yielded a $\delta^{13} \mathrm{C}$ $(-9.8 \%$ o) corrected AMS date of $480 \pm 25$ B.P. (UGAMS-7836). Some $30 \mathrm{~g}$ of matrix (\#1116-4-1a) were submitted for phytolith analysis. The phytolith results indicate a similar ratio of the major short cell groups on the floor of the pithouse, again dominated by hot dry chloridoids at 61.3 percent (Appendix B). No phytoliths of maize, beans, or squash were identified. Some unusual phytoliths present include spiny spheroid, spunge spicule, and sedges. The obsidian from the heavy fraction was sourced to Cerro Toledo (Appendix E).
The estimated top of the stain (30 to $40 \mathrm{cmbs}$ ) was at the same elevation as a variety of cultural materials that included 27 bone fragments, 1 edge-modified flake, 14 pieces of lithic debitage, 7 pottery sherds (includes 1 rim sherd), 5 pieces of daub, a few chunks of charcoal, and 3 small burned rocks. The eastern half was screened in the field and yielded a few pieces of lithic debitage, a few bone fragments, and a couple of tiny burned rock fragments.

This feature functioned as a heating element. Based on the diverse contents, some cultural trash entered the basin either during or shortly after its use as a heating element. The presence of burned bones in the fill indicates these were discarded into the feature while still hot.

\subsubsection{Feature 9}

This feature was in unit N696 E511 between 40 and $47 \mathrm{cmbs}$. The western edge of this unit intersected the firebreak. Feature 9 was less than $1 \mathrm{~m}$ east of the firebreak and in the same unit as Feature 11 (see 


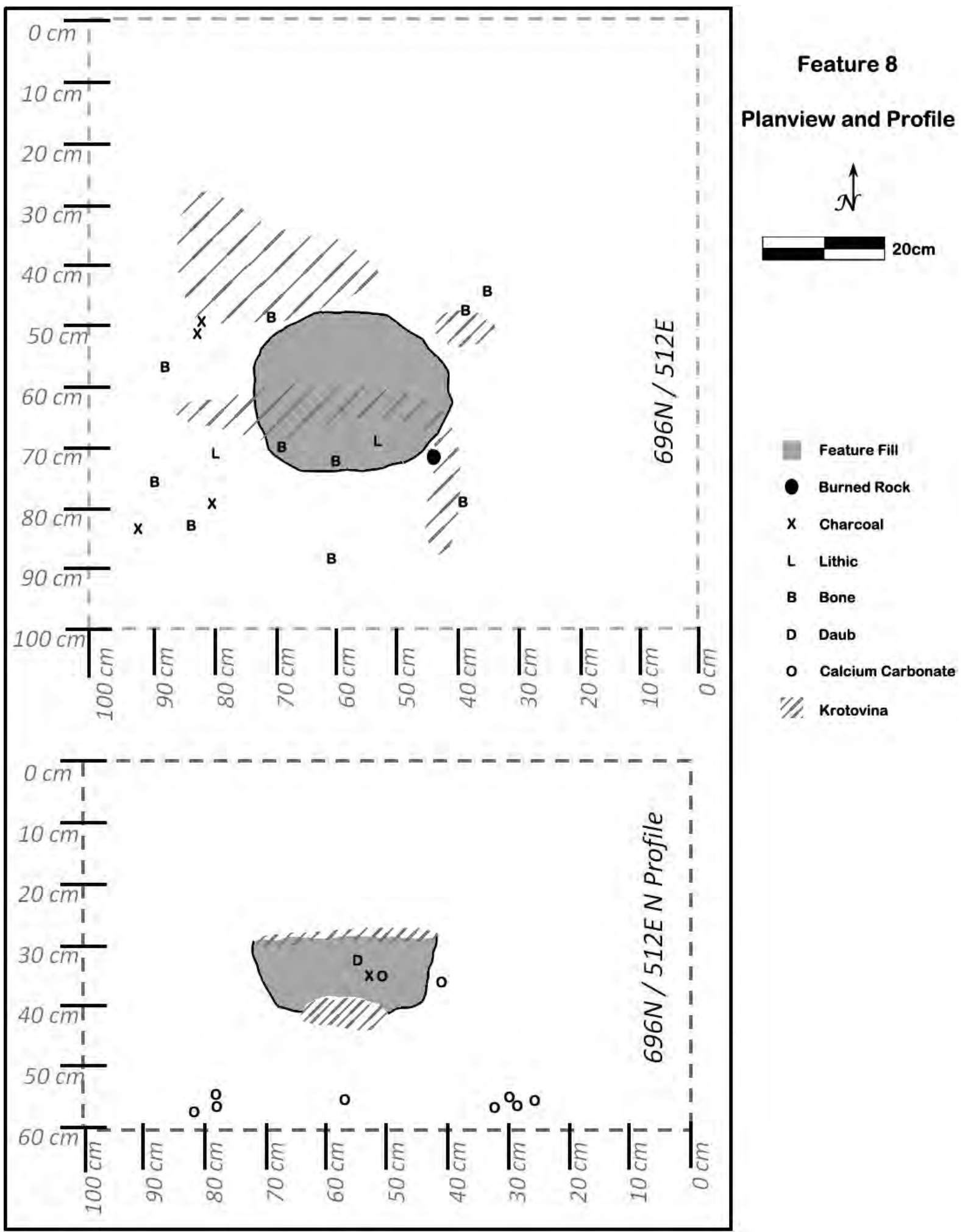

Figure 8-16. Plan and profile of Feature 8. 
Figure 8-1). This feature was first encountered at 40 $\mathrm{cmbs}$ and was recognized as a couple of burned rocks along the margins of a dark-stain in the southeastern corner of the unit (Figure 8-17). An east-west profile of the feature was created along the southern boundary of this unit. The dark-stained fill formed a shallow basin about 7-cm-deep and roughly 20-cmwide at the top (although the actual top of the feature may not have been recognized until the slightly darker fill in the basin became clear). In plan view, the dark sediment was ovoid that measured 15-by25-cm-wide.

The entire feature fill (about 3 liters, \#1028-4), from 40 to $47 \mathrm{cmbs}$, was collected and floated. The heavy fraction yielded $33.1 \mathrm{~g}$ of material that includes 10 tiny pieces of lithic debitage, many tiny pieces of charcoal, 25 seeds, 150 tiny bone fragments, and 50 tiny pieces of daub/burned clay (Table 8-4). In the heavy fraction, roughly 60 percent of the bone fragments were burned, some to a black and some to a gray color. Most fragments are too tiny to identify, but a couple of pieces reflect a medium-size mammal (deer/pronghorn), whereas most others appear to be from small mammals. Although a relatively limited amount of sediment was floated, this yielded the greatest frequency of bone compared to other features.

The light fraction yielded cheno-am seeds, squash rind, and maize cupules and kernels. Seed density is 3.67 parts/liter, one of the highest values for this project. Mesquite wood is most abundant, followed by juniper (Appendix C).

A carbonized maize kernel (\#1128-007-1) between 40 and $47 \mathrm{cmbs}$ yielded a $\delta^{13} \mathrm{C}(11.3 \%$ ) corrected AMS date of $480 \pm 20$ B.P. (UGAMS-7837).

The arbitrary levels from 30 to $60 \mathrm{cmbs}$ yielded diverse classes of cultural materials that include cordmarked ceramic sherds, Alibates flakes, scraps of bone and mussel shell, a piece of obsidian (\#1026-10), an edge-modified flake (\#1031-10), scattered pieces of charcoal, daub, scattered burned rock fragments, and Feature 11.

The function of Feature 9 is thought to be a heating element/hearth based upon the basin shaped cross sectioned and charcoal-laden sediment.

\subsubsection{Feature 10}

This feature was delineated across the southern end of unit N698 E511 and extended into Trench A-1 (see Figure 8-1). It was not recognized in the unit to the south. Feature 10 exhibited an irregularly shaped brown (10YR 5/3), charcoal-laden fill that measured 35-by-75 cm and was from 31 to $53 \mathrm{cmbs}$ (Figure 8-18). It was only about $20 \mathrm{~cm}$ southeast of heating element Feature 3 and at the same depth. The dark fill in the east-west profile on the southern wall extended to a depth of $53 \mathrm{cmbs}$ across the entire width of the unit profile. However, the apparent basin was only about 10 -cm-thick with sides that sloped up. Roughly 42 liters of dark-stained basin fill (\#1080-4) was collected and saved for flotation. The surrounding level yielded scattered bone fragments, charcoal chunks, lithic debitage, a pottery sherd, and one burned rock fragment. Scattered rocks were near the top of the basin across the rest of the unit.

The 41.5 liters of feature sediment (\#1082-4) were floated and heavy and light fractions were recovered. The $171 \mathrm{~g}$ of heavy fraction was sorted and yielded 18 tiny mussel shell fragments, 68 pieces of lithic debitage (1.1 g), a chunk of charcoal, a charred maize kernel, one burned seed, 100+ tiny bone fragments (55.7 g), and 100+ tiny pieces of daub/burned clay (38.8 g; Table 8-4). The tiny bone fragments include 60 to 70 percent that had been burned to a gray color, including small rodent- and deer/pronghorn-size fragments. The latter exhibit very porous cortical tissue and include tooth fragments that appear to represent a newborn animal. The light fraction was sent for macrobotanical identifications. The $109.3 \mathrm{~g}$ of light fraction yielded only two maize kernels with juniper and oak the most abundant wood types by far. Mesquite wood and thorns, and a few fragments of elm-family wood are also present (Appendix C).

A $31 \mathrm{~g}$ subsample (\#1080-4-1a) of feature fill was sent for phytolith analysis. Those results indicate no maize, beans, or squash phytoliths present, although the three major short cell phytolith groups are all equally represented with few burned phytoliths that appear to represent the normal background noise (Appendix B). A charred maize kernel (\#1080-7-1) from the fill was radiocarbon dated and yielded a $\delta^{13} \mathrm{C}(-10.6 \%$ ) corrected AMS date of $510 \pm 25$ B.P. (UGAMS-7834). 


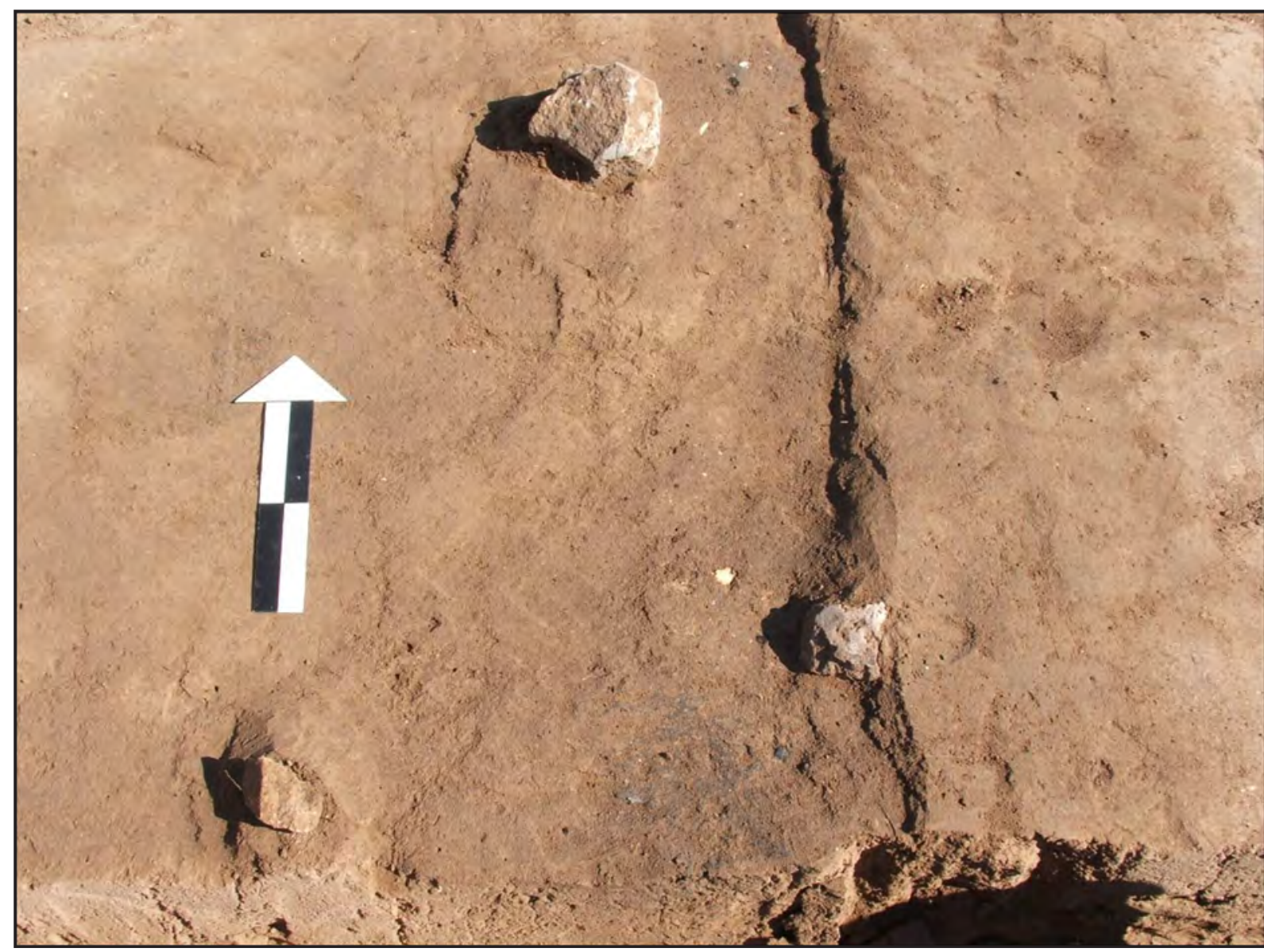

Figure 8-17. Small dark stained sediment of Feature 9 in southeastern corner of unit.

The dominance of charcoal, combined with obvious dark fill within a basin, indicate that Feature 10 was probably some type of heating element, which may have been associated with the nearby heating element, Feature 3.

\subsubsection{Feature 11}

This feature was near the center of unit N696 E511 and roughly 30 to $40 \mathrm{~cm}$ from Feature 9 in the southeastern corner of that unit (see Figure 8-1). Feature 11 consisted of a small, roughly circular patch of dark-stained fill within a shallow, irregularly pointed basin (Figures 8-19 and 8-20). The darkstained ashy fill measured roughly $25 \mathrm{~cm}$ in diameter with a rather pointed basin that extended between 43 and $57 \mathrm{cmbs}$. The feature fill was collected for flotation. Three burned rocks surrounded the stain near the top, along with a few scattered pieces of lithic debitage, tiny bone fragments, small burned rock fragments, and one obsidian flake. The overall shape and contents of Feature 11 were very similar to Feature 10; both were heating elements that pertained to the same occupational surface.

One charred maize kernel from the fill was sent for radiocarbon dating. This kernel (\#1032-7-1) yielded a $\delta^{13} \mathrm{C}(-12.5 \%)$ corrected AMS date of $500 \pm 25$ B.P. (UGAMS-7831). A small (75 g) burned rock fragment (\#1032-3-1a) was submitted for diatom analysis. This rock yielded only two diatoms and they were aquatic species indicative of a shallow stream (Appendix J). To account for stream diatoms on this burned rock is best explained by the rock having been placed in a container with water from the nearby stream. This was likely done as part of a cooking/boiling technique. A $2 \mathrm{~g}$ fragment of this same burned rock (\#1032-3-1b) was also submitted for starch grain analysis, but this piece did not yield 


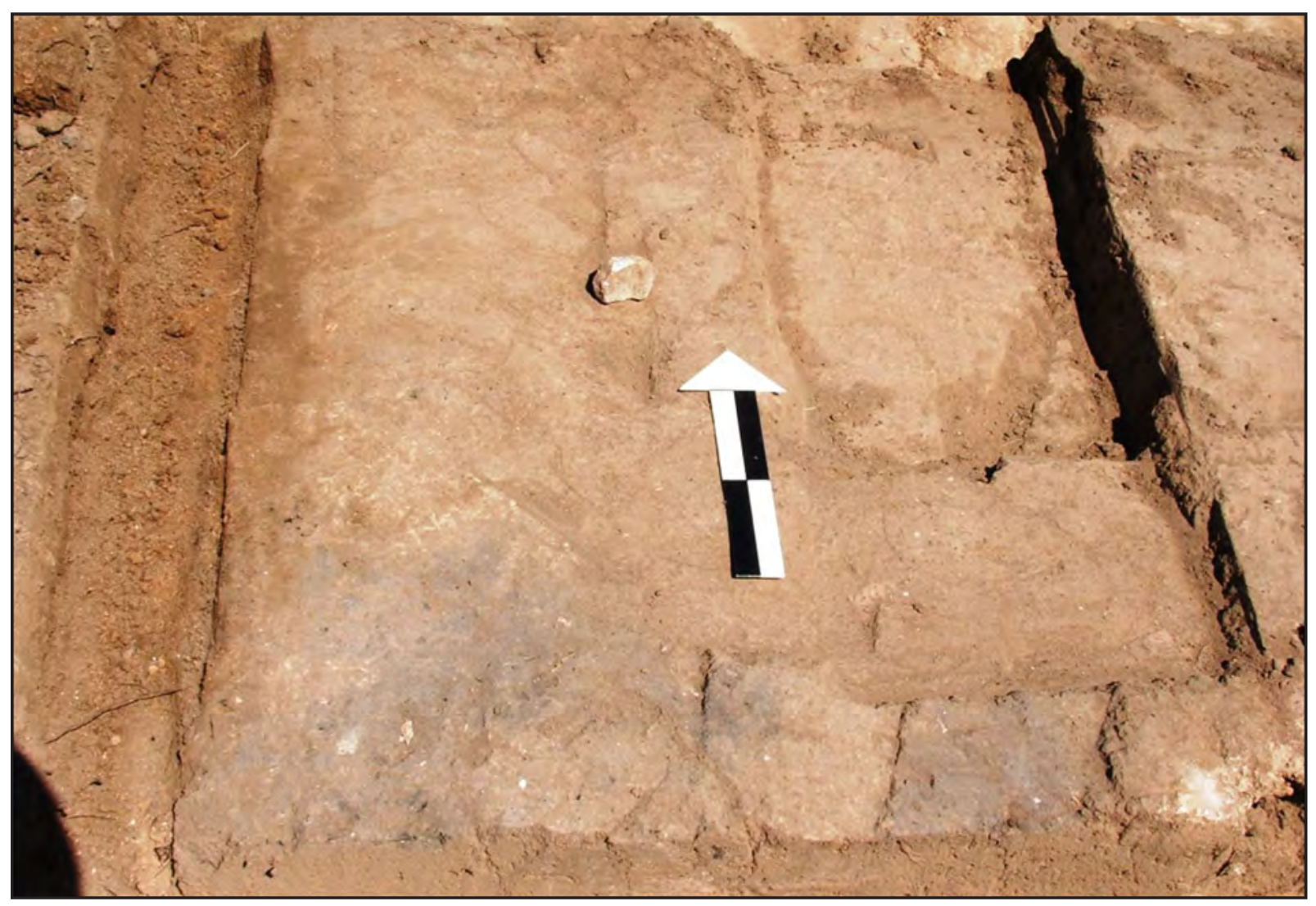

Figure 8-18. Overview of dark stained sediment of Feature 10 in foreground.

any starch grains (Appendix D). A $31 \mathrm{~g}$ sediment sample (\#1032-4) from between 50 and $60 \mathrm{cmbs}$ was submitted for phytolith analysis. The results indicate that the cool season pooid phytoliths dominate (47.3 percent) with at least one maize and sedge phytoliths (Appendix B). Again, no beans or squash phytoliths were identified. The cool season grasses may indicate the use of these grasses in the fires.

The 5.5 liters of floated feature fill yielded light and heavy fractions. The $24.7 \mathrm{~g}$ heavy fraction (\#10324) contained 5 tiny mussel shell fragments, 22 tiny pieces of debitage $(1.1 \mathrm{~g}), 1$ tiny fleck of charcoal, 1 burned seed, 5 tiny fragments of pottery, 50 tiny bone $(7.6 \mathrm{~g})$ fragments, 20 tiny pieces $(1.0 \mathrm{~g})$ of daub, and 1 tiny fragment of a circular shell bead (\#1032-10, Table 8-4, Figure 8-21). The tiny bone fragments are dominated by pieces burned to a gray color and include at least one burned rodent long bone fragment; two or three unburned pieces are also rodent-size bones. The $21.6 \mathrm{~g}$ of light fraction (\#1032-4b) was sent for macrobotanical analysis.
The results revealed maize cupules and kernels along with juniper and mesquite wood (Appendix C). This feature represents an in situ heating element.

\subsubsection{Feature 12}

Feature 12 was in the southwestern corner of N699 E513 (see Figure 4-3) near the middle of the northern excavation block. It consisted of an amorphous patch of gray-stained fill in a deep basin. The gray and charcoal flecked stain measured about $70 \mathrm{~cm}$ northsouth by $30 \mathrm{~cm}$ east-west when first encountered. The profile created along the western wall revealed the basin was only about $35 \mathrm{~cm}$ north-south, and 25-cm-deep, between 30 and $55 \mathrm{cmbs}$. The entire fill was collected for flotation. No sizeable chunks of burned rock were in the fill and the basin was not lined. No charcoal lens or oxidation rim was visible along the margins of the basin.

The 23 liters of floated feature fill (\#1125-4) yielded light and heavy fractions. The $38 \mathrm{~g}$ of heavy fraction (\#1125-4) yielded 1 tiny mussel shell fragment, 1 


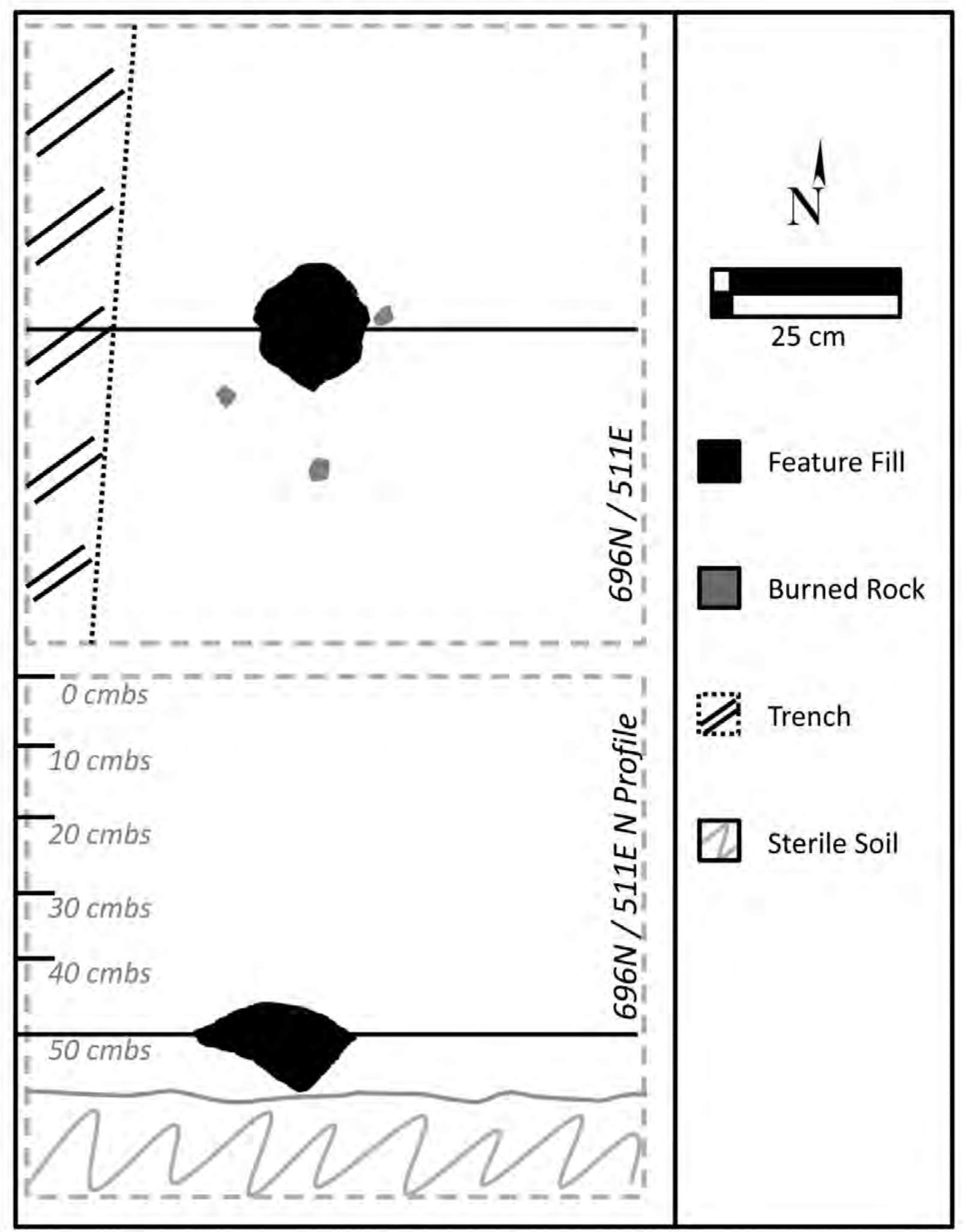

Figure 8-19. Plan view and profile of Feature 11. 


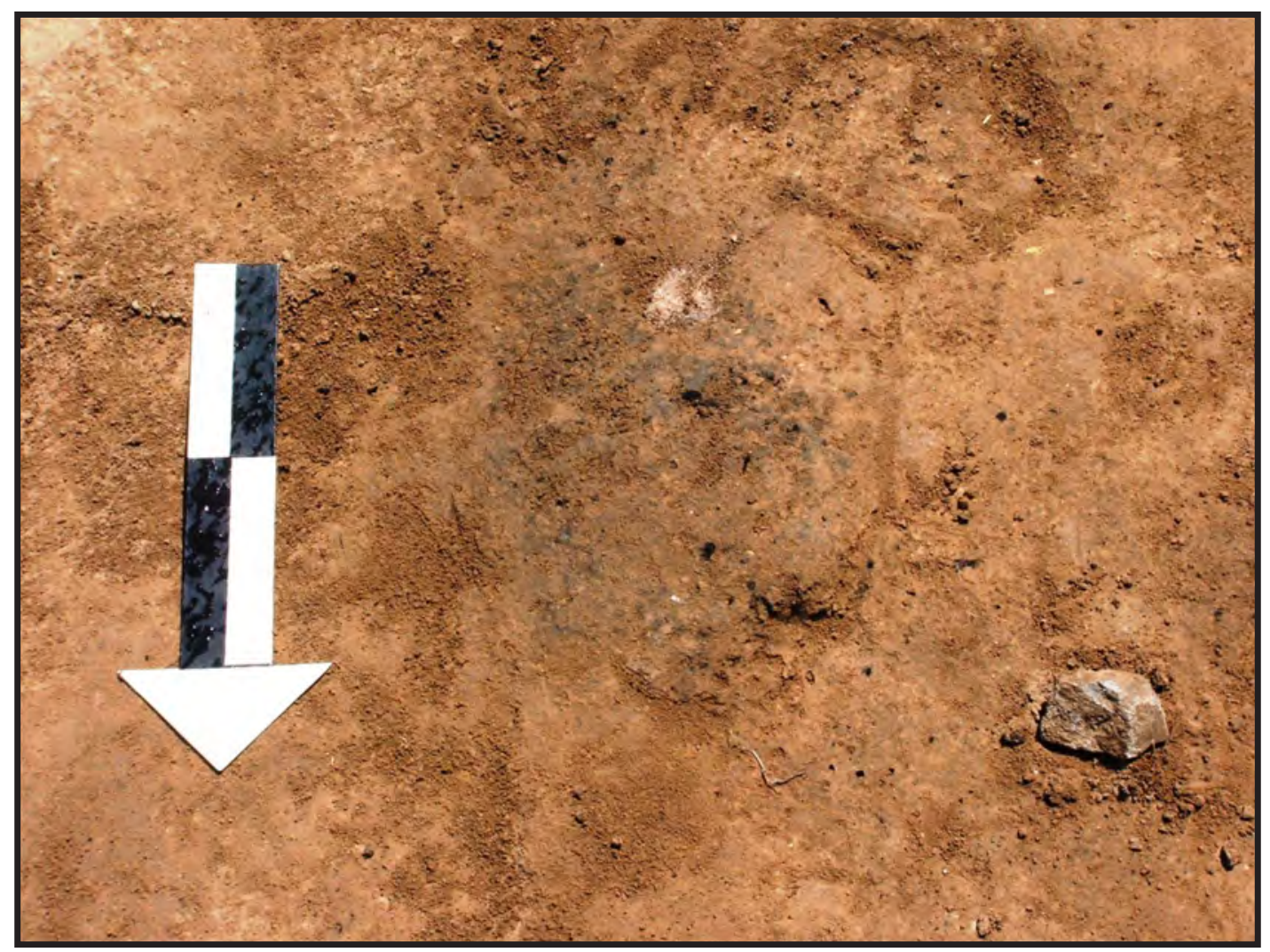

Figure 8-20. Overview of Feature 11, dark stained matrix with scattered charcoal.

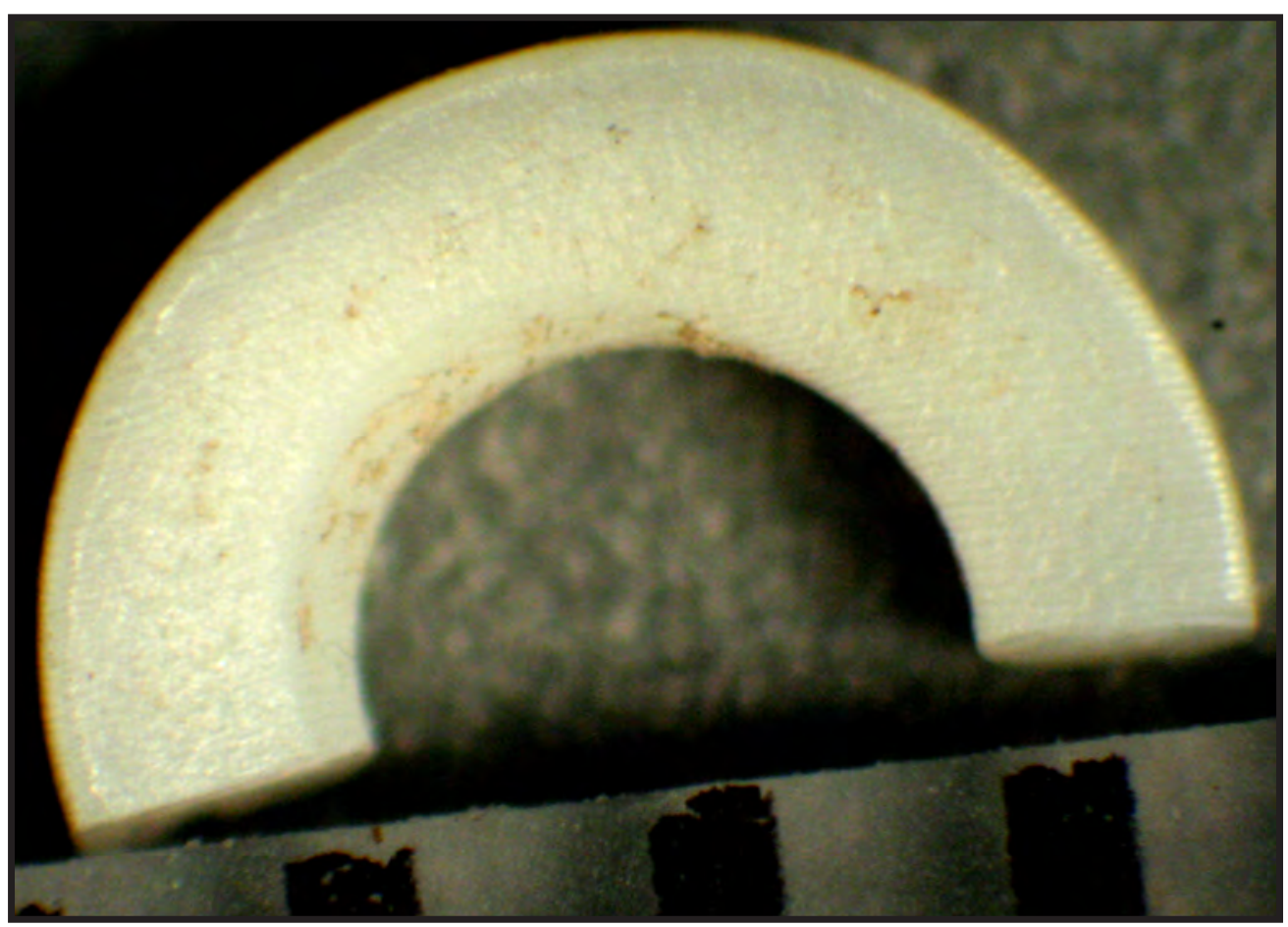

Figure 8-21. Close-up of half of a circular marine shell bead (\#1032-10). Scale is in millimeters. 
burned rock (157.8 g) fragment, 15 tiny pieces of debitage (3.8 g), 1 tiny fleck of charcoal, 11 burned seeds, 3 fragments of pottery, 30 tiny bone (5.4 g) fragments, and 20 tiny pieces $(0.9 \mathrm{~g})$ of daub/ burned clay (Table 8-4). The bone fragments are nearly all unburned with at least one unburned rabbit mandible. A few bone fragments were burned white. Two pieces of debitage are the white opalite that exhibit platforms and bulbs of percussion. One tiny piece of debitage is of obsidian (\#11251). This obsidian was sourced to Cerro Toledo (Appendix E). The $22.9 \mathrm{~g}$ light fraction (\#1125-4b) was sent for macrobotanical analysis and the results revealed mesquite seed and maize fragments. Wood types were diverse and include juniper, mesquite, cottonwood/willow and oak (Appendix C).

Cultural materials encountered during an excavation near the top of this basin included wood charcoal, bone fragments, tiny mussel shell fragments, lithic debitage, pottery sherds (including one rim sherd), possible ochre, and a couple of medium-size burned rock fragments. The bone fragments include pieces of turtle shells. This feature served as a heating element in which diverse cultural materials became incorporated into the basin fill.

\subsubsection{Feature 13}

This was a pit feature detected at the intersection of four units, N694 E513, N694 E514, N695 E513, and N695 E514, in the northern part of Component A about $4.0 \mathrm{~m}$ south of the pithouse - Feature 1 (see Figure 8-1). The fill was troweled from the feature, and cultural materials encountered were collected by level when observed during excavation.The feature was bisected along the east-west unit line and excavated in $10 \mathrm{~cm}$ arbitrary levels. At least six small sediment samples (roughly $500 \mathrm{~g}$ ) were collected from the bisected profile for chemical and other analyses. One column of three samples (47 to $49 \mathrm{cmbs}, 59$ to $61 \mathrm{cmbs}$, and 70 to $72 \mathrm{cmbs}$ ) was extracted from the east side and a second set (43 to $45 \mathrm{cmbs}, 53$ to $55 \mathrm{cmbs}$, and 63 to $65 \mathrm{cmbs}$ ) was collected from the western side. Two 10-by-10by-10 cm matrix columns were also collected from the pit profile, one column from the top $10 \mathrm{~cm}$ of the pit and the other from the bottom of the pit. The remaining pit fill was collected for flotation.
The top was somewhat diffused, so it was difficult to define the precise edge in the brown (7.5YR 5/4) sandy loam that was disturbed by rodent activity (Figures 8-22 and 8-23). This top exhibited a darkstained, organic-rich fill that contained scattered cultural materials at about 33 cmbs. The pit had been dug into the compact reddish gray (10YR 6/4) Bk horizon Ogallala Formation deposits, allowing easy definition of the bottom.

The pit measured roughly $50 \mathrm{~cm}$ in diameter by 39-cm-deep with the bottom at about 72 cmbs. This was a cylindrical pit with rounded corners at the bottom and the top appeared disturbed. The bottom was slightly irregular to convex with no obvious plaster or rock basal lining. The sidewalls were nearly vertical with no sign of a rock lining or clay plastering. The pit fill was a mottled light brown (7.5YR 6/4) sandy loam with tiny lighter spots of calcium carbonate and spots of darker charcoal chunks. Small insect burrows and minor rodent disturbances were observed in the fill. The relatively few items recovered during toweling include some 56 small bone fragments, 15 pieces of lithic debitage, 9 ceramic sherds, 8 burned rock fragments, 7 pieces of daub, and 1 mussel shell fragment.

Charles Frederick collected specific column samples from this feature to help document the internal stratigraphy. He collected and analyzed two oriented micromorphology blocks of sediment from this pit located at N695 E514. One block was collected from a depth of 43 to $55 \mathrm{cmbs}$ (\#1221-4), and the second was collected from 65 to $75 \mathrm{cmbs}$ (\#10234). Frederick made two thin sections from each block. The attributes of the deposit were similar in the upper and lower samples. In general terms, the sediment that filled the pit were derived from the Ogallala Formation and either represent gradual infilling of the pit from weathering of the sidewalls or intentional fill derived from the Ogallala Formation.

The sediment within the pit consisted of a silt loam that exhibited a weakly developed intergrain channel structure where the $\mathrm{c} / \mathrm{f} 63$ micron is about $1: 10$ and exhibits an open porphyric related distribution. Channels comprise between 5 to 15 percent of the area (and the proportion of channels was highly variable between the two samples) with 


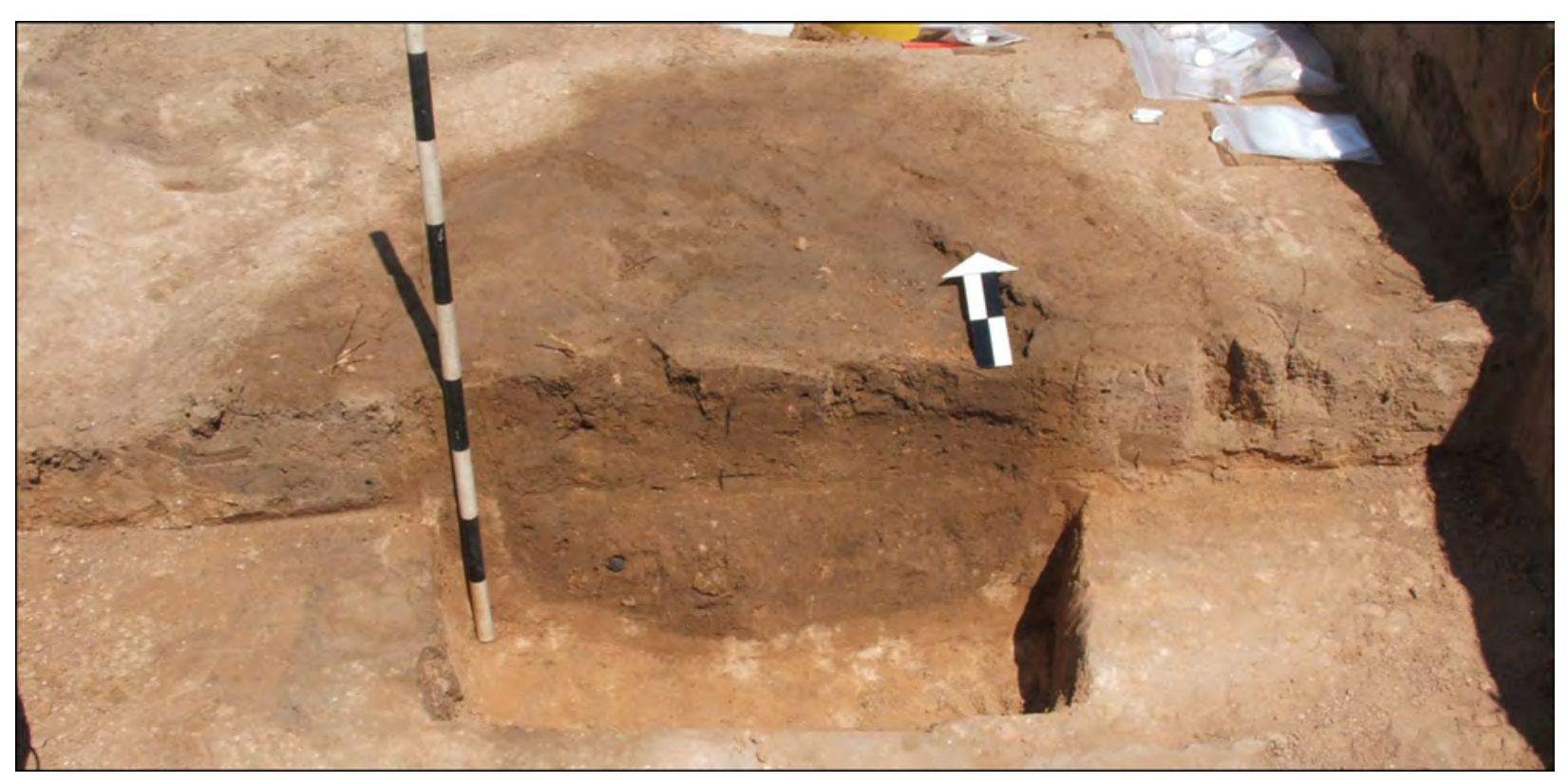

Figure 8-22. North profile of storage pit - Feature 13 (scale in 10-cm increments).

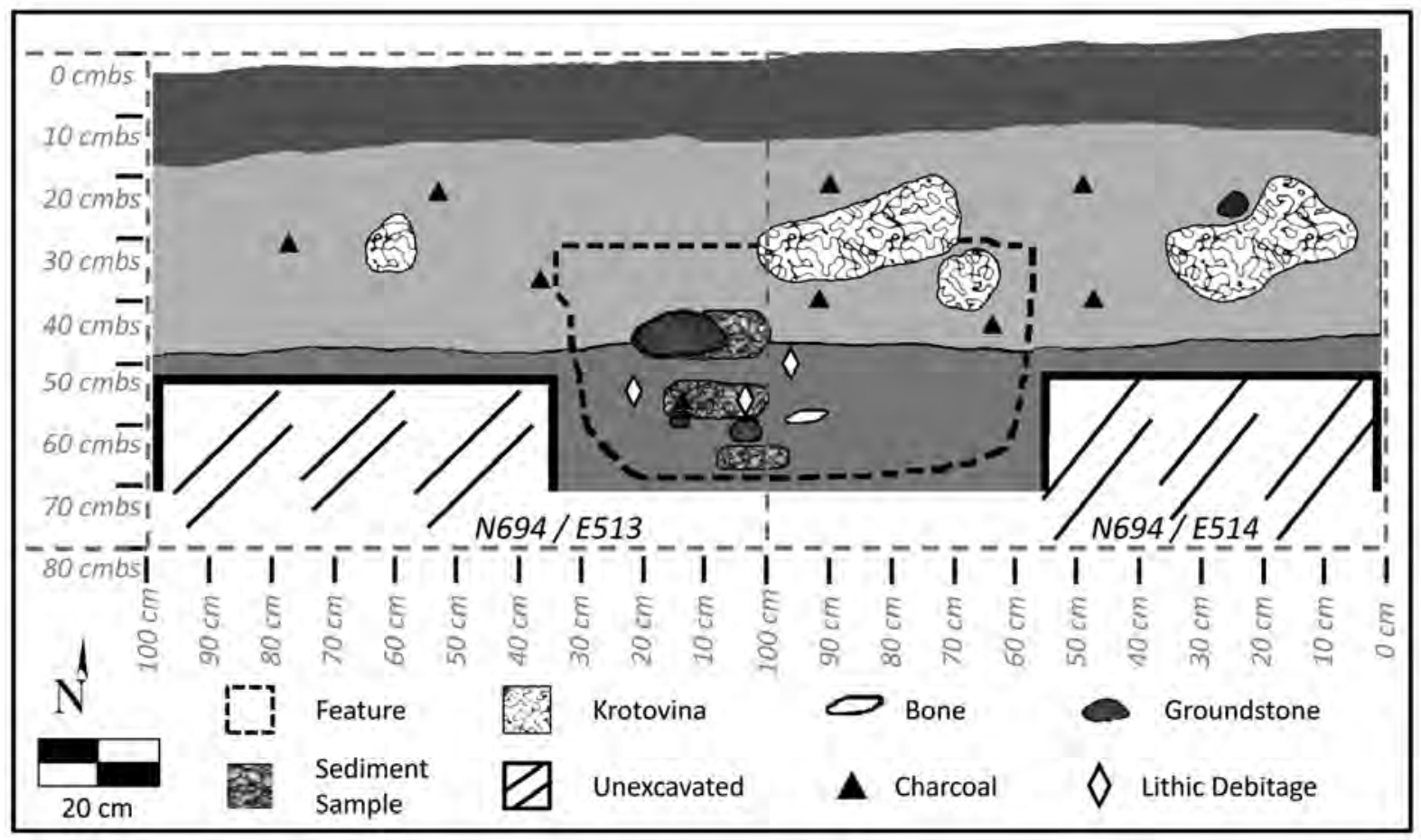

Figure 8-23. North profile drawing of storage pit - Feature 13. 
the shallower sample exhibiting more frequent and larger channels than the deeper sample. A few coarse fragments (greater than $1 \mathrm{~cm}$ ) of angular caprock caliche were noted, but all thin sections exhibited between 5 and 10 percent, 1 to $10 \mathrm{~mm}$ rounded fragments of calcium carbonate nodules derived from the Ogallala Formation. Some were clearly reworked as excrement by soil fauna, whereas others appeared similar to those observed in context in the Ogallala, but with sharper edges. Like all of the Ogallala sediments, the dominant minerals are quartz (around 80 percent) and feldspar (around 15 percent plagioclase and microcline). Faunal excrement was present, but the majority was strongly coalesced dense microaggregates, with only a few weakly coalesced pristine porous microaggregates. A few large (greater than $2 \mathrm{~mm}$ ) charcoal fragments were observed within the pit fill, and less than 1 percent of less than $0.1 \mathrm{~mm}$ fragments were noted.

The absence of micro-lamination that may accompany incremental sedimentary infilling of pit structures implies the pit was intentionally filled, or postdepositional floral and faunal activity destroyed it. The magnitude of faunal activity within the micromorphology samples is less than observed within the occupation surface, where eolian sand rests directly upon the Ogallala Formation. This pit filled gradually through time and likely the bedding was destroyed by floral root activity. This would be consistent with the channel microstructure exhibited by these samples, but the complete absence of bedding is somewhat surprising.

A variety of technical analyses were performed on materials from this pit feature. A small (184 g) burned rock fragment (\#985-3-1a) was submitted for diatom analysis. The analysts identified 16 diatoms with 75 percent Nitzschia amphibia that characterize freshwater lakes or streams (Appendix J). To account for stream diatoms on this burned rock, the rock must have come in contact with water from the nearby stream, which was likely during a cooking/boiling process. A thin sediment sample (\#1044-004-5b) from the pit bottom (between 59 and $61 \mathrm{cmbs}$ ) was submitted for phytolith analysis. The results indicate the dominance (48.5 percent) of cool season pooid grasses, with no maize, beans, or squash phytoliths identified (Appendix
B). The phytolith assemblage is very similar to the assemblages from the occupation zone, which also was dominated by cool season pooid grasses (see sample 8, Appendix B). The presence of cool season grass may indicate these accumulated in the abandoned pit during a cool season such as late fall or winter. A high frequency of hot dry, tall saddle shaped chloridoid phytoliths (58.3 percent) were present. A ceramic sherd (\#1021-8-1) from 40 to $50 \mathrm{cmbs}$, a burned rock fragment (\#985-3-1b; 197 g) from 41 to $46 \mathrm{cmbs}$, and a sample of sediment sample from 59 to $61 \mathrm{cmbs}$ were all subjected to starch grain analysis. The sherd yielded one maize and one damaged maize starch grains. The burned rock yielded one maize, two lenticular grains of little barley, and one damaged little barley grain (Appendix D). The same sediment sample (\#10144-5a) used for phytoliths analysis did not yield any starch grains, which supports the belief that the starch grains were derived from cultural processes and not from the surrounding natural sediments.

Two small chunks of charcoal were submitted for identification and Dering identified one as juniper wood, and the other is a tiny burned bone fragment (Appendix C). A $10.9 \mathrm{~g}$ bison bone fragment (\#10122-2) was submitted for stable carbon and nitrogen isotope analyses. The obtained $\delta^{13} \mathrm{C}$ value is $-12.5 \%$ and the $\delta^{15} \mathrm{~N}$ value is $3.7 \%$, which indicate this bison consumed roughly 85 percent $\mathrm{C}_{4}$ vegetation during its lifetime (Appendix I). Two tiny pieces of obsidian (\#1014-1-2 and \#1021-1-3) from the fill were subjected to source analysis. Analytical results indicate both pieces were from Cerro Toledo Ryholite obsidian source (Appendix E). A small chunk of daub (\#1012-5-1 = TRC643) from this pit was submitted for INAA. Those results reflect a general chemical composition similar to pottery and one piece of daub (\#1113-5-2 = TRC642) from the pithouse, but was not assigned to one of the pottery compositional groups (Appendix G).

Nearly 128 liters of fill were floated. Two light fractions (\#1014-4-1b and \#1014-4-3b) derived from 17 and 15 liters of floated fill from 45 to $55 \mathrm{cmbs}$ and 65 to $75 \mathrm{cmbs}$, respectively, were subjected to macrobotanical identifications. The results include eight maize cupules and three kernels. The identified wood types are diverse, and include juniper, 
mesquite, rose-family-type and cottonwood/willowtype (Appendix C). The $40.2 \mathrm{~g}$ of heavy fraction from 45 to 55 cmbs (\#1014-4-1) yielded 7 tiny mussel shell fragments, 66 tiny pieces of debitage $(6.0 \mathrm{~g}), 2$ flecks of charcoal, 5 ceramic sherds (3.5 g), 60+ tiny bone fragments (12.3 g), and 64 tiny pieces of daub (6.2 g, Table 8-4). Less than 20 percent of the tiny bone fragments were burned. The heavy fraction from just below, at 55 to $65 \mathrm{cmbs}$ (\#1014-4-2), yielded similar types and quantities of classes with 3 mussel shell fragments, 54 tiny pieces of debitage (2.4 g), 1 charcoal fleck, 2 pieces of pottery $(3.3 \mathrm{~g}), 30+$ tiny bone fragments (11.2 g), and $30+$ pieces of daub $(6.2 \mathrm{~g}$, Table 8-4). The lithic debitage from both proveniences includes at least chert and opalite. The tiny bone fragments include roughly 20 percent burned pieces, some a gray and some black. A tiny turtle carapace fragment is also present. At the very bottom of the pit, between 65 and $75 \mathrm{cmbs}$, the $65.8 \mathrm{~g}$ heavy fraction yielded one tiny mussel shell fragment, 48 tiny pieces of debitage $(0.4 \mathrm{~g})$, tiny flecks of charcoal, 2 ceramic sherds (11.3 g), 30+ tiny bone fragments (7.7 g), and 40 tiny pieces of daub (3.4 g). Roughly 15 percent of the tiny bone fragments are burned, which includes a complete, 6-mm-long caudal vertebrae of a small mammal.

This relatively small, 40 -cm-deep pit is interpreted as a storage facility. Apparently, the stored goods were removed during the occupation and then the pit accumulated sediment and diverse occupational trash consistent with the debris generated by the broader occupation. Consequently, the results of the analyses conducted on items from inside this storage pit do not reflect what was stored, but represent the general occupation of Component A.

\subsubsection{Feature 14}

This was a small cluster of cultural materials detected in the southern end of Component $\mathrm{A}$ on the margin of two units, the southern margin of N673 E509 and the northern margin of N672 E509 (see Figure 8-1). This cluster was about $20 \mathrm{~cm}$ northwest of a modern wooden fence post in N672 E509. The clustered materials were bisected along the east-west unit lines to create a profile. In this profile, a slightly darker stained matrix was observed and appeared to be part of an old, faint rodent burrow/fill (Figures 8-24 and 8-25). The clustered materials were drawn in both plan and profile, then collected along with the surrounding matrix. The materials include at least two chunks of burned caliche, a piece of daub, and two bone fragments (a bison vertebra and a bison long bone fragment), with tiny pieces of charcoal in the slightly darker sediment. This cluster measured about 10 to $12 \mathrm{~cm}$ in diameter, and was between 41 and $46 \mathrm{cmbs}$. The clustered materials were in an apparent rodent burrow that was eventually traced toward the north.

A small (46 g) burned rock fragment (\#800-3-1a) from between 40 and 50 cmbs was submitted for diatom analysis. Winsborough identified only two diatoms of Hantzschia amphioxys, which are aerial forms that occur on rocks, in damp mud and dry soil, also in sand and in fresh and brackish water of lakes and streams (Appendix J). A $160 \mathrm{~g}$ chunk of this same burned rock (\#800-3-1b) was subjected to starch analysis. However, it did not yield any starch grains (Appendix D).

A three liter sediment sample (\#816-4) from around the clustered items was floated. The $2 \mathrm{~g}$ heavy fraction yielded very limited and tiny pieces of cultural debris, which includes 3 tiny pieces of debitage, 1 fleck of charcoal, and 12 tiny bone fragments (0.1 g, Table 8-4). The light fraction revealed no charred macrobotanical remains and was not sent for analysis.

Feature 14 is not interpreted as a cultural feature and is, rather, attributed to postdepositional movement and clustering of cultural materials by rodents. Other cultural materials were widely dispersed in the area, with no intact cultural features in the southern area.

\subsubsection{Feature 15}

This was a small burned rock concentration buried in the southern end of Component $\mathrm{A}$, located along the southern margin of N679 E511 and the northern margin of N678 E511. No other in situ cultural features were identified in this area. These four clustered burned rocks were encountered during shovel shaving, after which the cluster was exposed with trowel and whisk broom and the rocks were mapped on the level record form. Feature matrix was screened separately in the field. The cluster of rocks was bisected along the east-west unit line to 


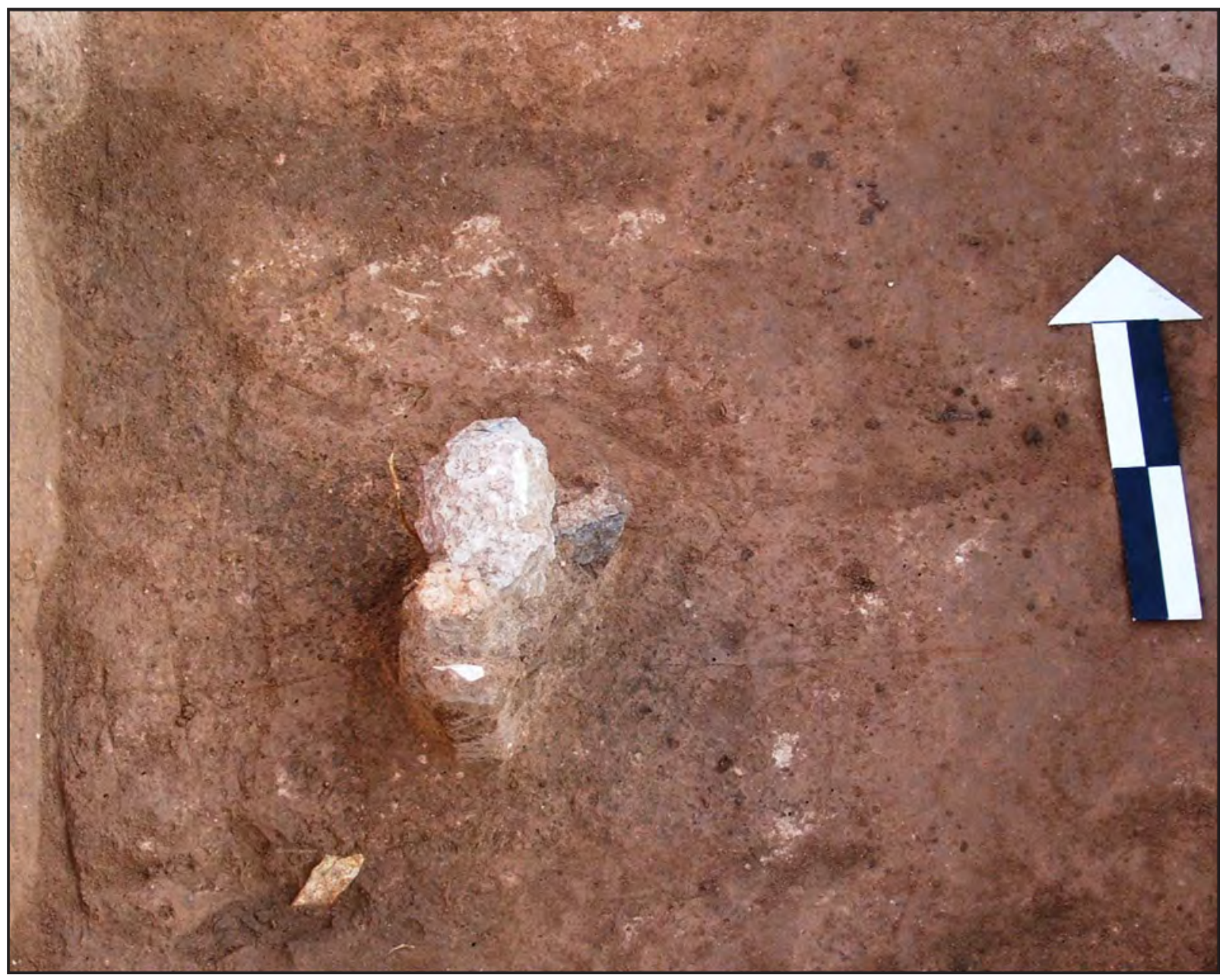

Figure 8-24. Oblique overview of clustered cultural material in darker stained rodent burrow.

create a profile. This cluster was between 18 and $35 \mathrm{cmbs}$ in a compact, sandy clay loam, just above the definable occupational zone. In plan view, the cluster measured about 15-by-17 cm. It contained three pieces of sandstone and one burned caliche rock, the largest piece of which was about $13 \mathrm{~cm}$ in diameter, whereas the smallest was about $2 \mathrm{~cm}$ in diameter (Figure 8-26).

The largest sandstone rock was on top of the caliche rock. No soil discoloration was observed around the rocks, and the feature matrix was the same color as the surrounding sediment. No charcoal staining or oxidation was observed. Tiny grass rootlets were present around the rocks. All the burned rocks and a couple of tiny charcoal chunks from nearby were collected. One unifacial Alibates scraper (\#859-10) was recovered in situ at $29 \mathrm{cmbs}, 60 \mathrm{~cm}$ to the north of this rock cluster. This scraper was documented as used for scraping hides and was possibly hafted (Appendix H).

A single chunk (0.4 g) of charcoal (\#860-7) was sent for wood species identification. Dering identified the charcoal as juniper (Appendix C). A $257 \mathrm{~g}$ burned rock (\#855-3-1a) was submitted for diatom analysis and it yielded a single Pinnularia sp. diatom (Appendix J). A $209 \mathrm{~g}$ chunk of this same burned rock (\#855-3-1b) was analyzed for starch, but did not yield any starch grains (Appendix D). This cluster of four burned rocks is considered a possible dump from a cooking event within the component, though it is likely that the clustering was caused by rodent disturbance. 


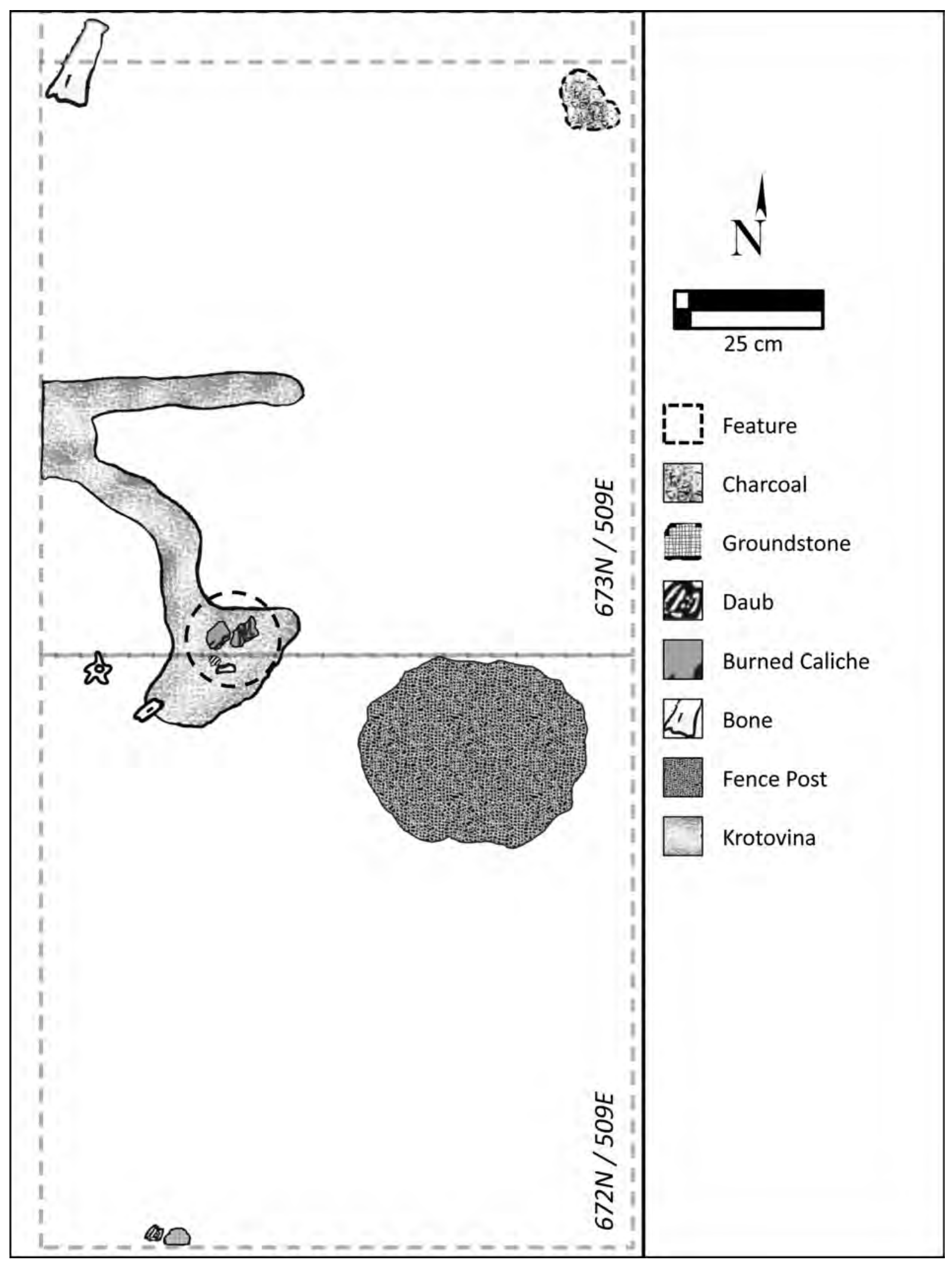

Figure 8-25. Plan view of Feature 14 and associated cultural materials. 


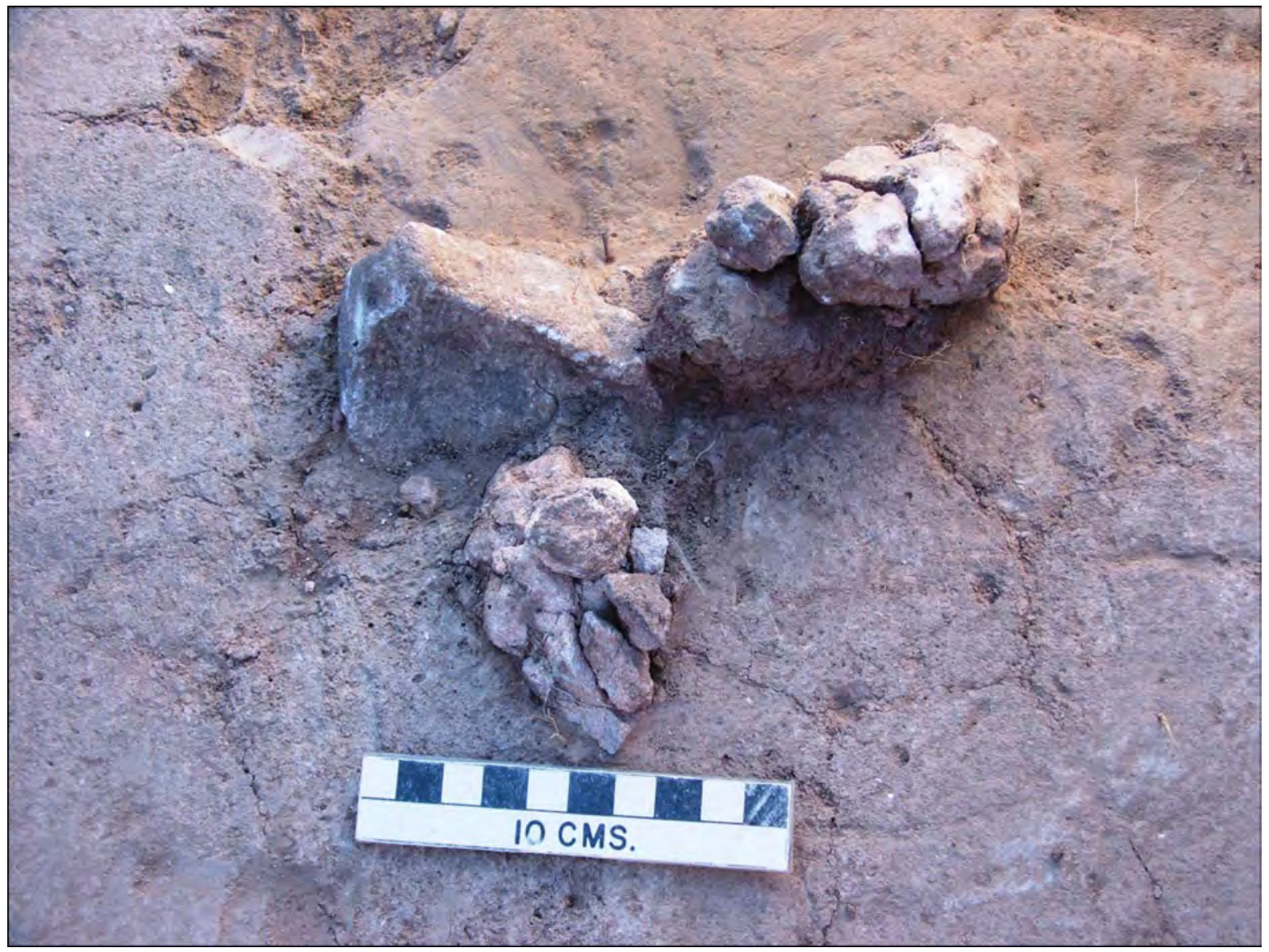

Figure 8-26. Cluster of burned rocks, Feature 15.

\subsubsection{Feature Summary and Discussions}

All 11 features are considered to represent a single Plains Village component. Nine were in situ, whereas Features 14 and possibly 15 may reflect secondary accumulations that resulted from rodent activity (Table 8-5). In fact, rodent activity was identified in and around nearly all features and throughout the occupation zone. This postdepositional activity caused vertical dispersal of many small cultural items throughout the sandy Holocene deposits and, possibly, minor disruption to most features, although nine identified features remained largely intact and in situ.

Component A yielded a limited suite of feature types that included one-half a pithouse (Feature 1), one small storage pit (Feature 13), seven heating elements (Features 3, 4, 8 through 12), and two clusters of cultural material possibly caused by rodents (Features 14 and 15). Based on their overall shapes and contents, these features represent a limited suite of human activities, which included cooking, heating, storage, and a semipermanent house. The latter is somewhat unusual for the Texas panhandle and has not been identified as part of the Antelope Creek phase structures. Unfortunately, only a limited area of that pithouse remained upon discovery and that excavated part was limited to less than $2 \mathrm{~m}$ in diameter. Therefore, a complete understanding of that structure is not possible.

The nine in situ cultural features were not randomly scattered across the long, narrow APE. They were concentrated in an area that encompassed roughly $32 \mathrm{~m}^{2}$ towards the northern end of the northern excavation block. The pithouse (Feature 1) was on the very eastern margin of the block, whereas another eight features were within $6 \mathrm{~m}$ west and southwest of the pithouse (see Figure 8-1). The one storage pit (Feature 13) was south of four heating elements (Features 3, 4, 8 and 10), and east of 
Table 8-5. Summary of Component A Features and Feature Data.

\begin{tabular}{|c|c|c|c|c|c|c|c|c|c|c|c|c|c|c|c|c|}
\hline $\begin{array}{c}\text { Feature } \\
\text { No. }\end{array}$ & $\begin{array}{c}\text { Feature } \\
\text { Type }\end{array}$ & $\mid \begin{array}{c}\text { Feature } \\
\text { Size }(\mathrm{cm})\end{array}$ & \begin{tabular}{|l} 
Depth \\
(cmbs)
\end{tabular} & $\begin{array}{c}\text { Conventional } \\
\text { Age B.P. }\end{array}$ & $\begin{array}{c}\text { Charcoal } \\
\text { Present }\end{array}$ & $\begin{array}{c}\text { Lithic } \\
\text { Debitage }\end{array}$ & Bones & Pottery & $\begin{array}{l}\text { Post } \\
\text { Holes }\end{array}$ & $\begin{array}{l}\text { Burned } \\
\text { Rocks }\end{array}$ & $\begin{array}{c}\text { Tools } \\
\text { Present }\end{array}$ & $\begin{array}{l}\text { Matrix } \\
\text { Floated }\end{array}$ & $\begin{array}{c}\text { Light } \\
\text { Fraction } \\
\text { Analyzed }\end{array}$ & $\begin{array}{c}\text { Native } \\
\text { Plants } \\
\text { Present }\end{array}$ & \begin{tabular}{|c|} 
Cultivated \\
Plants \\
Present
\end{tabular} & Other \\
\hline 1 & pithouse & $\begin{array}{c}250 \text { wide } \\
30 \text { deep }\end{array}$ & $30-65$ & $\begin{array}{l}710 \pm 40,1490 \\
\pm 40,590 \pm 25\end{array}$ & chunks & yes & no & yes & 16 & yes & yes & $\begin{array}{c}6=63.25 \\
\text { liters }\end{array}$ & yes & & maize & \\
\hline 3 & $\begin{array}{l}\text { basin } \\
\text { heating } \\
\text { element }\end{array}$ & $\begin{array}{l}35 \times \text { x 40, } \\
9 \text { deep }\end{array}$ & $32-50$ & $970 \pm 40$ & chunks & no & no & & no & no & $\begin{array}{l}1 \text { edge- } \\
\text { mod }\end{array}$ & $1=4$ liters & yes & & maize & \\
\hline 4 & $\begin{array}{l}\text { basin } \\
\text { heating } \\
\text { element }\end{array}$ & $\begin{array}{l}28 \text { x 28, } \\
15 \text { deep }\end{array}$ & $49-65$ & $710 \pm 40$ & chunks & 1 opalite & frags & & no & ? & no & $1=4$ liters & yes & $\begin{array}{l}\text { pigweed, } \\
\text { mesquite }\end{array}$ & $\begin{array}{l}\text { maize, } \\
\text { squash }\end{array}$ & \\
\hline 8 & \begin{tabular}{|c} 
basin \\
heating \\
element
\end{tabular} & $\begin{array}{l}30 \text { wide } \\
12 \text { deep }\end{array}$ & $30-42$ & $480 \pm 25$ & yes & $\begin{array}{c}\text { yes, } 1 \\
\text { obsidian }\end{array}$ & yes & & no & yes & $\begin{array}{l}\text { ground } \\
\text { stone }\end{array}$ & $1=20$ liters & yes & & & \\
\hline 9 & $\begin{array}{c}\text { basin } \\
\text { heating } \\
\text { element }\end{array}$ & $\begin{array}{l}25 \text { wide } \\
7 \text { deep }\end{array}$ & $40-47$ & $480 \pm 20$ & yes & no & no & & no & yes & no & $1=3$ liters & yes & & & \\
\hline 10 & \begin{tabular}{|c} 
basin \\
heating \\
element
\end{tabular} & $\begin{array}{l}75 \text { wide } \\
22 \text { deep }\end{array}$ & $31-53$ & $510 \pm 25$ & yes & yes & yes & & no & yes & edge-mod & $\begin{array}{c}2=41.5 \\
\text { liters }\end{array}$ & yes & & & \\
\hline 11 & $\begin{array}{l}\text { basin } \\
\text { heating } \\
\text { element }\end{array}$ & $\begin{array}{l}25 \text { wide } \\
14 \text { deep }\end{array}$ & $43-57$ & $500 \pm 25$ & yes & & yes & & no & yes & no & $1=5.5$ liters & yes & & & 1 bead \\
\hline 12 & \begin{tabular}{|c} 
basin \\
heating \\
element
\end{tabular} & $\begin{array}{l}70 \text { wide } \\
25 \text { deep }\end{array}$ & $30-55$ & & yes & $\begin{array}{c}\text { opalite, } 1 \\
\text { obsidian }\end{array}$ & yes & yes & no & no & $?$ & $1=23$ liters & yes & & & \\
\hline 13 & $\begin{array}{l}\text { storage } \\
\text { pit }\end{array}$ & $\begin{array}{l}35 \text { wide } \\
39 \text { deep }\end{array}$ & 33-72 & & yes & $\begin{array}{c}15,2 \\
\text { obsidian }\end{array}$ & 56 & 9 & no & 8 & no & $\begin{array}{c}4=127.5 \\
\text { liters }\end{array}$ & yes & & & \\
\hline 14 & $\begin{array}{l}\text { natural } \\
\text { cluster }\end{array}$ & $\begin{array}{l}10 \text { wide } \\
5 \text { deep }\end{array}$ & $41-46$ & & no & 2 caliche & 2 frags & & no & 1 & no & $1=3$ liters & yes & & & \\
\hline 15 & dump & $\begin{array}{l}17 \text { wide } \\
17 \text { deep }\end{array}$ & $18-35$ & & yes & no & no & & no & 4 & scraper & yes & no & & & \\
\hline
\end{tabular}


two other heating elements (Features 9 and 11). The heating and storage activities were near the habitation structure. These clustered features likely reflect activities of a small group, perhaps a nuclear family unit that occupied the pithouse for a unknown period. The restricted nature of the horizontal distribution may also reflect a particular seasonal use and the nonpermanent nature of the occupation.

Two small clusters of materials (Features 14 and 15), 15 and $21 \mathrm{~m}$ south of the storage pit, were near the middle of the more southern excavation block in Component A. That southern area also yielded numerous stone tools and likely represented a separate activity area that included butchering and hide-processing, as it yielded among many chipped stone tools, a cluster of four beveled knives ( 2 exhausted and 2 broken) and an end scraper, discarded $2.5 \mathrm{~m}$ south of Feature 14.

In total, nearly 273 liters of sediment from 10 features were floated and yielded $937.9 \mathrm{~g}$ of light fraction material and a variety of tiny cultural items. Many classes of cultural material were also present in the heavy fractions, such as wood charcoal, charred seeds, lithic debitage, pottery sherds, bone fragments, and daub/burned clay, and reflect similar types of cultural materials recovered from the 6.4 $\mathrm{mm}$ screening process with one notable exception. A tiny $2 \mathrm{~mm}$ marine shell bead fragment was recovered from Feature 11, an area that included multiple classes of cultural debris. Because of its tiny size, little can be extracted from this bead fragment, except to say it was nonlocal and from a distant source. This was the only bead recovered from Component A, which also lacked shell artifacts. The wood charcoal was dominated by juniper (average $0.012 \mathrm{~g} /$ /iter) with mesquite (average $0.003 \mathrm{~g} /$ liter) a secondary type, with juniper four times more abundant. Rose family, cottonwood/willow, oak and elm wood were also present in limited amounts. In terms of cultigens, the macrobotanical remains yielded considerable amounts of maize and minimal squash rinds, whereas wild plants identified include very minor amounts of cheno-ams and mesquite seeds.

Starch grain analysis was conducted on eight samples from three diverse materials (2 sherds,
5 burned rocks, and 1 sediment) from Features 1, $11,13,14$, and 15 and yielded a total of at least 14 grains. Lenticular little barley grains $(N=9)$ were on 1 sherd and two burned rocks. Maize grains $(N=$ 4) and one possible maize grain were on one sherd and one burned rock. Both damaged maize and little barley grains, and one unknown damaged grain were present.

Seven phytoliths samples from five features (Features 1, 8, 10, 11, and 13) were analyzed. All seven samples yielded phytoliths with a total of 1,335.5 short cell phytoliths that ranged from 35 to 237 per sample. The storage Feature 13 yielded the fewest short cells per sample $(N=35)$, whereas the fill from heating elements yielded a range from 158 to 237 short cells. The three samples from the floor of pithouse Feature 1 ranged from 218 to 228 short cells. The hot dry chloridoids dominated the short cells in Features 1 and 8, whereas cool season pooids dominated in Features 11 and 13. Only heating element Feature 10 yielded nearly equal percentages of pooids, chloridoids, and panicoids. No Pinaceae tracheid phytoliths that reflect pine wood were identified in any of these features. Overall, 21 large cross shaped phytoliths that represent maize leaves were in four features, but none were in the storage pit. One maize rondel shaped phytolith that represent maize cobs was found in the floor of the pithouse Feature 1. No beans or squash phytolith were positively identified. The off-site control sample did not yield any phytoliths from cultigens.

Diatom analysis was conducted on four burned rocks and one daub piece from Features 1, 11, 13, 14, and 15. These five samples yielded 152 diatoms with 131 from the daub. This included one burned rock each from Features 11, 13, 14, and 15 whereas the daub was from Feature 1. The daub yielded nearly all aquatic diatoms while the burned rocks yielded mostly aerial diatoms.

The aquatic diatoms in the daub indicate that this was a mixture of water and mud/sediment. The specific species indicates the water was clear, acidic, and soft with low alkalinity and phosphate, typical of a stream from the caprock. The burned rock from Feature 11 yielded two diatoms from a single aquatic species, which indicates that this rock may 
have been used in a boiling process with water form the nearby stream. The two other burned rocks from Features 13 and 14 yielded aerial species that are most abundant on freshly wetted surfaces and likely indicates that these rocks also came in contact with water, likely in a boiling process.

The tiny marine shell bead from Feature 11 fill reflects long distance trading from some unknown coast. A few pieces of Niobrara jasper form Kansas and the obsidian from north-central New Mexico also indicates interactions with groups to the north and west.

\subsection{Chipped Stone Tool Analyses}

Paul M. Matchen

The Component A lithic artifacts were recovered from the northernmost portion of the site, between N706 through N665 and E509 through E515. Table 8-6 provides the breakdown of tool classes. Radiocarbon dates for this component range from 510 to 480 B.P. (conventional age) based on nine acceptable dates on maize derived from various features (see Chapter 7 for discussion of stratigraphy). The following presentation discusses tool data stemming from analysis that provides a characterization of the assemblage and contributes information with which to address research questions as presented in the research design (see Chapter 4.0).
The hand-excavations (the entirety of the Component A block plus Test Units A-1, A-2, A-3, A-4, A-5, A-6, and A-8) yielded a sample of 205 chipped stone tools. This group represents six percent of the overall chipped stone lithic assemblage, the remainder being comprised mostly of debitage. Chipped-stone tool descriptions are presented below by tool class. A number of tools in each class were also selected for detailed description as representative examples of that class. Details of the quantitative and qualitative measurements of the chipped stone tool assemblage can be found in Appendix K.

Several tools were selected for high-powered microscopic use-wear analysis $(N=14$ or 7.2 percent of total) and starch grain analyses $(N=29$ or 14.9 percent of total). This use-wear analysis focused on identifying specific tool uses through detection of microwear left on tool surfaces, as well as identifying the organic materials left on the tool, presumably the result of contact with those materials. A summary of the use-wear results for each specimen is included in the individual tool descriptions below, where applicable.

\subsubsection{Projectile Points}

Projectile points comprised 10 percent $(N=19)$ of the chipped-stone tool assemblage in Component A. This group includes three complete specimens (\#2310, \#804-10, and \#695-10), two almost complete

Table 8-6. Artifact Class Frequency for Component A.

\begin{tabular}{|c|c|c|}
\hline Component & $\begin{array}{l}\text { Artifact } \\
\text { Classes }\end{array}$ & $\begin{array}{c}\text { Frequency } \\
(N)\end{array}$ \\
\hline A & $\begin{array}{l}\text { Projectile } \\
\text { Points }\end{array}$ & 19 \\
\hline A & Bifaces & 17 \\
\hline A & Drills & 4 \\
\hline A & Scrapers & 21 \\
\hline A & $\begin{array}{l}\text { Edge- } \\
\text { Modified } \\
\text { Flakes }\end{array}$ & 143 \\
\hline A & Chopper & 1 \\
\hline \multicolumn{2}{|c|}{ Total } & 205 \\
\hline
\end{tabular}


specimens, eight proximal fragments, five medial fragments, and one distal fragment.

These items are classified as triangular arrow points based on their metric and morphological characteristics, and their similarity to chipped-stone bifaces generally assumed to be arrow points (e.g., Suhm and Jelks 1962; Turner and Hester 1999). Nonetheless, we recognize that these specimens, as well as many other artifacts commonly identified as arrow points, could have had multiple uses (e.g., as both arrow points and knives).

There is a basic dichotomy of morphological styles present within this tool class assemblage: namely, those bifacial tools resembling the Fresno form and those that resemble the Washita form. Fresno points $(N=11)$ are described as small, triangular tools with straight to slightly convex lateral edges (Bell 1960:44; Suhm and Krieger 1954). The proximal end (i.e., base or wider end) is usually straight, but can be slightly convex or concave (Figure 8-27). These projectiles are typically finely flaked and thin, though many specimens have been recovered at various archeological sites having large remnant flake scars on one face (Suhm and Krieger 1954; Bell 1960:44). These remnant scar areas denote attributes of the parent flake from which the point was fashioned.
Washita points ( $N=7$; 36 percent) are described as small side-notched triangular forms whose sides are typically straight or slightly convex (Bell 1958; Cambron and Hulce 1964). In fact, aside from the lateral notching, they are very similar in form to the Fresno style.

Another triangular form present $(N=1)$ is the Harrell style (Figure 8-28). This form is practically identical to the Washita with the exception of the presence of a basal notch (Suhm and Krieger 1954:500; Bell 1958:30). Suhm and Krieger (1954) lumped the two styles together under the Harrell type, while Bell (1958) splits them, as is done in this report. As with the former style, the Harrell form is classified as a triangular point with nearly straight sides and a base shape that ranges between straight and slightly concave (Bell 1958).

Metric measurements for points of this and other types are presented in Table 8-7, with qualitative observations of complete specimens presented in Table 8-8.

\subsubsection{Descriptions of Complete Tools}

Specimen \#23-10 is a small side-notched triangular point, stylistically similar to a Washita form (Bell 1960; Suhm and Krieger 1954; Turner and Hester 1999) that was recovered from the surface of the road cut in the eastern portion of the excavation block. The flaking pattern on both faces is complete

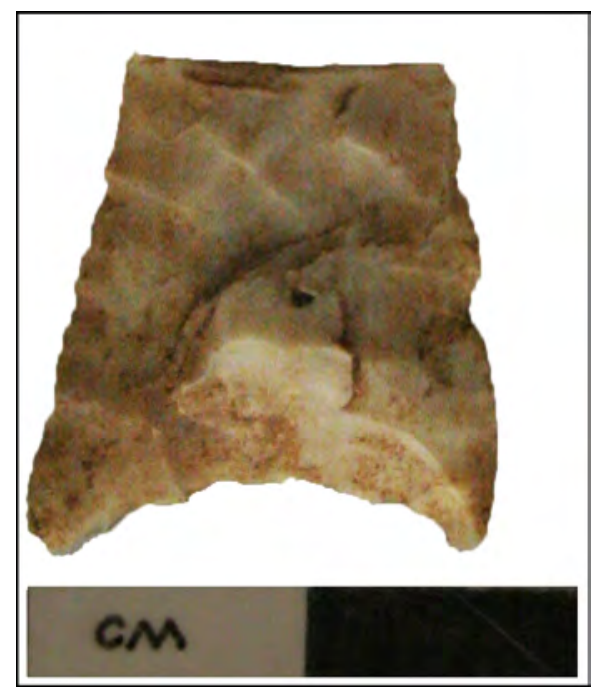

Figure 8-27. Fresno base (\#1216-10). 


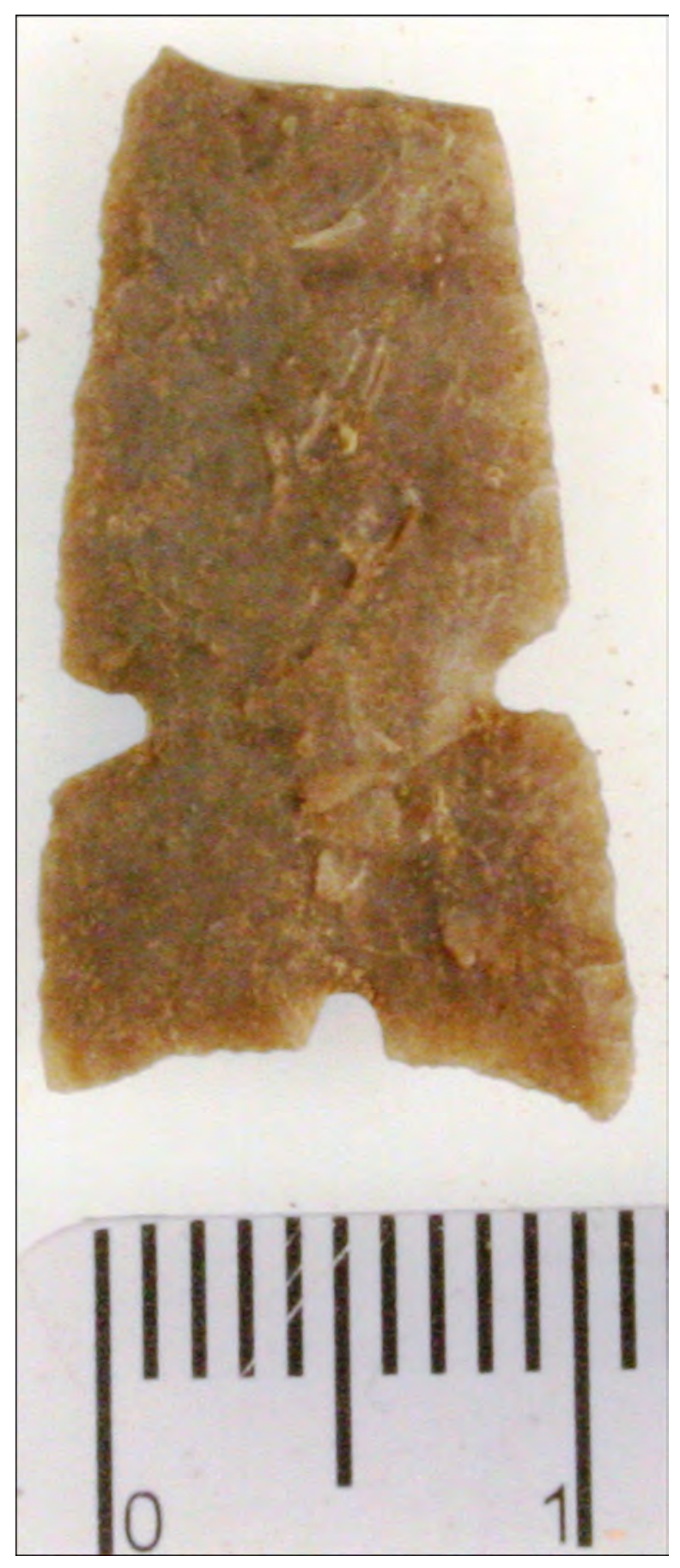

Figure 8-28. Harrell point (\#373-10) from Component A. Measurements in $\mathrm{mm}$. 
and random. This point is asymmetrical in shape and heavily re-worked on the lateral edges above the side notches (Figure 8-29). The lateral blade edges are concave, with average edge angle values at 50 and 55 degrees. Another distinctive aspect of this specimen is the fact that is fashioned from a chocolate-brown orthoquartzite (most likely the Dakota variety, whose source is about $161 \mathrm{~km}$ to the northeast), rather than the locally available Alibates. The nonlocal origin of the quartzite could explain the intensive reworking of this form, reflecting an effort to recycle and prolong the use of this exotic raw material.

Specimen \#804-10 is a small, triangular point that is stylistically similar to a Fresno form (Bell 1960; Suhm and Krieger 1954; Turner and Hester 1999) and was recovered at a depth of $10 \mathrm{cmbs}$ within excavation unit N672 E511. This point is asymmetrical in shape and heavily reworked on the lateral edges (Figure 8-29). The lateral blade edges are concave, with average edge angle values at 30 and 29 degrees.

Specimen \#822-10 is also a small, triangular point that is stylistically similar to the documented Fresno form (Bell 1960; Suhm and Krieger 1954; Turner and Hester 1999) and was recovered at a depth of 40 cmbs within excavation unit N673 E511. The flaking pattern on both faces is complete yet random. This point is asymmetrical in shape and heavily re-worked on the lateral edges (Figure 8-29). The lateral blade edges are concave, with average edge angle values at 37 and 43 degrees.

\subsubsection{Findings from Use-wear Analysis}

A Fresno-like point base (\#1216-10) was the sole specimen sent from this tool class sent to Bruce Hardy for use-wear analysis. No use-wear was observed on this specimen (Figure 8-30). These results can be interpreted in a couple ways: 1 ) this tool was not used; and 2) this tool was used but no discernable wear patterns could be detected. If this tool was used is possible that any wear pattern may have been apparent on the missing distal end. Another possibility could be that any prior evidence of use was removed during edge rejuvenation and/ or resharpening. Tool edge maintenance may have also been the cause of tool breakage. In any case, the absence of wear patterns on this specimen makes any determination of tool function inconclusive.

Seventy-nine percent $(N=15)$ of the tools in the point group were fashioned from Alibates silicified dolomite. Two specimens (10 percent) were made from Tecovas jasper, while the remaining two specimens were made from Dakota quartzite (5.5 percent) and an unknown chert (5.5 percent).

Overall, both the Washita- and Fresno-like points have similar dimensions. The Fresno group has a mean width of $13.8 \mathrm{~mm}$ (standard deviation $=2.44$ $\mathrm{mm}$ ) and a mean thickness of $3.3 \mathrm{~mm}$ (standard deviation $=0.61 \mathrm{~mm}$ ), while the Washita-like specimens have a mean width of $13.1 \mathrm{~mm}$ (standard deviation $=1.47 \mathrm{~mm}$ ) and a mean thickness of 3.3 $\mathrm{mm}$ (standard deviation $=0.48 \mathrm{~mm}$ ). Given the fact that a majority of the points are not complete, length cannot be adequately compared.

\subsubsection{Bifaces}

Fourteen bifaces comprise 8.3 percent of the chipped-stone tools from Component A. Table 8-9 shows the general dimension of each.

\subsubsection{Width-to-Thickness Ratios, Reduction Stage and Tool Use-life}

As explained in the methodology section of this report, width-to-thickness ratios were recorded to provide a morphological index for the tools in this class. Specifically, Callahan (1979) devised this classification scheme to acknowledge trends observed amongst bifaces in Paleoindian assemblages and suggested that they represented indices in a reduction scheme where low width to thickness ratios denoted earlier reduction stages and high ratios denoted later reduction stages or perhaps finished forms. TRC has acknowledged in recent publications (e.g., Quigg et al. 2010, 2011a) that microscopic wear data on such bifaces appear to show evidence of use and hafting across a wide range of early through late "stage" bifaces. These data could very well suggest that diversity in widthto-thickness ratios represent different stages in uselife that may not be directly proportional to level of reduction. Do these discrepancies constitute a reinterpretation of biface use-life and its association 
Table 8-7. Selected Quantitative Measurements for Projectile Points.

\begin{tabular}{|c|c|c|c|c|c|c|c|c|c|}
\hline PNUM & Unit & $\begin{array}{l}\text { Depth } \\
\text { (cmbs) }\end{array}$ & $\begin{array}{c}\text { Max } \\
\text { Length } \\
(\mathrm{mm})\end{array}$ & $\begin{array}{c}\text { Max } \\
\text { Width } \\
(\mathrm{mm})\end{array}$ & $\begin{array}{c}\text { Max } \\
\text { Thickness } \\
(\mathrm{mm})\end{array}$ & $\begin{array}{l}\text { Weight } \\
\text { (g) }\end{array}$ & $\begin{array}{c}\text { Morphol } \\
\text { ogical } \\
\text { Style }\end{array}$ & $\begin{array}{c}\text { Raw } \\
\text { Material }\end{array}$ & $\begin{array}{c}\text { Complete } \\
\text { ness }\end{array}$ \\
\hline $23-10$ & cutbank & Surface & 14.1 & 12.8 & 2.7 & 0.4 & Washita & $\begin{array}{c}\text { Dakota } \\
\text { Quartzite }\end{array}$ & Complete \\
\hline $692-10$ & $\begin{array}{l}\text { N665 } \\
\text { E509 }\end{array}$ & $10-20$ & 19.3 & 17.9 & 3.8 & 1.6 & Fresno & Alibates & $\begin{array}{l}\text { Proximal } \\
\text { Fragment }\end{array}$ \\
\hline $707-10$ & $\begin{array}{l}\text { N666 } \\
\text { E510 }\end{array}$ & $0-10$ & 11.7 & 13.1 & 2.6 & 0.5 & Fresno & Alibates & $\begin{array}{l}\text { Proximal } \\
\text { Fragment }\end{array}$ \\
\hline $727-10$ & $\begin{array}{c}\text { N667 E } \\
511\end{array}$ & $10-20$ & 16.4 & 16.1 & 3.2 & 0.7 & Fresno & $\begin{array}{l}\text { Unidentifi } \\
\text { ed Chert }\end{array}$ & $\begin{array}{l}\text { Proximal } \\
\text { Fragment }\end{array}$ \\
\hline $752-10$ & $\begin{array}{l}\text { N669 } \\
\text { E509 }\end{array}$ & $20-30$ & 8.9 & 11.7 & 2.6 & 0.3 & Washita & Alibates & $\begin{array}{l}\text { Proximal } \\
\text { Fragment }\end{array}$ \\
\hline 786-10 & $\begin{array}{l}\text { N671 } \\
\text { E510 }\end{array}$ & $10-20$ & 22.1 & 12.2 & 2.8 & 0.6 & Washita & Alibates & Fragment \\
\hline $804-10$ & $\begin{array}{l}\text { N672 } \\
\text { E511 }\end{array}$ & $0-10$ & 19.6 & 12.7 & 3 & 0.6 & Fresno & Tecovas & Complete \\
\hline $805-10$ & $\begin{array}{l}\text { N672 } \\
\text { E511 }\end{array}$ & $10-20$ & 22.3 & 14.4 & 4.8 & 1.3 & Fresno & Tecovas & Fragment \\
\hline $822-10$ & $\begin{array}{l}\text { N673 } \\
\text { E511 }\end{array}$ & $30-40$ & 15.4 & 10.5 & 3.4 & 0.5 & Fresno & Alibates & Complete \\
\hline $844-10$ & $\begin{array}{c}\text { N676 E } \\
509\end{array}$ & $30-40$ & 24.6 & 14.7 & 3.5 & 0.9 & Fresno & Alibates & Fragment \\
\hline $971-10$ & $\begin{array}{l}\text { N694 } \\
\text { E511 }\end{array}$ & $10-20$ & 8.8 & 11.3 & 2.3 & 0.2 & Washita & Alibates & $\begin{array}{l}\text { Proximal } \\
\text { Fragment }\end{array}$ \\
\hline $988-10$ & $\begin{array}{l}\text { N694 } \\
\text { E514 }\end{array}$ & $10-20$ & 18.5 & 10.7 & 2.7 & 0.6 & Fresno & Alibates & $\begin{array}{c}\text { Distal } \\
\text { Fragment }\end{array}$ \\
\hline $1009-11$ & $\begin{array}{l}\text { N695 } \\
\text { E513 }\end{array}$ & $15-20$ & 21.8 & 15.6 & 3.8 & 1.4 & Washita & Alibates & $\begin{array}{l}\text { Proximal } \\
\text { Fragment }\end{array}$ \\
\hline $1051-10$ & $\begin{array}{l}\text { N697 } \\
\text { E511 }\end{array}$ & $20-30$ & 26.5 & 13.4 & 2.9 & 0.9 & Washita & Alibates & Fragment \\
\hline $1051-11$ & $\begin{array}{l}\text { N697 } \\
\text { E511 }\end{array}$ & $20-30$ & 15.3 & 10.8 & 2.9 & 0.5 & Fresno & Alibates & Fragment \\
\hline $1061-10$ & $\begin{array}{l}\text { N697 } \\
\text { E513 }\end{array}$ & $15-25$ & 17.6 & 13.9 & 2.5 & 0.5 & Washita & Alibates & $\begin{array}{c}\text { Tip } \\
\text { missing }\end{array}$ \\
\hline $1216-10$ & $\begin{array}{l}\text { N703 } \\
\text { E515 }\end{array}$ & $20-30$ & 16.9 & 15.9 & 3.6 & 0.7 & Fresno & Alibates & $\begin{array}{l}\text { Proximal } \\
\text { Fragment }\end{array}$ \\
\hline $1270-10$ & $\begin{array}{l}\text { Fire } \\
\text { guard }\end{array}$ & surface & 23.5 & 13.0 & 2.6 & 0.6 & Harrell & Alibates & $\begin{array}{c}\text { Ear } \\
\text { missing }\end{array}$ \\
\hline $1269-12$ & $\begin{array}{l}\text { N695 } \\
\text { E509 }\end{array}$ & surface & 20.4 & 14.7 & 3.2 & 0.9 & Fresno & Alibates & $\begin{array}{l}\text { Proximal } \\
\text { Fragment }\end{array}$ \\
\hline
\end{tabular}


Table 8-8. Selected Qualitative Observations of Complete Points.

\begin{tabular}{|l|l|l|l|l|l|}
\hline PNUM & $\begin{array}{l}\text { Lateral } \\
\text { Edge A }\end{array}$ & $\begin{array}{l}\text { Lateral } \\
\text { Edge B }\end{array}$ & $\begin{array}{l}\text { Thermal } \\
\text { Alteration }\end{array}$ & Base Type & $\begin{array}{l}\text { Raw } \\
\text { Material }\end{array}$ \\
\hline $23-10$ & Concave & Concave & None & Straight & $\begin{array}{l}\text { Ortho- } \\
\text { Quartzite }\end{array}$ \\
\hline $804-10$ & Convex & Straight & None & Concave & $\begin{array}{l}\text { Tecovas } \\
\text { Jasper }\end{array}$ \\
\hline $822-10$ & Convex & Convex & None & Concave & Alibates \\
\hline
\end{tabular}

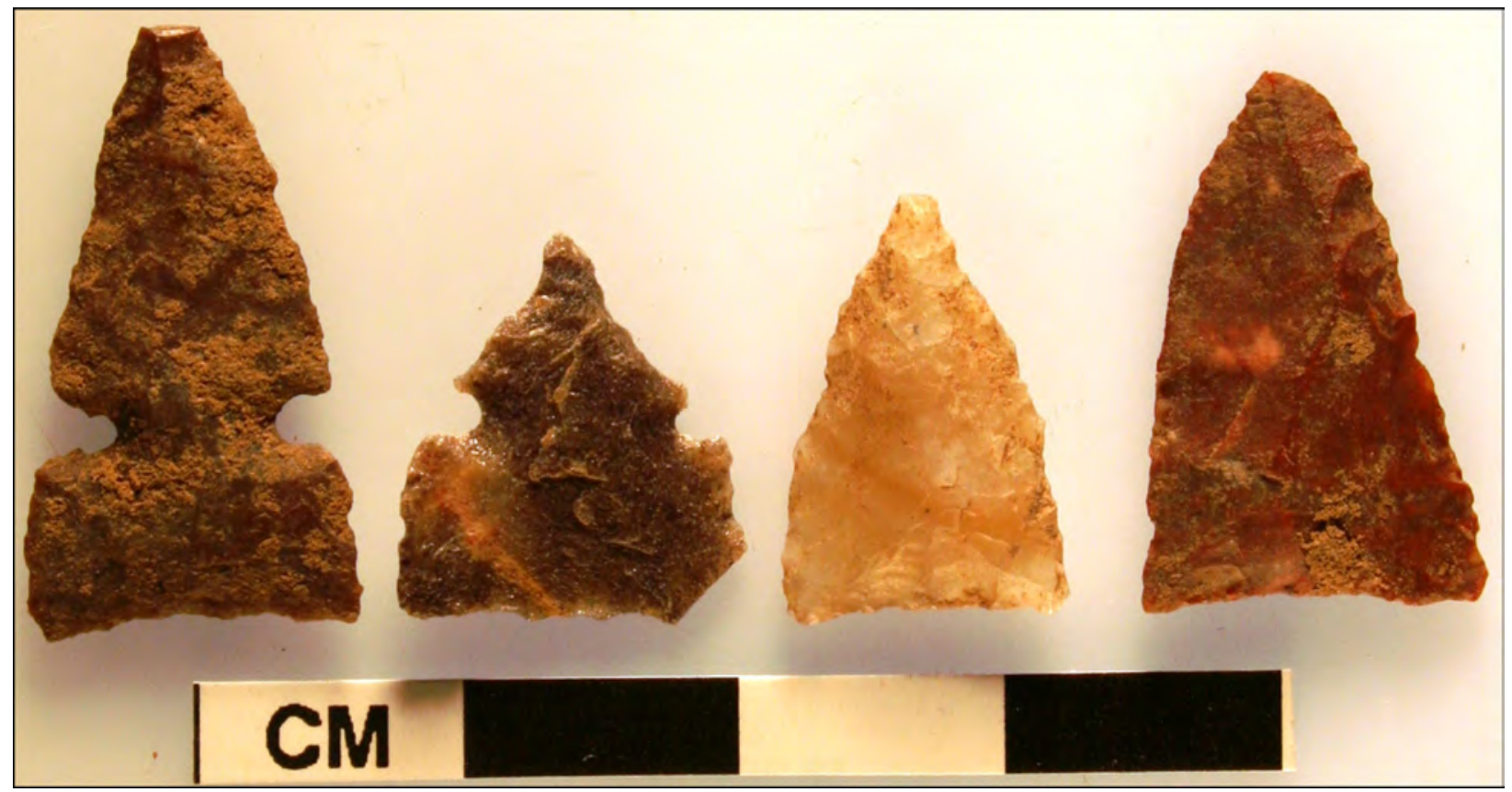

Figure 8-29. Complete projectile points (\#23-10, 786-10, \#804-10, and \#822-10).

Measurements in $\mathrm{mm}$

to morphological form? We believe so. However, we stop short of changing our classification terminology (i.e., Stages 1-5).

\subsubsection{Metric Attributes of Biface Assemblage}

Two specimens are complete, two are distal fragments, two are distal-medial fragments, and two are medial fragments. A sizeable percentage (42 percent) came from between 80 and 90 cmbs. Specimens in this group were primarily fashioned from Alibates ( $N=11 ; 78$ percent). Descriptions of the bifaces are presented below with metric attributes presented for each in Table 8-9. Also included are supplemental data derived from use-wear analysis performed by Bruce Hardy (Appendix H).

\subsubsection{Beveled Bifaces}

Four beveled bifaces were recovered in the southern portion of Component A. They were recovered together at approximately the same depth (about $28 \mathrm{cmbs}$ ). Two of the four were complete, but intensively resharpened (possibly to the point of tool exhaustion; Figures 8-31 and 8-32), while the other two were fragments, broken at the medial portion. Given that none of the four were in pristine condition, 
Table 8-9. Selected Attributes on Component A Bifaces.

\begin{tabular}{|c|c|c|c|c|c|c|c|c|c|}
\hline PNUM & Unit & Depth (cmbs) & $\begin{array}{c}\text { Max Length } \\
(\mathrm{mm})\end{array}$ & $\begin{array}{c}\text { Max Width } \\
\text { (mm) }\end{array}$ & \begin{tabular}{|c} 
Max \\
Thickness \\
$(\mathbf{m m})$
\end{tabular} & $\begin{array}{c}\text { Weight } \\
\text { (g) }\end{array}$ & Raw Material & Completeness & $\begin{array}{c}\text { Width to } \\
\text { Thickness Stage }\end{array}$ \\
\hline $2-11$ & Surface & Surface & 57.1 & 43.3 & 11 & 28.6 & Niobrara Jasper & Fragment & 4 \\
\hline $3-11$ & Fireguard & Surface & 10.3 & 12.3 & 4.5 & 0.6 & Alibates & Medial Fragment & 3 \\
\hline $733-10$ & N668 E509 & $0-10$ & 48.95 & 44.72 & 17.04 & 22.9 & Alibates & Distal fragment & $2-3$ \\
\hline $852-10$ & N678 E511 & $10-20$ & 14.1 & 10.4 & 4.2 & 0.6 & Alibates & Distal fragment & $2-3$ \\
\hline $854-10$ & N678 E511 & $20-30$ & 24.9 & 26.6 & 6 & 2.7 & $\begin{array}{c}\text { Opalite } \\
\text { (Thermally } \\
\text { Altered) }\end{array}$ & Medial Fragment & 4 \\
\hline $1106-11$ & N699 E511 & $20-30$ & 21.2 & 16 & 7.2 & 2.5 & Tecovas Jasper & Fragment & 2 \\
\hline $1271-10$ & Fireguard & Surface & 35.7 & 25.1 & 7.6 & 8.4 & Alibates & Fragment & $3-4$ \\
\hline $2-10$ & Surface & Surface & 62.9 & 32.4 & 13.1 & 21.3 & Alibates & Fragment & 3 \\
\hline $768-11$ & N670 E509 & $20-30$ & 64.9 & 34.6 & 8.5 & 25.5 & Alibates & Fragment & Beveled \\
\hline $768-13$ & N670 E509 & $20-30$ & 56.4 & 44.3 & 8.7 & 23.3 & Alibates & Fragment & Beveled \\
\hline $768-10$ & N670 E509 & $20-30$ & 76.6 & 26.2 & 8.7 & 17.6 & Alibates & Complete & Beveled \\
\hline $768-12$ & N670 E509 & $20-30$ & 71.9 & 17.9 & 7.6 & 9.9 & Alibates & Complete & Beveled \\
\hline $697-10$ & N665 E510 & $10-20$ & 32.3 & 29.4 & 10.9 & 12.3 & Alibates & Fragment & 3 \\
\hline $780-10$ & N671 E509 & $10-20$ & 44.3 & 36.7 & 7.5 & 13.2 & Alibates & Fragment & $4-5$ \\
\hline
\end{tabular}




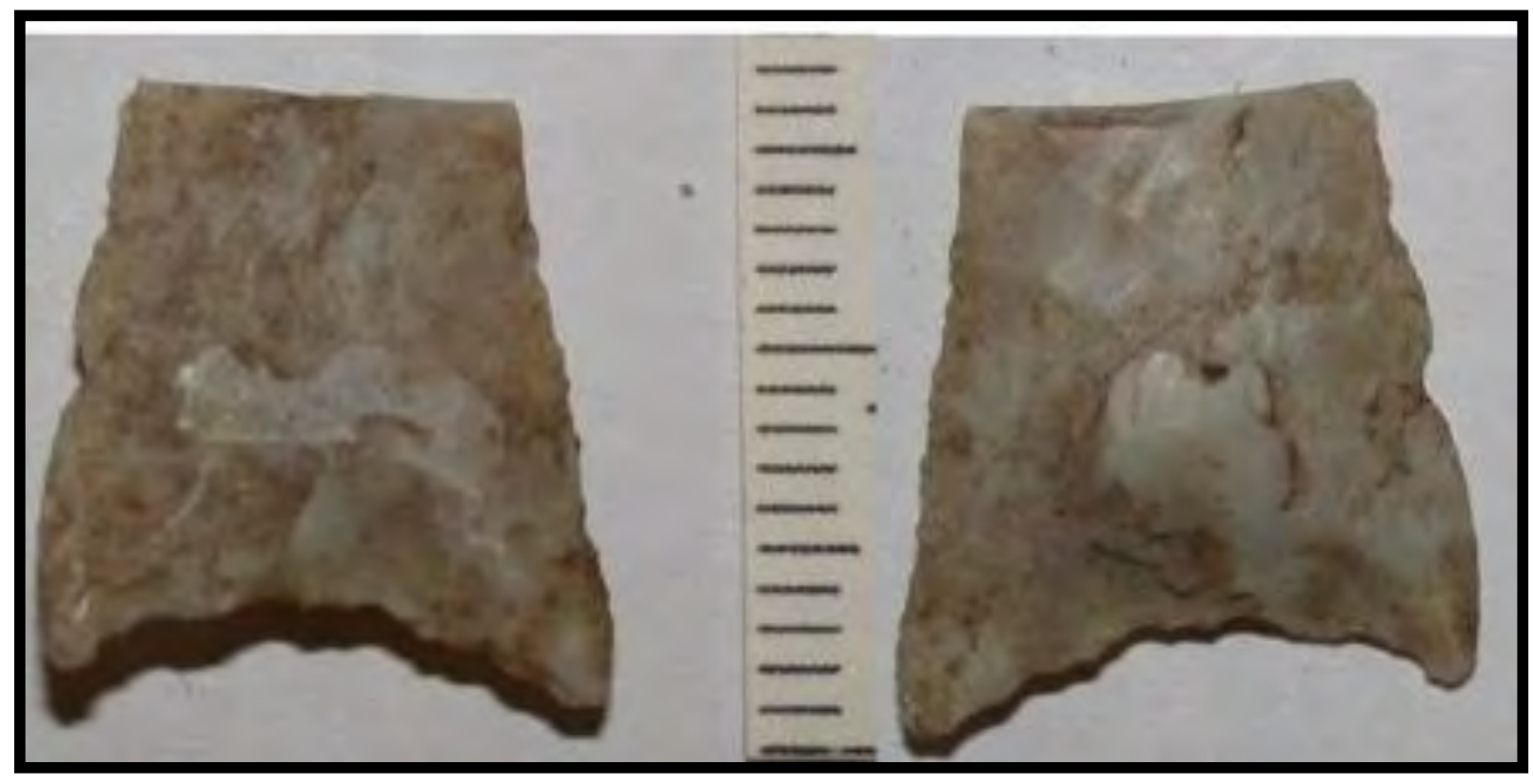

Figure 8-30. Specimen \#1216-10, a Fresno-like point base made from Alibates.

it can be surmised that they were discarded rather than cached for later use. All four were submitted for use-wear analysis. These findings will be used to not only indicate the presence or absence of wear on each tool, but give insight into what use and/or activity the tool was used for.

In summary, the mean width of the biface group is $28.57 \mathrm{~mm}$ and the average thickness is $8.75 \mathrm{~mm}$. The standard deviation of biface widths across all specimens, the tool dimension least affected by fragmentation, is $11.54 \mathrm{~mm}$. Biface thickness measurements represented have a standard deviation of $3.4 \mathrm{~mm}$. This range in biface size may be indicative of the variation in the size of raw material packages (i.e., cobble size). It is also possible that the biface size variance may have been functionally related, but to determine this would require further examination of microwear on a larger sample of bifaces from this component.

As a group, these bifaces reveal random flaking patterns, indicating an expedient or nonstandard reduction sequence. As mentioned above, Callahan (1979) provided a classification scheme for bifaces recovered from Paleoindian contexts, in which he used width-to-thickness ratios to determine biface reduction stages. In general, the preparation and reduction scheme for specimens included in Callahan's studies are more complex than what was observed at 41RB112. At least half (42 percent) the bifaces were classified as stage 3 .

Breakage of bifaces (86 percent of the assemblage) may have occurred during manufacture, use, or postdepositionally. By examining the break areas on each specimen, it was determined that at least four bifaces were broken during manufacture and at least two were broken during use.

\subsubsection{Data from Bifaces Sent for Use- wear Analysis}

Five bifaces (\#2-10, \#768-10, \#768-11, \#768-12, and \#768-13) were submitted for use-wear analysis. Biface \#2-10, a fragment that had been broken transversely, was observed to have evidence of high silica residue on both faces at the end (Figure 8-33). These findings signify this biface was used for the cutting of hard material. Biface \#768-10 is a beveled knife fragment that showed evidence of being hafted approximately two-thirds up the length of the tool fragment, leaving only 2 to $3 \mathrm{~cm}$ of the tip exposed. Use-wear analysis also identified evidence that the tip had been used to cut wood. In addition, 


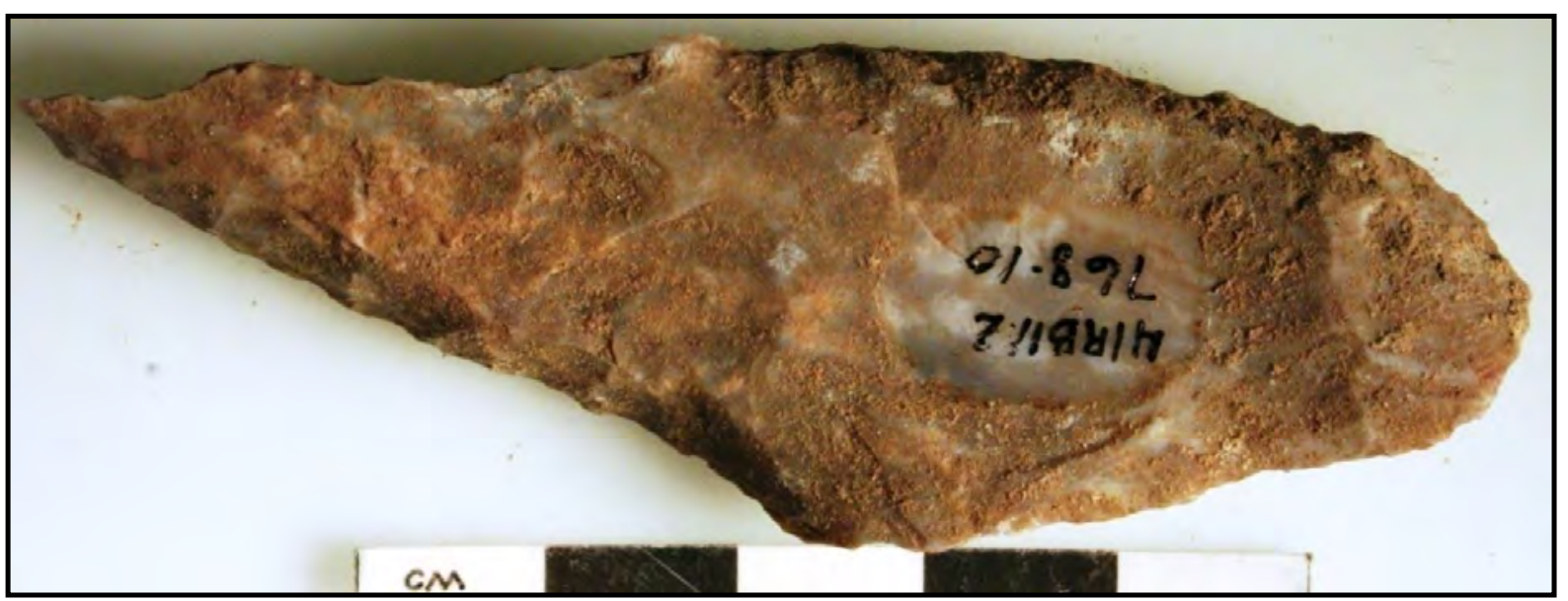

Figure 8-31. Complete unwashed alternately beveled biface (\#768-10) exhausted. Scale in $\mathrm{cm}$.

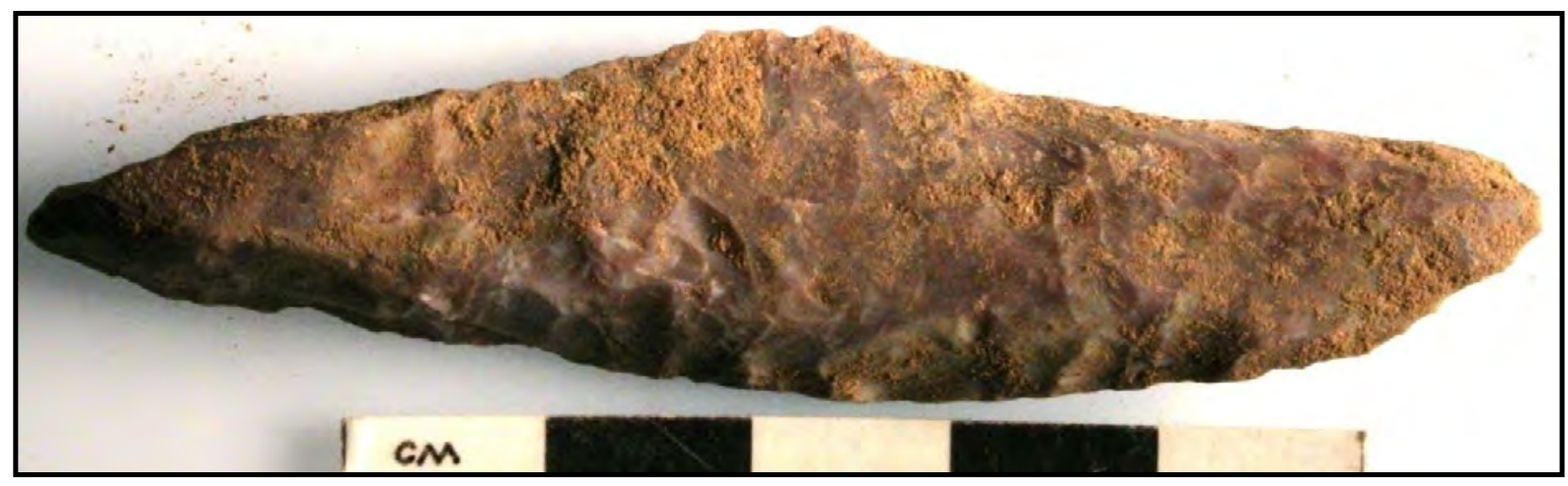

Figure 8-32. Complete unwashed exhausted alternately beveled biface (\#768-12). Scale in $\mathrm{cm}$

the prominent ridge on one face was abraded in two places. Biface \#768-11 is a complete diamond shaped, alternately beveled knife that exhibits evidence of hafting two thirds up the length of the tool. At the unhafted tip, wear indicates that this end was used for boring wood, as hard/high silica polish combined with wood striations are present. Biface \#768-12 is a complete diamond shaped, alternately beveled knife, that shows no evidence of hafting, but exhibits wear indicating cutting wood. Biface \#76813, a beveled knife fragment that shows evidence of cutting soft material (perhaps animal hide or meat). Surprisingly, 60 percent of all beveled knives have been used for wood working.

\subsubsection{Scrapers}

Scraping tools are typically unifacially worked and have steeply flaked tool edges, and compose about 8 percent of the entire Component A tool assemblage. It is thought the tools fashioned in this manner were used to scrape and prepare animal hides for domestic purposes or as commodities. Fifteen scrapers were recovered from across the excavated block at varying depths. The majority are made from Alibates and are planoconvex in form (Table 8-10; Figure 8-34), with the exceptions of scraper \#836-10, which is made of Niobrara jasper. Thus, a majority are morphologically similar to the teardrop-shaped scrapers often found in Late Prehistoric assemblages across the Southern Plains (Vehik and Baugh 1995). 


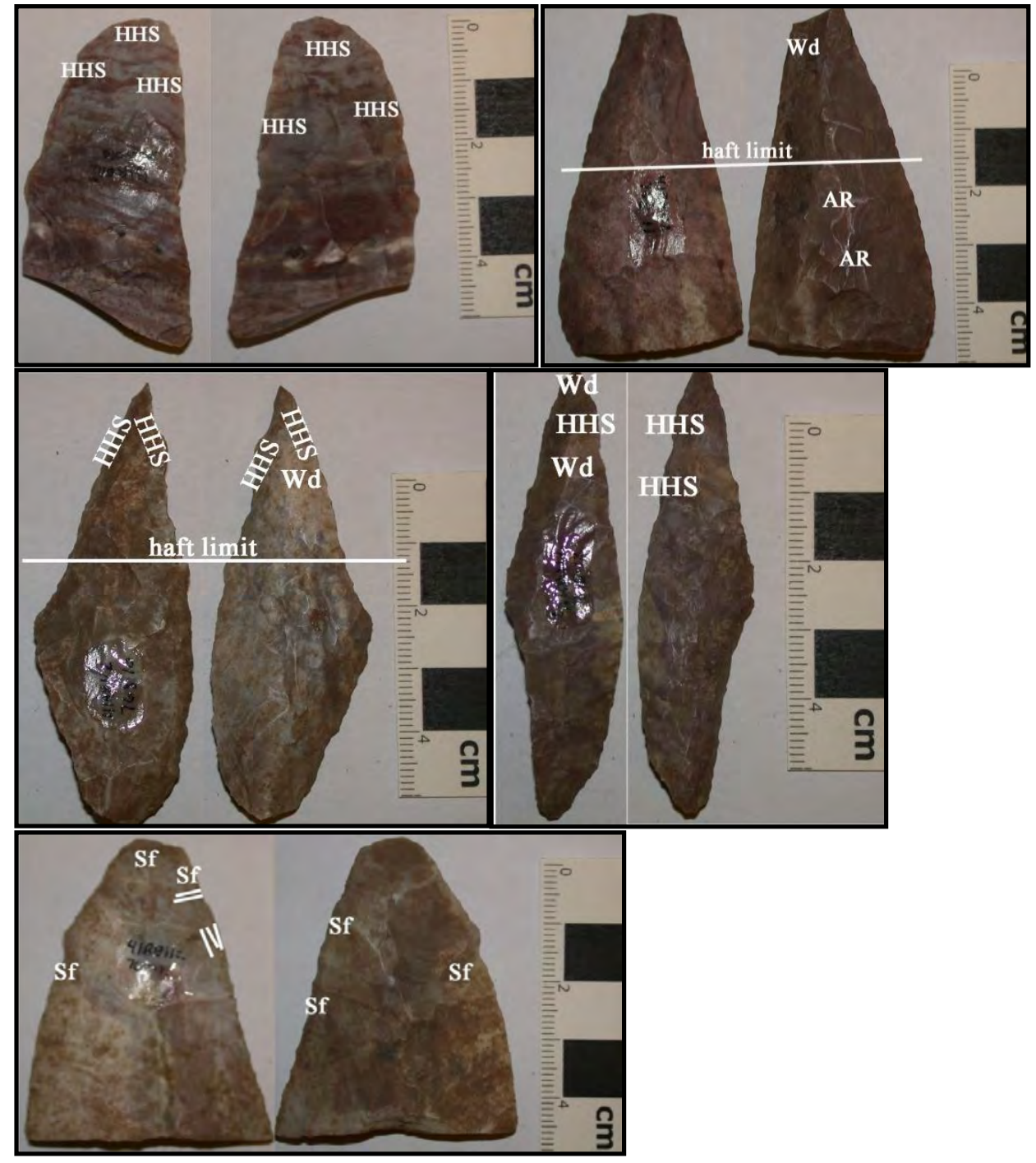

Figure 8-33. Beveled bifaces.

Top left is biface \#2-10 that shows evidence of cutting hard/ high silica material; Top right broken biface (\#768-11) shows haft limit and wood fiber. The complete beveled biface (\#768-10) shows the haft limit and hard/high silica polish. Middle right beveled biface (\#768-12) shows hard/high silica polish on one end. Bottom biface fragment (\#768-13) shows areas of soft polish. 


\subsubsection{Data from Scrapers Sent for Use- wear Analysis}

Five end scrapers (\#22-10, \#768-14, \#786-11, \#85910 , and \#883-10) and one side scraper (\#1042-10) were submitted for use-wear analysis. The results across this tool class were varied. Scraper \#22-10, an end scraper made from Alibates, had evidence of hard/high silica polish in multiple places surrounding the working end on the ventral surface. Plant fibers were also observed on the dorsal surface. These wear patterns seem to suggest scraping activities on plants. End scraper \#768-14 showed evidence of hafting spanning two-thirds the length of the tool, leaving only the end exposed as the working edge. Hardy interpreted wear around the end to signify the scraping of soft material (e.g., animal hides). Scraper \#786-11 showed no evidence of use-wear. End scraper \#859-10 showed evidence of possible hafting and wear that indicated hide scraping activities. End scraper \#883-10 showed evidence of being broken while in the haft, though no particular function was interpreted. Side scraper \#1042-10 showed evidence of wood scraping wear. Overall the scrapers examined seemed have been used on a diversity of material that included animal hides, plants, and woods.

\subsubsection{Drills}

Four drills, of which only one was complete, were recovered from Component A (Figure 8-36; Table 8-11). They were all fashioned from Alibates silicified dolomite. All of the fragments represent the chuck or hafted portion of the drill. The complete drill (\#943-10) was submitted for use-wear analysis. Wear patterns showed heavy striations and polish over most of the surface. Although used in some fashion, the function of this tool could not be determined from the observed wear.

\subsubsection{Edge-Modified Flakes}

One hundred forty-three edge-modified flakes were recovered and are considered informal tools that were likely produced, used, and discarded on-site. This group is the largest chipped-stone tool class, composing 67 percent of the Component A tool assemblage. Specifically, informal tools represent those specimens that have not been altered to a degree that significantly changed the shape and/or form of the original flake blank. In most instances, these flakes or parts of flakes have minimal, but noticeable edge scaring, flaking, or rounding. These

Table 8-10. Selected Scraper Attributes.

\begin{tabular}{|c|c|c|c|c|c|c|c|c|}
\hline PNUM & Cat & Unit & $\begin{array}{c}\text { Depth } \\
\mathbf{( c m b s})\end{array}$ & $\begin{array}{c}\text { Length } \\
\mathbf{( m m})\end{array}$ & $\begin{array}{c}\text { Width } \\
\mathbf{( m m})\end{array}$ & $\begin{array}{c}\text { Thickness } \\
(\mathbf{m m})\end{array}$ & $\begin{array}{c}\text { Weight } \\
(\mathbf{g})\end{array}$ & Material \\
\hline 22 & 10 & Surface & Surface & 32.6 & 22.6 & 6.4 & 6.5 & Alibates \\
\hline 768 & 14 & N670 E509 & $20-30$ & 41.2 & 31.9 & 6.9 & 9.8 & Alibates \\
\hline 786 & 11 & N671 E510 & $10-20$ & 22.7 & 28.2 & 10.7 & 8.4 & Alibates \\
\hline 859 & 10 & N679 E511 & $20-30$ & 29.4 & 22.8 & 5.5 & 4.7 & Alibates \\
\hline 883 & 10 & N687 E510 & $20-30$ & 30.6 & 26.3 & 7.9 & 7.5 & Alibates \\
\hline 1042 & 10 & N696 E513 & $40-50$ & 51.9 & 29.2 & 11.7 & 16.7 & Alibates \\
\hline 775 & 10 & N670 E511 & $10-20$ & 10.9 & 26.1 & 7.2 & 2 & Alibates \\
\hline 798 & 10 & N672 E509 & $30-40$ & 18.8 & 28.7 & 4.8 & 3 & Alibates \\
\hline 697 & 10 & N665 E510 & $10-20$ & 32.3 & 29.4 & 10.9 & 12.3 & Alibates \\
\hline 1004 & 11 & N695 E512 & $20-30$ & 27.1 & 26.7 & 7 & 3.8 & Alibates \\
\hline 771 & 10 & N670 E510 & $10-20$ & 28.2 & 17.5 & 9.3 & 4.4 & Alibates \\
\hline 836 & 10 & N675 E509 & $20-30$ & 21.3 & 10.3 & 8.5 & 2 & Niobrara \\
\hline 775 & 12 & N670 E511 & $10-20$ & 9.8 & 11.7 & 5.2 & 0.6 & Alibates \\
\hline 688 & 10 & N659 E509 & $30-40$ & 24.5 & 21.8 & 5 & 2.8 & Alibates \\
\hline 796 & 10 & N672 E509 & $10-20$ & 14.4 & 13.5 & 6.6 & 1.2 & Alibates \\
\hline
\end{tabular}




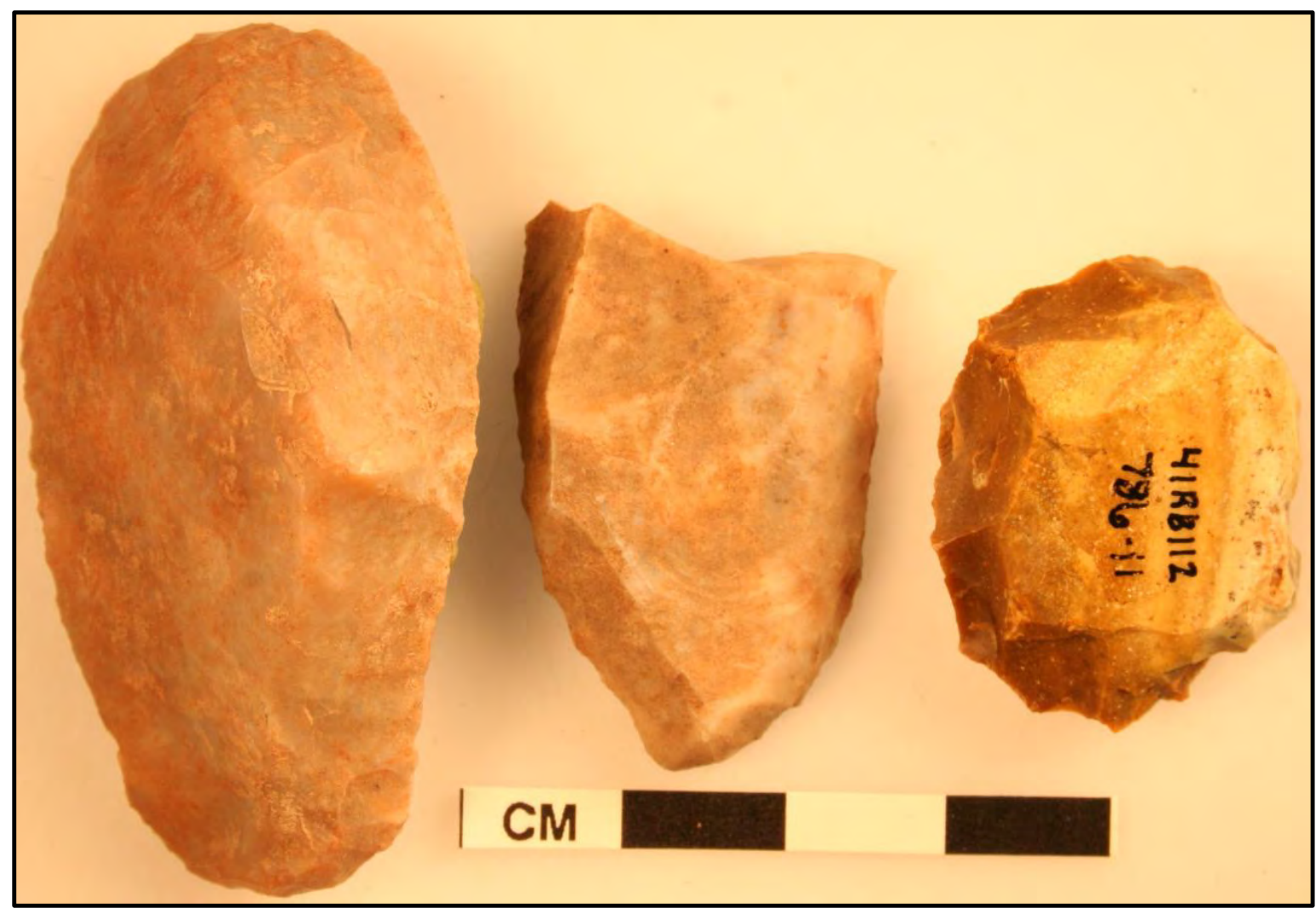

Figure 8-34. Selected scrapers from Component A (left to right, \#1042-10, \#22-10, and \#786-11).

Scale in $\mathrm{cm}$.

informal tools vary widely in size (Table 8-12). Edge angles measured for each modified edge were fairly consistent, with medians of 49 to 50 degrees and standard deviations of 11 to 12 degrees, respectively. These values indicate that most edgemodified flakes were subjected to similar types and intensities of modification. This is not surprising since, by definition, informal tools are not modified to any great extent prior to use.

Eighty percent of these specimens $(N=115)$ were fashioned from Alibates silicified dolomite. Other materials used in chipped-stone tool production $(N$ $=42 ; 20$ percent $)$ include unidentified jasper (4.3 percent); unidentified chert (2.9 percent); Tecovas jasper (2.4 percent); chalcedony (1.9 percent), Ogallala quartzite (1.9 percent), Niobrara/Smoky Hill jasper (1.9 percent), Day Creek dolomite (1.4 percent), unidentified rhyolite (1 percent), opalite (1.4 percent), silicified limestone ( 0.5 percent), and silicified sandstone $(0.5$ percent $)$. These raw materials were most likely gathered from nearby before being reduced on-site. Within this class, 11 percent $(N=$ 8) have 26 to 50 percent cortex on the dorsal face, 42 percent $(N=30)$ exhibit 1 to 25 percent cortex on the dorsal face, and 47 percent $(N=34)$ have no cortex on the dorsal face. The majority of incidences of cortex in this class are on tools that are made from non-Alibates material. The high incidence of cortex on the dorsal face in this class is a direct result of flake removal from a cobble core. Because of generally small cobble sizes, a large number of flakes exhibit only remnants of the outer cortical surface.

Interestingly, 34 percent exhibit evidence of thermal alteration in the form of color changes and pot lidding. This is a much larger percentage than in any other tool class. Alibates is a high-grade material that does not usually require heat treatment prior to flaking, as the fracture predictability is already high. Therefore, it must be assumed that thermal alteration occurred postuse as these expedient tools were 

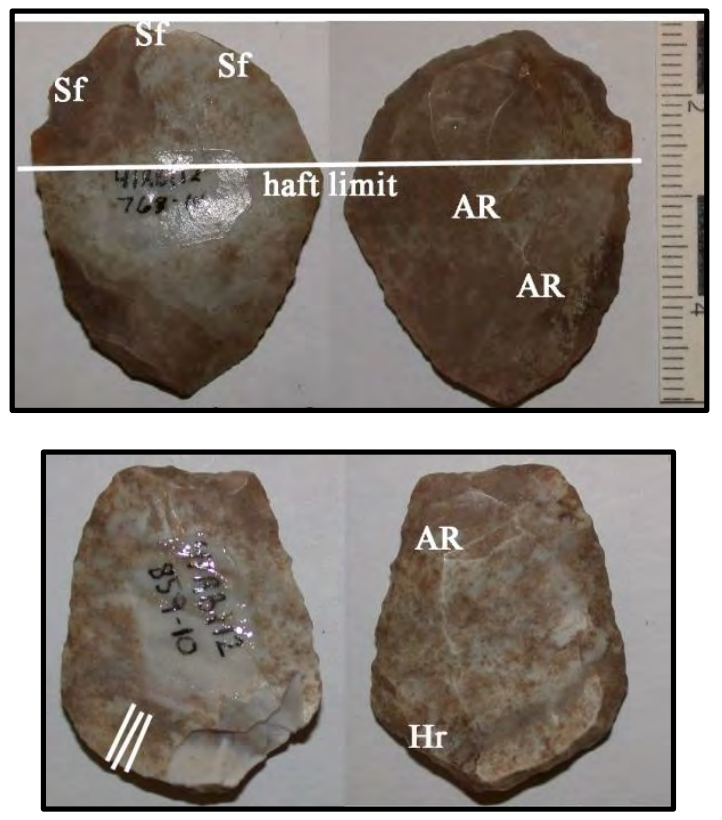

Figure 8-35. Observations from use-wear analysis scrapers \#22-10 (top) and \#768-14 (bottom).

Scale in $\mathrm{cm}$.

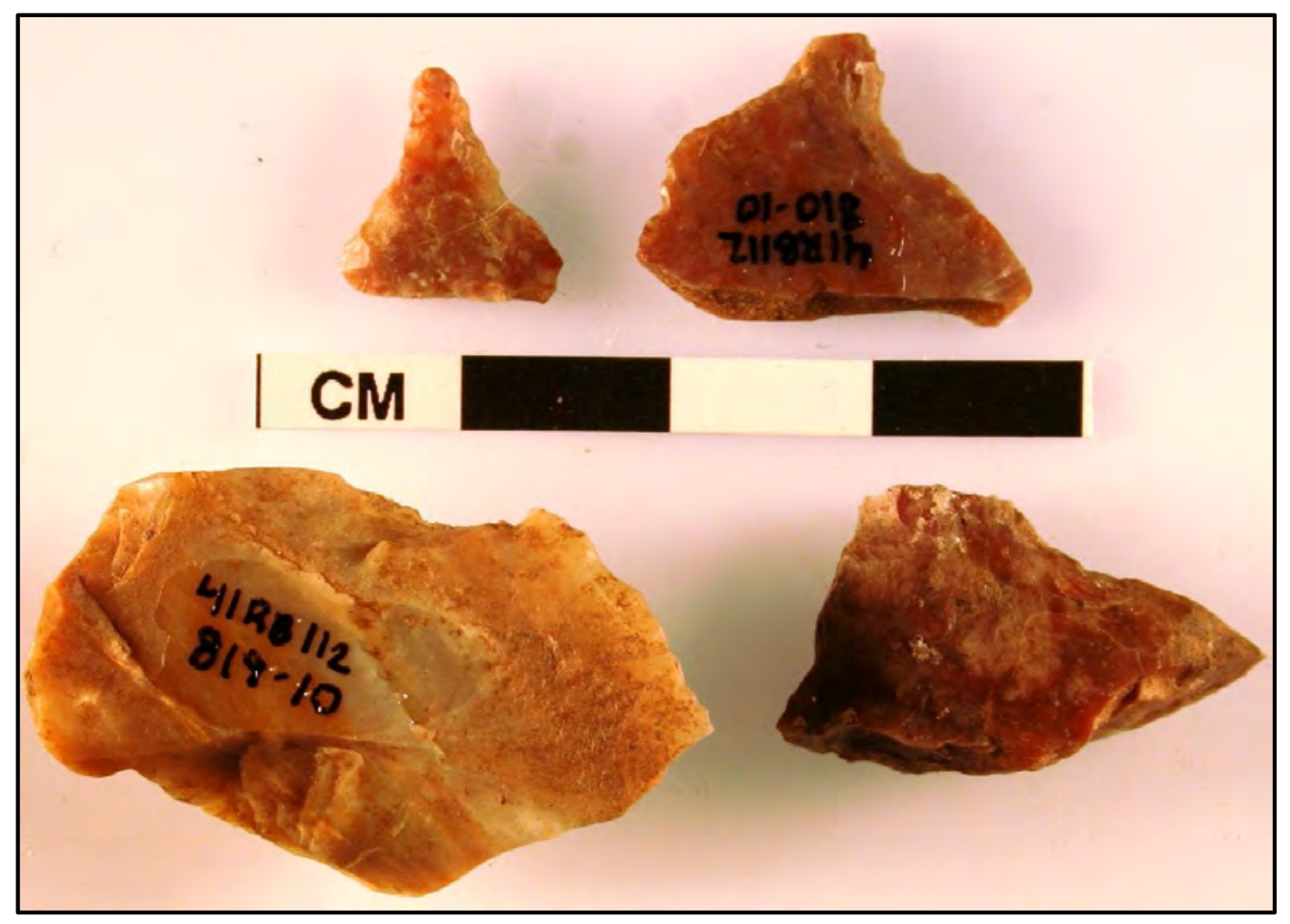

Figure 8-36. Selected drills from Component A.

Clockwise from upper left \#943-10, \#810-10, \#819-10, and \#42-12. 
Table 8-11. Metric Attributes of Drills from Component A.

\begin{tabular}{|c|c|c|c|c|c|c|c|c|c|}
\hline PNUM & Cat & Unit & $\begin{array}{c}\text { Depth } \\
\text { (cmbs) }\end{array}$ & $\begin{array}{c}\text { Length } \\
(\mathbf{m m})\end{array}$ & $\begin{array}{c}\text { Width } \\
\mathbf{( m m})\end{array}$ & $\begin{array}{c}\text { Thickness } \\
\mathbf{( m m})\end{array}$ & Alibates & Weight (g) & Completeness \\
\hline 42 & 12 & A-2 & 25 & 14.1 & 23.4 & 7.4 & Alibates & 1.9 & medial \\
\hline 810 & 10 & N672 E512 & $20-30$ & 13.7 & 19.2 & 4.3 & Alibates & 0.9 & proximal \\
\hline 819 & 10 & N673 E511 & $0-10$ & 19.3 & 31.7 & 9 & Alibates & 4.2 & proximal \\
\hline 943 & 10 & N692 E512 & $10-20$ & 11 & 10.6 & 2.5 & Alibates & & complete \\
\hline
\end{tabular}

Table 8-12. Metric Attributes of Edge-Modified Flakes from Component A.

\begin{tabular}{|c|c|c|c|}
\hline $\begin{array}{c}\text { Edge-Modified Flake } \\
(\boldsymbol{N}=\mathbf{1 4 3})\end{array}$ & $\begin{array}{c}\text { Length } \\
(\mathbf{m m})\end{array}$ & $\begin{array}{c}\text { Width } \\
(\mathbf{m m})\end{array}$ & $\begin{array}{c}\text { Thickness } \\
(\mathbf{m m})\end{array}$ \\
\hline Mean & 24.51 & 23.85 & 5.8 \\
\hline Median & 20.39 & 22.35 & 5.3 \\
\hline Standard Deviation & 13.39 & 10.06 & 3.37 \\
\hline
\end{tabular}

discarded, or otherwise accidentally incorporated into the fires of heating elements.

\subsubsection{Use-wear Analysis of Edge- modified Flakes}

Twelve edge-modified flakes were selected for usewear analysis (\#45-10, \#755-10, \#857-10, \#911-10, \#933-10, \#948-10, \#1004-10, \#1031-10, \#1051-11, \#1145-10, \#1152-10, and \#1194-10; Figure 8-38). Three (\#755-10,\#1004-10 and \#1031-10) had wear that indicated woodworking (cutting or scraping) activities. Another three (\#933-10, \#1145-10, and $\# 1152-10)$ exhibited no use-wear and were deemed unused or had uses that could not be determined. Two (\#857-10, and \#1051-10) exhibited evidence of hafting. Use-wear on the working areas of the both tool were different. Tool \#857-10 showed wear that suggested boring actions on a hard/high silica material; whereas, tool \#1051-10 indicated scraping hide activities. Three tools (\#45-10, \#948-19, and \#1194-10) showed cutting or scraping on hard/high silica materials. The remaining tool (\#45-10) had light polish but no use could be determined.

\subsubsection{Unifacial Tools}

Unifaces are defined as those tools that are flaked on one face/side to the degree that the original flake blank form is significantly modified (Figure 8-39). Ten unifacial tools were recovered from Component A. Like edge-modified tools, these specimens were likely produced, used, and discarded on-site. Seven do not fit any distinct morphological class. However, one (\#1039-10) has graver-like modifications along the perimeter that may have been used for perforating and/or engraving activities. A second unifacial tool (\#1040-10) possessed an incurvate edge-modification that is morphologically similar to a spokeshave, a tool used to scrape shape arrow shafts or other cylindrical wooden implements. None of this edge-modified subset was submitted for use wear analysis.

\subsubsection{Spatial Distribution of Stone Tools in Component $A$}

The distribution of stone tools recovered from Component A can be seen in Figure 8-40. Two main concentrations of discard, and a small scatter are observed. The larger of the two concentrations 


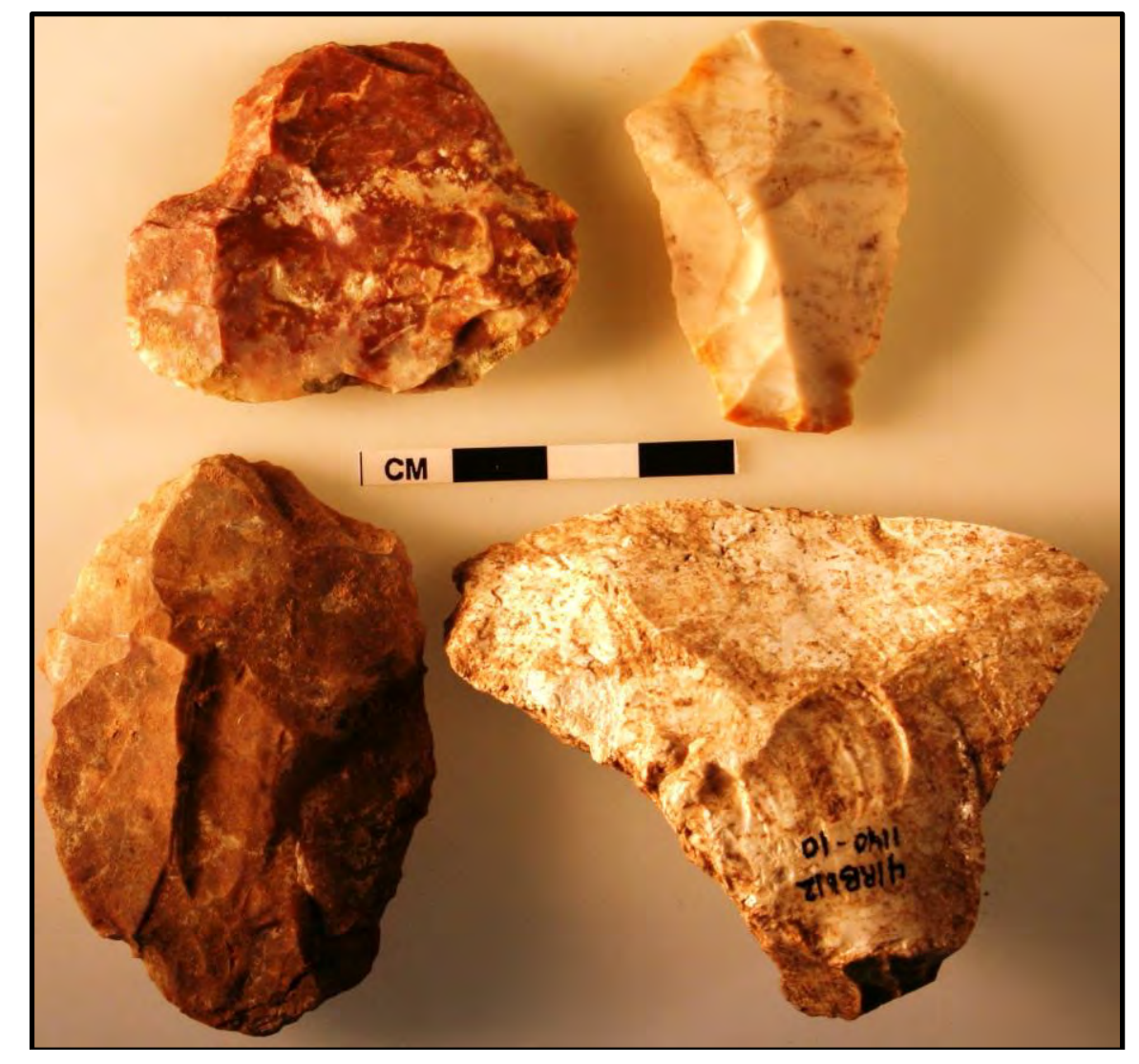

Figure 8-37. Selected edge-modified flakes from Component A. Clockwise from upper left:\#1270-10, \#947-10, \#948-10, and \#1140-10

occurs between N669 and N675 at the southern extent of the excavation block. Several bifaces $(N=6)$ and scrapers $(N=6)$ were documented in this concentration, as well as projectile points $(N$ $=4)$, drills $(N=2)$ and metate fragments $(N=2)$. Based on use-wear analysis results, several of these tools were used on wood products. The smaller concentration of tools at the northern portion of the excavation block has a large proportion of projectile points $(N=6)$, and smaller incidences of scrapers $(N=2)$ bifaces $(N=2)$ and ground stone $(N=4$; mano and metates). The small scatter of tools $(N=$ 5 ) was documented at the extreme southern edge of the excavation block. It consists of projectile points $(N=3)$, one biface and one scraper. It is unclear whether any of these groupings denote activity areas and movement of materials due to rodent activity and other natural occurrences may be a factor.

\subsection{Lithic Debitage Analyses}

Analysis of lithic debitage, the by-products of stone tool production, is an extremely informative means of defining certain patterns of human behavior (Andrefsky 1998). Attributes that can be documented within a debitage assemblage may be used to highlight trends that provide insight into resource procurement strategies, tool production locations, material reduction strategies, tool production techniques, and tool maintenance. The lithic debitage assemblage from Component $\mathrm{A}(N=$ $2,475)$ consisted of platform bearing flakes, distal flakes/shatter/angular debris, and cores. These primarily occurred within the A Horizon, with the majority of material recovered from 10 and $40 \mathrm{cmbs}$ (Figure 8-41).

A moderate diversity of raw material types is observable in the debitage assemblage, wherein 


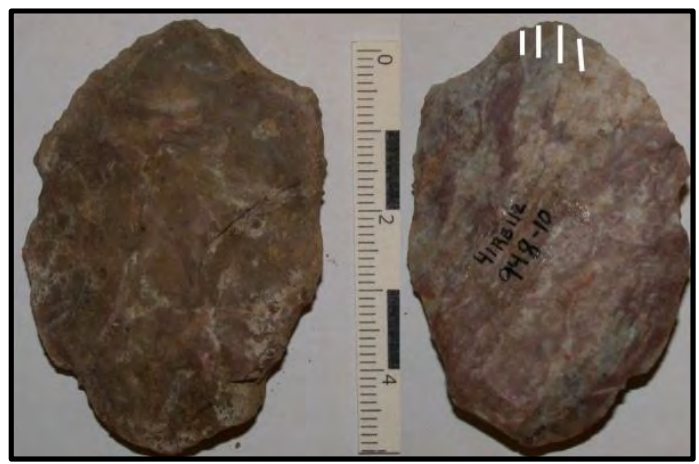

Figure 8-38. Observations from use-wear analysis of selected edge-modified flakes (\#94810(top; scale in $\mathrm{cm}$ ) and \#1270-11 (bottom; scale in $\mathrm{mm}$ ).

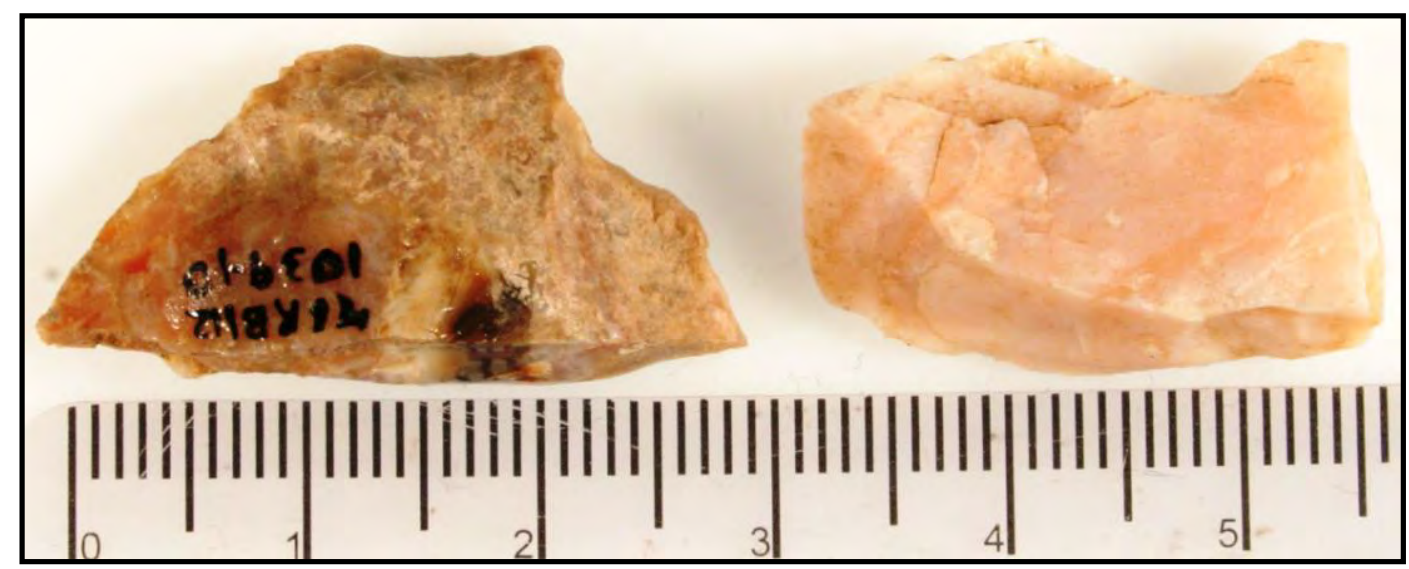

Figure 8-39. Examples of unifacial graver (\#1039-10) and unifacial spokeshave (\#1040-10) from Component $A$.

approximately 20 different materials are identified. However, a majority of the debitage assemblage is composed either of Alibates chert $(N=1,663$; 67 percent) or opalite (Figure 8-42; $N=524 ; 21$ percent). Other materials include Ogallala quartzite ( $N=136,5.4$ percent), which can be split into meta$(N=60,2.4$ percent) and orthoquartzite $(N=76,3$ percent) varieties); jasper $(N=24+32 ; 2.2$ percent $)$ which is split into Tecovas ( $N=32,1.2$ percent) and Niobrara $(N=24,1$ percent); obsidian (Figure 8-43; $N=51,2.1$ percent); unidentified sedimentary rock $(N=14 ; 0.5$ percent); other unidentified lithic (cortical) material $(N=19,0.7)$; silicified limestone ( $N=4 ; 0.02$ percent); chalcedony $(N=9 ; 0.03$ percent); and unidentified metamorphic rock $(N=$ $1 ; 0.05$ percent). It is likely that many (though not all) of these tool materials were collected from local drainages near 41RB112.
The majority of the debitage assemblage $(N=1,686$; 67 percent) falls within the $>6.4$ to $<12.8 \mathrm{~mm}$ size range (Figure 8-44). The second largest group varies according to which raw material group is considered. For this discussion, data on the three most abundant raw-material groups will be presented. The most abundant size group within the debitage made from Alibates is the $<6.4 \mathrm{~mm}$ group ( $N=356$; 21 percent) with the next most abundant size, in the $>12.8$ to $<19$ $\mathrm{mm}$ range, lagging far behind (7.5 percent). This indicates that a high proportion of smaller flakes were produced from Alibates, suggesting a greater emphasis on finishing and resharpening activities, or tool maintenance and/or conservation, than on primary tool production. A majority of the obsidian specimens fall into the $>6.4$ to $<12.8 \mathrm{~mm}$, or smaller, size ranges. This again suggests mostly maintenance and resharpening activities. The second largest size 


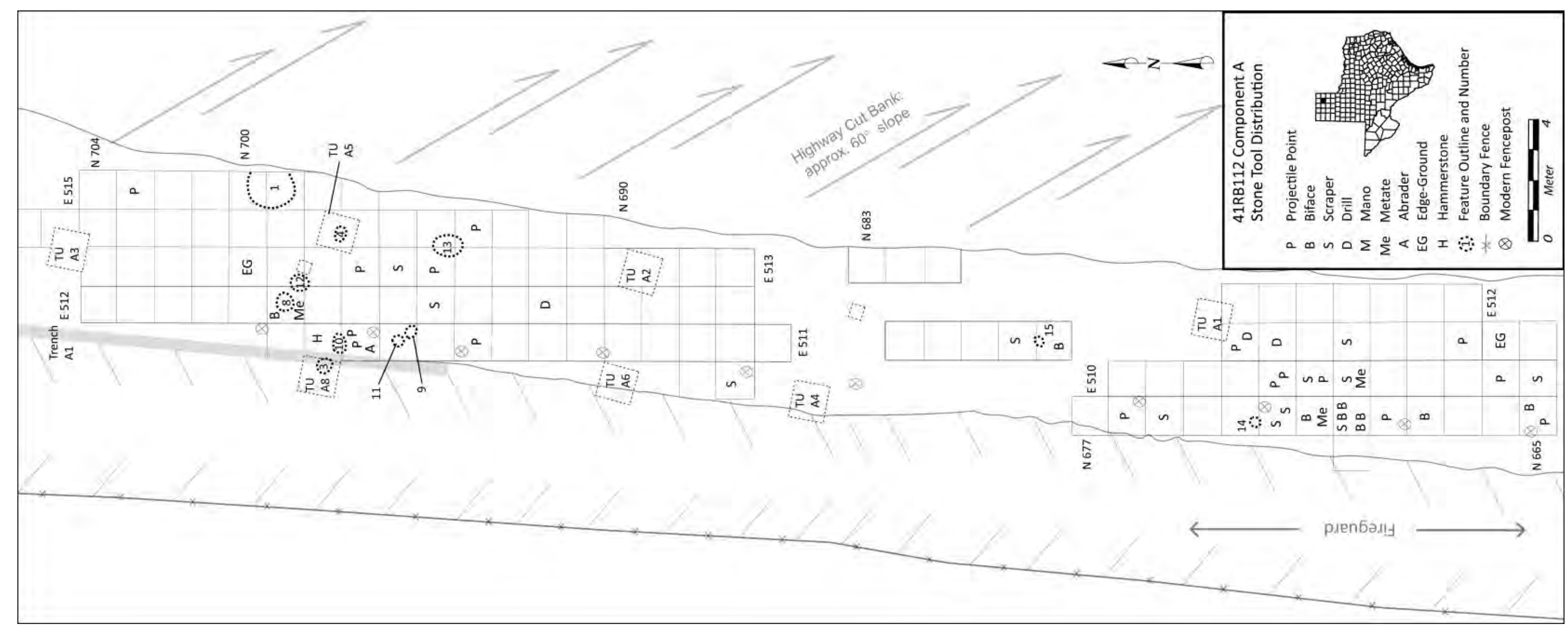


The Long View Site (41RB112): Data Recovery of Two Late Prehistoric Plains Village Period Components in Roberts County, Texas -Texas Department of Transportation 


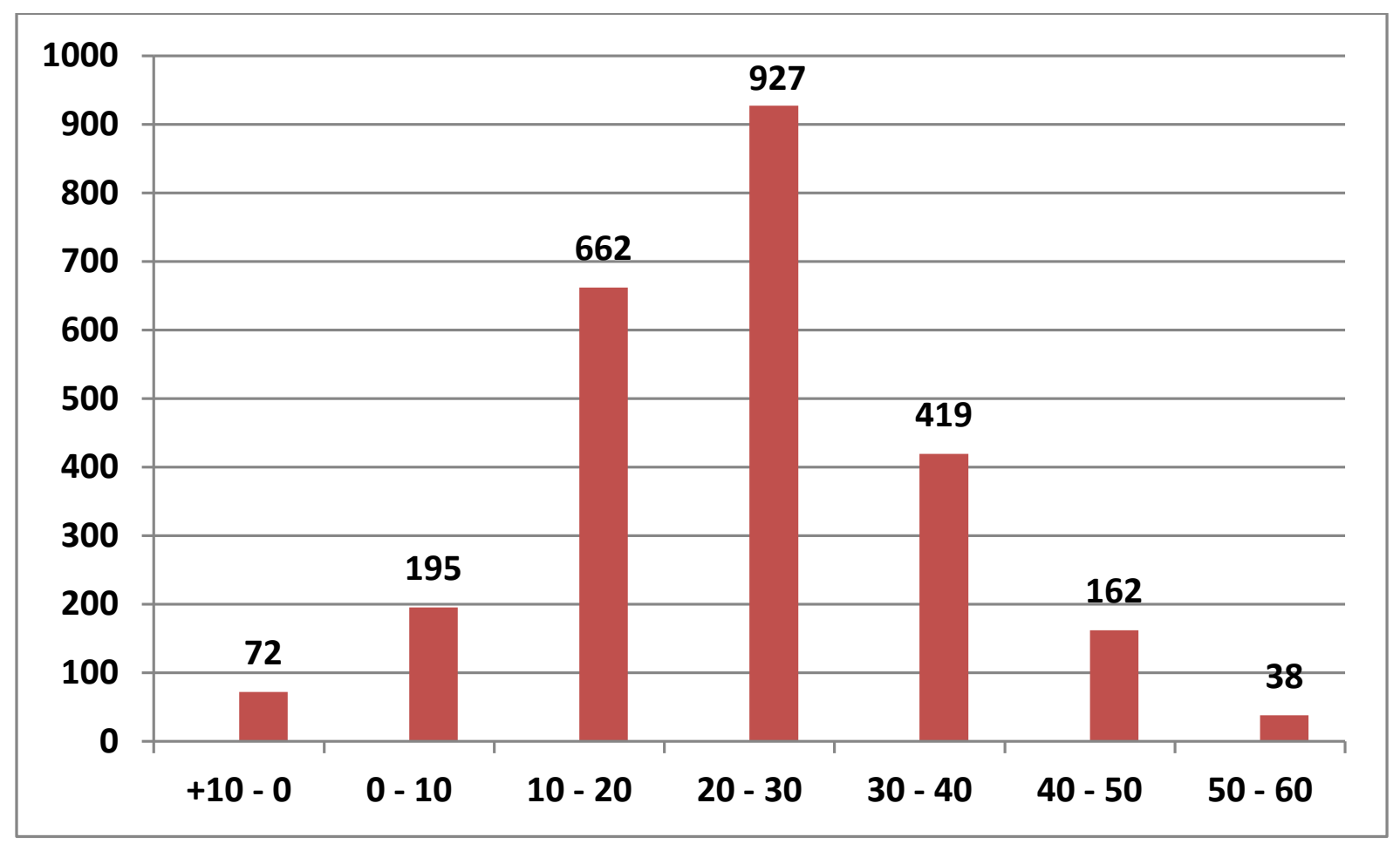

Figure 8-41. Depth range and frequency for lithic debitage from Component A.

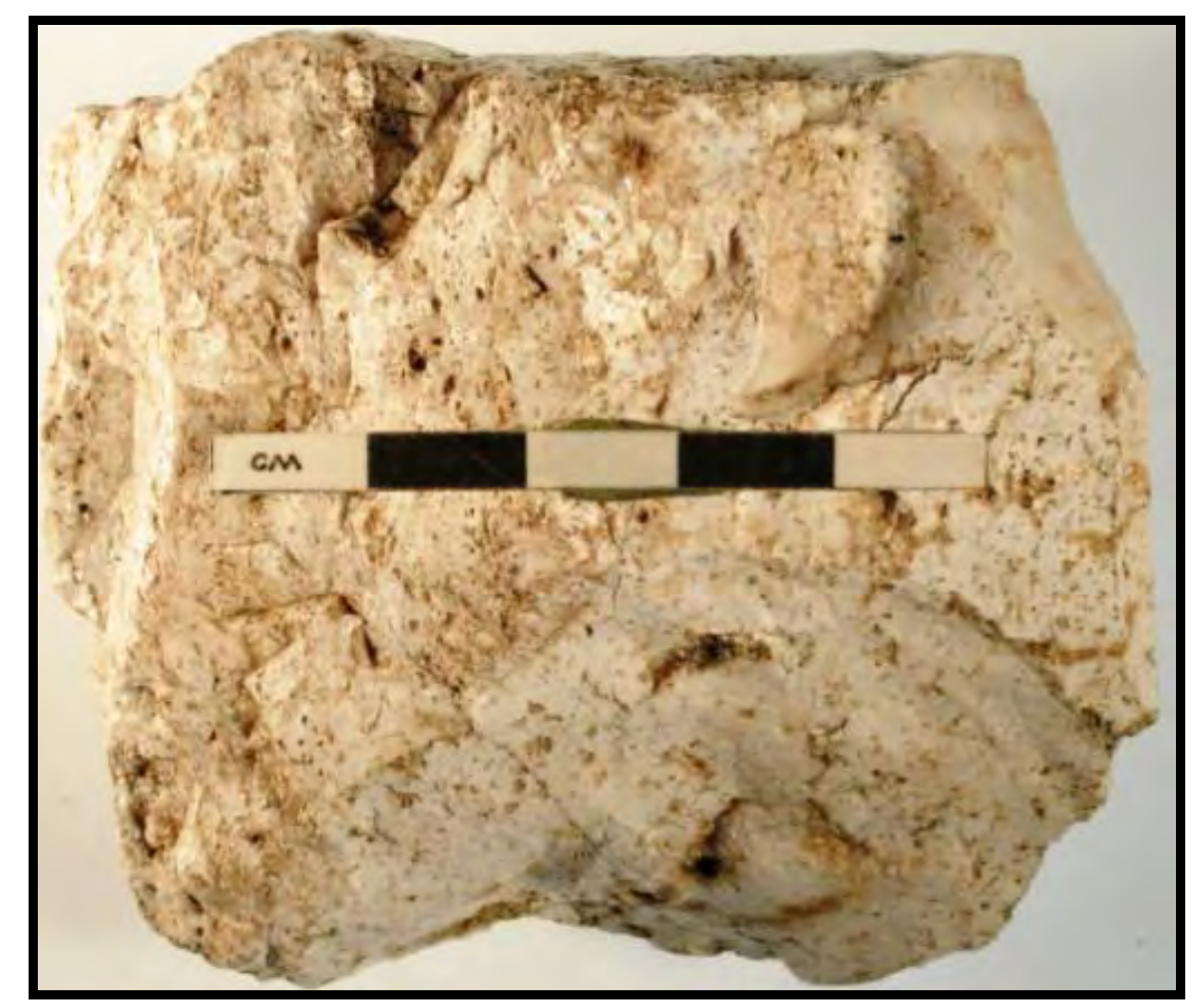

Figure 8-42. Example of an opalite chunk (likely tested) recovered from Component A. 


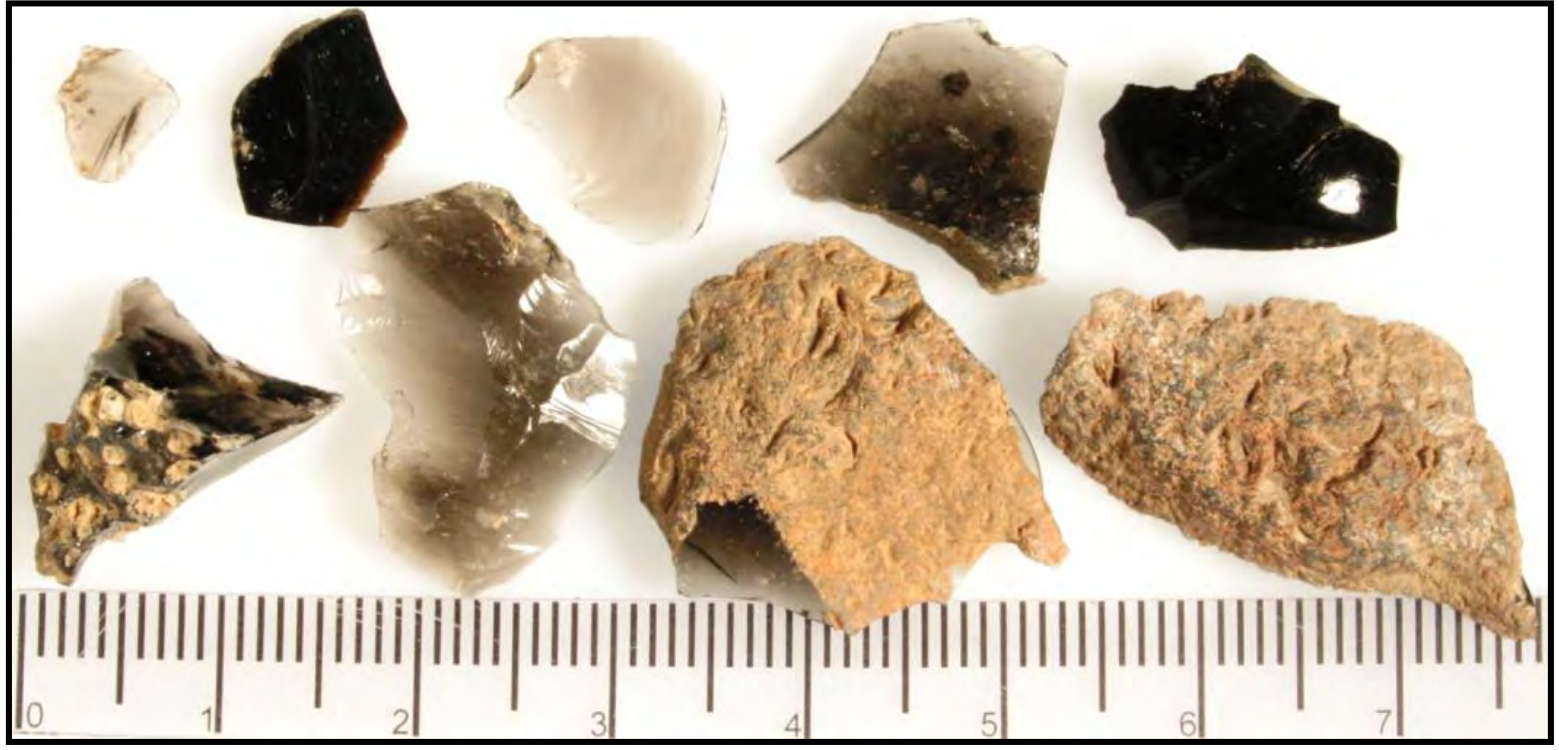

Figure 8-43. Examples of obsidian recovered from Component $\mathrm{A}$.

Note the rounded cortex on larger specimens indicating gravel sourcing.

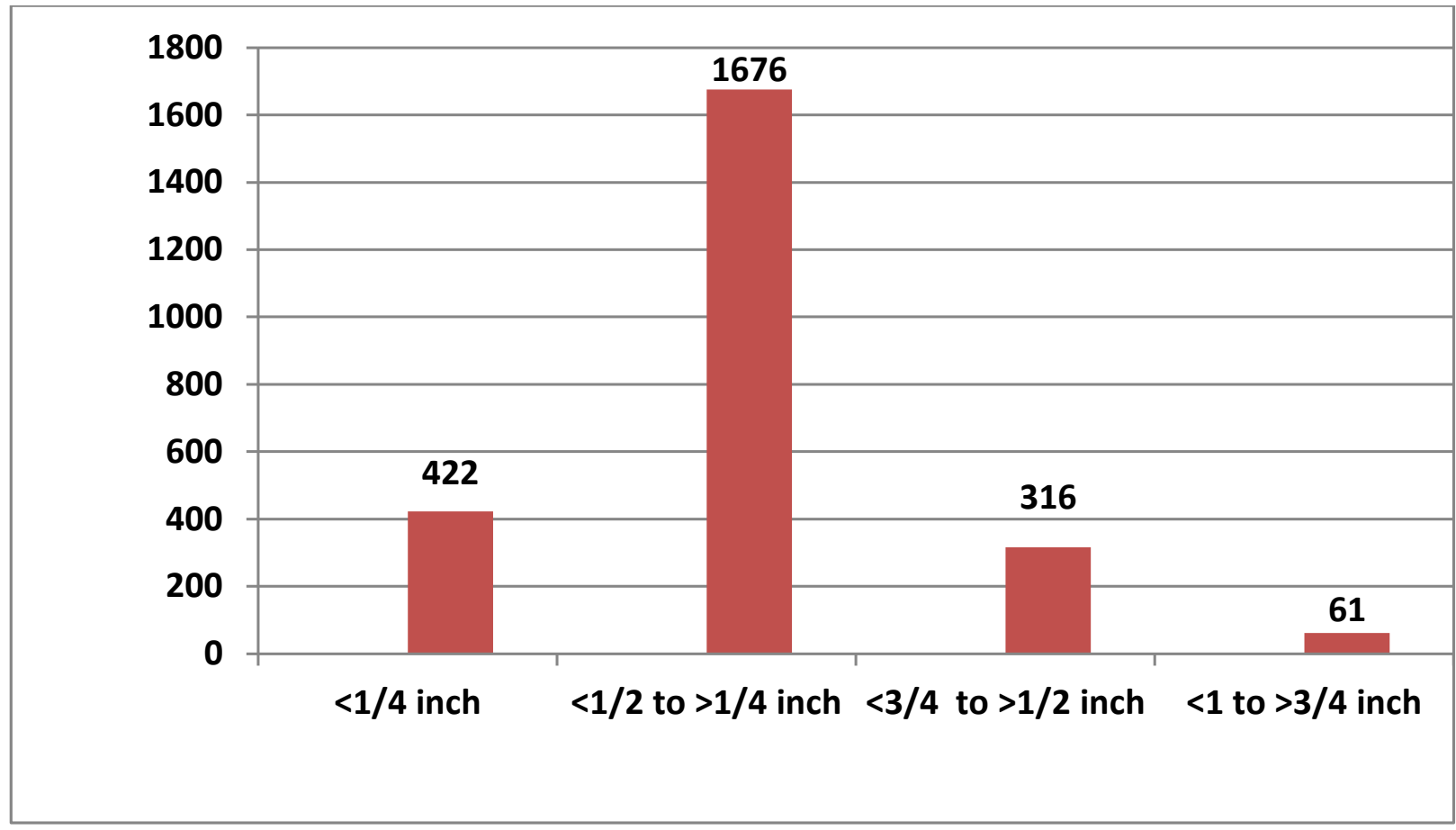

Figure 8-44. Size grade distribution of lithic debitage in Component A. 
group in opalite (a low quality tool material) is in the $>12.8$ to $<19$ to $\mathrm{mm}$ range. Although this debris is still relatively small, it is evident that opalite served a different role in tool manufacturing and use than did Alibates, most likely a reflection of the differences in material quality. The use of opalite involved a greater emphasis on primary material reduction/ production than on rejuvenation. This could also represent a highly expedient form of tool production intended to conserve material. Ogallala quartzite again shows a secondary frequency for the $>12.8$ to $<19$ to $\mathrm{mm}$ size range, though the proportion in the $>6.4$ to $<12.8 \mathrm{~mm}$ size range is much lower than what we see in the secondary group of the more prominent materials.

The frequency of thermal alteration among platform-bearing flakes ( $N=79 ; 5.3$ percent) and in the overall assemblage ( $N=139 ; 11$ percent) is low (Figure 8-45). It is evident primarily on the Alibates specimens (79 percent). The most obvious thermal alteration occurs in the form of potlid marks (saucer shaped divots) and thermal breaks. These are signs that heating probably occurred unintentionally, after discard. Purposeful and/or intentional heating of new material to improve quality for knapping would have involved removal from the heat source before such detrimental alterations could occur. The Alibates chert is of higher quality than locally available quartzite, opalite, and chalcedony, and is a very fine-grained material, quite suitable for knapping without heating.

The breakdown of platform types is depicted in Figure 8-46. There is a total of 1,480 platform-bearing flakes in this debitage assemblage, constituting approximately 59 percent of the debitage. Of these, approximately 42 percent exhibit multifaceted platforms (i.e., faceted plus complex groups). These flakes originate from more intensively modified objective pieces (e.g., bifaces or cores with prepared platforms). A majority of these (80 percent) are made from Alibates.

Flat striking platforms are the second largest type, representing 36 percent of the platform-bearing assemblage. Flat platform flakes were detached from nonbifacial tools or planar, unmodified core surfaces (Andrefsky 1998:94; Whittaker and Kaldahl 2001:54). Crushed platforms comprise 17.5 percent ( $N=260)$ of the flake assemblage. Approximately 1.9 percent $(N=29)$ of the platform-bearing flakes are cortical (Figure 8-46), representing initial flake detachment from a cortex-covered objective piece (e.g., a rounded river cobble).

Lithic debitage with evidence of cortex on the dorsal face signifies early-stage reduction of objective pieces (Figure 8-47). Only a small fraction (4 percent) of the platform-bearing flakes exhibit cortex. The most

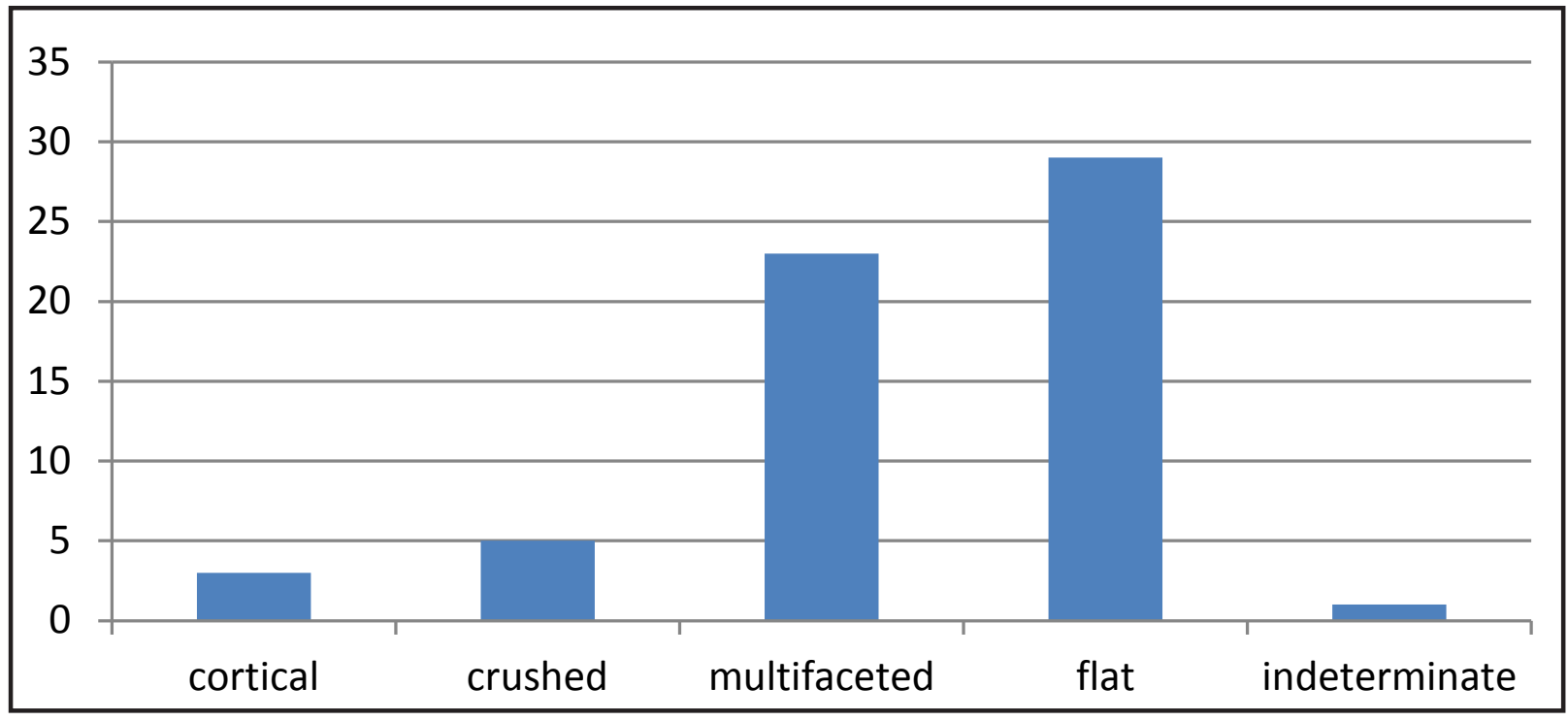

Figure 8-45. Distribution of platform-bearing flakes exhibiting thermal alteration. 
likely explanation of this low incidence of cortex is that the initial reduction of raw material packages was done off-site. Therefore, most of the knapping of raw material at Component A appears to have focused on later-stage reduction resulting in the production of flakes with no dorsal cortex.

The most interesting incidence of cortical surfaces among the raw material groups is seen in the case of obsidian. A small percentage possess cortex that appear to have been water-worn, which indicate that the initial forms were gathered from stream gravels (Figure 8-43). This attribute is not commonly observed on obsidian debris recovered at great distances from the original geologic source, and it may ultimately contribute to the understanding of obsidian procurement and distribution amongst Southern Plains groups in the Late Prehistoric.

The horizontal distribution of debitage by count and weight across Component A clearly reveals that many of the higher concentrations were located outside of designated cultural features (Figures 8-48 and 8-49). The features consisted largely of concentrations of darkened soil and burned rock representing secondary dumps, or discard locales of rocks from heating and/or cooking features.

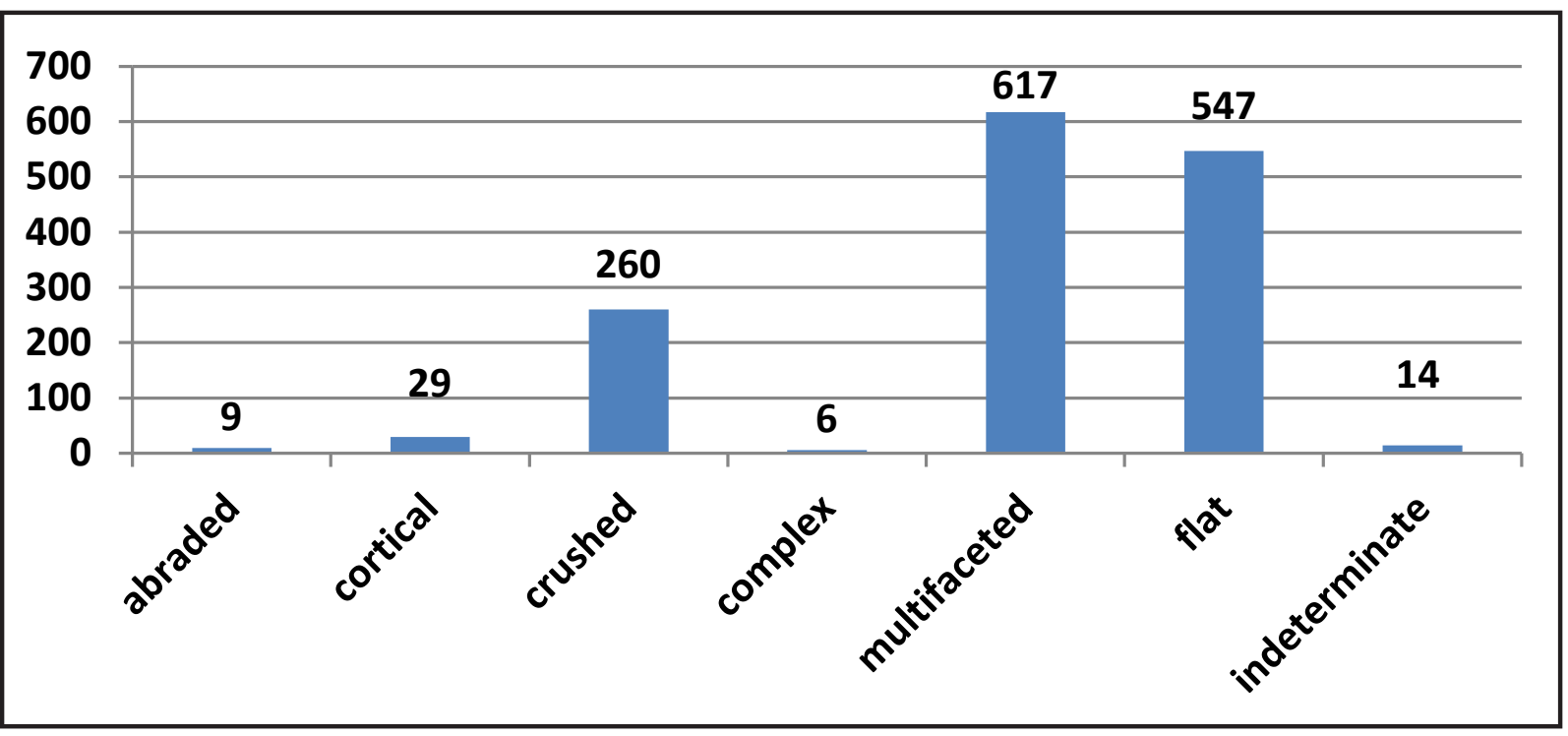

Figure 8-46. Frequency of platform types in Component A debitage assemblage.

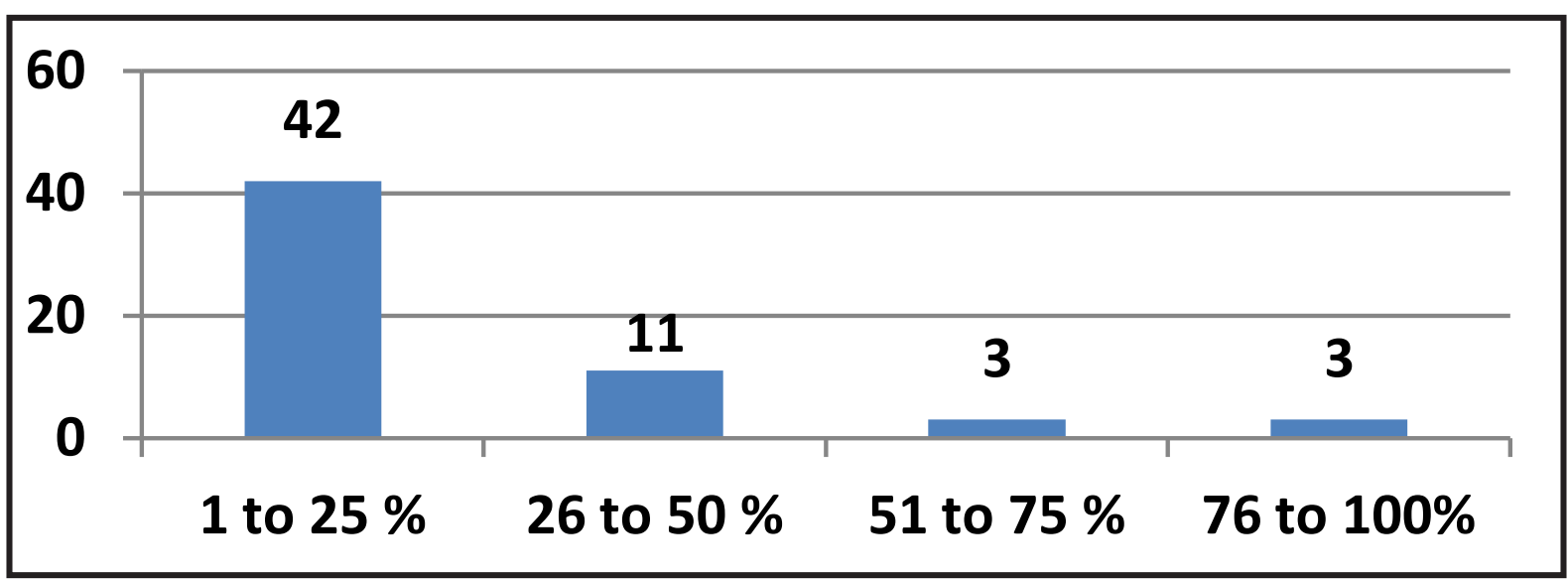

Figure 8-47. Cortex presence on platform bearing flakes from Component A. 


\subsubsection{Summary of Lithic Debitage Analyses}

In summary, the lithic debitage reveals clear patterns of local raw material procurement, reduction, and biface and flake tool production within Component A. The high frequency of Alibates silicified dolomite in this assemblage suggests it was the material for tool production preferred over all other local and nonlocal stone. Opalite is present in moderate quantities across this component but seems to be relegated to the production of expedient flake tools. Ogallala quartzite is available in the local upland gravel outcrops and in the gravel bars along the river. The minor incidence of Ogallala quartzite in this assemblage reflects the preference for higher quality material such as Alibates. Furthermore, the paucity of formal tools made of lower-quality silcates (e.g., chalcedony, quartzite) is supporting evidence that non-Alibates sources played a relatively minor role in formal tool production and were used more for expedient flake tool production (see Chapter 10, Questions 3, 9, and 10 for a more detailed examination of this relationship). The low incidence of cortex on platform-bearing flakes suggests off-site initial reduction of material. These raw material packages may have been gathered locally from nearby sources such as the Canadian River or its lateral tributaries (e.g., Sourdough and Dugout creeks) or from the quarry outcrops as far as $80.5 \mathrm{~km}$ southwest of this site.

Furthermore, the relatively restricted incidence of thermal alteration (5.3 percent of platform bearing flakes) suggests that intentional heat treatment of lithic materials was not a necessary precursor to material reduction/use. The small percentage of heataltered debitage most likely represents unintentional inclusion of materials in heating features and it does not appear that the site's occupants employed intentional heat treatment in their lithic reduction strategy.

The large proportion of platform-bearing flakes with two or more facets (42 percent) indicates that bifacial thinning and edge resharpening and/or rejuvenation were the primary source of the flakes produced on site. Core reduction is also indicated at this component by the presence of platform-bearing flakes with only a single facet. Bifacial reduction flakes represented by multifaceted platforms are also present and account for a significant proportion of the flakes present. Therefore, both bifacial and core forms were reduced on site. However, it is unclear by strictly examinating the platformbearing flakes what proportion of bifacial reduction flakes originate from bifacial cores as opposed to modification of large flakes. This distinction requires an examination of the relationship between debitage and chipped-stone tools (see Chapter 10, Question 3 for further discussion).

The horizontal distribution of lithic debitage across the Component A indicates dispersed knapping locations located away from delineated feature boundaries (i.e., organic soil and burned rock concentrations). The apparent lithic concentrations are interpreted as remnant reduction locations that have become horizontally dispersed over time due to rodent disburbance of the matrix and subsequent dune activity. In Chapter 10, these lithic concentrations will be examined more throughly in relation to the horizontal distribution of other artifact classes in order to gain a greater understanding of discrete activity areas and, by extension, overal site function.

\subsection{Ceramic Analyses}

\section{J. Michael Quigg}

The total number of sherds from hand-excavations is 1,217 , with total weight of $1,987.9 \mathrm{~g}$. An additional 52 sherds came from the surface, trenches, and cutbank and weigh $225 \mathrm{~g}$. Sherds from handexcavations weigh an average of $1.6 \mathrm{~g}$ each, whereas sherds from other contexts weigh an average of 4.3 g each, over twice that of those buried. In general, sherds are quite small and appear very similar to one another. The overall ceramic sherd density from the hand-excavations was 9.5 sherds per $\mathrm{m}^{2}(1,217$ sherds $\div 128 \mathrm{~m}^{2}$ ).

On the basis of the combined evidence, Component A is considered a single component and represents a very narrow time frame. However, bioturbation of the sandy deposits has vertically displaced many small artifacts from the surface of the bladed fireguard to a depth of about $60 \mathrm{cmbs}$. Although many 


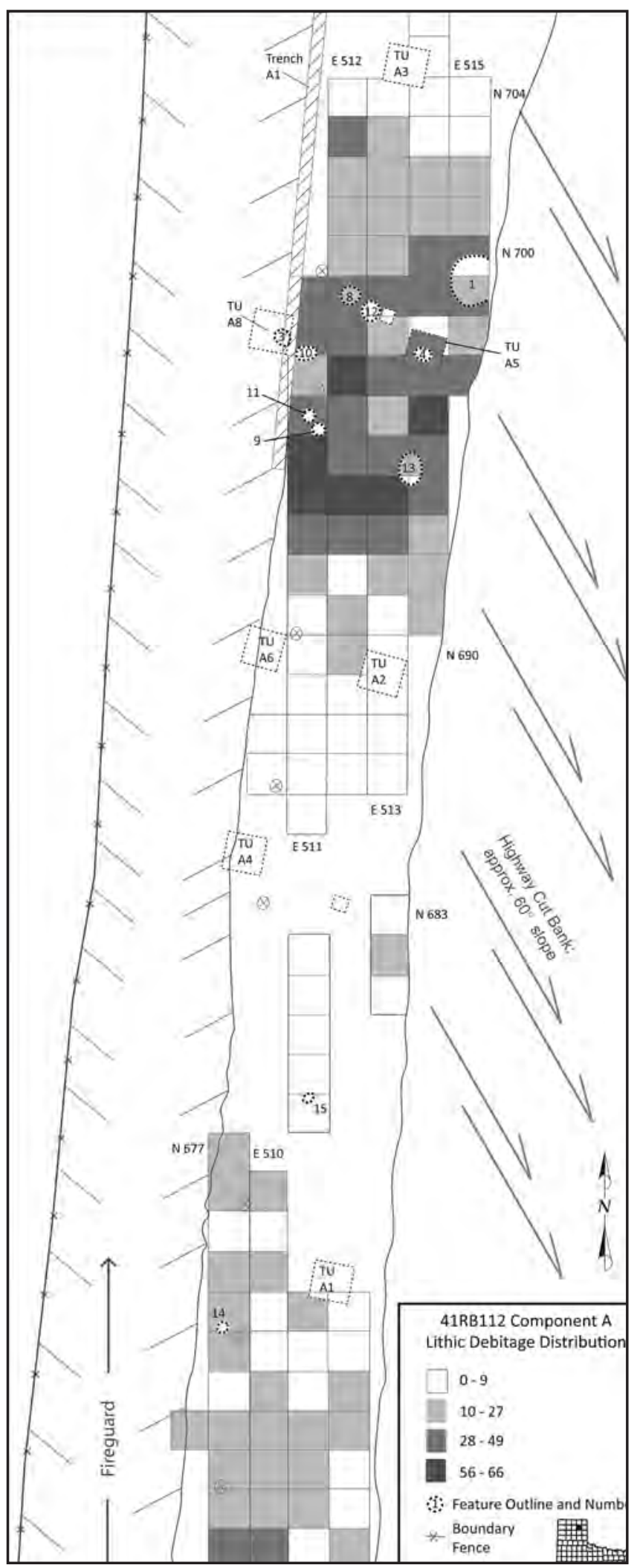

Figure 8-48. Spatial distribution of lithic debitage in Component A. 


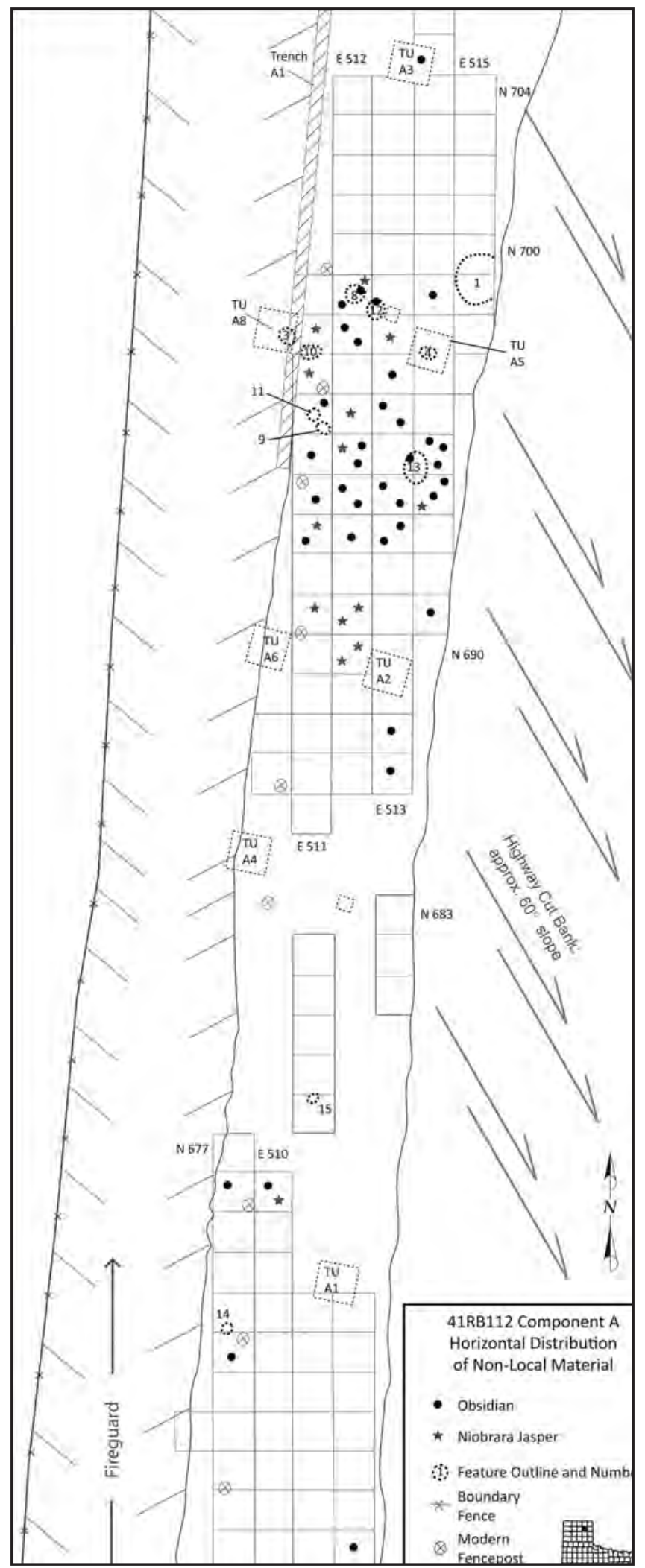

Figure 8-49. Horizontal distribution of nonlocal material at Component A. 
artifacts were vertically disturbed and displaced out of original context, the fact that the various material classes represent a single component allows for unified interpretation of the assemblage.

Initially, the largest sherds (those greater than $2 \mathrm{~cm}$ in diameter) were the focus of analysis, and these specimens were all macroscopically inspected to identify their characteristics and attribute variability. Following the first round of inspection, sherds were sorted into possible vessel groups on the basis of a variety of macroscopic characteristics such as exterior surface finish, rim attributes, internal core color, aplastic inclusions (tempering materials), decorations, etc. Refitting was attempted for each group of sherds using the pieces with diameters over $2 \mathrm{~cm}$. Sherd groups representing fourteen vessels (designated A through $\mathrm{N}$ ) were identified. In some cases, a vessel is represented by only 1 or 2 sherds, whereas other vessels are represented by as many as 34. Unfortunately, no pot drops or tight sherd clusters were recovered, with the exception of nine sherds clustered in N695 E511 that are assigned to Vessel F.

Not all sherds were assigned to vessel groups with complete confidence because the majority of sherds are relatively uniform in surface finish (cordmarked), thickness, and temper (macroscopically observed sand grains), and without a thorough understanding of what complete vessels looked like, it is not clear what variations across a single vessel might result in dissimilarities in sherds. As various authors have pointed out from observations of rare reconstructed vessels, vessel sections (i.e., rim, neck, base), exhibit considerable variability from side to side in exterior surface finishes, with patches of unmodified cordmarks, partially smoothed-over cordmarks, or completely smoothed areas near bases and along the necks (i.e., Bevitt 1999:122-124). With so much potential variability within a single vessel, the assignments of sherds to vessel groups are limited to 13.6 percent of the total sherd sample. Another factor was roughly 60 percent of the sherds are less than $2 \mathrm{~cm}$ in diameter and too small to analyze.

For the most part, sherds were not washed in order to help preserve any microfossils (i.e., phytoliths, diatoms, and starch grains) that might be present and might through analysis, contribute to a better understanding of functions of ceramic vessels (e.g., the foods prepared in cooking vessels). Some sherds have black organic residue on exterior surfaces (Figure 8-50) that was, in most cases, left undisturbed. In a few instances (i.e., \#1042-8-1, \#1162-8-1, \#1021-8-1, and \#1128-8-2) the encrusted residue was scraped from the sherds, or the sherds themselves were submitted for starch grain analysis or radiocarbon dating. Starch grain analysis was conducted on 23 sherds from at least 4 identified vessels, in an attempt to identify the kinds of foods cooked in these vessels.

Two technical analyses, petrography and instrumental neutron activation analysis (INAA) were conducted on 14 sherds that represent at least 10 vessels to; trace interactions among people of the Plains Village period, gain greater understanding of the construction techniques, the raw materials used, and potential sources of those materials. In nearly every instance, sherds selected for these analyses were broken into two pieces and each piece was sent for the two analyses. This process of breaking a sherd into two pieces insured that the two complementary analyses were conducted on the same vessel and vessel area.

Each vessel group is identified and discussed below, with the results of the technical analyses presented where appropriate. Following these vessel presentations, unassigned sherds are discussed. A summation and general discussion of the ceramic assemblage follows.

\subsubsection{Vessel A}

This vessel is represented by 34 sherds that include 22 body sherds, 6 rim sherds and 6 neck sherds, all of which have a combined weight of $91.2 \mathrm{~g}$. This vessel had a collared rim (thickened lip), cordmarked on the rim exterior and decorative punctations 18.5-mm-below the base of the collar (Figure 8-51). The punctations are shallow, 1.3- to 2.3-mm-deep, 9.6- to 10.6-mm-wide, and spaced $19.6 \mathrm{~mm}$ from center to center. The punctations appear to have been created by a finger tip, and a possible finger print was observed in one of the punctations. Only two rim sherds could be refit, which limits our understanding of the overall vessel shape and size. 


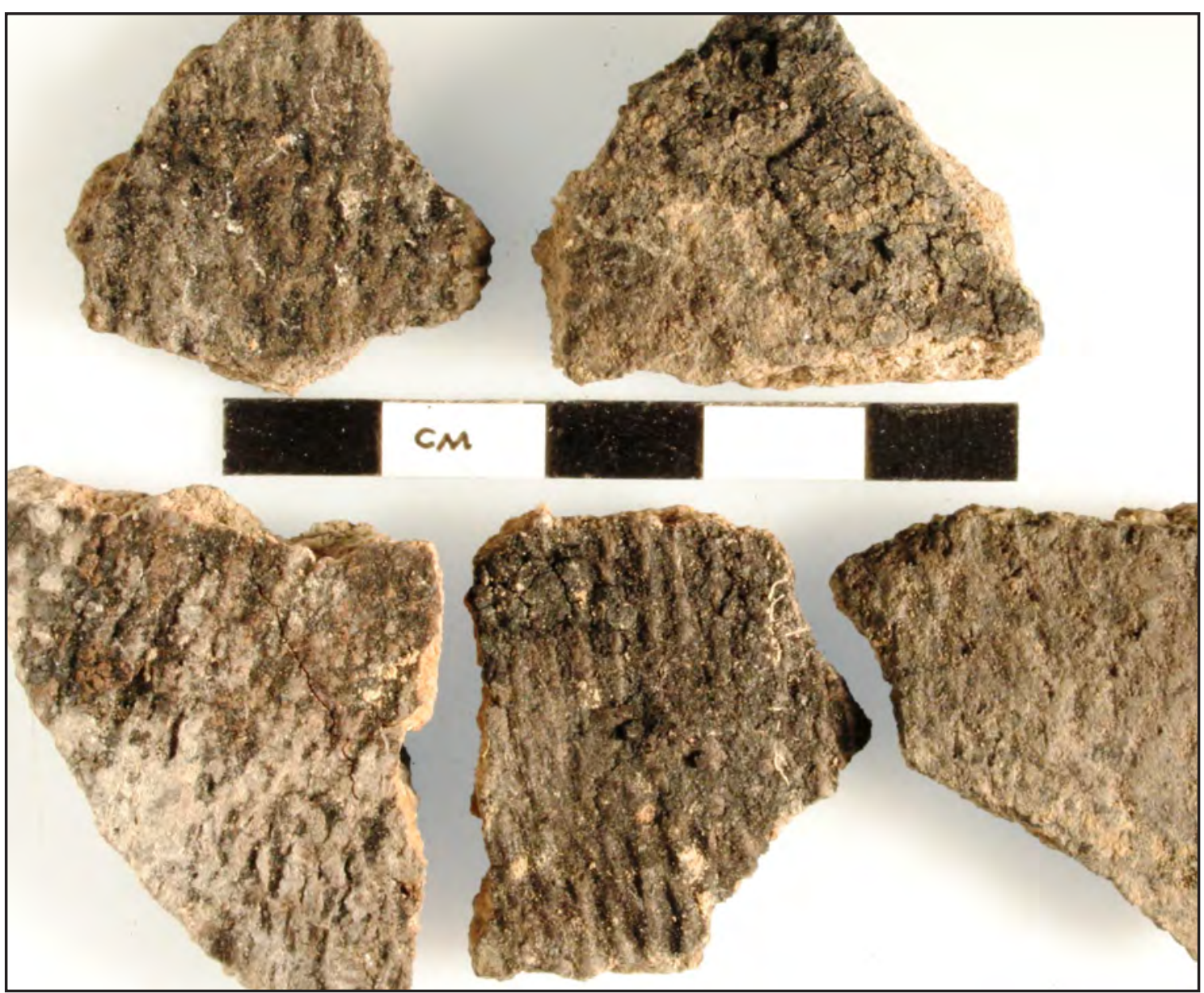

Figure 8-50. Sample of unwashed body sherds with organic residues adhering to exteriors. Scale in centimeters.

Shape: The overall body shape and the general vessel dimensions are unknown. With only about 12 percent of the rim present, the outside orifice diameter is projected to have been 12 to $13 \mathrm{~cm}$. No basal sherds were identified and therefore the bottom shape is unknown. It is not clear if this vessel had a shoulder as body sherds with pronounced curvatures are absent. The rim is direct, straight and shows variations from sherd to sherd (Figure 8-52).

Construction: Most broken edges are sharp, angular, and straight or irregular with no concave or convex edges such as would indicate coil breaks. The collared or thickened rim appears to have been created by folding over and pinching the exterior surface. The rounded lip is between 9.1- and 10.3-mm-thick. The pinched clay sections of the collar are irregularly spaced. No decorations are present on the rounded lip. The shallow punctations were added to the rim following the surface treatment as they interrupt the cordmarks. Four sherds from \#212-8-1 and \#1095-82 exhibit a single punctuation each. The body sherds are 3.0- to 7.6-mm-thick. At least one sherd has a crack in the profile wall indicative of a platy structure.

Exterior Surface: The surface is treated with vertically oriented cordmarks made with narrow, tightly twisted cords that created shallow impressions (see Figure 8-51). The cordmarkings extend toward the rim under the pinched collar. Many sherds exhibit a dark organic residue in the depressions left by the cords. No overlap in the cordmarkings could be observed, though only limited sections of the body are present and the sherd size is small. The rims are dark gray (10YR 4/1) and the body sherds are very dark gray (10YR $3 / 1)$. 


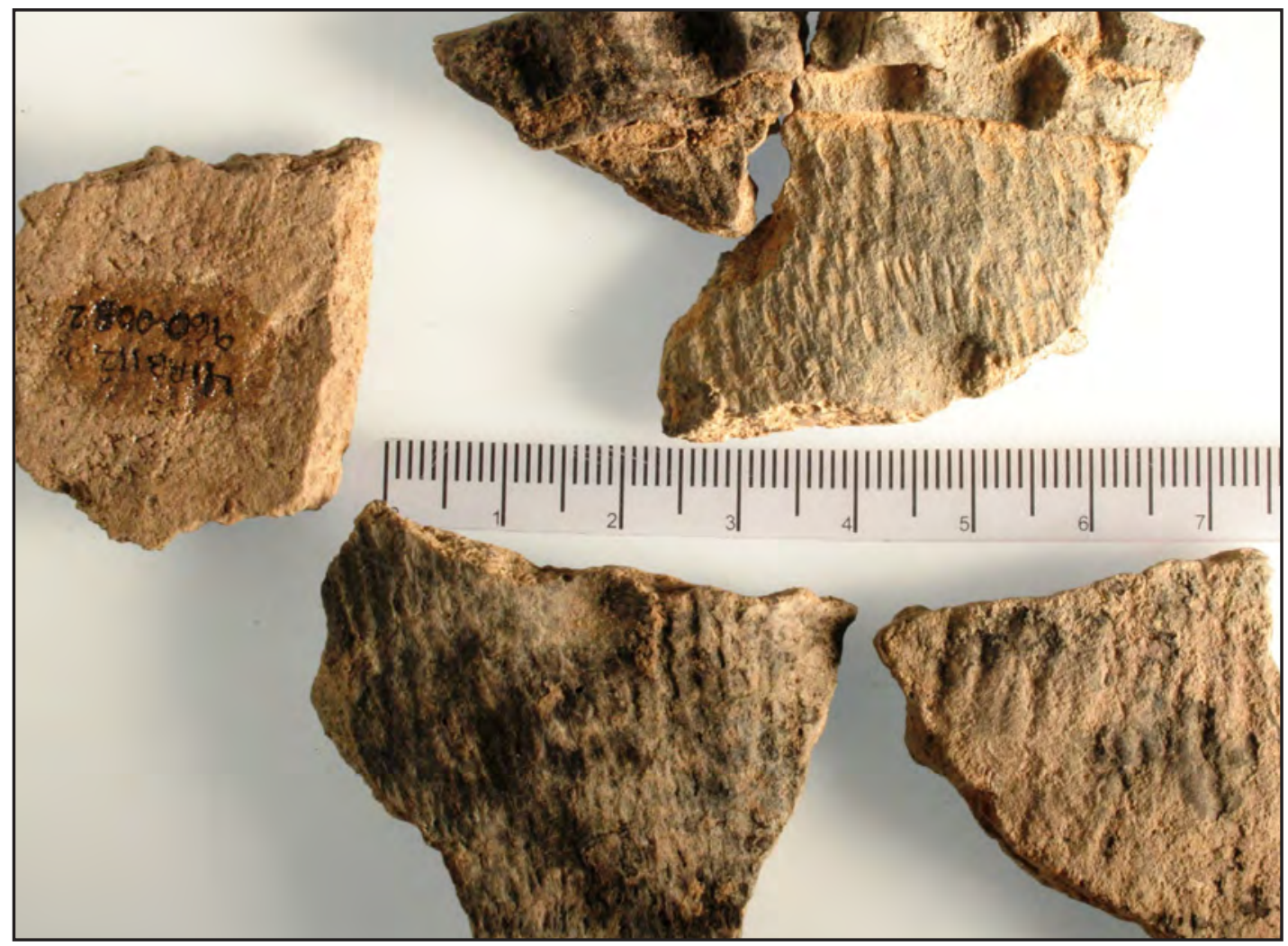

Figure 8-51. Vessel A rim and body sherds, left sherd shows interior.

Note two shallow finger punctations and the dark organic residues on sherd in lower center. Scale in centimeters.

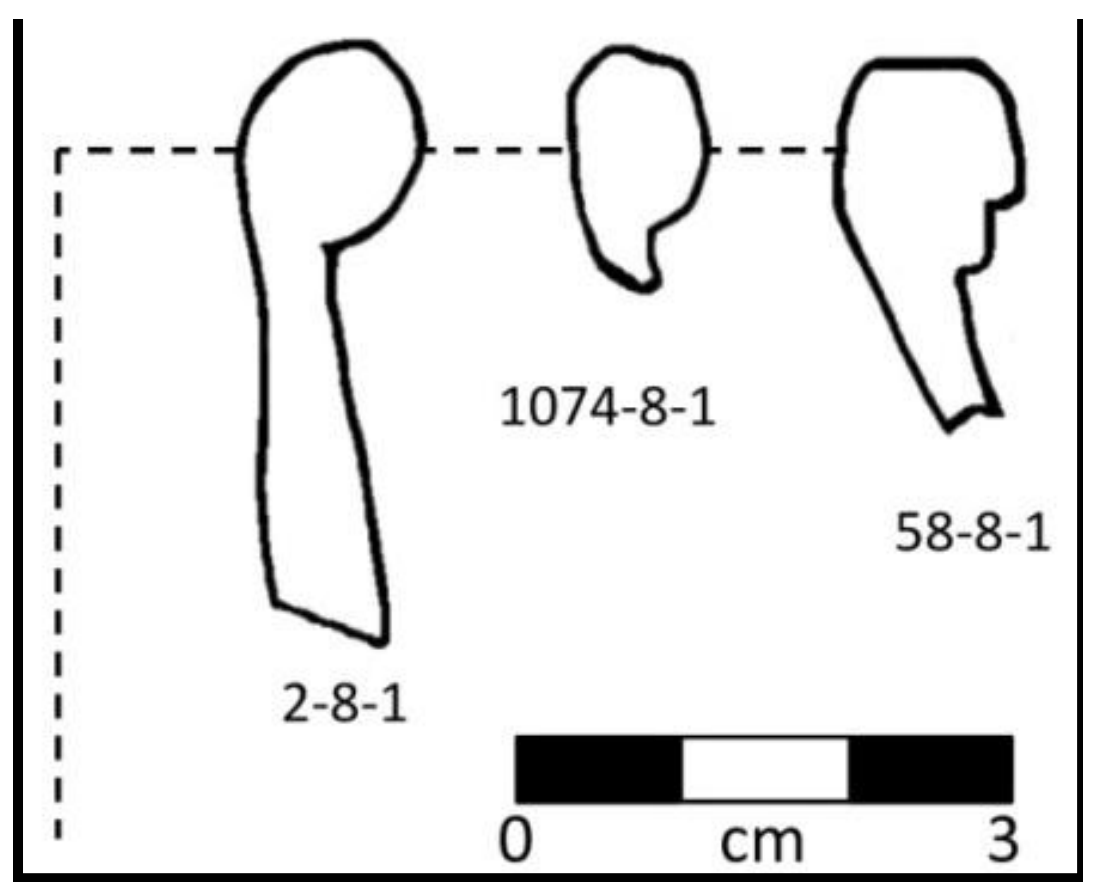

Figure 8-52. Vessel A rim profiles. 
Interior surface: The inside surface is smooth to slightly irregular with some thin striations, likely the result of horizontal wiping in the rim area prior to drying/firing of the clay (\#960-8-2; see Figure 8-51). The body sherds are light gray (10YR 7/2) whereas the rims are light yellow-brown (10YR 6/4).

Paste: Macroscopically the paste contains sand temper comprised of white and clear, rounded quartz particles. Temper is not visible on the exterior, but is on the interior surface near the upper rim. The cores of the rim sherds (\#2-8-1) are two-tone with gray (2.5 Y 6/0) towards the interior edge and very dark gray (7.5 YR 3/0) on the outer two-thirds. The petrographic analysis on sherd \#1040-8-1 exhibited massive, anisotropic paste with few voids, with between 13 and 20 percent temper that includes, 3 to 5 percent common quartz, 3 to 5 percent iron opaque, 2 to 3 percent calcite, and 1 to 2 percent other minor minerals (Appendix F). This has one of the highest percentages of hematite/iron opaques, along with Vessel $\mathrm{C}$ in this component. Base on paste color and isotropy, this sherd was assigned to a broad temper class of crushed rocks and minerals, and specifically to Paste Group B (Appendix F).

Starch Grain Analysis: Three sherds from this vessel (\#2-8-4, \#58-8-1, and \#979-8-1) were analyzed. One body sherd (\#2-8-4) yielded six lenticular little barley (Hordeum pusillum) starch grains and one damaged grain of the same species. The rim sherd (\#58-8-1) yielded one unknown starch grain and an unidentified gelatinized grain. The other body sherd did not yield any starch grains (Appendix D).

INAA: A single sherd (\#1140-8-1 = TRC555) was subjected to chemical analysis and the results indicate this sherd belongs within Chemical Group 2 , as did most analyzed sherds from this component (Appendix G).

Radiocarbon Dating: A 3.9-gram section of body sherd (\#60-8-2a) from 30 to $40 \mathrm{cmbs}$ in Test Unit A-5 was sent for radiocarbon dating. This sherd yielded a $\delta^{13} \mathrm{C}(-24.1 \%)$ corrected AMS, uncalibrated date of $1960 \pm 30$ B.P. (Beta-307379) or cal 40 B.C. to A.D. 80. This date is much older than the oldest AMS date on maize (590 \pm 25 B.P.; UGAMS-7839) by at least some 1,300 years and definitely not acceptable for the true cultural age of this vessel. Obviously, bulk sherds do yield radiocarbon dates but in this instance the date is unacceptable. It is clear that the paste date is significantly older than the associated maize date and likely reflects incomplete combustion of old organics in the original clay. The $\delta^{13} \mathrm{C}$ value is indicative of $\mathrm{C}_{3}$ grasses in the subfamily of Arundinoideae, Festucoideae (i.e., wildrye and little barley) and some Panicoideae (Smith and Brown 1973). The value indicates about 83 percent $\mathrm{C}_{3}$ residues were represented in this dated material.

Also AMS dated was burned organic residues scrapped from the exterior of this same exact body sherd (\#60-8-2b). This residue yielded an AMS date of $490 \pm 30$ B.P. (Beta-307380) or cal A.D. 1410 to 1450. This date is statistically identical to the nine accepted AMS maize dates.

Horizontal Distribution: The 34 sherds that pertain to this Vessel were recovered from the surface of the fireguard, and hand-excavations of Test Unit A, and 10 other units in the northern part of the excavation block (Figure 8-53). The sherds were scattered across multiple units, between the surface and $61 \mathrm{cmbs}$, but the general area around the heating elements was most likely where this vessel was used.

\subsubsection{Vessel B}

This vessel is represented by 14 body sherds with a combined weight of $28.5 \mathrm{~g}$. This was a very thinwalled vessel with smoothed-over cordmarkings and few diagnostic characteristics except that the sherds are thin and dark in color on both interior and exterior surfaces (Figure 8-54). Although several sherds refit, the combined results were of insufficient size to reveal attributes of form such as shape, etc. The largest sherd (\#1175-8) is slightly over 3-cmlong, whereas four sherds in the group are less than 1 -cm-across. Two sherds from the same provenience (\#1166-8) refit to create a combined dimension of $3.5-\mathrm{cm}$-long. Calcium carbonate film is prominent over most surfaces and obscures surface coloration in large areas.

Shape: The larger body sherds reveal a slight curvature, but the overall form is indeterminate, as are the vessel dimensions. 


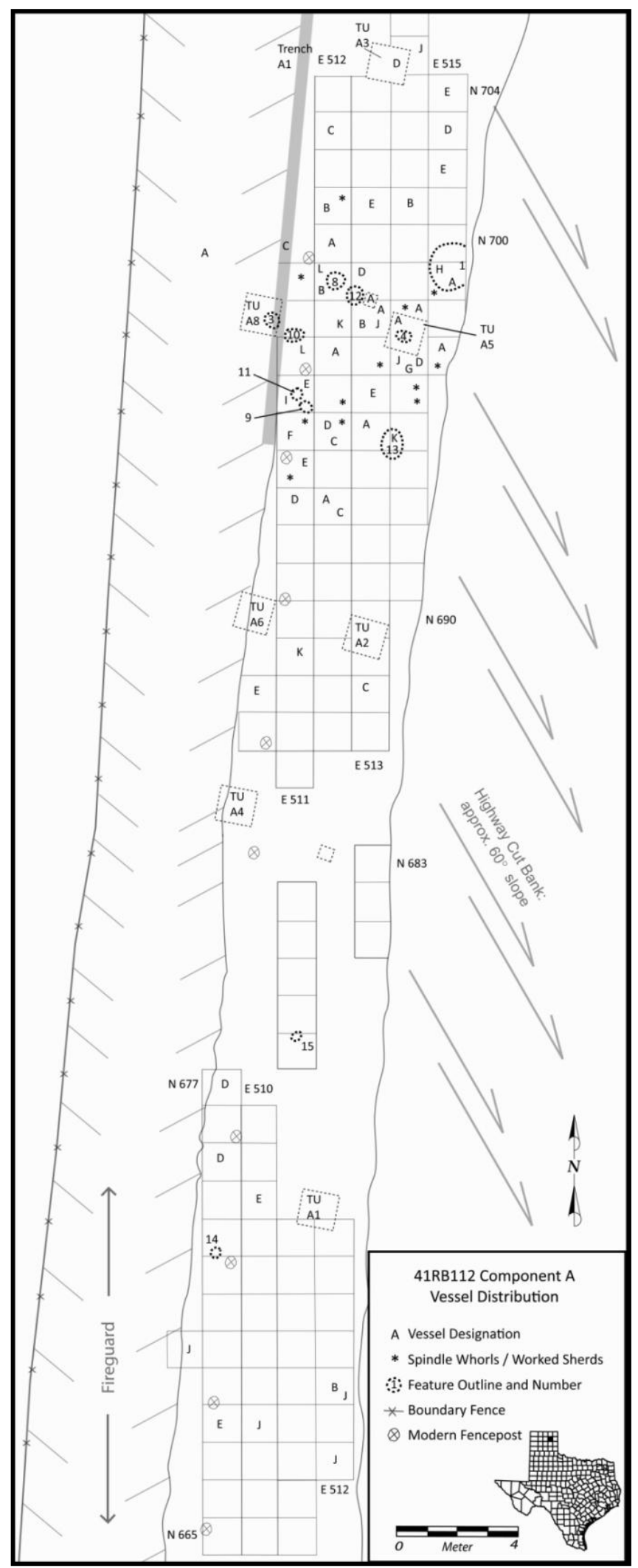

Figure 8-53. Horizontal distribution of sherds representing different vessels in Component A. 


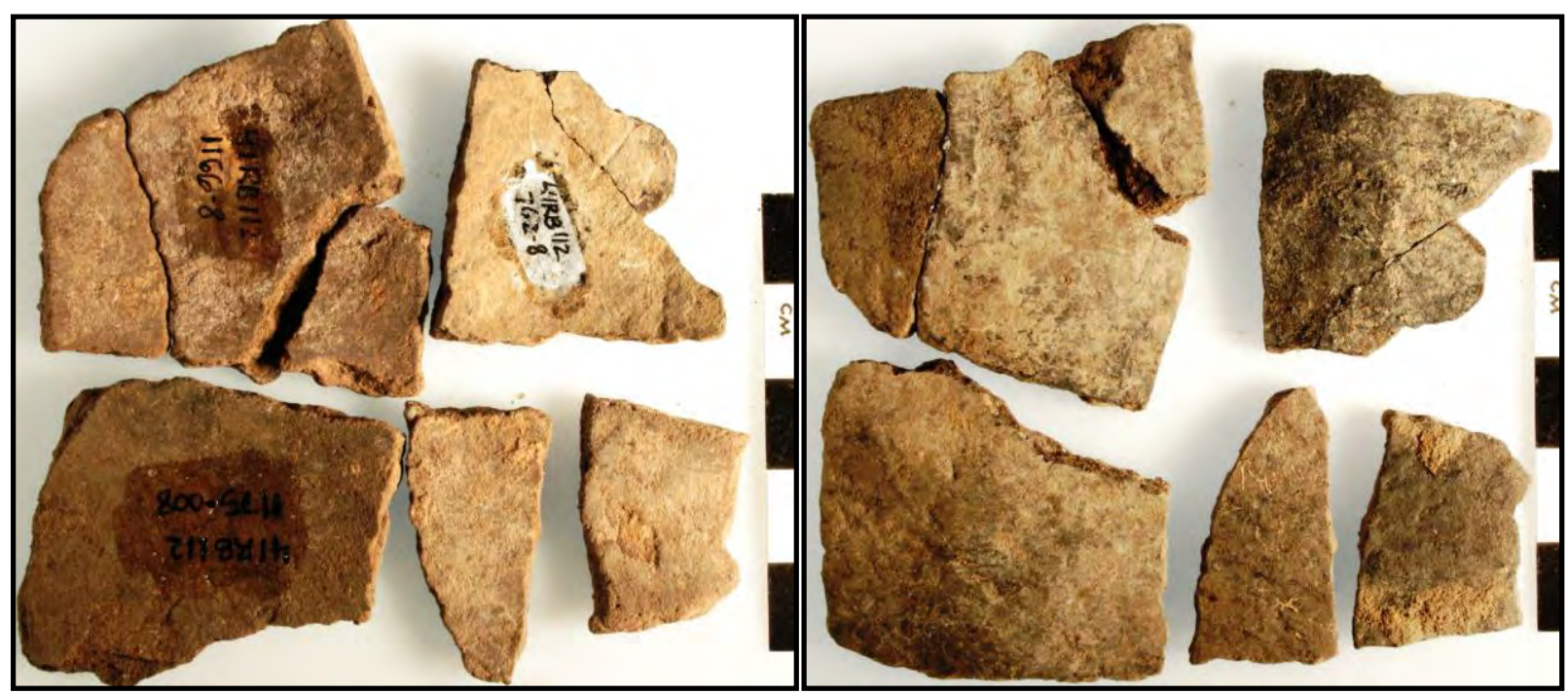

Figure 8-54. Vessel B body sherds, interior (left) and exterior (right). Scale in centimeters.

Construction: The broken edges are more or less straight, angular with no indications of coiling. The body sherds are quite thin and vary from 2.9to 4.2-mm-thick. The largest sherd (\#1175-8) has a crack in the core that parallels the surface, indicative of a platy structure.

Exterior Surface: The surface has very faint, shallow, and discontinuous cordmarks (see Figure 8-54). The faint, shallow cord impressions are so indistinct that at first glance, the surfaces appear plain. The exteriors are dark gray (10YR 4/1) with some calcium carbonate and limited carbonized residue present.

Interior Surface: These surfaces are smooth with tiny pits and very faint wiping striations (see Figure 8-54). The interiors are dark gray (10YR 4/2).

Paste: Visually the paste contains an abundance of fine sand grains along with some medium-size sand grains. Most grains are rounded white and clear quartz particles, and some flecks of mica are also present. Temper particles are visible on the interior surfaces of at least one sherd. The core is very dark gray (10YR 3/1), which in combination with the lighter dark gray (10YR 4/1, 10YR 4/2) of the surfaces, implies incomplete firing in an oxidizing (reducing) atmosphere. A single sherd (\#1175-8) was subjected to petrographic analysis and revealed massive dense, anisotropy paste with few voids, 9 to 15 percent inclusions that includes 5 to 7 percent common quartz grains, 1 to 2 percent orthoclase, 1 to 2 percent biotite, 1 to 2 percent muscovite, and 1 to 2 percent hematite/iron opaque (Appendix F). This sheds has the least percentage of particles with only six types identified of any of the vessels in this component. This sherd was within a broad crushed rock and mineral temper class and assigned specifically to Paste Group B. Sherds from Vessels A and $\mathrm{J}$ are also assigned to Paste Group B.

Starch Grain Analysis: One sherd (\#762-8-2) from this group was analyzed, but failed to yield any starch grains (Appendix D).

INAA: Two body sherds (\#1175-8-1b = TRC556 and \#762-8-1 = TRC651) were subjected to chemical analysis, which revealed that they belong to the same chemical group, Group 2 (Appendix G).

Horizontal Distribution: The 14 body sherds were distributed across 4 units west of the pithouse Feature 1 between 20 and $50 \mathrm{cmbs}$ (see Figure 8-53). Three additional sherds were recovered from N669 E512 in the southern section of Block A, 28 m south of the more clustered sherds. 


\subsubsection{Vessel C}

This vessel consists of 13 body sherds with a total weight of $51.2 \mathrm{~g}$. This vessel has a very smooth exterior that has a polished red finish (red wash) and lacks other decorations (Figure 8-55). Few sherds were able to be refit, so vessel general formal characteristics such as shape, height, width, and etc. are not discernible. The largest sherd measures 9.2-cm-long; the smallest are less than 2-cm-long.

Shape: The shape is unknown. Most sherds are only slightly curved, so it is unclear if the vessel had a neck or shoulder.

Construction: The fractured edges are sharp and relatively straight with no concave or convex edges to indicate a coil break. The manufacturing technique is unknown. The body sherds measure 5.8- to 6.3-mm-thick.

Exterior Surface: The surface is quite smooth (see Figure 8-55). Calcium carbonate film covers most sherds, although a light reddish (10YR 6/6) color lies under the carbonate. In profile, no evidence exists for this to be a true red slip, but likely the color is a red-wash. The red likely comes from a mixture of red hematite and water then applied to the surface.
Interior Surface: The interior is light brown (10YR 6/2) covered with calcium carbonate (see Figure 8-55). The surface is smooth with no visible divots or irregularities. Thin striations resulting from smoothing the inside are present on one sherd, whereas a slightly concave section with definable edges may indicate that a small pebble was used in the smoothing process.

Paste: Visually, the core is two-tone with a gray (7.5YR 6/0) band towards the interior and reddish yellow (7.5YR 6/6) band toward the outer edge. Macroscopically, tiny, dark, angular temper particles of sand are in abundance. At least one sherd (\#11208-1) has temper exposed on the exterior surface. Petrographic analysis on body sherd \#1206-8-1 revealed a massive, dense, anisotropy paste with few voids, 13 to 17 percent particles that includes 5 to 7 percent basalt, 3 to 5 percent biotite, 3 to 5 percent iron opaque/hematite, 1 to 2 percent common quartz grains, and 1 to 2 percent muscovite (Appendix F). Based on the paste color and isotropy this sherd was assigned to the broad basalt temper class that accounts for 36.5 percent of the analyzed sherds. It was specifically assigned to Paste Group $\mathrm{HH}$ and no other sherds from this component were assigned to this specific paste group. This is a unique paste in this component with its high basalt and biotite tempers and is more similar to the vessels in component $\mathrm{C}$ (see section 9.4 below).

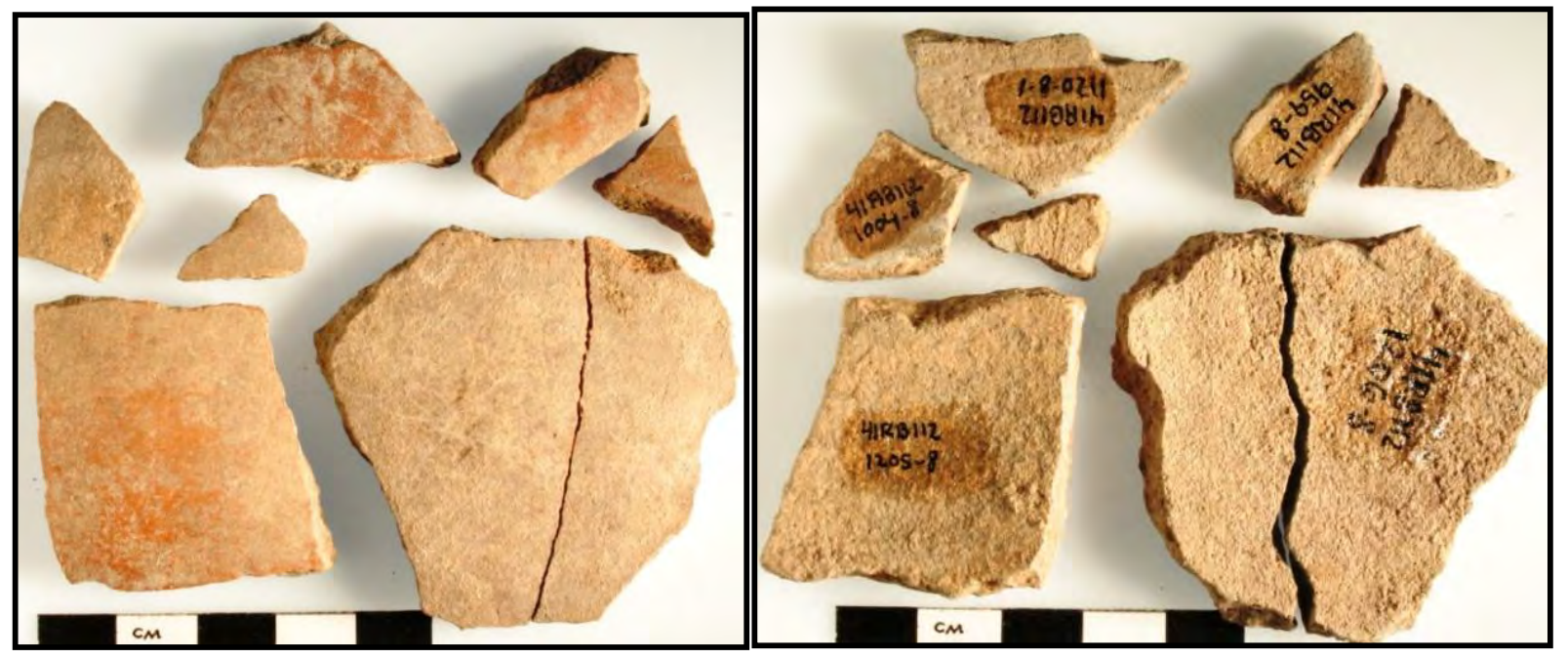

Figure 8-55. Vessel C body sherds, exterior (left) and interior (right). Scale in centimeters. 
INAA: Parts of two sherds $(\# 1206-8-1 \mathrm{~b}=$ TRC557 and \#1234-8-1 = TRC655) were submitted for chemical analysis. The results indicate both sherds are assignable to Chemical Group 4. No other sherds from this component were assigned to this chemical group (Appendix G), again supporting it is unique within this group of vessels.

Horizontal Distribution: The 13 sherds came from 6 units generally clustered in the northern block of Component $\mathrm{A}$ around the various heating elements. However, two tiny fragments were some 6 to $8 \mathrm{~m}$ further south (see Figure 8-54). These pieces were between 10 and 50 cmbs.

\subsubsection{Vessel D}

This vessel consists of 21 sherds with a total weight of $71.2 \mathrm{~g}$. Twelve are body sherds, three are rim sherds, and six are neck sherds (Figure 8-56). The vessel exterior was cordmarked with tight, shallow, vertically oriented impressions. Two groups of three sherds each could be refit. One group (\#46-8 and $\# 1044-8$ ) includes the rim and neck area, but the overall vessel shape is not represented. The largest sherd is a rim fragment that is just over 4-cm-tall.

Shape: The vessel shape and dimensions cannot be determined from these few sherds.

Construction: It is not clear how this vessel was manufactured, as no coil breaks were identified and the sherd profiles show no relevant clues. The breaks on some sherds occurred in the neck area and may indicate that this was a weak point even though the vessel wall thickens slightly in the neck. The lip is slopes slightly downward to the outside and is decorated (see Figure 8-56). It is 3.5- to $3.7-\mathrm{mm}$ thick. The rim wall increases in thickness, from 3.9 $\mathrm{mm}$ just below the lip to $6.8 \mathrm{~mm}$ just above the neck, a pronounced expanding towards the neck area that measured 7.7 to $8.7 \mathrm{~mm}$ in thickness. The rim height, measured between the top of the neck and the top of the lip is between 43 and $59 \mathrm{~mm}$.

Exterior Surface: The surface is marked by tight and narrow cord impressions that are vertical and extend to the lip (see Figure 8-57). The cordmarks extend down the neck and over the vessel body. The exterior is two-tone in color, with dark gray (10YR 4/1) mottled with black (10YR 2/1) which is encrustations of burned organic residue in places, mostly along the top of the rim area, presumably representative of foods cooked in the vessel.

Interior Surface: The surface is smooth with thin wiping striations inside the neck area and parallel to the rim (see Figure 8-57). Some sherds are covered with a film of calcium carbonate under which the surface is very dark gray (10YR 5/1) to black (10YR $2 / 1$ ). Tiny temper particles are visible on the interior surface of a few sherds.

Paste: Macroscopically, the clay body can be seen to contain quartz sand of various sizes, as well as infrequent carbonate chunks. The core is generally

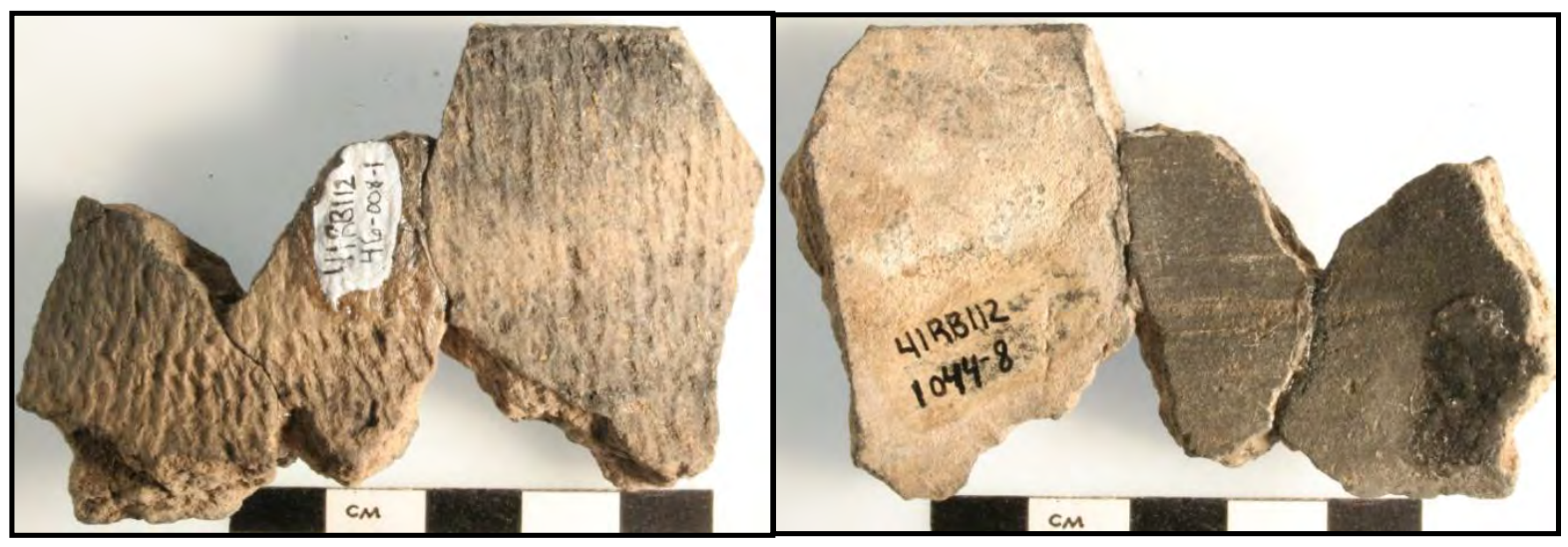

Figure 8-56. Vessel D rim and neck sherds refit, exterior (left) and interior (right). Scale in centimeters. 


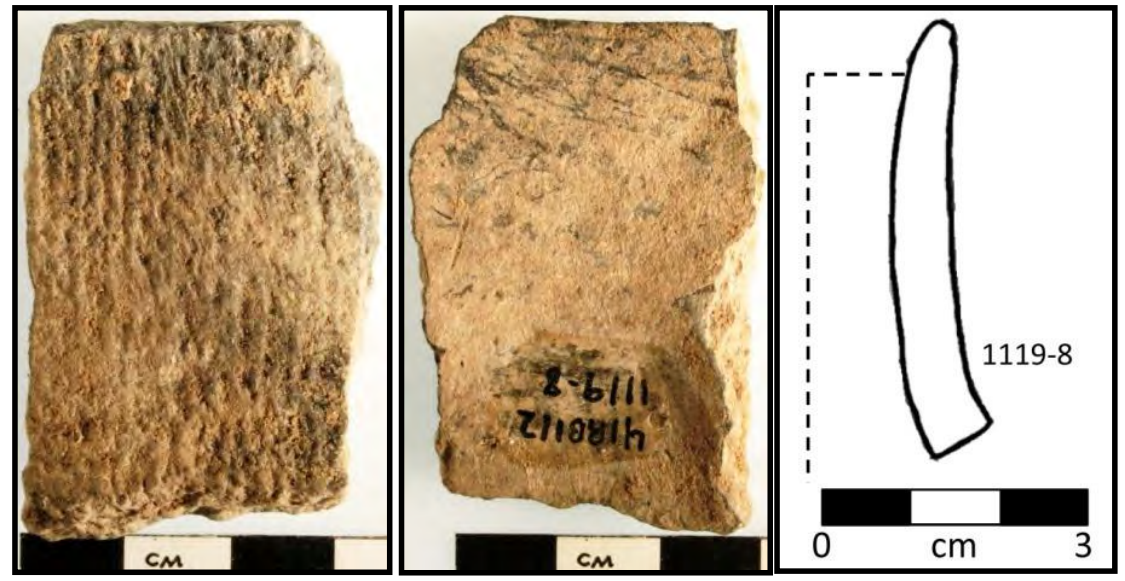

Figure 8-57. Detail of exterior (left) and interior (center) with rim profile (right) of Vessel D rim sherd (\#1119-8).

Scale in centimeters.

very dark gray (10YR 3/1) in color, and a thin black band is present along the interior edges of sherd profiles. Petrographic analysis on part of rim sherd \#1119-8-1 revealed a medium brown, isotopic paste with few voids, with 12 to 17 percent particles that includes 7 to 10 percent common quartz, 2 to 3 percent iron opaques, 1 to 2 percent composite quartz, 1 to 2 percent plagioclase, 1 percent orthoclase, and traces of limestone and caliche (Appendix F). This sherd was assigned to the broad crushed rock and mineral temper class and assigned specifically to Paste Group A. Sherds from Vessel E are also assigned to Paste Group A.

Starch Grain Analysis: One sherd (\#1044-8-1) was analyzed and yielded two little barley (Hordeum pusillum) grains, a little barley grain altered by grinding, and a cheno-am grain (Appendix D).

INAA: Part of rim sherd \#1119-8-1 (TRC558) was sent for analysis and was assigned to Chemical Group 2 along with most of the other sherds from this component (Appendix G).

Horizontal Distribution: The few sherds in this group were widely scattered across the excavations and horizontally distributed between 10 and 50 cmbs. Two sherds came from the southern block and the rest are from the northern block of Area A around heating elements (see Figure 8-53). The three joined sherds were estimated to have been $7 \mathrm{~m}$ apart, which cannot be accounted for by the blading of the fireguard, and probably reflects dispersal by prehistoric human activity.

\subsubsection{Vessel E}

This vessel group consists of 32 sherds with a total weight of $54.8 \mathrm{~g}$. The group includes 18 body, 11 rims, and 3 neck sherds (Figures 8-58 and 8-59). The largest piece is about 3.5-cm-long, and most sherds are less than $2 \mathrm{~cm}$ in length. Three neck sherds (\#1224-8) and one rim sherd (\#1223-8) fit together to form an 8-cm-long section of the upper part of the vessel. This vessel had a cordmarked exterior, and cordmarks orientated nearly vertically and extend to the lip (Figure 8-59).

Shape: These sherds probably represent a jar with a nearly vertical rim, a flat partially decorated lip and a slightly constricted neck (see Figure 8-58). The overall dimensions are unknown. The lip is undecorated for the most part. However, the lip of rim sherd \#1031-8-1 has two shallow cone-shaped impressions parallel to the rim. The impressions could have been made with a small grass stem pressed into the wet clay at an angle with the broken end pressed the deepest, whereas the opposite end of the impression shows the narrow tapered stem from the angled entry. The lip is generally the thinnest 


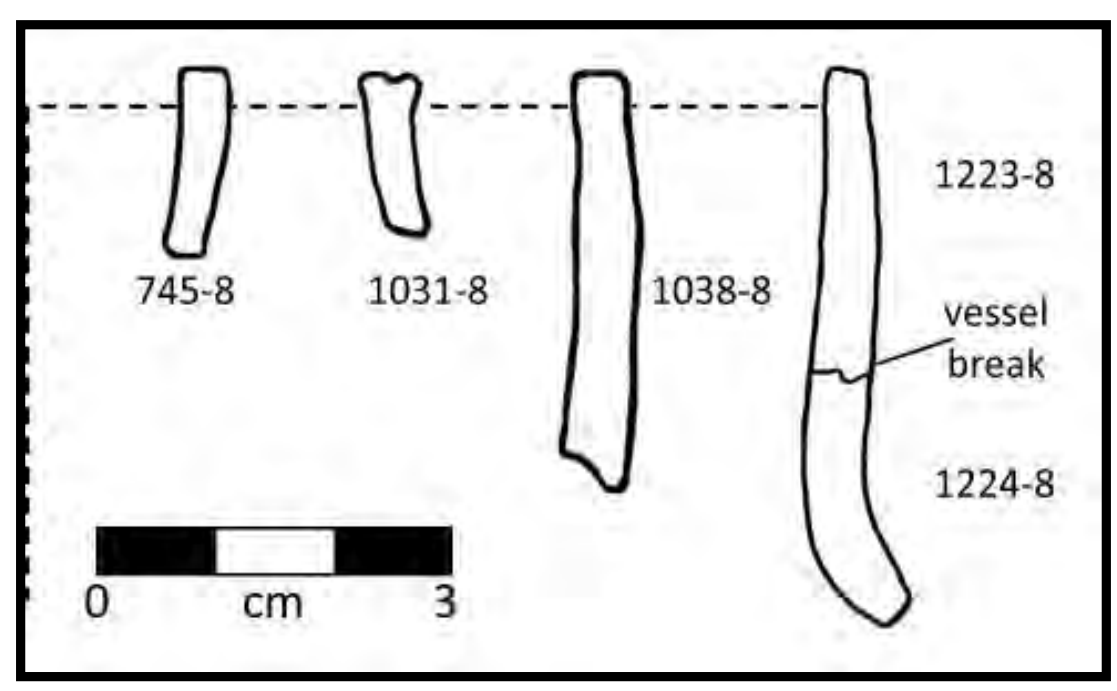

Figure 8-58. Profiles of rim sherds assigned to Vessel E.

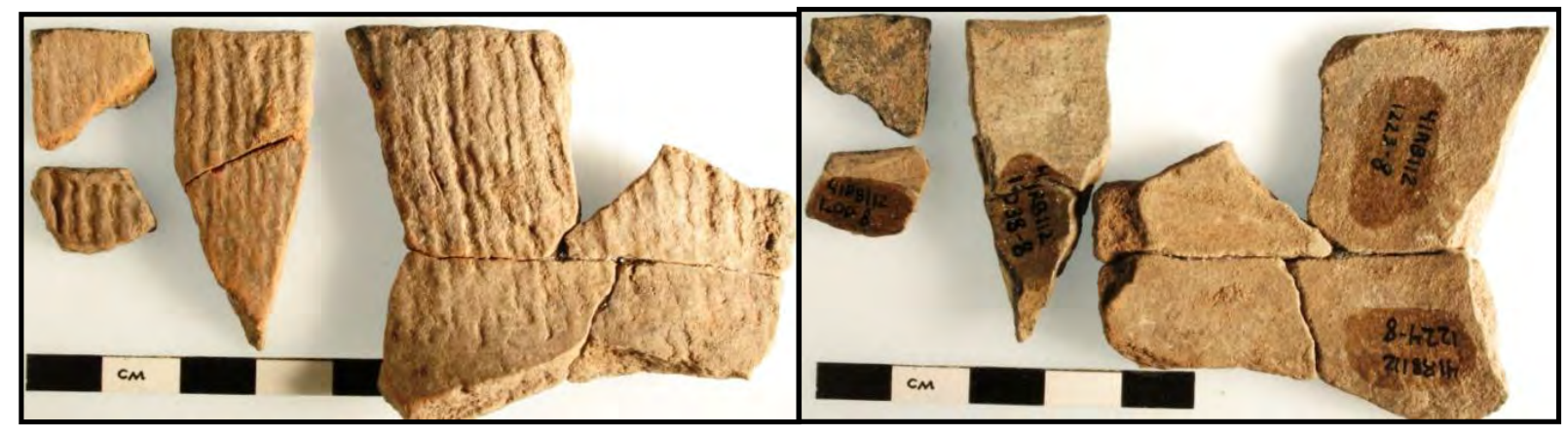

Figure 8-59. Vessel E rim and neck sherds, exterior (left) and interior (right). Scale in centimeters.

part of the vessel, measuring 3.5- to 5.3-mm-thick. The vessel wall thickens to 3.6 to $4.5 \mathrm{~mm}$ in the sub-lip rim area with thicknesses varying around the vessel. The neck portion is thicker still, measuring between 6.2 to $6.4 \mathrm{~mm}$, whereas the body sherds vary in thickness between 3.5 and $6.8 \mathrm{~mm}$. The rim height is about $47 \mathrm{~mm}$ from the top of the neck to the top of the lip. No basal sherds were identified. Based on roughly 20 percent of the neck region the inside diameter of the neck is projected to be about 12- to 13-cm-wide. The neck/shoulder angle is roughly 160 to 165 degrees and the cordmarks are nearly obliterated by smoothing over in this area.

Construction: The lip appears flattened while wet, as there is a slight bulge of clay is just beneath the lip (Figure 8-59). This flattening was done after the cord impressions were in place. Faint striations from smoothing are present inside the rim and above the neck (\#1223-8, \#1224-8 and \#1038-8). Rim sherd $\# 1038-8$ is split horizontally, indicating a platy structure.

Exterior Surface: The cordmarks vary from welldefined to partially obliterated even in the same area of the vessel, near the rim (Figure 8-59). The marks are narrow and shallow, and are nearly obliterated in the neck region. The exterior is dark gray (7.5YR 4/0) on \#1200-8, but most other sherds are lighter in color and are covered with a film of calcium carbonate.

Interior Surface: The surface is smooth and wellfinished, with faint striations on the rim (Figure 8-57). Most sherds are coated with a thin film of 
calcium carbonate, but tiny sand particles were observed in some places. The interior is very dark gray (2.5YR 3/0) on \#1200-8-1, whereas some are reddish yellow (5YR 6/6) due to the presence of calcium carbonate.

Paste: Macroscopically visible fine sand grains were observed along with some tiny black spots that may be burned bone fragments. The core of rim \#1224-8 is two-tone with a light gray (10YR 7/1) band towards the interior and a reddish yellow (7.5YR 6/6) band towards the exterior surface. Petrographic analysis on part of rim sherd \#1223-8-1 revealed a massive dense, isotopic paste with 10 about 1 percent voids, 10 to 18 percent particles that includes 5 to 7 percent common quartz, 1 to 3 percent composite quartz, 1 to 3 percent orthoclase, 1 to 2 percent plagioclase, and 1 percent muscovite, 1 to 2 percent limestone, and a trace of iron opaques (Appendix F). Based on paste color and isotropy this sherd was within a broad crushed rock and mineral temper class and specifically assigned to Paste Group A. The sherd from Vessel D is also assigned to Paste Group A, which has similar amounts of particles.

INAA: Two body sherds (\#973-8 = TRC654 and $\# 1223-8$ = TRC559) were subjected to chemical analysis. Both yielded similar chemistry and are assigned to Chemical Group 2, as are most sherds from this component (Appendix G).
Horizontal Distribution: Most sherds assigned to Vessel E were between 10 and $40 \mathrm{cmbs}$ in six units around the clustered features. Some sherds were found towards the northern margin of the north block, with single sherds widely scattered across the southern end of the block (see Figure 8-53). However, a couple of tiny rim and body sherds were found in two separate units in the southern block of Area A, away from any identified features.

\subsubsection{Vessel F}

This vessel is represented by nine body sherds (47.2 g) that were found together in N695 E511 between 20 and 25 cmbs. In the laboratory, the sherds were refit to form a section of the vessel body $8-\mathrm{cm}$ across (Figure 8-60). This section has well-defined to partially smoothed cordmarkings on the exterior.

Shape: The 8-cm-wide conjoined section of the body reveals a vessel with a projected width of roughly 21 to $25 \mathrm{~cm}$ in diameter.

Construction: This section was set apart from all other sherds and vessels because of irregularities and unevenness of the interior surface, but it may represent an unusually varied portion of one of the other identified vessels. The unevenness appears the result of finger tip impressions that may indicate that the vessel was hand-molded into shape (see Figure 8-60). Alternatively, fingers may have supported the

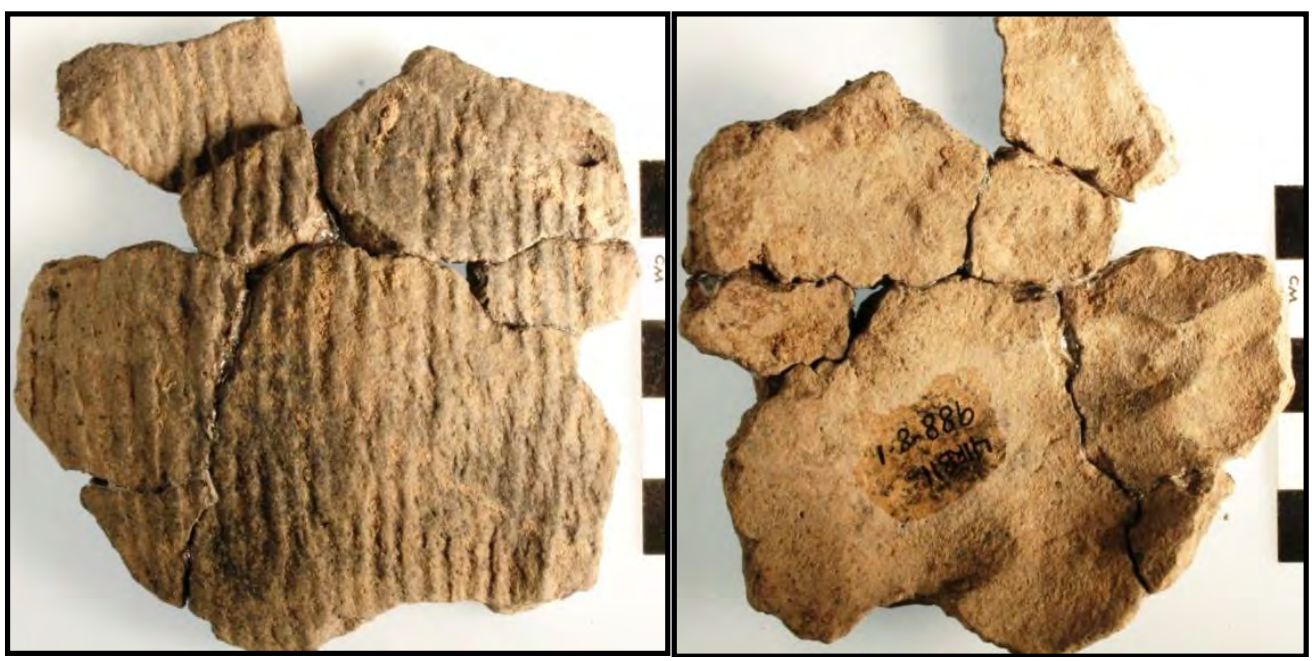

Figure 8-60. Vessel F conjoined body sherds (\#998-8-1), exterior (left) and interior (right). Scale in centimeters. 
vessel wall during the application of the cordmarking on the exterior. The unevenness results in variability of thickness, which ranges between 3.4 and $7.2 \mathrm{~mm}$.

Exterior Surface: Well-defined and relatively broad and deep cordmarkings cover the exterior surfaces (see Figure 8-60). However, towards the margin of the refit section, one sherd bears partially smoothed cordmarks. One sherd reveals a 1.4-mm-deep, smooth, ovate depression that is 4.6-mm-wide that may be an impression of a seed or large, rounded sand grain. The exterior is very dark gray (10YR 3/1).

Interior Surface: The very bumpy, uneven or irregular surface is thought to be created by finger impressions (see Figure 8-60). The color is dark gray (10YR 4/0), but is mostly covered with a calcium carbonate film.

Paste: Macroscopically, the temper can be seen to include various sizes of quartz sand as well as other particles of unidentified material. The core is dark gray (10YR 4/0). Petrographic analysis on part of sherd \#998-8-1 revealed a crushed rock and mineral temper class with a dark brown, dense, isotropic paste, with 5 to 7 percent voids, 21 to 32 percent particles that include 7 to 10 percent common quartz, 5 to 7 percent resident quartz, 3 to 5 percent composite quartz, 3 to 5 percent microcline, and minor amounts of other minerals. This sherd was assigned to Paste Group C (Appendix F). Sherds from Vessels H, G, and I are also assigned to Paste Group C and they all have similar quantities of identified particles.

INAA: Sherd (\#988-8-1 = TRC560) was analyzed for its chemical composition and yielded a signature that fit with Chemical Group 2. This same group into which fall most other sherds from this component (Appendix D).

Horizontal Distribution: This small group of sherds came from 20 to 25 cmbs in N495 E511, less than 1 $\mathrm{m}$ south of two heating elements, Features 9 and 11 (see Figure 8-53).

\subsubsection{Vessel G}

This vessel consists of one large, nearly 6-cm-long rim sherd (\#1066-8-1) from N697 E514 that displays a cordmarked exterior and a smooth interior (Figure 8-61).

Shape: While the overall vessel shape and dimensions are unknown, it is apparent that it had a vertical rim (see Figure 8-61). Projecting from this single sherd, which represents roughly 7 percent of the vessel rim, the orifice was about $25 \mathrm{~cm}$ in diameter.

Construction: The irregular fractures reveal no sign of coils on the broken edges. The rim is direct and vertical with no sign of a neck. The lip is narrow with thickness ranging from 4.7 to $5.1 \mathrm{~mm}$ and is
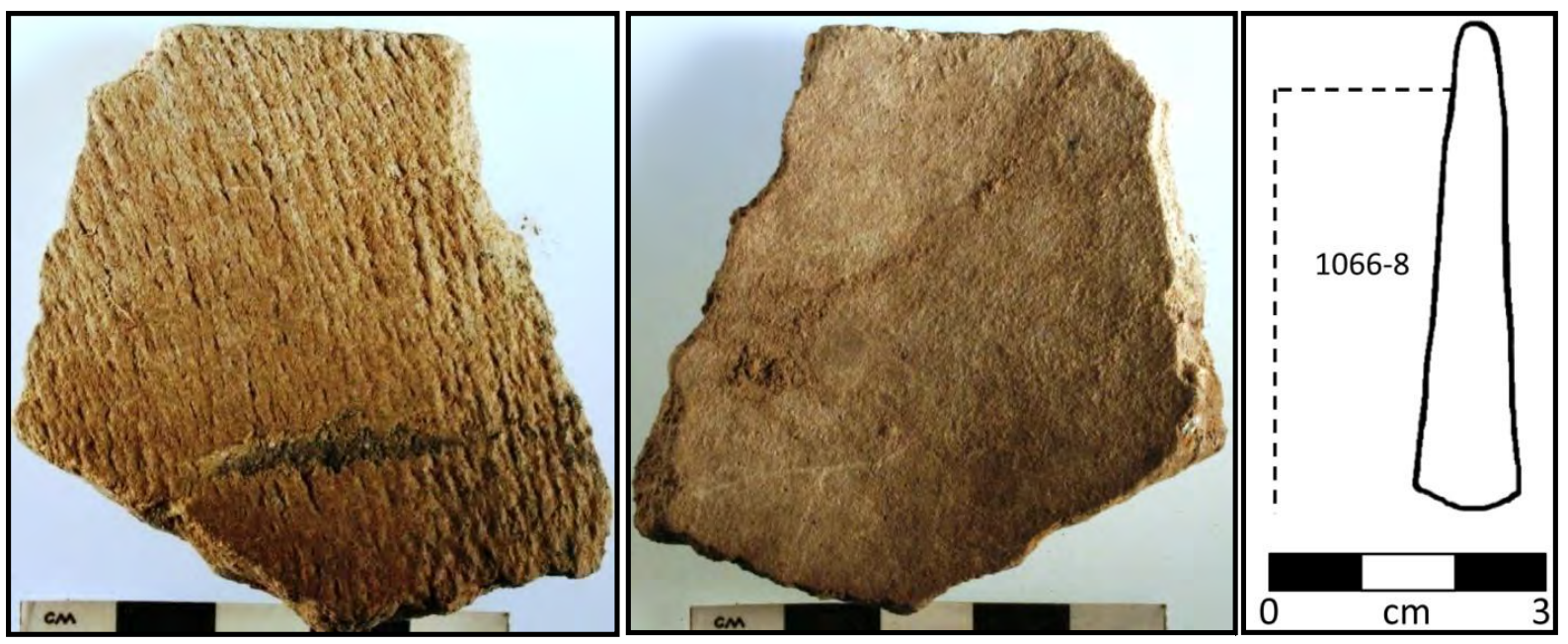

Figure 8-61. Vessel G rim sherd (\#1066-8-1), exterior (left), interior (center) and profile (right). Scale in centimeters. 
decorated with cordwrapped tool in a diagonal pattern (Figure 8-62). The rim thickens from the lip towards the main body, with the point furthest from the lip measuring $10.8 \mathrm{~mm}$.

Exterior Surface: The cordmarkings are narrow, shallow, and at a slight angle from vertical (see Figure 8-61). The surface is light gray (2.5Y 7/2) and bears a faint calcium carbonate film.

Interior Surface: Smooth with no visible pits, cracks or other imperfections, although the presence of calcium carbonate may obscure detail (see Figure 8-61). The surface is light yellow (10YR 6/4), due to the film of calcium carbonate.

Paste: Abundant rounded quartz sand grains, up to $2.3 \mathrm{~mm}$ in diameter are macroscopically visible. The core is dark gray (7.5YR 4/6), and there is a thin brown (2.5Y 5/0) band toward both the interior and exterior margins. Petrographic analysis on part of rim sherd \#1066-8-1 revealed a crushed rock and mineral temper class. Specifically it consists of moderate dense, isotropic paste with 15 to 20 percent voids, 22 to 38 percent particles that includes 5 to 10 percent common quartz, 5 to 7 percent composite quartz, 3 to 5 percent microcline, 3 to 5 percent Rocks $\mathrm{A}$ and 3 to 5 percent Rock $\mathrm{C}$ and other minor minerals. It was assigned to Paste Group $C$ (Appendix F). Sherds from Vessels F, H, and I are also assigned to this same paste group.

INAA: A portion of this rim was chemically analyzed (TRC561) and determined similar to most other sherds from this component and assigned to
Chemical Group 2 (Appendix G).

Horizontal Distribution: This rim sherd came from 19 cmbs in N699 E514, less than $1 \mathrm{~m}$ south of a heating element, Feature 4 (see Figure 8-53).

\subsubsection{Vessel H}

This vessel consists of two sherds (27.8 g) that fit together to form one rim sherd (Figure 8-63). The exterior surface is cordmarked.

Shape: The rim is over 50 -mm-tall with no sign of an inflection point (see Figure 8-63). The lack of sherds from other parts of the vessel prevents insight into the overall vessel shape and dimensions.

Construction: The broken edges reveal no sign of concave or convex edges that would indicate coil construction. The lip is rounded, undecorated and relatively narrow, with a width of $4.4 \mathrm{~mm}$ (see Figure 8-63). At least one small weathered irregularity along the lip may have been occurred during use. The rim section thickens below the lip to form a wedge-shaped cross section with a maximum thickness of $11.1 \mathrm{~mm}$ (see Figure 8-63). In cross section, the sherd core has two colors, a very dark gray (2.5YR 3/0) and light yellow brown (10YR 6/4) color. An abundance of temper comprised of fine to medium/coarse, rounded sand grains was visible along the edges.

Exterior Surface: The exterior is cordmarked with narrow impressions that extend to the lip (see Figure 8-63). The impressions run vertically and are partially obliterated in places, but otherwise

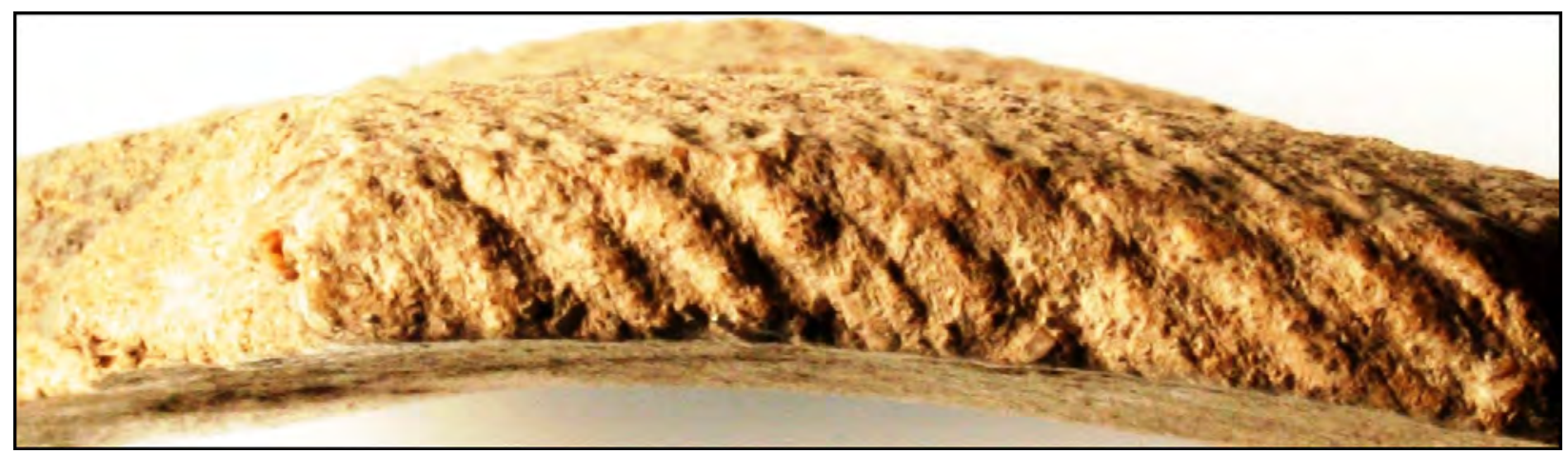

Figure 8-62. Detail of diagonal impressions on decorated lip (\#1066-8-1) of Vessel G. 


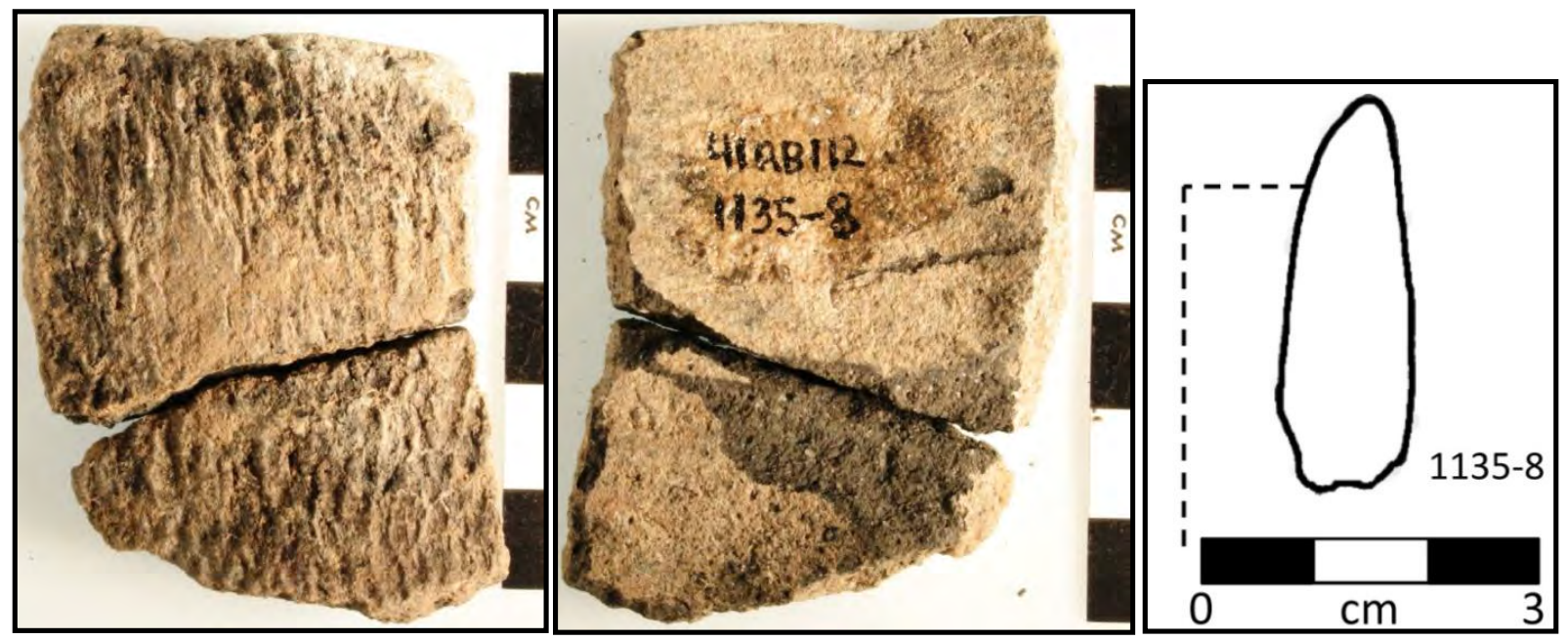

Figure 8-63. Vessel H rim and body sherd (\#1135-8-1), exterior (left), interior (center), and profile (right).

Scale in centimeters.

well-defined. Crusted dark organic residues are present on the surface. No decorations are on these two sherds, which have very dark gray $(2.5 \mathrm{Y} 3 / 0)$ exterior surfaces.

Interior Surface: The surface is smooth and covered with a calcium carbonate (see Figure 8-63). At the rim/lip juncture the inside is slightly beveled, creating a relatively thin lip. Thin striations are visible in the upper rim area. The interior surface bears a film of calcium carbonate.

Paste: Rounded sand is the primary macroscopic temper, with clear and opaque grains that vary in size from fine to medium in a mostly very dark gray core $(2.5 \mathrm{YR} 3 / 0)$. Petrographic analysis was conducted on part of rim sherd \#1135-8-1 and revealed a crushed rock and mineral temper in a dense, isotropic paste, with 5 to 7 percent voids, 27 to 43 percent particles that includes 7 to 10 percent common quartz, 5 to 7 percent resident quartz, 3 to 5 percent composite quartz, 3 to 5 percent microcline, 3 to 5 percent Rock C, 1 to 2 percent Rock A fragments, minor other minerals. This is the second high frequency of particles in vessels from this component. It was assigned to Paste Group C (Appendix F). Sherds of Vessels F, G, and I are also assigned to Paste Group C.
Starch Grain Analysis: The rim section was subjected to starch grain analysis, but no starches were found (Appendix D).

INAA: A fragment (\#1135-81 = TRC562) was chemically analyzed and determined to have a chemistry similar to most sherds from this component, assignable to Chemical Group 2 (Appendix G).

Horizontal Distribution: The two sherds in this group were found above the floor of the southern part of the pithouse Feature 1, in N699 E515 between 30 and $40 \mathrm{cmbs}$ (see Figure 8-53).

\subsubsection{Vessel I}

This vessel is comprised of 13 body sherds (58.9 g), which exhibit overlapping groups of cordmarks that are oriented in different directions on the same sherd (Figure 8-64). It is quite possible and even likely that these sherds represent two or more vessels, but based on their similar exterior markings were assigned to one group. These markings may represent the lower parts of vessels where it was difficult to maintain vertical orientations of the cord impressions. A single sherd (\#1036-8-1) was selected for INAA and petrographic analyses. 


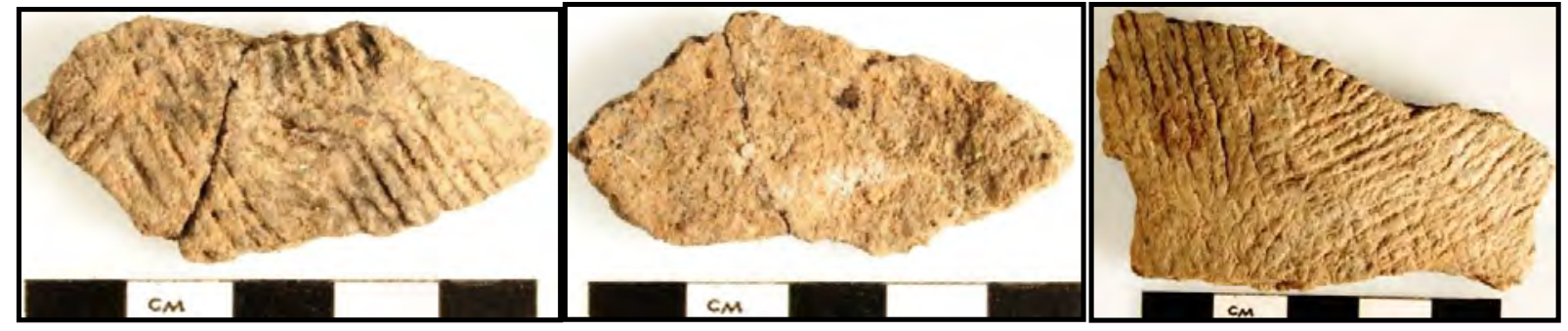

Figure 8-64. Photographs of Vessel I body sherd \#1036-8-1, exterior (left) and interior (center) and \#1072-8-1 (right).

Scale in centimeters.

Shape: Because only small body sherds are represented, neither shape nor dimensions of the vessel(s) can be determined.

Construction: No obvious concave or convex edges were observed to indicate coiling, and no other indications are present to indicate the construction technique. These sherds lack any type of decorations or appendages. However, if these are parts of the lower vessel body then these areas are the least likely to exhibit decorations, but leg appendages are possible on lower body. These body sherds reveal considerable variation in thickness with sherd \#7058 measuring 2.7 to $3.4 \mathrm{~mm}$, and sherd \#1072-8 measuring 4.1- to 6.1-mm-thick.

Exterior Surface: The exteriors are cordmarked, with different orientations to the impressions (see Figure 8-64). The impressions vary from welldefined (\#705-8, \#707-8, \#735-8, and \#1072-8) to partially obliterated (\#1091-8). Most exteriors are lightly coated with calcium carbonate that masks the original surface colors.

Interior Surface: Three sherds exhibit smooth interior surfaces (\#705-8, \#707-8 and \#735-8), whereas three others have bumpy or rough surfaces (\#1036-8-2,\#1072-8 and \#1091-8; see Figure 8-64). This type of variability may indicate multiple vessels are represented in this group. Most interiors are also lightly coated with calcium carbonate. Interior surface color is light brown (7.5YR 6/4).

Paste: The colors of the cores vary from reddish yellow (7.5YR 6/6) (\#735-8 and \#1036-8-1), to a gray and light brown (7.5YR 6/4) on others (\#707-8 and \#1091). Most have a reddish yellow (7.5YR 6/6) core. Macroscopically, fine sand is the dominant tempering agent. Petrographic analysis on part of body sherd \#1036-8-1 revealed a general crushed rock and mineral temper class. It revealed a dense, isotropic paste with 5 to 7 percent voids, 28 to 48 percent particles that includes 7 to 10 percent common quartz, 5 to 10 percent resident quartz, 3 to 5 percent composite quartz, 3 to 5 percent microcline, 3 to 5 percent Rock C, 1 to 2 percent Rock A, and minor amounts of other minerals. This sherd reflects the highest percentage of particles compared to any other vessels here with 13 particle types identified. This sherd was assigned to the broad crushed rock and mineral class and specifically to Paste Group C (Appendix F). Sherds of Vessels F, G, and H are also assigned to this same paste group (Appendix F). If the markings on this sherd represent the lower part of a vessel as suspected, then it would appear more particles were included in the lower part of the vessel. This may or may not have been a conscious decision by the maker.

INAA: Part of body sherd \#1036-8-1 (TRC563) was sent for chemical analysis and the results indicate that it belongs to Chemical Group 2, as do most other vessels in this component (Appendix G).

Horizontal Distribution: These six pieces were 10 to $50 \mathrm{cmbs}$ in six widely distributed units. At least two sherds were near the clustered heating elements in the northern block and three were near the southernmost end of the southern block of Area A (see Figure 8-53). 


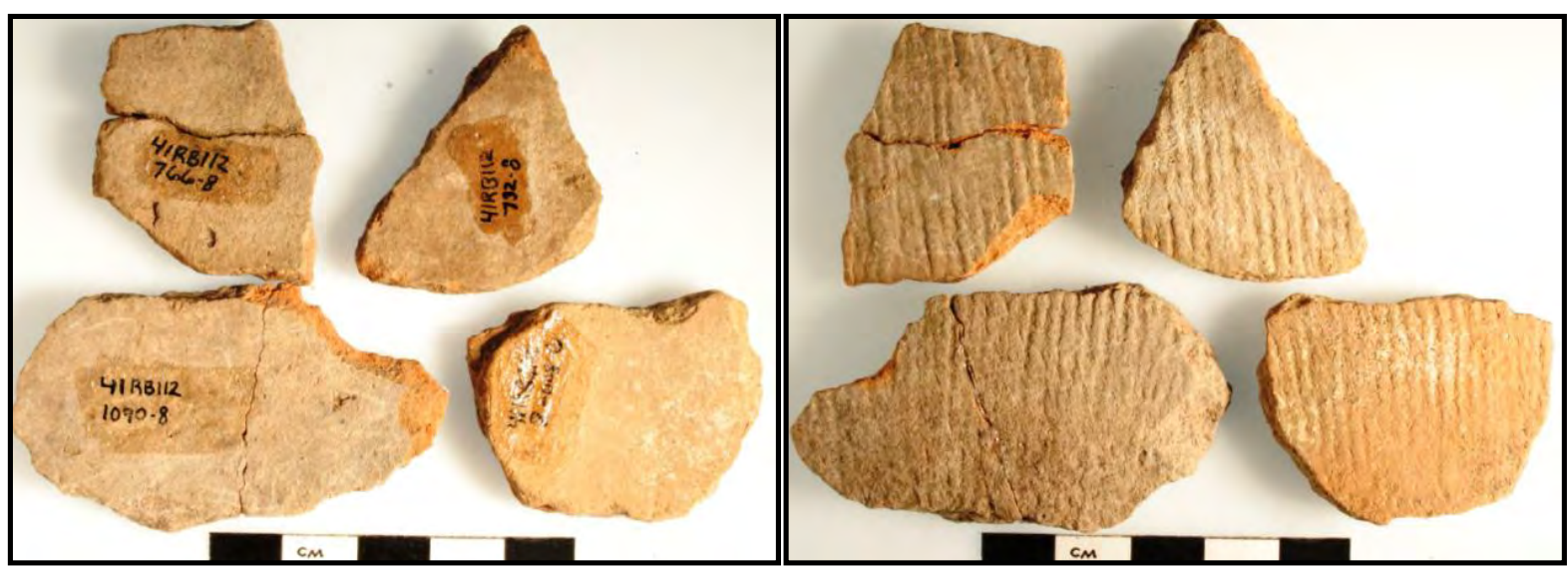

Figure 8-65. Vessel J body sherds, interior (left) and exterior (right).

Scale in centimeters.

\subsubsection{Vessel J}

This vessel group consists of 13 body sherds that weigh a total of $53.7 \mathrm{~g}$. These are smoothedover cordmarked sherds with faint, shallow cord impressions (Figure 8-65). The sherds are light weight and comparatively softer than other sherds as they crumble easily.

Shape: Because these are all body sherds, it is not possible to determine the overall vessel shape and dimensions.

Construction: The sherds are relatively soft and most breaks are irregular to angular with no indications of coil breaks. The construction technique is unknown. These body sherds reveal a range in thickness from 3.5 to $6.5 \mathrm{~mm}$. Three pieces exhibit a slight curve implying they represent a large bodied vessel.

Exterior Surface: The cordmarks are smoothed over, narrow, faint and shallow, with no visible overlap in the impressions (see Figure 8-65). The surface bears some calcium carbonate but generally is light brownish gray (10YR 6/2) in color.

Interior Surface: The surface is smooth with a few scattered pits or imperfections (see Figure 8-65). A couple of pieces have small, shallow concave depressions that resemble fingertip impressions. One sherd has fine lines likely created by wiping. Most surfaces are light gray (10YR 7/2) in color.
Paste: Macroscopically fine sand is the dominant temper. The core is two-tone, with reddish yellow (5YR 6/6) toward interior and very pale brown (10YR 7/4) toward exterior. Petrographic analysis on sherd \#2-8-6 revealed a crushed rock and mineral temper class. It consists of a dense, anisotropic paste with 15 percent voids, 11 to 21 percent particles that includes 3 to 5 percent common quartz, 3 to 5 percent orthoclase, and small percentages of other minor minerals. This sherd was assigned to the broad crushed rock and mineral class, and to Paste Group B (Appendix F). Sherds of Vessels A and B are also assigned to this same paste groups and have very similar frequencies of particles in the paste (Appendix F).

INAA: Sherd \#2-8-6 (TRC564) was subjected to chemical analysis and the results are interpreted to indicate that the sherd belongs in Chemical Group 2, as do most sherds from this component (Appendix $\mathrm{G).}$

Horizontal Distribution: These 13 sherds were widely scattered across the entire 38-m-long excavation area from N667 to N705 (see Figure 8-53). At least four (31 percent) sherds were towards the southern end of the southern block of Area A.

\subsubsection{Vessel K}

This vessel consists of three tiny sherds (\#912-82, \#1019-8-1 and \#1086-8-1) with a total weight of $9.8 \mathrm{~g}$. The largest piece is less than 3-cm-long 
(Figure 8-66). These are fragments of a collared rim (possibly a thickened-lip) with a pinched collar base. The limited sections below the collar (\#10868-1) show faint, shallow cordmarks.

Shape: These small pieces are inadequate for determining the overall shape or dimensions of the original vessel.

Construction: It is not possible to discuss the overall technique used to build this vessel. The thick collar appears to have been created by folding over the upper section towards the exterior, and then pinched along the base of the collar to create nodes that protrude outward (see Figure 8-66). The nodes are 12.2-mm-wide. The lip is broad and measures 11.0to $11.2-\mathrm{mm}$-wide and slopes/angles down to the pinched area.

Exterior Surface: Sherd \#1086-8-1 is the only fragment with part of the vessel body, which bears shallow cordmarks (see Figure 8-66). The upper rim section measures 5.8-mm-thick. The surface is very dark gray (10YR 3/1) to dark gray (10YR 4/1).

Interior Surface: Sand grains are visible on the surface. The surface is covered with calcium carbonate and is light yellow gray (10YR 6/4) to light gray (10YR 7/2).

Paste: An abundance of rounded quartz sand grains are visible, and at least one fleck of mica is discernible. No petrographic studies were undertaken on these sherds. The core is two-tone with a thin, light yellowish brown (10YR 6/4) zone on the interior edge with a thicker reddish yellow (7.5YR 6/6) zone towards the exterior edge. No petrography was conducted on this vessel.

Horizontal Distribution: The three sherds were from three separate units in the northern block, with one from Feature 13, one from more than $5 \mathrm{~m}$ south of Feature 13, and one $3 \mathrm{~m}$ to the north between Features 8 and 10 (see Figure 8-53).

\subsubsection{Vessel L}

This vessel consists of three rim sherds (\#10538, \#1113-8 and \#1117-8) that have smooth, plain exterior and interior surfaces (Figure 8-67). These pieces weigh a total of $11.5 \mathrm{~g}$.

Shape: The vessel dimensions and overall shape are indeterminate, except that the rim was vertical (see Figure 8-67).

Construction: No coil breaks are present and the rims are slightly wedge-shaped with a narrow lip and a rim section that thickens toward the body. The lip varies from 3.5- to 4.5-mm-thick, and the rim varies from 4.3 - to $6.7-\mathrm{mm}$-thick. The lip is flat to slightly rounded, and exterior slanted in one place (see Figure 8-67). The lip is not decorated. The rim is direct and straight with no curvature of a neck or other aspects to the vessel.

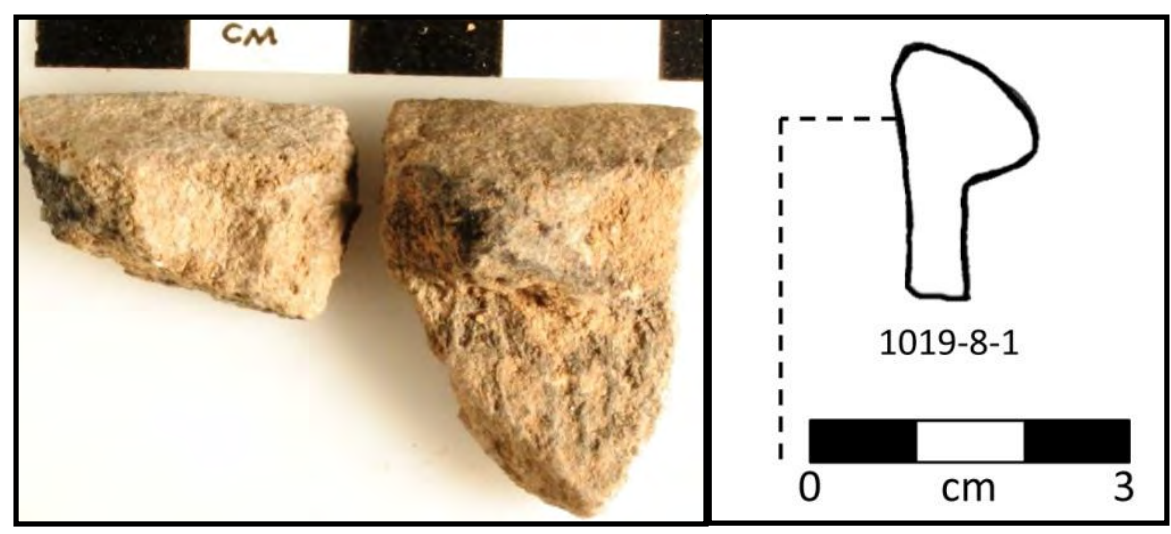

Figure 8-66. Photograph and profile drawing of Vessel K rim sherds (\#1086-8-1 and \#10198-1) showing thick, pinched collar, and slanted lip. Scale in centimeters. 


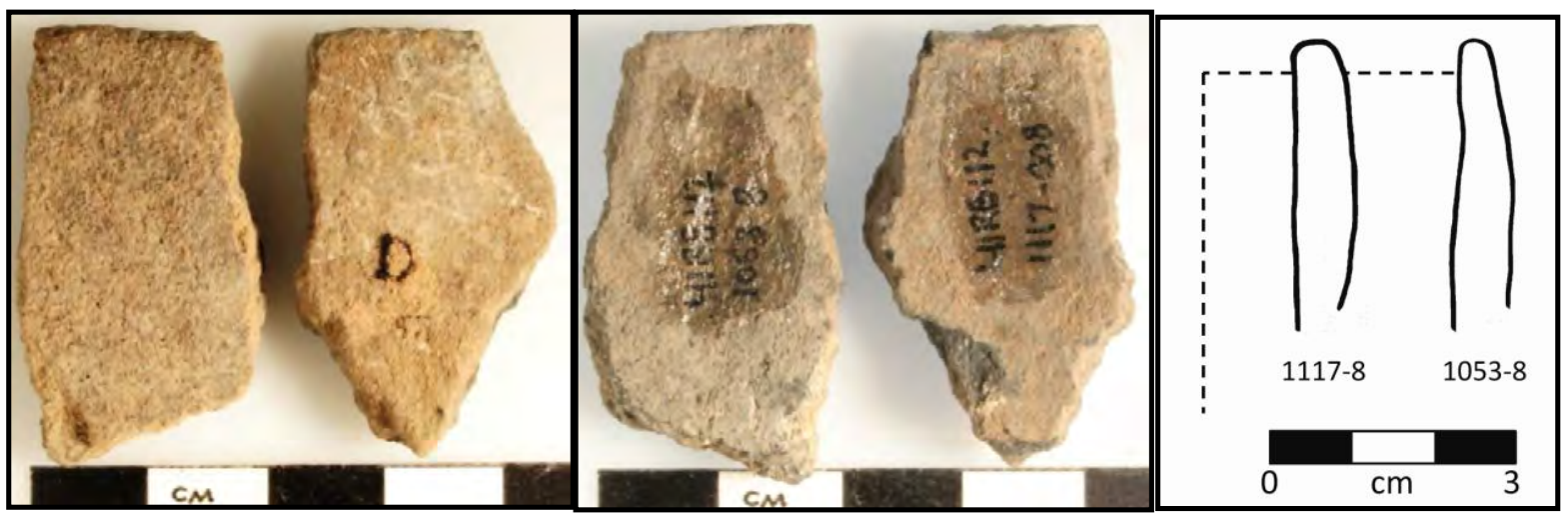

Figure 8-67. Vessel L rim sherds (\#1058-8 and \#1117-8) showing exterior (left), interior (center), and profile (right).

Scale in centimeters.

Exterior Surface: The surface is smooth and plain with no irregularities (see Figure 8-67). The exterior is grayish brown (10YR 5/2) and covered with calcium carbonate that obscures the original surface.

Interior Surface: The surface is smooth with a few tiny cracks and irregular divots visible under the calcium carbonate film (see Figure 8-67). Sand grains are visible on the surface in some places. The interior surface is grayish brown (10YR 5/2) in color.

Paste: Macroscopically, abundant rounded quartz sand grains are the most visible temper. An occasional piece of calcium carbonate is also present. The core is very dark gray (2.5 Y 3/0).

Horizontal Distribution: These three rims were found 30 and $60 \mathrm{cmbs}$ in two units adjacent to heating elements, Features 8 and 10, and generally in the same area as most sherds of the other identified vessels (see Figure 8-53).

\subsubsection{Vessel M}

This vessel consists of two rim pieces that refit and a tiny body sherd that weighs $18.3 \mathrm{~g}$. The rim section (\#1047-8-1) is less than 30-mm-tall, with a narrow and shallowly cordmarked exterior and smooth interior (Figure 8-68).

Shape: This two sherds are too small to allow for determination of vessel dimensions or overall shape.
Construction: It is unclear what technique was used to construct this vessel, as there are no discernible coil breaks or other indicators of how the vessel was constructed. The slightly thickened lip is 6.0- to $6.2-\mathrm{mm}$-thick and the sub-lip rim section is 5.1- to 5.7-mm-thick (see Figure 8-68). The lip thickening may have resulted from downward pressure when decoration was applied to the lip.

Exterior Surface: The cordmarks are shallow, narrow and extend to the lip (see Figure 8-68). Cordmarks appear on top of the lip but they are not distinct and it is not clear if they are continuous from the exterior surface or were applied separately (see Figure 8-68). The exterior surface is black (10YR 2/1).

Interior Surface: The interior is light brownish gray (10YR 6/2) covered with a film of calcium carbonate that hinders identification of the true underlying surface color. The surface is smooth and lacks any visible markings except a few tiny pits in the clay and the occasional sand grain.

Paste: The color is very pale brown (10YR 7/3) with the paste containing an abundance of fine to medium sand particles. No petrographic analysis was conducted.

Starch Grain Analysis: The entire left sherd was subjected to starch grain analysis. It yielded six lenticular little barley (Hordeum pusillum) grains plus two possible lily grains (Appendix D). 


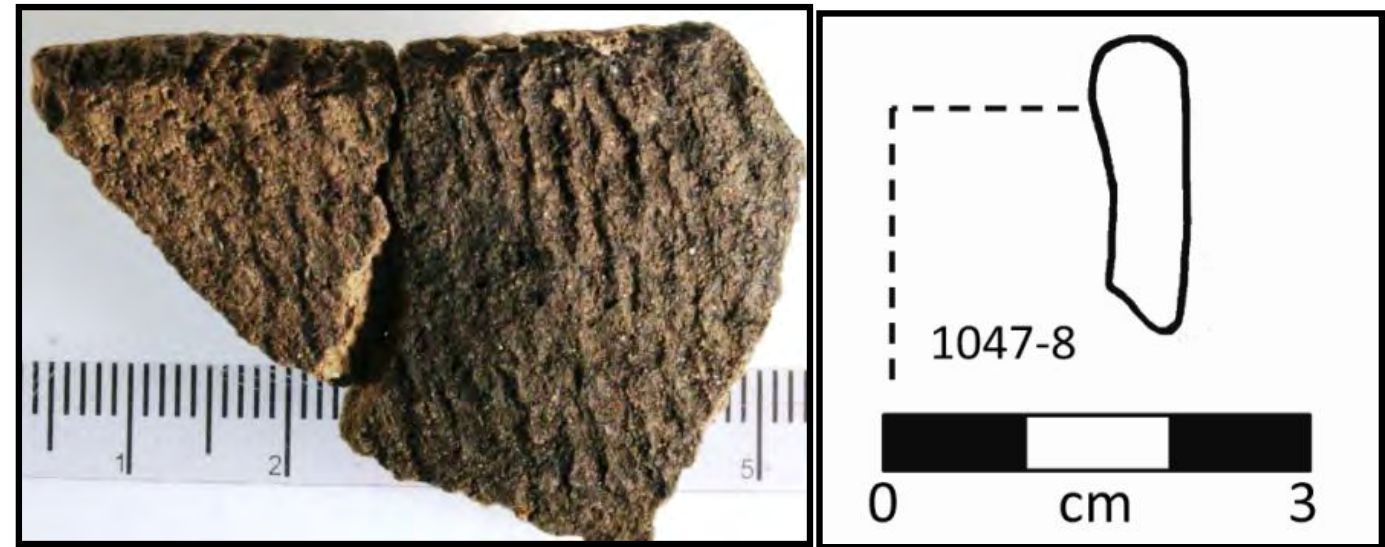

Figure 8-68. Exterior of Vessel M rim sherds (\#1047-8-1 and \#1044-8-1) showing cordmarked lip (left) and rim profile (right).

The left piece was sent for radiocarbon dating as was the organic residue scraped from its exterior. Left scale in millimeters.

INAA: No chemical analysis was conducted on this sherd.

Radiocarbon Dating: A 2.7-gram section of rim sherd (\#1047-8-1a) from 40 to 50 cmbs in N696 E514 was sent for radiocarbon dating. This sherd yielded a $\delta^{13} \mathrm{C}(-20.4 \%$ ) corrected AMS, uncalibrated date of $1190 \pm 30$ B.P. (Beta-307385) or cal A.D. 730 to 940. This date is some 600 years older than the oldest AMS date on maize (590 \pm 25 B.P.; UGAMS-7839) and not acceptable for the true cultural age of this vessel. At present, it is not clear what is causing this unacceptable date. The $\delta^{13} \mathrm{C}$ value is indicative of a combination of $\mathrm{C}_{4}$ and $\mathrm{C}_{3}$ materials. Also AMS dated was burned organic residues scrapped from the exterior of rim sherd (\#1021-8-1b). This residue yielded a $\delta^{13} \mathrm{C}(-20.4 \%$ ) corrected AMS date of 460 \pm 30 B.P. (Beta-307384) or cal A.D. 1420 to 1450 . This organic residue date is statistically identical to the nine accepted AMS maize dates.

Horizontal Distribution: These rims were found 40 to $50 \mathrm{cmbs}$ in N696 E514, about $1 \mathrm{~m}$ north of the storage pit, Feature 13 (see Figure 8-53).

\subsubsection{Vessel $\mathbf{N}$}

This vessel is represented by one small painted sherd $(1.4 \mathrm{~g})$ that is a Rio Grande Glaze Ware (Figure 8-68). It was imported into this region.
Shape: The overall shape and dimensions of the vessel are unknown.

Construction: The technique used to produce this vessel cannot be determined from this 17.4-mmwide sherd. This body sherd varies from 5.1- to 5.6-mm-thick and has sharp angular broken edges. It has a very slight curvature.

Exterior Surface: The surface is nearly flat and is well-finished and shows parts of two dark painted lines that parallel each other. One of the lines is at least 7.0-mm-wide and traverses the entire sherd (see Figure 8-69). The unpainted space between the dark lines is 4.2-mm-wide. The lines are very dark gray $(7.5 \mathrm{YR} 3 / 0)$ with very pale brown (10YR 7/3) intervening surface color.

Interior Surface: The surface is flat, partially covered with calcium carbonate, and shows a few tiny sand grains.

Paste: Sand particles are the most abundant visible temper in the dense paste. The core is two-tone with light gray (2.5Y $7 / 0)$ towards the interior and a light brown (7.5YR 6/4) towards the exterior.

Horizontal Distribution: This sherd was from the disturbed surface of the fireguard across from the cluster of heating elements in the northern part of 


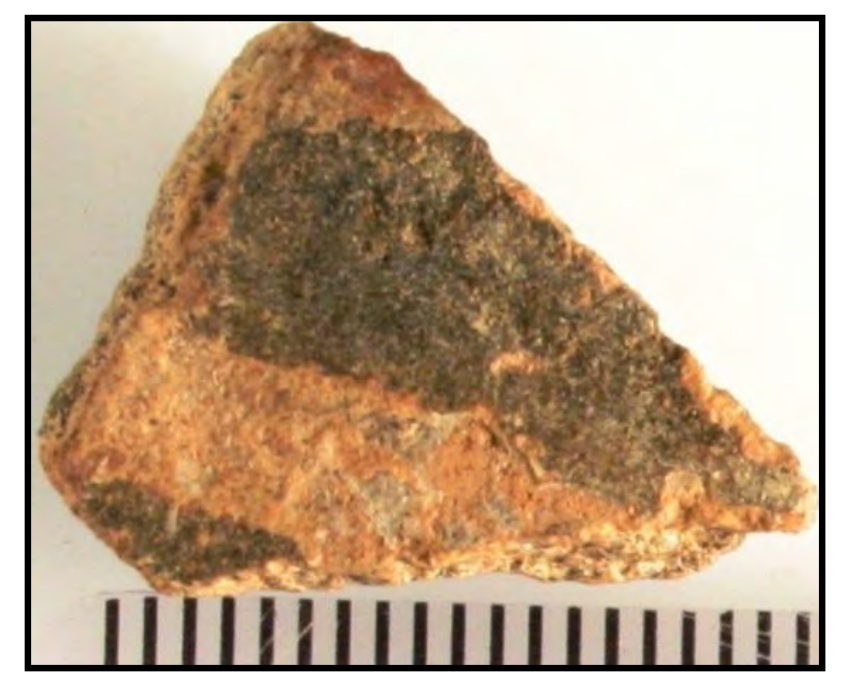

Figure 8-69. Vessel N painted sherd (\#12-8-1). Scale in millimeters.

the excavated area (see Figure 8-53). The fireguard surface was no more than 40 -cm-below the original ground surface.

\subsubsection{The Unassigned Sherd Assemblage}

The number of sherds not assigned to individual vessels is 1,107 and they weigh $1,659 \mathrm{~g}$ for an average weight of $1.5 \mathrm{~g}$. Seventy two percent of sherds are small, with diameters of less than $2 \mathrm{~cm}$. Sherd thickness is variable, ranging from 3.0 to 11.7 $\mathrm{mm}$ (\#972-8-1) with an average thickness of $5.8 \mathrm{~mm}$. Nearly all have cordmarked exteriors, some have cordmarkings partially obliterated by smoothing. Very few sherds are plain. The unassigned sherds are body sherds, with the exception of 15 tiny rim sherds and 7 neck sherds.

Radiocarbon Dating: A 4.7 gram piece of thin cordmarked body sherd (\#940-8-1a; Figure 8-70) from 30 to 40 cmbs in N692 E511 was sent for radiocarbon dating. This bulk sherd yielded a $\delta^{13} \mathrm{C}$ (-19.1\%) corrected AMS, uncalibrated date of 570 \pm 30 B.P. (Beta-307382) or cal A.D. 1330 to 1420. Burned organic residues scrapped from the exterior of this same body sherd (\#940-8-1b) and yielded a $\delta^{13} \mathrm{C}(-18.2 \%)$ corrected AMS date of $480 \pm 30$ B.P. (Beta-307383) or cal A.D. 1410 to 1450 . These two AMS dates barely overlap at the two sigma range with the organic date younger. Both dates are statistically within the range of the eight maize dates from this component and are thus accepted.

\subsubsection{Summary Discussion}

Only 162 sherds (12.8 percent of the total ceramic assemblage) were assigned to 14 vessel groups based primarily on differences in rim shapes and exterior surface finishes. These groups are comprised mostly of body sherds. Rim sherds are present in eight vessel groups, while three vessel groups contain obvious neck sherds $(N=15)$, and none contain identifiable basal sherds (Table 8-13).

Cordmarked pottery clearly dominates this ceramic assemblage, with 11 of the 14 (79 percent) identified vessels exhibiting cordmarked exteriors. The cordmarks vary in size, shape and clarity of impressions (Figure 8-71). In general, cordmarks are mostly narrow and shallow, and indicate that the tools used to finish and shape the vessels were similar and probably of a culturally standardized form. Cordmarked exteriors are by far the most common surface finish throughout the Antelope Creek phase sites (i.e., Lintz 1976, 1989, 1997; 2005; Brooks 1989:82, 2004:340) and even at sites further north into southern Kansas, such as the Bell (14CM407), Booth (14CM406), and Lundeen (14MD306) sites (Bevitt 1999). Cordmarked ceramic vessels are also prominent in other phases, 


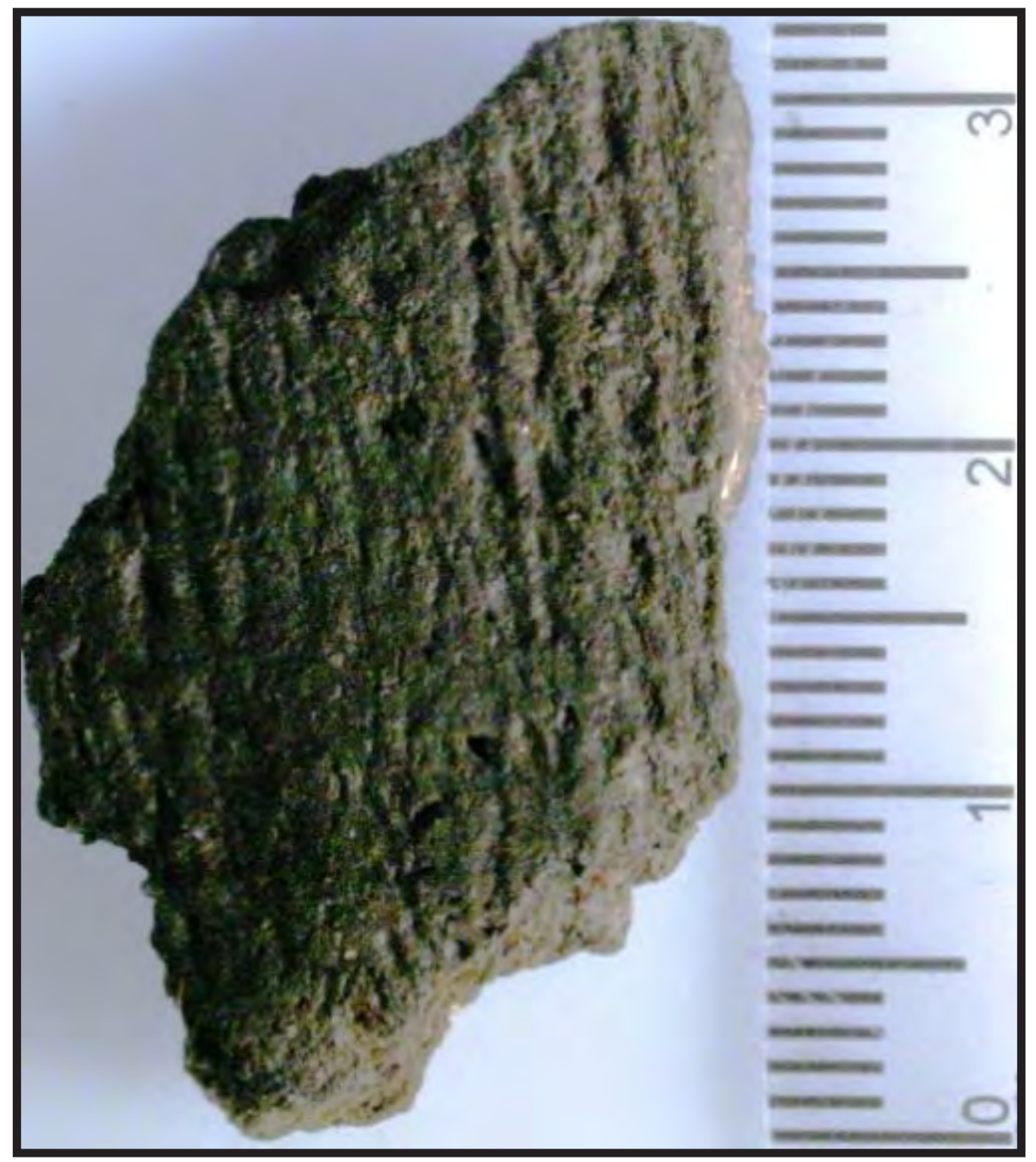

Figure 8-70. Unassigned body sherds (\#940-8-1) used in radiocarbon dating. Scale in millimeters.

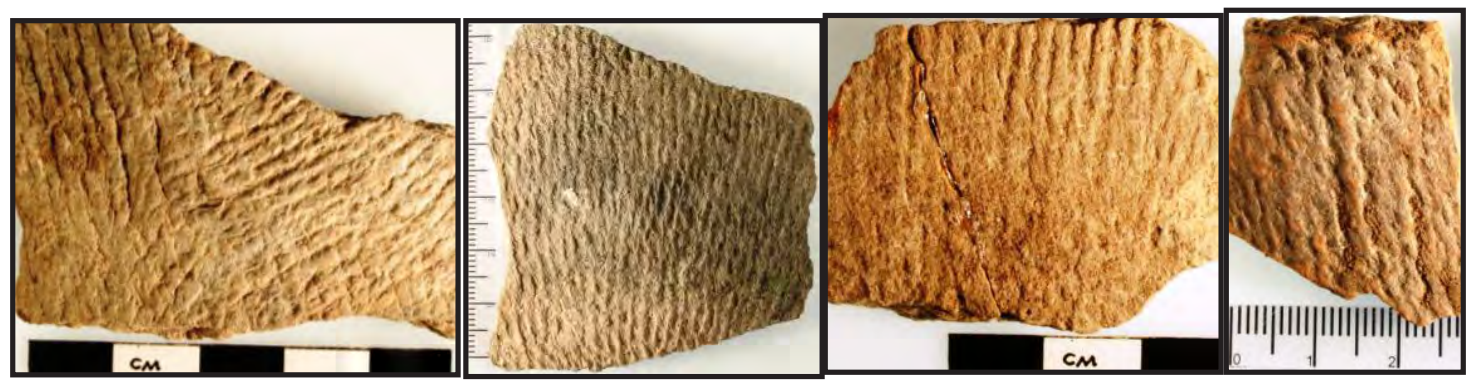

Figure 8-71. Body sherds showing exterior cordmarking variations. 
Table 8-13. Summary of the Assigned Sherds to Vessel Groups and Key Vessel Data.

\begin{tabular}{|c|c|c|c|c|c|c|c|c|c|c|}
\hline $\begin{array}{l}\text { Vessel } \\
\text { No. }\end{array}$ & $\begin{array}{l}\text { No. of } \\
\text { Sherds }\end{array}$ & $\left|\begin{array}{c}\text { Total } \\
\text { Weight (g) }\end{array}\right|$ & Surface Finish & Rim & Neck & Base & Core Color & $\begin{array}{c}\text { INAA } \\
\text { Group* }\end{array}$ & \begin{tabular}{|c|} 
Petrographic \\
Paste Group **
\end{tabular} & Starch Results \\
\hline A & 34 & 91.2 & $\begin{array}{l}\text { Cordmarked, } \\
\text { collared rim }\end{array}$ & yes & yes & no & $\begin{array}{c}\text { two tone, gray }(2.5 \text { Y } 6 / 0) \text { on interior edge, very dark } \\
\text { gray }(7.5 \text { YR } 3 / 0) \text { on outer two-thirds }\end{array}$ & 2 & B & $\begin{array}{c}6 \text { little barley, } 1 \text { damaged, } 1 \\
\text { unknown, } 1 \text { gelatinized }\end{array}$ \\
\hline $\mathrm{B}$ & 14 & 28.5 & $\begin{array}{c}\text { Cordmarked, } \\
\text { obliterated }\end{array}$ & no & no & no & very dark gray (10YR 3/1) & 2 & $\mathrm{~B}$ & none \\
\hline $\mathrm{C}$ & 13 & 51.2 & Plain - Red & no & no & no & $\begin{array}{c}\text { two tone, gray (7.5YR 6/0) band towards the } \\
\text { interior, a reddish yellow (7.5YR 6/6) toward outer } \\
\text { edge }\end{array}$ & 4 & $\mathrm{HH}$ & NA \\
\hline $\mathrm{D}$ & 21 & 71.2 & Cordmarked & yes & yes & no & $\begin{array}{c}\text { very dark gray (10YR 3/1) core with thin black band } \\
\text { on interior edge }\end{array}$ & 2 & A & $\begin{array}{l}2 \text { little Barley, } 1 \text { ground } \\
\text { little barley, cheno-am }\end{array}$ \\
\hline E & 32 & 54.8 & Cordmarked & yes & yes & no & $\begin{array}{l}\text { two tone; light gray (10YR 7/1) band on interior, } \\
\text { reddish yellow (7.5YR 6/6) band on outer edge }\end{array}$ & 2 & A & NA \\
\hline $\mathrm{F}$ & 9 & 47.2 & Cordmarked & no & no & no & dark gray (10YR 4/0) & 2 & $\mathrm{C}$ & NA \\
\hline G & 1 & 35.4 & Cordmarked, narrow & yes & no & no & $\begin{array}{c}\text { dark gray (7.5 YR 4/6) center, thin brown (2.5 Y 5/0) } \\
\text { bands on margins }\end{array}$ & 2 & $\mathrm{C}$ & NA \\
\hline $\mathrm{H}$ & 2 & 27.8 & Cordmarked & yes & no & no & $\begin{array}{c}2 \text { tone; light yellow (10YR 6/4), very dark gray } \\
(2.5 Y R 3 / 0)\end{array}$ & 2 & $\mathrm{C}$ & none \\
\hline I & 13 & 58.9 & $\begin{array}{l}\text { Cordmarked, } \\
\text { overlapping }\end{array}$ & no & no & no & most reddish yellow (7.5YR 6/6) & 2 & $\mathrm{C}$ & NA \\
\hline $\mathrm{J}$ & 13 & 53.7 & $\begin{array}{l}\text { Cordmarked, } \\
\text { shallow }\end{array}$ & no & no & no & $\begin{array}{l}\text { two tone: reddish yellow (5YR 6/6), very pale brown } \\
(10 \mathrm{YR} 7 / 4)\end{array}$ & 2 & NA & NA \\
\hline $\mathrm{K}$ & 3 & 9.8 & $\begin{array}{l}\text { Cordmarked, } \\
\text { collared rim }\end{array}$ & yes & no & no & $\begin{array}{c}\text { two tone, thin light yellowish brown (10YR 6/4) on } \\
\text { the inside edge, a thicker reddish yellow (7.5YR 6/6) } \\
\text { on outer edge }\end{array}$ & NA & NA & NA \\
\hline $\mathrm{L}$ & 3 & 11.5 & Plain & yes & no & no & dark gray $2.5 \mathrm{Y} 3 / 0$ & NA & NA & NA \\
\hline M & 3 & 18.3 & Cordmarked, narrow & yes & no & no & very pale brown 10YR 7/3 & NA & NA & 6 little barley, 2 possibly lily \\
\hline $\mathrm{N}$ & 1 & 1.4 & $\begin{array}{c}\text { Painted, Rio Grande } \\
\text { Glaze }\end{array}$ & no & no & no & $\begin{array}{c}\text { two tone, light gray }(2.5 Y \text { 7/0) on interior edge, light } \\
\text { brown }(7.5 Y R \text { R } 6 / 4) \text { on exterior edge }\end{array}$ & NA & NA & NA \\
\hline 14 & 162 & 560.9 & & 8 & 3 & 0 & & 10 & & 3 of 5 positive \\
\hline
\end{tabular}

* INAA = Instrumental neutron activation analysis assignment based on chemistry; NA = not applicable; ** Groups based of similar additives 
notably the Odessa phase, although the ceramics of the Odessa phase do show considerable variation and a high frequency of decorated rims (Brosowske 2005:157-160). In the three mentioned Kansas sites, cordmarkings are generally smoothed over to some degree (64, 71, and 80 percent, respectively; Bevitt 1999). Cordmarked surfaces are also represented at Buried City, specifically the Courson ruins where there is also greater diversity in the surface treatments, although actual counts and weights have not been presented (D. Hughes and Hughes-Jones 1987; D. Hughes 1991). Vessel B from Long View has obliterated cordmarked impressions that were smoothed to create the finished appearance of a plain exterior. This vessel is the thinnest vessel identified, with body walls that are 2.9- to 4.2-mm-thick. It is also one of two vessels that did not yield starch grains and potentially served a different function than the other vessels. The intentional removal of the cordmarks may have been a choice of the individual potter. The one vessel with a true smooth exterior, Vessel C, appears imported from beyond this area as the chemical constituents and exterior red-wash treatment are clearly different from the other 13 vessels. Another reddish ware, Agua Fria Glaze-on-Red has been recovered at Antelope Creek phase sites of Alibates Ruin 28, Antelope Creek 22, Saddleback Ruin, Big Blue, and Chicken Creek (Brosowske 2005:215). Vessel N was also clearly imported, as it reveals painted lines on the smooth exterior surface. Painted pottery has been recovered in limited quantities at many Antelope Creek phase sites (Lintz 1976, 1978, 1982, 1984, 1986; Brooks 1989, 2004; J. Hughes 1991). At least two identified vessels (14 percent) represented by 14 body sherds (8.6 percent of total sherds) are considered imported.

Vessel form is not readily obvious due to small sherd sizes and an absence of reconstructable vessels. Only three vessels (A, D and E) have neck sherds ( $N=$ $15)$ and only seven unassigned sherds exhibit the curved neck. At least three vessels had constricted necks and, likely, orifices that were narrow relative to vessel bodies. Basal and sharply curved shoulder sherds were not identified. This may indirectly imply a preponderance of neckless jars or at least tall rim sections with rounded bases. Orifice diameters were estimated for Vessels $E$ and $G$ at about 12 and $25 \mathrm{~cm}$ in diameter, respectively. The largest body section represented is the reconstructed part of Vessel F which allowed for a projected body diameter of about 21 to $25 \mathrm{~cm}$. No appendages such as straps, loops, lip tabs, etc., were represented on the identified vessels. No plates or bowls were identified. Antelope Creek phase vessels are typically globular jars with rounded bases, curved shoulders, somewhat constricted necks, with straight, mostly vertical, rims and lack straps, loops, or lip tabs (Lintz 1976, 1978, 1982, 1984, 1986; Brooks 1989, 2004).

Lip thicknesses are also quite variable, with the overall range from 3.5 to 11.2. However, the greatest thicknesses can be misleading, as Vessels $\mathrm{A}$ and $\mathrm{K}$ are collared or thickened and have much thicker lips than do the other vessels (Figure 8-72). The two collared lips vary from 9.1- to 11.2-mmthick in contrast to uncollared lips, which vary from 3.5- to 6.2-mm-thick. Collared rims are rare in Antelope Creek phase sites, but a few analyzed sites such as Roper (41HC6) and Cottonwood Creek Ruins (A119/120; Lintz 1997; Lintz and ReeseTaylor 1997) to the south of Long View yielded a few examples in those assemblages. Collared rims become more frequent in sites farther north such as in Buried City complex (D. Hughes and HughesJones 1987; D. Hughes 1991).

Rims from Component A are straight, nearly vertical or slightly outwardly angled, although their small size may be misleading as regards the true direction of the rim. The rims vary in thickness from $3.6 \mathrm{~mm}$ on Vessel $\mathrm{E}$ to about $11 \mathrm{~mm}$ on Vessels $\mathrm{H}$ and $\mathrm{I}$. Most rims are wedge shaped with the thinnest part at the lip and increase thickness towards the main body (Figure 8-73). The rim heights for Vessels $\mathrm{D}$ and $\mathrm{E}$, where both the neck and lip portions are represented, are between 41 and $42 \mathrm{~mm}$.

Neck sherds in Vessels D and E reveal thicknesses between 6.2 and $8.7 \mathrm{~mm}$ and are generally thicker than the rim area above. The necks were also frequently the point of vessel breakage; therefore, the body shape and thickness below the necks are virtually unknown. The breaks in this upper neck area may have resulted from a relatively weak point where the neck-rim section was added to the lower body during construction. The neck/shoulder angle on Vessel $\mathrm{E}$ is about 160 to 165 degrees. 


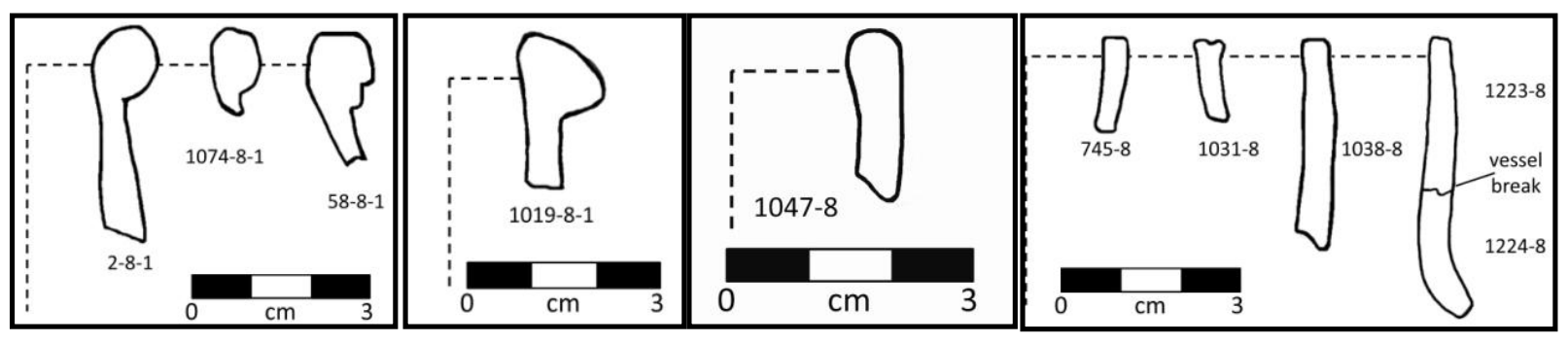

Figure 8-72. Lip/rim profiles showing thickness variations.

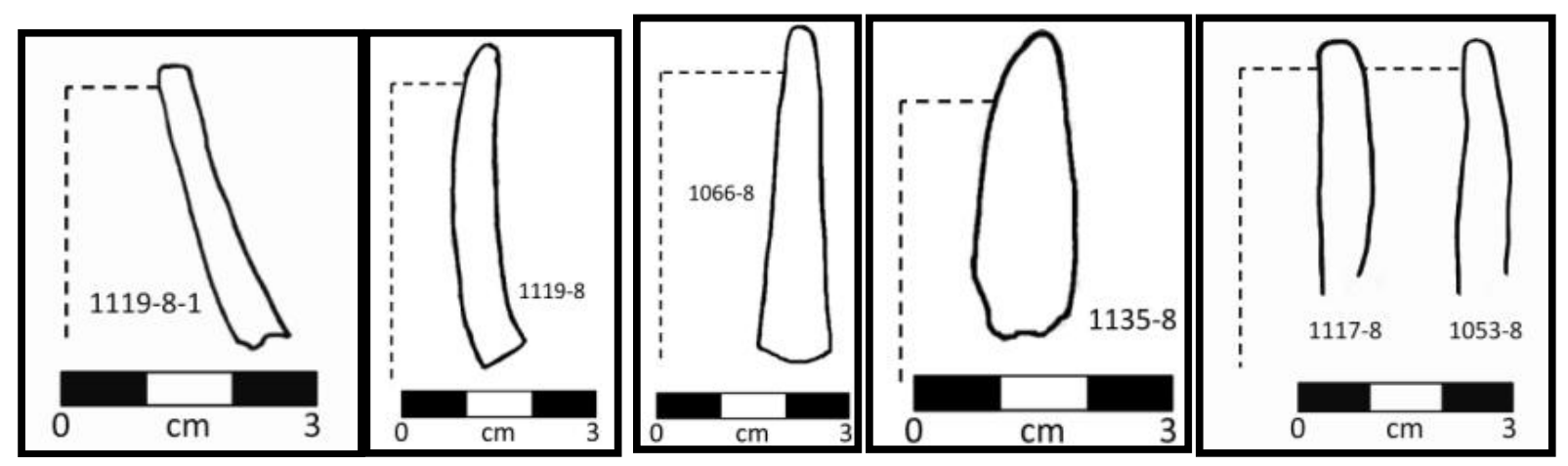

Figure 8-73. Profiles of selected vessels showing rim shapes.

Overall, body sherds vary in thickness from $2.7 \mathrm{~mm}$ in Vessel B to $10.8 \mathrm{~mm}$ in Vessel G, with most in the range between 3.0 and $6.3 \mathrm{~mm}$. The body of collared Vessel A has a similar range, from 3.0- to 7.6-mmthick, whereas collared Vessel $\mathrm{K}$ was 5.8 -mm-thick.

Decorations in the form of pinched outer lips occur on the two collared vessels (A and K) or 14 percent of the identified vessels. The collared, thickened rims were pinched with fingers (Figure 8-74). Vessel A also revealed shallow finger punctates on the rim which did not create interior bossing. Other decorations such as fingernail impressions, incised diagonal lines, tool impressions, etc., do not occur on the exterior surfaces of these vessels. Four rims of cordmarked vessels (D, E, G, and M) have decorations on their lips which may reflect individual preferences or may have served as identifiers of individual potters. Vessel D shows some pattern that is not clear but may reflect angled cordmarks. Vessel E has angled depressions that left elongated triangular impressions parallel to the lip (Figure 8-75). Vessel G has diagonal cordmarked impressions on the lip. The Vessel $\mathrm{M}$ lip has cordmarks with unclear orientations. In the three southern Kansas sites mentioned above, decorations are common (40 to 70 percent) on rim sherds, but infrequent on body sherds (Bevitt 1999). Decorated lips contrasts with the ceramic assemblages from Antelope Creek phase sites investigated so far as decorated lips are rare (i.e., Lintz 1976, 1986, 1989, 1997, 2005; Brooks 1989, 2004:340). Color as a decorative technique was added to the surfaces of two vessels (Vessels $\mathrm{C}$ and $\mathrm{N}$ ), representing 14 percent of the total number of identified vessels. Vessel $\mathrm{C}$ has a reddish wash exterior finish, whereas Vessel $\mathrm{N}$ has dark painted, parallel lines. Both vessels are considered to have been imported items, based primarily on these surface attributes.

Decorated vessels are rare in Antelope Creek phase assemblages to the south (i.e., Lintz 1976, 1989, 1997; 2005; Lintz and Reese-Taylor 1995), except for the imported Southwestern wares. Besides the imported wares, decorated vessels do occur in higher frequencies in the assemblages from Buried City in Wolf Creek Valley to the north (D. Hughes and Hughes-Jones 1987; D. Hughes 1991), Roy 


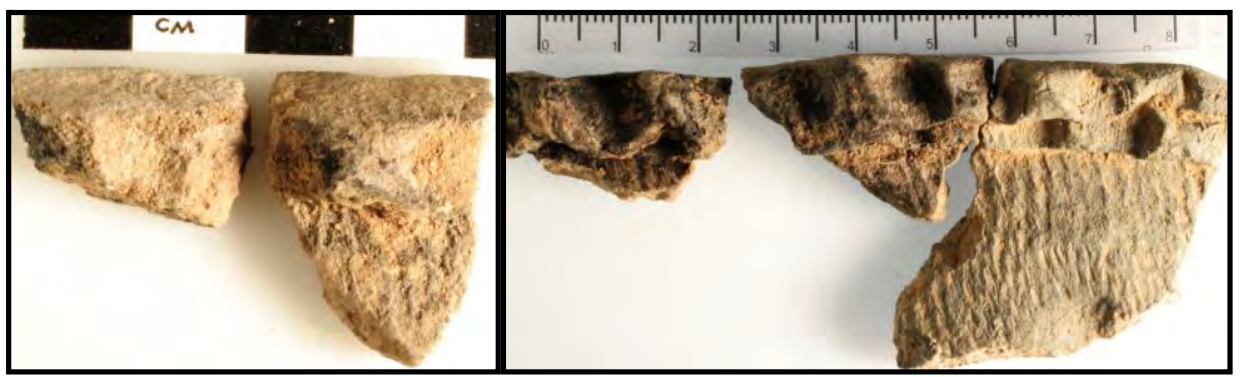

Figure 8-74. Pinched rims of vessels K (left) and A (right) with shallow punctates on vessel A.

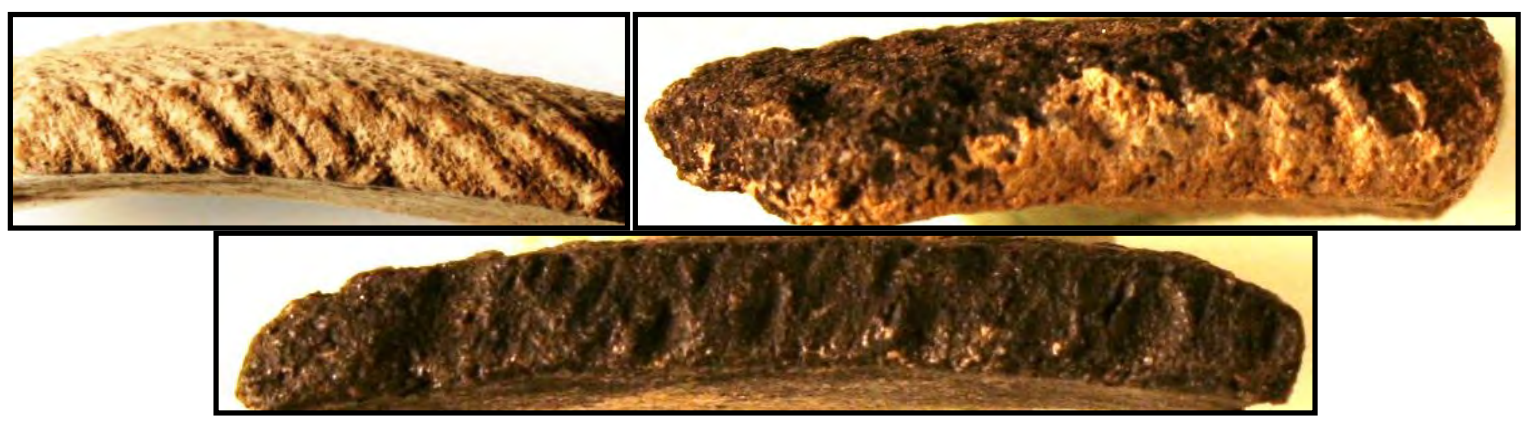

Figure 8-75. Decorated lips on vessels G (top left), M (top right) and D (bottom).

Smith in the Oklahoma panhandle (Lintz 1976:93; Schneider 1969), as well as in Odessa phase ceramic sites (Brosowske 2005) in western Oklahoma, and at sites in south-central Kansas (Bevitt 1999). Currently, this ceramic assemblage is unassigned to a particular phase/complex.

Although colors were recorded for the exterior and interior surfaces, it should be noted that these are affected by the calcium carbonate film on nearly all sherds. In regards to core colors and variations or combinations of colors, it is the author's opinion that much of the color observed was influenced by a number of factors and include, but not limited to repeated heating, cooking, and the type of materials cooked (greasy and oily substances versus plants), which likely penetrated the vessel walls during the life of the vessel. It is also unclear if core colors were consistent across the entire vessel, that is, was the core color(s) the same from the rim through the body and across the base or do different parts of the vessel reveal different core colors as a reflection of the firing technique, wall thickness, vessel shape, or contact with different temperatures and/or foods cooked throughout the life of the vessel.

Each vessel group was macroscopically viewed for initial impression of the temper used. Fine-tomedium-size sand grains were observed in nearly all instances. From this initial inspection, sherds from various vessel groups were selected for detailed microscopic, petrographic analysis by a trained specialist. In most instances, the same sherds and/or vessel parts selected for petrographic analysis were also selected for chemical analysis in order to support final identification of the constituent materials. The petrographic analysis generally confirmed the macroscopic observations, but permitted greater specificity in the identification of aplastic inclusions. Those results indicate crushed rock and minerals are prominent (particle quantities vary from 9 to 48 percent as determined by petrography) with limited 
amounts of other particles that include minor percentages of igneous and carbonate particles identified during the petrographic study (Table 8-14; Appendix F). The smooth, plain finished Vessel B exhibits the lowest percent of particles; whereas the overlapping cordmarked group of Vessel I exhibits the highest percent of particles and the most identifiable types. Hematite is present in small percentage, a trace to 5 percent, in all the sherds petrographically analyzed here.

These minor ingredients were used by Robinson to subdivide the vessels into four finer paste groups (Appendix F). Quartz sand dominates the tempers across 9 of the 10 vessels analyzed, which have been assigned to Paste Groups A, B, and C. Only Vessel C is the exception, which was assigned to Paste Group $\mathrm{HH}$ as it has more basalt and biotite present than quartz. Four vessels (F, G, H, and I) were assigned to Paste Group $\mathrm{C}$ and all have moderately high frequencies (21 to 48 percent) particles in their pastes, with granular rock types $\mathrm{A}, \mathrm{B}$, and $\mathrm{C}$ present. Three vessels (A, B, and J) were assigned to Paste Group $B$, all with relatively low percentage of particles ( 9 to 21 percent) and no granular rock types present. Only two vessels ( $\mathrm{D}$ and $\mathrm{E}$ ) were assigned to Paste Group A, with relatively low frequencies of particles (10 to 18 percent) and no granular rock types. Vessel C was assigned to Paste Group HH with relatively low, 13 to 21 percent particles no granular rock types, no carbonates, and very limited frequencies of quartz. Based on the homogeneity of the cordmarked ceramic vessels, Component A appears to represent a small distinct, discrete, autonomous population in which the ceramic technology was consistent and likely passed down through the generations. The red-washed exterior of Vessel $\mathrm{C}$ appears the only exception and likely reflects a vessel manufactured from a separate paste and likely was from another group or at least manufactured using a completely different paste.

Sand is the most common tempering agent macroscopically observed in vessels from Odessa phase sites (Brosowske 2005:154), although other observable additives include bone or scoria. The Lintz and Reese-Taylor (1997) petrographic study provided the initial data for Antelope Creek core area sites and yielded a number of key discoveries. First, quartz particles were the principal tempering agent in most Antelope Creek phase sherds. That study also showed a strong correlation of uncollared rim sherds with igneous particles. The collared rim sherds from the sites in the Canadian River valley (i.e., Roper [41HC6] and Cottonwood Creek [41HC141]) have stronger shared paste characteristics with the nearby Buried City complex than with the uncollared sherds from the same sites. The Roper site sherds revealed complex petrographic results, with data to indicate that the source of the Roper ceramics may have been from the Buried City complex in the Wolf Creek valley.

The INAA detected chemical signatures from 10 identified vessel groups (Vessels A through J, 12 sherds in total) indicate that all vessels were chemically similar and assigned to a single chemical group, Group 2, with the exception of Vessel C. This vessel, which is unusual in having a very smooth redwashed exterior, was assigned to Chemical Group 4 on the basis of its chemical constituents. The surface color and texture combined with the different chemical signature contrasts with the other nine vessels analyzed from Component $\mathrm{A}$, and support the proposition that Vessel C was imported and not manufactured anywhere within the region. Although the collared-rim Vessels A and $\mathrm{K}$ have decorations and stylistically distinctive lip/rim areas, their chemical signatures are similar to the other eight uncollared vessels analyzed; which are also placed in Chemical Group 2. This indicates that collared rim Vessels $\mathrm{A}$ and $\mathrm{K}$ were likely manufactured with the same chemical ingredients as the more common, uncollared vessels. This contrasts with what the Lintz and Reese-Taylor (1997:296) petrographic study found; that "the collared rim sherds from sites in the Canadian River valley have stronger shared paste characteristics with the nearby Buried City complex than with the uncollared sherds from the same sites.”

The starch grain analysis on 23 sherds from at least four vessel groups (Vessel A, B, H, and M), revealed that at least three species of plants were cooked in these vessels. The identified plant taxa consist of little barley $(N=81)$, maize $(N=10)$, mesquite $(N$ $=7)$, possibly lily $(N=2)$, and cheno-am $(N=1)$. Damaged grains were found that represent little 
barley $(N=6)$ of which three are gelatinized and three are ground, maize $(N=1)$, and damaged grains of unidentified taxa $(N=3)$. Clearly, these results indicate that little barley was the principle plant cooked in these vessels and, although maize is present, it does not appear have been the primary resource cooked in ceramic vessels. Interestingly, maize only accounts for roughly 12 percent of the identifiable starch grains. The starch grain data also indicates that little barley was processed through grinding before it was boiled. In addition to the native little barley, other native species such as lily bulbs, cheno-am, and mesquite were also cooked in these vessels. Sixty-nine percent of the sherds analyzed from Component A yielded some kind of starch grain and this analysis contributes significantly to our understanding of the kinds of plant resources cooked in the vessels and in many instances the actual processing (i.e., grinding and boiling) involved in preparing these food resources for consumption. Although Vessel A has a collared rim, which is rare in the Antelope Creek phase sites, it apparently served as a cooking vessel similar to the other cordmarked and uncollared vessels in that it yielded multiple starch grains from the foods cooked. This stylistically distinctive vessel apparently was not used in any unique manner; therefore, the pinched collar may indicate an individual's preference for the thick, decorated collar and potentially reflect the individual's background in the productions of pottery making.

These 14 vessel groups identified consist of 162 sherds that were horizontally distributed across at least 44 of the 128 units, or 34 percent overall. Thirty-three of those units were in the northern block of 78 units (42 percent of the northern units), whereas 11 units in the southern block of 50 units (20 percent of the southern units) yielded sherds (Figure 8-76). In other words, the northern block yielded nearly twice productive units than the southern area. The highest frequency of sherds was clustered around heating elements to the west and south of the pithouse Feature 1.

The overall horizontal distribution of all sherds by weight is depicted in Figure 8-77, which again maybe indicative of higher concentrations of sherds or thicker sherds around the features at the northern end. Small clusters of sherds are also present in the southern end, but they are lighter in weight and were not associated with cultural features.

\subsection{Animal Bone Analysis}

\section{J. Michael Quigg}

\subsubsection{Introduction}

A total of 3,905 vertebrate bone specimens, weighing 3,330.7 $\mathrm{g}$, were recovered from the 128 $\mathrm{m}^{2}$ excavated area in this component. Unidentifiable fragments clearly dominate (99 percent) the assemblage, and only a few specimens, mainly the smallest elements in the skeleton, are more or less complete. Extensively fragmented assemblages are not uncommon for open air sites in upland settings because exposure to weathering processes results in deterioration of the bone. Also, root etching, which occurred after the bone elements became buried by accumulating sediment, has significantly affected this assemblage. Many pieces exhibit surficial damage due to weathering and subsequent root etching. Moreover, many bones presumably were initially heavily processed (smashed, split) by humans prior to discard, resulting in a high degree of fragmentation. Some pieces are in such a deteriorated state that it seems likely some of the bones that were initially part of the assemblage are absent due to complete decay. Because of these various factors of deteriorization, most of the specimens are not identifiable according to species. Such specimens have been assigned to the "unknown" category.

Nonetheless, in some instances, a specimen could be assigned to a general size category (i.e., size of the animal). Only a single species is known to be represented for each of the animal size categories. For the largest size category, only bison (Bison bison) was represented, and no other very large species (e.g., elk, bear, or cow) could be identified. In most instances, thick-walled long bone pieces, lacking the articular ends that would allow confident assignment of an element to a specific species, are identified as bison because this is the only species assignable to this size group. In the medium-size mammal category only deer (Odocoileus sp.) remains can be specifically identified. It is possible that bones of pronghorn or even dogs (Canis) are also present, 
Table 8-14. Petrographic Identifications and Quantifications of Ceramic Data from Component A.

\begin{tabular}{|c|c|c|c|c|c|c|c|c|c|c|c|c|c|c|c|c|c|c|c|c|c|c|c|c|c|c|c|}
\hline \multirow[b]{2}{*}{$\begin{array}{c}\text { Component } \\
\text { A Sherd } \\
\text { PNUM }\end{array}$} & \multirow[b]{2}{*}{$\begin{array}{c}\text { Vessel } \\
\text { No. }\end{array}$} & \multirow[b]{2}{*}{$\begin{array}{l}\text { Paste } \\
\text { Group }\end{array}$} & \multicolumn{5}{|c|}{ Paste attributes } & \multicolumn{4}{|c|}{ Quartz } & \multicolumn{9}{|c|}{ Igneous } & \multirow{2}{*}{ 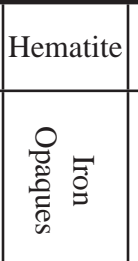 } & \multicolumn{3}{|c|}{$\begin{array}{c}\text { Granular } \\
\text { Rocks }\end{array}$} & \multicolumn{2}{|c|}{ Carbonates } & \multirow[b]{2}{*}{$\stackrel{n}{\Xi}$} \\
\hline & & & 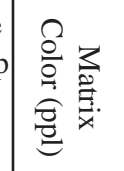 & 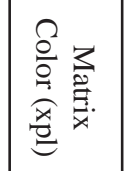 & 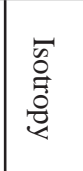 & ळ. & 常逽 & 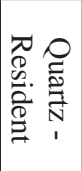 & 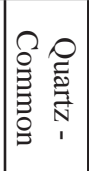 & 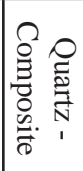 & $\stackrel{\varrho}{\overparen{Q}}$ & 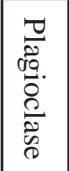 & 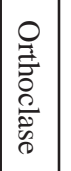 & $\begin{array}{l}3 \\
\text { 3. } \\
0 \\
\text { 号. }\end{array}$ & 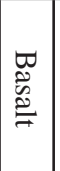 & 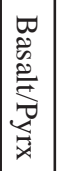 & $\begin{array}{l}0 \\
\vdots \\
0 \\
0 \\
0 \\
0 \\
0\end{array}$ & 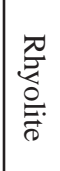 & 莺. & 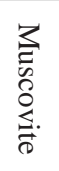 & & $\begin{array}{l}20 \\
0 \\
\frac{2}{\lambda} \\
>\end{array}$ & $\begin{array}{l}20 \\
0 \\
\frac{2}{\lambda} \\
\sigma\end{array}$ & $\begin{array}{l}20 \\
0 \\
0 \\
0 \\
0\end{array}$ & $\begin{array}{l}\text { 壱. } \\
\text { D } \\
0 \\
0 \\
0 \\
0\end{array}$ & $\stackrel{8}{\stackrel{8}{0}}$ & \\
\hline $1140-8-1$ & A & $\mathrm{B}$ & $\begin{array}{l}\text { greenish } \\
\text { brown }\end{array}$ & $\begin{array}{l}\text { golden } \\
\text { brown }\end{array}$ & aniso & few & massive & & $3-5$ & 1 & & $1-2$ & & $1-2$ & & & & & tr. & 1 & $3-5$ & & & & 1 & $2-3$ & \\
\hline $1175-8-1$ & $\mathrm{~B}$ & B & $\begin{array}{l}\text { yellow- } \\
\text { brown }\end{array}$ & $\begin{array}{l}\text { reddish } \\
\text { brown }\end{array}$ & aniso & few & massive & & $5-7$ & & tr. & & $1-2$ & & & & & & $1-2$ & $1-2$ & $1-2$ & & & & & & \\
\hline 1206-8-1 & $\mathrm{C}$ & $\mathrm{HH}$ & It. green & $\begin{array}{l}\text { lt. } \\
\text { greenish } \\
\text { gold }\end{array}$ & aniso & few & massive & & $1-2$ & & & & & & $5-7$ & & & & $3-5$ & $1-2$ & $3-5$ & & & & & & \\
\hline 1119-8-1 & $\mathrm{D}$ & A & $\begin{array}{l}\text { medium } \\
\text { brown }\end{array}$ & $\begin{array}{l}\text { reddish } \\
\text { brown }\end{array}$ & iso & few & massive & & $7-10$ & $1-2$ & & 1 & 1 & & & & & & & & $2-3$ & & & & tr. & tr. & \\
\hline $1223-8-1$ & E & A & $\begin{array}{l}\text { dk. Red- } \\
\text { brown }\end{array}$ & black & iso & 1 & massive & & $5-7$ & $1-3$ & & $1-2$ & $1-3$ & & & & & & & 1 & tr. & & & & $1-2$ & & \\
\hline $998-8-1$ & $\mathrm{~F}$ & $\mathrm{C}$ & $\begin{array}{l}\text { dark } \\
\text { brown }\end{array}$ & black & iso & $5-7$ & dense & $5-7$ & $7-10$ & $3-5$ & 1 & & & $3-5$ & tr. & & & & & & $1-2$ & $1-2$ & tr. & & & & \\
\hline 1066-8-1 & G & $\mathrm{C}$ & $\begin{array}{l}\text { dark } \\
\text { brown }\end{array}$ & black & iso & $15-20$ & moderate & & $5-10$ & $5-7$ & $1-2$ & $1-2$ & & $3-5$ & tr. & & & & & & $1-2$ & $3-5$ & & $3-5$ & & & tr. \\
\hline 1135-8-1 & $\mathrm{H}$ & $\mathrm{C}$ & $\begin{array}{l}\text { dark } \\
\text { brown }\end{array}$ & black & iso & $5-7$ & dense & $5-7$ & $7-10$ & $3-5$ & $1-2$ & $1-2$ & & $3-5$ & tr. & & & & & & $1-2$ & $1-2$ & tr. & 3-5 & $2-3$ & & tr. \\
\hline $1036-8-1$ & I & $\mathrm{C}$ & $\begin{array}{l}\text { dark } \\
\text { brown }\end{array}$ & black & iso & $5-7$ & dense & $5-10$ & $7-10$ & $3-5$ & $1-2$ & $1-2$ & $1-2$ & $3-5$ & tr. & & & & & & $1-2$ & $1-2$ & & $3-5$ & $2-3$ & & tr. \\
\hline 2/8/2006 & $\mathrm{J}$ & B & $\begin{array}{l}\text { reddish- } \\
\text { brown }\end{array}$ & $\begin{array}{l}\text { golden } \\
\text { brown }\end{array}$ & aniso & 15 & dense & & $3-5$ & $1-2$ & $1-2$ & $1-2$ & $3-5$ & & & & & & tr. & tr. & $2-5$ & & & & & & \\
\hline
\end{tabular}

The numbers refer to percentage 


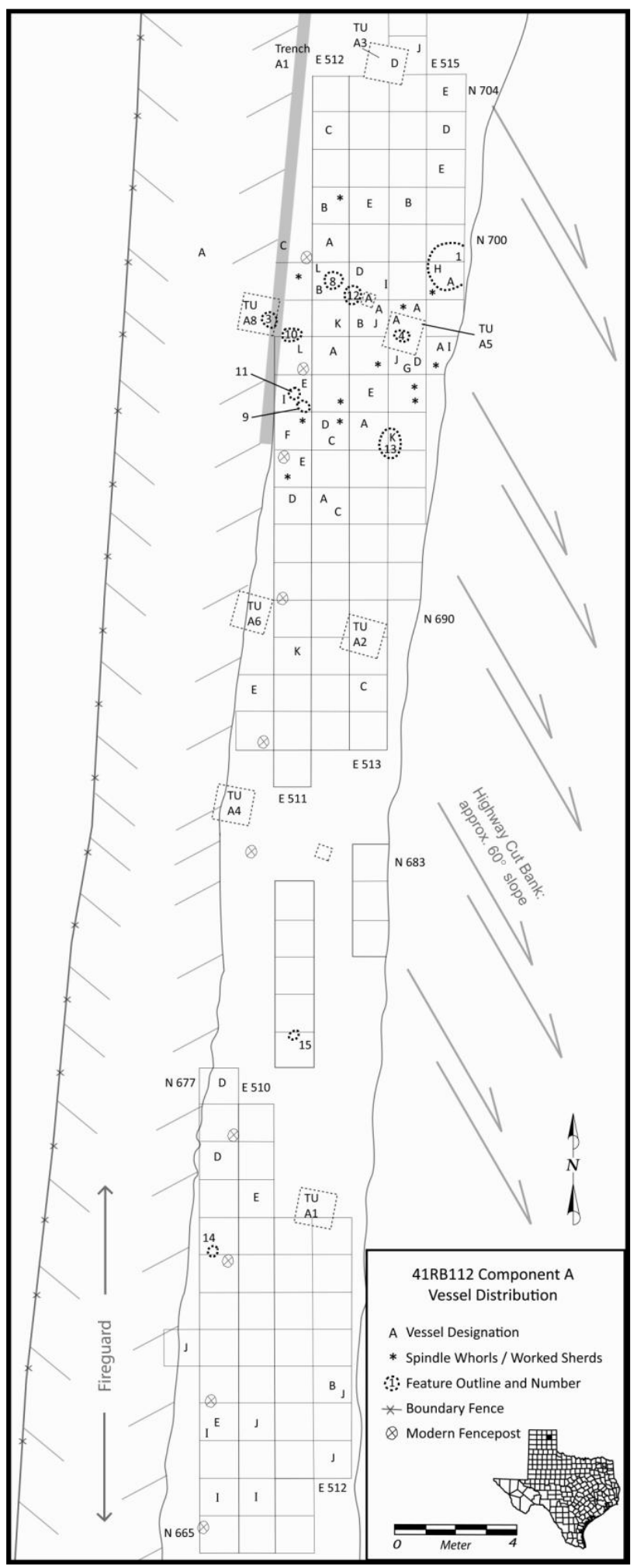

Figure 8-76. Horizontal distribution of identified vessel groups in Component A. 

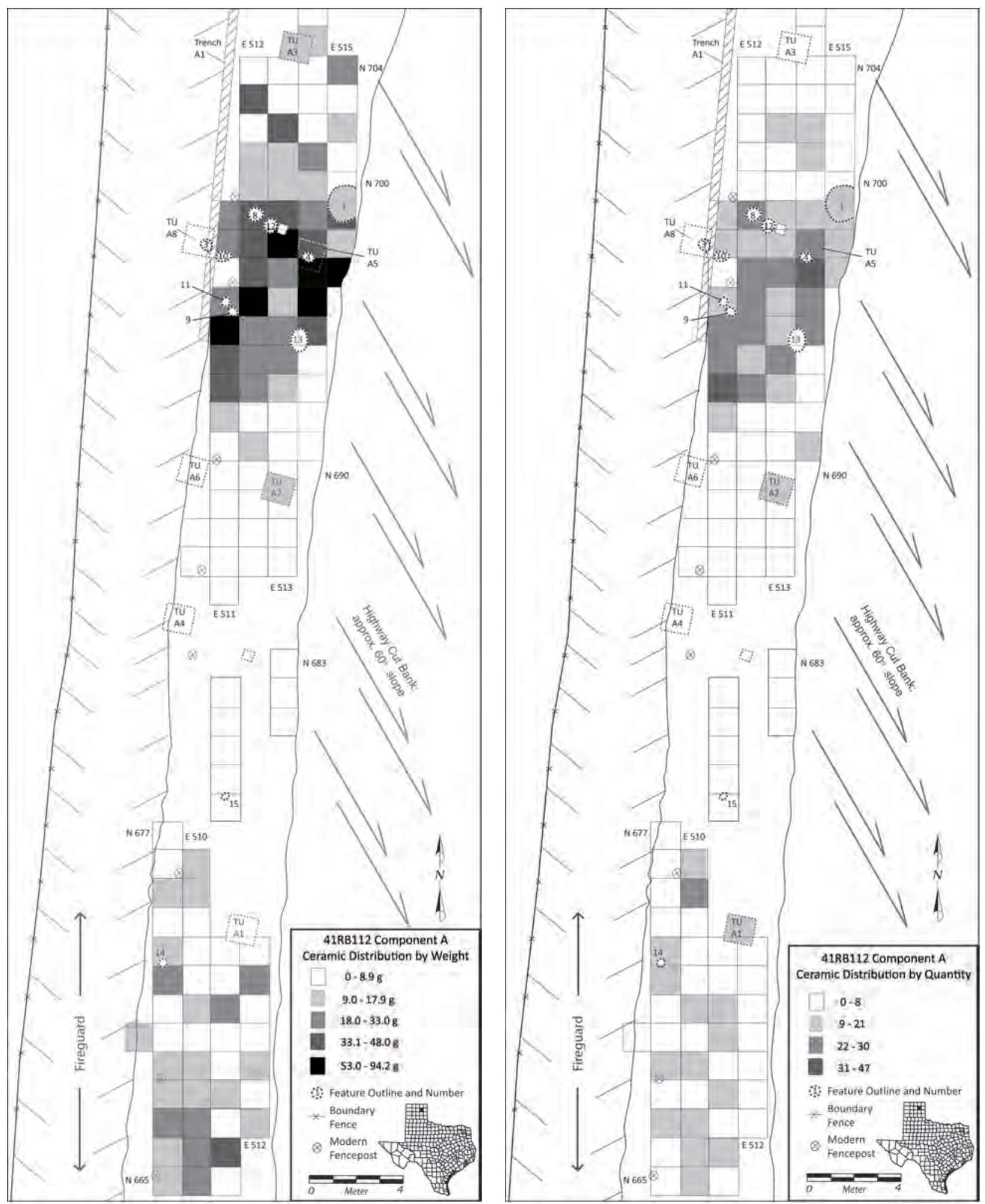

Figure 8-77. Horizontal distribution of all ceramic sherds by weight (left) and by quantity (right) in Component A. 
but the fact that not a single identifiable pronghorn (Antilocapra americana) or canid element was positively identified leads to the assumption that the medium-size fragments represent deer. The same is true with the rabbit-size (Leporidae) elements as only rabbits (Sylvilagus) were specifically identified and no other small mammal was attributable to this size category. An extremely high percentage (97.2 percent) of the assemblage was assigned to an unknown species category as the pieces were either so fragmented or weathered that positive assignment to species or general size category was impossible. In the end, only 111 pieces could be confidently assigned to a specific animal-size category.

\subsubsection{Nonbison Remains}

A total of 59 bone fragments, weighing only 81.9 g, represent animals other than bison. These represent less than 1 percent of the total faunal bone assemblage, or 53 percent of those assigned to a species, and a minimum of four taxa is represented (Table 8-15). These include deer (Odocoileus sp.), turtles (Testudines), rabbits (Leporidae), and a nonspecific rodent (Rodentia) category. Each taxa is separately discussed below.

Nineteen deer elements, weighing 67.0 g, were positively identified and represent all major parts of the animals' skeletons (Table 8-16). All were small fragments, and several of the relatively larger pieces exhibit spiral fractures that indicate intentional breakage for marrow extraction when the bone was in a fresh, or "green" state. Nearly all were weathered and root-etched, which hindered the identification of any fine cut lines that may have resulted from stone-tool butchering. A single distal humerus with minimal weathering and root etching did bear two or three visible cut lines near its articular end (Figure 8-78). Five specimens, including a tibia, phalanges, astragalus, and the inner ear bone, had been burned, resulting in a gray or black coloration.

Thirty-four turtle carapace plates (12.4 g) were recognized and all appear to represent box turtles (Terrapene ornate). At least one turtle is represented. Ninety-four percent of the carapace pieces were less than $3 \mathrm{~cm}$ long and two pieces are only slightly longer. Five carapace pieces are burned, which further indicates that turtles were utilized by humans as subsistence resources. One and possibly two pieces represent the appendicular skeleton.

Rabbits, specifically cottontails (Sylvilagus), are represented by three elements (total weight, $0.8 \mathrm{~g}$ ) consisting of two metapodials and one ulna notch. Three other pieces are rabbit-size but could not be positively identified. The ulna-notch piece is burned to a gray color, leading to the inference that this species was processed as a subsistence resource.

Two tiny $(0.2 \mathrm{~g})$ unidentified rodent bones are represented. These are fragmented pieces that could not be identified as to species. It is unlikely these served as food resources for the site's human inhabitants.

The horizontal distribution of these nonbison faunal remains are shown in Figure 8-79. As depicted, these specimens were found clustered around the cultural features identified in the northern end of the excavations. This clustering again supports the interpretation that these were subsistence resources exploited and used by the inhabitants and represent part of the range of resources exploited.

\subsubsection{Bison Remains}

Recognized bison elements include complete bone elements, medial bone fragments, proximal and distal bone fragments, and unknown fragments. Fifty-two pieces $(1,074.4 \mathrm{~g})$ were positively identifiable as bison (Table 8-17). These few, mostly fragmented pieces represent nearly all parts of the animal, with the exception of the vertebral column, and indicate that most of the carcass was brought to the site for processing. The caudal vertebrae were likely attached to the hide, which would account for their presence on the site. The extensive weathering and root-etching of the bone surfaces have obliterated any cut marks that may have once been present. Only a single impact fracture was observed on the medial section of an unidentified long bone. However, several long bone fragments exhibit spiral fractures, which indicate they were broken when fresh, presumably for marrow extraction. One nearly complete left scapula (\#82910) exhibits minor wear along a couple of the lateral margins and is considered to have been worked (see the discussion of worked bone for more details about this specimen). 
Table 8-15. List of Species Identified in Component A.

\begin{tabular}{l|c|c|}
\hline Animal/Species & NISP & MNI \\
\hline Bison & 52 & 2 \\
\hline Deer & 19 & 1 \\
\hline Turtle & 34 & 1 \\
\hline Rabbit & 4 & 1 \\
\hline Rodent & 2 & 1 \\
\hline
\end{tabular}
NISP = number of individual specimens;
MNI = minimum number of individuals

\subsubsection{Bison Age Groups and Gender Identification}

Three broad age categories of bison were recognized, namely, fetal, immature, and mature. Many specimens could not be placed within one of these categories. Only two fetal elements (\#11072-1 and \#1047-2-3), a right femur shaft from 20 to $30 \mathrm{cmbs}$ in N699 E511 and a very fragmented long bone from N696 E514, were identified (Figure 8-80). The femur exhibits a very small-size shaft (50-mm-long by 10.1-mm-wide at midshaft), which indicates it is only partially developed. This stage of development reflects a roughly half developed fetus, which indicates a late fall to winter death. The other long bone $(1.4 \mathrm{~g})$ is too fragmented for identification of specific element.

Not a single bison element exhibited unfused epiphyses. The fusion of the articular ends to the main shaft or body is the main characteristic in identifying mature versus immature elements. Bone growth is measured by the degree of epiphyseal fusion, which reaches completion at different times for different elements and is not well studied in modern North American bison. Most researchers use Koch's (1935) study of European bison (Bos or Bison bonasus) or Sisson and Grossman (1950) analysis of modern cattle (Bos taurus) to approximate the general trends in the timing of various epiphyseal fusions. A more recent attempt to determine the epiphyseal fusion schedule of North American bison, although it is on Bison antiquus, has been completed by Bement and Basmajian (1996). The rates of epiphysis fusion for Bison antiquus from the Folsom-age Cooper bison-kill site are significantly different than the previously published schedules and may more closely approximate those of modern Bison bison. Since bison bones fuse at different rates, some elements in a given animal may be classified as "mature", whereas other elements from the same animal may be interpreted as still "immature". Therefore, one must be careful when evaluating maturity/immaturity on this basis, as the same individual bison will have elements that are both fused and unfused if the animal is younger than about 5.3 years.

A single bison mandibular tooth (\#1061-2-1) is sufficiently complete to allow for approximate age estimation. This is a $\mathrm{P}_{4}$ tooth from 22 cmbs in N697 E513, just southwest of Feature 4. It exhibits no wear at all and was likely still in an eruption stage at the time of death (Figure 8-81). It is estimated that this tooth represents an animal that was roughly 2.5 years old on the basis of comparison with possibly 3.5 years old based on comparisons with the Glenrock bison sample (Frison and Reher 1970:46-47).

Of the 22 identified bison elements (636.2 g), all represent mature elements as they exhibit fused distal and/or proximal ends. However, the very fragmentary nature of most pieces limits such observations, as in some instances the articular ends are not represented. In support of a general assignment of bison remains to the mature category is the fact that no unfused ends are represented in this faunal sample.

Very few long bones were complete enough to extract metric data that would permit estimation of sex. A massive, mature right $1^{\text {st }}$ phalanx appears 
Table 8-16. Type and Number of Deer Elements in Component A.

\begin{tabular}{|c|c|c|c|c|c|c|c|c|}
\hline \multirow{2}{*}{ Body Element } & \multicolumn{2}{|c|}{ Complete } & \multicolumn{2}{|c|}{ Distal } & \multirow[b]{2}{*}{ Medial } & \multicolumn{2}{|c|}{ Proximal } & \multirow{2}{*}{ Fragment } \\
\hline & Left & Right & Left & Right & & Left & Right & \\
\hline \multicolumn{9}{|c|}{ Axial } \\
\hline Skull & & & & & & & & 2 \\
\hline \multicolumn{9}{|l|}{ Mandible } \\
\hline Tooth & & & & & & & & 2 \\
\hline Vertebrae & & & & & 1 & & & \\
\hline \multicolumn{9}{|c|}{ Front Leg } \\
\hline Scapula & & & & & & & & 1 \\
\hline Humerus & & & $1^{* *}$ & & & & & \\
\hline \multicolumn{9}{|l|}{ Radius } \\
\hline \multicolumn{9}{|l|}{ Ulna } \\
\hline \multicolumn{9}{|l|}{ Unciform } \\
\hline \multicolumn{9}{|l|}{ Scaphoid } \\
\hline Cuneiform & 1 & & & & & & & \\
\hline \multicolumn{9}{|l|}{ Lunate } \\
\hline Metacarpal & & & & & & 1 & & \\
\hline \multicolumn{9}{|c|}{ Rear Leg } \\
\hline \multicolumn{9}{|l|}{ Pelvis (Ischium, Illum) } \\
\hline Acetabulum & & & & & 1 & & & \\
\hline \multicolumn{9}{|l|}{ Femur } \\
\hline Patella & & 1 & & & & & & \\
\hline Tibia & & & $1,1^{*}$ & & & & & \\
\hline \multicolumn{9}{|l|}{ Lateral Malleolus } \\
\hline Astragalus & & 1 & & & & & & \\
\hline \multicolumn{9}{|l|}{ Navicular Cuboid } \\
\hline \multicolumn{9}{|l|}{ Calcanium } \\
\hline \multicolumn{9}{|l|}{ Magnum } \\
\hline \multicolumn{9}{|l|}{ Metatarsal } \\
\hline \multicolumn{9}{|c|}{ Other } \\
\hline Medipodial & & & & & 1 & & & 1 \\
\hline $1^{\text {st }}$ phalanx & & & & $1 *$ & & & & \\
\hline $2^{\text {nd }}$ phalanx & & 1 & & $1^{*}$ & & & & \\
\hline $3^{\text {rd }}$ phalanx & & & & & & 1 & & \\
\hline \multicolumn{9}{|l|}{ Sesamoids } \\
\hline Long bone fragments & & & & & & & & $2 *$ \\
\hline
\end{tabular}

* burned element, ** cut marks present 


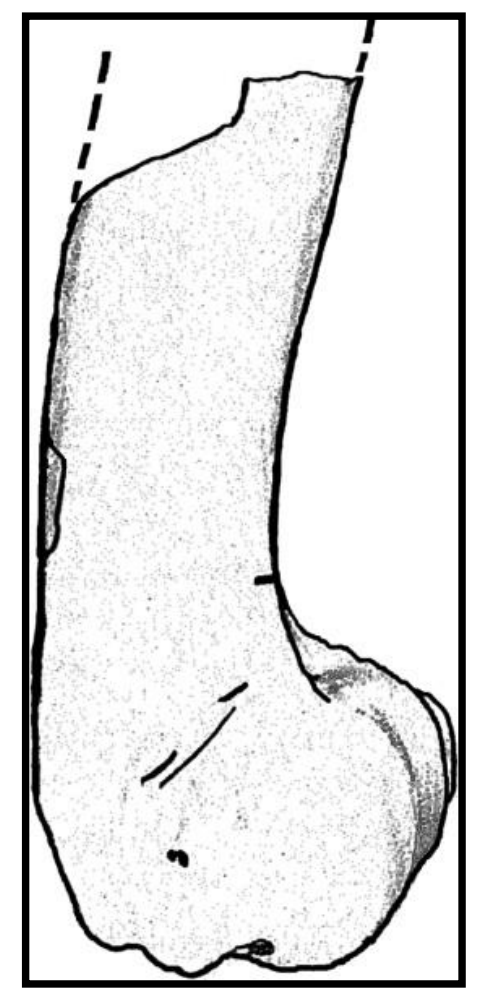

Figure 8-78. Distal deer humerus (\#1057-2-1) showing locations of cut lines.

to represent a male on the basis of its large size. Based on the fact it has a fused proximal end, age can be estimated at least 2.3 years and likely older, using the Bement and Basmajian (1996) fusion rate schedule. A proximal ulna fragment indicates an animal greater than 5.3 years old (Bement and Basmajian 1996), which may also be a male. Many other identified elements are of smaller size and represent at least one other animal. With the fetal bison present, a female must be present and can be assumed to have been more than 1.3 years old. Thus, at least one mature male and one mature female bison are represented. In total, at least two adults and one fetal animal appear to be the minimum number of bison represented. With most appendicular elements completely fused by 5.3 of the bison growth cycle, the recognized elements indicate the animals here did not die during the summer months.

\subsubsection{Bison Bone Processing}

Among all of the individual pieces in this assemblage, 32.7 percent fall within the smallest fragment-size category, that is, into the 0 to $3 \mathrm{~cm}$ size range. Only 23.7 percent are greater than 9.1 $\mathrm{cm}$ long. Obviously the small size of most pieces reflects extensive bone processing that involved intensive breakage to facilitate rendering of bone grease. Based on ethnographic references, bone grease processing appears to be the only reason that bones were smashed into small splinters. The typical procedure was to first break up the complete elements, extract the marrow, and then to smash those elements into small pieces in order to facilitate grease rendering through heating in boiling water (i.e., Mandelbaum 1940; Leechman 1951; Vehik 1977; Binford 1978). The smaller the pieces the more quickly the internal grease was released from the bone during the heating process. Bone grease extraction did not involve placing the fragments in direct contact with fire. Leechman (1951) indicates that the production of bone grease was not limited to any one season.

Less than 1 percent of the fragments from this component were burned (as indicated by black coloration). Among the identifiable bison elements, a single sesamoid and a number of rib fragments 


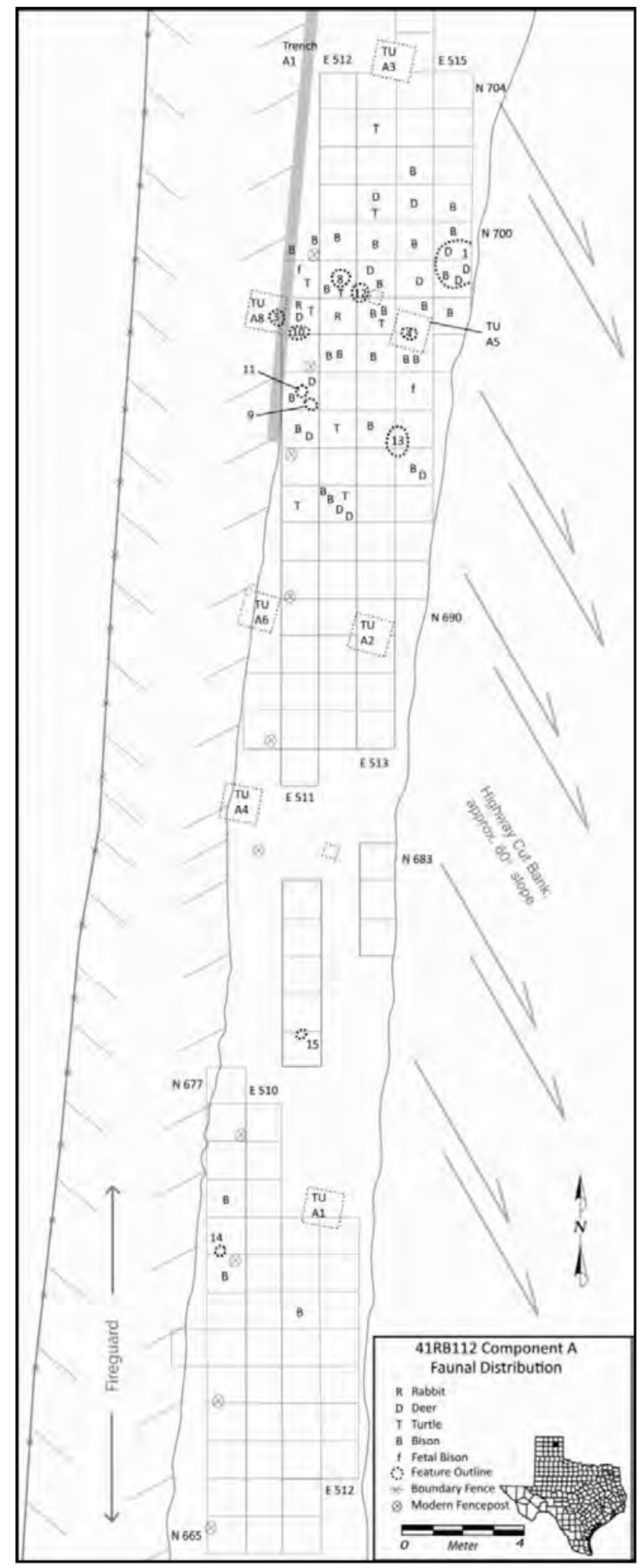

Figure 8-79. Horizontal distribution of nonbison species. 
Table 8-17. Type and Number of Bison Elements in Component $A$.

\begin{tabular}{|c|c|c|c|c|c|c|c|c|}
\hline \multirow{2}{*}{ Element/Fragment } & \multicolumn{2}{|c|}{ Complete } & \multicolumn{2}{|c|}{ Distal } & \multirow{2}{*}{ Medial } & \multicolumn{2}{|c|}{ Proximal } & \multirow[b]{2}{*}{ Fragment } \\
\hline & Left & Right & Left & Right & & Left & Right & \\
\hline \multicolumn{9}{|c|}{ Skull } \\
\hline Skull & & & & & & & & 1 \\
\hline \multicolumn{9}{|l|}{ Maxilla } \\
\hline \multicolumn{9}{|l|}{ Mandible } \\
\hline \multicolumn{9}{|l|}{ Hyoid } \\
\hline \multicolumn{9}{|l|}{ Incisor } \\
\hline Tooth & & 4 & & & & & & 1 \\
\hline \multicolumn{9}{|c|}{ Vertebrae + Pelvis } \\
\hline \multicolumn{9}{|l|}{ Atlas } \\
\hline \multicolumn{9}{|l|}{ Axis } \\
\hline \multicolumn{9}{|l|}{ Cervical } \\
\hline Thoracic & & & & & & & & 1 \\
\hline \multicolumn{9}{|l|}{ Lumbar } \\
\hline Caudal & \multicolumn{2}{|c|}{1} & & & & & & \\
\hline \multicolumn{9}{|l|}{ Rib (heads, shafts) } \\
\hline \multicolumn{9}{|l|}{ Sacrum } \\
\hline \multicolumn{9}{|l|}{$\begin{array}{l}\text { Pelvis (Ischium, } \\
\text { Ilium) }\end{array}$} \\
\hline \multicolumn{9}{|l|}{ Acetabulum } \\
\hline \multicolumn{9}{|c|}{ Front Leg } \\
\hline Scapula & 1 (tool) & & & & & & & 1 \\
\hline Humerus & & & & & & & & $1 * * *$ \\
\hline \multicolumn{9}{|l|}{ Radius } \\
\hline Ulna & & & & & & & 1 & \\
\hline \multicolumn{9}{|l|}{ Unciform } \\
\hline \multicolumn{9}{|l|}{ Scaphoid } \\
\hline \multicolumn{9}{|l|}{ Cuneiform } \\
\hline Lunate & & & & & & & & \\
\hline
\end{tabular}

\begin{tabular}{|c|c|c|c|c|c|c|c|c|}
\hline \multirow{2}{*}{ Element/Fragment } & \multicolumn{2}{|c|}{ Complete } & \multicolumn{2}{|c|}{ Distal } & \multirow{2}{*}{ Medial } & \multicolumn{2}{|c|}{ Proximal } & \multirow[b]{2}{*}{ Fragments } \\
\hline & Left & Right & Left & Right & & Left & Right & \\
\hline Metacarpal & & & & & & & 1 & \\
\hline \multicolumn{9}{|c|}{ Rear Leg } \\
\hline Femur & & & & & & & & 1 \\
\hline \multicolumn{9}{|l|}{ Patella } \\
\hline Tibia & & & 1 & & & & & \\
\hline \multicolumn{9}{|l|}{ Lateral Malleolus } \\
\hline \multicolumn{9}{|l|}{ Astragalus } \\
\hline \multicolumn{9}{|l|}{ Navicular Cuboid } \\
\hline \multicolumn{9}{|l|}{ Calcanium } \\
\hline \multicolumn{9}{|l|}{ Magnum } \\
\hline \multicolumn{9}{|l|}{ Metatarsal } \\
\hline \multicolumn{9}{|c|}{ Other } \\
\hline $1^{\text {st }}$ Phalanx & \multicolumn{2}{|c|}{2} & & & & & & \\
\hline $2^{\text {nd }}$ Phalanx & \multicolumn{2}{|c|}{1} & & & & & & \\
\hline \multicolumn{9}{|l|}{$3^{\text {rd }}$ Phalanx } \\
\hline \multicolumn{9}{|l|}{ Long Bone fragments } \\
\hline \multicolumn{9}{|l|}{ Cancellous } \\
\hline \multicolumn{9}{|l|}{ Unknown fragments } \\
\hline Sesamoids & & $*$ & & & & & & 1 \\
\hline Metapodial & & & & & & & 1 & \\
\hline TOTAL & & & & & & & & \\
\hline
\end{tabular}




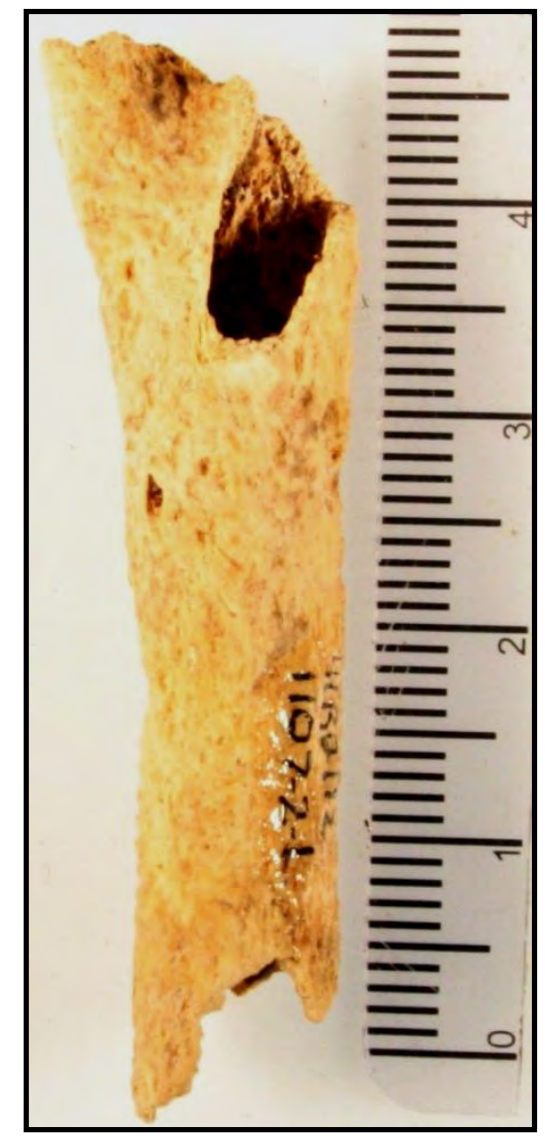

Figure 8-80. Fetal bison femur (\#1107-2-1) partially developed.

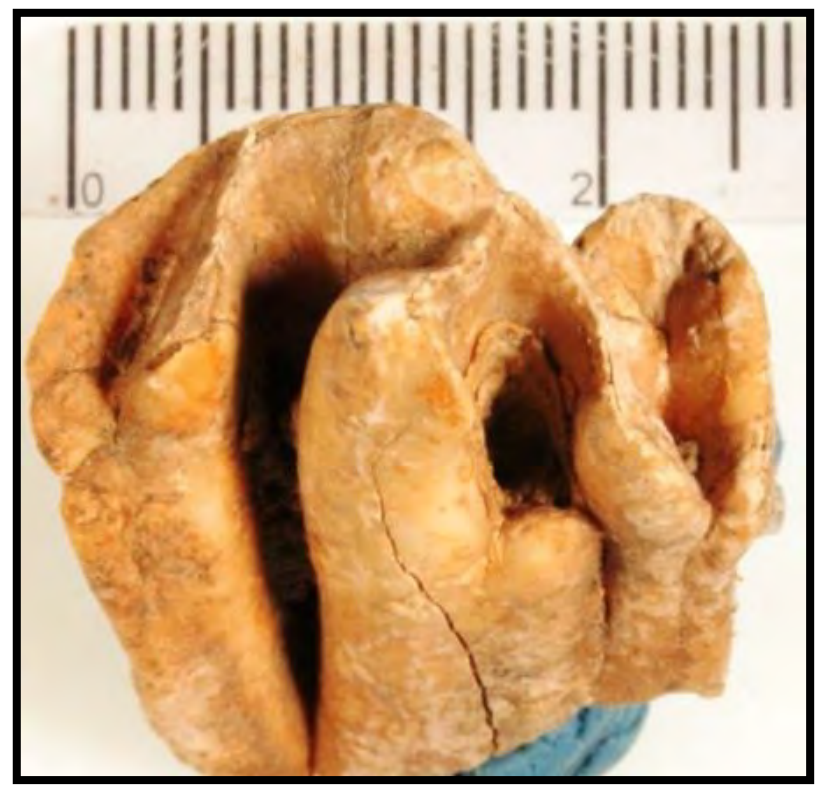

Figure 8-81. A young bison premolar tooth (\#1061-2), showing no wear on facets. 
were burned, indicating direct contact with fire. From this, one can assume that disposal of bone into the fire as a means of discard was not practiced. These burned pieces may reflect intentional discard or accidental inclusion in fires, since burning of bones is not a part of normal roasting, nor does it indicate boiling.

As previously stated, the bison bones are extensively weathered and root etched, removing or obscuring any evidence of stone tool cut marks, if such were once present. One particular specimen, however, may represent general defleshing and dismembering of carcasses. The midsection of a bison humerus bears an impact scar that represents intentional smashing of the bone for the purpose of extracting bone marrow from the interior cavity.

The horizontal distribution of identified bison elements is depicted in Figure 8-82, which indicates that bison bones were concentrated around the identified features in the northern part of the excavation block. This distribution pattern is similar to that of nonbison bones (i.e., deer, turtle and rabbit), which indicates use and discard of all taxa in the primary activity area immediately west and south of the pithouse and the heating elements. This is also the same pattern for the entire faunal assemblage and indicates a primary discard of bones near the heating elements and the pithouse (Figure 8-83).

\subsubsection{Summary}

In summary, the faunal bones in Component $\mathrm{A}$ indicate that at least four taxa-bison, deer, rabbits, and turtles - were exploited as parts of the food resource base. A minimum of one individual is represented by each of the identified taxa, with the exception of bison, which is represented by one large male and one adult female, which apparently carried a fetus. The entire bone assemblage was intensively processed, likely to extract bone marrow and render bone grease.

Based on very limited evidence, namely, two bison fetal elements and an unworn premolar, occupation, or at least bison hunting, can be estimated to have occurred during the fall and/or winter months. While the limited number of individual animals represented may indicate a seasonal focus on bison hunting, the presence of constructed domiciles (pithouses) and charred maize may indicate a multiseasonal semisedentary occupation.

\subsection{Worked Bone}

\section{J. Michael Quigg}

Ten pieces of bone, described below, reveal worked or used surfaces. Bone preservation was not great, and most specimens reveal various degrees of weathering and root etching. In some instances the weathering process has removed parts of the worked or used surfaces, making it difficult to detect use- wear. At least two specimens have been slightly burned, which undoughtedly helped in their preservation.

A medial fragment of an awl (\#20-10) came from the bladed surface of the fireguard. This short section was near the tip where it tapers toward the distal end (Figure 8-84; Table 8-18). The piece is weathered and partially covered in calcium carbonate. The awl exhibits a slightly concave interior surface representing the curvature of the natural marrow cavity. The thickness of the cortical wall indicates that this item was not made of bison bone.

The distal end of a burned long bone fragment (\#3110) came from below the eroding pithouse. The thickness of this piece indicates that it is made of bison bone that had been tapered to a pointed end which was blackened by burning (Figure 8-85; see Table 8-18). The exterior cortical wall exhibits the natural rounding of the bone surface. The burning of the distal tip may have been intentional, for the purpose of hardening for use, perhaps as a digging tool.

A fragmented and badly weathered specimen (\#78910) bears what appear to be intentionally placed notches along the exterior cortical wall (see Figure 8-85; see Table 8-18). Interior cancellous tissue is exposed on the bone surface opposite the notched surface. The notches are not equally spaced and are of slightly differing lengths. The piece exhibits a shallow, natural longitudinal groove between the two sides of the cortical wall, similar to the grooves on deer-size metapodial. 


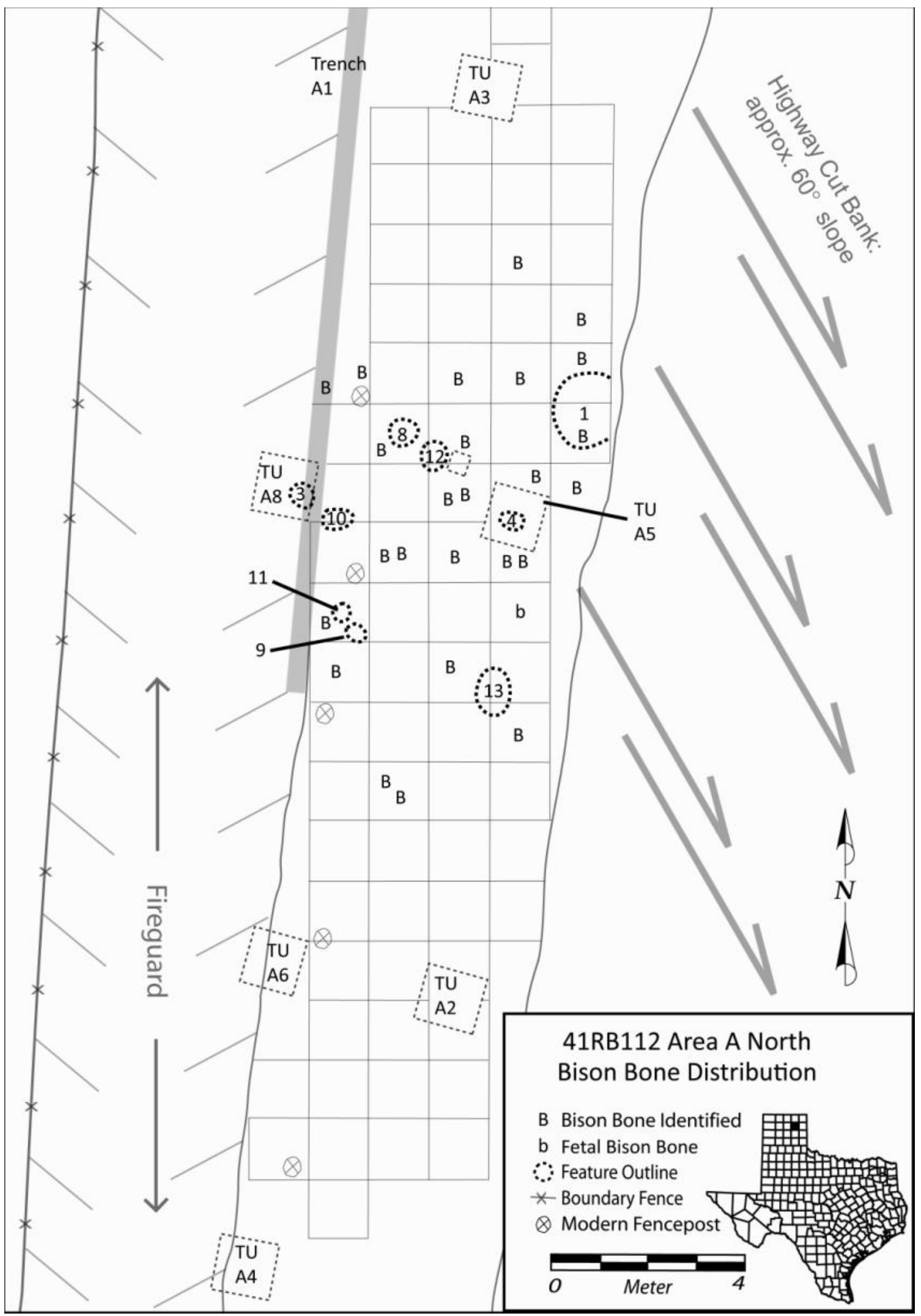

Figure 8-82. Horizontal distribution of identified bison elements. 


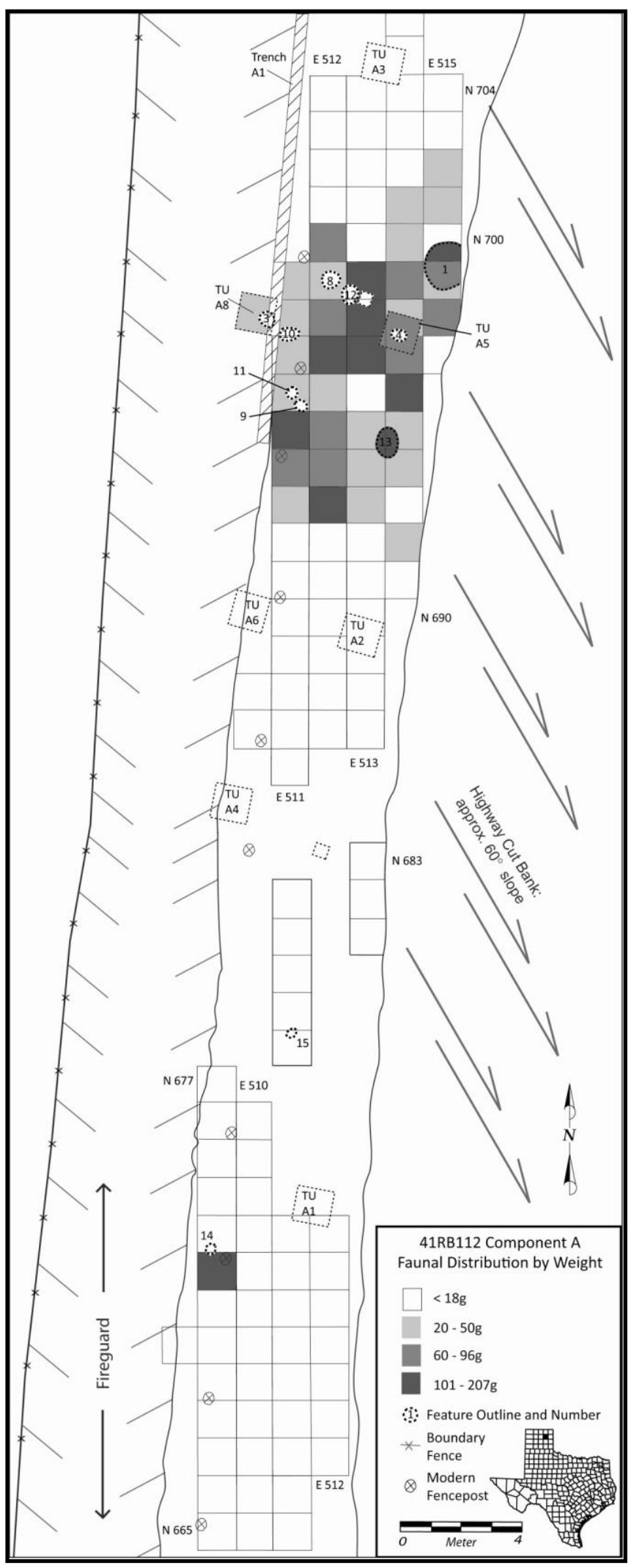

Figure 8-83. Horizontal distribution of all faunal material by weight in Component A. 


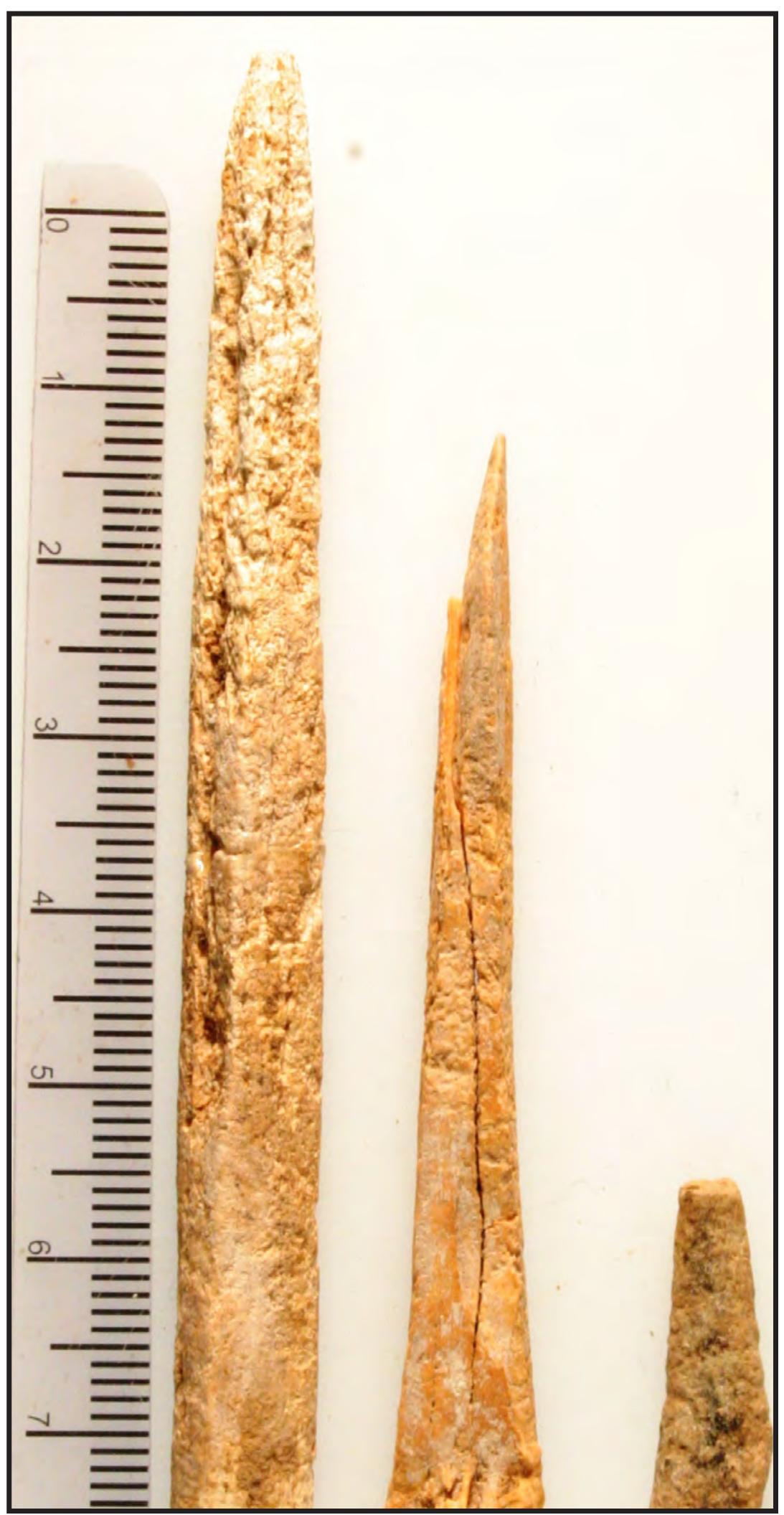

Figure 8-84. Bone awls (\#1090-10), (\#1047-10), and (\#20-10).

Scale is in centimeters. 
Table 8-18. Selected Worked Bone Data from Component A.

\begin{tabular}{|c|cc|c|c|c|c|c|c|c|}
\hline Catalogue No. & \multicolumn{2}{|c|}{$\begin{array}{c}\text { Unit No. } \\
\mathbf{N}\end{array} \mathbf{E}$} & Depth $(\mathbf{c m})$ & Feature No. & Tool Type & Weight (g) & $\begin{array}{c}\text { Length } \\
(\mathbf{m m})\end{array}$ & $\begin{array}{c}\text { Width } \\
(\mathbf{m m})\end{array}$ & $\begin{array}{c}\text { Thickness } \\
(\mathbf{m m})\end{array}$ \\
\hline $20-10$ & fireguard & surface & NA & awl frag. & 0.6 & 24.4 & 6.7 & 4.1 \\
\hline $31-10$ & cutbank & 44 & NA & ? digging & 5 & 42.7 & 14.9 & 13.5 \\
\hline $789-10$ & 671511 & $10-20$ & NA & notched rib & 2.4 & 49.6 & 16.8 & 5.4 \\
\hline $800-10$ & 672509 & $40-50$ & 14 & unknown & 5.5 & 69.6 & 23.5 & 7.1 \\
\hline $829-10$ & 674509 & $40-50$ & NA & spatula & 143.3 & 243 & 130 & 29.2 \\
\hline $1010-10$ & 695 & 513 & $20-30$ & NA & unknown & 20.5 & 92.8 & 28.6 & 13.3 \\
\hline $1031-10$ & 696511 & $50-60$ & NA & spatula & 0.1 & 17.1 & 11.3 & 4.3 \\
\hline $1047-10$ & 696 & 514 & 42 & NA & ? awl & 3.3 & 67.7 & 11.7 & 7.9 \\
\hline $1090-10$ & 698513 & $20-30$ & NA & awl & 2 & 88.5 & 8.1 & 7 \\
\hline $1192-10$ & 702513 & $10-20$ & NA & ? unknown & 2.8 & 40.1 & 10.1 & 9.5 \\
\hline
\end{tabular}

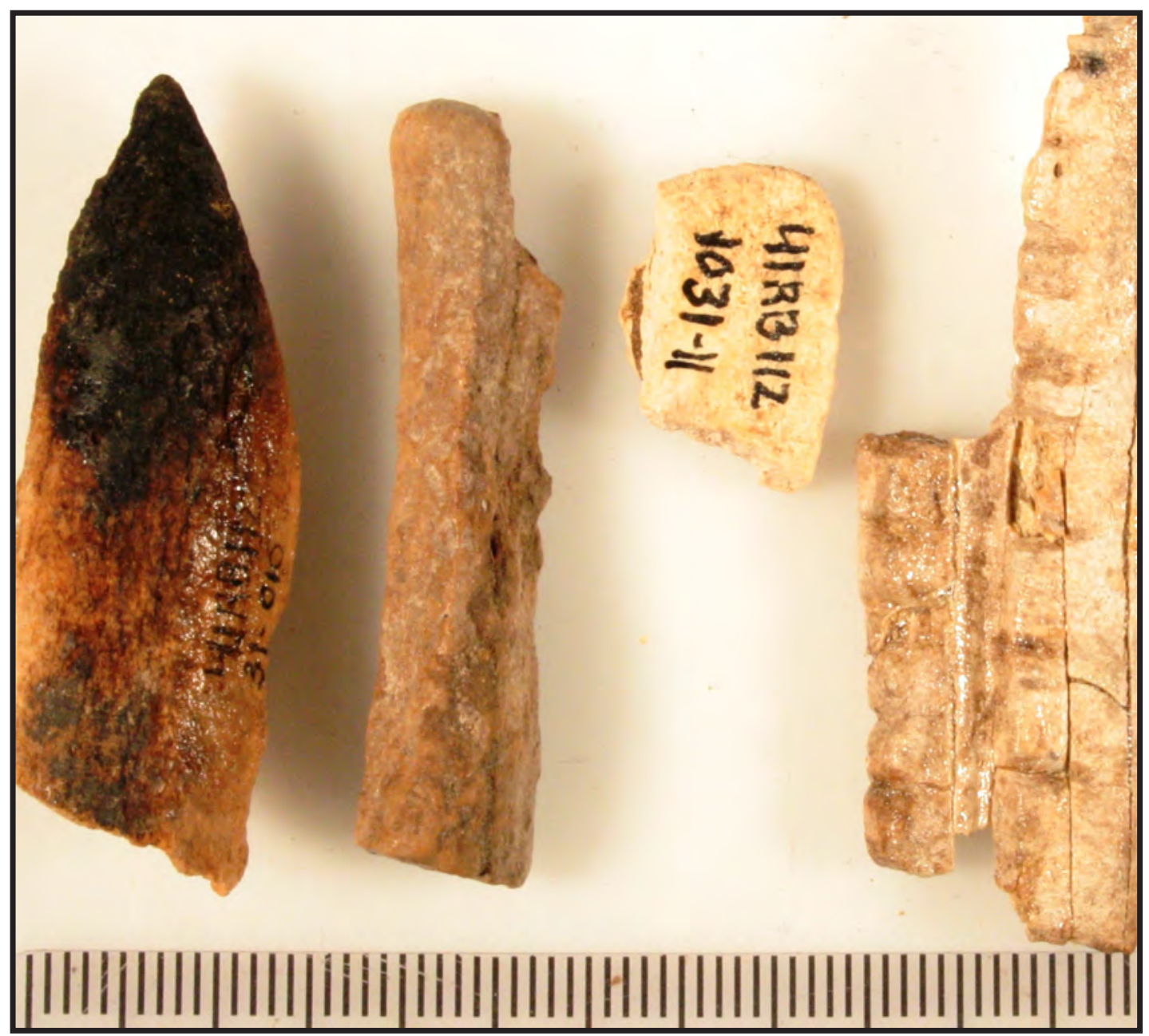

Figure 8-85. Bone tools; a burned pointed tip (\#31-10), a probable punch (\#1192-10), spatula tip (\#1031-11), and notched rasp (\#789-10).

Scale is in centimeters. 
Specimen \#800-10 is a small fragment of what appears to be the blade of a scapula as one edge thickens and could be the spine, whereas the opposite edge tapers to a section of thin cortical tissue (see Table 8-18). The thicker edge exhibits minor rounding near the exposed cancellous tissue. Both faces are weathered and root-etched. The function of this piece is not apparent.

Specimen \#1010-10 is a short fragment of a bison long bone, likely the midshaft of a tibia, judging by the angular edge of the cortical wall tissue (see Table 8-18). The surfaces are not badly weathered, although they do exhibit minor root etching. One broken edge exhibits two, or possibly three, small flake scars that originate on the broken edge. The opposite edge is rounded and is well worn from use. It is inferred that this is part of a bison tibia digging tool.

A small, flat fragment (\#1031-11) exhibits a curved and rounded end with cancellous tissue on one face and a thin cortical wall on the other face tissue (see Figure 8-85; see Table 8-18). It is difficult to identify the function of this piece, but it appears to be part of a spatulate tool.

Specimen \#1047-10 is a pointed sliver of a relatively thin bone (see Figure 8-84; see Table 8-18). Although weathered with some root etching, the very tip is slightly rounded. However, the lateral edges are angular and show no obvious wear. If used, it was only for a short time and does not exhibit the wellrounded tip seen on other awls.

Specimen \#1090-10 is a well-formed awl that exhibits extensive weathering and root etching (see Figure 8-84; see Table 8-17). The proximal end is worked to a rounded form. It was manufactured from the angular edge of a long bone or possibly a rib with cancellous tissue partially exposed on one of the three sides. The weathering has removed all signs of polish but the proximal end is well-rounded and the distal end tapers to a point.

This short, brown long bone fragment (\#1192-10) appears to have been lightly burned (see Figure 8-85; see Table 8-18). One end is rounded and blunt with minute flake scars and tiny scratch lines. It is not clear how this tool was employed, but it was artificially formed, and then used. It may have served as a "punch" used in flint knapping. This fragment is thick enough to have been made of the cortical portion of long bone from a large mammal such as a bison.

Amajor section of a right bison scapula (\#829-10) that lacks the glenoid fossa and parts of the lateral edges. The latter are possibly from weathering whereas the glenoid fossa was intentionally removed. The distal edge of the blade exhibits rounding and wear from use and may have been a hoe. (Figures 8-86 and 8-87).

\subsection{Burned Rock Analyses}

\section{J. Michael Quigg}

As one might expect, burned rocks have not been recovered in great quantities from Plains Village sites, which is also the case in Component $\mathrm{A}$. The hand-excavations yielded a low frequency of 356 pieces (Figure 8-88). None of the 11 cultural features, which included 7 heating elements, were dominated by burned rocks. Burned rocks were present in Component A, but they were generally scattered across the excavated areas. When encountered, their counts and weights were documented on excavation level records. The majority of burned rocks was discarded with only a few random samples from various proveniences collected for possible future analyses.

Of the reports on Plains Village sites (i.e., Watson 1950; Keller 1975; Lintz 1986, 1997; Bevitt 1999; Baker and Baker 2000; Brooks 2004; Weistein 2005), few mentioned burned rocks or quartzite pebbles among recovered assemblages (i.e., Duncan 2002:214). Others, (i.e., Duffield 1964; D. Hughes and Hughes-Jones 1987; J. Hughes 1991:32; Boyd and Wilkens 2001:3; Brosowske 2009:14) mention boiling stones in passing. Therefore, comparison of frequencies or material types from other Plains Village sites in the region is not possible.

Roughly 95 percent of the burned rock assemblage $(N=339)$ was recorded in detail and weighed 22,401 $\mathrm{g}$ for an average of $66.1 \mathrm{~g}$ per rock. Their sizes 


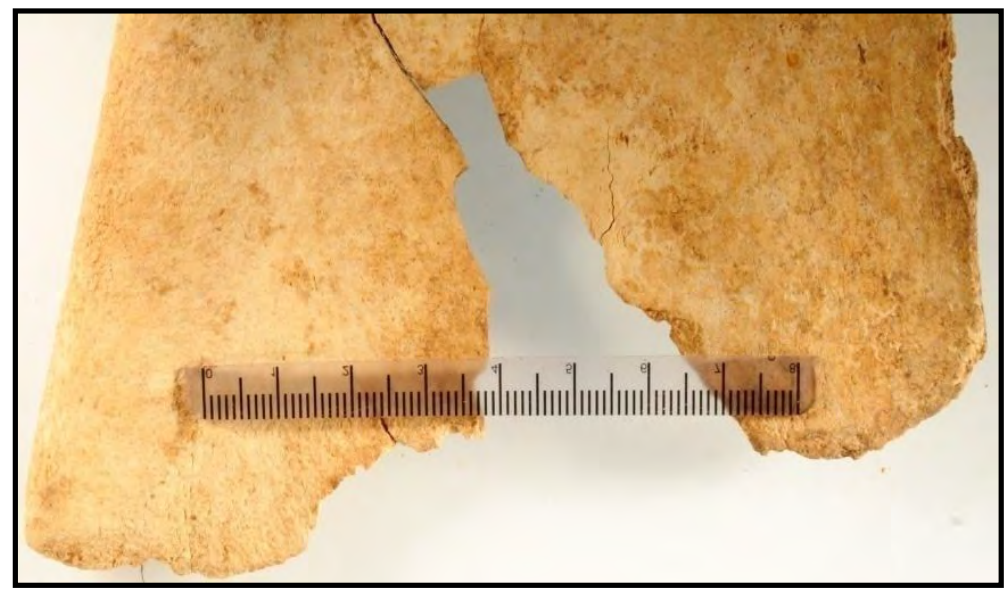

Figure 8-86. Closeup of worn distal end of a bison scapula (\#829-10) showing slight beveling at the very distal edge.

Scale is in centimeters.

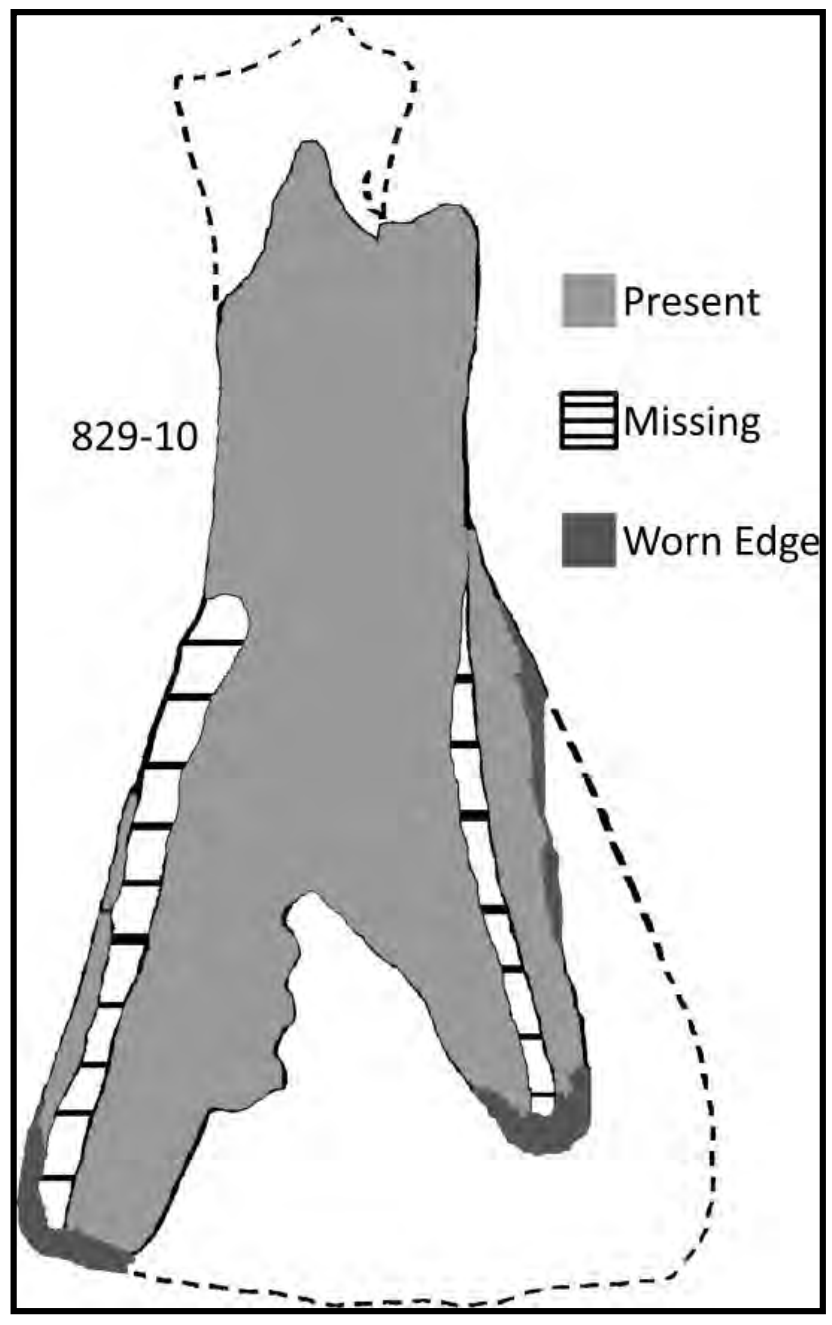

Figure 8-87. Bison scapula (\#829-10) showing manufactured and use areas. 


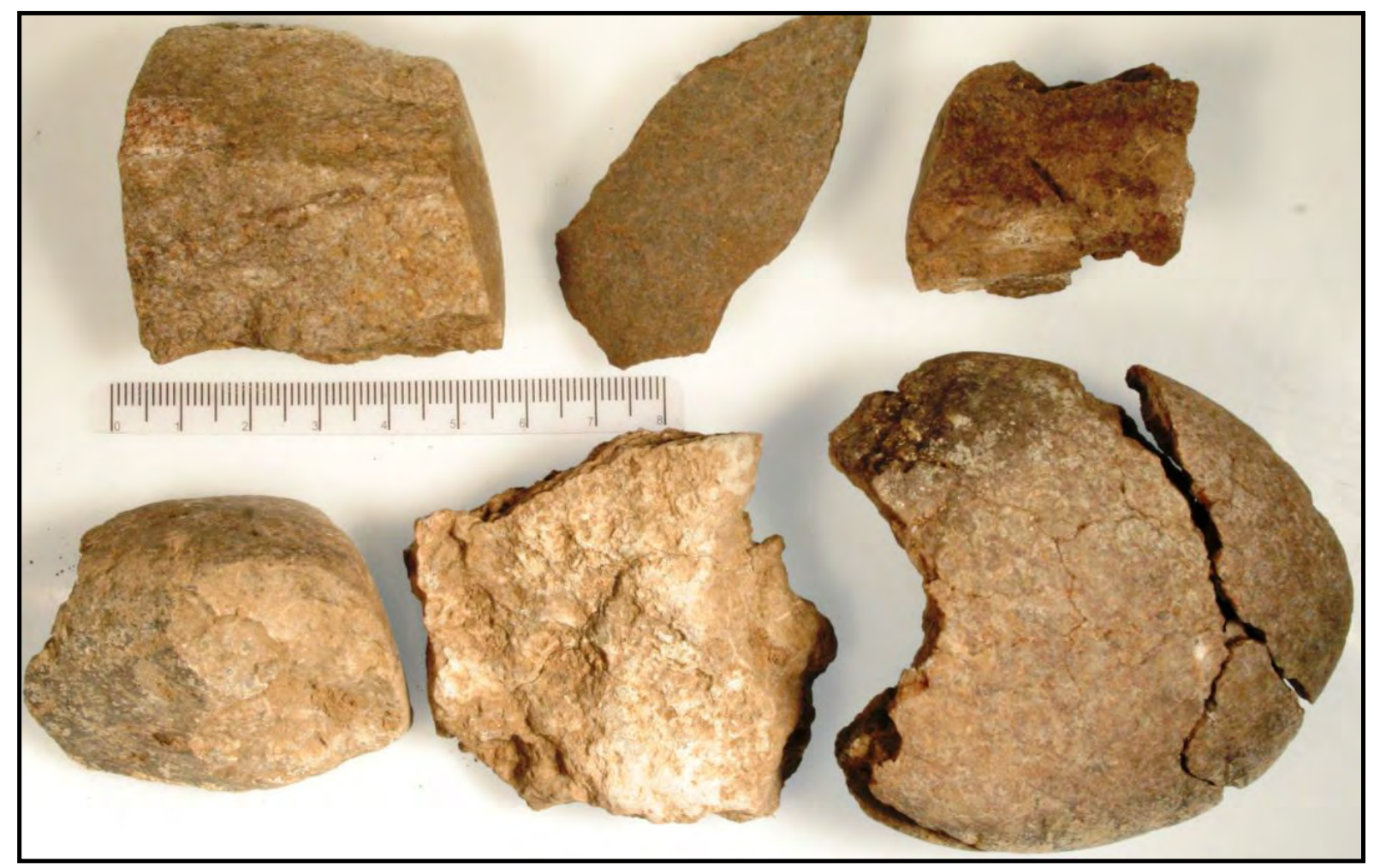

Figure 8-88. Photograph of sample of the burned rocks from Component A. Note hackled edges on two quartzite samples on right.

varied from 2 to $14 \mathrm{~cm}$ in diameter. The smallest size category, 0 to $4 \mathrm{~cm}$, dominated with 57.5 percent by count but only 7.9 percent by weight. The next size category, 4.1 to $9 \mathrm{~cm}$, accounted for another 37.2 percent by count, with 5.3 percent greater than $9.1 \mathrm{~cm}$. Although the larger categories account for a very small percentage by count, the burned rocks greater than $9.1 \mathrm{~cm}$ account for nearly 53 percent by weight.

Quartzite pebbles (0 to $6 \mathrm{~cm}$ ) accounted for some 14 percent of the total, and nearly 96 percent of those were fragmented or broken through the heating and cooling process. Quartzite cobbles $(>6 \mathrm{~cm})$ accounted for another 5.3 percent and again most were broken fragments. The majority or roughly 56 percent were amorphous chunks of caliche with 11.5 percent sandstone and a few unidentified pieces. Clearly, multiple rock types were sought and used, and the percentages present may reflect their availability over a clear selection process. The fragmented quartzite pebbles most often exhibit a hackled edge (see Figure 8-87, rock in lower right corner), which is often indicative of the rapid cooling that takes place when a hot rock enters a watery solution, likely in a cooking process. Assuming that the caliche was most readily available, it is of some importance that relatively small water rounded quartzite pebbles were present in the numbers that they were. It is possible that these had a specific purpose or functioned in a way that the other rocks could or did not. Based on the fracture pattern alone, it is apparent these small pebbles were used to transfer heat to a watery solution, mostly likely in a cooking vessel, which is best reflected in boiling food.

The function(s) of burned rocks in Plains Village sites has not been addressed. Here, it is assumed that most burned rocks were used for the same tasks as most mobile hunter-gatherer groups, which were to cook and/or heat food. Thirteen burned rocks were selected for two technical analyses from the small sample of retained burned rocks and were subjected 
to starch grain analysis to investigate what foods these rocks may have come in contact with. Seven pieces were sent for diatom analysis, which included one piece from Features 11, 13, 14, and 15 and three scattered pieces, to see if a specific cooking process, such as boiling, was a possibility for these stones and to help address water quality.

The diatoms $(N=82)$ from the analysis of seven burned rocks is relatively meager with one rock yielding the exception, \#836-3-1. This burned rock from N675 E509 at 20 to $30 \mathrm{cmbs}$ yielded 55 diatoms, the most of any burned rock in this sample. The identified diatoms are dominated (at least 65 percent) by aquatic benthic species that are associated with sediment, microbial mats, drifting mats of filamentous algae, and rooted vegetation on the floor of a stream (see Appendix J). This association of burned rock and stream water may be indicative of food preparatory activities, such as boiling. The other burned rocks yielded between 1 and 16 diatoms (see Appendix J). These specimens also yielded diatoms similar to the burned rock discussed above, which generally supports a similar postulated interpretation of how those diatoms could be associated with burned rocks.

Ten of the 13 burned rocks analyzed for starch yielded starchy remains of plant foods. Appendix D provides the procedures and the detailed individual results. Here, only a summary is presented. Most samples yielded only a few starch grains with two notable exceptions. Burned rock \#692-3-1b yielded 10 grains of maize (Zea mays) and 3 grains of little barley (Hordeum pusillum). Burned rock \#821-3$1 \mathrm{~b}$ yielded 9 grains of maize and 34 grains of little barley. The other 8 rocks yielded a total of 6 grains of maize, 21 lenticular grains of little barley, with 6 grains of an unidentified lily bulb. Besides these starch grains, one rock yielded a damaged grain of maize, one yielded a damage grain of little barley, and another yielded a gelatinized grain of little barley, with at least two rocks yielding unidentified gelatinized grains. Gelatinization occurs when heating starch in the presence of water. It is interpreted that these gelatinized grains support the conclusion that the burned rocks were used in the general cooking process, and more specifically for boiling maize and little barley.
Here, the horizontal distribution data contributes to a broader understanding of where cooking related activities occurred and if that contributes to various human behaviors. The low frequency of 356 rocks for the $128 \mathrm{~m}^{2}$ hand-excavated yields a low density of only 2.8 rocks $/ \mathrm{m}^{2}$. Interestingly, not a single feature was dominated by burned rocks and this is supported by the wide distribution pattern (Figure 8-89). Although burned rocks did not dominate any of the identified features, the heaviest concentration of burned rocks was in the immediate vicinity of the heating elements and the partial pithouse at the northern end of the excavations area. A couple of units that yielded moderate frequencies in the southern end of the block, hint at the present of another activity areas next to Feature 14.

\subsection{Burned Clay/Daub}

\section{J. Michael Quigg}

This artifact class is not often present or recognized, but is prevalent in some Plains Village sites and merits consideration. Here, hand-excavations yielded 368 pieces with a total weight of $938.1 \mathrm{~g}$ for an average of $2.5 \mathrm{~g}$. The largest chunk weighs roughly $250 \mathrm{~g}$, though most pieces are much smaller, weighing under $10 \mathrm{~g}$ each (Figure 8-90).

In most instances, the pieces are small, hard but friable, and roughly spherical or irregular lumps with few recognizable impressions. No consistent shapes or standard sizes are represented, since the majority are fragments with irregular shapes and broken edges. Many contain tiny sand grains in the clay matrix (i.e., \#1017-5; \#1021-5-1). Whether this was an intentional addition or not is unknown. A few pieces have tiny, whitish carbonate inclusions (i.e., \#723-5) whereas other pieces have calcium carbonate adhering to their surfaces (i.e., \#1017-5). Some exhibit one very shallow and smooth concave face (i.e., \#947-5; \#1021-5-1), apparently representing the impression of a wide stick or narrow pole. Often, the side opposite the concave face with the impression is slightly convex and generally smooth. In some instances, a flat surface is opposite the irregular face (i.e., \#705-5). Roughly 15 pieces exhibit small stick and/or grass-blade impressions In at least one instance (i.e., \#1037-5), multiple lines/impressions, similar to what would be made by multiple pieces of 


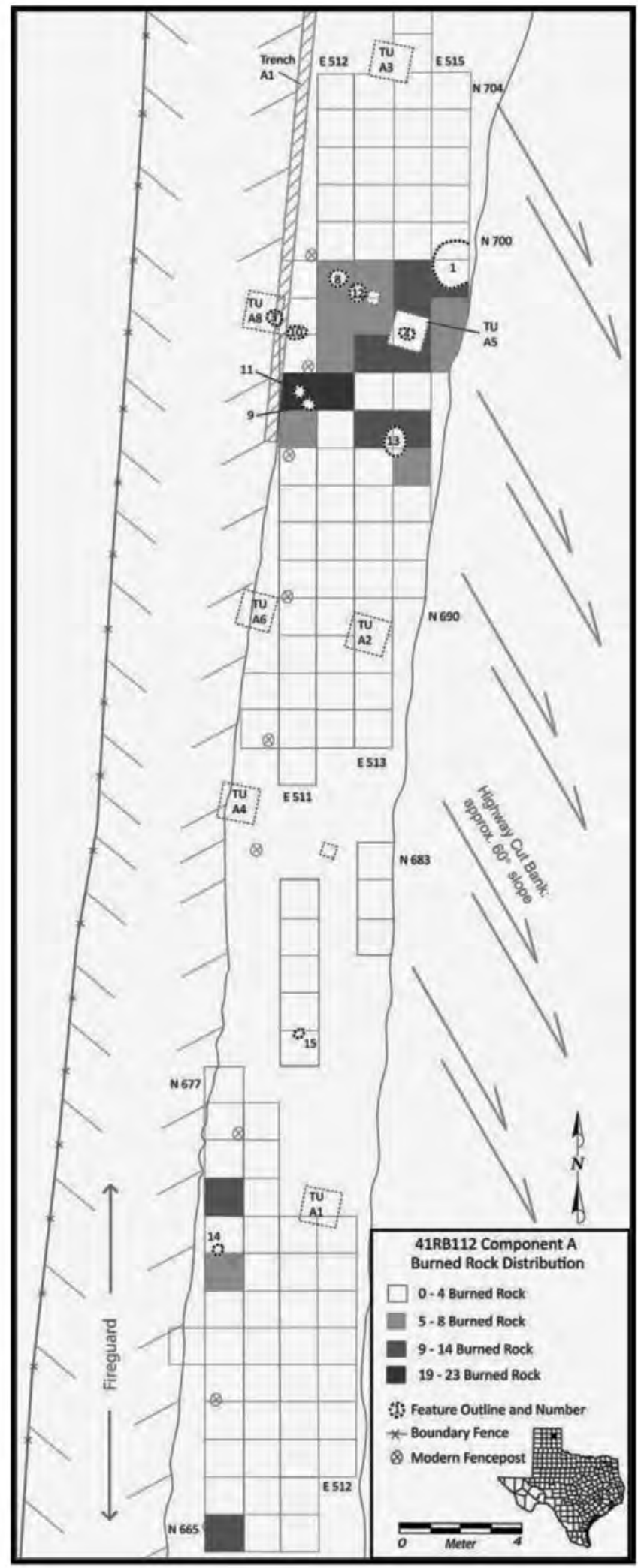

Figure 8-89. Horizontal distribution of burned rocks by count. 


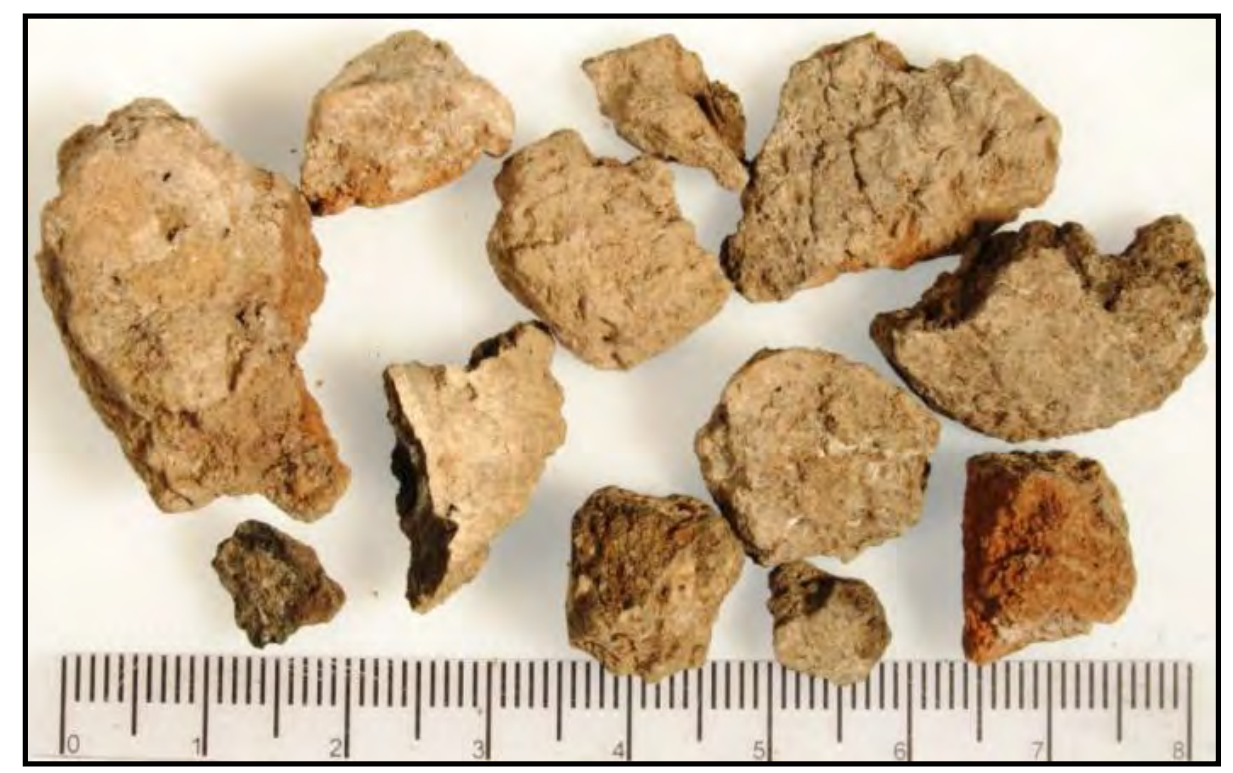

Figure 8-90. Examples of burned clay/daub (\#1113-5) that exhibit variations in size and shape. Scale in centimeters.

grass, originate along the same line. No impressions appear to represent basketry, fabrics, or cordage as observed on the pottery sherds, and no surfaces bear recognizable finger prints. Selected examples will be presented below.

The colors show some variations, with most exhibiting at least two or more colors. The exterior colors range from pink (7.5YR 7/4) to light brownish gray (10YR 6/2), to pale brown (10YR 6/3). Most brownish gray exteriors reflect a film of calcium carbonate. The core or interiors colors range from pink (7.5YR 7/4), to dark gray (01YR 4/1), to strong brown (7.5YR 4/6).

Two pieces (\#956-5-2 and \#1160-5), weighing $15.9 \mathrm{~g}$ and $7.5 \mathrm{~g}$ respectively, were sent for diatom analyses. Neither piece showed anything of particular interest such as stick impressions. Specimen \#1160-5 came from the upper part of the pithouse, Feature 1 . The two pieces yielded markedly different frequencies of diatoms, 4 from \#956-5-2 compared to 131 from \#1160-5. The reason for this difference is unknown. Winsborough (Appendix J) indicates that these daub samples contained two groups of diatoms, one belonging to the Aulacoseira distans complex, typical of very soft waters, of a shallow, lacustrine-palustrine (marsh, swamp or bog) environment that contained cool, acidic, dilute, low-conductivity water. Aulacoseira distans are found in the Pliocene Ogallala Formation (Selva 1976) and have been reported from many other fossil freshwater lacustrine deposits as well. The second group contained Tabellaria fenestrata and Staurosirella martyi, diatoms that are found in coldwater, low alkalinity, nutrient poor, and acid-water lakes. This second group, reflective of a hard-water stream species, may have been incorporated into clay exposed along a stream bank at the time when it was collected for use as daub. One explanation for the incorporation of alkaline stream diatoms into older lacustrine sediments would be that the clayey sediment (i.e., Ogallala sediments) excavated during pithouse construction was dampened with creek water in order to make it malleable for use. The available evidence indicates that the clayey Ogallala sediments from the base and below the pithouse were used to make daub (Appendix J).

Three chunks (\#1012-5-1, \#2213-5-2, and \#1140-54) were chemically analyzed through instrumental neutron activation analysis. These results are similar to the pottery samples in a broad regional way, but no direct link could be made between the pottery 
compositional groups and the daub (Appendix G). The visible aspects provide clues as to how it was used and how it functioned. Less than 10 percent of the specimens exhibit small stick and/or grass impressions, which can contribute to identifying probable functions. In some instances a small impression is present, but it is unclear what made the impression, given that small insects and/or worms can create similar lines/trails. Most pieces are so small that a series of impressions are not evident on any one piece. Often, only a small section of a single impression is present on a piece of clay/daub.

A few pieces are worthy of more detailed descriptions. A single, 1-mm-deep, 11-mm-long straight impression on \#1202-5 is about 1-mmwide and exhibits a well-defined " $U$ " shape in cross section (Figure 8-91). This impression was likely created by a grass stalk or a very small stick, judging by its straightness, shape, and size. This piece is relatively thin, with a bumpy face opposite the side with the impression. It came from N702 E515, a couple of meters north of the pithouse, Feature 1.

Specimen \#1021-5-1 (14.7 g) came from a storage pit, Feature 13. It bears a shallow concave impression roughly 14 -mm-wide by nearly 22-mm-long, which may have been created by pressing the clay against a clean stick from which the bark had been stripped (Figure 8-92). This is the only piece that has a sizable concave impression that might have been made by a thick stick. The surface opposite the impression is irregular, with a deep and narrow divot, plus a shallow impression with internal lines that may be from a blade of grass.
Specimen \#1101-5 (1.4 g) is roughly 6.8-mm-wide with one rough face and face with multiple stick impressions. The latter face exhibits a deep, narrow rounded groove on the right edge possibly made by a stick, a wider and shallower rounded groove on the left side with a narrow impression in the center (Figure 8-93). These multiple impressions are quite narrow with the one on the right likely created by a small stick, whereas the other impression may represent a woody stick or grass. This piece came from N698 E515, roughly $1 \mathrm{~m}$ west of a heating element, Feature 4.

What appears to be a grass-blade impression is on the outer convex, smooth left edge of \#1067-5 (Figure 8-94). The outer edge also shows small areas of other possible plant impressions that are very restricted in area. The opposite face is broken as are the top and bottom sections. This piece was from N691 E514, just south of heating element Feature 4.

The presence of the small stick/grass impression indicates that daub was used to cover or seal matting or possible structures such as a wattle and daub or other similar structures.

The lack of sizeable concentrations or large chunks of burned clay/daub in or around the pithouse, Feature 1, indicates that the structure did not burn (Figure 8-95). Burning would have resulted in massive quantities of burned daub, and at least some large pieces should have remained if the structure was of earth and wood construction. In fact, no concentrations or chunks greater than 6 $\mathrm{cm}$ in diameter were recovered or identified across

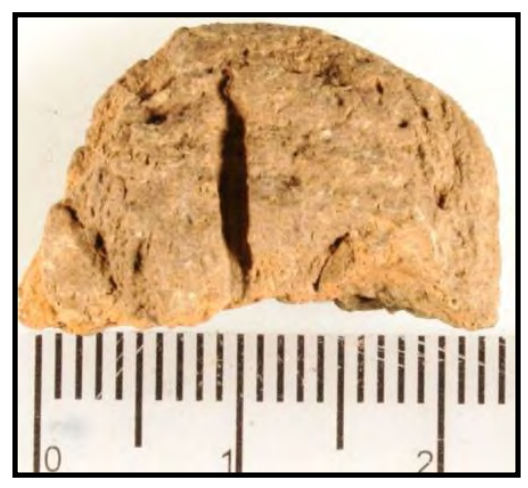

Figure 8-91. Burned clay/daub (\#1202-5) with narrow stick impression. 


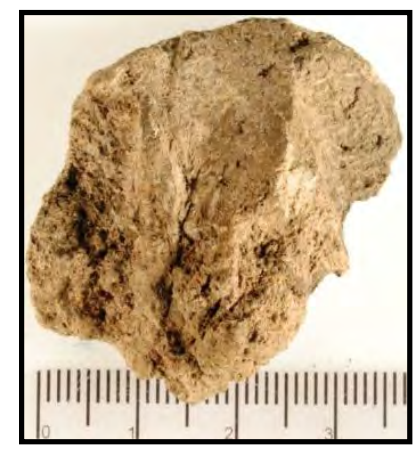

Figure 8-92. Burned clay/daub (\#1021-5) with smooth, wide stick impression on one side. Scale in millimeters.

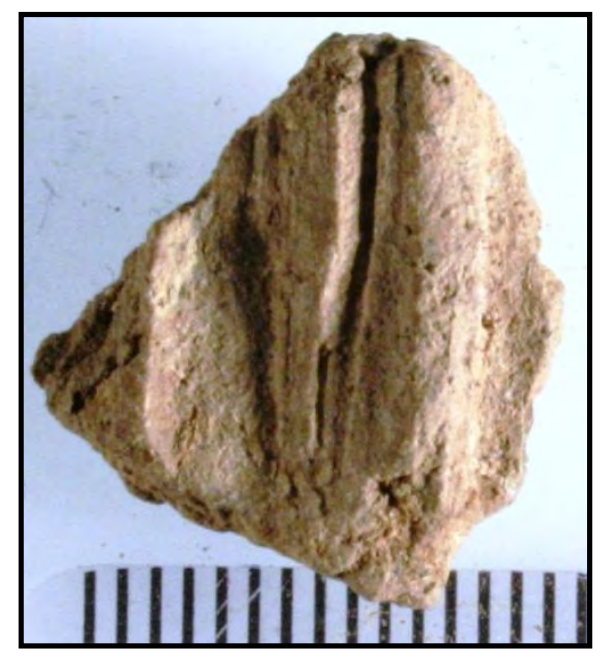

Figure 8-93. Burned clay/daub (\#1101-5) with multiple narrow impressions on one face. Scale in millimeters.

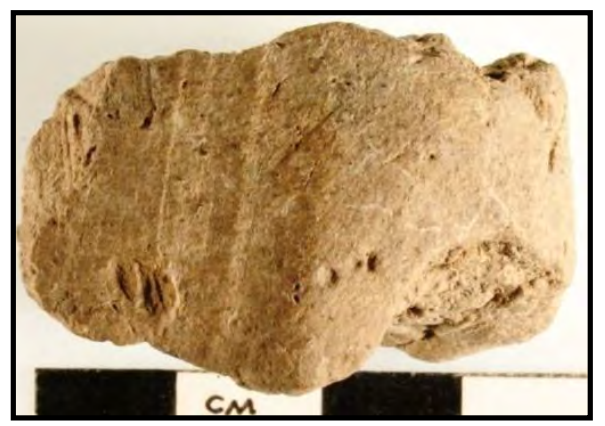

Figure 8-94. Burned clay/daub (\#1067-5) with faint and shallow, possible grass impression on left side. 
Component A. The greatest concentrations of daub by weight were in and around the various features, which included the pithouse (Feature 1), the storage pit (Feature 13), and even the suspected rodent concentrated materials in Feature 14 (see Figure 8-95). This horizontal distribution pattern indicates burned clay was connected to heating elements and likely resulted from the heat produced by the heating elements and related cooking activities. In at least two cases, a tiny piece of daub was recognized in the heavy fractions from floated feature sediment (i.e., Features 10 and 13). Feature 10 was a dump area that contained a variety of cultural debris. Feature 13 was a small circular storage pit that contained a variety of cultural debris that was not directly associated with the function of that pit. The daub did not originate in these features and likely was moved and discarded to those locations during cleaning and discard activities. Therefore, the provenience from which they were recovered does not directly contribute to understanding their function. Duffield 1964:69 recognized a similar broad distributional pattern and stated that the daub from Spring Canyon (41HC20) was widely scattered over the site and was not directly associated with structures. The daub maybe associated with something besides structures such as the manufacturing of pottery.

\subsection{Worked Clay}

\section{J. Michael Quigg}

\subsection{1 "Spindle Whorls"}

The recovered ceramic assemblage includes broken cordmarked sherds that have been reworked, as evidenced by rounded margins and, in one instance, a hole drilled near the middle to create what are referred to as spindle whirls or pottery disks (Bell 1980:95). Here, 12 broken sherds have been reworked along one or more edges to create smooth, rounded margins. One complete reworked sherd has rounded margins with a biconical hole drilled towards the middle of the roughly ovate specimen (\#1168-10; Figures 8-96 and 8-97). This complete reworked sherd is the template to which other worked sherds were compared, allowing small fragments with rounded edges to be assigned to this category. Most fragments lack any sign of the distinctive central hole. Their general attributes are provided in Table 8-19 and a representative sampling of the various specimens are shown in Figure 8-96. The one complete specimen is discussed separately.

Specimen \#1168-10 is an irregularly ovate reworded ceramic sherd with a biconically drilled hole positioned just off center. The hole itself is 3.6-mmwide, while the outer edge of the tapered perforation is $8.7-\mathrm{mm}$-wide. The interior of the sherd is irregular. The exterior has narrow, thin cordmarks that are well-defined. The outer margins are ground smooth, creating a somewhat rounded edge that in places bears flat spots of facets.

The function of these objects has not been clearly defined. Two specimens were sent for starch grain analysis. The notched specimen yielded one maize starch grain and one lenticular little barley grain (Appendix D). The complete spindle whorl yielded one lenticular little barley grain. These same starches were detected on other sherds analyzed are not restricted to these reworked sherds. Most likely, these starches reflect the original cooking functions of the vessels from which the sherds came. The lack of other types of grains or tissue does not help to resolve the function of these "spindle whorls", and currently little direct evidence is available which would allow us to specify their function. Culin (1992) mentions a variety of games that used small circular disks of one type or another and these may be parts of those games.

This artifact class, pottery disks or spindle whorls, is not always mentioned in summaries of Antelope Creek pottery assemblages (J. Hughes 1991; Brooks 2004), but they are listed as part of the broader assemblage, together with other clay items (i.e., Stamper site, Watson 1950:41; Duffield 1964:46-47; Roy Smith site, Schneider 1969; Lintz 1986:35; Blue Creek site, Couzzourt and SchmidtCouzzourt 1996). They are relatively common in central Oklahoma village sites (Bell 1980:95), but infrequent in the earlier Paoli phase and subsequent Washita River phase of the Washita and Canadian River valleys in central Oklahoma (Drass 1997). Similar pottery/ceramic disks are also present further north at some Plains Village sites in southern Kansas (i.e., Bevitt 1999). Bell (1980) points out that most of these artifacts are not suitable for use 


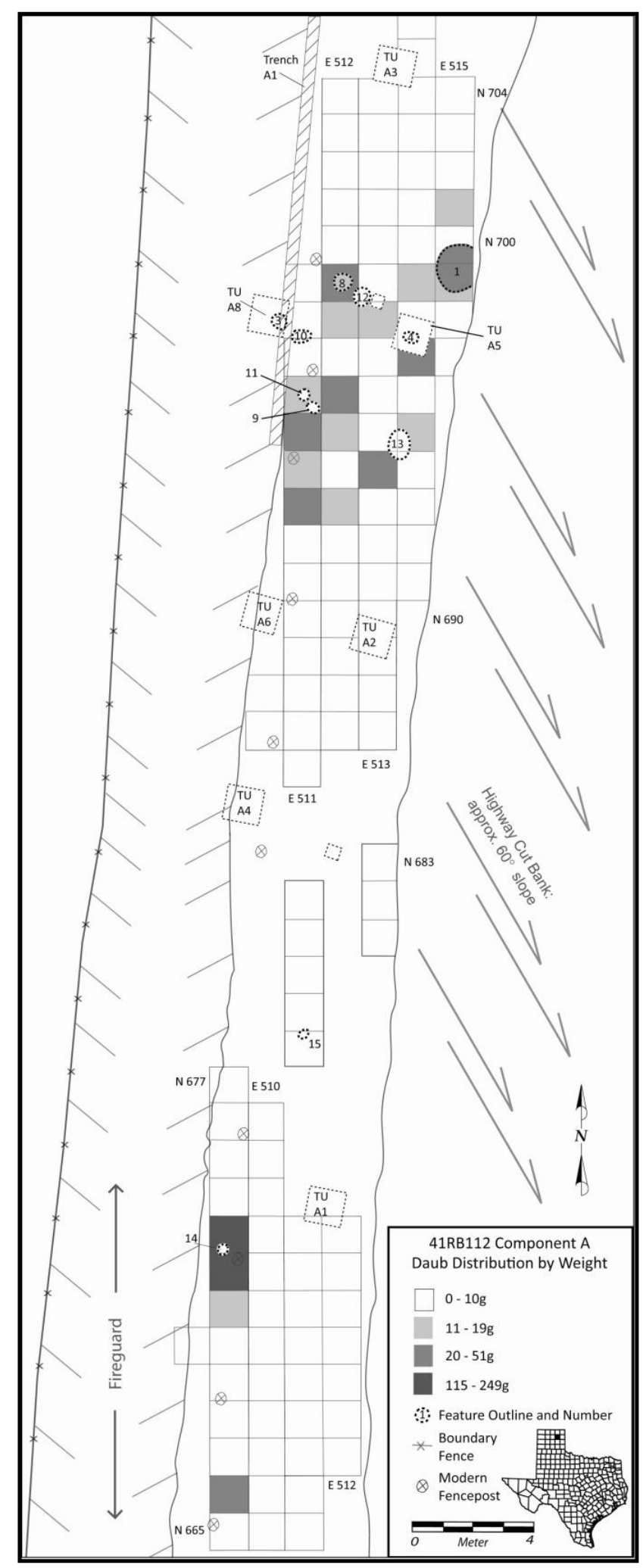

Figure 8-95. Horizontal distribution of daub weight across Component A. 


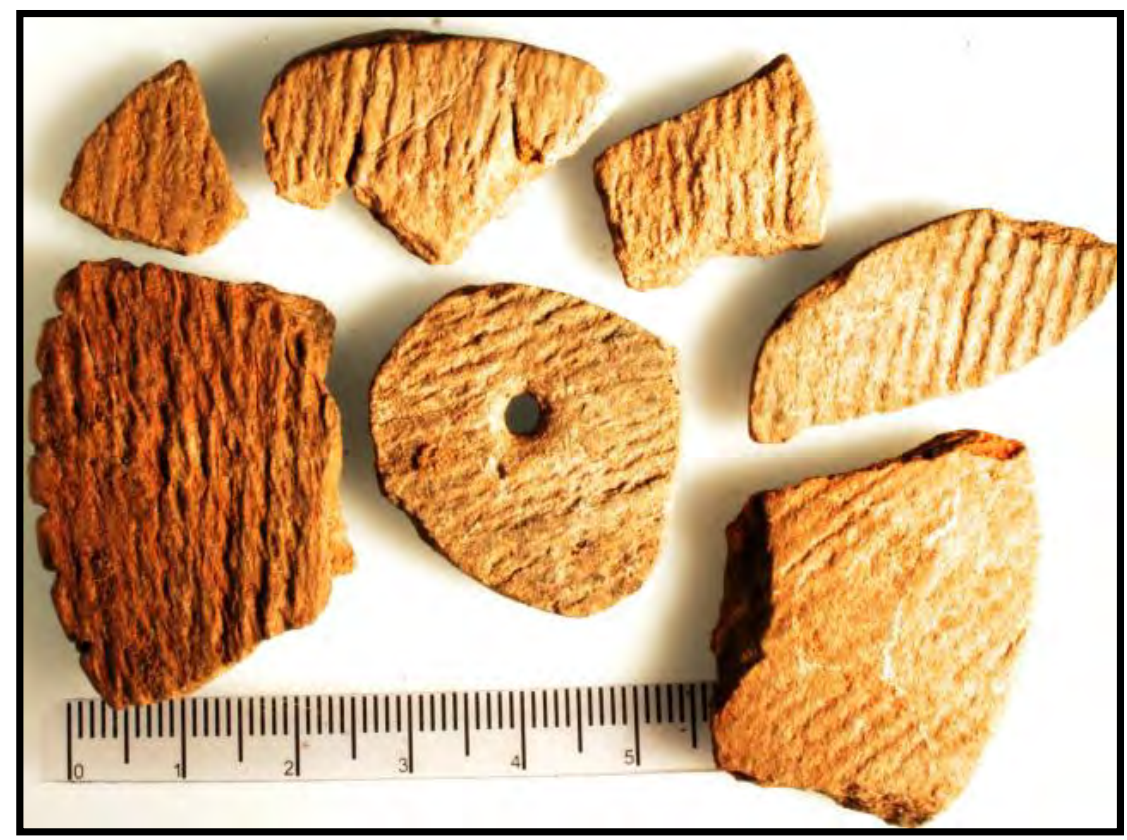

Figure 8-96. Reworked sherds with one complete "spindle whorl" and similar broken pieces. Scale in centimeters.

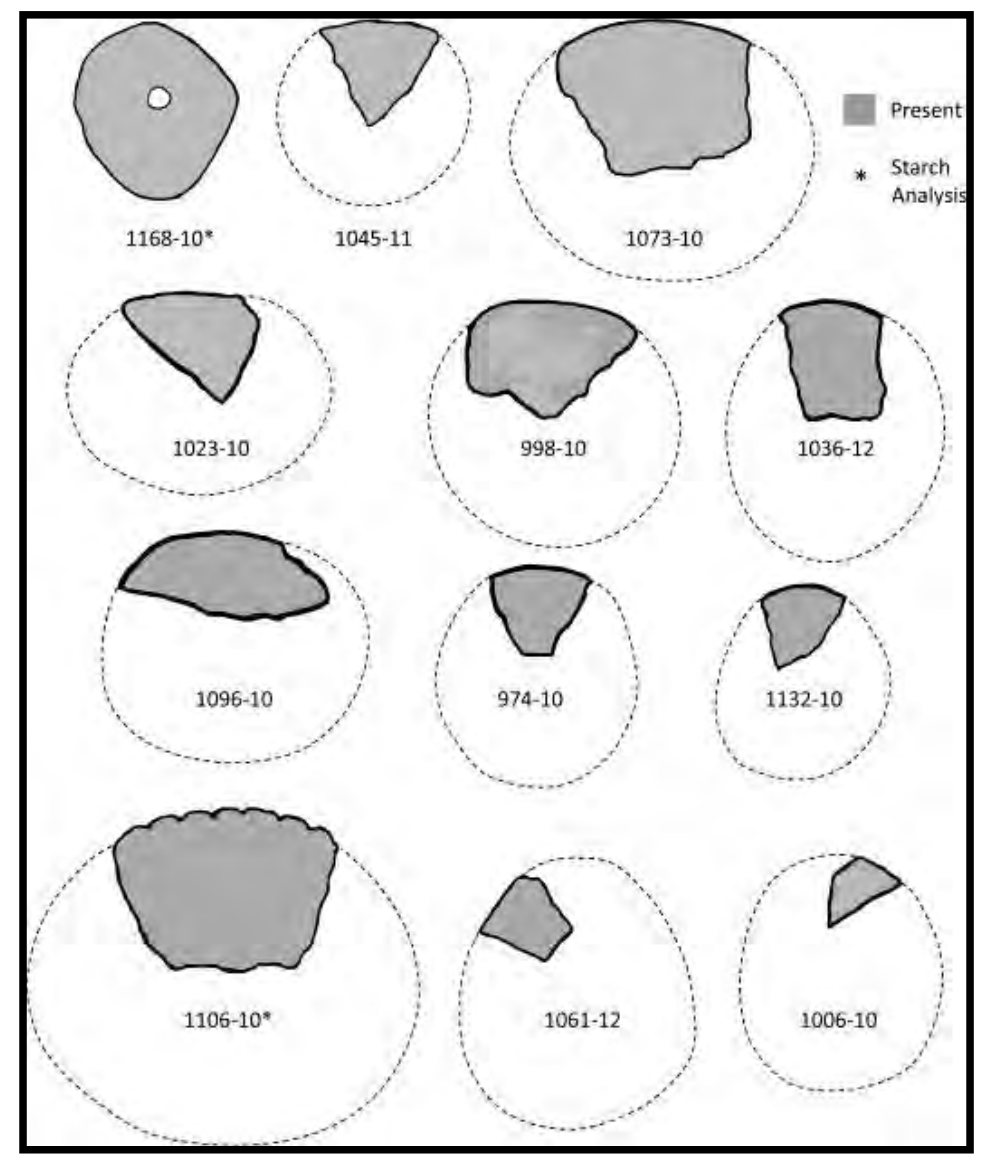

Figure 8-97. Reworked ceramic sherds projected on to postulated whole specimens. 
as weights on spindles and must have served some other function. It is possible that these disks were used as gaming pieces (Culin 1992).

The horizontal distribution of these 12 worked sherds is depicted in Figure 8-74 (see above). They were concentrated in the same area as the sherds were concentrated, that is, they were around the heating elements and other features just south of the pithouse. This distribution pattern indicates they probably had functions that related to the heating elements, the various vessels, or unknown activities that occurred around the features.

\subsubsection{Other Clay Objects}

Specimen \#2-8-2 was from the disturbed fireguard surface. This fired clay object has a convex exterior with a red (10YR 5/6) finish and is partially covered with calcium carbonate, which also covers the entire interior surface as well as the broken edges (Figure 8-98). The piece is broken on all four edges, with the two lateral edges bending towards the interior so that the breaks actually show a tightly curved profile. The two end breaks indicate that the original object extended in both directions. The main interior surface is flat with steep angles leading to tight curved edges. No striations or tool marks are visible on the interior. The exterior shows tiny pits and cracks with tiny sand grains also visible. In cross section, the paste is two-tone, with a reddish yellow on the exterior grading to a pale red (10YR 6/4). Also visible is an abundance of tiny dark temper particles. This fragment measures 32.1-mm-long by 25.9-mm-wide, and varies in thickness from 4.4 to $5.4 \mathrm{~mm}$. It weighs $5.0 \mathrm{~g}$.

A second unique object (\#11-8-1) was from the disturbed fireguard surface. This reddish brown (5YR 5/4) object is mostly covered with calcium carbonate on the interior and exterior surfaces (Figure 8-99). It is similar to \#2-8-2 in that has two lateral edges that curve towards the interior while the two ends continue. The interior is irregular but lacks any obvious striations, grooves, or lines to indicate manufacturing techniques. The exterior shows the same types of pits and cracks as the previous piece, but the two do not fit together. This piece measures 43.8-mm-long, 28.2-mm-wide, with a wall thickness that varies from 4.3 to $7.5 \mathrm{~mm}$, and it weighs $11.4 \mathrm{~g}$. In cross section, the paste is two-tone with a reddish yellow (5YR 6/6) grading to red (10R 5/6) with abundant tiny dark specks of temper visible at the macroscopic level. This piece was sent for starch-grain analysis and yielded 48 lenticular little barley (Hordeum pusillum) grains, 5 unidentified grains, plus parched, ground, and gelatinized grains (Appendix D). The starch-grain analysis results are indicative of a cooking vessel, but the shape is unlike any other vessel fragment.

A third item is a small curved section (\#1151-8-1) from 10 and 20 cmbs in N700 E514. It has three broken edges with one edge that has a smooth, rounded, curved lip (Figure 8-100). The exterior is convex in shape but opposite the rounded lip is a slight flaring of the clay just at the break. The exterior is a yellowish red (5YR 5/6) color, although some calcium carbonate is present. This color appears washed out and potentially was originally a deeper red. Tiny pits are visible on the exterior. Although partially covered with calcium carbonate the underlying surface appears to be reddish yellow (7.5YR 6/6). The interior has a narrow, 8.3-mmwide concave smooth area between the two broken edges. The rounded lip, combined with the narrow interior concavity just below the lip reflects the edge of a small pipe bowl. The curvature of the lip/rim indicates an orifice diameter of roughly $2 \mathrm{~cm}$ in diameter. This small fragment measures 13.2-mmtall, 17.2-mm-wide on the exterior, weighs $1.1 \mathrm{~g}$, and has a wall thickness between 4.3 and $4.9 \mathrm{~mm}$.

This apparent pipe fragment was sent for starchgrain analysis and yielded one maize grain, two lenticular little barley grains, and one gelatinized grain (Appendix D). These are the same starch species discovered in the ceramic vessel sherds analyzed, so the reason for their presence here is unclear. Perhaps nontobacco plants were burned in this pipe, or perhaps this piece is actually not a pipe fragment.

Two small, tightly curved fragments of fired clay (\#1185-8-2 and \#1195-8) from two adjacent units, N702 E514 and N701 E515 respectively, fit together (Figure 8-101). One piece was found between 0 and $10 \mathrm{cmbs}$ and the other piece came from between 40 and $50 \mathrm{cmbs}$. These form a partial pipe fragment 
Table 8-19. Attributes of Worked Sherds.

\begin{tabular}{|c|c|c|c|c|c|c|c|c|}
\hline Catalogue No. & North & East & $\begin{array}{l}\text { Depth } \\
\text { (cmbs) }\end{array}$ & $\begin{array}{c}\text { Thickness } \\
\text { (mm) }\end{array}$ & $\begin{array}{l}\text { Weight } \\
\text { (g) }\end{array}$ & Interior & Exterior & Comments \\
\hline $974-10$ & 694 & 511 & $40-50$ & 3.3-3.9 & 1 & flat, smooth & narrow cordmarked & $\begin{array}{c}\text { partially obliterated } \\
\text { cordmarks }\end{array}$ \\
\hline $998-10$ & 695 & 511 & $20-30$ & $5.2-6.0$ & 1.8 & flat, smooth & narrow cordmarked & possible edge of hole \\
\hline $1006-10$ & 695 & 513 & $20-30$ & $5.2-5.5$ & 0.6 & flat & indistinct cordmarks & \\
\hline $1023-10$ & 496 & 514 & $20-30$ & 4.6-4.9 & 2.3 & flat & narrow cordmarked & \\
\hline $1036-12$ & 696 & 512 & $40-50$ & $3.5-4.2$ & 1.8 & flat to irregular & narrow cordmarked & \\
\hline $1045-11$ & 496 & 514 & $20-30$ & $5.6-5.8$ & 1 & flat & narrow cordmarked & \\
\hline $1061-12$ & 697 & 512 & $15-25$ & $3.5-3.9$ & 0.9 & flat & narrow cordmarked & \\
\hline $1073-10$ & 697 & 515 & $20-30$ & 5.4-6.6 & 7.9 & smooth, depression & narrow cordmarked & $\begin{array}{c}\text { possible edge of hole, } \\
\text { partially obliterated } \\
\text { cordmarks }\end{array}$ \\
\hline $1096-10$ & 698 & 514 & $20-30$ & $4.4-5.2$ & 3 & smooth & narrow cordmarked & $\begin{array}{l}\text { well defined to partially } \\
\text { obilitered cords }\end{array}$ \\
\hline $1106-10 *$ & 699 & 511 & $20-30$ & $5.8-6.7$ & 8.8 & smooth & narrow cordmarked & $\begin{array}{l}6 \text { "V' shaped notches } \\
\text { perpendicular to edge }\end{array}$ \\
\hline $1132-10$ & 699 & 515 & $10-20$ & 4.4-4.9 & 0.9 & flat, smooth & narrow cordmarked & \\
\hline $1168-10^{*}$ & 701 & 512 & $35-40$ & $4.6-5.3$ & 4.8 & irregular & narrow cordmarked & biconical hole \\
\hline
\end{tabular}

* Specimen was analyzed for starch grains 


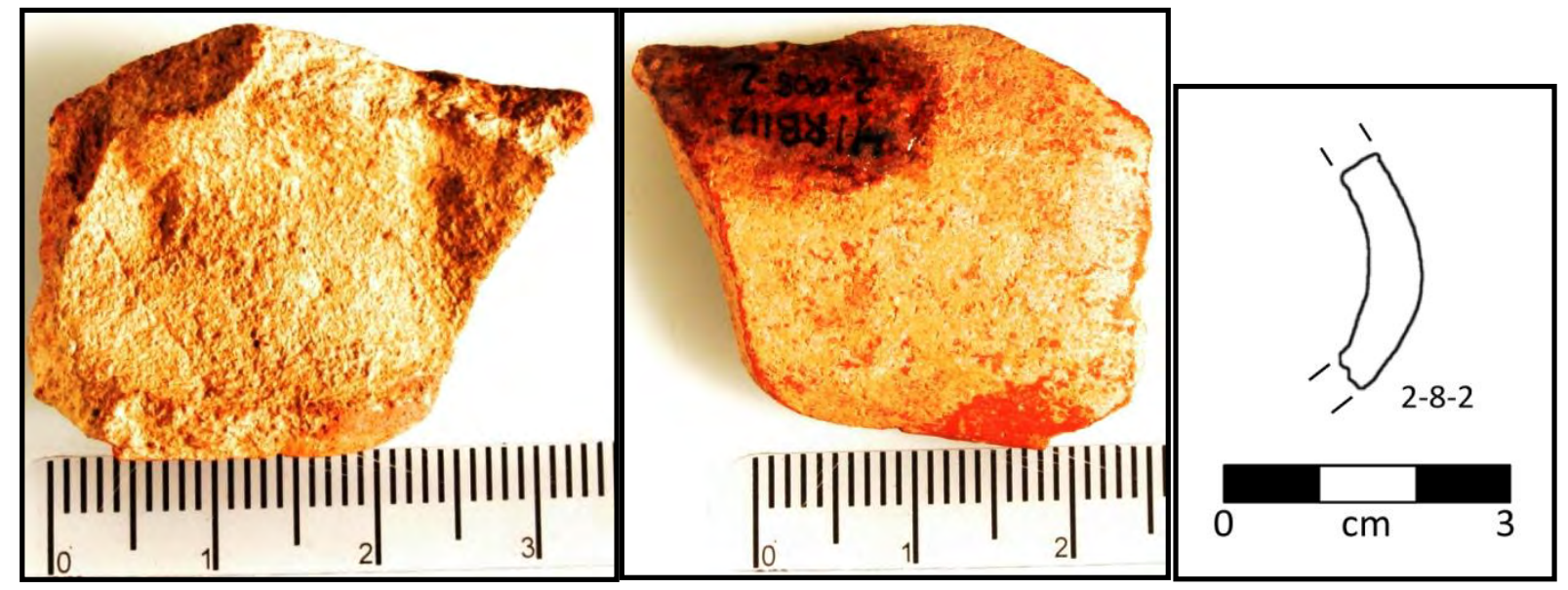

Figure 8-98. Interior (left), exterior (center), and profile (right) of red clay object (\#2-8-2). Scale in centimeters.
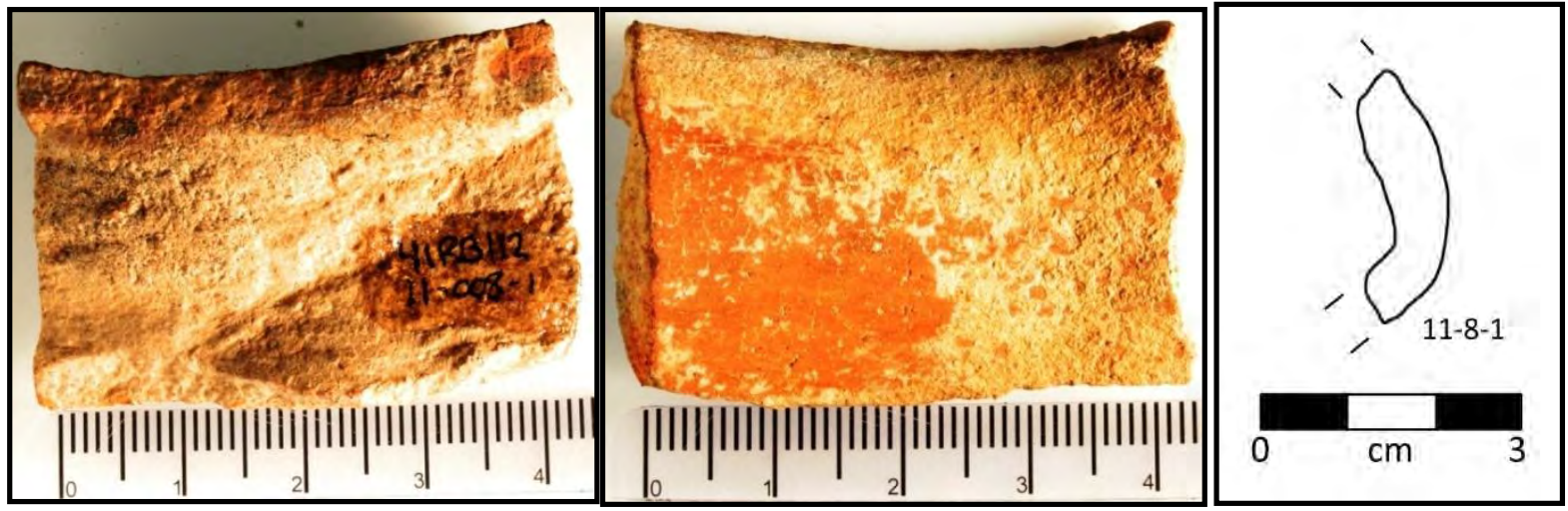

Figure 8-99. Interior (left), exterior (center), and profile (right) of red clay object (\#11-8-1). Scale in centimeters.

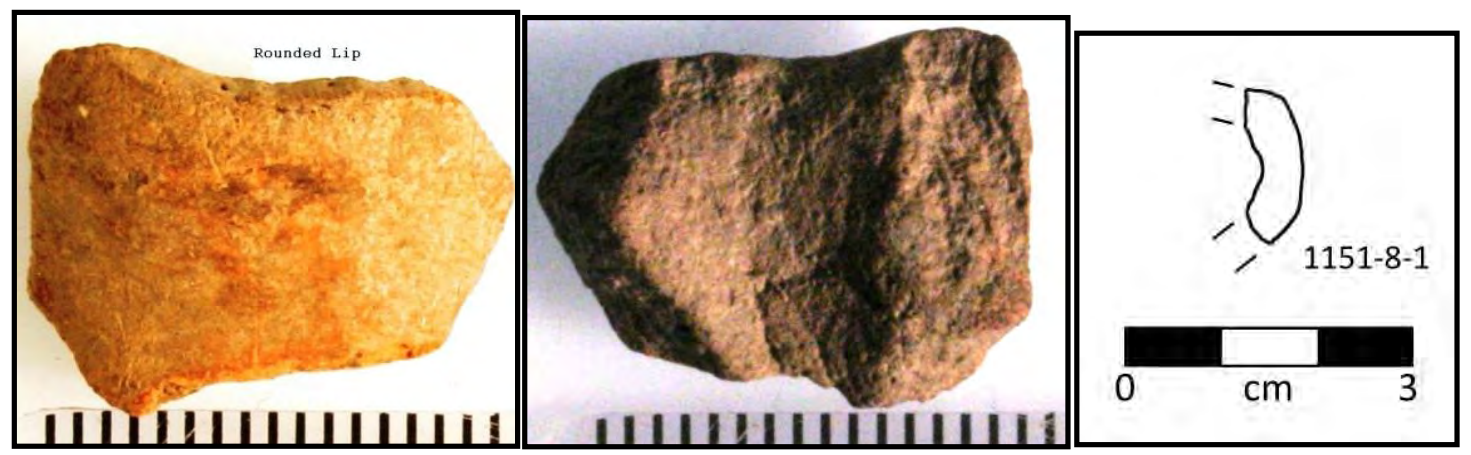

Figure 8-100. Photographs of small lipped section of probable pipe fragment (\#1151-8-1, exterior on left), interior (centre), profile (right).

Scale in millimeters. 
(3.6 g) that measures 26.6-mm-long, 17.4-mmwide, which has a thickness that varies from 5.5 to $7.1 \mathrm{~mm}$. The exterior is smooth with a reddish yellow (5YR 6/6) finish, while the interior surface is gray and partially covered with calcium carbonate. The interior of \#1185-8-2 reveals a relatively smooth and curved surface whereas the interior of the \#1195-8 is irregular and presumably represents the stem section, although it is not drilled nor is it part of a circular configuration.

A small, spherical, manmade clay marble-like specimen (9.5 to $10.1 \mathrm{~mm}$ in diameter) was recovered from N697 E515. This pea-to-marble-size object $(1.0 \mathrm{~g})$ is not perfectly round, but is well-formed with a smooth exterior that is only slightly out of round. The exterior has tiny cracks and a faint finger print. No sign of temper is visible on the exterior surface. Although there is no clear function for this small round ball, it would be of the size that could have been used in various games of chance or other skill games (Culin 1992).

Two pieces of worked clay (\#1026-10 and \#104410) appear to be sections of short figurine fragments or vessel legs (Figure 8-102). Both reveal smooth exterior surfaces on rounded, well-formed, short sections of linear clay. The distal ends have a rounded $\mathrm{U}$ shape, with gently expanding sides that extend to the opposite, broken end. Specimen \#1044-10 has a greatly expanding proximal end that exposes limited amounts of sand temper. Bell (1980:96) illustrates parts of nine human clay figurines which, though not common on Oklahoma sites, are known from Middle Woodland, Washita River villages, and Protohistoric Wichita sites. He indicates that they are crude and poorly dried, and that, based on their friability, may not have been fired.

In summary, the two refit possible pipe fragments (\#1185-8-2 and \#1195-8) are very similar in color and texture to the two unique pieces (\#11-8-1 and \#2-8-2), which are also nonvessel pieces. In fact, the exterior finish with reddish wash on these pieces is similar to the reddish exterior of Vessel C from this component. Lacking petrographic analysis on these unique pieces, the paste of Vessel $\mathrm{C}$ and the paste of these pieces cannot be directly compared. There are slight color differences between the pieces, but they still may have been manufactured from the same or similar clays.

\subsection{Ground Stone Analysis}

\section{J. Michael Quigg}

This assemblage is limited in terms of numbers with a total of nine artifacts and includes two edgeground quartzite pebbles, three metate fragments, two hammerstones, one mano, and one abrader. Individual observations and metric measurements on these nine artifacts are presented in Table 8-20. The two hammerstones are the largest and most complete specimens with limited crushing and pitting restricted to one end on each. These hammers are naturally rounded rocks that were used as percussion instruments in which small impact scars and small flakes have been removed from the end during impacts with hard materials. These do not exhibit extensive battering, which indicates limited use or short duration actions. These are of various shapes such as rounded, oblong, and ovate.

The one abrader exhibits a single, straight and narrow groove on a small piece of sandstone (Figure 8-103). The sandstone piece has relatively smooth sides and edges as if intentionally shaped and prepared. To investigate what was abraded by this piece, it was subjected to starch analysis. Perry documented one lenticular grain of little barley (Hordeum pusillum) and one unknown grain (Appendix D).

The three metate pieces are all fragments of much bigger metates (Figures 8-104 and 8-105). These small fragments hint at the original size and shape with the possibility that two were more basin shaped, possibly troughs in contrast to flatter metates. The two with steep worn surfaces, potential trough types, indicate more extensive use.

One mano (\#21-10) is a naturally water worn, rounded quartzite cobble with limited pitting on one end, which may indicate this piece also served as a hammer. The specimen does not have distinctive ground or worn surfaces to indicate extensive use as a mano.

A second mano (\#48-10) is a small fragment and does not appear of sufficient size to have been used 


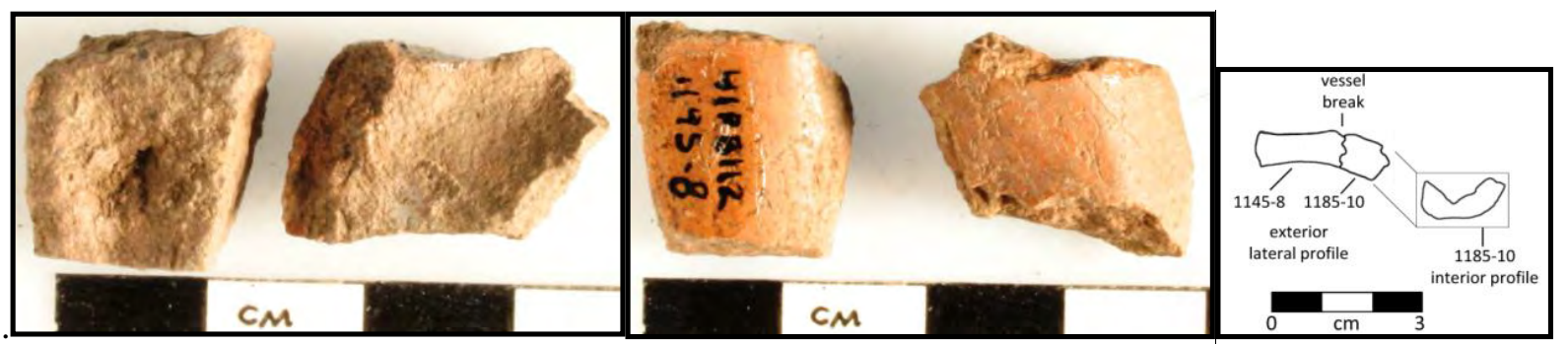

Figure 8-101. Interiors (left) and exteriors (center) of two clay sections (\#1195-8 left and \#1185-8-2 right) that refit with profiles (right).

Note in left picture the smoothed, curved interior bowl possible stem section on left.

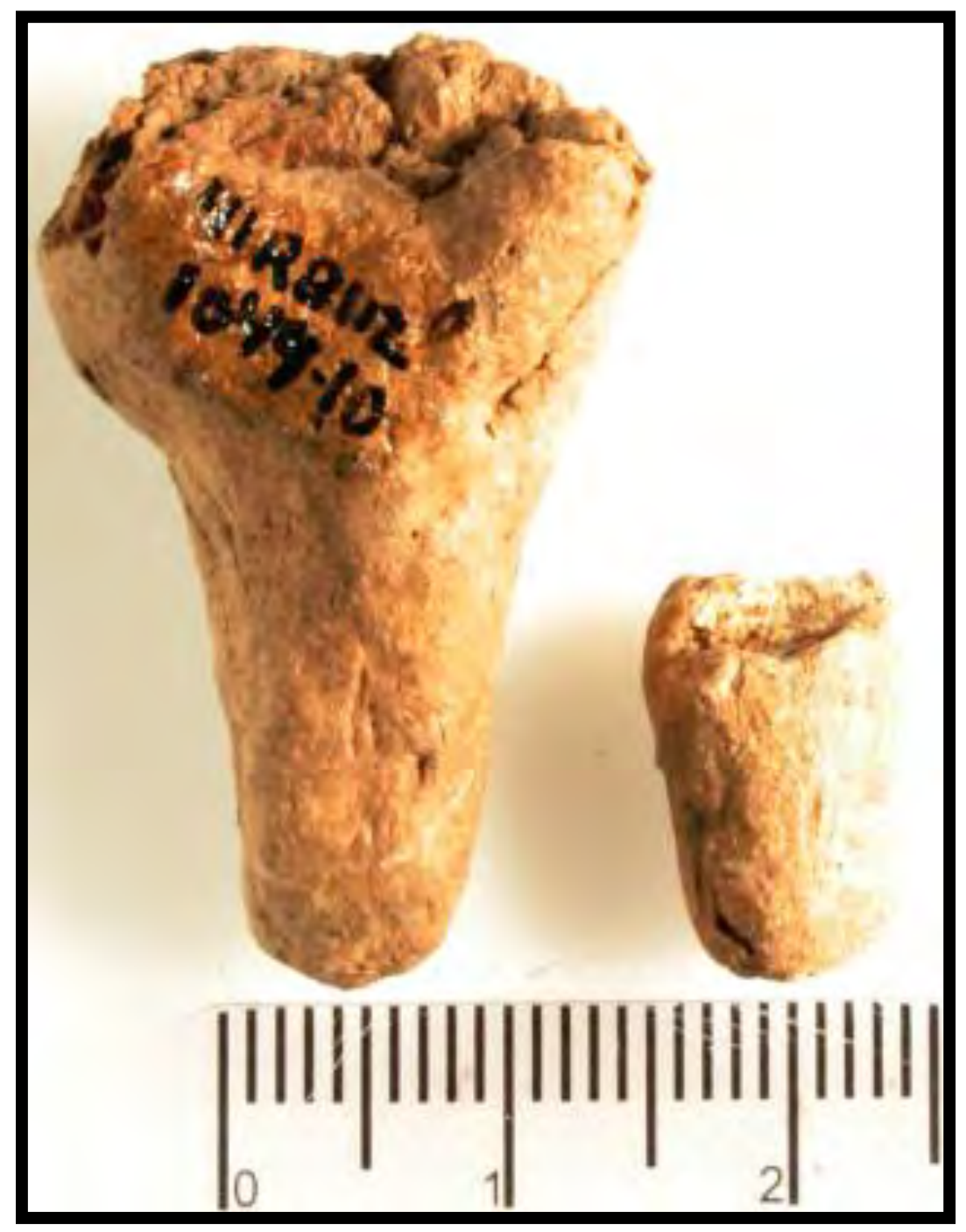

Figure 8-102. Possible figurine or vessel legs (\#1044-10 on left and \#1026-10 on right). Scale in centimeters. 
Table 8-20. Ground Stone Data from Component A.

\begin{tabular}{|c|c|c|c|c|c|c|c|c|c|c|c|}
\hline PNUM & Unit & $\begin{array}{l}\text { Depth } \\
\text { (cmbs) }\end{array}$ & Feature No. & Artifact Type & Length $(\mathrm{mm})$ & Width (mm) & Thickness (mm) & Weight (g) & $\begin{array}{c}\text { Depth of Worked } \\
\text { Surface }\end{array}$ & $\begin{array}{c}\text { Angle of } \\
\text { Worked } \\
\left.\text { Surface ( }{ }^{\circ}\right)\end{array}$ & $\begin{array}{l}\text { Material } \\
\text { Type }\end{array}$ \\
\hline $21-10$ & fireguard & surface & NA & mano/hammer & & 97.8 & 60.7 & 907.4 & 1 face 1 end & & quartzite \\
\hline $48-10^{*}$ & A-3 & 30 & NA & mano frag & 49.8 & 30.2 & 22.7 & 50.2 & 1 sided & & sandstone \\
\hline $709-10 *$ & N666 E510 & 31 & NA & edge-ground & 89.6 & 53.5 & 31.9 & 223.7 & battered edge & & quartzite \\
\hline $772-11 *$ & N670 E510 & 30 & NA & metate frag & 11.0 & 10.2 & 6.5 & 829.5 & 6.2 & 57 & caliche \\
\hline $783-10 *$ & N671 E509 & $40-50$ & NA & metate frag & 11.9 & 9.3 & 6.7 & 848.0 & 6.3 & 30 & sandstone \\
\hline $1056-10 *$ & N697 E512 & $20-30$ & NA & abrader & 38.6 & 26.4 & 13.9 & 16.8 & 1 straight groove & & sandstone \\
\hline $1080-10 *$ & N698 E511 & $30-40$ & NA & hammer & & 48.8 & 43.1 & 249 & 1 end & & rhyolite \\
\hline $1110-10 *$ & N699 E512 & $10-20$ & NA & metate frag & 7.8 & 7.6 & 3.4 & 263.5 & 0.3 & 5 & quartzite \\
\hline $1147-10 *$ & N700 E513 & $20-30$ & NA & edge-ground & 74.2 & 50.1 & 26.7 & 139.8 & battered lateral edge & & quartzite \\
\hline
\end{tabular}

$*=$ artifacts sent for starch analysis

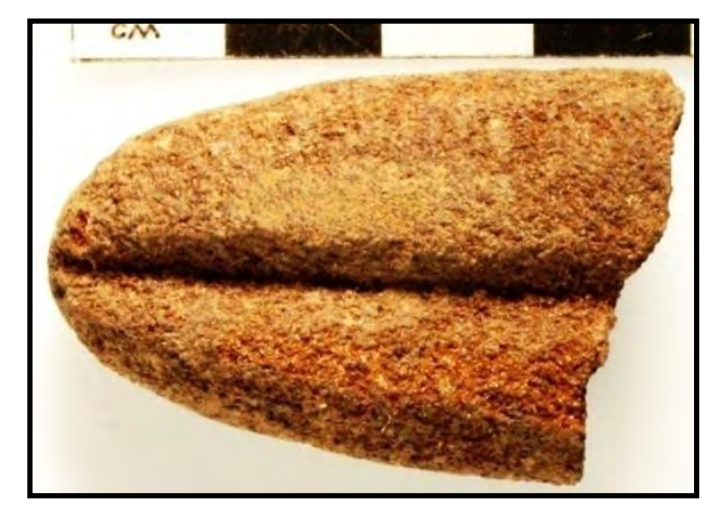

Figure 8-103. Photograph of one-half of a sandstone abrader (\#1056-10). 


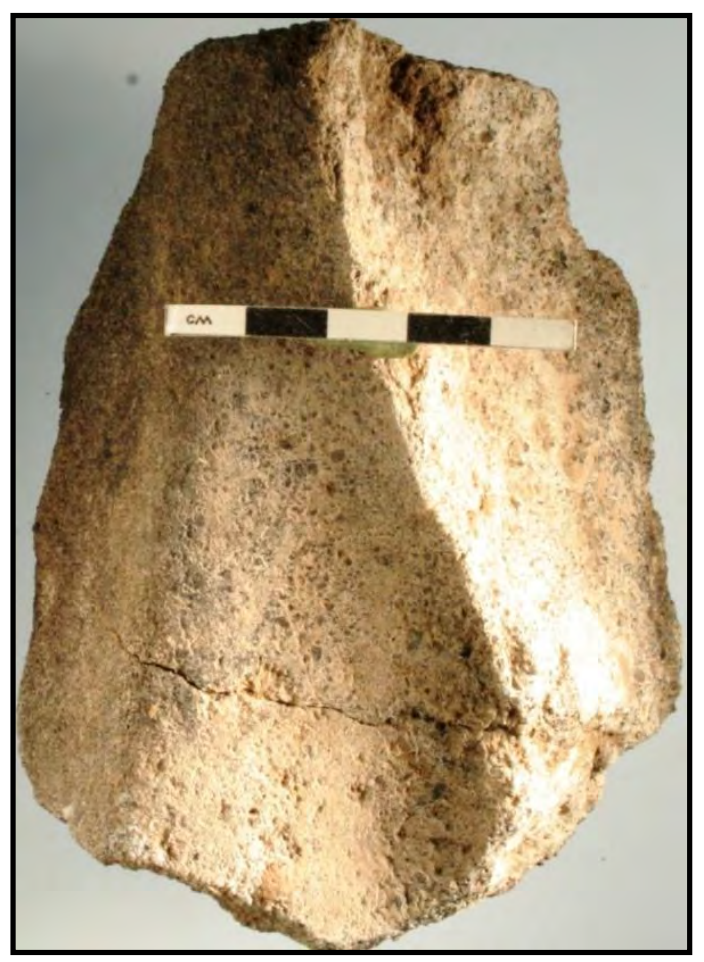

Figure 8-104. One end/edge of a long trough type metate (\#783-10).

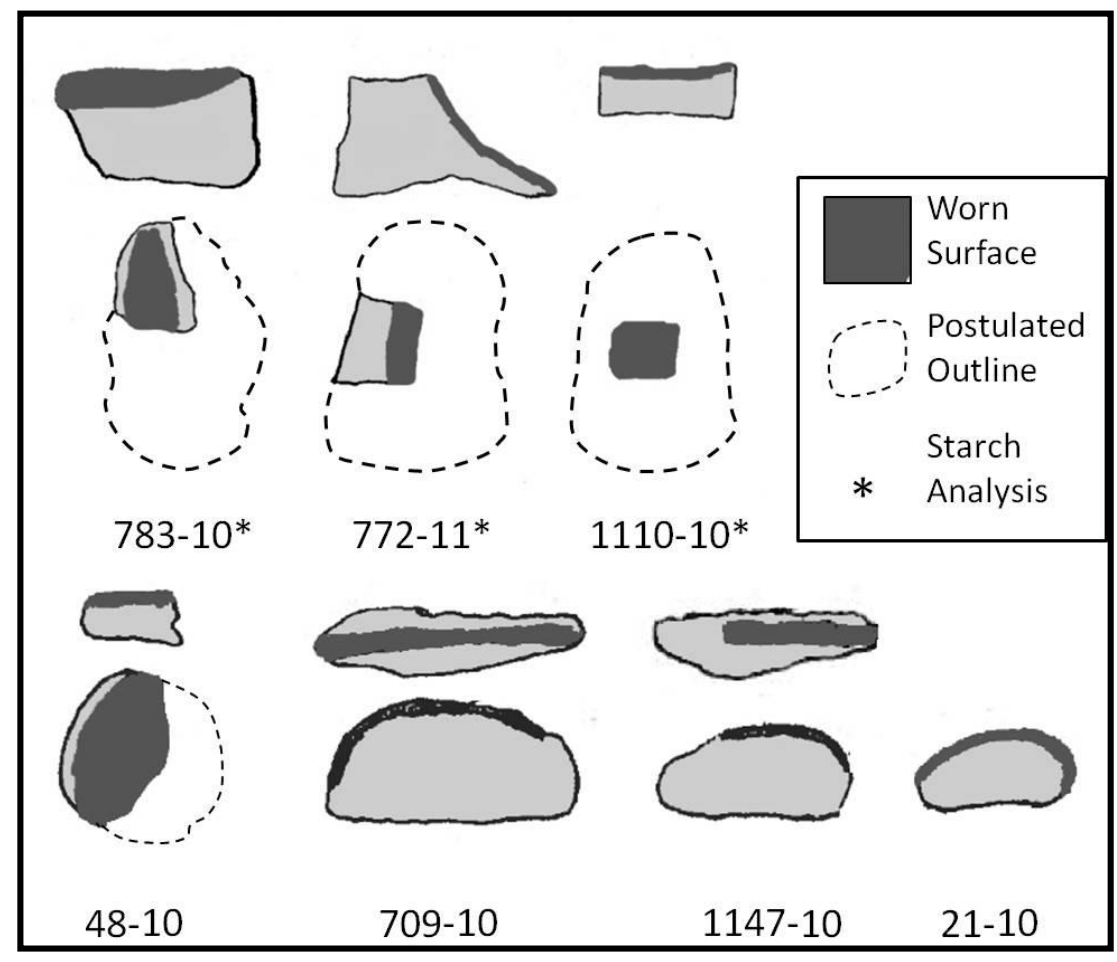

Figure 8-105. Plan view drawings of mano and metate fragments projected onto postulated whole metates. 
with the recovered metates (Figure 8-106). It is just under $5 \mathrm{~cm}$ in diameter and smaller than most hands. This piece was subjected to starch grain analysis. It yielded 38 starch grains, which included 33 lenticular grains of little barley, 5 grains of unknown and 1 unidentified grain (Appendix D).

Since the metate and manos exhibit a wide range of shapes, this may indicate the foods processed by these tools were sufficiently different in structure that they required different grinding strategies.

The two edge-ground quartzite pebbles (\#70910 and \#1147-10) are quite similar in appearance, outline, and size, each less than 9-cm-long, with one worked narrow edge (Figure 8-107). That one edge appears to have been intensively used, which resulted in the crushed and abraded edge. These may be one form of grinding instrument with a special purpose. Specimen \#709-10 was subjected to starch analysis and yielded 52 starch grains, which include 3 maize grains, 45 lenticular grains of little barley, 4 unknown grains, plus gelatinized grains of little barley (Appendix D). Here again, the native little barley grains far exceeds the maize grains and it was the little barley that was damaged through cooking.

\subsection{Shell Artifacts}

\section{J. Michael Quigg}

Half a tiny shell bead (\#1032-10) was recovered from the heavy fraction of floating Feature 11 fill. Feature 11 was in N696 E511 and the fill was between 50 and $60 \mathrm{cmbs}$. Feature 11 is interpreted as a dump with a diversity of classes of cultural materials. This half of a circular bead is about 3.0-mm-wide with a central hole that is about 1.5 -mm-wide creating a shell thickness of about $1.5 \mathrm{~mm}$. The margin of the hole is slightly beveled but does not appear drilled with a stone drill (Figure 8-108). Although it is difficult to see, very thin parallel lines are visible on the exterior and in the beveled margin of the interior that are similar in appearance to file marks. The shell does not appear similar to the freshwater mussel shells from this component. Since the freshwater mussel shells have a tendency to break in layers and not have solid structure it is possible this shell is not of this region and considered nonlocal. Therefore,

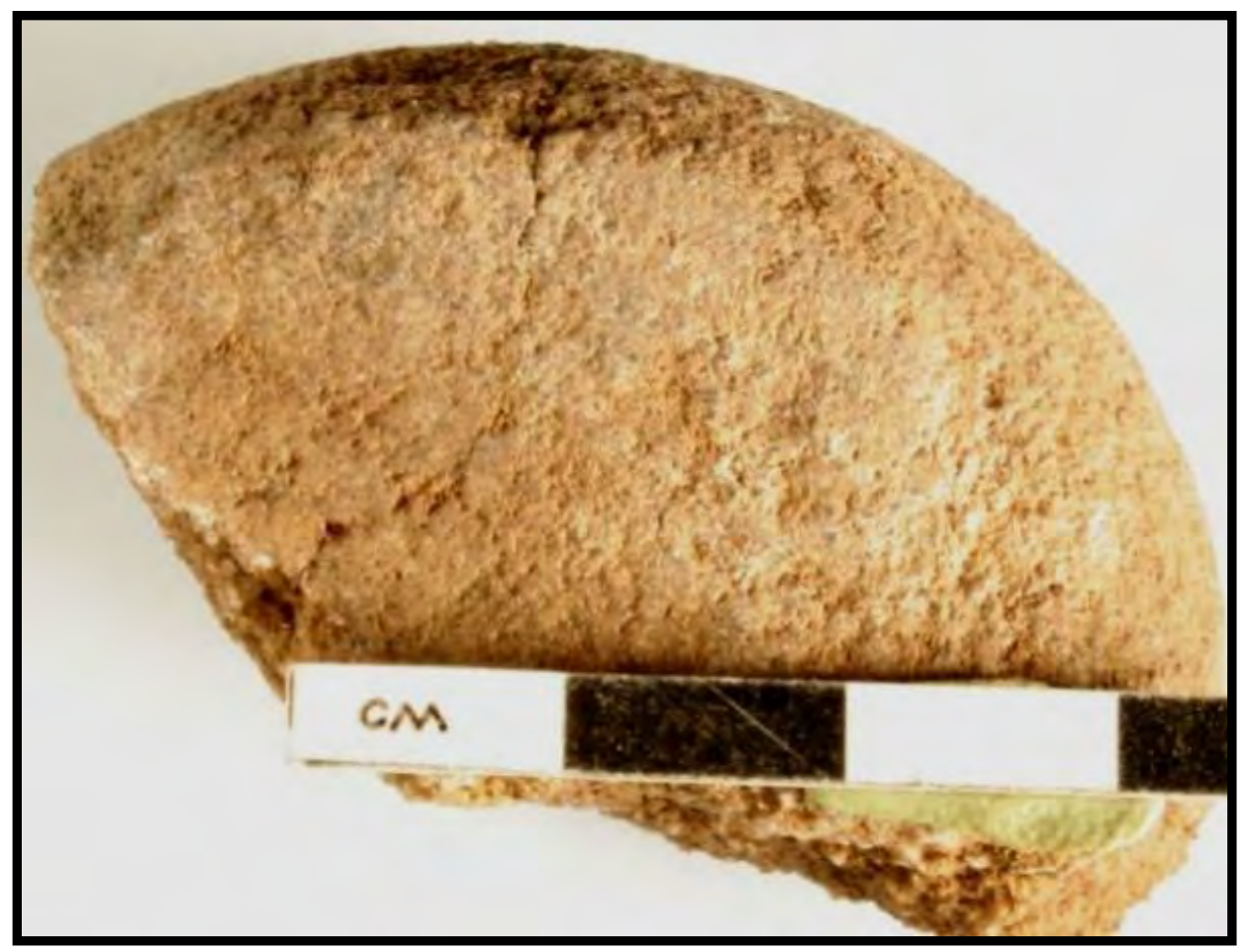

Figure 8-106. Mano fragment (\#48-10). 


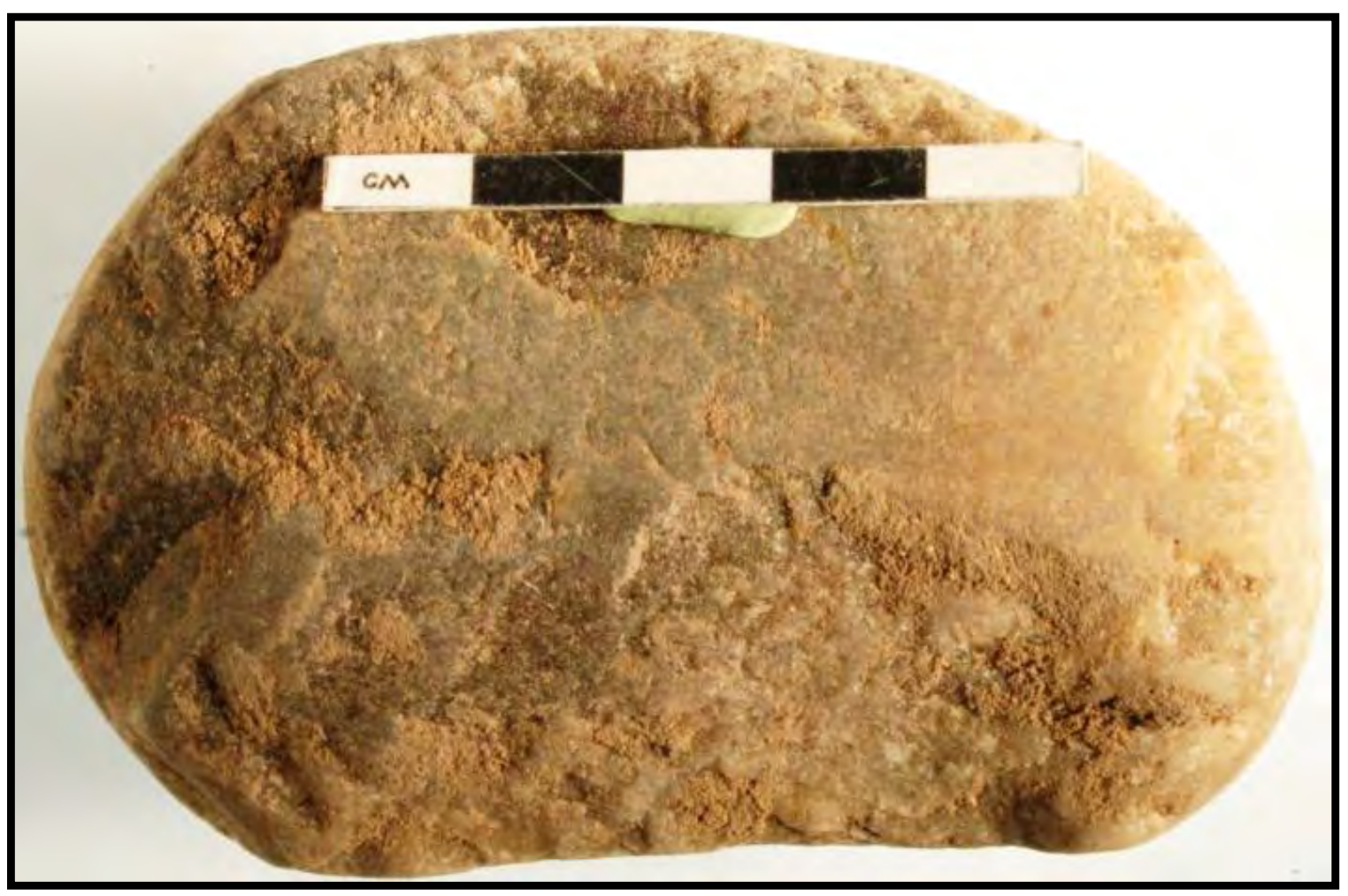

Figure 8-107. Photograph of edge-ground cobble (\#709-10), which yielded 45 lenticular grains of little barley.

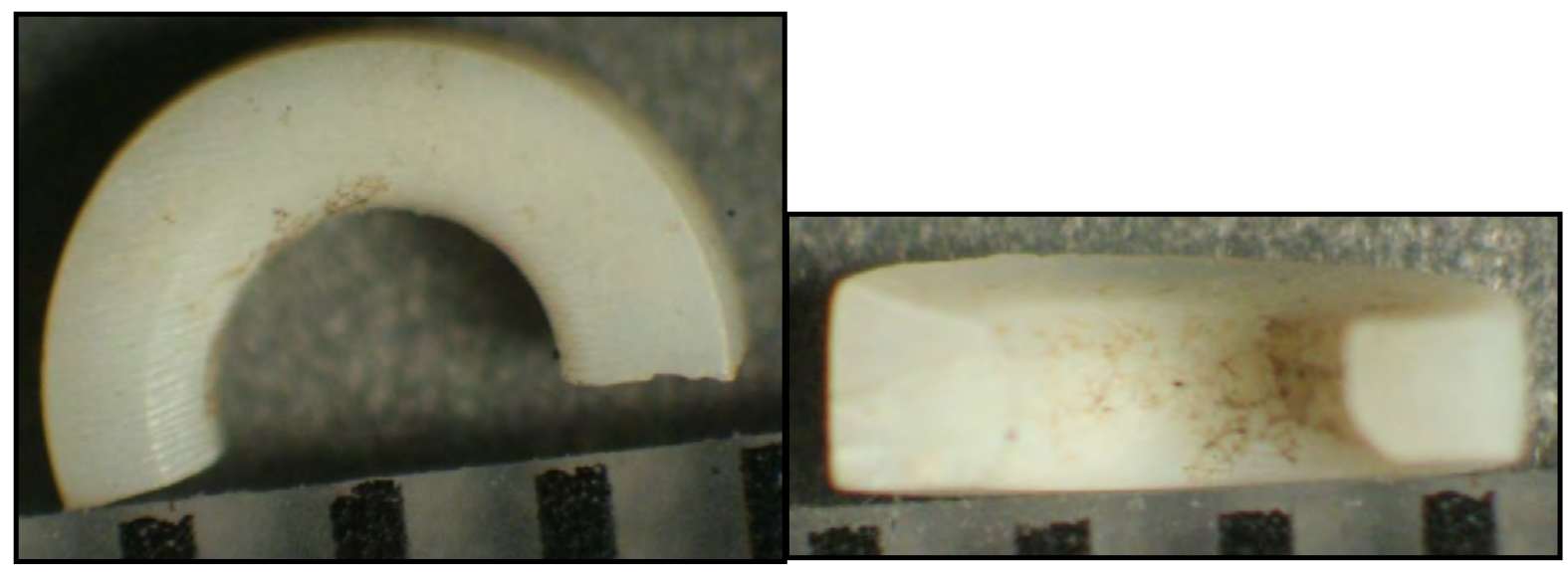

Figure 8-108. Plan and profile of shell bead (\#1032-10) from Feature 11. Scale is in milliliters.

it is quite possible this shell was traded for and came from a great distance. Trace element analysis using X-ray fluorescence determined this bead was entirely of calcium carbonate based on qualitative analysis (Appendix E). 
This page intentionally left blank. 


\subsection{COMPONENT C - SOUTHERN END OF SITE}

J. Michael Quigg and Paul M. Matchen with contributions by Charles Frederick and Brittney Gregory

This component was roughly $120 \mathrm{~m}$ south of Component A, and was separated from the latter area by Area B that was largely devoid of artifacts. Component $\mathrm{C}$ extends east-west across the entire width of the APE, which was between 10- and 16-m-wide. This narrow APE contained an approximately 2-m-wide strip of natural prairie along its eastern edge, a 5- to 6-m-wide strip of overgrown fireguard running north-south through its middle, and another 2- to 3-m-wide strip of natural prairie along its western edge adjacent to the new right-of-way fence line (see Figure 5-4). Component $\mathrm{C}$ extended roughly $90 \mathrm{~m}$ north-south, with the northern end being flat and the southern end sloping gently toward the south. The road cut on the eastern margin exposed sparse pieces of cultural material and faint, weathered features in the upper $60 \mathrm{~cm}$ of the vertical profile. In the flat northern part of Component $\mathrm{C}$, the sandy loam Holocene deposits varied from 40- to 55-cm-deep and overlay the much older Ogallala Formation with its mottled grayish-clay patches, white caliche chunks, and reddish sands. At the very southern end of Component $\mathrm{C}$, the sandy Holocene deposits increased to about 100 -cm-thick as this was near the end of the north-south ridge, with the Holocene deposits still overlying the older Ogallala deposits. The bedrock Ogallala deposits dipped sharply downward in the southern third of this southern area. This sharp dip in the Ogallala was filled with windblown sands that, over time, created relatively deep $(100 \mathrm{~cm})$ Holocene deposits at the southern end of the site.

Smaller cultural materials were vertically dispersed within the Holocene deposits as a result of extensive rodent turbation. However, cultural features had not been displaced and were concentrated in a relatively thin vertical zone between about 25 and 35 cmbs (see Figure 9-1). With the increased thickness of Holocene sands at the southern end, the cultural features and materials in that area were more vertically dispersed and often at deeper positions within the sediment profile (Figure 9-2).

The various artifact classes from Component $\mathrm{C}$ are presented further on in order to provide the reader with an understanding of the types and frequencies of materials obtained. First, however, the recognized features are described and functionally interpreted, along with summaries of associated artifacts, and results of their analyses are presented.

\subsection{Cultural Features}

Twenty-one cultural features were identified in this southern component (Figure 9-3). These included one complete pithouse (Feature 6), a second possible pithouse (Feature 18), one cairn burial (Feature 7), one human cremation (Feature 22), at least four basin-shaped heating elements (Features 5, 16/21,

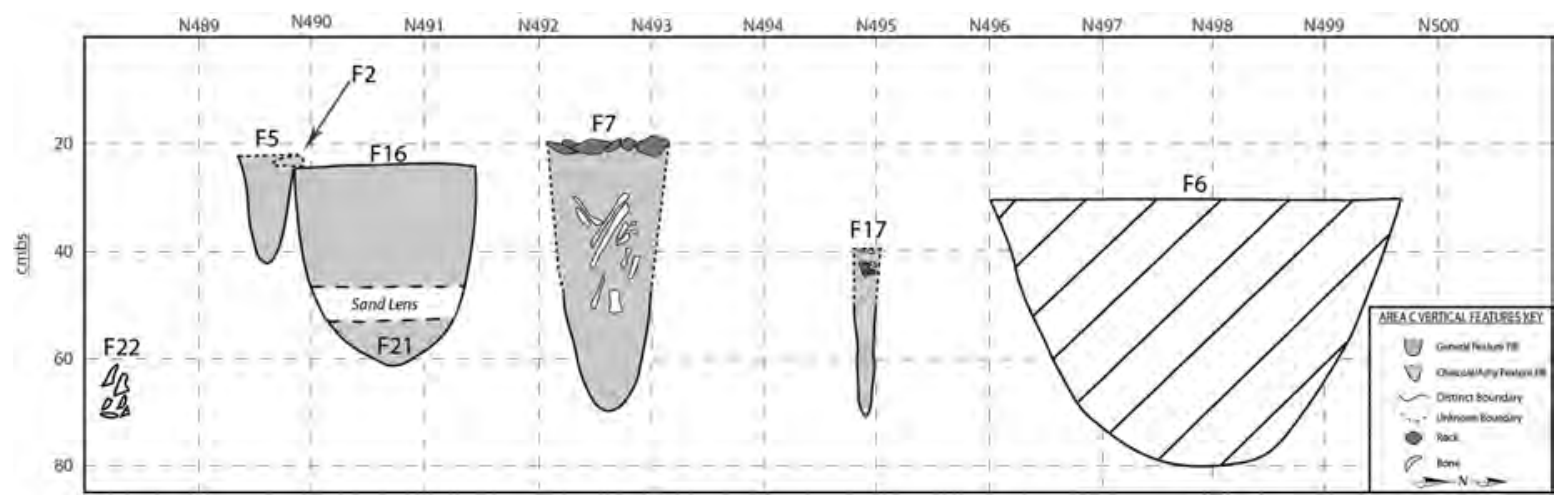

Figure 9-1. Vertical distribution of features in northern part of Component C. 


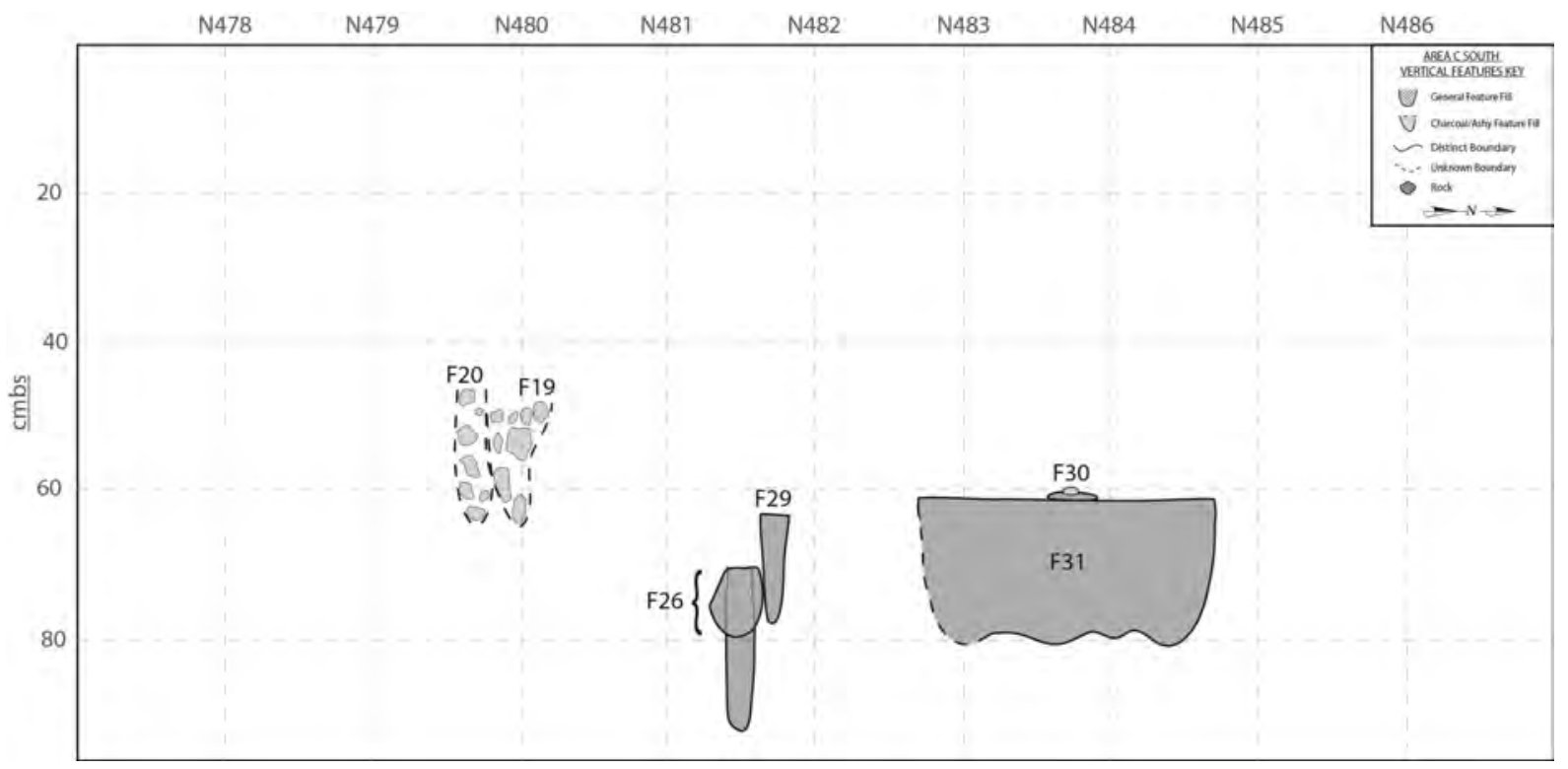

Figure 9-2. Vertical distribution of features in the deeper southern part of Component C.

26, and 29), a small storage pit (Feature 23), at least eight discard/dump areas (Features 2, 19, 20, 24, 25, 27, 30, and 31), two large postholes (Features 17 and 28), one rock alignment (possible structure), and a number of small post holes in the vicinity of the pithouses. The features were numbered in the field as they were encountered, and the numbers missing here were those assigned to features in Component $\mathrm{A}$ (see above). Each feature is individually presented in numerical order below, followed by a summary and discussion concerning the horizontal distribution of the features.

\subsubsection{Feature 2}

During site assessment, hand-excavation along the eastern margin of the APE and the eastern edge of the fireguard revealed a small carbonized stain below a large burned rock in the southeastern corner of Unit C-5, between 29 and 41 cmbs (Figure 9-4). This localized find was designated as Feature 2.

No basin or oxidized sediment was observed under or around the rock and charcoal chunks. A sediment sample was collected from under the rock for flotation. An Alibates flake and a chunk of charcoal were recovered in the northwestern corner at 38 and $39 \mathrm{cmbs}$, respectively. It is possible that the burned rock and charcoal represent a specific activity or, alternatively, they may be associated with Feature 5, a heating element located 50 to $60 \mathrm{~cm}$ to the east (see below). Four small chunks of probable daub, two burned rocks, a small and light charcoal concentration, four Alibates flakes, and 19 bone scraps were recovered from a 20 -cm-thick zone that surrounded the charcoal and burned rock of Feature 2. These items were just west of the Feature 5 heating element.

The six liter sediment sample (\#119-4) from under the burned rocks, between 30 and 40 cmbs, was floated and the heavy and light fractions were collected. The heavy fraction yielded $87.6 \mathrm{~g}$ of materials that include 4 tiny pieces of lithic debitage $(<0.1 \mathrm{~g}), 4$ possible burned seeds, 8 tiny bone fragments $(<0.1 \mathrm{~g})$, and 30 tiny pieces of daub (6.0 g). The light fraction yielded moderate amounts of wood charcoal and a considerable quantity of tiny rootlets. The light fraction was not submitted for macrobotanical analysis but was retained for curation.

A small and light charcoal concentration on the opposite side of this unit was also collected and floated. The 21 liters of sediment (\#118-4) yielded $127 \mathrm{~g}$ of heavy-fraction materials. This includes 27 tiny pieces of lithic debitage $(0.1 \mathrm{~g}), 30+$ tiny 


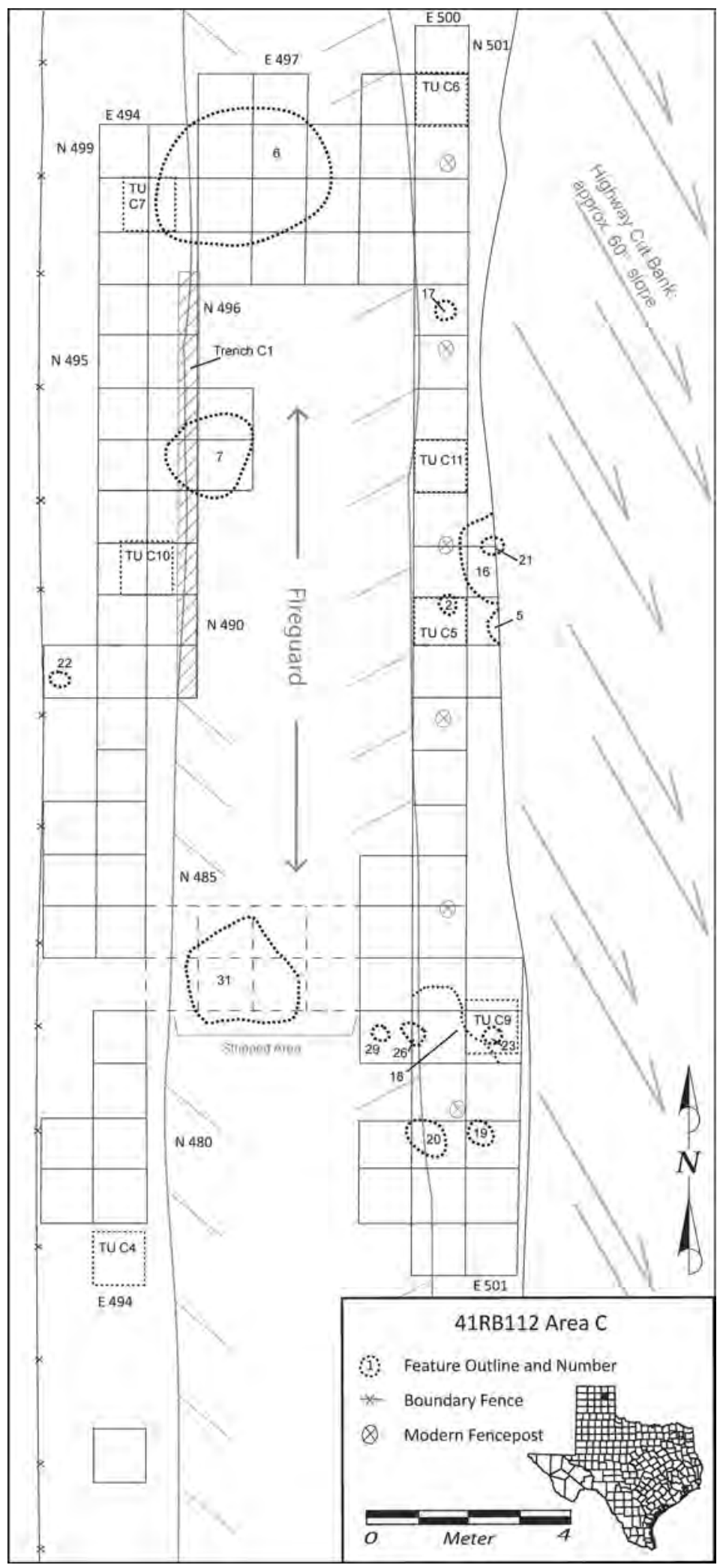

Figure 9-3. Horizontal distribution of features in Component C. 


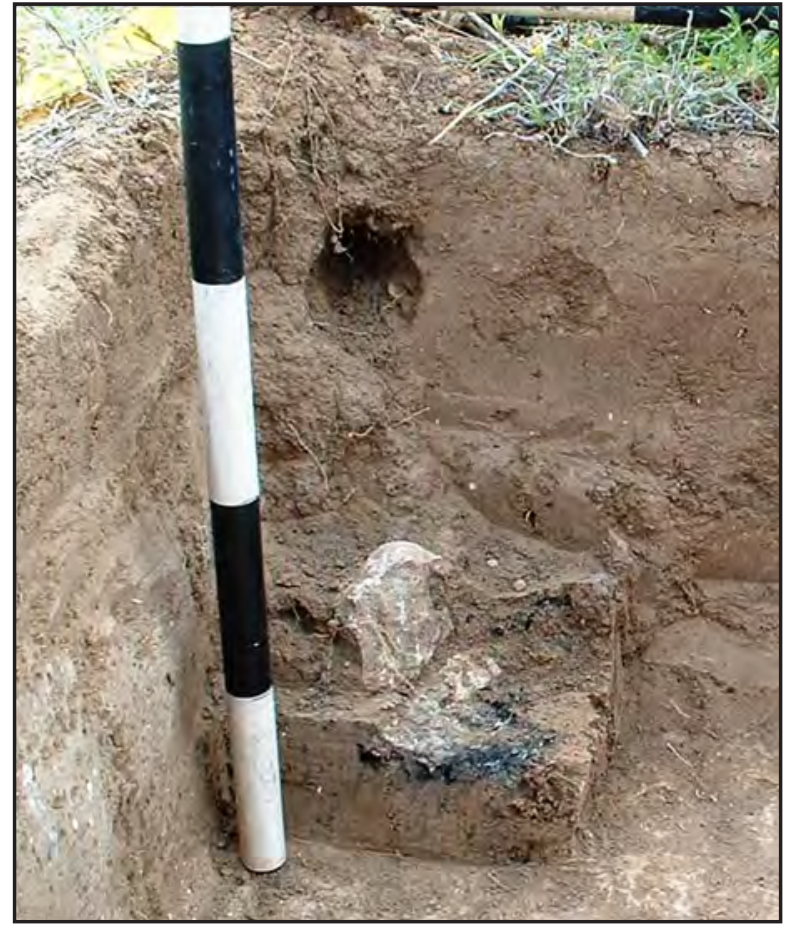

Figure 9-4. Large burned rock on patch of charcoal, Feature 2.

bone fragments (3.4 g), and 5 tiny daub pieces $(<0.1)$. These results are contrasted to the results from sediment in Feature 2 and reveal a significant difference in the materials represented. Therefore, the two charcoal deposits were derived from two separate events or different features. Feature 2 is interpreted as materials pulled from or dumped from the adjacent heating element, Feature 5.

\subsubsection{Feature 5}

Feature 5 was first recognized during site assessment as a basin-shaped dark stain eroding from near the top of the road cut at the southern end in Component C (Figure 9-5). This basin was exposed about $50 \mathrm{~cm}$ east of Unit C-5, nearly $7 \mathrm{~m}$ east of the north-south rock alignment, and immediately south of Feature $16 / 21$. This basin was not obvious in the weathered, eroded road cut, but once a fresh vertical cut was made, which removed about 4 to $5 \mathrm{~cm}$ of slump and weathered sediments, it became distinguishable. An initial profile was drawn, and the exposed cross section was photographed (Figure 9-6). Extensive rodent runs/holes, some quite fresh or recent and contained grasses, whereas others runs were older and less distinct, went through this basin. Discernible rodent burrows were identified on the northern and southern edges of the feature, and one very obvious recent burrow ran through the middle. These rodent disturbances created difficulty in distinguishing margins of the feature. In general terms, this feature exhibited a shallow basin with ill-defined lateral margins and a blurred, indistinguishable top. The basin was not lined and had no discernible charcoal lens, nor did it exhibit an oxidation rim. The upper northern edge exhibited characteristics that might imply materials had been pulled/scraped out in that direction, but disturbance by rodent activity may have contributed to that impression. The upper edge of the feature, identified on the basis of a slight color contrast with the surrounding dark-brown (10YR 4/3) sandy loam A horizon, was estimated to be at about $22 \mathrm{cmbs}$. In this initial profile, the basin measured $75 \mathrm{~cm}$ north-south and was estimated at least $30 \mathrm{~cm}$ east-west.

The remaining part of Feature 5 was hand-excavated in N490 E501 during data recovery. Once completed, excavation revealed the basin measured $75 \mathrm{~cm}$ north-south by at least $45 \mathrm{~cm}$ east-west, whereas 


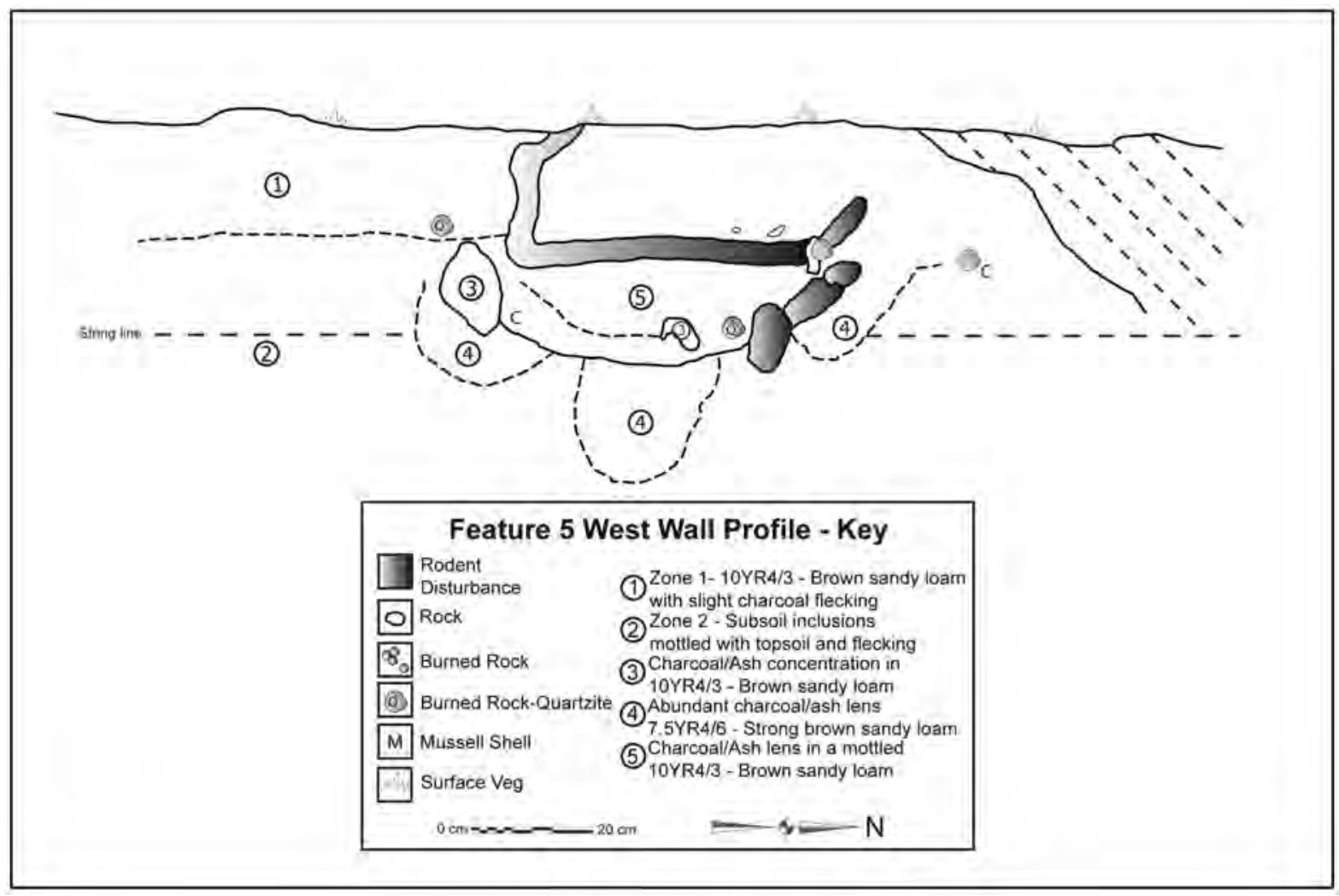

Figure 9-5. Profile drawing of west wall of Feature 5 exposed in road cut.

the top was detected at $22 \mathrm{cmbs}$ and the bottom was definable at $42 \mathrm{cmbs}$ (see Figure 9-6). The 20-cmdeep basin contained fill that was partially disturbed by rodent activity. The bottom margin was blurred by insect turbation. The basin was filled with an ashy, dark-grayish brown (10YR 4/2) sandy loam. Mottling was evident, with light-colored spots in the fill that may have been tiny lumps of burned clay.

The majority of the fill (\#120-4) was collected for flotation, during which tiny burned and unburned bone fragments, charcoal flecks/chunks, and tiny pieces of burned rocks were observed. Individual charcoal samples were also collected from the fill. Three burned rocks, one each of quartzite, caliche, and sandstone, each roughly $5 \mathrm{~cm}$ in diameter, were collected from along the southern margin of the basin. The quartzite specimen exhibited hackled edges indicative of rapid heating and cooling that occurs during stone boiling. The basal fragment of a Fresno arrow point (\#120-10) was recovered from near the burned rocks.
A charred maize kernel (\#120-4-3a) from the basin fill along the cut bank was sent for radiocarbon dating. This specimen yielded a $\delta^{13} \mathrm{C}$ (-9.7\%o) corrected AMS date of $630 \pm 40$ B.P. (Beta-206561).

During site assessment fieldwork, roughly 7.7 liters of basin fill, collected from the cut bank, were submitted to Phil Dering for flotation and macrobotanical identification. The floated fill (\#120-4-3a, 4a, 5a and 6a) contained 1 maize cob fragment, 18 maize cupule fragments, and 9 maize kernels. Juniper, mesquite, and indeterminate wood charcoal were noted as well (Appendix C). The heavy fraction also yielded a variety of items that includes tiny burned and unburned bone splinters, a tiny (1.5-mm-long) burned fish vertebra, and at least two lithic flakes (Table 9-1).

Another 26 liter sediment sample (\#120-4) was floated and the heavy fraction yielded $418.9 \mathrm{~g}$ of material. This includes 2 tiny mussel shell fragments, 3 tiny crumbs of burned rocks (84 g), 54 tiny pieces of debitage (2.1 g), 25 charred seeds ( $0.7 \mathrm{~g}), 60+$ tiny 


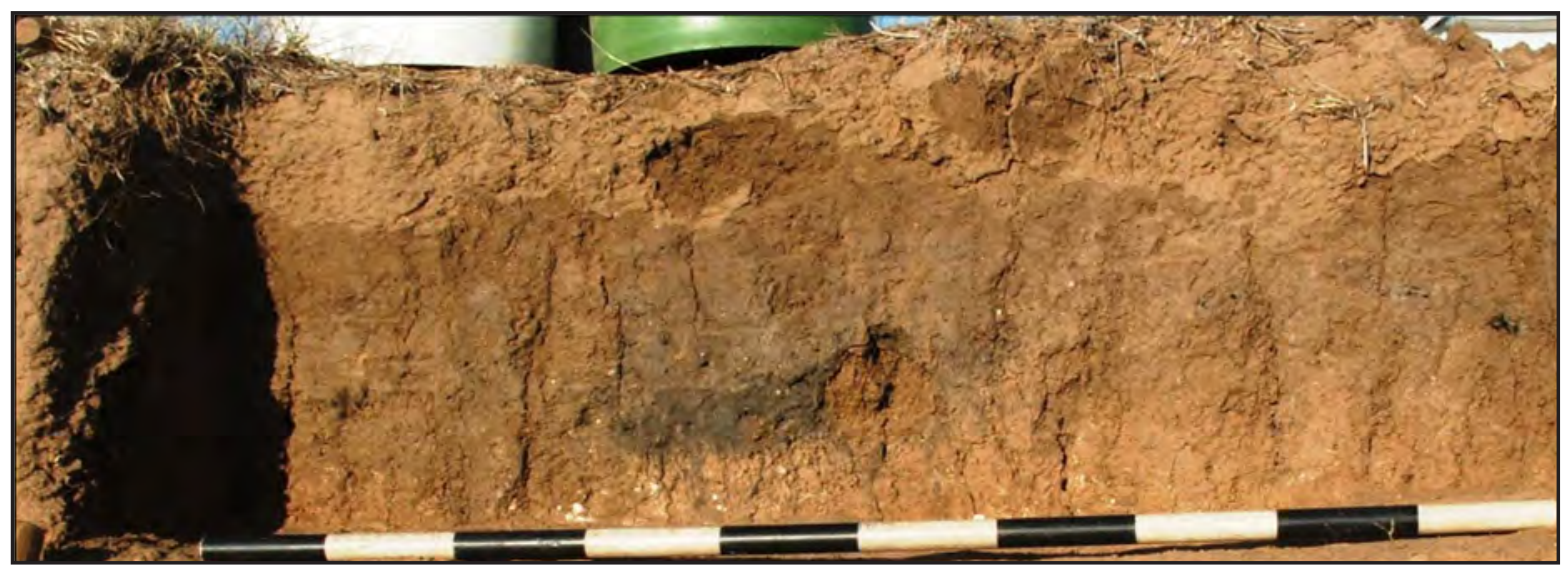

Figure 9-6. Picture of profile of western end of Feature 5 basin $20 \mathrm{~cm}$ from road cut.

bone fragments (25.4 g), and 75 tiny pieces of daub (53.3 g). The light fraction (\#120-4-2b) was sent for macrobotanical analyses. The $241.1 \mathrm{~g}$ of light fraction from 5 flotation samples (\#120-4) yielded 1 maize cob fragment, 30 cupules, and 26 kernels. Over $30 \mathrm{ml}$ of juniper charcoal dominated the wood assemblage. Mesquite wood charcoal was recovered in relatively minute quantities (Appendix C).

Subsequently, another 9.25 liters of feature fill (\#437-4 and \#439-4) were floated. The heavy fraction yielded $81.1 \mathrm{~g}$ of material that includes 3 tiny mussel shell fragments, 28 tiny pieces of debitage ( $0.3 \mathrm{~g}), 50+$ tiny bone fragments (3.4 g), and 16+ tiny daub pieces $(4.5 \mathrm{~g})$ with one piece that exhibits impressions. The light fraction (\#437-4) yielded many charred maize kernels and fragments of maize cobs, although neither this sample nor sample \#4394 was sent for macrobotanical analysis.

A 30.2 g phytolith sample (\#120-4-4) from between 32 and 36 cmbs, near the bottom of the basin, was sent for analysis. The results reflect a dominance (48.1 percent) of warm moist panicoids over the less frequent (33.9 percent) cool season pooids, and the relatively sparse (18.0 percent) hot dry chloridoids (Appendix B). A relatively high percentage of burned phytoliths were present and include high percentage of cool season pooids and warm moist panicoids, with no hot dry chloridoids (Appendix B). Large cross shaped phytoliths representative of maize leaves were present in the highest frequency of the analyzed samples. No beans or squash phytoliths were identified.

Feature 5 was a deep basin-shaped heating element that generally lacked burned rocks although other diverse cultural items were recovered. No discernable structure was observed in the fill, nor any detectable lining along the margins. This feature was used to generate heat, with the primary use of juniper wood and maize cobs and leaves, and may have had a functional relationship with adjacent Feature 16/21.

\subsubsection{Feature 6}

During site assessment, hand-excavation of 1-by1-m Unit C-7 revealed the western edge of a deep and large diameter pit that contained charcoal-rich sediments with well-defined margins that contrasted with the surrounding Ogallala deposit (Figures 9-7 and 9-8). The initial level in Unit C-7 exposed the northern end of the rock alignment that was partially discernable on the surface. he rocks that formed the alignment (roughly 8 to 9 rocks, 10 to $20 \mathrm{cmbs}$ ) were left in place along the western $30 \mathrm{~cm}$ of the unit with the remaining 90 percent of the unit excavated to $70 \mathrm{cmbs}$. At roughly $20 \mathrm{cmbs}$, a soil change was observed along the western third of the unit. This change was marked by the appearance of a dark-yellowish brown (10YR 4/4) sandy clay loam that contained a few fine mottles of strong brown (7.5YR 5/6) sandy clay loam. In contrast, the eastern half of the unit contained a dark brown (10YR 4/3) 
Table 9-1. Heavy and Light Fraction Results from Flotation Analysis of Feature Matrix, Component C.

\begin{tabular}{|c|c|c|c|c|c|c|c|c|c|c|c|c|c|c|c|c|c|c|c|c|c|c|}
\hline \multirow[t]{3}{*}{ Cat No. } & \multirow[t]{3}{*}{ Unit } & \multirow{3}{*}{$\begin{array}{l}\text { Depth } \\
\text { (cmbs) }\end{array}$} & \multirow{3}{*}{$\begin{array}{c}\text { Feature No. } \\
\text { Component } \\
\text { C }\end{array}$} & \multirow{3}{*}{$\begin{array}{c}\text { Weight } \\
\text { (g) }\end{array}$} & & \multicolumn{16}{|c|}{ Flotation Recovery } & \multirow{3}{*}{ Comments } \\
\hline & & & & & & \multicolumn{2}{|c|}{$\begin{array}{l}\text { Mussel } \\
\text { Shell }\end{array}$} & \multicolumn{2}{|c|}{$\begin{array}{c}\text { Burned } \\
\text { Rock }\end{array}$} & \multicolumn{2}{|c|}{ Debitage } & \multicolumn{2}{|c|}{ Charcoal } & \multicolumn{2}{|c|}{ Macrobotanical } & \multicolumn{2}{|c|}{ Ceramic } & \multicolumn{2}{|c|}{ Bone } & \multicolumn{2}{|c|}{ Daub } & \\
\hline & & & & & & $1 / 4$ & $<1 / 4$ & $1 / 4$ & $<1 / 4$ & $1 / 4$ & $<1 / 4$ & $1 / 4$ & $<1 / 4$ & $1 / 4$ & $<1 / 4$ & $1 / 4$ & $<1 / 4$ & $1 / 4$ & $<1 / 4$ & $1 / 4$ & $<1 / 4$ & \\
\hline \multirow[t]{2}{*}{ 118-004 } & C-5 & $20-30$ & - & 126.9 & $\mathrm{~N}$ & - & - & - & - & - & 27 & - & 1 & - & 1 & - & - & - & $30+$ & - & 5 & \\
\hline & - & - & & - & $\mathrm{Wt}$ & - & - & - & - & - & 0.1 & - & 0.6 & - & $<0.1$ & - & - & - & 3.4 & - & $<0.1$ & \\
\hline \multirow[t]{2}{*}{ 119-004 } & C-5 & $30-40$ & $\mathrm{~F} 2$ & 87.6 & $\mathrm{~N}$ & - & - & - & - & - & 4 & - & 1 & - & 4 & - & - & - & 8 & - & 30 & \\
\hline & - & - & & - & Wt & - & - & - & - & - & $<0.1$ & - & 0.2 & - & $<0.1$ & - & - & - & $<0.1$ & - & 6.0 & \\
\hline \multirow[t]{2}{*}{$120-004-1$} & Cutbank & $20-40$ & F5 & 178.2 & $\mathrm{~N}$ & - & - & 3 & - & - & 18 & - & 1 & - & 10 & - & - & - & $30+$ & - & 45 & Daub w/impressions \\
\hline & - & - & & - & $\mathrm{Wt}$ & - & - & 84.9 & - & - & 0.3 & - & 0.5 & - & 0.1 & - & - & - & 11.2 & - & 9.5 & \\
\hline \multirow[t]{2}{*}{$120-004-2$} & Cutbank & $23-40$ & F5 & 240.7 & $\mathrm{~N}$ & - & 2 & - & - & - & 36 & - & 1 & - & 15 & - & - & - & $30+$ & - & $30+$ & Daub w/impressions \\
\hline & - & - & & - & $\mathrm{Wt}$ & - & $<0.1$ & - & - & - & 1.8 & - & 1.4 & - & 0.6 & - & - & - & 14.2 & - & 43.8 & \\
\hline \multirow[t]{2}{*}{ 234-004 } & N480 & $40-50$ & F20 & 27.6 & $\mathrm{~N}$ & - & - & - & - & - & - & - & 1 & - & 1 & - & - & - & 5 & - & 5 & \\
\hline & E500 & - & & - & $\mathrm{Wt}$ & - & - & - & - & - & - & - & 0.1 & - & $<0.1$ & - & - & - & $<0.1$ & - & 0.6 & \\
\hline \multirow[t]{2}{*}{ 252-004-2 } & N480 & $40-50$ & F19 E1/2 & 33.7 & $\mathrm{~N}$ & - & - & - & - & - & 3 & - & 5 & - & - & - & - & - & 4 & - & 2 & \\
\hline & E501 & - & & - & Wt & - & - & - & - & - & $<0.1$ & - & $<0.1$ & - & - & - & - & - & 0.3 & - & 0.2 & \\
\hline \multirow[t]{2}{*}{ 252-004-2 } & N480 & $50-60$ & F19 W1/2 & 22.6 & $\mathrm{~N}$ & - & - & - & - & - & 2 & - & 1 & - & - & - & 1 & - & 5 & - & - & \\
\hline & E501 & - & Area C & - & Wt & - & - & - & - & - & 0.2 & - & 0.1 & - & - & - & 1.8 & - & 0.3 & - & - & \\
\hline \multirow[t]{2}{*}{ 294-004 } & N482 & $47-50$ & F26 & 131.2 & $\mathrm{~N}$ & - & 1 & - & - & - & 18 & - & 1 & - & 10 & - & - & - & $30+$ & - & $30+$ & Daub w/impressions \\
\hline & E499 & - & & - & Wt & - & $<0.1$ & - & - & - & 0.1 & - & 2 & - & 0.3 & - & - & - & 2.7 & - & 6.5 & \\
\hline \multirow[t]{2}{*}{$300-004$} & N482 & $70-80$ & F29 & 189.3 & $\mathrm{~N}$ & - & 4 & - & - & - & 25 & - & 1 & - & 4 & 2 & - & - & $30+$ & - & $30+$ & \\
\hline & E499 & - & & - & $\mathrm{Wt}$ & - & $<0.1$ & - & - & - & 0.3 & - & 1 & - & $<0.1$ & 8.1 & - & - & 2.2 & - & 2.9 & \\
\hline 328-004-1 & N482 & $70-82$ & F23 & 44.7 & $\mathrm{~N}$ & - & - & - & - & - & 17 & - & 1 & - & 1 & 3 & - & - & $30+$ & - & 23 & \\
\hline & E501 & - & & - & $\mathrm{Wt}$ & - & - & - & - & - & $<0.1$ & - & 0.6 & - & $<0.1$ & 11.7 & - & - & 5.0 & - & 1.6 & 1-wood sent for ID \\
\hline 331-004-1 & N482 & $80-90$ & F23 & 24.9 & $\mathrm{~N}$ & - & - & - & - & - & 3 & - & 1 & - & 1 & - & - & - & - & - & $10+$ & \\
\hline & E501 & - & & - & $\mathrm{Wt}$ & - & - & - & - & - & $<0.1$ & - & 0.7 & - & $<0.1$ & - & - & - & - & - & 0.7 & \\
\hline $350-004$ & N484 & $60-80 ?$ & F31 & 302.1 & $\mathrm{~N}$ & - & - & - & - & - & 23 & - & 1 & - & 2 & - & - & 1 & $25+$ & - & 4 & \\
\hline & E497 & - & & - & Wt & - & - & - & - & - & 18.4 & - & 0.2 & - & $<0.1$ & - & - & - & 19.3 & - & 0.3 & \\
\hline
\end{tabular}


Table 9-1. Heavy and Light Fraction Results from Flotation Analysis of Feature Matrix, Component C (cont.).

\begin{tabular}{|c|c|c|c|c|c|c|c|c|c|c|c|c|c|c|c|c|c|c|c|c|c|c|}
\hline \multirow{3}{*}{$\begin{array}{l}\text { Cat No. } \\
380-004 \\
\end{array}$} & \multirow{3}{*}{$\begin{array}{c}\text { Unit } \\
\\
\text { N486 } \\
\end{array}$} & \multirow{3}{*}{$\begin{array}{c}\begin{array}{c}\text { Depth } \\
\text { (cmbs) }\end{array} \\
70-80 \\
\end{array}$} & \multirow{3}{*}{\begin{tabular}{|c|}
$\begin{array}{c}\text { Feature No } \\
\text { Component } \\
\text { C }\end{array}$ \\
- \\
\end{tabular}} & \multirow{3}{*}{\begin{tabular}{c|}
$\begin{array}{c}\text { Weight } \\
\text { (g) }\end{array}$ \\
\\
\end{tabular}} & \multirow{3}{*}{\begin{tabular}{|l|} 
\\
$\mathrm{N}$ \\
\end{tabular}} & \multicolumn{16}{|c|}{ Flotation Recovery } & \multirow{3}{*}{ Comments } \\
\hline & & & & & & \multicolumn{2}{|c|}{$\begin{array}{l}\text { Mussel } \\
\text { Shell }\end{array}$} & \multicolumn{2}{|c|}{$\begin{array}{c}\text { Burned } \\
\text { Rock }\end{array}$} & \multicolumn{2}{|c|}{ Debitage } & \multicolumn{2}{|c|}{ Charcoal } & \multicolumn{2}{|c|}{ Macrobotanical } & \multicolumn{2}{|c|}{ Ceramic } & \multicolumn{2}{|c|}{ Bone } & \multicolumn{2}{|c|}{ Daub } & \\
\hline & & & & & & - & - & - & - & - & 1 & - & - & - & - & - & - & - & - & - & 1 & \\
\hline & E493 & - & & \begin{tabular}{|l|} 
\\
\end{tabular} & $\mathrm{Wt}$ & - & - & - & - & - & $<0.1$ & - & - & - & - & - & - & - & - & - & $<0.1$ & \\
\hline \multirow[t]{2}{*}{ 381-004-1 } & N486 & $90-100$ & Stain & 14.2 & $\mathrm{~N}$ & - & - & - & - & - & - & - & 1 & - & 1 & - & - & - & - & - & 6 & \\
\hline & E493 & & & - & $\mathrm{Wt}$ & - & - & - & - & - & - & - & $<0.1$ & - & $<0.1$ & - & - & - & - & - & 0.1 & \\
\hline \multirow[t]{2}{*}{ 437-004 } & N490 & $40-50$ & F5 & 58.9 & $\mathrm{~N}$ & - & 3 & - & - & - & 18 & - & 1 & - & 1 & - & - & - & $30+$ & - & $10+$ & Daub w/impressions \\
\hline & E501 & - & & - & $\mathrm{Wt}$ & - & $<0.1$ & - & - & - & 0.1 & - & 0.7 & - & 0.2 & - & - & - & 3 & - & 4.4 & 1-bug $<0.1 \mathrm{~g}$ \\
\hline \multirow[t]{2}{*}{ 439-004 } & N490 & $50-58$ & F5 & 22.2 & $\mathrm{~N}$ & - & - & - & - & - & 10 & - & 1 & - & - & - & - & - & 20 & - & 6 & \\
\hline & E501 & - & & - & $\mathrm{Wt}$ & - & - & - & - & - & 0.2 & - & 0.2 & - & - & - & - & - & 0.4 & - & 0.1 & \\
\hline \multirow[t]{2}{*}{ 446-004 } & N491 & $30-40$ & F16 & 11.8 & $\mathrm{~N}$ & - & - & - & - & - & 3 & - & 1 & - & 4 & - & - & - & 28 & - & - & seeds \\
\hline & E500 & - & & - & $\mathrm{Wt}$ & - & - & - & - & - & $<0.1$ & - & 0.2 & - & $<0.1$ & - & - & - & 0.2 & - & - & \\
\hline \multirow[t]{2}{*}{ 449-004 } & N491 & $35-40$ & F16 & 148.1 & $\mathrm{~N}$ & - & - & - & - & 20 & - & - & 1 & - & - & - & - & - & $30+$ & - & $10+$ & 3 -Larvae $<0.1 \mathrm{~g}$ \\
\hline & E501 & - & & - & $\mathrm{Wt}$ & - & - & - & - & 1.3 & - & - & 0.9 & - & - & - & - & - & 4.3 & - & 2.2 & \\
\hline \multirow[t]{2}{*}{ 451-004 } & N491 & $40-50$ & F16 & 391.9 & $\mathrm{~N}$ & - & - & - & - & - & $70+$ & - & 1 & - & 1 & - & - & - & $100+$ & - & $20+$ & 2-Larvae,1-Coal 2.5g \\
\hline & E501 & - & & - & $\mathrm{Wt}$ & - & - & - & - & - & 2.5 & - & 4.3 & - & 0.3 & - & - & - & 11.2 & - & 9.4 & \\
\hline \multirow[t]{2}{*}{ 453-004 } & N491 & $50-59$ & F16 & 183.5 & $\mathrm{~N}$ & - & - & - & - & - & $20+$ & - & 1 & - & 2 & - & - & - & $20+$ & - & - & 2 corn \\
\hline & E501 & - & & - & $\mathrm{Wt}$ & - & - & - & - & - & 0.7 & - & 1.1 & - & 0.2 & - & - & - & 1.7 & - & - & \\
\hline \multirow[t]{2}{*}{ 455-004 } & N491 & $66-74$ & F16 & 20.6 & $\mathrm{~N}$ & - & - & - & - & - & 18 & - & 1 & - & 1 & - & - & - & - & - & $10+$ & 1 seed \\
\hline & E501 & - & & - & $\mathrm{Wt}$ & - & - & - & - & - & $<0.1$ & - & 0.5 & - & $<0.1$ & - & - & - & - & - & 0.6 & \\
\hline $457-004$ & N491 & 63-70 & F16 & 64.2 & $\mathrm{~N}$ & - & - & - & - & - & 2 & - & 1 & - & - & - & - & - & 7 & - & - & \\
\hline & E502 & - & & - & $\mathrm{Wt}$ & - & - & - & - & - & 0.1 & - & 0.6 & - & - & - & - & - & 0.4 & - & - & \\
\hline 463-004 & $492 / 491$ & $40-84$ & - & 12.3 & $\mathrm{~N}$ & - & - & - & - & - & 1 & - & 1 & - & 4 & - & - & - & 3 & - & - & \\
\hline & E500 & - & & - & $\mathrm{Wt}$ & - & - & - & - & - & 0.1 & - & 0.2 & - & $<0.1$ & - & - & - & $<0.1$ & - & - & \\
\hline 468-004 & N492 & $36-37$ & F16 & 5.5 & $\mathrm{~N}$ & - & - & - & - & - & 12 & - & 1 & - & - & - & - & - & $10+$ & - & - & \\
\hline & E501 & - & & - & $\mathrm{Wt}$ & - & - & - & - & - & $<0.1$ & - & 0.2 & - & - & - & - & - & 1.1 & - & - & \\
\hline 470-004 & N492 & $40-50$ & F16 & 600.5 & $\mathrm{~N}$ & - & 2 & - & - & $50+$ & - & - & 2 & - & 12 & - & - & - & $30+$ & - & $30+$ & \\
\hline 471-004 & N493 & $40-51$ & & 601.5 & $\mathrm{~N}$ & - & 3 & - & - & $50+$ & - & - & 3 & - & 13 & - & - & - & $30+$ & - & $30+$ & \\
\hline
\end{tabular}


Table 9-1. Heavy and Light Fraction Results from Flotation Analysis of Feature Matrix, Component C (cont.).

\begin{tabular}{|c|c|c|c|c|c|c|c|c|c|c|c|c|c|c|c|c|c|c|c|c|c|c|}
\hline \multirow{3}{*}{$\begin{array}{l}\text { Cat No. } \\
\text { 472-004 }\end{array}$} & \multirow{3}{*}{$\begin{array}{l}\text { Unit } \\
\text { N492 }\end{array}$} & \multirow{3}{*}{\begin{tabular}{c|}
$\begin{array}{c}\text { Depth } \\
\text { (cmbs) }\end{array}$ \\
$50-60$
\end{tabular}} & \multirow{3}{*}{\begin{tabular}{|c|}
$\begin{array}{c}\text { Feature No. } \\
\text { Component } \\
\text { C }\end{array}$ \\
F16
\end{tabular}} & \multirow{3}{*}{$\begin{array}{c}\begin{array}{c}\text { Weight } \\
\text { (g) }\end{array} \\
85.7\end{array}$} & \multirow[b]{3}{*}{$\mathrm{N}$} & \multicolumn{16}{|c|}{ Flotation Recovery } & \multirow{3}{*}{$\begin{array}{c}\text { Comments } \\
\text { corn }\end{array}$} \\
\hline & & & & & & \multicolumn{2}{|c|}{$\begin{array}{c}\text { Mussel } \\
\text { Shell }\end{array}$} & \multicolumn{2}{|c|}{$\begin{array}{c}\text { Burned } \\
\text { Rock }\end{array}$} & \multicolumn{2}{|c|}{ Debitage } & \multicolumn{2}{|c|}{ Charcoal } & \multicolumn{2}{|c|}{ Macrobotanical } & \multicolumn{2}{|c|}{ Ceramic } & \multicolumn{2}{|c|}{ Bone } & \multicolumn{2}{|c|}{ Daub } & \\
\hline & & & & & & - & - & - & - & - & 17 & - & 1 & - & 2 & - & - & - & $20+$ & - & - & \\
\hline & E501 & - & & - & $\mathrm{Wt}$ & - & - & - & - & - & 0.4 & - & 0.5 & - & 0.2 & - & - & - & 0.7 & - & - & \\
\hline \multirow[t]{2}{*}{ 474-004-1 } & N492 & $50-60$ & F21 & 120.2 & $\mathrm{~N}$ & - & 2 & - & - & - & 62 & - & 1 & - & - & - & - & - & $20+$ & - & - & 5-Larvae $1.0 \mathrm{~g}$ \\
\hline & E501 & - & & - & $\mathrm{Wt}$ & - & $<0.1$ & - & - & - & 1.1 & - & 0.5 & - & - & - & - & - & 1.1 & - & - & \\
\hline \multirow[t]{2}{*}{ 476-004 } & N492 & $60-70$ & F21 & 43.7 & $\mathrm{~N}$ & - & - & - & - & - & - & - & 1 & - & - & - & - & - & 5 & - & $10+$ & \\
\hline & E501 & - & Area C & - & Wt & - & - & - & - & - & - & - & 0.1 & - & - & - & - & - & 0.4 & - & 0.4 & \\
\hline \multirow[t]{2}{*}{ 478-004 } & N492 & $60-71$ & F21 & 31.6 & $\mathrm{~N}$ & - & - & - & - & - & 6 & - & 1 & - & 1 & - & - & 3 & $30+$ & - & - & 1 corn \\
\hline & E502 & - & Area C & - & Wt & - & - & - & - & - & 0.2 & - & 0.9 & - & $<0.1$ & - & - & - & 3.2 & - & - & \\
\hline \multirow[t]{2}{*}{ 520-004-2 } & N496 & $54-72$ & F17 & 20.4 & $\mathrm{~N}$ & - & - & - & - & - & 1 & - & 1 & - & - & - & - & - & 7 & - & 3 & 1-wood sent for ID \\
\hline & E500 & - & & - & $\mathrm{Wt}$ & - & - & - & - & - & 0.1 & - & 4.9 & - & - & - & - & - & $<0.1$ & - & $<0.1$ & \\
\hline $520-004-1$ & N496 & $42-54$ & F17 & 7.3 & $\mathrm{~N}$ & - & - & - & - & - & - & - & 1 & - & - & - & - & - & $30+$ & 1 & - & \\
\hline \multirow{3}{*}{$1232-004$} & $\mathrm{E} 500$ & - & & - & Wt & - & - & - & - & - & - & - & $<0.1$ & - & - & - & - & - & 0.8 & 1.8 & - & \\
\hline & N482 & $70-85$ & F26 & 43.9 & $\mathrm{~N}$ & - & - & - & - & - & 1 & - & 1 & - & - & - & - & - & 16 & - & $40+$ & \\
\hline & E500 & - & & - & Wt & - & - & - & - & - & 0.3 & - & 0.8 & - & - & - & & - & 0.3 & - & 6.5 & \\
\hline \multirow[t]{2}{*}{$1236-004$} & N499 & $38-50$ & F28 & 138 & $\mathrm{~N}$ & - & - & - & - & - & 11 & - & 1 & - & - & - & - & - & 20 & - & 7 & \\
\hline & E498 & - & & - & Wt & - & - & - & - & - & 0.1 & - & $<0.1$ & - & - & - & - & - & 0.3 & - & $<0.1$ & \\
\hline \multirow[t]{2}{*}{ 1241-004 } & N484 & $?$ & F31 & 469.3 & $\mathrm{~N}$ & - & - & - & - & - & 32 & - & 1 & - & 2 & - & - & 1 & $30+$ & - & 3 & \\
\hline & E495 & - & & - & $\mathrm{Wt}$ & - & - & - & - & - & 0.3 & - & 0.1 & - & $<0.1$ & - & - & 12.2 & 5.5 & - & 0.4 & \\
\hline
\end{tabular}




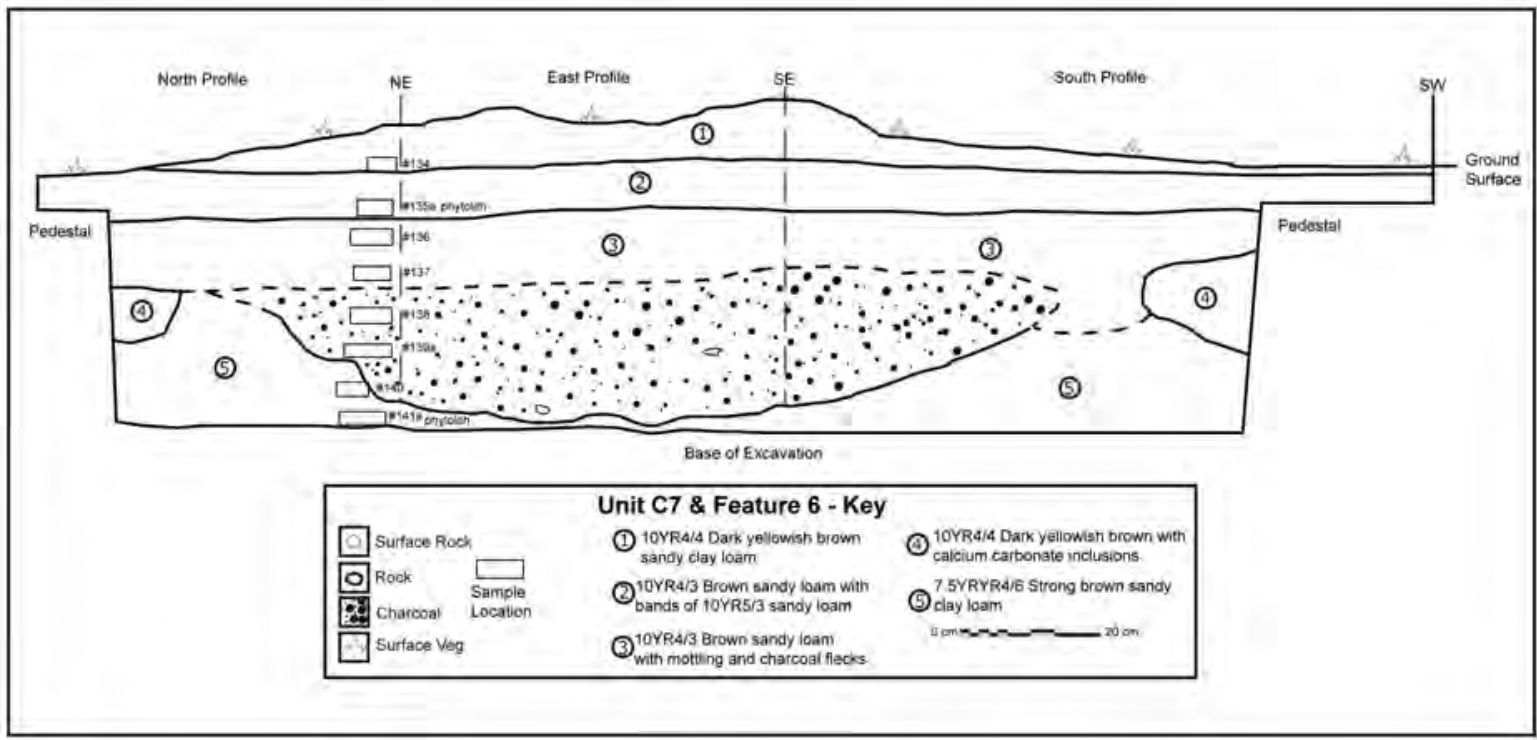

Figure 9-7. Profile drawing of three adjoining walls of Unit C-7 that depicts the location, shape, and size of a broad cultural basin (Feature 6).

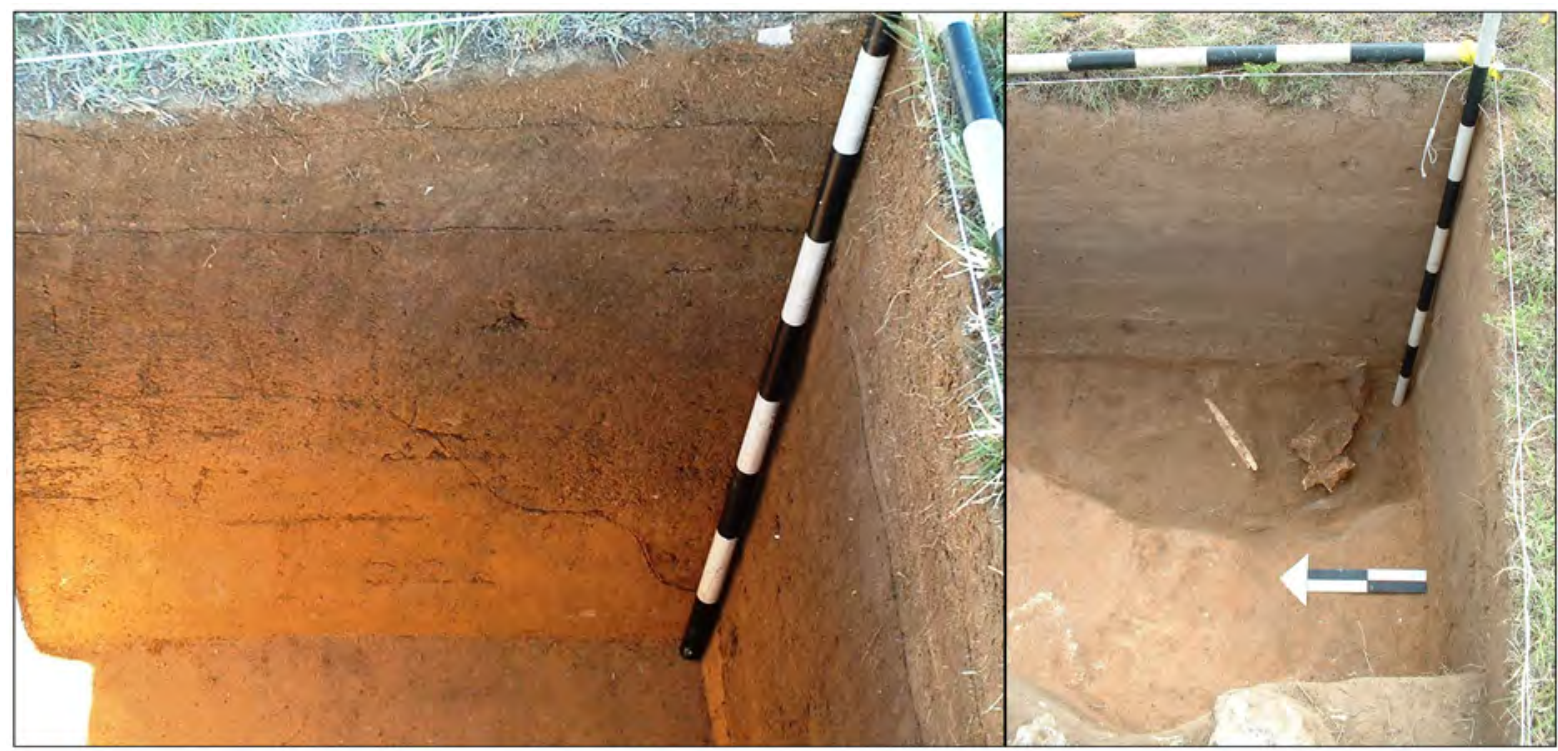

Figure 9-8. Photographs of wall profile (left) and bottom edge (right) of deep pit as revealed in Unit C-7. 
sandy loam with abundant fine mottles of brown (10YR 5/3) sandy loam and charcoal flecking. As excavations proceeded downward, the demarcation line between these two distinctive sediments gradually moved eastward that indicated the sloping edge of a large pit. The upper rim of the pit was not obvious, as the dark A horizon was a similar color to the dark cultural fill. The first recognizable soil distinction was at roughly 30 cmbs. As the excavations proceeded with depth, the interior basin fill became darker with increased scattered charcoal, and the outer margins became distinguishable as the basin penetrated into the underlying Ogallala.

Beginning with level 5, (ca. 40 to $50 \mathrm{cmbs}$ ), the deeper and more obvious pit fill was bagged without screening as it was collected for fine-screening or flotation in the laboratory. The deeper the excavations, the more pronounced the distinction between the pit fill and the surrounding matrix. At about 50 cmbs, cultural materials were encountered within the pit. At about $60 \mathrm{cmbs}$, the darker basin fill was limited to about the eastern $30 \mathrm{~cm}$ of the unit wherein there were four burned rocks, three large chunks of butchered bison bone, and a mono (\#132100). Between 60 and $70 \mathrm{cmbs}$, four small burned rocks were detected in the bottom of the basin in the northeastern corner of the unit. The excavations stopped at $70 \mathrm{cmbs}$ and wall profiles were drawn and photographed (see Figure 9-7).

Eleven liters of charcoal-laden pit fill (\#132-4a) from 50 to $60 \mathrm{cmbs}$ in Unit C-7 were submitted to Dr. Dering for flotation and macrobotanical identification. The $25.2 \mathrm{~g}$ of light fraction yielded 2 mesquite seeds, 2 maize kernels, 18 maize cupules, and mesquite and juniper charcoal (Appendix C). A chunk of juniper charcoal from the unfloated basin fill, between 60 and $70 \mathrm{cmbs}$ at the west end of this bottom basin was sent for radiocarbon dating. This juniper charcoal yielded a $\delta^{13} \mathrm{C}(-24.4 \%)$ corrected AMS date of $700 \pm 40$ B.P. (Beta-206562).

This pit feature was subsequently targeted for excavation during data recovery (see Figures 9-3 and 9-9). The mechanically scraped fireguard, which crossed immediately above the targeted basin, was not deep enough to impact the feature. In anticipation of the possible presence of a pithouse feature, the data recovery excavation left two 20-cm-wide east-west baulks in place along N498 and N499, which allowed detailed inspection of the fill sequences, documentation through photographs and drawings, extraction of columnar sediment and micromorphological (MM) samples, and collection of individual charcoal samples at different points across the pithouse (Figure (9-9).

The excavations revealed a complete pithouse, ovate in plan view that measured about $3.8 \mathrm{~m}$ east-west by roughly $2.8 \mathrm{~m}$ north-south. A narrow entryway, roughly 60 -cm-wide, faced nearly due east and sloped down from the original higher surface into the pithouse basin (Figure 9-9). The pit was initially recognizable between 30 and $35 \mathrm{cmbs}$, and the slightly undulating floor was between 76 and $80 \mathrm{cmbs}$. The lower $30 \mathrm{~cm}$ was dug into the Ogallala deposits, permitting easy distinction of the lower portion of the feature. Most side walls were quite steep, sloping inward towards the center, with an overall shape similar to a cereal bowl with a couple of irregularities. The west end revealed an abrupt and nearly vertical wall with some waves in the lower wall. The exception was the entryway that sloped down at a steep angle from about 35 to $40 \mathrm{cmbs}$ at the surface to nearly $80 \mathrm{cmbs}$ at the bottom (Figure 9-10).

The greatest width would have been at the top (surface), though this aspect of the feature was not readily distinguishable. In a number of areas around the lower margin of the pithouse, the side walls revealed excavation marks that were scalloped to wavy, which created irregular edges (Figures 9-9 and 9-11).

The pithouse floor was littered with diverse classes of cultural material (Figures 9-12 and 9-13) that included relatively large chunks of burned and unburned caliche cobbles up to $15 \mathrm{~cm}$ in diameter, quantities of butchered animal bones (mostly bison and deer), multiple fragments of metates and manos, the occasional bone tool (awl, scapula hoe, and tibia hoe), a few cordmarked ceramic sherds from multiple vessels, scattered chunks of tiny pieces of daub, occasional chipped stone tools (drill, biface, and projectile point), small quartzite burned pebbles, chert flakes, scattered charcoal, and pockets of ash. This density, diversity and horizontal distribution 


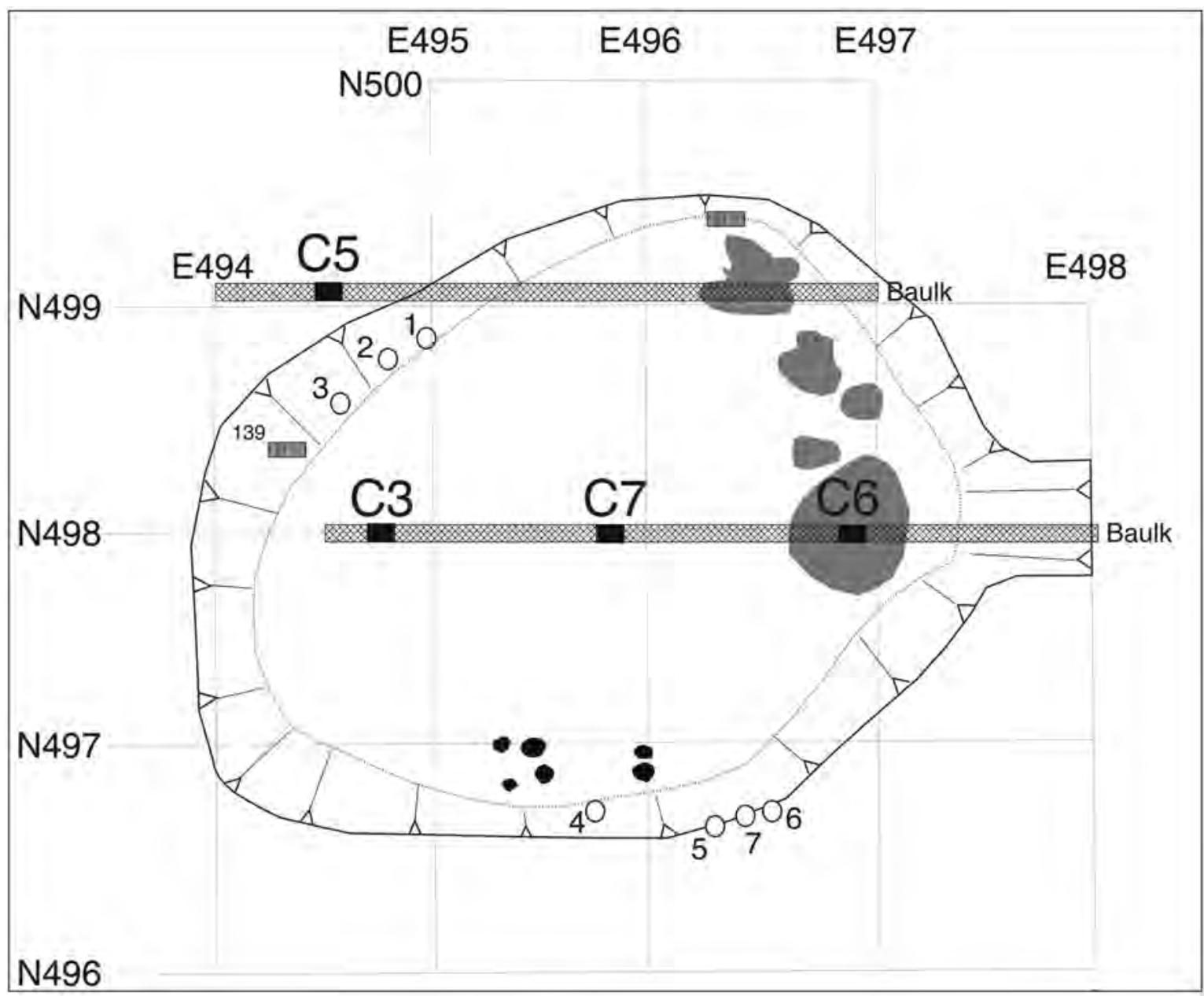

Figure 9-9. General plan drawing of Feature 6 outline.

clearly reflects disposal and not in situ debris. The floor lacked a well-defined central fireplace, although a few ash pockets were detected with ash Feature 24 near the middle, and no signs of structural elements such as large interior support post holes. It is possible, however, that small features went undetected under the 20 -cm-wide baulks that were left unexcavated.

Along and immediately outside the northwestern edge of the pit, three relatively closely spaced (ca. $25 \mathrm{~cm}$ apart), small diameter post holes (\#1, \#2 and \#3) were detected at roughly $45 \mathrm{cmbs}$ in unit N499 E495 (Figures 9-14 through 9-16). Just above this level (at $40 \mathrm{cmbs}$ ), the dark pithouse fill extended over these three post holes that indicate the upper, outer margin of the pithouse extended past these holes. In other words, the poles that created these holes were on the inside of the outer margin of the pit. On the opposite wall along the southeastern side in N497 E496 and N497 E497, another three possible four closely spaced, small diameter post holes (\#5, \#6 and \#7) were detected along the outer margin of the pit. Post hole \#4 was detected at roughly 50 cmbs, whereas holes \#5 through \#7 were at 47 and $48 \mathrm{cmbs}$, respectively (Table 9-2). Three holes (\#5, \#6, and \#7) were outside of the dark basin fill, whereas post hole \#4 was just inside. Post hole \#7 is the more questionable, as it was not readily visible until slightly below the adjacent holes.

Another two possible post holes, \#8 and \#9, were recorded inside the outer wall on the eastern end adjacent the entryway in N499 E498 (Figures 9-15 and 9-16). After reviewing the profiles of that unit, it was determined that these apparent holes 


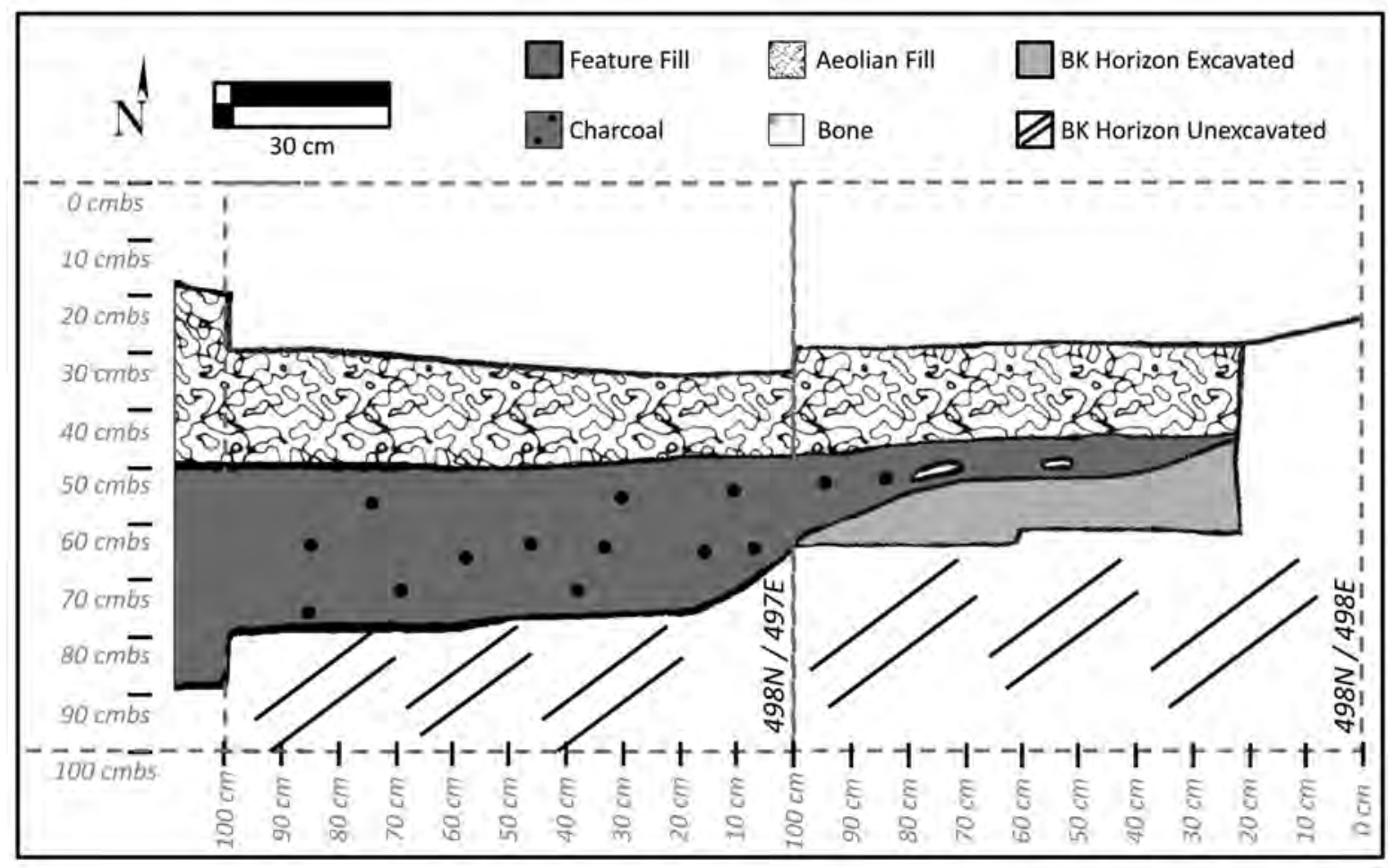

Figure 9-10. Partial profile drawing of entryway at eastern end of pithouse (N498 E497 and E498), view north.

were within the pithouse fill and did not penetrate the Ogallala sediments below the fill. Therefore, these are not considered cultural holes from posts associated with the pithouse framework.

Because this structure was not burned, many details concerning its superstructure were not readily visible. The identification of at least seven small-diameter $(<8$ $\mathrm{cm})$ postholes mostly on the outer margin on at least two sides indicates the superstructure consisted of small diameter posts. The positions of the identified posts indicate at least two sets of post were likely used for the framework. Feature 28, a vertical pit about $20 \mathrm{~cm}$ in diameter in N499 E498, may have been a support post on the north side of the entryway, but it is far from clear.

An entryway was documented at the eastern end of the ovate structure, most notably along the southern half of N499 E498. This was evident by a ramp that sloped down from the original surface into the bottom of the pithouse. The sloping deposits were visible in the southern wall of N499 E498 (Figure 9-17).
Potentially, the dark sedimentation the floor in the southeastern corner of N499 E497 may be associated with the entryway.

Many bulk sediment samples from the floor and just above the floor were collected for flotation and/or curation. Numerous smaller sediment samples were collected in vertical columns from the interior fill and profiles for use in phytolith, isotope, sediment grainsize analysis, and other potential analyses. From the two baulks, individual charcoal samples were piece plotted and individually collected. It was anticipated that analysis of charcoal above the actual pithouse floor would indicate the types of wood that were used in the construction, as opposed to the kind(s) of wood used for fuel. The baulks also allowed the project geoarcheologist to carefully select horizontally specific locations across the pithouse for extraction of multiple microstratigraphic samples that vertically encompassed the floor and various fill events (Figures 9-18 and 9-19). The sequence of filling events was interpreted on the basis of detailed stratigraphic data collected and analyzed by Charles 


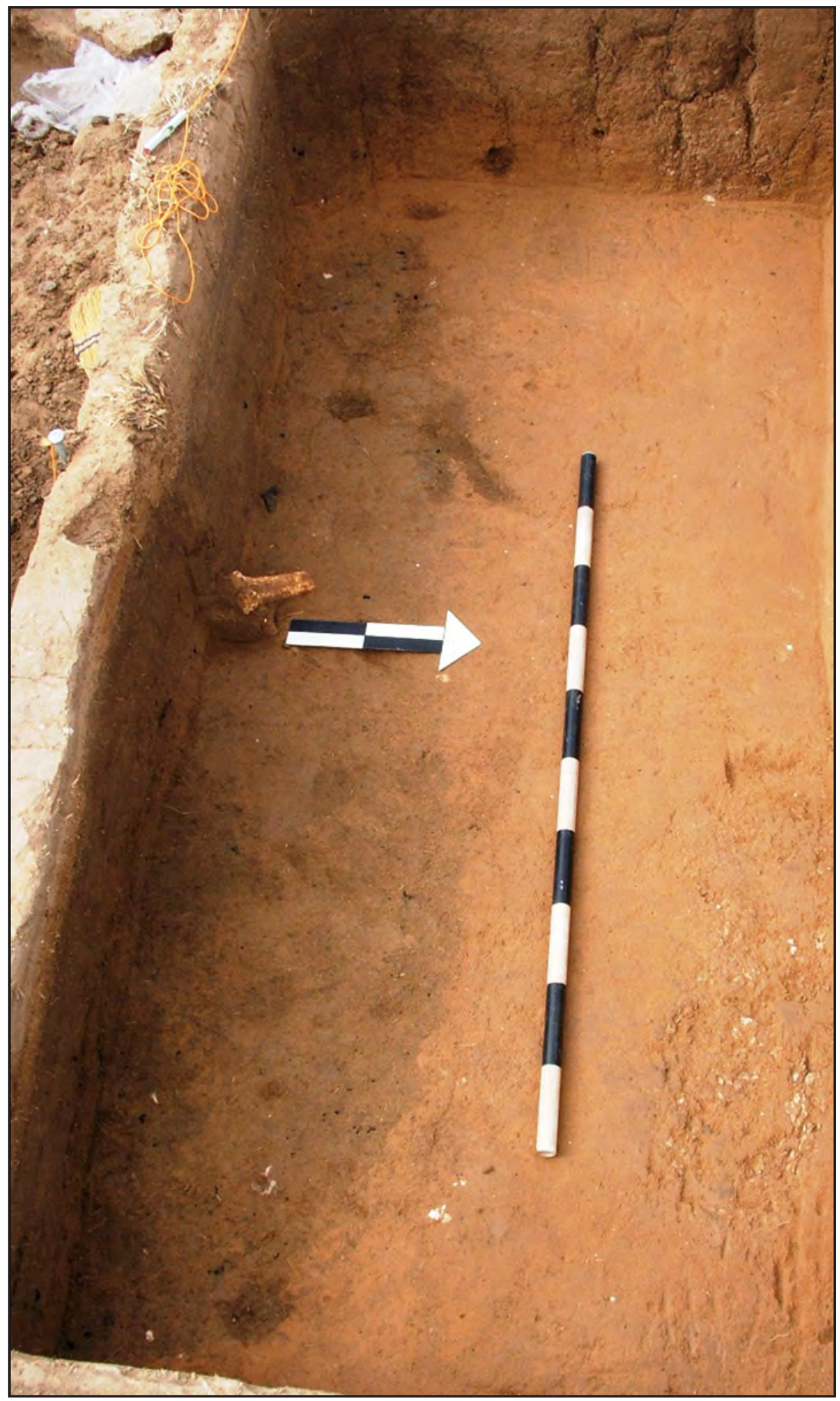

Figure 9-11. Photograph of northern edge of pithouse.

(Note: dark sediment is pithouse fill (left) and light colored sediment (right) is Ogallala. Scalloped pit edge in lower part of photograph.) 


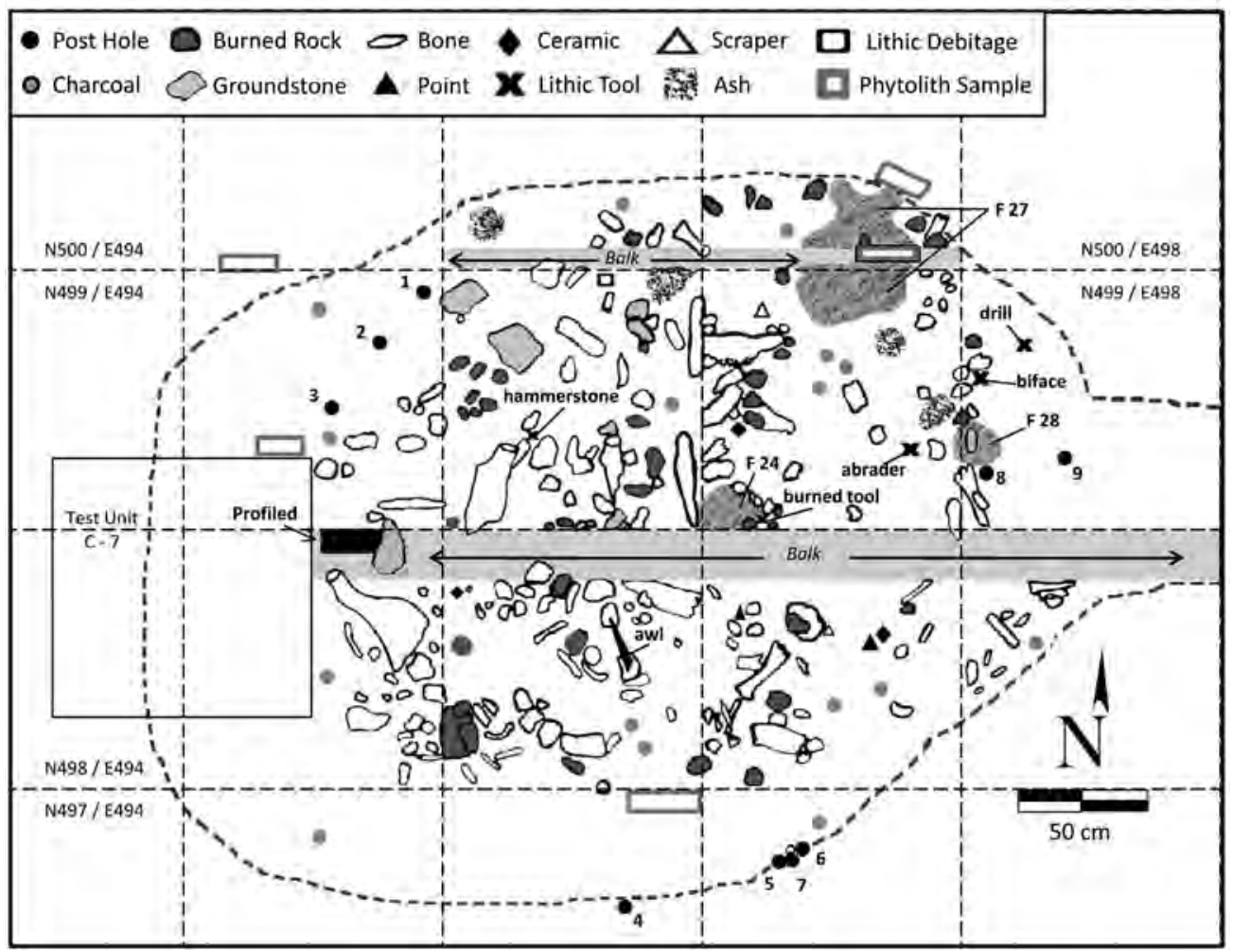

Figure 9-12. Drawing of the large cultural materials and features plotted across the pithouse floor.

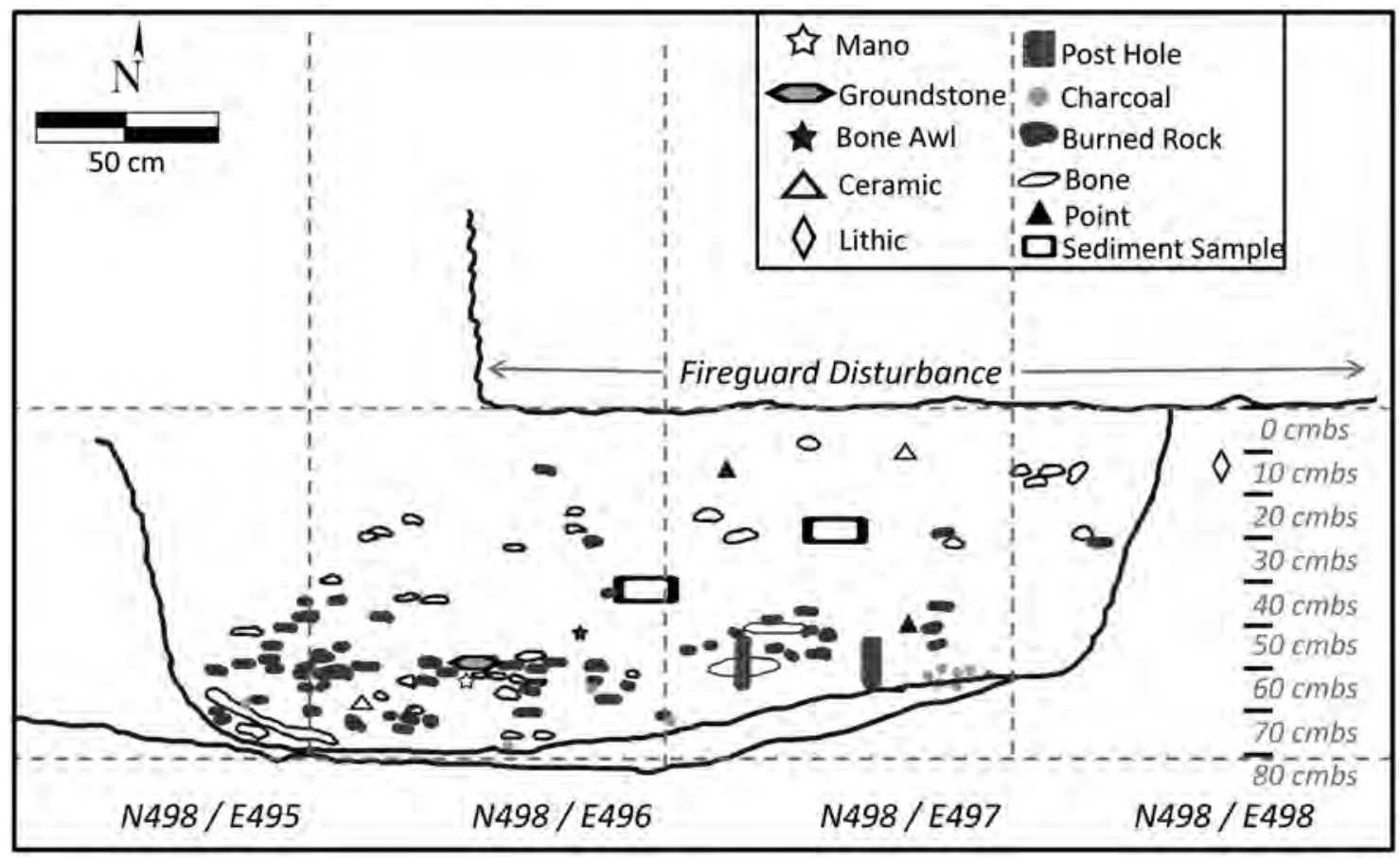

Figure 9-13. West to east profile drawing of $1 \mathrm{~m}$ of the cultural material back plotted in the pithouse along N498 line. 


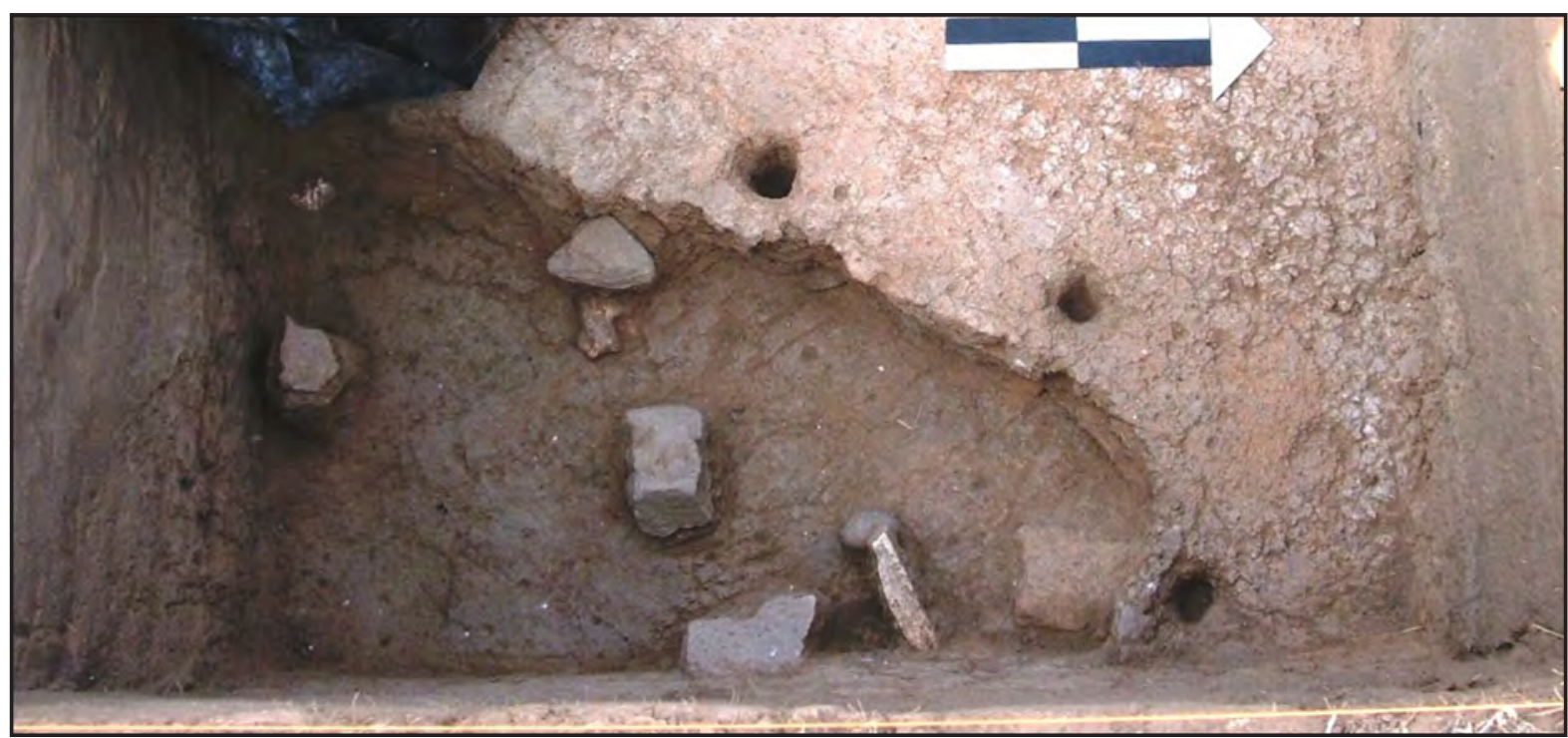

Figure 9-14. Overview of post holes (\#1, \#2 and \#3, right to left) on outside edge, along the northwestern side of pithouse and cultural refuse discarded on sloping floor of pithouse.

Frederick with assistance from Ms. Gregory and is presented below.

\subsubsection{Stratigraphy by Charles D. Frederick and Brittney Gregory}

The deposits associated with Feature 6 were studied by means of two narrow (20-cm-wide) east-west oriented baulks that cross-cut the feature along the site grid (Figure 9-18). These two baulks, which exposed the stratigraphic profile from the ground surface to the Ogallala Formation beneath the structure, provided an extremely useful perspective of the building and form the basis of the following discussion. The more useful of the two baulks was the N498 grid line baulk, which almost perfectly bisected the pit house.

This 3.5-m-long exposure starts just inside the western side of the structure and ends in the doorway. Three soil columns were collected from this profile, one on the western side (C-3), one in the middle (C-7) and one on the eastern side just inside the doorway (C-6). A fourth column (C-5) was collected from immediately outside the structure on the N499 baulk immediately west of the building, just northwest of post molds 1,2 and 3 . This column was considered at the time of excavation to serve as a kind of control sample for the natural deposits unassociated with the pit house. A second baulk, located along the northern perimeter of the building $1 \mathrm{~m}$ to the north (along N499 grid line), was also drawn and described.

For each column, the deposits were described in profile, drawn and sampled in a continuous column, and the column samples were examined for basic physical properties (e.g., texture, organic carbon content, calcium carbonate content, magnetic susceptibility, and phosphorus content (Figure 9-19 presents plots of these data by depth). The textural and compositional variation of the different deposits was also explored via a number of bivariate plots (Figures 9-20, 9-21, 9-22). Samples for micromorphological examination of the sediments were collected from the N498 baulk adjacent to each column profile as well as from places where features of interest were observed. These samples were embedded in polyester resin, and then slabbed with a rock saw, and thin sections prepared from these slabs from various stratigraphic contexts.

Upon close examination of the baulk exposures in the field it was immediately apparent that the structure contained a distinct floor deposit that was in turn buried by a thick, but irregular mantle of 


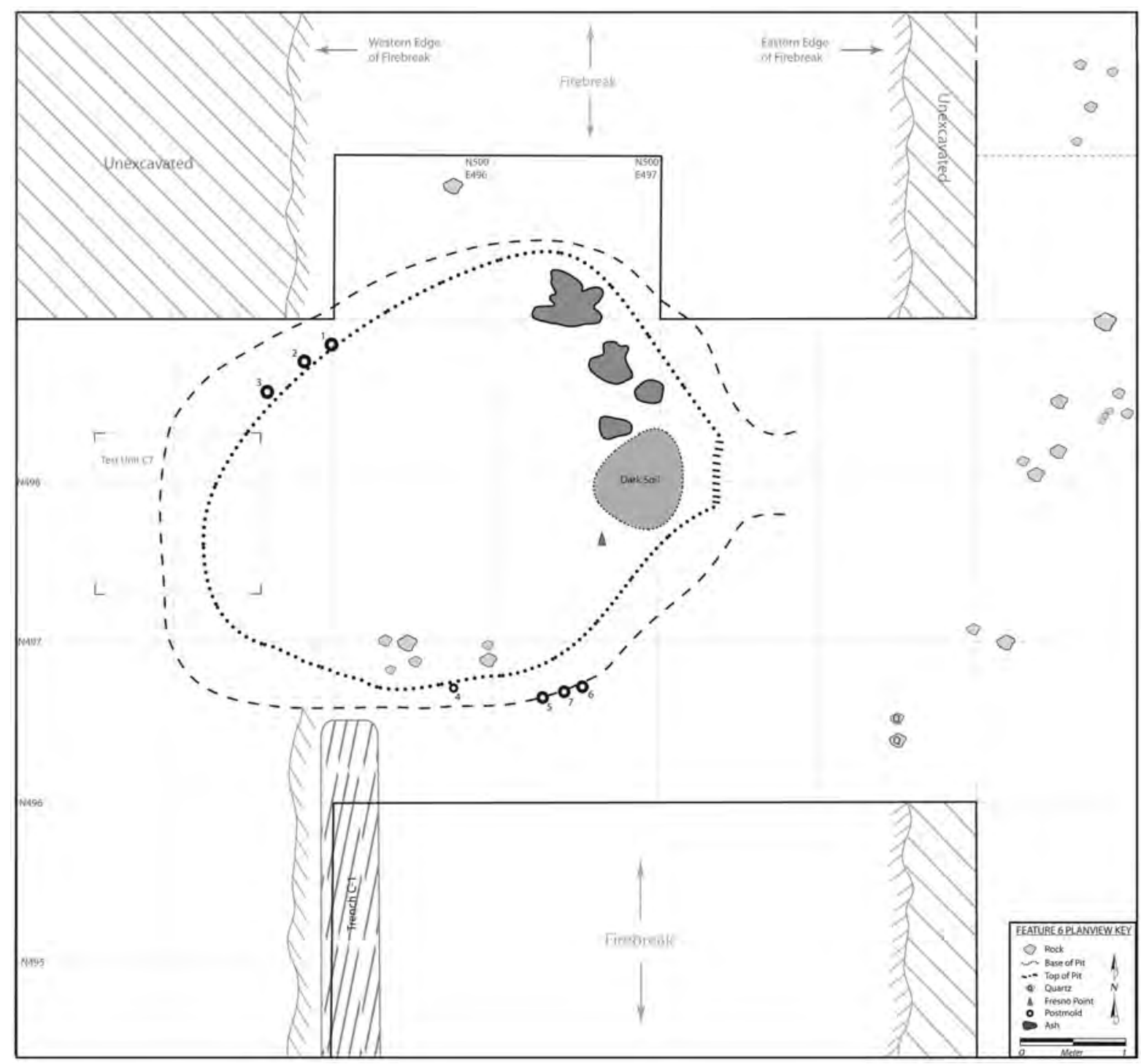

Figure 9-15. Overall plan view drawing of pithouse structure - Feature 6.

Table 9-2. Post Hole Data from Pithouse, Feature 6.

\begin{tabular}{|c|c|c|c|c|c|c|c|}
\hline $\begin{array}{c}\text { Hole } \\
\text { Number }\end{array}$ & Unit & $\begin{array}{c}\text { Depth } \\
\text { (cmbs) }\end{array}$ & $\begin{array}{c}\text { Hole } \\
\text { Location }\end{array}$ & $\begin{array}{c}\text { Hole } \\
\text { Width }\end{array}$ & $\begin{array}{c}\text { Hole } \\
\text { Depth }\end{array}$ & $\begin{array}{c}\text { Sediment } \\
\text { collected }\end{array}$ & $\begin{array}{c}\text { Post Mold } \\
\text { Made }\end{array}$ \\
\hline 1 & N499 E495 & ca. 49 & outside & 4 & 6 & yes & yes \\
\hline 2 & N499 E495 & ca. 49 & outside & 4 & 6 & yes & yes \\
\hline 3 & N499 E495 & ca. 49 & outside & 7 & 10 & yes & yes \\
\hline 4 & N497 E496 & ca. 50 & outside & ca. 5 & & no & no \\
\hline 5 & N497 E497 & 47 & outside & ca. 5 & 7 & yes & yes \\
\hline 6 & N497 E497 & 48 & outside & ca. 5 & 3 & yes & yes \\
\hline 7 & N497 E497 & ca. 48 & outside & 4 & 13 & no & no \\
\hline
\end{tabular}




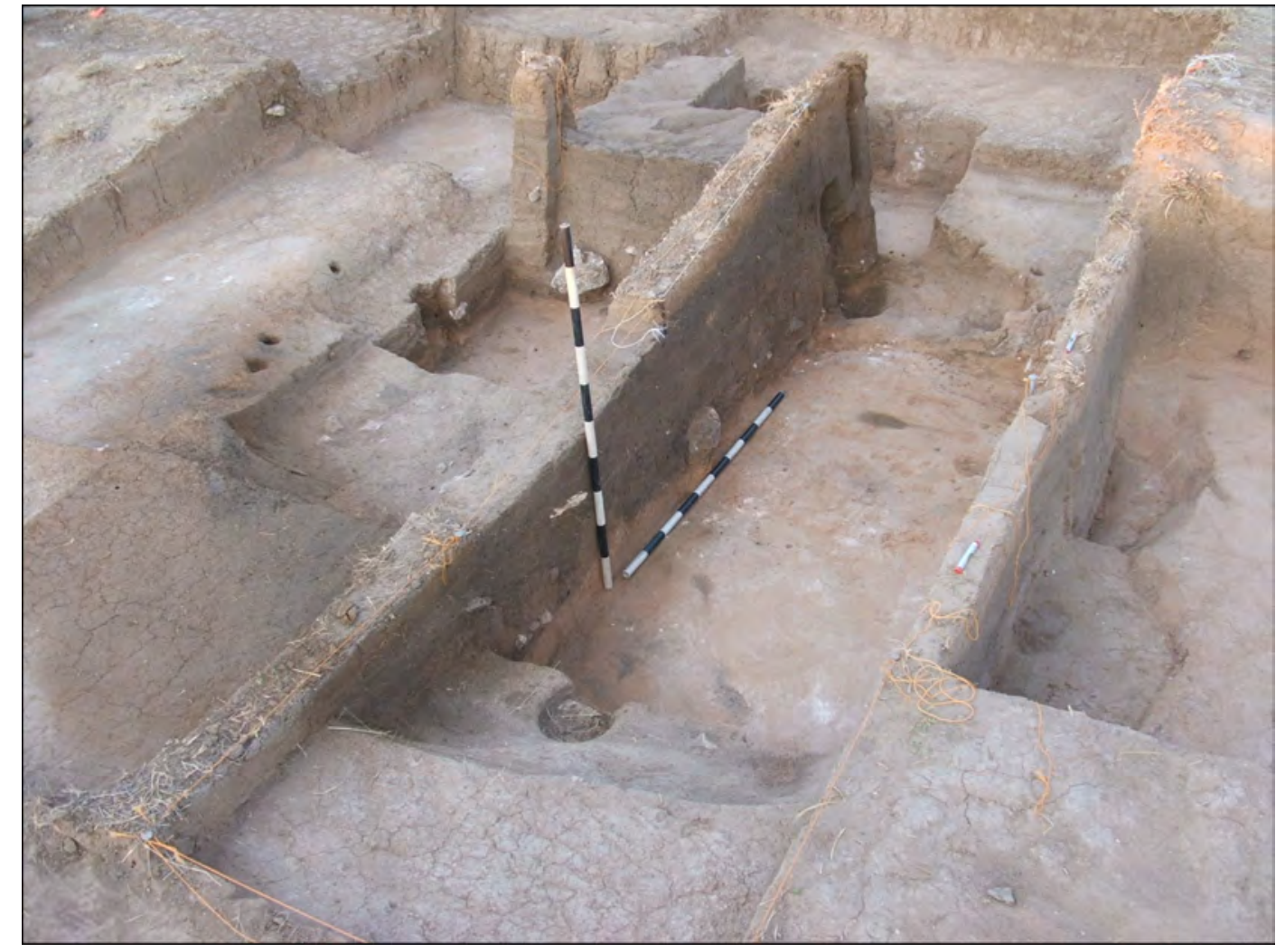

Figure 9-16. Overall photograph of completed pithouse - Feature 6 following excavation, with baulk down middle and at northern edge, view west.

Note: three small post holes on left [\#4, \#5, and \#6], southern margin and two post holes [\#2 and \#3] on right back margin).

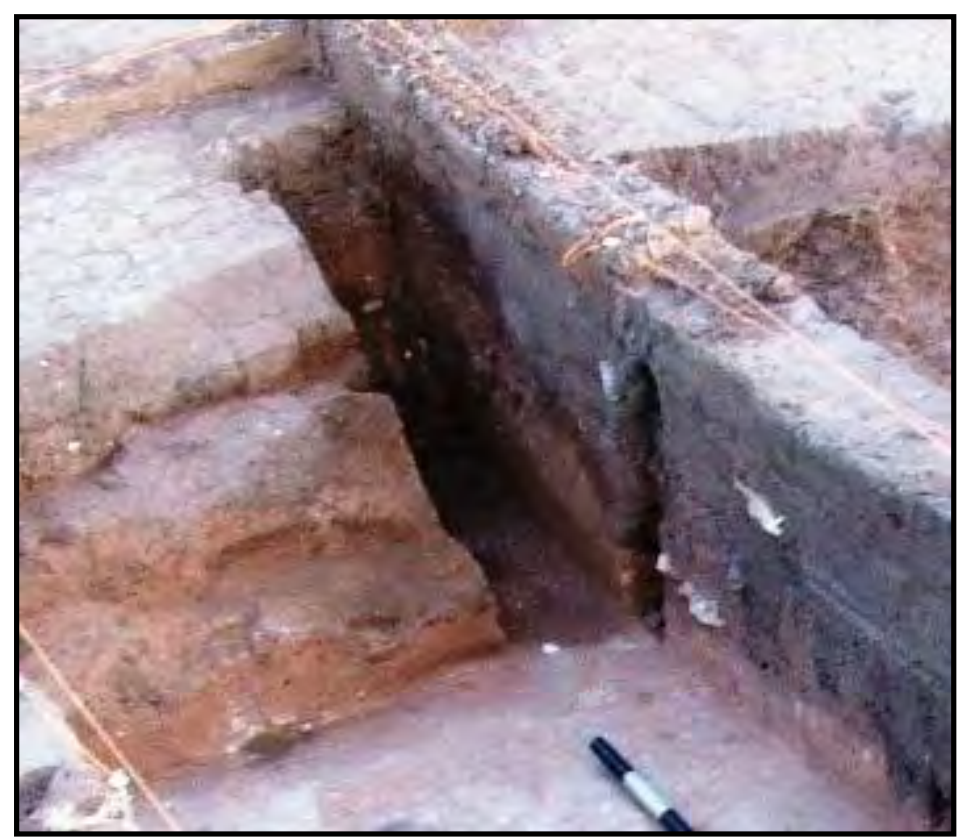

Figure 9-17. Photograph of sloping entryway along south wall of N499 E498. 


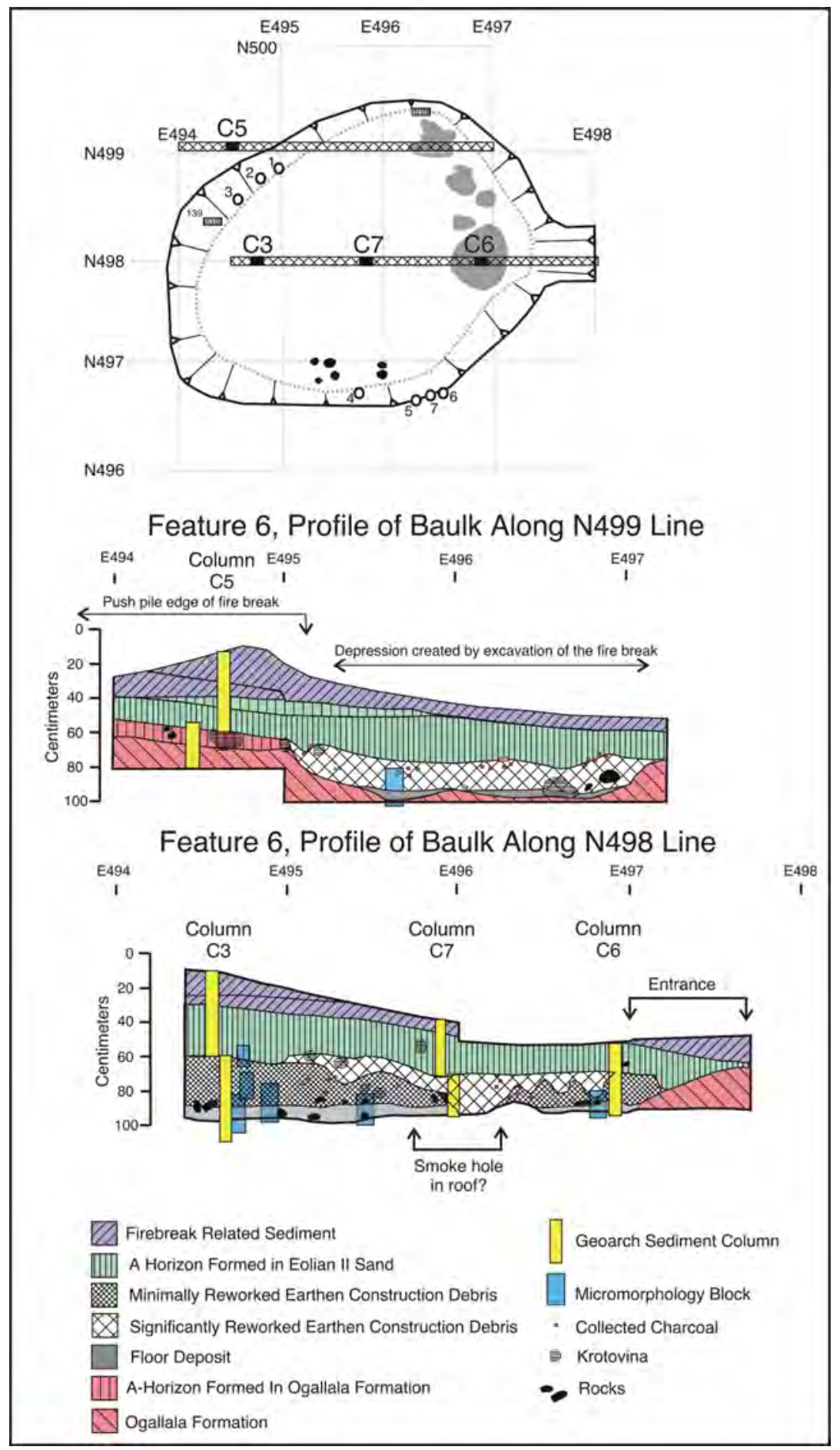

Figure 9-18. Top panel: map of Feature 6 showing the location of the two baulks profiles and column samples. Middle panel: drawing of the stratigraphy revealed by the northern wall of the northern baulk (along the N499 grid line).

Note that the topography shown here is directly related to the fireguard which was directly over the feature. Lower Panel: drawing of the stratigraphy exposed on the northern wall of the southern baulk through Feature 6 which was situated along the N498 grid line. 


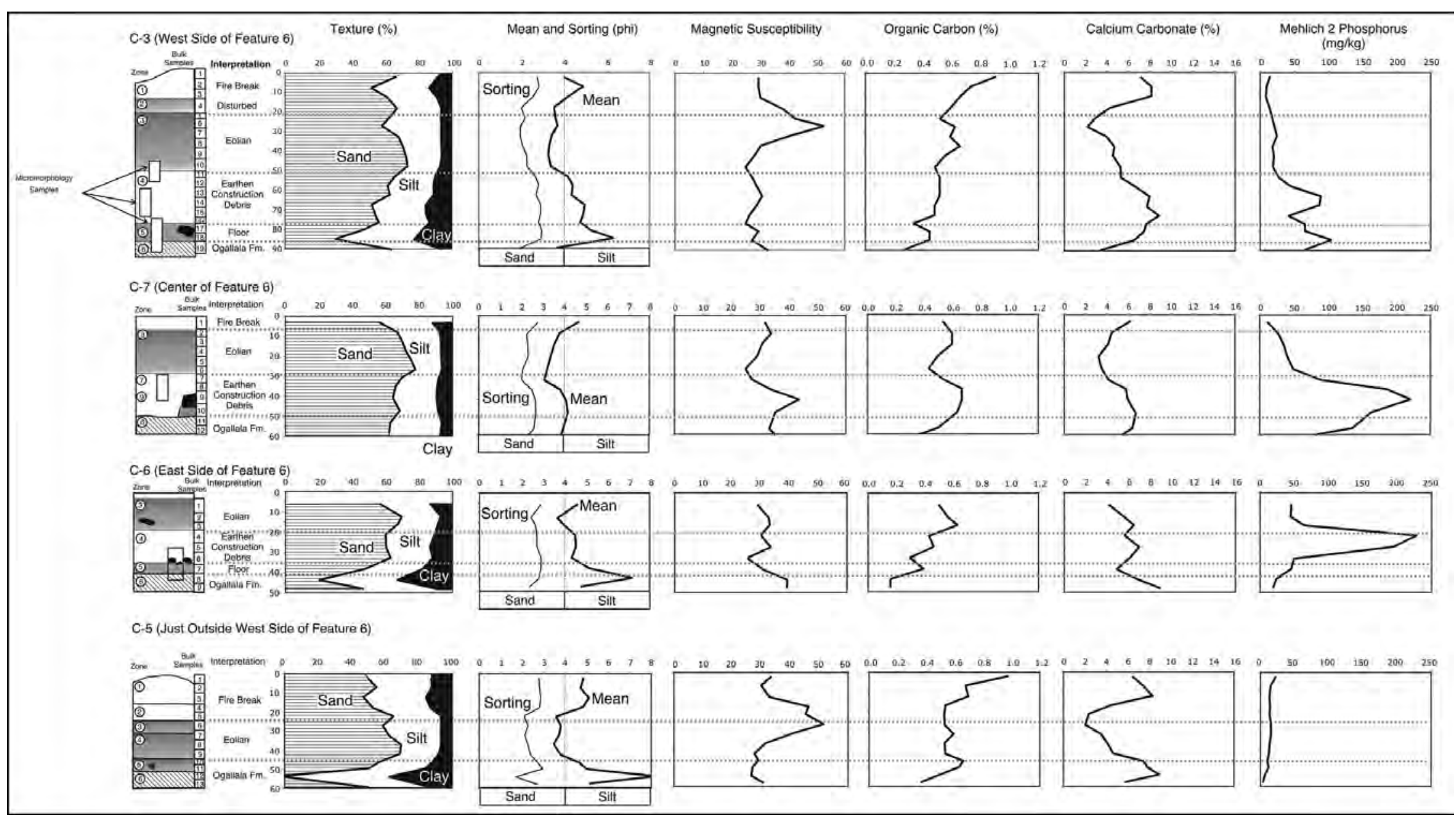

Figure 9-19. Plots of physical properties of sediment samples collected from the four column samples in and adjacent to Feature 6. 


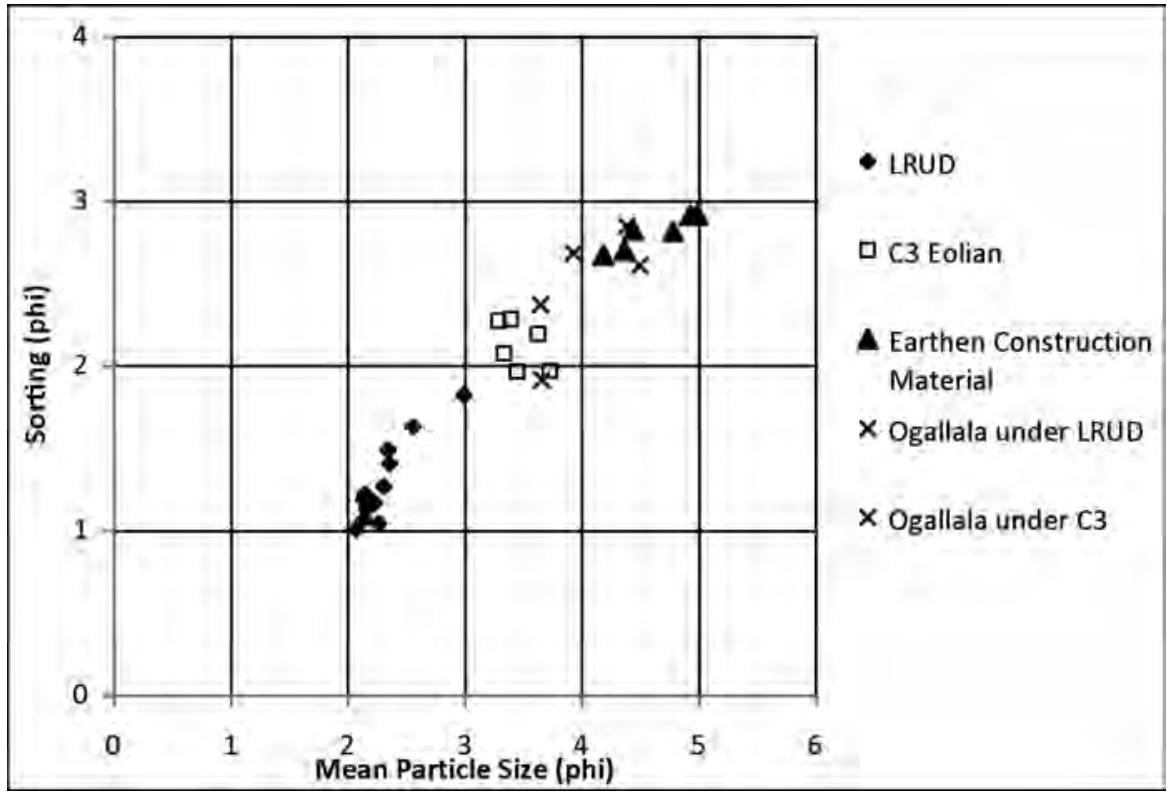

Figure 9-20. Plot of the mean particle size (in phi) versus the sorting (the standard deviation of the mean particle size distribution, also in phi) for different sediment groups associated with Feature 6.

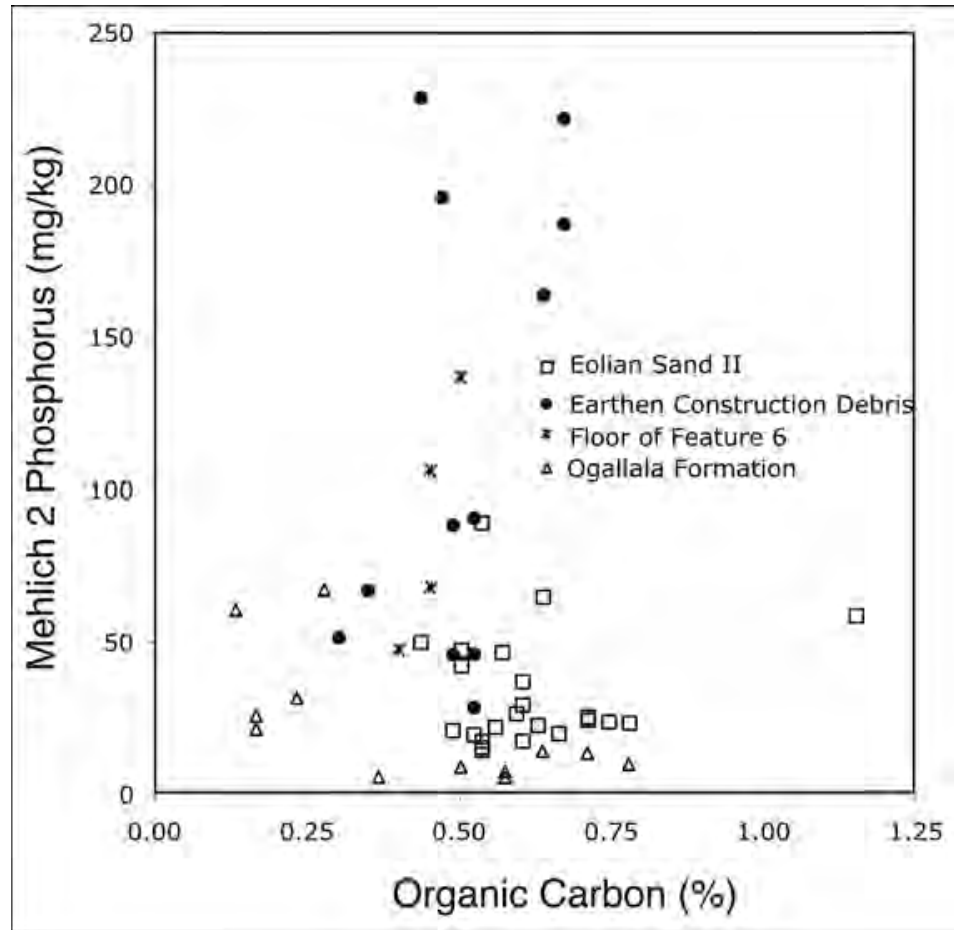

Figure 9-21. Plot of the percentage organic carbon versus the available phosphorous (Mehlich 2 digestion) for the deposits associated with Feature 6.

Ogallala Formation sediments are generally low in organic carbon and phosphorus, where as the Eolian Sand II, which buries the structure is generally low in phosphorus but moderately enriched in carbon. The floor and earthen construction debris exhibited organic enrichment on the same order as the eolian sand that buried it, but often exhibited significant phosphorus enrichment, upwards of almost 5 times the natural sediments. 


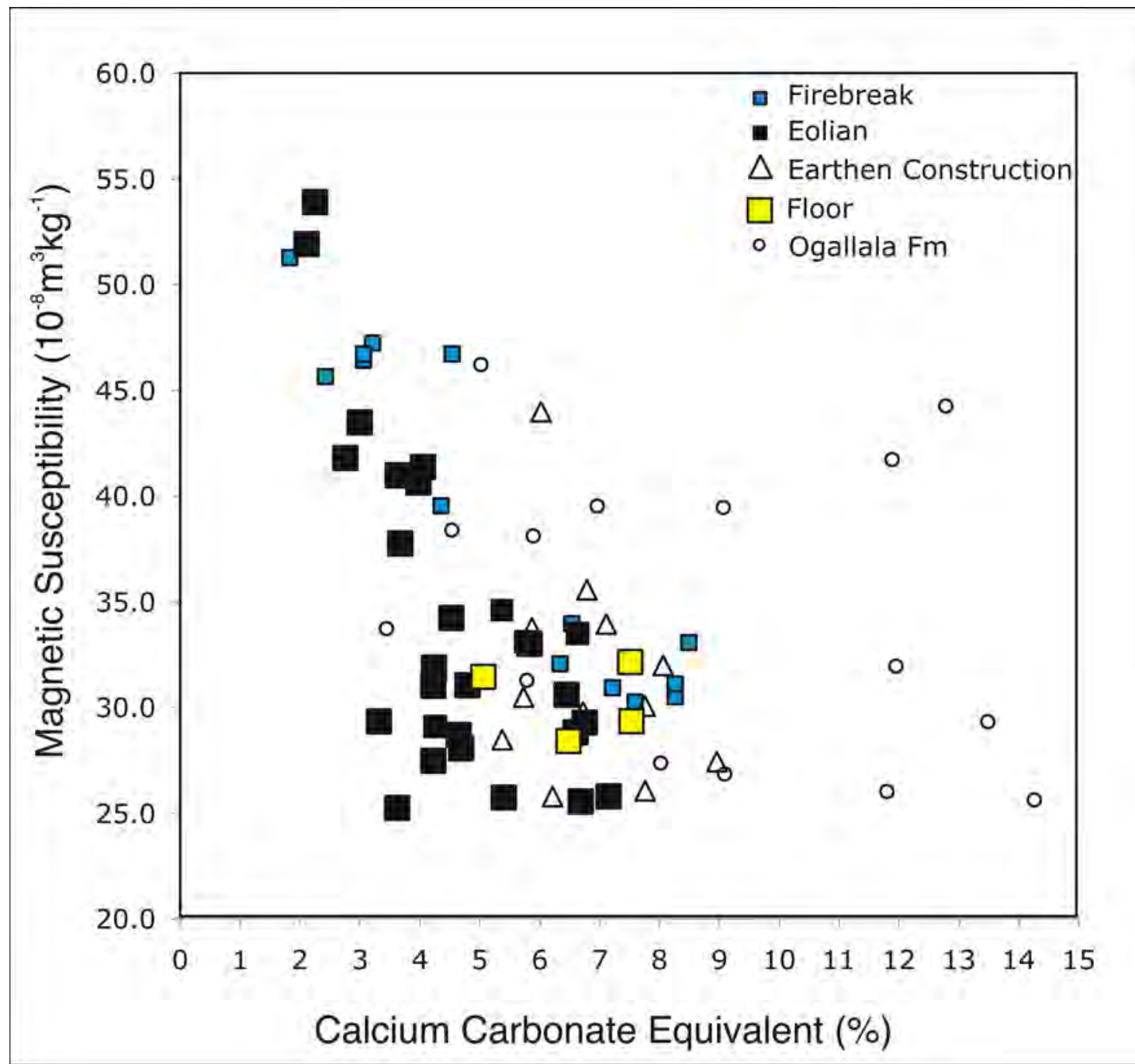

Figure 9-22. Plot of the calcium carbonate content (or calcium carbonate equivalent, in \%) versus the magnetic susceptibility for deposits associated with Feature 6.

finer textured sediment, which in turn was buried by an almost equally thick drape of eolian sand (Figures 9-23 and 9-24). The sequence was capped and truncated by deposits associated with the construction of a fireguard parallel to the TxDOT right-of-way fence and that was located directly over the feature. The sediment that buried the floor deposit was immediately hypothesized to be earthen debris that once plastered the timber frame of the pithouse. This interpretation was obvious for a number of reasons. First, the building is situated on the drainage divide, and there is no immediate colluvial source of sediment from which this amount of sediment could have been derived. Second, the deposit was thick and had a very irregular upper surface and did not appear to have been significantly reworked by water, and presents an appearance opposite of the smooth, fan-like surfaces colluvial deposition into the building depression would have created. Documenting the nature these deposits and testing this formation process model became one of the primary foci of the Feature 6 geoarcheological investigations.

The sedimentary deposits excavated in association with Feature 6 can be divided into three groups: 1) those that predate the structure, 2) deposits directly associated with the construction, use and abandonment of the building, and 3) deposits that postdate the building and that are not directly associated with it. 


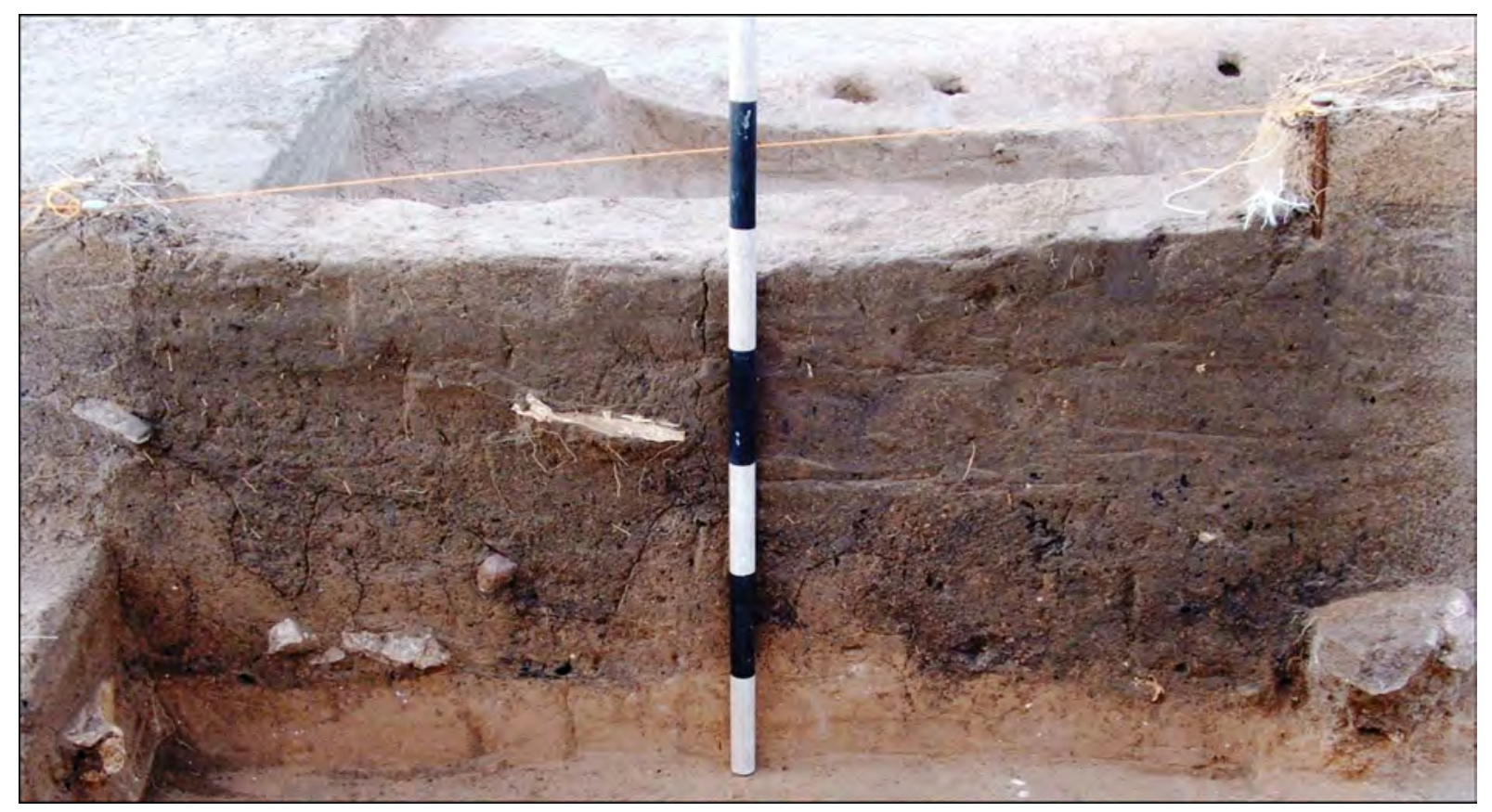

Figure 9-23. Close-up photograph of baulk profile of interior fill near the middle of the pithouse - Feature 6, showing uneven construction fill above floor with eolian fill above (block in upper right corner).

Note southern post holes (\#6, \#5 and \#4) in background.

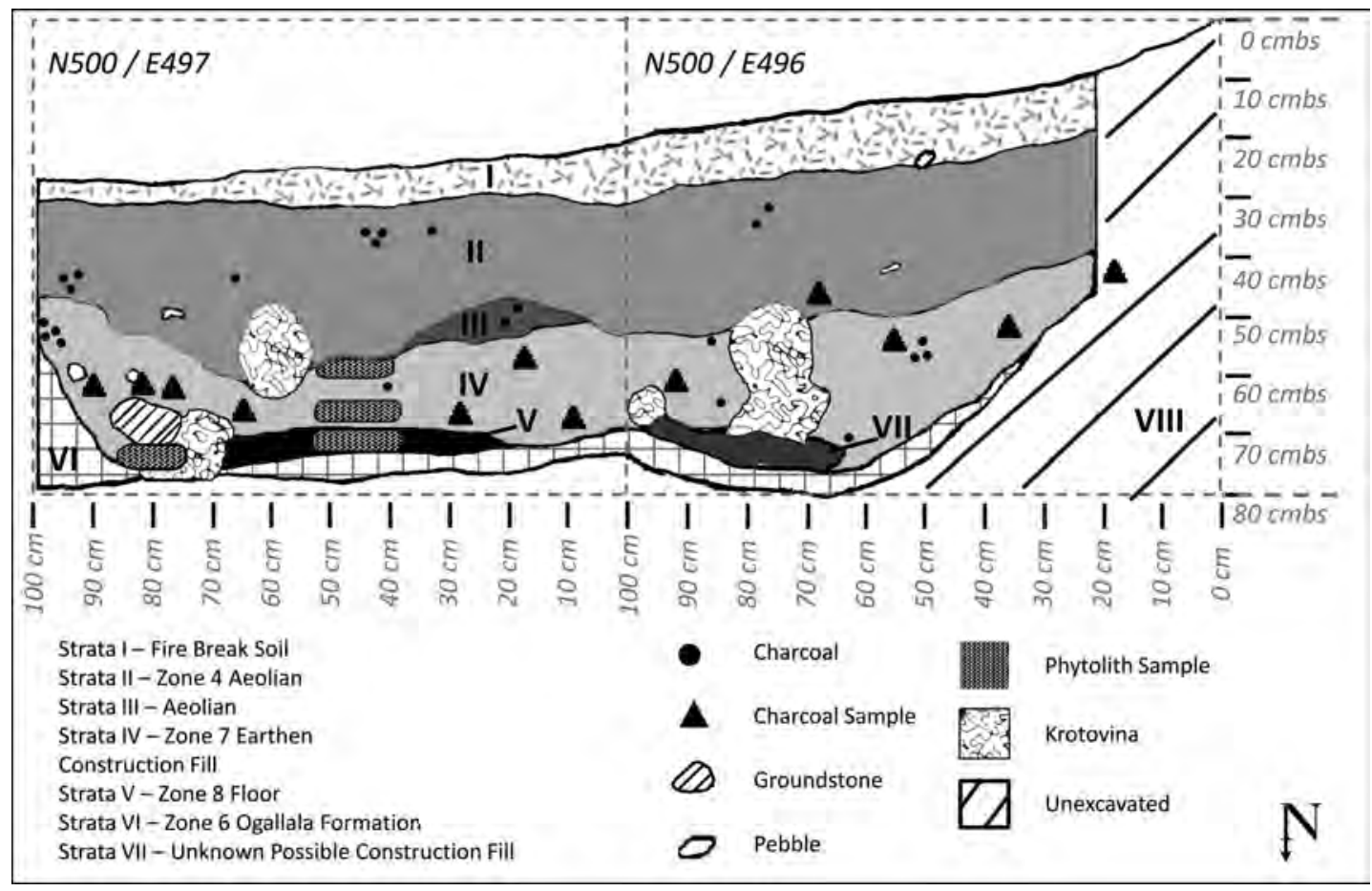

Figure 9-24. Profile drawing that shows the sequence of filling events in pithouse and distribution of the charcoal. 
The deposits that predate and postdate the structure have been introduced in the Natural Stratigraphy Chapter (6.0), but some are briefly discussed here in the context of the more detailed analysis performed in association of Feature 6, most notably with respect to petrographic examination of the sediments.

The deposits encountered in proximity to Feature 6 that predate the structure include the MiocenePliocene age Ogallala Formation, into which the house was excavated, and the Pleistocene age Eolian Sand I (ESI). The latter was not encountered in the immediate vicinity of the pithouse and is therefore not discussed here.
The Ogallala Formation, however, was exposed during excavation of the feature, which the attributes of this deposit are discussed in more detail. As noted previously in the discussion of the natural sediments, the Ogallala Formation deposit in direct proximity to the Long View site comprise the local bedrock (Zone 6 on Table 9-3) and consists largely of two facies: a coarse facies of sandy loam, and a fine facies of silt loam and silty clay loam. Both facies were deposited in a fluvial depositional environment. Bulk analysis of these samples revealed a wide range of size variation (see Figure 9-20) and calcium carbonate content (see Figure 9-22). These deposits have been altered by pedogenesis on more than one occasion, the most notable evidence of this is the large calcium

Table 9-3. Primary Field Descriptions, N498 Grid Line Baulk Profile.

Note the zones here refer to the zones on column profiles 3, 6 and 7 , collected from this profile. See Figures 9-20 for the depth of each zone, as they vary significantly along the profile

\begin{tabular}{|c|c|c|c|}
\hline Zone & Horizon & Description & Interpretation \\
\hline 1 & Ap & $\begin{array}{l}\text { Yellowish brown (10YR 5/4, d; 10YR 4/3, m) loam and sandy loam, friable, weak } \\
\text { fine subangular blocky structure, abrupt smooth boundary. }\end{array}$ & Fireguard Spoil \\
\hline 2 & Ap & $\begin{array}{l}\text { Dark yellowish brown (10YR 4/4, d; } 10 \mathrm{YR} 3 / 2, \mathrm{~m}) \text { sandy loam, friable, weak } \\
\text { medium subangular blocky structure, abrupt smooth boundary. }\end{array}$ & Transition to Eolian Sand II \\
\hline 3 & $2 \mathrm{Ab}$ & $\begin{array}{l}\text { Brown (10YR 4/3, d; } 10 \text { YR } 2 / 2, \mathrm{~m}) \text { sandy loam to loamy sand, very friable, weak } \\
\text { medium prismatic structure parting to weak medium subangular blocky structure, } \\
\text { clear smooth boundary. }\end{array}$ & Eolian Sand II \\
\hline 4 & $3 C$ & $\begin{array}{l}\text { Brown }(7.5 Y R 5 / 4 \text {, d; } 7.5 Y R \quad 4 / 3, \mathrm{~m}) \text { sandy loam, very friable, moderate medium } \\
\text { prismatic structure parting to moderate fine subangular blocky structure, abrupt } \\
\text { smooth boundary, few charcoal fragments, few faint patchy calcium carbonate coats } \\
\text { on ped faces, very few reworked calcium carbonate nodules. }\end{array}$ & $\begin{array}{l}\text { Primary Earthen } \\
\text { Construction Debris }\end{array}$ \\
\hline 5 & $3 C$ & $\begin{array}{l}\text { Brown }(7.5 Y R \quad 4 / 3 \text {, d; } 7.5 Y R \quad 4 / 3 \text { and } 7.5 Y R 3 / 2, \mathrm{~m} \text { ) loam to sandy loam, very } \\
\text { friable, weak to moderate medium prismatic structure parting to weak to moderate } \\
\text { medium subangular blocky structure, abrupt smooth to irregular boundary, few } \\
\text { burnt rocks and bone fragments. }\end{array}$ & Floor Deposit \\
\hline 6 & $4 \mathrm{Bk}$ & $\begin{array}{l}\text { Reddish yellow }(7.5 \mathrm{YR} 6 / 6, \mathrm{~d} ; 7.5 \mathrm{YR} 4 / 6, \mathrm{~m}) \text { sandy loam, silt loam and loam, } \\
\text { friable, moderate to strong medium prismatic structure, few }(1-5 \%) \text { fine to coarse } \\
(1-15 \mathrm{~mm}) \text { white irregular calcium carbonate nodules, few }(3 \%) \text { calcium carbonate } \\
\text { filaments. }\end{array}$ & Ogallala Formation \\
\hline 7 & $3 C$ & $\begin{array}{l}\text { Dark grayish brown (10YR 4/2, d; } 10 \text { YR } 3 / 2, \mathrm{~m}) \text { sandy loam, very friable, weak } \\
\text { coarse prismatic structure to massive, abrupt irregular to wavy boundary, common } \\
\text { charcoal fragments, looks slightly darker than bounding strata; stratigraphically } \\
\text { above zone } 4 \text {. }\end{array}$ & $\begin{array}{l}\text { Secondary Earthen } \\
\text { Construction Debris }\end{array}$ \\
\hline 8 & $3 C$ & $\begin{array}{l}\text { Brown ( } 7.5 \text { YR 5/4, d; } 7.5 Y R \text { 5/3, m) sandy loam, friable, massive, abrupt smooth } \\
\text { boundary, few burned rocks; situated between zone } 4 \text { and zone } 5 \text { in the center of the } \\
\text { building. }\end{array}$ & $\begin{array}{l}\text { Primary Earthen } \\
\text { Construction Debris }\end{array}$ \\
\hline 9 & $3 C$ & $\begin{array}{l}\text { Dark gray (10YR 4/1, d; } 10 \mathrm{YR} 3 / 1, \mathrm{~m}) \text { sandy loam, very friable, massive, abrupt } \\
\text { smooth boundary, contains abundant charcoal. }\end{array}$ & $\begin{array}{c}\text { Secondary Earthen } \\
\text { Construction Debris/Floor }\end{array}$ \\
\hline
\end{tabular}


carbonate nodules associated with the Stage II calcic horizon observed in many of these sediments. These nodules are ancient and would have required tens of thousands of years to develop. More recently, the Ogallala has been exposed by erosion, then left to form a new soil mantle. Soils associated with this more recent phase of pedogenesis appear to have formed over a short period of time and have generally developed thin topsoils or A horizons over the much older calcic horizons inherited from a much older period of pedogenesis. The best example of this is the soil formed within the Ogallala near the base of profile C-5, immediately outside of Feature 6 to the northwest (Table 9-4).

The petrographic appearance of the coarse facies of the Ogallala Formation was observed in several thin sections but none of the fine-grained facies were represented in the thin sections (Figure 9-25, panels A, B, C and D). The coarse facies consist of a framework dominated by very fine sand, with lesser amounts of fine to medium sand, and a groundmass dominated by medium to coarse silt, which are generally arranged in a enaulic to porphyric related distribution (where the coarse framework grains are either touching and the interstitial spaces nearly filled by fine-grained material [enaulic] or where the coarse material is "floating" within the finer groundmass). These deposits exhibited variable degrees of reworking by soil fauna (specifically worms), which is generally represented by spherical to mammilated broad to very broad (1 to $5 \mathrm{~mm}$ ) excrements that exhibit a wider range of aging, from weakly to strongly disintegrated. Pedogenic calcium carbonate masses and nodules in the Ogallala Formation were generally large, well-indurated fragments of calcium carbonate rich sediment that in thin section were grayer than the groundmass in plane light and lighter colored in cross-polarized light (Figure 9-25, Panels A and B). These nodules were typic, impregnative features that were often disjointed in nature.

In the field the floor deposits within Feature 6 were distinctly different from the sediment that buried them as well as the Ogallala Formation upon which

Table 9-4. Column Sample C-5.

Note this profile was situated on the N498 grid line immediately outside Feature 6 , about $20 \mathrm{~cm}$ from the edge of the pit, and immediately north of post holes 1,2 and 3. It was described and sampled to provide a control column for the deposits within the structure.

\begin{tabular}{|c|c|c|c|c|}
\hline Zone & Horizon & Depth (cm) & Description & Interpretation \\
\hline 1 & $\mathrm{Ap} / \mathrm{C}$ & $0-16$ & $\begin{array}{l}\text { Light yellowish brown (10YR 6/4, d; 7.5YR 5/4, m) loam to sandy loam, friable, } \\
\text { moderate medium subangular blocky structure, abrupt smooth boundary. }\end{array}$ & Fireguard Spoil \\
\hline 2 & $\mathrm{Ap} / \mathrm{C}$ & $16-25$ & $\begin{array}{l}\text { Brown (10YR 5/3, d; 7.5YR 4/2, m) sandy loam, very friable, massive, abrupt } \\
\text { smooth boundary, laminated in places, sheetwash. }\end{array}$ & Fireguard \\
\hline 3 & 2Ab1 & $25-32$ & $\begin{array}{l}\text { Brown }(10 \text { YR } 5 / 3 \text {, d; } 7.5 Y R \text { R } 4 / 3, \mathrm{~m}) \text { sandy loam, very friable, weak coarse } \\
\text { prismatic structure, clear discontinuous boundary, could not trace to the west, } \\
\text { pinches to east adjacent to Feature } 6 \text {. }\end{array}$ & Eolian Sand II \\
\hline 4 & 2Ab2 & $32-45$ & $\begin{array}{l}\text { Dark grayish brown }(10 \mathrm{YR} 4 / 2, \mathrm{~d} ; 10 \mathrm{YR} 3 / 2, \mathrm{~m}) \text { sandy loam, very friable, } \\
\text { weak to moderate medium to coarse prismatic structure, abrupt wavy } \\
\text { boundary, many worms casts/passage features. }\end{array}$ & Eolian Sand II \\
\hline 5 & $3 \mathrm{Ab}$ & $45-52$ & $\begin{array}{l}\text { Brown }(7.5 Y R \text { R/2, d; } 7.5 Y R \text { R/2, m) sandy loam to loam, friable, Moderate } \\
\text { coarse prismatic structure parting to strong medium to fine subangular blocky } \\
\text { structure, clear smooth boundary, many worm casts/passage features, trace } \\
\text { of charcoal, few burned rocks; Late Prehistoric occupation surface outside } \\
\text { of the structure. }\end{array}$ & $\begin{array}{l}\text { Soil formed in } \\
\text { Ogallala Formation }\end{array}$ \\
\hline 6 & $3 \mathrm{Bk}$ & $52-60+$ & $\begin{array}{l}\text { Light brown }(7.5 Y R \text { R } 6 / 4, \mathrm{~d} ; 7.5 \mathrm{YR} 5 / 4, \mathrm{~m}) \text { loam to silty clay loam, friable, } \\
\text { weak to moderate coarse prismatic structure parting to strong fine subangular } \\
\text { blocky structure, few } 1-3 \text { coarse }(5 \mathrm{~cm}) \text { white calcium carbonate nodules. }\end{array}$ & Ogallala Formation \\
\hline
\end{tabular}




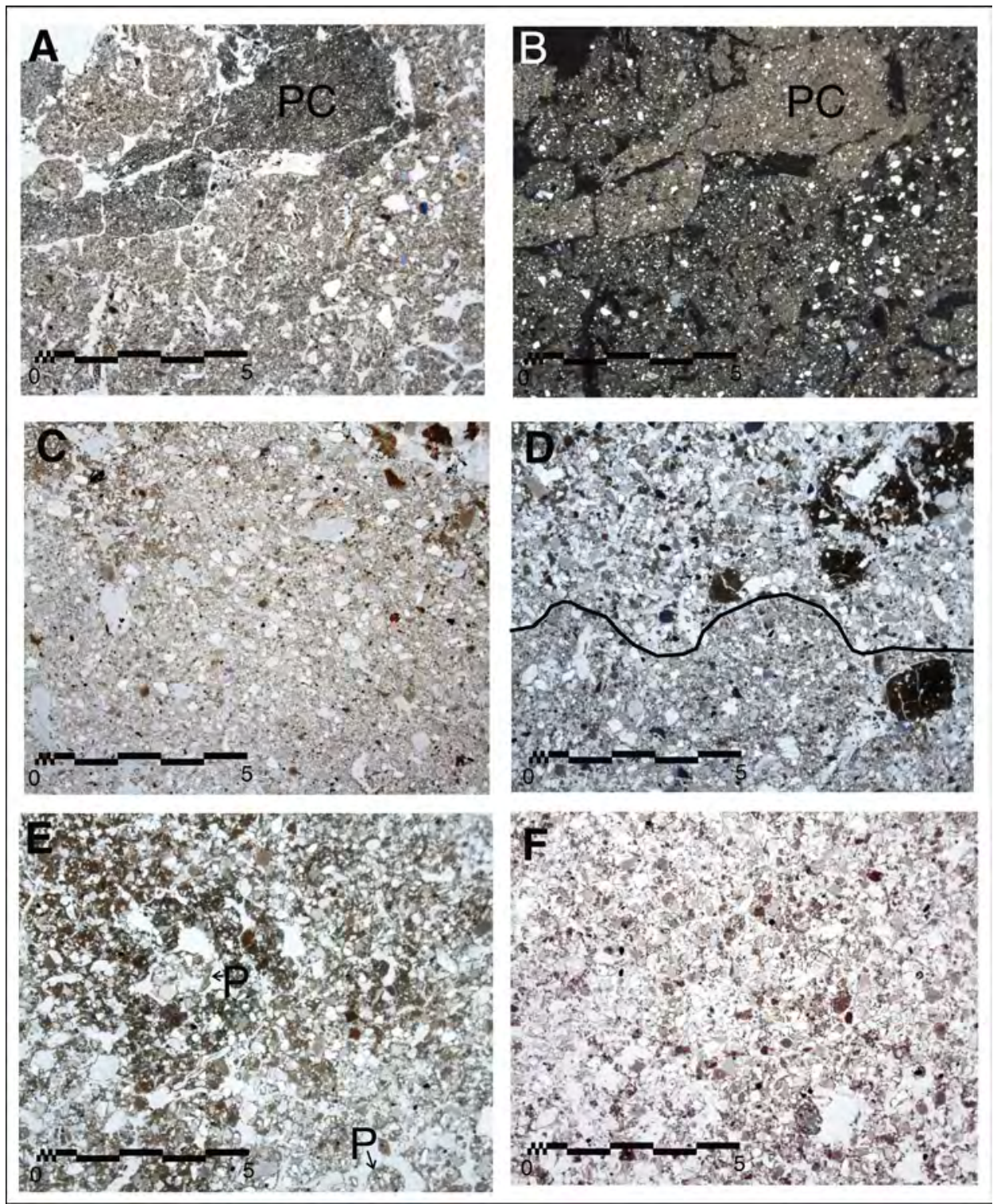

Figure 9-25. Suite of representative low magnification images of the main sediment groups associated with Feature 6: the Ogallala Formation, floor, earthen construction debris, and the Eolian Sand II.

Scale (in bottom left of each photomicrograph) is same for all photos, and is 5 millimeters. A and $B$ are low magnification images of the coarse facies of the Ogallala Formation from Profile A. Two fabrics shown are pedogenic calcium carbonate nodule (PC) and a fine sandy deposit with numerous excrement pedofeatures (worm passages). Image A is shown in plane light, whereas image B is shown under crossed polarizers. Image $\mathrm{C}$ is a plane light image of the sandy Ogallala Formation facies from immediately beneath the floor deposit adjacent to Column C-3 (Micomorphology sample $498 \mathrm{MZ2}$ ). Note the small medium sand and abundant fine sand components present. D. Plane light image showing the contact between the floor deposit (above the black line) and the Ogallala Formation (beneath the black line). Note the difference in dominant sand size across the interface. Image $E$ is a plane light image of the Earthen Construction Debris (sample C3M2a) from profile C-3 on the north 498 grid line. Note the abundant fine-grained material (brown colored material), and rounded excrement pedofeatures $(P)$. Image $F$ is a plane light image of Eolian Sand II from profile C-3 (sample C3M3). Note the relatively coarse sand and lack of significant fine sand. 
they rested. The most notable difference was the darker color (lower value and chroma) and slightly finer texture. In two of the three profiles (C-3 on the western side and C-6 near the entryway) collected from the floor these deposits were a brown $(7.5 \mathrm{YR}$ 4/3, dry; 7.5YR 4/3 to 7.5YR3/2, moist) loam, and one (profile C-7 near the middle of the building) was a sandy loam. The finer texture of the floor may have been an artifact of trampling and/or incorporation of fragments of the daub. The distinctive color of the floor deposits was difficult to discern in bright full sun, but stood out clearly in the diffuse light at dawn or dusk. A sharp lower boundary separated the floor deposits from the underlying Ogallala Formation. Chemical analysis of the floor deposits indicates that the organic content was moderate, but three of the four floor samples examined exhibited elevated phosphorus content.

Petrographic examination of the floor sediments (Figure 9-25, Panel C) revealed that these deposits were dominated by medium to fine sand, but contained a highly variable amount of finer-grained sediment (light brown color in plane light) that was often significantly reworked by fauna (specifically worms). Floor sediments exhibited chitonic to gefuric related distributions (where the finer material either bridges or coats the coarser framework grains) and contained small amounts ( 1 to 3 percent) of $<0.2$ mm charcoal.

None of the floor deposits examined exhibited fabrics attributable to trampling, and these sediments were distinctly different from the coarse facies of the Ogallala Formation. The petrographic appearance of the floor deposits, however, bore a strong resemblance to the sediments that buried the floor (discussed in detail, below).

Resting directly upon the floor deposits was a suite of distinctly lighter colored sediment that in the N498 profile exhibited a wavy to irregular upper boundary (see Table 9-3, Zone 4). These deposits consisted of a brown (7.5YR 5/4, d; 7.5YR 4/3, m) sandy loam that rested on top of the floor deposits with an interface that ranged from abrupt to clear. Although a few isolated fragments of what appeared to be daub were observed within this deposit (and which were subsequently targeted by micromorphology
[MM] samples), the primary earthen construction deposits did not exhibit any clear internal structure as is often associated with redeposited earthen construction materials in adobe buildings (such as wedge shaped deposits that slope to the center of the building). The structure and upper interface of these sediments clearly was not the result of gradual overland flow infilling of the structural depression as such processes typically create either fan or apron like triangular wedges of sediment with smooth, sloping upper surfaces. The deposits were much more consistent with earthen plaster/daub falling onto the floor from gradual decay of the wooden framed structure. A moderate scatter of charcoal was observed across the top of this deposit, in the depressions formed by its upper surface, and in the base of the reworked material above it, which may be evidence of burning of the structural timber after the earthen plaster had fallen off the timber frame from rain wash, and was subsequently ignited by a grass fire. The spatial pattern of these sediments suggests that the earthen component of the building was asymmetrical, with a significantly thicker amount on the west side than the east, which corresponds with the direction of the prevailing winds.

Given that a moderate amount of sediment was created by the pit excavation, it was initially assumed that the earthen construction material was derived from the Ogallala Formation. Texturally, the primary earthen construction debris is similar to the coarser end of the Ogallala Formation sediments with mean particle sizes in very poorly sorted very fine sand to medium silt (see Figure 9-22; USDA textural class of sandy loam), but this comparison with the Ogallala Formation is misleading. Detailed analysis of the particle size distribution curves for these deposits revealed that all samples of this material exhibited polymodal particle size distributions dominated by a fine to medium sand (modal diameter of 2.29 phi) and broad secondary modes in the fine to very fine silt range centered on 7.7 phi, and smaller clay mode centered on 9.8 phi (see Figure 9-26, middle panel). Individual samples varied in terms of the proportion of fines, but the modes were consistent from sample to sample. The coarse facies of the Ogallala Formation contained a dominant mode of fine sand (3.77 phi) that was significant and a secondary mode of fine sand (2.16 


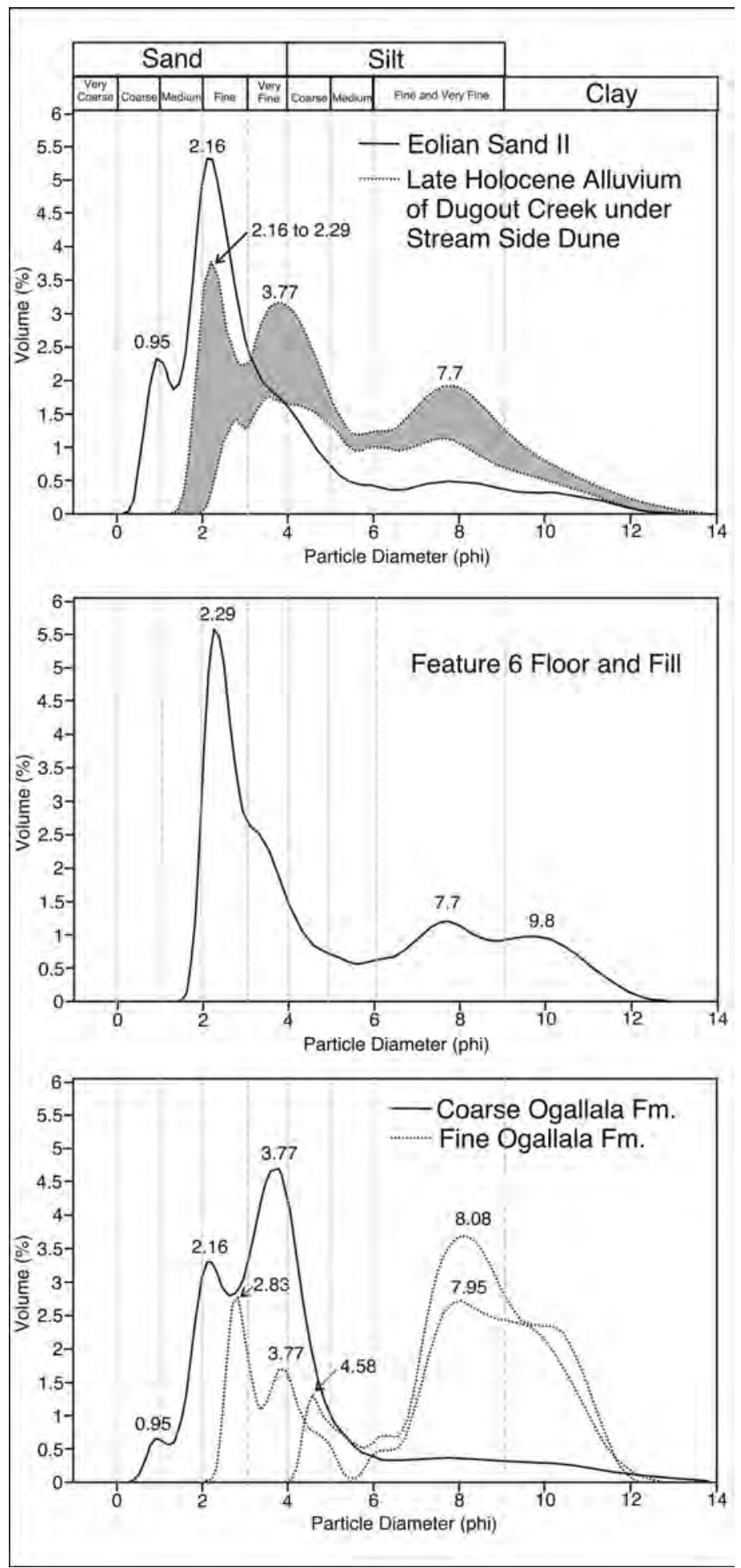

Figure 9-26. Plots of the particle size distributions for different deposits associated with Feature 6.

Number below each peak (or mode) is the particle size (in phi values) of the center of the mode. Plots obtained from particle size analysis of the Ogallala Formation beneath the structure and elsewhere on the site. Two facies are recognized; a coarse facies (solid line) and a fine facies (dotted lines). 
phi) and silty/clay tail with no defined mode. The fine-grained Ogallala sediments were dominated by very fine silt (modal diameters of 7.95 to $8.1 \mathrm{phi}$ ) and less distinct bulge in the clay range, and small modes in the fine to very fine sand and coarse silt range (modal diameters of 2.83, 3.77, and 4.58 phi, respectively).

Although it is clear from these data that the earthen construction material was not directly derived from the Ogallala, this was also very apparent in thin section, where the two deposits were distinctly different in appearance. The coarser sand of earthen construction material was immediately obvious especially when examining the interface between the floor and the underlying Ogallala (see Figure 9-25, Panel D, a line has been drawn at the interface to facilitate comparison). The sand in the earthen construction debris was much closer in size to the sand that comprised the overlying Eolian Sand II than the major sand in the coarse facies of the Ogallala (see Figure 9-25, Panel F; and Figure 9-26, middle and upper panels).

But the most distinct difference between these deposits was noted in the petrography appearance of the earthen construction debris, where the fine-textured material was represented by light brown silty clay. In most thin sections of this deposit it was apparent that the material had been significantly reworked by soil fauna, and the fine-grained material occured in rounded excrement bundles which exhibited a wide range of aging (from discrete and separate balls to strongly coalesced masses; see Figure 9-25, Panel E). But a few samples were collected that revealed much less altered fragments that clearly showed that the earthen construction material was a mixture of two different sediments, one a silty clay that contained no sand, and a fine sand.

Figure 9-27 illustrates one such example collected from the thick layer of earthen construction debris observed on the floor on the western side of the pithouse. Micromorphology (MM) field sample MMZ2 was collected a short distance east of C-3, and targeted an area where it appeared there was clear internal differentiation of this deposit. The polyester embedded sample was slabbed and revealed many fragments of relatively well-preserved earthen construction material in both the floor deposit an on top of the floor. Thin sections made from this slab clearly reveal this deposit to be comprised of small subangular blocky fragments (generally $<1$ $\mathrm{cm}$ in diameter) of silty clay, some of which have no sand at all (Figure 9-27, lower left), which are most likely primary fragments of the fine material used in plastering the building. Also visible was a wide range of sand inclusion into this silty clay that resulted in admixtures that range from fine dominated to sand dominated (Figure 9-27, lower right). The latter often exhibited discrete crumb-like domains similar to that seen with grog additions to pottery, which exhibited distinctly different optical orientations. Conspicuously missing from the earthen construction debris are the calcium carbonate nodules that are such a dominant feature of the Ogallala Formation at this site. These nodules, even if they were removed because of their size, would have left significant domains of secondary calcium carbonate that would have been visible in thin section, but only one such feature was observed in multiple thin sections of this deposit. A few nodules were also seen in the baulk profile, but the number was significantly lower than present in the Ogallala deposits that were removed when the pit was excavated for the house. The absence of such features is consistent with the null hypothesis that the Ogallala Formation was not the main sediment source for the daub. When the bulk texture data and physical attributes of the earthen construction material (like organic matter and calcium carbonate content) are considered together, it seems that the most likely source for the building material was alluvium from one of the local streams. A small number of samples of late Holocene alluvium were sampled from beneath the Lipps Ranch Stream Side Dune and these fine-grained deposits contained 20 to 33 percent calcium carbonate and exhibited two of three textural modes nearly identical to those observed in the earthen construction material (Figure 9-27, top panel). Dilution of this deposit with sand would bring the carbonate content down to the range observed among the earthen construction material within the pithouse. The fine-grained sediment source used for the building appeared to contain no sand (unlike the sediment beneath the dune), but our single opportunistic source of Dugout Creek sediment is undoubtedly not representative of the 


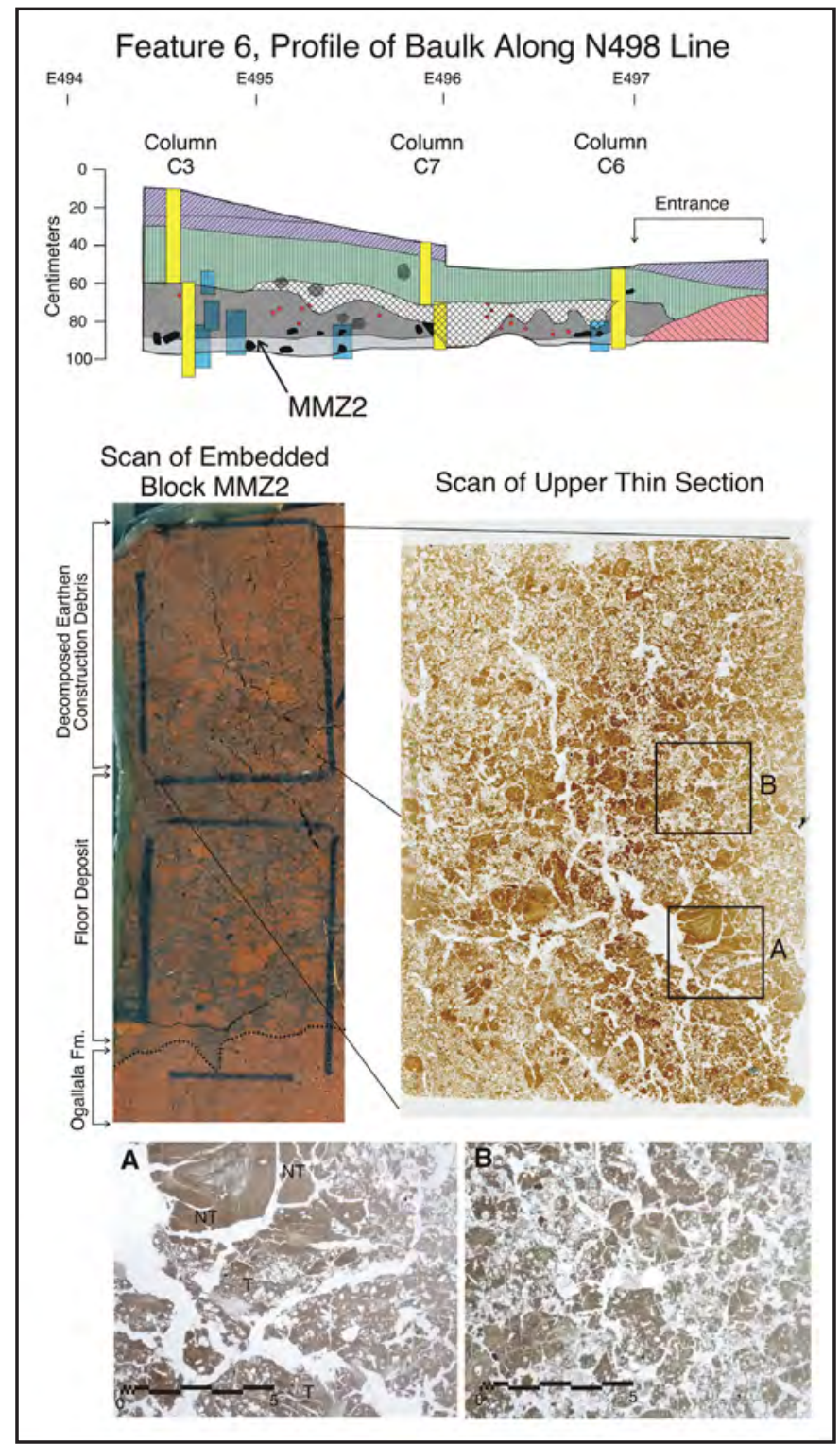

Figure 9-27. Suite of images of the best preserved earthen construction material observed in the polyester embedded blocks collected from Feature 6 (sample MMZ2, immediately east of Column 3, on the west side of the structure).

Top: drawing of the stratigraphy of the N498 gridline baulk, showing the location of micro morphology sample MMZ2. Middle Left: scan of a slab cut from the embedded block MMZ2 that was used for making the thin sections. Slab is approximately $17 \mathrm{~cm}$ long. Middle Right: transmitted light scan of the upper thin section made from the slab at left. Two boxes show the location of the photomicrographs shown below. Bottom Left: plane light photomicrograph showing the area of box A in the scanned thin section illustrating the range of preservation of earthen construction material. Fragments labeled "NT" are pieces of silty clay that have not been tempered with added sand. Fragments labeled " $T$ " illustrate same material with medium sand added as temper resulting in a porphyritc related distribution. Scale is 5-mm-long. Bottom Right: magnified view of box B shown on the scanned thin section illustrating a plane light view of the earthen construction material with intimately mixed fragments of silty clay and medium sand. 
late Quaternary deposits of this stream. Hence, from the data in hand, we have no precise match for the earthen construction material resting upon the floor of the pithouse, but it appears likely that the earth used to make the daub used in plastering the building was not the Ogallala Formation material excavated to create the pithouse, but rather a mixture of sand and mud derived from one of the local streams. If alluvium was the choice of daub materials, Sourdough Creek is closer to the site and may have been the point of origin of the raw materials.

Unfortunately, none of the fragments examined from the structure appeared to retain their architectural orientation and context that would allow more specific comment on the use of materials on the walls. Specifically, were the daub walls plastered or was the crude daub the finished surface? A few fragments did appear to retain a crudely laminated appearance, but it was not certain that this was a vestige of the original orientation of the material on the wall/ceiling.

Resting upon the primary earthen construction debris within the pithouse, but beneath the Eolian Sand II was a deposit that was not initially understood in the field. This sediment, like the earthen construction debris was a sandy loam, but in the field was separated by a clear to abrupt boundary, was clearly darker colored in places, and often contained a significant amount of charcoal. Examination of thin sections of this deposit clearly demonstrated that deposit was earthen construction material that had been significantly reworked, primarily by soil fauna. Although water erosion is one of the most likely vectors, no evidence of this (e.g., lamination, size sorting, etc...) was noted in the field or thin sections. Rather, these sediments appeared much more altered by postdepositional faunal activity, which has more intimately mixed the fine and sandy fractions of the original construction material.

One of the more interesting but surprising trends observed in association with Feature 6 was the distribution of phosphorus (P). Two forms of phosphorus analysis were performed, total and the Mehlich II digestion. As expected, the sulfuric acidhydrogen peroxide-hydroflouic acid total phosphorus digestion yielded $\mathrm{P}$ values that were often significantly greater than the Mehlich digestion (approximately 30 to 150 times greater), but exhibited erratic variation in most profiles and a very poor correlation with the Mehlich II phosphorus concentration. The reason for this is not well understood and currently thought to be associated with phosphorus derived from framework minerals within the sediments, and unfortunately, this fraction appears to be of little archeological utility. It is also possible that there was fluorine interference with the measurement, but the method employed should have compensated for this known interference. The available phosphorus obtained by the Mehlich II digestion, however, yielded a very interesting stratigraphic and spatial patterns (Figure 9-28) that appear to underlie an archeological reality, which is precisely what Terry et al. (2000) argued about the Mehlich II digestion. The deposits within Feature 6 specifically the Ogallala Formation under the floor, the floor deposits, and the earthen construction material, all exhibited significant phosphorus enrichment when compared to the profile collected just outside the structure (C-5). But surprisingly, the most enriched deposits were the earthen construction materials that came from the center and eastern side of the structure. As can be seen in the upper panel of Figure 9-28 several ash and charcoal stains were observed on the floor of the structure, but none were conclusively identified as hearths in the field. But it seems logical to assume the spatial location of these deposits to either represent or have been close to where fires were kindled in the structure. If this assumption is correct, then the phosphorus enrichment of the earthen construction debris may have been due to the accumulation of soot on the walls and ceiling of the building. Although it was difficult to find good information on the phosphorus content of soot derived from wood fires, one source noted that soot may contain between 0.5 percent and 11 percent P2O5 by weight (Zublena et al. 1991).

On the other hand, it is impossible to rule out other forms of phosphorus enrichment of the earthen construction material, such as some uses of the roof of the structure for preparing hides, or even the use of dung in preparing the daub which is common throughout the world today. However, in the case of the latter one would not necessarily expect patterned variation. 


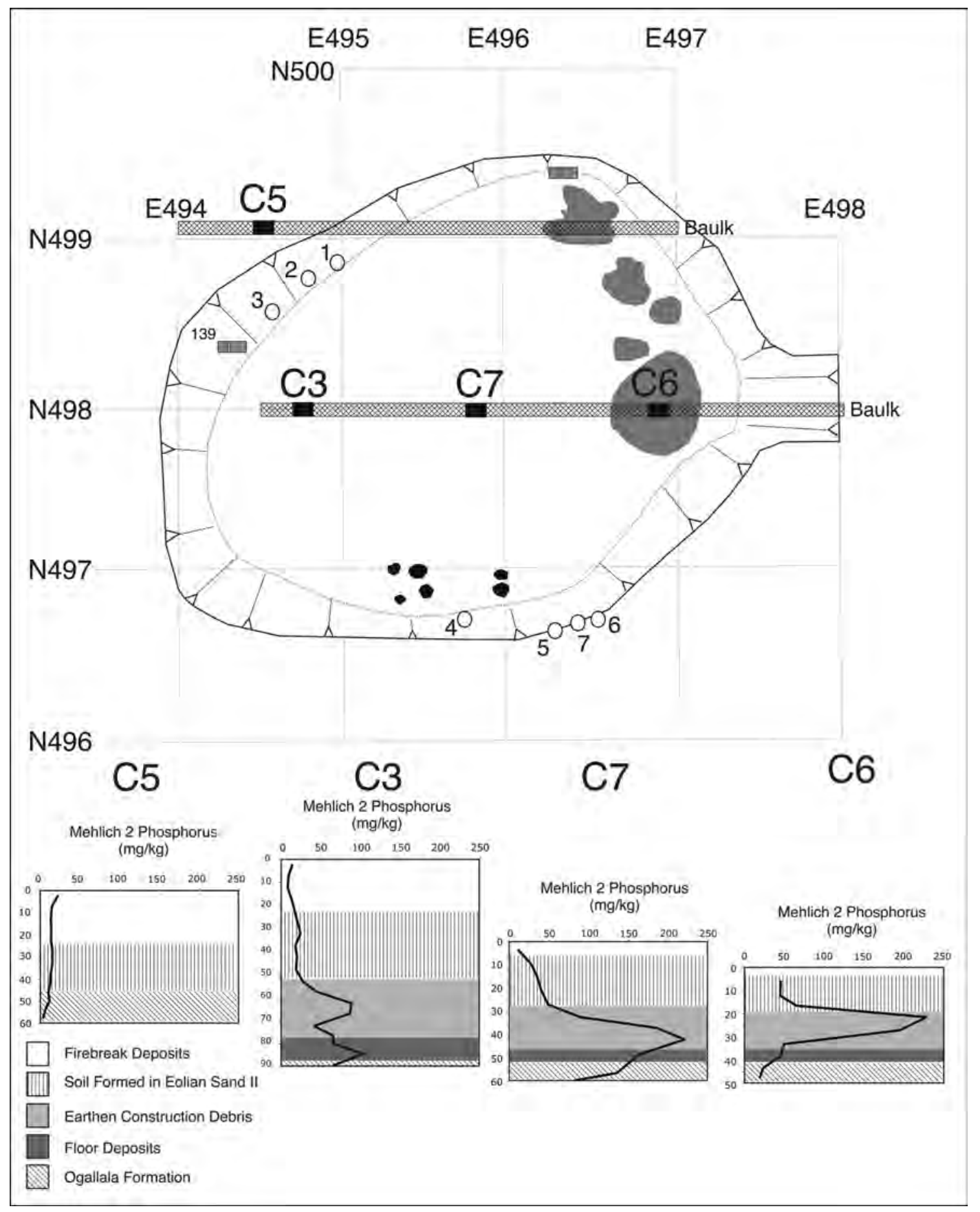

Figure 9-28. Upper panel: map of Feature 6 showing the location of the column samples shown below.

Lower Panel: plot of the available phosphorus (in $\mathrm{mg} / \mathrm{kg}$ of dry soil) obtained by the Mehlich II digestion for column samples collected through the deposits associated with Feature 6 . The area of each plot has been shaded to indicate the deposit sampled. Note how outside the building the soil exhibits no significant phosphorus enrichment and that how the floor, but more interestingly the earthen construction debris on top of the floor is significantly enriched in phosphorus. 
Two deposits postdate the construction, use and abandonment of Feature 6, namely Eolian Sand II and the fireguard. The Eolian Sand II formed a thin veneer of sand sheet sediments that buried Feature 6 following its collapse and these deposits were discussed in more detail under Natural Stratigraphy (see Chapter 6.0), and will not be discussed in great detail here. In thin section, the Eolian Sand II exhibited a gefuric to chitonic related distribution, dominated by fine sand with lesser amounts of medium to coarse sand and a minor amount of $<4$ phi fines. Like all of the sand in the valley, the mineralogy was dominated by quartz, with significantly lesser amounts of plagioclase and microcline feldspar.

The one attribute of the sand sheet deposit worth mentioning here is the presumably cumulic soil formed in the deposit. This A horizon formed a conspicuous cap over the structure and appeared to be slightly more organically enriched inside the structure than outside. Analysis of the organic matter content of the column profiles associated with Feature 6 indicate that there is indeed slightly more organic carbon in this soil inside the structure (about 0.1 percent or about 16 percent more). This slightly elevated level of organic carbon is probably due to water ponding inside the structure after it fell apart, but before eolian sedimentation could eradicate the depression.

In summary of the geological findings, the construction of Feature 6 began with the excavation of about 1 to $2 \mathrm{~m}^{3}$ of Ogallala Formation to form a shallow (ca. $60 \mathrm{~cm}$ ) depression. This span was then bridged with narrow diameter (5 to $7 \mathrm{~cm}$ ) timber, only a few of which appear to have been deeply anchored in the ground. This timber frame was then plastered with earthen daub that was apparently made of a mixture of two sediment sources, a fine silty clay and a medium to fine sand, that, converse to original expectations, appears derived from Holocene alluvium, and not the Ogallala Formation removed during the excavation of the pit depression. The lack of clear fragments of integral or intact construction material precludes more definitive comment on the preparation of this earthen veneer (such as the use of fiber temper, presence of more than one grade of plaster, and maintenance of the structure). The pattern of daub on the floor in the N498 baulk profile suggests that the daub was thicker on the western side of the structure, from where the prevailing winds originate. The structure and arrangement of the residue of earthen construction debris on the floor suggests that the building gradually disintegrated, with the daub falling onto the floor covered with cultural materials, which eventually left the timber frame exposed. The resulting pile of earthen construction debris was only slightly reworked by water before the entire building was buried by eolian sedimentation. The scatter of charcoal chunks across the top of the earthen debris and the absence of burned daub from the house suggests that the timber frame burned after all of the earth had fallen from the walls and roof. Use of the building resulted in phosphorus enhancement of the floor and the underlying Ogallala sediments, but also somewhat surprisingly phosphorus was most prevalent in the earthen construction material. The source of this phosphorus is not immediately apparent, but the concentration of enhancement in the east and central portions of the building may be an indication of soot accumulation on the walls and ceiling.

\subsubsection{Cultural Materials in Feature 6}

An extensive suite of cultural artifacts, faunal bones, burned rocks, pottery sherds, lithic and bone tools and debitage was recovered from the floor of the pithouse. This includes projectile points, bifaces, scrapers, drills, abraders, and ground stone metates and manos. Eight chipped stone artifacts that include four edge-modified flakes, a uniface, a biface, a drill and a scraper were selected for high powered use-wear analysis. Briefly, the use-wear results are presented here with details and pictures presented in Appendix $\mathrm{H}$. The complete and minimally flaked uniface (\#589-12) was hafted and used for scraping hides. The proximal scraper (\#1233-10) also has one lateral edge used to scrap hides, but did not show signs of being hafted, although it may have snapped at the end of the haft. The 2-cm-long, diamond shaped drill stem (\#648-10) reveals no sign of usewear and may have broken shortly after its initial use, so as not to have accumulated sufficient wear to observe. The rough biface (\#646-12) exhibited one edge used for whittling wood. Three edge-modified flakes (\#593-10,\#593-11, and \#599-10) were used in cutting motions with two on wood or hard materials and one on starchy plants. The fourth edge-modified flake (\#643-18) appeared unused (Appendix H). 
Two ceramic sherds, five burned rocks, and six ground stone fragments were sent for starch grain analysis. The rim sherd from Vessel 2 (\#635-81) yielded one lenticular little barley (Hordeum pusillum) grain and gelatinized little barley grains (Appendix D). The body sherd (\#643-8-1) from an unknown vessel yielded an unidentified gelatinized and parched grains. The five burned rocks yielded a total of four maize starch grains, three lenticular little barley starch grains, one cheno-am grain, two probable mesquite grains, one probable lily grain and one unknown grain (Appendix D). Mano fragment \#629-12 yielded a single cheno-am starch grain. A second mano fragment (\#1229-11) yielded a single lenticular little barley grain. Combined the three metate fragments (\#671-10, \#1229-12, and \#1231-11) yielded one little barley, and two unknown starch grains.

Two potsherds (\#639-8-3b and \#643-8-1b) from the pithouse floor were sent for INA and petrographic analysis. The maize cob impressed body sherd \#639-8-3b from Vessel 6 yielded chemical results that were assigned to Compositional Group 1 and similar to most other vessels in this component. However, the thick cordmarked body sherd (\#6438-1b) from an unassigned vessel was chemically different than most other vessels, and assigned to Compositional Group 4. It is similar to thick bodied Vessel 3 (Appendix G). Two sherds from the obliterated cordmarked Vessel 5 (\#628-008-1 and \#629-008-6) were assigned to Compositional Group 1 and have similar chemistry to most other identified vessels in this component (Appendix G).

The petrographic analysis on the same two sherds that were subjected to INA revealed similar results and assigned to a broad basalt temper class. The maize cob impressed sherds (\#639-8-1a) revealed a dense matrix with 3 to 5 percent voids, 10 to 15 percent common quartz, 20 to 25 percent basalt with pyroxene and minor amounts of chert and calcite (Appendix G). The thick body sherd (\#643-8-1a) from an unknown vessel revealed a dense matrix with 10 to 15 percent voids, 5 to 7 percent common quartz, 3 to 5 percent basalt with pyroxene, 3 to 5 percent muscovite, and minor amounts of chert and calcite (Appendix G).
Two burned rocks (\#586-3-4a and \#643-3-11a), two sediment samples (\#1288-4-7 and \#1289-4-13), and one piece of daub (\#643-5-2) were subjected to diatom analysis. Neither burned rock yielded diatoms, which may indicate that neither were burned rocks after all, or not used in conjunction with water. The daub yielded only six Aulacoseria distans, which are aquatic planktonic diatoms that likely reflect the Ogallala sediments (Appendix J). The two sediment samples were part of longer sediment columns, but both were thought to reflect construction fill above the actual floor of the pithouse. One sample (\#1288-4-7) did not yield any diatoms at all, where sample \#1289-4-13 yielded only seven diatoms representing at least four species (Appendix J). The lack of significant quantities of diatoms in these two samples indicate the sediment was not saturated with water from the nearby streams.

Two bison long bone fragments (\#572-2-1a and \#580-2-1a) were sent for stable carbon and nitrogen isotope analyses. The laboratory results yielded $\delta^{13} \mathrm{C}$ values of $-8.2 \%$ and $-8.0 \%$, whereas the $\delta^{15} \mathrm{~N}$ values are 5.8\% and 5.5\% (Appendix P). The $\delta^{13} \mathrm{C}$ values indicate the bison represented by these two bones consumed roughly 93 percent $C_{4}$ grasses over their lives and had grazed predominately in a short grass plains environment.

Besides the extensive cultural artifacts, a diverse suite of samples from Feature 6 was selected for various technical analyses, and these materials and results are discussed here. Thirty-four chunks of wood charcoal (61 percent from the profiles) were sent to Dering for identification. At least six species were identified and include oak, mesquite, elm family, rose family, maize, and juniper with five pieces unidentifiable. Juniper accounts for at least 60 percent of the identified pieces (Appendix C).

A total of 3,440.5 liters of bulk sediment samples collected from across the inside of the pithouse were floated, and heavy and light fractions collected. The heavy fractions yielded 4,638 g of material and were sorted by class, with the results presented in Table 9-5. Tiny lithic debitage ( $N=1,168 ; 19.6$ g), tiny bone fragments $(N=2,199 ; 88.3 \mathrm{~g})$, and tiny pieces of daub $(N=141 ; 30.3 \mathrm{~g})$ were the most abundant materials recovered. Nearly every sample that 
yielded macrobotanical materials includes maize fragments. In the heavy fractions from between 50 and 60 cmbs in N498 E496, a tiny whole marine shell bead was identified (Figure 9-29). Two tiny, less than 2-mm-long unburned fish vertebrae were identified from 60 to $70 \mathrm{cmbs}$ in N499 E495. The fish bones are unidentified, but represent very small individuals and not of the size one might think would be a food resource.

Of the 30 samples floated, 10 light fractions, which encompassed 140.5 liters and yielded $287.4 \mathrm{~g}$ of materials, were selected and sent for macrobotanical analysis. Dering indentified abundant maize fragments; six cob fragments, 50 cupules, and 8 kernels. Most maize material was too fragmented to determine row number, but one cob fragment from sample \#669-7-2 represents a 10 row cob. Other macrobotanical evidence of plant use includes a squash rind, cheno-am seed, prickly pear seeds, and mesquite seeds (Appendix C).

Ten phytoliths samples from different fills identified in the profiles and different parts of the pithouse were selected for phytolith analysis. These included five different locations across the pithouse floor, four from construction fill, and one eolian sample from the top of the construction fill (25 to $30 \mathrm{cmbs}$ ) that covered the pithouse. Beginning with the floor of the pithouse, the five samples came from the very western end (Unit C-7, 60 to 64 cmbs, \#139-4), one from the northeastern side (N500 E497, 71 to 73 cmbs, \#1284-4), two from Column 3 (78 to 83 cmbs and 83 to $87 \mathrm{cmbs}$ ) towards the western side, and one from Column 7 (44 to $51 \mathrm{cmbs}$ ) near the center (see Figure 9-28). Sudbury identified frequencies of short cell phytoliths in three major groups with considerable variability between the samples (Table 9-6; Appendix B). Large cross shaped phytoliths that represent maize leaves were found in two of the five samples. No beans or squash phytoliths were identified in any of the floor samples (Appendix B). This may indicate limited food was prepared, consumed or possibly discarded inside the structure. The detailed geomorphological data indicates that the floor was primarily covered with the construction fill and more or less reflects roof deposits.

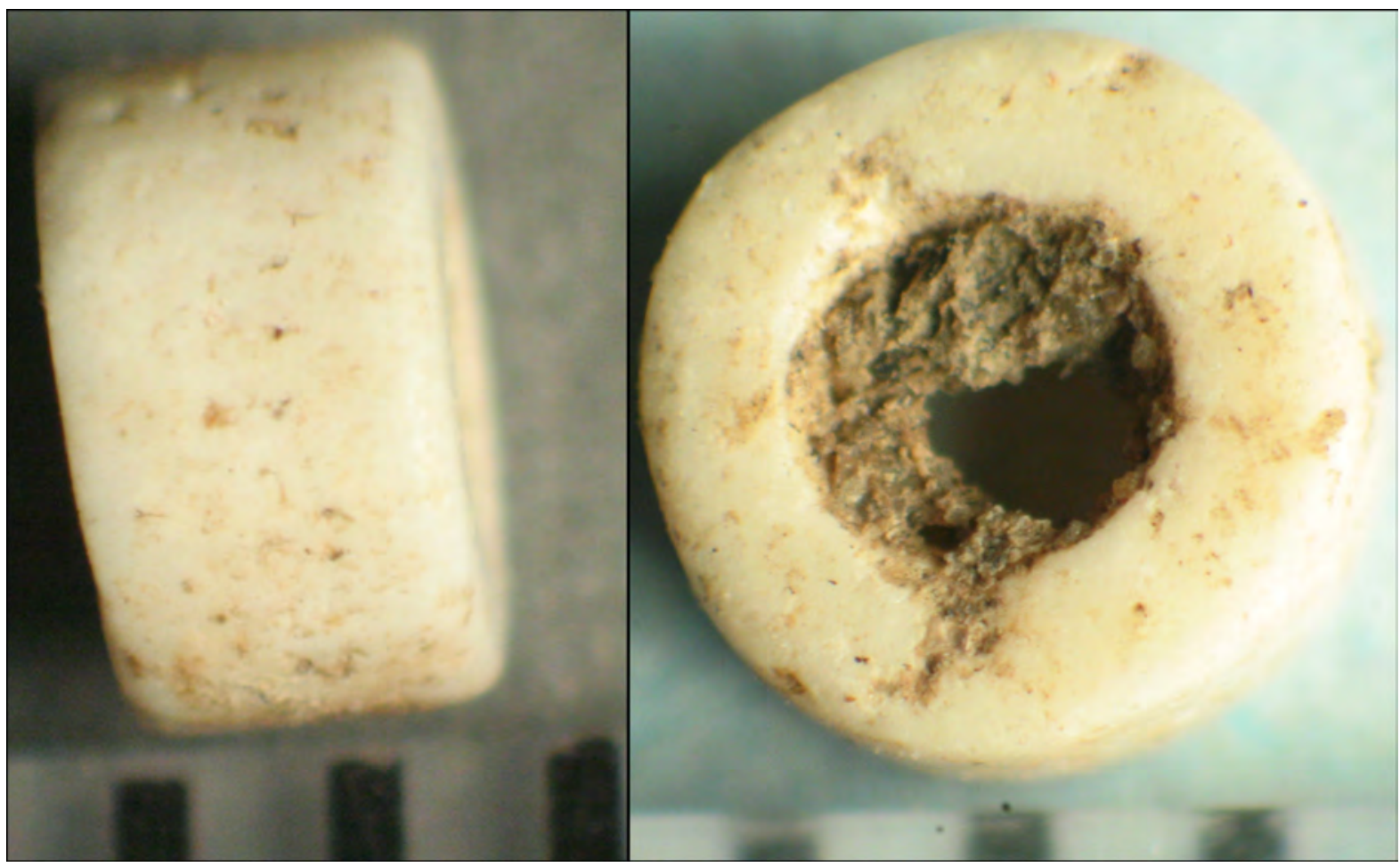

Figure 9-29. Close-up photograph of a whole shell bead from pithouse (scale in millimeters). 
Table 9-5. Heavy Fraction Flotation Results from Pithouse, Feature 6.

\begin{tabular}{|c|c|c|c|c|c|c|c|c|c|c|c|c|c|c|c|c|c|c|c|c|c|c|}
\hline \multirow{3}{*}{$\begin{array}{l}\text { Cat No./ } \\
\text { No. of Liters }\end{array}$} & \multirow{3}{*}{ Unit } & \multirow{3}{*}{$\begin{array}{l}\text { Depth } \\
\text { (cmbs) }\end{array}$} & \multirow{3}{*}{ Feature No. } & \multirow{3}{*}{$\begin{array}{c}\text { Weight } \\
\text { (g) }\end{array}$} & \multicolumn{17}{|c|}{ Flotation Recovery } & \multirow{3}{*}{ Comments } \\
\hline & & & & & \multicolumn{3}{|c|}{ Mussel Shell } & \multicolumn{2}{|c|}{$\begin{array}{c}\text { Burned } \\
\text { Rock }\end{array}$} & \multicolumn{2}{|c|}{ Debitage } & \multicolumn{2}{|c|}{ Charcoal } & \multicolumn{2}{|c|}{ Macrobotanical } & \multicolumn{2}{|c|}{ Ceramic } & \multicolumn{2}{|c|}{ Bone } & \multicolumn{2}{|c|}{ Daub } & \\
\hline & & & & & & $1 / 4$ & $<1 / 4$ & $1 / 4$ & $<\mathbf{1} / \mathbf{4}$ & $1 / 4$ & $<1 / 4$ & $1 / 4$ & $<\mathbf{1} / \mathbf{4}$ & $1 / 4$ & $<1 / 4$ & $1 / 4 \mid<$ & $<1 / 4 \mid 1$ & $1 / 4 \mid<$ & $<\mathbf{1} / \mathbf{4}$ & $1 / 4$. & $<1 / 4$ & \\
\hline 131-004 & C-7 & $40-50$ & F6 & 154.8 & $\mathrm{~N}$ & - & - & - & - & - & 50 & - & 1 & - & 6 & - & - & -12 & $40+$ & - & - & \\
\hline 31 liters & - & - & & - & $\mathrm{Wt}$ & - & - & - & - & - & 1.2 & - & 0.5 & - & $<0.1$ & - & - & - & 39.4 & - & - & $\begin{array}{l}\text { possible squash } \\
\text { seed burned? }\end{array}$ \\
\hline 132-004 & C-7 & $50-60$ & F6 & 305.4 & $\mathrm{~N}$ & - & - & - & - & - & 16 & - & 1 & - & - & - & - & - & $30+$ & - & 3 & \\
\hline liters 27 & - & - & & - & $\mathrm{Wt}$ & - & - & - & - & - & 0.8 & - & 0.3 & - & - & - & - & - & 5.7 & - & 5.3 & \\
\hline 133-004 & C-7 & $60-70$ & F6 & 232.5 & $\mathrm{~N}$ & - & - & - & - & - & 16 & - & 1 & - & - & - & - & -3 & $30+$ & - & - & \\
\hline 12 liters & - & - & & - & $\mathrm{Wt}$ & - & - & - & - & - & $<0.1$ & -1 & $<0.1$ & - & - & - & - & - & 0.5 & - & - & \\
\hline 525-004 & N497 & $30-40$ & F6 & 13.1 & $\mathrm{~N}$ & - & - & - & - & - & 13 & - & 1 & - & 2 & - & - & - & - & - & $20+$ & - \\
\hline 6.75 liters & E495 & - & & - & $\mathrm{Wt}$ & - & - & - & - & - & 0.1 & - & 0.1 & - & $<0.1$ & - & - & - & - & - & 5.7 & - \\
\hline 527-004 & N497 & $40-50$ & F6 & 11.9 & $\mathrm{~N}$ & - & - & - & - & - & 29 & - & 1 & - & - & - & - & - & 29 & - & - & \\
\hline liters 2.5 & E495 & - & & - & $\mathrm{Wt}$ & - & - & - & - & - & 0.9 & - & 0.1 & - & - & - & - & - & 0.2 & - & - & \\
\hline 529-004 & N497 & $50-60$ & F6 & 1.1 & $\mathrm{~N}$ & - & 1 & - & - & - & 1 & - & - & - & - & - & - & - & 6 & - & - & \\
\hline 3 liters & E495 & - & & - & $\mathrm{Wt}$ & - & $<0.1$ & - & - & - & $<0.1$ & - & - & - & - & - & - & - & 0.1 & - & - & \\
\hline 532-004 & N497 & $30-40$ & F6 & 16.3 & $\mathrm{~N}$ & - & - & - & - & - & 4 & - & 1 & - & 1 & - & - & - & 15 & - & - & \\
\hline 2.5 liters & E496 & - & & - & $\mathrm{Wt}$ & - & - & - & - & - & 0.1 & - & $<0.1$ & - & $<0.1$ & - & - & - & 1.9 & - & - & \\
\hline 534-004 & N497 & $40-50$ & F6 & 11.9 & $\mathrm{~N}$ & - & - & - & - & - & 4 & - & 1 & - & 1 & - & - & - & $20+$ & - & - & \\
\hline liters 2.75 & E496 & - & & - & $\mathrm{Wt}$ & - & - & - & - & - & 0.1 & - & 0.4 & - & $<0.1$ & - & - & - & 1.6 & - & - & \\
\hline 536-004 & N497 & $50-60$ & F6 & 14.2 & $\mathrm{~N}$ & - & 6 & - & - & - & 8 & - & 1 & - & - & - & - & - & 20 & - & 2 & \\
\hline 2 liters & E496 & & & & & & $<0.1$ & & & & 0.1 & & & & & & & & 0.5 & & 0.1 & \\
\hline 539-004 & N497 & $27-40$ & above F6 & 14.9 & $\mathrm{~N}$ & - & - & - & - & - & 14 & - & 1 & - & - & - & - & - & 15 & - & 10 & \\
\hline 2.5 liters & E497 & - & & - & $\mathrm{Wt}$ & - & - & - & - & - & $<0.1$ & - & 0.3 & - & - & - & - & - & 0.5 & - & 0.5 & \\
\hline
\end{tabular}


Table 9-5. Heavy Fraction Flotation Results from Pithouse, Feature 6. (cont.).

\begin{tabular}{|c|c|c|c|c|c|c|c|c|c|c|c|c|c|c|c|c|c|c|c|c|c|c|}
\hline \multirow{3}{*}{$\begin{array}{l}\text { Cat No./ } \\
\text { No. of Liters }\end{array}$} & \multirow[t]{3}{*}{ Unit } & \multirow{3}{*}{$\begin{array}{l}\text { Depth } \\
\text { (cmbs) }\end{array}$} & \multirow[t]{3}{*}{ Feature No. } & \multirow{3}{*}{$\begin{array}{c}\text { Weight } \\
\text { (g) }\end{array}$} & \multicolumn{17}{|c|}{ Flotation Recovery } & \multirow{3}{*}{ Comments } \\
\hline & & & & & & \multicolumn{2}{|c|}{ Mussel Shell } & \multicolumn{2}{|c|}{$\begin{array}{c}\text { Burned } \\
\text { Rock }\end{array}$} & \multicolumn{2}{|c|}{ Debitage } & \multicolumn{2}{|c|}{ Charcoal } & \multicolumn{2}{|c|}{ Macrobotanical } & \multicolumn{2}{|c|}{ Ceramic } & \multicolumn{2}{|c|}{ Bone } & \multicolumn{2}{|c|}{ Daub } & \\
\hline & & & & & & $1 / 4$ & $<1 / 4$ & $1 / 4$ & $<1 / 4$ & $1 / 4$ & $<1 / 4$ & $1 / 4$ & $<1 / 4$ & $1 / 4$ & $<1 / 4$ & $1 / 4$ & $<1 / 4$ & $1 / 4$ & $<1 / 4$ & $1 / 4$ & $<1 / 4$ & \\
\hline 541-004 & N497 & $40-50$ & F6 & 45 & $\mathrm{~N}$ & - & - & 1 & - & - & 25 & - & 1 & - & - & - & - & - & 30 & - & 9 & \\
\hline 2.5 liters & E497 & - & & - & $\mathrm{Wt}$ & - & - & 26.2 & - & - & $<0.1$ & - & 0.1 & - & - & - & - & - & 0.2 & - & 1.4 & \\
\hline 574-004 & N498 & $70-80$ & F6 floor & 137.2 & $\mathrm{~N}$ & - & - & - & - & - & 26 & - & 1 & - & - & - & - & - & $30+$ & - & 4 & \\
\hline 16 liters & E495 & - & & - & $\mathrm{Wt}$ & - & - & - & - & - & $<0.1$ & - & $<0.1$ & - & - & - & - & - & 3 & & $<0.1$ & \\
\hline 580-004 & N498 & $50-60$ & F6 & 106.9 & $\mathrm{~N}$ & - & 2 & - & - & - & 400 & - & 1 & - & 7 & - & - & - & $30+$ & - & $30+$ & whole bead $<0.1 \mathrm{~g}$ \\
\hline 11 liters & E496 & - & & - & $\mathrm{Wt}$ & - & $<0.1$ & - & - & - & 10.5 & - & 4.6 & - & $<0.1$ & - & - & - & 5 & - & 6.8 & corn \\
\hline 584-004 & N498 & $70-80$ & F6 floor & 259.4 & $\mathrm{~N}$ & - & - & - & - & - & 63 & - & 1 & - & - & - & - & - & $20+$ & - & - & 9- Larvae $0.2 \mathrm{~g}$ \\
\hline 14 liters & E496 & - & & - & $\mathrm{Wt}$ & - & - & - & - & - & 0.2 & - & 0.1 & - & - & - & - & - & 4 & - & - & \\
\hline 595-004 & N498 & $64-72$ & F6 & 260.9 & $\mathrm{~N}$ & - & - & - & - & - & 36 & - & 1 & - & - & - & - & - & $30+$ & - & 7 & \\
\hline 10 liters & E497 & - & & - & $\mathrm{Wt}$ & - & - & - & - & - & 0.5 & - & 2.0 & - & - & - & - & - & 4.6 & - & 1 & \\
\hline 597-004 & N498 & $70-80$ & F6 floor & 276.6 & $\mathrm{~N}$ & - & - & 3 & - & - & 75 & - & 1 & - & 1 & - & - & - & $30+$ & - & 14 & \\
\hline 15 liters & E497 & - & & - & $\mathrm{Wt}$ & - & - & 73.5 & - & - & 0.5 & - & 0.3 & - & $<0.1$ & - & - & - & 1.3 & - & 1 & \\
\hline 617-004 & N499 & $20-30$ & F6 & 10.6 & $\mathrm{~N}$ & - & - & - & - & - & 7 & - & 1 & - & 6 & - & - & - & 32 & - & 5 & \\
\hline 14 liters & E495 & - & & - & $\mathrm{Wt}$ & - & - & - & - & - & 0.2 & - & $<0.1$ & - & $<0.1$ & - & - & - & $<0.1$ & - & $<0.1$ & \\
\hline 621-004 & N499 & $40-50$ & F6 & 15.7 & $\mathrm{~N}$ & & & & & & 3 & & 1 & & & & & & 12 & & & \\
\hline 4.5 liters & E495 & - & & - & $\mathrm{Wt}$ & - & - & - & - & - & 0.5 & - & $<0.1$ & - & - & - & - & - & 0.2 & - & - & \\
\hline 623-004 & N499 & $50-60$ & F6 & 100.4 & $\mathrm{~N}$ & - & 1 & - & - & - & 29 & - & 1 & - & - & - & - & - & $30+$ & - & 13 & \\
\hline 49 liters & E495 & - & & - & $\mathrm{Wt}$ & - & $<0.1$ & - & - & - & $<0.1$ & - & 0.2 & - & - & - & - & - & 0.5 & - & 4.5 & \\
\hline 625-004-1 & N499 & $60-70$ & F6 & 338.5 & $\mathrm{~N}$ & - & 1 & - & - & - & 39 & - & - & - & 2 & - & - & - & $30+$ & - & 3 & 2 -fish bones $0.1 \mathrm{~g}$ \\
\hline 10 liters & E495 & - & & - & $\mathrm{Wt}$ & - & $<0.1$ & - & - & - & 0.3 & - & - & - & $<0.1$ & - & - & - & 0.1 & - & 0.1 & \\
\hline 625-004-2 & N499 & $69-72$ & F6 & 69.4 & $\mathrm{~N}$ & - & - & - & - & - & 7 & - & 1 & - & - & - & - & - & 9 & - & - & \\
\hline 0.5 liters & E495 & - & & - & $\mathrm{Wt}$ & - & - & - & - & - & $<0.1$ & - & $<0.1$ & - & - & - & - & - & $<0.1$ & - & - & \\
\hline 627-004 & N499 & $20-30$ & above F6 & 4.9 & $\mathrm{~N}$ & - & - & - & - & - & - & - & 1 & - & - & - & - & - & 15 & - & - & \\
\hline
\end{tabular}


Table 9-5. Heavy Fraction Flotation Results from Pithouse, Feature 6. (cont.).

\begin{tabular}{|c|c|c|c|c|c|c|c|c|c|c|c|c|c|c|c|c|c|c|c|c|c|c|}
\hline \multirow{3}{*}{$\begin{array}{l}\text { Cat No./ } \\
\text { No. of Liters }\end{array}$} & \multirow[t]{3}{*}{ Unit } & \multirow{3}{*}{$\begin{array}{l}\text { Depth } \\
\text { (cmbs) }\end{array}$} & \multirow{3}{*}{ Feature No. } & \multirow{3}{*}{$\begin{array}{c}\text { Weight } \\
\text { (g) }\end{array}$} & \multicolumn{17}{|c|}{ Flotation Recovery } & \multirow{3}{*}{ Comments } \\
\hline & & & & & & \multicolumn{2}{|c|}{ Mussel Shell } & \multicolumn{2}{|c|}{$\begin{array}{c}\text { Burned } \\
\text { Rock }\end{array}$} & \multicolumn{2}{|c|}{ Debitage } & \multicolumn{2}{|c|}{ Charcoal } & \multicolumn{2}{|c|}{ Macrobotanical } & \multicolumn{2}{|c|}{ Ceramic } & \multicolumn{2}{|c|}{ Bone } & \multicolumn{2}{|c|}{ Daub } & \\
\hline & & & & & & $1 / 4$ & $<1 / 4$ & $1 / 4$ & $<1 / 4$ & $1 / 4$ & $<1 / 4$ & $1 / 4$ & $<1 / 4$ & $1 / 4$ & $<1 / 4$ & $1 / 4$ & $<1 / 4$ & $1 / 4$ & $<1 / 4$ & $1 / 4$ & $<1 / 4$ & \\
\hline 2 liters & E496 & - & & - & $\mathrm{Wt}$ & - & - & - & - & - & - & - & $<0.1$ & - & - & - & - & - & 0.2 & - & - & \\
\hline 629-004 & N499 & $30-40$ & F6 & 2.1 & $\mathrm{~N}$ & - & - & - & - & - & 8 & - & 1 & - & - & - & - & - & $20+$ & - & - & \\
\hline 2 liters & E496 & - & & - & $\mathrm{Wt}$ & - & - & - & - & - & $<0.1$ & - & $<0.1$ & - & - & - & - & - & 0.3 & - & - & \\
\hline 637-004 & N499 & $10-20$ & F6 & 26.8 & $\mathrm{~N}$ & - & - & - & - & - & 8 & - & 1 & - & - & - & - & - & 21 & - & 3 & $\begin{array}{l}\text { Daub w/ } \\
\text { impressions }\end{array}$ \\
\hline 2 liters & E497 & - & & - & $\mathrm{Wt}$ & - & - & - & - & - & $<0.1$ & - & 0.3 & - & - & - & - & - & 0.3 & - & 6.6 & \\
\hline 643-004 & N499 & $40-43$ & F6 & 838.1 & $\mathrm{~N}$ & - & 3 & - & - & 1 & 6.6 & - & 1 & - & 1 & - & - & - & $30+$ & - & 6 & \\
\hline 16 liters & E497 & - & & - & Wt & - & $<0.1$ & - & - & 3.2 & 0.4 & - & $<0.1$ & - & $<0.1$ & - & - & - & 3.9 & - & 0.9 & \\
\hline 641-004 & N499 & $39-40$ & F6 & 39.4 & $\mathrm{~N}$ & - & - & - & - & - & 26 & - & 1 & - & - & - & - & - & $30+$ & - & 7 & \\
\hline 3 liters & E497 & - & & - & $\mathrm{Wt}$ & - & - & - & - & - & 0.3 & - & $<0.1$ & - & - & - & - & - & 5 & - & 0.2 & \\
\hline 648-004 & N499 & $10-20$ & above F6 & 62.1 & $\mathrm{~N}$ & - & 1 & - & - & - & 72 & - & 1 & - & 1 & - & - & - & $30+$ & - & 11 & Edge-Mod 1.0g \\
\hline 13 liters & E498 & - & & - & $\mathrm{Wt}$ & - & $<0.1$ & - & - & - & 1.4 & - & 1.2 & - & $<0.1$ & - & - & - & 2.1 & - & 0.8 & \\
\hline 1229-004 & N499 & $47-50$ & F6 & 518.9 & $\mathrm{~N}$ & - & - & - & - & - & 38 & - & 1 & - & 4 & - & - & - & $30+$ & - & 3 & \\
\hline 21 liters & E496 & - & & - & $\mathrm{Wt}$ & - & - & - & - & - & 0.3 & - & 0.5 & - & $<0.1$ & - & - & - & 2.8 & - & 0.7 & \\
\hline 1231-004-1 & N499 & $50-60$ & F6 & 618.4 & $\mathrm{~N}$ & - & - & - & - & - & 87 & - & 1 & - & - & - & - & - & $30+$ & - & 4 & \\
\hline 15 liters & E496 & - & & - & $\mathrm{Wt}$ & - & - & - & - & - & 0.3 & - & 0.2 & - & - & - & - & - & 3.9 & - & $<0.1$ & \\
\hline 1236-004 & N499 & $38-50$ & F28 & 138 & $\mathrm{~N}$ & - & - & - & - & - & 11 & - & 1 & - & - & - & - & - & 20 & - & 7 & \\
\hline 11 liters & E498 & - & & - & $\mathrm{Wt}$ & - & - & - & - & - & 0.1 & - & $<0.1$ & - & - & - & - & - & 0.3 & - & $<0.1$ & \\
\hline
\end{tabular}


Table 9-6. Percentages of Major Short Cell Phytoliths on Floor of the Pithouse.

\begin{tabular}{|c|c|c|c|c|c|}
\hline Short Cell Major Types & $\begin{array}{c}\text { N500 E497, 71-73 } \\
\text { cmbs, \#1282-4 } \\
\text { (phytolith sample } \\
11 \text { ) }\end{array}$ & $\begin{array}{c}\text { Unit C-7, 60-64 } \\
\text { cmbs, \#139-4 } \\
\text { (phytolith sample } \\
13)\end{array}$ & $\begin{array}{c}\text { Column C-3, } \\
78-83 \text { cmbs, } \\
\text { (phytolith } \\
\text { sample 16) }\end{array}$ & $\begin{array}{c}\text { Column C-3, } \\
\text { 83-87 cmbs, } \\
\text { (phytolith } \\
\text { sample 17) }\end{array}$ & $\begin{array}{c}\text { Column C-7, 44- } \\
51 \text { cm, (phytolith } \\
\text { sample 20) }\end{array}$ \\
\hline Cool Season Pooids, $C_{3}$ & 43.4 & 40 & 36.3 & 70.6 & 21 \\
\hline Hot Dry Chloridoids, $C_{4}$ & 41 & 45 & 36.4 & 29.4 & 37.4 \\
\hline Warm Moist Panicoids, $\mathrm{C}_{3} \& \mathrm{C}_{4}$ & 15.6 & 15 & 27.3 & 0 & 41.6 \\
\hline
\end{tabular}

The four samples from the construction fill included one from the northeastern side (N500 E497, 66 to 68 cmbs, \#1282-4), one Column 3 on the western side (phytoliths sample 15, 65 to $70 \mathrm{cmbs}$ ), two from Column 7 near the middle (phytoliths samples 18 and 19; geoarcheological samples 8 and 9). Again, frequency variability is represented across the four samples, which indicate that a variety of grasses were incorporated into the construction deposits (Table 9-7). The variability may stem from mixing soil, water, and plants prior to the application onto the structure. Large cross shaped phytoliths that represent maize leaves were identified in all four samples at higher frequencies than in the floor samples. No beans or squash phytoliths were identified (Appendix B).

The single phytolith sample from the upper part of the eolian deposits above the construction fill yielded a dominance (50.4 percent) of hot dry chloridoids with relatively high (44.4 percent) cool season pooids assemblage. The latter frequencies are similar to the modern phytolith sample from the area, but the hot dry chloridoids in the modern assemblage is 62.9 percent. No maize, beans, or squash phytoliths were identified in any of these samples, which were not expected in the post collapse eolian deposits (Appendix B).

Table 9-7. Percentages of Major Short Cell Phytoliths in Construction Fill above Pithouse Floor.

\begin{tabular}{|c|c|c|c|c|}
\hline Short Cell Major Types & $\begin{array}{c}\text { N500 E497, 66-68 cmbs, } \\
\# 1282-4 \text { (phytolith } \\
\text { sample 12) }\end{array}$ & $\begin{array}{c}\text { Column C-3, 65-70 cmbs, } \\
\text { (phytolith sample 15) }\end{array}$ & $\begin{array}{c}\text { Column C-7, } \\
33-38 \text { cmbs, } \\
\text { (phytolith sample } \\
18)\end{array}$ & $\begin{array}{c}\text { Column C-3, } \\
38-44 \text { cmbs, } \\
\text { (phytolith sample } \\
19)\end{array}$ \\
\hline Cool Season Pooids, $C_{3}$ & 38.5 & 33.9 & 30.3 & 22.9 \\
\hline Hot Dry Chloridoids, $C_{4}$ & 36.4 & 15.8 & 23.9 & 47.1 \\
\hline Warm Moist Panicoids, $\mathrm{C}_{3} \& \mathrm{C}_{4}$ & 25.1 & 50.3 & 45.8 & 30 \\
\hline
\end{tabular}

Five radiocarbon dates have been obtained for this pithouse. Two maize kernels (\#625-7-1 and \#6437-1a) and one bison bone fragment (\#641-2-1a) from data recovery were subjected to radiocarbon dating. One maize kernel (\#625-7-1) yielded a $\delta^{13} \mathrm{C}$ $(-10.3 \%$ ) corrected AMS date of $580 \pm 20$ B.P. (UGAMS-7828). The second maize kernel (\#6437-1a) yielded a $\delta^{13} \mathrm{C}(-10.0 \%)$ corrected AMS date of $590 \pm 25$ B.P. (UGAMS-7830). The bison bone yielded a $\delta^{13} \mathrm{C}(-8.0 \%$ o) corrected AMS date of $630 \pm 25$ B.P. (UGAMS-7829). These three dates, combined with the two previous dates of $580 \pm 20$ B.P. (UGAMS-7822) on a maize kernel (\#131-71) and one charcoal (\#133-4-a) date of $700 \pm 40$ B.P. (Beta-206562), provide the absolute age range for this pithouse. The juniper charcoal yielded the oldest date and may represent older dried wood used in a fire during the occupation. The second oldest date was obtained from the bison bone. The three dates on maize kernels are 580, 580, and 590 B.P. Assuming maize kernel dates are most accurate, given they represent annuals, the pithouse dates to ca. $580 \pm 20$ B.P. or cal A.D. 1309 to 1412. Given the variations in the materials dated and the close agreement of the three maize dates, it is likely that only one occupational episode is represented. 
In summary, Feature 6 represents a complete pithouse dug to about $60 \mathrm{cmbs}$ into the underlying Ogallala Formation sediments. It was constructed with a wooden frame that was covered with a thick layer of earth that was not from the Ogallala deposits. At least six wood species were part of this pithouse construction with juniper accounting for at least 60 percent of identified pieces. The phytolith data indicates a variety of grasses were incorporated into the roof construction deposits and maize leaf phytoliths were identified in all four construction fill samples. Following its abandonment, the standing structure was used as a garbage disposal area for quantities of all different classes of artifacts. This included, but not limited to diverse faunal remains, chipped and ground stone tools, burned rocks, pottery, and macrobotanical remains. The earthen roof deteriorated and finally collapsed onto the cultural deposits on the floor and sealed and protected them from decay and disturbances. The exposed wood framework apparently burned after the earthen roof collapsed and then was buried by eolian sands.

\subsubsection{Feature 7 (Cairn Burial)}

Feature 7 was discovered during site assessment in hand-excavated Trench C-1, which paralleled the stone alignment along the western edge of the fireguard (see Figure 9-3). The tops of clustered caliche rocks were encountered and partially exposed in this roughly 30 -cm-wide trench. The trench excavation crossed over the 100-cm-long, buried rock cluster, and continued without disturbance to the rocks (Figure 9-30). This horizontal rock cluster extended roughly $100 \mathrm{~cm}$ north-south and was at least 30-cm-wide, with rocks extending into the east and west trench walls. The discernable part of the cluster consisted of at least 19 caliche cobbles of irregular shapes that ranged in size from 9 to 17 $\mathrm{cm}$ in maximum dimension. The tops of the rocks were encountered at roughly $20 \mathrm{cmbs}$ in an Ap2 soil horizon. This soil zone was a dark-grayish brown (10YR 4/2) sandy loam that contained thin, irregular, linear, and ephemeral bands of pale brown (10YR 6/3) and brown (10YR 5/3) sandy loam. The rocks rested in or slightly below these bands, which are thought to have developed from the windblown sands derived from the adjacent bladed fireguard. This rock cluster was near the top of an Ab horizon, a brown (10YR 4/3) sandy loam that contained slight charcoal flecking in this area (see Figure 9-30). This rock cluster was nearly $2 \mathrm{~m}$ east of the stone alignment, and nearly opposite the center of the north-south axis of that rock alignment.

Feature 7 was entirely excavated during the mitigation phase at the junction of four adjoining units, N 493 E495, N493 E496, N494 E495, and N494 E496. Hand-excavations were taken down in all four units at the same time in $10 \mathrm{~cm}$ arbitrary levels, materials were plotted as they were encountered, and profiles were drawn as needed. The excavations revealed that the rock cluster was only $100 \mathrm{~cm}$ north-south by $80 \mathrm{~cm}$ east-west, and a second layer of rocks was immediately under the first layer (Figure 9-31). One rock in the second layer, towards the middle of the cluster, was relatively large, roughly 45 to $50 \mathrm{~cm}$ in diameter (Figures 9-31, 9-32 and 9-33). The eastern edge of the cluster appeared disturbed by mechanical blading the fireguard. The cluster included 64 caliche rocks that weighed $64 \mathrm{~kg}$. No rocks appeared artificially modified or shaped in any way.

As badly weathered human bones were exposed at the northern end of the rock cluster, it became evident that the rocks comprised a cairn that covered a human burial. The remains of a single adult were discovered mostly in the southeastern quadrant of a discernible burial pit (Figure 9-34). The body was in a flexed position with knees pulled up to the chest. The individual was positioned on its right side with the head to the south and face likely to the east. During the excavations, parts of the skull were recovered in proximity to the northern edge of the rocks, whereas the upper extent of the post cranial skeleton lay at the southern end of the pit, opposite where it should have been anatomically, and skull parts were missing. The odd location of the cranial bones supports that part of this feature was disturbed during the blading of the fireguard. Tiny scattered fragments of the skull were recovered from excavation units to the west of the cairn. No grave offerings, possessions, or any artifacts were associated with the skeletal remains, nor was any trace of red ocher observed on the bones. The four units excavated around the top of this rock cluster yielded only a few fragments of caliche rock, and contained no identifiable cultural materials. 


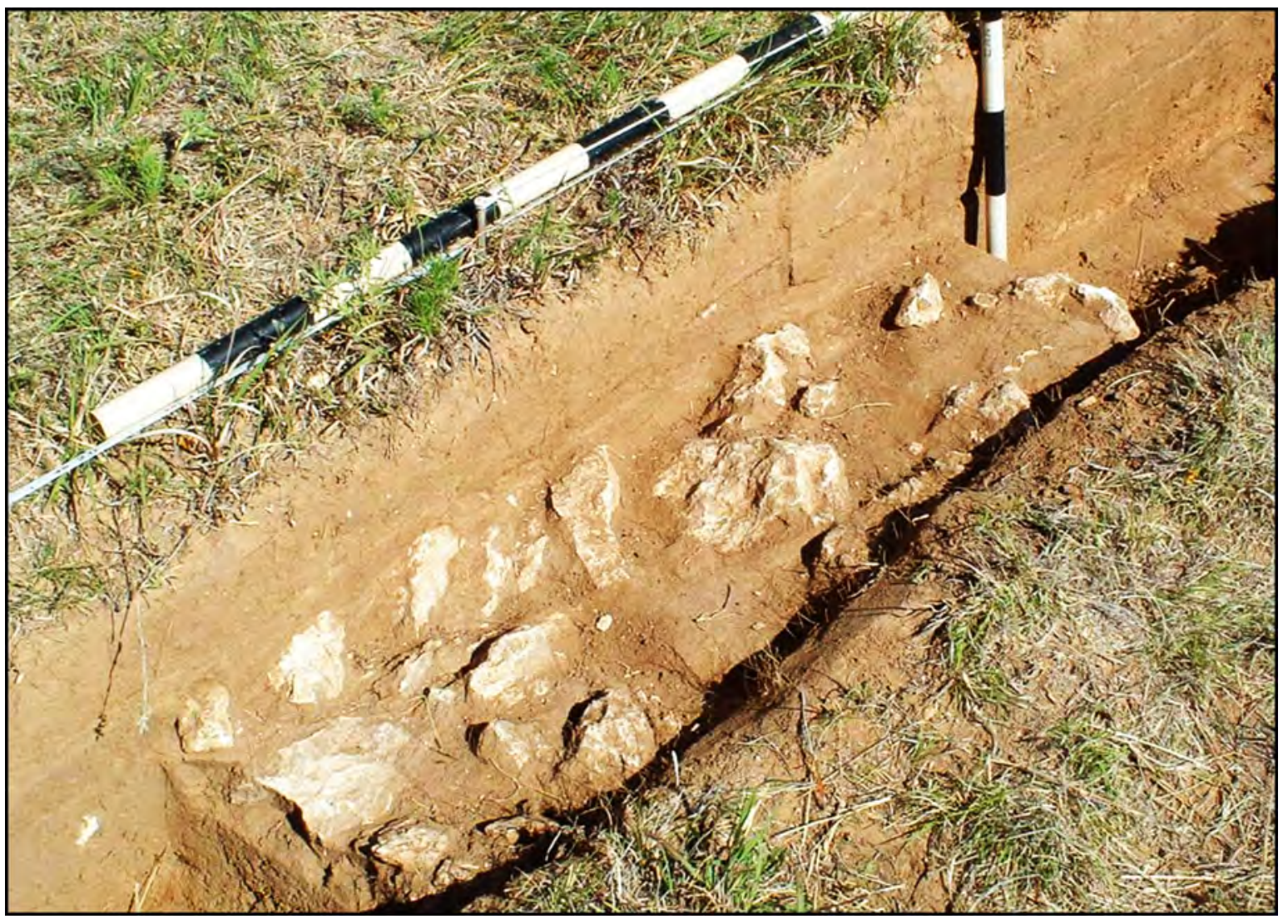

Figure 9-30. Overview of clustered rocks in Trench C-1 that was a buried cairn that covered a human burial.

(Note, the thin light and dark sediment lenses just above rocks, these likely originate from windblown sediments from the fireguard)

Below the rocks at about $30 \mathrm{cmbs}$, the burial pit became discernable (Figures 9-34 and 9-35). The pit contained the majority of the human bones associated with this interment. The pit measured roughly $100 \mathrm{~cm}$ north-south by 70 to $80 \mathrm{~cm}$ eastwest and was dug to a depth of about $70 \mathrm{cmbs}$ and extended into the gray clay and reddish sands of the underlying Ogallala Formation. The fill was a brown (10YR 5/3) clay loam that contained no calcium carbonate nodules.

Drs. M. Kate Spradley and Michelle D. Hamilton of the Forensic Anthropology Center at Texas State University (FACTS) performed an inventory of the human remains recovered from Feature 7 (see Individual 1 in Appendix S). The inventory revealed the remains of a single human individual. Interpretations developed by these forensic anthropologists are summarized here. The individual is an older adult female, whose remains are only 30 percent complete. Trauma is evident on the individual in the form of ante-mortem phalangeal damage. Specifically, the tip of one finger on the right hand appears to have been amputated, and damage to an adjacent finger is also apparent. Pathological indicators indicate arthritic conditions consistent with an older individual. Osteometric measurements are consistent with those of a Native American. It is not possible, however, to determine the cultural affiliation of this individual.

Although this cairn burial was relatively close in elevation to the other cultural materials recovered, it is not clear if this burial was part of the broader Plains Village occupation identified. With the rock bases at the same level of the thin sediment lenses, 


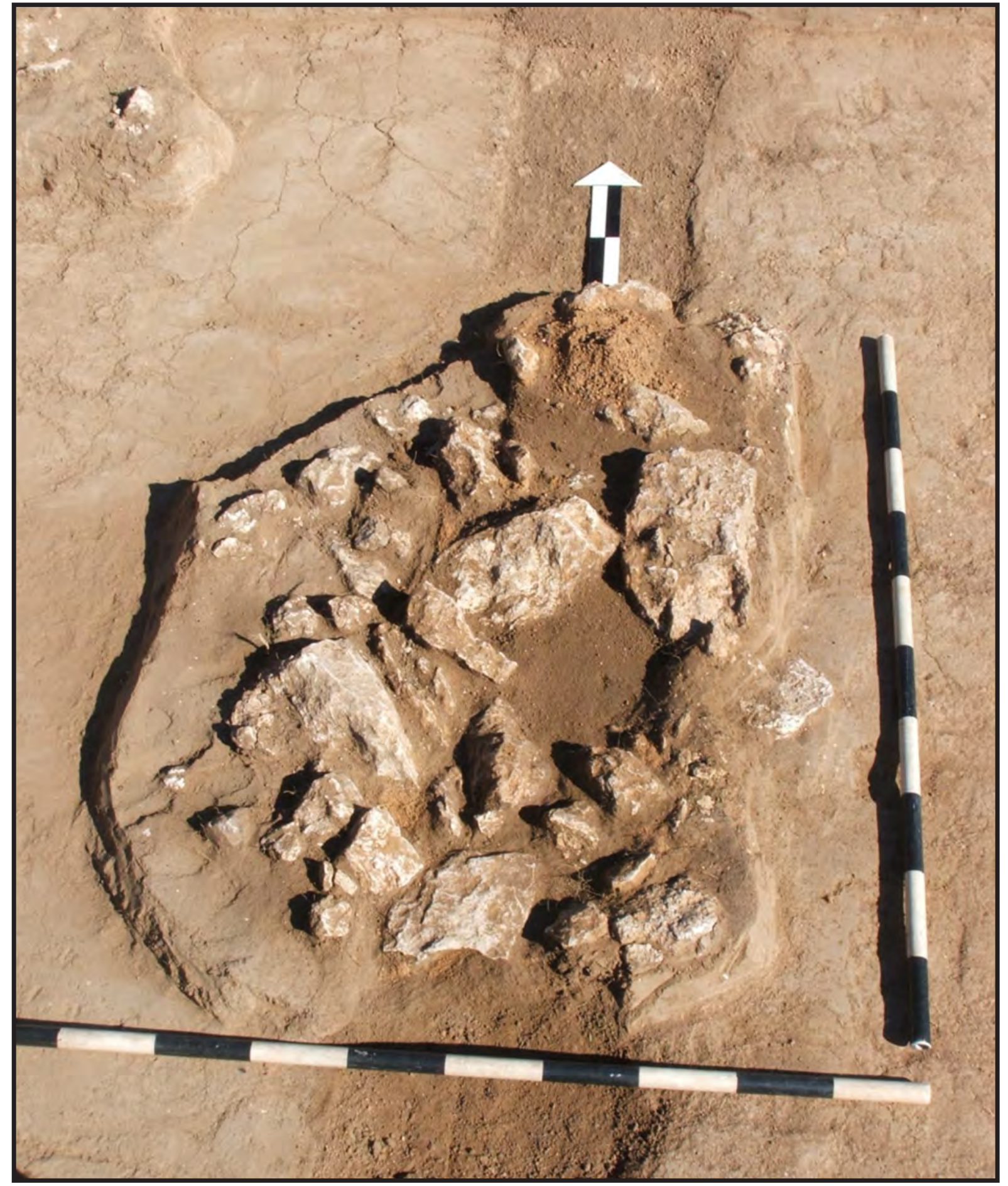

Figure 9-31. Photograph of Feature 7 showing upper caliche rock cairn covering. (Note: the rectangular north-south dark-stain is the backdirt in the initial hand-excavated Trench $1-\mathrm{C})$. 
The Long View Site (41RB112): Data Recovery of Two Late Prehistoric Plains Village Components in Roberts County, Texas -Texas Department of Transportation

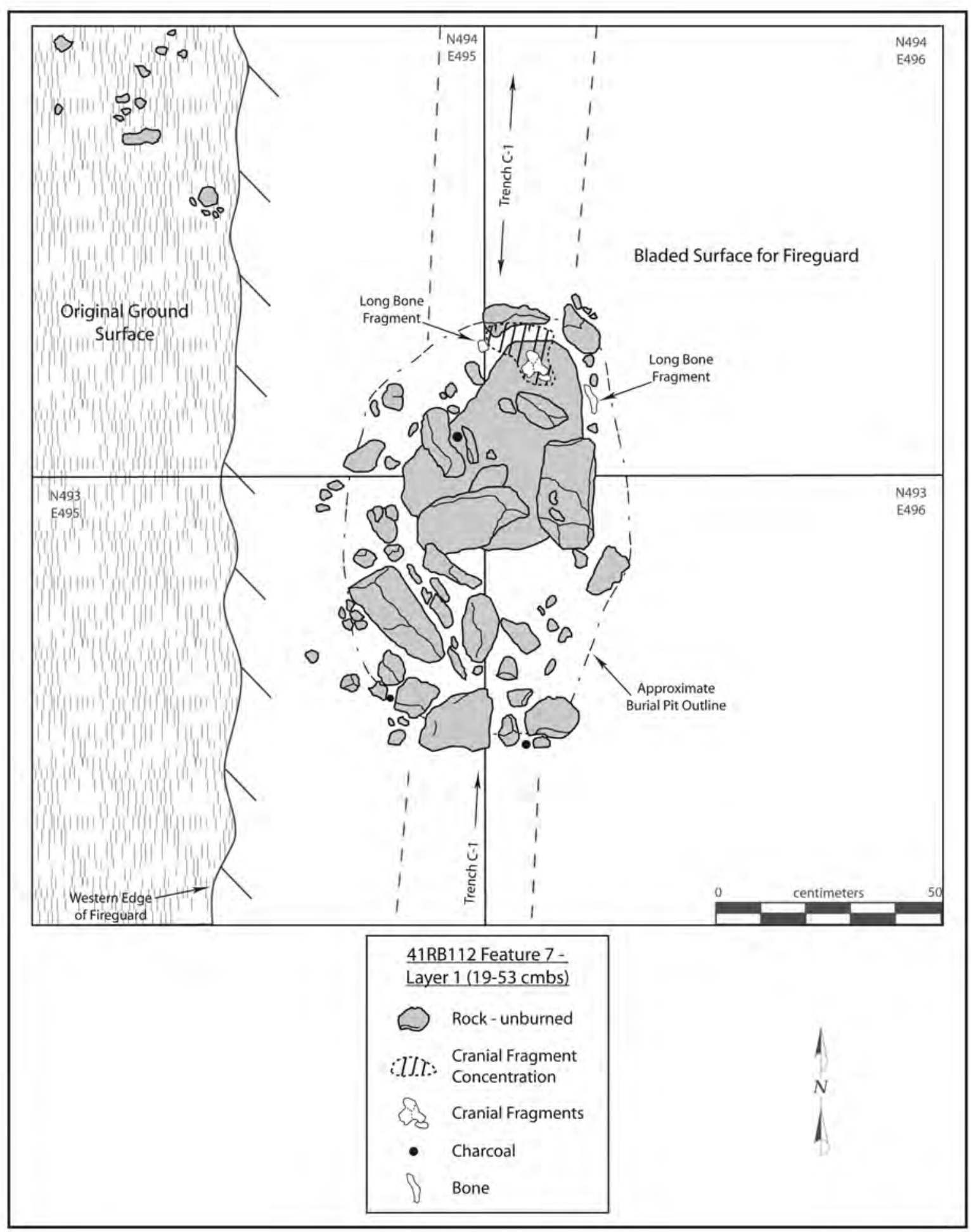

Figure 9-32. Drawing of the upper layers of the rock cairn and approximate pit outline. 


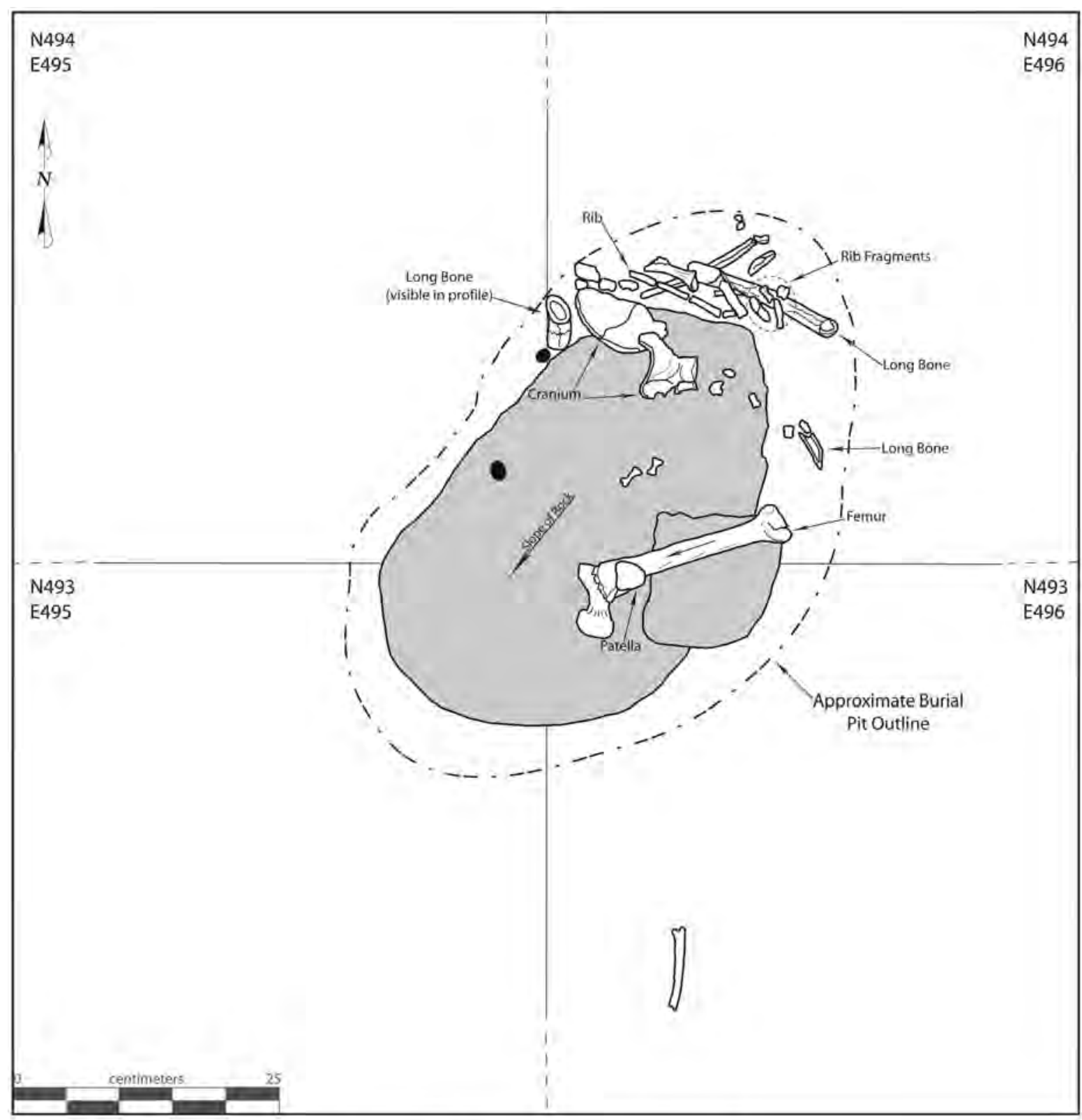

$\begin{aligned} & \text { Feature 7-Layer } 2 \\ & \text { Limestone Rock-unburned } \\ & \text { Bone } \\ & \text { Charcoal }\end{aligned}$

Figure 9-33. Plan View of Feature 7 showing underlying caliche slabs and uppermost reaches of human remains. 


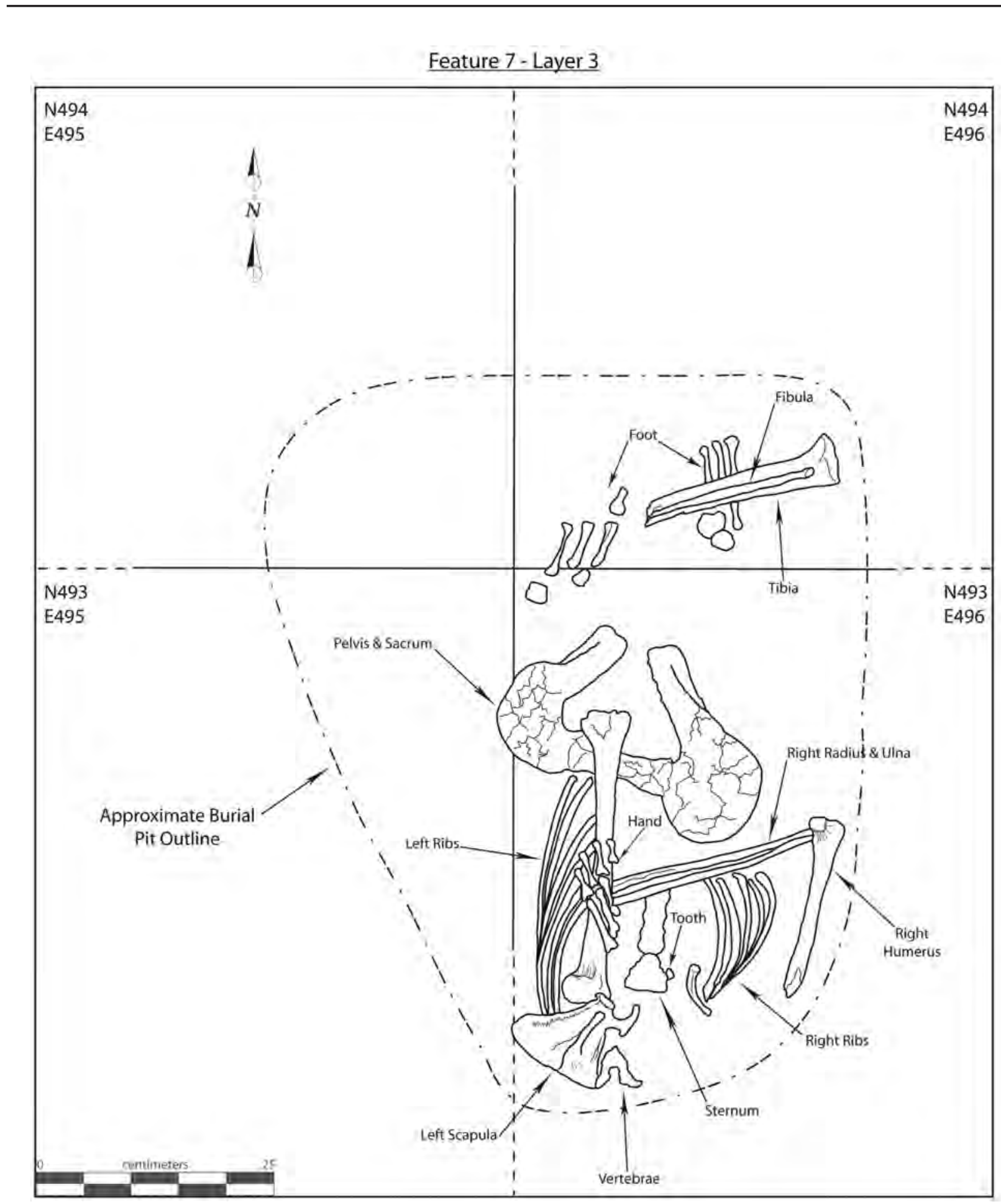

Figure 9-34. Plan view of Feature 7 showing lower reaches of interment. 


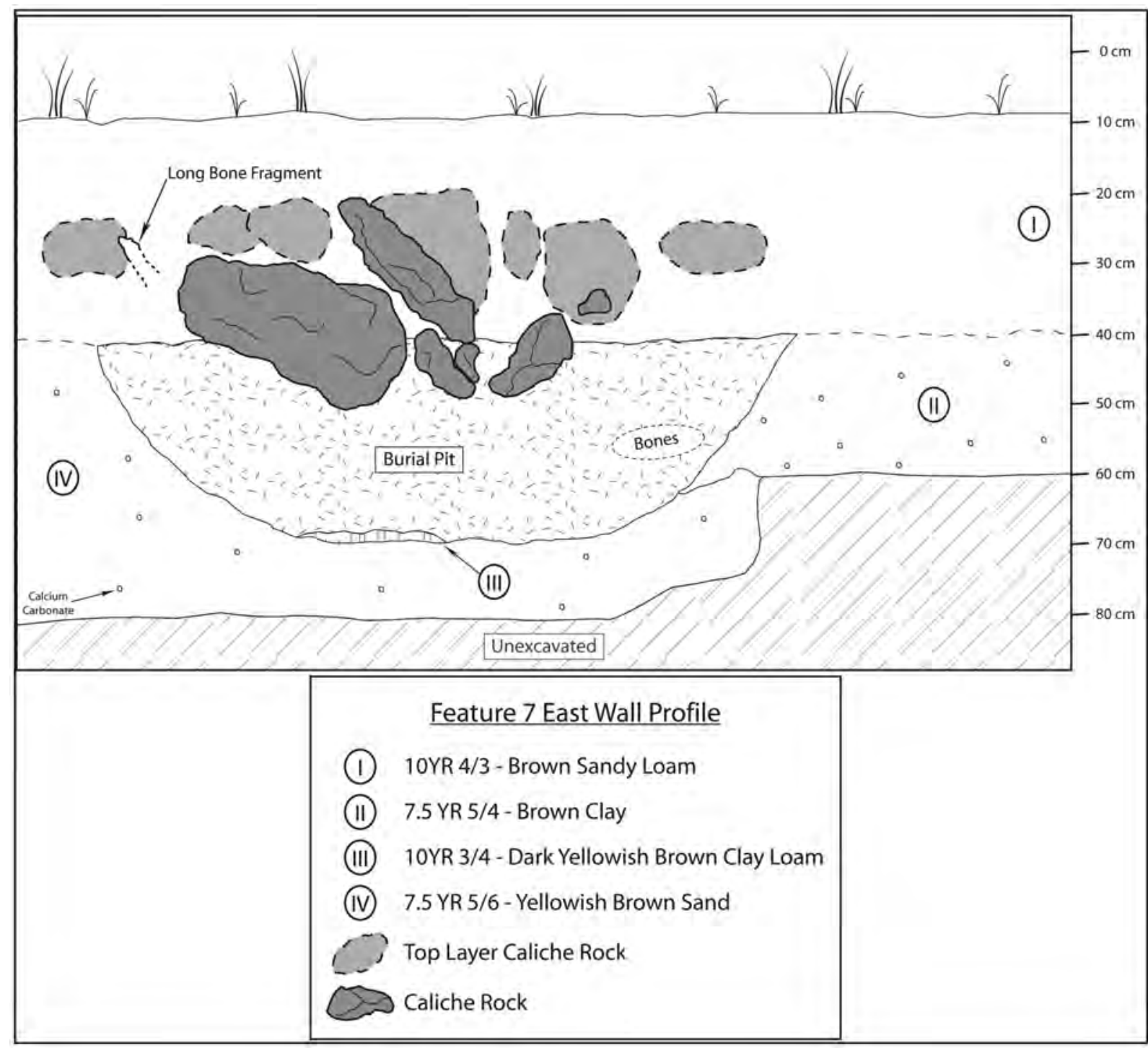

Figure 9-35. Profile of burial pit with rock covering.

this indicates that these rocks were placed on the original surface and became buried over time by the windblown eolian sediments from the fireguard. TRC was informed by TxDOT that no destructive analyses were possible on the materials from this burial. Without an absolute radiocarbon age for this individual, it is likely it postdates the earlier and well-defined Plains Village occupation based on the vertical positions of the rocks compared to the other cultural features. The human bones and other associated materials were returned to TxDOT and repatriated.

\subsubsection{Feature 16/21}

Feature 16/21 first appeared in unit N491 E500 at about $35 \mathrm{cmbs}$, then extended into three adjacent units N492 E500, and eastward off the grid into the road cut. The southern edge of this complex feature was roughly $20 \mathrm{~cm}$ north of heating element Feature 5 (Figures 9-36 and 9-37). Feature 16/21 consisted of two vertically stacked basins with a 6- to 8-cmthick, clean sand lens between the top basin (Feature 16) and the lower basin (Feature 21).

The top basin was encountered at about $35 \mathrm{cmbs}$ and was characterized by a dark, organic-rich lens with 
charcoal chunks and ashy fill that extended over an area at least $130 \mathrm{~cm}$ in diameter with an ill-defined and irregular boundary. This dark fill yielded lithic debitage, a formal scraper, 25+ tiny bone scraps, a number of thick cordmarked ceramic sherds (\#405008-1 and \#628-008-1b), small pieces of daub, three Fresno points (\#451-10, \#464-10, and \#464-11), one complete Huffaker point (\#460-10), one point fragment (\#449-12), an end scraper (\#508-10), and at least two edge-modified flakes.

As excavation continued through this organic-rich and ash-stained fill in the two units, burned rocks, chunks of charcoal, and unburned bone fragments were scattered horizontally across the basin between 44 and 56 cmbs, with scattered charcoal that increased with depth (Figure 9-38). A welldefined, hardened shallow basin was detected at 62 cmbs. Below that circular basin was a sterile, light yellowish brown (10YR 6/4) sand lens roughly 6to 8-cm-thick that contained no cultural materials. Below this sand lens was a roughly 2- to 3-cmthick ashy, organic-rich, black (5YR 2.5/1) fill that contained chunks of charcoal and at least parts of four burned maize cobs, all within a well-defined, shallow, circular basin. The bottom of the basin was at roughly $75 \mathrm{cmbs}$, and exhibited a partially oxidized yellowish red (5YR 5/8) zone in the center with a strong brown (7.5YR 5/6) sediment in the surrounding parts of the basin (Figures 9-39 through 9-41). The lower basin (Feature 21) was $65 \mathrm{~cm}$ in diameter, and had been dug into the lower reddish yellow (7.5YR 5/6) compact silty clay of the Ogallala Formation. Dark fill was found in the upper part of the basin, whereas the lower part contained sandy fill. In viewing the various profiles, it became clear that the originally observed dark fill of Feature 16 was nearly 15-cm-thick in the middle, and was directly above the lighter sandy fill that was actually a lens inside the lower basin of Feature 21.

A charred maize kernel (\#470-7-1a) from between 40 and 50 cmbs in Feature 16, within unit N491 E501, was sent for radiocarbon dating. This kernel yielded a $\delta^{13} \mathrm{C}(-10.0 \%$ ) corrected AMS date of 610 \pm 20 B.P. (UGAMS-7827). A second maize kernel (\#455-7-1a) from between 60 and 70 cmbs in N491 E501 in Feature 21 was sent for radiocarbon dating. This kernel yielded a $\delta^{13} \mathrm{C}(-11.0 \%)$ corrected AMS date of $530 \pm 25$ B.P. (UGAMS-7826). The two dates are reversed with respect to their stratigraphic positions, but overlap at their two sigma values, so the dates are statistically the same.

Three pottery sherds, two from Vessel 4 (\#405-0081 = TRC568 and \#405-008-12 = TRC653; Figure 9-42), and one partially obliterated cordmarked body sherd (\#468-008-4b = TRC574; Figure 9-43) that represents Vessel 7 from N492 E501 were sent for INA analysis. Both plain rims sherds from Vessel 4 yielded similar chemical results and were assigned to Compositional Group 2, which are different from other identified vessels in this component (Appendix G). Sherd \#468-008-4b assigned to Vessel 7 was chemically similar to the Vessel 4 sherds and also assigned to Compositional Group 2 (Appendix G). All three sherds are chemically different from most other vessels in this component.

The fill from these two stacked features was collected by unit and level for floatation. A total of 279.5 liters was floated and the light and heavy fractions collected. Three light fractions (\#451-4b, \#453-4b, and \#470-4b) from 162 liters of Feature 16 were sent for macrobotanical analysis. The results reveal 56 maize cupules, and 57 kernels and a common bean cotyledon, a rare occurrence in open sites in the Southern Plains (Appendix C). One light fraction (\#474-004-1b) of 19 liters from Feature 21 was sent for macrobotanical analysis. That sample yielded maize cupules, kernels, and glumes. A single juniper seed was the only noncultigen noted. The single macrobotanical sample of less than $0.1 \mathrm{~g}$ includes juniper and rose family wood (Appendix C).

The heavy fractions of these samples yielded a considerable quantity of materials. The heavy fraction from \#474 yielded 2 tiny mussel shells fragments, 62 tiny pieces $(1.1 \mathrm{~g})$ of debitage, 20+ tiny bone fragments (1.1), and insect larvae. The heavy fraction from \#453 yielded 20+ tiny pieces (0.7) of debitage, $20+$ tiny bone (1.7 g) fragments, and 2 pieces of charred maize. The heavy fraction from \#470 yielded 2 tiny mussel shell fragments, $50+$ tiny pieces $(50 \mathrm{~g})$ of debitage, $30+$ tiny pieces of bone (30 g), and $30+$ pieces $(30+\mathrm{g})$ of daub, while that from \#451 yielded 70 tiny (2.5 g) pieces of lithic debitage, 100+ tiny bone fragments (11.2 


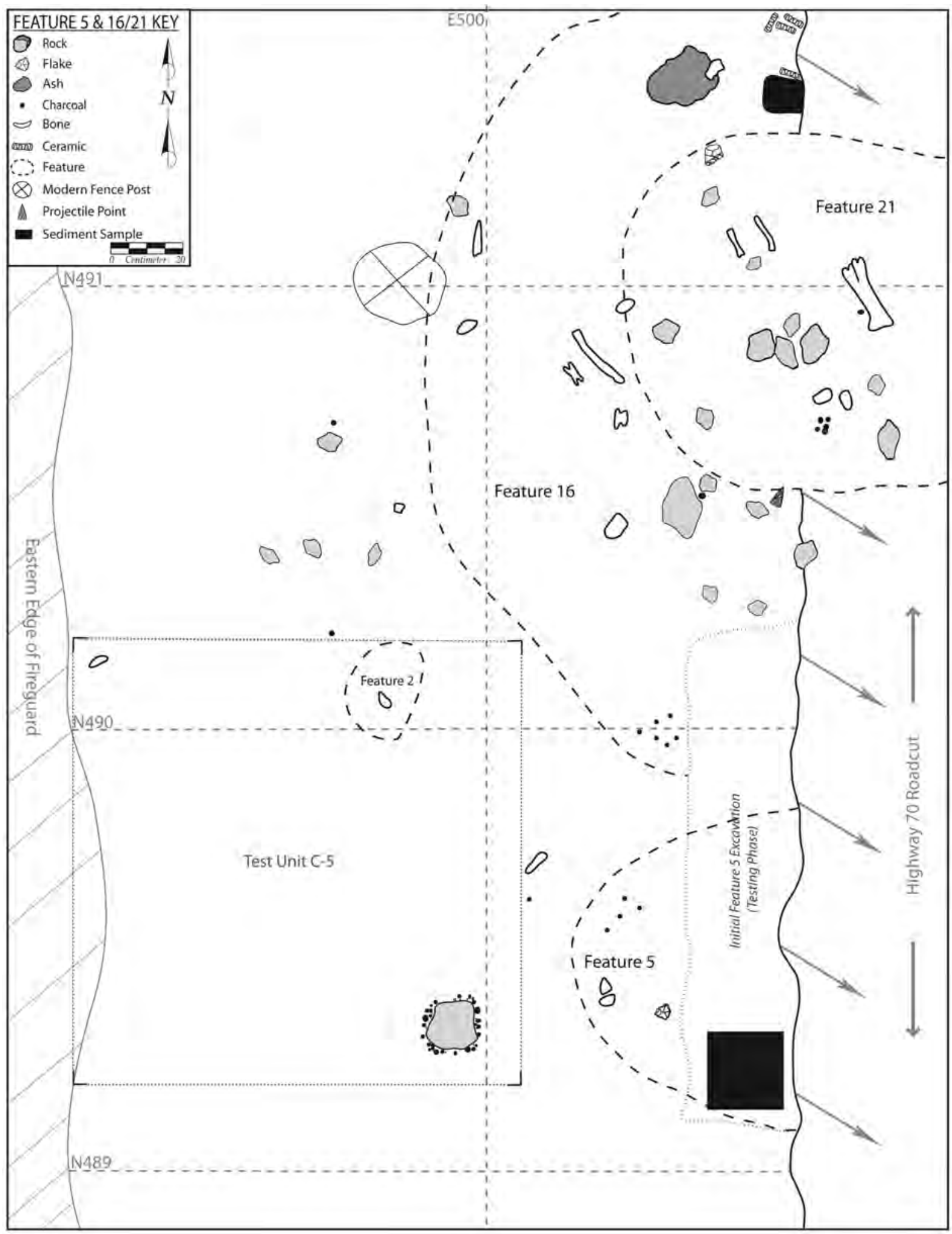

Figure 9-36. Plan view drawing of horizontal positions of Features 2, 5, and 16/22. 


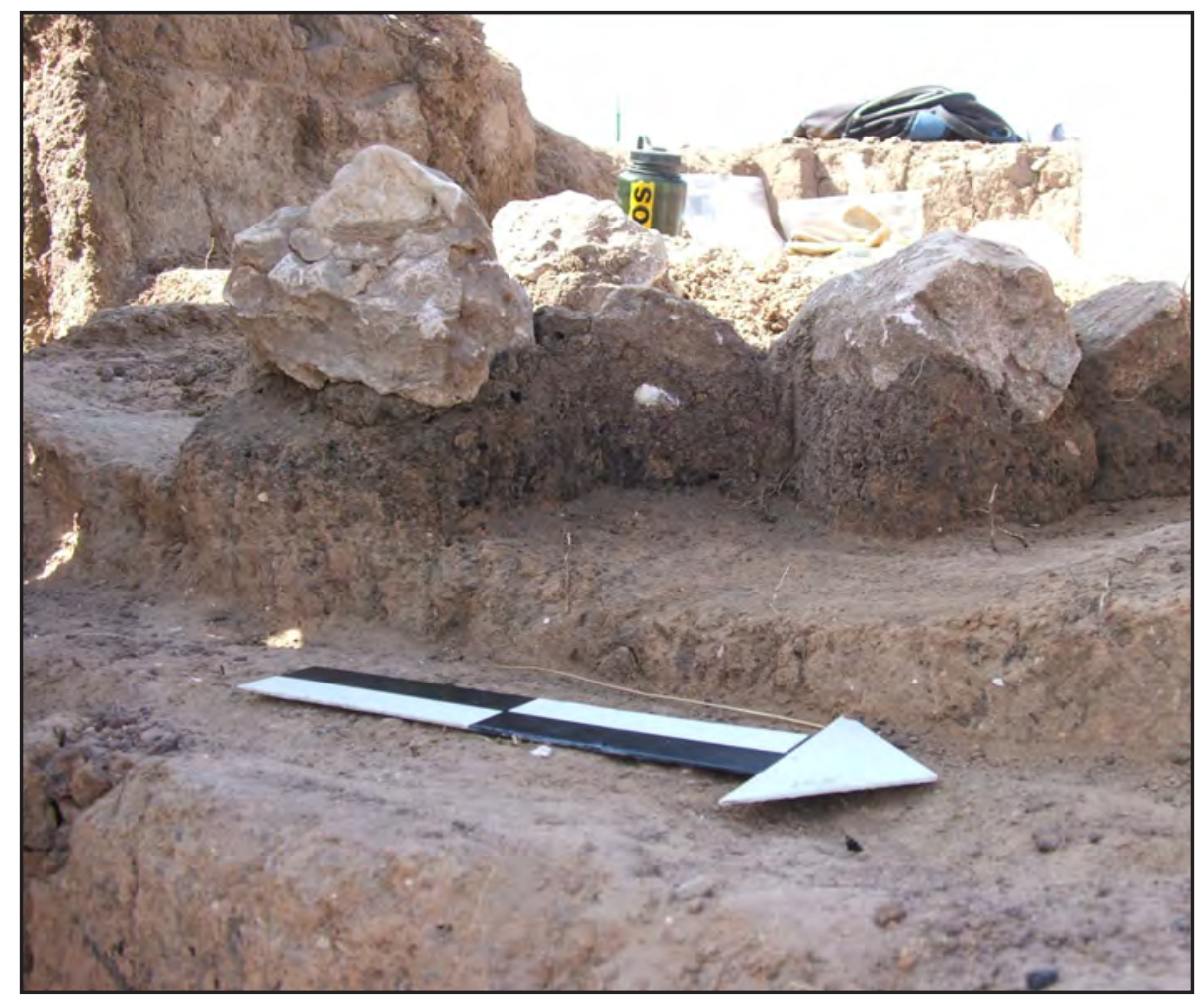

Figure 9-37. Partial profile picture of Feature 16 showing burned rocks in Feature 16 basin above sand lens that filled Feature 21 basin in lower foreground.

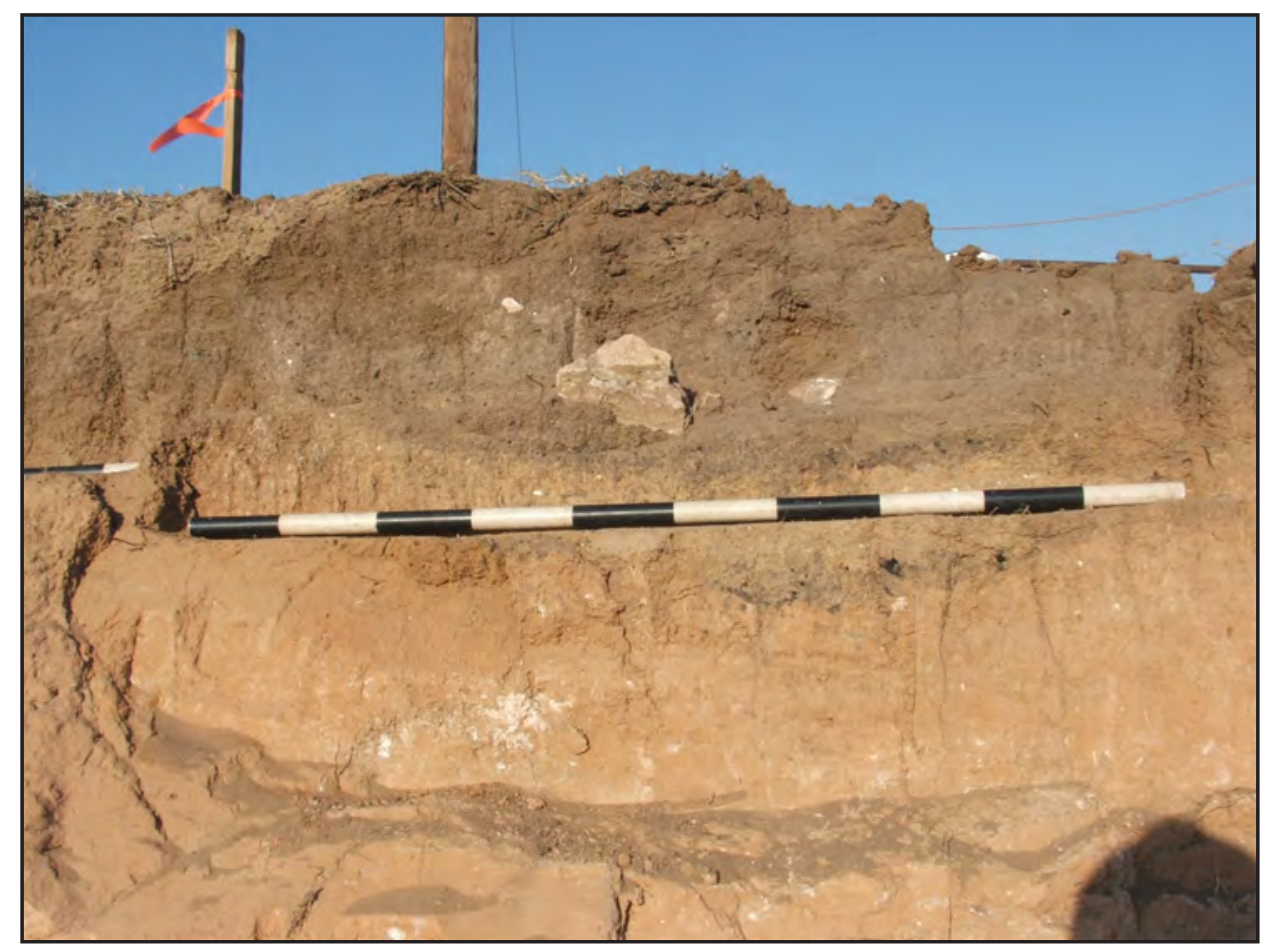

Figure 9-38. Road-cut profile picture depicting Features 16 (top) and 21 (bottom) separated by sand lens (behind meter rod). 


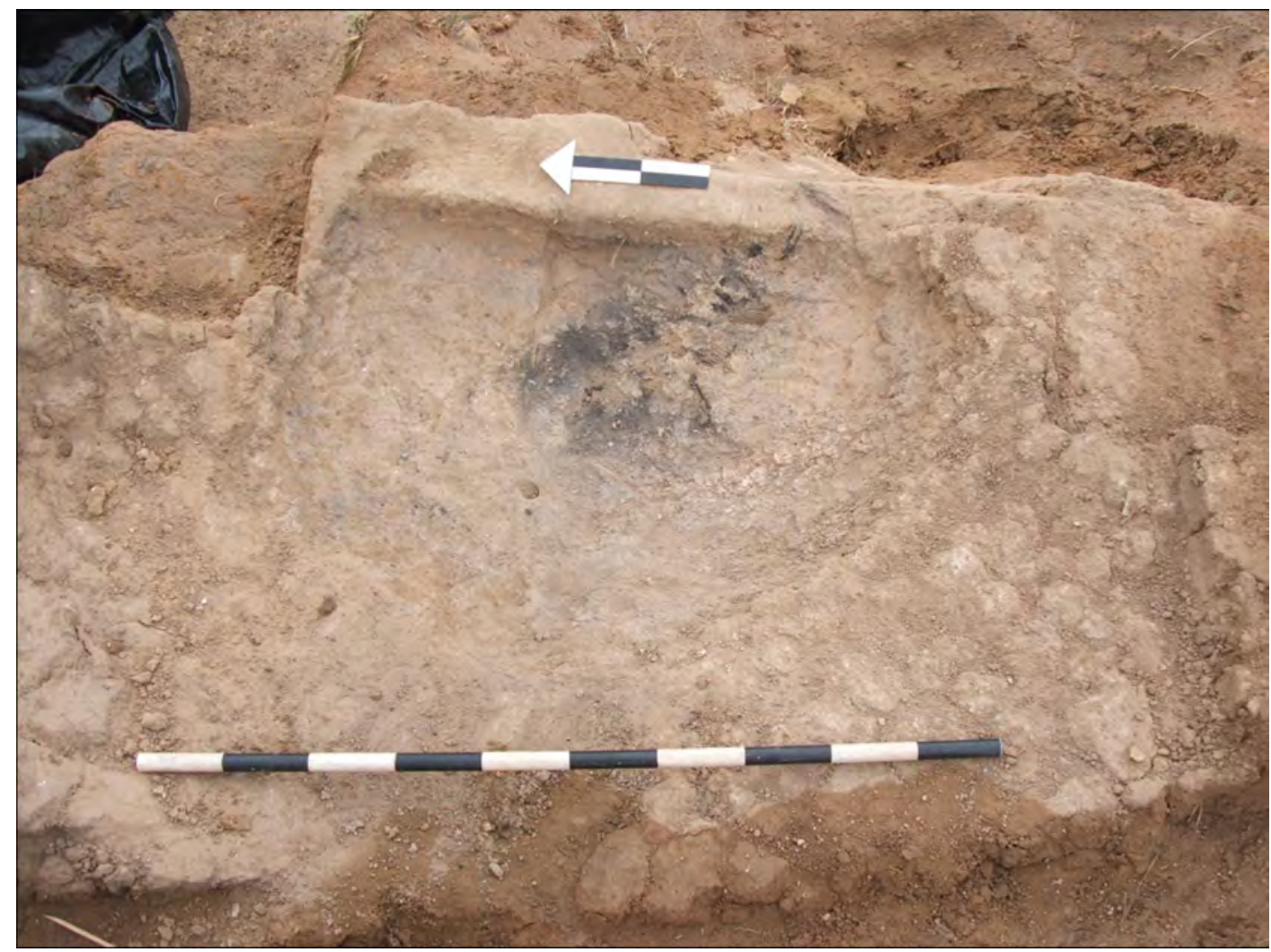

Figure 9-39. Overhead view of Feature 21 basin with burned maize cobs in fire-hardened bottom.

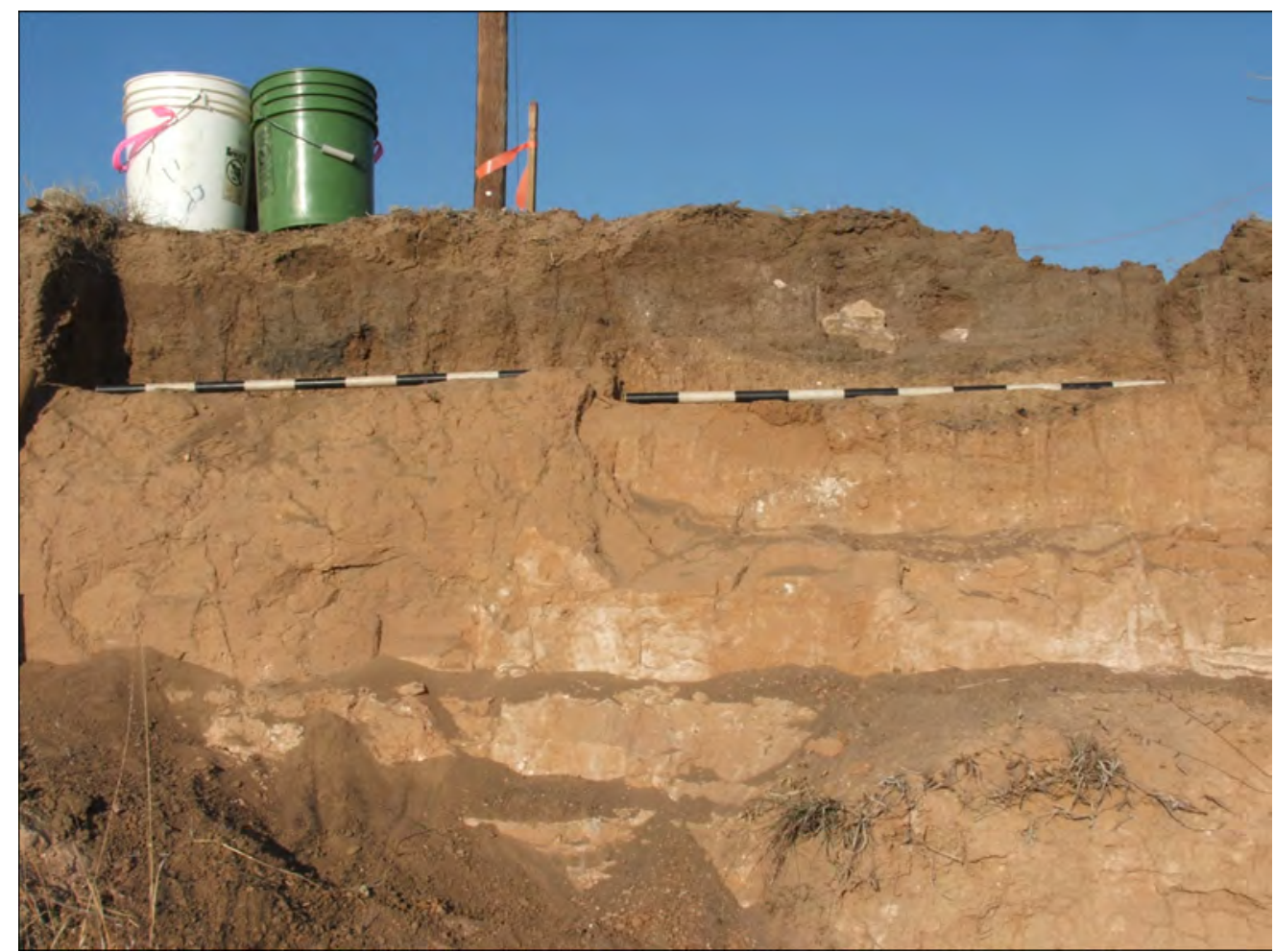

Figure 9-40. Profile photograph of road-cut showing Features 5 (left) and 16/21 (right). 


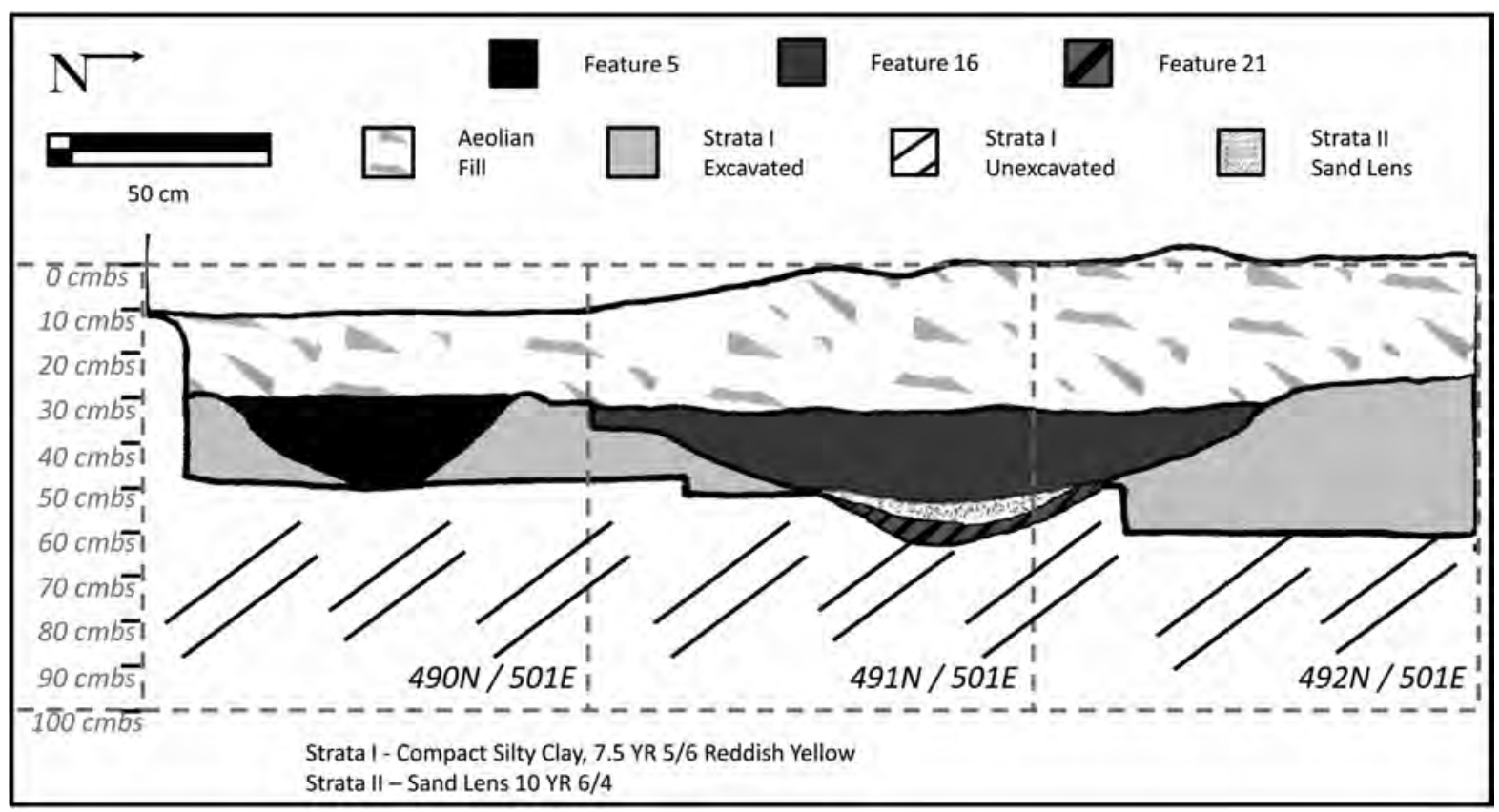

Figure 9-41. Profile drawing showing the association of Features 5 and 16/21.

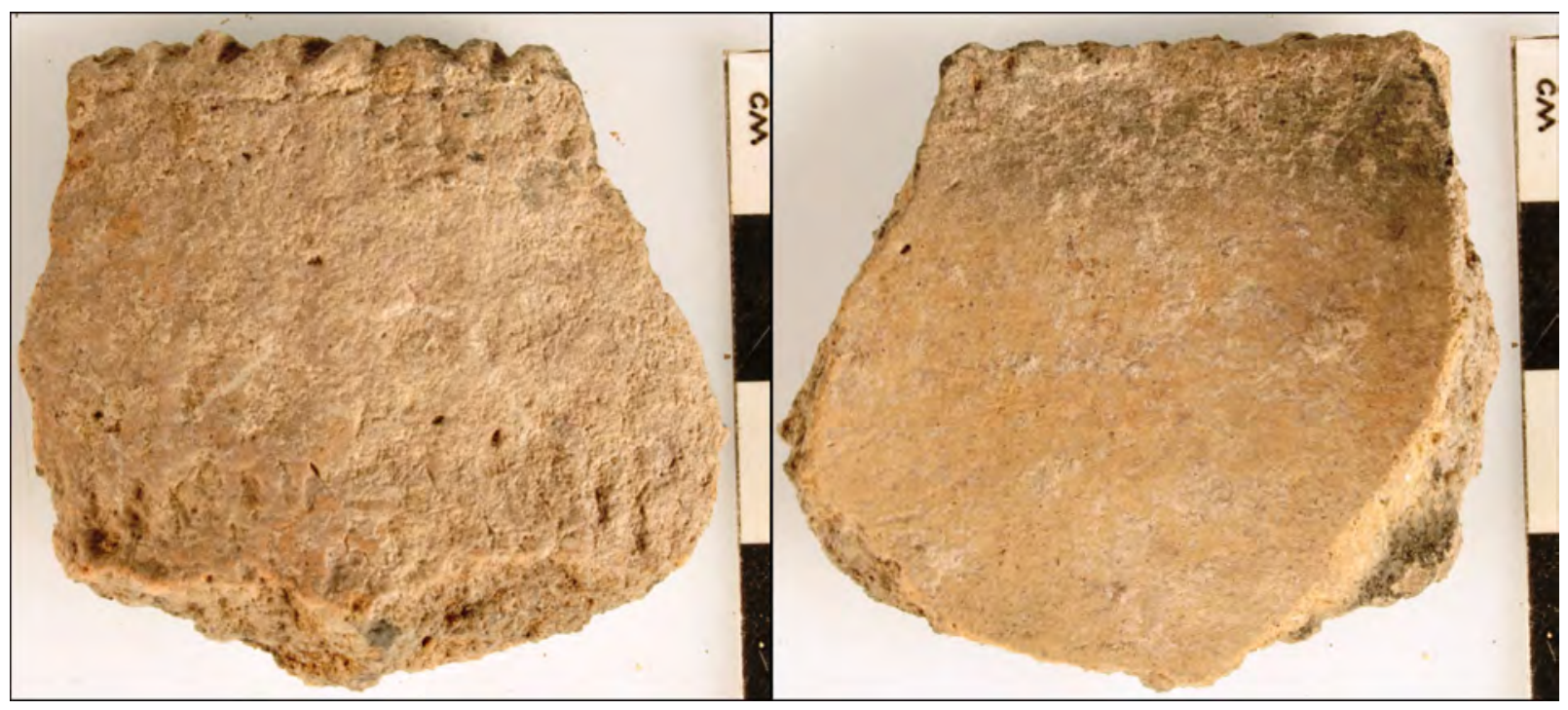

Figure 9-42. Photograph of exterior and interior of plain rim sherd (\#405-8) with decorated lip representing Vessel 4. 


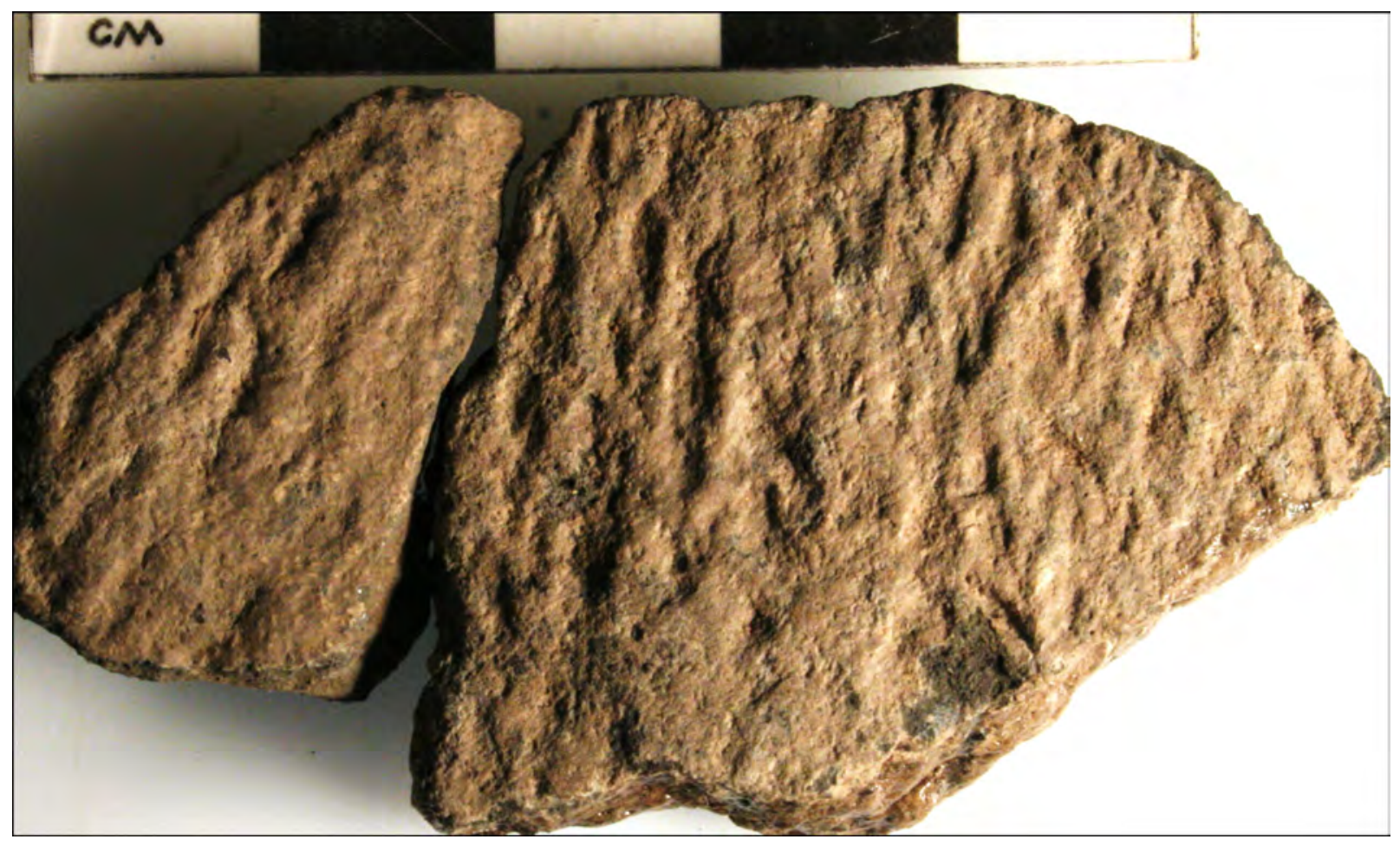

Figure 9-43. Photograph of partially obliterated cordmarked body sherd (\#468-008-4b) that represents Vessel 7.

g), 20+ tiny pieces of daub (9.4 g), insect larvae and, surprisingly, 1 piece ( $2.5 \mathrm{~g}$ ) of coal. In general, these results are remarkable in their consistency with the exception of the one piece of coal. The macrobotanical remains included burned mesquite seeds and charred maize cob fragments (Figure 9-44).

A 30.8 g phytolith sample (\#472-4) from Feature 16, between 50 and 59 cmbs in N492 E501, yielded a grass assemblage dominated (57.8 percent) by hot dry chloridoids with 34.5 percent cool season pooids (Appendix B). Although the warm moist panicoids were very low in over all frequency ( 7.7 percent) these phytoliths were most often burned (66.7 percent). A single large cross shaped phytoliths that reflects maize leaves was identified, but no beans or squash phytoliths were identified.

This complex feature is interpreted to represent a reused, two-tiered, shallow basin-shaped heating element with a lens of sand that separated the two basins of the earlier and later use episodes. It is not clear if the sand lens represents a short or long period of nonuse, but was intentionally added between the two use episodes that were closely spaced in time. The nature of the clean sand and lack of other cultural materials indicates very limited time passed between the two events. The horizontal position immediately north of Feature 5 indicates a possible functional connection with that heating element (see Figures 9-40 and 9-41).

\subsubsection{Feature 17}

This feature was detected about $38 \mathrm{cmbs}$ in N496 E500. It was less than $1 \mathrm{~m}$ from the road cut and roughly $3 \mathrm{~m}$ southeast of pithouse Feature 6 (see Figure 9-3). The top elevation was similar to that of most other cultural materials. Feature 17 first appeared as a flat-lying bison scapula over a couple of caliche rocks and small bone fragments with an ill-defined dark-stain around them. The brown (10YR 5/3) stain around this cluster was about 23 $\mathrm{cm}$ in diameter and immediately beneath the rocks, but was difficult to distinguish in the top $10 \mathrm{~cm}$. The 


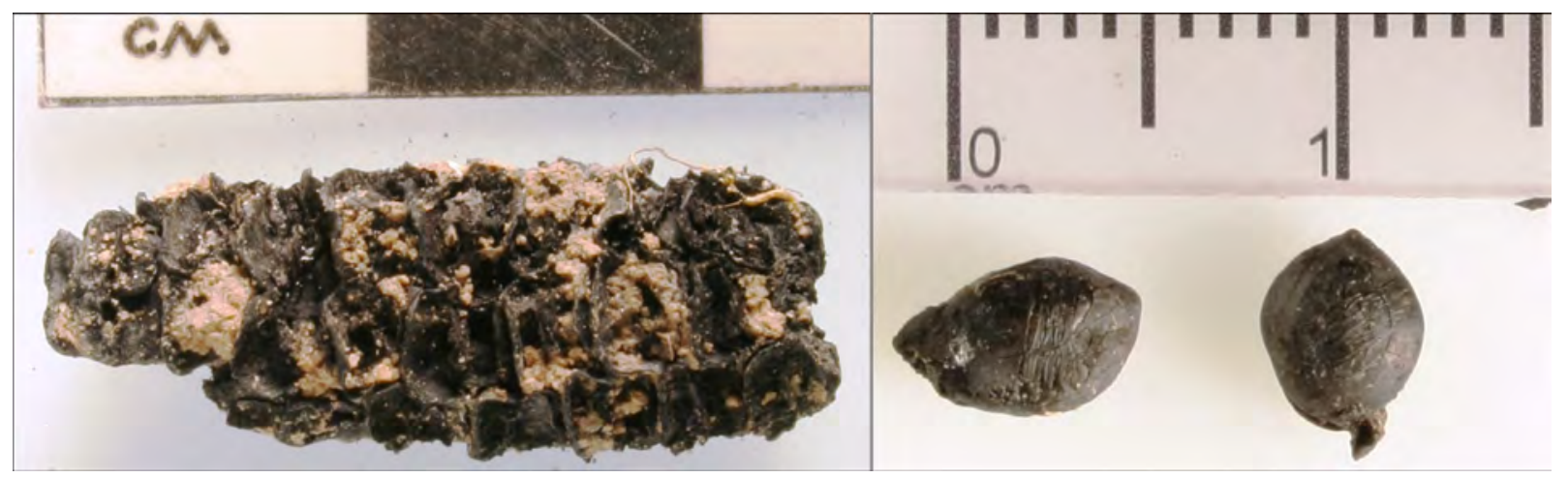

Figure 9-44. Charred maize cob fragment (\#453-5-7 left) and charred mesquite beans (\#4555-10 right) from Feature 16.

brown stain was cross-sectioned, and revealed that the stain continued downward to 72 cmbs, which terminated in a blunt bottom (Figure 9-45). The sides tapered slightly inward as the stain increased with depth. Small chunks of charcoal were scattered throughout the stain with no obvious concentration or pattered distribution. The bones and rocks near the top were about 42 to $44 \mathrm{cmbs}$ near the middle of the stain.

Sediment (\#520) from the top and lower half of the dark fill was bagged for possible flotation. The 3.75 liters of upper sediment (\#520-4-1) from 42 to $54 \mathrm{cmbs}$ were floated and yielded a heavy and light fraction. Very limited carbonized organic remains were in the light fraction and these were not analyzed. The heavy fraction yielded $7.3 \mathrm{~g}$ of material and includes 30+ tiny bone fragments (0.8 g), 1 tiny piece of daub (1.8 g), and tiny charcoal flecks. The lower sample (\#520-4-2) of 2.75 liters from 54 and $72 \mathrm{cmbs}$ was also floated with similar results. The $20.4 \mathrm{~g}$ of heavy fraction yielded similar classes of material, although the frequency of tiny bone fragments decreased. The light fraction contains limited carbonized materials and was curated. This deep dark fill is interpreted to have been the fill in a large-diameter post hole. However, it is not clear with what this post was associated nor, indeed, if it is a prehistoric feature.

\subsubsection{Feature 18}

This feature was in the southeastern corner of Component $\mathrm{C}$ along the road cut between N478 and N483 (see Figure 9-3). In that area of roughly $16 \mathrm{~m}^{2}$, a number of probable post holes similar in diameter to those in the pithouse Feature 6 were encountered, along with a small storage pit (Feature 23 see below), at least two small basin-shaped heating elements (Features 26 and 29 below), and two irregularly shaped clusters of burned rock (Features 19 and 20 below). After identifying the first post hole, charcoal-laden sediments similar to the fill in Feature 6 were also encountered in parts of the surrounding units. However, extensive rodent disturbance throughout the sandy deposits made it impossible to follow the light charcoal staining across the units. The charcoal-stained sediments were thought to represent a possible pithouse in association with the other features in that immediate area. Therefore, feature number 18 was assigned, but no specific boundaries or well-defined edges of a pithouse were definable. Feature 18 represented a "ghost" feature since specific dimensions or positive margins could not be clearly defined. In units N483 E500 and N482 E501, a faint boundary between two visibly distinct sediments was identified, possibly the edge of a larger structural feature. In partial support for the presence of a structure were nine post holes and/or possible post holes scattered in the vicinity (Figures 9-46 and 9-47). Various sediment samples were collected from the more obvious features and the probable post holes were carefully inspected and recorded. The potentially associated features are discussed below.

Diverse cultural materials were recovered throughout this $16 \mathrm{~m}^{2}$ area. These include eight 


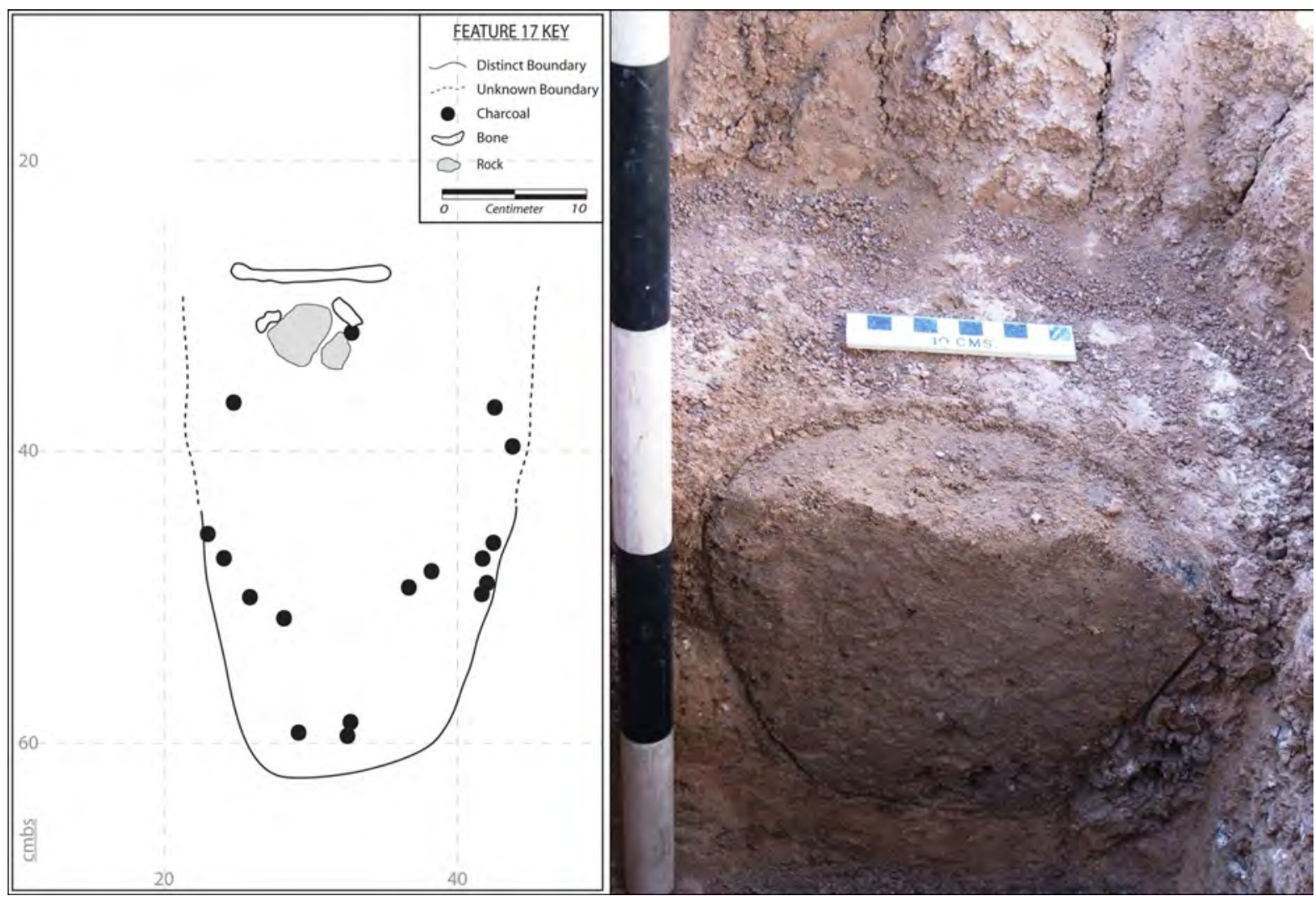

Figure 9-45. Profiles of post hole, Feature 17.

Fresno points (\#180-10, \#204-10, \#206-10, \#21010, \#224-10, \#281-10, \#301-11, and \#1262-10), four Washita points (\#200-10, \#200-11, \#291-11, and \#360-10), four point fragments (\#175-10, \#18210 , \#193-10, and \#236-10), three biface fragments (\#200-11, \#246-10, and \#265-11), one drill (\#23111), many edge-modified flakes, pottery sherds, a few weathered bone fragments, and many burned rocks (Figure 9-48).

Three stone tools were selected for high-power usewear. The distal end of an edge-modified flake (\#21011) revealed the tip was used for boring on hard, high silica material (Appendix H). The distal end of a biface (\#246-10) shows extensive wear indicative of cutting hard, high silica material (likely wood). The base of a drill (\#231-11) was hafted as indicated by abraded ridge near the middle (Appendix $\mathrm{H}$ ). The use of the edge-modified flake and biface on hard, high material like wood, indicates these tools were likely used during the construction of a wood frame for the pithouse.
A charred maize kernel (\#266-7-1) from between 50 and $60 \mathrm{cmbs}$ in N481 E500 was radiocarbon dated. This yielded a $\delta^{13} \mathrm{C}(-10.0 \%)$ corrected AMS date of $590 \pm 20$ B.P. (UGAMS-7823).

Multiple rim, body, and basal sherds, representing a single large, thick-walled vessel (Vessel 1), were subjected to various technical analyses. A thick body sherd (\#342-8-9) from between 70 and $80 \mathrm{cmbs}$ in N483 E500 was sent for starch grain analysis. This sherd yielded one possible maize grain and one lenticular grain of little barley (Appendix D). An extremely thick basal sherd (\#303-8-1 = TRC573; Figure 9-49) from between 40 and $50 \mathrm{cmbs}$ in N483 E500 was subdivided and sent for INA and petrographic analyses.

A second thick basal sherd (\#118-008-1 = TRC650: Figure 9-50) from an unidentified vessel was also sent for INA. The Vessel 1 basal sherd is chemically similar to other Vessel 1 sherds and assigned to Compositional Group 1, along with the majority of 


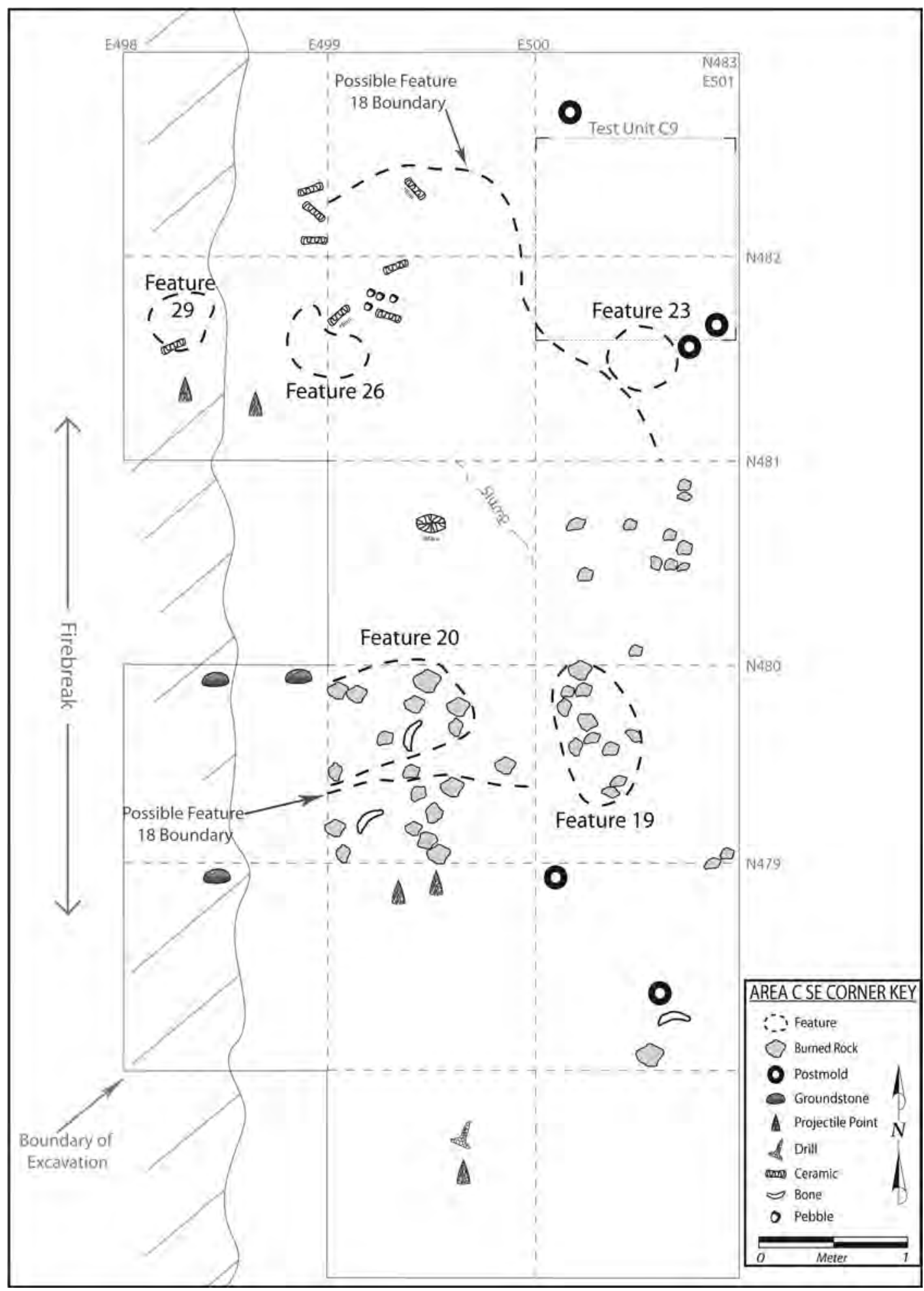

Figure 9-46. Overview drawing of the southeast part of Component $C$ that shows a possible margin of Feature 18, in association with Features 19, 20, 23, 26, and 29 and probable post hole. 


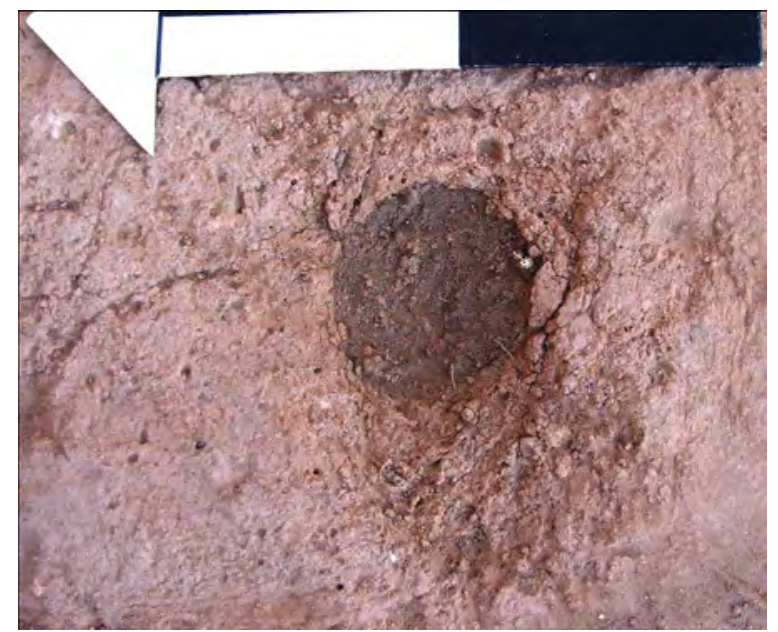

Figure 9-47. Post hole 7 north of Feature 23 in N483 E501

the other identified vessels. Interestingly, the second basal sherd is chemically different from most other sherds and was assigned to Compositional Group 4, and similar to the rim of Vessel 3 (Appendix G and F). A thick rim sherd (\#338-8-6 = TRC569) from N483 E500 representing Vessel 1 was also subdivided and sent for INA and petrographic analyses. The INA results show that this sherd is chemically similar to other Vessel 1 sherds (Compositional Group 1, Appendix G). A second thick rim sherd (\#308-008-2 $=$ TRC648) was also sent for INA. The latter sherd was chemically similar to the other Vessel 1 sheds and most of identified vessel (Appendix G). Six other sherds that represent Vessels 2 (\#259-008$2 \mathrm{~b}=$ TRC567) and 3 (\#349-008-1b = TRC566 and \#350-008-1 = TRC649) and one unnumbered vessel (\#362-008-1b = TRC565) were also sent for INA and petrographic analyses. The two Vessel 3 sherds are chemically different (assigned to Compositional Group 4) than Vessel 1 and the other identified vessels (Appendix G).

Five piece-plotted charcoal chunks (\#308-7-1, \#310-7-1, \#312-7-7, \#323-7-1, and \#325-7) from various proveniences in the northern part of Feature 18 were sent for species identification. Dering identified these pieces as juniper, rose family, and oak (Appendix C).

In amongst the scattered cultural debris were human teeth; 1 left deciduous canine, 1 left premolar,
1 unsided premolar crown, 6 enamel and root fragments of a deciduous molar and permanent incisor crown (\#338-002; Appendices $\mathrm{K}$ and S). These are interpreted to represent a single child of about 2 to 5 years old.

Although Feature 18 was not conclusively demonstrated to be a pithouse, the circumstantial evidence of the post holes, a storage pit, the concentration of chipped stone tools, burned rocks, ceramics, and daub in association with a distinct soil color change between two horizontal deposits at least indicates this possibility. Without understanding what the adjacent unexcavated area might have revealed, this can only be suggested as a possibility.

\subsubsection{Feature 19}

This feature was in the southeastern corner of Component C, specifically in N480 E501, about 1 $\mathrm{m}$ west of the road cut. It was within the confines of proposed Feature 18, towards the southern end (see Figure 9-3). Feature 19 consisted of a loose grouping of roughly 12 small burned rocks between 48 and 64 cmbs. This group measured roughly $45 \mathrm{~cm}$ northsouth by $25 \mathrm{~cm}$ east-west. The 12 rocks ranged in size from 1 to $15 \mathrm{~cm}$ in maximum dimensions, with 60 percent between 4 and $7 \mathrm{~cm}$. The rocks were water-rounded quartzite cobbles and chunks of caliche. The group was bisected, which created a profile that was drawn and photographed. The 


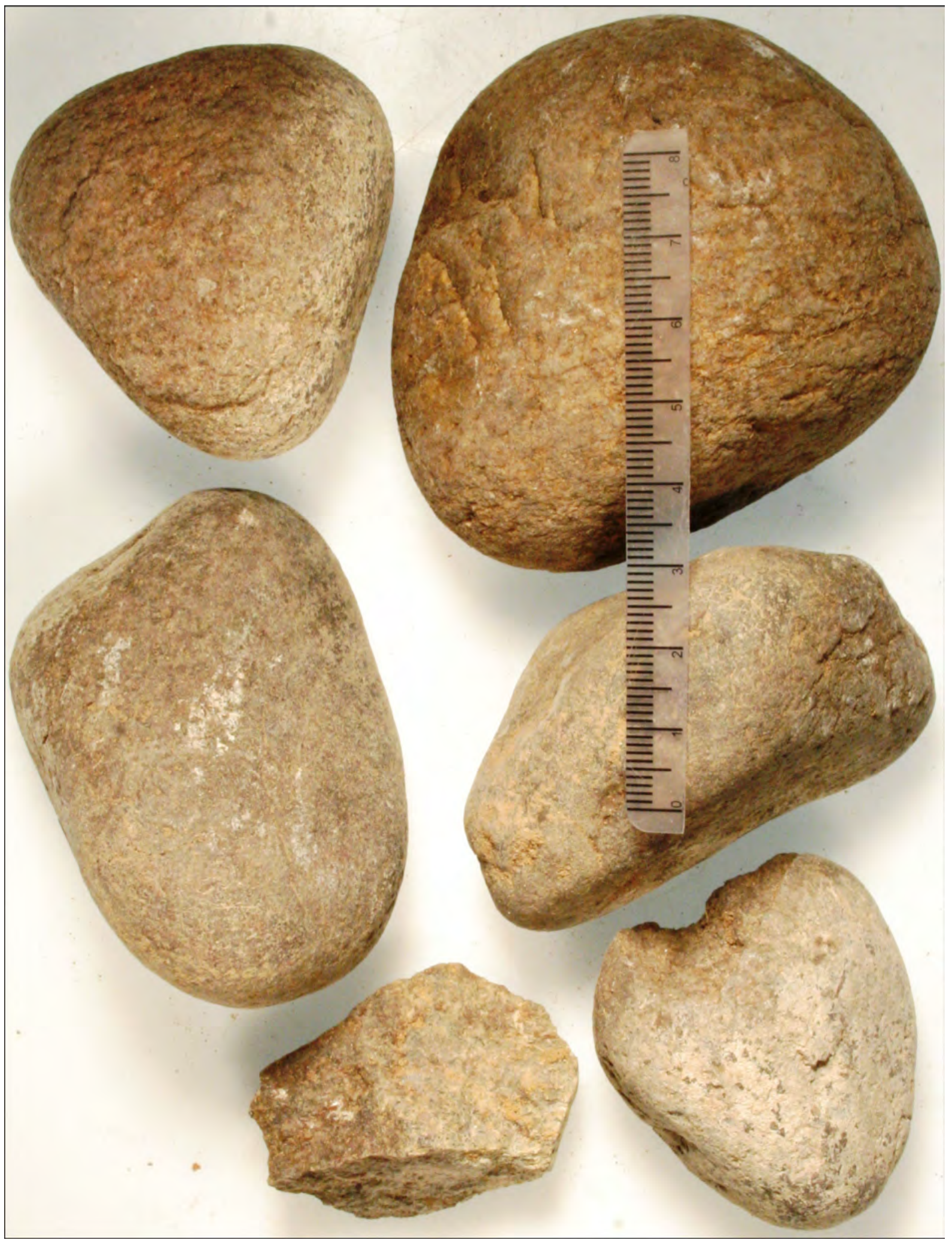

Figure 9-48. Sample of rock shapes, sizes, and material types from Feature 18. 


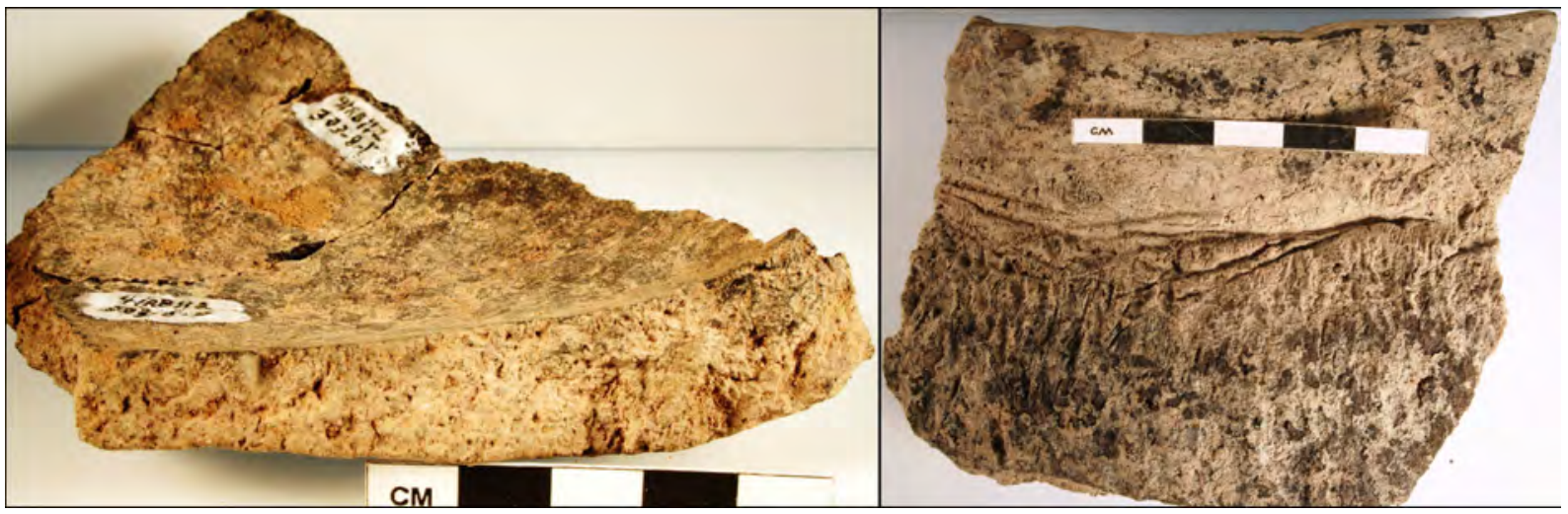

Figure 9-49. Oblique view of thick basal sherd (\#308-8; left) and large rim and neck sherd (\#308-8-3) of Vessel 1.

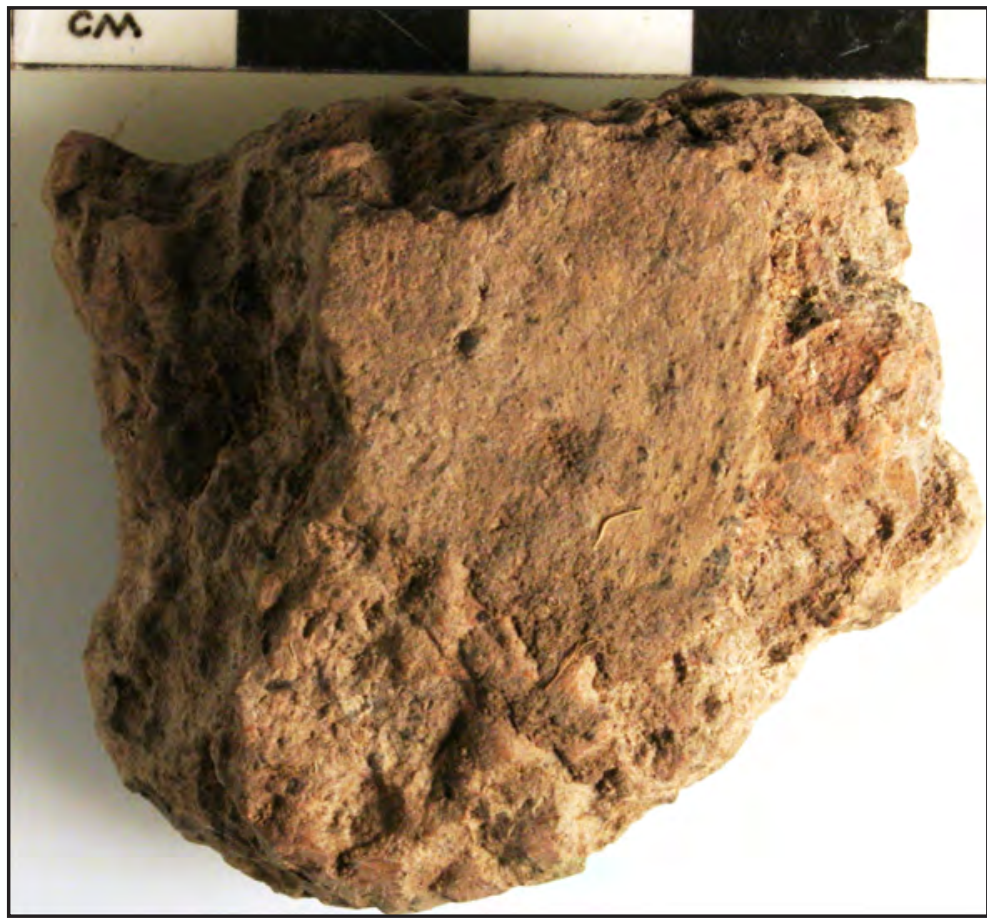

Figure 9-50. View of thick basal sherd (\#118-8-1) from unknown vessel, likely Vessel 3. 
profile revealed no detectable basin, dark-stained sediments, nor signs of in situ heating (Figure 9-51). The surrounding light yellowish brown (10YR 6/4) sediment was similar to the sediments surrounding the rocks. The sediment from immediately around and below the rocks was collected for possible flotation. Rodent disturbance was intensive along the eastern and western sides, above and below this level, and in adjacent units.

A one liter sediment sample (\#252-4-1) from the eastern half of Feature 19 was floated, and heavy and light fractions were collected. The light fraction contains minimal carbonized remains, which were not further analyzed. The heavy fraction (\#252-4) yielded $33.7 \mathrm{~g}$ of material that includes 3 tiny pieces of debitage ( $0.1 \mathrm{~g}), 4$ tiny bone fragments $(0.3 \mathrm{~g})$, and 2 tiny daub pieces $(0.2 \mathrm{~g})$. A one liter sample (\#2524-2) from the western side yielded similar results. The heavy fraction yielded $22.6 \mathrm{~g}$ of materials that includes almost no cultural materials. The light fraction contains a few charred wood fragments, but these were not sent for macrobotanical analysis.

These burned rocks were generally surrounded by and associated with diverse and scattered cultural materials that include chipped and ground stone tools, charcoal-laden sediments, thick ceramic sherds, pieces of debitage, bone scraps, a tiny mussel shell fragment, heating elements Features 26 and 29, and other clustered burned rocks immediately to the west. Feature 19 is interpreted to represent discarded burned rocks used in a heating/cooking capacity. This nonstructured cluster was similar to burned rocks just to the west that are considered part of Feature 20 (see below).

\subsubsection{Feature 20}

Feature 20 was also in the southeastern corner of Component C, specifically in N480 E500, about 2 $\mathrm{m}$ west of the road cut and only about $50 \mathrm{~cm}$ west of Feature 19. It was also within the confines of proposed Feature 18 (see Figure 9-3). It consisted of a dispersed group of roughly 10 small (4 to $9 \mathrm{~cm}$ in maximum dimension) burned rocks between 46 and $63 \mathrm{cmbs}$. The rocks were in an area roughly $75 \mathrm{~cm}$ east-west by $65 \mathrm{~cm}$ north-south, in a loose cluster that had no obvious boundary or distinct shape (Figure 9-52). No change in soil color or intensive charcoal flecking was detected around or under the rocks. A brown (10YR 5/3) silty sand sample (\#2344) was collected from around the rocks. Extensive rodent disturbance was observed throughout the unit and around the rocks.

Two chunks of burned rocks (\#234-3-1a and \#2343-2a), 198 and $141 \mathrm{~g}$ respectively, were sent for diatom analysis. One piece yielded only three diatoms and the second yielded 14 diatoms. The latter diatoms represent at least six different species. They all reflect aquatic species that are prominent in streams (Appendix J). The most likely scenario that would account for this association of diatoms with these rocks would be that the rocks were placed in water that was collected from a nearly stream, likely during a cooking activity.

Parts of these same two burned rocks (\#234-3-1b and \#234-3-2b) were subjected to starch analysis. Specimen \#234-4-1b yielded one lenticular grain of little barley. The other yielded 32 grains that include 8 grains of maize, 18 lenticular grains of little barley, with some parched, and 6 grains tentatively identified as mesquite (Appendix D). The starch grain analysis definitely supports these burned rocks were used in cooking and also document the specific foods cooked.

Various classes of cultural materials were scattered around the rocks and in the immediate area, and include pieces of lithic debitage, thick cordmarked potsherds (\#236-8), bone fragments, scattered chunks of daub/baked clay, and a lateral fragment of an arrow point (\#236-10).

A 1.5 liter sample of sediment (\#234-4) from between the rocks was floated. The light fraction reveals only a few flecks of charcoal and insect parts and was not analyzed. The heavy fraction also yielded almost no carbonized material, but includes 5 tiny bone fragments ( $<0.1 \mathrm{~g})$ and 5 tiny daub pieces $(0.6 \mathrm{~g})$.

A 30.3 g sediment sample (\#234-4-1a) from 40 to $50 \mathrm{cmbs}$ in N480 E500 was sent for phytolith analysis. The analysts identified short cell grass phytoliths dominated (63.3 percent) by hot dry chloridoids, followed by 30.6 percent cool season pooids (Appendix B). No short cell phytoliths 


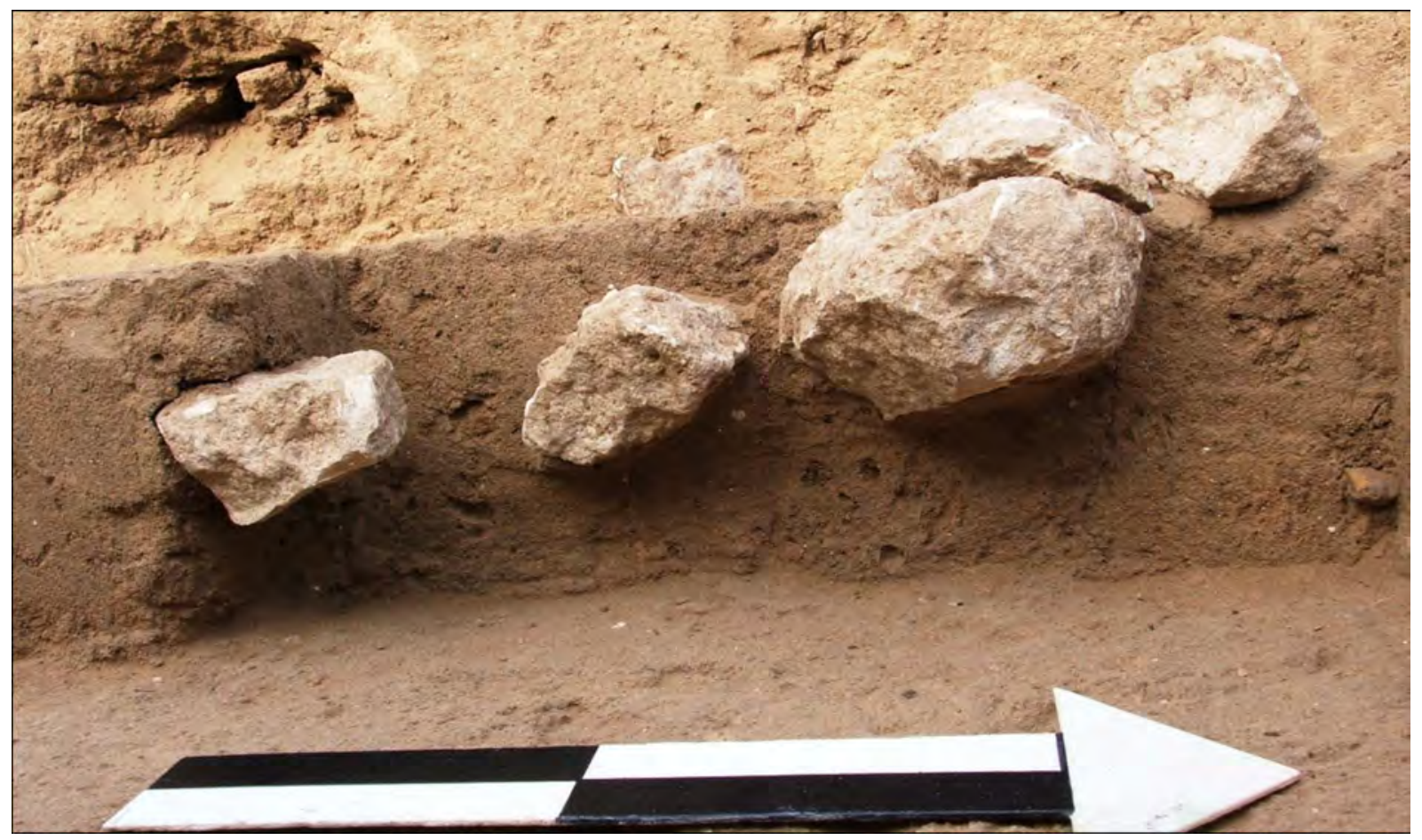

Figure 9-51. Profile of the burned rocks in Feature 19.

were burned. A few diatoms and sedge phytoliths were recognized, but no maize, beans, or squash phytoliths were identified. The burned rocks in Feature 20 are interpreted as the remains of heating and/or cooking elements, which were discarded here after use. These rocks may have been heated in the adjacent heating elements, Features 26 and/or 29 (see below).

\subsubsection{Feature 21}

See the description and discussion of Feature 16/21 above.

\subsubsection{Feature 22}

This feature was discovered in the subsurface about $1 \mathrm{~m}$ east of the new right-of-way fence and about $1 \mathrm{~m}$ south of the wooden power pole in unit 489N 494E (Figure 9-3). Feature 22 was beneath the southern extension of the stone alignment and recognized within a sandy loam matrix in level 7 , between 60 and $70 \mathrm{cmbs}$. The feature was distinguishable as intensively burned (black) and partially calcined (white) long bone and rib fragments grouped as a loose cluster with no clear distributional pattern (Figure 9-53). The bones were concentrated in an area that measured roughly $50 \mathrm{~cm}$ north-south by $60 \mathrm{~cm}$ east-west. The individual pieces varied in depth from 60 to $72 \mathrm{cmbs}$ and were not within a constraining pit.

A minimum of 16 bone fragments or partial elements were observed and plotted, with a number of small ( $<3 \mathrm{~cm}$ long) burned and calcined fragments amongst the larger fragments. None of the collected pieces are longer than about $13 \mathrm{~cm}$. A few element fragments rested at an angle that diverged from the horizontal by 40 to 60 degrees. Of the roughly 16 plotted bone fragments/elements, 12 were intensively burned to a black and/or calcined state. At least four plotted pieces appeared to be unburned. These include one nearly complete human patella, one unburned questionable deer axis, one distal deer femur section, and one unburned and possibly human metapodial. One caliche rock, $8 \mathrm{~cm}$ in diameter, and a single, complete musselshell valve were within this loose cluster of mostly calcined bones. The outer edge of the valve appears 


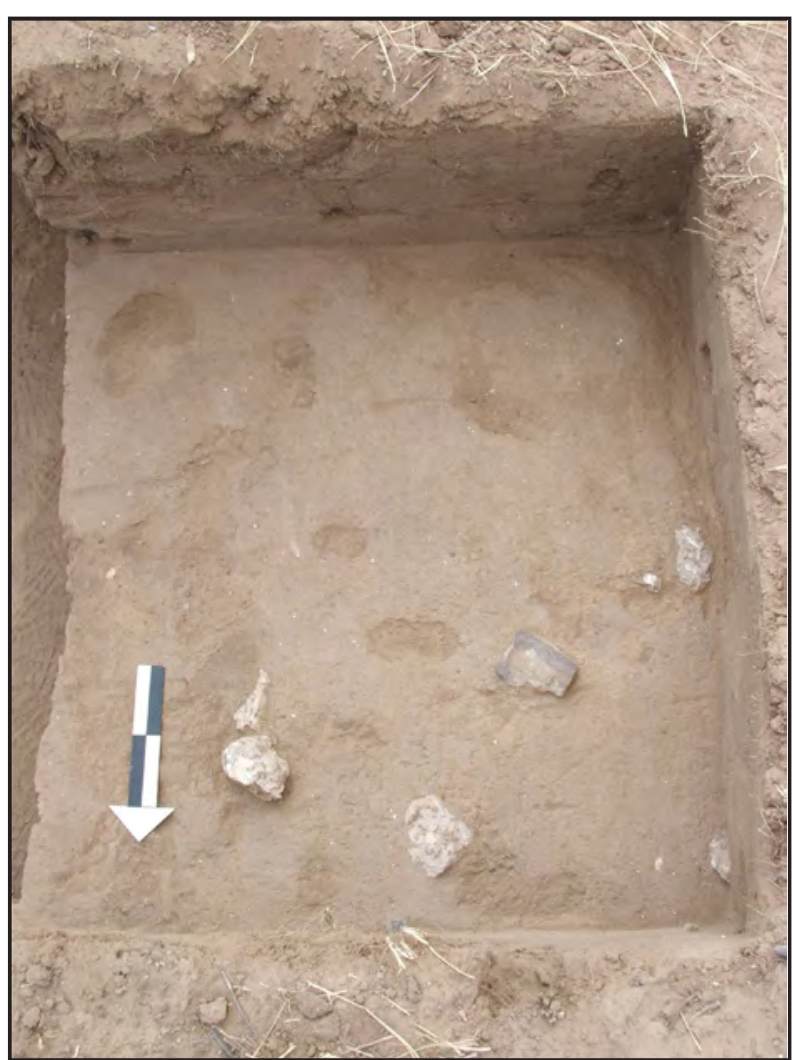

Figure 9-52. Overview of first partially exposed burned rocks in Feature 20

smoothed and rounded through use (Figure 9-54). A tiny chunk of charcoal was also detected among the charred bones. No lithic debitage, burned rocks, or other cultural remains were recovered from the 10-cm-thick excavation level that contained Feature 22. No evidence of in situ burning, such as oxidized soil or an ash lens, was observed at this location.

A small ( $<2$ liters) sample of sediment was collected from around some of the burned bones. The cluster was carefully mapped, the depths of individual bones were recorded, preliminary identifications of the bones were made in the field, and the bones were placed in individual numbered bags. The sediment color and texture around the bones was similar to that in the rest of the unit, a soft sandy loam, with no signs of a pit, basin, or dark soil were associated. Little or no rodent disturbance was observed in or around the bones.

Our initial field interpretation was that these bones represented the remains of a cremated human individual in secondary context. Once in the laboratory and after another assessment, the remains were sent to forensic anthropologists for detailed analysis.

Drs. M. Kate Spradley and Michelle D. Hamilton of FACTS performed an inventory of the human remains recovered from Feature 22 (see Appendices $\mathrm{K}$ and $\mathrm{S}$ ). The inventory identified a single human individual represented by the materials from Feature 22 (Individual 2 in Appendix S). The interpretations derived by these forensic anthropologists regarding this individual are summarized here. This individual was an adult of indeterminate sex, whose remains, aside from the missing skull/mandible, are only 10 percent complete. Alteration of the bones is present in the form of post-mortem thermal damage. A majority of the remains from this individual exhibit this effect, with the exception of three elements (knee, hand, and foot fragments). This individual was also identified as a Native American. Due to the incomplete, burned and fragmentary nature of the remains, however, no further assessment of cultural affiliation was possible.

Feature 22 is considered a Native American that was cremated. This feature is a secondary deposition of cremated human bones mixed with other nonhuman bones and a couple of other items. Since no in situ burning (e.g., reddened earth, charcoal lens, or ash deposit) was evident, these materials were likely placed here following their intentional burning elsewhere. TxDOT instructed TRC not to conduct destructive analysis (i.e., radiocarbon dating, chemical analyses) on any of the human remains or associated items. The human bones and other associated materials were returned to TxDOT and repatriated.

\subsubsection{Feature 23}

This feature was detected roughly $60 \mathrm{~cm}$ west of the road cut in the southeastern end of the component in unit N482 E501, at the northern margin of Feature 18 (see Feature 9-46). Feature 23 first appeared as a brown (10YR 5/3) circular stain, nearly $30-\mathrm{cm}-$ diameter, toward the lower part of the sandy fill at roughly $70 \mathrm{cmbs}$ (Figure 9-55). The stain was readily distinguishable from the surrounding Ogallala deposits. The fill from the top $10 \mathrm{~cm}$ was 


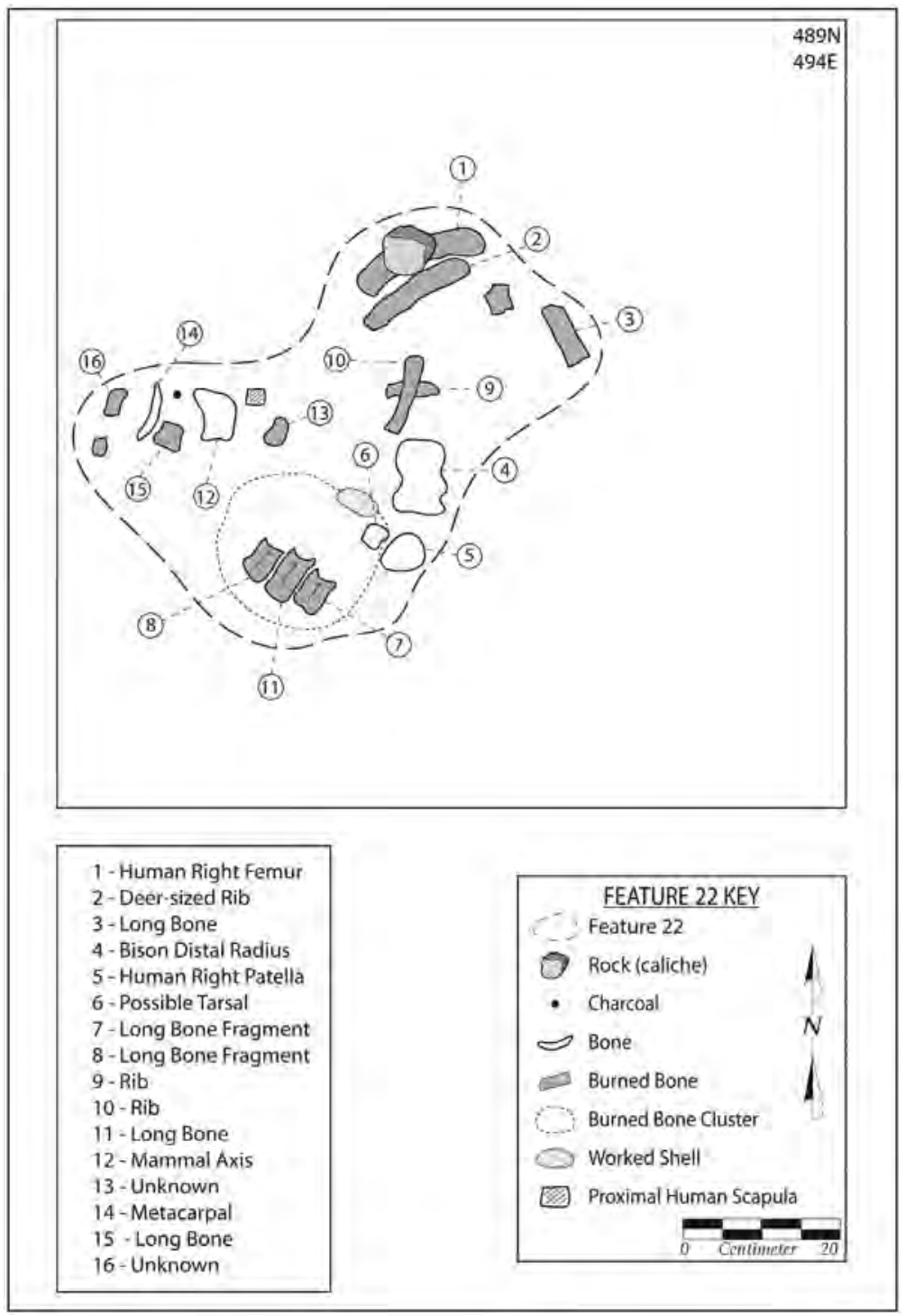

Figure 9-53. Plan view drawing of burned human remains, Feature 22, in secondary deposits.

removed and collected without screening, after which the feature was cross-sectioned and multiple samples collected. The brown fill revealed a vertical pit dug about 22-cm-deep into the older, calcium carbonate rich deposits (Feature 9-55). The dark interior fill contrasted with the calcium carbonates and reddish sandy sediment that surrounded it. In profile, the pit revealed no lining of the walls or internal stratification. Very limited charcoal flecking was discernable in the profile.

Geoarcheologist Charles Frederick collected two oriented micromorphology blocks of sediment from this pit. One block (\#1221-4) was collected from a depth of 43 to 55 cmbs and the second (\#1023-4) was collected from 65 to 75 cmbs. Dr. Frederick made and analyzed two thin sections from each block and his results are presented here. The attributes of the upper and lower deposit were similar. In general, the sediment that filled this pit was derived from the Ogallala Formation and either represents gradual infilling from weathering of the sidewalls, or intentional fill derived from the Ogallala Formation.

The sediment within the pit consisted of a silt loam that exhibited a weakly developed intergrain channel structure where the $\mathrm{c} / \mathrm{f} 63$ micron is about $1: 10$ and exhibited an open porphyric related distribution. 


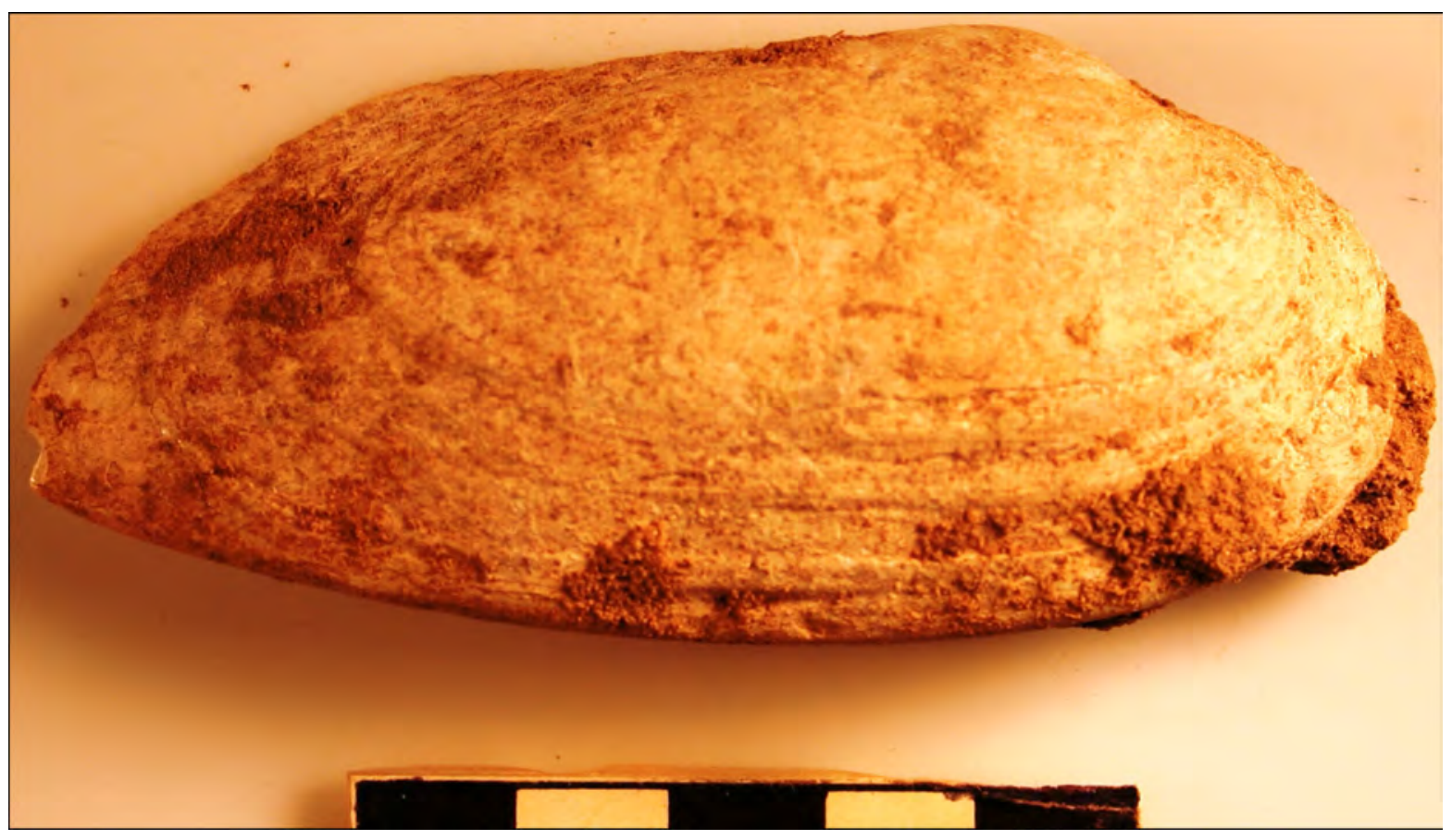

Figure 9-54. Edge rounded freshwater mussel shell associated with Feature 22.

Channels comprised between 5 and 15 percent of the area (and the proportion of channels was highly variable between the two samples), but the shallower sample exhibited more frequent and larger channels than the deeper sample. A few coarse fragments (greater than $1 \mathrm{~cm}$ ) of angular caprock caliche were noted, but all thin sections exhibited between 5 and 10 percent, 1 and $10 \mathrm{~mm}$ rounded fragments of calcium carbonate nodules derived from the Ogallala Formation. Some nodules were clearly reworked as excrement by soil fauna, whereas others appeared similar to those observed in context in the Ogallala, but with sharper edges. Like all of the Ogallala sediments, the dominant minerals were quartz (around 80 percent) and feldspar (around 15 percent plagioclase and microcline). Faunal excrement was present, but the majority was strongly coalesced dense microaggregates, with only a few weakly coalesced pristine porous microaggregates. A few large (greater than $2 \mathrm{~mm}$ ) charcoal fragments were observed within the pit fill, and less than 1 percent of less than $0.1 \mathrm{~mm}$ fragments were noted.

The absence of microlamination that may accompany incremental sedimentary infilling of pit structures implies the pit was intentionally filled, or postdepositional floral and faunal activity destroyed it. The magnitude of faunal activity within the micromorphology samples is significantly less than that observed within the occupation surface in Column 1 next to Feature 16/21, where eolian sand rests directly upon the Ogallala Formation. Consequently, if this pit filled gradually through time, it is most likely the bedding was destroyed by floral root activity. This would be consistent with the channel microstructure exhibited by these samples, but the complete absence of bedding is somewhat surprising.

Rodent burrows were seen in the immediate vicinity, but none directly intersected the pit. The top edge of the pit was at the same elevation as the surrounding scattered cultural materials and features. This feature appeared associated with the indistinct and possible pithouse, Feature 18, which was defined by an area of charcoal-rich sand immediately to the southwest in N482 E501 between 60 and 70 cmbs (see Figure 9-46). At least one probable post hole (\#9) was roughly $20 \mathrm{~cm}$ to the northeast of Feature 23. The sediment from post hole \#9 (6-cm-wide by 5-cm-deep) was collected and a foam mold of the hole was made and retained. The post hole was readily discernable as its 
base protruded into the Ogallala just to the side of Feature 23.

The southwestern half of N482 E501, between 70 and $80 \mathrm{cmbs}$ and the projected interior of Feature 18, yielded very sparse cultural materials (a tiny piece of daub/baked clay and a couple of lithic flakes). Most of the sandy fill (\#328-4-1 and \#331-4-1) from Feature 23 was collected without screening for subsequent flotation. A small sediment sample for phytolith analysis (\#331-4-2) was collected from the very bottom of the pit between 87 and 90 cmbs.

Five liters of sediment from 70 to $80 \mathrm{~cm}$ (\#332-41) yielded a $44.7 \mathrm{~g}$ heavy fraction. This contains 17 tiny pieces of lithic debitage ( $<0.1 \mathrm{~g}), 3$ ceramic sherds (11.7 g), 30+ tiny bone fragments (5.0 g), and 23 tiny pieces of daub (1.6 g). The light fraction was sent for macrobotanical analysis and yielded 20 maize cupule fragments, 3 kernels, and 1 glume. Wood types are juniper and mesquite (Appendix C). Two liters of fill (\#331-4-1) from 80 to 90 cmbs in Feature 23 was floated for heavy and light fractions. The light fraction contains quantities of charred wood and maize fragments, but was not sent for macrobotanical analysis. The $24.9 \mathrm{~g}$ of heavy fraction was sorted into material classes; it contains 3 tiny pieces of debitage $(<0.1 \mathrm{~g})$ and $10+$ tiny pieces of daub (0.7 g).

A charred maize kernel (\#331-7-1) was extracted from the feature fill between 80 and $90 \mathrm{cmbs}$ and sent for radiocarbon dating. This kernel yielded a $\delta^{13} \mathrm{C}(-8.6 \%$ ) corrected AMS date of $570 \pm 25$ B.P. (UGAMS-7825). This date overlaps with a maize date derived from Feature 18.

A $31.6 \mathrm{~g}$ subsample of the feature fill (\#331-4-1a) from between 80 and $90 \mathrm{cmbs}$ near the very bottom of the pit was submitted for starch grain analysis. The analyst found no starch grains in the sediment, which supports the idea that starch grains recovered from other cultural items were derived from cultural use and not from contact with the soil (Appendix D). It also indicates that starchy foods were not left in this storage pit upon abandonment.

A second subsample of fill (31.6 g, 331-4-2b) from 87 to $90 \mathrm{cmbs}$ near the bottom of the pit was sent for phytoliths analysis. This sample was dominated

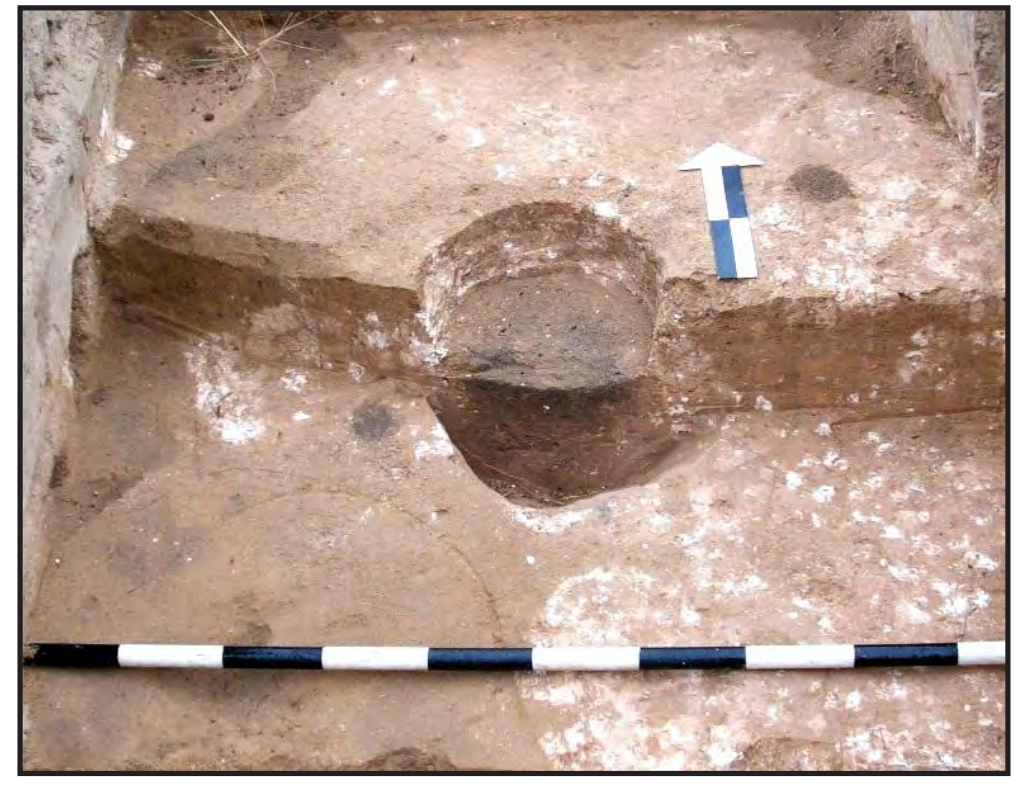

Figure 9-55. Oblique view of storage pit - Feature 23 dug into the Ogallala Formation, post hole \#9 next to north arrow with possible post hole on left edge.

Note the color distinction left of the pit from the modeled Ogallala deposits that surround the pit. This is postulated as the northeastern edge of the possible pithouse Feature 18. 
(57.6 percent) by short cell phytoliths that represent cool season pooids with some 14.3 percent of those burned, followed by 28.8 percent warm moist panicoids (Appendix B). A single large cross shaped phytolith from maize leaves was identified, but no beans or squash phytoliths were present.

Feature 23 was a small, well-formed, straight walled storage pit in apparent association with the possible pithouse, Feature 18 and at least two small post holes. This storage pit was near the northeastern corner of the possible pithouse. The presence of a maize leaf phytoliths indicates that maize was likely stored in this pit. Once the maize was removed it was intentionally filled.

\subsubsection{Feature 24}

This feature was inside Feature 6, a pithouse (see Figure 9-12). It consisted of a localized area of dark-grayish brown (10YR 4/2) ashy fill in the southwestern corner of N499 E497 and was discernible between 40 and 48 cmbs. This patch of ashy seidment measured roughly $20 \mathrm{~cm}$ in diameter and had poorly defined boundaries, though it could be defined as roughly circular in shape. This ash was on the floor of the pithouse and exhibited no oxidation rim or other signs of in situ heating under the ash. It was surrounded by diverse cultural materials that included butchered bison bones, lithic debitage, ground and chipped stone tools, ceramic sherds, caliche rocks, chunks of daub, charcoal chunks, and other localized areas of ashy matrix.

The ashy sediment (\#644-4-1) was collected for possible flotation, which was not conducted. A 30.1 g subsample (\#644-4-1) was sent for phytolith analysis, which revealed the short cells were relatively equally divided between the three major short cell groups with warm season panicoids the most frequent (42.8 percent; Appendix B). Five large cross shaped phytoliths from maize leaves were identified, but no beans or squash phytoliths were present. Pinaceae tracheid elements $(N=9)$ were present and indicate an unknown species of pine wood is represented. This feature is interpreted as an ash dump or the remains from a small hearth likely inside the pithouse where pine wood and maize were at least some of the plants used in the fire.

\subsubsection{Feature 25}

This feature was also in pithouse, Feature 6 (Figure 9-12). Feature 25 was a small irregular patch of dark-grayish brown (10YR 4/2) ashy fill in the southeastern corner of N499 E497, recognized between 40 and $50 \mathrm{cmbs}$. It was not well-defined and was eventually determined not to be a feature, but rather is believed to have been part of the fill on the floor of the pithouse at the base of the entryway. No special samples were collected from this area.

The rest of the unit yielded diverse cultural materials that include butchered bison bones, lithic debitage, ground and chipped stone tools, ceramic sherds, caliche rocks, chunks of daub, charcoal chunks, and other localized areas of ashy fill.

\subsubsection{Feature 26}

This feature was on the north-south dividing line between N482 E499 and N483 E500 within the projected boundaries of postulated "ghost" pithouse Feature 18, just $40 \mathrm{~cm}$ east of Feature 29 (see Figure 9-46). Feature 26 was an irregularly shaped, dark stain that contained chunks and flecks of charcoal. The gray (10YR 5/1) mottled ashy stain was roughly $55 \mathrm{~cm}$ north-south by $30 \mathrm{~cm}$ east-west, and between 68 and $80 \mathrm{cmbs}$ (Figure 9-56). This gray sediment contrasted with the surrounding brown (7.5YR 5/3) sandy loam, though the western edge was barely distinguishable during excavation. An irregularly shaped basin, roughly 10 - to 12-cm-deep, was present. This basin had ill-defined margins, as insect turbation blurred the margins. Rodent activity was also detected around this stain.

The western half of the gray mottled (10YR 5/1) basin fill (\#294-4) exhibited patches of very darkgray (10YR 3/1) areas from 47 to $50 \mathrm{cmbs}$, and nine liters of fill was collected and floated. The heavy fraction (131 g) yielded 1 tiny mussel shell fragment, 18 tiny pieces of lithic debitage $(0.1 \mathrm{~g}), 10$ burned seeds, 30+ tiny bone fragments (2.7 g), and 30+ tiny pieces of daub (6.5 g), 1 of which bears small stick impressions. The nine liters or $52.2 \mathrm{~g}$ of light fraction (\#294-4b) was sent to Phil Dering for macrobotanical analysis. He identified maize kernels, cupules, and glumes and a fragment of knobby tissue. The latter tissue is a lignified part of a stem, usually found 


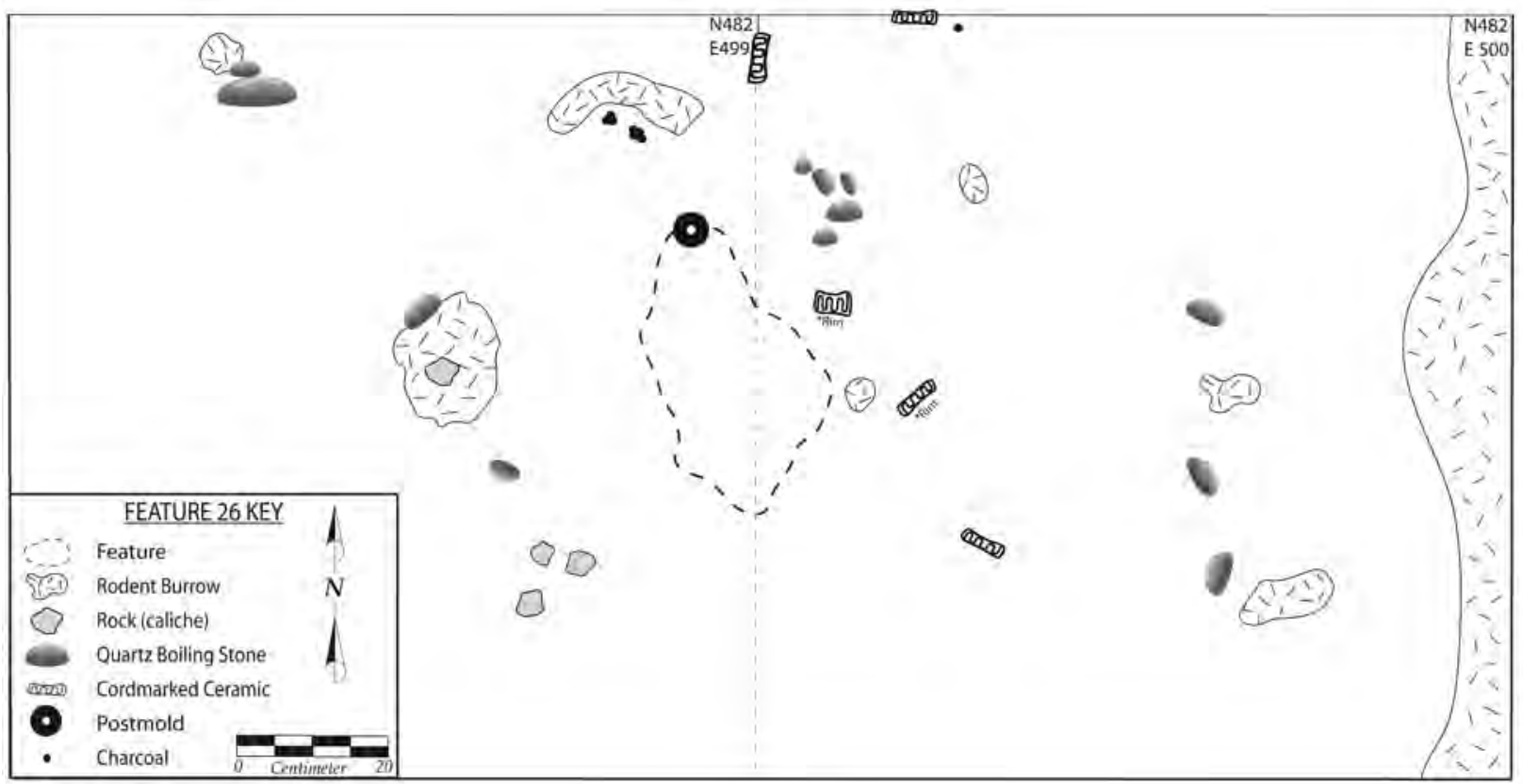

Figure 9-56. Plan view drawing of Feature 26 showing distribution of in situ thick ceramic sherds (Vessel 1) and rounded boiling stones all within Feature 18.

around the base of the plant. It is common in many types of plants, including maize and sunflowers, which are herbaceous annuals, but also in perennial plants such as yuccas. Often adventitious roots, such as prop roots in corn, emerge from this area of the plant (Appendix C). The wood charcoal is dominated by juniper with oak and mesquite also present in much smaller quantities. The $45 \mathrm{ml}$ total of juniper charcoal was the single largest concentration of wood charcoal in the flotation samples from this site (Appendix C). A sample of fill from the eastern part of the basin (\#1232-4) was also floated. The light fraction contains quantities of charred wood and has been curated. The heavy fraction contains 1 tiny piece of debitage ( $0.3 \mathrm{~g}), 16$ tiny bone fragments $(0.3 \mathrm{~g})$, and 40+ tiny pieces of daub (6.5 g).

This small basin was surrounded by numerous large pieces of a very thick ceramic vessel (Vessel 1), and many small, water-rounded quartzite pebbles with one cluster of five pebbles just $15 \mathrm{~cm}$ to the northeast of the basin (see Figure 9-57). The thick Vessel 1 sherds (rim, body, and base) were vertically distributed from roughly 48 to $70 \mathrm{cmbs}$, and indicate disturbance by rodent activity. The highest frequency of sherds was between 60 and 70 cmbs, generally in the vicinity of Features 26 and 29.

A cluster of five rounded quartzite pebbles was less than $20 \mathrm{~cm}$ to the northeast of the ashy fill with at least six similar water-worn pebbles scattered across the adjoining two units (see Figure 9-56). Although still complete, these pebbles were likely heated in this small basin and used during the cooking process for heating and/or boiling water. The association of the basin pit, Vessel 1 sherds, and the small pebbles is intriguing. It is not clear how the cooking process occurred, but it can be suggested that the stones were first heated in the fire, then were used for cooking, potentially in Vessel 1. Feature 26 is interpreted as an in situ heating element used in conjunction with the associated vessel and small pebbles.

\subsubsection{Feature 27}

This feature was inside the northeastern corner of the Feature 6 pithouse between 65 and 71 cmbs in N500 E497 and N499 E497 (Figure 9-12). Feature 27 was a pinkish gray (10YR 6/2) ash concentration that yielded flecks and tiny chunks of charcoal. It had an amorphous shape, roughly $30 \mathrm{~cm}$ north-south by 45 
cm east-west and roughly 6-cm-thick. This pocket of ash was on the floor of the pithouse with no oxidation rim or other signs of in situ heating under the ash. Also on the floor and in N500 E497 was a fragment of a large metate (\#671-10), a cordmarked rim sherd from Vessel 5 (\#671-8), a couple of Alibates flakes, a complete bison metatarsal fleshing tool (\#671-11), charcoal chunks, at least 14 burned rocks, and 8 other rocks. The latter group of rocks included five pieces of calcium carbonate, two rounded quartzite pebbles, and one volcanic rock. Rodent burrows were noted throughout this unit.

A small sediment sample (\#672-4-2) was collected for possible flotation, but was curated without analysis. This ash concentration is interpreted as a dump area and not an in situ heating locality.

\subsubsection{Feature 28}

This feature was just inside the eastern edge of pithouse Feature 6, between 40 and $60 \mathrm{cmbs}$ on the western edge of N499 E498 (Figure 9-12). Feature 28 was first detected just to the side and near the base of the entryway. It was characterized by a piece of ground stone that rested on a roughly $20 \mathrm{~cm}$ diameter circular shaped, dark stain that contained chunks and flecks of charcoal and called cyst 2 on the level record. The fill from the upper two-thirds of the circular stain was removed and retained for flotation. Once the cultural items across the floor of the pithouse in the western half of the unit were exposed, two $25-\mathrm{cm}$ wide trenches were hand-excavated in a west-east direction into the eastern wall of the pithouse to explore the vertical nature of this edge of the pithouse and Feature 28. The apparent pit had relatively straight sides, with a slightly irregular base that just penetrated into the underlying Ogallala (Figure 9-58). The lower third yielded two medium sized caliche rocks, one of which was at the very base. The larger rock was about $12 \mathrm{~cm}$ in diameter, whereas the smaller rock at the bottom was about $6 \mathrm{~cm}$ in diameter. A slightly darker fill surrounded the burned rocks. However, review of the field profile drawing generally showed this apparent pit was mostly in the fill of the pithouse and therefore, not a true cultural feature that was functional during the operation of the pithouse.

Eleven liters of sediment (\#1236-004) from 38 to 50 cmbs was floated and the heavy and light fraction collected. The light fraction contains minimal carbonized materials and was not further analyzed. The heavy fraction yielded 11 tiny flakes $(0.1 \mathrm{~g})$, 20 tiny bone fragments $(0.3 \mathrm{~g})$, and 7 tiny pieces of daub/burned clay (<0.1 g).

Feature 28 had fill from the pithouse on the western and northern sides, but it was not clear if the fill on the southeastern side was from the entryway or not. This circular pit-like feature resembles a large post and its position next to the entryway may support that possibility. The function is unclear as it was above the pithouse floor, so whatever this represented was in the fill.

\subsubsection{Feature 29}

This feature was between 63 and 77 cmbs in N482 E499, part of a block of units that targeted Feature 18 (see Figure 9-46). Feature 29 was roughly $40 \mathrm{~cm}$ west of Feature 26, a small basin-shaped heating element. Feature 29 consisted of an organic-rich, light yellowish brown (10YR 6/4) sediment within a shallow pit/basin that contained flecks and chunks of charcoal (Figure 9-59). The ovate outline measured roughly 25 -by-30 $\mathrm{cm}$ in diameter, and the pit was 14-cm-deep. The pit exhibited relatively steep side walls with a somewhat pointed bottom and no discernable oxidation rim or charcoal lens was apparent at the bottom. No internal structure was observed in the pit fill. This pit was dug into the older Ogallala. A rodent run was detected near the bottom and disturbed those deposits. Tiny insect holes were observed along the pit edges, which blurred the margins. A plan map was drawn, the basin was cross-sectioned, a north-south profile drawn, and photographs taken. The entire organic-rich sediment from within the pit was collected.

The 21.5 liters of collected sediment (\#300-4) were floated. The heavy fraction (189.3 g) yielded 4 tiny mussel shell fragments $(<0.1), 25$ tiny pieces of lithic debitage ( $0.3 \mathrm{~g}), 4$ burned seeds, 2 ceramic fragments (8.1 g), 30+ tiny bone fragments (2.2 g), and 30+ tiny pieces of daub (2.9 g). The $17.6 \mathrm{~g}$ of light fraction (\#300-4b) was sent to Dering for macrobotanical analysis. Sparse wood charcoal was present in contrast to a large quantity of soot and flecks. Maize was evenly divided between cupules and kernels. A few juniper and oak fragments comprised the wood assemblage (Appendix C). 


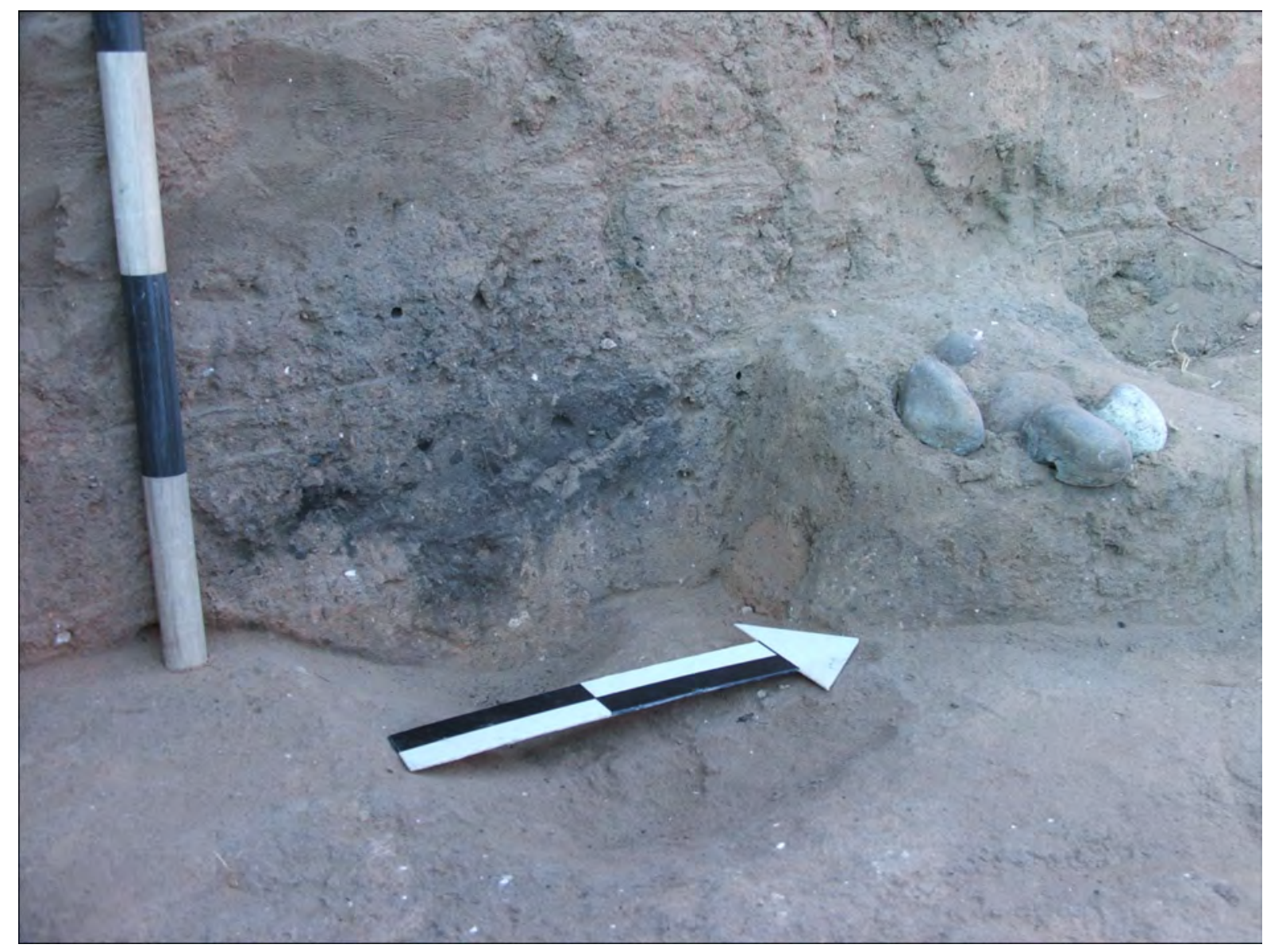

Figure 9-57. Profile photograph of charcoal ladened basin shaped heating element, Feature 26 with associated small quartzite boiling stones.

A charred maize kernel (\#300-7-1) from the feature fill was sent for radiocarbon dating. This maize yielded a $\delta^{13} \mathrm{C}(-9.9 \%)$ corrected AMS date of 570 \pm 20 B.P. (UGAMS-7824). A chunk of charcoal (\#297-7-2) from outside the feature fill was sent for identification. Dering identified the charcoal as rose family wood (Appendix C).

Unit N482 E499 yielded 1 small bone fragment, roughly 13 small burned rock fragments (163.9 g), 2 medium-size burned rocks (119.4 g), a couple chert flakes, 3 thick body sherds from Vessel 1 (\#297-8, $\# 300-8$, and \#301-8), 1 edge-modified flake (\#301$10)$, and 1 Fresno arrow point (\#301-11). One ceramic sherd was found on the southeastern edge of the Feature 29. Feature 29 is interpreted as an in situ heating element used for a short period.

\subsubsection{Feature 30}

This feature was recognized during the mechanical stripping that followed the hand-excavations. The stripping occurred at the very southern end of Component $\mathrm{C}$, just west of the hand-excavation area that targeted Feature 18. This location was projected to have been in N484 E498 and below the bladed fireguard. Feature 30 was a complete mano (\#35110) at $62 \mathrm{cmbs}$ (roughly $30 \mathrm{~cm}$ below the base of the fireguard) that rested in dark organic-rich sediment with light charcoal flecking and ashy soil. Once the mano was recognized, the stripping was stopped and hand-excavations were conducted in the immediate vicinity. The mano was mapped, a cross-section was cut, and the profile examined. No discernable pit was present, with the charcoal flecking only extended $2 \mathrm{~cm}$ below the mano. A thick cordmarked sherd 


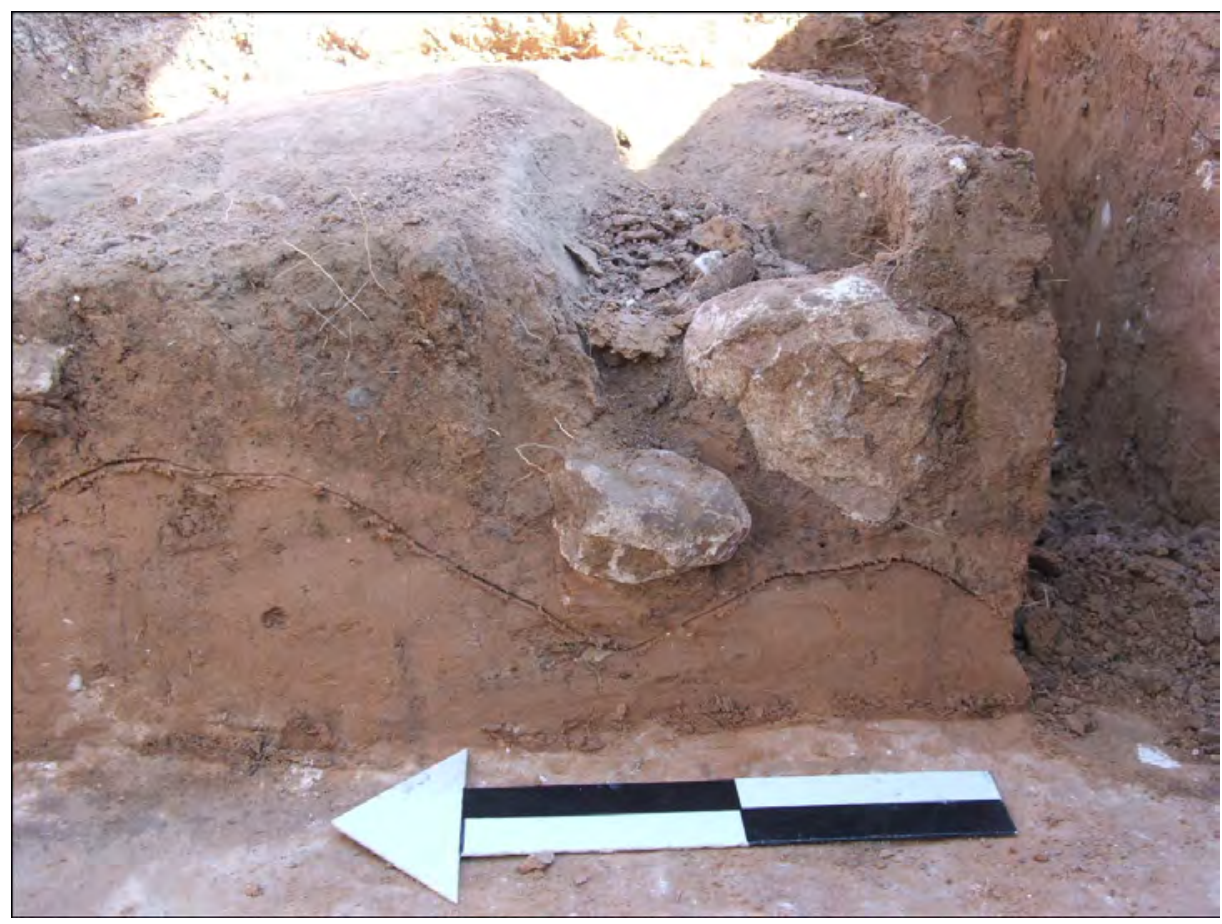

Figure 9-58. Profile photograph of Feature 28 at or next to the entryway.

(\#351-8) pertaining to Vessel 3 was in the immediate vicinity. The yellowish brown (10YR 5/4) fill (\#3514) from around the mano was collected and curated.

The one-handed mano (523.2 g) was sent to Dr. Perry for starch grain analysis. She discovered a single unknown starch grain (Appendix D).

Feature 30 is interpreted as an area of cultural refuse that included the mano, scattered bison bones, turtle shell, ceramic sherds (Vessel 3), and other cultural debris.

\subsubsection{Feature 31}

This feature was also discovered during mechanical stripping at the completion of the hand-excavations and across the southern end of Component C, roughly $6 \mathrm{~m}$ southeast of Feature 22, and beneath the fireguard (see Figure 9-3). This feature was projected to have been about $11 \mathrm{~m}$ north of Feature 30, primarily in N484 E496 and N484 E497. Feature 31 was a scatter of diverse cultural materials across the projected occupation zone that includes butchered, burned and unburned bison bones, turtle bones, scattered burned caliche rocks, a few chert flakes, two ceramic sherds (\#350-8), and dark organic-rich matrix. These cultural materials were not in any recognizable pattern and were scattered across an uneven surface (Figures 9-60 and 9-61). Most items were vertically distributed between 60 and $80 \mathrm{cmbs}$. These items were collected along with two samples of the brown (10YR 5/3) sandy loam sediments.

A single piece of wood charcoal (\#349-7) from 70 cmbs was sent for identification. Dering identified the charcoal as juniper (Appendix C). Two sherds (\#349-8-1c and \#350-8-1c) from Vessel 3 were sent for starch grain analysis. Specimen \#349-81c yielded three grains of maize with one damaged grain of maize (Appendix D). The second sherd yielded 20 lenticular grains of little barley (Appendix D). One 25 g chunk of bison bone (\#349-2-6) from $60 \mathrm{cmbs}$ was sent for stable carbon and nitrogen isotope analysis. The laboratory results yielded $\delta^{13} \mathrm{C}$ value of $-9.3 \%$ and a $\delta^{15} \mathrm{~N}$ value of 6.2\% (Appendix $\mathrm{P})$. The $\delta^{13} \mathrm{C}$ value indicates the bison represented by this bone consumed nearly 85 percent $\mathrm{C}_{4}$ grasses over the life of that individual. 


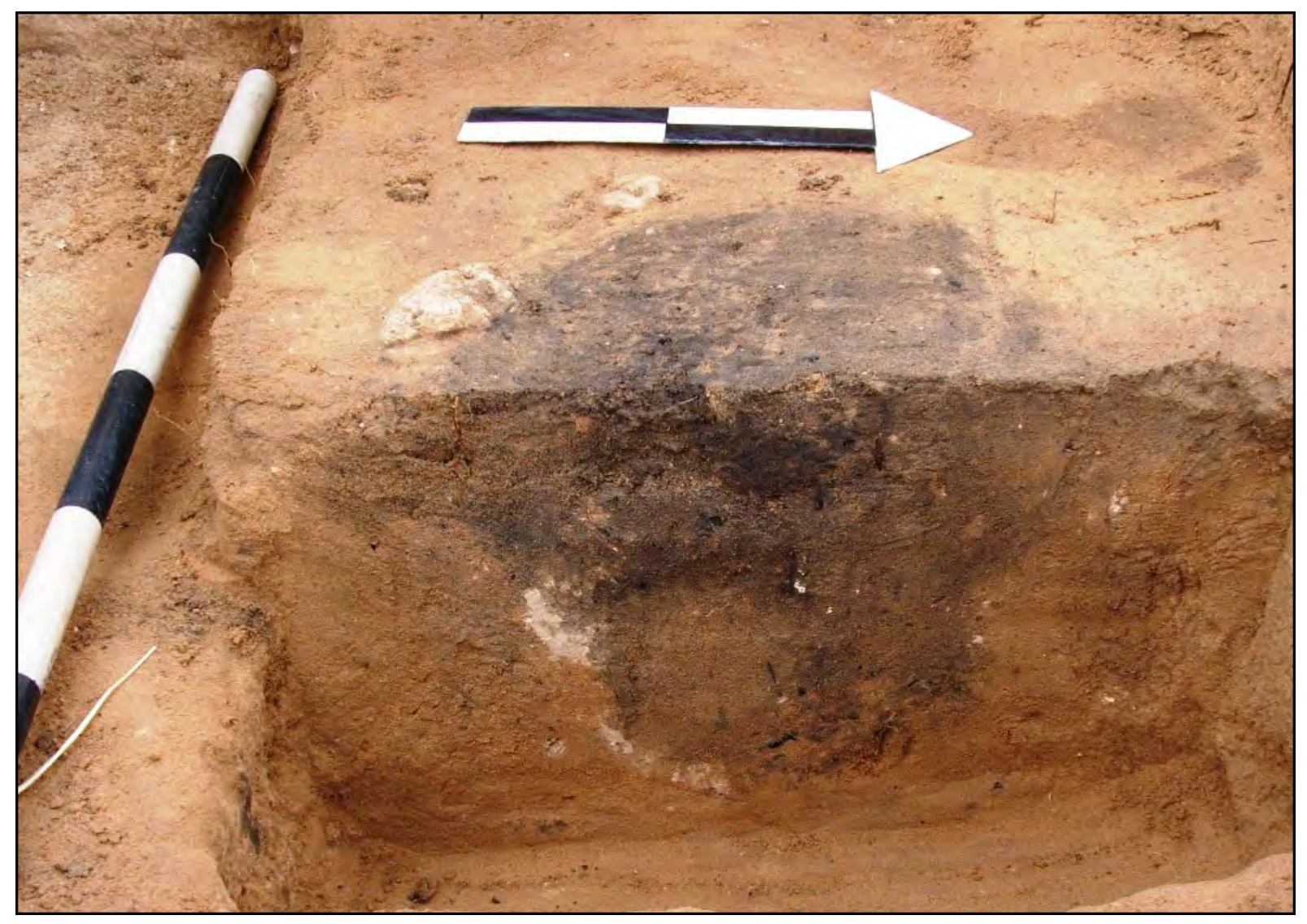

Figure 9-59. Profile of organic rich basin, heating element, Feature 29.

Two sediment samples (\#350-4 and \#1241-4) from the two adjacent units were floated. The 18 liters from 60 to $80 \mathrm{cmbs}$ in N484 E497 (\#350-4) yielded $302 \mathrm{~g}$ of heavy fraction that includes 23 tiny pieces of lithic debitage (18.4 g), 25+ tiny fragments of bone (19.3 g), and 4 tiny pieces of daub (0.3 g). The light fraction contains very limited quantities of charred materials and was curated. The 14 liters from N484 E495 yielded $469.3 \mathrm{~g}$ of heavy fraction (\#1241-4) materials that includes 32 tiny debitage ( $0.3 \mathrm{~g}), 31+$ tiny bone fragments $(17.7 \mathrm{~g})$, and 3 tiny daub pieces (0.4 g). Again, the light fraction contains minimal charred materials and was curated.

Feature 31 is viewed as general occupational refuse that pertained to the broader Plains Village occupation, and exhibited the same vertical dispersion of artifacts as observed in other parts of Component C.

\subsubsection{Rock/Stone Alignment}

During the initial site visit in February 2005, Mr. Quigg and Dr. Abbott inspected the area that extended $300 \mathrm{~m}$ south of Shovel Tests 1 and 2 (now at the northern end of Component A). An area around $280 \mathrm{~m}$ south of those shovel tests revealed a nearly straight north-south alignment of nearly totally buried rocks. This rock alignment was $6.5 \mathrm{~m}$ west of the old right-of-way fence and inside the proposed APE (Figure 9-62). At that time, this alignment was considered a possible prehistoric structure related to the cultural materials observed in the adjacent bladed fireguard.

The alignment generally consisted of a single row of roughly 65 caliche rocks that formed a ca. 10-m-long alignment that paralleled the new right-of-way fence $1.5 \mathrm{~m}$ to the west and was $4 \mathrm{~m}$ west of the northsouth fireguard (Figure 9-24). The rocks were buried 


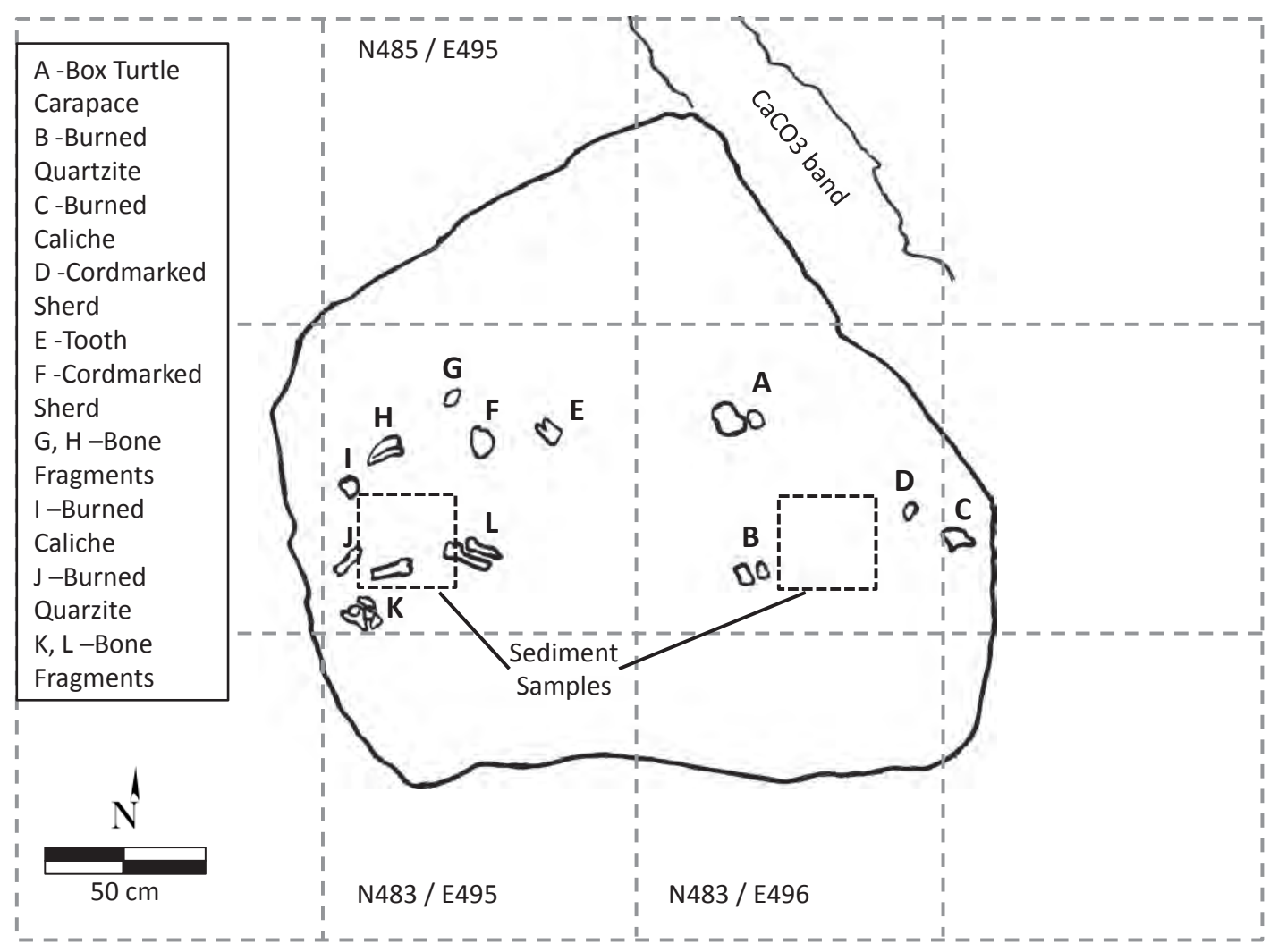

Figure 9-60. Plan view drawing of artifacts scattered across in Feature 31.

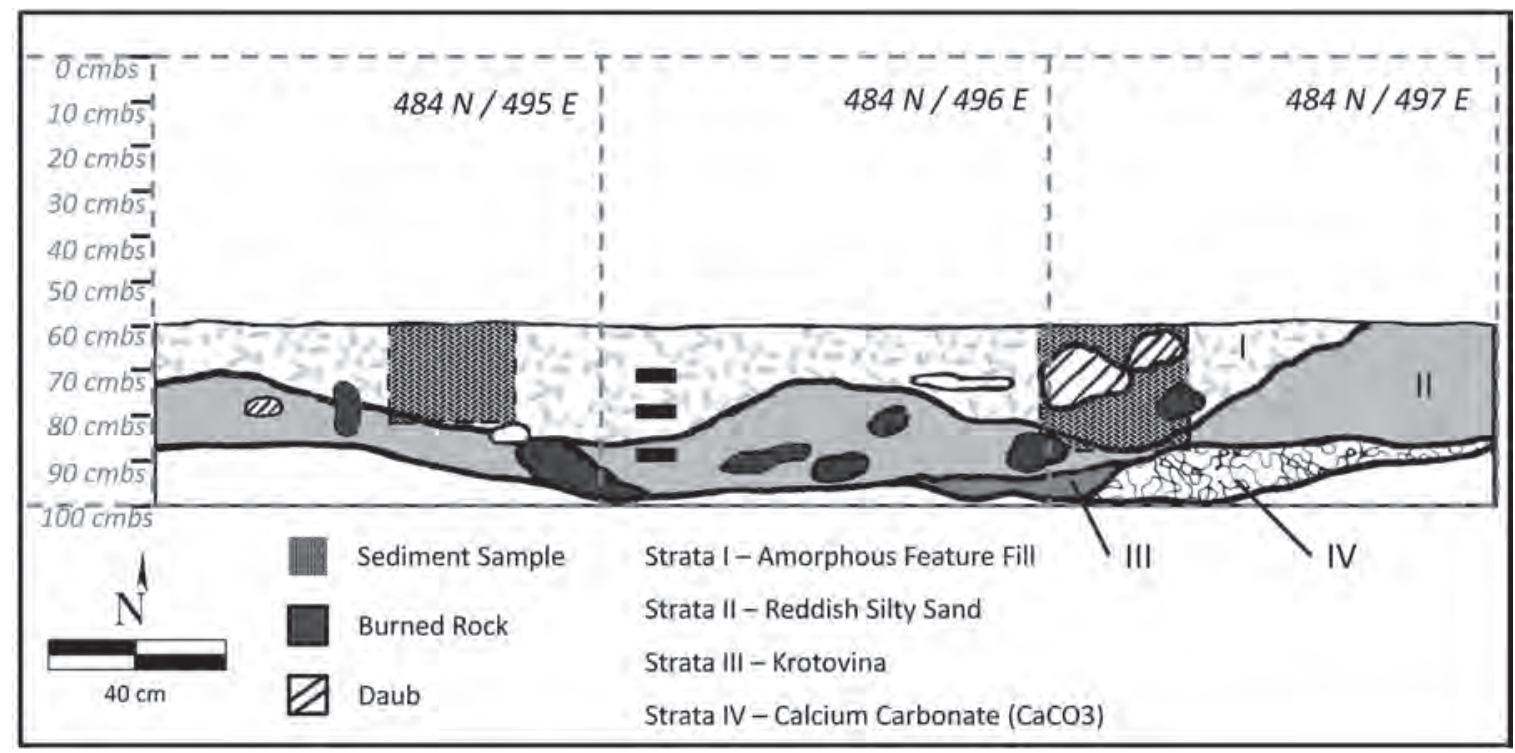

Figure 9-61. Profile drawing of deposits and artifacts scattered across Feature 31. 

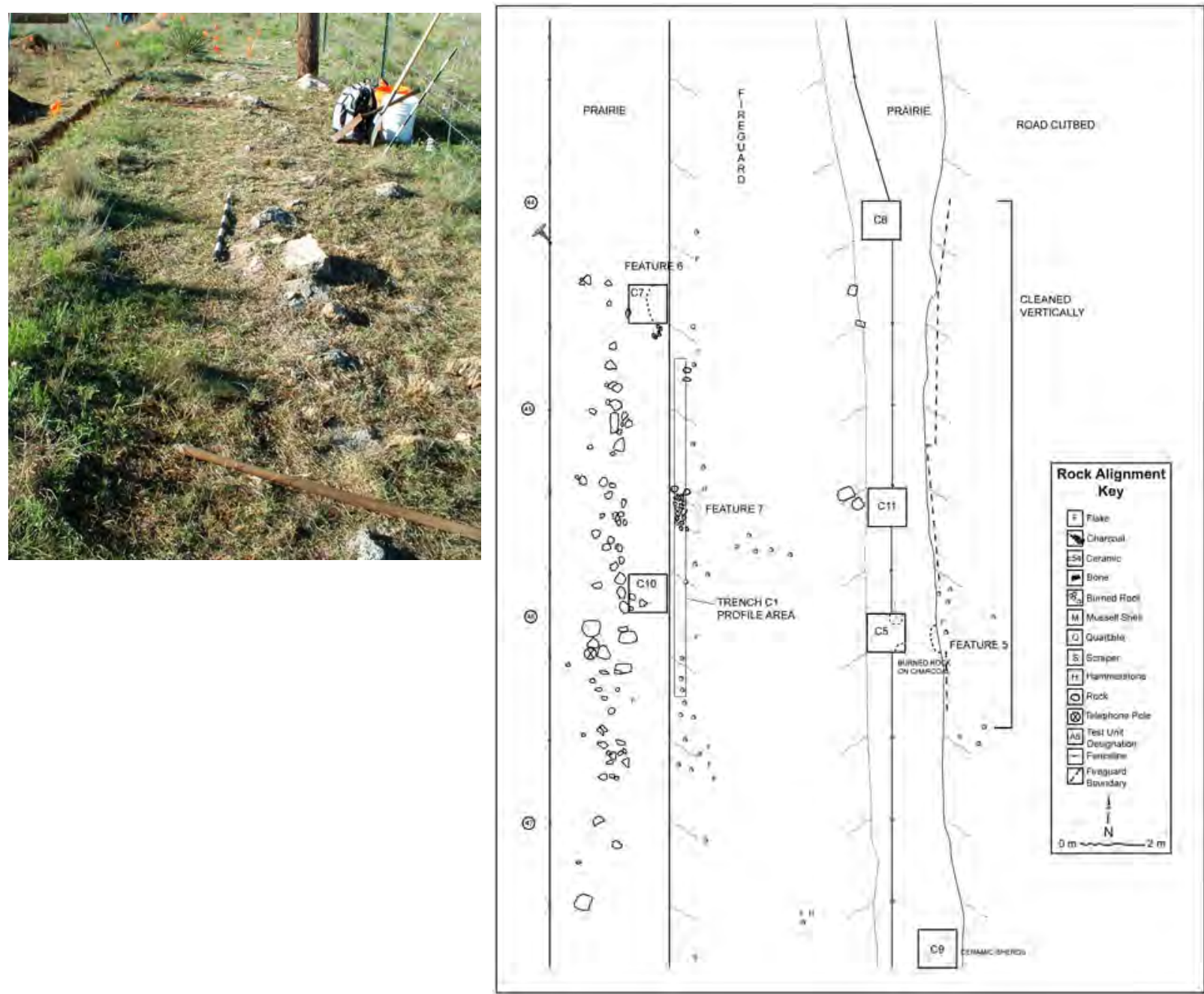

Figure 9-62. Surface and plan view drawing of rock alignment.

between 8 and $16 \mathrm{cmbs}$, with only the top one-third of the rock visible, and most were estimated to be roughly 20 to $30 \mathrm{~cm}$ in diameter. The alignment was not perfectly straight, as some of the rocks were slightly displaced to one side or the other. Other, smaller rocks were often to the east or the west of the larger rocks. Some scattered rocks were barely discernable further south of this alignment, which may have been a continuation of the more discernable and intact alignment. If these scattered rocks were once part of the more visible alignment, they would extend the line another 2 to $3 \mathrm{~m}$.

The rocks in the alignment were irregularly shaped pieces of caliche caprock with only one or two resting in a vertical orientation. Towards the southern end of the alignment, a wooden power pole was inserted about $25 \mathrm{~cm}$ west of the alignment with three larger rocks resting on the surface around the pole. These three rocks appeared to have been removed from the alignment, as a gap in the alignment was noted opposite the power pole.

This mostly buried rock alignment was originally postulated to represent the base of a wall pertaining to a possible prehistoric structure. Trench C-1 was handexcavated about 120 to $130 \mathrm{~cm}$ east of the exposed rocks along the very western edge of the fireguard (Figure 9-63). This trench was about 8-m-long and roughly 25-to-30-cm-wide, and paralleled the rock alignment. It was anticipated that this trench might expose or intersect some part of an east-west rock alignment and/or detect the occupation floor if the rock alignment was truly part of a structure. However, 


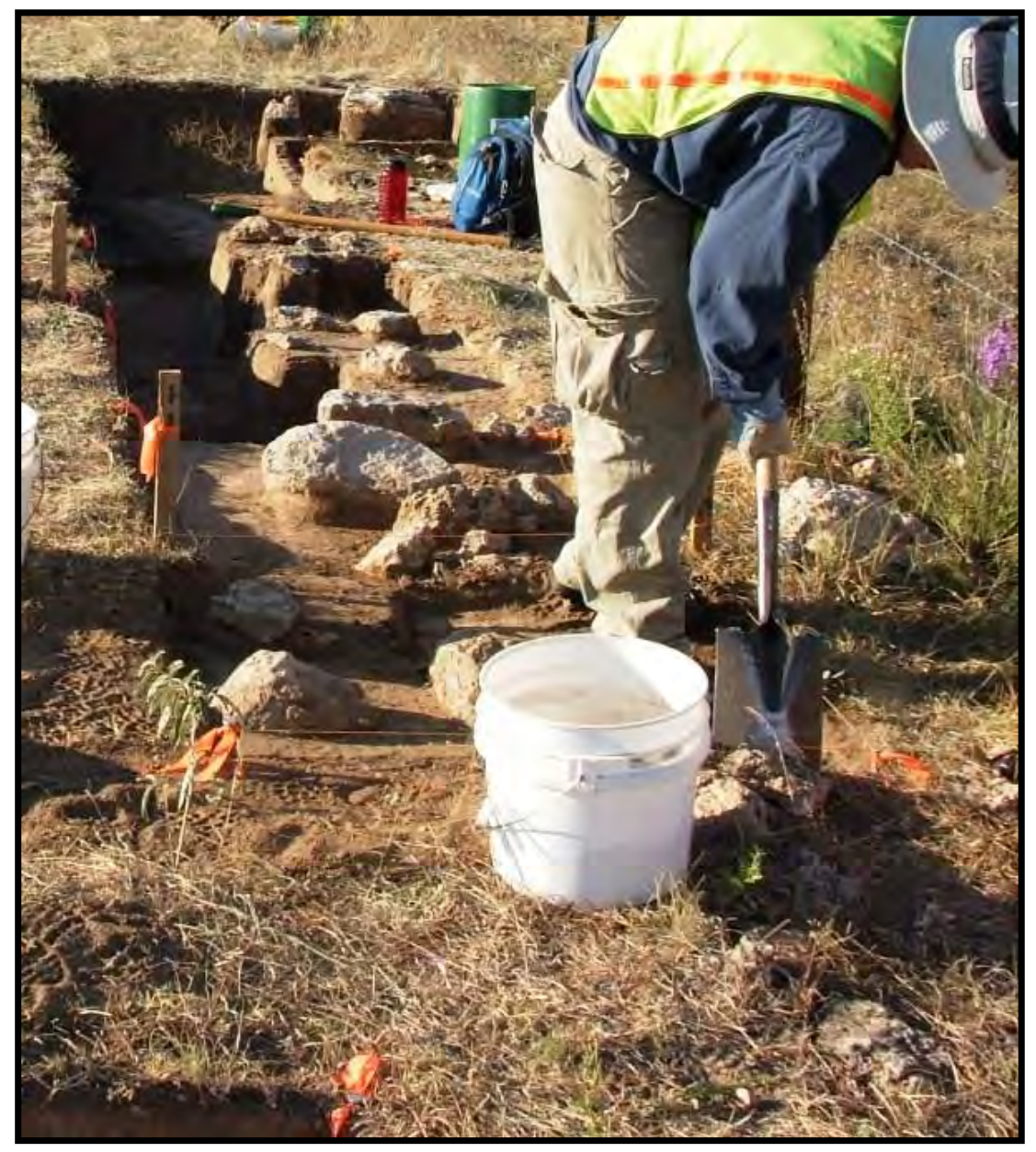

Figure 9-63. Hand-excavation exposed rocks along the alignment.

no east-west lines of rock were detected in Trench C-1, though a tight, 1-m-long cluster of smaller rocks, each about 10 to $15 \mathrm{~cm}$ in diameter, was encountered in Trench C-1. These were left in situ (see Feature 7 above). During site assessment, this linear feature was further documented and assessed by excavation of two 1-by-1 m test units (C-7 and C-10) next to the alignment.

The 4-m-wide fireguard that parallels the rock alignment and had been bladed to a depth of roughly 30 to 40 cmbs was less than $1 \mathrm{~m}$ west of the old rightof-way fence. Only four sizable caliche rocks were observed along the eastern margin of the fireguard. These had likely been displaced by blading of the fireguard. The absence of numerous large rocks that could represent other parts of a potential foundation of Structure 1 indicated the improbability that the rock alignment functioned as a possible foundation for a structure.

Trench C-2 was hand-excavated perpendicular to the fireguard and about $9 \mathrm{~m}$ north of the northern end of the stone alignment. In that location, the fireguard had been bladed to a depth of some $40 \mathrm{~cm}$, but this had not completely removed the lower part of the brown (10YR 4/3) sandy loam A horizon. The fireguard apparently had removed a zone of probable cultural materials that was roughly 4-m-wide by 30to 40 -cm-deep. If cultural features such as storage pits or postholes were associated with this rock alignment, many of those should have still been present beneath the base of the fireguard.

During the data recovery, some 22 1-by-1 m units were hand-excavated in a $16 \mathrm{~m}$ line along the rock 
alignment. Unit N499 E494 was the most northern unit, whereas N484 E494 was the southernmost unit in the alignment. The rock weights and depths were measured and recorded. In the final assessment, some 197 rocks were recorded as part of this alignment. One-hundred and thirty-eight of the rocks were weighed for a total of $282 \mathrm{~kg}$, for an average rock weight of $2.04 \mathrm{~kg}$.

Feature 22 was discovered in one unit towards the southern end of the alignment, but it was some 40+ $\mathrm{cm}$ below the lowest rock and thus was not associated. Feature 6, the pithouse, was also discovered below the rocks at the northern end of this alignment. At about 20 to $30 \mathrm{cmbs}$, the pithouse (Feature 6) was detected at a distinctly lower elevation than the rock alignment.

Although diverse prehistoric cultural materials were encountered near the base of the rocks during the hand-excavations as well as on the surface of the adjacent fireguard, it was ultimately concluded that the rock alignment is a feature of relatively recent historic age. Unit C-10, excavated at the eastern edge of the alignment during the testing investigations, yielded additional buried caliche rocks and other cultural materials in the top $20 \mathrm{~cm}$. These include small bone fragments, a few charcoal chunks, small caliche rocks, and a few Alibates flakes from the top $20 \mathrm{~cm}$, mostly from between 8 and $18 \mathrm{cmbs}$. A few scattered pieces were found at depths of up to 39 cmbs, probably the result of vertical translocation by rodent activity.

The 1- to 2-cm-thick alternating sand lenses near the base of the rocks are interpreted to represent episodes of eolian deposition of sand that originated from the ground disturbance in the adjacent fireguard (Figure
9-64). Assuming this to be the case, the fact that the bases of most rocks in the alignment rested either within or above the windblown sand lenses serves to confirm the historic age of this rock alignment. The windblown sand would also explain the deeply buried nature of the rocks in this alignment.

A chunk of unidentifiable wood charcoal, piece plotted at $19 \mathrm{cmbs}$ in the northeastern quadrant in $\mathrm{C}-10$, yielded a $\delta^{13} \mathrm{C}(-23.6 \%)$ corrected AMS date of $650 \pm 40$ B.P. (Beta-206563). A second chunk of charcoal, identified as juniper, from $34 \mathrm{cmbs}$ of this same unit yielded a $\delta^{13} \mathrm{C}(-23.0 \%)$ corrected AMS date of $1290 \pm 40$ B.P. (Beta-206564). The age difference of 640 radiocarbon years is considerable. The 1290 B.P. date is too old for the well-defined Plains Village occupation of the site, and may represent a piece of older wood used at a much later time or, perhaps, a natural fire. No cultural materials were recovered that might represent the earlier date. However, neither date appears to apply to the rock alignment based on the stratigraphic position of the rocks in the alignment combined with the recognized thin lenses of alternating eolian sands at and just below the base of the rocks.

This rock alignment is interpreted to be of historic age and not associated with the Plains Village occupation that is generally below this feature. The function of this alignment is unknown.

\subsubsection{Summary of Component C Features}

Twenty-one cultural features were identified in Component $\mathrm{C}$ at the southern end of the Long View

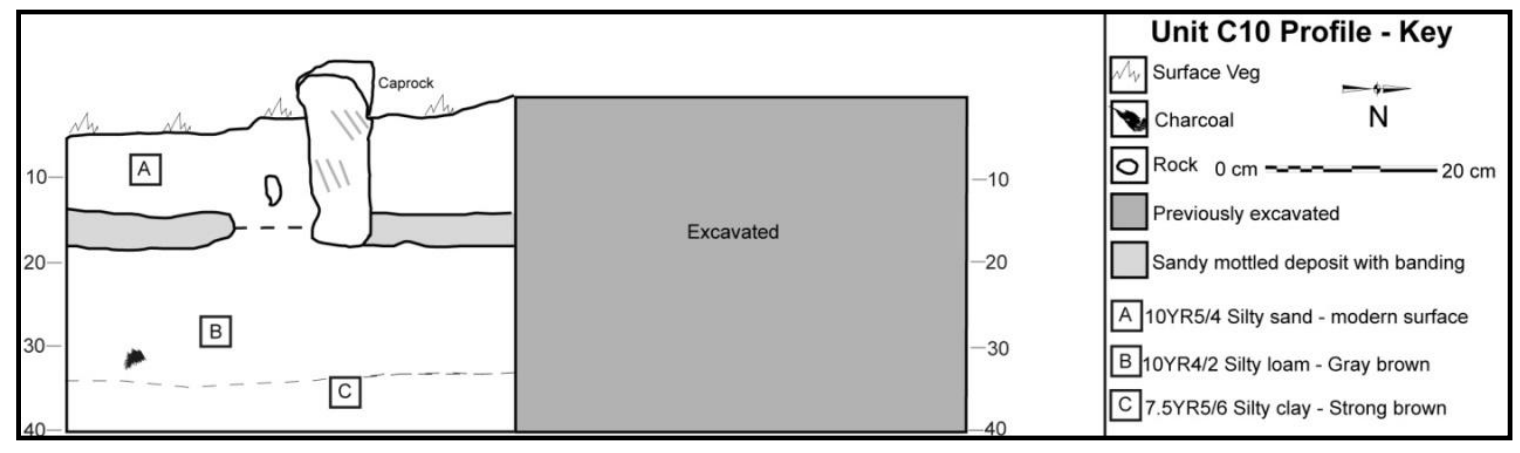

Figure 9-64. Profile drawing of deposits at the rock alignment in Unit C-10. 
Table 9-8. Summary of Component C Features and Feature Data.

\begin{tabular}{|c|c|c|c|c|c|c|c|c|c|c|c|c|c|c|c|c|}
\hline $\begin{array}{c}\text { Feature } \\
\text { No. }\end{array}$ & $\begin{array}{c}\text { Feature } \\
\text { Type }\end{array}$ & $\begin{array}{c}\text { Feature } \\
\text { Size }(\mathrm{cm})\end{array}$ & $\begin{array}{l}\text { Depth } \\
\text { (cmbs) }\end{array}$ & $\begin{array}{c}\text { Conventional } \\
\text { Age B.P. }\end{array}$ & $\begin{array}{c}\text { Charcoal } \\
\text { Present }\end{array}$ & $\begin{array}{c}\text { Lithic } \\
\text { Debitage }\end{array}$ & Bones & Pottery & \begin{tabular}{|l} 
Post \\
Holes
\end{tabular} & $\begin{array}{c}\text { Burned } \\
\text { Rocks }\end{array}$ & $\begin{array}{c}\text { Tools } \\
\text { Present }\end{array}$ & $\begin{array}{l}\text { Matrix } \\
\text { Floated }\end{array}$ & $\begin{array}{c}\text { Light } \\
\text { Fraction } \\
\text { Analyzed }\end{array}$ & $\begin{array}{c}\text { Native } \\
\text { Plants } \\
\text { Present }\end{array}$ & \begin{tabular}{|c|} 
Cultivated \\
Plants \\
Present
\end{tabular} & Other \\
\hline 2 & dump & $20 \times 20$ & $22-30$ & & chunks & no & no & no & no & 1 & no & $1=6$ liters & no & & & \\
\hline 5 & $\begin{array}{c}\text { basin } \\
\text { heating } \\
\text { element }\end{array}$ & $\begin{array}{l}75 \text { wide, } \\
20 \text { deep }\end{array}$ & $22-42$ & $630 \pm 40$ & chunks & yes & yes & no & no & 3 & Fresno & $\begin{array}{c}8=44.45 \\
\text { liters }\end{array}$ & yes & & maize & $\begin{array}{c}\text { fish } \\
\text { bones }\end{array}$ \\
\hline 6 & pithouse & $380 \times 280$ & $30-85$ & $\begin{array}{c}700 \pm 40,580 \\
\pm 20,700 \pm 40 \\
580 \pm 20,630 \\
\pm 25,590 \pm 25\end{array}$ & chunks & yes & lots & yes & 7 & yes & lots & $\begin{array}{c}27=3440.5 \\
\text { liters }\end{array}$ & yes & mesquite & maize & 1 bead \\
\hline 7 & $\begin{array}{c}\text { cairn } \\
\text { burial }\end{array}$ & $100 \times 80$ & $22-25$ & & yes & no & yes & no & no & no & no & none & no & & & \\
\hline 16 & $\begin{array}{c}\text { basin } \\
\text { heating } \\
\text { element }\end{array}$ & $\begin{array}{l}130 \text { wide } \\
30 \text { deep }\end{array}$ & $35-62$ & $610 \pm 20$ & yes & yes & yes & yes & no & yes & $\begin{array}{c}1 \text { scraper, } \\
3 \text { Fresno, } \\
\text { I Harrell } \\
\text { point }\end{array}$ & $\begin{array}{c}9=174.5 \\
\text { liters }\end{array}$ & yes & & maize & \\
\hline 17 & post hole & $\begin{array}{l}23 \text { wide } \\
34 \text { deep }\end{array}$ & 38-72 & & yes & no & yes & no & no & yes & no & $2=6.5$ liters & & & & \\
\hline 18 & pithouse? & unclear & unclear & $590 \pm 20$ & yes & yes & yes & lots & 10 & yes & $\begin{array}{c}8 \text { Fresno, } \\
4 \text { Washita, } \\
4 \text { point } \\
\text { frags, } 2 \\
\text { bifaces }\end{array}$ & no & & & & \\
\hline 19 & dump & $\begin{array}{l}45 \text { wide } \\
16 \text { deep }\end{array}$ & 48-64 & & yes & no & no & no & no & no & no & $2=2$ liters & & & & \\
\hline 20 & dump & $\begin{array}{l}75 \text { wide } \\
17 \text { deep }\end{array}$ & 46-63 & & few & 3 & yes & no & no & yes & no & $1=1.5$ liters & & & & \\
\hline 21 & $\begin{array}{c}\text { basin } \\
\text { heating } \\
\text { element }\end{array}$ & $\begin{array}{c}65 \text { wide } \\
5 \text { deep }\end{array}$ & $70-75$ & $530 \pm 25$ & yes & 8 & yes & no & no & no & no & $3=27$ liters & yes & & maize & \\
\hline 22 & $\begin{array}{c}\text { human } \\
\text { cremation }\end{array}$ & $\begin{array}{l}50 \text { wide } \\
12 \text { deep }\end{array}$ & $60-72$ & & few & $?$ & yes & no & no & no & $\begin{array}{c}1 \text { worked } \\
\text { shell }\end{array}$ & no & & & & \\
\hline 23 & storage pit & & & $570 \pm 20$ & & & & yes & & & & $2=7$ liters & yes & & & \\
\hline
\end{tabular}


Table 9-8. Summary of Component C Features and Feature Data (cont.).

\begin{tabular}{|c|c|c|c|c|c|c|c|c|c|c|c|c|c|c|c|c|}
\hline $\begin{array}{c}\text { Feature } \\
\text { No. }\end{array}$ & $\begin{array}{c}\text { Feature } \\
\text { Type }\end{array}$ & $\begin{array}{c}\text { Feature } \\
\text { Size }(\mathrm{cm})\end{array}$ & $\begin{array}{l}\text { Depth } \\
\text { (cmbs) }\end{array}$ & $\begin{array}{c}\text { Conventional } \\
\text { Age B.P. }\end{array}$ & $\begin{array}{c}\text { Charcoal } \\
\text { Present }\end{array}$ & $\begin{array}{c}\text { Lithic } \\
\text { Debitage }\end{array}$ & Bones & Pottery & $\begin{array}{l}\text { Post } \\
\text { Holes }\end{array}$ & $\begin{array}{c}\text { Burned } \\
\text { Rocks }\end{array}$ & $\begin{array}{c}\text { Tools } \\
\text { Present }\end{array}$ & $\begin{array}{l}\text { Matrix } \\
\text { Floated }\end{array}$ & $\begin{array}{c}\text { Light } \\
\text { Fraction } \\
\text { Analyzed }\end{array}$ & $\begin{array}{c}\text { Native } \\
\text { Plants } \\
\text { Present }\end{array}$ & \begin{tabular}{|c|} 
Cultivated \\
Plants \\
Present
\end{tabular} & Other \\
\hline 24 & ash pocket & $\begin{array}{l}15 \text { wide } \\
8 \text { deep }\end{array}$ & $40-48$ & & no & no & no & & no & no & no & yes & & & & \\
\hline 25 & ash & & & & & & & & & & & & & & & \\
\hline 26 & $\begin{array}{c}\text { basin } \\
\text { heating } \\
\text { element }\end{array}$ & $\begin{array}{l}20 \text { wide } \\
10 \text { deep }\end{array}$ & $70-80$ & & yes & no & no & & no & no & no & $1=9$ liters & yes & & & \\
\hline 27 & ash dump & $\begin{array}{l}40 \text { wide } \\
6 \text { deep }\end{array}$ & $65-71$ & & yes & yes & yes & & no & yes & bone tool & yes & & & & \\
\hline 28 & $\begin{array}{c}\text { Post hole } \\
\text { with BR }\end{array}$ & $\begin{array}{l}20 \text { wide } \\
18 \text { deep }\end{array}$ & $35-53$ & & yes & no & no & & yes & yes & $\begin{array}{c}\text { ground } \\
\text { stone }\end{array}$ & yes & & & & \\
\hline 29 & $\begin{array}{c}\text { basin } \\
\text { heating } \\
\text { element }\end{array}$ & $\begin{array}{l}30 \text { wide } \\
14 \text { deep }\end{array}$ & $63-77$ & $570 \pm 20$ & yes & yes & yes & yes & no & yes & yes & yes & yes & & & \\
\hline 30 & dump & $\begin{array}{l}45 \text { wide } \\
2 \text { deep }\end{array}$ & $60-62$ & & yes & yes & yes & & no & yes & mano & no & & & & \\
\hline 31 & dump & $\begin{array}{l}200 \text { wide } \\
20 \text { deep }\end{array}$ & $60-80$ & & yes & yes & yes & & no & yes & no & $1=18$ liters & & & & \\
\hline \begin{tabular}{|c|} 
Structure \\
1
\end{tabular} & $\begin{array}{c}\text { rock } \\
\text { alignment }\end{array}$ & 1200 long & ?8-16 & $650 \pm 40$ & Chunks & yes & yes & & no & yes & $\begin{array}{l}\text { biface, } \\
\text { scraper }\end{array}$ & No & & & & \\
\hline
\end{tabular}


site (see Figure 9-3; Table 9-8). Component $\mathrm{C}$ is spatially separated from Component A by nearly $120 \mathrm{~m}$ (Area B), which was nearly void of cultural materials and no cultural features were detected. Therefore, Component $\mathrm{C}$ is viewed as distinct and separate from Component A.

These features included one complete pithouse (Feature 6), a possible "ghost" pithouse (Feature 18), one cairn burial (Feature 7), one human cremation (Feature 22), at least four basin-shaped heating elements (Features 5, 16/21, 26, and 29), a small cylindrical storage pit (Feature 23), at least eight discard/dump areas (Features 2, 19, 20, 24, 25, 27, 30, and 31), one large posthole (Feature 17), one historic rock alignment, and a number of small post holes in the vicinity of the pithouses (Features 6 and 18).

It is unclear if the cairn burial and human cremation represent the same occupation as the rest of the prehistoric materials as these two features were not directly radiocarbon dated (as pre Native American stipulations). The depths of these two burial features, Feature 7 at roughly $20 \mathrm{~cm}$ below the current surface, whereas Feature 22 was roughly $65 \mathrm{cmbs}$ in a much thicker sandy deposit, are not in vertical accordance with the principal zone ( 25 to $35 \mathrm{cmbs}$ ) that yielded the majority of the Plains Village materials. Therefore, without the aid of radiocarbon dates on the human bones or associated materials, combined with the lack of diagnostic artifacts in these two features, it is not clear if they were deposited at the same time as the rest of the occupational materials. Currently, from the limited data available it is assumed these human remains were interred following the primary function of Component $\mathrm{C}$ as an occupation locality. The scattered and broken teeth of a 2 to 5 year old child were generally associated with "ghost" pithouse Feature 18 indicate at least one individual was directly associated with this component.

The rock alignment barely exposed on the surface was definitely higher in the profile than the majority of the prehistoric cultural debris recovered. It appeared the sediments exposed following the modern mechanical grading of the fireguard were blown from the fireguard, a meter or two to west and accumulated around the rocks and partially buried them. Therefore, this rock alignment is thought to represent a historic feature of unknown function much latter than the prehistoric occupation. Extensive rodent activity throughout these sandy deposits could explain the prehistoric artifacts near the base of the rocks in the alignment.

Consequently, 19 features, minus the historic rock alignment, the undated human cremation, and the undated cairn burial, are interpreted to be directly associated with the prehistoric cultural materials recovered, which pertain to the Plains Village period. The features reflect at least food storage, cooking, cleaning and discard of habitation debris, and likely other related habitation activities. The pithouse, Feature 6 and likely Feature 18 are interpreted to have functioned as small habitation structures with diverse contemporaneous activities conducted in their immediate area.

Following pithouse Feature 6 use for habitation, the abandoned, still erect pithouse served as a disposal area for various types of unwanted cultural debris until the earthen cover fell and sealed the cultural materials on the floor. The wooden framework remained following the collapse of the earthen cover, but apparently burned at a later date. The earthen cover was a mixture of sand and mud derived from one of the local streams and definitely not from the Ogallala sediments excavated from the pit.

The presence of at least one pithouse, and possibly a second poorly preserved one (Feature 18), indicates one or two family units probably account for the limited occupational debris and cultural features identified. The presence of a pithouse(s) is unusual for the Texas panhandle and definitely not part of the standard or known habitation structures for the Antelope Creek phase (Lintz 1986; Brooks 1989, 2004).

The horizontal distribution of 19 associated features is somewhat skewed and/or misleading by the presence of the modern bladed fireguard down the middle of the investigated APE combined with the limited and long, narrow excavation zone. The area investigated south of the pithouse appears to have functioned primarily as a cooking and working area with no obvious overlap in features to indicate multiple occupations. The exception being the probably reuse of this location to inter two human 
burials followed by the construction of the rock alignment at undocumented times following the one principal Plains Village occupation.

Nearly 380 liters of sediment from seven cultural features (Features 5, 6, 16, 21, 23, 26, and 29) were floated and yielded diverse classes of tiny carbonized remains from 1,544.3 $\mathrm{g}$ of light fraction material. The classes recovered include primarily maize $(N$ $=320$ pieces) and wood charcoal (24.9 g), plus 12 other limited plant remains that include 4 mesquite seeds, 3 prickly pear cactus seeds, 1 mesquite thorn, 1 cheno-am seed, 1 bean, 1 squash rind, and 1 juniper seed. These plants represent diverse resources, both cultivated and gathered, that were likely processed and cooked. The carbonized maize pieces are the most frequent and consistent plant, which may indicate it, was a primary part of the subsistence.

Starch grain analysis was conducted on four diverse materials (sherds, ground stone, burned rocks, and sediment) from Features 6, 18, 20, 23, and 30 and yielded a total of at least 81 grains. Lenticular little barley grains dominated $(N=46)$, followed by maize $(N=15)$, and unknowns $(N=15)$ with at least 2 cheno-am grains with both little barley and maize grains parched and gelatinized. The 7 burned rocks analyzed from Features 6 and 20 yielded 12 maize grains, 22 lenticular little barley grains, 10 unidentified grains with likely some mesquite, lily bulb grains with at least 1 parched little barley grain. The 7 ground stone items from Features 6 and 30 yielded no maize starch grains, only 2 lenticular little barley grains, 2 cheno-am grains, and 5 unknown grains. The five sherds from Features 6, 18, and 31 yielded 3 maize grains, 1 possible maize grain, 22 lenticular little barley grains, 1 gelatinized lenticular little barley grain, and 1 unknown damaged grain.

Use-wear and residue identification was conducted on 11 stone tools from two features, 8 from pithouse Feature 6 and 3 from "ghost" pithouse Feature 18. These 11 tools revealed a diverse range of tasks that included minimally hide scraping $(N=2)$, wood working $(N=4)$, cutting starchy plants $(N=1)$, slicing meat $(N=1)$, and at least one tool was hafted.

Sixteen phytoliths samples were analyzed with 15 from 6 features $(5,6,16,20,23$, and 24) with 10 from pithouse Feature 6, plus one off-site control sample. All 16 samples yielded phytoliths with the 6 features yielding 2,649.5 short cell phytoliths that ranged from 17 to 354.5 per sample. Pithouse Feature 6 floor yielded the fewest short cells per sample, whereas the construction fill yielded a much higher average of short cells. Four pithouse samples yielded Pinaceae tracheid phytoliths that reflect pine wood, both on the floor and in the construction fill, which was one species used in the construction of the pithouse. No tracheid phytoliths were identified in any of the other features. Overall, 11 samples yielded large cross shaped phytoliths that represent maize leaves with no maize rondel shaped phytoliths that represent cobs. No beans or squash phytoliths were positively identified. The off-site control sample did not yield any phytoliths from cultigens.

Diatom analysis was conducted on four burned rocks and three daub pieces from two features. This included two burned rocks from Feature 20, two burned rocks from pithouse Feature 6, along with three daub samples from the pithouse. The 2 scattered discarded burned rocks from a likely boiling/cooking task of Feature 20 yielded only 3 and 14 diatoms each. The rock with the fewest diatoms reflected mostly aerial species, whereas the rock with the most diatoms yielded aquatic species. The latter rock documents the use in water, likely in a boiling technique. The two rocks from Feature 6 failed to yield diatoms, which may reflect their use as something besides cooking rocks. The 3 pieces of daub yield very few diatoms, 6 and 7 a peace with a mixture of 2 assemblages.

The tiny marine shell bead from the pithouse Feature 6 reflects long distance trading from some unknown coast. A few pieces of Niobrara jasper form Kansas also indicate interactions with groups to the north.

\subsection{Chipped Stone Tools}

Paul M. Matchen

The Component $\mathrm{C}$ lithic artifacts sample consists of materials recovered from the southernmost portion of the site, between N473 through N501 and E493 through E501. Table 9-9 provides the breakdown of tool classes. Radiocarbon dates for this component range from 510 to 480 B.P. (conventional age) 
Table 9-9. Artifact Class Frequency for Component C.

\begin{tabular}{|c|c|c|}
\hline Component & $\begin{array}{c}\text { Artifact } \\
\text { Classes }\end{array}$ & Frequency $(\boldsymbol{N})$ \\
\hline C & $\begin{array}{c}\text { Projectile } \\
\text { Points }\end{array}$ & 34 \\
\hline C & Bifaces & 8 \\
\hline C & Drills & 5 \\
\hline C & Scrapers & 5 \\
\hline C & $\begin{array}{c}\text { Edge- } \\
\text { Modified } \\
\text { Flakes }\end{array}$ & 90 \\
\hline C & $\begin{array}{c}\text { Spokeshaves } \\
\text { C }\end{array}$ Gravers & 1 \\
\hline C & $\begin{array}{c}\text { Non-descript } \\
\text { Unifacial } \\
\text { Tools }\end{array}$ & 2 \\
\hline \multicolumn{2}{|c|}{ Total } \\
\hline
\end{tabular}

based on nine acceptable dates on carbonized maize derived from various features (see Chapter 7.0 for discussion of cultural stratigraphy). The following presentation discusses tool data stemming from analysis that provides a characterization of the assemblage and contributes information with which to address research questions as presented in the research design (see Chapter 4.0).

The hand-excavations in this area (the entirety of the Component $\mathrm{C}$ block plus Test Units C-4, C-5, C-6, C-7, C-9, C-10, and C-11) yielded a sample of 146 chipped stone tools. This group represents six percent of the overall chipped stone lithic assemblage, the remainder being comprised mostly of debitage. Chipped-stone tool descriptions are presented below by tool class. Specific tools in each class were also selected for detailed description as representative examples of that class. Details of the quantitative and qualitative aspects of the chipped stone tool assemblage can be found in Appendix O.

Several tools were selected for high-powered microscopic use-wear ( $N=23$ or 16 percent of total) and starch-grain analyses $(N=28$ or 19 percent of total). This use-wear analysis focused on identifying specific tool uses through detection of microwear left on tool surfaces, as well as identifying the organic materials left on the tool, presumably the result of contact with those materials. A summary of the use-wear results for each specimen is included in the individual tool descriptions below, where applicable.

\subsubsection{Projectile Points}

Projectile points comprised 24 percent $(N=34)$ of the chipped-stone tool assemblage in Component C. This group includes 7 complete specimens, 9 almost complete specimens, 11 proximal fragments, 2 medial fragments, and 5 distal fragments.

These items are classified as triangular arrow points, based on their metric and morphological characteristics, and their similarity to chipped-stone bifaces generally assumed to be arrow points (e.g., Suhm and Jelks 1962; Turner and Hester 1999). Nonetheless, we recognize that these specimens, as well as many other artifacts commonly identified as arrow points, could have had multiple uses (e.g., as both arrow points and knives).

There is a basic dichotomy of morphological styles present within this tool class: mainly, those bifacial tools resembling the Fresno form and those that resemble the Washita form (Figure 9-65). Fresno forms $(N=12)$ are described as small, triangular tools with straight to slightly convex lateral edges (Bell 1960:44; Suhm and Krieger 1954). The proximal 


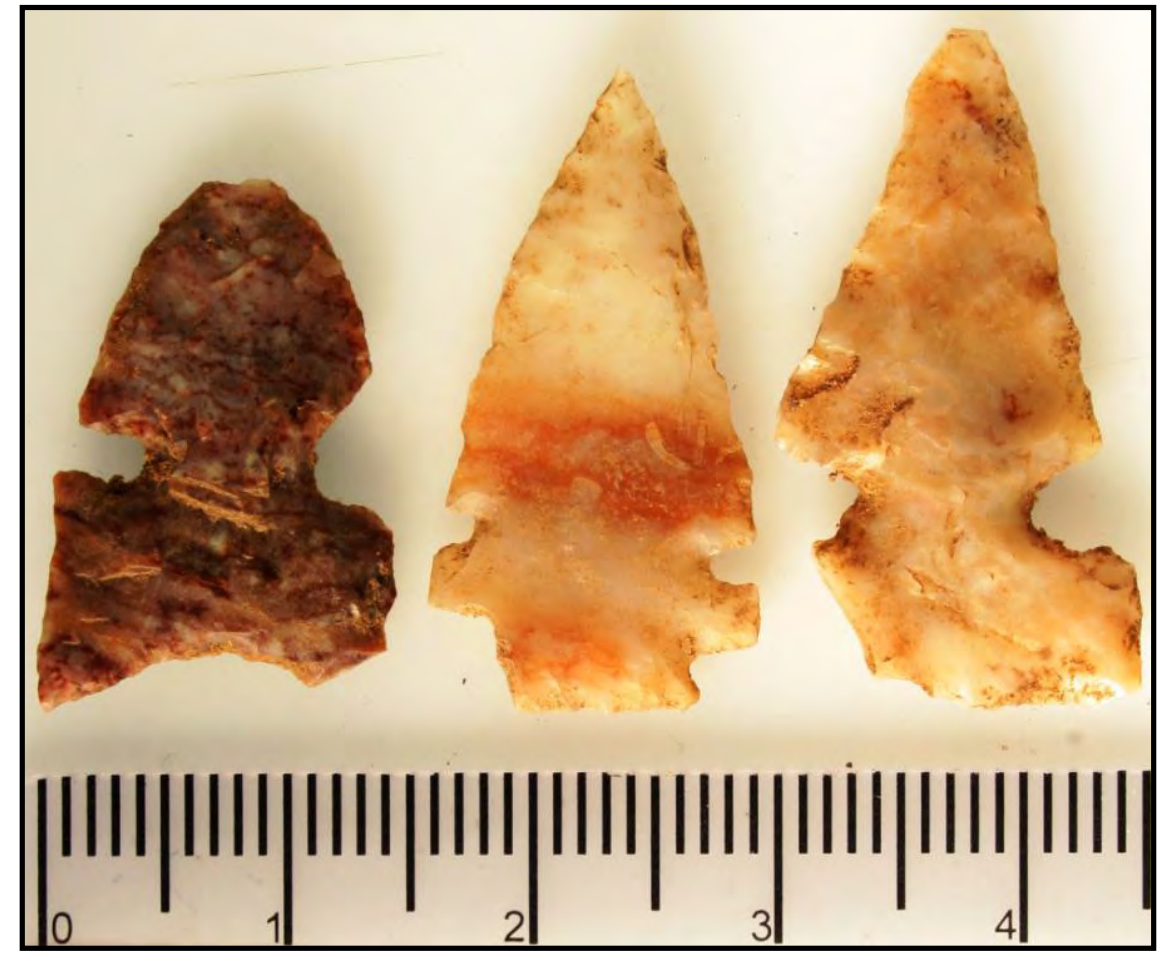

Figure 9-65. Washita (\#368-10), Huffaker (\#510-10), and Washita points (\#510-12). Scale in $\mathrm{cm}$.

end (i.e., base or wider end) is usually straight but can be slightly convex or concave. Tool faces are typically finely flaked, though many specimens have been recovered at various archeological sites having relatively large remnant flake scars on one face (Suhm and Krieger 1954; Bell 1960:44). These remnant scar areas denote attributes of the parent flake from which the point was fashioned.

Washita forms $(N=8)$ are described as small sidenotched triangular points whose sides are typically straight or slightly convex (Bell 1958; Cambron and Hulse 1964). In fact, they are very similar in form to the Fresno style.

Another triangular form present in this assemblage is the Harrell style $(N=4)$. This form is practically identical to the Washita with the exception of the presence of a basal notch (Suhm and Krieger 1954:500; Bell 1958:30). Suhm and Krieger lumped the two styles together under the Harrell type, while Bell splits them, as we do in this report. As with the former style, the Harrell form is classified as a triangular point with nearly straight sides and a basal shape that ranges between straight and slightly concave (Bell 1958).

A fourth variant of the triangular form present in Component $\mathrm{C}$ is the Huffaker Style ( $N=7$; Baerreis 1954:4 Bell 1958). This form has multiple side notches on the basal portion of each lateral edge. These points may have a straight or slightly concave base, but may instead have a basal notch.

\subsubsection{Discussion of Complete Projectile Points}

Specimen \#145-10 is a small triangular point which is stylistically similar to a Fresno form (Bell 1958; Suhm and Krieger 1954; Turner and Hester 1999) and was recovered from the surface. The flaking pattern on both faces is mostly complete with a small area on one face that exhibits the remnant of the ventral surface of the parent flake. This point is asymmetrical in shape and heavily reworked on the lateral edges (Figure 9-66). The lateral blade edges are concave and have average edge angle values at 39 and 40 degrees. Another distinctive aspect of this 


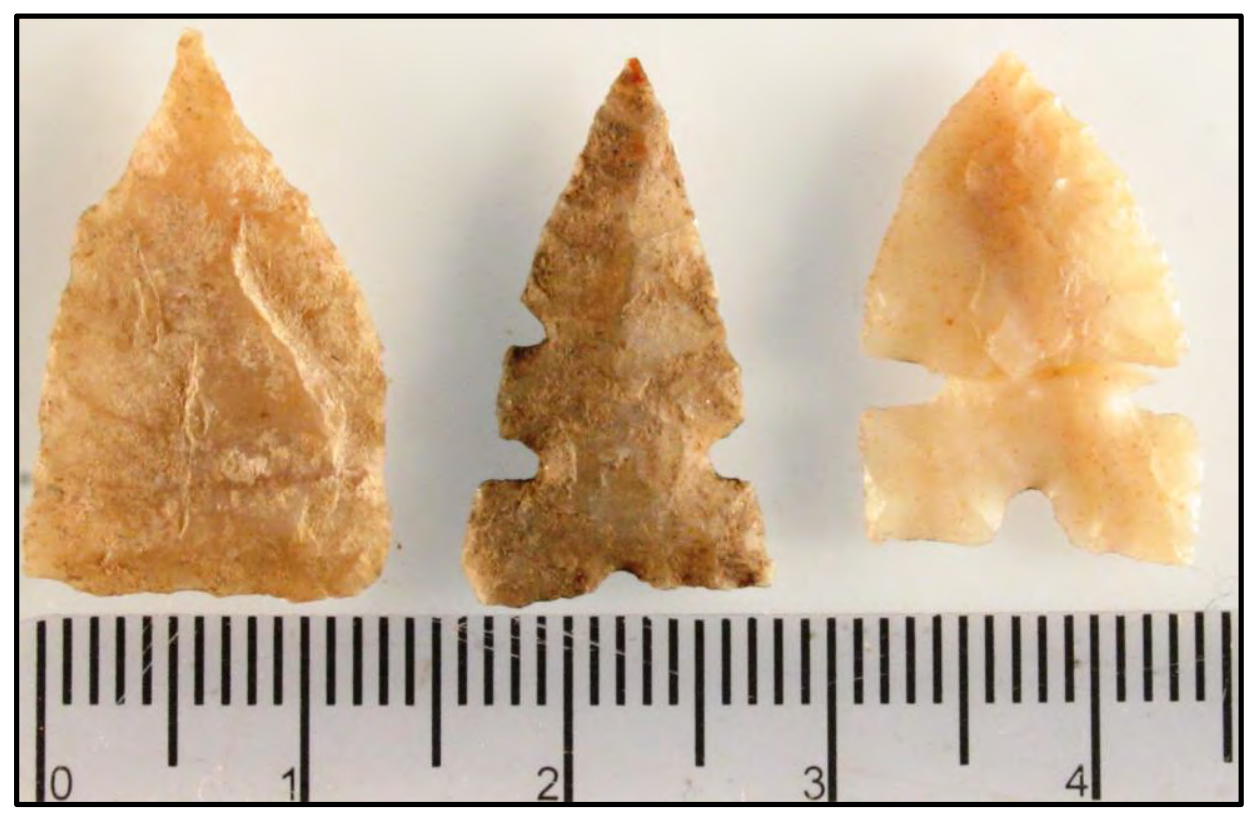

Figure 9-66. Reworked Fresno (\#145-10), Huffaker (\#460-10), and Harrell (\#410-11) points from Component $\mathrm{C}$.

Scale in $\mathrm{cm}$. Metric measurements for this and other points are presented in Table 9-10 with qualitative observations of complete specimens presented in Table 9-11.

specimen is the fact that it is fashioned from chert or chalcedony (locally available) rather than Alibates. Specimen \#301-10 is a small, triangular point that is stylistically similar to the documented Fresno form (Bell 1960; Suhm and Krieger 1954; Turner and Hester 1999). It is fashioned from chalcedony and was recovered at a depth of 90 cmbs within N482 E499. The flaking pattern is complete on one face and only marginally flaked on the opposing face. This point is slightly asymmetrical in shape and shows some reworking at the distal end. The lateral blade edges are concave, and the average edge angle values are 36 and 41 degrees.

Specimen \#200-10 is a small, triangular point which is stylistically similar to the Washita form (Bell 1960; Suhm and Krieger 1954; Turner and Hester 1999). It is made of Alibates, and was recovered at a depth of 40 cmbs in unit N479 E500. Both faces are completely flaked. This point is slightly asymmetrical in shape and appears to have been reworked above the side notches as there is a noticeable narrowing of the lateral edges distal to those areas. The lateral blade edges are concave and have average edge angle values of 43 and 44 degrees.
Specimen \#410-10 is also a small, triangular point that is stylistically similar to the documented Washita form (Bell 1958; Suhm and Krieger 1954; Turner and Hester 1999) and was recovered at a depth of $5 \mathrm{cmbs}$ in N489 E494. The flaking pattern on both faces is complete yet random. This point has been broken (both pieces are present and refit to a complete form) just above the side notches. The lateral blade edges are concave and have average edge angle values of 34 and 35 degrees.

Specimen \#451-10 is a small, triangular point which is stylistically similar to a Fresno form (Bell 1960; Suhm and Krieger 1954; Turner and Hester 1999) and was recovered at a depth of $10 \mathrm{cmbs}$ in unit N491 E501. This point is symmetrical in shape. The lateral blade edges are straight with average edge angle values at 31 and 34 degrees.

Specimen \#460-10 is also a small, triangular point that is stylistically similar to the documented Huffaker form (Bell 1958; Suhm and Krieger 1954; Turner and Hester 1999) and was recovered at a depth of 30 cmbs in N492 E500. This point has two notches on one lateral edge and one notch on the opposing edge. 
Table 9-10. Selected Quantitative Measurements for Projectile Points.

\begin{tabular}{|c|c|c|c|c|c|c|c|c|c|}
\hline PNUM & Unit & $\begin{array}{l}\text { Depth } \\
\text { (cmbs) }\end{array}$ & $\begin{array}{c}\text { Max } \\
\text { Length } \\
\text { (mm) } \\
\end{array}$ & $\begin{array}{c}\text { Max } \\
\text { Width } \\
\text { (mm) }\end{array}$ & $\begin{array}{c}\text { Max } \\
\text { Thickness } \\
(\mathbf{m m}) \\
\end{array}$ & $\begin{array}{c}\text { Weight } \\
\text { (g) }\end{array}$ & $\begin{array}{c}\text { Morphological } \\
\text { Style }\end{array}$ & $\begin{array}{c}\text { Raw } \\
\text { Material }\end{array}$ & Completeness \\
\hline $145-10$ & C-8 & $30-40$ & 21.3 & 13.6 & 3.5 & 0.8 & Fresno & Chert & Complete \\
\hline $152-10$ & C-9 & $20-30$ & 8.6 & 15.4 & 2.6 & 0.3 & $\begin{array}{c}\text { Indeterminate } \\
\text { Triangular }\end{array}$ & Alibates & $\begin{array}{l}\text { Proximal } \\
\text { Fragment }\end{array}$ \\
\hline $175-10$ & $\begin{array}{l}\text { N478 } \\
\text { E500 }\end{array}$ & $30-40$ & 12 & 9.1 & 2.6 & 0.2 & Indeterminate & Alibates & $\begin{array}{c}\text { Distal } \\
\text { Fragment }\end{array}$ \\
\hline $180-10$ & $\begin{array}{l}\text { N478 } \\
\text { E501 } \\
\end{array}$ & $20-30$ & 7.9 & 14.7 & 3.3 & 0.4 & $\begin{array}{l}\text { Possible } \\
\text { Washita }\end{array}$ & Alibates & $\begin{array}{l}\text { Proximal } \\
\text { Fragment }\end{array}$ \\
\hline $182-10$ & $\begin{array}{l}\text { N478 } \\
\text { E501 }\end{array}$ & $30-40$ & 16.1 & 11.7 & 2.9 & 0.5 & Washita/Harrell & Alibates & Medial \\
\hline $193-10$ & $\begin{array}{l}\text { N479 } \\
\text { E499 }\end{array}$ & $30-40$ & 18.9 & 13 & 2.7 & 0.7 & $\begin{array}{c}\text { Indeterminate } \\
\text { Triangular }\end{array}$ & Chert & Distal/Medial \\
\hline $204-10$ & $\begin{array}{l}\text { N479 } \\
\text { E501 }\end{array}$ & $20-30$ & 20.2 & 14.4 & 3.8 & 1 & Fresno & Alibates & $\begin{array}{c}\text { Proximal/ } \\
\text { Medial }\end{array}$ \\
\hline 206-10 & $\begin{array}{l}\text { N479 } \\
\text { E501 }\end{array}$ & $50-60$ & 19.4 & 12.4 & 2.2 & 0.6 & Fresno & Alibates & $\begin{array}{l}\text { Proximal/ } \\
\text { Medial }\end{array}$ \\
\hline $224-10$ & $\begin{array}{l}\text { N480 } \\
\text { E499 }\end{array}$ & $30-40$ & 11.1 & 14.5 & 3.2 & 0.3 & Fresno & Alibates & proximal \\
\hline $236-10$ & $\begin{array}{l}\text { N480 } \\
\text { E500 } \\
\end{array}$ & $50-60$ & 20.5 & 9 & 2.6 & 0.4 & Indeterminate & Chert & $\begin{array}{c}\text { Distal } \\
\text { fragment }\end{array}$ \\
\hline $281-10$ & $\begin{array}{l}\text { N481 } \\
\text { E501 }\end{array}$ & $60-70$ & 17.9 & 10.2 & 2.7 & 0.5 & Fresno & Alibates & $\begin{array}{l}\text { missing base } \\
\text { corner }\end{array}$ \\
\hline 291-11 & $\begin{array}{l}\text { N482 } \\
\text { E499 } \\
\end{array}$ & $20-30$ & 21.2 & 15.3 & 2.4 & 0.7 & Washita & Alibates & $\begin{array}{c}\text { missing base } \\
\text { corner }\end{array}$ \\
\hline $301-11$ & $\begin{array}{l}\text { N482 } \\
\text { E499 }\end{array}$ & $80-90$ & 20.3 & 13.2 & 2.5 & 0.6 & Fresno & Chert & Complete \\
\hline $360-10$ & $\begin{array}{l}\text { N484 } \\
\text { E500 }\end{array}$ & $20-30$ & 12.1 & 11.8 & 2.3 & 0.2 & Washita/Harrell & Alibates & $\begin{array}{c}\text { Medial } \\
\text { Fragment }\end{array}$ \\
\hline $200-10$ & $\begin{array}{l}\text { N479 } \\
\text { E500 }\end{array}$ & $30-40$ & 20.1 & 15.5 & 3.4 & 0.7 & Washita & Alibates & Complete \\
\hline 200-12 & $\begin{array}{l}\text { N479 } \\
\text { E500 }\end{array}$ & $30-40$ & 20.6 & 13.9 & 2.9 & 0.7 & Washita & Alibates & Tip missing \\
\hline $368-10$ & $\begin{array}{l}\mathrm{N} 485 \\
\mathrm{E} 493 \\
\end{array}$ & $30-40$ & 26.4 & 13.6 & 2.8 & 0.9 & Huffaker & Alibates & $\begin{array}{l}\text { Proximal } \\
\text { Fragment }\end{array}$ \\
\hline $\begin{array}{c}1270- \\
10\end{array}$ & Fireguard & Surface & 23.5 & 13.0 & 2.6 & 0.6 & Harrell & Alibates & Ear missing \\
\hline $\begin{array}{c}1269- \\
12\end{array}$ & Fireguard & Surface & 20.4 & 14.7 & 3.2 & 0.9 & Fresno & Alibates & $\begin{array}{c}\text { Complete/ } \\
\text { missing small } \\
\text { part of base } \\
\text { corner }\end{array}$ \\
\hline $373-10$ & $\begin{array}{l}\text { N485 } \\
\text { E494 }\end{array}$ & $10-20$ & 21.8 & 12.4 & 3 & 0.8 & Harrell & Alibates & Missing tip \\
\hline $210-10$ & $\begin{array}{l}\text { N479 } \\
\text { E501 }\end{array}$ & $60-70$ & 12.4 & 19 & 2.6 & 0.7 & Possible Fresno & Alibates & $\begin{array}{l}\text { Proximal } \\
\text { Fragment }\end{array}$ \\
\hline $410-11$ & $\begin{array}{l}\text { N489 } \\
\text { E494 }\end{array}$ & 7 & 17.6 & 12.8 & 2.6 & 0.6 & Harrell & Alibates & Complete \\
\hline $449-12$ & $\begin{array}{l}\text { N491 } \\
\text { E501 } \\
\end{array}$ & $30-40$ & 13.2 & 11.3 & 2.2 & 0.3 & $\begin{array}{c}\text { Indeterminate } \\
\text { triangular }\end{array}$ & Alibates & $\begin{array}{c}\text { Distal } \\
\text { Fragment }\end{array}$ \\
\hline $451-10$ & $\begin{array}{l}\text { N491 } \\
\text { E501 }\end{array}$ & $40-50$ & 17.7 & 14.6 & 2.5 & 0.6 & Fresno & Alibates & Complete \\
\hline $460-10$ & $\begin{array}{l}\text { N492 } \\
\text { E500 }\end{array}$ & $20-30$ & 20.1 & 11.6 & 2.6 & 0.5 & $\begin{array}{l}\text { Harrell/ } \\
\text { Huffaker }\end{array}$ & Alibates & Complete \\
\hline
\end{tabular}


Table 9-10. Selected Quantitative Measurements for Projectile Points (cont.).

\begin{tabular}{|l|c|c|c|c|c|c|c|c|c|}
\hline PNUM & Unit & $\begin{array}{c}\text { Depth } \\
\text { (cmbs) }\end{array}$ & $\begin{array}{c}\text { Max } \\
\text { Length } \\
\text { (mm) }\end{array}$ & $\begin{array}{c}\text { Max } \\
\text { Width } \\
(\mathbf{m m})\end{array}$ & $\begin{array}{c}\text { Max } \\
\text { Thickness } \\
(\mathbf{m m})\end{array}$ & $\begin{array}{c}\text { Weight } \\
\text { (g) }\end{array}$ & $\begin{array}{c}\text { Morphological } \\
\text { Style }\end{array}$ & $\begin{array}{c}\text { Raw } \\
\text { Material }\end{array}$ & Completeness \\
\hline $464-11$ & $\begin{array}{l}\text { N492 } \\
\text { E500 }\end{array}$ & $40-50$ & 10.5 & 12.4 & 2.1 & 0.2 & Fresno & Alibates & $\begin{array}{c}\text { Proximal } \\
\text { fragment }\end{array}$ \\
\hline $510-10$ & $\begin{array}{l}\text { N495 } \\
\text { E494 }\end{array}$ & $10-20$ & 21.9 & 14.3 & 3.4 & 0.9 & Washita & Alibates & Missing tip \\
\hline $510-12$ & $\begin{array}{l}\text { N495 } \\
\text { E494 }\end{array}$ & $10-20$ & 27.6 & 13.4 & 3.5 & 1.1 & Washita & Alibates & $\begin{array}{c}\text { Base corner } \\
\text { missing }\end{array}$ \\
\hline $589-10$ & $\begin{array}{l}\text { N498 } \\
\text { E501 }\end{array}$ & $30-40$ & 26.8 & 12.8 & 2.6 & 0.6 & Harrell & Alibates & Complete \\
\hline $589-11$ & $\begin{array}{l}\text { N497 } \\
\text { E501 }\end{array}$ & $30-40$ & 9.7 & 16.2 & 2.2 & 0.2 & Washita & Chert & $\begin{array}{c}\text { Proximal } \\
\text { broken at } \\
\text { notches }\end{array}$ \\
\hline $595-10$ & $\begin{array}{l}\text { N498 } \\
\text { E497 }\end{array}$ & $60-70$ & 23.7 & 16.3 & 3.2 & 1.2 & Fresno & Alibates & Missing tip \\
\hline $648-14$ & $\begin{array}{l}\text { N499 } \\
\text { E498 }\end{array}$ & $10-20$ & 25.8 & 13.4 & 2.8 & 0.7 & Washita & Alibates & Medial/Distal \\
\hline $669-11$ & $\begin{array}{l}\text { N500 } \\
\text { E497 }\end{array}$ & $40-60$ & 9.2 & 9 & 2.1 & 0.3 & Indeterminate & Alibates & Medial \\
\hline $626-10$ & $\begin{array}{l}\text { N499 } \\
\text { E496 }\end{array}$ & $+19-1$ & 15.6 & 13.9 & 2.6 & 0.6 & Fresno & Alibates & Proximal \\
\hline
\end{tabular}

The flaking pattern on both faces is complete yet random. This point is slightly asymmetrical in shape. The lateral blade edges are straight with average edge angle values at 34 and 35 degrees.

Specimen \#589-10 is also a small, triangular point that is stylistically similar to the documented Harrell form (Bell 1960; Suhm and Krieger 1954; Turner and Hester 1999) and was recovered at a depth of $40 \mathrm{cmbs}$ within N498 E497. The flaking pattern on both faces is complete yet random. This point is symmetrical in shape with slightly convex lateral edges above the side notches. The lateral blade edges have average edge angle values of 27 and 28 degrees.

Seventy-nine percent $(N=30)$ of the point group were fashioned from Alibates silicified dolomite. Five specimens (21 percent) were made from indeterminate chert and/or chalcedony.

Overall, both the Washita- and Fresno-like points have similar dimensions. The Fresno group has a mean width of $13.82 \mathrm{~mm}$ (standard deviation $=1.6$ $\mathrm{mm}$ ) and a mean thickness of $2.86 \mathrm{~mm}$ (standard deviation $=0.54 \mathrm{~mm}$ ), while the Washita-like specimens have a mean width of $14.57 \mathrm{~mm}$ (standard deviation $=1.56 \mathrm{~mm}$ ) and a mean thickness of 2.94 $\mathrm{mm}$ (standard deviation $=0.51 \mathrm{~mm}$ ). The Harrell and Huffaker group has a mean width of $12.7 \mathrm{~mm}$ (standard deviation $=.67 \mathrm{~mm}$ ) and a mean thickness of $2.68 \mathrm{~mm}$ (standard deviation $=0.16 \mathrm{~mm}$ ). Given the fact that a majority of the points are not complete, length cannot be adequately compared.

\subsubsection{Bifaces}

Eight additional bifaces comprise 4.8 percent of the chipped stone tools from Component C. Table 9-11 provide the general dimension of each biface.

\subsubsection{Width-to-Thickness Ratios, Reduction Stages and Tool Use- Life}

As explained in the methodology section of this report, width to thickness ratios were recorded to provide a morphological index for the tools in this class. Specifically, Callahan (1979) devised this classification scheme to acknowledge trends observed among bifaces in Paleoindian assemblages and suggested that it reflects a reduction scheme in which low width-to-thickness ratios denoted earlier reduction stages and high width-to-thickness ratios denoted later reduction stages or finished forms. TRC has demonstrated in recent publications (e.g., Quigg et al 2010, Quigg et al. 2011) that microscopic wear data on such bifaces appear to show evidence of use 
Table 9-11. Selected Attributes on Component C Bifaces.

\begin{tabular}{|c|c|c|c|c|c|c|c|c|c|}
\hline PNUM & Unit & $\begin{array}{c}\text { Depth } \\
\mathbf{( c m b s )}\end{array}$ & $\begin{array}{c}\text { Max } \\
\text { Length } \\
\text { (mm) }\end{array}$ & $\begin{array}{c}\text { Max } \\
\text { Width } \\
\text { (mm) }\end{array}$ & $\begin{array}{c}\text { Max } \\
\text { Thickness } \\
(\mathbf{m m})\end{array}$ & $\begin{array}{c}\text { Weight } \\
\mathbf{( g )}\end{array}$ & $\begin{array}{c}\text { Raw } \\
\text { Material }\end{array}$ & Completeness & $\begin{array}{c}\text { Width-to- } \\
\text { Thickness } \\
\text { Stage }\end{array}$ \\
\hline $417-10$ & $\begin{array}{c}\text { N489 } \\
\text { E495 }\end{array}$ & $30-40$ & 36.6 & 27.1 & 9.6 & 8.8 & Alibates & Complete & 3 \\
\hline $246-10$ & $\begin{array}{l}\text { N480 } \\
\text { E501 }\end{array}$ & $30-40$ & 27.7 & 27.6 & 8.1 & 5.8 & Alibates & $\begin{array}{c}\text { Transverse } \\
\text { Fragment }\end{array}$ & 3 \\
\hline $646-12$ & $\begin{array}{c}\text { N499 } \\
\text { E498 }\end{array}$ & $0-10$ & 69.1 & 53.4 & 15.3 & 45.7 & Alibates & Distal fragment & $3-4$ \\
\hline $90-10$ & Fireguard & Surface & 42 & 27.1 & 12.5 & 8.7 & Niobrara & $\begin{array}{c}\text { Transverse } \\
\text { Fragment }\end{array}$ & 2 \\
\hline $265-11$ & $\begin{array}{l}\text { N481 } \\
\text { E500 }\end{array}$ & $30-40$ & 28.4 & 29.3 & 11.5 & 12.2 & Alibates & Medial & 2 \\
\hline $648-20$ & $\begin{array}{l}\text { N500 } \\
\text { E496 }\end{array}$ & $0-20$ & 25.9 & 22.7 & 2.9 & 1.8 & Alibates & $\begin{array}{c}\text { Fragment } \\
\text { transverse break }\end{array}$ & $5+$ \\
\hline $200-11$ & $\begin{array}{l}\text { N479 } \\
\text { E500 }\end{array}$ & $30-40$ & 22.7 & 19.3 & 7.9 & 2 & Alibates & $\begin{array}{c}\text { Fragment broken } \\
\text { longitudinally } \\
\text { and transversally }\end{array}$ & 2 \\
\hline $242-10$ & $\begin{array}{l}\text { N480 } \\
\text { E501 }\end{array}$ & $0-10$ & 25 & 22.8 & 6.6 & 3.1 & Alibates & Medial fragment; & $3-4$ \\
\hline
\end{tabular}

and hafting across a wide range of early through late "stage" bifaces. These data could very well indicate that diversity in width-to-thickness ratios represent different stages in use-life that may not be directly proportional to levels of reduction. Do these discrepancies constitute a reinterpretation of biface use-life and its association to morphological form? We believe so. However, we stop short of changing our classification terminology (i.e., Stages 1 through 5) as theses indices still convey a concept of proportion to the reader. Stages 1 through 5, as listed in Table 9-11, represent "earliest" to "latest" stages of reduction.

\subsubsection{Metric Attributes of the Biface Assemblage}

Two specimens are complete, two are distal fragments, eight are distal-medial fragments, and two are medial fragments. Bifaces were primarily fashioned from Alibates ( $N=11 ; 78$ percent). Descriptions of the bifaces are presented below with metric attributes presented for each in Table 9-11. Also included are supplemental data derived from use-wear analysis performed by Bruce Hardy (Appendix H).

\subsubsection{Beveled Bifaces}

Two fragmentary bifaces (\#242-10 and \#648-20), exhibiting a medial break, were recovered in the southern portion of Component $\mathrm{C}$. It can be surmised that they were discarded rather than cached for later use. Tool \#242-10 was submitted along with three others for use-wear analysis (Figure 9-68). These findings identify the presence or absence of wear and provide insight into how, and on what material each was used.

In summary, the mean width of bifaces was $29.5 \mathrm{~mm}$ and the average thickness was $8.56 \mathrm{~mm}$. The standard deviation of biface widths across all specimens, the tool dimension least affected by fragmentation, is $11.08 \mathrm{~mm}$. The biface-thickness measurements yield a standard deviation of $3.97 \mathrm{~mm}$. These ranges may be indicative of the variation in the initial size of raw material package (i.e., cobble size). It is also possible that the biface size variance may have been functionally related, but to determine this would require further examination of microwear on a larger sample of bifaces from this component. 


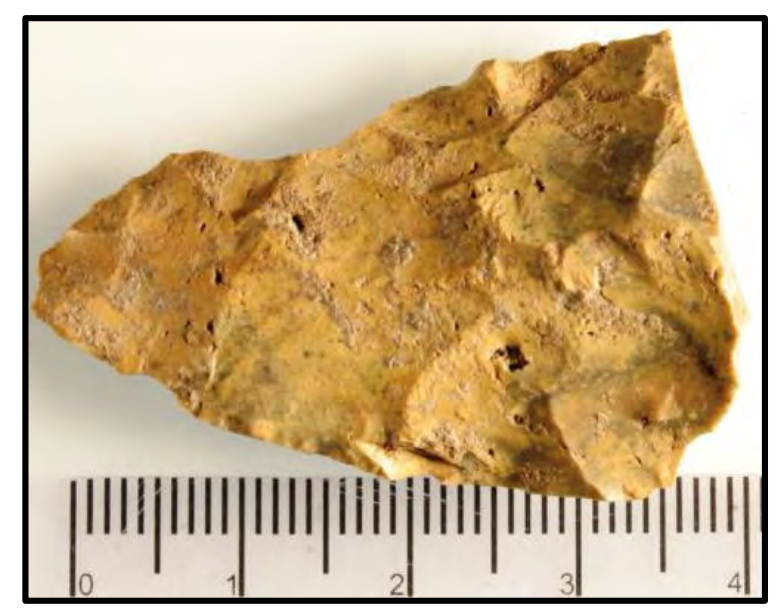

Figure 9-67. Biface fragment \#90-10 made of Niobrara jasper.

Scale in $\mathrm{cm}$.

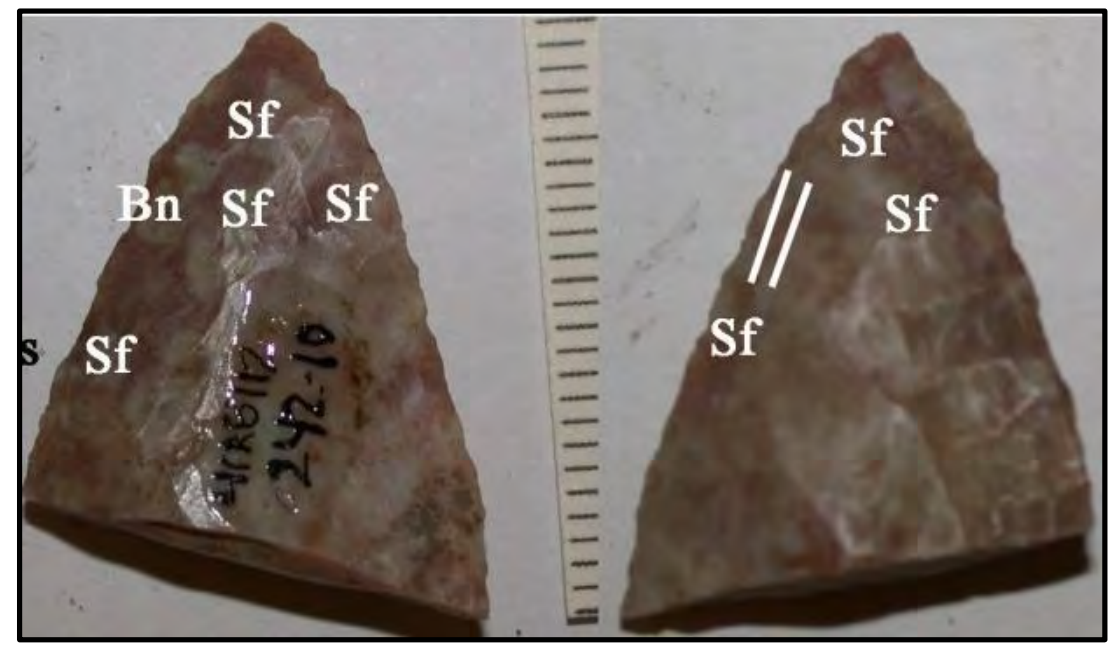

Figure 9-68. Unwashed alternately beveled biface fragment (\#242-10).

Use-wear evidence indicates these were used for slicing meat and butchery. Scale in millimeters.

As a group, these bifaces reveal random flaking patterns, indicating an expedient or nonstandardized reduction sequence. As mentioned above, Callahan (1979) provided a classification scheme for bifaces recovered from Paleoindian contexts in which he used width-to-thickness ratios to determine biface reduction stages. In general, the preparation and reduction scheme for specimens included in Callahan's studies are more complex than what was observed at 41RB112. More than half (57 percent) of the bifaces were classified as stage 3 , with no percentage of the biface assemblage unclassifiable due to fragmentation. Use-wear analysis (see below) on selected bifaces reveals some use-wear and/or plant microfossils, despite the fact that the bifaces were not always finished according to Callahan's (1979) definitions.

Breakage of bifaces (86 percent of the assemblage) may have occurred during manufacture, use, or postdepositionally. By examining breaks on broken specimens, it was determined that at least two bifaces (\#246-10 and \#646-12) were likely broken during use. 


\subsubsection{Use-wear Results}

Four bifaces were sent for use-wear analysis (\#24210, \#246-10, \#417-10, and \#646-12). Two broken bifaces (\#417-10 and \#646-10) with roughly shaped sinuous edges had evidence that suggested use in wood whittling activities. The distal tip of a beveled knife (\#242-10) yielded marks that indicate it was used for meat slicing and butchery tasks. Biface \#246-10 showed that it was used to cut hard/high silica material.

It is apparent that these bifacial tools were used for a variety of activities and were functional end products rather than preforms for more specialized tools. The fact that half of the bifaces examined were used on wood is intriguing and unexpected. These findings indicate bifaces were likely used as multi-functional tools rather than strictly for one type of task.

\subsubsection{Scrapers}

Scraping tools are primarily unifacially flaked implements that possess steeply flaked edges, with edge angles that measure roughly 60 degrees or more (Figure 9-69). Here, they compose 4.1 percent of the entire Component $\mathrm{C}$ tool assemblage. It is generally thought that tools fashioned in this manner were used to scrape and prepare animal hides for domestic purposes or as commodities. Six scrapers were recovered from across the excavated block at various depths. All were made from Alibates and are plano-convex in form (Table 9-12). Thus, a majority are morphologically similar to the teardrop-shaped scrapers often found in Late Prehistoric assemblages across the Southern Plains (Vehik and Baugh 1995).

\subsubsection{Use-wear Results}

Four scrapers were submitted for use-wear analysis (\#352-10, \#1233-10, \#1273-10, and \#1287-10). Complete scraper \#352-10 shows evidence that it was hafted (Figure 9-70). The distal end shows steep flaking along this edge, exhibts wear indicative it was used to scrape soft material. The wear observed on scraper \#1233-10 indicates it was used to scrap hides. Scraper \#1273-10 possesses wear that indicates it also scraped soft material. No evidence of hafting was observed on this latter scraper. The wear observed on scraper \#1287-10 showed that it functioned for scraping wood.

\subsubsection{Drills}

Five drills, of which only one was complete, were recovered from Component $C$ (Table 9-13). They were all fashioned from Alibates silicified dolomite with the exception of one proximal bit (\#231-11). Three fragments represent the chuck portion or the base, and two are distal or bit fragments (Table 9-13). Four drill fragments were submitted for use-wear analysis (\#174-10, \#202-12, \#231-11, and \#648-15). Drill \#174-10 showed wear patterns that indicated it was used to bore holes in wood. Another specimen, as drill base fragment (\#231-11) showed evidence of hafting. The remaining two drills (\#202- 12 and \#648-15) showed no discernable wear and were either unused or functioned in an unknown capacity.

\subsubsection{Edge-Modified Flakes}

Ninety edge-modified flakes are considered informal tools fashioned from flakes, then used and discarded on-site. This is the largest chipped-stone tool class, composing 53 percent of Component $\mathrm{C}$ tool assemblage. Specifically, informal tools represent those specimens that have not been altered to a degree that significantly changed the shape and/or form of the original flake blank. In most instances, these flakes or parts of flakes have minimal, but noticeable edge scaring, flaking, or rounding. These informal tools vary widely in size (Table 9-14). Edge angles measured for each modified-edge were fairly consistent with medians of 49 to 50 degrees and standard deviations of 11 to 12 degrees. These values indicate that most edge-modified flakes were subjected to similar types and/or use modifications. This is not surprising since, by definition, informal tools are not modified to any great extent prior to use.

Seventy seven percent $(N=90)$ were fashioned from Alibates silicified dolomite with only other materials represented include; unidentified chert $(N$ $=6 ; 4$ percent), Tecovas jasper ( $N=5$; 3.5 percent), chalcedony ( $N=4$; 3 percent), Niobrara jasper ( $N$ $=1 ; 0.5$ percent $)$, Ogallala quartzite $(N=1 ; 0.5$ percent), and unidentified jasper $(N=1 ; 0.5$ percent). Within this class, 4 percent $(N=3)$ exhibit 1 to 25 percent cortex on the dorsal face, and 96 percent $(N$ $=87$ ) have no cortex on the dorsal face. 


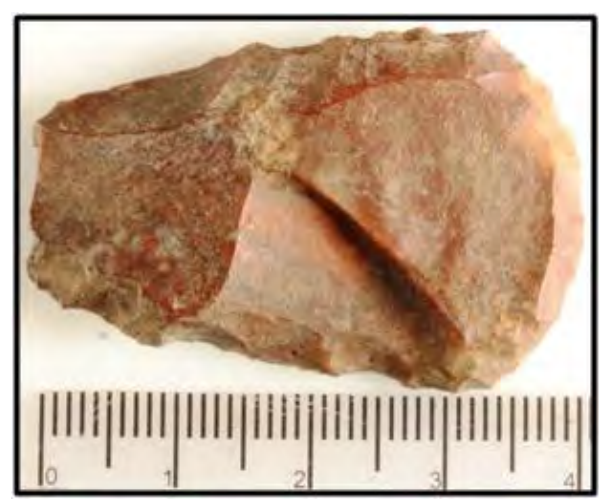

Figure 9-69. Plano-convex scraper from Component C. Scale in $\mathrm{cm}$.

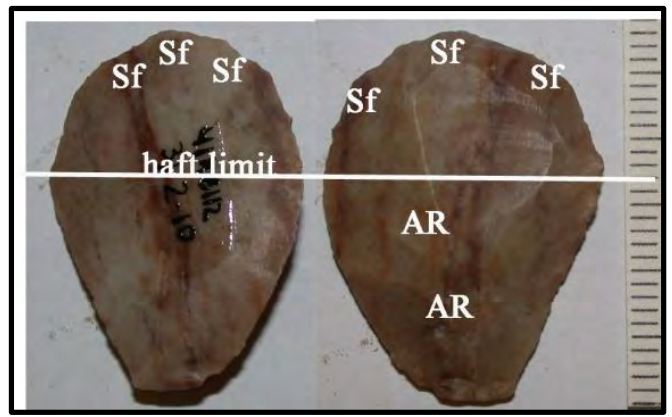

Figure 9-70. Plano convex scraper (\#352-10) that exhibits evidence of hafting and use for scraping soft material.

Scale in millimeters.

Interestingly, 34 percent exhibit evidence of thermal alteration in the form of a color changes and potlidding. This is a much larger percentage in any other tool class. Alibates is a high grade raw material that does not usually require heat treatment prior to flaking, as its fracture predictability is high. Therefore, it must be assumed that thermal alteration occurred postuse, as these expedient tools were discarded and/or intentionally incorporated into the fires of heating elements.

\subsubsection{Use-Wear Results}

Eleven specimens were submitted for use-wear analysis (Appendix C). On the whole, most were used for cutting $(N=4)$, with a number of unknown functions $(N=4)$, although scraping $(N=1)$. whittling $(N=1)$, and boring $(N=1)$ were detected (Appendix $\mathrm{C}$ ). These diverse uses document the range of tool functions that informal tools can be expected to represent.

\subsubsection{Unifacial Tools (Non-Scrapers) and Other Specialized Informal Tools}

Unifaces are defined as those tools that are flaked on one face and/or side to the degree that the original flake blank form is significantly modified (Figure 9-73). Edge angles are primarily less than 60 degrees. A total of 10 unifacial tools were recovered from Component C. Like edge-modified flake tools, these were probably produced, used, and discarded onsite. Two do not fit into any distinct morphological class. However, one specimen (\#615-10) has been fashioned with an incurvate edge-modification that is morphologically similar to a spokeshave (a tool used to straighten or shape arrow shafts or other wooden implements). Another tool (\#95-10) appears 
Table 9-12. Selected Scraper Attributes.

\begin{tabular}{|c|c|c|c|c|c|c|c|c|}
\hline PNUM & Cat & Unit & $\begin{array}{c}\text { Depth } \\
\mathbf{( c m b s )}\end{array}$ & $\begin{array}{c}\text { Length } \\
\mathbf{( m m})\end{array}$ & $\begin{array}{c}\text { Width } \\
\mathbf{( m m})\end{array}$ & $\begin{array}{c}\text { Thickness } \\
\mathbf{( m m})\end{array}$ & $\begin{array}{c}\text { Weight } \\
\mathbf{( g )}\end{array}$ & Material \\
\hline 643 & 10 & N499 E497 & 52 & 39.2 & 26 & 9.7 & 11.3 & Alibates \\
\hline 1233 & 10 & N499 E498 & $30-40$ & 31.9 & 33 & 9.3 & 10.2 & Tecovas \\
\hline 1273 & 10 & Southern end & Surface & 27.6 & 27.2 & 6.9 & 5.2 & Alibates \\
\hline 1287 & 10 & C-5 & $0-60$ & 20.6 & 27.1 & 9.6 & 8.4 & Alibates \\
\hline 352 & 10 & N484 E494 & $10-20$ & 31.5 & 23.8 & 6.8 & 4.8 & Alibates \\
\hline 468 & 10 & N492 E501 & $30-40$ & 33.9 & 25.1 & 4.6 & 3.9 & Alibates \\
\hline
\end{tabular}

Table 9-13. Metric Attributes of Drills at Component C.

\begin{tabular}{|c|c|c|c|c|c|c|c|c|}
\hline PNUM & Unit & $\begin{array}{c}\text { Depth } \\
\mathbf{( c m b})\end{array}$ & $\begin{array}{c}\text { Length } \\
\mathbf{( m m})\end{array}$ & $\begin{array}{c}\text { Width } \\
\mathbf{( m m}\end{array}$ & $\begin{array}{c}\text { Thickness } \\
\mathbf{( m m})\end{array}$ & $\begin{array}{c}\text { Raw } \\
\text { Material }\end{array}$ & $\begin{array}{c}\text { Weight } \\
\mathbf{( g )}\end{array}$ & Completeness \\
\hline $254-10$ & N480 E501 & $60-70$ & 21.5 & 16.6 & 6.9 & Alibates & 2.5 & Proximal \\
\hline $174-10$ & N478 E500 & $20-30$ & 27.3 & 7.6 & 3.6 & Alibates & 0.8 & Distal (bit) \\
\hline $202-10$ & N479 E500 & $50-60$ & 26.8 & 24.2 & 6.3 & Alibates & 4.2 & proximal \\
\hline $648-15$ & N499 E498 & $10-20$ & 17.5 & 6.3 & 4.5 & Alibates & 0.4 & Distal (bit) \\
\hline $231-11$ & N480 E500 & $30-40$ & 24.7 & 22.4 & 6.5 & $\begin{array}{c}\text { Tecovas } \\
\text { Jasper }\end{array}$ & 3.1 & Proximal \\
\hline
\end{tabular}

Table 9-14. Summary of Metric Measurements on Edge-Modified Flakes.

\begin{tabular}{|c|c|c|c|}
\hline $\begin{array}{c}\text { Edge-Modified Flake } \\
(\boldsymbol{N}=\mathbf{7 8})\end{array}$ & $\begin{array}{c}\text { Length } \\
(\mathbf{m m})\end{array}$ & $\begin{array}{c}\text { Width } \\
\mathbf{( m m )}\end{array}$ & $\begin{array}{c}\text { Thickness } \\
(\mathbf{m m})\end{array}$ \\
\hline Mean & 20.6 & 20.2 & 4.7 \\
\hline Median & 26.82 & 23.32 & 5.76 \\
\hline Standard Deviation & 11.31 & 6.63 & 3.20 \\
\hline
\end{tabular}


modified into a graver with pointed tips. It is likely that this modification was used for puncturing or incising other materials.

\subsubsection{Use-wear Results}

One specialized informal tool (\#589-12) was submitted for use-wear analysis. Microscopic examination showed evidence that it had been hafted (Figure 9-74). In addition, wear observed along the tool edges indicates it was used for scraping hides.

\subsubsection{Horizontal Distribution of Formal and Selected Informal Tools}

Three main concentrations of tools are evident at Component C (Figure 9-75). The northernmost concentration was contained within the pithouse structure (Feature 6) and composes the largest of the concentration $(N=25)$. A majority of these tools were in the fill of the features, which suggests this was primarily a discard location rather than a use and/or storage location. The second largest concentration of tools $(N=22)$ was at the southern end, east of the fireguard. Fifty percent of the tools in this concentration are projectile points. Other tools represented with some frequency include bifaces ( $N=3$; 14 percent), drills $(N=3 ; 14$ percent) and edge-modified flakes ( $N=2 ; 9$ percent). Given the classes of tools represented, which also included one mano and one hammerstone, it is unclear if this concentration represents an activity area or a discard area. A third concentration of tools was documented in Features 5 and 16/21 complex on the eastern margin of the excavation block. Although the number of tools recovered was small $(N=5)$, they are confined to a small area, that was not impacted by the construction of the highway. Again, projectile points comprise the majority of the tools in this concentration ( $N=3$; 60 percent). The remaining tools in this feature complex, like those documented in Feature 6, are thought to represent a discard area.

\subsection{Lithic Debitage}

The lithic debitage assemblage from Component $\mathrm{C}$ $(N=862)$ consists of platform bearing flakes, distal flakes, shatter, and/or angular debris, and cores. These primarily occurred within the A horizon,with the majority of material from 10 to 50 cmbs (Figure 9-76). The raw material diversity throughout the debris assemblage is moderate, with at least 12 unique raw material types recognized. However, the great majority of the debitage is composed of Alibates silicified dolomite $(N=779$; 89 percent; Figure 9-77). Other materials include Ogallala quartzite ( $N$ $=36,4$ percent [meta-quartzite $N=31,3.5$ percent] and ortho-quartzite $[N=5,0.5$ percent $])$; jasper $(N$ $=23,2.6$ percent) which is split into Tecovas $(N=$ 3, 0.3 percent), nonspecific $(N=4$; 0.4 percent), and Niobrara $(N=16,1.8$ percent); quartz $(N=8,0.9$ percent); Day Creek dolomite $(N=4$; 0.4 percent); other unidentified lithic (cortical) material $(N=4,0.4$ percent); silicified limestone $(N=4 ; 0.02$ percent); chalcedony ( $N=3$; 0.3 percent); and basalt $(N=1$; 0.1 percent). It is likely that most (though not all) materials were collected from local drainages near 41RB112, with the exception of the Niobrara jasper, which originated from north-central Kansas.

The majority of the debitage assemblage ( $N=538$; 62 percent) falls within the $>6.4$ to $<12.8 \mathrm{~mm}$ size range (Figure 9-78). The second largest group is the $<6.4 \mathrm{~mm}$ group ( $N=220$; 25 percent) followed by $>12.8$ to $<19 \mathrm{~mm}$ with only 9 percent. The general small size suggests that a high proportion of flakes were produced as by-products of finishing and/or resharpening activities, further reflecting material conservation rather than an emphasis on tool production. Ogallala quartzite shows a secondary frequency of the $>12.8$ to $<19 \mathrm{~mm}$ range, though the proportion in the $>6.4$ to $<12.8 \mathrm{~mm}$ size range is much lower than what is present in the more prominent materials.

The frequency of thermal alteration among platform-bearing flakes is low ( $N=44$; 5 percent; Figure 9-79). Thermal alteration can occur as potlid marks (saucer-shaped divots) and thermal breaks. Indications of heating are primarily observed on the Alibates material, which accounts for 86 percent of the thermally altered material. These are signs that heating probably occurred after discard. Purposeful or intentional heating of new raw material to improve quality for knapping would have been monitored and the material would have been removed from the heat source before such detrimental alterations occurred. Furthermore, the Alibates silicified dolomite is a very fine-grained material, of higher quality than locally available quartzite, jasper, or 

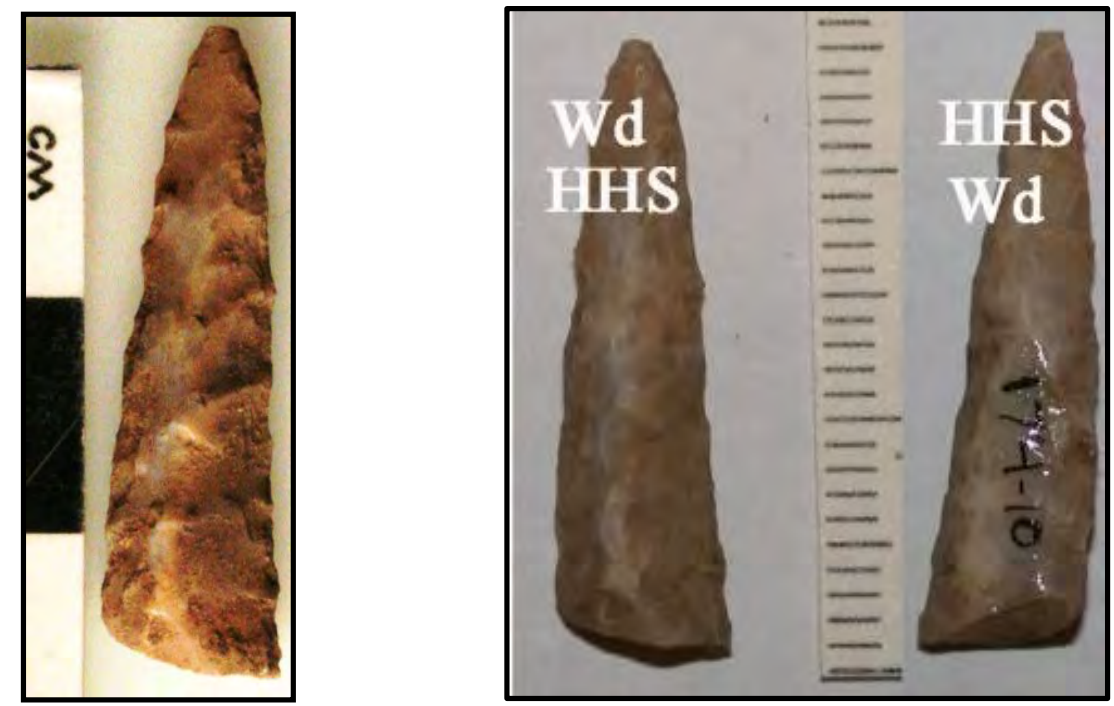

Figure 9-71. Drill bit (\#174-10) shows signs of use for boring wood. Scales in $\mathrm{cm}$ and millimeters.

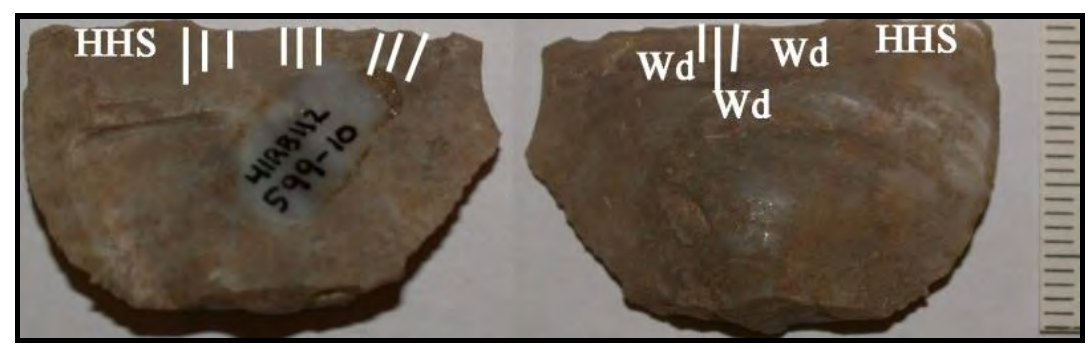

Figure 9-72. Edge-modified flake (\#599-10) that exhibits wear that suggests use in wood whittling.

Scale in millimeters.

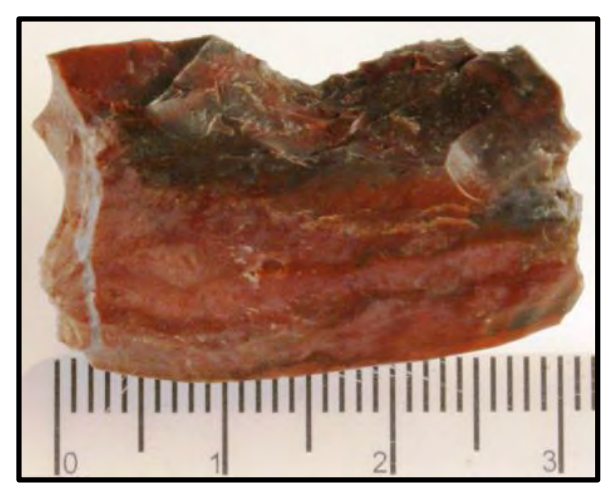

Figure 9-73. Unifacial spokeshave (\#615-10) tool from Component C.

Scale in $\mathrm{cm}$. 


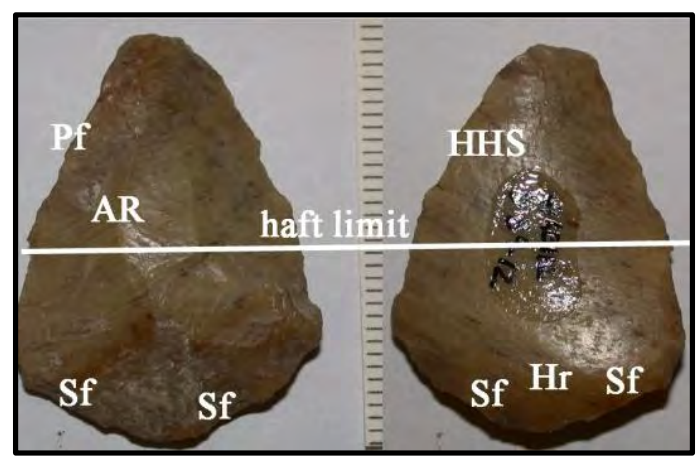

Figure 9-74. Nondescript uniface (\#589-12) that exhibits signs of hafting and hide scraping. Scale in millimeters.

chalcedony, and quite suitable for knapping without heating. Consequently, Alibates would not likely been targeted to heat alter.

The breakdown of platform types is depicted in Figure 9-80. A total of 495 platform-bearing flakes were identified, and constitute about 57 percent of the debitage from Component $\mathrm{C}$. Of these, nearly 52 percent exhibit multifaceted platforms, and represent reduction of more intensively modified objective pieces (e.g., bifaces or cores with prepared platforms). Approximately 4 percent of the platformbearing flakes are cortical flakes (Figure 9-80). Flat striking platforms are prominent and represent 42 percent of the platform-bearing assemblage. Flatplatform flakes were detached from nonbifacial tools or planar, unmodified core surfaces (Andrefsky 1998:94; Whittaker and Kaldahl 2001:54)

Lithic debitage with cortex on the dorsal faces signifies early-stage reduction of objective pieces (Figure 9-81). Only a small fraction (7.6 percent) of the platform-bearing flakes exhibit cortex. The most likely explanation of this low incidence of cortex is that the initial reduction of raw material packages was done off-site or a second probable explanation is that the dominate Alibates was not derived from rounded water-worn cobbles, but was blocky quarry chunks. Therefore, most knapping of raw material at Component $\mathrm{C}$ represents later-stage reduction, which resulted in the production of a great majority of flakes with no dorsal cortex.

\subsubsection{Horizontal Distribution of Lithic Debitage}

The horizontal distribution of debitage by count across the Component $\mathrm{C}$ reveals that many of the highest counts were inside the pithouse Feature 6 and in the "ghost" Feature 18 in the southeastern end plus a few small areas outside designated cultural features (Figure 9-82). The features consisted of remnant structures, concentrations of darkened soil, burned rock secondary dump or discard locales.

\subsubsection{Summary of Lithic Debitage Analysis}

In summary, the lithic debitage reveals clear patterns of intensive use of Alibates raw material that arrived on-site in relatively small chunks, rough bifaces, and/or finished tools. The high frequency of Alibates silicified dolomite, a regionally available material whose nearest primary source is $80.5 \mathrm{~km}$ away, but small rounded pebbles and/or cobbles are available in the Canadian River gravels, reflects it was used in higher quantities over all other local and nonlocal matierials. However, the absence of water-worn cortical pieces on Alibates debitage in this assemblage lends support to this material having been procured at the quarry upstream to the southwest.

Small jasperoid and Ogallala quartzite pieces are present in moderate amounts across the component, but seem relegated primarily to expedient flake tool production. These local materials are available in the high Pleistocene gravel terreces along the river and 


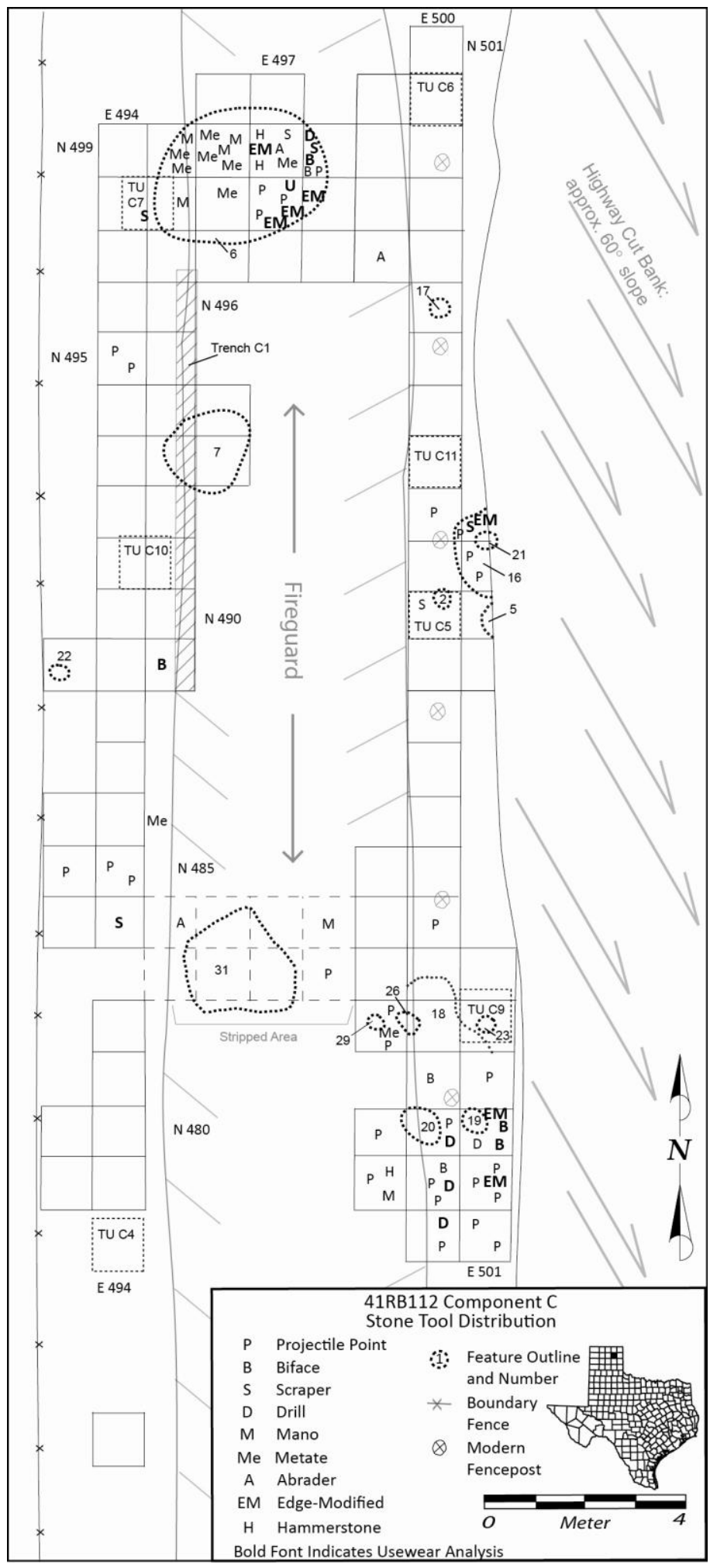

Figure 9-75. Stone tool spatial distribution at Component C. Note bold denotes tools examined for use-wear. 
Table 9-15. Metric Attributes of Specialized Informal Tools.

\begin{tabular}{|c|c|c|c|c|c|c|c|}
\hline PNUM & Unit & $\begin{array}{l}\text { Depth } \\
\text { (cmbs) }\end{array}$ & $\begin{array}{l}\text { Length } \\
\text { (mm) }\end{array}$ & $\begin{array}{l}\text { Width } \\
\text { (mm) }\end{array}$ & $\begin{array}{l}\text { Thickness } \\
\text { (mm) }\end{array}$ & $\begin{array}{c}\text { Weight } \\
\text { (g) }\end{array}$ & Material \\
\hline 643-19 & N499 E497 & $40-50$ & 16.1 & 13.8 & 3.4 & 0.6 & Alibates \\
\hline $508-10$ & N494 E500 & $20-30$ & 36.3 & 19.6 & 7.1 & 4.6 & Alibates \\
\hline $615-10$ & N499 E495 & $10-20$ & 20.4 & 30.3 & 7.7 & 6.7 & $\begin{array}{c}\text { Tecovas } \\
\text { Jasper- } \\
\text { spokeshave }\end{array}$ \\
\hline $589-10$ & N498 E497 & $20-30$ & 35.6 & 27 & 6.9 & 6.2 & Alibates \\
\hline $95-10$ & $\begin{array}{l}\text { North of Rock } \\
\text { Alignment }\end{array}$ & Surface & 27.2 & 21 & 14.5 & 7 & $\begin{array}{c}\text { Alibates- } \\
\text { graver }\end{array}$ \\
\hline
\end{tabular}

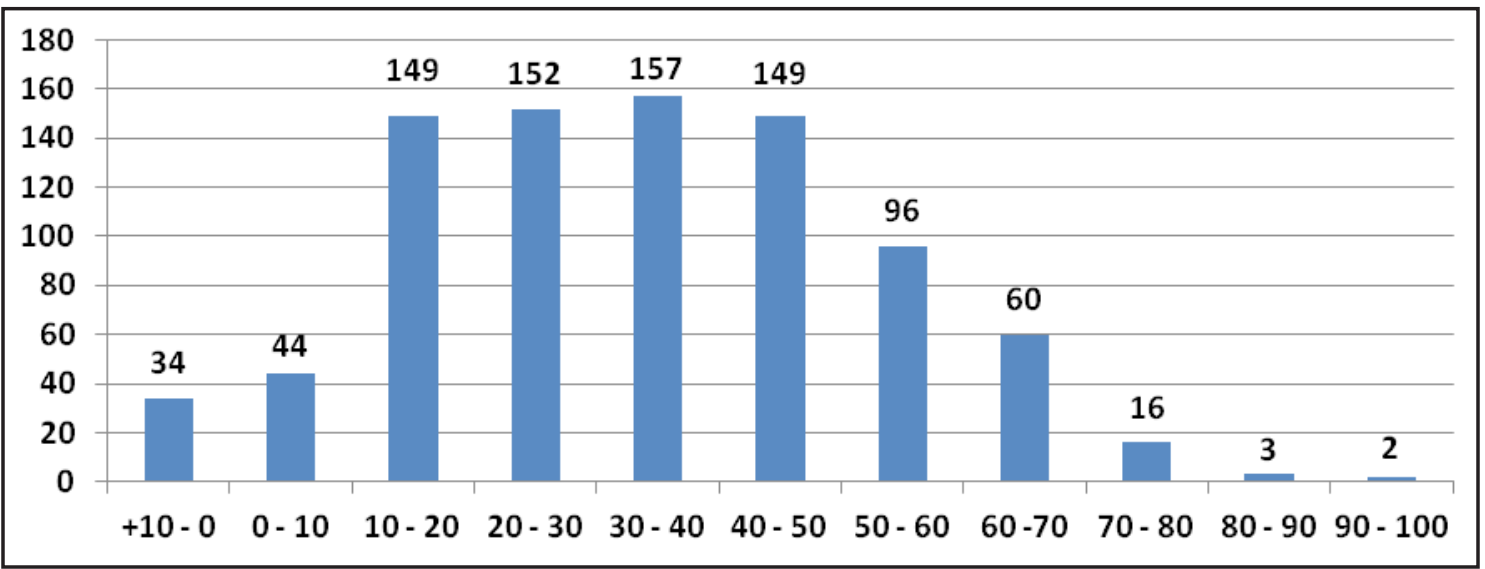

Figure 9-76. Depth range and frequency for lithic debitage from Component $\mathrm{C}$.

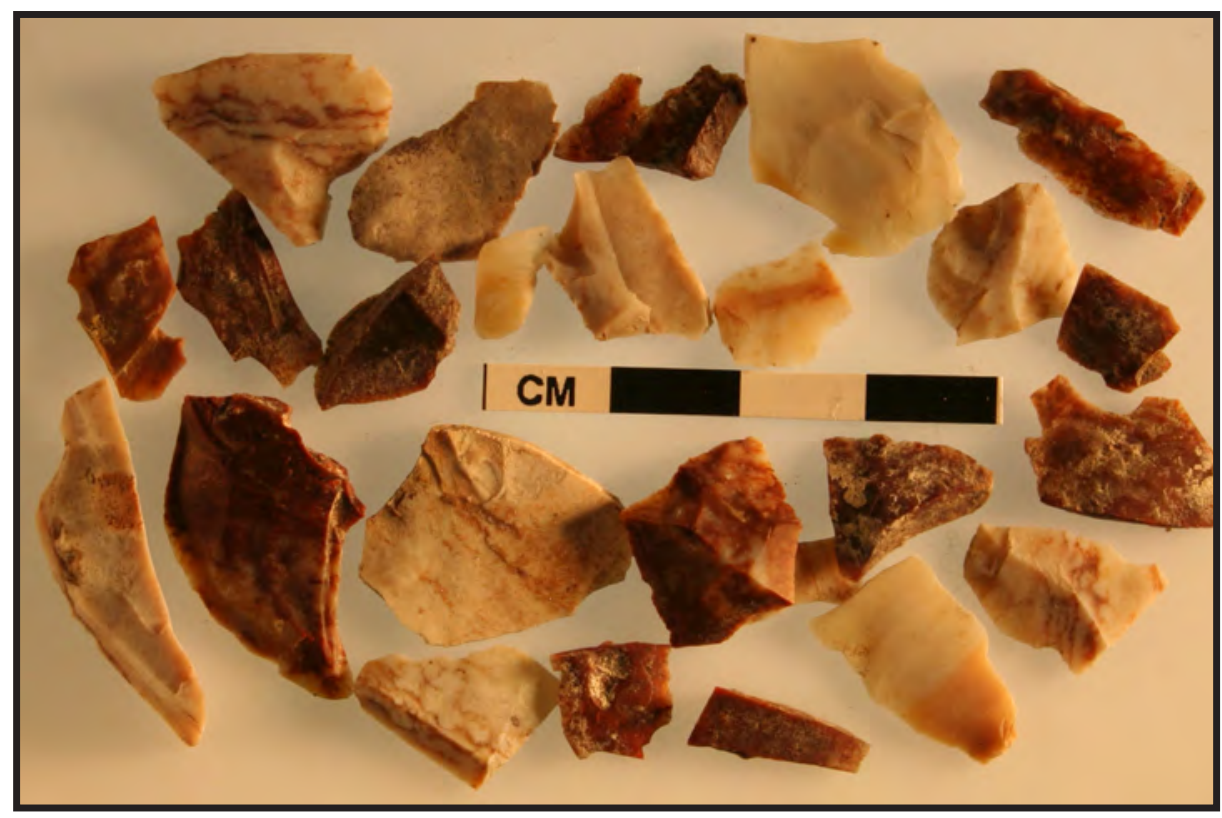

Figure 9-77. Debitage mostly comprised of Alibates from Component C.

Scale in $\mathrm{cm}$. 


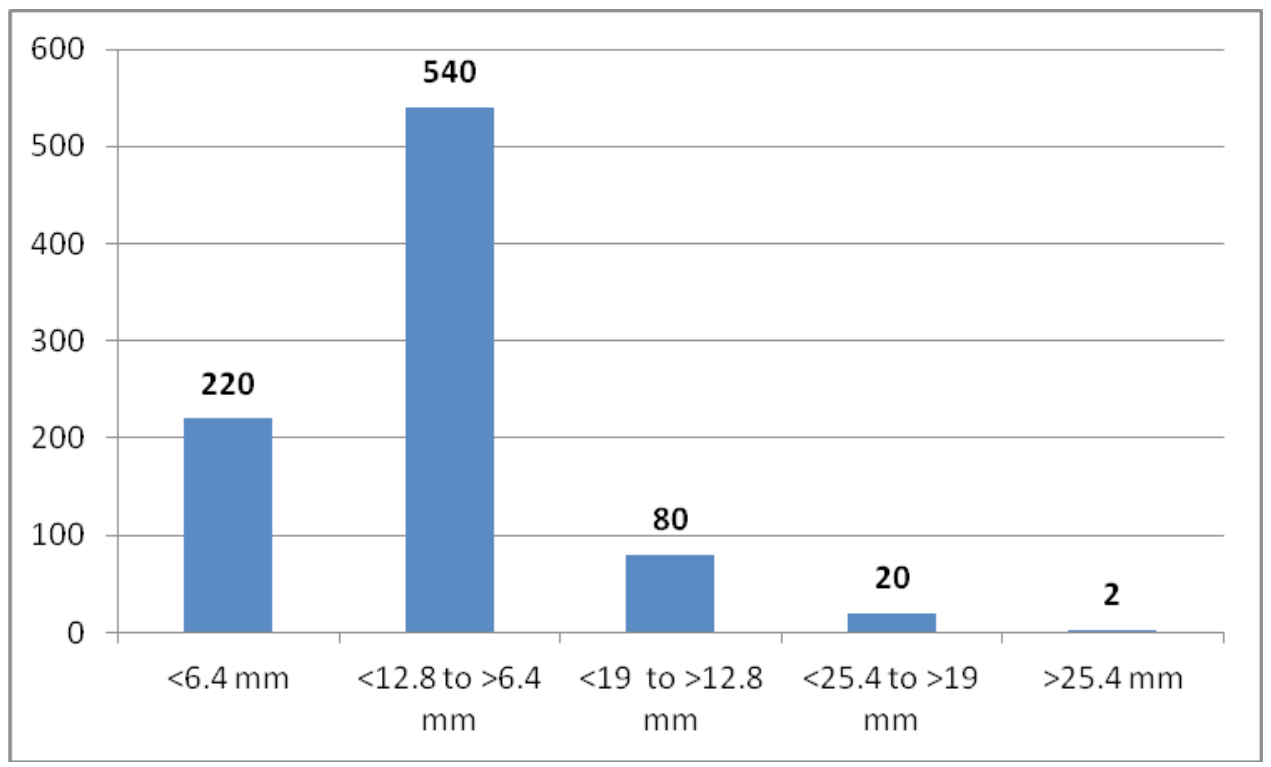

Figure 9-78. Size grade distribution of lithic debitage in Component C.

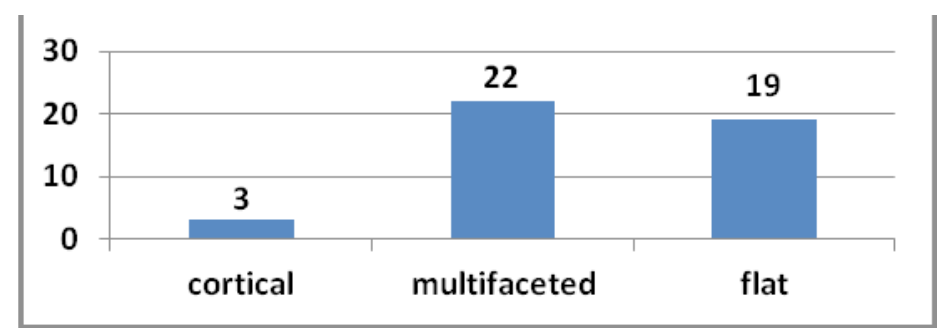

Figure 9-79. Distribution of platform-bearing flakes exhibiting thermal alteration.

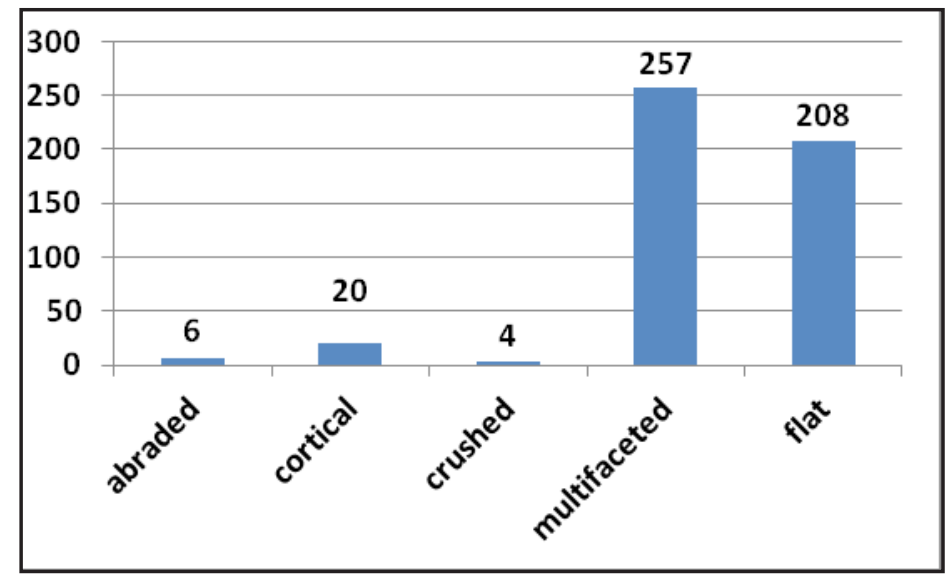

Figure 9-80. Frequency of platforms types in Component $C$ debitage assemblage. 
in the gravel bars along the creeks and river. Also, the paucity of formal chipped stone tools composed of lower quality silicates (e.g., chalcedony, quartzite) is further indication that these raw materials were not selected for producion of formal tools (see Chapter 10.0, Questions 3, 9, and 10 for a more detailed examination of this relationship). The low incidence of cortex on platform-bearing flakes supports the off-site initial reduction of most material and/or use of rounded pebbles and cobbles.

The moderate 57 percent frequency of flatform bearing flakes indicates controlled knapping with a high incidence of biface reduction through 52 percent multifacted platforms plus some core reduction through 42 percent flat platforms. Given that only 4 percent reveal cortical platforms, documents pebbles and/or cobbles were not reduced on-site. Overall, the lithic debitage reflects limited primary or initial reduction of lage packages, with a focus on tool finishing and maintenance.

The very low 5 percent incidence of thermal alteration observed on platform-bearing flakes reflects intentional heat treatment of raw materials was not often perforemed before material reduction. It is quite possible that this small percentage with heat alteration most likely represents discard into thermal features and not intentiaonal heat treatment.

The high frequency of platform-bearing flakes with two or more facets (52 percent) indicates bifacial thinning and/or edge resharpening/rejuvenation were the primary source of the flakes produced on site. Core reduction is also indicated by the presence of platform-bearing flakes with only a single facet. Bifacial reduction flakes, represented more often by multifaceted platforms, are also present and account for a significant proportion of the flakes. Therefore, it is apparent that both bifacial and core forms were reduced on site. However, examination of platformbearing flakes alone cannot reveal what proportion of bifacial reduction flakes originate from bifacial cores as opposed to the modification of large flakes. For that, one must examine the relationship between debris and chipped stone tools (see Chapter 10.0, Question 3 for further discussion).

The horizontal distribution of lithic debitage across Component $\mathrm{C}$ indicates primarily dedicated discard locations (i.e., Features 6 and 18) with possible small dispersed knapping locations away from the boundaries of delineated features. The apparent lithic concentrations away from delineated features are interpreted as remant reduction locations that have been horizontally dispersed over time due to rodent disburbance.

\subsection{Ceramic Analysis}

J. Michael Quigg

The combined cultural data from this component indicates that most recovered artifacts, regardless of their vertical provenience, reflect a single component with only a couple of possible exceptions in the case of individual features. Therefore, the association between the artifacts and artifact classes is very important and contributes to a greater understanding of human behavior and decision making, as reflected in the ceramic assemblage. This component yielded 262 sherds that weigh 2,209.7 $\mathrm{g}$ for an average sherd weight of $8.4 \mathrm{~g}$. This is significantly heavier than the average sherd from Component $\mathrm{A}$, which was $1.2 \mathrm{~g}$.

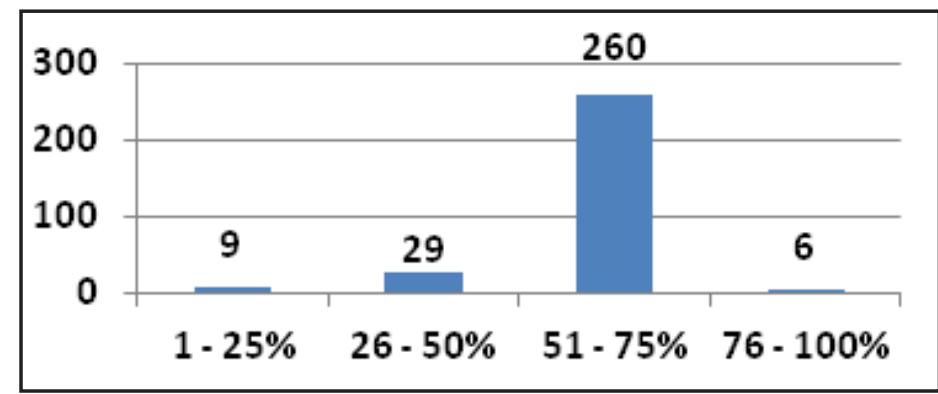

Figure 9-81. Cortex presence on lithic debitage from Component C. 


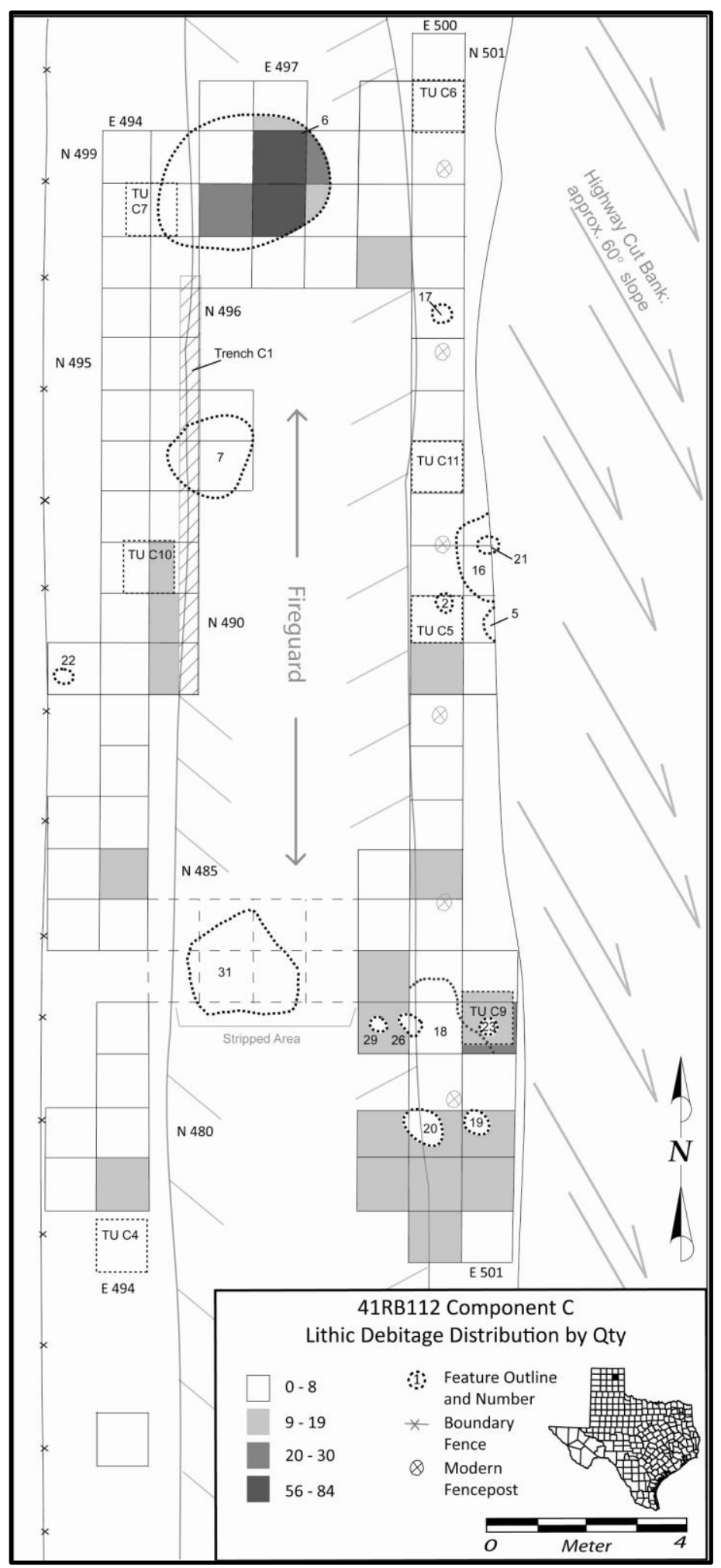

Figure 9-82. Horizontal distribution of flake debris at Component C. 
The overall density was 2.8 sherds per $\mathrm{m}^{2}(262 \div 93$ $\mathrm{m}^{2}$ excavated).

As was the strategy for the ceramic assemblage in Component A, all sherds were macroscopically inspected to identify worked areas, followed by classification into individual vessel groups if possible on the basis of similar visual characteristics of sherds, such as exterior finish, rim similarities, internal core color, tempering agents, decorations, etc. Seven vessels or vessel groups (designated Vessel 1 through 7) were identified, some with as few as 5 sherds and others with as many as 110 sherds. Forty sherds could not be assigned to vessel groups with confidence, as body sherds in general are relatively uniform in surface finish and paste. Given that there is inherent variation in attributes within a single complete vessel, it is not always clear if differences between sherds reflect single vessel variability or represent different vessels. Differences in thickness and exterior variation, allowed for nearly 85 percent of the ceramic assemblage to be assigned to one of the seven identified vessel groups. Only about 4.5 percent of the sherds are less than $2 \mathrm{~cm}$ in diameter, and these are considered crumbs or sherdlets too small to effectively analyze.

Sherds were not brushed or washed in order to preserve any residues or microfossils that might be present and which, through analysis, could identify food resources cooked or stored in the vessels. Sherds with black organic residues adhering to their exterior surfaces were set aside for possible starch grain analysis or radiocarbon dating. In four instances (\#335-8-1, \#342-8-9, \#643-8-1, and $\# 1233-8-1$ ) the crusted organic residue was scraped from sherd exteriors. Starch grain analysis was conducted on 10 sherds that represent a minimum of 3 vessels from 3 different features.

Instrumental neutron activation analysis (INAA) was done to investigate the chemical constituents of the individual sherds and vessels to determine similarities and differences with the potential to identify ceramic production areas. This chemical analysis was conducted on 16 sherds that represent all 7 vessels. To compliment this INAA, petrographic analysis (microscopic examination of the pastes) was also performed on the same sherds to provide a means of identifying the size and type of particles used to temper the clays and enable comparisons of the constituent materials in vessels and parts of vessels.

Each identified vessel group is discussed below, with descriptions of the visual and chemical characteristics of each group, augmented by photographs and illustrations of parts of each vessel. Where appropriate, the results of the technical analyses are presented in each discussion of the vessel group.

\subsubsection{Vessel 1}

This vessel consists of 110 sherds that include 98 body, 5 rim, 4 neck, and 3 basal sherds with a total combined weight of 1,628.8 g (Figure 9-83). This cordmarked vessel is distinctive, in that it is considerably thicker than all save Vessel 3. A relatively large percentage of Vessel 1 is present, which allowed for the reconstruction of major sections of the vessel, thus providing a relatively complete perspective on its overall shape and size. Consequently, more technical analyses were conducted in order to gain an appreciation of the various aspects of a more complete vessel.

Shape: This was a rather squat, wide-mouth jar with an outside orifice diameter of about $18 \mathrm{~cm}$, an estimation based on the presence of roughly 33 percent of the rim. This jar has a vertical rim that is 2.8- to 3.0-cm-tall with a low-angle (144 degrees) shoulder that gradually curves into a rounded base (Figure 9-83). The overall vessel height is projected to have been roughly $22 \mathrm{~cm}$ with a maximum width of $34 \mathrm{~cm}$ at the shoulder. No appendages (e.g., lugs, legs, or handles) were observed on this vessel. The shapes of the rim and shoulder vary slightly on different areas of the vessel.

Construction: At least 19 sherds (i.e., \#153-81, \#338-8-1, \#340-8-3, and \#342-8-8) reveal coil breaks, with concave edges (on minimally 9 sherds), convex edges (on at least 10 sherds; Figure 9-84), and joints or welds visible on at least 5 (Figure 9-85). These recognizable coil breaks occur only on body sherds and indicate that the main body was constructed using a coiling technique. However, no coil lines or joints were observed in the multiple rim 
sherds or near the base as indicative of construction by coiling.

The uppermost recognizable coil break is approximately 64-mm-below the lip on \#247-8-1 and \#342-8-3. The rim, which varies in thickness between 4.8 and $7.6 \mathrm{~mm}$, was apparently added to the shoulder as a single piece. Support for this interpretation comes from one section of rim that reveals multiple linear cut lines at the (\#308-8-3) at the rim shoulder juncture, where it appears that clay was removed from the rims exterior (Figure 9-86). The rim section was perhaps thicker than desired in this area and was thinned by cutting away excess clay, after which no attempt was made to smooth over the resulting cut marks.

The basal sherds of this group are extremely thick (10.0 to $19.0 \mathrm{~mm}$ ) with the first recognizable coil break some $100 \mathrm{~mm}$ from the projected middle of the base. The edges of the basal sherds \#153-8-2 and \#303-8-1 are friable, not sharp or curved like edges observed in the body or neck (Figure 9-87). The base appears to have been formed from a single lump of clay onto which the main vessel body was built through coiling. This would account for the very thick base, crumbly edges, and an abrupt change in thickness of the vessel wall near the lowest discernible coil break. In this manufacturing process, the vessel was constructed in three sections; the base, the body, and the rim. The rim is direct and straight above the slightly curved shoulder. The lip is of variable thickness (4.0- to 7.0-mm-thick) and was flattened while still wet, as indicated by a small lip protrusion of the inner rim in a couple of places. The neck varies from 5.1- to 8.4-mm-thick and gradually thickens to the shoulder area, which is 9.4- to 10.5 -mm-thick. The thickness of the body sherds varies from 8.1 to $10.5 \mathrm{~mm}$. No decorations were present on either the lip or the rim.

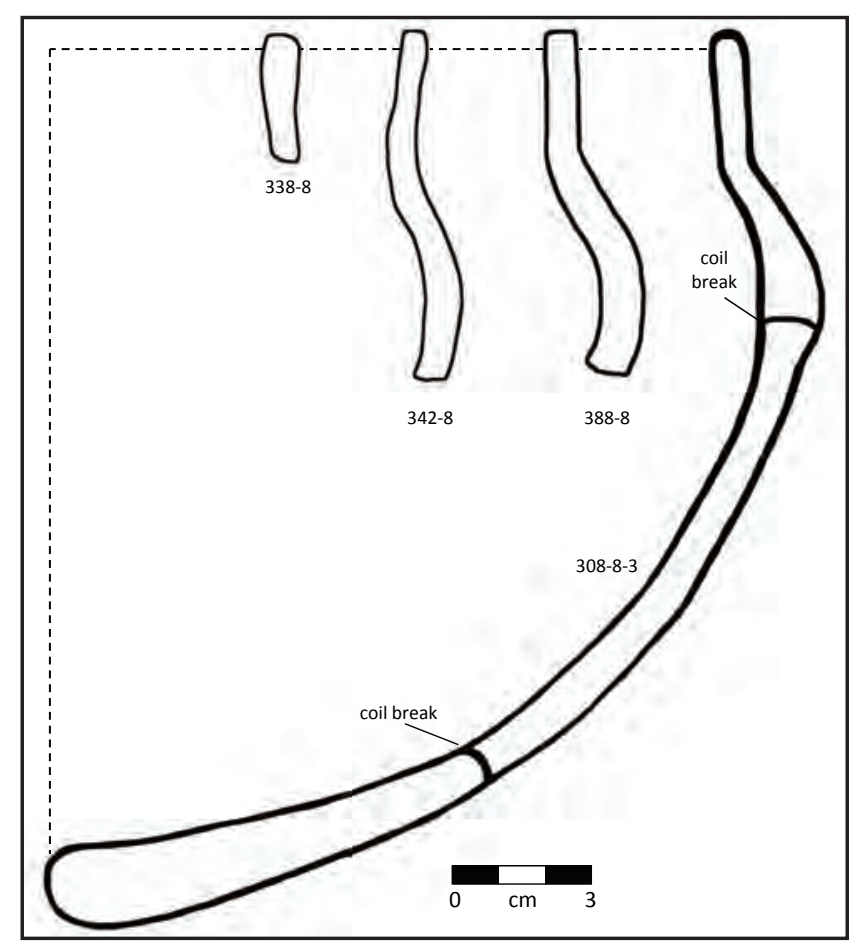

Figure 9-83. Profile drawings of rim sherds from Vessel 1 showing slight variations in rim and shoulder shapes. 


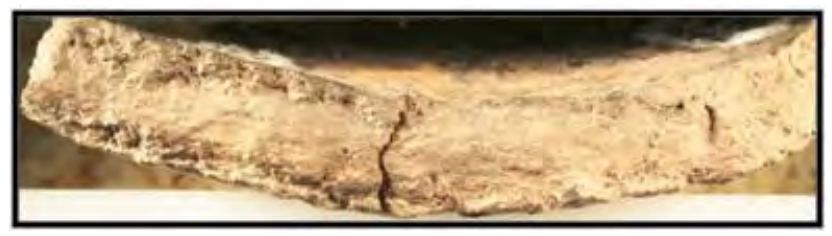

Figure 9-84. Photograph of Vessel 1 sherd \#303-8-1 profile showing the curved edge of a coil.

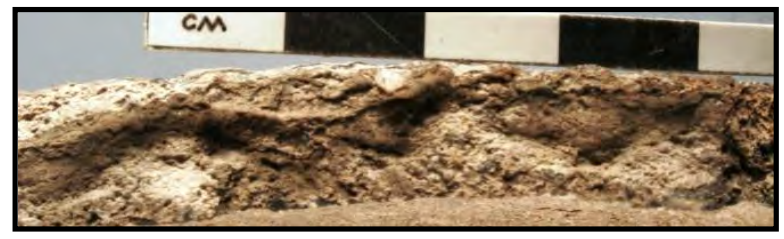

Figure 9-85. Detail of poorly welded coils in rim sherd \#303-8-1 of Vessel 1.

Exterior Surface: The surfaces exhibit variable cordmarkings, predominately broad, deep, welldefined and distinct cordmarks over the vessel body (Figure 9-88) that stop at the rim/neck juncture. The 28- to 30-mm-tall rim has no cordmarkings on it whatsoever. As previously mentioned, one portion of the rim juncture exhibits a series of horizontal cut lines that may be the result of thinning of this section (see Figure 9-86). Such cut lines are absent on sherds from other parts of the rim of this vessel. Most body sherds have deep, wide vertical cordmarks that do not overlap, with the exception of one sherd (\#333-8-1) that measures 7.5-by-5.5 cm, with overlapping cordmarkings at slightly different angles to one another.

Most basal sherds have partially or completely obliterated cord impressions (Figure 9-87). One basal sherd (\#153-8-2) reveals only scattered and partial cord impressions on the convex exterior that is covered with a film of calcium carbonate (Figure 9-89). The shoulder area (i.e., \#308-8-2 and \#308-83 ) has very dark organic crusts adhering to the cord impressions. Most surfaces are light gray (10YR $7 / 2$ ) and bear some amount of calcium carbonate.

Interior surface: Sherd surfaces are variable, some rough and irregular, while others are relatively smooth to somewhat bumpy. The rim areas are uneven to bumpy, with pits and cracks in places. As can been seen on rim/neck/shoulder sherd (\#3088-3) in Figure 9-90, small pits, linear cracks, and imperfections are at the rim/shoulder juncture. These cracks likely mark differential drying where the rim section was joined to the rest of the already leather-hard vessel. No smoothing or wiping lines are visible through the shoulder region (i.e., \#308-81 ). The lower shoulder reveals linear cracks and coil breaks (\#250-8-2). A couple of sherds have what appear to be small finger- or thumb-size shallow impressions. The interiors of the base and some of the body sherds are very smooth and very dark gray (10YR 3/0). On sherd \#153-8-2, the surface is quite smooth, with very faint lines created during smoothing of the damp clay, whereas some tiny pits and dents may be use attritions. The interior surfaces are mostly light gray (10YR 7/2), although the base sherd is very dark gray (10YR 3/0).

Paste: Macroscopic observations reveal abundant quartz sand temper along with what appears to be tiny chunks of scoria (Figure 9-91). The profiles of selected sherds also show variability in core colors in different parts of the vessel. Most cores are zoned, with two and sometimes three colors, as in body sherd \#362-8-1, with gray (10YR 6/1) at the center, with occasional thin black (7.5YR 2/0) banding of interior edge and dark brown (7.5YR 4/4) on exterior edge. Petrographic analysis on three sherds from different parts of Vessel 1 (body \#362-8-1, 

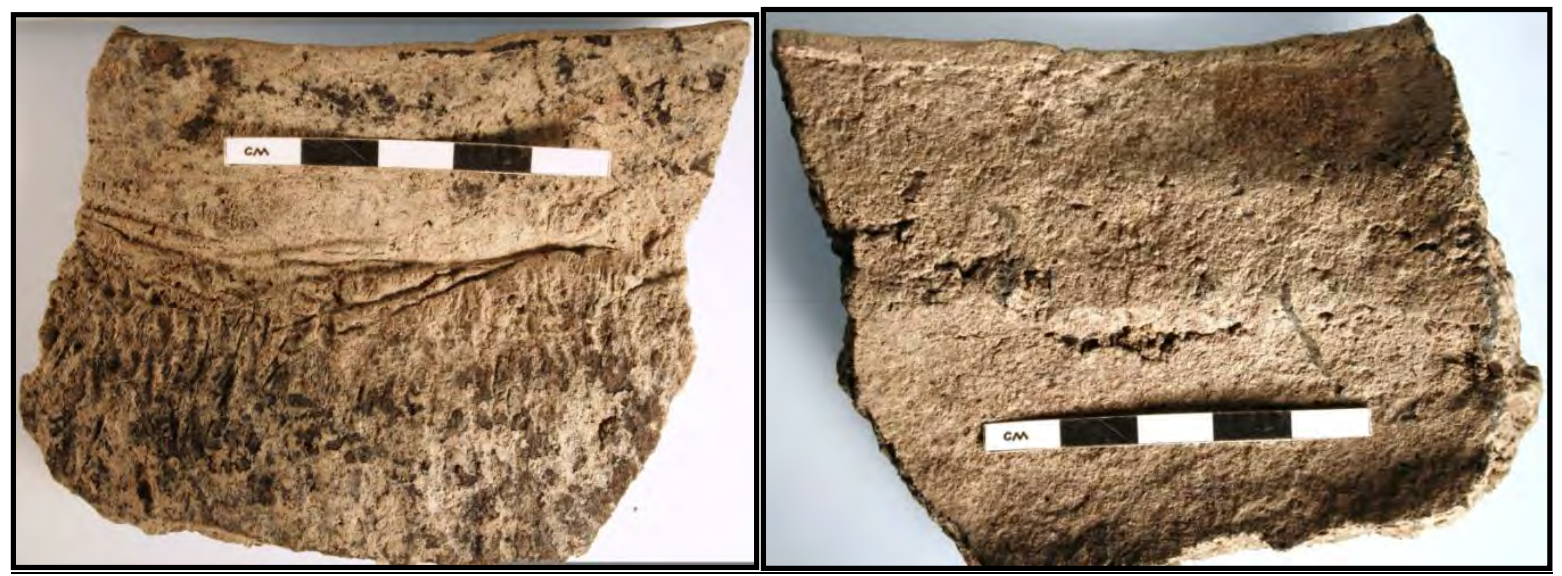

Figure 9-86. Close-up photographs of rim/neck/shoulder sherd (\#308-8-3); exterior (left) and interior (right) from Vessel 1.

Note that the exterior exhibits cut lines at the neck and the interior exhibits longitudinal cracks at $\mathrm{rim} /$ neck juncture that may indicate a poorly welded coil edge.

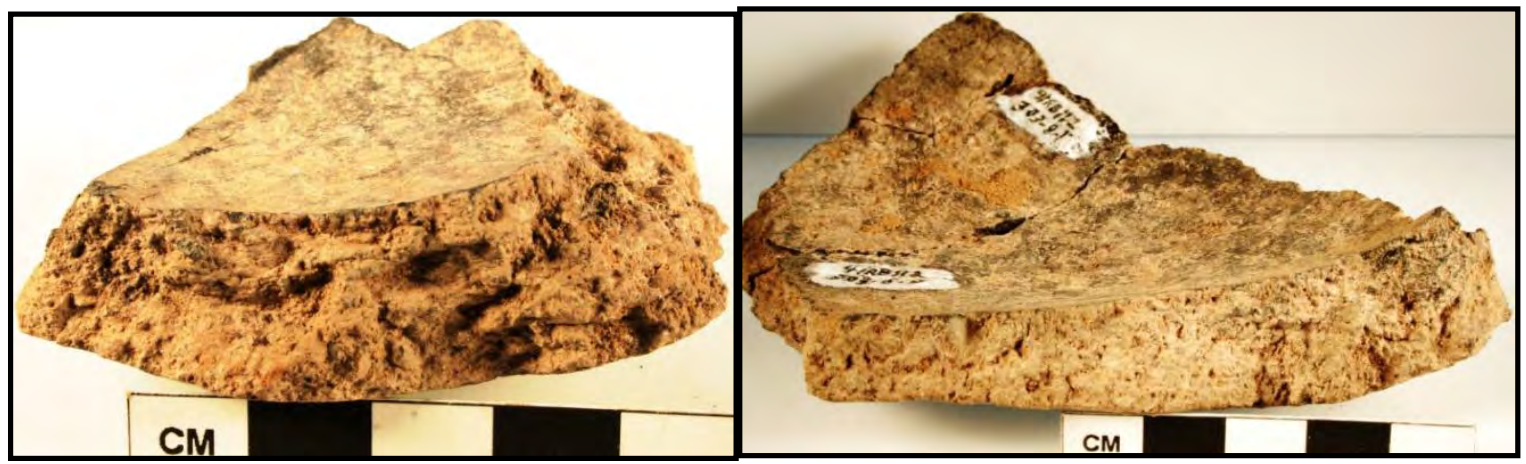

Figure 9-87. Detail of friable edges of thick basal sherds \#153-8-2 (left) and \#303-8-1/\#3088-2 (right) of Vessel 1.

rim \#338-8-6, and base \#303-8-1) revealed all three sherds were dominated by basalt with pyroxene (10 to 15 percent) and minor amounts of other minerals and assigned to the same broad basal temper class. However, because of minor difference in the various constituents documented, these three sherds were assigned to three different Paste Groups (Table 9-16; Appendix F). The observations on the individual sherds indicate that the rim paste is different from the paste in the body and base sherds. The estimated amount of particles present in the clay is quite high (28 to 57 percent), with the rim having the least particles (28 to 44 percent) and the base the most particles (47 to 57 percent). The percent voids and the identified materials are also different between the vessel parts. This may reflect the tiny percentage of the vessel represented by the thin sections and therefore, just a normal sampling difference, or perhaps the rim, base and body were actually formed from separate lumps of clay with slightly different paste composition. This is a very significant discovery as it indicates considerable diversity within a single vessel and should point out the fallacy of only sampling one sherd from a single pot to identify the constituents of the entire pot. It also reflects on the manufacturing technological of this and likely other vessels. 


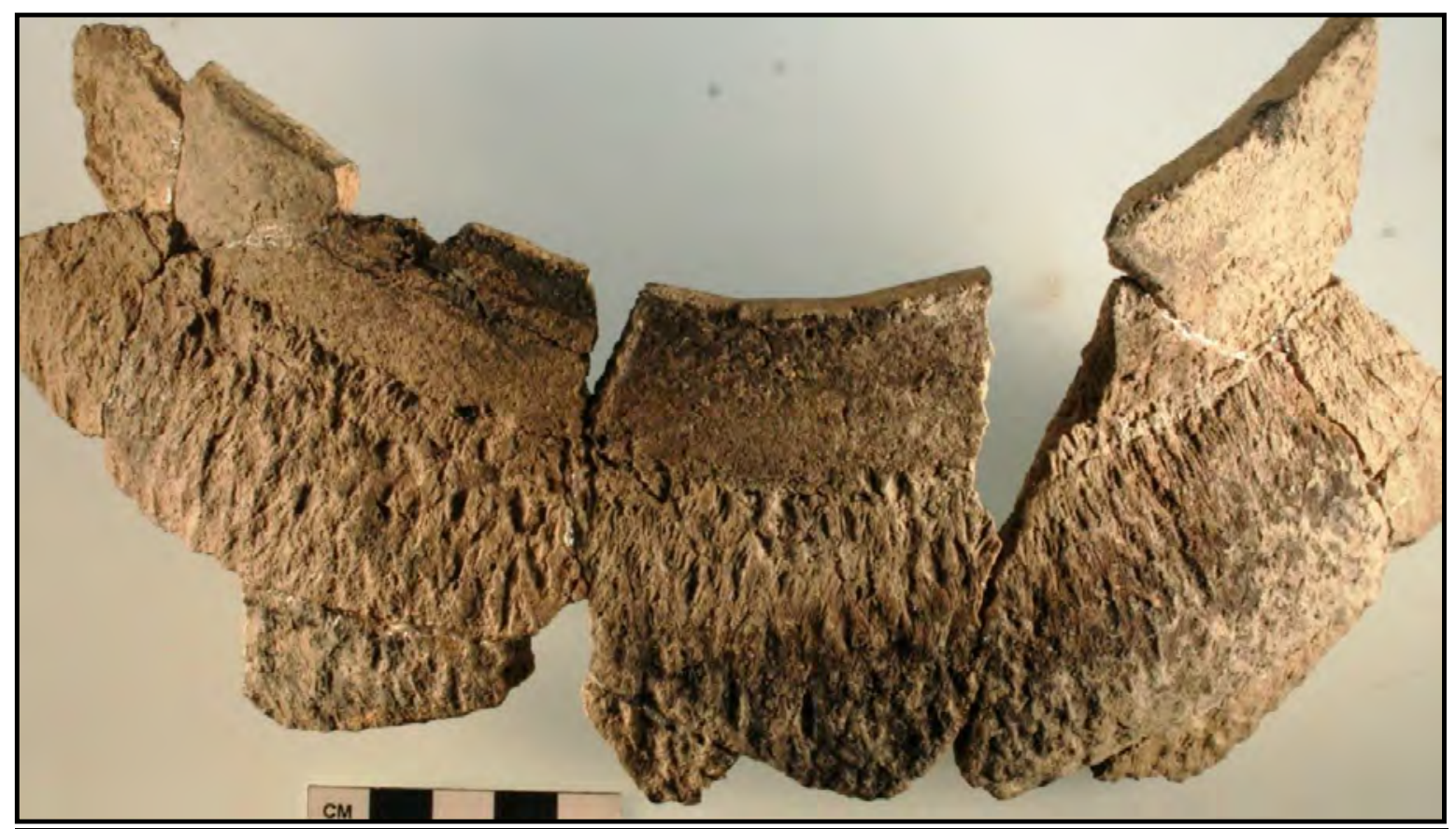

Figure 9-88. Partially reconstructed upper section of Vessel 1, showing detail of exterior lip, rim, neck, and shoulder area markings.

Note abrupt stoppage of well-defined cordmarks at base of rim and the presence of dark organic residues.

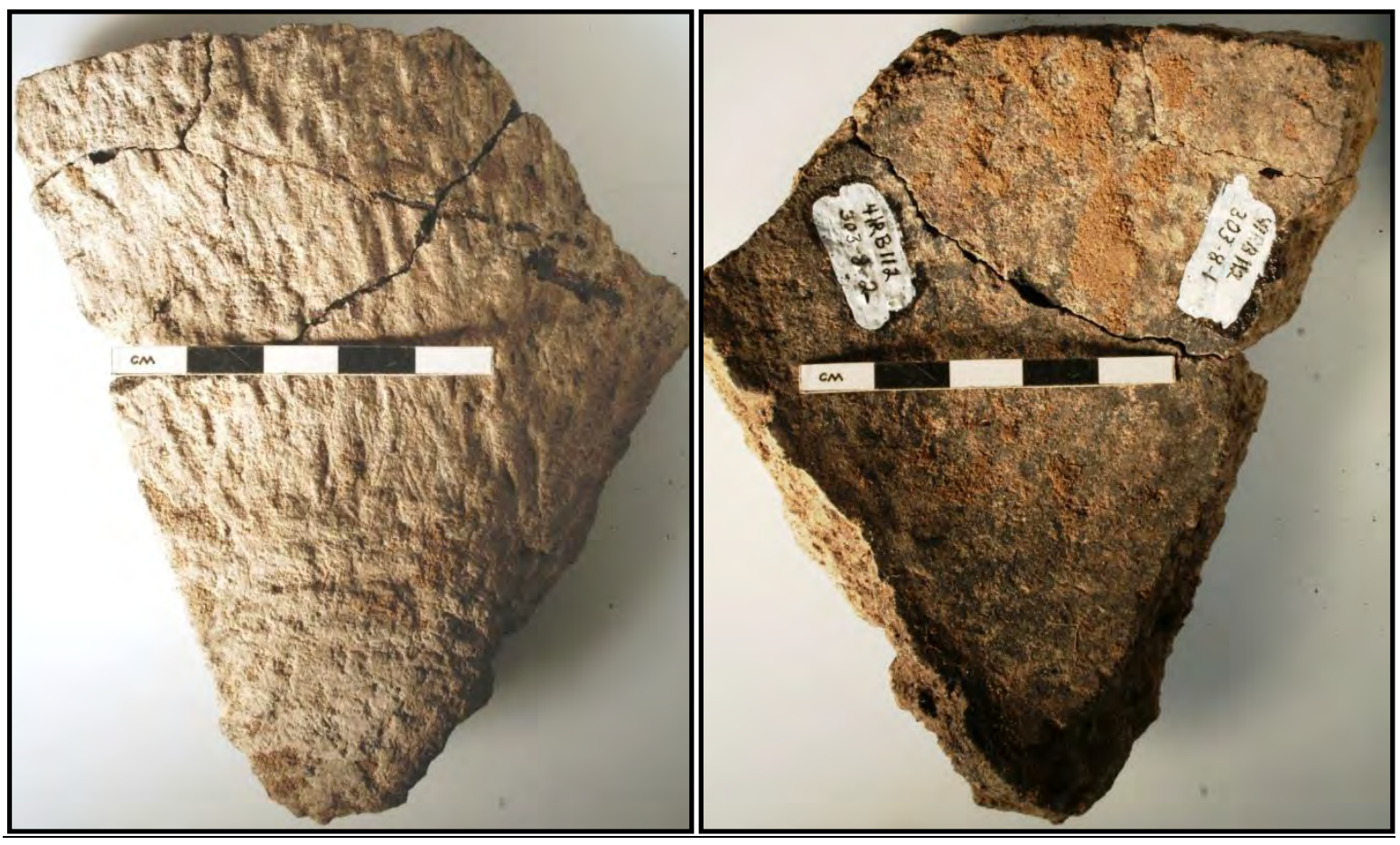

Figure 9-89. Detail of thick basal sherd (\#303-8-1 and \#303-8-2), exterior (left) and interior (right) from Vessel 1.

Note the partially obiliterated cordmarks at the very bottom and the dark organic stain on the interior. The first detectable coil break is at the very top of the sherd. 


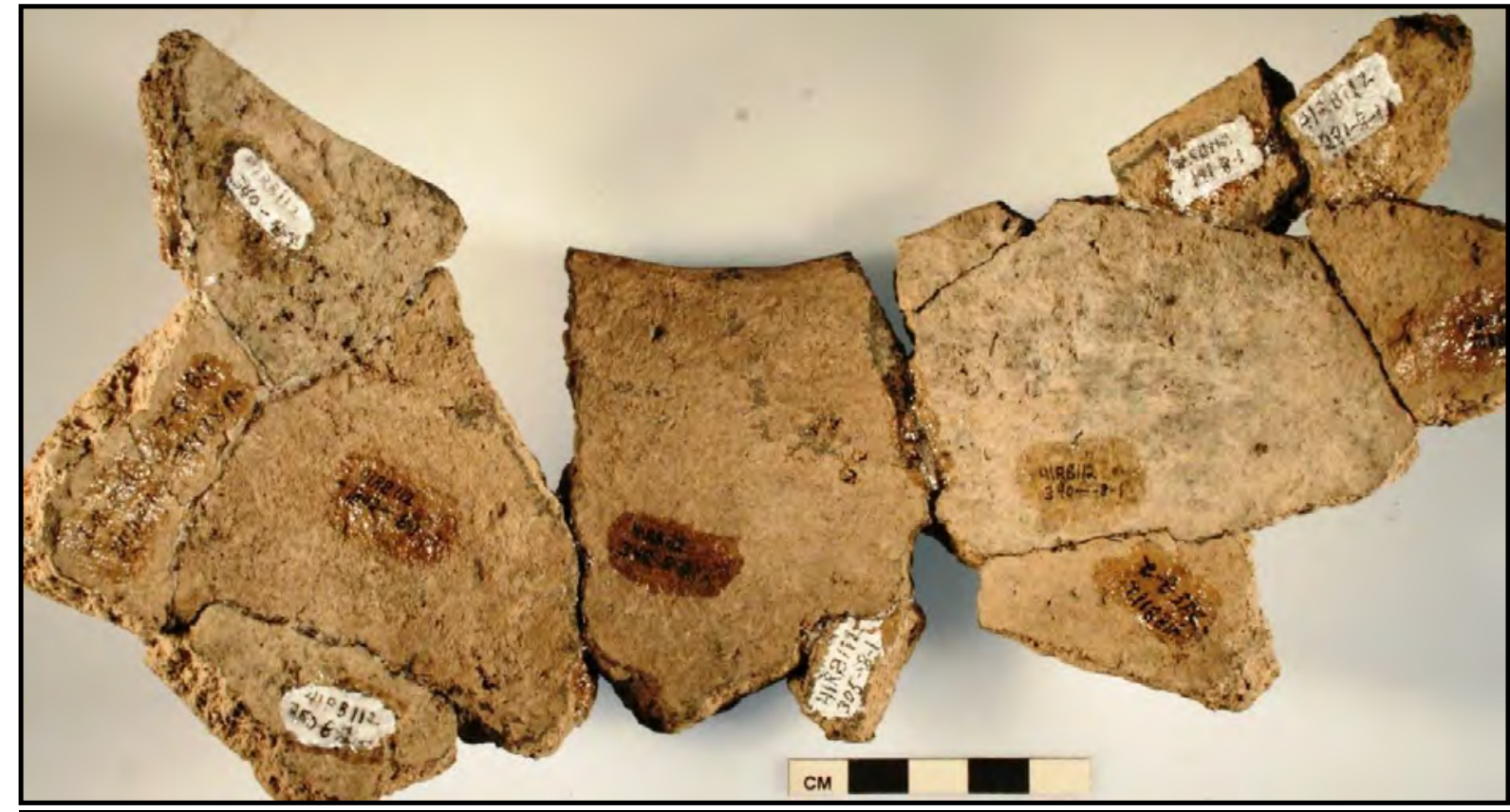

Figure 9-90. Partially reconstructed upper part of Vessel 1, showing detail of interior of lip, rim, and shoulder area.

Note minor imperfections.

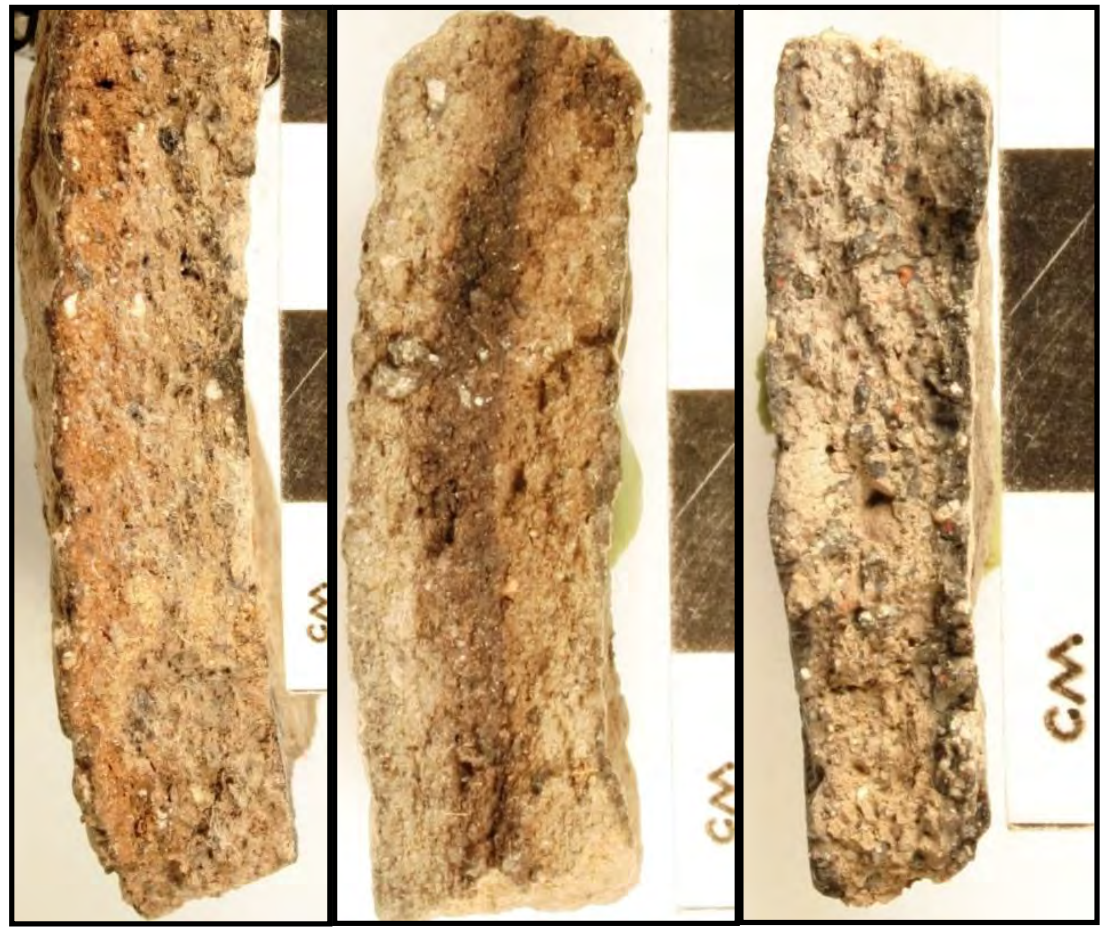

Figure 9-91. Profile photographs showing paste from base (\#303-8-1, left), body (\#335-8-1, middle), and rim (\#342-8-1, right) sherds of Vessel 1.

Note core color and temper density variations between vessel sections. Scales are not identical. 
Starch Grain Analysis: Six sherds were analyzed, which included two rims (\#308-8-2 and \#308-83 ), one shoulder (\#308-8-1), two body (\#177-8-1 and \#342-8-9), and one basal sherd (\#153-8-2). Two sherds (base and one body) yielded relatively few starch grains, whereas the others yielded high quantities of starch grains. The base and one body sherd yielded two grains of possible lily bulb. The highest frequencies per sherd were 24 grains of maize starch from one rim and 16 grains of little barley (Hordeum pusillum) starch from one of the body sherds. One possible mesquite grain was present, and at least two unidentifiable grains were gelatinized (Appendix D). In total, these 6 sherds yielded: 36 maize grains, 1 possible maize grain, 2 damaged maize grains, 51 lenticular little barley grains, 2 damaged little barley grains, 9 unknown grains, and two possible lily grains (Appendix D).

INAA: Six sherds (two rims [\#308-8-2 = TRC648 and \#338-8-2 = TRC569], two body [\#308-8-6 = TRC646 and \#362-8-1 = TRC565], and two basal [\#118-8-1 = TRC650 and \#303-8-1 = TRC573]) were chemically analyzed. Four of the six sherds were chemically similar and were assigned to Chemical Group 1. One basal sherd (\#118-8-1 = TRC650) was assigned to Chemical Group 4 (Appendix G) and apparently was not, in fact, part of Vessel 1 , and was re-evaluated and assigned to Vessel 3.

Radiocarbon Dating: A 19-gram section of the upper rim sherd (\#308-8-19) from 67 to $70 \mathrm{cmbs}$ in N482 E500 was sent for radiocarbon dating. This sherd yielded a $\delta^{13} \mathrm{C}(-29.1 \%$ o) corrected AMS date of $21,550 \pm 70$ B.P. (UGAMS-8457) or cal 24,230 to 23,444 B.C. This date is extremely old and definitely not acceptable for the true cultural age of this vessel. A plausible explanation for this date is that very old organic material was in the clay selected for construction of this vessel and those organic particles were not totally combusted during the firing process. The combination of thick vessel walls and probable low firing temperature potentially had a significant role in preventing the total combustion of the old organics. The very negative $\delta^{13} \mathrm{C}$ value is indicative of $\mathrm{C}_{3}$ grasses in the subfamily of Arundinoideae, Festucoideae (i.e., wildrye and little barley) and some Panicoideae (Smith and Brown 1973). The value indicates 100 percent $C_{3}$ plant residues were inside the vessel walls. The little barley starch grains identified reflects a $\mathrm{C}_{3}$ grass and support the very negative $\delta^{13} \mathrm{C}$ value obtained during the radiocarbon dating. Significantly, obvious $\mathrm{C}_{4}$ products recovered from this component, such as bison, maize residues, and maize starch grains, were not represented in the $\delta^{13} \mathrm{C}$ value of this dated sherd.

Crusted organic residues scrapped from the exterior of Vessel 1 sherd \#305-8-19 were also AMS dated. This residue yielded a $\delta^{13} \mathrm{C}(-19.9 \%)$ corrected AMS date of $590 \pm 30$ B.P. (Beta-307381) or cal A.D. 1300 to 1410 . This date is statistically identical to the 12 accepted AMS dates from two wood charcoal, one bone collagen, and nine maize kernels from Component $\mathrm{C}$. The $\delta^{13} \mathrm{C}$ value is indicative of nearly equal parts of $\mathrm{C}_{4}$ and $\mathrm{C}_{3}$ products, which is supported by the starch identifications of two primary food items, maize $\left(\mathrm{C}_{4}\right)$ and little barley $\left(\mathrm{C}_{3}\right)$.

Horizontal Distribution: Sherds that represent this vessel were widely distributed across the excavations area (Figure 9-92). A dense concentration was in the vicinity of Features 23, 26, and 29 in the area of the Feature 18 "ghost" pithouse. Sherds from Vessel 1 were also recovered from the floor of pithouse Feature 6, at the northern end of the excavation area, as well as around Feature 18, definitively linking these two features together.

\subsubsection{Vessel 2}

This vessel consists of five sherds that include three body, one rim, and one rim/neck sherd that weigh a total of $30.8 \mathrm{~g}$. Faint cordmarked impressions are present on the exterior surface (Figure 9-93).

Shape: Based on the rim and neck area the vessel is likely a globular jar but the basal shape is unknown. The rim-neck angle is about 135 degrees, but it is not clear if a defined shoulder is present or the angle continues into a rounded body. Only about 10 percent of the rim is present, with a calculated orifice diameter of roughly $11 \mathrm{~cm}$. The lip is flat with slightly rounded margins. The rim is vertical and straight and both the lip and rim lack decorations. The lip is 6.5-mm-thick, the rim averages about 6.7-mm-thick, and the neck is 4.7 - to 5.6-mm-thick. 
Table 9-16. Petrographic Identifications and Quatifications on Three Different Parts of Vessels 1.

\begin{tabular}{|c|c|c|c|c|c|c|c|c|c|c|c|c|c|c|c|c|c|c|c|c|c|}
\hline \multirow[b]{2}{*}{ 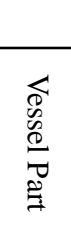 } & \multirow[b]{2}{*}{ 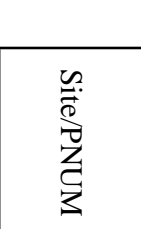 } & \multirow[b]{2}{*}{ 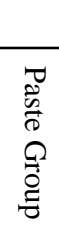 } & \multicolumn{5}{|c|}{ Paste Attributes } & \multicolumn{3}{|c|}{ Quartz } & & \multicolumn{6}{|c|}{ Igneous } & \multirow{2}{*}{ 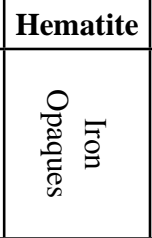 } & \multicolumn{3}{|c|}{ Other } \\
\hline & & & 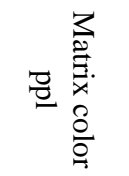 & 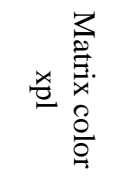 & 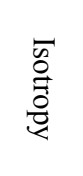 & के & 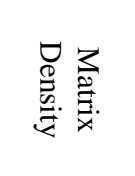 & 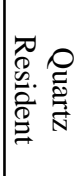 & م & 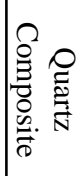 & 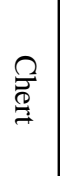 & 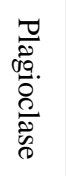 & 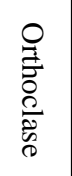 & 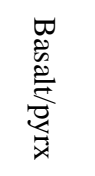 & $\begin{array}{l}\text { d } \\
0 \\
0 \\
0 \\
0 \\
0\end{array}$ & : & 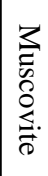 & & $\begin{array}{l}\text { : } \\
: \\
0 \\
0 \\
0 \\
0 \\
0\end{array}$ & $\stackrel{\overbrace{}}{\stackrel{8}{2}}$ & $\frac{\Omega}{\mathscr{2}}$ \\
\hline Rim & \#338-6 & I & $\begin{array}{c}\text { medium } \\
\text { brown }\end{array}$ & $\begin{array}{l}\text { dark } \\
\text { golden } \\
\text { brown }\end{array}$ & iso & 5 & moderate & $5-7$ & $3-5$ & $1-2$ & & $3-5$ & & $10-15$ & $3-5$ & & & $1-2$ & & tr. & $2-3$ \\
\hline Body & \#362-8-1 & $\mathrm{FF}$ & $\begin{array}{c}\text { light } \\
\text { tannish- } \\
\text { gray }\end{array}$ & $\begin{array}{c}\text { medium } \\
\text { gray }\end{array}$ & iso & 20 & light & 25 & $2-3$ & 1 & $1-2$ & $1-2$ & $1-2$ & $10-15$ & & 1 & 1 & $1-2$ & $2-3$ & & \\
\hline Base & \#303-8-1 & GG & $\begin{array}{c}\text { light } \\
\text { tannish- } \\
\text { gray }\end{array}$ & $\begin{array}{l}\text { golden } \\
\text { brown }\end{array}$ & aniso & $10-15$ & moderate & 25 & $2-3$ & 1 & $1-2$ & $1-2$ & $1-2$ & $10-15$ & & 1 & 1 & $1-2$ & $2-3$ & & \\
\hline
\end{tabular}

Numbers are in percentages, see Appendix F for descriptions of categories 
Construction: A neck section that is thinner than the overlying rim area and the underlying body section may indicate that the rim was not added as a separate section, but was pinch-pulled from the neck. No coil breaks were observed that would indicate that this vessel was manufactured by the coiling technique. The rim/neck sherd is relatively soft and breaks easily.

Exterior Surface: The surface has shallow, faint impressions that are too unclear for determination of the precise orientations of the markings. The markings may actually be impressions of a net and/ or fabric, rather than cordmarks. The impressions start at the lip and continue downward along the neck without any significant visible changes. The surface is a light gray (10YR 7/2), partly due to the presence of a film of calcium carbonate.

Interior surface: Tiny imperfections such as pits and cracks are present on the relatively smooth surface that is covered with a white (10YR 8/1) film of calcium carbonate (see Figure 9-93). No striations or wiping marks are visible. A slight ridge is present at the juncture of the rim and neck.

Paste: Macroscopically visible quartz sand grains and black particles (possibly basalt) are present in the reddish yellow (7.5YR 6/6) paste. The petrographic analysis on part of \#259-8-2 revealed a dense anisotropy paste, with 5 to 10 percent voids, 16 to 28 percent particles that include 3 to 5 percent resident quartz grains, 2 to 3 percent common quartz, 3 to 5 percent rhyolite, 2 to 3 percent biotite, and 3 to 5 percent other minerals (Appendix F). This is the only sherd from Long View in which rhyolite was identified and the only sherds in this component with no basalt with pyroxene. This sherd was in the broad crushed rock and mineral class, specifically assigned to Paste Group EE and the only specimen in that group. This vessel paste is different from other vessels in this component.

Starch Grain Analysis: Sherd \#659-8-1 yielded one lenticular little barley (Hordeum pusillum) grain plus one gelatinized grain of little barley (Appendix D).

INAA: A rim section that refit with rim/neck \#2598-2 (TRC567) was subjected to chemical analysis with the result that this sherd belongs in Chemical Group 1 (Appendix G). This is the same group to which Vessels 1, 5, and 6 are assigned.

Horizontal Distribution: These five sherds came from widely dispersed units, which included one unit in pithouse Feature 6 (see Figure 9-92).

\subsubsection{Vessel 3}

This vessel is represented by 16 sherds that include 14 body, 1 rim, and a possible basal sherd, with a total weight of $188.2 \mathrm{~g}$. This is a relatively thick vessel of predominately faintly cordmarked exterior treatment (Figure 9-94). The largest piece is a rim sherd (\#350-8-1) about 9-cm-long with a 3-cm-long lip, which refits with a second large sherd (\#3498-1) to reveal the general shape of the upper part of a neckless vessel (Figure 9-94). Most sherds are coated with a film of calcium carbonate.

Shape: The refit upper section lacks any sign of a neck, indicating an elongated jar. The 30-mm-long lip section (\#350-8-1) represents roughly 7 to 10 percent of the rim, allowing for a projected orifice diameter of about $10 \mathrm{~cm}$. The apparent basal sherd (\#118-8-1) is quite small in diameter and thicker than the other sherds, and if this is a true indication of the vessel bottom, then the base was nearly flat or broadly rounded (Figure 9-94).

Construction: Most breaks are straight and angular, though one sherd (\#297-8-1) bears a convex edge indicative of the edge of a coil. It is believed the main body of the vessel was constructed by coil building. The lip is thin, varying from 8.1 to $8.2 \mathrm{~mm}$, and slightly slanted to the inside where the edge of the lip is rounded, in contrast to the angled outer lip edge. The outer edge reveals a slight polish, is well-defined, and shows no obvious chipping from use. The lip lacks decorations. The body varies from 6.4- to 10.4-mm-thick, whereas the base varies from 10.3- to 12.6-mm-thick. The bottom sherd is friable with irregular breakage patterning in comparison to the other sherds (Figure 9-95). Sherd \#349-8-1 exhibits very shallow and faint wiping striations that are parallel to the rim.

Exterior Surface: The cordmarked exterior varies somewhat, with shallow impressions that 


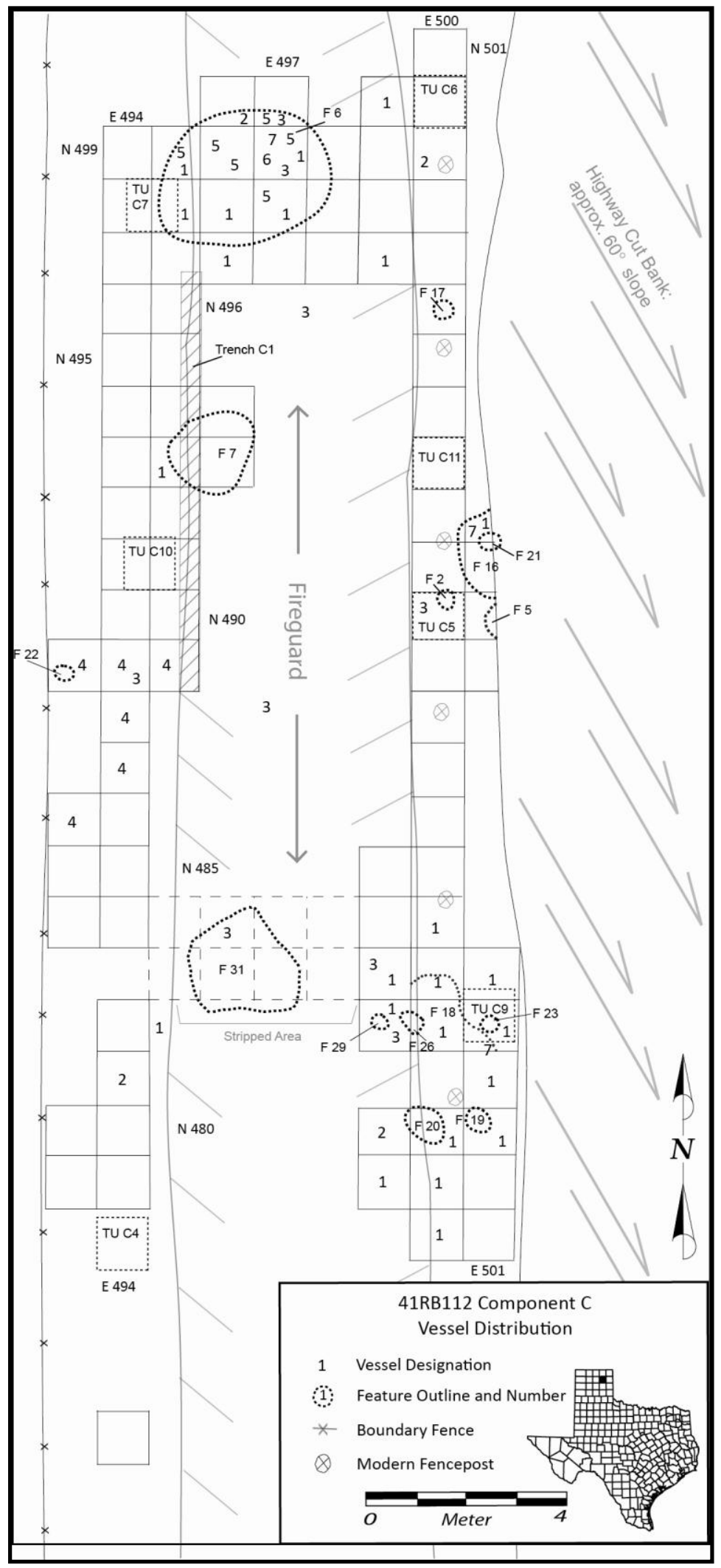

Figure 9-92. Horizontal distribution of sherds of identified vessel groups across the excavations area. 


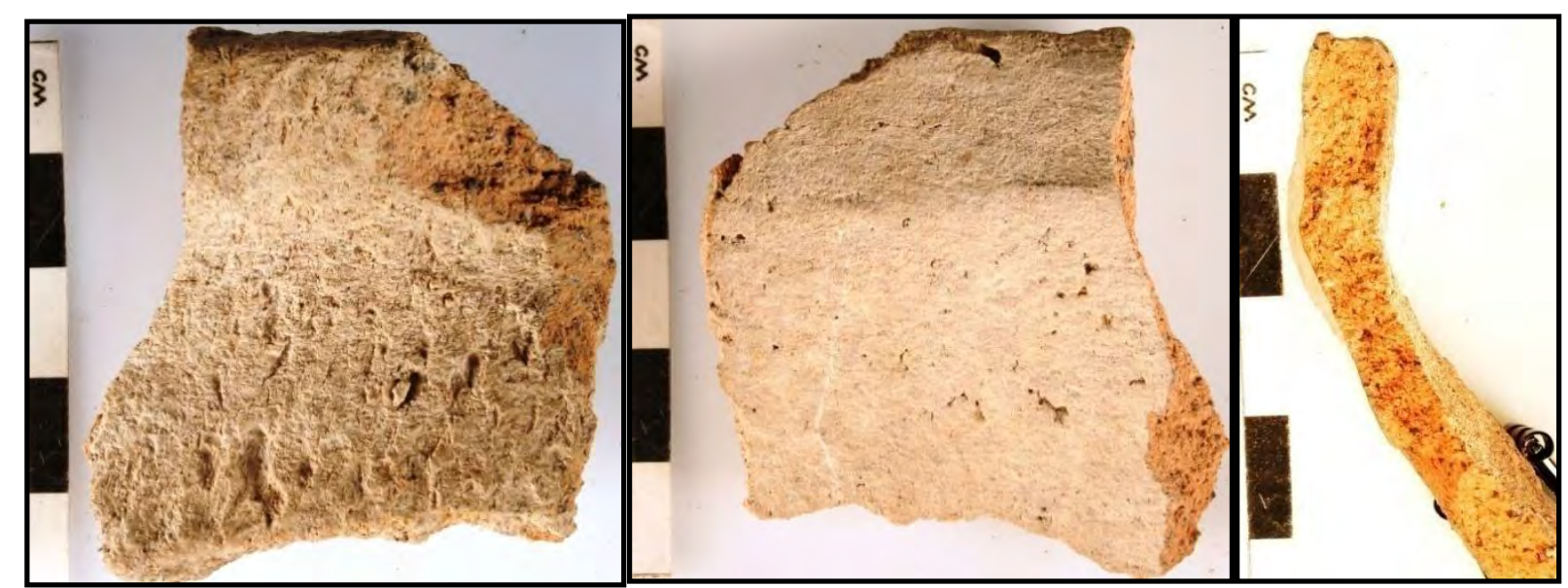

Figure 9-93. Vessel 2 rim sherd \#259-8-1 showing detail of exterior (left), exterior (middle), and profile (right).

Note the faint, shallow cordmarks on exterior, minor imperfections on interior and limited temper in profile.
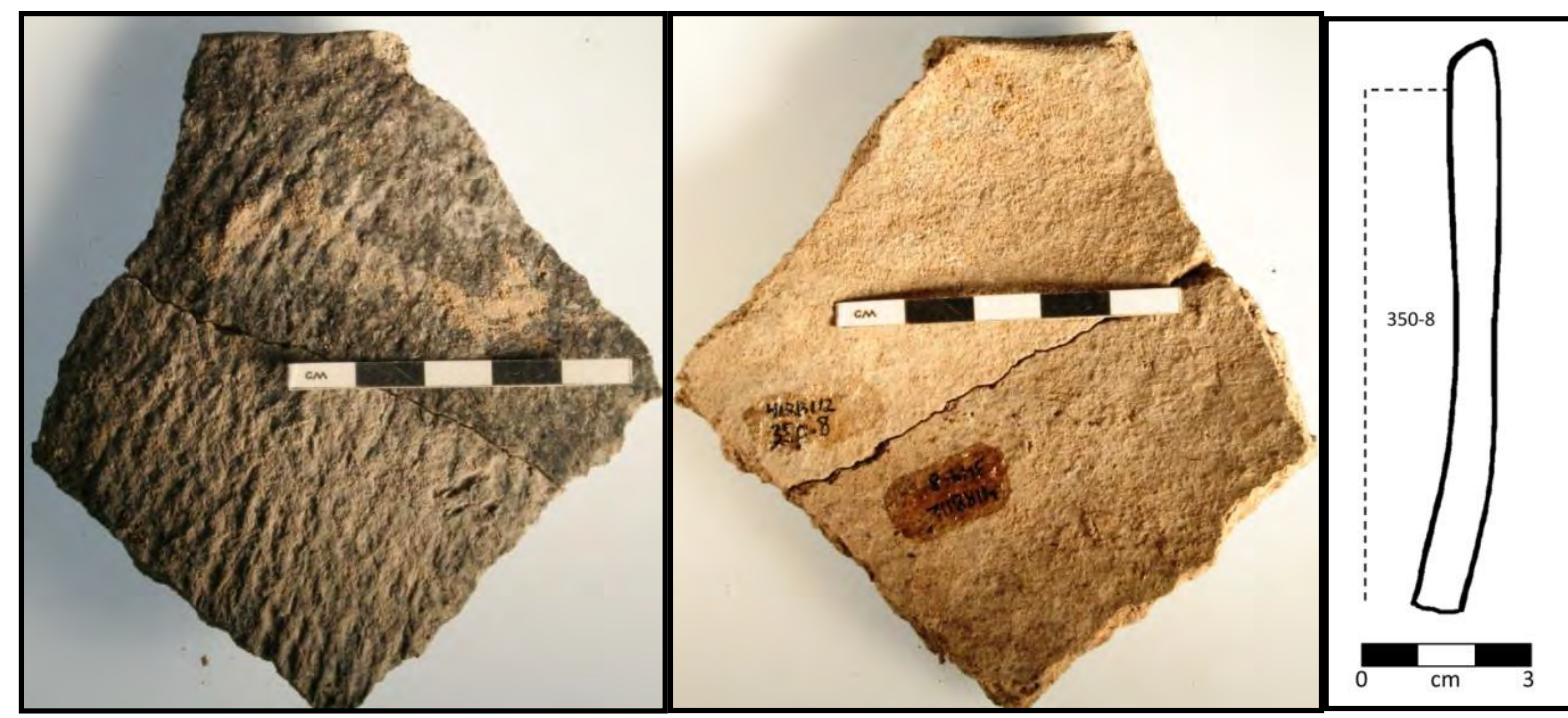

Figure 9-94. Vessel 3 rim refit (\#350-8-1 and \#349-8-1) showing details of exterior (left), interior (middle), and rim profile (right). 


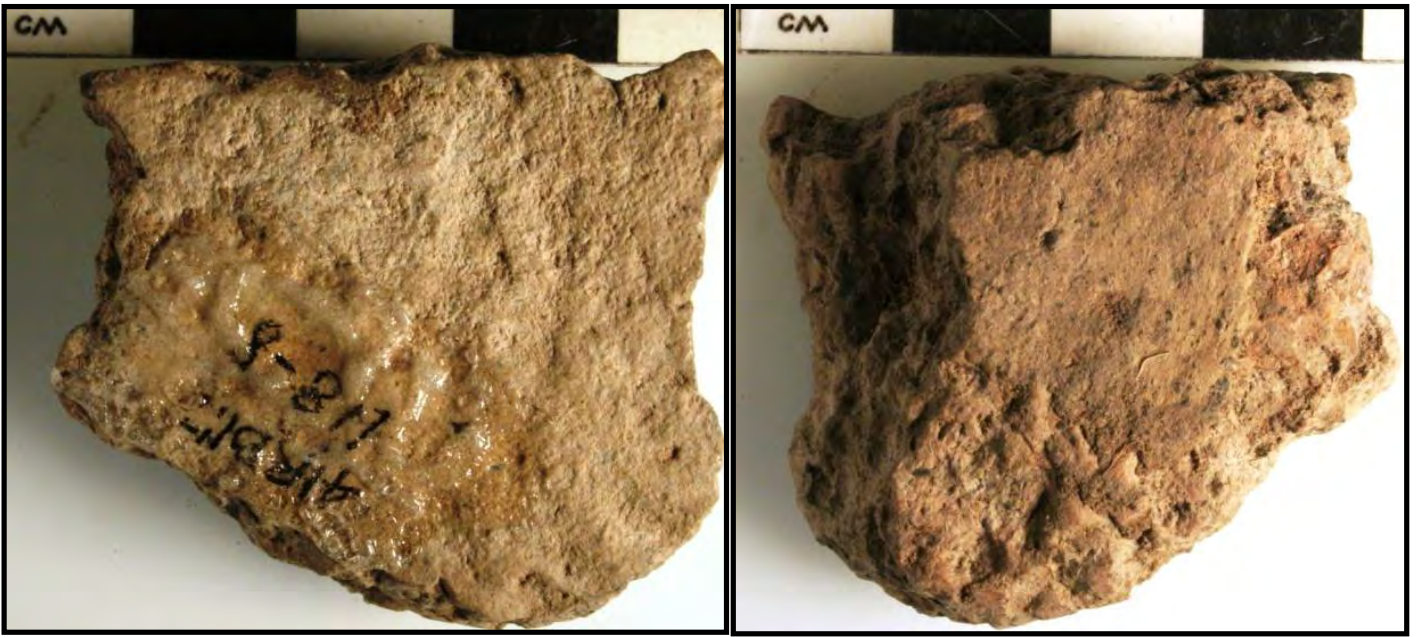

Figure 9-95. Basal sherd (\#118-8-1) of Vessel 3 showing details of exterior (left) and interior (right).

Note crumbly and uneven breaks compared to other sherds.

are well-defined on most sherds but partially smoothed on a few others (see Figure 9-95). The cord impressions extend to the lip and are oriented at roughly 35 degrees to the rim, angling from the upper right to the lower left. The upper rim portion of \#350-8-1 and \#349-8-1 is covered with crusted organic residue under a calcium carbonate film. The one probable basal sherd (\#118-8-1) has mostly obliterated cord impressions. The exterior is a very dark gray (10YR 3/1) where it is not obscured by white (10YR 8/2) calcium carbonate.

Interior Surface: In general, the surface is relatively smooth with no significant flaws or imperfections, though tiny pits and cracks are present on a few sherd interiors (see Figure 9-94). The base has a very smooth interior with tiny temper particles near the surface. The interior is brownish gray (10YR $6 / 2$ ) where not obscured by calcium carbonate.

Paste: Macroscopic inspection reveals relatively densely tempered sherds with abundant dark, angular particles that resemble scoria, with sparse rounded quartz sand grains. The texture of the basal sherd differs from the other sherds in that it crumbles compared to the dense paste in other sherds. The core is mostly reddish yellow (7.5YR 6/6). Petrographic analysis on part of body sherd \#349-8-1 revealed dense isotropy paste with 7 to 10 percent voids, 17 to 29 percent particles that include 10 to 15 percent basalt with pyroxene, 3 to 5 percent common quartz grains, 3 to 5 percent caliche, and 1 to 2 percent other minor particles. This sherd was assigned to the broad basalt temper class and specifically to Paste Group I (Appendix F). It is generally similar to all other vessel pastes in this component, except the paste in Vessel 2.

Starch Grain Analysis: Two sherds, one upper body (\#349-8-1), and one rim (\#350-8-1) were analyzed. The body sherd yielded three maize grains, a damaged maize grain, and one damaged unidentified grain. The rim yielded 20 lenticular little barley (Hordeum pusillum) grains (Appendix D). Here, an obvious difference is apparent in the amount of starch near the rim as compared to the body.

INAA: Three sherds, a basal sherd (\#118-8-1 $=$ TRC650), the upper body sherd (\#349-8-1 = TRC566), and a rim (\#350-8-1 = TRC649) were subjected to analysis. All three yielded similar chemical constituents and are assigned to Chemical Group 4 (Appendix G). Surprisingly, this is the only vessel in this component to be assigned to this group and it is same chemical group to which the red-washed Vessel C in Component A was assigned. 
Radiocarbon Dating: A chunk (11.1 g) of the upper body of \#349-8-1d, which came from 60 to $80 \mathrm{cmbs}$ in Feature 31, was sent for radiocarbon dating. This 8.1- to 8.8-mm thick sherd yielded a $\delta^{13} \mathrm{C}(-21.7 \%)$ corrected AMS date of $940 \pm 25$ B.P. (UGAMS-8456) or cal A.D. 1029 to 1156. Based on eight radiocarbon dates, on individual maize kernels, Component $\mathrm{C}$ is dated to between uncalibrated 530 and 630 B.P. Obviously this directly dated sherd is some 300 to 400 years older than the well-dated component with which it appears to be associated. It is believed that organic residues in the vessel walls derived from cooking were dated. It is unclear if these residues were contaminated or represent the true age of this vessel. If this is the true age of this vessel then it lasted a lot longer than we normally think of for the life of a vessel. The context of Vessel 3 would indicate it belongs with the Plains Village occupation dated here, and therefore, the residues are presumed to have been contaminated. The $\delta^{13} \mathrm{C}$ value of $-21.7 \%$ indicates a roughly 90 percent $\mathrm{C}_{3}$ plant residue in the vessel walls. The two most prominent food resources recovered from this component, bison meat and maize, both $\mathrm{C}_{4}$ products, were apparently not cooked in this vessel, or at least their chemical signatures were not preserved in this sherd. Grasses, flowering plants, and deer meat are all $\mathrm{C}_{3}$ products and would be the major contributors to this low $\mathrm{C}_{3}$ value.

Horizontal Distribution: These 16 sherds were widely distributed across the component, with three from the disturbed surface of the fireguard in the middle of the excavation area and the two largest sherds from under the fireguard in Feature 31 towards the southern end of the excavated area. A couple of pieces were on the eastern side of the fireguard, just east of Feature 31 and in Feature 29 (see Figure 9-92). Three small pieces (10.4 g of \#669-8-1) were also in the pithouse (Feature 6) between 40 and $55 \mathrm{cmbs}$. It is possible that the blading of the fireguard displaced parts of the vessel northward from the projected original locality in the vicinity of Feature 31.

\subsubsection{Vessel 4}

This vessel consists of 65 sherds that include 61 body, 3 rim sherds, and 1 neck sherd, all having a total weight of $80.7 \mathrm{~g}$ ). Unlike the sherds from other vessel groups, Vessel 4 sherds were concentrated in one area. The largest sherd in this group is a rim section (\#405-8-1, Figure 9-96) about 4-cm-long, which refits with a small neck sherd (\#404-8-4) to reveal the general shape of the upper part of a small jar. Most sherds have an obliterated cordmarked exterior surface. Calcium carbonate coating is limited to small, randomly distributed spots.

Shape: On the basis of roughly 10 percent of the rim, the orifice diameter is calculated as 8 to $9 \mathrm{~cm}$. The nearly vertical rim thickens toward the neck which abruptly angles outward at about a 100-degree angle (see Figure 9-96). The rim height is $34.0 \mathrm{~mm}$. Basal sherds were not recognized. The vessel appears to have been a small jar.

Construction: The thin sherds are broken into small pieces, some with straight, angular edges, but none show convex or concave edges such as would indicate coil breaks or coil construction. The technique used to build this vessel is unknown. The thickest part is the neck, which is 7.5- to $8.5-\mathrm{mm}$ thick. The lip is relatively thin and measures 3.6 to $4.2 \mathrm{~mm}$ on a rim that gradually thickens to the neck and ranges from 3.8- to 7.0-mm-thick. The body is also quite thin, with most sherds measuring 3.0- to 5.9-mm-thick. The thin lip is flat to rounded and decorated with uniform diagonal (45 degree) impressions that are closely spaced (see Figure 9-96). Eight 1.8-mm-deep impressions are along the 28-mm-long lip. The impressions are about 1.7-mmwide. No appendages were observed.

Exterior Surface: The exterior exhibits nearly obliterated cordmarks, with shallow faint impressions near the lip, through the neck area and on parts of the body (Figure 9-97). Tiny temper particles are visible on the surface, as are tiny pits. No organic residues were observed on the surface. The surface is pale brown (10YR 6/3).

Interior surface: The surface is quite smooth and polished from the lip down the interior rim, and onto the neck and most of the body (see Figure 9-96). Tiny temper particles are visible on the surface. The rim area is well-finished, whereas the body sherds are not quite as smooth and show tiny pits and irregularities. The surface is light brown (7.5YR 6/4). 


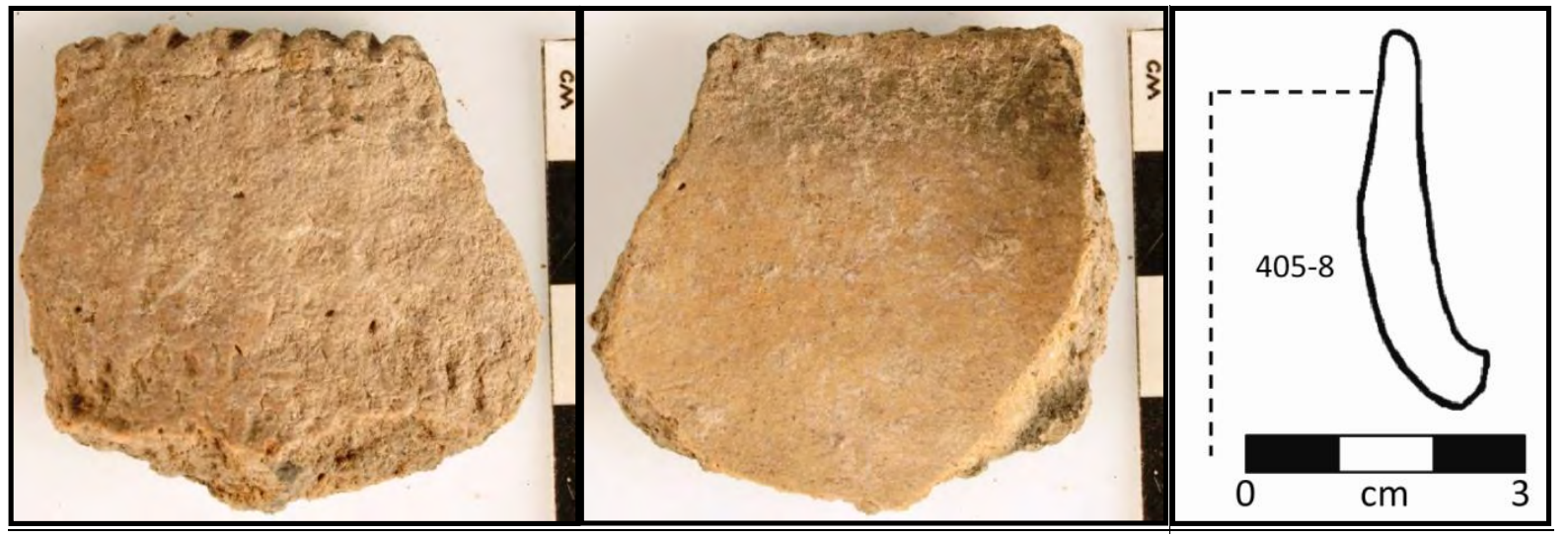

Figure 9-96. Vessel 4 showing detail of exterior (left), interior (middle), and profile (right) of rim (\#405-8-1).

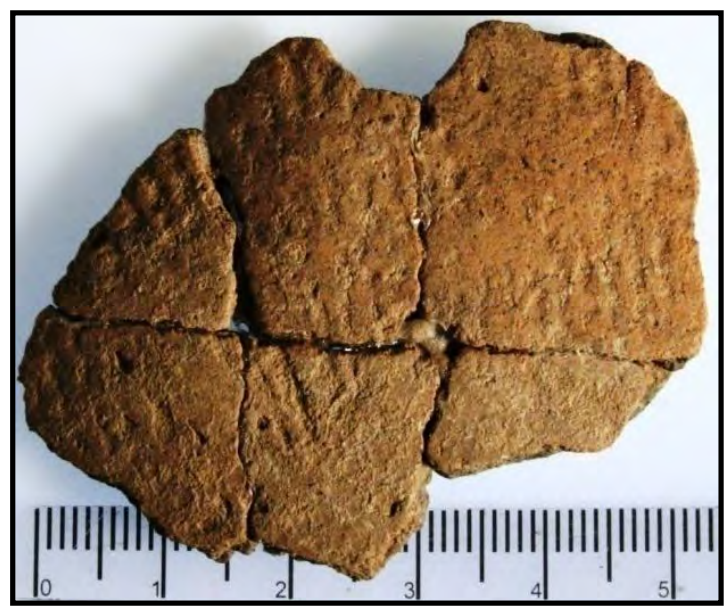

Figure 9-97. Vessel 4 refit body sherds (\#405-8-2) showing obliterated cordmarks on exterior surface.

Paste: Macroscopic inspection of the core reveals abundant fine- to medium-size, rounded quartz sand grains with some angular dark particles of unknown material. The core is two-tone in color, with a very dark gray (2.5Y 3/0) center and light brownish gray (10YR 6/2) outer margin. Petrographic analysis was conducted on rim \#405-8-1 and revealed moderate dense, isotropy paste with 10 percent voids, 21 to 36 percent particles that includes 7 to 10 percent resident quartz residue, 3 to 5 common quartz, 3 to 5 percent basalt with pyroxene, 2 to 5 percent hematite, 2 to 3 percent calcite, 2 to 3 percent chert, and minor amounts of other particles. This sherd was assigned to the broad basalt temper class and Paste Group I (Appendix F). These attributes are generally similar to other vessel pastes in this component, except Vessel 2 (Appendix F).

INAA: Two body sherds, \#405-8-1 (TRC568) and \#405-8-12 (TRC653), were subjected to chemical analysis. Both yielded chemical signatures that place these sherds within Chemical Group 2 (Appendix G). This is the same chemical group as Vessel 7, but unlike most other vessels in this component. Chemical Group 2 is prominent in Component A. 
Horizontal Distribution: These 73 sherds were relatively clustered in 6 units along the western edge of the excavations, with 25 pieces in N489 E493 and 30 sherds in adjacent N489 E494 (see Figure 9-92). Vertically, the sherds were dispersed between 20 and 50 cmbs.

\subsubsection{Vessel 5}

This vessel consists of nine sherds that include four body, four rims, and one neck sherd, which have partially obliterated cordmarked exteriors (Figure 9-98). Most sherd surfaces are covered with a thin film of calcium carbonate. The largest piece is about 30-mm-long, and over half of the remaining sherds are less than 2-mm-long.

Shape: The orifice is projected to be 20 to $21 \mathrm{~cm}$ in diameter, based on 4 to 5 percent of the rim. The presence of a neck sherd indicates a probable jar with a constricted neck. The rims are straight and direct (Figure 9-99).

Construction: The mostly straight and angled breaks show no concave or convex edges that would indicate coil construction. The lips are flat to slightly rounded and are uneven and poorly finished with no decorations (see Figure 9-98). The rims are straight or slightly curved. The impressions on the exterior appear to have been applied when the clay was quite wet, resulting in sloppy and indistinct, shallow impressions. Rim sherd \#626-8-1 has a small lump of clay that protrudes outwardly from just below the lip. The lip thickness varies from 5.3 to $6.2 \mathrm{~mm}$. Rim sherds vary from 5.2 to $8.4 \mathrm{~mm}$ in thickness, whereas body sherds vary from 6.1 to $8.2 \mathrm{~mm}$ in thickness.

Exterior Surface: The cordmarked impressions are variable (see Figure 9-98), with some welldefined (i.e., \#671-8-1 and \#626-8-4) and others poorly distinguishable (i.e., \#626-8-1). Tiny temper particles are visible on the surfaces. The light brownish gray (10YR 6/2) surface is covered with a film of calcium carbonate.

Interior surface: These surfaces are mostly smooth with a few isolated lumpy spots (see Figure 9-98). The lower rim has a shallow, linear concave area just above the break at the neck. This concave impression is parallel to the rim. Tiny temper particles are visible on the surfaces. The surface is reddish yellow (5YR 6/6).

Paste: Macroscopically, quantities of tiny dark temper particles are present with some clear and gray quartz grains, and what appear to be dark, irregularly shaped scoria fragments. The core is mostly a strong brown color (7.5YR 5/6). Petrographic analysis on body sherd \#628-8-1 revealed dense, isotropy paste with 10 percent voids, 10 to 19 percent particles that include 5 to 10 percent basalt with pyroxene, 3 to 5 percent resident quartz grains, 1 to 2 percent hematite, 1 to 2 percent caliche, and minor amounts of other particles. This sherd was assigned to the broad basalt temper class and specifically to Paste Group I. It is generally similar to all other vessel pastes in this component, except Vessel 2 (Appendix F).

Starch Grain Analysis: No starch grain analysis was conducted on sherds from this vessel.

INAA: Two sherds (\#628-8-1 = TRC570 and \#6298-1 = TRC645) were subjected to chemical analysis. Both yielded similar chemical signatures and are assigned to Chemical Group 1 (Appendix G). This is the same chemical group to which Vessels 1, 2, and 6 pertain.

Horizontal Distribution: The nine sherds in this group were from five units within the pithouse Feature 6 . They were vertically scattered from 0 to 70 cmbs (see Figure 9-92).

\subsubsection{Vessel 6}

Six small body sherds that weigh $22.8 \mathrm{~g}$ and exhibit a maize cob impressed surface, all from N499 E497 in the pithouse Feature 6, are assigned to this vessel (Figure 9-100). The largest piece is about $4.5-\mathrm{cm}-$ long. No organic residues are adhering to these unwashed sherds.

Shape: The curvature of the two largest sherds is nearly flat, which indicate a relatively large diameter vessel. The shape and size are unclear due to the absence of sherds from other parts of the vessel.

Construction: The broken edges are relatively straight with no sign of concave or convex margins 


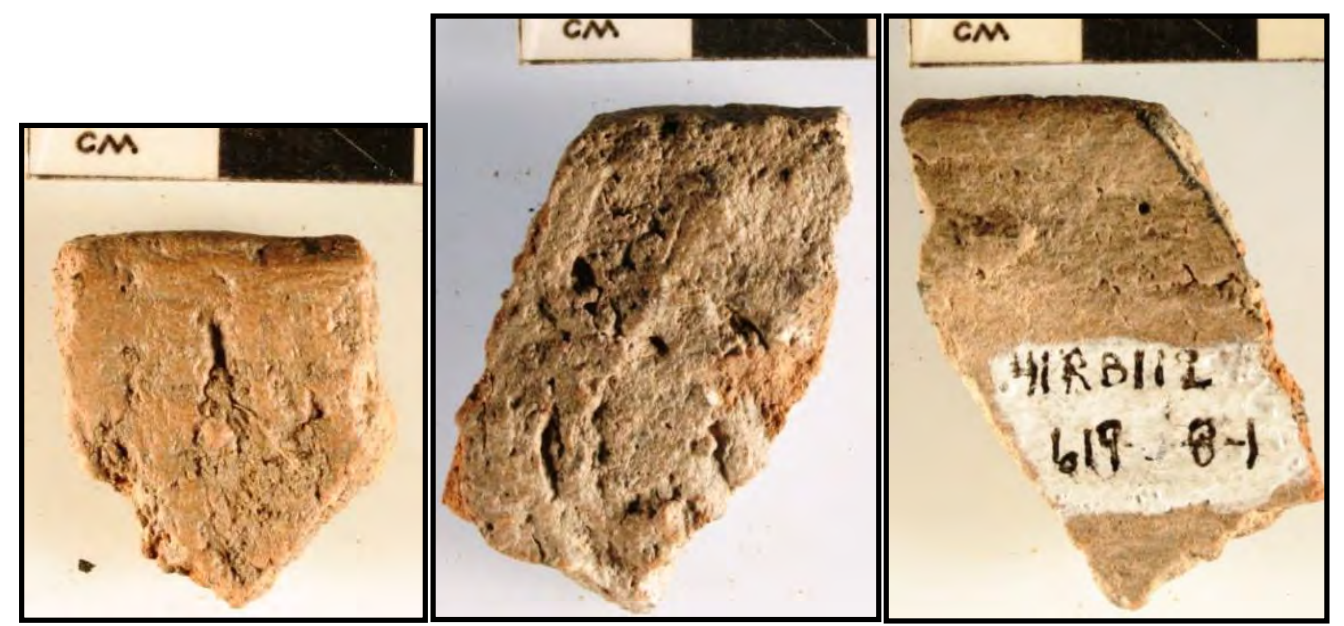

Figure 9-98. Rim sherds (\#519-8-1) and (\#619-8-1) exterior (left and middle) and interior (right) of Vessel 5.

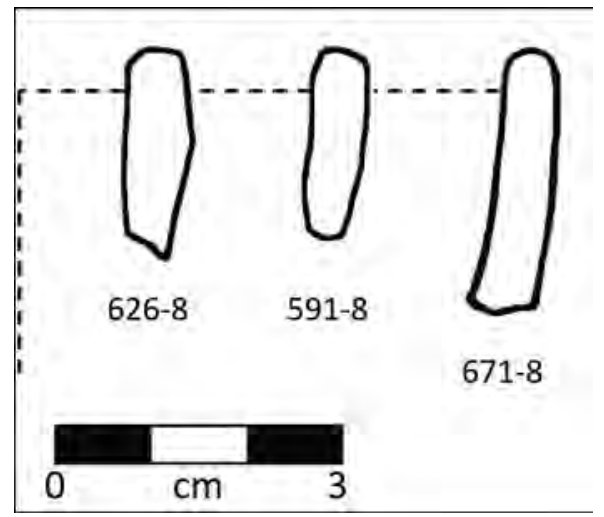

Figure 9-99. Profile drawings of Vessel 5 rim sherds (\#626-8, \#519-8-1, and \#671-8).

to indicate possible coil breaks. The clay is dense and moderately hard, with no obvious indications as to the construction methods used to create this vessel. The body sherds are moderately thick and vary from 8.1 to $9.3 \mathrm{~mm}$.

Exterior Surface: The surface is bumpy and lacks an obvious pattern to the well-defined impressions (see Figure 9-100). The impressions are relatively shallow and not of a standard or recognizable pattern. The surface impressions are different from those of other vessels from the site. A few temper particles are visible on the surface. The surface is dark grayish brown (10YR 4/2), but is partially covered by a film of calcium carbonate.
Interior surface: The interior is irregular to slightly bumpy, with at least two shallow concave impressions the size of finger tips (see Figure 9-100). No cracks or divots are visible and no temper particles are visible on the surface. The surface color is gray (10YR 6/1).

Paste: The core is reddish yellow (5YR 6/6) and grayish brown (10YR 5/2) with dark temper particles that macroscopically appear to be scoria, as well as occasional sand grains. The petrographic analysis on a fragment of body sherd \#639-8-3 revealed dense, isotropy paste with 3 to 5 percent voids, 20 to 25 percent basalt with pyroxene, 32 to 44 percent particles that include 10 to 15 percent resident quartz grains, and less than 4 percent other particles. This 


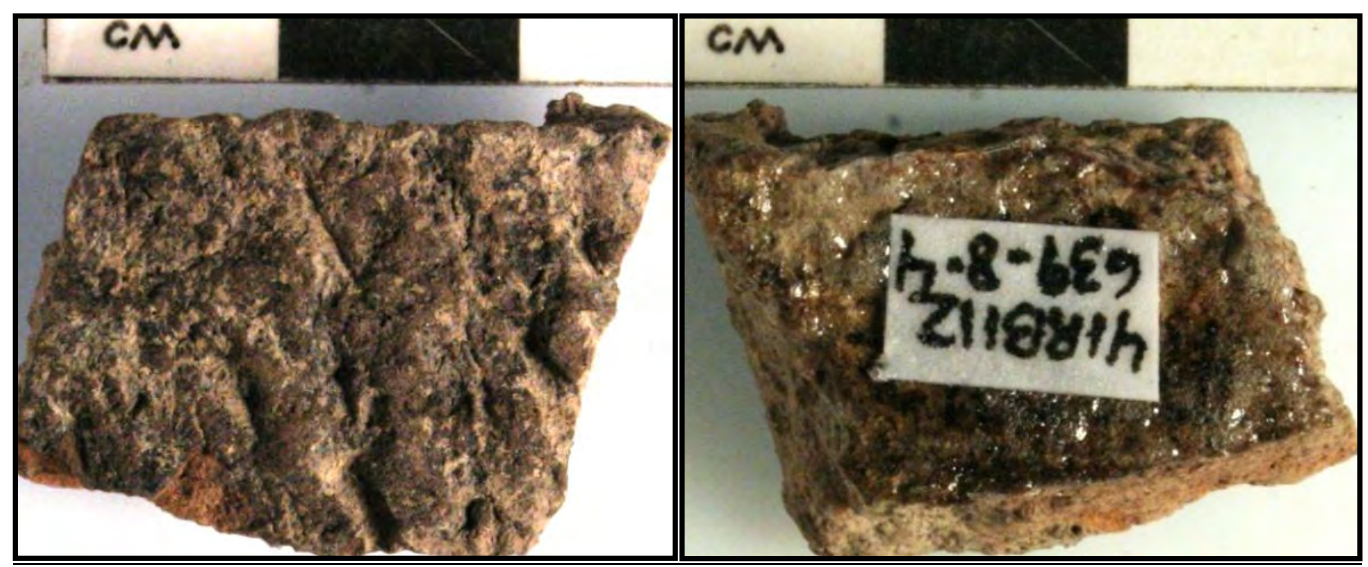

Figure 9-100. Detail of maize cob impressed sherd (\#649-8-4), exterior (left) and interior (right) of Vessel 6.

sherd was assigned to broad basalt temper class and Paste Group I. It is generally similar to other vessel pastes in this component, except Vessel 2 (Appendix F).

INAA: One sherd (\#639-8-3 = TRC571) was split into two parts and one fragment was then sent for chemical analysis. The results allowed its assignment to Chemical Group 1, which is similar to Vessels 1, 2, and 5 in this component (Appendix G).

Horizontal Distribution: These sherds were found inside the pithouse Feature 6, together with sherds from Vessels 1, 2, 3, and 5 (see Figure 9-92).

\subsubsection{Vessel 7}

This vessel consists of nine sherds, which include eight body and one rim with a total weight of 65.1 g. Exterior surfaces are cordmarked, with partially to mostly obliterated cord impressions (Figure 9-101). Five body sherds refit to form a 6.5 -cm-long section. The rim does not refit with the body sherds. A calcium carbonate film covers most sherds.

Shape: The rim is straight and vertical. The refit body section has a slight degree of curvature. The absence of sherds from other parts of the vessel hinders understanding of the overall vessel shape and dimensions.

Construction: Broken edges are relatively straight, but no concave or convex edges are present that would indicate coil breaks. The body sherds are 7.8to $11.3-\mathrm{mm}$-thick, and the rim sherd is 5.8 to $7.2-\mathrm{mm}$ thick with a 6.1- to 6.3-mm-thick lip. The lip of the rim sherd (\#635-8-1) is flat and slightly outflaring, with thin ridge of clay on the exterior. It also exhibits three small, approximately 2-mm-wide punctates in a row along the lip that penetrate vertically into the rim (Figure 9-102). The exact configuration and depth of these holes is not clear as they are filled with black organic residues. One partial impression next to the inside edge reveals circular margins with a tiny lump in the center of the roughly 1-mm-deep impression. All impressions appear to have been made with a thin, hollow plant stem.

Exterior Surface: The cordmarkings are shallow and variable, predominately indistinct, on body sherds (see Figure 9-101). Body sherd \#319-8-2 has very faint cordmarks without close observation it appears to have a plain surface. A small light gray (10YR 7/1) rim (\#635-8-1) exhibits partially obliterated vertical cordmarks that extend to the lip. Some black residues and a film of calcium carbonate adhere to the exterior surface.

Interior surface: Clustered body sherds from \#4688 exhibit a bumpy and irregular surface with visible temper particles (see Figure 9-101). Other body and rim sherds are relatively smooth with tiny pits and visible temper. No striations or other finishing marks are visible. Surface is light brown gray (10YR 6/2). 


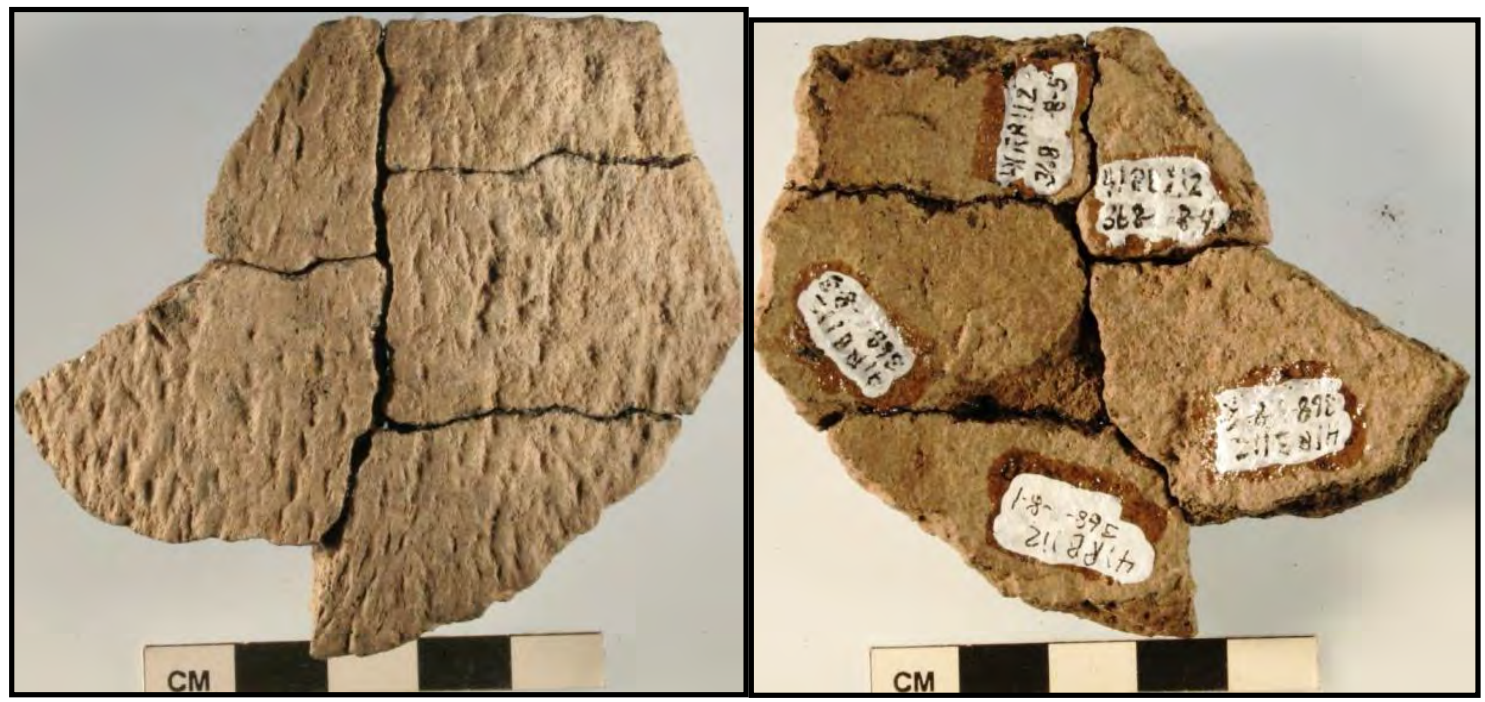

Figure 9-101. Vessel 7 refit sherds; exterior (left) and interior (right) surface treatments.

Paste: Although exterior surfaces exhibit variable cordmarks, pastes are homogeneous in color and texture. Macroscopically, the paste is very dark gray (10YR 3/1) with abundant, dark temper particles that appear to be scoria. Temper is relatively fine, and also includes some clear and opaque quartz sand grains. A part of the refit body sherds (\#4688-4) was sent for petrographic analysis and revealed a loose, isotropy paste with 20 percent voids, 44 to 54 percent particles that include 25 percent resident quartz, 10 to 15 percent basalt with pyroxene, 2 to 3 percent common quartz grains, 1 to 2 percent plagioclase, 1 to 2 percent orthoclase, 1 percent muscovite, and less than 2 percent other particles. This sherd was assigned to the basalt temper class and Paste Group FF (Appendix F). It is generally similar to other vessel pastes in this component, except Vessel 2, and in the same specific paste group as body sherd \#362-8-1 of Vessel 1(Appendix F).

INAA: Chemical analysis of body sherd \#468-8-4 yielded results that place this in Chemical Group 2 (Appendix G). This is the same group as Vessel 4, and unlike most other vessels from this component. However, it is chemically similar to nearly all vessels in Component $\mathrm{A}$.

Horizontal Distribution: These few sherds came from various horizontally dispersed contexts, with one sherd from the pithouse Feature 6, one from heating element Feature 16, and others were nonfeature associated (see Figure 9-92).

\subsubsection{The Unassigned Sherd Assemblage}

There are 42 unassigned sherds, 41 body and one small rim, with a total weight of $145.9 \mathrm{~g}$, and an average weight of $3.5 \mathrm{~g}$ per sherd. The largest is 78-mm-long, with an overall range from 9.8 to $78.0 \mathrm{~mm}$, whereas 12 sherds are less than $20-\mathrm{mm}$ long, for an average sherd length of 22.6-mm-long. The thicknesses range from 6.5 to $11.2 \mathrm{~mm}$ with an average of $8.9 \mathrm{~mm}$. Most unassigned sherds are relatively thick, but with three thick vessels represented (Vessels 1, 3 and 7), it was not clear which sherds pertain to which thick vessel.

A part of unassigned body sherd (\#643-8-1) was sent for petrographic analysis and revealed a dense, isotropy paste with 5 to 10 percent voids, 16 to 26 percent particles that include 5 to 7 percent resident quartz, 3 to 5 percent basalt, 3 to 5 percent muscovite, 2 to 3 percent common quartz grains, 1 to 2 percent chert, 1 to 2 percent caliche, and 1 to 2 percent unknowns (Appendix F). This sherd was assigned to the broad basalt temper class and specifically to Paste Group II (Appendix F). It is generally similar to most other vessel pastes in this component, except Vessel 2, but lacks the pyroxene and iron opaques of most other vessels. 


\subsubsection{Summary of the Vessel Assemblage}

A total of 220 sherds, 84 percent of the component total, with a total weight of 2,063.8 g, were assigned to 7 vessel groups, primarily on differences in vessel wall thickness, exterior surface finishes, and rim styles and shapes. These seven groups are comprised mostly of body sherds. Six vessel groups contain identifiable rim sherds, three contain neck sherds, and two contain apparent basal sherds (Table 9-17).

Exterior surfaces are 86 percent cordmarked. Only Vessel 6 has maize cob impressed surface, rather than cordmarkings. Cordmarked impressions vary in size, shape, and clarity on the different vessels (Figure 9-103). In the most complete vessel, Vessel 1 , the approximately 3-cm-tall rim is plain, whereas the shoulder and main body are cordmarked with broad, well-defined impressions, although the rounded basal sherds reveal partially obliterated cordmarks. Thus, this particular vessel exhibits considerable variability in surface finish, which cautions against the assignment of very small sherds to vessels based solely on surface finish. Cordmarks are vertical, broad and well-defined, and mostly distinct, with exception of Vessels 2 and 4. Vessel 2 cordmarkings appear to have been applied into very wet clay that has left variable markings that are predominately indistinct. Cordmarks on Vessel 4 body sherds are very faint, nearly obliterated (see Figure 9-103). Vessel 3 has angled cordmarks that extend from the lower left to the upper right. This is the only vessel that reveals this obviously angled cordmarking, which is said to be typical of Plains Woodland vessels of the South Plate phase in the northeastern Colorado region, and date to A.D. 100 to 1050 (Johnson and Johnson 1998:211). Variations observed in cordmarks on body sherds indicate that cord wrapped paddles used to finish forming and shaping these vessels were varied and not standardized among potters. Therefore, the surface finish is dependent on individual preferences and choices.

Cordmarking is the most common form of exterior finish throughout Antelope Creek phase sites (e.g., Lintz 1976, 1989, 1997; 2005; Brooks 1989, 2004:340; D. Hughes 2002) and even in sites farther north into southern Kansas, such as the Bell (14CM407), Booth (14CM406), and Lundeen (14MD306) sites (Bevitt 1999). However, in the three Kansas sites, cordmarkings are generally smoothed over to some degree $(64,71$, and 80 percent respectively; Bevitt 1999). Studies of Buried City pottery reveals 52 percent are cordmarked, 28 percent are smoothed-over cordmarked, 16 percent are plainware, and 4 percent are decorated (D. Hughes 2002).

Only Vessel 6, maize cob impressed, collectively 14 percent of the total vessel sample, exhibits a different textured exterior. Maize cob impressions have been identified on a small percentage of sherds from the Wolf Creek complex, specifically the upper house at Courson B (D. Hughes and Hughes-Jones 1987:75; D. Hughes 2002) and a "paint pot" from

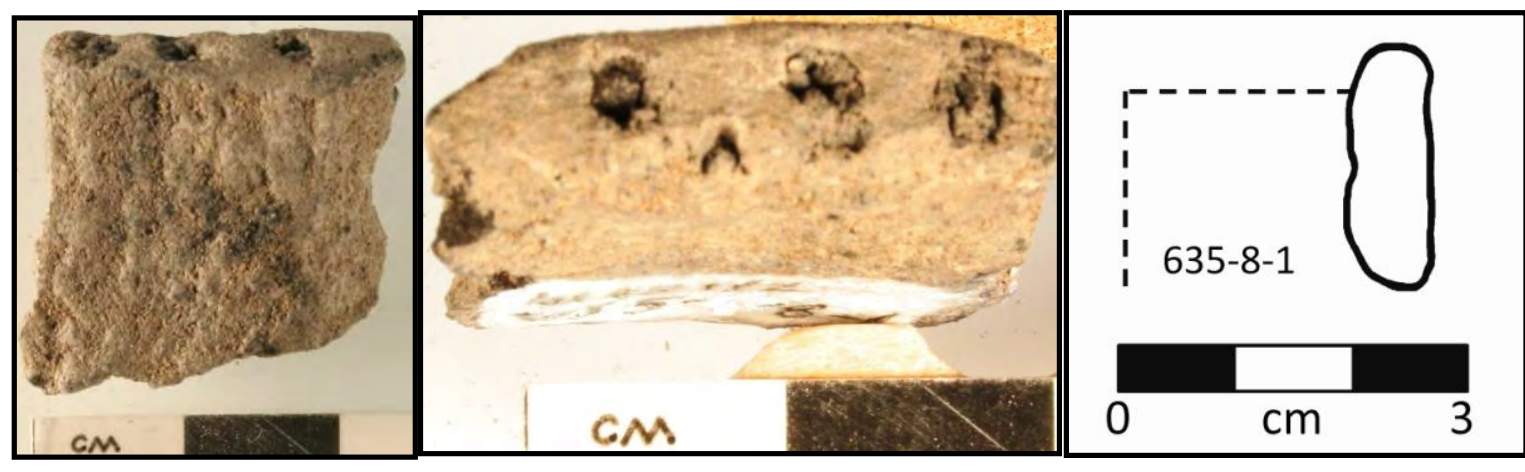

Figure 9-102. Decorated lip on rim sherd (\#635-8-1) of Vessel 7. Exterior (Left), Close-up of Lip Decoration (Center), and Profile (Right) 
Table 9-17. Summary of the Assigned Sherds to Vessel Groups and Key Vessel Data from Component C.

\begin{tabular}{|c|c|c|c|c|c|c|c|c|c|c|}
\hline $\begin{array}{l}\text { Vessel } \\
\text { No. }\end{array}$ & $\begin{array}{l}\text { No. of } \\
\text { Sherds }\end{array}$ & $\begin{array}{l}\text { Total } \\
\text { Weight } \\
\text { (g) }\end{array}$ & $\begin{array}{l}\text { Surface } \\
\text { Finish }\end{array}$ & Rim & Neck & Base & Core Color & $\begin{array}{c}\text { INAA } \\
\text { Group* }\end{array}$ & $\begin{array}{c}\text { Petrographic } \\
\text { Group } * *\end{array}$ & $\begin{array}{l}\text { Starch } \\
\text { Results }\end{array}$ \\
\hline 1 & 110 & $1,628.80$ & Cordmarked, & yes & no & yes & $\begin{array}{l}3 \text { tone in spots, gray (10YR } \\
6 / 1) \text {, dark brown ( } 7.5 \mathrm{YR} \\
4 / 4) \text {, black ( } 7.5 \mathrm{YR} 2 / 0) \text { on } \\
\text { interior edge }\end{array}$ & 1 & $\begin{array}{c}\text { Basalt/ } \\
\text { pyroxene, } \\
\text { Group I, FF, } \\
\text { GG }\end{array}$ & $\begin{array}{l}32 \text { maize, } 28 \\
\text { little barley, } \\
9 \text { unknown, } 2 \\
\text { possible lily, } \\
2 \text { gelatinized }\end{array}$ \\
\hline 2 & 5 & 30.8 & $\begin{array}{c}\text { Cordmarked, } \\
\text { obliterated }\end{array}$ & yes & yes & no & reddish brown (7.5YR 6/6) & 1 & $\begin{array}{c}\text { rock \& mineral, } \\
\text { Group EE }\end{array}$ & $\begin{array}{l}1 \text { little barley, } \\
1 \text { gelatinized }\end{array}$ \\
\hline 3 & 16 & 188.2 & Cordmarked & yes & no & yes & reddish yellow (7.5YR 6/6). & 4 & $\begin{array}{l}\text { Basalt/ } \\
\text { pyroxene, } \\
\text { Group I }\end{array}$ & $\begin{array}{c}3 \text { maize, } 1 \\
\text { damaged } \\
\text { maize, } 20 \\
\text { little barley, } \\
1 \text { damaged } \\
\text { unknown }\end{array}$ \\
\hline 4 & 65 & 80.7 & $\begin{array}{c}\text { Obliterated } \\
\text { cordmarked }\end{array}$ & yes & yes & no & $\begin{array}{c}\text { two tone; very dark gray } \\
(2.5 Y \text { Y } 3 \text { ) center, light } \\
\text { brownish gray (10YR 6/2) } \\
\text { outer margins }\end{array}$ & 2 & $\begin{array}{l}\text { Basalt/ } \\
\text { pyroxene, } \\
\text { Group I }\end{array}$ & NA \\
\hline 5 & 9 & 47.4 & Cordmarked & yes & yes & no & strong brown (7.5YR 5/6) & 1 & $\begin{array}{l}\text { Basalt/ } \\
\text { pyroxene, } \\
\text { Group I }\end{array}$ & NA \\
\hline 6 & 6 & 22.8 & $\begin{array}{l}\text { Maize cob } \\
\text { impressed }\end{array}$ & no & no & no & $\begin{array}{c}2 \text { tone, reddish gray (5YR } \\
6 / 6 \text {, grayish brown (10YR } \\
5 / 2)\end{array}$ & 1 & $\begin{array}{l}\text { Basalt/ } \\
\text { pyroxene, } \\
\text { Group I }\end{array}$ & NA \\
\hline 7 & 9 & 65.1 & Cordmarked & yes & no & no & $\begin{array}{c}2 \text { tone, gray }(10 Y R \text { R } 6 / 10 \\
\text { towards interior, very dark } \\
(10 \text { YR } 3 / 1) \text { towards exterior } \\
\text { edge }\end{array}$ & 2 & $\begin{array}{l}\text { Basalt/ } \\
\text { pyroxene, } \\
\text { Group FF }\end{array}$ & NA \\
\hline 7 & 220 & $2,063.80$ & & 6 & 3 & 2 & & & 9 basalt & $\begin{array}{c}3 \text { of } 3 \\
\text { positive }\end{array}$ \\
\hline
\end{tabular}

* INAA = Instrumental neutron activation analysis assignment based on chemistry; NA = not applicable; ** Groups based of similar mineral additives 


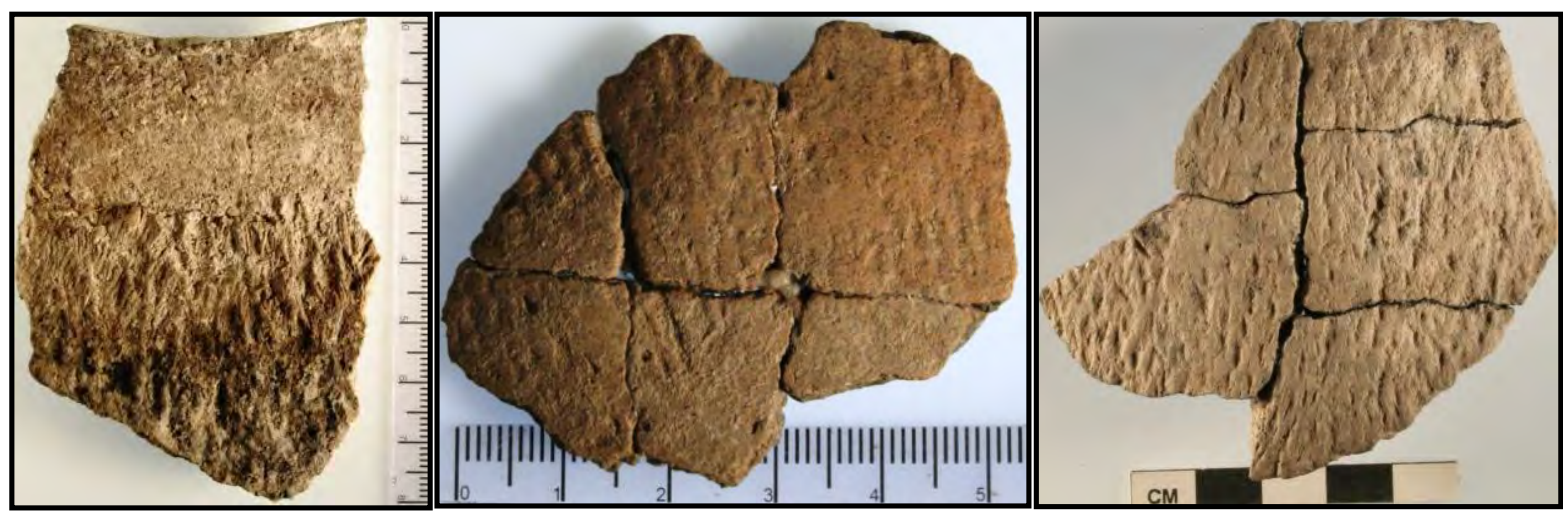

Figure 9-103. Different surface finishes on Vessels 1 (left, well-defined), Vessel 4 (center, obliterated), and Vessel 7 (right, partially obliterated).

Scales in centimeters.

Courson A (D. Hughes and Hughes-Jones 1987), but are rare or nonexistent in Antelope Creek phase sites (i.e., Lintz 1976, 1978, 1989, 1997, 2005, 2010). The paint cups of southwestern Oklahoma and a few in north-central Texas are primarily finished with maize cob impressions (Brooks and Drass 2005). These are generally crudely hand-molded, have circular to oval bell-shaped lids, with little rim modification, untempered, and poorly fired, with variable body shape and height. Body sherds range from 7.5 to $29.4 \mathrm{~mm}$ in thickness with bases that are flat, cob impressed, and the thickest portion of the cups (Brooks and Drass 2005).

It is speculated that Vessel 4 was finished to look like a plain exterior by obliterating the cordmarks (see Figure 9-96). Obliterated cordmarks are common in some Antelope Creek phase sites such as 41PT109 (77 percent, Lintz 2010), in Buried City complex at 41OC20 (67 percent, Duffield 1964), although most vessels have cordmarked surfaces and no vessels exhibit a true plain, smooth exterior. However, plainware/smoothed sherds represent nearly 23 percent of the sherds from the Franklin Ranch site in Gray County (Lintz 2010:57). Farther north, plain pottery becomes more prominent. For example, the Little River focus (A.D. 1450 to 1700) of the Great Bend aspect in central Kansas has mostly plain exteriors and only the occasional cordmarked vessels (Vehik 2007). In southern Kansas, the Pratt complex (A.D. 1300 to 1500) ceramic assemblages are predominantly cordmarked (80 to 85 percent) often exhibiting at least partial smoothing of the impressions. Plain wares (15 to 20 percent) are also present (Brosowske and Bevitt 2006:194).

Vessel form in Component $C$ is variable. Vessel 1 is a squat, wide-mouthed jar with an estimated width of about $34 \mathrm{~cm}$, a height of about $22 \mathrm{~cm}$, and orifice diameter of about $18 \mathrm{~cm}$. Vessel 3 is postulated to have been a tall and narrow neckless jar with a projected orifice diameter of 10 to $11 \mathrm{~cm}$. Vessels 2 and 4 are small jars with slightly constricted necks and orifice diameters of 8 to $11 \mathrm{~cm}$. Most rims are straight, nearly vertical or slightly outflaring, although the small sizes of rims may be misleading as to the actual direction of the rim. Vessels 1, 2, 4, and 5 have necks, but it is not clear about the other three as there are few sherds present. The necks are seated at angles of 100,135, and 144 degrees to the rims. Shoulders are not present in most instances; however, Vessel 1 has a partially rounded shoulder with the shape varying slightly around the vessel. This variability in shoulder shape is not observed in other Antelope Creek phase assemblages, which are dominated by globular jars with rounded bases, well-defined necks, and straight rims (Lintz 1976, 1986, 1997; Brooks 1989:82, 2004:340; Duncan 2002:232, Figure 6.8). Most Antelope Creek phase vessels have rounded bodies that transition directly into the constricted neck without well-defined shoulders (Suhm and Jelks 1962, Plate 8; Duncan 
2002:232). Interestingly, D. Hughes (2002:1), in discussing Buried City pottery, states that "earlier ceramics include sub-conical vessel forms with direct rims and a temper of crushed scoria. It is not clear if he is suggesting that multiple occupations are indicated.

Thicknesses of the seven vessels are variable, with Vessels 1, 3 and 7 having body sherds that range from 7.8 to $11.3 \mathrm{~mm}$ in thickness and bases that range in thickness from 10.3 to $19.1 \mathrm{~mm}$. Body sherds from other vessels range in thickness from 3.0 to $9.3 \mathrm{~mm}$. The lips of these vessels range between 3.5- and 8.2-mm-thick, again showing considerable range. The few neck sherds on Vessels 1 and 4 are generally thicker than the lips and overlap in thickness with rims and body sherds. Rim thicknesses are variable and range from 4.2 to $8.4 \mathrm{~mm}$. In keeping with other measurements, orifice diameters also vary, from about 8 to $21 \mathrm{~cm}$. The neck-shoulder angle ranges from around 100 to 144 degrees. These measurement ranges are more variable than reported from analyses of Antelope creek phase assemblages. Thick cordmarked sherds are generally not thought of as the norm for Antelope Creek phase ceramics. Previously, thick cordmarked sherds were thought of as a characteristic of the earlier Woodland/Early Ceramic period (Lake Creek complex) assemblages in Texas (i.e., J. Hughes 1962, 1991; Couzzourt 1985:75; Brosowske 2005:72-73). In the Central Plains region the Late Woodland (A.D. 750 to 1000) is characterized by "thick-walled, stone tempered cord-roughened pottery" (Johnson and Johnson 1998:204). However, Duffield (1964:67) reports thick sherds tempered with crushed quartzite and sand 48 percent) as well as thin sherds tempered with sand (32 percent) from the Spring Canyon site (41HC20) in the Antelope Creek phase core area. If the thick sherds represented only the basal sherds then one would expect a much smaller percentage compared to the thinner sherds. The comparative percentage of thick to thin sherds indicates that thick sherds could not be representative only of basal portions of vessels. Watson (1950:30) also reports thicknesses up to $10 \mathrm{~mm}$ on sherds from the Stamper site (34TX1) in the Oklahoma panhandle. Thick-walled vessels from Component $\mathrm{C}$ have counterparts in the Buried City complex site 410C29, where Brosowske (2005) reports numerous vessels from well-dated Middle Ceramic contexts with thicknesses greater than $15 \mathrm{~mm}$. Previously, in a comparative study of sherds, D. Hughes (2002) stated that Buried City and Alibates 28 pottery are of similar thickness and that pottery from both sites seems statistically similar in terms of metric attributes.

Prominent decorations were not observed on the rims, shoulders or bodies of the presently reported vessels. However, lips on two cordmarked vessels (Vessels 4 and 7) have minor decorations that include small holes on Vessel 7 and tool impressions on Vessel 4, which likely reflect individual preferences or identifying characteristics. The vertical holes in Vessel 7 lip appear quite similar to a decorated lip from Stamper (Watson 1950:45, Plate 4:H). The roughly horizontal cut lines on the lower rim of Vessel 1 are not considered decorations. Their presence likely reflects poor finishing after the rim was thinned by slicing excess clay from the exterior. This is quite unusual and is not reported in the various references consulted. The rim areas of Vessels 1 and 4 appear to have never been cordmarked and therefore, the plain surface finish on the rims of those vessels possibly served as stylistic markers. On a sample of 192 rim sherds from Alibates 28, none are ornamented or decorated in any way (D. Hughes 2002). Four percent of the sherds from Buried City are decorated, and decoration is confined to the neck and rim and only rarely extends onto the shoulders (D. Hughes 2002).

Most sherds are partially or totally covered postdepositionally with a film of calcium carbonate. This has greatly hindered the detection of the exterior and interior colors. Consequently, surface colors were not useful distinguishing characteristics in sorting the sherds. No color was apparently applied onto the natural clays used in the construction or decoration of these seven vessels.

Fresh edges of each vessel group were initially macroscopically viewed to identify temper particles. On the basis of those initial observations, sherds from different vessels were selected for INAA and petrographic analyses. Visually, fine-to-mediumrounded quartz sand and small dark angular particles (possibly basalt) appeared to dominate as temper. 
Subsequent petrographic analysis provides much greater detail concerning the types and quantities of temper. Petrographic analysis was conducted on 10 sherds from 7 identified vessels. Based on petrographic observations, the seven vessels were grouped according to their physical constituents (Table 9-18). In broad terms, 8 of 10 sherds that represent 6 different vessels are dominated by basalt tempers with pyroxene and minor amounts of biotite, muscovite, and minor amounts of quartz (Appendix F). Within this broad basalt group the sherds were assigned to three paste subdivisions (I, FF, and GG) based on the frequencies of the minor particles, paste color, and isotropy. Sherd \#259 that represents Vessel 2 is unique in that it is the only vessel to contain rhyolite and lacks the combined basalt with pyroxene, although it has a trace of pyroxene, and was assigned to Paste Group EE. The other unique paste was identified in sherd \#643 from an unknown vessel, as it lacked the basalt with pyroxene and thus assigned to Paste Group II (Appendix F). This sherd was not assigned to any vessel group. Based on specific paste constituents Vessels 1, 3, 4, 5, and 6 were all assigned to the same Paste Group I and reveal considerable homogeneity. The slight variation in the paste of Vessel 7 maybe just that, a slight variation as it still contains basalt with pyroxene and other similar constituents. However, the more distinct paste of Vessel 2 indicates it was manufactured from a different source and may have been manufactured by an outside group and traded/brought in.

Based on a sample of 192 rim sherds from Alibates 28, D. Hughes (2002) determined that the temper consisted predominantly of medium-size particles of highly angular quartz and feldspar (crushed-rock) with less than 1 percent revealing sub-rounded polished, medium to fine quartz sand. D. Hughes (2002) also states that the Buried City paste is consistently tempered with fine eolian quartz sand. In about one-third of the Buried City sherds, other aplastic additives are present that include grog, burned and unburned bone, shell and unidentifiable particles (D. Hughes 2002). Most references to the temper in sherds from phases and complexes including Antelope Creek, Buried City, Odessa Yates, and others have not undergone detailed petrographic analysis and therefore the terminology and accuracy of the observations of the various analysts have provided a mixture of observations and results. This has hindered clear communication and possibly misled readers as to what temper materials were used in these various cultural manifestations.

Following his metric and macroscopic analyses of a sample of sherds from Alibates 28, D. Hughes (2002) states that Borger Cordmarked pottery, representative of the Antelope Creek phase, differs from the Buried City pottery primarily in temper, rim form, decorations, and overall size. This is part of the basis upon which Brosowske (2005) and Brosowske and Bevitt (2006) assigned the Buried City assemblages to Brosowske's Odessa phase.

INAA detected chemical signatures from 16 sherds that represent 7 identified vessel groups, while 2 sherds could not be assigned to groups. Based on the chemical results, these six vessels were assigned to three chemical groups, Group $1(N=9)$, Group $2(N$ $=3$ ), and Group $4(N=4)$. All Vessel 1 sherds (rim, body, and base) were assigned to Chemical Group 1, as were sherds from Vessels 2, 5 and 6. Three Vessel 3 sherds and one unassigned sherd (\#643-8-1) were assigned to Chemical Group 4. Two Vessel 4 sherds, one Vessel 7 sherd, and one unassigned sherd (\#6848-1) were assigned to Chemical Group 2. Therefore, four vessels (Vessels 1, 2, 5, and 6) were of similar chemical composition, two vessels (Vessels 4 and 7) pertain to another chemical group, and Vessel 3 represents a third chemical group. Vessel 3 is also visibly different from other vessels in that it has a tall vertical rim on a neckless jar with a narrow orifice (10 to $11 \mathrm{~cm}$ in diameter), angled cordmarkings, and a different color core.

Starch grain analysis was conducted on 10 sherds from Component C. Seven sherds represent three identified vessels (Vessels 1, 2, and 3) and three sherds are unassigned. These 10 sherds yielded starch grains that represent maize $(N=34)$, possible maize $(N=1)$, damaged maize $(N=2)$, parched maize $(N=1)$, little barley $(N=93)$, ground little barley $(N=1)$, gelatinized little barley $(N=1)$, possible lily $(N=5)$, unknowns $(N=3)$, gelatinized unknowns $(N=6)$, and parched unknowns $(N=2)$. The parched grains (from \#643-8-1 and \#335-8-1, two unassigned sherds) were heated without water, whereas the gelatinized grains (from \#177-8-1, 
Table 9-18. Petrographic Identifications and Quantifications of Ceramic Data from Component C.

\begin{tabular}{|c|c|c|c|c|c|c|c|c|c|c|c|c|c|c|c|c|c|c|c|c|}
\hline \multirow{2}{*}{$\begin{array}{c}\text { Sample } \\
\text { No. }\end{array}$} & \multirow[t]{2}{*}{ Vessel No. } & \multicolumn{6}{|c|}{ Paste Attributes } & \multicolumn{3}{|c|}{ Quartz } & \multicolumn{10}{|c|}{ Igneous } \\
\hline & & $\begin{array}{l}\text { Paste } \\
\text { Group }\end{array}$ & $\begin{array}{c}\text { Matrix } \\
\text { Color ppl }\end{array}$ & $\begin{array}{c}\text { Matrix } \\
\text { Color } \\
\text { xpl }\end{array}$ & Isotropy & $\begin{array}{l}\text { Voids } \\
\text { (\%) }\end{array}$ & $\begin{array}{l}\text { Matrix } \\
\text { Density }\end{array}$ & $\begin{array}{c}\text { Quartz } \\
\text { Resident } \\
\text { (\%) }\end{array}$ & $\mid \begin{array}{c}\text { Quartz } \\
\text { Common } \\
(\%)\end{array}$ & $\begin{array}{c}\text { Quartz } \\
\text { Composite } \\
\text { (\%) }\end{array}$ & $\begin{array}{l}\text { Chert } \\
(\%)\end{array}$ & \begin{tabular}{|c} 
Plagioclase \\
(\%)
\end{tabular} & $\begin{array}{c}\text { Orthoclase } \\
(\%)\end{array}$ & $\begin{array}{c}\text { Microcline } \\
\text { (\%) }\end{array}$ & $\begin{array}{c}\text { Basalt } \\
\text { (\%) }\end{array}$ & $\begin{array}{c}\text { Basalt/pyrx } \\
\text { (\%) }\end{array}$ & $\begin{array}{c}\text { Pyroxene } \\
(\%)\end{array}$ & $\begin{array}{c}\text { Rhyolite } \\
\text { (\%) }\end{array}$ & $\begin{array}{c}\text { Biotite } \\
(\%)\end{array}$ & $\begin{array}{c}\text { Muscovite } \\
(\%)\end{array}$ \\
\hline $405-1$ & 4 & I & $\begin{array}{l}\text { reddish } \\
\text { black }\end{array}$ & black & iso & 10 & moderate & $7-10$ & $3-5$ & & $2-3$ & $1-2$ & & & & 3-5 & $1-3$ & & & \\
\hline 628-1 & 5 & I & $\begin{array}{l}\text { reddish- } \\
\text { brown }\end{array}$ & $\begin{array}{c}\text { blackish } \\
\text { brown }\end{array}$ & iso & 10 & dense & 3-5 & & tr. & & tr. & tr. & & & $5-10$ & tr. & & & \\
\hline $338-6$ & 1 & I & $\begin{array}{l}\text { medium } \\
\text { brown }\end{array}$ & $\begin{array}{c}\text { dk. } \\
\text { golden } \\
\text { brown }\end{array}$ & iso & 5 & moderate & $5-7$ & 3-5 & $1-2$ & & $3-5$ & & & & $10-15$ & 3-5 & & & \\
\hline $349-1$ & 3 & I & $\begin{array}{l}\text { yellowish- } \\
\text { brown }\end{array}$ & black & iso & $7-10$ & dense & & 3-5 & tr. & & & & & & $10-15$ & $1-2$ & & & \\
\hline 639-3 & 6 & I & $\begin{array}{l}\text { reddish- } \\
\text { brown }\end{array}$ & $\begin{array}{l}\text { v.dk. } \\
\text { Reddish- } \\
\text { brown }\end{array}$ & iso & 3-5 & dense & $10-15$ & & & $1-2$ & & & & & $20-25$ & & & & \\
\hline $259-2$ & 2 & $\mathrm{EE}$ & $\begin{array}{l}\text { greenish } \\
\text { brown }\end{array}$ & $\begin{array}{l}\text { golden } \\
\text { brown }\end{array}$ & aniso & $5-10$ & dense & 3-5 & $2-3$ & $1-2$ & tr. & $1-2$ & tr. & & tr. & & $1-2$ & $3-5$ & $2-3$ & $1-2$ \\
\hline $362-8-1$ & 1 & $\mathrm{FF}$ & $\begin{array}{l}\text { It. tannish- } \\
\text { gray }\end{array}$ & $\begin{array}{l}\text { medium } \\
\text { gray }\end{array}$ & iso & 20 & light & 25 & Robin 2-3 & 1 & $1-2$ & $1-2$ & $1-2$ & & & $10-15$ & & & 1 & 1 \\
\hline 468-8-4 & 7 & $\mathrm{FF}$ & $\begin{array}{l}\text { It. tannish- } \\
\text { gray }\end{array}$ & $\begin{array}{c}\text { medium } \\
\text { gray }\end{array}$ & iso & 20 & light & 25 & $2-3$ & 1 & & $1-2$ & $1-2$ & & & $10-15$ & & & 1 & 1 \\
\hline 303-8-1 & 1 & GG & $\begin{array}{l}\text { It. tannish- } \\
\text { gray }\end{array}$ & $\begin{array}{l}\text { golden } \\
\text { brown }\end{array}$ & aniso & $10-15$ & moderate & 25 & $2-3$ & 1 & $1-2$ & $1-2$ & $1-2$ & & & $10-15$ & & & 1 & 1 \\
\hline $643-1$ & unassigned & II & $\begin{array}{l}\text { deep } \\
\text { reddish- } \\
\text { brown }\end{array}$ & \begin{tabular}{|c} 
reddish \\
black
\end{tabular} & iso & $10-15$ & dense & $5-7$ & $2-3$ & & $1-2$ & & & tr. & 3-5 & & tr. & & & 3-5 \\
\hline
\end{tabular}

$1=$ Sandstone fragment. 2 = Possibly organic material. 
Table 9-18. Petrographic Identifications and Quantifications of Ceramic Data from Component C (cont.).

\begin{tabular}{|c|c|c|c|c|c|c|c|c|c|c|c|c|c|}
\hline \multirow[t]{2}{*}{$\begin{array}{c}\text { Sample } \\
\text { No. }\end{array}$} & \multirow[t]{2}{*}{ Vessel No. } & \multirow[b]{2}{*}{$\begin{array}{l}\text { Paste } \\
\text { group }\end{array}$} & \multirow{2}{*}{\begin{tabular}{|c} 
Hematite \\
$\begin{array}{c}\text { Iron } \\
\text { Opaques } \\
(\%)\end{array}$
\end{tabular}} & \multicolumn{5}{|c|}{ Granular Rocks } & \multicolumn{3}{|c|}{ Carbonates } & \multirow{2}{*}{$\begin{array}{c}\text { Bone } \\
\begin{array}{c}\text { Bone } \\
(\%)\end{array}\end{array}$} & \multirow[b]{2}{*}{\begin{tabular}{|l|} 
Unknown \\
Rare (\%)
\end{tabular}} \\
\hline & & & & $\begin{array}{c}\text { Rock A } \\
(\%)\end{array}$ & \begin{tabular}{|c|} 
Rock B \\
$(\%)$
\end{tabular} & \begin{tabular}{|c} 
Rock C \\
$(\%)$
\end{tabular} & $\begin{array}{c}\text { AVRF } \\
(\%)\end{array}$ & $\operatorname{VRFB}^{2(\%)}$ & $\begin{array}{c}\text { Limestone } \\
(\%)\end{array}$ & $\begin{array}{c}\text { Calcite } \\
(\%)\end{array}$ & \begin{tabular}{|c} 
Caliche \\
$(\%)$
\end{tabular} & & \\
\hline 405-1 & 4 & I & $2-5$ & & & & & tr. & & $2-3$ & & & \\
\hline 628-1 & 5 & I & $1-2$ & & & & & & & & $1-2$ & & \\
\hline $33 /-6$ & 1 & I & $1-2$ & & & & & & & tr. & $2-3$ & & \\
\hline $349-1$ & 3 & I & $1-2$ & & & & & & & tr. & $3-5$ & & tr. $^{1}$ \\
\hline 639-3 & 6 & I & & & & & & & & $1-2$ & & & \\
\hline $239-2$ & 2 & $\mathrm{EE}$ & $1-2$ & & & & & & $1-2$ & tr. & tr. & & \\
\hline $362-8-1$ & 1 & $\mathrm{FF}$ & $1-2$ & & & & & & $1-2$ & & & & \\
\hline $468-8-4$ & 7 & FF & $1-2$ & & & & & & $1-2$ & & & & \\
\hline 303-8-1 & 1 & GG & $1-2$ & & & & & & $2-3$ & & & & \\
\hline 643-1 & unassigned & II & & & & & & & & tr. & $1-2$ & & $1-2^{2}$ \\
\hline
\end{tabular}


\#308-8-2, \#335-8-1, \#643-8-1, and \#1233-8-1) were heated with water (i.e., boiled). The damaged grains are from processing (i.e., pounding, grinding, etc.) prior to being cooked. Even though Vessels 1, 2, and 3 reflect significantly different shapes and sizes, all three appear to have functioned in the same manner and were used to cook various plant food resources. It does not appear that the various forms represented were restricted to certain cooking processes or were used for one type of food. Significantly, native wild plant remains outnumber the cultivated plant remains nearly 3 to 1 in these vessels. The presence of possible lily is surprising, as is the absence of mesquite and cheno-ams starch grains, which were recovered from sherds from Component A. That the two recognized types of grain processing (i.e., parching and grinding) were performed on both the domesticated and wild plants is expected, though usually not detected in archeological investigations.

Vessel 1 yielded the highest frequency of maize starches on any artifact from either component. The presence of hard endosperm type starch grains as opposed to floury morphologies in the maize grains indicates that maize was popped (Appendix D). Lintz (1986:33) mentions both pop maize and small flint maize for the Antelope Creek phase. The basal sherds from Vessel 1 yielded the fewest starch grains in comparison to the upper body and rim sherds. Vessels 1 and 3 contained the starch grains of both maize and little barley, and at least gelatinization of little barley grains were noted from Vessel 1. Three unassigned sherds and Vessels 1 and 2 yielded starches that were clearly gelatinized by cooking in the presence of heat and water, likely through boiling.

Sherds from Vessels 1 and 3 were also directly radiocarbon dated. That is, residues in the walls from one sherd from each of these two vessels were AMS dated to obtained precise ages for these two unusually thick vessels. The 21,550 \pm 70 B.P. date (UGAMS-8457) from a Vessel 1 sherd is not accepted as the construction or use date. It is likely this date was derived from original organic residues that remained inside the clay from which this vessel was constructed. Apparently these organic residues were not totally combusted during the vessel firing process, which the thick-walls potentially helped preserve. The $940 \pm 25$ B.P. date (UGAMS-8456) from a Vessel 3 sherd is some 300 to 400 years older than the well-established date range of 530 to 630 B.P. for Component $\mathrm{C}$ as determined by eight maize-kernel dates. It is not clear if this is the actual date the vessel was constructed and used or not. If it is, then the vessel was recycled long after it was constructed, though this seems an extremely long time for a clay vessel to have survived. Based on this one date for thick Vessel 3, it appears older than the main occupation and other thinner vessels. However, the context of Vessel 3 indicates it does in fact pertain to Component C. It is possible, that in the construction of this thick-walled Vessel 3, older organic residues were in the clay used in the manufacturing and were not combusted during the firing process as was the case in Vessel 1. Also, cooking processes of boiling at least maize and little barley might not have facilitated the penetration of organic residues into the vessel walls in these two vessels, and might not have produced sufficient residues to yield an accurate age related to the vessel use. The results from these two dated sherds indicate that radiocarbon dates derived from thick-walled sherds are not good indicators of the specific age of the occupations from which they were derived.

The brownware pottery associated with the Palo Duro complex further south (Boyd 1995, 1997, 2005) is not represented in Component C. Southwestern painted or glaze wares are also not represented in this assemblage. Nonlocal Southwestern ceramics occur at many Antelope Creek phase sites (Lintz 1984, 1986, 1991; Brooks 1989, 2004). In contrast, Buried City, both Courson A (41OC26) and Courson B did not yield Southwestern pottery (D. Hughes and Hughes-Jones 1987). Previously discussed Component A at Long View yielded a single, nonlocal, glaze sherd as well.

The overall horizontal distribution of the sherds is depicted by weight and quantity in Figure 9-104. The distribution by weight reveals a concentration in the immediate vicinity of heating elements and/ or cooking-related Features 23, 26, and 29 which were projected to be inside or on the margin of Feature 18, the "ghost" pithouse. The considerable weight reflected in this concentration is primarily from Vessel 1, a large, thick pot represented by 


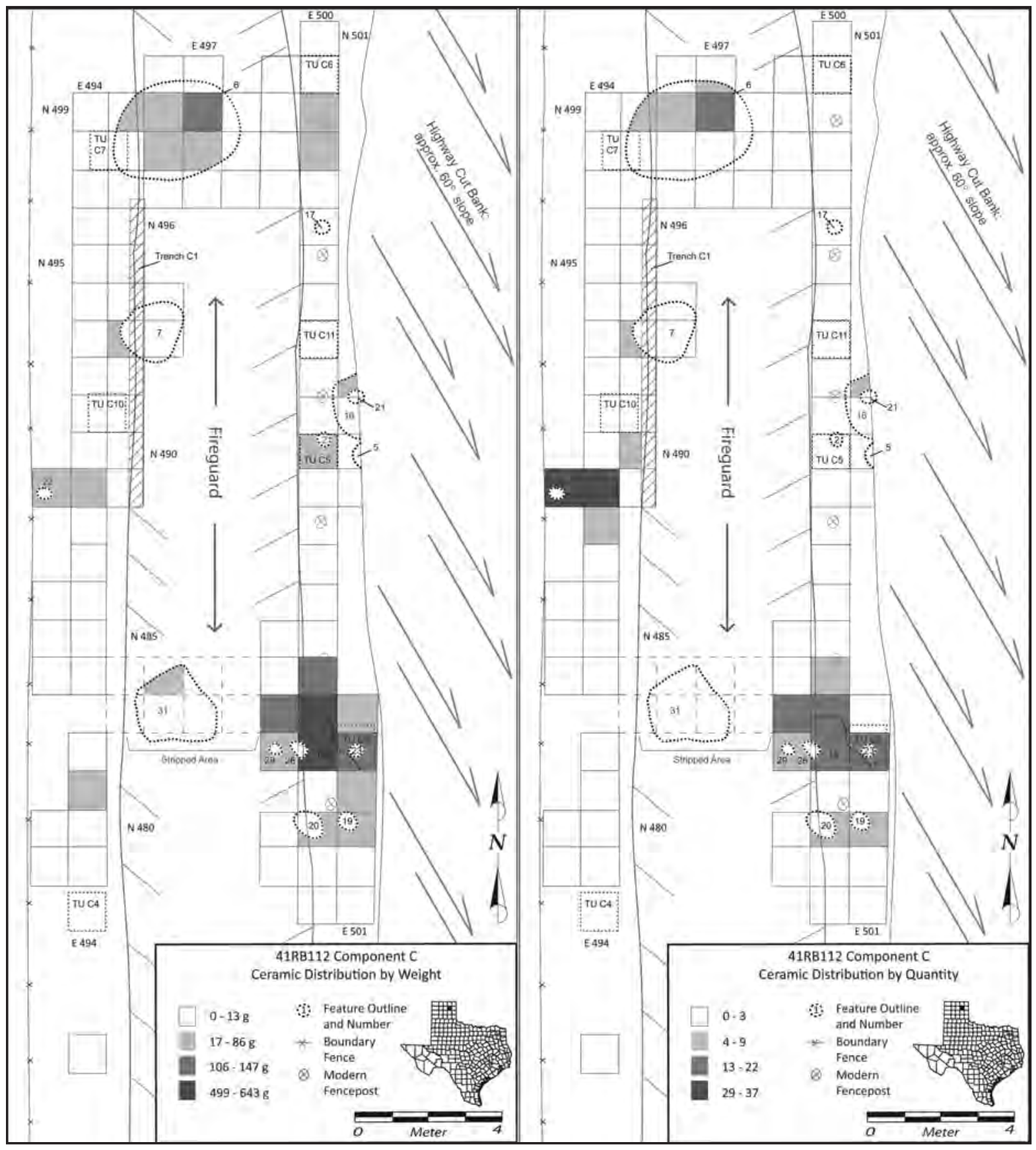

Figure 9-104. Horizontal distributions of ceramic sherds by weight (left) and quantity (right). 
many sherds. Other units with lighter sherd weights were near Features 2, 5, and 16/21, which were also heating elements/cooking features. The light to medium weights in the Feature 6 pithouse represent sherds from multiple vessels that were discarded onto the floor after the structure was abandoned. The light weight and dense quantity in two units near Feature 22 reflects a relatively small Vessel 4 . This vessel was not associated with Feature 22, as the sherds from this vessel were recovered from the upper $30 \mathrm{cmbs}$, and Feature 22 was some 65 cmbs.

The distribution of sherds by quantity is nearly identical to the distribution by weight. The principal differences reflect the more numerous small sherds that have little weight. In general, the very well-defined distribution is interpreted to reflect patterned human behavior, namely the use and breakage of ceramic vessels adjacent to the heating elements/cooking features, and the intentional discard of sherds into the pithouse as a means of disposal, a behavior that is the end product of the intentional cleaning of activity areas. Parts of six of the seven identified vessels, the exception being Vessel 4, were discarded in the pithouse. This sort of intentional clearing behavioral pattern suggests a relatively lengthy occupation- sufficient length that undesirable waste materials had accumulated in activity areas to the point that there was a desire or need to clean that area. The disposal of the debris was, in effect, a behavior similar to discard of debris in a midden area.

\subsection{Animal Bone Analysis}

\section{J. Michael Quigg}

\subsubsection{Introduction}

Component $C$ yielded 2,571 vertebrate faunal remains $(10,858 \mathrm{~g})$ that account for roughly 46 percent of the entire component assemblage. However, bone preservation was generally poor with most specimens revealing weathered and root etched surfaces, except those from inside the pithouse. The pithouse yielded 58 percent of the faunal bones from this component, and those pieces were much better preserved with only limited root etching and minor effects from weathering. The bones from outside of the pithouse were likely exposed on the surface for a lengthy period before burial, which allowed the weathering processes to degrade and fragment the bones. Weathering caused cracking, dry bone splintering, and exfoliation of surfaces, which caused many bones to fragment over time. After burial, the bones were subjected to further postdepositional deterioration processes. These natural alterations to the bone surfaces hinder the detection of stone tool cut marks and the identification of lightly worn and/or polished surfaces such as would indicate use as tools. The poor preservation also raises the question of whether or not small animal bones with thin cortical walls have been preserved in this deposit. The fragmentation resulting from natural agencies makes it difficult to assess how much breakage may have been caused by intentional processing of animal bones by humans. During excavation, a cluster of pieces that appeared to represent a single weathered element was most often bagged together and subsequently recorded as a single element, even though that element was represented by multiple pieces.

Pieces retaining their articular ends were identified according to taxa. However, most fragments beyond the pithouse do not exhibit articular ends and could only be assigned to general animal-size classes based on the thickness of cortical walls. Bison was the only very large animal positively identified on the basis of articular-end morphology; consequently, those pieces with thick cortical walls were assigned to the bison-size class without being specifically identified. Similarly, as deer was the only animal positively identified as a medium size animal, fragments with medium-thick cortical walls were assigned to the deer-size category. It is possible that pronghorn antelope were present in this assemblage, but no elements were positively identified as such. Fragmented rabbit bones were positively identified and it is likely that cottontail and jack rabbit are both represented. Turtle bones were identified and represent box turtles. Several rodent bones, including positively identified prairie dog, were recovered, but it is unclear if these were culturally introduced into the assemblage or are commensal parts of the natural environment. Unless burned, these very small rodent bones are considered part of the natural background. Fish bones were recovered from the floor of the pithouse and their presence is assumed to represent human activity. 
The pithouse contained a relatively large sample of faunal bone $(N=1,471 ; 8,669.8 \mathrm{~g})$ that is much better preserved than the faunal materials from the rest of Component C. For this reason, the pithouse assemblage is dealt with separately, below. The lack of extensive weathering and root etching on the pieces from within the pithouse allows for greater understanding of the animal processing, as cut marks and impact fractures can be more readily recognized. Following the discussion of the faunal remains from the pithouse, the rest of the animal bone from Component $\mathrm{C}$ will be discussed. Only 32 percent of the pithouse assemblage was identifiable to taxa, and the following discussion focuses on those identifiable remains. The nonbison remains will be presented first, followed by discussion of the bison remains.

\subsubsection{Nonbison Remains from the Pithouse}

At least seven different taxa are recognized in the assemblage from the pithouse; these consist of deer, turtle, rabbits, prairie dog, unidentified rodent, fish, and snake (Table 9-19). Twenty-eight fragments (133.1 g) were identified as deer elements and include front (radius, lunate, scaphoid, and scapula) and rear leg parts (femur), which include phalanges and metapodials, whereas the axial skeleton is represented by only a few fragmented vertebrae bodies and one incisor tooth. The individual fragments represent at least one mature deer, since the proximal and distal ends of the long bones (i.e., radius and femur) exhibit fused articular surfaces and are of similar size.

Thin cut lines occur on the proximal femur (\#5822-2, Figure 9-105), a proximal radius, and a distal metapodial. These cut lines testify to the removal of soft tissues in the butchering process. The entire deer carcass was brought to this camp for processing with fine-edged stone tools employed in the defleshing and disarticulation of the carcass. The small size of most deer bone fragments (65 percent in the 0 to $3 \mathrm{~cm}$ size class) indicates that the bones were not only broken to extract marrow, but further smashed to subsequently extract bone grease through boiling. One distal $2^{\text {nd }}$ phalanx and one unidentified deersize long bone fragment were burned black. These two pieces were likely discarded into a fire, which caused their black color, then in a subsequent cleaning activity were discarded within the pithouse.

Twenty-five pieces $(9.3 \mathrm{~g})$ of turtle carapace were identified. These are small pieces of disarticulated shell with one burned to a light gray color. These represent at least one box turtle. Based on the one burned piece and their scattered distribution inside the pithouse, this turtle is considered part of the repertoire of resources exploited by the site's inhabitants.

Twenty-four rabbit element fragments (8.6 g) were identified and represent parts of the entire skeleton with fragments identified as parts of the mandible, vertebrae, pelvis, tibia, femur, and calcanium. The size of most pieces best reflects a cottontail with the exception of two pieces, a rib and an immature tibia, which are of jackrabbit size. Thus, a minimum of two individuals are represented. One calcanium was burned to a black color and none exhibit cut marks. These rabbits are considered to represent utilized food resources.

Two prairie dog skulls (11.9 g) with teeth still present were recovered. Neither was burned nor showed evidence of being butchered. Although in a cultural context in the pithouse, it is likely these elements were introduced following occupation of the site and do not represent a part of the exploited resource base. Three tooth fragments $(0.5 \mathrm{~g})$ of an unidentified rodent were also present and may also represent a prairie dog.

Positively identified fish remains include three tiny vertebrae, all unburned and recovered from the heavy fractions of floated sediment. A tiny mandible with sharp, pointed teeth was recovered from the same provenience (\#591-4), 40 to 50 cmbs in N498 E497 of the pithouse, along with one possible, but unconfirmed, fish vertebrae. Four fish skull elements (\#582, at $2.8 \mathrm{~g}$ ) were also recovered from the floor of the pithouse at 60 to $70 \mathrm{cmbs}$ in N498 E496. Since these elements were on the floor of the pithouse, it is assumed they reflect part of the subsistence base.

Three small snake vertebrae $(0.3 \mathrm{~g})$ were found above the floor of the pithouse in N499 E497. These vertebrae were not burned or otherwise altered. 
Table 9-19. List of Taxa Identified and Bone Counts in Feature 6, the Pithouse in Component C.

\begin{tabular}{|l|c|c|l|}
\hline Taxa & NISP & MNI & \\
\hline Bison & 386 & 5 & \\
\hline Deer & 28 & 1 & \\
\hline Turtle & 25 & 1 & \\
\hline Rabbit & 24 & 1 & \\
\hline Prairie Dog & 2 & 2 & \\
\hline Rodent & 3 & 1 & \\
\hline Fish & 4 & 1 & $591,120=$ Feat 5 \\
\hline Snake & 3 & 1 & \\
\hline Unidentifiable & 996 & & \\
\hline Total & $\mathbf{1 4 7 1}$ & $\mathbf{1 3}$ & \\
\hline NISP = number of individual specimens; & \\
\hline MNI = minimum number of individuals & \\
\hline
\end{tabular}

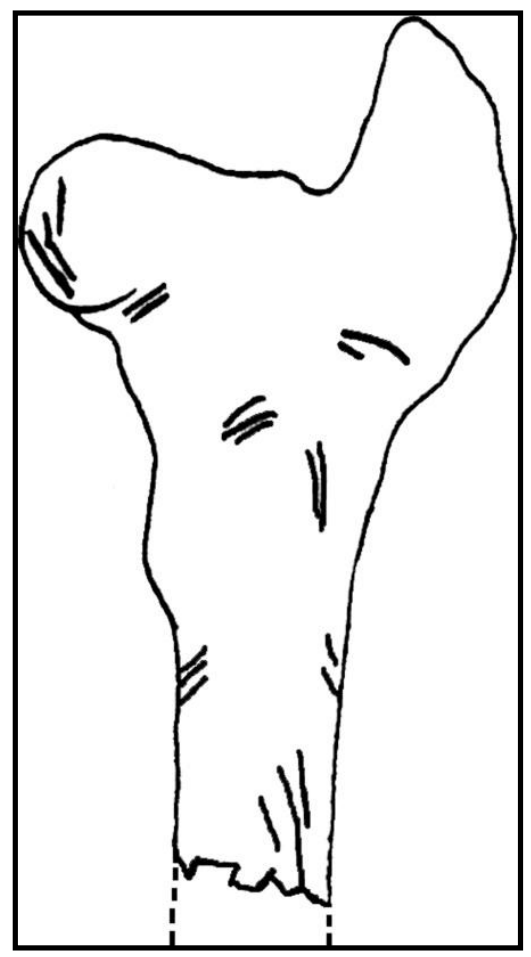

Figure 9-105. Proximal deer femur (\#582-2-2) showing location of cut lines. 
Snakes are not considered a targeted food resource, but rather natural inclusions in the sediments.

\subsubsection{Bison Remains from the Pithouse}

A total of 386 pieces of bison bones weighing 7,724.5 g were from the pithouse. Recognized elements were categorized into complete, medial, proximal, distal or unknown fragments (Table 9-20). Fragments dominate (99\%) the assemblage by count. Only 12 complete or mostly complete elements, which consist of three mature and one immature metacarpal, a scapula, an astragalus, a calcanium, together with small elements such as sesamoids and phalanges. All parts of the skeletons are represented with front and rear legs that include the phalanges, skull parts, vertebrae, and spinous processes. Caudal vertebrae are the exception and were not identified. It is likely the caudal bones remained attached to the skins when they were removed from the carcasses. Ribs, although present, were quite infrequent and are represented only by small chunks.

An articulated section of four mature, mostly complete vertebrae bodies (\#582-2-4) that lack their dorsal spines was recovered. Three vertebrae exhibit a lightly burned area (brown in color) on one side, plus small impact or puncture marks that did not break through the bones. Two detached, long thoracic spines reveal thin cut lines next to their proximal ends, indicating cutting of soft tissues to facilitate their removal from the vertebrae bodies.

\subsubsection{Bison Age Groups and Gender Identification}

Four broad age categories of bison were recognized: fetal, immature, mature, and unknown. Only a single fetal element (\#568-2), a left humerus shaft (12.5 g), was identified (Figure 9-106). This is a relatively large fetal shaft (79-mm-long by $16-\mathrm{mm}$-wide at midshaft), which indicates this humerus reflects a fetus that was nearly fully developed. This one element indicates a probable late February or March season of death, assuming that this individual was part of the normal birthing cycle.

A single, nearly complete left metacarpal (\#639-2$1,82.0 \mathrm{~g}$ ) from $28 \mathrm{cmbs}$ in the fill of the pithouse in N499 E497 lacks the unfused distal epiphyses.
This represents an immature animal less than 3.3 years old (see Bement and Basmajian 1996). This metacarpal is well preserved with only minor root etching evident, but has considerable rodent gnawing on the anterior side and proximal end. Two short, thin cut lines are side-by-side near the distal end on the posterior side of the shaft. The position of the cuts indicates they occurred during disarticulation. The overall metacarpal length is $15.5 \mathrm{~cm}$, which is roughly $1.0 \mathrm{~cm}$ longer than a three-day-old bison calf metacarpal that measures 14.6-cm-long. This unfused metacarpal likely represents a relatively new calf, which if not an out-of-season birth, places the time of death during the spring months (April/ May).

Fifteen proximal and distal ends of mature long bones are present and sufficiently complete to allow measurements to determine sex. These consist of 10 left-side and 4 right-side elements from multiple animals; the number and sexes of the individuals are discussed below. Males and females are represented.

Seven major sections of scapula represent at least four animals based on four right sections (see Table 9-20). All scapula pieces appear worked or altered in one way or another (see section 9.6). Four pieces have their spines removed and four have a series of long cut lines on the scapular blades. However, none appear to have been utilized, as they do not show extensive wear or have rounded or polished edges. Two scapula medial blade sections (\#582-2-5 and \#643-2-3) with their partial spines intact appear lightly burned (light brown) along the medial blade sections. The MNI in the pithouse is five animals and includes at least four mature, one immature, and one pregnant female carrying a fetus. The sex of the immature animal is indeterminate.

\subsubsection{Bison Bone Processing}

The overall skinning process is not detectable from the few visible cut marks. Only five fragments that include the four scapulas discussed above and one rib, reveal cut marks. Often, when the skin was detached from the lower leg, cut marks perpendicular to the metapodials are present, but none of the metapodials in our sample exhibit such cut marks. Skinning was likely initiated above the metapodials. 
Table 9-20. Identified Bison Elements from the Pithouse in Component C.

\begin{tabular}{|c|c|c|c|c|c|c|c|c|}
\hline \multirow{2}{*}{ Element/Fragment } & \multicolumn{2}{|c|}{ Complete } & \multicolumn{2}{|r|}{ Distal } & \multirow{2}{*}{ Medial } & \multicolumn{2}{|c|}{ Proximal } & \multirow[b]{2}{*}{ Fragments } \\
\hline & Left & Right & Left & Right & & Left & Right & \\
\hline \multicolumn{9}{|c|}{ Skull } \\
\hline Skull & & & & & & & & 4 \\
\hline Maxilla & & & & & 2 & & & \\
\hline Mandible & & & & & $1 * * *$ & & & \\
\hline \multicolumn{9}{|l|}{ Hyoid } \\
\hline \multicolumn{9}{|l|}{ Incisor } \\
\hline Tooth & & M2 & & & & & & 3 \\
\hline \multicolumn{9}{|c|}{ Vertebrae + Pelvis } \\
\hline \multicolumn{9}{|l|}{ Atlas } \\
\hline \multicolumn{9}{|l|}{ Axis } \\
\hline \multicolumn{9}{|l|}{ Cervical } \\
\hline Thoracic & & & \multicolumn{2}{|c|}{$1^{* *} 1^{*}$} & 1 & & & \\
\hline Lumbar & & & & & $3^{*}$ & & & \\
\hline \multicolumn{9}{|l|}{ Caudal } \\
\hline Rib (heads, shafts) & & & & & yes*, $1 * * *$ & \multicolumn{2}{|c|}{$1 * *$} & yes \\
\hline \multicolumn{9}{|l|}{ Sacrum } \\
\hline \multicolumn{9}{|l|}{ Pelvis (Ischium, Ilium) } \\
\hline Acetabulum & & & & & & & 2 & \\
\hline \multicolumn{9}{|c|}{ Front Leg } \\
\hline Scapula & $1^{* *}$ & & & $1^{* *}$ & $2 * *$ & & $3 * *$ & $1^{* *}$ \\
\hline \multicolumn{9}{|l|}{ Humerus } \\
\hline Radius & & & & $1 * \mathrm{M}$ & & 1 & $1 \mathrm{M}$ & \\
\hline Ulna & & & & & & $\begin{array}{l}1,1^{*}, 1 \\
\text { Tool }\end{array}$ & & \\
\hline \multicolumn{9}{|l|}{ Unciform } \\
\hline \multicolumn{9}{|l|}{ Scaphoid } \\
\hline \multicolumn{9}{|l|}{ Cuneiform } \\
\hline \multicolumn{9}{|l|}{ Lunate } \\
\hline Metacarpal & $1 \mathrm{~F}$ & $2 \mathrm{~F}$ & $3 * \mathrm{M} 1 \mathrm{~F}$ & $1 \mathrm{~F}$ & 1 & & & \\
\hline \multicolumn{9}{|c|}{ Rear Leg } \\
\hline Femur & & & & & & $1 \mathrm{M}$ & $1 \mathrm{~F}$ & 2 \\
\hline Patella & & & & & & & & \\
\hline Tibia & & & $1^{*} \mathrm{~F}$ & 1* M 1-tool F & & & 1 & \\
\hline Lateral Malleolus & & 1 & & & & & & \\
\hline Astragalus & & $1^{*}$ & & & & & & \\
\hline Navicular Cuboid & & & & & & & & \\
\hline Calcanium & $1 \mathrm{M}$ & & & & & & & \\
\hline Magnum & & & & & & & & \\
\hline Metatarsal & & 1 & $1 * \mathrm{M}$ & & & $1^{*} \mathrm{~F}$ & & \\
\hline
\end{tabular}


Table 9-20. Identified Bison Elements from the Pithouse in Component $\mathrm{C}$ (cont.).

\begin{tabular}{|c|c|c|c|c|c|c|c|c|}
\hline \multirow{2}{*}{ Element/Fragment } & \multicolumn{2}{|c|}{ Complete } & \multicolumn{2}{|c|}{ Distal } & \multirow{2}{*}{ Medial } & \multicolumn{2}{|c|}{ Proximal } & \multirow[b]{2}{*}{ Fragments } \\
\hline & Left & Right & Left & Right & & Left & Right & \\
\hline \multicolumn{9}{|c|}{ Other } \\
\hline $1^{\text {st }}$ Phalanx & \multicolumn{2}{|c|}{2} & \multicolumn{2}{|c|}{1} & & & & \\
\hline $2^{\text {nd }}$ Phalanx & \multicolumn{2}{|c|}{$3,1^{* * *}$} & & & & & & \\
\hline $3^{\text {rd }}$ Phalanx & \multicolumn{2}{|c|}{2} & & & & & & \\
\hline \multicolumn{9}{|l|}{ Long Bone fragments } \\
\hline \multicolumn{9}{|l|}{ Cancellous } \\
\hline \multicolumn{9}{|l|}{ Unknown fragments } \\
\hline Sesamoids & \multicolumn{2}{|c|}{3} & & & & & & \\
\hline \multicolumn{9}{|l|}{ Metapodial } \\
\hline TOTAL & \multicolumn{2}{|c|}{22} & & 13 & 12 & \multicolumn{2}{|c|}{13} & 11 \\
\hline
\end{tabular}

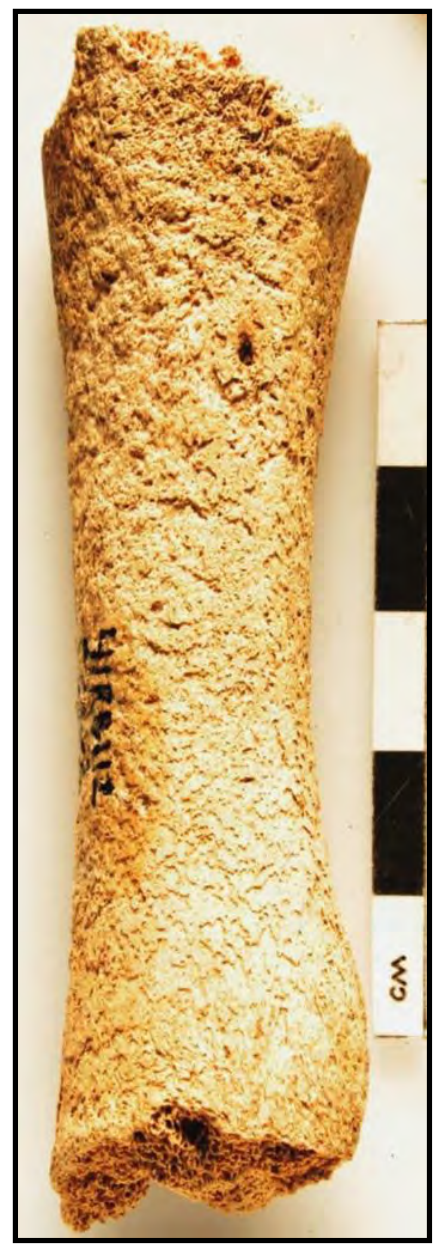

Figure 9-106. Fetal humerus shaft (\#568-2).

Note the flakey, unsolitified exterior tissue. 
One technique employed by the inhabitants of $41 \mathrm{RB} 112$ in processing the defleshed bones was that of placing a complete long bone in or next to a fire to burn the periosteum tissues and/or cause the cortical bone to become brittle in order to facilitate breakage of the thick green bones (Bonnichsen 1973:10). This strategy of burning is detected on a few different elements where a light brown burned area and splintering of the cortical wall is present near the midshaft of broken elements or in a few instances on the distal or proximal ends (Figure 9-107). A burned distal tibia (\#1229-2-2) that is partly black and partly brown likely was subjected to this same type of processing. This burning and breaking of the midshaft of the long bones was done to facilitate extraction of the marrow.

This was not the case for the three complete metacarpals. A possible explanation for the intact condition of three metacarpals is that this bone element contains a low volume of marrow compared to larger leg bones such as the humerus, radius, femur, and tibia (Emerson 1990:338; Brink 1995). It is safe to suggest that these metacarpals were not preferred sources of bone marrow, and therefore, were not broken like the other, more marrow-rich, long bones.

Sixty-two percent of the bison bones fall into the smallest fragment size class (0 to $3 \mathrm{~cm}$ in length), while 84 percent are less than 9-cm-long. Given the intensively fragmented nature of this assemblage, it is difficult to identify any particular butchering sequence or pattern. The scarcity of discernible cut marks also hinders reconstruction of the animal butchering/disarticulation process. The small size of most pieces does indicate that following a general breakage to remove marrow, most bones were then intentionally smashed into small pieces, inferably for the purpose of rendering bone grease through a boiling process. Although unbroken bones are not numerous, comprising only 7.7 percent of the bison bone, their presence, along with intact distal and proximal ends of long bones, plus the three complete metapodials and the relatively complete scapulas, indicates that not all bison bones were smashed for grease extraction and a selection process was implemented.

\subsubsection{Bison Bone Distribution}

The bison bones were scattered across the floor of the pithouse (Figure 9-108). Both male and female animals are represented as are left- and rightsides. These elements also represent all parts of the animal: skull, vertebrae, ribs, and front and rear legs. Generally speaking, no one part of the animal was specifically discarded in this pithouse, with the possible exception of the scapulas. This apparent scattering of different recognizable bones from multiple animals of both sexes indicates no special discard or selection pattern. The variety of elements potentially represents the random tossing of bones into a midden area. In support of a midden-like discard area, at least one localized area in N498 E498 yielded nearly $100 \mathrm{~g}$ of very small burned bone fragments, which may represent a single cleaning and dumping episode. Several other small clusters of fragments were present and indicate possible multiple dumping events from various tasks or cleaning episodes. Not only were animal bones discarded on the floor of the pithouse, so were many other classes of cultural debris, supporting the notion that this pithouse served as a convenient place to discard various unwanted materials after its abandonment.

\subsubsection{Faunal Remains from Beyond the Pithouse}

The remaining part of Component C yielded 43 percent of the component's bone assemblage or 1,100 pieces that weigh 3,132.9 g. As stated previously, the exterior surfaces of the pieces are weathered and/or root etched, which makes identification of cut marks difficult. Even the identification of taxa was difficult as reflected by the fact that 80 percent $(1,044.2 \mathrm{~g})$ of this assemblage is not identifiable to taxa.

\subsubsection{NonBison Remains}

Nonbison bones are again represented across the rest of the occupation and basically consist of the same taxa identified in the pithouse, which include deer, turtle, rabbit, fish, and rodent (Table 9-21). Deer are represented by only five pieces $(11.1 \mathrm{~g})$ that consist of a $2^{\text {nd }}$ phalanx, a rib, a scaphoid, and an astragalus. All are burned except for the one rib head. It is likely that small, fragmented long bones of deer that lack their proximal and distal ends are present in the 


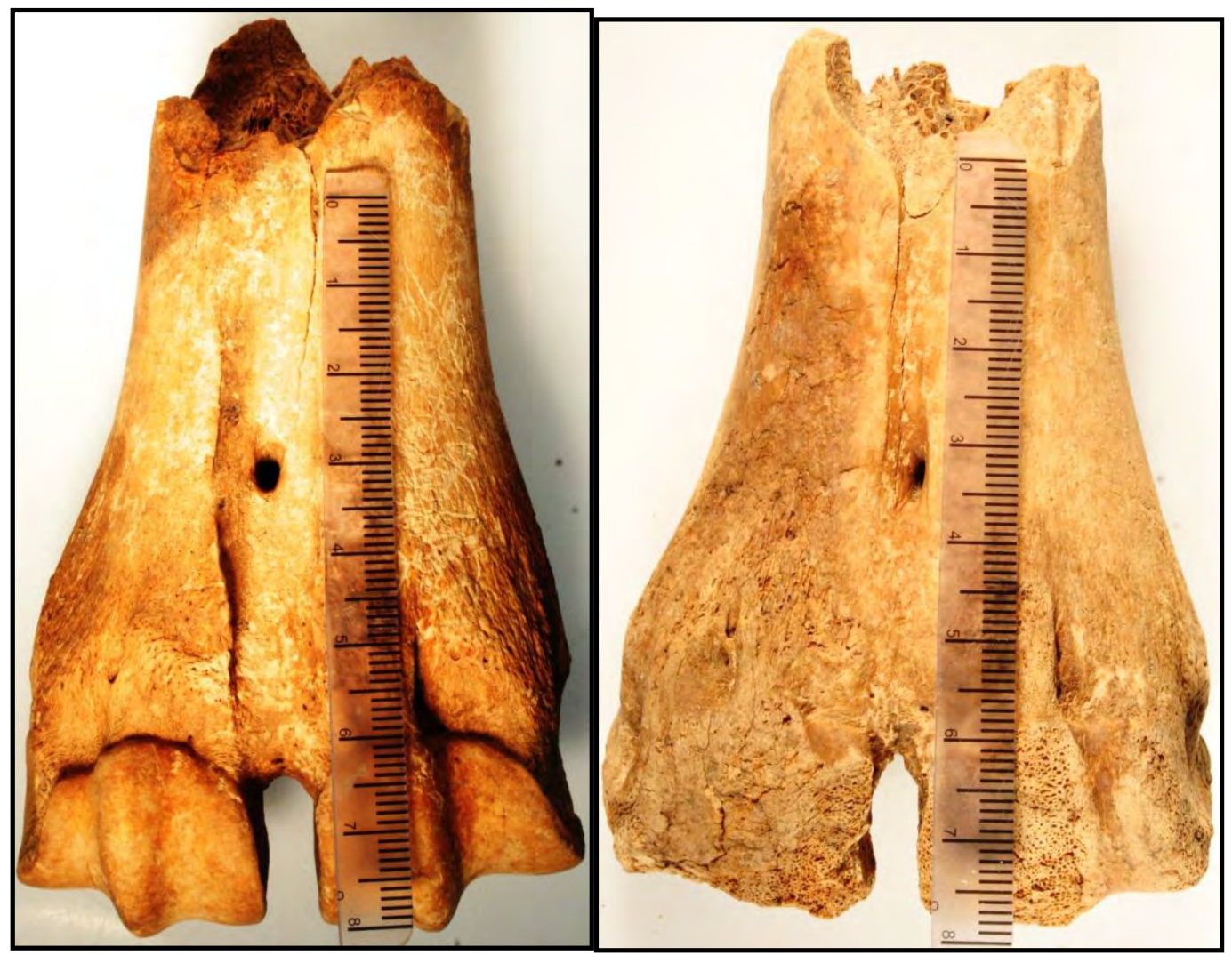

\section{Figure 9-107. Lightly burned midshaft of metatarsal (\#643-2-10, left) and lightly burned distal end of metacarpal (\#643-2-1, right). \\ Scale in centimeters.}

unidentifiable portion of the assemblage. Fifty turtle carapace pieces $(26.9 \mathrm{~g})$ were identified, none of which are burned. Feature 31, a general occupational surface encountered during stripping, yielded 44 pieces of a nearly complete carapace of a box turtle. Tiny fragmented long bones and one tooth of a rabbit (1.4 g) were recovered from N484 E496. A single burned fish vertebra (1.5-mm-long) was recovered from floating the matrix from Feature 5. The four taxa just discussed, namely deer, turtle, rabbit, and fish, are all considered to represent cultural food resources. In addition to these taxa, 51 unidentifiable rodent bones (2.0 g) are represented. None are burned or show cut marks, and are considered to be noncultural, natural inclusions in the deposits.

These nonbison remains again reflect diversified subsistence practices, assuming that all but the rodents were consumed as foods. The tiny snake and prairie dog bones found in the pithouse, are not represented in the faunal assemblage from the remaining component and are not believed to have been food resources.

\subsubsection{Bison Remains}

Bison elements and fragments, weighing 2,047.3 g, again dominate the identified pieces in the broader component outside the Feature 6 pithouse. The 89 pieces are roughly one quarter the number of bison pieces from inside the pithouse. All pieces have suffered extensively from weathering and acid etching. Twenty-nine elements $(1,589.8 \mathrm{~g})$ were positively identified as bison and only a few small elements such as phalanges, a lateral malleolus, astragalus, and two metacarpals are complete (Table 9-22). Many small fragmented sections of long bones could not be specifically identified as bison. 


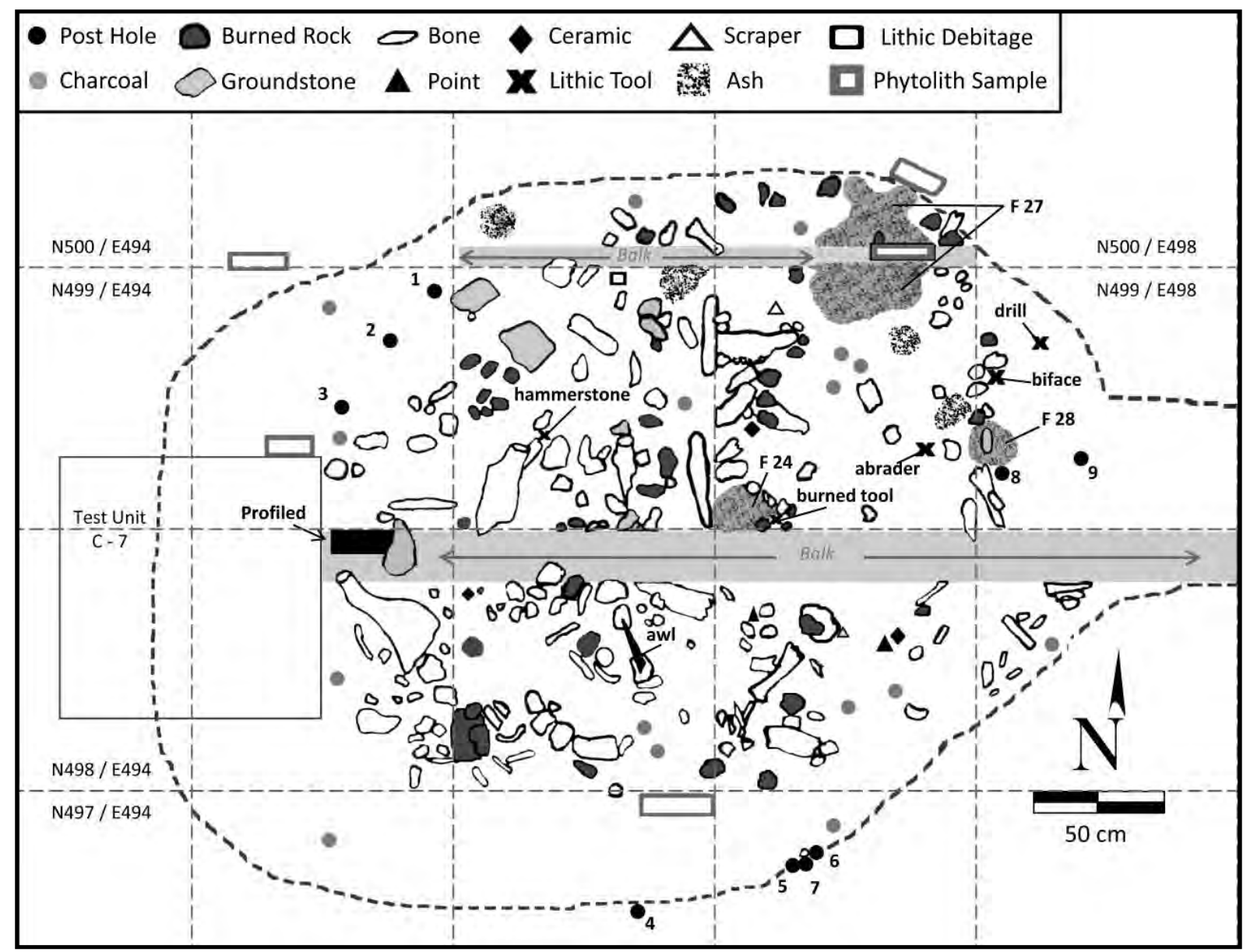

Figure 9-108. Bison bones and other cultural materials scattered across the pithouse.

Table 9-21. List of Taxa Represented and Bone Counts from Outside the Pithouse, Feature 6.

\begin{tabular}{|l|c|c|}
\hline Taxa & NISP & MNI \\
\hline Bison & 89 & 6 \\
\hline Deer & 5 & 1 \\
\hline Turtle & 50 & 2 \\
\hline Rabbit & 25 & 2 \\
\hline Rodent & 51 & 2 \\
\hline Unidentifiable & 881 & \\
\hline Total & 1100 & 10 \\
\hline
\end{tabular}

$\mathrm{NISP}=$ number of individual specimens;

$\mathrm{MNI}=$ minimum number of individuals 
The Long View Site (41RB112): Data Recovery of Two Late Prehistoric Plains Village Components in Roberts County, Texas -Texas Department of Transportation

Table 9-22. Identified Bison Elements from Beyond the Pithouse in Component C.

\begin{tabular}{|c|c|c|c|c|c|c|c|c|}
\hline \multirow{2}{*}{ Element/Fragment } & \multicolumn{2}{|c|}{ Complete } & \multicolumn{2}{|c|}{ Distal } & \multirow{2}{*}{ Medial } & \multicolumn{2}{|c|}{ Proximal } & \multirow{2}{*}{$\begin{array}{l}\text { Frag } \\
\text { ments }\end{array}$} \\
\hline & Left & Right & Left & Right & & Left & Right & \\
\hline \multicolumn{9}{|c|}{ Skull } \\
\hline Skull & & & & & & & & 1 \\
\hline \multicolumn{9}{|l|}{ Maxilla } \\
\hline \multicolumn{9}{|l|}{ Mandible } \\
\hline \multicolumn{9}{|l|}{ Hyoid } \\
\hline \multicolumn{9}{|l|}{ Incisor } \\
\hline Tooth & & & & & 2 & & & \\
\hline \multicolumn{9}{|c|}{ Vertebrae + Pelvis } \\
\hline \multicolumn{9}{|l|}{ Atlas } \\
\hline \multicolumn{9}{|l|}{ Axis } \\
\hline \multicolumn{9}{|l|}{ Cervical } \\
\hline Thoracic & & & & & 2 & & & \\
\hline \multicolumn{9}{|l|}{ Lumbar } \\
\hline \multicolumn{9}{|l|}{ Caudal } \\
\hline Rib (heads, shafts) & & & & & 5 & & & 1 \\
\hline \multicolumn{9}{|l|}{ Sacrum } \\
\hline \multicolumn{9}{|l|}{ Pelvis (Ischium, Ilium) } \\
\hline \multicolumn{9}{|l|}{ Acetabulum } \\
\hline \multicolumn{9}{|c|}{ Front Leg } \\
\hline Scapula & & & & & 1 & & & 3 \\
\hline Humerus & & & 1 & & 1 & & & \\
\hline Radius & & & & & & & $1 \mathrm{M}$ & \\
\hline Ulna & & & & & 1 & & & \\
\hline Unciform & 1 & & & & & & & \\
\hline \multicolumn{9}{|l|}{ Scaphoid } \\
\hline \multicolumn{9}{|l|}{ Cuneiform } \\
\hline \multicolumn{9}{|l|}{ Lunate } \\
\hline Metacarpal & & $\begin{array}{c}1 \mathrm{M}, 1 \\
\mathrm{~F}^{* * *}\end{array}$ & $1 \mathrm{~F}$ & & & $1 \mathrm{~F}$ & & \\
\hline \multicolumn{9}{|c|}{ Rear Leg } \\
\hline Femur & & & & & & $1 \mathrm{M}$ & & \\
\hline Patella & & & & & & & & \\
\hline Tibia & & & & 1 & 2 & & & \\
\hline Lateral Malleolus & 1 & & & & & & & \\
\hline Astragalus & & 1 & & & & & & \\
\hline Navicular Cuboid & & & & & & & & \\
\hline Calcanium & & & & & & & & \\
\hline Magnum & 1 & & & & & & & \\
\hline Metatarsal & & & 1 & & & & & 1 \\
\hline
\end{tabular}


Table 9-22. Identified Bison Elements from Beyond the Pithouse in Component C (cont.).

\begin{tabular}{|c|c|c|c|c|c|c|c|c|}
\hline \multirow{2}{*}{ Element/Fragment } & \multicolumn{2}{|c|}{ Complete } & \multicolumn{2}{|c|}{ Distal } & \multirow{2}{*}{ Medial } & \multicolumn{2}{|c|}{ Proximal } & \multirow{2}{*}{$\begin{array}{l}\text { Frag } \\
\text { ments }\end{array}$} \\
\hline & Left & Right & Left & Right & & Left & Right & \\
\hline \multicolumn{9}{|c|}{ Other } \\
\hline $1^{\text {st }}$ Phalanx & & 2 & & & & & 1 & \\
\hline $2^{\text {nd }}$ Phalanx & & 3 & & & & & & \\
\hline \multicolumn{9}{|l|}{$3^{\text {rd }}$ Phalanx } \\
\hline \multicolumn{9}{|l|}{ Long Bone fragments } \\
\hline \multicolumn{9}{|l|}{ Cancellous } \\
\hline \multicolumn{9}{|l|}{ Unknown fragments } \\
\hline Sesamoids & & 1 & & & & & & \\
\hline \multicolumn{9}{|l|}{ Metapodial } \\
\hline TOTAL & & & & & & & & \\
\hline
\end{tabular}

\section{Bison Age Groups and Gender Identification}

Except for two unfused vertebrae epiphysis, no immature bison long bones are represented by the elements from beyond the pithouse. All bison represented are mature animals that were greater than about 4.0 years old at the time of death.

All complete or nearly complete mature distal and proximal ends of bison long bones from Component C were measured and weighed. As Speth (1983) and others (i.e., Lorrain 1968; Duffield 1973; Bedford 1974, 1978; Todd 1986; Morlan 1991) have shown, measurements on various mature long bones can reveal the sex of the represented animals. Table 9-23 presents the pertinent data concerning the measured elements from Feature 6 pithouse and the rest of Component $\mathrm{C}$, and identifies sex on the basis of measurements of individual proximal and distal ends and comparisons with measured elements of modern animals of known sex (Speth 1983). Our limited sample of measurable proximal and distal ends $(N=27$ with 13 from outside Feature 6 pithouse) reveals a nearly equal number of male and female elements (12 male and 15 female). Assigning each element to a side of the skeleton, 13 rights and 14 lefts are represented. The unfused vertebrae may be from one of these animals as vertebrae fuse later in life.
The minimum number of individuals (MNI) is four mature females and two mature males based on these measurements. One male was a large, robust animal represented by a complete metacarpal (\#4702-1), a complete right calcanium (\#619-2-2), a $2^{\text {nd }}$ phalanx, and a right proximal radius (\#572-2-1). One of the two maxillary sections that exhibit old and worn molars (\#643-2-5) may also represent this robust male. The massive distal radius as well as the massive calcanium represents an animal older than 5.3 years (Bement and Basmajian 1996) and the robust male is at least that old. One mature distal femur represents a female, also greater than 5.3 years old. In addition to these six animals, one immature animal of indeterminate sex is represented by an immature left metacarpal from the pithouse.

Two lower molars are sufficiently complete to provide approximate age estimations. A right third molar (M3) represented by rear two thirds of a tooth (\#413-2-1) was recovered from 36 cmbs in N489 E494. The second cusp is worn, whereas the third cusp is not (Figure 9-109). This tooth represents an animal that is estimated to be 3.5 to 3.7 years old based primarily on comparison with wear patterns documented on bison mandibles from the Hawken site in Wyoming (Frison et al. 1976). A second mandibular tooth (\#349-2-1) from 60 to $80 \mathrm{cmbs}$ in Feature 31 at N484 E496 is a right M2. This tooth exhibits no wear on the cusps and was still in the 
Table 9-23. Measurements on Mature Bison Elements that Indicate Male and Female Elements.

\begin{tabular}{|c|c|c|c|c|c|c|c|}
\hline Catalog No. & Bison Element & $\begin{array}{r}\text { Unit } \\
\text { E }\end{array}$ & $\begin{array}{l}\text { Depth } \\
\text { (cmbs) }\end{array}$ & $\begin{array}{c}\text { Weight } \\
\text { (g) }\end{array}$ & Side & Location and Measurement ${ }^{* *}(\mathrm{~mm})$ & Gender \\
\hline $572-2-1^{*}$ & Proximal radius & 498495 & $60-70$ & 355.5 & $\mathrm{R}$ & $A=106.1, B=56.2, C=36.4, D=60.6, E=42.6$, & M \\
\hline $582-2-3 *$ & Proximal radius & 498496 & $60-70$ & 292.5 & $\mathrm{~L}$ & $\mathrm{~A}=102.2, \mathrm{~B}=51.8, \mathrm{C}=35.5, \mathrm{D}=48.1, \mathrm{E}=41.8$, & $\mathrm{M}$ \\
\hline $1260-2$ & Proximal radius & 484494 & 80 & 243.4 & $\mathrm{R}$ & $A=105.9, C=35.9$ & M \\
\hline $580-2-1 *$ & Distal radius & 498496 & $50-60$ & 201.3 & $\mathrm{~L}$ & $\mathrm{H}=47.9, \mathrm{I}=54.6, \mathrm{~K}=36.9, \mathrm{I}=19.1$ & M \\
\hline $625-2-3 *$ & Distal radius & 499495 & 67 & 320.2 & $\mathrm{R}$ & $G=93.6$ & M \\
\hline $201-2$ & Proximal metacarpal & 479500 & 39 & 42.1 & $\mathrm{~L}$ & $A=63.7, B=40.1, C=37.8$ & $\mathrm{~F}$ \\
\hline $470-2-1$ & Proximal metacarpal & cutbank & 55 & & $\mathrm{R}$ & $\mathrm{A}=74.4, \mathrm{~B}=42.8, \mathrm{C}=46.3$, & M \\
\hline $1290-2-2$ & Proximal metacarpal & stripping & $60-80$ & 112.5 & $\mathrm{R}$ & $A=62.6, B=36.2, C=38.2$, & $\mathrm{F}$ \\
\hline $595-2^{*}$ & Proximal metacarpal & 498497 & $61-69$ & & $\mathrm{~L}$ & $\mathrm{~A}=62.5, \mathrm{~B}=37.5, \mathrm{C}=35.3$, & $\mathrm{F}$ \\
\hline $662-2$ & Proximal metacarpal & 500496 & 61 & \multirow{2}{*}{217.5} & $\mathrm{R}$ & $A=59.3, B=37.736 .6, C=$, & $\mathrm{F}$ \\
\hline $662-2$ & Distal metacarpal & 500496 & 61 & & $\mathrm{R}$ & $\mathrm{D}=61.1 \mathrm{E}=30.7 \mathrm{~F}=29.1, \mathrm{G}=25.2, \mathrm{H}=24.1, \mathrm{I}=34.8, \mathrm{~J}=33.5$ & $\mathrm{~F}$ \\
\hline $1290-2-2$ & Distal metacarpal & stripping & $60-80$ & 112.5 & $\mathrm{R}$ & $\mathrm{D}=61.5, \mathrm{E}=29.5, \mathrm{~F}=, \mathrm{G}=26.8, \mathrm{H}=, \mathrm{I}=34.3, \mathrm{~J}=33.6$ & $\mathrm{~F}$ \\
\hline $21-2$ & Distal metacarpal & 479501 & 71-75 & 46.4 & $\mathrm{~L}$ & $\mathrm{D}=60.8$ & $\mathrm{~F}$ \\
\hline $470-2-1$ & Distal metacarpal & cutbank & 55 & & $\mathrm{R}$ & $\mathrm{D}=75.5, \mathrm{E}=36.8, \mathrm{~F}=34.7, \mathrm{G}=28.6, \mathrm{H}=26.7, \mathrm{~J}=33.8$ & M \\
\hline $578-2$ & Distal metacarpal & 498496 & $40-50$ & 67.8 & $\mathrm{R}$ & $\mathrm{D}=62.1, \mathrm{E}=32.4, \mathrm{~F}=29.3, \mathrm{H}=24.5, \mathrm{I}=36.5, \mathrm{~J}=35.4$ & $\mathrm{~F}$ \\
\hline $595-2 *$ & Distal metacarpal & 498497 & $61-69$ & & $\mathrm{~L}$ & $\mathrm{D}=62.0, \mathrm{E}=29.9, \mathrm{~F}=29.7, \mathrm{G}=27.9, \mathrm{H}=24.9, \mathrm{I}=37.0, \mathrm{~J}=35.4$ & $\mathrm{~F}$ \\
\hline $643-2-1 *$ & Distal metacarpal & 499497 & 42 & 82.8 & $\mathrm{~L}$ & $\mathrm{D}=63.5, \mathrm{E}=30.6, \mathrm{~F}=32.5, \mathrm{G}=24.4, \mathrm{H}=26.5, \mathrm{I}=34.2, \mathrm{~J}=34.7$ & F \\
\hline $1290-2-1$ & Distal metacarpal & stripping & $60-80$ & 100.6 & $\mathrm{~L}$ & $\mathrm{D}=61.5, \mathrm{E}=30.5, \mathrm{~F}=28.5, \mathrm{G}=28.0, \mathrm{H}=24.0, \mathrm{I}=35.5, \mathrm{~J}=33.6$ & $\mathrm{~F}$ \\
\hline $365-2-1$ & Proximal femur & 485500 & $20-30$ & 213.7 & $\mathrm{~L}$ & $\mathrm{~A}=136.9, \mathrm{~B}=80.4, \mathrm{E}=34.1, \mathrm{G}=65.4$ & M \\
\hline $574-2-1 *$ & Proximal femur & 498495 & $70-80$ & 92 & $\mathrm{R}$ & $\mathrm{D}=64.6$, & $\mathrm{F}$ \\
\hline $643-2-2 *$ & Proximal femur & 499497 & 42 & 252.6 & $\mathrm{~L}$ & $\mathrm{~A}=152.8, \mathrm{~B}=82.9, \mathrm{C}=58.5, \mathrm{D}=82.9, \mathrm{E}=32.6, \mathrm{G}=45.6$, & $\mathrm{M}$ \\
\hline $629-2-1 *$ & Distal tibia & 499496 & 39 & 294.7 & $\mathrm{R}$ & $\mathrm{J}=50.5, \mathrm{I}=54.4, \mathrm{H}=75.3, \mathrm{~K}=48.8, \mathrm{~L}=56.2$ & $\mathrm{M}$ \\
\hline $671-11$ & Distal tibia - tool & 500497 & 70 & 114.2 & $\mathrm{R}$ & $\mathrm{J}=43.1, \mathrm{I}=42.7, \mathrm{H}=61.5, \mathrm{~K}=39.7, \mathrm{~L}=47.2$ & $\mathrm{~F}$ \\
\hline $1229-2-2 *$ & Distal tibia & 499496 & $40-50$ & 142.5 & $\mathrm{~L}$ & $\mathrm{H}=73.1, \mathrm{I}=52.2, \mathrm{~J}=49.4$ & $\mathrm{~F}$ \\
\hline $1235-2 *$ & Proximal metatarsal & 499498 & 48 & 131.1 & $\mathrm{~L}$ & $A=52.3, B=48.7, C=31.6$ & $\mathrm{~F}$ \\
\hline $629-2-1 *$ & Distal metatarsal & 499496 & 37 & 136 & $\mathrm{~L}$ & $\mathrm{D}=65.8, \mathrm{E}=29.6, \mathrm{~F}=31.2, \mathrm{G}=26.9, \mathrm{H}=28.8, \mathrm{I}=38.0, \mathrm{~J}=39.3$ & $\mathrm{M}$ \\
\hline $643-2-10 *$ & Distal metatarsal & 499497 & 52 & 134.6 & $\mathrm{~L}$ & $\mathrm{D}=66.5, \mathrm{E}=31.9, \mathrm{~F}=30.7, \mathrm{G}=25.2, \mathrm{H}=28.9, \mathrm{I}=36.3, \mathrm{~J}=39.4$ & $\mathrm{M}$ \\
\hline
\end{tabular}




\section{Table 9-23. Measurements on Mature Bison Elements that Indicate Male and Female Elements (cont.).}

Metapodials: A= greatest breath of proximal end, B=greatest depth of proximal end, $\mathrm{C}=$ greatest breath of articular facet of fused 2d-3d, $\mathrm{D}=$ greatest breath of distal end, E=breth of medial condyle, $\mathrm{F}=$ breath of lateral condyle, $\mathrm{G}=$ depth of medial trochlea, $\mathrm{H}=$ depth of lateral trochlea, $\mathrm{I}=$ depth of medial sagittal, $\mathrm{J}=\mathrm{depth}$ of lateral sagittal ridge.

Tibia: $\mathrm{H}=$ greatest breath of distal end; $\mathrm{I}=$ greatest depth of distal end; $\mathrm{J}=$ greatest breath of lateral and medial articular grooves.

Humerus: I=greatest breath of distal condyle, J=length of trochlea from bottom of shallow depression immediately caudal to proximal edge of articular surface of trochlea to bottom of shallow depression immediately caudal to distal edge of articular surface, $\mathrm{M}=$ breadth of distal condyle at proximal edge of articular surface, $\mathrm{O}=$ length of lateral epicondyle from and perpendicular to distal edge of lateral epicondyle to proximal eminence of lateral epicondyloid crest.

Radius: A=greatest depth of proximal end, $\mathrm{B}=$ greatest depth of proximal end, $\mathrm{C}=$ depth of capitular articular surface, $\mathrm{D}=$ breath between lateral and medial ulnar facets, E=depth of sagittal ridge, $\mathrm{F}=$ length of proximal ulnar articulation from proximal end of interosseous sapce to proximal eminence forme by medial edge of medial ulnar facet. $\mathrm{G}=$ greatest breath of distal end between points of lateral and medial epiphyseal fusion, $\mathrm{H}=$ length (medial) od distal epiphysis form distal extremity of carpal articular surface to proximal edge of prominent tuberosity for attachment of medial carpal ligament, $\mathrm{I}=$ grathest breath of articular surfaces or facets of intermdediate and radial carpals, $\mathrm{J}=$ minimum breath of radial carpal facet.

Femur: $\mathrm{C}=$ greatest craniocaudal diameter of head, $\mathrm{H}=$ greatest breath of medial condyle, $\mathrm{I}=$ greatest breath of distal end, $\mathrm{J}=$ greatest length of lateral condyle from bottom of shallow depression immediately cranial to proximal edge of articular surface to distal edge of articular surface,, M=greatest breath of lateral condyle.

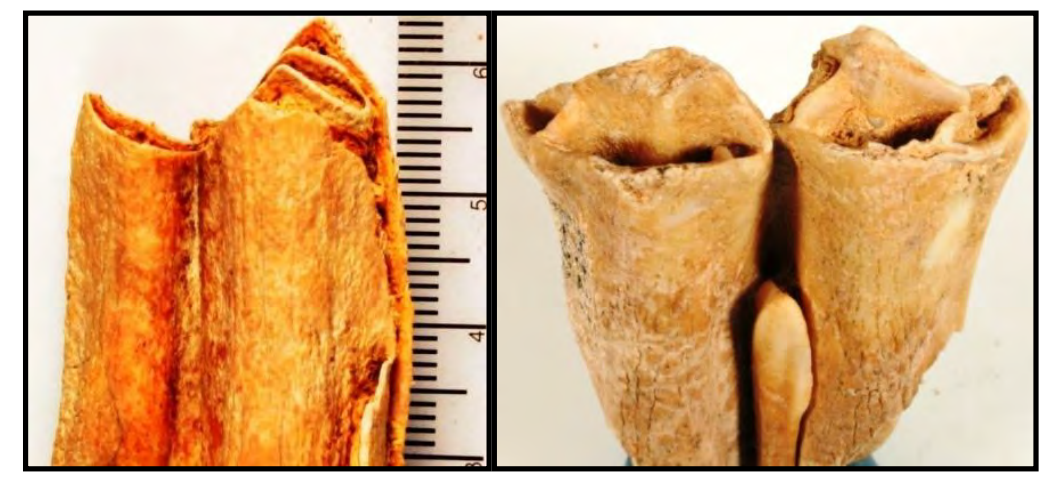

Figure 9-109. Close-up of M3 Showing limited wear on facets (\#413-2-1, left) and M2 with no wear on facets (\#349-2-1, right). 
eruption stage (Figure 9-107). On this basis, it is estimated that the tooth is from an individual that was approximately 2.5 to 2.7 years old (Frison et al. 1976).

\section{Bison Bone Processing}

The bison bones are mostly quite small, with 29.2 percent in the 0 to $3 \mathrm{~cm}$ size class, 39.3 percent in the 3.1 to $6 \mathrm{~cm}$ size class, 16.9 percent in the 6.1 to $9 \mathrm{~cm}$ size class, and only 14.6 percent greater than $9.1 \mathrm{~cm}$. The best explanation for the small size of the fragments is that the elements were smashed in preparation for extracting bone grease. Weathering potentially contributed that reduced the size of some pieces, but probably only a relatively small percentage, given that most pieces were fragmented in a green-bone state.

The burned fragments are all quite small, mostly less than 2-cm-long. Their small size definitely hindered positive identification as did the fact that large, medium, and small animals are represented. Many fragments represent ribs from either bison and/or deer size mammals; however, some chunks of cancellous tissue are also burned. Nearly all unburned pieces are root etched and/or weathered, making it nearly impossible to identify tool cut marks on the pieces so that no tool cut marks could be identified on any bison bones. This does not necessarily indicate that none were originally present. A couple of impact marks were observed, but these were on small, mostly unidentifiable long bone fragments. Although the majority of elements were broken, regardless of which large animal was being processed, it is not possible to detect any particular breakage pattern, given the highly fragmented nature of the assemblage.

The distribution of the identified taxa, minus those in the pithouse (Feature 6), is depicted in Figure 9-110.

Clearly, this shows that not many of the fragments were identifiable and those that were identified were concentrated in three principal areas, those in the pithouse, those in and around heating elements --Features 16/21, and those in the area of "Ghost" Feature 18 (possible pithouse) in the southeastern corner.

\subsubsection{Summary}

In summary, the nonhuman bone assemblage indicates that a diverse range of animal resources was utilized. Identified taxa include a minimum of seven bison (both male and female), one deer, one rabbit, two turtles, and one fish (see Table 9-19). The snake, prairie dog, and other unidentifiable rodent bones are thought to reflect animals whose remains are natural inclusions in the deposits. The rabbits, turtle, and fish were undoubtedly procured in a different manner than the large game animals and may have been procured opportunistically. However, the two large game animals, bison and deer, were specifically targeted species. After these animals were killed, their carcasses were brought to this camp for intensive processing that included butchering, defleshing, bone breaking for marrow extraction, and bone smashing for grease rendering, as well as utilization of specific bone elements in tool production.

Scant evidence such as a one fetal bison bone, wear patterns on a couple of loose bison teeth, and the projected bison ages based on fusion rates, generally support the interpretation that this habitation was a multiple seasonal, semipermanent camp occupied over a period of time. The period of occupation appears to span minimally from late summer to early spring based on the faunal remains. This is tentative as the evidence is limited and spotty. The limited number of the individual animals that represent each taxon may also indirectly support a nonpermanent settlement by a small group of people.

The 2,570 pieces of bone from the $93 \mathrm{~m}^{2}$ in Component $\mathrm{C}$ represents a density of nearly 28 pieces per $\mathrm{m}^{2}$. The pithouse, Feature 6 , contained 58 percent of the total in less than $7 \mathrm{~m}^{2}$ that indicates it served as a disposal area following its abandonment as a habitation structure (Figure 9-111). The limited number of bones beyond the pithouse were too scattered to indicate any one intensive bone processing area. No other bone concentrations were detected in the excavated areas to signal a meat or bone processing area. 


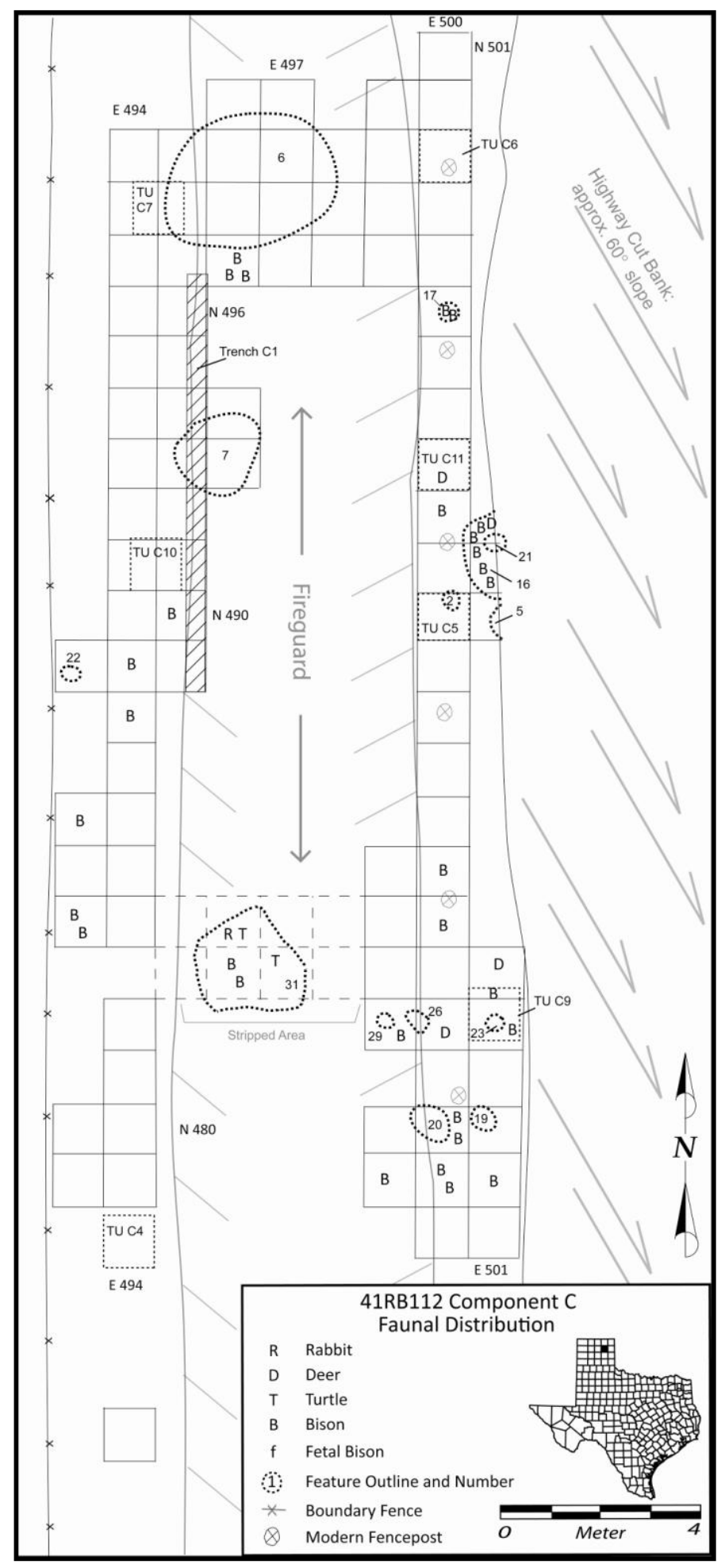

Figure 9-110. Horizontal distribution of the identified taxa in Component C. 


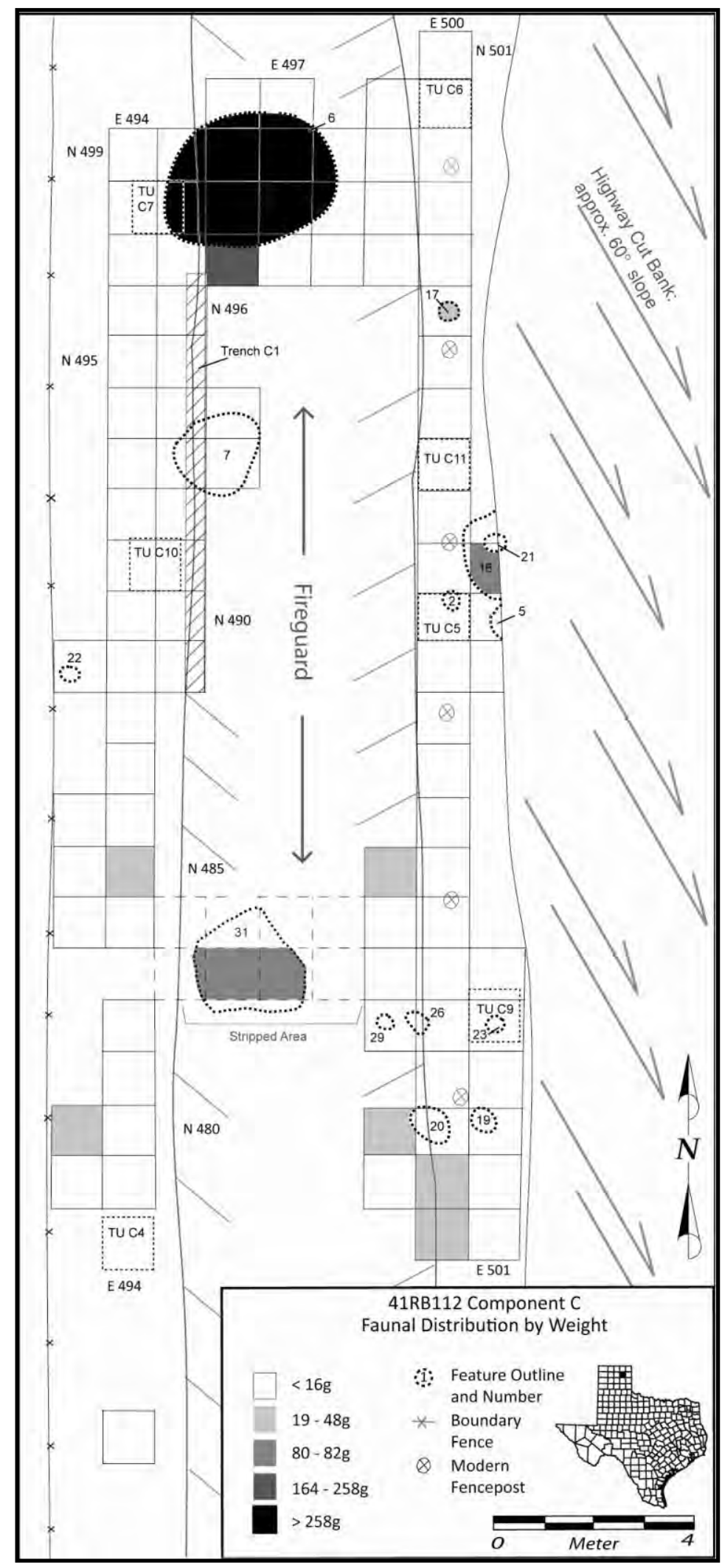

Figure 9-111. Faunal distribution by weight across Component $\mathrm{C}$. 


\subsection{Worked Bone}

\section{J. Michael Quigg}

Fifteen pieces of bone reveal worked and/or used surfaces. Bone preservation was best on bones from Feature 6 pithouse, whereas those from outside that pithouse exhibit various degrees of weathering and root etching. In some instances the weathering process has removed parts of the worked or used surfaces, making it difficult to detect use-wear. These worked pieces are individually discussed below.

The proximal half of a right bison scapula (\#582-2-6) from the floor of Feature 6 pithouse, between 60 and 70 cmbs in N498 E496, is a well-preserved fragment on which the spine was intentionally removed and multiple fine-line incisions were made along the interior side of the spine to form a deep, narrow groove (Figures 9-112 and 9-113). Apparently, the incisions were made in anticipation of removing the blade segment by means of the groove-and-snap technique, which was never completed. Assuming this to be the case, this scapula fragment represents a discarded byproduct of tool manufacturing rather than a finished tool. Either the removal of the blade was unsuccessful or the distal section broke before the blade was snapped off. At the break on the lateral edge opposite the spine, a 2-cm-long flake scar is present, running along and parallel to the long axis. The point of impact is the broken edge, which is slightly rounded and worn, and where there is a tiny hinge scar on the interior side. This apparently utilized corner of the bone was probably used subsequent to breakage of the piece. A few long, narrow cut lines made with a stone tool are visible on the opposite side of, and parallel to, the spine.

The proximal portion of a mature bison ulna (\#64316) was recovered from the pithouse floor at $52 \mathrm{cmbs}$ in N499 E497. The pointed edge of the coronoid process exhibits one 2-cm-long flake scar, around which is considerable wear and rounding of the surfaces (Figure 9-114; Table 9-24). It is postulated that this dense, pointed projection served as a hammer. On what substance this hammer was used is unknown, but the rounding and polish indicate a soft, pliable material. A green bone break along the shaft lacks impact scars. About 3.5 to $6 \mathrm{~cm}$ below the articular facet are at least four 1-cm-long cut lines, which likely resulted from cutting soft tissue from the proximal end of the bone.

The distal end and most of the medial shaft of a right bison tibia (\#671-11) was recovered from Feature 6 pithouse floor at $70 \mathrm{cmbs}$ in N500 E497. This is a classic tibia tool with a 2.5-cm-wide, oval hole created in the distal end that removed most of the cancellous tissue and opened into the marrow cavity. It is difficult to see the wear inside this cavity, but it appears, based on macroscopic wear, that a shaft that served as a handle was inserted at least 5 to $6 \mathrm{~cm}$ into the bone cavity. The tibia midshaft is split along the long axis, exposing the interior marrow cavity (Figure 9-115; see Table 9-24). The cortical walls along the lateral edges on either side of the opening exhibit multiple partial impact cones, created from direct hard-hammer impacts. These broken edges show extensive wear and rounding, either from use or as the result of intentional grinding. The broken end, close to the midpoint of the tibia shaft, exhibits beveling on both faces that converges at a 75-degree angle. These beveled edges and surfaces of the shaft itself exhibit extensive polish. Light and sporadic root etching is present on the exterior surfaces.

Three bone awls or parts of awls were recovered from this component. One complete, well-formed awl (\#582-11) was found on Feature 6 pithouse floor at 60 to $70 \mathrm{cmbs}$ in N498 E496. This specimen (Figure 9-116) is well-preserved, probably due to rapid burial by sediment accumulation, thus preventing exposure to weathering processes. It was well manufactured from a portion of a long bone fragment (a deer-size metapodial shaft) with relatively thin cortical walls that show thin, short cut lines along the cortical walls. The interior, concave marrow cavity is still partially intact. The exterior exhibits longitudinal, thin cut lines parallel to the long axis on two sides. This long bone fragment was ground and smoothed to a sharp point with polish on the surfaces, except on the proximal one-third.

Two other fragmentary awls were recovered from the pithouse floor, one (\#582-13) from 60 to $70 \mathrm{cmbs}$ in N498 E496 and the other (\#216-11) from 40 to 50 cmbs in N480 E493. The former is an elongated 


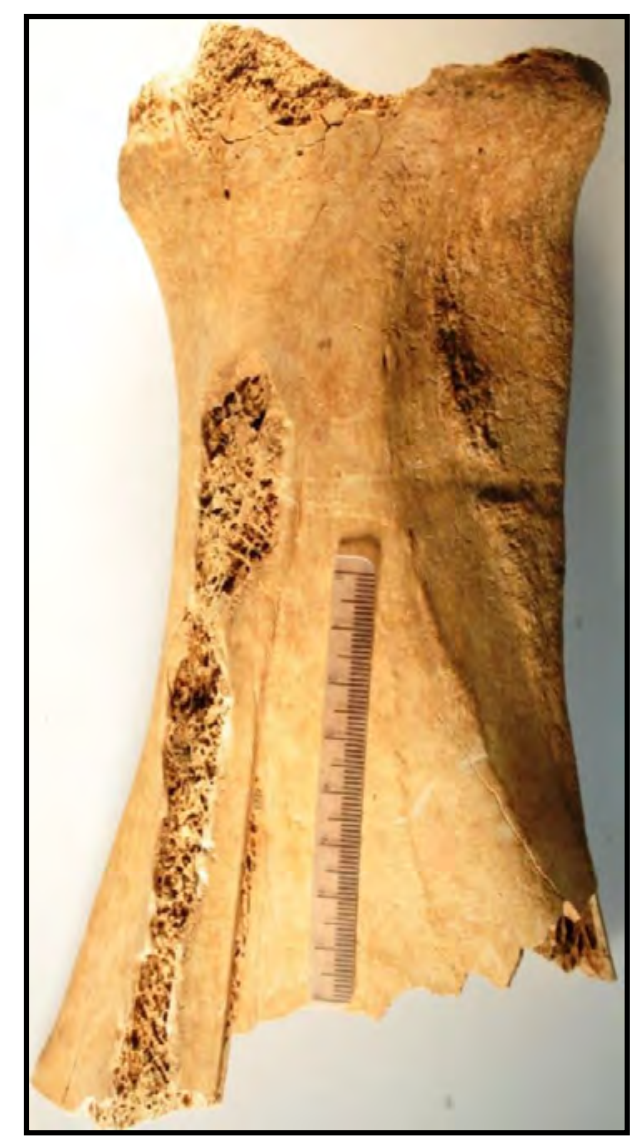

Figure 9-112. Photograph of proximal end of a bison scapula (\#582-2-6) with a deeply incised groove along the inside (to the right) of the removed spine.

Scale in centimeters.

bone splinter that retains one slightly polished tip at one end (see Figure 9-116). Cortex is present on one side, while interior cancellous tissue is exposed on the opposite side. This awl was broken near its midsection, and the proximal end is missing (Figure 9-116). The third specimen (\#216-11) appears to represent the midshaft of an awl. This splinter is part of a small cortical long bone with rounded edges parallel to the interior marrow cavity.

A medial bison scapula fragment (39.3 g) with long, thin cut lines next to the spine came from $53 \mathrm{cmbs}$ in N499 E497, inside the pithouse. This fragment is broken on all margins. The long cut lines are assumed to have been an attempt to create a deep groove in the bone to allow a selected portion to be snapped off (Figure 9-117). This apparent groove-and-snap technique was intended to facilitate the removal of the blade section from the spine. Assuming this to be the case, this specimen is a byproduct of the tool manufacturing process rather than an actual tool. The opposite side also exhibits multiple long cut lines, but they are scattered across the blade rather than localized to form a narrow groove (Figure 9-117). The majority of these cut lines are parallel to the long axis of the blade, while a few short cut lines are visible near, and approximately perpendicular to, the broken edge.

The lateral edge fragment of a right scapula was recovered from 60 to 63 cmbs in N498 E497. This fragment includes the spine area, but most of the spine has been intentionally removed by a few impacts near the proximal end. The proximal end was also removed by percussive impacts, as indicated by green-bone breaks. One lateral edge exhibits slight 


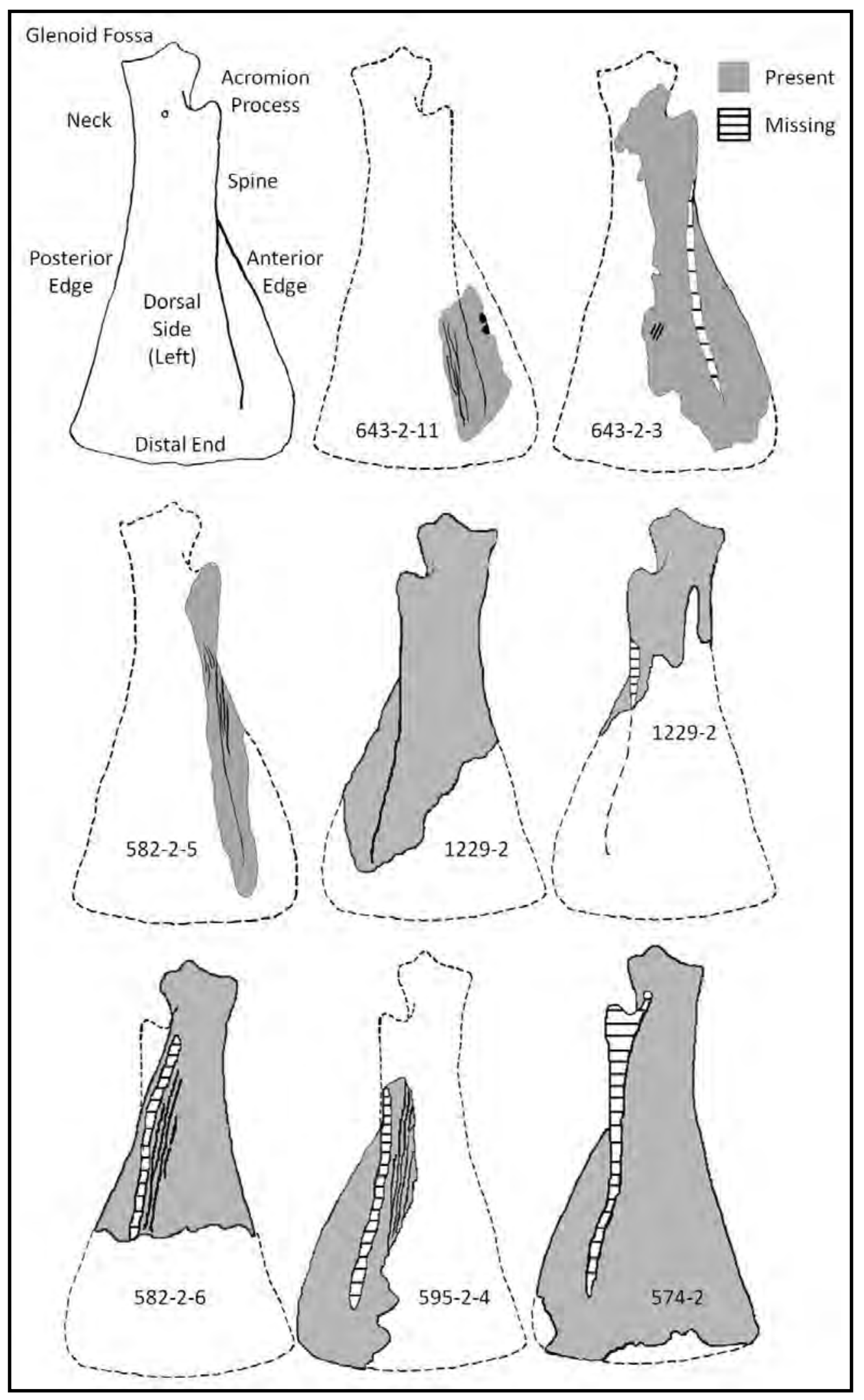

Figure 9-113. Drawing of bison scapulas from Component $\mathrm{C}$ that exhibit alterations. 


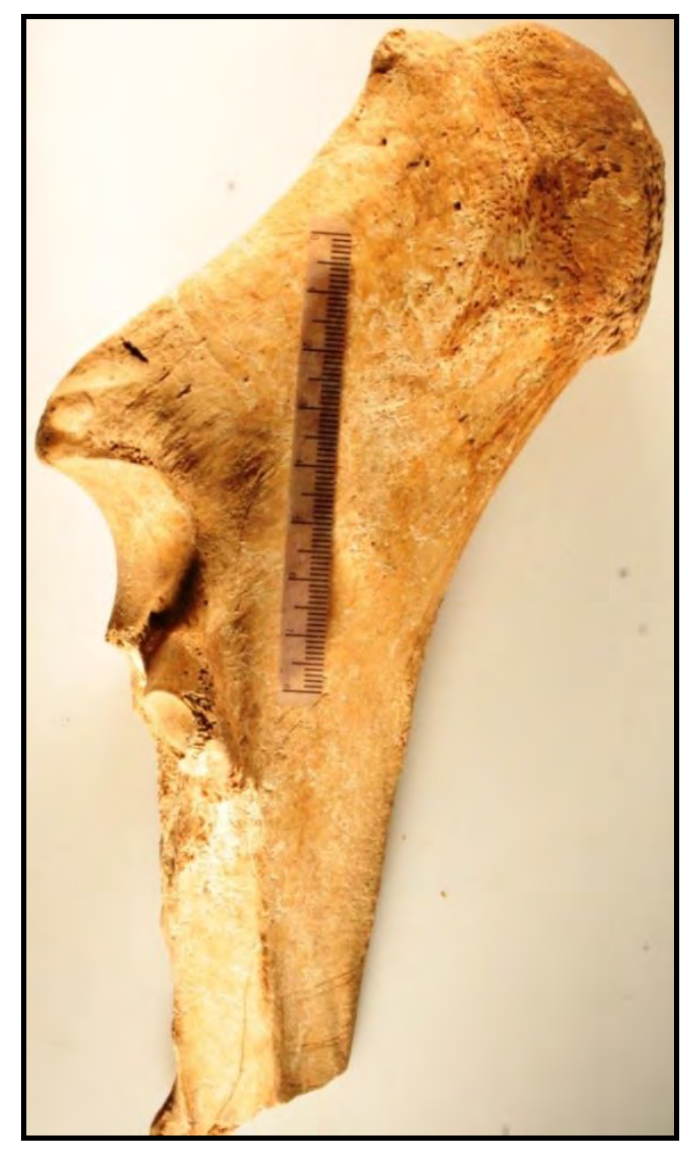

Figure 9-114. Proximal end of a bison ulna (\#643-16) with flaked and worn coronoid process. Note cut marks on lower part of shaft. Scale in centimeters.

Table 9-24. Selected Worked Bone Data from Component C.

\begin{tabular}{|c|cc|c|c|c|c|c|c|c|}
\hline $\begin{array}{c}\text { Catalogue } \\
\text { No. }\end{array}$ & \multicolumn{2}{|c|}{$\begin{array}{c}\text { Unit No. } \\
\text { N }\end{array}$} & $\begin{array}{c}\text { E } \\
\text { (cm) }\end{array}$ & $\begin{array}{c}\text { Feature } \\
\text { No. }\end{array}$ & Tool Type & $\begin{array}{c}\text { Weight } \\
(\mathbf{g})\end{array}$ & $\begin{array}{c}\text { Length } \\
(\mathbf{m m})\end{array}$ & $\begin{array}{c}\text { Width } \\
(\mathbf{m m})\end{array}$ & $\begin{array}{c}\text { Thickness } \\
(\mathbf{m m})\end{array}$ \\
\hline $216-11$ & 480 & 493 & $40-50$ & NA & Awl & 2.1 & 57.3 & 12.1 & 5.3 \\
\hline $566-10$ & & & & 6 & ?hammer & 71 & 113.4 & 74.8 & 33.4 \\
\hline $582-11$ & 498 & 496 & $60-70$ & 6 & Awl & 6.6 & 116.1 & 10.5 & 6.9 \\
\hline $582-13$ & 498 & 496 & $60-70$ & 6 & Awl & 1.2 & 54.4 & 6.5 & 4.3 \\
\hline $671-11$ & 500 & 407 & 70 & 6 & Digging & 114.2 & 170 & 62.3 & 42.7 \\
\hline & & & & & & & & & \\
$643-16$ & 499 & 497 & 52 & 6 & Hammer & 148.6 & 218 & 80.2 & 51.8 \\
\hline
\end{tabular}




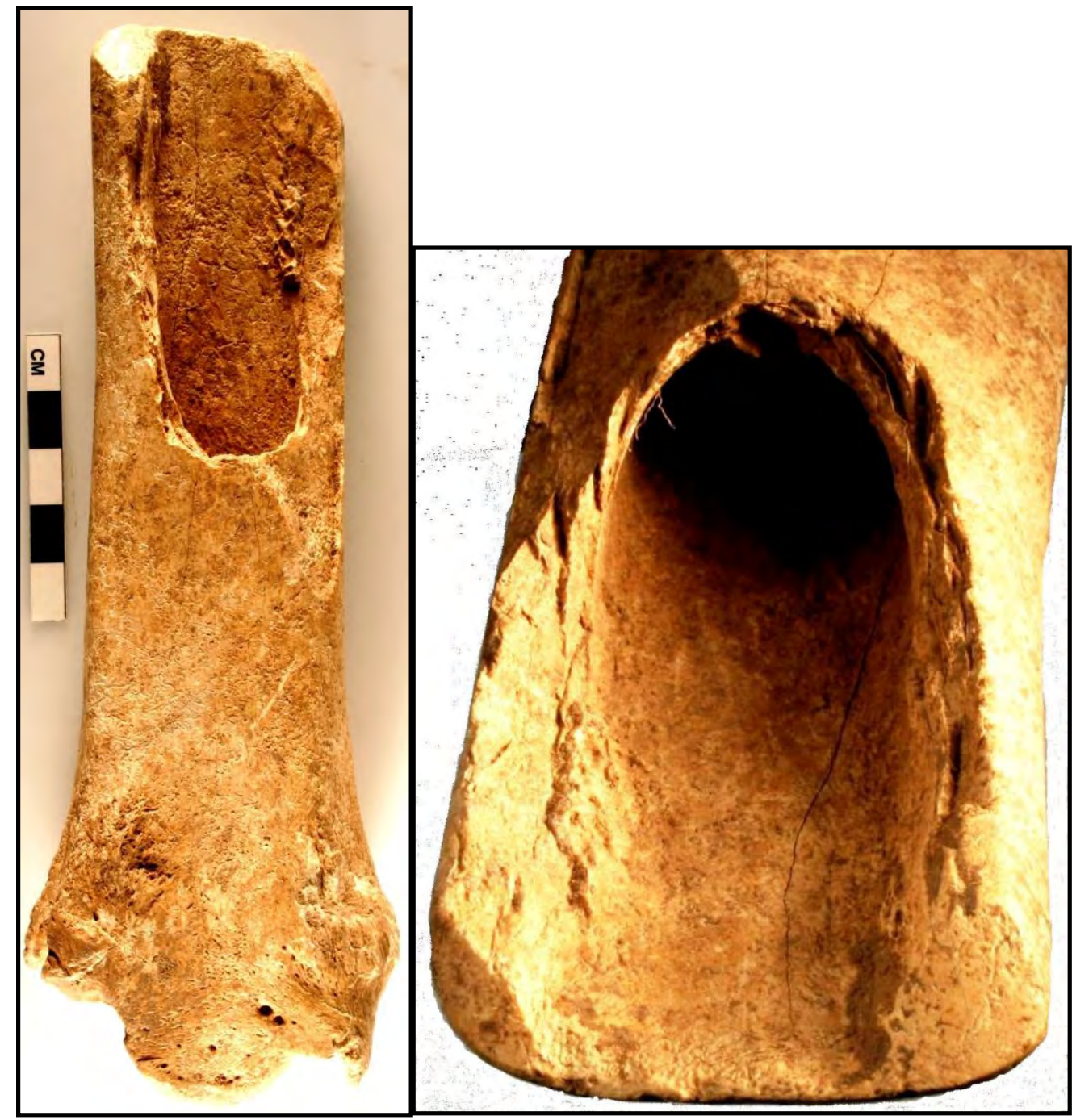

Figure 9-115. Two views of bison tibia digging tool (\#671-11), the complete tool (left) and close-up of the interior or the worked end (right). 


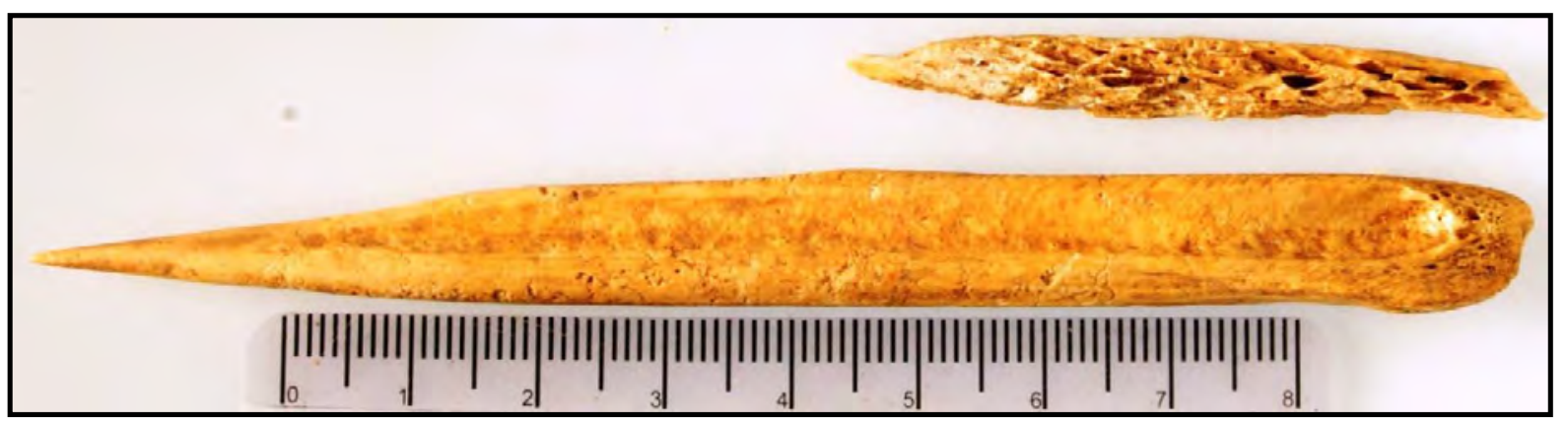

Figure 9-116. Two bone awls, a complete awl on bottom (\#582-11) and a fragment on top (\#582-13).

Scale in centimeters.

rounding, but it is not clear if this is use-wear or a result of natural weathering. The medial blade section has been removed with many long cut lines along the edge of the spine. These cuts are parallel to the long axis and were presumably an attempt to create a groove that could then facilitate the snapping off of the blade from the spine. This scapula fragment is apparently another byproduct of tool manufacture.

\subsection{Burned Rock Analyses}

\section{J. Michael Quigg}

The hand-excavations in Component $\mathrm{C}$ yielded a moderate number of burned rocks, specifically 1,434 pieces with $90+$ percent weighing $71,339 \mathrm{~g}$ for an average weight of nearly 50 g. Minus Feature 6 pithouse, the remaining 21 cultural features included 4 heating elements and 8 discard/dumps; only 2 discard features (Feature 19 and 20) were dominated by burned rocks. Besides the concentrations in these two burned rock discard features, relatively limited quantities of burned rocks and quartzite pebbles were unevenly distributed. Burned rock counts and weights were recorded by unit and level on level records. The majority was discarded with random samples collected for possible future analyses. However, there was considerable difficulty in differentiating burned rock from unaltered rock. Specifically, quartzite pebbles, when fragmented, exhibit well-defined hackled edges from use, whereas complete specimens found in similar contexts were less definitive in this regard. The burned rock material types were varied and consisted of local chunks of sandstone, caliche, rounded quartzite pebbles, and even a few chunks of opalite (Figures 9-118 and 9-119).

Given their uniqueness, burned rocks from the Feature 6 pithouse will be discussed separately. This will allow comparisons between the burned rocks discarded in the pithouse and those scattered across the remaining component. In the paragraphs to follow, the burned rocks outside and inside Feature 6 pithouse will be addressed.

Outside Feature 6 pithouse yielded 797 pieces or 55.6 percent of the total from this component with 89 percent weighing 39,609 g (55.5 percent of the total weight) for an average weight of $56 \mathrm{~g}$. The sizes of the burned rocks varied from 2 to $16 \mathrm{~cm}$ in diameter. The smallest size category, 0 to $4 \mathrm{~cm}$, dominated with 67 percent by count but only 16.4 percent by weight. The next size category, 4.1 to 9 $\mathrm{cm}$, accounted for another 30.7 percent by count, with only 2.1 percent greater than $9.1 \mathrm{~cm}$. Although the latter category accounts for a very small percentage by count, the burned rocks greater than $9.1 \mathrm{~cm}$ account for 23.2 percent by weight. Many burned rocks were relatively small, water rounded quartzite pebbles between 2 and $6 \mathrm{~cm}$, similar to those found both clustered and in the vicinity of Feature 26 (Figure 9-120).

A sample of the 225 burned rocks (28 percent) from outside Feature 6 pithouse were brought to the laboratory and investigated further to determine the number of quartzite pebbles and cobbles, 


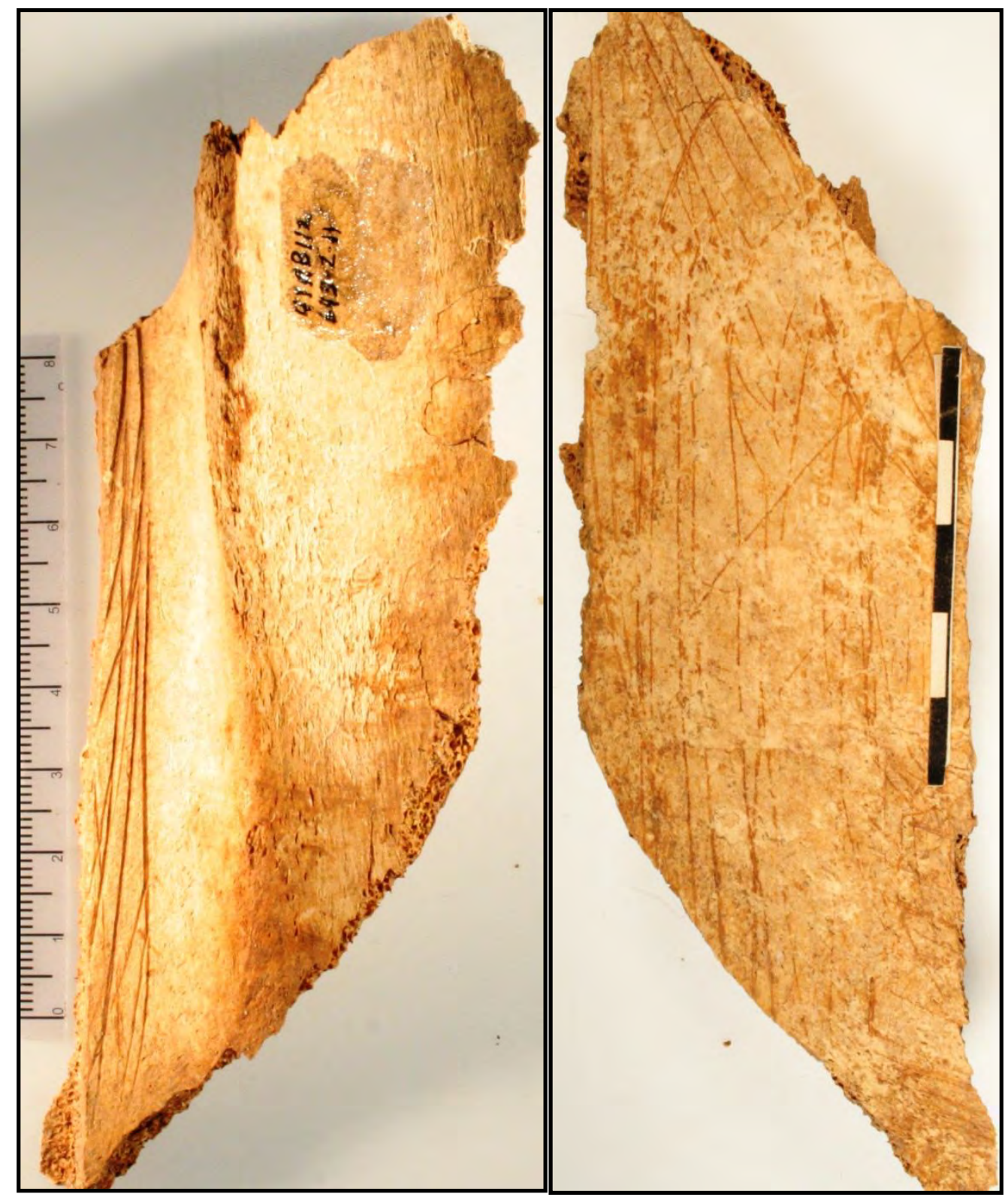

Figure 9-117. Medial section of bison scapula (\#643-2-11) that exhibits extensive, long cut lines next to spine (left), with impact marks on opposite edge, and scattered cut lines on opposite face (right).

Scale in centimeters. 


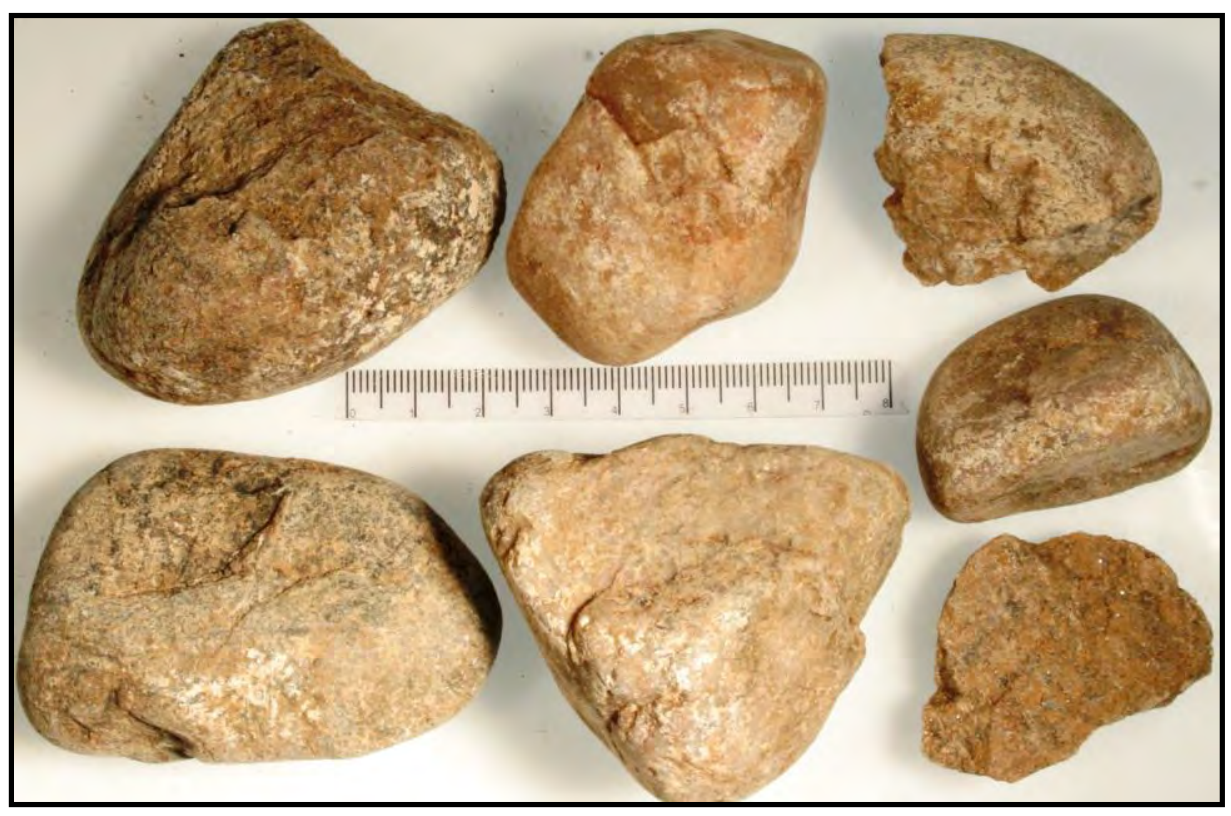

Figure 9-118. Samples of quartzite pebbles from Component C. Note hackled edges on rock in upper right corner.

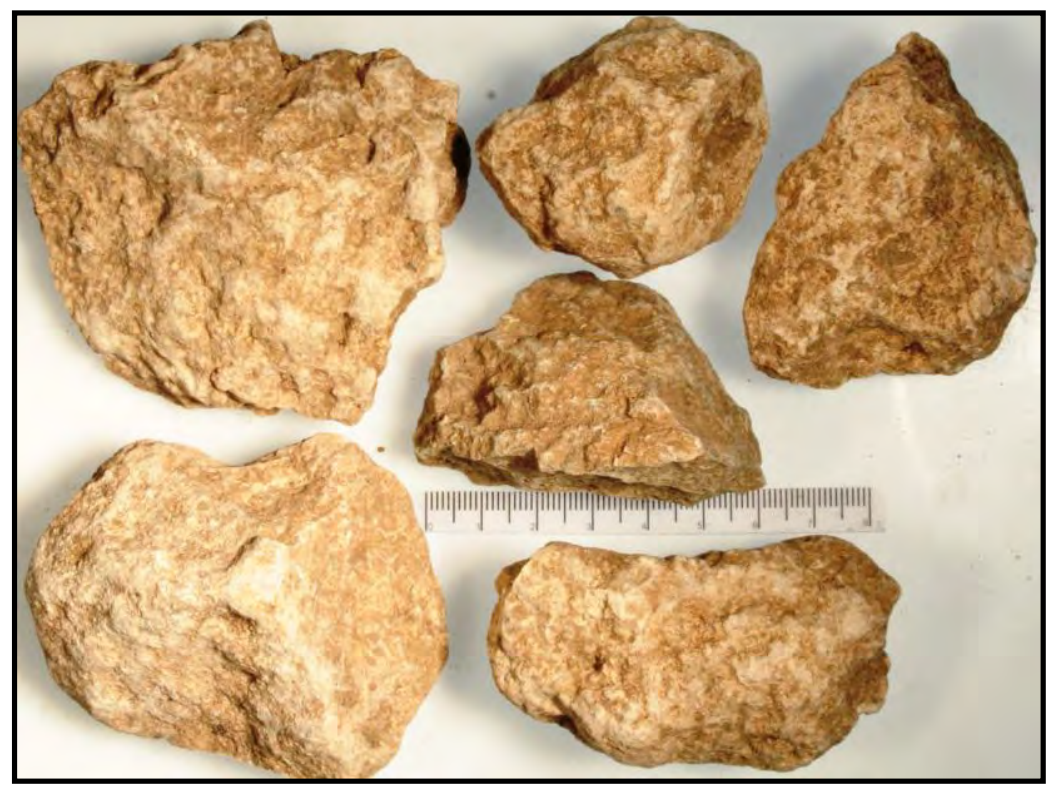

Figure 9-119. Sample of burned caliche rocks from Component C. 
and their general size. Roughly 20 percent of the collect pieces were identified as quartzite pebbles and cobbles. Of that 20 percent, 73 percent were small, less than 4-cm-long, and nearly two-thirds were broken. Of the 27 pieces greater than $4.1 \mathrm{~cm}$, nearly 70 percent were broken. Those that exhibited broken edges were definitely used as burned rocks and it is assumed that the roughly 30 that were not broken were also used, but did not break during use (see Figure 9-116). This assumption is supported by the fact that immediately next to heating element Feature 26, a tight cluster of five unbroken quartzite pebbles was present (Figure 9-120).

Feature 6 pithouse yielded another 637 burned rocks that weighted $31,730 \mathrm{~g}$. These numbers are roughly 44 percent of the component total. The density of burned rock is much greater in the pithouse where roughly just under $7 \mathrm{~m}^{2}$ were excavated. About 73 percent were in the smallest size category, 0 to 4 $\mathrm{cm}$, followed by 23.4 percent in the 4.1 to $9 \mathrm{~cm}$ size class, with only 3.7 percent greater than $9 \mathrm{~cm}$. The burned rocks in Feature 6 pithouse were just slightly smaller (49.8 g) than those outside the pithouse. The similarity of size and types of burned rocks inside and outside the pithouse supports the idea that these artifacts represent similar activities and the burned rocks in the pithouse originated in activities outside the pithouse.
In an attempt to investigate possible construction materials used in the roof and wall coverings of Feature 6 pithouse, the burned rocks in the units that encompassed the pithouse were vertically divided between the pithouse floor (roughly between 50 to $70 \mathrm{cmbs}$ ) and the potential construction deposits immediately above the floor (20 to $50 \mathrm{cmbs}$ ). It was assumed that the floor of the pithouse contained mostly burned rocks (i.e., chunks of caliche, and rounded quartzite pebbles and cobbles) and diverse other cultural debris that had been discarded into the pithouse. The pithouse floor was uneven and hence encountered at slightly different depths, causing the possible construction deposits just above the floor to be proportionately uneven.

The contents of Feature 6 pithouse did not clearly define those materials used in the construction wall/roof covering. The 10 centimeter arbitrary excavation levels may have contained a mixture of materials from two zones and some of what we are trying to separate may be mixed in one level. Although we have attempted to separate zones of material using the level data, the potential mixing may be blurring the outcome. We examined the burned rock data for possible changes in the sizes and types of rocks and/or the quantity of burned rocks in the two zones to see if something could contribute to our understanding of the construction of the roof and/or walls of the pithouse.

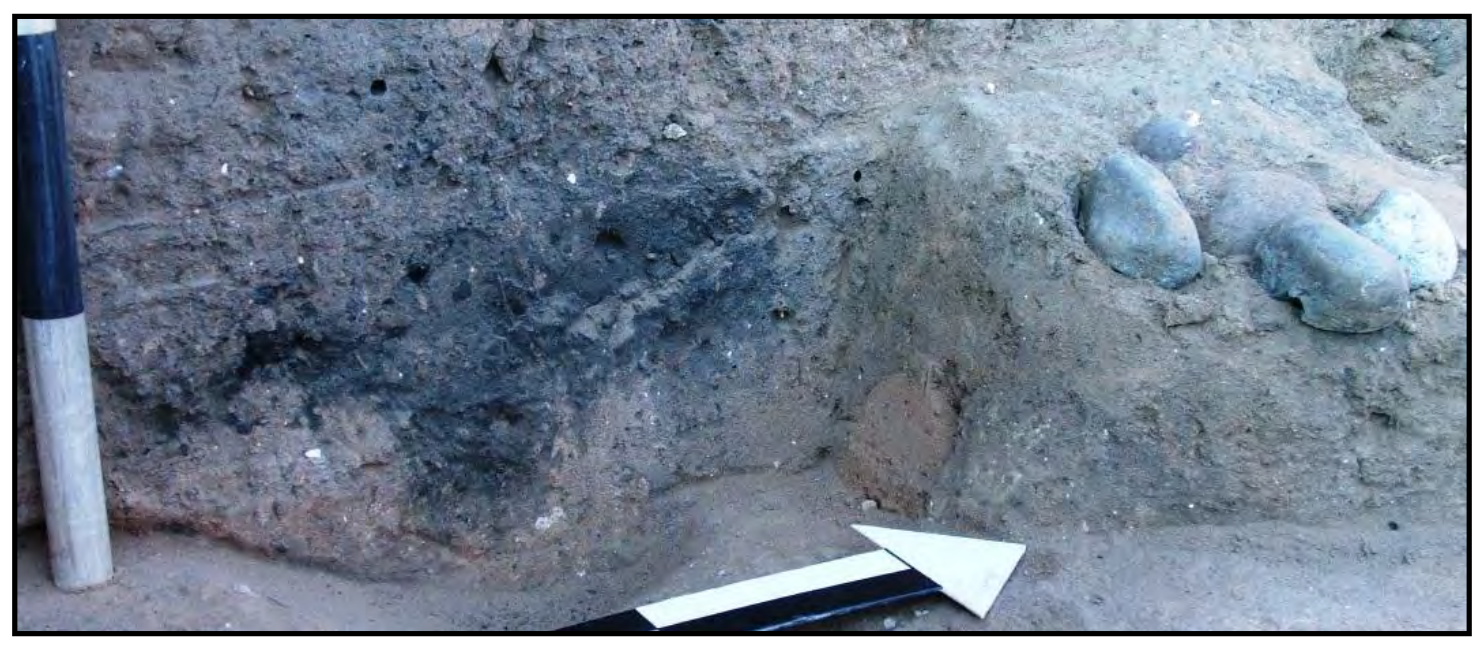

Figure 9-120. Cluster of five small rounded quartzite pebbles next to a basin heating element, Feature 26.

Scale in 10 centimeter increments. 
In the units that encompassed the pithouse, some 300 rocks were referred to as burned rocks between 20 and 50 cmbs. Of those, nearly 73 percent were smaller than $4 \mathrm{~cm}$ in diameter, with 24 percent in the 4.1 to $9 \mathrm{~cm}$ size class and less than 1 percent greater than $9.1 \mathrm{~cm}$. From this, it can be interpreted that large building rocks were not incorporated into the construction of the walls or roof of this pithouse. As best as could be determined, the floor yielded nearly 333 burned rocks. The majority (73 percent) were less than $4 \mathrm{~cm}$, with 23 percent in the 4.1 to $9 \mathrm{~cm}$ size class, 3 percent in the 9.1 to $15 \mathrm{~cm}$ size class, and 0.6 percent greater than $15 \mathrm{~cm}$. The general size ranges of rocks from the floor are identical to those above the floor, showing no change in size or frequency between the two projected zones.

Quartzite pebbles were separated from the rest of the burned rocks to investigate if they showed a specific trend. A total of 137 pebbles and cobbles were between 20 and $90 \mathrm{cmbs}$ in the units associated with Feature 6 pithouse. Sixty-four percent were less than $4 \mathrm{~cm}$ in size with nearly 36 percent between 4.1 and $9 \mathrm{~cm}$, and none were greater than $9 \mathrm{~cm}$. A total of 81 pebbles and cobbles or 59 percent were in the possible construction fill, whereas 56 or 41 percent were in the floor debris. The differences between the two zones is not great, roughly 19 percent given all the uncertainties in the identifications combined with the unclear demarcation between the floor and possible construction materials. It appears that small quartzite pebbles and a few cobbles were above the floor and likely incorporated into the walls or roof. It has been demonstrated that Feature 6 pithouse was covered with dirt and that the dirt potentially contained many small quartzite pebbles that were not separated out before the dirt was incorporated in the walls and roof.

It is assumed that most burned rocks were used for cooking and/or heating purposes directed towards the preparation of food. Seven burned rocks, two from a discard pile (Feature 20) and five from Feature 6 pithouse were selected from the arbitrarily collected samples and subjected to starch grain analysis to investigate which foods may have been prepared. Five specimens were sent for diatom analysis, which included two pieces each from Features 6 and 20 , and one piece from outside recognized features, to investigate if a specific cooking process, i.e., boiling, was a possibility for these stones.

The diatom presence ( $N=192)$ from the analysis of five burned rocks is meager at best, with one exception (Appendix J). Burned rock \#1256-3 from a nonfeature at $30 \mathrm{cmbs}$ in N485 E494 yielded 175 diatoms, by far the most recovered from the burned rocks analyzed. The recovered diatoms are dominated (at least 82 percent) by aquatic benthic species that are associated with sediment microbial mats and rooted vegetation on the floor of a stream. The three most prominent species Gomphonema lateripunctatum $(N=55)$, Denticula kuetzingii ( $N$ $=47)$, and Delicata delicatula $(N=32)$ indicate the water from which these diatoms were associated with was a flowing stream, probably from a spring that had low total organic nitrogen and phosphate (Appendix J). To obtain this diatom assemblage association, it is projected that the rock had to be submerged in water collected from the adjacent stream. This was likely done in conjunction with boiling food remains and documents one cooking process.

Five of the seven burned rocks analyzed for starch grains yielded 44+ starchy remains of plants (Appendix D). Appendix D provides the specific results on the individual rocks with only a general summary presented here. The actual number of grains obtained from the five rocks is quite low, but the grains present are informative. Three rocks yielded a total of 12 maize (Zea maize) starches, 3 rocks yielded 22 lenticular little barley (Hordeum pusillum) grains, 2 rocks yielded 8 grains of possible mesquite (Prosopis), 1 rock yielded 1 grain of an unidentifiable lily bulb, and 1 yielded cheno-am starch. Besides these, rock \#234-3-2b yielded parched starch grains. No starch grains were gelatinized to indicate they were heated in the presence of water. It should be noted that a sediment sample from this component was analyzed for starch and it did not yield any starch grains. This supports the contention that the starches on the burned rocks reflect plants used by the inhabitance and not from the surrounding dirt or natural processes. The identification of parched starch grains documents at least one type of cooking procedure. 
In support of the small quartzite pebbles encountered across the component having been used for cooking/ boiling, is the close association of a cluster of five small rounded pebbles less than $20 \mathrm{~cm}$ from the basin heating element Feature 26 (see Figure 9-120), potentially inside Feature 18. Besides the adjacent positioning of this cluster of pebbles and a basin heating element, many ceramic sherds from a single, thick-walled Vessel 1 were also in these same and adjacent units. The relatively small size of most pebbles would be appropriate for use in this cooking pot. The fact that most rounded pebbles exhibited hackled broken edges indicates they experienced thermal shock, which is associated with the rapid cooling of a hot rock placed in a cool watery solution. As discussed above, many small rounded quartzite pebbles were also recovered from the diverse cultural debris discarded on Feature 6 pithouse floor, some in clusters of two to four stones.

The horizontal distribution of burned rocks and quartzite pebbles contributes to a broader understanding of where the rocks were used and/ or discarded, and potentially how they were used (Figure 9-121). It is also apparent from this welldefined distribution that the clustering likely indicates specific activity areas and the probability that this component represents a single occupation, which lacks smearing and overprinting from multiple occupations. Setting the Feature 6 pithouse aside for the moment, the greatest concentration was in the area defined as Feature 18, the "ghost" pithouse, in the southeastern corner of the component. Besides two burned rock dumps (Features 19 and 20), scattered burned rocks were also in the immediate vicinity of those two features. This apparent dispersal may have resulted from extensive rodent activity in those sandy deposits. The moderate concentration of rocks on the northern side of heating elements Feature 16/21 indicates rocks were likely used in conjunction with the cooking process as those features were definite cooking facilities with chunks of carbonized maize cobs and other plant residues present.

Just east of the apparent entryway to Feature 6 pithouse in the northeastern corner of the component was another broader area with lots of burned rocks. This distribution out in front of the pithouse would indicate that this could have been a general toss zone where unwanted rocks were tossed or discarded following their use in the pithouse.

\section{$9.8 \quad$ Burned Clay/Daub}

\section{J. Michael Quigg}

Relatively few specimens of this class were found in this component. One hundred and seventy five pieces were identified and most are quite small, with a total weight of $315.1 \mathrm{~g}$ for an average of $1.8 \mathrm{~g}$ per piece. The largest chunk weighs roughly $43 \mathrm{~g}$, and the majority is much smaller, weighing under $10 \mathrm{~g}$. The entire assemblage was macroscopically examined for signs of recognizable impressions, which would help inform us as to their use. Specific observations were not made on these tiny lumps of burned clay/ daub. In general, most are spherical or irregularly shaped lumps, firm and hard, and a few exhibit small stick or grass impressions on at least one face/surface (Figure 9-122). No consistent shapes or standard sizes are recognized, and many have obviously broken edges, that create irregular shapes. Some pieces exhibit one flat or smoothed surface/face. A few broken pieces have tiny sand grains within the clay matrix. It is not clear if the sand was an intentional addition or a natural inclusion in the clay. At least a couple of broken pieces contain tiny calcium carbonate inclusions (i.e., \#417-5), which indicate that the clay originated in the Ogallala Formation. At least one thin piece (\#641-5-1; 1.0 g), found in Unit N499 E497 within the Feature 6 pithouse exhibits a fingerprint impression on a smooth, slightly convex surface. The opposite and nearly flat face exhibits an impression of wide-bladed grass.

The colors show considerable variation, with most burned pieces exhibiting at least two or more colors. The exterior colors range from light brownish gray (10YR 6/2), to reddish yellow (7.5YR 6/6), to light gray $(2.5 \mathrm{Y} 7 / 0)$. Those that exhibit a light brownish gray color primarily reflect a film of calcium carbonate covering. The core colors range from a very dark gray (10YR $3 / 1$ ), to grayish brown (10YR 5/2), to light brown (10YR 6/4).

Two pieces of daub (\#195-5 and \#643-5-2), weighing $7.6 \mathrm{~g}$ and $43.2 \mathrm{~g}$ respectively, were sent for diatom analysis. Specimen \#643-5-2 came from within Feature 6 pithouse. These two pieces, which lacked 


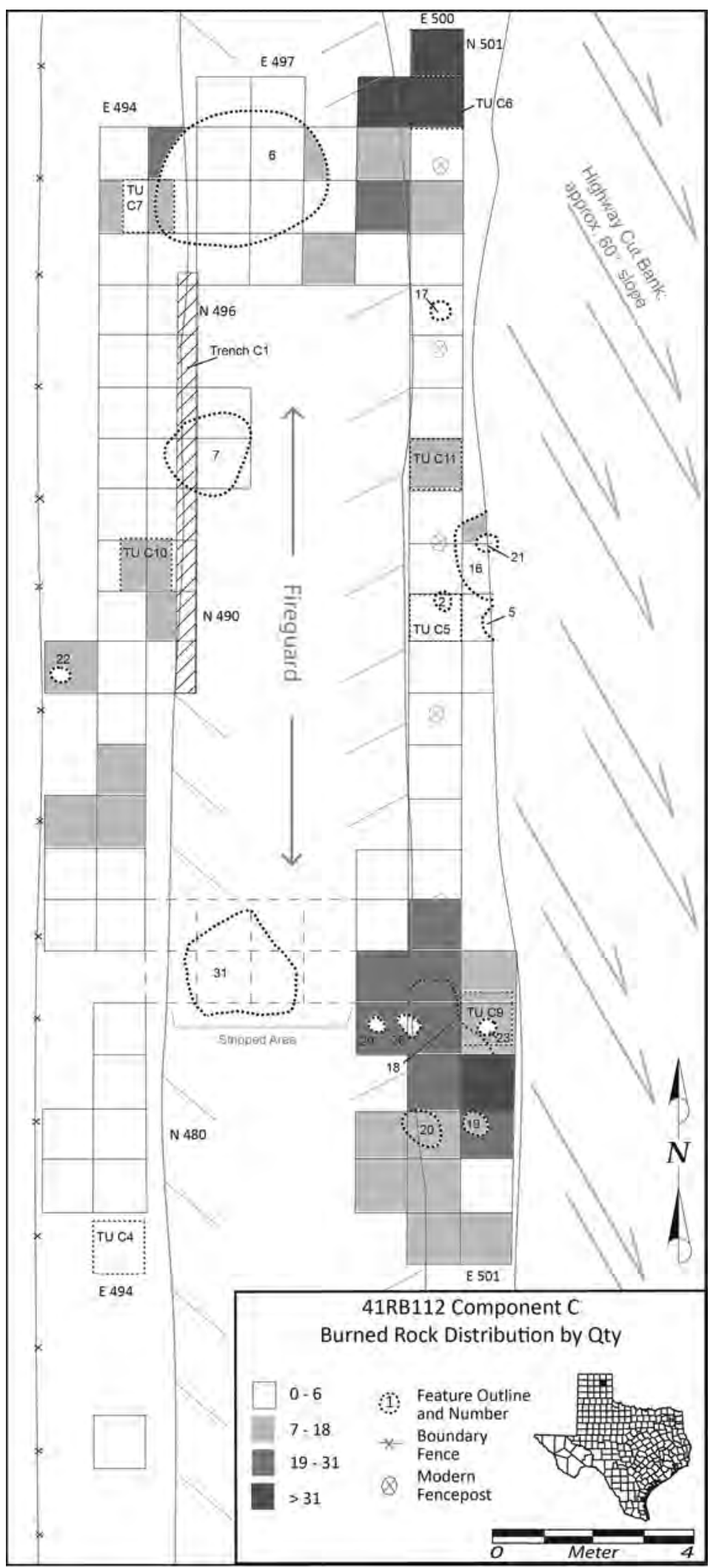

Figure 9-121. Horizontal distribution of burned rocks across Component C, minus data from the pithouse Feature 6. 


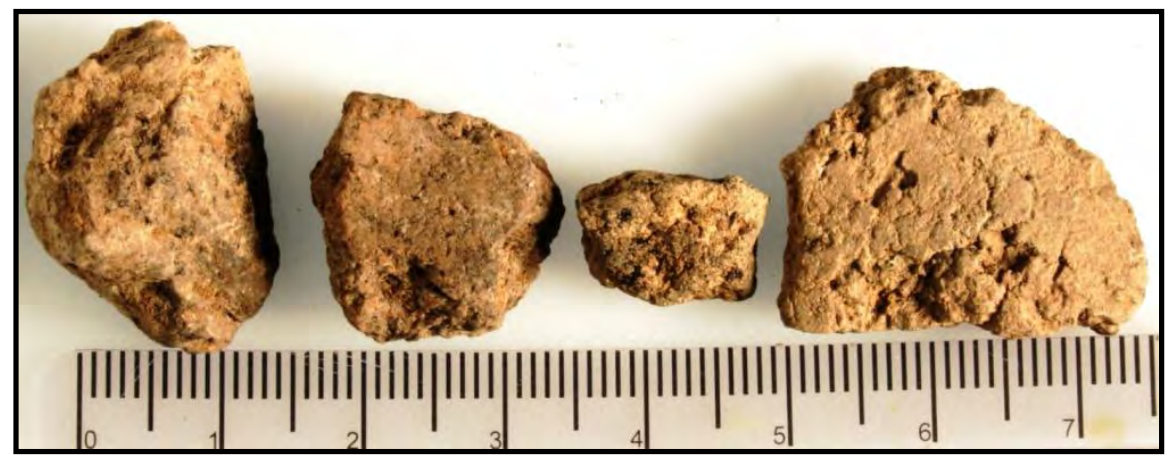

Figure 9-122. Examples of burned clay/daub (\#641-5) that exhibit rounded and curved surfaces and lack well-defined stick impressions.

Scale in centimeters.

any significant stick or grass impressions, yielded vastly different frequencies of diatoms: 741 from \#195-5 as compared to only 6 from \#643-5-2. Currently, there is no explanation for this disparity. Winsborough (Appendix J) indicates that sample \#195-5 contained two sets of diatoms. One set consists of aquatic species associated with sediments, microbial mats, drifting mats of filamentous algae, and rooted vegetation as is found on the floors of streams and lakes (benthic species, e.g., Amphora pediculus, typically found in small, shallow alkaline, nutrient-rich, hard water streams). In contrast, the second set includes aquatic planktonic species (e.g., Aulacoseira distans) that live suspended in the water columns of shallow, low-alkalinity, low-nutrient, soft-water, lakes, bogs, and reed swamps. This second diatom assemblage implies that the clayey Ogallala sediment, with the addition of water from the nearby shallow hard-water streams, was used to make daub.

Three chunks of daub (\#294-5, \#1229-5, and \#12355) that lacked macroscopic signs of impressions were subjected to chemical analysis through instrumental neutron activation analysis. The results indicated no obvious correlation with the pottery results, although there was generally regional similarity. One consistent difference between the clays and the pottery was the presence of barium in the clays (Appendix G). No consistent matches were made between the daub and the various pottery groups, not even the pottery from this site.
Macroscopic examination of the pieces revealed a few with plant impressions. The few stick and possible grass impressions on the daub pieces provide indications as to how the daub functioned. Although only a few pieces exhibit impressions, these merit special attention and are described in detail here. Most pieces are so small that a series of impressions are not evident on any one piece, with the exception of one specimen (\#315-5), a piece measuring 17 - by 8 -mm-wide, weighing 0.8 $\mathrm{g}$ and bearing a series of three apparent impressions of thin sticks along one narrow (3-mm-wide) edge (Figure 9-123). Opposite the scalloped impression is a flat smooth surface (Figure 9-123), which may indicate that the clay was pressed against a series of small sticks, after which the opposite (or outside) surface was smoothed flat. This piece was recovered from N482 E501 at the northern end of Feature 18, the "ghost" pithouse.

The inside of specimen \#629-5 exhibits a shallow, smooth impression, 3-mm-wide, that appears to have been made when the clay was pressed against a smooth, thin stick (Figure 9-124). The opposite side reveals a smooth, slightly convex surface with faint lines across it. One edge is rounded and smooth, whereas the other edges are broken. This small ( $<3$-cm-long) piece came from N699 E496 within the northern margin of the pithouse.

Specimen \#453-5, from Feature 16, a heating element in N491 E501, at 54 cmbs, is a very hard and dense piece of clay that bears an unusual design 


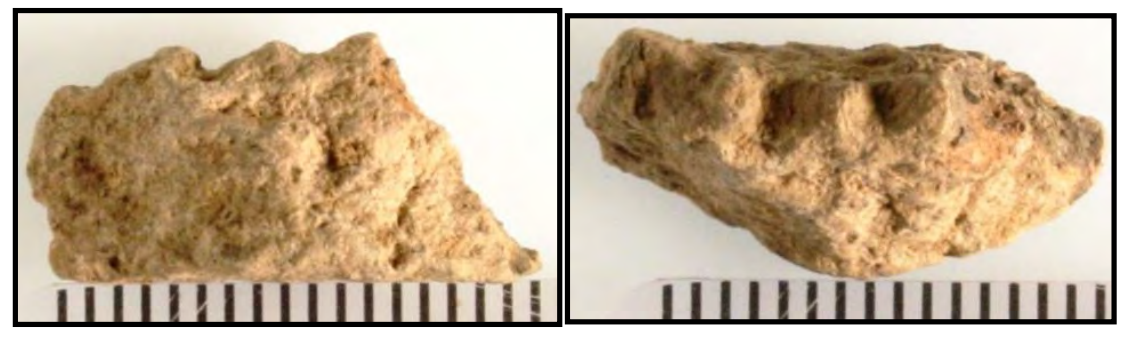

Figure 9-123. Example of burned clay/daub (\#315-5) with a series of three small, narrow stick-like impressions, side view (left) and top view (right).

Scale in millimeters.

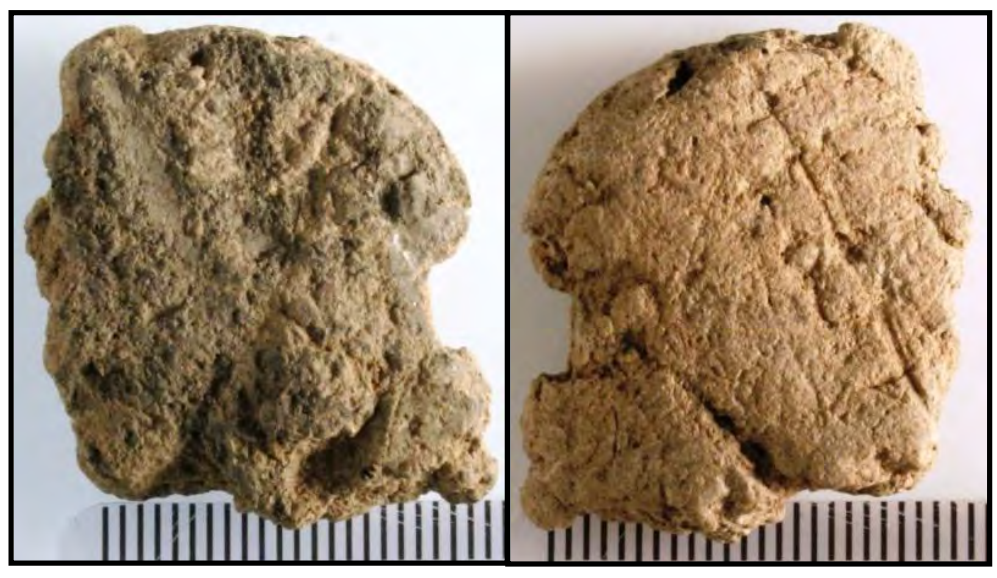

Figure 9-124. Example of burned clay/daub (\#629-5) revealing a shallow, narrow stick impression (left) with a smooth convex face on opposite side (right).

Scale in millimeters.

(Figure 9-125) made by a series of what appear are thin and shallow lines incised into the clay when still wet and create a checkerboard pattern across one face. In fact, each line is actually comprised of two closely spaced lines that may have been incised using a stone tool. It is postulated that a seriated bifacial tool was used to incise the clay since it created two closely spaced thin parallel lines, a pattern repeated with each incision. If the pattern was not created by incising the lines they may have been created by a fiber net. This $9.9 \mathrm{~g}$ piece has mostly broken edges except for the one relatively flat face that is incised. The function of this piece is unknown.

One of the largest pieces of daub, roughly spherical in shape, 3-cm-long, and weighing $27.6 \mathrm{~g}$, bears five parallel, narrow impressions on one irregularly concave surface. A sixth impression, similarly narrow, cross cuts the main group at a nearly 60-degree angle (Figure 9-126). A couple of parallel impressions exhibit very tiny lines within the larger impression that may indicate that the impressions were not created by small sticks, but by some other type of more fibrous plant stalk. The right side or edge is well rounded and smooth, whereas the opposite face is rough and irregular and likely broken and weathered.

The impressions appear to have been created when the wet clay was pressed against a series of parallel sticks or plant stalks, as could have been the case in a structure built using a wattle-and-daub, or jacaltype construction technique.

Specimen \#417-5 (4.1 g) has multiple thin, crisscrossing lines that may reflect brushing of the wet clay surface, or perhaps are impressions created by 


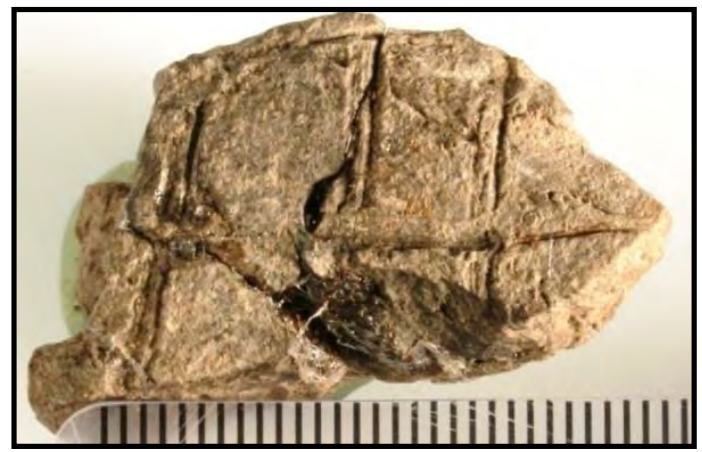

Figure 9-125. Burned clay/daub (\#453-5) that exhibits geometric pattern incised into this hard piece.

Scale in millimeters.

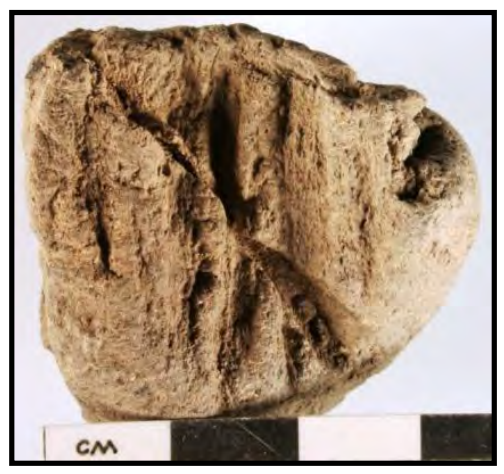

Figure 9-126. Burned clay/daub (\#643-5-1) that exhibits multiple well-defined impressions. Scale in centimeters.

some form of matting (Figure 9-127). There may be two layers of impressions represented, as two sets of faint lines are observed at slightly different angles. The opposite face is quite irregular and bumpy. The bottom edge appears to have been recently broken. This piece came from N489 E495 at 30 to 40 cmbs and was not associated with any recognized cultural feature, but was found below the southern end of the stone alignment.

Figure 9-128 provides the horizontal distribution of the burned clay/daub. No concentrations, or chunks greater than $5 \mathrm{~cm}$ in size, were present in Component C. The lack of sizeable concentrations or large chunks of burned clay/daub in Feature 6 pithouse indicates that these small pieces did not result from a burned structure. The daub from Feature 6 pithouse likely resulted from dumping unwanted materials into the pithouse and not from in situ development. The daub in and next to the heating elements, Features 16/21 may reflect actual in situ development. This is, these small pieces were likely created from or during the fires related to the heating elements. Those pieces in the southeastern corner near Features 19 and 20 may have also resulted from heating activities. The presence of small stick and grass impressions on a few specimens may be related to the use and function of the fires and not actual structural type features. The function(s) of this class of material cannot be defined with any certainty from either their shapes or distributions. 


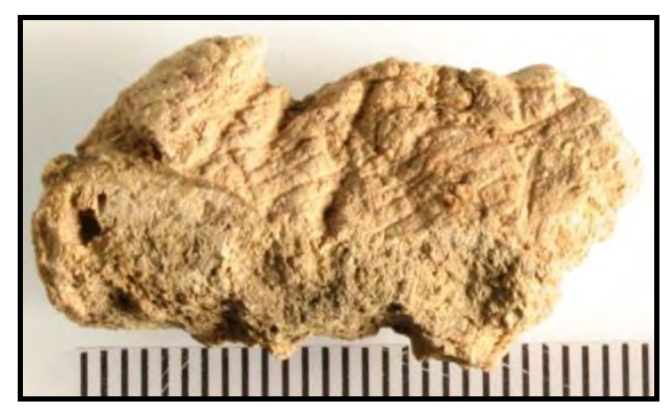

Figure 9-127. Burned clay/daub (\#417-5) exhibiting multiple thin, criss-crossing lines on one face.

Scale in millimeters.

\section{$9.9 \quad$ Worked Clay}

\section{J. Michael Quigg}

Only a single object of clay was identified that is not part of a ceramic vessel. This object is described below.

Specimen \#471-10 was 50 to 60 cmbs in N496 E501 along the northern edge of heating elements, Features $16 / 21$. This is a small elongated, miniature cigar shaped clay object that is 28.9-mm-long by 10.2-mm-wide and weighs $2.3 \mathrm{~g}$. It has two rounded and finished ends with an overall shape similar to a tiny coil of clay (Figure 9-129). It is covered with a thin film of calcium carbonate whereas the interior core is a light brown (7.5YR 6/4) to very pale brown (10YR 7/3). Three quarters of the surfaces are smooth and convex with a limited area that is slightly irregular. No striations or fingerprints are visible. Tiny, quartz sand grains are visible on the surface and in the core. It is not clear how this piece functioned or was intended to function. It may have been intended as an attachment to a vessel, possibly to make some part of a figurine, or just a leftover coil fragment from pottery construction.

\subsection{Ground Stone Assemblage}

\section{J. Michael Quigg}

This assemblage consists of 23 artifacts and includes 10 metates, 6 manos, 4 hammerstones, and 3 abraders. Individual observations and metric measurements concerning these artifacts are presented in Table 9-25. The assemblage is composed of 78 percent sandstone with the quartzite pieces primarily limited to hammerstones. The hammerstones are natural water rounded rocks that exhibit impact scars on one end or a corner. All four hammers are small, less than 100-mm-long and weigh less than 410 g. These have not been shaped and appear to have impacted hard materials, which created the small impact scars. Because they are relatively small, it is possible they were used as percussion instruments in knapping activities.

The three abraders exhibit small narrow "U" shaped grooves, which were created during an abrading motion that targeted narrow items (Figure 9-130). All three abraders are sandstone. These are small pieces and it is not clear if these represent the original size or if these are just fragments of larger pieces.

The two more complete manos are small, less than $150 \mathrm{~mm}$ in length. These are considered one-handed manos. The mano pieces are relatively broad and thin, tabular sandstone with one exception (\#122911), which is triangular (Figures 9-131 and Figure 9-132).

No complete metates were recovered; therefore, no clear picture is available of what their original shape was. However, the recovered pieces indicate at least two types, deep basins and more or less flat forms, are represented (Figures 9-132 and 9-133). The small pieces do not allow determination of the 


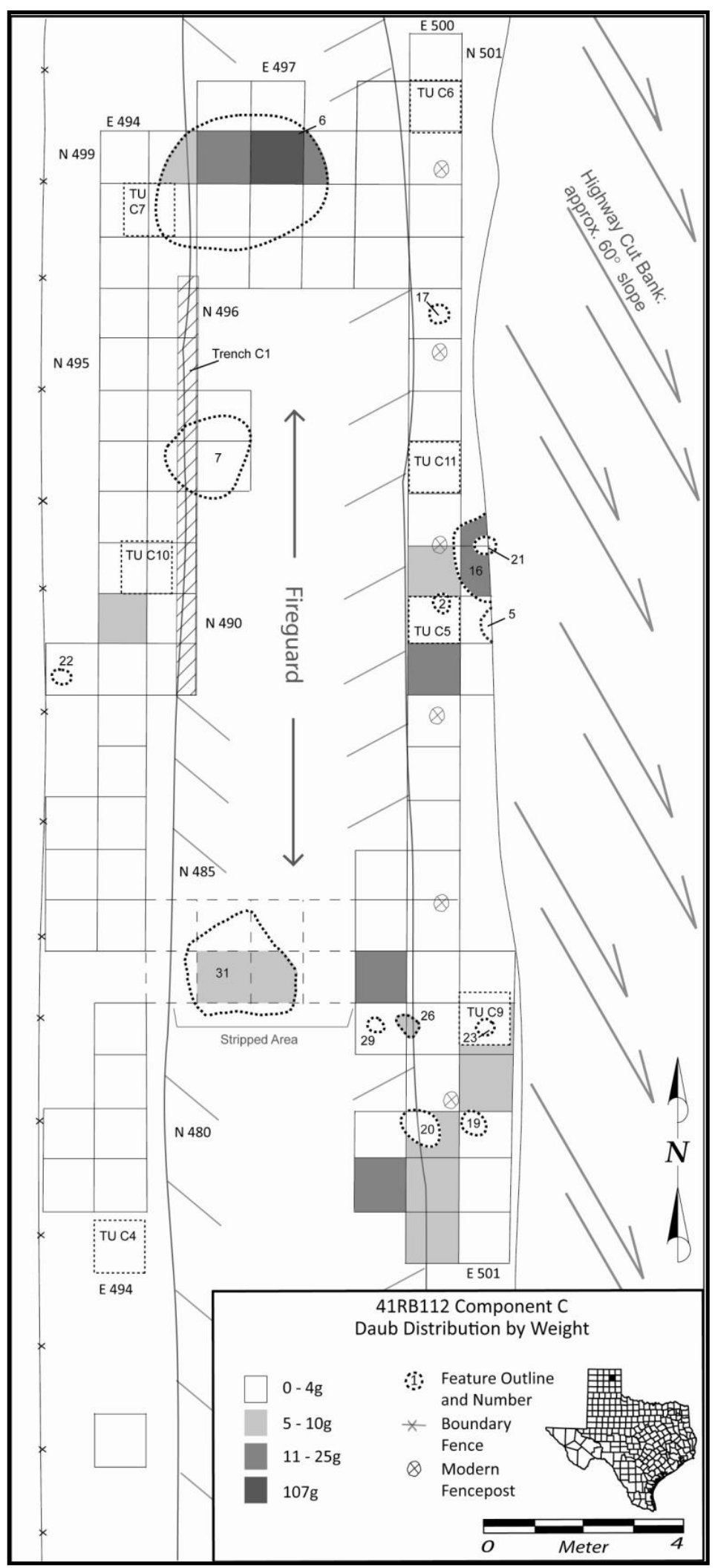

Figure 9-128. Horizontal distribution of daub weight across Component C. 


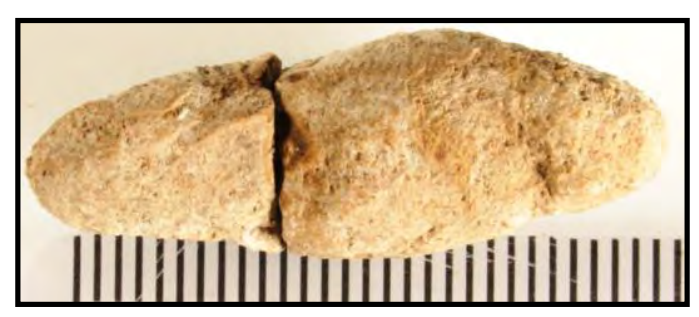

Figure 9-129. Photograph of a small clay coil (\#471-10).

Scale in millimeters.

frequencies of the types or if a standard size/shape was preferred.

For the most part, the original margins of the metate pieces are rounded and lack flake scars that would indicate intentional shaping. However, since most are sandstone, the shaping could have been conducted by abrading, which is difficult to detect on these weathered pieces.

Twelve pieces (52 percent) including five metate fragments, four manos, and three abraders were sent for starch analysis (see Table 9-25). Two abraders (\#545-10 and \#643-12) yielded four and two unknown starch grains respectively (Appendix D). Three of the four manos (Figure 9-132) yielded limited starch grains with one lenticular grain that is from little barley (Hordeum pusillum) and a chenoam grain. The exception being the nearly complete mano \#191-10 (Figure 9-134), from the southern end of Feature 18, which yielded four maize grains, damaged maize grains, and cheno-am grains (Appendix D).
The five metate fragments yielded only seven starch grains, all but one are unknown (Appendix D). The only identified grain was a lenticular grain of little barley. It is interesting that no maize grains, damaged or otherwise were on these metates. Five manos and metates were from the floor of pithouse Feature 6, so the preservation should be excellent.

\subsection{Shell Artifacts}

\section{J. Michael Quigg}

A single shell bead (\#580-10) was recovered from floating pithouse fill from 50 to $60 \mathrm{cmbs}$ in N498 E496. This bead came from sorting the heavy fraction. This shell bead is whole, circular in form and is about 3.1-mm-wide with a central hole that is about $1.7-\mathrm{mm}$-wide creating a shell thickness of about $1.0 \mathrm{~mm}$ (Figure 9-135). The edges of the hole do not appear to be beveled in the side of being drilled. No striations are visible on the edges or the exterior sides. The shell does not appear similar to the freshwater mussel shells from this component. At present is it undetermined what kind of shell this is. Freshwater mussel shells have a tendency to break in layers and not have solid structure, thus it is possible this shell is not of this region and considered nonlocal. It is very similar in size and shape to the shell bead in component $\mathrm{A}$, although no "file marks" are visible on this bead. Trace element analysis using X-ray fluorescence determined this bead was entirely of calcium carbonate based on qualitative analysis (Appendix E). The spectrum is nearly identical to the bead fragment in component A and therefore, these two beads likely came from the same source. 
Table 9-25. Component C Ground Stone Data.

\begin{tabular}{|c|c|c|c|c|c|c|c|c|c|c|c|}
\hline PNUM & Unit & $\begin{array}{l}\text { Depth } \\
\text { (cmbs) }\end{array}$ & $\begin{array}{c}\text { Feature } \\
\text { No. }\end{array}$ & $\begin{array}{c}\text { Artifact } \\
\text { Type }\end{array}$ & $\begin{array}{l}\text { Length } \\
(\mathrm{mm})\end{array}$ & $\begin{array}{l}\text { Width } \\
\text { (mm) }\end{array}$ & $\begin{array}{c}\text { Thickness } \\
\text { (mm) }\end{array}$ & Weight (g) & $\begin{array}{l}\text { Depth of } \\
\text { Worked } \\
\text { Surface }\end{array}$ & $\begin{array}{c}\text { Angle of } \\
\text { Worked } \\
\text { Surface ( }\left(^{\circ}\right)\end{array}$ & Material Type \\
\hline $191-10^{*}$ & N479 E499 & 23 & NA & mano frag & 141.7 & 100.3 & 47.3 & 956.3 & 1 sided & & sandstone \\
\hline $195-10$ & N479 E499 & 58 & NA & hammer & 80.8 & 68.2 & 55 & 405.3 & 1 end & & quartzite \\
\hline $292-10 *$ & N482 E499 & 38 & NA & metate frag & 14.8 & 11.7 & 8.0 & 1677.0 & 1.4 & 26 & sandstone \\
\hline $351-10 *$ & N484 E498 & 60 & 30 & mano & 121.8 & 108.2 & 41.1 & 523.2 & 1 sided & & sandstone \\
\hline $545-10 *$ & N497 E499 & $20-30$ & & abrader & 30.4 & 25.6 & 14.7 & 11.2 & 2 sided & & sandstone \\
\hline $574-10$ & N498 E495 & $70-80$ & 6 & mano frag & 57.1 & 51.7 & 33.9 & 108.8 & 2 sided & & sandstone \\
\hline $582-10$ & N498 E496 & $60-70$ & 6 & metate frag & 106.7 & 107.1 & 73.2 & 885.3 & 3.1 & & sandstone \\
\hline $623-10$ & N499 E495 & 54 & 6 & metate frag & 67.2 & 46.7 & 17 & 52.6 & 3.1 & & sandstone \\
\hline $623-11$ & N499 E495 & 56 & 6 & mano frag & 71.7 & 71.8 & 24.5 & 121.7 & 1 sided & & sandstone \\
\hline $629-11$ & N499 E496 & $35-40$ & 6 & metate frag & 146.9 & 90.9 & 48.5 & 623.7 & 6.8 & 30 & sandstone \\
\hline $629-12 *$ & N499 E496 & 36 & 6 & mano frag & 89.5 & 93.4 & 36.1 & 471 & 2 sided & & sandstone \\
\hline $643-12 *$ & N499 E497 & 52 & 6 & abrader & 57.6 & 55.4 & 20.7 & 95.8 & $\begin{array}{l}1 \text { straight } \\
\text { groove }\end{array}$ & & sandstone \\
\hline $643-13$ & N499 E497 & 45 & 6 & hammer & 97.5 & 47.3 & 30.5 & 181 & 1 end & & quartzite \\
\hline $643-20$ & N499 E497 & 45 & 6 & hammer & 72.7 & 61.6 & 42.8 & 220 & 1 corner & & quartzite \\
\hline $643-21$ & N499 E497 & 42 & 6 & metate frag & 75.4 & 62.3 & 43.8 & 248.5 & 1.5 & 25 & sandstone \\
\hline $671-10 *$ & N500 E497 & 68 & 6 & metate frag & 22.0 & 15.2 & 10.5 & 3253.1 & 3.6 & 50 & sandstone \\
\hline $1229-11$ & N499 E495 & 44 & 6 & metate frag & 141.1 & 97 & 54 & 761.4 & 7.9 & $30-40$ & sandstone \\
\hline $1229-11 *$ & N499 E496 & 45 & 6 & mano & 148.9 & 69.5 & 64.2 & 1006 & 2 sided & & quartzite \\
\hline $1229-12 *$ & N499 E496 & 46 & 6 & metate frag & 20.6 & 17.0 & 13.6 & 4562.7 & 8.2 & 51 & sandstone \\
\hline 1229-13 & N499 E495 & $40-50$ & 6 & hammer & 94.9 & 61.4 & 49.6 & 360 & 1 end & & quartzite \\
\hline $1231-11^{*}$ & N499 E496 & 68 & 6 & metate frag & 15.2 & 10.9 & 6.2 & 1219.5 & 3.7 & 67 & sandstone \\
\hline $1260-10 *$ & N484 E494 & 80 & & abrader & 54.4 & 33.5 & 13.9 & 30.2 & 1 groove & & sandstone \\
\hline $1261-10 *$ & N486 E495 & 60 & NA & metate frag & 12.5 & 10.2 & 8.4 & 940.1 & 3.2 & 36 & sandstone \\
\hline
\end{tabular}

$*=$ artifacts sent for starch grain analysis 


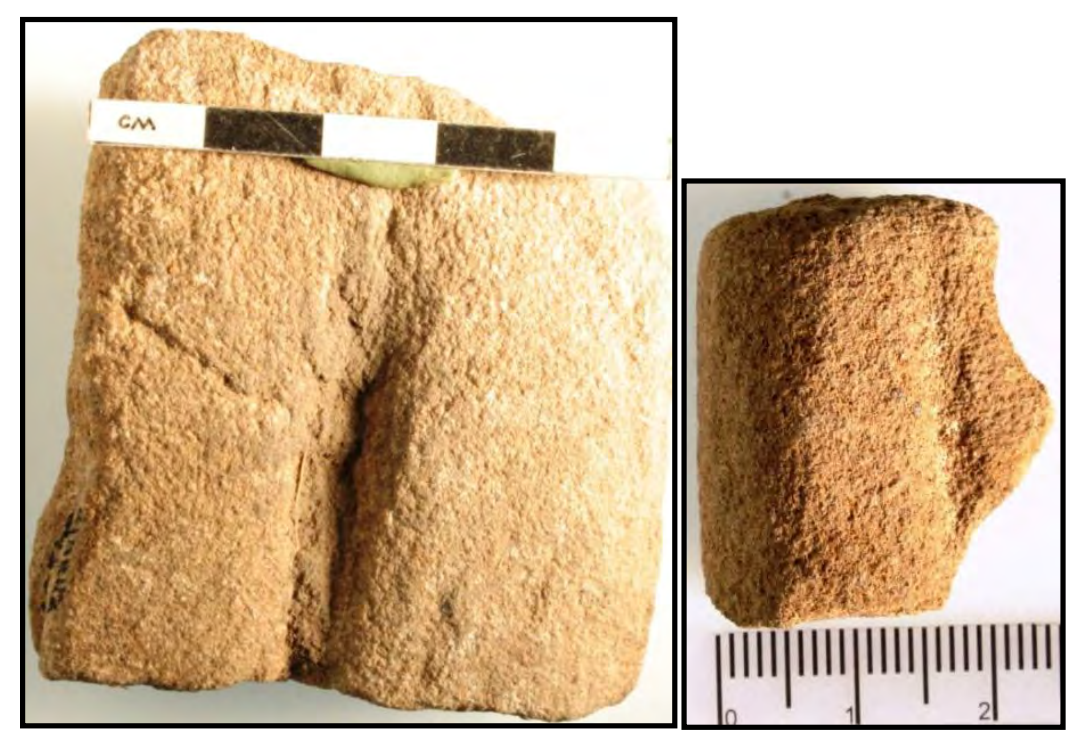

Figure 9-130. Examples of two single grooved abraders (\#643-12 and \#545-10).

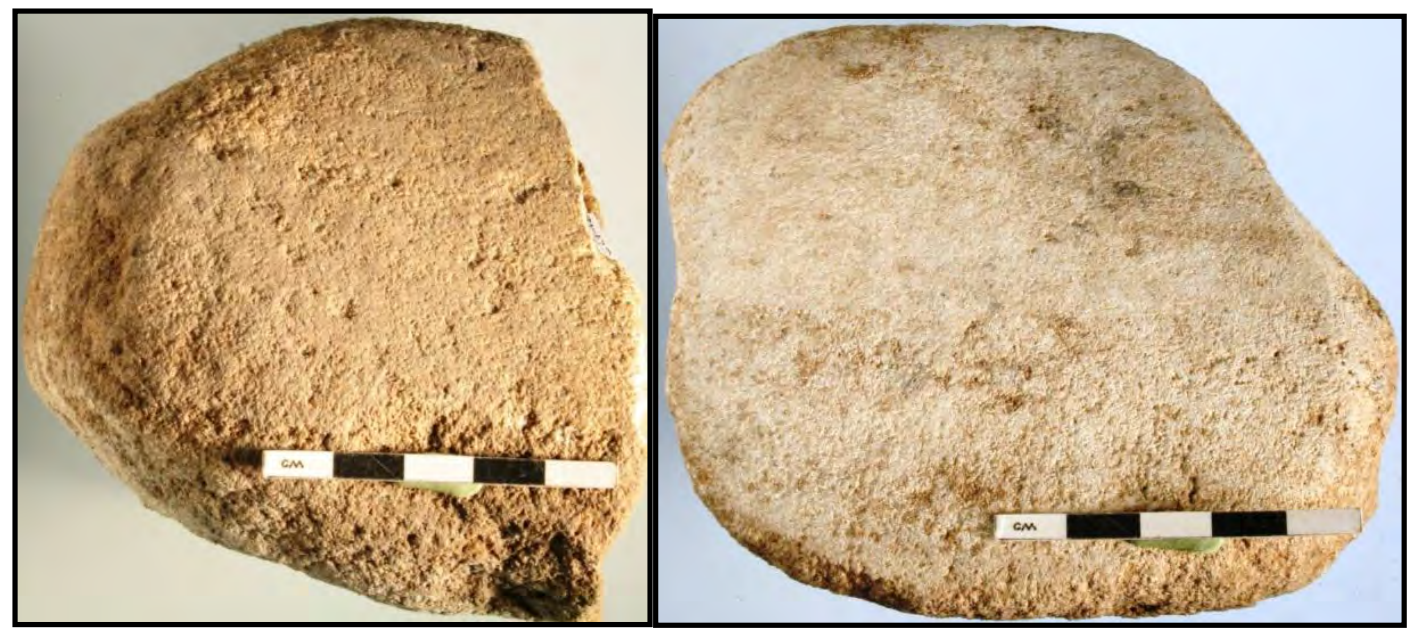

Figure 9-131. Two examples of small one handed manos (\#629-10 and \#351-10). 


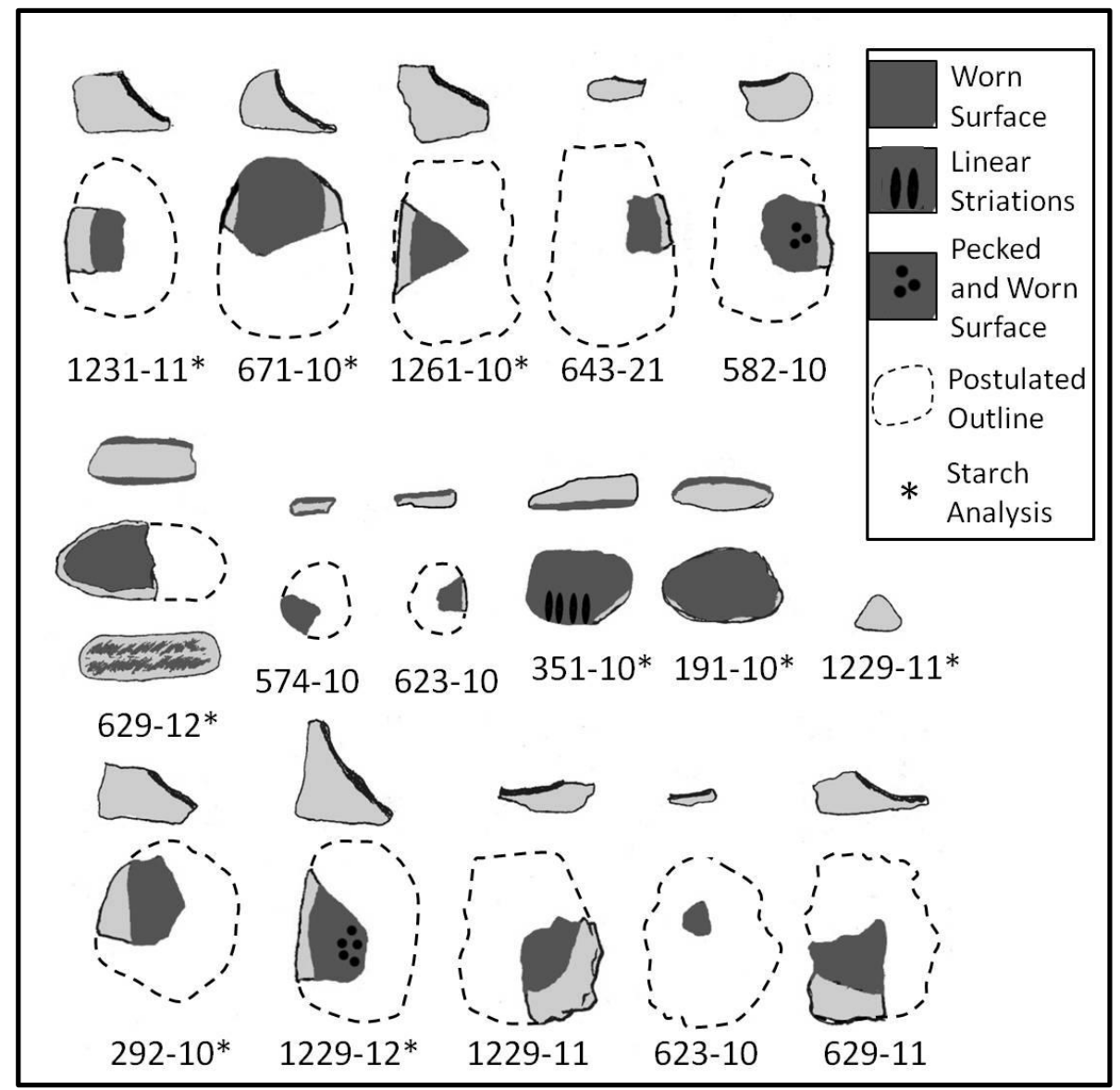

Figure 9-132. Plan and profile drawings of mano and metate fragments projected onto postulated whole metates.

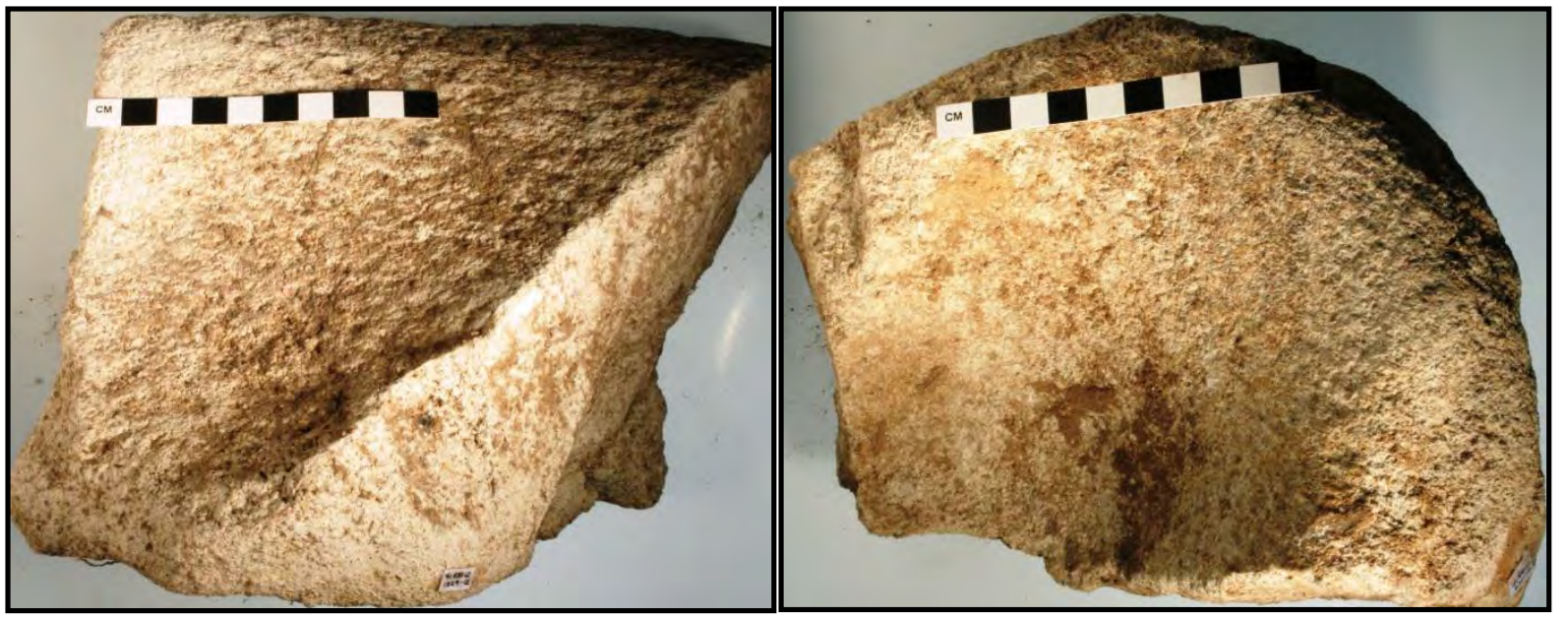

Figure 9-133. Photographs of pieces of deep basin-shaped metates (\#1229-12 and \#671-10). 


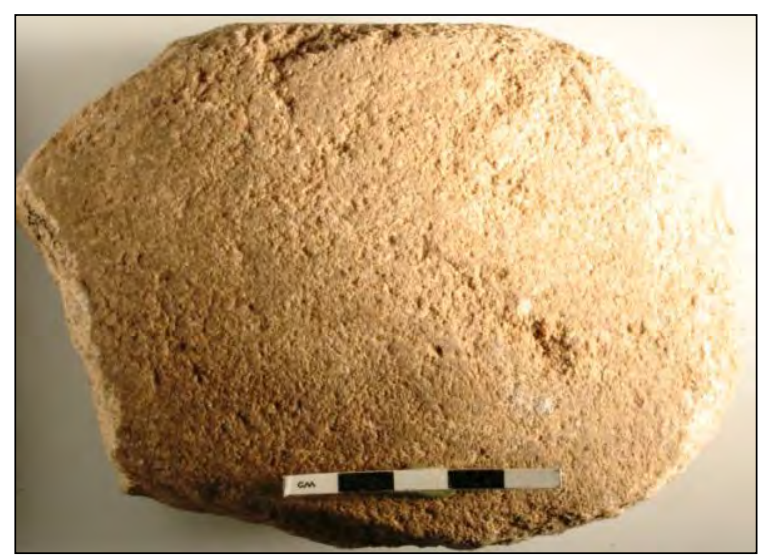

Figure 9-134. Nearly complete one handed sandstone mano (\#191-10) that yielded maize and cheno-am starch grains.

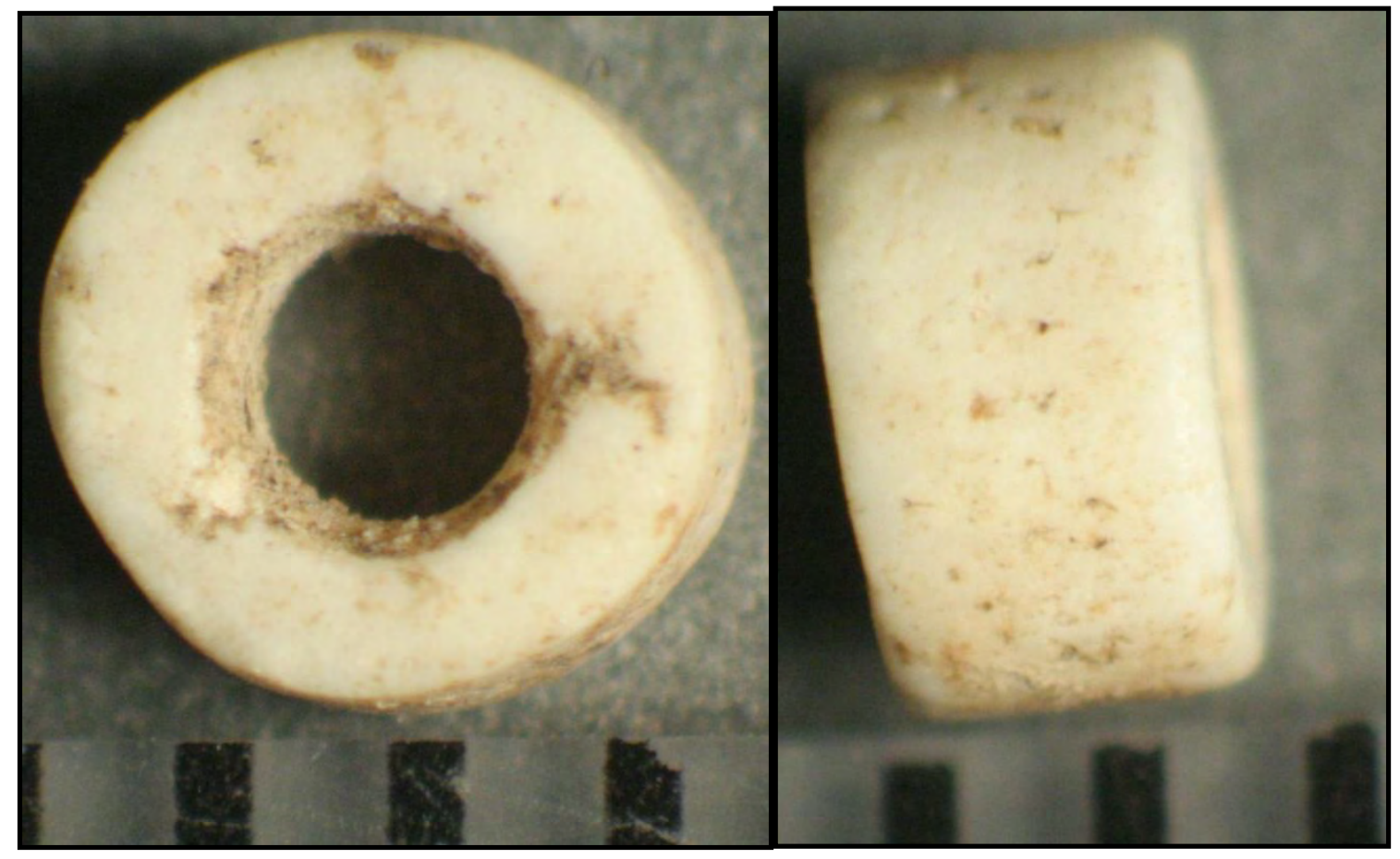

Figure 9-135. Plan and profile of shell bead (\#580-10) from 50 to $60 \mathrm{cmbs}$ in Pithouse, Feature 6.

Scale is in milliliters. 
Chapter 9: Component C - Southern End of Site

This page intentionally left blank. 


\subsection{RESEARCH QUESTIONS ADDRESSED}

By J. Michael Quigg, Paul M. Matchen, Charles D. Frederick, Brittney Gregory and Robert A. Ricklis

\subsection{Introduction}

Chapter 4.0 presented a series of 11 specific questions that formulated the strategies for analyses directed towards material remains from the Long View site. This research design was approved by TxDOT archeologists prior to undertaking these analyses and reporting. Here, we address each of the 11 stated research questions. The underlying assumption is that the artifacts and ecofacts recovered combined with the features documented at the two components are residues of past human activities and, as such, reflect technoeconomic, social and demographic dimensions of the culture, as a complex adaptive system (see Butzer 1982), that informed and influenced the behavioral patterns of the occupants.

The ultimate goal of the analyses was to (a) delineate basic adaptive mechanisms by which Plains Village folk at the Long View site survived and met their basic social and economic needs, and (b) place, to the extent possible within the limits of the data, the defined adaptive patterns within the larger context of Late Prehistoric culture in this sector of the high plains environment.

\subsection{Question 1}

Are Components $A$ and $C$ contemporaneous or do they represent chronologically distinct Plains Village occupations?

\section{J. Michael Quigg}

Following the testing phase, eight radiocarbon dates, seven from wood charcoal and one from carbonized maize, with four from each component, were obtained to provide an initial understanding of the age of the two components. These did not provide an entirely clear picture of the ages of the two recognized components at Long View. The eight dates range from uncalibrated $530 \pm 20$ to $1490 \pm 40$ B.P. (calibrated [cal] A.D. 460 to 1437). Three of the eight (38 percent) dates were older than uncalibrated $900 \pm 40$ B.P. (cal A.D. 1035 to 1152), two from Component $A$ and one from Component C (Quigg and Smith 2005:46). Since no cultural artifacts appear associated with these three early dates, they were rejected. The remaining five dates create two clusters that were thought to best represent the two components and consist of two samples dating to $710 \pm 40$ B.P. (cal A.D. 1260 to 1310) from Component $A$ and three samples dating $580 \pm 20$ B.P., $650 \pm 40$ B.P. and $700 \pm 40$ B.P. (range cal A.D. 1260 to 1310) from Component C. The youngest date of $580 \pm 20$ B.P. (cal A.D. 1321 to 1405) was from maize, which created uncertainty as to the validity of the older wood charcoal dates. In general, an "old wood" problem has been widely documented (Smiley 1985; Schiffer 1986; Bowman 1990; Roper and Adair 2011), which indicates that wood charcoal generally provides earlier dates than the actual occupation being investigated because the wood used in fires was generally older, dried wood gathered from multiple sources.

Major deficiencies exist in the chronological placement of Plains Village tradition occupations due to the paucity of intensively radiocarbon dated sites. Although providing a general and informative age range for Plains Village period, investigated sites in the Texas and Oklahoma panhandles have narrowly focused on individual structures and/or burials (Lintz 1984, 1986; Brooks 1989, 2004, Boyd and Wilkens 2001; Boyd 2005), and in general, only one or two dates were obtained from each structure or feature per site. This has created uncertainty concerning how individual structures and features relate in age to the larger-scale community and communities to one another. Not only has archeological sampling been too limited to analyze community patterning and activities, most field investigations of Plains Village sites in the Texas and Oklahoma panhandles were conducted at least 30 to 40 years ago (sites include McGrath [Lintz 1976], Two Sisters [Duncan 2002, 2006], Roy Smith [Schneider 1969], Stamper [Watson 1950; Lintz 2003a, 2003b, 2003c, 2004], Antelope Creek Ruin 22 and Alibates Ruin 28, 28A, and 30 [Baker and Baker 2002], and others, see Table 3-1). At those times, field procedures were not as developed as at present, nor were recovery procedures as systematic. Many excavations were conducted prior to the availability of radiocarbon 
dating, and, when implemented, were often done with scattered pieces of charcoal collected from multiple proveniences.

Chronometric dates from Antelope Creek phase sites are scarce and tend to be problematic for one reason or another. Since Long View is one of the few recently excavated Plains Village sites, it was imperative we thoroughly dated its two identifiable components. The advantages of using annual plants (i.e., maize, nuts, or seeds) rather than wood charcoal for radiocarbon dating has recently been well-illustrated and documented by Roper and Adair (2011). Their analysis compared the differences between previously obtained ages on wood charcoal with the distribution of ages derived from annual plants. The results show that dating annual plants provides a much tighter, more reliable and more interpretable age distribution for selected Central Plains tradition sites in Kansas.

Hand-excavation and subsequent floating of bulk matrix from individual features at the Long View site yielded considerable quantities of maize kernels, cupules, and cobs, as well as quantities of wood charcoal from which to obtain radiocarbon dates. It was deemed appropriate to expand the sample of dates using annuals in order to evaluate if the previously obtained wood charcoal dates did not reflect the precise age of the components, attempt to narrow the time range of the occupations, determine the most accurate age for each component, and assess their contemporaneity. It was also thought that it would be advantageous to use one plant species, in this case the abundant maize remains, in order to eliminate variability that might stem from using multiple species.

The subsequent Accelerator Mass Spectrometry (AMS) dating of 17 carbonized maize kernels and 1 unburned bison bone (collagen fraction) from the two components provides a larger suite of absolute dates to refine the age of both components, test for their contemporaneity, identify specifically where these dates fall in relationship to the broader Plains Village manifestations across the broader region, and assess/evaluate the difference between the wood charcoal results and the results from annuals (maize kernels). The results from the two components are discussed separately below.

\subsubsection{Age of Component A}

For Component A, nine new AMS dates were obtained on maize to compliment the four previous wood charcoal AMS dates (Table 10-1). The thirteen AMS dates range from $480 \pm 20$ B.P. to $1490 \pm 40$ B.P. (cal A.D. 460 to 1447). The four uncalibrated AMS dates on wood charcoal are two at $710 \pm 40$ B.P. (cal A.D. 1260 to 1310 ), one at $970 \pm 40$ B.P. (cal A.D. 1000 to 1170 ), and the oldest at $1490 \pm 40$ B.P (cal A.D. 460). The latter two AMS dates on wood charcoal are considerably older than the eight AMS dates on maize, presumably due to the "old wood" factor mentioned previously, and are rejected. Two wood charcoal dates (\#31-4-2a or Beta-206557 and \#62-7a or Beta-206560) are potentially only slightly earlier (Table 10-1). The oldest AMS date on maize is $590 \pm 25$ B.P. (cal. A.D. 1301-1411) and overlaps the younger two of the wood charcoal dates. Eight of the AMS dates on maize create a tight cluster spanning 75 years from 460 to 535 B.P. (cal. A.D. 1398 to 1447) with a mean of cal A.D. 1423. These are considered to accurately represent the temporal position of Component $\mathrm{A}$.

\subsubsection{Age of Component C}

For Component C, eight new AMS dates were obtained on maize and one on bison bone. The 13 dates now available from this component range from $530 \pm 25$ B.P. to $1290 \pm 40$ B.P. (cal. A.D. 660 to 1437) (Table 10-1). The wood charcoal date of $1290 \pm 40$ B.P. (cal A.D. 660 to 790) is aberrantly older, and is not accepted as representing the true age of Component $\mathrm{C}$. All nine AMS dates including maize and bison bone span 170 years from 530 B.P. to 700 B.P. (cal A.D. 1280 to 1437) and are accepted as accurately representing the age of this Plains Village component (Figure 10-1). The mean date is cal A.D. 1359.

\subsubsection{Age Comparison between Component $\mathrm{A}$ and $\mathrm{C}$}

When the two accepted sets of AMS dates from Components $\mathrm{A}$ and $\mathrm{C}$ derived primarily from maize are compared, they statistically overlap and are quite close in time. However, the mean uncalibrated date for Component C is 615 B.P. (cal A.D. 1359) and 64 calibrated years older than the mean date of 498 B.P. (cal A.D. 1423) for Component A. The answer to the 
Table 10-1. Radiocarbon Dates from Components A and C.

\begin{tabular}{|c|c|c|c|c|c|c|c|c|c|c|c|}
\hline $\begin{array}{c}\text { Catalog } \\
\text { No. }\end{array}$ & 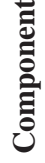 & $\begin{array}{l}\text { Unit } \\
\text { No. }\end{array}$ & $\begin{array}{l}\text { Depth } \\
\text { (cmbs) }\end{array}$ & $\begin{array}{c}\text { Feature } \\
\text { No. }\end{array}$ & $\begin{array}{c}\text { Material } \\
\text { Dated }\end{array}$ & $\begin{array}{l}\text { Wt. } \\
\text { (g) }\end{array}$ & $\begin{array}{l}\text { Lab. } \\
\text { No. }\end{array}$ & $\begin{array}{c}\text { Measured } \\
\text { Age }\end{array}$ & $\begin{array}{c}{ }^{13} \mathrm{C} /{ }^{12} \mathrm{C} \\
\text { Ratio (\%o) }\end{array}$ & $\begin{array}{c}\text { Conventional } \\
\text { Age (B.P.) }\end{array}$ & $\begin{array}{c}2 \text { Sigma } * * \\
\text { Calibration } \\
\text { Range }\end{array}$ \\
\hline $31-4-2 a$ & A & Cutbank & $62-64$ & 1 & $\begin{array}{c}\text { wood } \\
\text { charcoal }\end{array}$ & 0.1 & B-206557 & $680 \pm 40$ & -23.0 & $710 \pm 40$ & $\begin{array}{l}\text { AD } 1260-1310 \\
\text { AD } 1370-1380\end{array}$ \\
\hline $31-7-1$ & A & Cutbank & 52 & 1 & $\begin{array}{c}\text { wood } \\
\text { charcoal }\end{array}$ & 0.1 & B-206558 & $1460 \pm 40$ & -23.3 & $1490 \pm 40 *$ & $\begin{array}{l}\text { AD 460-480, } \\
\text { AD 520-650 }\end{array}$ \\
\hline $34-7-2$ & A & Trench A-1 & 36 & 3 & $\begin{array}{c}\text { wood } \\
\text { charcoal }\end{array}$ & 0.5 & B-206559 & $940 \pm 40$ & -23.2 & $970 \pm 40 *$ & AD 1000-1170 \\
\hline $62-7 a$ & A & Unit A-5 & $50-60$ & 4 & $\begin{array}{c}\text { wood } \\
\text { charcoal }\end{array}$ & 0.1 & B-206560 & $690 \pm 40$ & -24.0 & $710 \pm 40$ & $\begin{array}{l}\text { AD } 1260-1310 \\
\text { AD } 1370-1380\end{array}$ \\
\hline $1032-7-1$ & A & N695 E511 & $50-60$ & 11 & 1 maize & 0.1 & U-7831 & & -12.5 & $500 \pm 25$ & AD 1406-1444 \\
\hline 1064-7-1a & A & N697 E513 & $45-55$ & NA & 1 maize & 0.1 & U-7832 & & -9.9 & $510 \pm 20$ & AD 1406-1439 \\
\hline 1074-7-1a & A & N697 E515 & $30-40$ & NA & 1 maize & 0.1 & U-7833 & & -12.7 & $510 \pm 25$ & AD 1398-1444 \\
\hline 1080-7-1 & A & N698 E511 & $31-53$ & 10 & 1 maize & 0.1 & U-7834 & & -10.6 & $510 \pm 25$ & AD1398-1444 \\
\hline 1093-7-1a & A & N698 E513 & $50-60$ & NA & 1 maize & 0.1 & U-7835 & & -11.4 & $480 \pm 20$ & AD 1416-1445 \\
\hline 1116-7-1 & A & N699 E512 & $40-50$ & 8 & 1 maize & 0.1 & U-7836 & & -9.8 & $480 \pm 25$ & AD 1413-1447 \\
\hline 1128-7-1 & A & N696 E511 & $40-47$ & 9 & 1 maize & 0.1 & U-7837 & & -11.3 & $480 \pm 20$ & AD1416-1445 \\
\hline $1064-7-2$ & A & N697 E513 & $50-60$ & NA & 1 maize & 0.1 & U-7838 & & -11.3 & $490 \pm 25$ & AD 1410-1445 \\
\hline 1164-7-3 & A & N700 E515 & $50-60$ & 1 & 1 maize & 0.1 & U-7839 & & -9.9 & $590 \pm 25$ & AD 1301-1411 \\
\hline 120-4-3a & $\mathrm{C}$ & Cutbank & $30-40$ & 5 & 1 maize & 0.1 & B-206561 & $380 \pm 40$ & -9.7 & $630 \pm 40$ & AD 1290-1410 \\
\hline $131-7-1$ & $\mathrm{C}$ & Unit C-7 & $40-50$ & 6 & 1 maize & 0.1 & U-7822 & & -9.4 & $580 \pm 20$ & AD 1309-1412 \\
\hline 133-4-a & $\mathrm{C}$ & Unit C-7 & $60-70$ & 6 & $\begin{array}{c}\text { wood } \\
\text { charcoal }\end{array}$ & 0.1 & B-206562 & $690 \pm 40$ & -24.4 & $700 \pm 40$ & $\begin{array}{l}\text { AD } 1260-1310 \\
\text { AD } 1360-1390\end{array}$ \\
\hline $164-7-1$ & $\mathrm{C}$ & Unit C-10 & 19 & \begin{tabular}{|c|} 
Below \\
Structure \\
1 \\
\end{tabular} & $\begin{array}{c}\text { wood } \\
\text { charcoal }\end{array}$ & 0.1 & B-206563 & $630 \pm 40$ & -23.6 & $650 \pm 40$ & AD $1280-1400$ \\
\hline $167-7-1$ & $\mathrm{C}$ & Unit C-10 & 34 & \begin{tabular}{|c} 
Below \\
Structure \\
1
\end{tabular} & $\begin{array}{c}\text { wood } \\
\text { charcoal }\end{array}$ & 0.1 & B-206564 & $1260 \pm 40$ & -23.0 & $1290 \pm 40 *$ & AD 660-790 \\
\hline $266-7-1$ & $\mathrm{C}$ & N481 E500 & $50-60$ & 18 & 1 maize & 0.1 & U-7823 & & -9.2 & $590 \pm 20$ & AD 1305-1408 \\
\hline $300-7-1$ & $\mathrm{C}$ & N482 E499 & $70-80$ & 29 & 1 maize & 0.1 & U-7824 & & -9.9 & $570 \pm 20$ & AD 1313-1416 \\
\hline $331-7-1$ & $\mathrm{C}$ & N482 E501 & $80-90$ & 23 & 1 maize & 0.1 & U-7825 & & -8.6 & $570 \pm 25$ & AD 1308-1419 \\
\hline $455-7-1 \mathrm{a}$ & $\mathrm{C}$ & N491 E501 & $60-70$ & 21 & 1 maize & 0.1 & U-7826 & & -11.0 & $530 \pm 25$ & AD 1324-1437 \\
\hline 470-7-1a & $\mathrm{C}$ & N491 E501 & $40-50$ & 16 & 1 maize & 0.1 & U-7827 & & -10.0 & $610 \pm 20$ & AD 1298-1400 \\
\hline $625-7-1$ & $\mathrm{C}$ & N499 E495 & $60-70$ & 6 & 1 maize & 0.1 & U-7828 & & -10.3 & $580 \pm 20$ & AD 1309-1412 \\
\hline 641-2-1a & $\mathrm{C}$ & N499 E495 & $30-40$ & 6 & $\begin{array}{l}\text { Bison } \\
\text { bone }\end{array}$ & & U-7829 & & -8.0 & $630 \pm 25$ & AD 1288-1411 \\
\hline 643-7-1a & $\mathrm{C}$ & N499 E497 & $40-50$ & 6 & 1 maize & 0.1 & U-7830 & & -10.0 & $590 \pm 25$ & AD 1301-1411 \\
\hline
\end{tabular}

cmbs = centimeters below surface, $\mathrm{g}$ = grams; B = Beta Analytical Inc., U = University of Georgia AMS, * date is not accepted, **CALIB REV 6.0.0; 


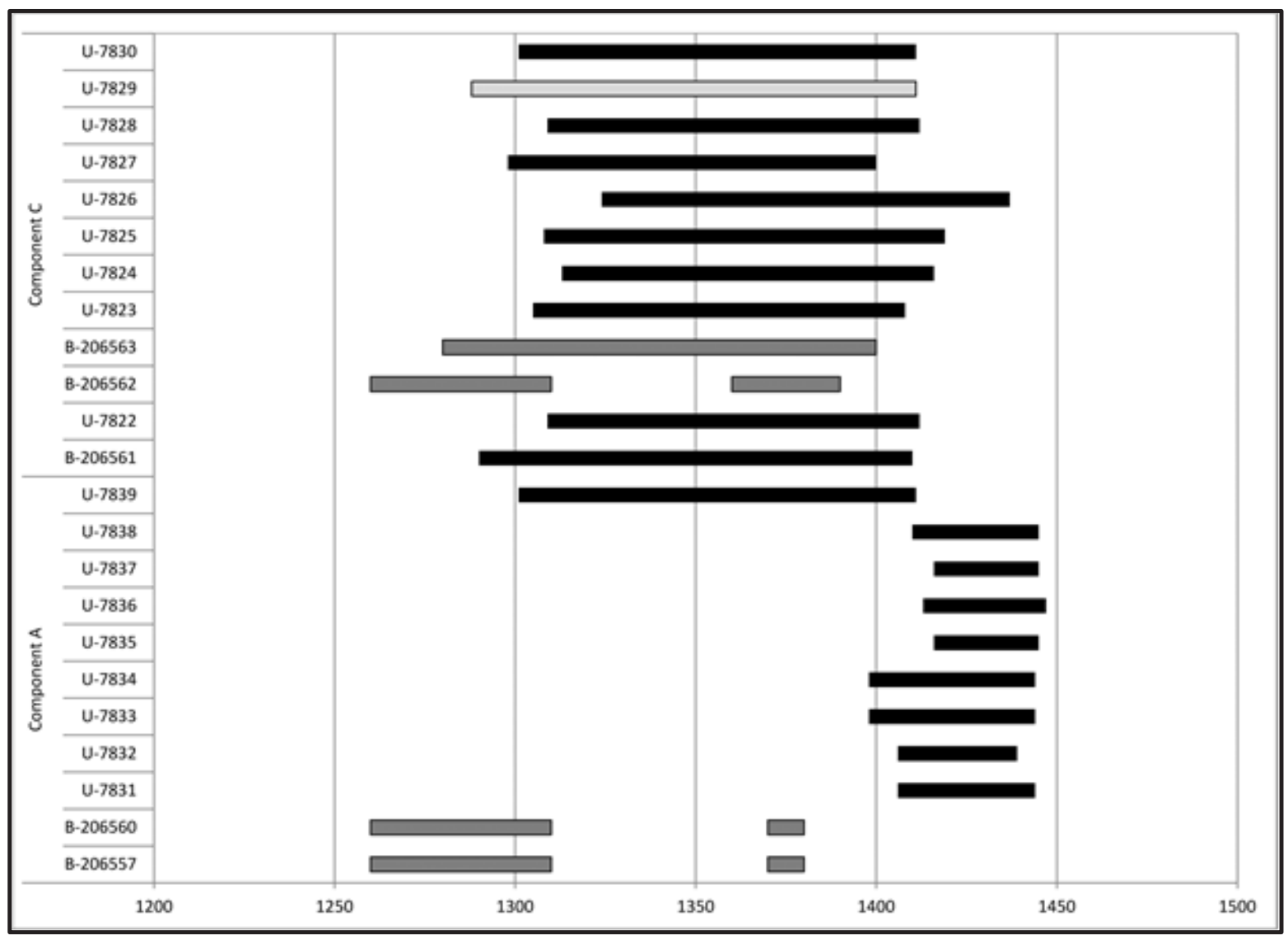

Figure 10-1. Distribution of age determinations on charred maize (black bars), bison bone (light gray) and wood charcoal (dark gray bars) from Component A and Component C. Dates are calibrated (CALIB REV 6.0.0) and presented as A.D. with two sigma ranges. $U=$ University of Georgia AMS dates and B = Beta Analytic AMS date.

question, "are the two components chronologically distinct as well as physically separate in horizontal space?" is affirmative, as the dates from Component C cluster within an slightly earlier time range (Figure 10-1), and the mean date for that component is over 60 years earlier than the mean date for Component A. While both components represent the Southern Plains Village tradition, they apparently were not occupied contemporaneously.

\subsubsection{Dating Organic Residues In and On Ceramic Sherds}

In an attempt to precisely determine the age of thick, cordmarked pottery from Component $\mathrm{C}$ at Long View four thick-walled body sherds representing four different vessels from three excavated sites (41RB112, 41RB81, and 41OC29) were directly
AMS radiocarbon dated (Table 10-2). The dates on maize from Long View serve as the control for comparison to the two thick-walled vessels. Direct dating was performed on organic residues from within each sherd to determine if thick-walled cordmarked sherds were truly associated with Plains Village period occupations, or if they might actually date to the earlier Plains Woodland period. From Component $\mathrm{C}$ at Long View, three thickwalled vessels, Vessels 1, 3, and 7, were identified. One sherd each from Vessels 1 and 3 (\#308-8-19 and \#349-8-1 respectively) were selected for AMS dating (Figure 10-2). Because neither sherd revealed an organic accumulation or crust adhering to either interior or exterior surfaces, organic matter within the clay was targeted for dating. The two sherds were found less than $5 \mathrm{~m}$ apart, within apparently 
Table 10-2. Provenience and Pertinent Data Concerning Radiocarbon Dated Sherds and Organics Scraped from Sherds.

\begin{tabular}{|c|c|c|c|c|c|c|c|c|c|}
\hline $\begin{array}{l}\text { Site/Feature/ } \\
\text { Component }\end{array}$ & Cat. No. & $\begin{array}{l}\text { Provenience } \\
\text { (Unit, Depth) }\end{array}$ & Vessel No. & Sherd Characteristics & $\begin{array}{l}\text { Lab. No. } \\
\text { (UGAMS) }\end{array}$ & $\begin{array}{c}\text { Measured } \\
\text { Age }\end{array}$ & $\begin{array}{c}{ }^{13} \mathrm{C} /{ }^{12} \mathrm{C} \\
\text { Ratio (\%o) }\end{array}$ & \begin{tabular}{|c|} 
Conventional \\
Age B.P.
\end{tabular} & $\begin{array}{c}2 \text { Sigma Calibration } \\
\text { Range* }^{*}\end{array}$ \\
\hline $\begin{array}{l}\text { 412RB81 } \\
\text { Structure } 1^{* *}\end{array}$ & 291 & $\begin{array}{c}\text { Unit 26, Level 6, } \\
214.2 \text { cmbd }\end{array}$ & Unassigned & $\begin{array}{l}\text { Bulk sherd dated, Plain exterior, base }=10.5- \\
11.0 \mathrm{~mm} \text { thick, fine sand + bone temper, dark } \\
\text { core, } 12 \mathrm{~g} \text {; }\end{array}$ & 8459 & $\begin{array}{l}\text { not } \\
\text { reported }\end{array}$ & -16.5 & $1120 \pm 25$ & cal AD 881- 988 \\
\hline $\begin{array}{l}410 \mathrm{OC} 9 \\
\text { Pithouse }\end{array}$ & $346-4$ & $\begin{array}{l}\text { Pithouse fill, } \\
\text { Feature A-3 } \\
\text { N217 E315 }\end{array}$ & Unassigned & $\begin{array}{c}\text { Bulk sherd dated, Cordmarked exterior, body } \\
=7.4-11.3 \mathrm{~mm} \text { thick, fine sand tempered, } \\
\text { dark gray core }\end{array}$ & 8458 & $\begin{array}{l}\text { not } \\
\text { reported }\end{array}$ & -18.2 & $1340 \pm 25$ & cal AD 646- 765 \\
\hline $\begin{array}{c}\text { 41RB112/ } \\
\text { Component C }\end{array}$ & $349-8-1$ & $\begin{array}{l}\text { N484 E496, } 60- \\
\quad 80 \mathrm{cmbs}\end{array}$ & 3 & \begin{tabular}{|c|} 
Bulk sherd dated, Cordmarked exterior, body \\
$=8.1-8.8 \mathrm{~mm}$ thick, sand and scoria temper, \\
$11.1 \mathrm{~g}$
\end{tabular} & 8456 & $\begin{array}{l}\text { not } \\
\text { reported }\end{array}$ & -21.7 & $940 \pm 25$ & cal AD 1029- 1156 \\
\hline $\begin{array}{c}\text { 41RB112/ } \\
\text { Component C }\end{array}$ & $308-8-19$ & $\begin{array}{l}\text { N482 E500 67- } \\
70 \text { cmbs }\end{array}$ & 1 & $\begin{array}{l}\text { Bulk sherd dated, Cordmarked exterior, body } \\
\quad=9.7-10.2 \mathrm{~mm} \text { thick, } 19 \mathrm{~g}\end{array}$ & 8457 & $\begin{array}{l}\text { not } \\
\text { reported }\end{array}$ & -29.1 & $21,550 \pm 70$ & cal 24,230-23,444 BC \\
\hline $\begin{array}{c}\text { 41RB112 } \\
\text { Component C }\end{array}$ & $305-8-1 a$ & $\begin{array}{l}\text { N482 E500, 60- } \\
\quad 70 \mathrm{cmbs}\end{array}$ & 1 & $\begin{array}{c}\text { Organic residue dated, scraped from exterior } \\
\text { cordmarked Vessel } 1\end{array}$ & B-307381 & $510 \pm 30$ & -19.9 & $590 \pm 30$ & cal AD 1300-1410 \\
\hline $\begin{array}{l}\text { 41RB112/ } \\
\text { Component A }\end{array}$ & $60-8-2 a$ & A-5, $30-40 \mathrm{cmbs}$ & A & $\begin{array}{c}\text { Bulk sherd dated, Collared rim of cordmarked } \\
\text { vessel from which organic residues were } \\
\text { scraped }\end{array}$ & B-307379 & $1950 \pm 30$ & -24.1 & $1960 \pm 30$ & cal 40 BC- AD 80 \\
\hline $\begin{array}{c}\text { 41RB112/ } \\
\text { Component A }\end{array}$ & $60-8-2 b$ & A-5, 30-40 cmbs & A & $\begin{array}{l}\text { Organic residue dated, scraped from exterior } \\
\text { of collared rim of cordmarked vessel }\end{array}$ & B-307380 & NA & NA & $490 \pm 30$ & cal AD 1410-1450 \\
\hline $\begin{array}{c}\text { 41RB112 } \\
\text { Component A }\end{array}$ & $940-8-1 a$ & $\begin{array}{l}\text { N692 E511, 30- } \\
40 \mathrm{cmbs}\end{array}$ & unassigned & $\begin{array}{l}\text { Bulk sherd dated, Unassigned cordmarked } \\
\text { sherd from which organic residues were } \\
\text { scraped from exterior }\end{array}$ & B-307382 & $470 \pm 30$ & -19.1 & $570 \pm 30$ & cal AD 1300-1420 \\
\hline $\begin{array}{c}\text { 41RB112 } \\
\text { Component A }\end{array}$ & $940-8-1 b$ & $\begin{array}{l}\text { N692 E511, 30- } \\
40 \text { cmbs }\end{array}$ & unassigned & $\begin{array}{c}\text { Organic residue dated, scraped from exterior } \\
\text { of unassigned sherd }\end{array}$ & B-307383 & $370 \pm 30$ & -18.2 & $480 \pm 30$ & cal AD 1410-1450 \\
\hline $\begin{array}{c}\text { 41RB112 } \\
\text { Component A }\end{array}$ & 1021-8-1a & $\begin{array}{l}\text { N696 E514, 40- } \\
50 \mathrm{cmbs}\end{array}$ & M & $\begin{array}{l}\text { Organic residue dated, scraped from exterior } \\
\text { of Vessel M rim }\end{array}$ & B-307384 & $360 \pm 30$ & -18.9 & $460 \pm 30$ & cal AD 1420-1450 \\
\hline $\begin{array}{c}\text { 41RB112 } \\
\text { Component A }\end{array}$ & $1047-8-1 a$ & $\begin{array}{l}\text { N696 E514, 40- } \\
50 \mathrm{cmbs}\end{array}$ & M & $\begin{array}{l}\text { Bulk sherd dated, Rim sherd of Vessel M } \\
\text { from which organic residue was removed }\end{array}$ & B-307385 & $1110 \pm 30$ & -20.4 & $1190 \pm 30$ & cal AD 730-940 \\
\hline
\end{tabular}

cmbs = centimeters below surface; mm = millimeters; $\mathrm{g}=$ grams; UGAMS = University of Georgia AMS date; B = Beta Analytic; * = CALIB REV 6.0.0; ** Structure 1 was radiocarbon dated to $1040 \pm 40$ B.P. (Beta-212298, cal A.D. 910-1039) on charcoal from Feature 5 also within Structure 1 and $1130 \pm 40$ B.P. (Beta-223739; cal A.D. $790-1000$ ) on charcoal from Feature 6 inside Structure 1 (Cruse 2007:14) 


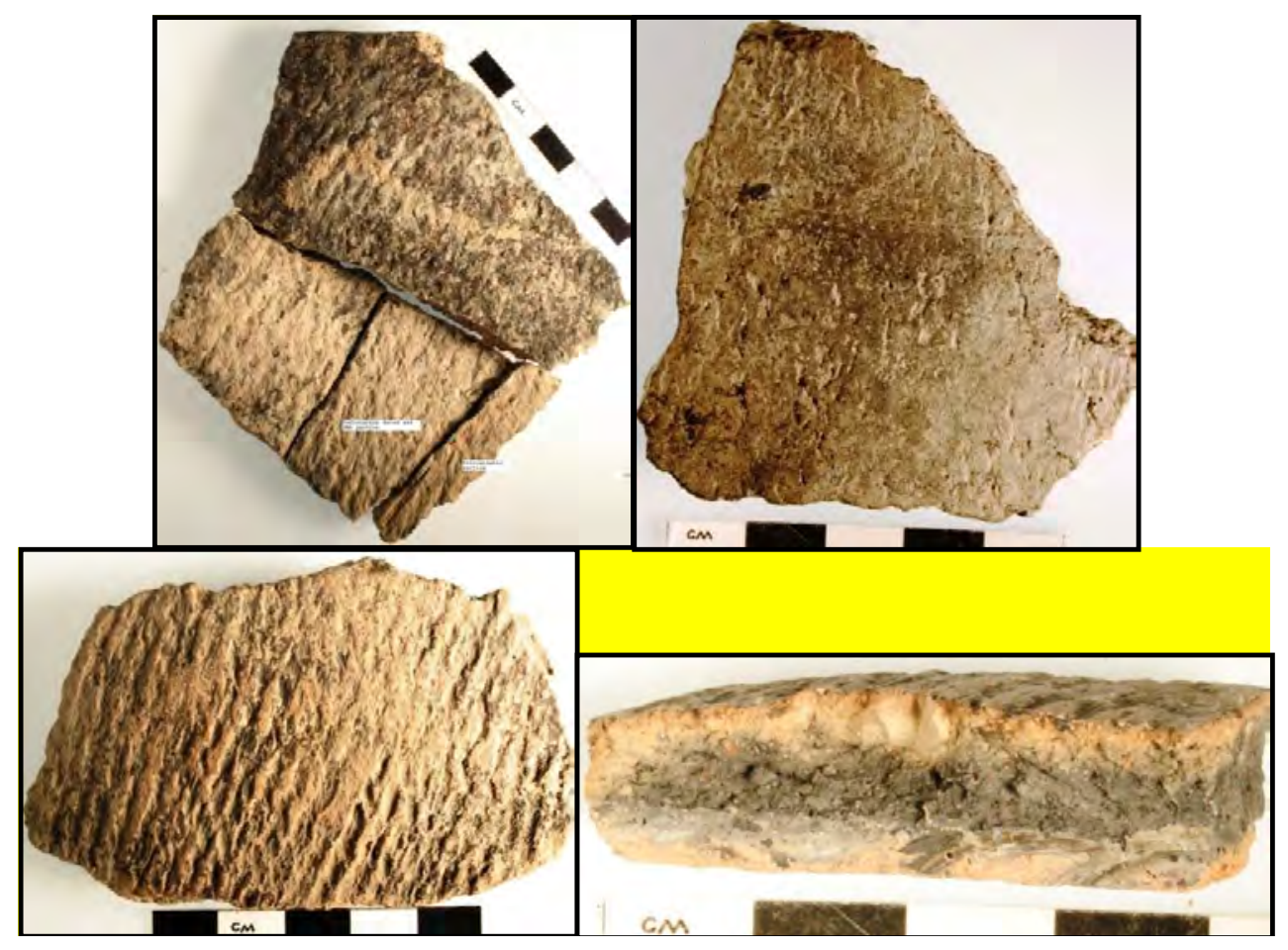

Figure 10-2. AMS radiocarbon dated sherds: 41RB112-349-8-1 Vessel 3; 41RB81-291 basal sherd unassigned; and 410C29-346-4 body sherd from pithouse A-3, exterior and profile.

secure contexts directly associated with the welldated Plains Village Component C between 530 and 700 B.P. (cal A.D. 1280 to 1437) as established by the 12 accepted radiocarbon dates.

Two thick-walled sherds from two other excavated sites in the region, Indian Springs (41RB81) in M-Cross Ranch (Cruse 2007) and a pithouse in Area A at Courson D (410C29) in Buried City (Brosowske 2005) were also targeted for AMS radiocarbon dating. The cultural/chronological affiliation(s) of these two sherds is not as well controlled or understood and may pertain to either Plains Woodland or Plains Village occupations. A radiocarbon date from Indian Springs on wood charcoal from Feature 6 inside Structure 1, a rectangular rock foundation thought to represent a Plains Woodland house (Cruse 2007:14) yielded a date of $1130 \pm 40$ B.P. (Beta-223739; Cruse 2007:14) or cal A.D. 780 to 992. The relatively thick cordmarked basal sherd selected (291/124.1) came from hand-excavated Unit 26, located within this Structure 1. Area A pithouse at Courson D was radiocarbon dated with two samples of maize from Feature A, an oval, rockless pithouse, to $700 \pm 40$ B.P. (cal A.D. 1229 to 1391; Beta-185071) and 660 \pm 40 B.P. (cal A.D. 1274 to 1397; Beta-185070; Brosowske 2005; Brosowske and Bevitt 2006). The selected cordmarked body sherd (346-4) from Feature A pithouse was apparently from the fill within this pithouse.

Three of the four AMS dates (75 percent) on the thick sherds are older than expected, whereas the fourth is extremely old (21,550 \pm 70 B.P., or cal A.D. 24,230 to 23,444; UGAMS-8457), and is clearly unacceptable (see Table 10-2). The clay used in Vessel 1 from Long View apparently contained exceedingly old organic residues. It is postulated that the thick-wall and/or a low firing temperature accounts for these old residues incompletely combusted during the firing process and subsequent use. The other three bulk sherd AMS dates range from $940 \pm 25$ to $1340 \pm 25$ B.P. (combined date 
range of cal A.D. 640 to 1156) and predate Plains Village occupations in the region. The Long View Vessel 3 sherd date of $940 \pm 25$ B.P. (cal A.D. 1029 to 1156; UGAMS-8456) is some 300 to 400 years older than the occupation date established from nine AMS dates on maize kernels though, organic residues within the thick-walls could account for this older date. The Indian Springs sherd date of $1120 \pm 25$ B.P. (cal A.D. 881-988; UGAMS-8459) is statistically identical to the wood charcoal dated from Feature 6 inside Structure 1 at that site. If this sherd date is accepted at face value, the two AMS dates support one another and indicates Structure 1 likely represents the Plains Woodland/Early Ceramic period. The Courson D sherd date of 1340 \pm 25 B.P. (cal A.D. 646 to 765; UGAMS-8458) from Area A pithouse is older by some 640 to 680 years compared to the two AMS dates on maize kernels from that same pithouse (Brosowske 2005). Three of the four AMS dates (75 percent) derived from sherds are definitely older, and one is far older than any of the acceptable associated dates on the same features/components. Consequently, it is not clear if the Indian Springs sherd actually reflects the true age of either the vessel or Structure 1, or yielded an older date as did the other three sherds.

In a further attempt to resolve questions concerning AMS dating of pottery sherds, three more sherds with dark, charred organic food residues adhering to their exterior surfaces were selected from Long View for further AMS dating. Crusted organic residues were scraped from each sherd exterior with a metal exacto knife and retained in a labeled plastic vial. Then the exterior of each sherd was further cleaned with a nylon toothbrush and distilled water to remove any remaining residues, which were not retained. The recovered organic residues and the same sherd from which the residue was scraped were submitted to Beta Analytic for AMS dating. Also, the charred residue from the exterior of a sherd (\#305-8-19) that represents Vessel 1 was removed in the same manner as the other three and also submitted for AMS dating. Table 10-2 provides the relevant sample data and results from AMS dating on the four paired exterior residues and bulk sherds. The following discussion considers the results on each of the four pairs.
The organic residue from the exterior of Vessel 1 yielded a conventional, uncalibrated date of $590 \pm$ 30 B.P. (cal A.D. 1317 to 1400 ), which is statistically identical to the 12 accepted AMS dates from 2 wood charcoal, 1 bison bone, and 9 maize kernels samples from Component C. The AMS date on the bulk sherd from Vessel 1 (21,550 B.P.) was much too old and unacceptable, and is clearly not comparable with the residue date.

For Component $\mathrm{A}$, the organic residue from the exterior of Vessel A yielded an uncalibrated AMS date of $490 \pm 30$ B.P. (cal A.D. 1420 to 1438), but the AMS date on the bulk sherd from which the residue was extracted yielded an uncalibrated date of $1960 \pm 30$ B.P. (cal 40 B.C. to A.D. 10). The two dates are not statistically the same.Only the date on the exterior residue is acceptable; it is, in fact, statistically identical to the nine accepted maize dates for this component.

The sherds representing Vessel $\mathrm{M}$ again reveal a similar discrepancy as the sherd from Vessel A. The exterior residue yielded an uncalibrated AMS date of $460 \pm 30$ B.P. (cal A.D. 1420 to 1450) compared to the bulk sherd date of $1190 \pm 30$ B.P. (cal A.D. 730 to 740). The latter is significantly older, by at least 700 years, than the former, but the exterior residue date is statistically identical to the various other documented ages for Component A.

An unassigned sherd (\#940-8-1) from Component A yielded an uncalibrated date of $570 \pm 30$ B.P. (cal A.D. 1300 to 1360 ) on the bulk sherd, whereas the exterior residue from that same sherd provided an uncalibrated date of $480 \pm 30$ B.P. (cal A.D. 1410 to 1450). The two AMS dates overlap at the two sigma range and also overlap with the nine maize dates from this component. In this instance, both AMS dates on the exterior residues and the bulk sherd are acceptable, insofar as they match well with the nine maize dates from the component.

In general, the four separate organic residues removed from the exteriors of four separate Vessels yielded acceptable AMS dates that are statistically similar to the AMS maize dates for the two components at the two sigma range. In contrast, the AMS dates derived from six of seven bulk sherds are all older, 
with one exception, than the accepted dates for each component. The one exception is from the Long View unassigned sherd (\#940-8-1) which yielded a statistically similar age. The bulk sherd date from the $410 \mathrm{OC} 29$ pithouse is some 600 to 700 years older than the two AMS dates on maize from that same pithouse (Brosowske 2005). The component age for Indian Springs, 41RB81, at M-Cross Ranch has not been clearly established, so some uncertainty exists concerning the dated sherd results. However, considering the AMS results from the four Long View sherds, it is apparent that bulk sherd dates are generally older than the actual associated cultural occupations. Organic residues adhering to the exterior of the sherds, thought to derive from actual foods cooked, yield dates that represent the time of the associated occupation. Although bulk sherds do provide AMS dates, these dates are less reliable, as they generally tend to be older than the associated occupations.

A possible explanation for the bulk sherds yielding dates that are too old lie in the internal contents of the sherds. In the case of the Long View Vessel 1 sherd (\#308-8-19) some of the original organic matter in the clay used in the construction of the vessel probably remained even after the firing and use of the vessel. The extremely negative $\delta^{13} \mathrm{C}$ ratio (-29.1\%) derived from AMS dating documents 100 percent $\mathrm{C}_{3}$ plant residues were dated. This indicates the original clay came from a wet $C_{3}$ environment with $C_{3}$ plant residues in the clays and the probable organics which were radiocarbon dated. Hedges et al. (1992) review a number of sources of the carbon in pottery and can be consulted for a more detailed discussion.

\subsubsection{Summary and Discussion of Age of Thick-Walled Vessels/Sherds}

Sherds from Vessels 1, 3, and 7 in Component C were found on the floor of the pithouse Feature 6, directly dated to between 530 and 700 B.P. (cal A.D. 1280 to1437) based on eight maize AMS dates (see Table 10-1), and adjacent to the "ghost pithouse", Feature 18. Exterior organic residues adhering to Vessel 1 were also AMS dated to $510 \pm 30$ B.P. (Beta307381) or cal A.D. 1300 to 1410 , documenting the use of this vessel during the Plains Village period. Component $\mathrm{C}$ is also directly associated with small Washita $(N=10)$, Harrell $(N=12)$, and Fresno $(N=$
4) arrow points, and lacks the Scallorn arrow points often associated with Plains Woodland occupations. Therefore, Vessels 1, 3 and 7 from Component $C$ are definitely assignable to a Plains Village occupation rather than a Woodland/Early Ceramic period event.

Thick-walled sherds have also been recovered from other apparent Plains Village sites. For example, the floor of the pithouse feature at Courson B is reported to have yielded "some kinds of pottery that indicate terminal Woodland or initial Neoindian in the region" (D. Hughes 2001:4). Some 58 thick-walled (average about $10 \mathrm{~mm}$ ) sherds were recovered from the Main Structure at the Antelope Creek phase Roy Smith site in the Oklahoma panhandle (Schneider 1969). The three thick-walled vessels from Component $\mathrm{C}$ are quite significant for understanding not only Plains Village ceramic assemblages in general, but their relationship with pithouses, possible functional variability, and also their distribution across the broader region. Our various technical analyses sampled these three vessels to determine their composition, address form and function, and better define their cultural affiliation. As a result of the research conducted here, it should be apparent that similarly thick-walled vessels deserve more indepth scrutiny and should no longer be automatically assumed to represent Plains Woodland/Early Ceramic occupations in this region.

\subsection{Question 2}

What role did Components $A$ and $C$ at the Long View site play in the settlement pattern of the broader Southern Plains Village community?

\section{J. Michael Quigg and Robert A. Ricklis}

The previous chapters (8.0 and 9.0) sections have described and documented the types and quantities of features, formal and informal tools, local and nonlocal raw materials, lithic debitage, ceramic materials, macrobotanical remains, and faunal remains. Tables 10-3 and 10-4 list the types and classes of artifacts recovered from Components A and $\mathrm{C}$ and assign them to generalized activities.

Faunal bones and macrobotanical remains from each of the two Long View components were examined for clues to seasonality. Seasonality can only be estimated, 
Table 10-3. Artifacts and Artifact Classes Recovered from Component A at Long View, Assigned to Preconceived Generalized Activities.

\begin{tabular}{|c|c|c|c|c|c|}
\hline $\begin{array}{c}\text { Artifacts, Classes and } \\
\text { Traits }\end{array}$ & $\begin{array}{c}\text { Horticulture } \\
\text { Activities }\end{array}$ & $\begin{array}{l}\text { Hunting } \\
\text { Activities }\end{array}$ & $\begin{array}{l}\text { Gathering } \\
\text { Activities }\end{array}$ & $\begin{array}{c}\text { General } \\
\text { Village } \\
\text { Activities }\end{array}$ & $\begin{array}{c}\text { Other } \\
\text { Activities }\end{array}$ \\
\hline Washita point & & $\mathrm{x}$ & & & \\
\hline Fresno point & & $\mathrm{x}$ & & & \\
\hline Harrell point & & $\mathrm{x}$ & & & \\
\hline Point fragments & & $\mathrm{x}$ & & & \\
\hline Bifaces & & $\mathrm{x}$ & & $\mathrm{x}$ & \\
\hline Scrapers & & $\mathrm{x}$ & & & \\
\hline Drills & & & & $\mathrm{x}$ & \\
\hline Edge-modified flakes & & $\mathrm{x}$ & & $\mathrm{x}$ & \\
\hline Manos & $\mathrm{x}$ & & $\mathrm{x}$ & $\mathrm{x}$ & \\
\hline Metates & $\mathrm{x}$ & & $\mathrm{x}$ & $\mathrm{x}$ & \\
\hline Abraders & & & & $\mathrm{x}$ & \\
\hline Hammerstones & & & & $\mathrm{x}$ & \\
\hline Choppers & & $\mathrm{x}$ & & $\mathrm{x}$ & \\
\hline Edge-ground cobble & $\mathrm{x}$ & & $\mathrm{x}$ & & \\
\hline Worked bison scapulas & $\mathrm{x}$ & & & $\mathrm{x}$ & \\
\hline \multicolumn{6}{|l|}{ Worked bison tibias } \\
\hline Notched bison ribs & & & & & $\mathrm{x}$ \\
\hline Bone awls & & & & $\mathrm{x}$ & \\
\hline Small Bone spatulas & & & & $\mathrm{x}$ & \\
\hline Lithic debitage & & & & $\mathrm{x}$ & \\
\hline Ceramic Vessels & & & & $\mathrm{x}$ & \\
\hline Spindle Whorls & & & & $\mathrm{x}$ & $?$ \\
\hline Clay Pipes & & & & & $\mathrm{x}$ \\
\hline Maize (corncobs) & $\mathrm{x}$ & & & & \\
\hline Charcoal samples & & & & $\mathrm{x}$ & \\
\hline Bison and deer bones & & $\mathrm{x}$ & & & \\
\hline Unidentifiable bones & & $\mathrm{x}$ & & & \\
\hline Turtle bones & & & $\mathrm{x}$ & & \\
\hline Fish bones & & & $\mathrm{x}$ & & \\
\hline Mussel shells & & & $\mathrm{x}$ & & \\
\hline Burned rocks & & & & $\mathrm{x}$ & \\
\hline Daub/burned clay & & & & $\mathrm{x}$ & $\mathrm{x}$ \\
\hline \multicolumn{6}{|l|}{\begin{tabular}{|l|} 
Features \\
\end{tabular}} \\
\hline Basin hearths & & & & $\mathrm{x}$ & \\
\hline Storage pits & $\mathrm{x}$ & & $\mathrm{x}$ & & \\
\hline Post holes & & & & $\mathrm{x}$ & \\
\hline Pithouse & & & & $\mathrm{x}$ & \\
\hline Discard/dumps & & & & $\mathrm{x}$ & \\
\hline
\end{tabular}


Table 10-4. Artifacts and Artifact Classes Recovered from Component C at Long View, Assigned to Preconceived Generalized Activities.

\begin{tabular}{|c|c|c|c|c|c|}
\hline $\begin{array}{c}\text { Artifacts, Classes and } \\
\text { Traits }\end{array}$ & $\begin{array}{c}\text { Horticulture } \\
\text { Activities }\end{array}$ & $\begin{array}{l}\text { Hunting } \\
\text { Activities }\end{array}$ & $\begin{array}{l}\text { Gathering } \\
\text { Activities }\end{array}$ & $\begin{array}{c}\text { General } \\
\text { Village } \\
\text { Activities }\end{array}$ & $\begin{array}{c}\text { Other } \\
\text { Activities }\end{array}$ \\
\hline Washita point & & $\mathrm{x}$ & & & \\
\hline Fresno point & & $\mathrm{x}$ & & & \\
\hline Harrell point & & $\mathrm{x}$ & & & \\
\hline Huffaker points & & $\mathrm{x}$ & & & \\
\hline Point fragments & & $\mathrm{x}$ & & & \\
\hline Bifaces & & $\mathrm{x}$ & & $\mathrm{x}$ & \\
\hline Scrapers & & $\mathrm{x}$ & & & \\
\hline Drills & & & & $\mathrm{x}$ & \\
\hline Edge-modified flakes & & $\mathrm{x}$ & & $\mathrm{x}$ & \\
\hline Manos & $\mathrm{x}$ & & $\mathrm{x}$ & $\mathrm{x}$ & \\
\hline Metates & $\mathrm{x}$ & & $\mathrm{x}$ & $\mathrm{x}$ & \\
\hline Edge-ground cobble & $\mathrm{x}$ & & $\mathrm{x}$ & & $\mathrm{x}$ \\
\hline Abraders & & & & $\mathrm{x}$ & \\
\hline Hammerstones & & & & $\mathrm{x}$ & \\
\hline Worked bison scapulas & $\mathrm{x}$ & & $\mathrm{x}$ & $\mathrm{x}$ & \\
\hline Worked bison tibias & $\mathrm{x}$ & & $\mathrm{x}$ & $\mathrm{x}$ & \\
\hline Notched bison ribs & & & & & $\mathrm{x}$ \\
\hline Bone awls & & & & $\mathrm{x}$ & \\
\hline Small Bone spatulas & & & & $\mathrm{x}$ & \\
\hline Lithic debitage & & & & $\mathrm{x}$ & \\
\hline Ceramic Vessels & & & & $\mathrm{x}$ & \\
\hline Maize (corncobs) & $\mathrm{x}$ & & & & \\
\hline Charcoal samples & & & & $\mathrm{x}$ & \\
\hline Bison and deer bones & & $\mathrm{x}$ & & & \\
\hline Unidentifiable bones & & $\mathrm{x}$ & & & \\
\hline Turtle bones & & & $\mathrm{x}$ & & \\
\hline Fish bones & & & $\mathrm{x}$ & & \\
\hline Mussel shells & & & $\mathrm{x}$ & & \\
\hline Burned rocks & & & & $\mathrm{x}$ & \\
\hline Daub/burned clay & & & & $\mathrm{x}$ & $\mathrm{x}$ \\
\hline \multicolumn{6}{|l|}{ Features } \\
\hline Basin hearths & & & & $\mathrm{x}$ & \\
\hline Storage pits & $\mathrm{x}$ & & & & \\
\hline Post holes & & & & $\mathrm{x}$ & \\
\hline Pithouse & & & & $\mathrm{x}$ & \\
\hline Discard/dumps & & & & $\mathrm{x}$ & \\
\hline
\end{tabular}


given the inherent range of variables involved. The greatest confidence in identifying seasonality derives from multiple lines of evidence with abundant data. Unfortunately, very limited seasonality data are present. Cultigens (maize, beans, and squash) reflect food procurement activities during the springsummer-fall growing and harvesting seasons, and wild plant products (little barley, mesquite beans, cheno-ams, possibly lily bulbs, and juniper seeds) would have been gathered during the spring, summer and early fall. The presence of storage facilities may imply the use of these subsistence resources during the subsequent winter season. The presence of fetal/ newborn bison remains provides a direct and likely reliable indicator of a particular season: midwinter to early spring (assuming the normal seasonal birthing cycle is represented). Therefore, many seasons appear represented by the different lines of data. Specific seasonality data for each component are discussed below.

\subsubsection{Role of Component A}

The pithouse Feature 1 in Component A yielded numerous post holes that indicate a wood-framed structure, but one that lacked an earthen cover and a hard packed or plastered floor, which implies a relatively short-term use. The time and effort involved in the construction of the pithouse (excavation of the pit, collection of wood for the framework and other organic materials for covering) indicates the occupants planned a residential occupation lasting for more than a few days or even weeks. However, lack of a packed floor also indicates that this residence was only in use for a relatively short duration. This house was unlikely to have been a more permanent, year-round domicile. The fact this pithouse lacked an earthen cover may also indicate it was not intended for use through the cold winter season, when a tightly sealed house, insulated by an earthen cover, would have been more suitable. The absence of internal storage pits may also reflect a nonwinter occupation of the structure. The location of a storage pit outside the pithouse hints at warm-season use, whereas the small size of the pit indicates relatively shortterm storage of limited quantities of goods, further implying a relatively short-term occupation.

The distribution of cultural features and artifact classes reveals good horizontal patterning that represents discrete activity areas. The general absence of a palimpsest effect, as created by overprinting or shifting of activity areas over a more extended period of occupation, indicates use of this structure for a relatively limited time, perhaps on the order of a few months. This occupation left behind relatively few artifacts and a clear horizontal patterning of artifacts and features, which may not indicate a permanent or continuous year-round occupation. A relatively extended period of occupation may have resulted in a more mixed and less clear patterning, and perhaps larger quantities of debris, than were actually present.

Artifacts and artifact classes from Component A were assigned to preconceived, generalized activity categories that reveal multiple food procurement and camp activities (see Table 10-3). Processing of horticultural products is probably represented by the manos, metates, and edge-ground cobbles. Worked bison scapulas may represent tilling of fields, although these same tools may have served in gathering wild plant foods, for example, in digging up edible roots and/or tubers. The macrobotanical remains directly reflect the presence of maize and squash, as do the microfossils of maize phytoliths, and the maize starch grains.

Hunting and animal processing activities are indicated by projectile points, bifacial knives, choppers, scrapers and edge-modified flakes used in butchering and hide processing. Direct evidence in the form of variety and quantities of animal bones documents the diverse range of game resources that was hunted and processed.

Gathering wild plants is generally reflected by the same stone grinding tools associated with processing horticultural plants. Direct evidence of wild plants is present as macrobotanical remains in the form of mesquite and cheno-ams seeds, as well as starch grains of little barley, mesquite, and possible tubers.

Generalized village activities are indicated by the pithouse habitation structure, and heating elements that likely served dual purpose functions for warmth and cooking. The presence of burned rocks and ceramic vessels also reflect cooking activities. A variety of tools such as abraders, hammerstones, 
edge-modified flakes, notched bison ribs, and bone awls represent a range of on-site tasks that included hide working, pithouse construction and maintenance, tool production and maintenance, and clothing production. High-power microscopic use-wear analysis conducted on 27 tools from this component documents the use of a variety of stone tools in the scraping and cutting of hard, high-silica plants (likely wood), boring tasks, and the scraping of hides.

This diverse data set represents multiple food procurement activities combined with generalized on-site activities in a multipurpose occupation rather than any type of special use area or specialized resource- procurement site. The combined evidence of a semipermanent village that exhibited reasonable horizontal patterning of artifacts and features, relatively few artifacts, a single small external storage pit, the presence of multiple food resources, the construction and use of a pithouse that lacked an earthen cover and packed floor, all indicate a mixed economy based on horticulture, hunting, and plant gathering during an occupation that likely lasted many months, but likely less than a full year.

The presence of multiple cultigens, especially maize leaves, indicates that fields with crops were nearby, so it is likely that Component A was occupied most of the time from spring planting, through summer tending the fields, and at fall harvest (Figure 10-3).
Little barley (Hordeum pusillum), a short winter $\mathrm{C}_{3}$ annual bunch grass that develops a brown seed after spring, is available in the early summer, and hints at an occupation at that time of year.

Component A probably served as a semipermanent village during multiple seasons, possibly from spring planting through fall harvest. The small family unit(s) that likely occupied this structure may not have done so full time and may have temporarily left the site to conduct other resource-procurement tasks. Males may have spent periods of time away to hunt large game. Females may have spent time away to gather wild plant resources and/or to collect clay to manufacture pottery, and then returned to the village to tend and protect crops and collect the harvest. It is unlikely the whole group would have left the fields unattended throughout the growing season, so some of the group may have been present at the village most of the time, but groups of people may have been absent from the village periodically. Therefore, the number of occupants present at any one time may have varied over the postulated 6 to 8 months the component was occupied. This generalized scenario is similar to Newcomb's (1961:257) suggestion for the Wichita, wherein he postulates that "The village was inhabited from spring until fall while the women were planting, tending and harvesting their crops. After the crops were harvested and stored in late fall or early winter, the Wichita abandoned their villages for a winter

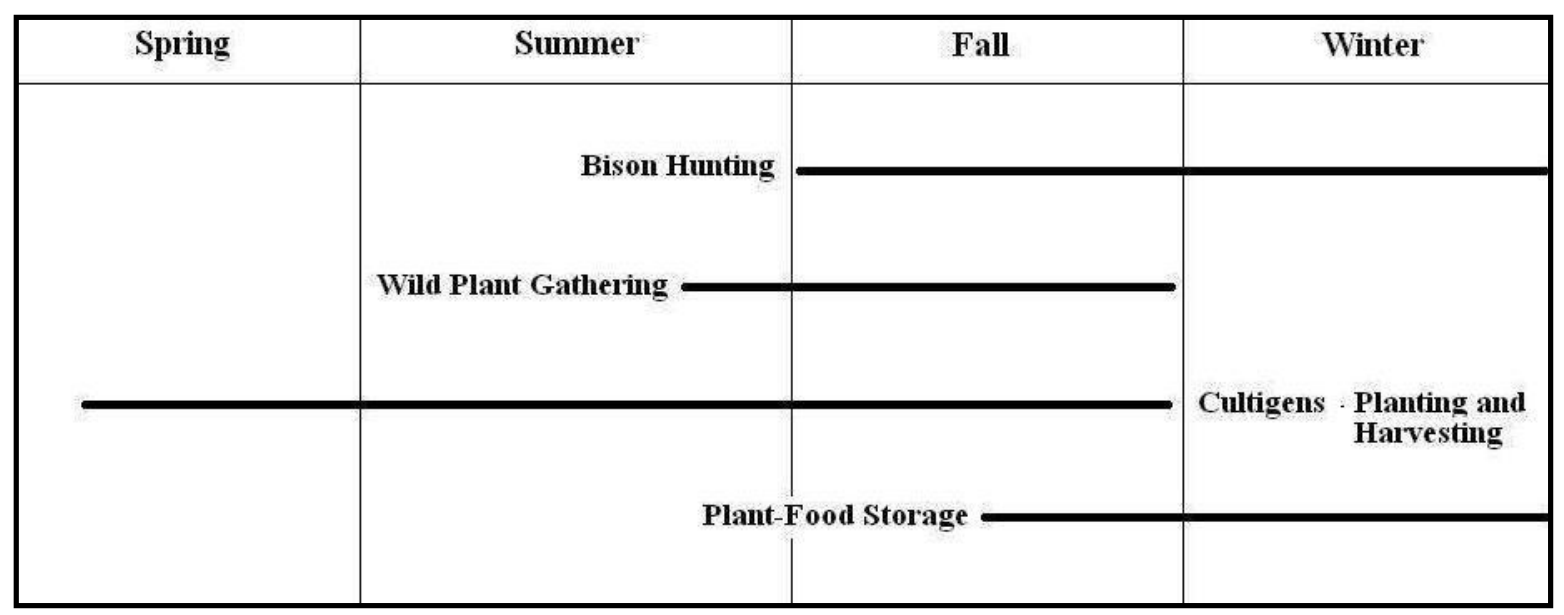

Figure 10-3. Seasonality of occupations at the Long View site, on the basis of different lines of evidence discussed in the text. 
buffalo hunt." Dunbar's (1918:602-613) first-hand account of the Chawi in A.D. 1843-1835 documents a winter hunt that lasted some 156 days (some 5.2 months) and used 33 encampments during that period. This winter hunt also included one winter camp occupied for 38 days, or 24 percent, of the time away from the village.

\subsubsection{Role of Component C}

The recovered artifacts and classes of artifacts from Component $\mathrm{C}$ were also assigned to categories of preconceived generalized activities (see Table 10-4). Based on this assignment, at least four major kinds of activities are reflected by this assemblage. As in Component $\mathrm{A}$, the activities included horticulture, hunting, gathering, and a general range of on-site village activities.

Horticulture is indirectly represented by a suite of tools such as manos, metates, edge-ground cobbles, bison scapula hoes and bison tibia tools. As noted earlier, however, these tools potentially served in other activities as well, such as the gathering and processing of wild plants. Direct evidence for horticulture is in the form of macrobotanical remains that include carbonized maize, beans, and squash, plus microfossil data in the forms of maize phytoliths and maize starch grains.

Hunting and processing of game animals is inferred through a suite of stone tools that include projectile points, bifaces, scrapers, and edge-modified tools. Successful hunting is directly reflected in the form of the many butchered animal bones that represent at least four species. The bones of turtles and fish plus the shells of mussels reflect gathering of nonmammalian meat resources.

Gathering and processing wild plants are possibly represented by the same ground stone tool assemblage that has most often been assumed to reflect horticultural activities. However, microfossil evidence in the form of starch grains of little barley, cheno-ams, mesquite seeds, and tubers testify that various wild plants were gathered and processed. Macrobotanical data that includes carbonized seeds of prickly pear, juniper, hackberries, mesquite, and cheno-am also directly documents the presence of these wild plants.
General on-site village activities are represented by various tools that include abraders, hammerstones, drills, bone awls, small bone spatulas, plus lithic debitage, pottery, burned rocks, heating elements, and burned rock discard features used to manufacture clothing, create and refurbish wooden handles, shafts, snares and traps, digging instruments, stone tools, and other items. Taken together, this broad cultural assemblage is evidence for a diverse range of resource exploitation and related activities that are more likely to represent a multiple seasons of residential occupation rather than short-term specialized activity at a resource-extraction locale. Most likely, these diverse activities occurred over a period of several months.

Component $\mathrm{C}$ also yielded Feature 6, a pithouse which had an earth-covered wooden superstructure over an approximately 60-cm-deep basin pit, the sides of which served as the lower portion of the structure walls. The decision to spend time and energy in construction of a pithouse with a substantial earthen cover implies the group intended to spend a relatively lengthy period at this site. However, the pithouse lacked a hard-packed or plastered floor, which might reflect relatively limited use rather than a year-round habitation structure. This earthcovered pithouse might have better served a winter occupation than would the brush-covered pithouse in Component A. In discussing the transition from pit structures to Pueblos in the American Southwest, Gilman (1987) cited ethnographic data to show that pit structures were used for biseasonal settlement in conjunction with simultaneous use of foodstorage facilities and that most pit structures are used as winter-only domiciles (Gilman 1987:541). She went on to state that subterranean structures were particularly useful as cold-season habitations because of their thermal efficiency resulting from the insulating effect of the surrounding earth, and she also noted that the distribution of pithouses in the Southwest correlates with areas with relatively cold winters (Gilman 1983). These structures were often used by groups of relatively small size who practiced agriculture on a limited scale.

Once abandoned, the still-intact pithouse in Component $\mathrm{C}$ served as a dumping ground for unwanted cultural debris, which implies continued 
extramural residence during favorable weather. The fact it was used as a refuse receptacle indicates that the group did not plan to reoccupy the pithouse. This abandonment without the intention of reoccupation also indicates the group's residential pattern entailed some degree of residential mobility, perhaps in a semisedentary settlement pattern in which sites such as Long View were abandoned after an occupation of much of the year. A possible scenario for the period of occupation would be from the spring planting season through the late fall and into winter.

Occupational debris associated with this pithouse yielded limited evidence of multi-seasonal occupation. A single fragmented fetal bison humerus is of sufficient size to indicate a late winter (i.e., February to March) time of death, assuming this animal represents a normal birthing cycle (see Figure 10-3). An unfused bison metacarpal is of a size that best reflects a summer death. Two lower bison molars reflect an animal(s) that died in the late summer or early fall. Cultivated products such as maize, beans, and squash are all present as are charred wild plant remains that consist of seeds of mesquite, cheno-am, prickly pear, hackberry nut, juniper, and microfossil remains of little barley, possible lily bulb, and several unidentified plants. The cultivated products are not specific indicators of a single season, since they were planted in spring, tended during the summer, and harvested in the fall, and possibly stored over the winter months. It is not clear if the maize was harvested while still green in the summer or when it was yellow in the fall; both are possibilities. Although the duration of pithouse occupation is open to question, the combined seasonality evidence in Component $\mathrm{C}$ indicates a multi-seasonal residence. Considering that the pithouse was likely a winter domicile, it appears that 9 to 12 -month semipermanent village is evident (see Figure 10-3).

The excellent horizontal patterning of features and artifacts with no overlapping features or midden deposits, plus the relatively low frequency of recovered artifacts and features, combined with the few recognized discard features, implies infrequent maintenance of living and activity areas, and might contradict the proposed nearly yearlong occupation. The amount of debris that would be generated during an occupation over a year is unknown. In a semipermanent village such as this, some occupants likely spent periods of time off-site to procure other resources such as clay for pottery, wild plants, and/or hunt big game animals. In such a scenario, the amount of cultural debris represented would be lower than one would expect for full-time residence by the population. Some of the group (possibly women and children) would likely occupy the village from spring planting through the summer until the fall harvest was complete. It is also possible this village was temporarily abandoned for short periods by groups or even the whole population after the fall harvest to hunt bison and obtain other resources for winter.

\subsubsection{Overall Settlement Pattern}

Both Long View components reflect small semipermanent village settlements with planned abandonment, as revealed by emptied external storage pits, the absence of evidence for caching of heavy ground stone metates, ceramic vessels, or other goods, and in the case at Component $\mathrm{C}$, the discarded trash in the pithouse Feature 6 before site abandonment.

On the basis of considerable artifact diversity, low artifact density, and projected multiple activities represented by different classes of cultural materials, combined with their well-defined horizontal distribution, Components $\mathrm{A}$ and $\mathrm{C}$ best reflect small semipermanent populations who occupied this site over multiple seasons, but likely not multiple years. It is also likely that various task groups left this village for short periods of time to engage in various off-site activities such as hunting and plant gathering.

In particular, features such as storage pits, post holes, pithouses, discrete dump areas, as well as the presence of clay daub, imply multi-seasonal occupation that required substantial shelters. These components involved diverse activities that included, but were not limited to: hunting of large game animals (bison and deer), butchering and processing hides, meat, and bones of such animals (i.e., bifaces, scrapers, small smashed bones), collection of wild plant foods (i.e., little barley, cheno-ams, mesquite beans) and small game resources (i.e., turtles and fish bones), processing of plant resources (i.e., parching, grinding with manos, metates), cooking (i.e., pottery and 
burned rocks) and maintenance of fires for cooking (i.e., basin hearths and ceramic vessels), storage of plant foods (i.e., storage pits and ceramic vessels), building of domiciliary structures, cleaning of activity areas (i.e., burned rock dumps, discard piles), and maintenance of domestic habitation loci (i.e., digging out). Although our horizontally restricted excavation area did not allow broad exposure, the two excavated areas appear to reflect use by small family units on this high ridge during at least two different periods of occupation, as represented by the remains in Components $\mathrm{A}$ and $\mathrm{C}$.

The recovered data from Long View provides some of the best evidence for seasonality currently available for a Plains Village site in this region. Unfortunately, the near-absence of detailed faunal and macrobotanical analyses from most previously excavated Plains Village sites in the region (i.e., Antelope Creek phase sites, the Buried City complex, and Odessa Yates) makes establishing seasonality for most village sites in the region impossible. Not even the more thoroughly excavated and reported sites attributed to the semisedentary people of the Palo Duro complex, with its nearly dozen sites that include residential bases, rock shelters and various camps, provide reliable evidence of seasonality (Boyd 1995, 1997, 2004).

More extensive Plains village sites with pithouses are known (but unpublished) in the immediate area (e.g., Chill Hill [41RB132] roughly $2 \mathrm{~km}$ south of Long View) and may reflect extended periods of occupation, perhaps within major villages occupied by coalescent groups. Currently, it is not known if large sites like Chill Hill were occupied by larger populations or for longer periods of time, or if that locality was re-occupied by many small groups over multiple years to accumulate the quantities of debris present. Only a narrow slice through the Long View site was excavated, so it is not clear if our excavated data represent small residential loci, a field house or a fraction of a much larger settlement, as is apparent at Chill Hill.

The difficulty in addressing how the Long View site components fit into the larger settlement pattern currently lies in the lack of information for the specific phase or complex to which these two occupations pertain. A single site does not allow a pattern of settlement to be discerned. With limited published data concerning phases/complexes with pithouses across the Texas and Oklahoma panhandles, it is currently unrealistic to assign these two components to one of the poorly understood cultural manifestations across the area. The contextual placement the Long View components will have to await additional publication of comprehensive data from other sites, such as those at Buried City, the Odessa Yates site, the multiple sites at M-Cross Ranch, and others. Additionally, the question of overall seasonality in settlement patterns can only be addressed if and when clear seasonal data becomes available from a larger range of sites in the area.

In a general review of pithouse use, function, and mobility, Gilman (1997) found that a critical variable in the use of pithouse structures was a nontropical environment and the presence of large amounts of storable food. Diehl (1992) and Diehl and Gilman (1994), in assessing mobility and pithouse use, found that earthen construction was associated with moderate residential mobility. Researchers using both archeological and ethnographic data have suggested that groups living in pithouses did not inhabit them year-round (Mauldin 1983; Gilman 1987). The broader data concerning pithouse and mobility support the findings at Long View that the pithouses were used by populations who practiced some degree of residential mobility. Ethnographic records from the Southwest indicate that pithouse use was most likely during cold months (Gilman 1997:7), and worldwide they were not used during the hottest months (Gilman 1987). The findings from the two Long View components are in accord with these generalizations.

\subsection{Question 3}

Is there evidence at Components $A$ and $C$ to suggest length of occupation for represented settlements, and where does this fit into a continuum of residential mobility and sedentism?

\section{J. Michael Quigg and Paul M. Matchen}

Question 3 is concerned with the role of the two Long View components, and is related to Question 2 (discussed above), wherein the different datasets, 
seasonality, and other aspects of the roles of each component were addressed. This question focuses on the length of occupation per component. Determination of the duration of occupation, when possible, leads to a greater understanding of how a site fits into a larger mobility/sedentism continuum and hypothetical spectrum of residential patterning (ranging from relatively high mobility to full sedentism), and ultimately the overall settlement and land-use strategy utilized by Plains Village groups.

The two Long View components are similar to many of Antelope Creek phase semipermanent settlements that exhibit one or a few stone slab, semisubterranean structures combined with limited quantities of cultural materials described by Lintz (1984, 1986; Brooks 2004). These smaller settlements with limited cultural debris contrast larger, more complex multi-room settlements, likely reflecting permanent occupation. These larger sites include Antelope Creek phase village sites such as Antelope Creek Ruin 22 and 24, Alibates Ruin 28, Stamper and others (Lintz 1986; Brooks 2004), possibly some Buried City complex sites (D. Hughes and Hughes-Jones 1987, 1991), and the Odessa Yates site (Brosowske 2005). Unfortunately, the reports for these larger sites lack details such as counts of materials classes or density per area excavated.

As excavations at Long View had been restricted to a narrow $10-\mathrm{m}$-wide zone, it is possible that defining attributes of a larger occupation with multiple structures were not encountered. Several factors at Components A and C, including feature location and geophysical data, indicate these occupations potentially extended further west. The narrow limits on the investigations constrained understanding of spatial extents of habitation for Components A and $\mathrm{C}$, and precluded potential discovery of elements such as additional house structures, features, and/or activity areas that may exist beyond the limitations of the scope of work.

Direct evidence for approximating length of occupation is limited at best, and subject to debate. Supporting evidence contributing to interpretation of occupation duration includes quantity, density and horizontal distribution of artifacts and features, presence and diversity of early-to-late-stage raw material reduction, construction and use of habitation structures, food processing (milling activities, faunal exploitation, etc.), and horticultural pursuits.

The diversity and density of cultural materials and features are documented for Components A and C in Table 10-5, while a gross projection of food procurement tasks was represented in Tables 10-3 and 10-4 in the previous section. Both components reflect great diversity in food procurement, lithic tools and ceramic assemblages, as well as a limited range of feature types and function, and a primary habitation structure. The many unknowns include: length of time required to construct a pithouse, use period of associated features, and actual quantities of cultural debris that would have been generated over any given period of time. Without determination of these temporal factors, it is difficult to accurately delineate the length of a specific occupation. It is proposed that these two components were occupied for multiple seasons, but the exact length of time is not clear. The various indicators of seasonality discussed under Question 2 are solid evidence, but exceptions and variation in presence or absence of many of these can and do occur. Therefore, the answer to the first part of the question is there is only circumstantial evidence for occupation duration and is subject to interpretation. The lack of definitive data would therefore preclude a concrete determination of specific length of occupation.

If occupations lasted between six and nine months, then these two components may represent semipermanent villages used by groups in cyclic residential relocations of variable lengths of time. Each Long View component is indicative of a village near the center of the hypothetical residential mobility patterning spectrum, reflective of a settlement used for multiple seasons, but neither permanent nor multi-year.

\subsubsection{Residential Mobility and INAA}

Portions of 21 vessels from the 2 ceramic assemblages and 2 experimentally tempered local clays from Long View were submitted for instrumental neutron activation analysis (INAA). Results provide indirect support of multi-locality settlement patterns by occupants of Long View. The INAA results indicate clay used for production of pottery came from more 
Table 10-5. Summary of Artifacts and Classes of Artifacts from Components A and C.

\begin{tabular}{|c|c|c|c|}
\hline Artifact/Class & Component A & Component C & Totals \\
\hline Radiocarbon Age & $\begin{array}{c}460 \text { - } 535 \text { B.P. Cal } \\
\text { A.D. } 1398 \text { - } 1447\end{array}$ & $\begin{array}{l}530 \text { - } 700 \text { B.P. Cal } \\
\text { A.D. } 1280 \text { - } 1437\end{array}$ & \\
\hline Washita points & 7 & 10 & 17 \\
\hline Fresno points & 11 & 12 & 23 \\
\hline Harrell points & 1 & 4 & 5 \\
\hline Huffaker points & - & 7 & 7 \\
\hline Point fragments & 6 & 7 & 13 \\
\hline Bifaces & 17 & 8 & 25 \\
\hline Scrapers & 21 & 5 & 26 \\
\hline Drills & 4 & 5 & 9 \\
\hline Edge-modified flakes & 136 & 81 & 217 \\
\hline Manos & 1 & 6 & 7 \\
\hline Metates & 3 & 10 & 13 \\
\hline Abraders & 1 & 3 & 4 \\
\hline Hammerstones & 2 & 4 & 6 \\
\hline Unifaces & 7 & 3 & 10 \\
\hline Chopper & 1 & - & 1 \\
\hline Edge-ground cobble & 2 & - & 2 \\
\hline Bone tools & 10 & 15 & 25 \\
\hline Exotic sherds & 11 & - & 11 \\
\hline Cordmarked sherds & 1,249 & 262 & 1,511 \\
\hline Plain sherds & 3 & - & 3 \\
\hline Number of Vessels & 14 & 7 & 21 \\
\hline Spindle Whorls & 12 & - & 12 \\
\hline Clay Pipes & 4 & - & 4 \\
\hline Lithic Debitage, Total & 2,501 & 862 & 3,363 \\
\hline Alibates/chert & 1,663 & 771 & 2434 \\
\hline Opalite & 524 & - & 524 \\
\hline Ogallala quartzite & 136 & 35 & 171 \\
\hline Tecovas jasper & 32 & 3 & 35 \\
\hline
\end{tabular}

\begin{tabular}{|c|c|c|c|}
\hline Artifact/Class & Component A & Component C & Totals \\
\hline Radiocarbon Age & $\begin{array}{c}460 \text { - } 535 \text { B.P. Cal } \\
\text { A.D. } 1398 \text { - } 1447\end{array}$ & $\begin{array}{c}530 \text { - } 700 \text { B.P. Cal } \\
\text { A.D. } 1280 \text { - } 1437\end{array}$ & \\
\hline Other & 47 & 24 & 71 \\
\hline Nonlocal - Niobrara & 24 & 16 & 40 \\
\hline Nonlocal - Obsidian & 53 & - & 53 \\
\hline Maize (corn cobs) & 7 & 15 & 22 \\
\hline Charcoal samples & 37 & 63 & 100 \\
\hline Bison bones & 52 & 89 & 141 \\
\hline Deer/antelope bones & 19 & 5 & 24 \\
\hline Turtle bones & 34 & 50 & 84 \\
\hline Rabbit bones & 4 & 25 & 29 \\
\hline Unidentifiable bones & 3,794 & 932 & 4,726 \\
\hline Burned rocks & 356 & 1,434 & 1790 \\
\hline Daub/burned clay & 368 & 175 & 543 \\
\hline Shell beads & 1 partial & 1 patial & 2 partial \\
\hline Totals per component & 11174 & 4948 & 16122 \\
\hline Feature Totals & 11 & 14 & 25 \\
\hline Basin hearths & 5 & 4 & 9 \\
\hline Rock alignment & - & 1, not associated & 1 \\
\hline Cairn burial & - & 1 , not associated & 1 adult female \\
\hline Human cremation & - & 1, not associated & $\begin{array}{c}1 \text { adult, } \\
\text { unknown sex }\end{array}$ \\
\hline Storage pit & 1 & 1 & 2 \\
\hline Post holes & 17 & 3 & 20 \\
\hline Pithouse & 1 partial & $1+1$ possible & 3 \\
\hline Discard/dumps & 4 & 4 & 8 \\
\hline Hand-excavated area $\mathbf{m}^{2}$ & 128 & 93 & 221 \\
\hline Artifact density per $\mathbf{m}^{2}$ & 68 & 44.2 & 58 \\
\hline
\end{tabular}


than one source area and neither Component A nor C occupants manufactured their pottery at Long View or at least used the samples of clay we selected for analysis. This implies that pottery was made at a previous site or sites. It is suggested that multiple clay source areas indicated by INAA were encountered and collected during movements by the Long View occupants across the regional landscape. Pottery would likely have been produced during times of warm, dry weather to facilitate successful drying, as opposed to cold, freezing, or rainy weather.

INAA indicates a minimum of two separate clay sources for Component $\mathrm{A}$. If Component $\mathrm{A}$ reflects multiple seasons that ended in the late fall as proposed, multiple sites prior to Component A were likely occupied where clay sources were likely procured and pottery produced under optimal conditions. This implies that the pottery in question was likely made months before the occupants arrived at this location.

INAA results from parts of seven vessels and comparative samples of clay from Component $\mathrm{C}$ also indicate nonlocal production of those vessels from minimally three separate source areas. This indirectly implies this population collected clays from three different sources to manufacture their pottery. The interpretation of the seasons of occupation for Component $\mathrm{C}$ was over several seasons that included occupation during cold weather months.

\subsubsection{Chipped Stone Tool Assemblage Formation at the Long View Site}

Magne (1989) indicates that differences in technological strategies can be identified by examining the debitage-to-tool ratios and proportional frequency of late-stage debitage (Figure 10-4). According to Magne's assemblage formation model, sites with assemblages that exhibit a high debitage-to-tool ratio and a low percentage of latestage debitage can be viewed as having relatively limited completion of tools on site, and perhaps blanks/unfinished pieces were transported elsewhere for finishing. Sites exhibiting a low debitage-to-tool ratio and low late-stage debitage percentage are thought have a high discard rate of manufactured tools and/or blanks, perhaps due to expedient tool manufacturing. Sites with high debitage-to-tool ratios and high late-stage debitage percentage likely represent a highly conservative tool maintenance strategy that involved low degrees of discard. Sites with low debitage-to-tool ratios and high percentage of late-stage debitage also follow a tool maintenance strategy, but with a high tool discard pattern. Other scenarios that take into account situational tool repair activities and site reoccupation are also delineated in smaller niches of the model.

Debitage-to-tool ratios and proportional relationship to late-stage debitage were examined to further understand the activities within Components A and C. In this context, "late-stage debitage" means pieces without dorsal cortex.

\subsubsection{Stone Tool Manufacture and Use in Component A}

The chipped stone tools $(N=205)$ described for Component A in Chapter 8.0 are separable into six classes: projectile points, bifaces, scrapers, drills, edge-modified flakes, and choppers (Figure 10$5)$. Tools account for only 7.4 percent of the entire chipped stone assemblage $(N=2,818)$ with formal tools only accounting for 30 percent of the tools. Component A raw material replacement rates by artifact class can be examined by comparing the frequency of tools and tool fragments to the relative amounts of flakes (platform-bearing debitage). It is possible to gauge material discard and replacement in the occupational episode that is represented for each raw material type (Magne 1989:22).

Figure 10-6 shows debitage-to-tool comparisons (complete and fragmented specimens), by raw material type. It is evident that Alibates was the predominant raw material used at this location. The significant reliance on Alibates could have reflected preferential use at this location or local abundance of secondary source stream cobbles and gravels. However, as discussed in Research Question 10 (see below), low incidences of cortex on Alibates debris from Component $\mathrm{A}$, combined with the fact that no cortex represents water-worn cobbles/ gravels, indicates the majority of Alibates present either originated from the primary quarry location, or initial reduction from stream cobbles off-site before transport to Component A. Another aspect of Component A evident in Figure 10-6 is an extremely 


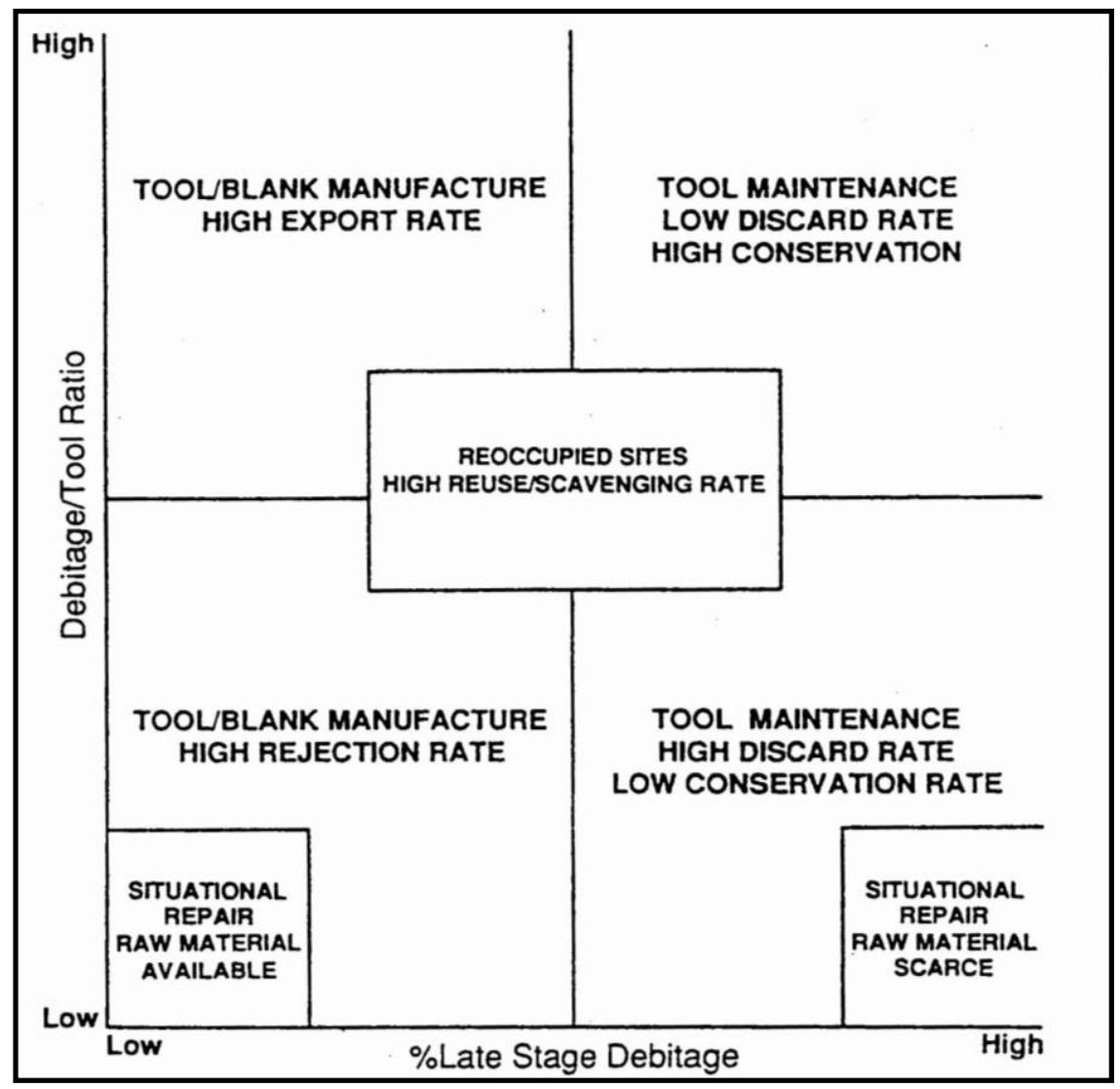

Figure 10-4. Magne's assemblage formation model (1989).

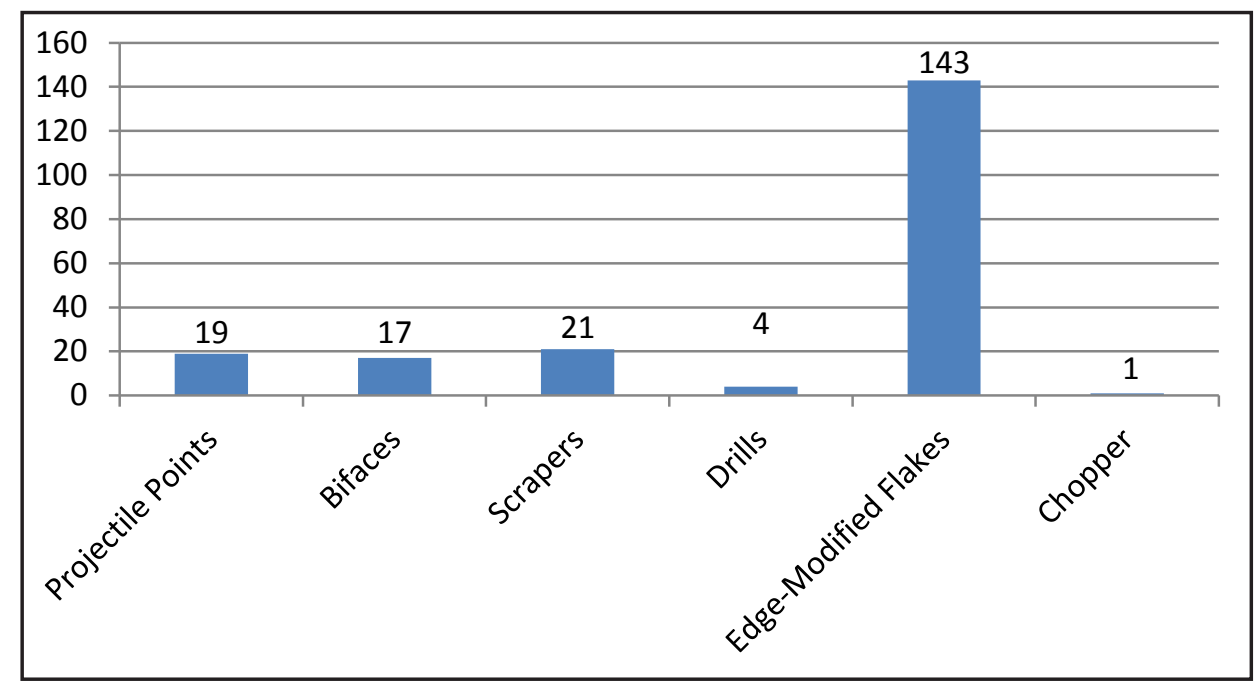

Figure 10-5. Component A stone tool frequency. 


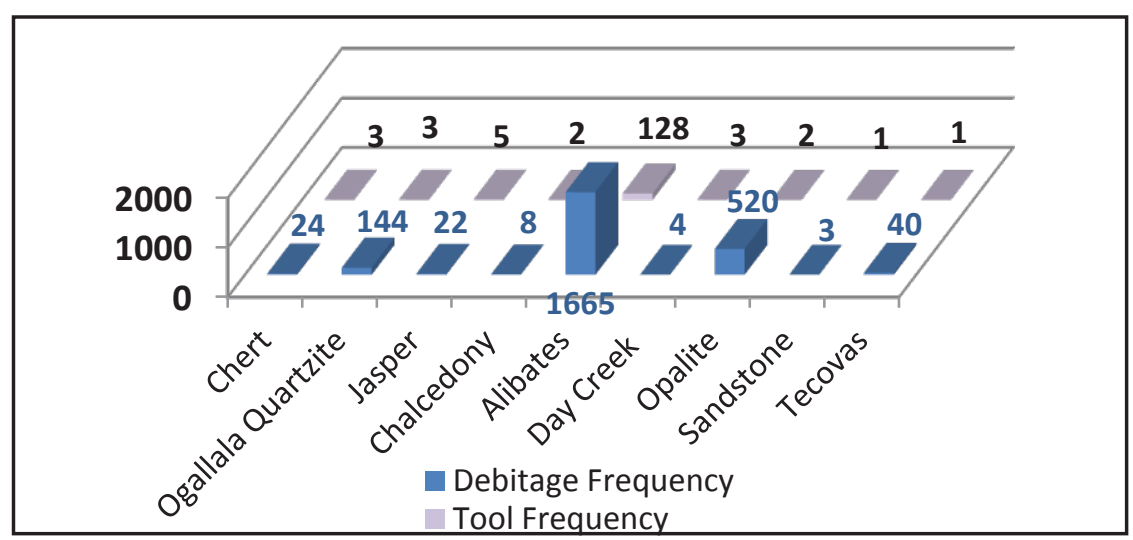

Figure 10-6. Component A raw material use.

low number of tools of non-Alibates materials. The ratio of debitage-to-tools is low (average 12:1), too low, in fact, to denote emphasis on formal tool production. This proportion likely reflects a focus on expedient tool production (flake tools) and formal tool resharpening and/or maintenance, which comprises 70 percent of the chipped stone tool inventory at this location.

\subsubsection{Stone Tool Manufacture and Use in Component C}

Stone tools $(N=138)$ recovered from Component C and discussed in Chapter 9.0 are separable into five general classes: projectile points, bifaces, scrapers, drills, and edge-modified flakes (Figure 10-7). These tools account for only 16 percent of the entire chipped stone assemblage $(N=862)$. Formal tools $(N=54)$ account for only 39 percent of all tools.

Raw material replacement rates by artifact class frequency were examined for Component C. Figure 10-8 shows the debitage-to-tool comparisons (both complete and fragmented), using raw material as a common factor. Not surprisingly, Alibates was again the predominant material used. Interestingly, local raw materials, such as Tecovas jasper and nonspecific chert, exhibit higher numbers of tools than associated debitage. The overall ratio of debitage-to-tools is extremely low, on average, 4:1. The low frequency indicates that a limited emphasis was placed on formal tool production at Component
C. This likely reflects a focus on expedient flaketool production to meet immediate needs. The informal tool assemblage comprises 61 percent of the chipped stone tool inventory of Component C.

\subsubsection{Regional Comparisons}

When these data are compared against otherprehistoric components from sites in western Oklahoma and the Oklahoma panhandle (Table 10-6), a general trend of low debitage-to-tool ratios is apparent. At sites such as Cottonwood Creek Ruins (41HC141), a Plains Village site in the Antelope Creek phase core area (Lintz 1997), it is evident that lithic reduction activities via tool production occurred at higher rates. This increase in debitage frequency could stem from longer site occupations, more individuals participating in material reduction, or close proximity to the Alibates quarry. In general, components with low debitage-to-tool ratios are locations where very little formal tool production occurred. The production of flakes at these components was likely the result of expedient tool production.

It is necessary to compare the data from Long View to other Late Prehistoric Plains Village assemblages to derive meaning from these values. For clarity, the comparison is limited to three other assemblages: Tucker Blowout (34TX71), a Late Prehistoric bison processing camp in Texas County, Oklahoma (Matchen 2002a, 2002b); the Two Sisters site (34TX32), a Late Prehistoric Plains Village site in Texas County, Oklahoma (Duncan 2002); and the 


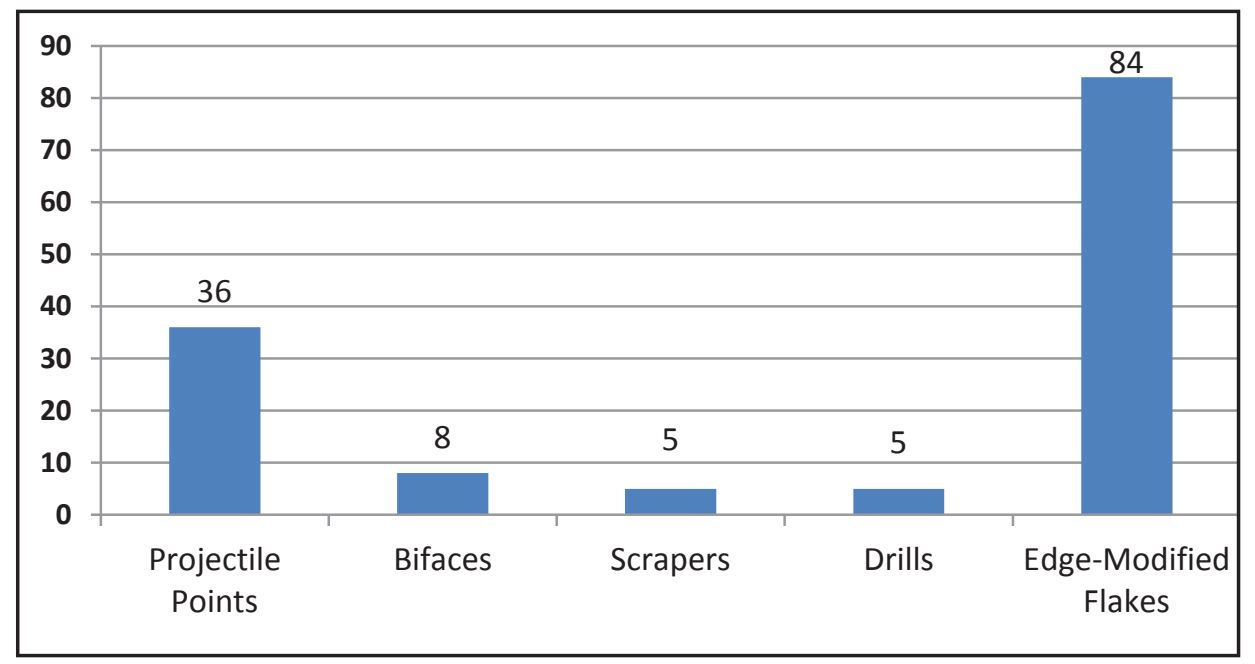

Figure 10-7. Component C stone tool frequency.

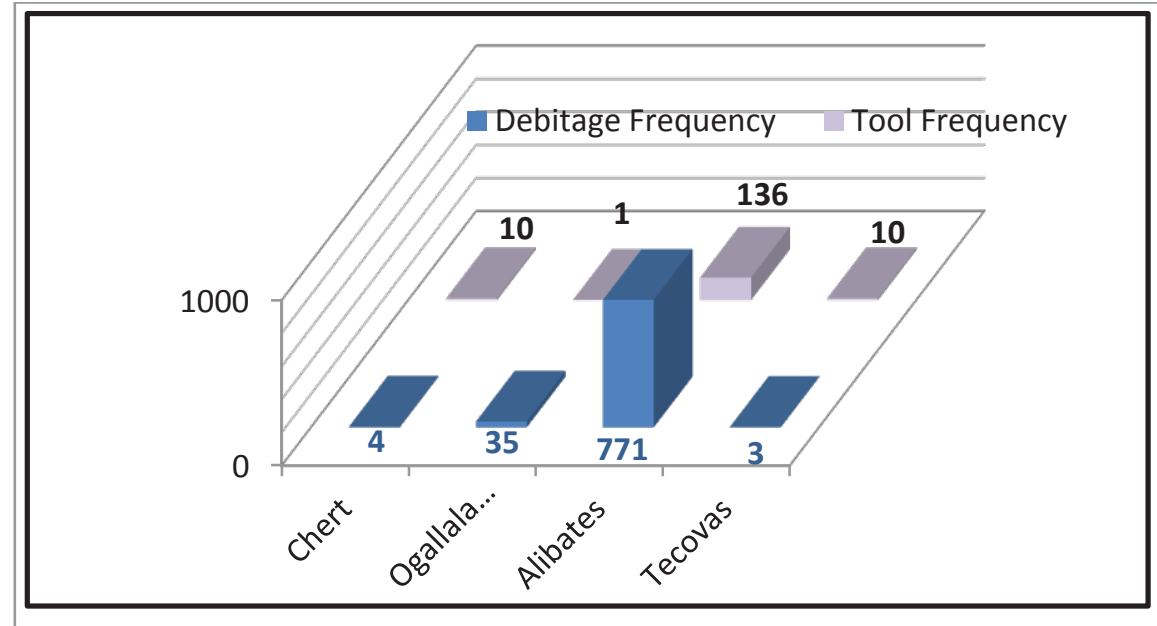

Figure 10-8. Component $\mathrm{C}$ raw material use. 
Table 10-6. Debitage-to-Tool Ratios from Selected Late Prehistoric Sites.

\begin{tabular}{|c|c|c|}
\hline Site Trinomial & Debitage-to-tool Ratio & Reference Citation \\
\hline 34TX71 Tucker Blowout & $1: 01$ & Matchen 2002a, 2002b \\
\hline 14MD306 Lundeen & $2: 01$ & Bevitt 1999 \\
\hline 34TX32 Two Sisters & $3: 01$ & Duncan 2002, 2006 \\
\hline 41RB112 Component C & $4: 01$ & This document \\
\hline 34BV14 Roy Smith & $6: 01$ & Schneider 1969 \\
\hline 41RB112 Component A & $7: 01$ & This document \\
\hline $\begin{array}{c}\text { 41HC141 Cottonwood } \\
\text { Creek Ruins }\end{array}$ & $12: 01$ & Lintz 1997 \\
\hline
\end{tabular}

Lundeen site (14MD306) a Late Prehistoric Plains Village in Meade County, Kansas (Bevitt 1999).

Other site assemblages were sought for this comparison, but inconsistencies in data presentation such as omission of presence attributes, late-stage debris, and/or the proportions of complete and fragmented flakes precluded use here. Figure 10-9 plots the relationship between platform-bearing flake debitage-to-tool ratios and percentage of latestage debitage (platform-bearing flakes for these sites. All exhibit low debitage-to-tool ratios and high late-stage debitage percentages, placing them in the tool maintenance and high discard quadrant of Magne's model (see Figure 10-4). Component C shows a marked similarity with the Late Prehistoric component at Two Sisters (Duncan 2002, 2006). The Lundeen site exhibits the highest percentage of late-stage debitage and one of the lowest debitageto-tool ratios. It can be considered with Two Sisters and Component $\mathrm{C}$ assemblages as examples of situational repair and raw material scarcity.

Component A, in contrast, exhibits a somewhat higher debitage-to-tool ratio (7:1) and a somewhat lower percentage of late-stage debitage than Component C. The higher diversity of raw materials represented, including opalite and obsidian, may account for this difference in ratio. Without a larger sample of sites with which to compare, it is difficult to identify the significance of this debitage increase in terms of the formation model. However, it can be assumed that a higher ratio in Component $\mathrm{A}$ represents a higher incidence of material reduction at that location. The debitage-to-tool ratio of the Tucker Blowout assemblage is the lowest at a ratio of $1: 1$, with a relatively high late-stage debitage assemblage. This ratio denotes formal tool off-site manufacture and on-site maintenance, along with minimal expedient tool production using local materials (Matchen 2002a, 2002b).

\subsubsection{Discussion of Occupation Span at Long View}

In addressing the question of occupation span with the data presented above, it quickly becomes clear that a complex relationship between resource use and site use exists. Any interpretation of occupation length must take into account all evidence present. As discussed, indirect evidence can be gathered from patterns of features and artifacts through inquiry lines such as: presence or absence, type and function, frequency, density, and proportional and spatial relationships.

Low debitage-to-tool ratios, coupled with high percentages of late-stage debris, are exhibited at both Long View components. According to Magne (1989), this would indicate short occupation spans, specifically ones characterized by the influx of prefashioned tools and/or blanks, with occupations long enough to require flake production for expedient tool use and tool maintenance before proportionately high numbers of tools were discarded. In these instances, however, the low debitage-to-tool ratios 


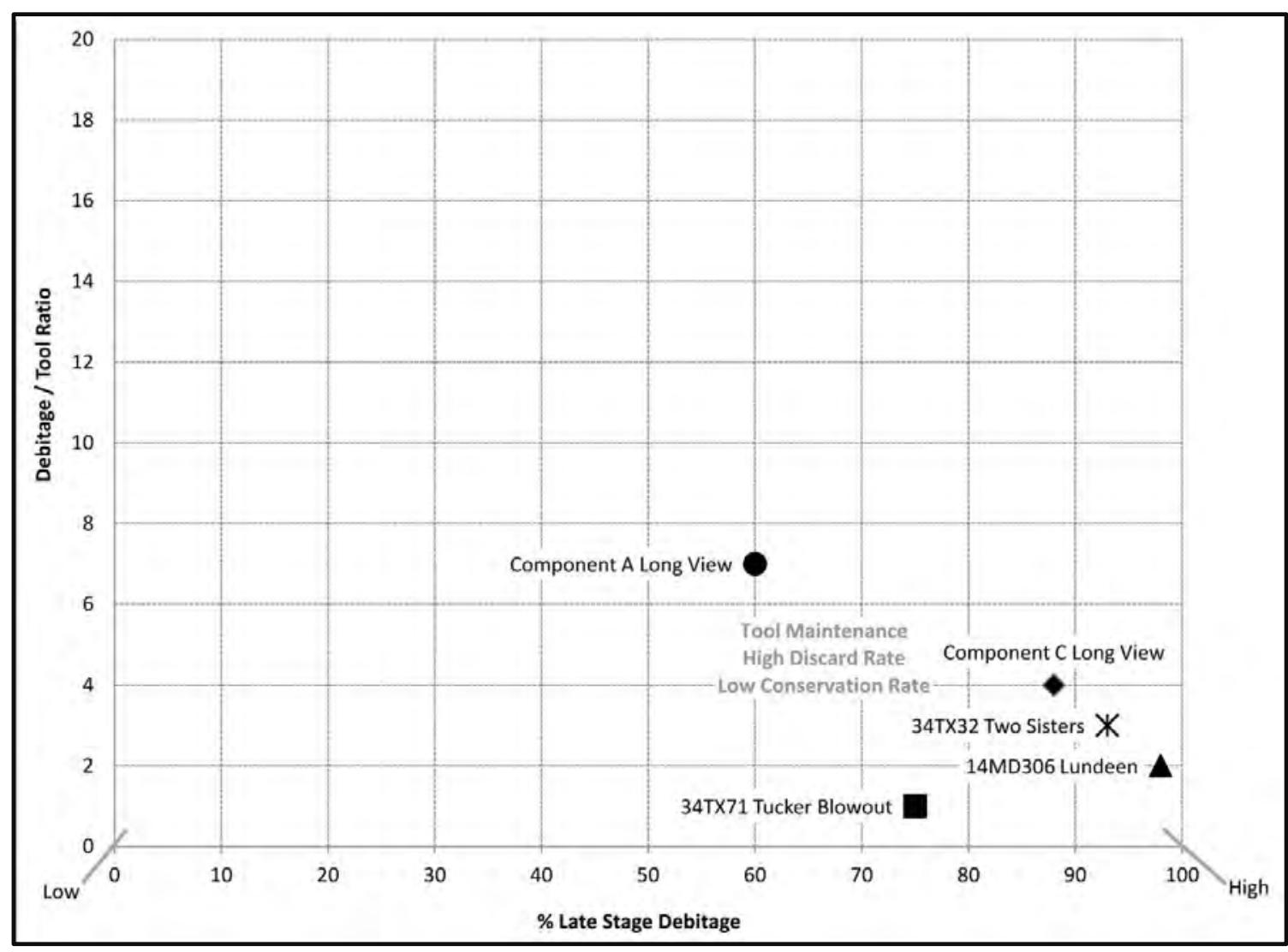

Figure 10-9. Index of tool technology strategy at multiple sites with late prehistoric components.

exhibited do not denote short occupation spans by inhabitants at 41RB112, in contrast to previous studies with similar results (Quigg at al. 2010). Overall, lithic tool assemblages at Long View show little evidence of formal tool and/or blank production, but rather a focus on formal tool maintenance and informal tool production. One explanation for the structure of the lithic assemblage may lie in the nature of Alibates resources, discussed in Question 10. Tool and cobble assessments indicate Alibates material was obtained from quarry sources $80.5 \mathrm{~km}$ from Long View. If so, much of the initial material reduction and/or blank production would likely have occurred off-site, at locations at or near the quarry to facilitate transport. Consequently, earlystage reduction activities on-site focused primarily on locally available materials, such as Ogallala quartzite, assorted jaspers, and chert.
Archeological evidence at Components A and C, including expedient tool production, pottery, and structures, in conjunction with procurement and processing of a variety of resources, supports an interpretation of a relatively sedentary residence pattern. In addition, evidence of horticultural pursuits, combined with the seasonality evidence of bison remains, implies that both occupations spanned multiple seasons.

\subsection{Question 4}

Were the two occurrences of human remains directly associated with the recognized pithouse occupation at the southern end of the Long View site?

\section{J. Michael Quigg}

TRC proposed to directly radiocarbon date the human bones represented by each of the two Long 
View site burials (Features 7 and 22 in Component $\mathrm{C})$, to determine if they were contemporaneous with the Plains Village assemblage from Component C. However, TxDOT informed TRC that consistent with NAGPRA and the expressed wishes of consulting tribes that radiocarbon dating and other destructive analysis of the human bones or materials directly associated with the bodies was not permissible. Thus, radiocarbon dating, as well as planned stable carbon and nitrogen isotope analyses to address dietary patterns, were not undertaken. Therefore, no pertinent data from the burials are available to determine if they were contemporaneous with each other or with the main Plains Village Component C. Therefore, we can only address this question without the aid of absolute dates, which makes the final interpretation open to question.

Metric and nonmetric analyses were conducted on the human bones to identify their age, sex, body structure, health conditions, and abnormalities, and these data were to be compared with other documented human remains from the region, particularly those from Buried City and sites ascribed to the Antelope Creek phase.

\subsubsection{Discussion of Cairn Burial, Feature 7}

Based solely on the vertical position of Feature 7, the base of the rocks that formed the cairn above the pit burial were a few centimeters higher in the profile in comparison to most other recognized cultural features in Component $\mathrm{C}$, including the pithouse Feature 6. The rock cairn that covered the human remains would have been exposed at the surface prior to the historic blading of the fireguard immediately next to the cairn. The blading removed the prairie grasses and exposed sandy deposits to wind erosion. The sandy eolian deposits were blown out of the fireguard and eventually totally buried the nearby rocks. The thin lenses of sand around and slightly above the cairn rocks document this process. The burial contained no preserved grave goods/offerings that could be used to establish the time of burial or the cultural manifestation with which the burial was associated.

The remains in the pit under the cairn were that of a single, older adult female placed on her right side in a flexed position with the head on the southern side of the pit and facing east (Appendix K). The presence of only 30 percent of the skeleton and, specifically, the absence of the skull and mandible, combined with generally poor bone preservation, precludes a complete understanding of the ostelogical and biological characteristics of this individual. The tip of one finger on the right hand had apparently been amputated, an action that also resulted in damage to an adjacent finger. Arthritic conditions are present and suggest an older individual. Osteometrics are consistent with those of a Native American, but specific cultural identification is not possible.

The recovered materials from across Component $\mathrm{C}$ indicate an occupation by a single Plains Village population, which is also supported by eight radiocarbon dates on maize parts and two wood charcoal dates. Lacking grave goods of any nature and direct chronometric data with which to place this cairn burial in time, it is currently not possible to assign this burial to this component. Based on stratigraphic evidence, it is likely that Feature 7 was constructed following the abandonment of this occupation. That does not rule out this individual pertained to the Plains Village period. Based on the depth of the stones that covered this burial, it is likely the burial postdates this ca. 530 B.P. (cal A.D. 1360) Plains village occupation.

\subsubsection{Discussion of Human Cremation, Feature 22}

Towards the southern end of Component C, where the sandy deposits thickened, was a human cremation and other associated materials, designated Feature 22. This cremation was between 60 and $70 \mathrm{cmbs}$ and some $30 \mathrm{~cm}$ deeper than most Plains Village materials at roughly 30 to $35 \mathrm{cmbs}$. However, the sandy deposits are relatively easily excavated and the interment may have been placed at this depth within a burial pit. This burial also lacked diagnostic grave goods that would allow for assignment to a general cultural period or group. An unburned, worked mussel shell was present with the clustered cremated bones, but this artifact is not diagnostic of any one particular cultural taxon. Feature 22 was intrusive into the deposits, but it is not clear when it was excavated or if it was older or younger than the main occupation as no relevant stratigraphy was discernible. In the absence of chronometric data, associated time-diagnostic 
artifacts, and/or stratigraphic factors, the question of association is unanswerable.

The cremation consisted of a single adult of undetermined sex with only 10 percent of the skeleton represented mostly by burned black to calcined rib and long bone fragments less than 13-cm-long. Again, the skull and mandible are missing. Most fragmentary elements reflect postmortem thermal damage whereas the knee, hand, and foot elements were not burned. The overall characteristics are representative of a Native American, but specific cultural affiliation was not determined (Appendix K).

\subsubsection{Discussion of Scattered Human Remains from Component C}

During the faunal analysis a number of tiny human teeth and tooth fragments (\#338-002-2) were recognized in among the animal bones from "ghost" pithouse Feature 18. These teeth were subsequently identified by a physical anthropologist as representing one left deciduous canine, one left premolar crown, one unsided premolar crown, and six enamel and root fragments of a deciduous molar and permanent incisor crown (Appendix S). If from the same individual, these teeth represent an approximately 2- to 5-year-old child. These remains represent a third individual in Component $\mathrm{C}$ and are definitely associated with that component. It appears this young child was not buried in a designated grave, and it is not clear what became of the rest of the skeletal material, if it was present at all.

\subsubsection{Discussion of Human Burial Practices}

Relatively few human burials have been directly radiocarbon dated to the Antelope Creek phase and fewer yet reported in detail. The limited published information on biological affiliations of Southern Plains Village populations, specifically that of the Antelope Creek phase and Buried City complex, hinders comparison except at the very broadest scale. A number of Plains Village sites in the region such as Antelope Creek Ruin 22 (41HC23) and Alibates Ruin 28 (41PT11, Baker and Baker 2000), Footprint (41PT25, Green 1967; Lintz 1986), Buried City (D. Hughes and Hughes-Jones 1987), Big Blue/ Blue Creek (41MD35, Lintz 1986; Couzzourt and
Schmidt-Couzzourt 1996), and New Smith (Brooks et al. 1992) have yielded human burials, but they have not been directly dated, which creates uncertainty as to their age. Many interments in these sites occurred in abandoned structures or midden deposits that indicate they occurred after abandonment (Table 107). Therefore, since burials were interred subsequent to site occupations, their chronological positions are rather unclear. A number of interments from Antelope Creek phase and Buried City complex sites were covered with stones (i.e., cairn burials, Lintz 1986; D. Hughes and Hughes-Jones 1987; Couzzourt and Schmidt-Couzzourt 1996; Baker and Baker 2000), and these were often placed on promontories or knolls. Most interments in Antelope Creek phase sites were single interments, semiflexed in shallow pits, and usually not accompanied by grave goods (Baker and Baker 2000; Lintz 1986; Brooks 1989:81). Those that yielded nonperishable grave goods often reflected sexual division of labor in that males tended to have utilitarian goods such as arrow points and ceramic sherds/vessels that may reflect food or other goods for use in the afterlife, whereas females were often associated with bone digging tools (Lintz 1986:173-174).

Most interments from Antelope Creek phase sites to the southwest of Long View represent single individuals, although at least one cemetery is known at Big Blue/Blue Creek (41MD35, Couzzourt and Schmidt-Couzzourt 1996). The cemetery was adjacent to an Antelope Creek phase village. The burials in the cemetery at Blue Creek were different in that the four cairn burials investigated represented young individuals; an infant, a toddler and perhaps two adolescents, in contrast to most burials that contain adult individuals. Three of the four were associated with grave goods, which in two cases were large portions of ceramic vessels. Three of the four bodies were flexed and the other was semiflexed, with heads not consistently oriented in any particular direction (Couzzourt and SchmidtCouzzourt 1996:15-21).

The individuals from the Footprint site (41PT25) are also exceptional in that an estimated 32 individuals were within a single structure (Structure 1; Green 1967). Three burial pits in the floor of the structure yielded at least the partial remains of seven flexed 
Table 10-7. Antelope Creek Phase Burial Locations and Types in Selected Sites.

\begin{tabular}{|c|c|c|c|c|c|c|c|c|}
\hline Antelope Creek Phase Sites & Above Floor & On Floor & In Midden & Below Floor & Cairn & Unknown & Cemetery & Total \\
\hline Alibates 28, Unit I & 8 & 2 & 2 & & & & & 12 \\
\hline Alibates 28, Unit II & 2 & & 1 & & & & & 3 \\
\hline Antelope Creek 22 & $1^{*}$ & & & & & & & 1 \\
\hline Antelope Creek 22A & 4 & 2 & 7 & 2 & & 1 & & 16 \\
\hline Big Blue Creek & & & & & $5^{* *}$ & & yes & 5 \\
\hline Coetas Ruin & & & & & & & $2 * *$ & 2 \\
\hline Footprint & & 10 & & 7 & & & & estimated 32 \\
\hline Sanford Ruins & & & & & 1 & & & 1 \\
\hline Tarbox Ruin & & 1 & 1 & & & & & 2 \\
\hline
\end{tabular}

individuals, including a pile of crania, and other bone elements, some burned, scattered within the room fill (Lintz 1986:374). Poor understanding of the complex stratigraphy and the burning of the structure limited interpretation of these remains, which may represent an ossuary.

For the Buried City complex just to the north of Long View, D. Hughes and Hughes-Jones (1987:104-105) indicate that few burials have been excavated under controlled conditions and details concerning the burials are lacking. Those recovered were generally semiflexed and rested variously on the back, the side, or the stomach. There were relatively few associated grave goods. Five burials at Courson B (410C27) were in a mass grave capped by stones. These included four adults and one juvenile in various orientations and lacked grave goods, except for a stone pendant with the juvenile (D. Hughes and Hughes-Jones 1987; D. Hughes 1991). Another example was a tightly flexed female, aged 20 to 25 years, covered by a cairn above the bench floor in the southwestern corner of a large rock-foundation structure at Courson B (D. Hughes and HughesJones 1987; D. Hughes 1991). At the Handley ruin, a burial that lacked grave goods was inside a rock wall, face-down, with head toward the northwest. The arms were flexed, and the legs were flexed at the knees (Moorehead 1920; D. Hughes and HughesJones 1987:20). At 41OC1, another cairn burial contained a single body with grave offerings that included a few beads of unspecified type, as well as unspecified tools (D. Hughes and Hughes-Jones 1987:104). These Buried City interments have not been described in detail and their cultural affiliation and precise age are unknown.

Further north, the Odessa phase mortuary practices are poorly documented (Brosowske 2005; Brosowske and Bevitt 2006:190-191). Some bodies were buried in storage pits and some were under rock cairns with ceramic vessels smashed on top of the rocks. Here again, although detailed information concerning the burials is not published, it is known that mortuary practices included both single and multiple interments. It is quite possible that human interments in these sites/phases represent groups or populations that post-date the defined occupations, especially those buried in abandoned structures and pits.

Dr. Douglas Owsley of the Smithsonian Institution has a sizable database with metric and nonmetric data on human remains from Plains Village sites, but that database is not published. He has at times verbally passed on information to researchers regarding the Plains Village populations. Owsley indicates that biological investigations of human skeletal materials show that the individuals interred at Buried City differ from those from the ruins in the Antelope Creek phase core area (Brooks 2004:335). The biological characteristics studied by Owsley indicate little biological continuity between Antelope Creek phase and the earlier Woodland populations or even with other Southern Plains Village populations 
such as the Washita River phase or groups in the central Plains (Brooks 2004:335). They are distinct and separate from adjacent groups. Owsley's craniometric analyses indicates the individuals from Antelope Creek phase sites were of moderate height, round-headed with moderate cranial vaults, with relatively low incidence of dental problems (Brooks 2004:335). Overall, these groups appear to have been healthy and free of severe nutritional stress. Unfortunately, neither of the interments or the scattered teeth of the child in Component $\mathrm{C}$ at Long View had crania present, so comparisons are not possible. Consequently, we cannot determine how these three individuals at Long View may have been related to the Antelope Creek phase or Buried City populations.

Two different types of treatment of the dead were represented at Long View, which implies two different mortuary patterns/traditions, or possibly variability within a single tradition. One body was placed in an excavated pit under a rock cairn and the other was a secondary cremation. At least one other cremation is known for the immediate region, a probable adult female was cremated and the burned remains placed or scattered in the bottom of a shallow, oval pit at the Erickson Caprock site (41RB102, Wilkens et al. 2005). The radially fractured bones indicate the body was cremated with the flesh still present. No cultural assignment or affiliation was made for this individual. No cremations have been reported from Antelope Creek phase sites (Lintz 1986:164). Likewise, no human cremations have been reported for the Buried City complex (D. Hughes and Hughes-Jones 1987; D. Hughes 1991). Summers (1977:122), in an early study of 145 burials in the 32 northern counties of the Texas panhandle, mentions that a single secondary cremation was excavated, but he cited no pertinent published report concerning that cremation. However, human cremations have been reported for both the Woodland $(N=3)$ and Late Prehistoric $(N=1)$ periods in Kansas (Owsley 1989:127-128). Only two cremations are reported for the Late Prehistoric period in Oklahoma (Owsley 1989:127-128). In general, cremations are rare, geographically widespread, and not limited to any specific time period or cultural group. In discussing general Plains burial practices, Lowie (1954:40-77) does not mention cremations as one of the four modes of burial.
Cairn-covered burials are common throughout this region and across the broader Plains, but the cultural affiliation of most excavated burials is unknown. A rock cairn burial was discovered at the Sam Wahl site (41GR291). This burial was radiocarbon dated by bone collagen to $1720 \pm 60$ B.P. (Beta-61496) or cal A.D. 256 to 415, which is some two centuries earlier than the earliest Palo Duro complex occupation at that site (Boyd et al. 1994; Boyd 1995, 1997, 2004b). The skeletal remains were in an excavated pit and indicated a secondary bundle burial. Although far to the south of Long View, this find documents cairn burial practice was present at least for the last 1,800 years in the region. The strategy of covering a body with rocks was likely not limited to a particular time period, group, or population area.

Currently, the limited data reported for burial practices across the Southern Plains during the Plains Village period hinders a complete understanding of phase/complex mortuary practices. The lack of permission to radiocarbon date and conduct chemical studies directed towards the three bodies from Component $\mathrm{C}$ at the Long View site prevents an unambiguous contribution to the understanding of mortuary practices on the Southern Plains and, more specifically, during the Plains Village period. The two interments and the scattered child remains do, however, document the existence of three distinct kinds of strategies in the area, of which at least two have been previously identified for the region and the general time period.

\subsection{Question 5}

Do the architectural features (pithouses) identified at the Long View site represent outside groups of Southern Plains Villagers moving into the region, or do these features represent one or more of the previously identified Southern Plains Village complexes/phases in the region?

\section{J. Michael Quigg}

Unfortunately, pithouses have only been recognized in the Texas and Oklahoma panhandles over the last 12 years or so, and very limited published literature is currently available on these structures (see Chapter 3.0). A very limited understanding of regional architectural patterns is due to a general 
lack of intensive scientific excavations over the last 30 or so years that have encountered structures immediately predating the Plains Woodland period subterranean, slab-foundation structures of the Antelope Creek phase and other contemporaneous phases/complexes in the region.

Several Southern Plains Village archeological manifestations have been defined for the general region. These include: the Antelope Creek phase to the southwest and northwest in the North Canadian River valley (Duncan 2002, 2006; Watson 1950; Schneider 1968; Lintz 1975, 2003a, 2003b, 2004), centered along the Canadian River at Lake Meredith (Brooks 2004; Lintz 1978b, 1982, 1984, 1986, 1989); the Apishapa phase in southeastern Colorado (R. Campbell 1969; Cassells 1997; Zier and Kalasz 1999); the Buried City complex immediately to the north along Wolf Creek (D. Hughes and HughesJones 1987; D. Hughes 1991, 2001; Brosowske 2005); the Odessa phase to the north, mostly in the Oklahoma panhandle (Brosowske 2005; Brosowske and Bevitt 2006); the Zimms complex immediately to the east, in extreme western Oklahoma (Flynn 1984; Drass et al. 1987; Drass 1989; Brooks 1989; Brooks et al. 1992; Brosowske 2002b); the Custer and Turkey Creek phases farther east in western Oklahoma (Brooks 1989; Drass 1999); and the Paoli and Washita River phases in central and western Oklahoma (Brooks 1989; Drass 1999). Pithouses are known to be present in the Odessa phase (Brosowske 2005; Brosowske and Bevitt 2006). Although not referred to as such, pithouses are likely present at a few scattered Antelope Creek phase sites (i.e., Stamper, and probably Alibates Ruin 28 [Lintz, 2003c, 2004]). A few sites at Buried City, Courson B (41OC27) and Courson D (410C29), also appear to have pithouses (D. Hughes and Hughes-Jones 1987, D. Hughes 2001; Brosowske 2005; Table 10-8). Pithouses are also present at the Greenbelt site (41DY17) fruther south in the Rollings Plains, but the affiliation is uncertain (T. Campbell 1983, 1996). The current literature is unclear as to whether other Southern Plains Village groups utilized these types of houses during this period or earlier, since relatively few detailed descriptions and radiocarbon dates are published for the relevant pithouse structures.
A clear definition of a pithouse, versus other kinds of subterranean and semisubterranean structures, has not been formulated for the Southern Plains. This partially reflects the limited recognition of the need for a clear definition, as houses of various depths have just recently been recognized and discussed in the regional literature. The term "pithouse" is potentially confusing due to this lack of a consistently applied definition. For example, Boyd (2008:44) uses the term pithouse in discussing structures very similar to Lintz's (1986; Figure 12) classic Type I Antelope Creek phase houses with rock foundations, which Lintz (1986) does not refer to as pithouses. Many structures in the Antelope Creek phase (Watson 1950; Schneider 1969; Lintz 1986; 2003a, 2003b, 2003c, 2004 2010; Duncan 2002, 2006), the pithouses at Palo Duro complex (Cruse 1999; Boyd 1995, 1997, 2004b), and the various structures at M-Cross Ranch (Boyd and Wilkens 2001; Boyd 2008) had floors roughly 25 to $35 \mathrm{cmbs}$, while the greater part of the walls were above ground. In contrast, a greater portion of the walls of the pithouses at Long View were comprised of the sides of the pits, dug to depths of 40 to $55 \mathrm{~cm}$ or deeper below the surface, as were many of the circular structures at Chill Hill (41RB132, Brosowske 2009), most of those at Odessa Yates (34BV100, Brosowske 2005), some circular pithouses at Buried City (Brosowske 2005) and the one excavated Archie King II pithouse (41RB121, Brosowske 2009c).

At the Long View site, two pithouses have been identified and directly radiocarbon dated, one each in Components A and C. The documented ages indicate that both pithouses were constructed during the same general period, roughly between 480 and 710 B.P. (cal A.D. 1260 to 1447). This is the same general period identified for and roughly contemporaneous with adjacent Plains Village phases and complexes that include, but are not limited to, the Antelope Creek phase, the Buried City complex in Wolf Creek valley, the Odessa Yates site, and some sites at M-Cross Ranch, such as Indian Springs and Hank's House (Boyd and Wilkens 2001; Boyd 2008; Figure 10-10).

Specific radiocarbon dates on Southern Plains pithouses fall within this same general, 500-year period (Figure 10-10). As shown in Figure 10-11, the 
Table 10-8. Cultural Manifestations in the Texas and Oklahoma Panhandles with Various Types of Habitation Structures.

\begin{tabular}{|c|c|c|c|c|c|c|c|c|}
\hline \multirow{2}{*}{ House Structure Types } & \multicolumn{2}{|c|}{$\begin{array}{l}\text { Long View }^{1} \\
\text { Components }\end{array}$} & \multirow{2}{*}{$\begin{array}{c}\text { Antelope Creek } \\
\text { Phase Sites }^{2}\end{array}$} & \multirow{2}{*}{$\begin{array}{c}\text { Buried City } \\
\text { Complex }\end{array}$} & \multirow{2}{*}{$\begin{array}{l}\text { Odessa Yates } \\
\left(^{(34 B V 100)}{ }^{4}\right.\end{array}$} & \multirow{2}{*}{$\begin{array}{l}\text { Palo Duro } \\
\text { Complex }^{5}\end{array}$} & \multirow{2}{*}{$\begin{array}{c}\text { M-Cross } \\
\text { Ranch } \\
\text { Sites }^{6}\end{array}$} & \multirow{2}{*}{$\begin{array}{l}\text { Lundeen in } \\
\text { SW Kansas } \\
(14 M D 306)^{7}\end{array}$} \\
\hline & A & C & & & & & & \\
\hline Single square with rocks & - & - & $\mathrm{x}$ & $\mathrm{x}$ & - & - & $\mathrm{x}$ & - \\
\hline Single round with rocks & - & - & $\mathrm{x}$ & - & - & - & - & - \\
\hline Single rectangular with rocks & - & - & $\mathrm{x}$ & $\mathrm{x}$ & - & - & $\mathrm{x}$ & - \\
\hline Round pithouse, no rocks & $\mathrm{x}$ & $\mathrm{x}$ & - & $\mathrm{x}$ & $\mathrm{x}$ & $\mathrm{x}$ & $\mathrm{x}$ & $\mathrm{x}$ \\
\hline Square pithouse, no rocks & - & - & - & - & $?$ & - & - & - \\
\hline Unknown pithouse, no rocks & - & - & - & $\mathrm{x}$ & ? & - & - & - \\
\hline Rectangular pithouse & - & - & - & - & - & $\mathrm{x}$ & - & - \\
\hline Multiple adjoining structures & - & - & $\mathrm{x}$ & - & - & - & - & - \\
\hline Contiguous rooms with rock & - & - & $\mathrm{x}$ & - & - & - & - & - \\
\hline Megapit, no rocks & - & - & - & - & - & - & - & $\mathrm{x}$ \\
\hline
\end{tabular}

\section{$1=$ This report.}

2 = Watson 1950; Green 1967, Duffield 1964, 1970, Keller 1975, Lintz 1986, 2003a, 2003b, 2003c, 2004; Duncan 2002, 2006;

3 = D. Hughes and Hughes-Jones 1987; Brosowske 2005; limited reporting on the older work with some supplemented data provided by Brosowske 2005 4 = Brosowske 2005. Analyses have not been completed or reported.

5 = Cruse 1992; Boyd 1995, 1997, 2005;

6 = Cruse 2001, Boyd 2008; the data from multiple sites has not been analyzed, results are incomplete.

7 = Bevitt 1999, one of the few fully analyzed and reported Plains Village sites in region. 
emergence of pithouse architecture across the Southern Plains was apparently not time-transgressive.

In the Antelope Creek phase, the use of large vertical stone slabs generally characterizes the lower wall construction of various architectural structures (Lintz 1978, 1982, 1986; J. Hughes 1991; Boyd 1997; Brooks 1989, 2004). Such masonryfoundation type structures are quite variable in size and shape, and Lintz (1986) has identified at least 11 types, 6 of which are residential aggregations, whereas the remaining 5 are ancillary structures. The residential structures vary from large singleroom units, often with complex internal features, internal divisions, variable floor plans, and support posts, to large structures with as many as 30 rooms. These structures vary in shape from square, to rectangular, to circular with low, narrow entryways (Lintz 1986). Lintz (1986) attributes the variability of structure size and shape to functional differences and engineering constraints. He does not discuss "pithouses" in association with the Antelope Creek phase, since he does not consider the roughly 30to 35 -cm-deep foundations to represent pithouses.
However, the floors of most slab-foundation houses can be considered to be shallow-subterranean in character, as they are most often roughly $30 \mathrm{~cm}$ below the ground surface, and have interior floor channels that are even deeper. These Antelope Creek phase residential structures are different from the two pithouses identified at Long View, which lack the characteristic masonry-foundation type construction and many details of those semisubterranean structures. Although in general, the artifact assemblages (i.e., stone and bone tools, pottery, and subsistence remains) are similar in most aspects, it is unclear if the builders of the Long View pithouses where the same groups that constructed the Antelope Creek rectangular stone slab houses with central floor channels. The Long View site is not considered part of the Antelope Creek phase as it is currently defined.

\subsubsection{Discussion of Structures in the Region}

At M-Cross Ranch just $10 \mathrm{~km}$ to the east, Hank's House (41RB109), a burned structure, is considered

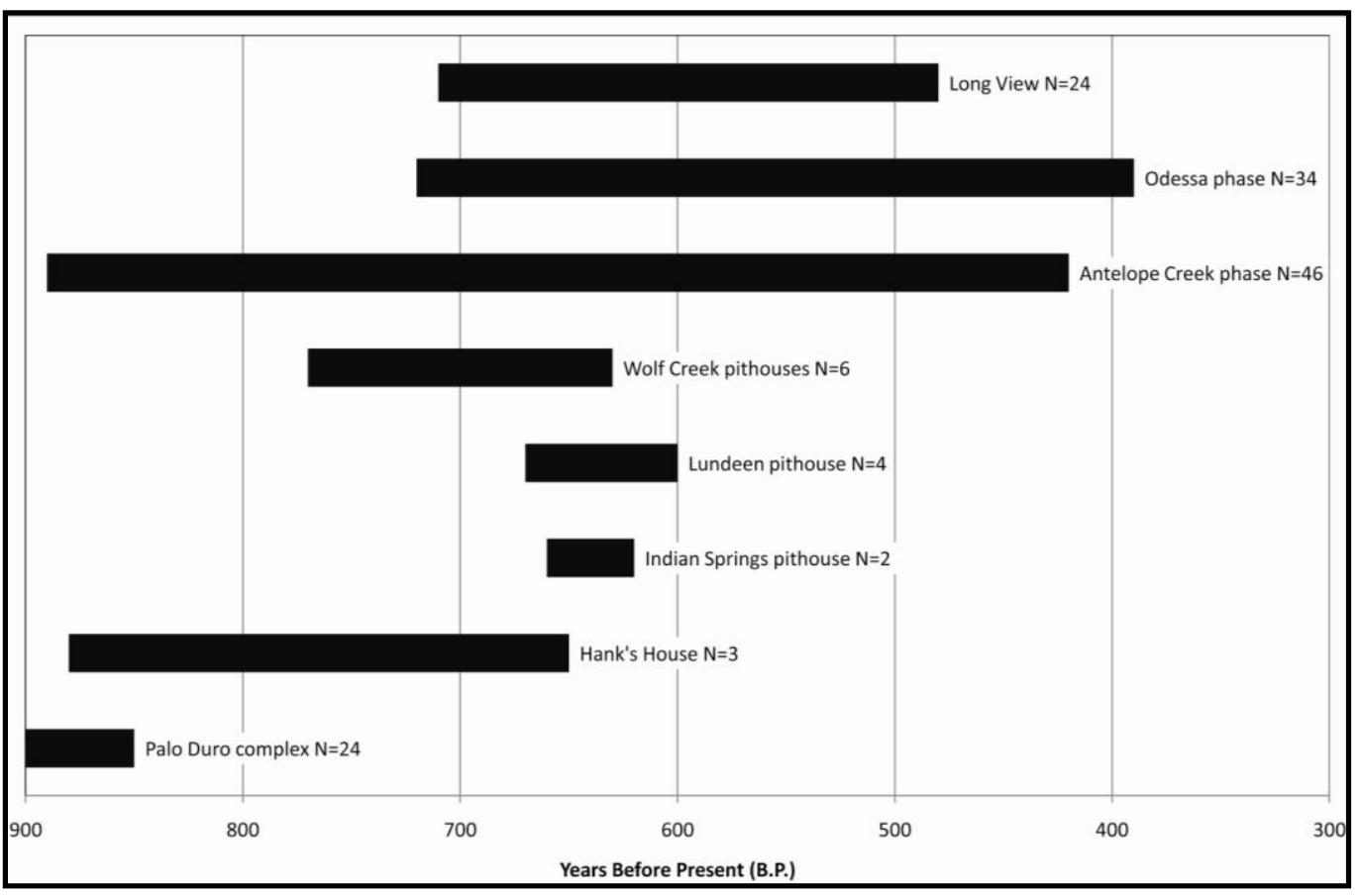

Figure 10-10. Radiocarbon age ranges for archeological manifestations in the Texas and Oklahoma panhandles.

Numbers indicate quantity of radiocarbon dates used in this graph. 
a pithouse by Boyd and Wilkens (2001), though Boyd (2005) has yet to assign Hank's House to a named archeological phase or complex. Hank's House is a rectangular semisubterranean structure (dug to roughly $70+\mathrm{cmbs}$ ) that measured about 6-m-long, lacked a stone foundation, faces east, and had a row of small diameter, vertical wall posts along each side, four large (15-cm-diameter) interior support posts, a clay-lined central hearth, a 10-cm-deep floor channel, interior plastered walls, clay-plastered sloping entryway, and an earthen cover (Boyd and Wilkens 2001; Boyd 2005). The lack of a stone-foundation sets Hank's House apart from most Antelope Creek phase structures to the southwest, but it was similar in many other aspects with a central hearth, central support posts, and a central channel. The Antelope Creek phase structure at Jack Allen site, toward the eastern end of the Antelope Creek phase core area, is also quite similar to Hank's House. This structure had a rectangular outline, walls lined with small diameter wooden posts rather than rocks, a central floor channel, a central hearth, four larger interior support posts, and an east-facing, sloping entryway (Lintz 1986). Hank's House is also similar to Structure 1 at the Zimms site (34RM72) in extreme western Oklahoma, which was square with outside wall posts, central roof support posts that supported wattle-and-daub walls, a semisubterranean floor, and lacked a stone foundation (Flynn 1984, 1986; Brooks 1989; Brooks et al. 1992; Brosowske 2002b). The average date for the Zimms structure is slightly later than those at Long View for Components A and C. Hank's House and the Zimms structure are unlike the small oval pithouses at Long View with their picket-post wall supports in roughly square outline, multiple central posts, central hearths, and central channels.

Also at M-Cross Ranch, the completely excavated Structure 4 at Indian Springs (41RB81) is referred to as a circular pithouse (Cruse 2007:15). It measured $2.3 \mathrm{~m}$ north-south by $2.2 \mathrm{~m}$ east-west and was about 40-cm-deep with sloping ramp-like entrance that was $1.8-\mathrm{m}$-long and 0.6 -m-wide on the west side. It lacked structural support post holes and foundation rocks, but did yield three small internal pit features filled with ash. Two charred maize cobs and a cordmarked sherd were from the central ash pit (see Appendix Q, sherds from 41RB81 for analyses of sherd 156). The fill within this pithouse was gray clay that had obviously been brought in and used to cover the entire structure (Cruse 2007:15). Structure 4 has not yet been assigned to a cultural manifestation and is similar in shape to the pithouses at Long View. Charred wood from one of the internal ash pits was radiocarbon dated to A.D. 1280 to 1400 (corrected 2-sigma range; conventional radiocarbon age is A.D. $1330 \pm 40$, Cruse 2007:15). A second wood charcoal sample from a second internal ash feature yielded a date A.D. 1290 to 1410 (corrected 2-sigma range; conventional radiocarbon age is A.D. $1370 \pm$ 40, Cruse 2007:15).

Three sites at Buried City, along Wolf Creek, north of Long View, have also yielded pithouses (D. Hughes 1991:120; D. Hughes 2001; Brosowske et al. 2003; Brosowske 2005), and many more may be present if, as Brosowske (2005:129) believes, the semisubterranean pithouses were the dominant house form at Buried City. These pithouses at Courson A (41OC26), Courson B (41OC27) and Courson D (41OC29) are not as yet well-described in the current literature, but the generalized descriptions are similar to those at Long View. All lacked stone-foundations, central floor channels, and raised benches. One apparent pithouse in Courson $\mathrm{B}$ is dated by wood charcoal from a fire pit on the floor of the structure to 770 B.P. (D. Hughes 2001). The current six dates from five Buried City pithouses (see Chapter 3.0; Table 3-6) are earlier than the large stone-foundation structures there, which are superimposed above earlier pithouses (Brosowske 2005:129). The cultural assemblages associated with the pithouses appear similar to those associated with the stone-foundation structures (Brosowske 2005). Unfortunately, meaningful comparisons of these pithouses are precluded by the lack of published descriptions of details of cultural assemblages, stratigraphy, and context.

The type site for the Odessa phase, Odessa Yates site (34BV100), in Beaver County, Oklahoma also has well-defined ovate to circular pithouses (Brosowske 2005; Brosowske and Bevitt 2006). However, few have been completely excavated or thoroughly reported, so understanding of specific architectural details is limited. Small, closely spaced posts 5 to $10 \mathrm{~cm}$ in diameter are typically found around the 
perimeter and within the pit itself. Single or paired larger central posts served as roof supports. Internal features included shallow basin-shaped hearths, small antechambers, and shallow depressions of unknown function. After abandonment of the structures, these pithouses were typically filled with trash (Brosowske 2005:143). Figure 10-11 presents the available radiocarbon dates on the pithouses from Odessa Yates. As best that can be determined with currently published descriptions, these structures appear to be roughly similar to the pithouses at Long View.

As depicted in Figure 10-11, the Palo Duro complex, far to the south, has pithouses and storage pits that have yielded wood charcoal dates of 1450 to 850 B.P. (cal A.D. 500 to 1100), a few hundred years earlier than the Long View pithouses (Boyd 1995, 1997, 2004b). The Palo Duro complex is considered indigenous to the region, with links to groups farther southwest in eastern New Mexico (Cruse 1989, 1992; Boyd 1995, 1997, 2004b). The rockless, rectangular, 30- to 35-cm-deep pithouses at Kent Creek (41HL66) appear different: Structure 1 was interpreted to be a wattle-and-daub structure, whereas Structure 2 had a plastered floor and walls (Cruse 1989, 1992). Cruse (1992) believes the two had different functions based on their different constructional features. The oval pithouse at the Sam Wahl (41GR291) site exhibited no post holes, but was postulated to have been a jacal-like structure (Boyd 1995, 1997, 2004b). These three known pithouses (all shallow, dug to 30 to 35 cmbs) assigned to the Palo Duro complex reveal a wide range of construction techniques and the differences may be related to seasonal requirements or to differing functions (Boyd 1995, 1997, 2004b; Cruse 1992). The approaches to the way pithouses were constructed in the Palo Duro complex may have influenced those groups that occupied Long View. Considerably more detailed excavations and dating of pithouses are needed to assess this possibility, as well as to better compare construction practices among the various cultural manifestations

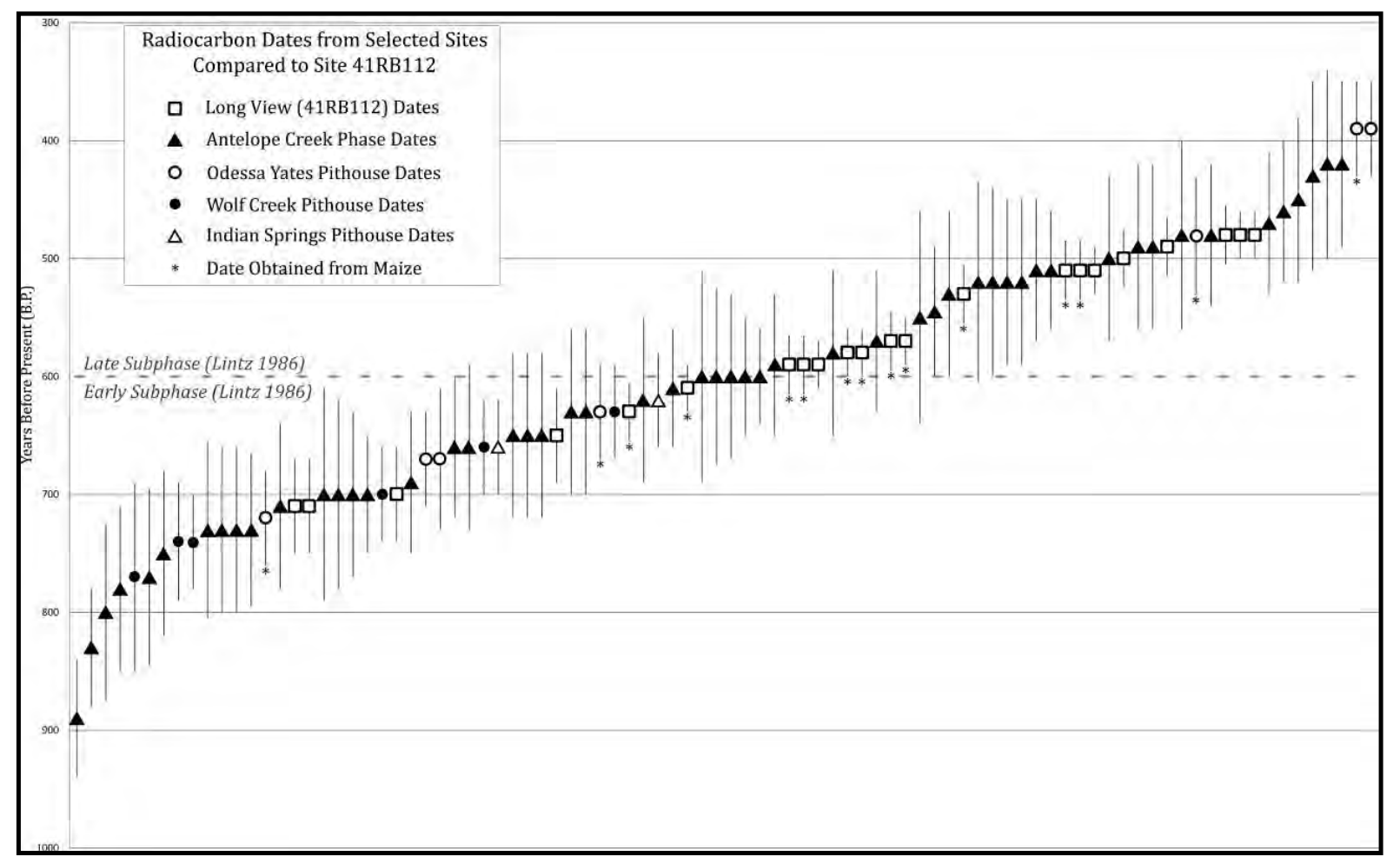

Figure 10-11. Radiocarbon dates before present (B.P.) for archeological manifestations in the Texas and Oklahoma panhandles. 
in the region. Pottery is also a key material class as differences have been detected in the various assemblages, and may lead to cultural influences or differences.

The two Long View pithouses currently do not appear to reflect intrusive population immigration into the area, although the builders of these structures may have been influenced by architectural practices elsewhere. Until more regional excavations are conducted at pithouses, radiocarbon dated, and detailed descriptions and results published, the origin of pithouse architecture in the Texas panhandle will remain obscure. Current analyses of pithouse structures indicates they primarily functioned as seasonal houses, but other functions (e.g., storage, social/ceremonial use) cannot be ruled out, as detailed information on these structures is lacking. After the original function of these pit structures had terminated, at least a few were used as trash disposal areas as their floors were covered in quantities of cultural debris while the structure was still standing. This indicates that the immediate site surrounding the pit structure was still occupied.

Recent excavations in the eastern section of the Texas panhandle at M-Cross Ranch (Boyd and Wilkens 2001; Boyd 2008; Cruse 2007) and Courson Land holdings that include Buried City, Chill Hill (41RB132), and other sites (Brosowske 2008, 2009a, 2009b; 2009c) will undoubtedly bring forth new information concerning Plains Village period structures, cultural assemblages, population aggregations, and social identity. Archeologists working in the region are just beginning to identify considerable intra-regional variation in living structures associated with similar artifact assemblages. In a preliminary report on the picket-post house at the Franklin site (41GY80) in Gray County $60 \mathrm{~km}$ south of Long View, Lintz (2011) indicates the presence of similar picketpost structures assigned to several Middle Ceramic phase cultural manifestations at numerous sites in the Texas and Oklahoma panhandles, western Oklahoma, and even in the Antelope Creek phase core area. These include Zimms complex, Antelope Creek phase, Buried City complex and potentially others. This one specific type of structure crosscuts multiple manifestations, and we may see changes and reevaluations in the Plains Village period cultural taxonomy as more data is compiled.

\subsection{Question 6}

Were the ceramic sherds represented in Components $A$ and $C$ manufactured locally or were they imported from Southern Plains Village complexes/phases in surrounding areas?

\section{J. Michael Quigg}

The ceramic sherd assemblage $(N=1,541)$ from Long View Components A $(N=1,279)$ and C $(N=262)$ were metrically and nonmetrically analyzed, with 21 total vessel groups identified (14 in Component $\mathrm{A}$ and 7 in Component C). However, 80 percent of the sherds were too small $(<2 \mathrm{~cm})$ to be confidently assigned to vessel groups. Components $\mathrm{A}$ and $\mathrm{C}$ each yielded ceramic assemblages representative of the Plains Village Tradition, supported by 18 radiocarbon dates on maize. As previously demonstrated (see Section 10.2, Question 1), the two components are not contemporaneous, although they were both occupied within a period of roughly 240 years between approximately 460 and 700 B.P. (cal A.D. 1280 to 1447). Macroscopic observations, metric attributes, chemical composition, and mineral identifications reveal differences in the two Long View ceramic assemblages. Although both components are dominated by over 75 percent cordmarked vessels, visible differences in cordmarkings, as well as thicknesses and shapes of cordmarked vessels, were recognized. Macroscopic observations of pottery from each component are separately discussed below, followed by results from two technical analyses directed toward identifying constituents of 32 sherds from both Long View assemblages, plus 80 sherds and 8 natural, experimentally tempered clay samples from other sites in the region.

\subsubsection{Discussion of Component A Ceramic Assemblage}

Component A yielded 79 percent cordmarked exterior vessels, including all sherds too small ( $N=963)$ to be assigned to specific vessels. In general, exterior cordmarkings are mostly narrow and vertically oriented, even on pinched/collared 
rim vessels (Vessels A and K). Vessel body walls are generally thin, but range between 2.7 and 10.8 $\mathrm{mm}$ in thickness, and have a mean thickness of approximately $4.7 \mathrm{~mm}$. Base sections were not distinguishable, implying basal portions of vessels were rounded and similar in curvature and thickness to body walls. The cordmarked assemblage is similar to broadly defined Borger Cordmarked vessels that dominate the Antelope Creek phase assemblages to the southwest, considered manufactured within this general panhandle region and representative of the Plains Village period.

Four exceptions to the predominant cordmarked surface treatment were recognized in the Component A assemblage. Vessel B is obliterated cordmarked; cordmarking subsequently smoothed over, which produced the appearance of a plain exterior. Vessel $\mathrm{L}$ has a smooth, plain exterior, at least in the rim area, which is the only section identified. Also present is a single sherd of a Rio Grande glaze vessel (Vessel N; see Figure 8-68), 13 sherds of a smooth vessel with a red-washed exterior (Vessel C) that likely originated in the Southwest, and two thick pinched- or collared-rim cordmarked vessels (Vessels A and K). In conjunction with the thick pinched-rim, Vessel A bears a single row of shallow, small fingertip punctations below the lip (see Figure 8-51). These two pinched/decorated rims are similar to vessels assigned to the Courson pinched-rim class from the Buried City complex (Hughes and HughesJones 1987; D. Hughes 1991) and the Odessa phase (Brosowske 2005). Such decorative attributes are rare (less than 10 percent on average) in the Antelope Creek phase core area sites (Lintz 1978a). However, the four excavated Antelope Creek phase sites in the Oklahoma panhandle (Two Sisters, McGrath, Roy Smith, and Stamper) yielded slightly higher percentage of decorated rims in comparison to the Antelope Creek phase sites in the core area (Lintz 1976).

\subsubsection{Discussion of Component C Ceramic Assemblage}

Component $\mathrm{C}$ was also dominated by cordmarked exterior vessels, however, visible cordmarkings tend to be broader than those on vessels from Component A(Figure 10-12). Six of seven (86 percent) identified vessels were cordmarked, whereas Vessel 6 exhibits a maize cob-impressed exterior surface. Sherds assignable to Vessel 1 comprise 42 percent of the total Component $\mathrm{C}$ assemblage. The higher percentage of Vessel 1 sherds recovered allowed reconstruction of major sections and determination of general form and size, in contrast to the majority of the vessels, which are represented by significantly fewer sherds that represent small percentages of the vessels. Vessels 2 and 4 are obliterated cordmarked, a manufacturing technique where initial cordmarking is subsequently smoothed over to create an essentially smooth, plain exterior surface treatment. Component $C$ yielded three cordmarked vessels (Vessels 1, 3, and 7) with relatively thick-walled bodies ( 7.8 to $11.3 \mathrm{~mm}$ ) and even thicker, on average, basal portions (10.3 to $19.1 \mathrm{~mm}$ ). In contrast, similarly thick-walled vessels were not represented in Component $\mathrm{A}$. These three vessels are significantly thicker-walled than other Component $\mathrm{C}$ vessels and are similar in thickness to some vessels previously identified as Plains Woodland (J. Hughes 1962, 1991; Couzzourt 1985; Johnson and Johnson 1998:204). Thick-walled vessels were previously thought of as diagnostic of Plains Woodland/Early Ceramic occupations (e.g., the Lake Creek complex in the Texas panhandle) across the broader region (J. Hughes 1962, 1991). As an example, a Woodland vessel (see Figure 3-1 from the Panhandle-Plains Historical Museum in Canyon, Texas), has walls approximately 8- to 9-mm-thick at the rim and stands approximately 33-cm-tall, narrow cord roughened exterior, and conical base characteristic of Woodland vessels (see Figure 3.1 in Chapter 3.0). In contrast, the thickwalled, broad cordmarked, partially reconstructed Vessel 1 from Component $C$ has a rounded base (see Figure 9-81 in Chapter 9.0). See the discussion of the radiocarbon dating of thick-walled vessels in Section 10.2 above.

\subsubsection{Technical Analyses}

Following macroscopic and metric analyses, 32 sherds were selected (15 from Component A and 17 from Component C) that represent 17 individual vessels (10 from Component $A$ vessels and 7 from Component $\mathrm{C}$ vessels), as well as a sample of unassigned sherds from both components, for INAA and petrographic analysis. These analyses were directed toward understanding the Long View assemblage, in order to gain a greater perspective on 


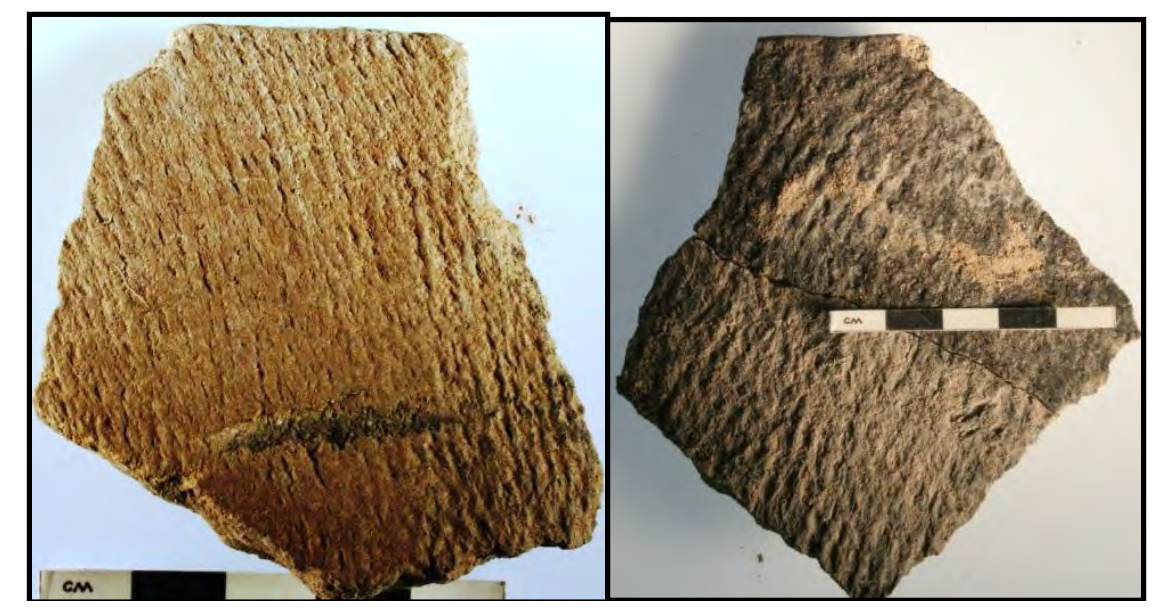

Figure 10-12. Vessel G (\#1066-8-1) from Component A and Vessel 3 (\#350-8-1 and \#349-8-1) from Component $\mathrm{C}$ illustrating difference in exterior cordmarking breadth.

composition and potential source areas for ceramic manufacturing materials, movement of people/ vessels across the region and relative to these resources. Additionally, a regional sample of 80 sherds from 4 groups of Plains Village sites in the surrounding region were procured and submitted for these same analyses (Table 10-9; Figure 10-13). This includes sherds from three sites at Buried City along Wolf Creek (410C27, 29, and 43) to the north, the four excavated and reported Antelope Creek phase sites in Oklahoma panhandle (Stamper, McGrath, Roy Smith and Two Sisters) to the north, four sites from the Antelope Creek phase core area (Alibates Ruin 28, Antelope Creek Ruin 22, Cottonwood Creek, and Roper) to the southwest, and four sites at the M-Cross Ranch (41RB81, 108, 109, and 110) to the east (Table 10-9; see Appendix Q for details and pictures of each sherd). Also included in these two technical analyses were eight natural clay samples from the same four general areas that were experimentally tempered with regionally available tempers. Conducting the same technical analyses on all 112 sherds allows for direct comparison of sherd composition of Long View site components with surrounding Plains Village ceramic assemblages. A portion of the sherd sample subjected to INAA from the Antelope Creek phase core area sites utilized the same sherds that Lintz and Reese-Taylor previously used in their 1997 petrographic analysis.
INAA and petrographic analysis was also conducted on 6 pieces of daub (3 each from Components A and C), and 12 experimentally tempered natural clay and alluvial matrix samples (2 from Long View and 8 from the surrounding region) to compare clays used in manufacturing the vessels to available sources. Analyses of the chemical composition of each sample compared to local clay sources near sites or within the region allowed inference regarding possible interactions between occupants of Long View and regional Plains Village complexes/phases, as well as perspective into broader Plains Village ceramic traditions. INAA and petrographic results are discussed below.

\subsubsection{Instrumental Neutron Activation Analysis}

INAA was conducted through the Archaeometry Laboratory at the University of Missouri (MURR; see Appendix G). Analysts examined a total of 112 pottery samples (32 from Long View, 80 from selected regional sites), 12 experimentally tempered regional clay samples (2 Long View, 10 regional) and 6 Long View daub samples. The 10 regional clay samples were combined with measured quantities of regionally available tempering materials such as scoria, quartz sand and sandstone and baked at controlled temperatures, and submitted to provide control comparisons with submitted tempered sherds. INAA results from submitted samples of 
Table 10-9. Sherd and Clay Samples for INAA Analysis from Sites in Regions Adjacent to Long View.

\begin{tabular}{|c|c|c|c|}
\hline Site Number & Site Name & $\begin{array}{l}\text { Number of } \\
\text { Sherds }\end{array}$ & $\begin{array}{c}\text { Natural } \\
\text { Clay }\end{array}$ \\
\hline \multicolumn{4}{|c|}{ Buried City Sites along Wolf Creek } \\
\hline $410 \mathrm{OC} 27$ & Courson B & 9 & 1 \\
\hline $410 \mathrm{OC} 29$ & Courson D & 4 & 1 \\
\hline $410 \mathrm{OC} 43$ & Kit Courson & 2 & \\
\hline \multicolumn{4}{|c|}{ Four Antelope Creek Phase Sites in Oklahoma Panhandle } \\
\hline 34TX1 & Stamper & 6 & \\
\hline 34TX31 & McGrath & 3 & \\
\hline $34 \mathrm{TX} 32$ & Two Sisters & 7 & 2 \\
\hline 34BV14 & Roy Smith & 7 & \\
\hline \multicolumn{4}{|c|}{ Antelope Creek Phase Core Area Sites } \\
\hline 41PT11 & Alibates Ruin 28 & 9 & \\
\hline 41HC6 & Roper & 6 & \\
\hline 41HC23 & Antelope Creek Ruin 22 & 6 & 1 \\
\hline 41HC141 & Cottonwood Creek & 3 & \\
\hline \multicolumn{4}{|c|}{ M-Cross Ranch Sites } \\
\hline 41RB81 & Indian Springs & 9 & 1 \\
\hline 41RB108 & Whistling Squaw & 1 & \\
\hline 41RB109 & Hank’s & 5 & 2 \\
\hline 41RB110 & Three Toes & 3 & \\
\hline Total & & 80 & 8 \\
\hline
\end{tabular}

pottery, clay and daub (MURR assigned numbers: TRC528 through 636, and 644 through 655) were then comparatively assessed with previously analyzed Plains Village samples (Meier 2007; Quigg et al. 2010) present in the MURR database. At that time, the MURR master database contained nearly 90,000 previously analyzed ceramic and raw material samples (Appendix G). The resulting dataset contains 193 pottery samples, 42 clays, 6 daub, and other raw material samples.

Comparative analyses determined that neither the 112 TRC samples, nor the previously analyzed 75 sherds from Meier's (2007) dataset, were compositionally similar to the Central Plains samples in the MURR database. The Central Plains samples have been redefined here as Compositional Group 5 (see Appendix G). The current Southern Plains Village dataset has only one possible sample that may overlap at a very low 7 percent probability with the Central Plains Group. Therefore, only the Southern Plains dataset need be considered here.

Compositional groups were assigned based on visual and mathematical analyses of bivariate elemental plots of the ceramic samples (Appendix G). The Southern Plains dataset was divided into unassigned sherds and 13 compositional groups, including the Central Plains Compositional Group 5. The 193 pottery samples from four regions plus the Long View site, includes a total of 23 sites were assigned to these new 13 compositional groups. The following discussion focuses on the Long View site samples from the two components, followed by a discussion concerning the entire analyzed pottery population.

The 15 sherds from Component A were assigned to only 2 compositional groups: Group $2(N=12$ or 80 percent), and Group 4 ( $N=2$ or 13 percent), with 1 unassigned sherd (Appendix G; Table G-1). 


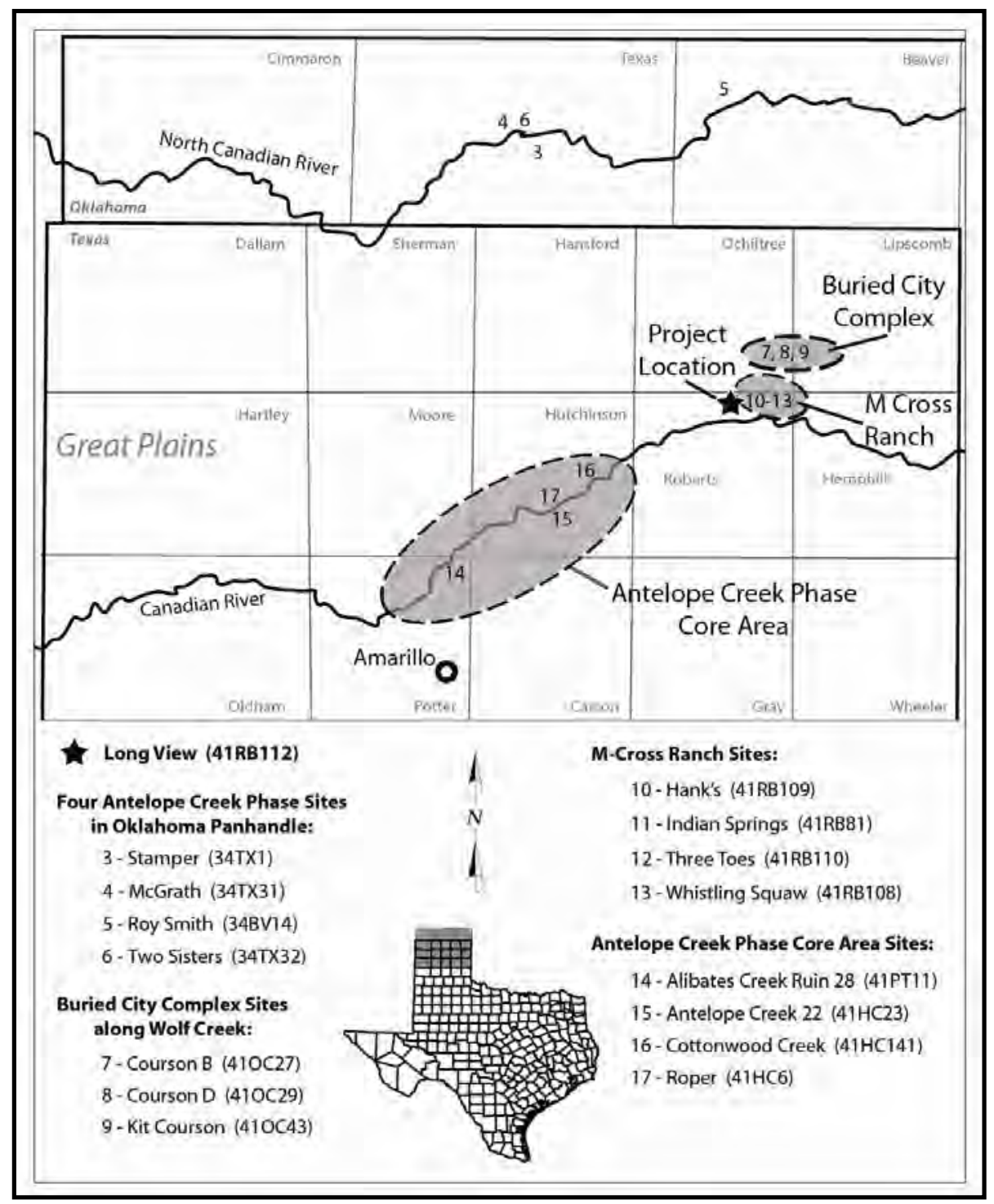

Figure 10-13. Map showing location of sites from which selected pottery samples were used in the two technical analyses. 
The 17 sherds from Component $\mathrm{C}$ were assigned to 3 compositional groups: Group 1 ( $N=9$ or 53 percent), Group 2 ( $N=3$ or 18 percent), and Group $4(N=4$ or 24 percent), and 1 sherd unassigned. This indicates the two assemblages utilized different sources with different chemical constituents for their primary source of raw materials, as Component $\mathrm{C}$ has nearly 53 percent of sherds in Compositional Group 1, whereas Component A has 80 percent of sherds in Compositional Group 2. None of the 42 local or regional clay sources MURR has analyzed to date show strong chemical similarities to the two component ceramic samples; only a general similarity to the regional ceramic samples. The two local clay samples from Long View, one from an off-site local buried A horizon (\#C-Aa = TRC554, with 50 percent crushed sandstone temper from a near site specimen), and one from the on-site old Ogallala Formation (\#OCa = TRC553, with 25 percent crushed sandstone temper from a near site source), lack close chemical correspondence to any Long View ceramic vessels. Although this could mean none of the vessels were manufactured on-site or from surrounding available clays, the only clear implication is the clay used in their manufacture was not from either of those sources sampled. Similarly, the vessels did not match other regional clay sources, that included clays from Buried City $(N=2$, \#WCC1a = TRC549, \#WC-C3a = TRC550) to the north; Hank's, West Pasture and Indian Springs at M-Cross Ranch $(N=3$, \#C1a = TRC546, \#WP-C10a = TRC547, \#C2a = TRC548) to the east; Government Canyon $(N=1$, \#Gc-Ca = TRC552) to the west; the Two Sisters site $(N=1$, \#420a = TRC637) to the northwest; Alibates Ruin area $(N=5$, HAM076, 077, 078, 079, and 082 from Meier 2007) to the southwest; and Blue Creek, north of Lake Meredith ( $N=1$, \#BC-Ca = TRC551), also to the southwest.

From Component A at Long View, sherds \#10348 = TRC655 and \#1206-8-1b = TRC557 represent Vessel C, a vessel with a smooth red-washed exterior surface with an appearance of a nonlocal trade ware. The chemical analysis of the two sherds indicates that Vessel C belongs to Compositional Group 4, a group that includes three sherds (\#118-8-1 = TRC650, \#349-8-1b = TRC566, and \#350-8-1 = TRC649) from Vessel 3, and one unassigned cordmarked sherd (\#643-8-1b = TRC572) from Component C
(Appendix G, Table G-1). Vessel 3 is a thick-walled (6.4 to $10.4 \mathrm{~mm}$ ), cordmarked vessel that lacks a neck and shoulder. Only one other sherd from Antelope Creek 22 (41HC23) was assigned to Group 4. The latter sherd (\#R2/15 = TRC617) is a thick (8.9 to $12.5 \mathrm{~mm}$ ) obliterated cordmarked sherd with very fine quartz sand temper that is likely a basal sherd (see Appendix Q). Although quite distinct visually, chemical composition links these sherds to a common source area. These seven sherds from three distinct vessels are believed to be made within the region, despite the smooth, red-washed exterior on Vessel C.

Considering the chemical evidence that the 32 sherds from the Long View site originated elsewhere, we compare those results to the 161 sherds from the 15 selected sites from the four surrounding regions and the 13 compositional groups they were assigned to. Unfortunately, 32 percent of the entire pottery assemblage ( $N=61$ pieces) was unassignable to a specific chemical compositional group, leaving only 68 percent $(N=131)$ assignable to a compositional group at this time (Appendix G, Table G-1). The high reliability of the MURR chemical groupings is indicated by the fact that the analysis of multiple sherds from eight different Long View vessels showed that where sherds from the same vessel were chemically analyzed, they pertain to the same compositional group, with only one exception (Table 10-10). It is likely this one exception is the result of a misidentification of vessel, rather than chemical composition error.

Compositional Group 7 is the chemical group represented by the most sherds $(N=56), 91$ percent of which came from six Antelope Creek phase sites located to southwest of Long View. No sherds from Long View were assigned to Compositional Group 7 , so it is highly unlikely that any of the 21 vessels from Long View were manufactured from the same clay sources used in the manufacturing of the analyzed Antelope Creek phase ceramic assemblage.

Compositional Group $2(N=29)$ is the second largest group with 52 percent $(N=15)$ of its constituent sherds coming from Long View. All four surrounding areas sampled contain small percentages of sherds in Compositional Group 2, which includes 14 percent each of the total from 
Table 10-10. Chemical Group Assignments by MURR for Multiple Samples from Individual Vessels at Long View.

\begin{tabular}{|c|c|c|}
\hline Vessel & Catalog No. & $\begin{array}{c}\text { Chemical } \\
\text { Group }\end{array}$ \\
\hline A & $1140-8-1 B=$ TRC555 & 2 \\
\hline A & $2-8-4=$ TRC647 & Unassigned \\
\hline B & $762-8-1=$ TRC651 & 2 \\
\hline B & $1175-8-1 B=$ TRC556 & 2 \\
\hline C & $1034-8=$ TRC655 & 4 \\
\hline C & $1206-8-1 \mathrm{~b}=$ TRC557 & 4 \\
\hline E & $973-8-1=$ TRC654 & 2 \\
\hline E & $1223-8-1 B=$ TRC559 & 2 \\
\hline 1 & $362-8-1 B=$ TRC565 & 1 \\
\hline 1 & $338-8-6 B=$ TRC569 & 1 \\
\hline 1 & $303-8-1 B=$ TRC573 & 1 \\
\hline 1 & $308-8-2=$ TRC648 & 1 \\
\hline 3 & $349-8-1 B=$ TRC566 & 4 \\
\hline 3 & $643-8-1 B=$ TRC572 & 4 \\
\hline 3 & $350-8-1=$ TRC649 & 4 \\
\hline 3 & $118-8-1=$ TRC650 & 4 \\
\hline 4 & $405-8-1 B=$ TRC568 & 2 \\
\hline 4 & $405-8-12=$ TRC568 & 2 \\
\hline 5 & $628-8-1 B=$ TRC570 & 1 \\
\hline 5 & $629-8-1=$ TRC645 & 1 \\
\hline
\end{tabular}

Buried City and the four excavated Antelope Creek phase sites in the Oklahoma panhandle, and 10 percent each at the M-Cross Ranch and Antelope Creek phase core area sites. This wide distribution indicates the possibility that vessels assigned to Compositional Group 2 were manufactured from clays with similar chemical composition from one or more localities, likely within this northeastern region. The vessels manufactured from this clay source(s) were easily accessible and widely used by populations who primarily resided and ranged north of Long View, barring the unlikely possibility that the same clay and temper were widely available across a broad region north of the Canadian River.

In the third largest group, Compositional Group 1 ( $N$ $=10$ ), 90 percent of the sherds are from Long View. These sherds represent four vessels from Component C. The remaining 10 percent (one sherd, \#374-1a =
TRC541) is from Indian Springs (41RB81), some $10 \mathrm{~km}$ to the east. This dominance of Component C sherds in Compositional Group 1 likely reflects a relatively localized clay source, distinct from the clays in other source areas. This production source apparently was used extensively, if not exclusively, by the population represented by Component C.

The fourth largest group, Compositional Group 12, is represented by eight sherds, with nearly 88 percent coming from three Antelope Creek phase sites with three sherds from the core area and four sherds from Cross Bar Ranch site (41PT109) situated a few kilometers west of the core area. No Long View sherds were assigned to Compositional Group 12.This again clearly indicates that production was really restricted, in this case to groups residing/ operating further west. 
The fifth group, Compositional Group 4, is represented by seven sherds, 86 percent of which are from the combined components at Long View. The remaining 14 percent came from Antelope Creek Ruin 22. Unless chemically similar clay was available across a broad area, this distribution implies that a single clay source was used by different groups or that vessels were transported across the region.

Vessel A from Component A at Long View, assigned to Compositional Group 2, is a pinched or collaredrim vessel that is visibly similar to the Courson pinched rims from Courson B (410C27) of the Buried City complex (D. Hughes and HughesJones 1987; D. Hughes 1991). Of the 15 sherds analyzed from Buried City, four (27 percent) were assigned to Compositional Group 2, with only one having a thickened/pinched rim. Unfortunately, the other 11 sherds (73 percent) from Buried City were unassignable to any chemical group (Appendix G; Table G-1). The chemical composition of the pinched/collared rims from Component A links the manufacturing ingredients with at least three sherds (27 percent) from Area A at Courson B (410C27) and one sherd from Kit Courson (410C43, \#325.7 = TRC588), both at Buried City. The three sherds from Courson B include one pinched thickened/ collared rim (\#338-1 = TRC586), one thin plainsurface sherd (\#338-07 = TRC587), and one thick maize-cob-impressed sherd (\#343-22a = TRC585). These vessels with visually distinct surface finishes were manufactured from raw materials with the same chemical components that likely came from the same source. This generally supports the suggestion made by Lintz and Reese-Taylor (1997), on the basis of their petrographic data that collaredrim vessels from the Roper site in the Antelope Creek phase core area were made with clays from the Buried City area.

Three collared rims $(\# 542=$ TRC622, $\# 543=$ TRC623, and \#544 = TRC624) from Roper (41HC6) in the Antelope Creek phase core area were unassignable, however, three uncollared rims (\#545 = TRC625, \#546 = TRC626, and \#547 = TRC627) from the same site were assigned to Compositional Group 7 (Appendix G; Table G-1). These chemical results indicate that collared vessels are not chemically similar to uncollared rims, but currently cannot be matched with any of the 13 currently identified compositional groups. This may reflect the fact that so few collared rims have been chemically analyzed that a group cannot yet be identified. This also reflects the fact that 73 percent of the analyzed sherds (11 of 15) from Buried City sites could not be assigned to a particular compositional group. However, neither were they chemically similar to current the Central Plains Compositional Group 5 , which indicate that the ingredients used in the manufacture of pinched/collared vessels from Buried City sites did not originate from within the Central Plains region. More likely, these were manufactured from a local yet unidentified source in the Buried City region or other locality in the Southern Plains. In contrast to these findings, at Cottonwood Creek (41HC141) two uncollared rims (\#104.1 = TRC619 and \#109.3 = TRC620) were unassigned, while the one collared rim (\#111.4 = TRC621) was assigned to Compositional Group 7 (Appendix G, Table G-1). It appears that no single source was used to manufacture the collared/pinched vessels present across the region. The data also indicates they were manufactured with regionally available ingredients.

Overall, a strong spatially restricted distributional pattern is represented by the chemical compositional groups, indicating many localized production resources. Significantly, this demonstrates that regional-specific production signatures have been detected by INAA. Only Compositional Group 2, which includes 15 sherds (47 percent) from the Long View site, has widespread regional distribution across multiple sites in multiple areas. This implies that either a single source was repeatedly utilized by different populations or vessels made from these sources were traded regionally, or that the clays and/or tempers from across this broad region were sufficiently uniform to yield a similar chemical signature. The bedrock across the region is dominated by Ogallala Formation clays with significant quantities of eolian sand covering. Based on the current chemical evidence, the 21 vessels identified at Long View were not imported from any of the 15 specific Plains Village sites sampled or made of clays from the 42 sampled sources. With 32 percent (61 of 193) of sherds unassigned to any of the 13 chemical compositional groups and no strong matches with any of the 42 natural clay source 
samples, additional pottery and clay samples will have to be added to the current database in order to identify specific source areas for unassigned vessel production. Of significance, although the cordmarked ceramics of Plains Village sites appear similar at the macroscopic scale, the chemical analysis definitively demonstrates there is detectable chemical variability that could eventually lead to a greater understanding of human behavior.

The answer to the question posed above, "are the ceramic sherds represented of the Long View components manufactured locally or were they imported?”, is that the chemical compositional data indicate that the vessels were not manufactured onsite from either of the two local Long View clay samples analyzed. Nor are chemical data present to indicate that these vessels were manufactured at great distances beyond this region and imported to this site. The chemical compositional data indicates that vessels from both components were manufactured from multiple clay sources in the general region. Minimally one and, quite possibly two source areas represented in the Long View pottery assemblage are not represented in the pottery analyzed from any of the other 21 sites sampled across the surrounding region (Appendix $\mathrm{G}$ ). This indicates a clay source used only by the Long View occupants.

\subsubsection{Petrographic Analysis}

Petrographic analysis was conducted on 87 sherds and 10 clay samples (8 tempered with regionally available materials) from 16 Plains Village sites in the region (Table 10-11). This includes 20 sherds from Long View, 10 from Component A and 10 from Component $\mathrm{C}$. The 87 sherds were assigned to 35 paste groups based on a suite of characteristics that include paste color, temper, isotropism, and paste density (Appendix F). The 35 paste groups are divided within 4 broad temper classes based primarily on the dominant temper observed. These four broad temper classes include: 1) crushed rock and mineral, 2) bone, 3) bone combined with basalt, and 4) basalt (Table 10-12). The two Long View components exhibit distinct and separate temper classes. Component A sherds are predominately (9 of 10) tempered with crushed quartz rock and other minerals, whereas Component $\mathrm{C}$ sherds are predominately (9 of 10) basalt tempered. Overall, petrographic results reveal considerable diversity in proportional quantity of tempers present. The following briefly summarizes the four broad temper classes identified in the analyzed samples.

Temper of crushed rock and mineral accounts for 47 percent of all sherds in the 13 paste groups. This temper class is present in sherds from 62.5 percent (10 of 16) of the regional sites chosen for analysis. Nine Long View Component A sherds (90 percent) have this temper, and these account for 25 percent of all crushed rock and mineral tempered sherds identified $(N=40)$. This consistent use of the same temper reflects a very homogenous group of vessels from Component $\mathrm{A}$.

The bone tempered class contains only four paste groups (E, F, G and Y) and only 10.6 percent $(N=$ 9 ) of the analyzed sherds. These sherds are present at 19 percent (3 of 16) of the analyzed sites. Sixty seven percent of the bone tempered sherds $(N=6)$ are from Indian Springs at M-Cross Ranch, and may represent multiple components (Cruse 2007). Two sherds are from Courson B and one is from Two Sisters. All bone tempered sherds come from areas north and east of Long View and the Antelope Creek phase core area.

The temper class that contains a combination of bone and basalt is represented by only three paste groups $(\mathrm{H}, \mathrm{CC}$ and DD) and comprises a low 5.9 percent $(N$ $=5$ ) of the total sherds. This combination is present in sherds from 25 percent ( 4 of 16) of the analyzed sites, and includes two sherds from Indian Springs, and one sherd each from Three Toes, Courson B, and Roy Smith. This combination of bone and basalt tempered sherds also comes from the area north and east of the Antelope Creek phase core area and Long View.

The basalt tempered class contains 14 paste groups and accounts for the second highest frequency, comprising 36.5 percent $(N=31)$ of the analyzed sherds. Basalt temper is present in sherds from 75 percent of the selected sites (12 of 16) and multiple sites across the region surrounding Long View (Appendix F). One sherd (10 percent) from Component $\mathrm{A}$ and nine sherds (90 percent) from Component C from Long View represented 32.2 percent (10 of 31 sherds) in this class. 
Table 10-11. Sites and Sherd Designation Selected for Petrographic Analysis.

\begin{tabular}{|c|c|c|c|}
\hline Site Number & Site Name & Sherd Designation & $\begin{array}{c}\text { Natural } \\
\text { Clay }\end{array}$ \\
\hline \multicolumn{4}{|c|}{ Buried City Sites along Wolf Creek } \\
\hline $410 C 27$ & Courson B & $335,386,216,398,243,383,556,256$, and 462 & 1 \\
\hline $410 C 29$ & Courson D & 338-07, 338-1, 343-22, 346 & 1 \\
\hline $410 C 43$ & Kit Courson & $325.7,65$ & \\
\hline \multicolumn{4}{|c|}{ Four Antelope Creek Phase Sites in Oklahoma Panhandle } \\
\hline 34TX1 & Stamper & $10,14,155,377,407,408$ & \\
\hline 34TX31 & McGrath & $74,175.1,175.2$ & \\
\hline 34TX32 & Two Sisters & $71,302,364,427,580,600$ & 2 \\
\hline 34BV14 & Roy Smith & $21,44,53,284,285-1,285-2$ & \\
\hline \multicolumn{4}{|c|}{ Antelope Creek Phase Core Area Sites } \\
\hline 41PT11 & Alibates Creek Ruin 28 & 7, 2, 28-71, 28-73, 28-A-21, 28-A8-60, 28-A2-8, 28-A2-R3, 545 & \\
\hline 41HC6 & Roper & 545 & \\
\hline 41HC23 & Antelope Creek 22 & 3c7, R2/13, R2/15, 5I/45, 7A-20 & 1 \\
\hline 41HC141 & Cottonwood Creek & $111.4,104.1,109.3$ & \\
\hline \multicolumn{4}{|c|}{ M-Cross Ranch Sites } \\
\hline 41RB81 & Indian Springs & 156, 291, 374-2, 381, 505 & 1 \\
\hline 41RB108 & Whistling Squaw & WP6 & \\
\hline 41RB109 & Hank’s & WP2, 3, 4, 5 & 2 \\
\hline 41RB110 & Three Toes & WP7, 8, 9 & \\
\hline \multicolumn{4}{|c|}{ Long View } \\
\hline 41RB112 & Long View Component A & 2, 998, 1036, 1066, 1119, 1135, 1140, 1175, 1223, 1206, & \multirow{2}{*}{2} \\
\hline 41RB112 & Long View Component C & 259, 303, 338, 349, 362, 405, 468, 639, 628, 643 & \\
\hline Total & & 87 & 10 \\
\hline
\end{tabular}

Overall, petrography reveals that no single material was consistently used as temper by Southern Plains Village potters across the panhandle region. A minimum of four broad temper classes with many minor variations have been identified across the 16 sites in the general Texas and Oklahoma panhandle region. Variability of temper types in sherds from a single site may indicate the presence of different vessels, variability in the tempering choices made by individual potters or occupations, and/or different production/source areas for raw materials. The analyzed sherds from Component A represent at least 10 vessels, whereas analyzed sherds from Component C represent at least 7 vessels. Long View is unusual in that each component has pottery tempered predominately by one broad temper class: crushed rock and minerals in Component A, and basalt with pyroxene in Component C. Multiple minor variations are present within the broad temper classes utilized by the separate populations.

An example of the minor variations detected are two sherds (WP1 [E3] and WP2 [E3]) from the same reconstructed vessel from a cairn burial at Hank's site (41RB109-E) at M-Cross Ranch (Boyd, personal communication 2010). The two sherds, one from the upper body (WP1) and one from the base (WP2) of the vessel, had the same basic temper - crushed rock and minerals, dominated by quartz, feldspars, and volcanic minerals. These two sherds were assigned to the same chemical composition group (Group 2) by INAA. However, these two sherds were assigned 
Table 10-12. Sherds Assigned to Four Temper Classes by Site.

\begin{tabular}{|c|c|c|c|c|c|}
\hline $\begin{array}{c}\text { Site } \\
\text { Number }\end{array}$ & Site Name & Rock and Mineral & Bone & $\begin{array}{c}\text { Bone and } \\
\text { Basalt }\end{array}$ & Basalt \\
\hline \multicolumn{6}{|c|}{ Buried City Sites along Wolf Creek } \\
\hline $410 C 27$ & Courson B & 216, 355, 386, 398 & 243,383 & 556 & 256,462 \\
\hline $410 C 29$ & Courson D & $338-1,338-7,343-22$ & & & 346 \\
\hline $410 C 43$ & Kit Courson & & & & $65,325.7$ \\
\hline \multicolumn{6}{|c|}{ Four Antelope Creek Phase Sites in Oklahoma Panhandle } \\
\hline 34TX1 & Stamper & $10,155,377,407,408$ & & & 14 \\
\hline $34 \mathrm{TX} 31$ & McGrath & & & & $74,175.1,175.2$ \\
\hline 34TX32 & Two Sisters & $21,44,53,285-1,285-2$ & 284 & & \\
\hline 34BV14 & Roy Smith & 302 & & 580 & $71,364,438,427,600$ \\
\hline \multicolumn{6}{|c|}{ Antelope Creek Phase Core Area Sites } \\
\hline 41PT11 & Alibates Creek Ruin 28 & $\begin{array}{c}\text { 28-A-21, 28-A8-60, 28-A2- } \\
\text { R3, 28-71, 28-73 }\end{array}$ & & & $\begin{array}{c}\text { 2, 7, 28-A8-16, 28-A6-92, 28- } \\
\text { A2-8, 28-A8-42 }\end{array}$ \\
\hline 41HC6 & Roper & $543,544,546,547$ & & & 542,545 \\
\hline $41 \mathrm{HC} 23$ & Antelope Creek 22 & $\mathrm{R} 2 / 13, \mathrm{R} 2 / 3, \mathrm{R} 2 / 15,3 \mathrm{c} 7$ & & & $74-20,5 \mathrm{I} / 45$ \\
\hline 41HC141 & Cottonwood Creek & 111.4 & & & $104.1,109.3$ \\
\hline \multicolumn{6}{|c|}{ M-Cross Ranch Sites } \\
\hline 41RB81 & Indian Springs & & $\begin{array}{c}156,291,347 \\
374-2,381,505\end{array}$ & 370,492 & $374-1$ \\
\hline 41RB108 & Whistling Squaw & & & & WP6 \\
\hline 41RB109 & Hank’s & WP2, WP1 & & & WP3, WP4, WP5 \\
\hline 41RB110 & Three Toes & WP7, WP8 & & WP9 & \\
\hline \multicolumn{6}{|c|}{ Long View } \\
\hline 41RB112 & Long View Component A & $\begin{array}{c}\text { 2, 998, 1036, 1066, 1119, } \\
1135,1140,1175,1223\end{array}$ & & & $1206-1$ \\
\hline 41RB112 & Long View Component C & 259 & & & $\begin{array}{c}303,338,349,362,405,468, \\
628,639,643\end{array}$ \\
\hline
\end{tabular}

to different petrographic temper paste groups (B and D) based on temper frequency variations, paste color, and isotropism (Appendix F). Additionally, Lintz and Reese-Taylor (1997) document a 7 percent difference in the primary ingredient, quartz, 9 percent difference in alkali feldspar, and differences in minor minerals, between two sherds (410C4364 and 410C43-329.1) from the same vessel from Kit Courson. Similarly, two sherds (\#338 and \#362) from Vessel 1 from Long View Component C were assigned to the same general basalt temper class, but two different paste groups (I and FF, Appendix F). The pastes were different colors, red-brown versus tannish gray, which likely reflects variable firing temperatures and atmospheres for a single vessel. One sherd also exhibits few minor minerals, while the other has abundant minor minerals (Appendix F). These examples illustrate the minor variations that can occur across a single vessel.

These three examples highlight the fact that thin cross sections of a single sherd represent a very tiny percentage of the vessel. Minor variations and differences do exist across handmade vessels. Variable mixing of clay and temper can result in variability in the thin sections. It is also quite possible that different portions of the vessel (base, body, and rim) were built with different pieces of clay, and 
perhaps even different batches of mixed ingredients. Multiple paste groups may seem disconcerting, but it is better to observe and document in as much detail as possible and combine results into broader categories as needed.

The 10 analyzed Component $A$ vessels generally have less particles in the paste with 60 percent containing 9 to 21 percent particles and only 30 percent with over 25 percent. In contrast the seven plus vessels (the plus is an unassigned sherd) analyzed from Component $\mathrm{C}$ vessels generally have more particles with 88 percent greater than 20 percent particles (Figure 10-14). The higher percentage particles in Component $C$ vessels appear to reflect a higher percentage of resident quartz. The actual temper in Component $\mathrm{C}$ vessels created the separation of the two components with component A vessels mostly assigned to crushed rock and mineral with trace to 5 percent Rock A, B, and C plus more schist (Table 10-13). In contrast Component $\mathrm{C}$ has no Rock A, B, or C and no schist. Component $\mathrm{C}$ is dominated by basalt with pyroxene along with rhyolite, and slightly more biotite and muscovite. Both components contain roughly similar presence of and percentages of hematite, chert, orthoclase, and limestone (Table 10-13). None of the 17 vessels analyzed have bone or grog temper.

\section{General Petrographic Observations}

Petrography reveals that multiple temper classes were employed by the Southern Plains Village populations, with crushed rock and minerals dominant and in widespread use, present in 47 percent of the sherds analyzed. This temper was readily available across the region. The second highest prevalence was basalt with pyroxene in 36.5 percent, followed by crushed bone in 10.6 percent, and bone combined with basalt in 5.9 percent. It does not appear that any one site or region yields one specific temper class, except for the two Long View components. Multiple alternatives are possible given diverse use of tempering materials. Variability in temper within a site and/or within a group may imply potters may have chosen tempers as individuals. The two Long View components do not reflect that individual choice was operative at this site. Each component implies a single line of direct transmission of pottery manufacturing technology, which indicates manufacture by a single family group as they moved across the landscape. If groups or family units followed family traditions in tempering their pottery, then pots made by groups/ families may have been traded across the region. It is also possible that female exogamy and pottery technology through the female line would result in high variability of nonvisible technological traits. It is also likely that potters relocated through marriage and subsequently moved across the region with their extended family groups, but continued to manufacture pottery as they were originally taught as children. Future petrography will hopefully help to address these and many other questions.

Crushed bone, as the least-used tempering material of the analyzed sherds, sometimes in combination with basalt temper, is interesting and requires a closer examination. Petrography documented crushed bone in 10.6 percent $(N=9)$ of the analyzed sherds from three sites, with 67 percent of the bone tempered sherds originating from Indian Springs at M-Cross Ranch. Twenty-two percent came from Courson B just a few kilometers north at Buried City along Wolf Creek, whereas the remaining 11 percent came from Two Sisters in Oklahoma. Bone combined with basalt was also identified in 5.9 percent $(N=5)$ of the analyzed sherds, and is present at Indian Springs and Courson B as well, plus Three Toes at M-Cross Ranch and Roy Smith in the Oklahoma panhandle. The use of crushed bone as a tempering agent at these sites in the Oklahoma panhandle, but not in any of the sherds from Antelope Creek phase sites in the core area, indicates a regionally confined selection process, rather than temporal, as the Oklahoma sites are also part of the Antelope Creek phase (Lintz 1986). Cordmarked sherds, prominent in Antelope Creek phase sites, are thus not standardized in tempering materials across the entire distribution of Antelope Creek phase sites, as bone tempered sherds (14 sherds or 16.5 percent) are present at these five sites north of the Canadian River, outside the Antelope Creek phase core area. No bone temper was identified in the 15 sherds analyzed by Lintz and Reese-Taylor (1997) from four Antelope Creek phase sites (Roper, Antelope Creek 22, Alibates Ruin 28, or Cottonwood Creek) in the core area. 

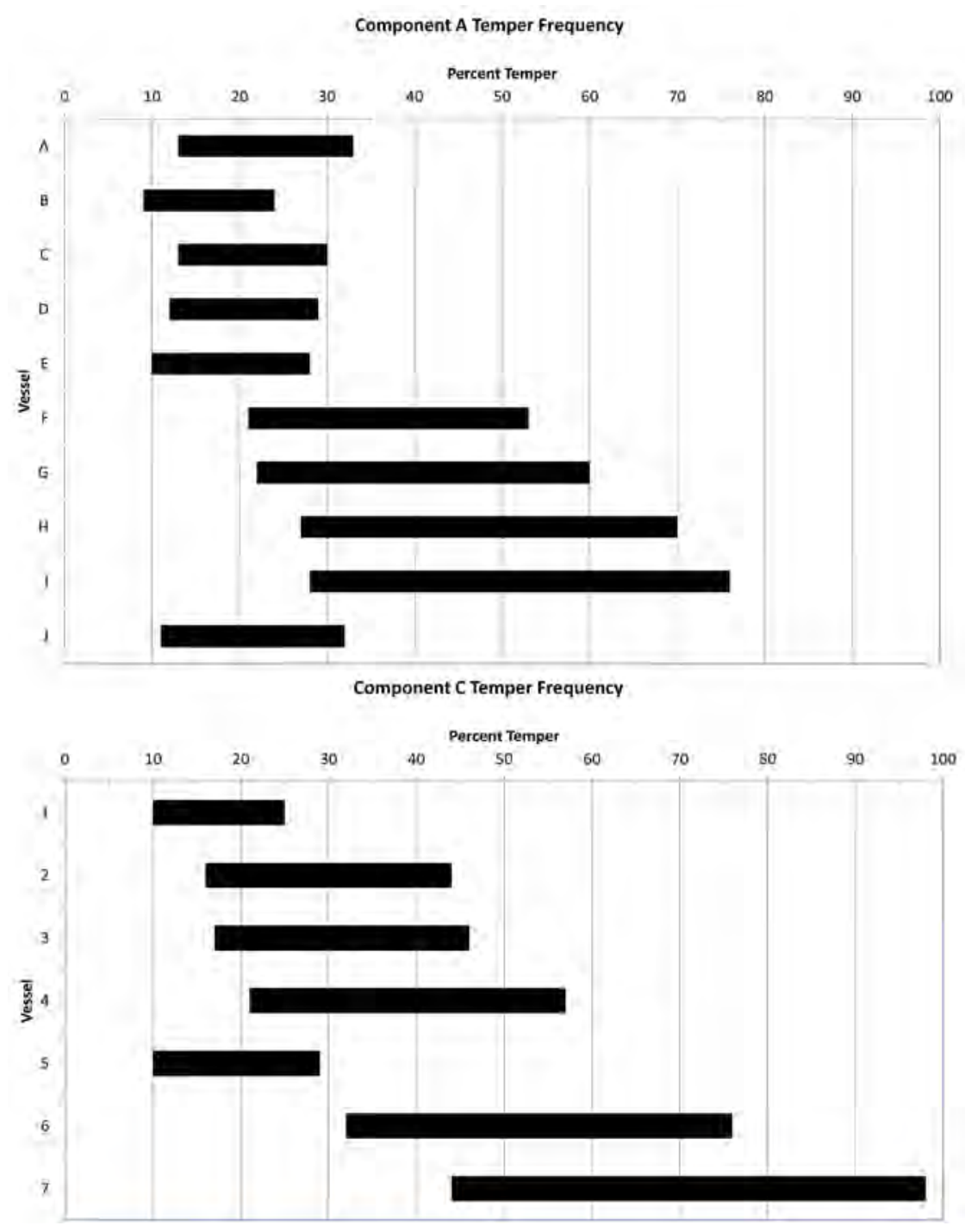

Figure 10-14. Graph showing the range of temper frequency by Long View component.

Bone temper appears rare in most Plains Village assemblages where petrography has been conducted. Three whole or nearly whole vessels attributed to the Apishapa phase in southeastern Colorado exhibit variable temper characteristics, but no bone was detected (Ellwood 1995:140, 2002:41-47). In northeastern Colorado, the Upper Republican pottery generally exhibits crushed biotite-rich granite temper (Ellwood 1995:136 and Ellwood and Parker 1994). For a Late Woodland/Middle Ceramic occupation (ca. 647 B.P. or A.D. 385) at the Sperry site in Jackson County, Missouri, O’Malley (1981) documented 11 sherds with temper of 55 percent granite and 16 percent sand, but no bone. Consequently, the use of crushed bone may be an isolated regional trait or potentially limited to sites or occupations where intensive processing of bison created easy access to bone at the same time pottery production occurred. Bone temper use does not appear random, as the Late Prehistoric Toyah phase across much of Texas typically contains bone (Reese-Taylor 1993b, 1995a, 1995b; Reese-Taylor et al. 1994; Perttula et al. 2003).

Bone is often thought of as the temper used in the Woodland/Early Ceramic period. However, a review by Quigg (1997) revealed a few instances of early ceramic sherds in the region surrounding Long View with multiple other tempers. One cordmarked sherd from a Late Archaic bison processing site (41HF128), some $60 \mathrm{~km}$ to the northwest in Palo Duro Creek 
Table 10-13. Comparison of Temper Classes by Site.

\begin{tabular}{|c|c|c|c|c|}
\hline \multirow[b]{2}{*}{ Site/Count } & \multicolumn{4}{|c|}{ Broad Temper Class/Paste Group } \\
\hline & Rock and Mineral & Basalt with Pyroxene & Bone & Bone with Basalt \\
\hline \multicolumn{5}{|c|}{ Long View Site } \\
\hline 41RB112 - Comp. A $(N=10)$ & A, B, C, EE & $\mathrm{HH}$ & & \\
\hline 41RB112 - Comp. C $(N=10)$ & $\mathrm{EE}$ & I, FF, GG, HH, II & & \\
\hline \multicolumn{5}{|c|}{ Four Oklahoma Antelope Creek Phase Sites } \\
\hline $34 \mathrm{TX} 1(N=6)$ & $\mathrm{M}, \mathrm{O}, \mathrm{T}$ & $\mathrm{U}$ & & \\
\hline $34 \mathrm{TX} 31(N=3)$ & & $\mathrm{Q}, \mathrm{S}$ & & \\
\hline $34 \operatorname{TS} 32(N=6)$ & $\mathrm{K}, \mathrm{V}, \mathrm{W}, \mathrm{X}$ & & $\mathrm{Y}$ & \\
\hline 34BV114 $(N=7)$ & $\mathrm{Z}$ & $\mathrm{AA}, \mathrm{BB}$ & & CC \\
\hline \multicolumn{5}{|c|}{ Three Buried City Complex Sites in Wolf Creek } \\
\hline $41 \mathrm{OC} 27(N=9)$ & $\mathrm{M}, \mathrm{O}, \mathrm{T}$ & $\mathrm{N}, \mathrm{L}$ & $\mathrm{E}$ & $\mathrm{H}$ \\
\hline $410 \mathrm{OC} 29(N=4)$ & $\mathrm{M}, \mathrm{O}$ & $\mathrm{P}$ & & \\
\hline $410 C 43(N=3)$ & & $\mathrm{Q}, \mathrm{R}$ & & \\
\hline \multicolumn{5}{|c|}{ Four M-Cross Ranch Sites } \\
\hline 41RB81 $(N=9)$ & & $\mathrm{I}$ & E, F, G & $\mathrm{H}$ \\
\hline 41RB108 $(N=1)$ & & $\mathrm{L}$ & & \\
\hline $41 \mathrm{RB} 109(N=5)$ & $\mathrm{B}, \mathrm{D}$, & $\mathrm{L}$ & & \\
\hline $41 \mathrm{RB} 110(N=3)$ & $\mathrm{D}$ & & & DD \\
\hline \multicolumn{5}{|c|}{ Four Antelope Creek Phase Core Area Sites } \\
\hline 41PT11 $(N=6)$ & A, J, K & I, FF, GG, HH, II & & \\
\hline $41 \mathrm{HC} 23(N=6)$ & A, B, C, EE & I, FF, GG, HH, II & & \\
\hline $141 \mathrm{HC6}(N=6)$ & yes & yes & & \\
\hline $141 \mathrm{HC} 141(N=2)$ & yes & yes & & \\
\hline
\end{tabular}

1 Data from Lintz and Reese-Taylor 1997 petrographic study

valley, contained 8.5 percent bone and 8.0 percent quartz temper (Quigg 1997). This may indicate an early, localized use of bone, possibly due to easy access through association with bison processing. Lynn (1982) mentions that bone, scoria and other materials are found in a few Borger Cordmarked sherds, but they were not the usual tempering materials. Without mentioning specific sites or samples Lynn does indicate that crushed quartz, sand and mica were used in Borger Cordmarked pottery. The crushed quartz is the most prominent followed by sand, and the mica being a by-product from the weathered Trujillo sandstone (Lynn 1982:7). He cites the Grinnell (1961:255) account of Pawnee Indians roasting rocks and pounding them into power or sand and mixing them with clay (Lynn 1982:6).

\subsubsection{Long View Ceramic Component Discussions}

Support for the regional manufacture of Long View pottery vessels comes from the petrographic results. Both dominant temper classes, crushed rocks/ minerals (90 percent of Component A vessels), and basalt (87 percent of Component $C$ vessels) are also present at the other 16 analyzed regional Plains Village sites (Appendix F). This probably reflects a broad, generalized pattern of using multiple temper types for the Texas and Oklahoma panhandle region during the Plains Village period. Below, each component from Long View is briefly discussed.

At least two chemical source areas in the general region provided clay and/or temper for pottery 
manufacture, as indicated by the 16 pottery sherds representing at least 10 vessels, analyzed from Component A. Ninety percent of the vessels ( 9 of 10 analyzed) reflect a single chemical source. The redwashed Vessel $\mathrm{C}$ is the only vessel not manufactured from this source. Petrography reveals nine of ten vessels from Component A utilize only crushed rock and miscellaneous minerals, predominately quartz as temper. Combined, the INAA chemical analysis and petrography document a prominent and consistent pattern of temper and clay use by that specific population (Table 10-14). These results support the presence of a pottery tradition passed down from one member to another, and likely reflects a closeknit social grouping, possibly a family unit, that occupied Component A. Although the tempers are similar, three different paste colors were noted in those nine sherds. The color differences most likely reflect variation in the firing processes, the portion of vessel (rim, body, or base) represented by the thin section, the amount of use of that vessel, and/or the foods cooked in these different vessels. For instance, oily and/greasy foods may create color differences in contrast to maize or little barley mush.

The chemical compositional data from 16 Component $\mathrm{C}$ sherds that represent at least 7 vessels indicates at least three clay sources, two of which were the same clay sources identified for Component A. This data indicates that clays used in pottery manufacturing were likely from this general area and exploited by both groups. In Component $\mathrm{C}$, results document four of seven identified vessels (Vessels 1, 2, 5, and 6), were manufactured from apparently the same source clay. These four vessels visually are quite different in form and surface finish. In particular, Vessel 1 has very thick walls and a large squat form, compared to other vessels. Vessel 2 is a faintly cordmarked small globular jar with a thin rim and neck. Vessel 6 exhibits a maize cob-impressed exterior finish.

The petrographic results document that eight of nine analyzed vessels contain principally basalt with pyroxene, although in slightly different frequencies (Appendix F). Only sherd \#259, representing Vessel 2 from Component $\mathrm{C}$, is unique in that it was assigned to the crushed rock and mineral temper class and contains common quartz and rhyolite. These temper observations do not fully support the chemical results (see Table 10-14). One plausible explanation of the differences is that chemical analysis assignment appears primarily influenced by the dominant mineral, whereas petrography may be more focused on diversity of individual temper particles. Additionally, the tiny portion of the vessel represented in the thin section petrographic slide and the $1 \mathrm{~g}$ sample for INAA may have resulted in sample skew in the results.

\subsubsection{Other Petrographic Analysis and Further Discussions}

Previous detailed descriptions and technical studies are nearly nonexistent for ceramic assemblages across the region encompassing the Buried City complex, the Odessa Yates site, the multiple M-Cross sites and the Antelope Creek phase sites. One exception is a petrographic analysis conducted on 22 sherds from 6 sites Lintz and Reese-Taylor (1997). They included 15 sherds from 4 Antelope Creek phase core area sites (Alibates Ruin 28 [41PT11], Antelope Creek Ruin 22 [41HC23], Roper [41HC6], Cottonwood Creek Ruin [41HC141]), 3 sherds from the Buried City complex Kit Courson site (41OC43), and 4 sherds from 25NC29, an Itskari phase site in western Kansas, with Upper Republican assemblages. Their analysis focused on determining if collared-rim vessels are nonlocal in origin. Eleven collared and 11 uncollared rim sherds were included in their study, although three collared rims from Kit Courson may not be true collared rims, but merely thickened and pinched rims. Their general petrographic results indicate that collaredrim vessels from Antelope Creek phase sites at Lake Meredith in the core area were manufactured from local clays (Lintz and Reese-Taylor 1997). Collared/ decorated rims are most common in the Odessa phase (Brosowske 2005) and at Buried City (D. Hughes and Hughes-Jones 1987; D. Hughes 2001).

Additionally, the Lintz and Reese-Taylor (1997) petrographic analysis delineated two fundamentally distinct mineralogical groups/classes: one pertaining to sedimentary rock (which possibly corresponds to the crushed rock and mineral paste group here) and the other to igneous rock (likely corresponds to the basalt class here) based on mineral content and shape and size of temper. The authors do not state whether or not one or the other mineralogical group 
Table 10-14. INAA and Petrography Result Comparison for the Two Long View Components.

\begin{tabular}{|c|c|c|c|c|c|c|c|c|}
\hline \multirow{2}{*}{\begin{tabular}{|c|} 
Long View Components \\
Vessels
\end{tabular}} & \multicolumn{4}{|c|}{ Pertrographic Broad Temper Classes } & \multicolumn{4}{|c|}{ INAA Compositional Groups } \\
\hline & Rock \& Minerals & Basalt & Bone & Basalt \& Bone & 1 & 2 & 3 & 4 \\
\hline \multicolumn{9}{|l|}{ Component A } \\
\hline Vessel A & $\mathrm{x}$ & & & & & $\mathrm{x}$ & & \\
\hline Vessel B & $\mathrm{x}$ & & & & & $\mathrm{x}$ & & \\
\hline Vessel C & & $\mathrm{x}$ & & & & & & $\mathrm{x}$ \\
\hline Vessel D & $\mathrm{x}$ & & & & & $\mathrm{x}$ & & \\
\hline Vesesl E & $\mathrm{x}$ & & & & & $\mathrm{x}$ & & \\
\hline Vessel F & $\mathrm{x}$ & & & & & $\mathrm{x}$ & & \\
\hline Vessel G & $\mathrm{x}$ & & & & & $\mathrm{x}$ & & \\
\hline Vessel H & $\mathrm{x}$ & & & & & $\mathrm{x}$ & & \\
\hline Vessel I & $\mathrm{x}$ & & & & & $\mathrm{x}$ & & \\
\hline Vessel J & $\mathrm{x}$ & & & & & $\mathrm{x}$ & & \\
\hline \multicolumn{9}{|l|}{ Component C } \\
\hline Vessel 1 & & $\mathrm{x}$ & & & $\mathrm{x}$ & & & \\
\hline Vesesl 2 & $\mathrm{x}$ & & & & $\mathrm{x}$ & & & \\
\hline Vessel 3 & & $\mathrm{x}$ & & & & & & $\mathrm{x}$ \\
\hline Vesesl 4 & & $\mathrm{x}$ & & & & $\mathrm{x}$ & & \\
\hline Vesesl 5 & & $\mathrm{x}$ & & & $\mathrm{x}$ & & & \\
\hline Vessel 6 & & $\mathrm{x}$ & & & $\mathrm{x}$ & & & \\
\hline Vessel 7 & & $\mathrm{x}$ & & & & $\mathrm{x}$ & & \\
\hline
\end{tabular}

is local. The sedimentary class consists of 11 sherds (50 percent) with rounded quartz sand (49 to 99 percent), various quantities of alkali feldspar (0 to 50 percent), and traces of mica, biotite and carbonates. This sedimentary class was subdivided into three subgroups based on minor variations in temper. Subgroup 1 consists of two collared rims (\#64 and \#188), from Kit Courson, likely representing the same vessel, and one uncollared rim (\#547) from Roper. Subgroup 2 consists of five sherds: one collared rim (\#111.4) from Cottonwood Creek Ruin, two collared rims (\#543 and \#544) representing a single vessel from Roper, one uncollared rim (\#546) from Roper, and one collared rim (\#329.6) from Kit Courson. Subgroup 3 consists of a single collared rim (\#F-19) from 25NC29. Lintz and Reese-Taylor (1997) include in their igneous group/class 11 sherds (60 percent) with 16 to 35 percent temper, mostly quartz (57 to 79 percent), alkali feldspar (0 to 23 percent), and rocks of the "granite family" (4 to 37 percent) that contain traces of mica, biotite, carbonates, volcanic rock, and chert. All three sherds from Kit Courson were sedimentary with low amounts of mica. This contrasts with eight of nine (89 percent) sherds from three Antelope Creek phase core area sites (Alibates Ruin 28, Antelope Creek Ruin 22, and Cottonwood Creek Ruin) that contain primarily igneous materials. Sherds from Roper reveal more complexity with four of six (67 percent) manufactured with sedimentary materials. Although the sample size was small, the petrographic results indicate granite-tempered sherds were apparently manufactured in the Antelope Creek phase core area, whereas sherds from Kit Courson were tempered with sand. This data reflects two geographically separated sources of primary tempering agents: sedimentary and granitic.

Unfortunately, the three sherds from Kit Courson petrographically analyzed by Lintz and ReeseTaylor (1997) could not be relocated and thus were not included in this study. However, 14 of 15 sherds from the other 4 Antelope Creek phase sites in the 
core area analyzed by Lintz and Reese-Taylor were subjected to INAA in the current study. Nine sherds (60 percent) were assigned to Compositional Group 7 , five (33 percent) were unassigned, and one was part of Compositional Group 2. Whereas Lintz and Reese-Taylor's petrographic analysis (1997) identified two mineralogical groups/classes, our INAA identified at least two chemical compositional groups from those same sherds that cross-cut the two petrographic mineralogical groups/classes (Appendix G). Compositional Group 7 included both sedimentary sand-tempered and granite tempered sherds. Obviously, a one-to-one correspondence does not exist between chemical compositional group and temper type; therefore, the difference must lie within the clay. However, INAA results on six sherds from Roper indicate those sherds reflect at least two, and likely three, source localities. The Lintz and Reese-Taylor (1997) petrographic results on nine sherds (three Cottonwood Creek sherds, three Antelope Creek Ruin 22 sherds, and the three Alibates Ruin 28 sherds) all indicate a minimum of two broad temper categories, which may or may not equate with source areas.

Exterior surface treatment shows no consistent correlation with tempering agents. For an example, the three maize cob-impressed sherds, from three separate sites (410C29/343-22, 410C27/386 and 41RB112/639), belong to three different paste groups (O, M and I respectively), based on petrographic observations (Appendix F). The use of collared and uncollared rims across the region also do not correlate to temper type, as sedimentary and igneous tempers are both present in rims of both types (Table 10-15). Of the total 41 rims analyzed, only 39 percent $(N=$ 16) were manufactured with igneous materials and only one was a collared rim. Therefore, 91 percent of collared rims were manufactured using sedimentary materials, whereas 50 percent of the uncollared sherds were manufactured using igneous materials. The data indicates that vessels were manufactured using a variety of materials and no direct correlation is obvious between temper choice and exterior treatments such as form, surface treatment, or rim style. It is not clear if vessels were traded across the landscape or if the differences reflect different choices by individual potters within a given group of people.
The 15 random sherds subjected to petrographic analysis from three Buried City sites likely represent multiple components or occupational episodes. Therefore, caution must be used in interpreting the brief observations presented here. These 15 sherds were placed into four broad temper classes; crushed rock and mineral $(N=6)$, the basalt with pyroxene $(N=5)$, bone $(N=2)$, and combined bone and basalt $(N=1)$. Obviously, these 15 sherds do not represent a single homogenous manufacturing technology, but rather show considerable diversity. Many more sherds per site need to be subjected to petrography to gain a clearer understanding of the behavior and pottery manufacturing process represented. This need is illustrated through INAA results that were only able to assign 26.7 percent of the analyzed sherds to a particular compositional group (Group 2), whereas 73.3 percent went unassigned because of the limited number of samples available for defining clear associations (Appendix G, Table G-1).

INAA reflects the highest frequency of the major chemicals present, whereas minor chemical constituents were not as useful for assigning sherds to compositional groups. Consequently, INAA may have combined sherds into broader groups based on high frequencies of one or more chemicals, in contrast to petrographic division of sherds into 35 paste groups, based on the presence of numerous individual material types and other characteristics. It is likely that the assignments of sherds in each of the two technical analyses were done based on divergent approaches, INAA utilizing general lumping, and petrography employing detailed splitting.

\subsubsection{Summary of Ceramic Sherd Analyses from Long View}

Macroscopic inspection and analysis of Component $\mathrm{A}$ and $\mathrm{C}$ ceramic assemblages reveal that only two vessels, Vessel $\mathrm{N}$ and Vessel C, both from Component A, were nonlocally manufactured and imported from great distances. Vessel $\mathrm{N}$ is characterized by a well-executed dark line painted on a smooth gray surface. The sherd representing this vessel is tiny, less than 2-cm-wide, too small for technical analyses. Therefore, only the painted line is suggestive of a nonlocal vessel, as the only representation of such treatment among the assemblage overwhelmingly dominated by vessels with unpainted and cordmarked 
Table 10-15. Associations of Temper Types with Collared and Uncollared Vessels from the Region.

\begin{tabular}{|c|c|c|c|}
\hline $\begin{array}{l}\text { Site } \\
\text { Number }\end{array}$ & Site Name & $\begin{array}{l}\text { Uncollared Rim } \\
\text { Sherds (sherd } \\
\text { designations) }\end{array}$ & $\begin{array}{l}\text { Collared Rim Sherds } \\
\text { (sherd designations) }\end{array}$ \\
\hline $410 \mathrm{C} 27$ & Courson B & & $256-57$ \\
\hline $410 \mathrm{OC} 29$ & Courson D & & $338-1$ \\
\hline $410 C 43$ & Kit Courson & & $16,188,329.6$ \\
\hline $34 \mathrm{TX} 1$ & Stamper & $10, \mathbf{1 4}, 155,377,407$ & \\
\hline $34 \mathrm{TX} 31$ & McGrath & 175.1 & \\
\hline $34 \mathrm{TX} 32$ & Two Sisters & 427 & \\
\hline 41PT11 & Alibates Creek Ruin 28 & $\begin{array}{c}\mathbf{1 6 7}, \mathbf{2 9 5}, 330,28-\mathrm{A} 8-42,28 \\
\text { A8-16, 28-A6-92 }\end{array}$ & \\
\hline 41HC23 & Antelope Creek 22 & \begin{tabular}{|l|} 
7A-20 \\
\end{tabular} & \\
\hline 41HC141 & Cottonwood Creek & 104.1, 109.3 & 111.4 \\
\hline 41HC6 & Roper & $545,546,547$ & $542,543,544$ \\
\hline 41RB109 & Hank's & WP1(E3) & \\
\hline 41RB112 & Long View Component A & 1066 & 2,1140 \\
\hline 41RB112 & Long View Component C & $259,338,349,405,628$ & \\
\hline Total & & 15 igne ous & 1 igne ous \\
\hline \multicolumn{4}{|c|}{$\begin{array}{l}\text { Bold = bas alt and/or granite/igneous by Lintz and Reese-Taylor 1997; normal = } \\
\text { quartz and other minerals }\end{array}$} \\
\hline
\end{tabular}

surfaces. It is believed that this vessel was likely manufactured in the Pueblos of New Mexico and arrived through trade. Vessel $\mathrm{C}$ is represented by a red-washed plain-textured surface exterior, unique and distinct from other plain surface vessels present and therefore is also thought to reflect a nonlocal vessel. However, petrographic analysis of a Vessel C sherd indicates the temper was part of the broad basalt class, which contains at least 31 analyzed sherds for across this region. The INAA results from two Vessel C sherds placed both in Compositional Group 4, which comprises only 5 percent of all 102 assigned sherds (Appendix G). Although this surface finish is unique at this site and rare for this region, Vessel $\mathrm{C}$ was probably manufactured in this region based on the paste composition. The unique surface treatment may indicate some special use or function within the local population, or perhaps a local imitation of pottery from a different ceramic tradition. Therefore, only painted Vessel $\mathrm{N}$ of the 21 identified vessels from these two components is considered nonlocally manufactured, based on these analyses. The overall Long View ceramic assemblage was documented both physically and chemically as manufactured with variations in tempers and clays from multiple sources within the broader region. However, neither Long View component assemblage was manufactured from sampled local analyzed on-site sources, which may indicate either off-site manufacture or a nearby source that was not sampled for INAA analysis.

\subsection{Question 7}

What proportional roles did horticulture, hunting, and plant gathering play in the lives of the populations that occupied Components $A$ and $C$ at the Long View site?

\section{J. Michael Quigg}

To address this question, diverse data sets were targeted from across the components. Bulk sediment samples were consistently collected from identified features that included all recognized types. Thirtyfour bulk samples were floated, macrobotanical remains collected, identified where possible, and counted. Cross-feature ubiquity of various plant parts recovered was determined. Recovered faunal remains were identified to species, and the 
minimum numbers of specimens and individuals was determined. Microfossils such as phytoliths and starch grains were targeted and analyzed from different artifact classes that included selected ceramics, ground and chipped stone tools, and burned rocks. High-powered use-wear analysis, combined with identification of microfossils, was conducted on both formal and informal chipped stone tools to determine the type and amount of wear, with supporting evidence coming from microscopic plant remains observed on those tools. Chipped stone and worked bone were classified into broad functional categories based on their individual and overall shape and form (see Table 10-4 in Question 2). Each broad food procurement strategy of horticulture, hunting, and gathering, is addressed below. TxDOT personnel determine the lipid residue analysis proposed by TRC in the Research Design (see Chapter 4.0) was not to be used. Initial tests for pollen indicated poor preservation and thus was not pursued in the end

\subsubsection{Discussion of Horticulture}

Horticulture is thought to have been practiced more intensively in the Southern Plains Village complexes than the earlier Plains Woodland period, but data to demonstrate this assumption has been slow to accumulate. The lack of macrobotanical recovery from most early excavations at Plains Village sites has greatly limited our understanding of the role of horticulture in most Antelope Creek phase sites (Table 10-16). Direct evidence of horticultural activities is sparse and only reported from a few Antelope Creek phase sites across the Texas panhandle, primarily in the form of charred maize (see Green 1967; Keller 1975; Duffield 1970; Lintz 1984, 1989, 1986; Dean 1986; Duncan 2002, 2006), plus at Buried City sites (Brosowske 2005, Table 4.10), at Hank's House (Boyd 2008), and at Odessa Yates site (Brosowske 2005). The presence of ground stone tools such as manos and metates, and an assortment of bone tools that include bison tibia digging tools, bison scapula hoes, and possibly horn-core hoes, is often assumed to be indirect evidence of horticulture. To date, no prehistoric fields or water control devices or systems have been recognized in Plains Village complexes in the panhandle region. Only one attempt was directed towards finding fields through pollen analysis, and that was in the vicinity of Landergin Mesa, in far western Texas panhandle in Oldham County (Dean 1986).

At Long View, direct evidence of horticultural activities is present at both components in the form of carbonized maize (Zea mays), squash (Cucurbita sp.), and beans (Phaseolus vulgaris), all identified during macrobotanical analysis (Appendix C). The presence of charred maize cobs supports the tenet that maize was grown locally, as the kernels would have been stripped from the cob to reduce bulk in transport if maize were traded in. Additional supporting evidence of locally grown maize is the presence of maize leaf phytoliths from a number of the features (Appendix B). Extensive flotation results (samples total of 556.7 liters of matrix; Appendix C) from 32 of 34 flotation samples that included 16 features, document a very high presence value of 94.1 percent with abundant maize cupules $(N=246)$, kernels $(N=140)$, and cob fragments $(N=$ 22 ). Presence value is the percentage of all analyzed samples in which a particular taxon is present. Charred maize cob fragments were recovered from a number of proveniences in both components. At least seven were recovered from Component A, including one from heating element Feature 11. Fifteen cob fragments were recovered from Component $\mathrm{C}$, including cobs from heating element Features 16 and 21 (Figure 10-15). Cupules are more resistant to postdepositional destruction and are, therefore, usually more abundant than kernels. Dering (Appendix C) believes the abundance of kernels is a noteworthy occurrence.

Other direct evidence comes from the starch grain analysis, which also documents the presence of maize in both components (Table 10-17). Maize is only represented by 11.2 percent of the starch grains in Component A and only 24.4 percent of the starch grains in Component $\mathrm{C}$. If the starch results were the sole indication of the relative importance of each cultivated plant, maize production would seem to have been quite limited. However, cultivated plants such as squash and beans are not represented in the starch grains, although their presence is documented in the macrobotanical remains. Squash fragments were present in three samples (Features 4 and 9, both hearths, and pithouse Feature 6) for a presence value 
Table 10-16. Plant and Animal Resources Identified at Long View and other Sites and Cultural Manifestations in the Region.

\begin{tabular}{|c|c|c|c|c|c|c|c|c|}
\hline \multirow[t]{2}{*}{$\begin{array}{l}\text { Artifacts and } \\
\text { Classes of Artifacts }\end{array}$} & \multicolumn{2}{|c|}{$\begin{array}{l}\text { Long View } 1 \\
\text { Components }\end{array}$} & \multirow{2}{*}{$\begin{array}{l}\text { Antelope } \\
\text { Creek Phase } \\
\text { Sites } 2\end{array}$} & \multirow{2}{*}{$\begin{array}{l}\text { Buried } \\
\text { City } \\
\text { Complex } 3\end{array}$} & \multirow[t]{2}{*}{$\begin{array}{l}\text { Odessa Yates } \\
(34 B V 100) 4\end{array}$} & \multirow[t]{2}{*}{$\begin{array}{l}\text { Palo Duro } \\
\text { Complex } 5\end{array}$} & \multirow{2}{*}{$\begin{array}{l}\text { M-Cross } \\
\text { Ranch } \\
\text { Sites } 6\end{array}$} & \multirow{2}{*}{$\begin{array}{l}\text { Lundeen in } \\
\text { SW Kansas } \\
(14 M D 306) 7\end{array}$} \\
\hline & A & C & & & & & & \\
\hline \multicolumn{9}{|l|}{ Cultigens } \\
\hline Maize & $\mathrm{x}$ & $\mathrm{x}$ & $\mathrm{x}$ & $\mathrm{x}$ & $\mathrm{x}$ & & $\mathrm{x}$ & $\mathrm{x}$ \\
\hline Squash & $\mathrm{x}$ & $\mathrm{x}$ & & $\mathrm{x}$ ? & $\mathrm{x}$ & & & $\mathrm{x}$ \\
\hline Beans & & $\mathrm{x}$ & $\mathrm{x}$ & & $\mathrm{x}$ & & & \\
\hline \multicolumn{9}{|l|}{ Wild Plants } \\
\hline Cheno-ams & $\mathrm{x}$ & $\mathrm{x}$ & $\mathrm{x}$ & & $\mathrm{x}$ & $\mathrm{x}$ & & $\mathrm{x}$ \\
\hline Mesquite beans & $\mathrm{x}$ & $\mathrm{x}$ & $\mathrm{x}$ & & & $\mathrm{x}$ & & \\
\hline Juniper seeds & & $\mathrm{x}$ & & & & & & \\
\hline Little barley & $\mathrm{x}$ & $\mathrm{x}$ & & & & & & \\
\hline Grass seeds & & & $\mathrm{x}$ & & $\mathrm{x}$ & & & \\
\hline Prickly pear seeds & & $\mathrm{x}$ & $\mathrm{x}$ & & & & & \\
\hline Oak & & & & & & $\mathrm{x}$ & & \\
\hline Hackberry & & & $\mathrm{x}$ & & $\mathrm{x}$ & $\mathrm{x}$ & & $\mathrm{x}$ \\
\hline Gourd & & & & & & & & $\mathrm{x}$ \\
\hline Wild plum & & & $\mathrm{x}$ & & & & & $\mathrm{x}$ \\
\hline Wild grape & & & & & & & & $\mathrm{x}$ \\
\hline Black walnut & & & & & & & & $\mathrm{x}$ \\
\hline Sunflower & & & & & $\mathrm{x}$ & & & $\mathrm{x}$ \\
\hline Wild buckwheat & & & $\mathrm{x}$ & & & & & \\
\hline Ground cherry & & & & & $\mathrm{x}$ & & & \\
\hline Marshelder & & & & & $\mathrm{x}$ & & & \\
\hline Persimmons & & & $\mathrm{x}$ & & & & & \\
\hline Pinon nut & & & & $\mathrm{x}$ ? & & & & \\
\hline \multicolumn{9}{|l|}{ Meat Resources } \\
\hline Bison & $\mathrm{x}$ & $\mathrm{x}$ & $\mathrm{x}$ & $\mathrm{x}$ & $\mathrm{x}$ & $\mathrm{x}$ & & $\mathrm{x}$ \\
\hline Deer & $\mathrm{x}$ & $\mathrm{x}$ & $\mathrm{x}$ & $\mathrm{x}$ & $\mathrm{x}$ & $\mathrm{x}$ & & $\mathrm{x}$ \\
\hline Antelope & & & $\mathrm{x}$ & & $?$ & $\mathrm{x}$ & & $\mathrm{x}$ \\
\hline Turtles & $\mathrm{x}$ & $\mathrm{x}$ & $\mathrm{x}$ & & $\mathrm{x}$ & & & $\mathrm{x}$ \\
\hline Fish & $\mathrm{x}$ & $\mathrm{x}$ & $\mathrm{x}$ & & $\mathrm{x}$ & $\mathrm{x}$ & & $\mathrm{x}$ \\
\hline Rabbits & $\mathrm{x}$ & $\mathrm{x}$ & $\mathrm{x}$ & & $\mathrm{x}$ & $\mathrm{x}$ & & $\mathrm{x}$ \\
\hline Canid & & & $\mathrm{x}$ & $\mathrm{x}$ & $\mathrm{x}$ & & & $\mathrm{x}$ \\
\hline Birds & & & $\mathrm{x}$ & & $\mathrm{x}$ & & & $\mathrm{x}$ \\
\hline Mussels & & & $\mathrm{x}$ & $\mathrm{x}$ & $\mathrm{x}$ & & & $\mathrm{x}$ \\
\hline Bobcat & & & $\mathrm{x}$ & & & & & \\
\hline \multicolumn{9}{|l|}{$1=$ This report. } \\
\hline \multicolumn{9}{|c|}{$\begin{array}{l}2=\text { Green 1967, Duffield 1970, Keller 1975, Lintz 1986; Duncan 2002, 2006; Most results came from three site reports, but flotation has been limited or nonexistent in most Antelope Creek } \\
\text { phase sites. }\end{array}$} \\
\hline \multicolumn{9}{|c|}{3 = D. Hughes and Hughes-Jones 1987; Brosowske 2005; limited reporting on the older work with some supplemented data provided by Brosowske 2005} \\
\hline \multicolumn{9}{|c|}{4 = Brosowske 2005. Analyses have not been completed or reported. } \\
\hline \multicolumn{9}{|c|}{$5=$ Boyd $1995,1997,2004 b$; flotation has been variable between sites. } \\
\hline \multicolumn{9}{|c|}{6 = Cruse 2001, Boyd 2008; the data from multiple sites has not been analyzed, results are incomplete. } \\
\hline $7=$ Bevitt 1999 , one of the few & ully at & 1 and repo & ed Plains Village perio & s in region. & & & & \\
\hline
\end{tabular}




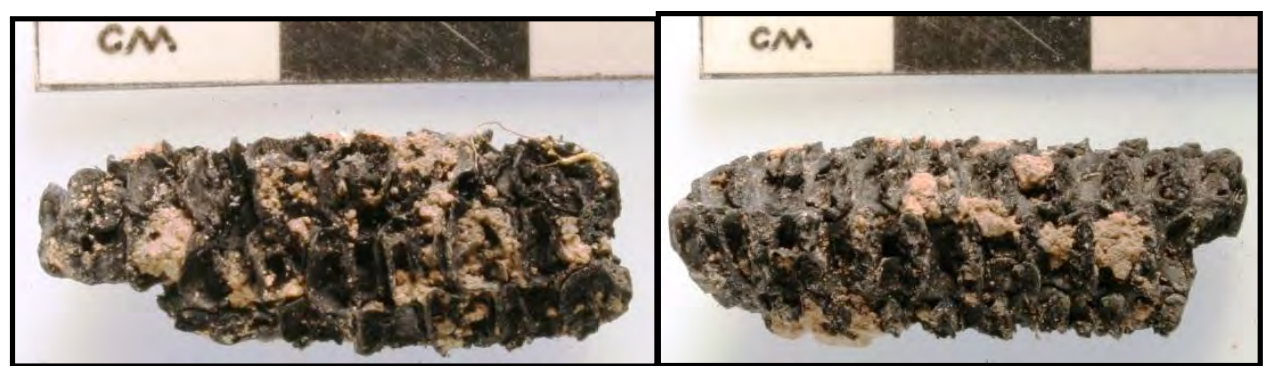

Figure 10-15. Two examples of charred maize cobs (\#453-5-7 left and \#1093-5-7 right).

of 8.8 percent. A single carbonized common bean was recovered from heating element Feature 16, for a presence value of 2.9 percent. The recovery of beans is rare, as beans generally did not come into direct contact with fire in the normal course of cooking, and thus had relatively little chance to become preserved by carbonization (Munson et al. 1971).

Indirect evidence for horticultural activities is also present at both Long View components in the form of worn bison scapulas (possible hoes), bison tibia digging tools, manos, and metates (see Tables 10-3 and 10-4). However, these same tools may have been multifunctional tools used in other activities and may not have been exclusively for horticultural purposes. The bone tools may have been employed to dig and move sediment in other excavation tasks, such as pithouses or storage pits. The stone grinding tools could well have served to process gathered wild plant seeds or nuts. In the case of the one mano analyzed for starch grains, it did not yield a single grain of maize starch, but did produce 33 grains of little barley (Hordeum pusillum). Starch grain analysis on three metate fragments yielded 52 little barley grains, but only a single maize starch grain (Appendix D). A small edge-ground cobble from Component A yielded 45 grains of little barley and only 3 grains of maize. The starch grain results imply that cultivated maize was processed less with ground stone tools than were seeds of the wild little barley, and it is possible this finding reflects a relatively limited dietary importance for maize.

\subsubsection{Discussion of Hunting}

The animal bones recovered from excavations are, for the most part, direct indicators of the species of animals that were hunted. At Long View, both components yielded bones of bison, deer, rabbits, turtles, and fish that indicate a diverse suite of animals procured (see Table 10-16). Hunting strategies were likely directed towards the first three species, whereas one might argue that the turtles and fish were gathered through chance encounters and not directly targeted by hunting. Indirectly, hunting is also represented by the presence of 46 projectile points, while butchering of carcasses is presumably indicated by 21 thin bifaces (knives), and hide working is evidenced by the presence of 20 scrapers. The use-wear results provide support for animal processing, insofar as at least 6 of the 52 (11.5 percent) analyzed tools were determined to have functioned in scraping hides, or cutting hides and meat (Appendix H).

\subsubsection{Discussion of Gathering}

Plant gathering is represented by very limited but direct evidence of charred remains in 8 of the 34 (23.5 percent) flotation samples (Appendix C). Mesquite (Prosopis sp.) seeds have a presence value of 11.8 percent and generally reflect the preparation of flour through the process of grinding and pounding the hard, dry beans. Mesquite seeds came from three heating elements, Features 4, 12, 16/21 and pithouse Feature 6. Six cheno-am seeds (Chenopodium spp. and Amaranthus spp.) were recovered from three Features (4, 6, and 9), a juniper (Juniperus sp.) seed came from heating element Feature 16/21, three prickly pear (Opuntis sp.) seeds came from the pithouse Feature 6, and a hackberry (Celtis sp.) nut was found in heating element Feature 5. The very low abundance of these wild plant resources may also indicate they were not actual food resources, but were carbonized through use as fuel. Mesquite wood and thorns were also carbonized in the heating 
Table 10-17. Summary of Plants Identified During Starch Grain Analysis and Conditions of the Grains.

\begin{tabular}{|c|l|l|l|}
\hline Plant & Component A & Component C & Totals \\
\hline Maize & 46 & 54 & 100 \\
\hline Damaged & 6 & 4 & 10 \\
\hline Parched & 0 & 1 & 1 \\
\hline Little Barley & 269 & 124 & 393 \\
\hline Ground & 6 & 1 & 7 \\
\hline Gelatinized & 4 & 1 & 5 \\
\hline Parched & 0 & 1 & 1 \\
\hline Cheno-am & 3 & 4 & 7 \\
\hline $\begin{array}{l}\text { Possible } \\
\text { Mesquite }\end{array}$ & 7 & 8 & 15 \\
\hline Possible Lily & 14 & 6 & 20 \\
\hline Unknown & 73 & 25 & 98 \\
\hline Damaged & 2 & 0 & 2 \\
\hline Ground & 0 & 1 & 1 \\
\hline Parched & 0 & 2 & 2 \\
\hline Gelatinized & 4 & 6 & 10 \\
\hline Total & 434 & 238 & 672 \\
\hline
\end{tabular}

elements, which indicates this resource was used for other purposes aside from food, so the occurrence of a few mesquite seeds may be incidental. The same might be true for the juniper seed, as quantities of juniper wood charcoal were recovered. Starch-grain analysis provides other direct evidence, and consists of four identified wild plants: little barley, possible lily, possible mesquite, and cheno-ams (Appendix C). In the two combined Long View components little barley is represented by 62 percent of the total starch grains, possible bulbs of the lily family are represented by 3.2 percent, possible mesquite seeds are represented by 2.4 percent, and cheno-ams are represented by 1.1 percent of the total starch grains (see Table 10-17). These results are from a suite of 102 artifacts that included 28 chipped and 17 ground stone tools, 37 pottery sherds, and 20 burned rocks. If the starch grains identified are a good indication of the role of gathered wild plants, then the ratio of 9:1 of wild verses cultivated plants indicates gathered plants were much more important as a source of edible plants than horticulture. However, starch grain results may provide a skewed picture of gathered versus cultivated plants as it is unclear if counts of grains can be viewed as a direct reflection of the relative quantities processed and eaten.

The evidence from ground stone tools (manos and metates) summarized above, documents use in processing both cultivated maize and wild plants (i.e., little barley). Although not directly relatable to the relative importance or frequency of use of wild verses cultivated plant foods, use-wear results from the diverse sample of analyzed stone tools $(N=52)$ also provides indirect evidence for use on plants in general and other activities. Based on microfossils adhering to the artifacts, at least four analyzed tools (7.7 percent) were directly interpreted to have been used on plants: three edge-modified flakes (two used in cutting plants, and one served to scrape hard/high silica plant material), and an end scraper used to scrape a hard/high silica plant, most likely 
wood. Although the frequency for direct use through microremains is not high, the use-wear results document that even chipped stone tools were used on plant materials.

\subsubsection{Summary and Discussion of Roles}

The accumulated data from diverse lines of evidence (faunal, botanical, stone and bone artifacts, and starch grain and use-wear analyses) from Components A and $\mathrm{C}$ provide a foundation for assessing the roles played by these different food procurement strategies. While all three principle food procurement strategies, hunting, gathering, and horticulture are identified per component or site, they likely varied from place to place and according to season. If a component was occupied over a period of months, labor investment would have been allocated among this mix of subsistence strategies. The relative emphasis placed on each strategy undoubtedly also changed between environmental settings such as open plains (short grass plains, mixed and tall grass areas), verses intravalley settings. This makes direct comparisons with other investigated sites from across the region such as western and central Oklahoma difficult. How much time was devoted to each basic economic activity cannot be directly addressed with archeological data. It can only be roughly inferred based on the relative frequency of cultivated products verses gathered and hunted food products, as determined by the quantitative representation of cultigens, wild plants, and animals.

Considerable time and energy went into the construction of a pithouse in each of the two Long View components. Examination of the recovered stone tool assemblages from each component does not reveal any one tool or tool class that can be readily linked to the pithouse construction activities. No large tools often considered to be used in woodworking such as chopping tools, gouges, grooved mauls/axes, chipped axes/hoes, or celts were recovered (see Tables $10-3$ and 10-4). It is likely that some of the more standard classes of stone tools such as bifaces and scrapers may have played a role in the construction process. The use-wear analyses combined with the microfossil identification of a diverse sample of 52 stone tools provides support for various tasks directed towards woodworking. From Component A three of the four beveled knives analyzed yielded results that indicate they were used on wood. Two of the beveled knives were used for cutting and one for boring (Appendix $\mathrm{H}$ ). Three of 12 (25 percent) edge-modified flakes indicated use on wood (two for cutting and one for scraping) and also yielded wood fibers. One edge-modified flake yielded wood fragments that included bark cells with hard/ high silica polish. A formal chert end scraper was also used to scrape wood. From Component C 7 of the 25 (28 percent) artifacts analyzed revealed use on wood. This includes a drill and edge-modified flake used to bore wood, two bifaces and edge-modified flake for whittling wood, plus two chert scrapers for scraping wood (Appendix H). Consequently, standard tools often associated with processing meat and hides, bifaces and end scrapers, were documented to have been used on wood.

A few bone tools, such as the modified bison tibias and bison scapulas might have served for the digging and shoveling dirt during pithouse construction. Often, these specific bone tools are classified as horticultural tools used for planting and maintaining crops. As chipped stone tools often are multifunctional, used for a variety of tasks, it is likely these bone tools also had multiple functions. The digging through the sandy and clayey deposits to create a 3-m-wide and 50-cm-deep pithouse would likely create considerable wear and breakage of a bison tibia digging tool. More wear attrition would have accumulated from digging large pits (storage or pithouse) than during the digging of small holes to plant seeds. However, it is likely that the wear from digging, either small holes for seed planting or deep pits for a structure or storage pit would result in similar use-wear on the tools, so one would likely not detect the difference. The same could be said for the bison scapula hoe. Given thoughtful consideration to hoes, it seems logical that they would perform better as a shovel for moving dirt than as a gardening tool with the crop maintenance.

Boyd (2008) challenged the long-standing assumption that the abundance of bison scapula hoes, bison tibia digging tools, and squash knives reflect the importance of farming activities at sites. He cites Huhnke's (2001) use-wear study of 68 scapula tools and 112 tibia tools from Alibates Ruin where she concludes that these were likely general 
earth-moving tools, and archeologists should not assume they were only for farming (Boyd 2008:37). Boyd (2008) also cites two ethnographic accounts that reflect the specific use of bone "hoes". One use was cutting grass to use as a layering of roof material in earth lodges (Wilson 1934:365), whereas the Pawnee used scapula hoes for digging soil to repair the roofs of lodges (Weltfish 1965:93). These two accounts document that hoes were used in activities related to house construction and repair, and not specifically agricultural tools.

Comparison of procurement strategies with Antelope Creek phase sites is virtually impossible. Most core area sites have not been reported on, and only limited datasets are available. The 29 sites considered by Lintz (1986) were excavated before archeological sampling strategies included macrobotanical and faunal remains. Complete descriptions of artifact assemblages are available from very few core area sites. Faunal and macrobotanical evidence for basic food procurement strategies is quite limited and comes from only a few sites. Two Antelope Creek phase sites in the Oklahoma panhandle (Two Sisters and Stamper) yielded evidence of maize and beans; whereas Roy Smith, Two Sisters, and Stamper sites all yielded what are believed to be bone horticultural tools (Watson 1950; Schneider 1969; Duncan 2002, 2006; Lintz 2003c). Duncan (2002, 2006) conducted a diet breadth and site catchment analysis of the Two Sisters site and concluded that maize agricultural was not very important to the overall diet. If this interpretation is correct, then the population that occupied that site was relatively more focused on hunting and gathering.

Excavations at the Odessa Yates site (34BV100) in the Oklahoma panhandle yielded maize, beans, sunflower (Helianthus annuus), goosefoot, grass seeds, hackberry, cactus, marshelder (Iva annus), and bulrush (Scirpus sp.). The faunal assemblage from Odessa Yates is extensive and represents a broad array of animals (see Table 10-16), though complete analysis has not been reported (Brosowske 2005). Apparently, a mixed horticultural/wild resource procurement and hunting economy was in place at Odessa Yates, but the amount of time and labor directed towards each procurement aspect of this economy remains to be determined.
Human skeletal remains from two Plains Village sites in the core area of the Antelope Creek phase have been subjected to isotopic analyses to explore their dietary patterns. Stable carbon and nitrogen isotope data was derived from 29 human skeletal remains from Antelope Creek Ruin 22 and 28 (Habicht-Mauche et al. 1994). The results revealed different dietary patterns between males and females. In general, the stable carbon isotope evidence from human bones indicates that about 90 percent of the population's diet consisted of $\mathrm{C}_{4}$ plants (i.e., maize, cheno-ams, various grasses, etc.) and animal products such as bison (Habicht-Mauche et al. 1994). They concluded that maize was not very important to the Antelope Creek phase populations. This interpretation implies that wild $\mathrm{C}_{4}$ plants and bison products accounted for the very high $\mathrm{C}_{4}$ signatures.

Boyd (2008) argued for the importance of horticulture among the peoples who lived in the Canadian River valley and its tributaries in the Texas panhandle, based on studies conducted on the M-Cross Ranch sites, about $10 \mathrm{~km}$ east of Long View. Much of his discussion consisted of general data and assumptions, supported by very limited archeological data, to interpret a dual economy of hunting and horticulture in Southern Plains Village populations. Boyd (2008) concluded that horticulture played a major role in regional economies, and involved primarily dry farming in the extensive sandy soils found throughout the region.

Much perceived uncertainty concerning possible horticulture practice and role within those societies stems from a lack of extensive investigations and reporting from Plains Village sites in the region, combined with imprecise temporal control for known Antelope Creek phase sites investigated prior to technological advances in the last 20 to 30 years. Complete technical reports on Antelope Creek phase sites in and around the core area are few in number. Those that were reported lack details concerning faunal and botanical remains. Duffield's work (1970) used faunal remains from sites where artifacts were not systematically collected, which creates potentially unreliable results (Lintz 1986), though his work does provide evidence for the diversity of food resources utilized. Although contexts and associations may be questionable, 
Duffield (1970) reports a very diverse range of faunal resources, including birds, reptiles, small mammals, turtles, deer, antelope, bison, and even fish species.

Drass (2008) has reviewed work from the last 25 years and presented very detailed paleobotanical data on economies from Late Prehistoric villages dating to the last 1,000 years across the plains of Oklahoma and Texas. He points out very limited ethnohistorical descriptions are available for plants used by these peoples. He discusses wild plants such as amaranth/goosefoot (cheno-ams), purslane, sunflower, ragweed, marshelder, various grass seeds (i.e., little barley, dropseed [Sporobolus sp.], etc.), bulrush, knotweed (Ploygonum erectus), sedges, fruits and nuts. Drass (2008:26) also notes tubers and roots are not well represented in the assemblages and attributes this to poor preservation. He also presents data on cultivated and potentially cultivated plants that include, but are not necessarily limited to, maize, beans, squash, sunflower, and marshelder. Maize is ubiquitous at Plains Village sites of all periods. Previous faunal studies have documented that bison hunting was a significant procurement activity for these villagers. In summary, the analyses of macrobotanical remains from Southern Plains sites, although admittedly limited, combined with the previous faunal data, reveal that a great diversity of wild plants and animals were procured and that cultivated plants included maize, beans, and squash, marshelder, and potentially other native species such as little barley (Drass 2008:26).

Considering the macrobotanical and faunal data from the Palo Duro complex (1450 to 850 B.P.; cal A.D. 500 to 1200), far to the south of Long View, direct evidence exists for the use of native plants (e.g., pigweed, goosefoot, and purslane). Remains of cultivated plants such as maize and squash have not been recovered, although their presence has been postulated (Boyd 1995, 1997, 2004b). The Palo Duro complex includes rectangular and circular pithouses, storage pits, baking pits, and ceramics. Boyd (1995, 1997, 2004b) sees a mixed hunting and gathering subsistence economy for this cultural pattern, which precedes the Long View components by a few hundred years.
Bison populations were scattered across much of the Southern Plains during the Plains Village period (i.e., Duffield 1970; Dillehay 1974; DeMarcay 1986, S. Baugh 1986; Brooks and Flynn 1988; Butler 1992; Quigg et al. 1993; Drass 1997, 1998; Brosowske 2005) and were hunted by most peoples of the region. Bison bones have been recovered from many village sites in the Antelope Creek phase core area (Duffield 1970), at Antelope Creek phase sites in the Oklahoma panhandle (Duncan 2002; 2006), and from most other Southern Plains Village sites across the region (Brosowske 2005; Drass, et al. 1990; Lintz 1976, 1984, 1986, 2003c; Drass 1997, 1999). Drass and Flynn (1990) detected a greater dependence on bison, especially after about 700 B.P., and other prairie resources at villages in the western mixed prairie of Oklahoma. They also detected that use of bison increased through time in the complexes and phases in western Oklahoma. This finding might contradict a postulated increase of horticultural activities based on bison bone digging tools at Washita River phase sites (Hofman 1978), and might also contradict Duffield's (1970) suggestion that bison populations and use of bison decreased at Texas Antelope Creek phase sites after 650 B.P., based on a limited sample of five dated sites. Brosowske (2005) sees the Odessa Yates site (34BV100) as evidencing a more specialized bison hunting practice, which yielded a surplus of bison products that were used for exchange during ca. 400 to 700 B.P.

The two Long view components appear similar to many Plains Village sites across the Southern Plains, reflecting activities during the Early Ceramic period (ca. 1550 to 750 B.P.). Based on limited seasonality data, these semisedentary hunters, gatherers, and horticulturalists conducted diverse procurement strategies during the occupation of the site. The occupations of Components A and C may represent semisedentary populations that moved periodically as local natural resource became sparse.

In summary, macrobotanical identifications indicate that the occupants of Long View grew the "Three Sisters" of Native American cultigens (maize, beans, and squash) and also gathered a range of wild plant foods (minimally little barley, mesquite seeds, and cheno-ams). Starch grain analysis 
reveals which specific wild plants were gathered, a focus on little barley grass seeds. Cultigens were only minimally detected through starch analysis. The faunal analysis reveals hunting was practiced, which specific animal species were targeted, and indicates their relative importance at a general level. High-powered use-wear analysis, combined with microfossil identifications, revealed specific functions of chipped stone tools, including expedient utilized flakes, employed in various processing tasks and indicated that woodworking was also conducted.

Overall, data from Long View clearly indicates that hunting of large game, gathering of multiple wild plant foods and small game, and cultivation of at least three domesticated plants were all utilized at this site, within a mixed economic strategy. The starch grain analyses, in particular through counts, imply that horticultural products may have played a secondary economic role in relation to gathering of wild plant food resources. Future investigations of Southern Plains Village sites should attempt to clarify the relative economic importance of these three basic kinds of economic pursuit in the Texas panhandle and adjacent areas.

Significantly, one or more of the food procurement strategies would not have been detected without employing a wide range of analytical processes that targeted different data sets. It is argued the multiple strategies for extracting information must be pursued at each and every site or one or more important food pursuits or aspects at that site may not be detected.

\subsection{Question 8.}

Were the modified faunal bones recovered from 41RB112 used primarily for tools (horticulture, awls, needles) or did they serve another function?

\section{J. Michael Quigg}

This question is relevant to understanding the role of horticultural and/or other activities within the adaptive strategies of the occupants of the Long View site and other Plains Village sites across the region. In years past, the mere presence of bison tibia digging tools, squash knives, and scapula hoes were assumed to be direct evidence for horticultural activities. Other possible functions of these tools have been largely ignored. Therefore, the Antelope Creek phase literature contains many references to these modified bones as horticultural tools, but this is assumed (i.e., Krieger 1946:56; Watson 1950; Green 1986; Keller 1975; Lintz 1986; Baker and Baker 2000; Brooks 2004).

The recent discovery of pithouses in the region, combined with other excavation activities, new consideration must be given to the assumed horticultural use of many bone tools and the possibility of them having multifunctionality. Considering the amount of digging required to create storage pits of various sizes and pithouses with depths of 30 to $60 \mathrm{cmbs}$ and diameters of 2 to $3 \mathrm{~m}$, there would have been a significant need for substantial digging tools. Thick-walled bison tibia could have served as a strong tool to break ground, whereas green bison scapulas could have served to shovel and scoop dirt. Both the squash knife and scapula tools would also have made excellent tools for mixing mud used to plaster houses or for loosening earth that was to be placed on the walls and/or roofs of wood-frame structures. Nabokov and Easton (1990) in discussing the construction of subterranean architecture provides an ethnographic account where the Natives "using sharpened sticks and flat-bladed wooden scraper, the women broke up the earth and hauled it to the side in baskets until they had a hole 3 to 4 feet deep with sloping sides" (1990:176). Bison bone tools could easily be adapted to fill this role where wood was used.

In a use-wear analysis of bone tools, specifically 112 tibia tools and 68 scapula tools from Alibates Ruins in the heart of the Antelope Creek phase core area, Marie Huhnke (2001) determined that many scapula tools did not function as horticultural tools, but were used for mixing and applying adobe for houses. She also determined bison tibia tools were for digging, but did not limit them to one specific task and suggested a number of potential uses such as digging roots of wild plants, housepits, storage pits, and borrow pits (Huhnke 2001:53-59). While acknowledging that these tools were most likely used in conjunction with digging/moving soil, she suggests that they should not automatically be considered to have served strictly as horticultural tools. 
Boyd (2008:36-37) has recently discussed this same point and cautions against assuming that bison bone tools were used strictly to conduct horticultural activities. He supports the use of these bison bone tools for other functions by providing ethnographic accounts of their use in building and maintaining houses.

To address this question, the animal bone assemblages from Components $\mathrm{A}$ and $\mathrm{C}$ at Long View were examined macroscopically to identify worked specimens. Once worked bones were identified, each piece was more carefully examined. Specimens identified as tools were described though qualitative observations and by means of metric measurements. Bone tools from each of the two Long View components are discussed below.

\subsubsection{Discussion of Bone Tools in Component A}

Ten bone pieces from Component A were identified as modified on the basis of macroscopic observations. These 10 specimens comprise 0.2 percent of the total bone assemblage recovered and are considered to be a minimum representation, as weathering processes have removed or damaged many bone surfaces, combined with the fragmented nature of the overall faunal assemblage, made detection of worked pieces difficult. The 10 identified worked pieces consist of a medial section of a thin bone awl, 2 complete bone awls, 3 other worked pieces, 1 thin spatula like tool, 1 bison scapula tool, 1 notched bison rib, and 1 thinwalled pointed tool with a burned tip. One worn piece may be a fragment of a tibia digging tool. The bison scapula tool is similar to a hoe or large spatula and may have served multiple functions. No definitive bison tibia tools were recognized. It is proposed that the absence of recovered tibia tools does not mean they were not utilized at this component, as tools may have been removed from the site upon abandonment or poor preservation of bone has prevented their identification. Since an earthen cover at pithouse Feature 1 was not evident, scapula tools may not have been used as shovels here, and this might account for the paucity of this tool type. The low occurrence of bison scapula hoes cannot be taken to reflect a corresponding paucity of horticultural activity, given that the macrobotanical data show the presence of maize in 88 percent of the samples and features.

\subsubsection{Discussion of Bone Tools in Component C}

Component $\mathrm{C}$ yielded 15 modified bones or 0.6 percent of the total faunal assemblage. These include eight bison scapulae with worn and smoothed edges, often with spines removed, three small bone awls, one bison ulna hammer, one tibia digging tool, and one bison scapula fragment with multiple long cut lines that indicate modification of the bone related to tool production.

A single, macroscopically use-worn tibia digging tool (Figure 10-16) was selected for high-powered microscopic use-wear analysis. This test case was to determine if a specific function could be identified by means of high-powered microscopic examination. Dr. Hardy observed polish, striations, and microflake scarring, but was unable to specify a function for this tool (Hardy, personal communication 2010). Dr. Hardy was unable to state positively how this specific tool functioned and was not able to assert that this tool was used for digging in general, or for specific tasks such as planting seeds or for excavating a pithouse. Therefore, no further microwear analysis was conducted on other bone tools. Hardy's observations were no more definitive than those made by Huhnke (2001) on similar tools.

While use-wear was macroscopically observed on bone tools, only a relatively few specimens can be suggested to have served horticultural functions (e.g., as bison tibia digging tools or scapula tools). Although these tools were present at Long View, they cannot be positively demonstrated to have served in any particular task. The tibia digging tool was used for digging and was likely quite suitable for digging pits (i.e., storage or pithouses) and various other tasks. The same can be said for the bison scapula tools, as they undoubtedly had multiple functions (i.e., hoeing, shoveling, scooping, or mixing). The one burned and/or fire-hardened thick-walled pointed bison long bone fragment from Component A potentially could have served very efficiently as a digging stick for creating small holes to plant seeds, but possibly served in a multifunctional capacity for a variety of other unidentified tasks. 


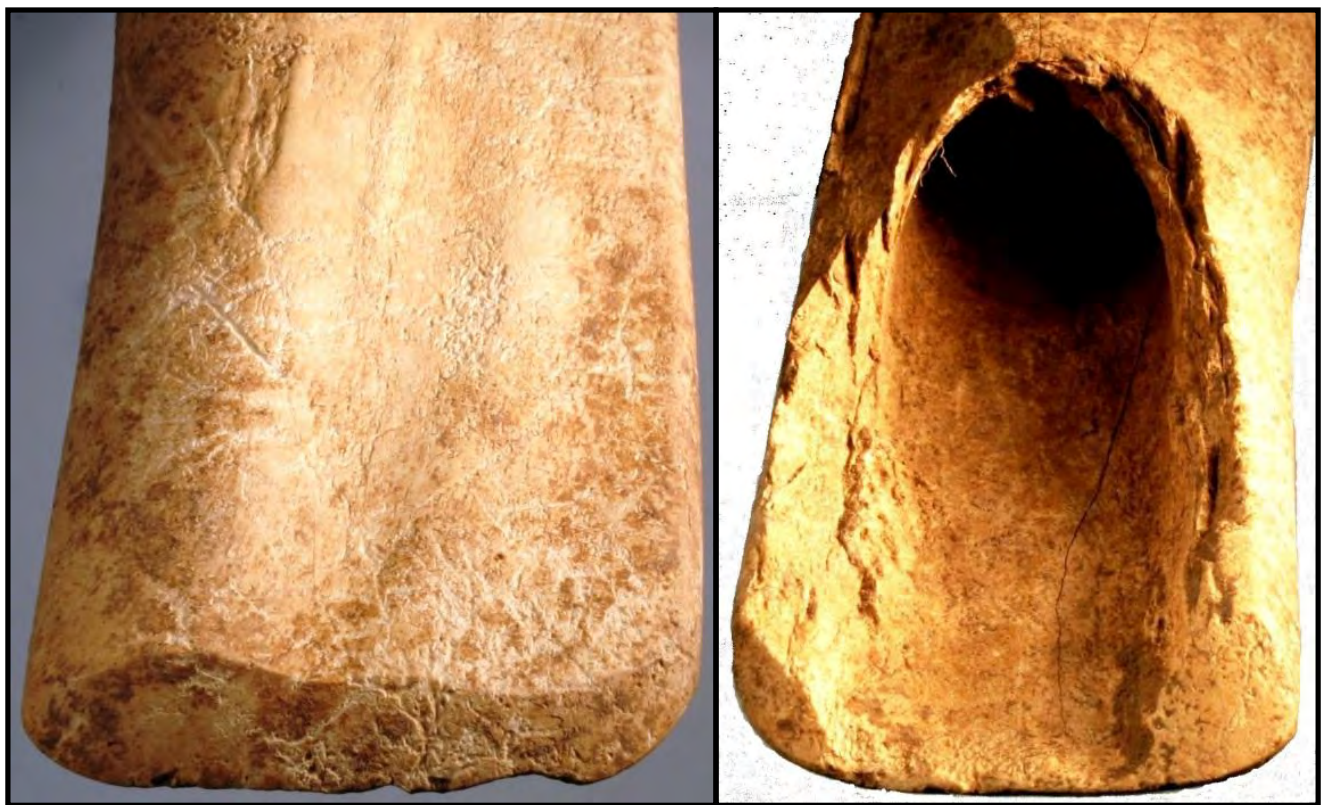

Figure 10-16. Close-up views of beveled outer edge (left) and inner edge (right) of bison tibia digging tool \#671-5-11 from pithouse Feature 6 floor in Component C.

The production of various household items from animal hides, such as clothing, bedding, and day-today tools and equipment, house furniture, structure coverings, etc., would have required the use of numerous small tools. These would have included bone tools used as needles, awls, and other piercing implements made from deer metatarsals and turkey long bones (Brooks 1989:81-82; Brooks 2005:341).

\subsubsection{Discussion of Bone Tools}

Bone tool assemblages similar to that recovered from the two Long View components have been identified for other Southern Plains Village manifestations (Table 10-18). The frequencies of tool types may differ between sites, but the overall impression is that bone tools identified at Long View are of similar description as those found at many Plains Village sites. Such tools were likely to have been included among the range of bison-derived products exchanged in the latter half of the Antelope Creek phase, along with Alibates lithic material, to obtain maize, ceramic vessels, obsidian, turquoise, shell pendants, and Olivella shell beads supplied by Southwestern Puebloans of northeastern New Mexico (Brooks 1989:83; Vehik and Baugh 1994:257).

\subsubsection{Discussion of Bone Debris}

At some Antelope Creek phase settlements and other Plains Village period sites in the region, evidence is present for a dichotomy of faunal bone utilization (Brooks 2005) that involved tool production on the one hand, and marrow and/or bone grease extraction on the other. As just discussed, specific green bison elements were selected for making tools such as scapulas for hoes, shovels, or knives; tibias for digging tools, cancellous ends of long bones for hide processing, ribs for arrow shaft wrenches or for stone tool handles, and metapodials for hide defleshers. Many remaining bone elements were selected for further processing and reduction to obtain bone marrow and bone grease. To determine the amount of further processing required for these extractions, analyses documented the maximum dimension of every piece. If the faunal bones were utilized to extract just bone marrow, most long bones would be broken near the midshaft area, leaving the two articular ends relatively intact; but if bone grease was the objective, a preponderance of the bone assemblage would be smashed further and the resulting pieces would fall into smaller size categories (Figure 10-17). 
Table 10-18. Overview of Bone Tool Types from Selected Phases and Complexes.

\begin{tabular}{|c|c|c|c|c|c|c|c|c|}
\hline \multirow[t]{2}{*}{ Bone Tools } & \multicolumn{2}{|c|}{$\begin{array}{l}\text { Long View }^{1} \\
\text { Components }\end{array}$} & \multirow{2}{*}{$\begin{array}{c}\text { Antelope Creek } \\
\text { Phase Sites }^{2}\end{array}$} & \multirow{2}{*}{$\begin{array}{c}\text { Buried City } \\
\text { Complex }^{3}\end{array}$} & \multirow{2}{*}{$\begin{array}{c}\text { Odessa Yates } \\
(34 B V 100)^{4}\end{array}$} & \multirow{2}{*}{$\begin{array}{l}\text { Palo Duro } \\
\text { Complex }^{5}\end{array}$} & \multirow{2}{*}{$\begin{array}{c}\text { M-Cross } \\
\text { Ranch Sites }{ }^{6}\end{array}$} & \multirow{2}{*}{$\begin{array}{l}\text { Lundeen in } \\
\text { SW Kansas } \\
\text { (14MD306) }\end{array}$} \\
\hline & A & $\mathrm{C}$ & & & & & & \\
\hline Bison scapula hoe & 1 & 8 & $\mathrm{x}$ & $\mathrm{x}$ & & 0 & & 13 \\
\hline Bison tibia digging tool & 1 & 1 & $\mathrm{x}$ & $\mathrm{x}$ & & 0 & & 1 \\
\hline Notched bison rib & 1 & 0 & $\mathrm{x}$ & $\mathrm{x}$ & & 0 & & 13 \\
\hline Bone awl & 3 & 3 & $\mathrm{x}$ & $\mathrm{x}$ & & 0 & & 14 \\
\hline Bone needle & 0 & 0 & 0 & 0 & & 0 & & 0 \\
\hline Antler billets/tine & 0 & 0 & $\mathrm{x}$ & $\mathrm{x}$ & & 0 & & 2 \\
\hline Bone pin & 0 & 0 & 0 & 0 & & 0 & & 0 \\
\hline Squash knife & $?$ & 0 & $\mathrm{x}$ & 0 & & 0 & & 0 \\
\hline Shaft wrench & 0 & 0 & 0 & 0 & & 0 & & 3 \\
\hline Spatula & 2 & 1 & 0 & 0 & & 0 & & 2 \\
\hline Ulna hammer & 0 & 1 & 0 & 0 & & 0 & & 0 \\
\hline
\end{tabular}

$1=$ This report.

2 = Watson 1950; Green 1967, Duffield 1964, 1970, Keller 1975, Lintz 1986; Duncan 2002, 2006;

3 = D. Hughes and Hughes-Jones 1987; Brosowske 2005; limited reporting on the older work with some supplemented data provided by Brosowske 2005

4 = Brosowske 2005. Analyses have not been completed or reported.

5 = Boyd 1995, 1997, 2004b;

6 = Cruse 2001, Boyd 2008; the data from multiple sites has not been analyzed, results are incomplete.

7 = Bevitt 1999, one of the few fully analyzed and reported Plains Village period sites in region. 
The process of extracting bone grease has been documented ethnographically across the Plains by various authors (i.e., Catlin 1857; Leechman 1951; Schoolcraft 1854; Wilson 1924; Wissler 1910). The process involved smashing and breaking faunal bone to expose the marrow and facilitate the extraction of natural oils in the bone. Once bones were broken into fingernail-sized pieces (Leechman 1951:355) they were then boiled/simmered in water within a container. The oil/grease rose to the top and was skimmed off and placed in a separate container, usually an animal stomach, for later consumption through addition to other foods, as "butter" (Leechman 1951:355). Historically, this substance was mixed with dried meat and berries to produce pemmican (Leechman 1950:355; Vehik 1977:171).

By documenting the degree to which bone grease processing was conducted, indicated by faunal fragmentation indices, at each occupation, versus other activities that employed bone elements, we can investigate the probable choices site occupants made concerning utilization of faunal skeletal materials, as discussed by Brooks (2005).

The analysis of the faunal bones from Component A at Long View revealed that 99 percent of the assemblage was comprised of tiny fragments, less than 6-cm-long, with 32 percent less than 3 -cm-long and only 23 percent greater than $9-\mathrm{cm}$ long. No complete distal or proximal ends were present, which would be indicative of bone marrow extraction. The small size of recovered pieces is believed to reflect intensive smashing to facilitate bone grease extraction. However, the weathered nature of much of this assemblage could also be partially responsible for the fragmentation that contributed to the final size of specimens.

The analysis of the animal bones from Component $\mathrm{C}$ at Long View documented that, again, 99 percent of the assemblage was tiny fragments and only 7.7 percent of elements were complete. Sixty two percent of fragments are less than 3-cm-long, with only 14.6 percent greater than $9 \mathrm{~cm}$. Again, the preponderance of data implies bone grease was targeted for extraction from the bones.

This documentation of bone grease production at Long View is in accord with similar findings from other Plains Village sites across the region. For example, the findings at the Two Sisters site, a semipermanent Antelope Creek phase settlement in the Oklahoma panhandle, suggest intentional bone breakage around the early and late houses, which was interpreted as a by-product of bone grease production (Duncan 2002:281; 2006). Similar findings were also made at Cottonwood Creek (Lintz 1997), and at the Odessa Yates site (Brosowske 2005), where 87 percent of the faunal bone assemblage was comprised of small fragments

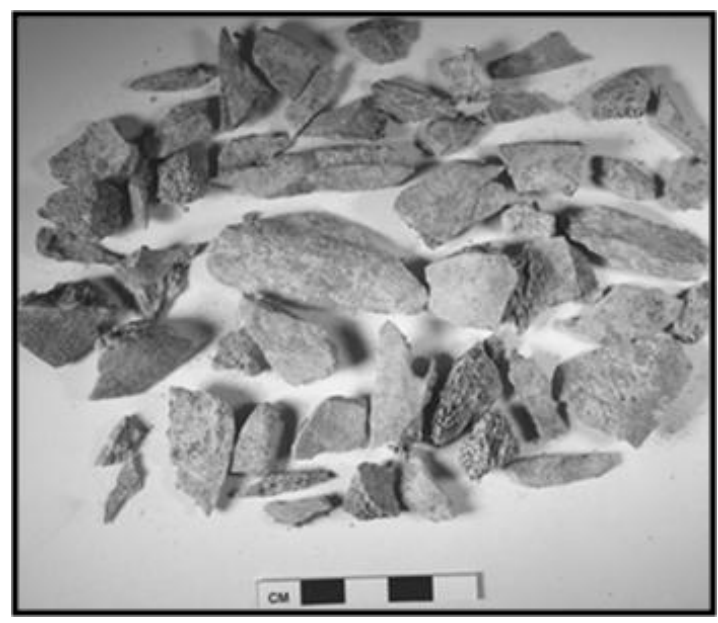

Figure 10-17. A sample of highly fragmented bone, indicative of bone grease extraction, from the northern part of Component A, 41RB112. 
of bison bone. In combination, the data from these sites indicate that bone grease production was a commonly employed part of the overall subsistence strategy in the region during the Plains Village period.

\subsection{Question 9.}

What role did exotic goods (i.e., nonlocal obsidian, pottery, and tool stone) play in the lives of the occupants?

\section{J. Michael Quigg and Paul M. Matchen}

The various classes of cultural material recovered (i.e., lithic debitage, stone tools, pottery, bone tools, shell, etc.) were examined to identify items that might be considered nonlocal. The lithic debitage and stone tool material types were macroscopically identified with the aid of Quigg's comparative collection. In a few instances, some nonlocal lithic types probably went undetected, as not all lithic types are known. Although pottery manufacturing localities have not been previously identified in the region, it is assumed that vessels with cordmarked exteriors that exhibit well-defined and partially or mostly obliterated markings were manufactured within the local region. In contrast, painted or colored-exterior vessels are thought to have been nonlocal, originating beyond the region. Mussel shell is considered to have been procured locally, whereas marine shells can be assumed to have had nonlocal origins. Each of the two Long View components is addressed separately below.

\subsubsection{Component A Discussions}

Component Ayielded 51 pieces of nonlocal obsidian, 21 pieces of nonlocal Niobrara/Smoky Hill jasper, 1 piece visibly similar to Socorro jasper, and 1 tiny bead made of shell thought to be of marine origin (Table 10-19). The 73 pieces of nonlocal debitage represent 3.1 percent of the total debitage from Component A. This low frequency indicates that, while nonlocal raw material was in use by this group, it comprised only a minor portion of the tool stone used.

The 51 obsidian pieces recovered from Component A comprises about 2 percent of the entire debitage assemblage. Fifty-five percent of obsidian specimens are between 6.4 and $12.8 \mathrm{~mm}$ in size. This small size likely reflects mostly maintenance and resharpening activities. However, the incidence of cortical surfaces among obsidian is intriguing. A sizeable percentage ( $N=13$; 25 percent) possess cortex that represents rounded water-worn nodules. This type of cortex indicates these nodules were gathered from secondary sources in alluvial stream gravels in the Rio Grande River (Church 2000; Shackley 2005). Their presence demonstrates that cobbles of obsidian were transported here and that some primary reduction occurred at Component A. The presence of water-worn cortex is not commonly observed on obsidian debris recovered at great distances from the original geologic source, and it may ultimately contribute to the understanding of obsidian procurement and distribution amongst Southern Plains groups in the Late Prehistoric. Both water-worn and angular fractured pieces exhibit a wide range of translucency from nearly translucent through opaque black varieties, which indicate that multiple obsidian pieces were in use at Component A. Forty-nine pieces were subjected to X-ray florescence (XRF) source analysis. The results indicate all pieces are of Cello Toledo Rhyolite, which originated at a source some $500 \mathrm{~km}$ west of Long View in the mountains of New Mexico (Appendix E).

About 61 percent of the obsidian debris is fragmented and represents shatter that resulted from nodule reduction. The recognizable flake types include pressure ( $N=10$; 20 percent); hard-hammer $(N=5$; 10 percent); soft-hammer $(N=4 ; 8$ percent); and a core-platform-rejuvenation flake ( $N=1 ; 2$ percent). Eighty percent of the hard-hammer flakes exhibit smooth, water worn cortex on the dorsal surfaces. This indicates that hard-hammer percussion technique was used for initial decortication and/ or to break open the small obsidian nodules. The highest incidence of cortex was observed among the fragment/shatter class. Flake shatter is assumed to have been more prevalent during hard-hammer reduction episodes. Seventy-five percent of the softhammer flakes exhibit no cortex, which implies this flake removal technique was implemented subsequent to primary cortex removal. Ninety percent of the pressure flakes had no cortex, 
Table 10-19. Presence/Absence of Nonlocal Goods in Plains Village Sites across the Texas Panhandle Region.

\begin{tabular}{|c|c|c|c|c|c|c|c|c|c|}
\hline 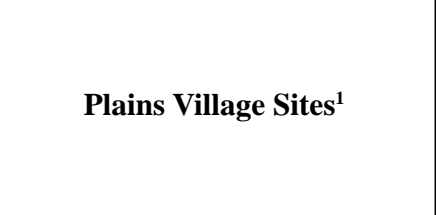 & 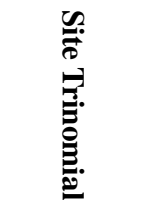 & 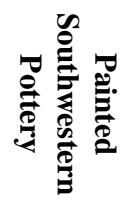 & 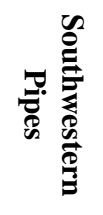 & 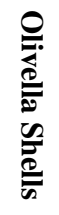 & 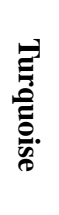 & 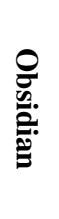 & 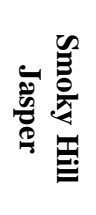 & 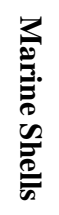 & References \\
\hline Long View - Component A & 41RB112 & 2 & - & - & - & 51 & 21 & 1 & This Report \\
\hline Long View - Component C & 41RB112 & - & - & - & - & - & 16 & 1 & This Report \\
\hline Alibates Ruin 28 & 41PT11 & $\mathrm{x}$ & $\mathrm{x}$ & $\mathrm{x}$ & $\mathrm{x}$ & $\mathrm{x}$ & - & - & Studer 1942; Baker and Baker 2000; Krieger 1946; Lintz 1986 \\
\hline Alibates Ruin 28A & - & $\mathrm{x}$ & - & - & $\mathrm{x}$ & $\mathrm{x}$ & - & $\mathrm{x}$ & Baker and Baker 2000; Lintz 1986 \\
\hline Alibates Ruin 30 & 41PT31 & $\mathrm{x}$ & - & - & - & - & - & - & Baker and Baker 2000; Lintz 1986 \\
\hline Antelope Creek Ruin 22, 22A & $41 \mathrm{HC} 23$ & $\mathrm{x}$ & - & $\mathrm{x}$ & - & - & - & $\mathrm{x}$ & $\begin{array}{l}\text { Baker and Baker 2000; Holden 1930; Lowrey 1932; Krieger 1976; } \\
\text { Lintz 1986 }\end{array}$ \\
\hline Antelope Creek Ruin 23 & 41HC25 & - & - & - & - & - & - & - & Baker 1939a; Lintz 1986 \\
\hline Antelope Creek Ruin 24 & & $\mathrm{x}$ & - & $\mathrm{x}$ & $\mathrm{x}$ & $\mathrm{x}$ & - & - & Lintz 1986 \\
\hline Arrowhead Peak & 41HC19 & $\mathrm{x}$ & - & $\mathrm{x}$ & $\mathrm{x}$ & $\mathrm{x}$ & - & - & Green 1967; Lintz 1986 \\
\hline Big Blue Creek & $41 \mathrm{MO} 35$ & - & - & $\mathrm{x}$ & - & - & - & - & Lintz 1986; Davis 1986; Couzzourt, and Schmidt-Couzzourt 1996; \\
\hline Black Dog Village & 41HC30 & - & - & - & - & - & - & - & Keller 1975; Lintz 1986 \\
\hline Canadian River 1 and $1 \mathrm{~A}$ & - & - & - & - & - & - & - & - & Lintz 1986 \\
\hline Chimney Rock Ruin 51 and 51A & - & $\mathrm{x}$ & $\mathrm{x}$ & $\mathrm{x}$ & $x^{*}$ & $\mathrm{x}$ & - & - & Studer n.d.; Baker and Baker 2000; Lintz 1986 \\
\hline Coetas Ruin, No. 55 & 41PT2 & - & $\mathrm{x}$ & $\mathrm{x}$ & $\mathrm{x}$ & - & - & - & Studer 1934; Lintz 1986:307 \\
\hline Conner & 41HC7 & - & - & - & - & - & - & - & Duffield 1964; Lintz 1986 \\
\hline Cottonwood Creek Ruin & 41HC141 & - & - & - & - & - & - & - & Holden 1929; Lintz 1986, 1997 \\
\hline Footprint & 41PT25 & & $\mathrm{x}$ & $\mathrm{x}$ & & $\mathrm{x}$ & & $\mathrm{x}$ & Green 1967; Lintz 1986 \\
\hline Jack Allen & (A654) & - & - & - & - & - & - & - & Harrison 1983; Lintz 1986 \\
\hline Lookout Ruin & - & - & - & - & - & - & - & - & Lowrey 1932; Lintz 1986 \\
\hline Marsh & - & - & - & - & - & - & - & - & Lintz 1986 \\
\hline Medford Ranch & $41 \mathrm{HC} 10$ & - & - & - & - & $\mathrm{x}$ & - & - & Duffield 1964; Lintz 1986 \\
\hline
\end{tabular}


Table 10-19. PresencelAbsence of Nonlocal Goods in Plains Village Sites across the Texas Panhandle Region (continued).

\begin{tabular}{|c|c|c|c|c|c|c|c|c|c|}
\hline Plains Village Sites $^{1}$ & 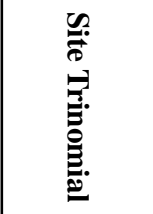 & 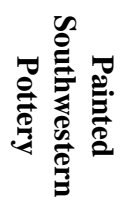 & 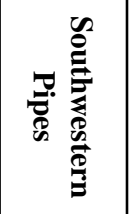 & 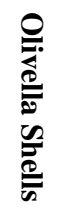 & 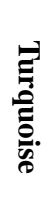 & 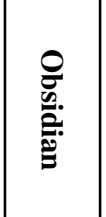 & 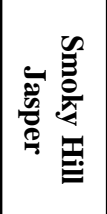 & 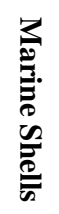 & References \\
\hline Ozier & $41 \mathrm{MO} 96$ & - & - & - & - & - & - & - & Lintz 1986 \\
\hline Pickett Ruin & - & - & - & - & - & - & - & - & Carter and Carter 1958; Duffield 1970; Lintz 1986 \\
\hline Roper & 41HC6 & - & - & - & - & - & - & - & Lintz 1986 \\
\hline Sanford Ruin & 41HC3 & - & - & - & - & - & - & - & Lintz 1986 \\
\hline Spring Canyon & 41HC20 & - & - & - & - & - & - & $\mathrm{x}$ & Duffield 1964; Lintz 1986 \\
\hline Tarbox & 41HV2 & - & - & - & - & $\mathrm{x}$ & - & - & Holden 1929; Lintz 1986 \\
\hline Turkey Creek Ruins & 41PT8 & 1 & possible & - & - & $\mathrm{x}$ & - & - & Green 1967; Lintz 1986 \\
\hline Zollers & - & - & - & $\mathrm{x}$ & - & $\mathrm{x}$ & - & - & Smith and Smith 1982; Lintz 1986 \\
\hline 41MP7 & 41MP7 & - & - & - & - & - & - & - & Lintz 1986 \\
\hline Stamper & $34 \mathrm{TX} 1$ & $\mathrm{x}$ & - & $\mathrm{x}$ & $\mathrm{x}$ & $\mathrm{x}^{*}$ & $\mathrm{x}$ & - & $\begin{array}{l}\text { Watson 1950; Baerreis and Bryson 1966; Lintz 2003a, 2003b, 2003c, } \\
\qquad 2004\end{array}$ \\
\hline McGrath & 34TX31 & $\mathrm{x}$ & - & - & - & $\mathrm{x}$ & $\mathrm{x}$ & - & Lintz 1976; \\
\hline Two Sisters & 34TX32 & - & - & $\mathrm{x}$ & - & $\mathrm{x}$ & $\mathrm{x}$ & - & Lintz 1979; Duncan 2004, 2006 \\
\hline Roy Smith & 34BV14 & - & - & $\mathrm{x}$ & $\mathrm{x}$ & $\mathrm{x}^{*}$ & $\mathrm{x}$ & - & Schneider 1969 \\
\hline Odessa Yates & 34BV100 & & & & & $2000+$ & & & Brosowske 2005 \\
\hline Lundeen & 14MD306 & - & - & 15 & - & - & $\begin{array}{c}60 \% \\
35 \% * *\end{array}$ & - & Bevitt 1999 \\
\hline
\end{tabular}

${ }^{1}$ Core Antelope Creek sites from Lintz 1986 with selected others; * = Obsidian source analysis conducted; ** 35 percent Alibates 
indicative of late-stage reduction or refinishing as one would expect. Given the diversity of flake types, it appears that whole water-worn cobbles were acquired, reduced, and fashioned into usable tools on-site and curated prior to breakage. The scarcity of obsidian implies it is also likely that any sizable flakes produced during the cobble reduction were also curated. The sharp edges of obsidian flakes may have served as expedient tools without alteration.

The nonlocal Niobrara/Smoky Hill jasper originated in the Niobrara Formation of Kansas, Nebraska, and South Dakota (Loetterle 1937). This material is readily available in western Kansas, roughly $400 \mathrm{~km}$ north of Long View (Banks 1990:96). The 21 pieces of Niobrara jasper represent the second largest subgroup of identified jasperoid material in Component A, the first being local jaspers. Fourteen percent possess 1 to 25 percent cortex on their dorsal faces. Platform-bearing flakes comprise 71 percent of the Niobrara debitage with 51 percent multifaceted. Flat platforms comprise 25 percent, whereas the remaining 38 percent are distal flake fragments. Based on what is present, the Niobrara brought to Component A was initially reduced before it arrived on site and likely transported as blocks and/or cores reduced to finished bifacial tools and usable flake tools.

No recognizable cherts from Oklahoma, such as Kay County/Florence-A chert from the Barnstone Formation, or Winfield or Welford cherts of the Flint and Osage Hills of Oklahoma and Kansas (Banks 1990:96-101) were identified in this component.

The Socorro jasper is from the Chupadera Mountains west and southwest of Socorro, New Mexico (DelloRusso 2004). Multiple source areas are known in the region. This is a reddish-orange silicified rhyolite. This one piece is macroscopically similar in texture and color (light olive brown [2.5Y 5/6] with mottled gray [7.5YR 5/0]) to hand specimens in Quigg's lithic reference collection from Socorro County, New Mexico. This specimen has a flat platform and 1 to 25 percent cortex on the dorsal side. It is difficult to interpret the range of activities that would have occurred with the current data. At minimum, some middle- to late-stage cobble reduction occurred at this component.
Two of the 14 identified ceramic vessels are of suspected nonlocal origins. Vessel $\mathrm{N}$ is represented by a single, tiny painted sherd (dark strips on gray surface). This painted sherd likely came from New Mexico, although it is too tiny to be specifically identified. The function of this nonlocal vessel is unclear, though it likely served as a container for traded goods or perhaps as high-status objects. Because the local population made their own pottery, this exotic vessel was presumably not imported due to a lack of technically functional vessels, but more likely was valued for aesthetic appeal and/or the status it imparted to its owners. Certainly, the low quantitative representation of such imported vessels indicates limited trade in goods transported in vessels to the Long View site.

A second Vessel (C), represented by 10 sherds, has a smooth, red-washed exterior finish and presumably was imported to this region. It contrasts with nearly all local vessels that exhibit a cordmarked or smoothed surface and are absent of color. However, the petrographic data on one Vessel C sherd (\#12068-1 ) indicates that the temper was within a broad basalt temper class, very similar to many tempers used in local cordmarked vessels with a dominance of basalt with pyroxene (Paste Group HH, Appendix F). The INAA on two Vessel C sherds indicates they are chemically similar to at least one cordmarked vessel, thick-walled Vessel 3 from Component C, locally manufactured (Appendix G). Consequently, although the smooth reddish surface finish is quite unusual for this area and region, the chemical and temper constituents reveal a likely local manufacture for Vessel C.

One-half a tiny (about 3.0-mm-wide) shell bead was recovered during flotation of matrix from a dump area assigned Feature 11. Trace element analysis using X-ray fluorescence determined this bead is comprised entirely of calcium carbonate (Appendix E). It is concluded this is a marine shell of definitely nonlocal origin. This is the only marine shell item recovered and it represents long-distance trade/ interactions, but from an unknown direction.

In sum, the presence of obsidian from northcentral New Mexico, Socorro jasper from central New Mexico, and Southwestern pottery indicates 
interactions with groups in the Southwest or, possibly, long-distance forays to that region. Although these nonlocal Southwestern goods are present, they are so infrequent that they played a minor role in the everyday lifeway of the occupants. The Niobrara jasper from some $400 \mathrm{~km}$ to the north also indicates interactions with groups in a second direction. Again, the nonlocal jasper was not a major technological factor, since the local population had easy access to high quality Alibates, as well as an abundance of coarser-grained tool stone for use as ground stone tools. In short, the people who occupied Component A had at least limited contact and interactions with distant groups in two widely divergent directions. The low frequency of imported, nonlocal goods indicates that the local population operated without significant technoeconomic dependency on outside populations, and the exchanges of goods may have been motivated more by an aesthetic interest in exotic materials or acquisition of items that served as markers of status rather than by economic necessity.

\subsubsection{Component C Discussions}

Component C yielded 19 pieces of nonlocal Niobrara/ Smoky Hill jasper. This tool stone from farther north is quite limited and represents only 1.9 percent of the overall tool-stone debitage assemblage. This material potentially served in exchange for materials to which the Long View occupants had ready access, such as high quality Alibates and abundant coarsegrained stone. Niobrara/Smoky Hill is the most abundant identified jasper ( $N=16 ; 79$ percent) of the jasper subgroups represented $(N=19)$ in this component. No Niobrara specimens exhibit cortex. Of the Niobrara debris, 63 percent exhibit flat platforms. Nearly 32 percent are categorized as shatter. Given the lack of cortex the shatter was likely derived during hard-hammer flake detachment from cores. The absence of multifaceted platforms among those present also indicates that flakes were derived through core-reduction technology.

A tiny shell bead with chemical properties that indicate marine origin was recovered from pithouse Feature6 in Component C (Appendix E). It is identical to the tiny shell bead recovered from Component A. No Southwestern pottery sherds or obsidian was recovered from Component $\mathrm{C}$, which is somewhat surprising, given their presence in Component A.
The presence of obsidian in Component $\mathrm{A}$ and not in Component $\mathrm{C}$ implies that site size or age is not the primary cause behind the difference. A possible explanation for this difference is that systematic trade relations between people of the Southern Plains and the Puebloan area of eastern New Mexico became more firmly established with the emergence of Pecos Pueblo as a major inter-regional trading center in the Fifteenth Century, wherein Plains groups were able to exchange bison products (e.g., hides) for various Southwestern materials including pottery and obsidian. This may also indicate that individual groups had access to trade partners in New Mexico, whereas others did not. The group that occupied Component $\mathrm{C}$ may not have had the same trading partners as those in Component A. However, Niobrara jasper appears in both components, which may imply mutual contacts to the north. Similarly, both components had nearly identical tiny marine shell beads, which also support similar contacts or at least similar trading connections.

\subsubsection{General Discussion}

Although the cultural assemblages from most Antelope Creek phase sites in the core area have not been thoroughly analyzed or reported, some easily recognizable types of nonlocal goods such as obsidian, marine shells, Southwestern ceramic pottery, and ceramic pipes have been reported, though generally as infrequent occurrences (Table 10-20). Consequently, the specific counts of these imported goods should be considered as potentially under-represented in the extant literature. The four excavated Antelope Creek phase sites in the Oklahoma panhandle (Stamper, McGrath, Two Sisters and Roy Smith) reveal minor differences in the representation of trade items (Table 10-20). These sites have all yielded obsidian, whereas Olivella shell beads are reported from three sites and Southwestern pottery is known only from the McGrath and Stamper sites. Only 37 percent of the Antelope Creek phase sites in the core area examined by Lintz (1986) have yielded obsidian.

Spielmann (1991) has discussed Plains/Pueblo interactions, suggesting that such intergroup relations provided mutually beneficial outcomes for the people who were involved. It is thought that bison products were traded by Plains Village people to the Puebloans for obsidian, pottery and 
Table 10-20. Comparison of Exotic Goods from Sites and Phases/Complexes in the Region.

\begin{tabular}{|c|c|c|c|c|c|c|c|c|}
\hline \multirow{2}{*}{ Material Goods } & \multicolumn{2}{|c|}{$\begin{array}{l}\text { Long View }^{1} \\
\text { Components }\end{array}$} & \multirow{2}{*}{$\begin{array}{c}\text { Antelope Creek Phase } \\
\text { Sites }^{2}\end{array}$} & \multirow{2}{*}{$\begin{array}{l}\text { Buried City } \\
\text { Complex }^{3}\end{array}$} & \multirow{2}{*}{$\begin{array}{l}\text { Odessa Yates } \\
\text { (34BV100) }^{4}\end{array}$} & \multirow{2}{*}{$\begin{array}{l}\text { Palo Duro } \\
\text { Complex }^{5}\end{array}$} & \multirow{2}{*}{$\begin{array}{l}\text { M-Cross Ranch } \\
\text { Sites }{ }^{6}\end{array}$} & \multirow{2}{*}{$\begin{array}{c}\text { Lundeen in SW Kansas } \\
(14 \mathrm{MD} 306)^{7}\end{array}$} \\
\hline & A & $\mathrm{C}$ & & & & & & \\
\hline \multicolumn{9}{|l|}{ Tool Stone } \\
\hline Alibates & $65 \%$ & $89 \%$ & $95 \%$ & $80 \%$ & $45.5 \%$ & $1.4 \%$ & & $60 \%$ \\
\hline Obsidian & $2 \%$ & 0 & 6,634 & 200 & $2000+$ & 8 & & $300 \%$ \\
\hline Niobrara & $1 \%$ & $1.9 \%$ & $<0.1 \%$ & $4.8 \%$ & $27.7 \%$ & & & $35 \%$ \\
\hline Ogallala gravels & $5.4 \%$ & $4 \%$ & $4-5 \%$ & $?$ & $?$ & $6.4 \%$ & & \\
\hline Opalite & $21 \%$ & 0 & & & & & & \\
\hline Tecovas jasper & $1.2 \%$ & $0.3 \%$ & & & & $90.6 \%$ & & \\
\hline Edwards chert & & & & & & & & $x$ \\
\hline Other & & & & $14.7 \%$ & $26.8 \%$ & $\mathrm{x}$ & & \\
\hline \multicolumn{9}{|l|}{ Pottery } \\
\hline Southwestern pipes & 2 & 0 & 10 & 0 & $10 \%$ & 0 & & 0 \\
\hline Southwestern pottery & 1 & 0 & 339 & 10 & 10 & brownware & & 3 \\
\hline Unknown & 3 & & & & & & & \\
\hline Turquoise & 0 & 0 & 27 & $\mathrm{x}$ & 10 & 0 & & 1 \\
\hline Mica & 0 & 0 & 1 & 0 & $\mathrm{x}$ & 0 & & 0 \\
\hline Copper & 0 & 0 & 0 & 0 & 0 & 0 & & 0 \\
\hline Marine shells & 1 & 1 & 6 & $\mathrm{x}$ & $\mathrm{x}$ & 0 & & 0 \\
\hline Olivella shells & 0 & 0 & 170 & $100+$ & $240+$ & 0 & & 15 \\
\hline Marine disk beads & 0 & 0 & 1174 & $\mathrm{x}$ & $\mathrm{x}$ & 0 & & $\mathrm{x}$ \\
\hline Kansas pipestone & 0 & 0 & 0 & 10 & $10+$ & 0 & & 0 \\
\hline Green celts & 0 & 0 & 1 & 1 & 1 & 0 & & 0 \\
\hline Quartzite crystals & 1 & 0 & $\mathrm{x}$ & 0 & $\mathrm{x}$ & 0 & & 0 \\
\hline Lip plug & 0 & 0 & $\mathrm{x}$ & 0 & 1 & 0 & & 0 \\
\hline \multicolumn{9}{|c|}{1 = This report. } \\
\hline $\begin{array}{l}2=\text { Green 1967; Duffield } 19 \\
3=\text { D. Hughes and Hughes } \\
4=\text { Brosowske 2005. Analy } \\
5=\text { Boyd 1995, 1997, 2004; } \\
6=\text { Boyd and Wilkens } 2001 \\
7=\text { Bevitt 1999, one of the } f\end{array}$ & $\begin{array}{l}1975 \text {; L } \\
\text {; Broso } \\
\text { been co } \\
\text { as been } \\
7 \text {; Boyd } \\
\text { lalyzed a }\end{array}$ & $\begin{array}{l}986 \text {; D } \\
\text { 2005; li } \\
\text { ted or r } \\
\text { le betw } \\
\text {; the da } \\
\text { ported }\end{array}$ & $\begin{array}{l}\text { can } 2002,2006 \text {; most rest } \\
\text { ited reporting on the older } \\
\text { prted, percentages are on } \\
\text { n sites. } \\
\text { from multiple sites has n } \\
\text { ains Village period sites in }\end{array}$ & $\begin{array}{l}\text { came from thr } \\
\text { ork with some } \\
\text { pped stone tool } \\
\text { een analyzed, } \\
\text { gion. }\end{array}$ & $\begin{array}{l}\text { reports, but flota } \\
\text { mented data prov }\end{array}$ & $\begin{array}{l}\text { has been limite } \\
\text { by Brosowske }\end{array}$ & $\begin{array}{l}\text { r nonexistent in mo } \\
05 .\end{array}$ & Antelope Creek phase site \\
\hline
\end{tabular}


other material items. Since Spielmann's (1991) publication, the Odessa phase has been identified by Brosowske (2005; Brosowske and Bevitt 2006). His fieldwork focused mostly in the panhandle of northwestern Oklahoma, north of the Long View site. Odessa Yates and other sites that Brosowske (2005) assigned to the Odessa phase have also yielded nonlocal goods, which include New Mexico obsidian and Southwestern ceramic sherds (see Table 10-20). Overall, Southern Plains villages have sporadically yielded durable trade goods that originated from the eastern Pueblos of New Mexico.

Brosowske (2005) focused on the economic intensification and emergent social complexity of the Middle Ceramic period, in which the Long View site is included. He sees exchange as embedded in the larger social realm, and suggests that models of technological organization and optimal foraging hold little power for elucidating the acquisition of utilitarian tools manufactured from exotic stone, and believes that archeologists must consider the social value of these utilitarian items (Brosowske 2005). He further suggests that these trade items, which are concentrated in relatively few sites, reflect the emergence of social hierarchy in smallscale societies such as represented in the Middle Ceramic period of the Southern High Plains and that possession/control of these objects enabled leaders to augment their prestige. He asserts three widely scattered Plains Village sites, Chimney Rock Ruin, Alibates Ruins both of the Antelope Creek phase sites in the core area and Odessa Yates of the Odessa phase in the eastern Oklahoma panhandle served as intraregional redistribution centers, with established independent trade relationships with Puebloan settlements for exotic goods obtained by means of long-distance trading expeditions (Brosowske 2005). Cerro Toledo Rhyolite is the most common source for obsidian across a wide area of the Southern Plains and crosscuts a number of named cultural manifestations. Cerro Toledo Rhyolite accounts for 100 percent of the Long View obsidian, 80 percent of Odessa phase, 100 percent from four Antelope Creek phase sites along the Canadian River, and 62 percent of the sourced obsidian from two Antelope Creek phase sites in the Oklahoma panhandle (Brosowske 2005:343). Obviously, the obsidian, and even the nonlocal Niobrara/Smoky Hill jasper, was not restricted to the Antelope Creek phase, as these same materials appear in Odessa phase sites, and likely in other regional manifestations.

Nonlocal durable goods at Long View played a minor role. The occurrence of such goods is not unusual or unique, as sites and phases and/or complexes in adjacent areas have yielded similar items in varying frequencies, mostly in limited numbers (see Table 10-20). At present, durable exotic goods are inferred to have served to enhance the social prestige of individuals who possessed them. Hopefully, further excavations and analysis of various types of Southern Plains village sites across the region will add to our understanding of the roles and functions of exotic goods acquired through long-distance exchange networks and/or the redistribution of goods through trade centers and accompanying social implications.

\subsection{Question 10}

Was the Alibates recovered from the occupations at 41 RB112 obtained locally from Canadian River gravels or was it procured from the Alibates quarries, located some $80.5 \mathrm{~km}$ (50 miles) to the west?

\section{Paul M. Matchen and J. Michael Quigg}

This question involves possible mechanisms by which Alibates silicified dolomite (hereafter referred to as Alibates) was procured at the Long View site; either from the known quarry $80.5 \mathrm{~km}$ upstream, or alternatively, via collection from local gravels washed downstream from the primary outcrop at Lake Meredith in the Canadian River valley. Considerable discussion has been put forth about the nature and origin of Alibates at sites east of the known outcrop in the north-central portion of the Texas panhandle. Wyckoff (1989, 1993), Kraft (1997), and Brosowske (2012) demonstrated that natural water-worn cobbles/clasts of Alibates of appreciable size could be obtained along the Canadian River and possibly the Cimarron River drainages as far east as Lake Eufaula in southeastern Oklahoma, at great distances from the primary quarries. However, evidence suggests that the material used at Long View did not originate as stream cobbles.

To address the question of origin of Alibates at Long View, early-stage debitage cortex was examined 
to identify the presence of cortical surfaces from the bedrock source versus smooth, water-worn secondary gravels. Raw material choices made by the site occupants regarding Alibates use in tool production were also examined in order to gauge whether certain lithic materials were more likely to be curated or conserved than others. Tool length, width and thickness were measured to address durability, a factor in the extension of tool use-life (Brooks 2005). In addition, the overall size of Alibates tools was used to gauge whether the projected original cobble size projected from the recovered artifacts are larger than the average natural clasts documented in gravel sources downstream from the known quarries (Wyckoff 1989, 1993). While clast sizes of Alibates gravels are expected to decrease the further the distance from the source, variations in amount of sediment introduced into the channel, the velocity and consistency of water flow, and rate of sediment accumulation on the channel floor, all might affect this trend (Boggs 1987).

\subsubsection{Technological Choices}

At Component A, Alibates was used for both formal tools that were maintained through edge rejuvenation (e.g., alternately beveled knives, drills, scrapers) as well as expedient tools produced for immediate use and subsequent discard (e.g., edgemodified flakes). This diversity in usage indicates an abundant raw material source from which useable material could be procured for immediate tasks, but also high quality, valued and conserved for certain anticipated uses over longer periods.

In Component A the vast majority of formal tools ( $N=50$; 80 percent) were Alibates. Eighty percent $(N=115)$ of the edge-modified flake tools were also Alibates. Other materials used in chippedstone tool (both informal and formal) production $(N=42 ; 20$ percent) include unidentified jasper (4.3 percent); unidentified chert (2.9 percent); Tecovas jasper (2.4 percent); chalcedony (1.9 percent), Ogallala quartzite (1.9 percent), Niobrara/Smoky Hill jasper (1.9 percent), Day Creek dolomite (1.4 percent), unidentified rhyolite (1 percent), opalite (1.4 percent), silicified limestone $(0.5$ percent $)$, and silicified sandstone ( 0.5 percent). Figure 10-18 shows the proportion of formal to informal tools among non-Alibates materials. A trend towards the use of locally available materials for the production of informal tools (edge-modified flakes, etc.) is evident in this figure.

In Component $\mathrm{C}, 88$ percent $(N=122)$ of all chipped stone tools were Alibates. Of these Alibates tools, edge modified flakes make up approximately 77 percent $(N=94)$, leaving 23 percent $(N=28)$ represented as formal tools. These proportions are similar to those observed in Component A. Chipped stone tools made from other materials comprise a smaller percentage than in Component A, representing only 12 percent $(N=18)$ of the assemblage (Figure 10-19). Specifically, other materials include unidentified chert $(N=6 ; 4$ percent), Tecovas jasper ( $N=5$; 3.5 percent), chalcedony ( $N=4$; 3 percent), Niobrara jasper $(N=1$; 0.5 percent), Ogallala quartzite $(N=1 ; 0.5$ percent), and unidentified jasper ( $N=1 ; 0.5$ percent). The occupants had a greater reliance on local materials for formal tool production in Component $\mathrm{C}$ than in Component A, implying that availability of Alibates resources was being exhausted while the demand for expedient tools persisted.

\subsubsection{Evaluating the Cortex}

The early-stage Alibates debitage in Component A exhibits very little cortex. All 22 pieces of earlystage debitage (1.3 percent of the entire Alibates debris) were classified as having the lowest presence amount (1 to 25 percent) of cortex on dorsal faces. As a result, cortex classification was problematic in some instances. However, all cortical pieces appear to exhibit unaltered or nonwater-worn surfaces, that indicates these pieces were likely procured from a bedrock quarry source (e.g., the Alibates quarries at Lake Meredith) rather than from gravel sources within the Canadian River valley.

Component $\mathrm{C}$ also shows an intensive reliance on Alibates (88 percent) for the production of formal and informal tools reflected in discarded tools and debitage. Similar to Component A, Alibates was used to make expedient tools for immediate tasks and subsequent discard, as well as for use in tasks (e.g., animal butchery) that required highly maintained and sustainable tools (e.g., scrapers and beveled knives) that were most often curated for repeated use. 


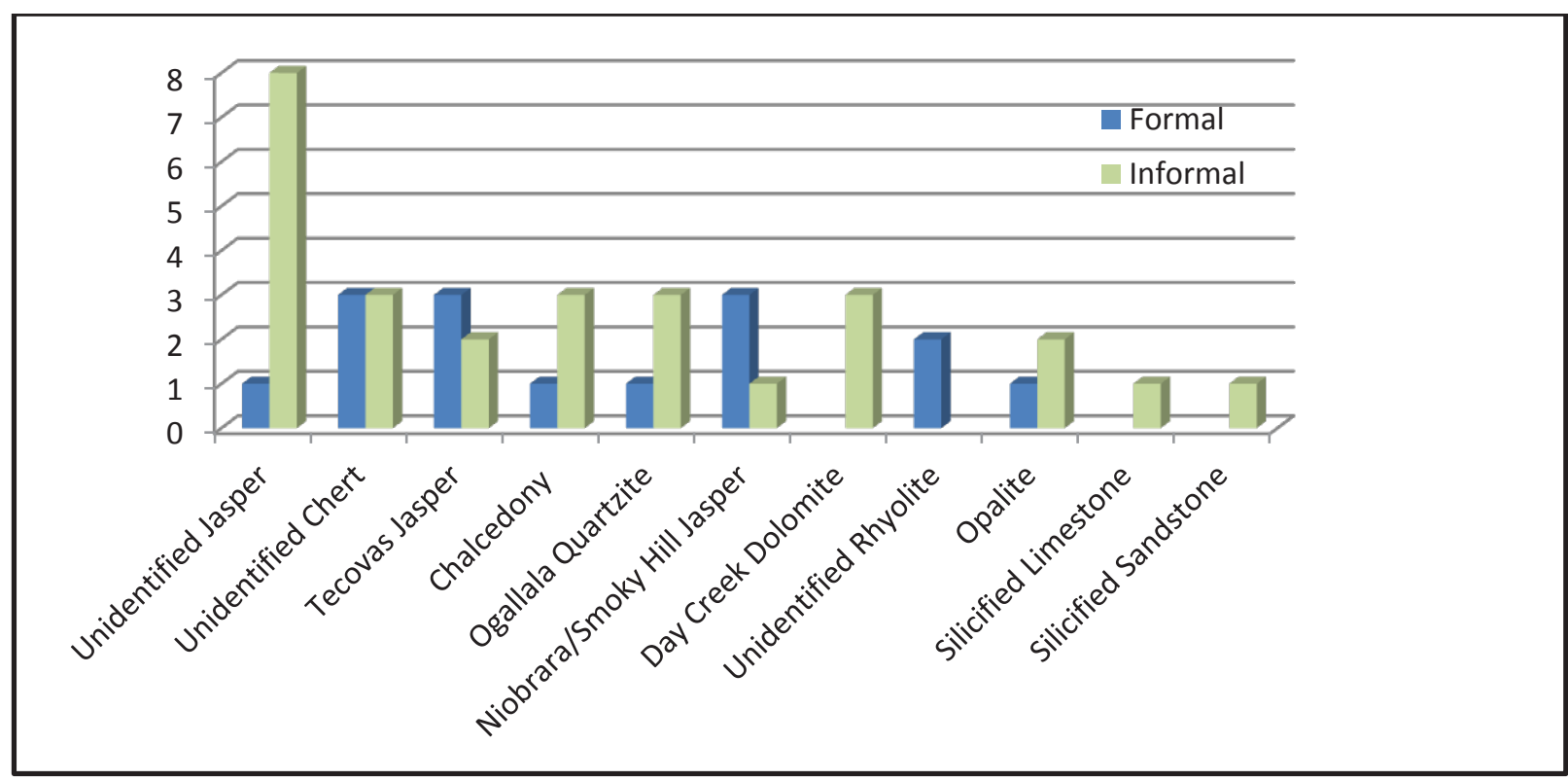

Figure 10-18. Frequency of formal and informal tool use of non-Alibates materials at Component A.

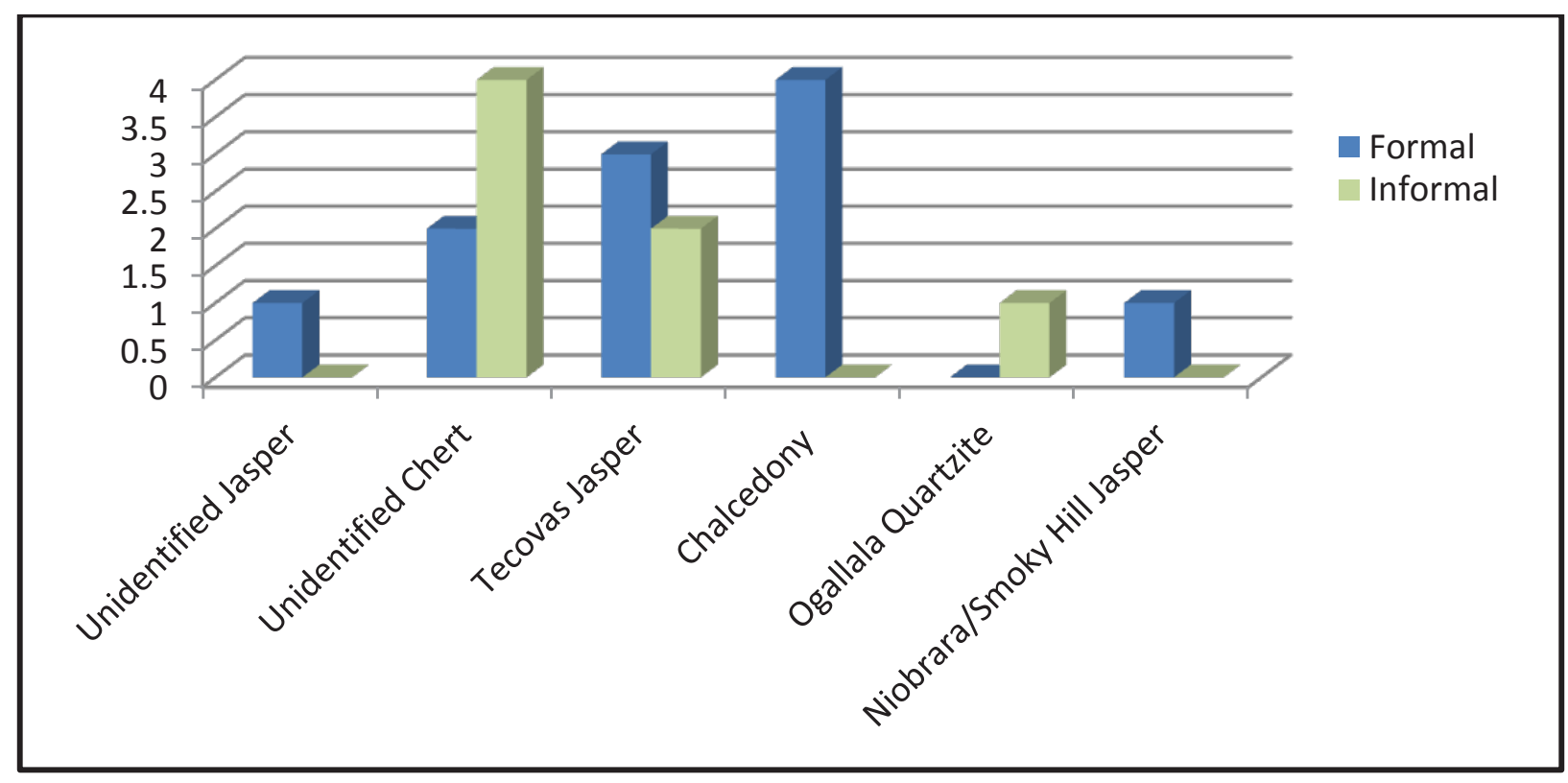

Figure 10-19. Frequency of formal and informal tool use of non-Alibates materials at Component C. 
Component C has 23 cortex-bearing specimens that comprise only 3 percent of the entire recovered Alibates debris assemblage. A majority $(N=21$; 91 percent) exhibit 1 to 25 percent cortex, whereas a low 9 percent $(N=2)$ show 26 to 50 percent cortex coverage. As with cortical debitage from Component A, specimens exhibit cortical surfaces unaltered by stream transport, implying Alibates procurement at Component $\mathrm{C}$ likely occurred at quarry sources as well.

\subsubsection{Size of Alibates Tools}

The use of Alibates cobbles and coarse gravels from secondary sources downstream from the main outcrop at Lake Meredith has been investigated by a few individuals (Brosowske 2012; Wyckoff 1989, 1993). Wyckoff (1989) documented 39 exposures of Alibates across three transects of the Canadian River valley in western Oklahoma and documented Alibates cobbles at four of the exposures that ranged in size from 128 to $145 \mathrm{~mm}$. The mean lengths of chipped stone tools made from Alibates at Components A and $\mathrm{C}$ are $23.8 \mathrm{~mm}$ and $22.5 \mathrm{~mm}$, respectively. The longest tool in component A measures $76.6 \mathrm{~mm}$, whereas the longest tool at Component $\mathrm{C}$ measures $69.1 \mathrm{~mm}$. Seven tools (three alternately beveled knives, three edge-modified flakes, and a biface) from Component $\mathrm{A}$ and two tools (both bifaces) from Component $\mathrm{C}$ measure greater than $60 \mathrm{~mm}$ in length. Using the data collected by Wyckoff (1989), Component A and C Alibates tools are well within range of the larger Alibates pieces.

Recently, Brosowske (2012) conducted an analysis of Alibates collected along Couch Creek (a few km west of Long View) that documented 28 Alibates cobbles 64- to 256-mm-long, and 20 coarse-grained Alibates gravels 2- to 64-mm-long (Wentworth Scale). Only 20 percent of the cobbles documented were considered good knapping quality. Many Component A tools are as long or longer, than the Couch Creek documented cobble sample. Conversely, nearly all Component $\mathrm{C}$ tools fall within the possible range for tool production using cobbles of similar dimensions as those collected at Couch Creek.

Experimental bifacial tool production has recently been conducted using bedded Edwards chert of the
Lampasas and Georgetown varieties from western Williamson County, Texas (Ringstaff, personal communication, 2012). These source pieces were substantially larger (some approaching $700 \mathrm{~mm}$ in length) than most cobbles and gravels observed at secondary source locations by Wyckoff (1989, 1993) and Brosowske (2012). Ringstaff drove off macro-flakes (average 150-mm-long) to initiate production of bifaces. The final length of the bifaces averaged approximately $115 \mathrm{~mm}$ in length. In this experiment, the average length differential between initial macro-flakes and finished bifaces was approximately 35 mm (Ringstaff 2012; Ricklis 2011). With these data, the experimental biface reduction interval can be used as a buffer statistic to gage initial cobble size for finished tool dimensions.

Considering the experimental biface production data, it is probable that at least a third of the tools from Component $\mathrm{A}$ and a small percentage from Component $\mathrm{C}$ could not have been produced from secondary source gravels such as those from Couch Creek due to cobble/gravel size restrictions (Figures 10-20 and 10-21). Cobbles documented by Wyckoff at four exposures, on the other hand, are large enough to have been used to produce all Long View tools. However, both sets of data reveal that finding Alibates cobbles of good quality and useable size (64 $\mathrm{mm}$ and greater) in the downstream exposures $80 \mathrm{~km}$ or more from the primary source would be rare. One would likely have to visit many exposures before finding cobbles of sufficient size, and then only a small percentage would be of a suitable quality for reduction and tool production.

\subsubsection{Maintenance Practices}

Controlled consumption of Alibates, documented through continued maintenance of alternately beveled Alibates knives, is a prime example of maximizing tool use-life. By beveling to resharpen tool edges, the knapper was able to conserve tool surface area, thereby slowing the decrease in tool size. his resharpening strategy made the most efficient use of valuable high-quality material by extending the use-life of these tools. Sollberger (1971) has shown how this material-saving technology resulted in a morphological alteration of thinned bifacial knives from ovate to diamond forms. 


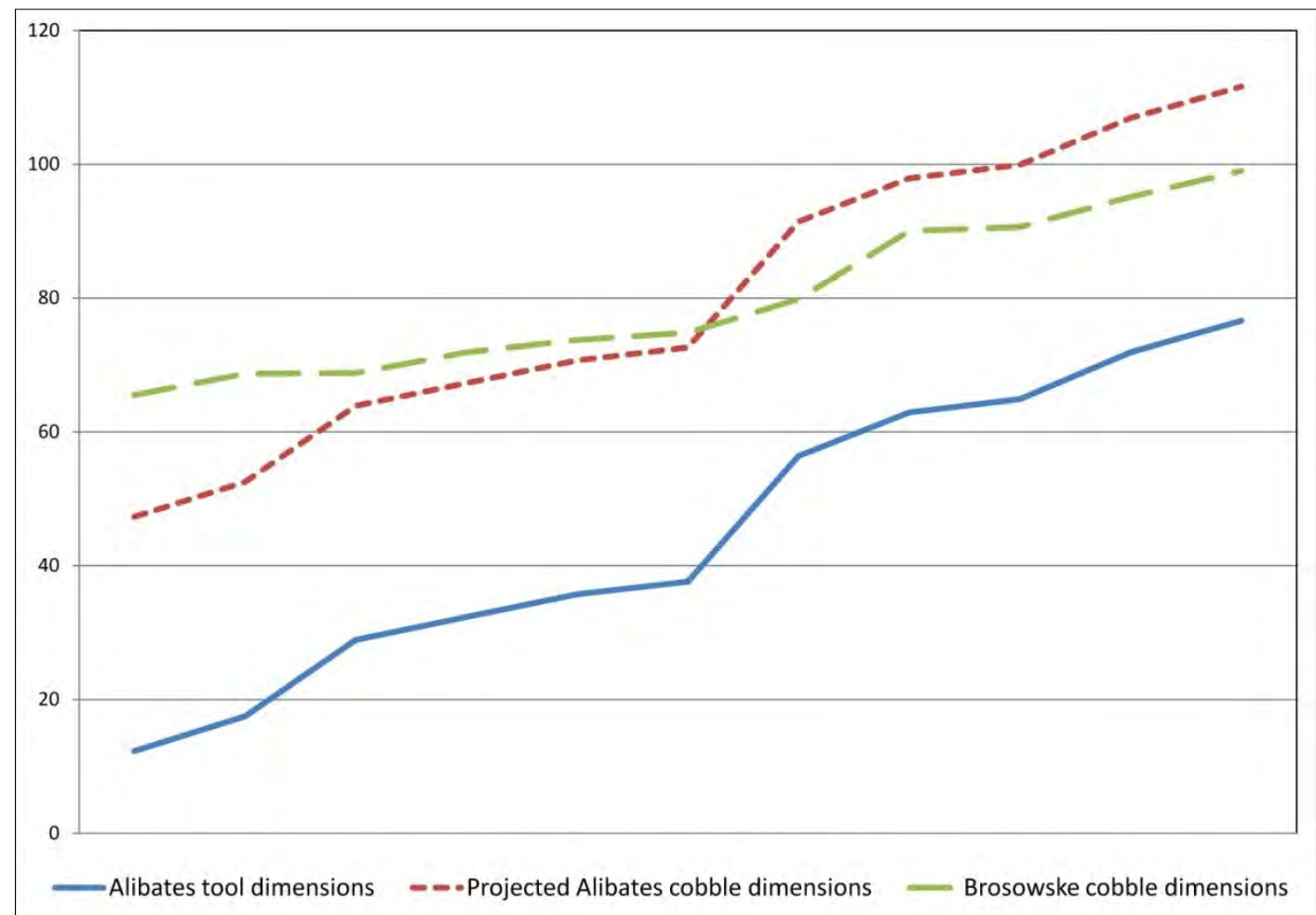

Figure 10-20. Line plots comparing maximum dimensions of Alibates tools in Component A to documented cobbles (data from Brosowske 2012) and projected cobble size (data from Ringstaff 2012).

Four alternately beveled knives were recovered from the southern end of Component $\mathrm{A}$. The specimens reflect different stages in the use-life cycle. A single beveled fragment was recovered from Component C. Based on information presented above, it appears that conservation of large Alibates knives was practiced by site occupants. However, this conservation practice may have been utilized during long hunting forays away from Long View and primary tool-source locations rather than reflecting material consumption while within the village.

In answer to the question posed above, Alibates recovered from the Long View site originated from the bedrock source at quarries some $80.5 \mathrm{~km}$ upstream. Evidence of controlled consumption of Alibates in the form of alternately beveled knives indicates efforts by inhabitants to ensure these butchering tools lasted as long as possible, thereby minimizing the labor investment needed while maximizing the usefulness of the Alibates. Alibates was also used for expedient tool production use, as were other available materials. Therefore, site selection for these two occupations was not dictated by the need to be near the source of highquality lithic materials such as Alibates. However, origination of raw Alibates from a source at such a distance may indicate the territory and/or range these two groups operated within or potentially indicates the existence of a trading network with other Plains Village groups linked to the Alibates quarry.

\subsection{Question 11}

What information can the Late Holocene Eolian deposits in the Canadian Breaks provide concerning the patterns and timing of environmental change during the Plains Village Period?

Charles D. Frederick and Brittney Gregory with contribution from Mark Bateman 


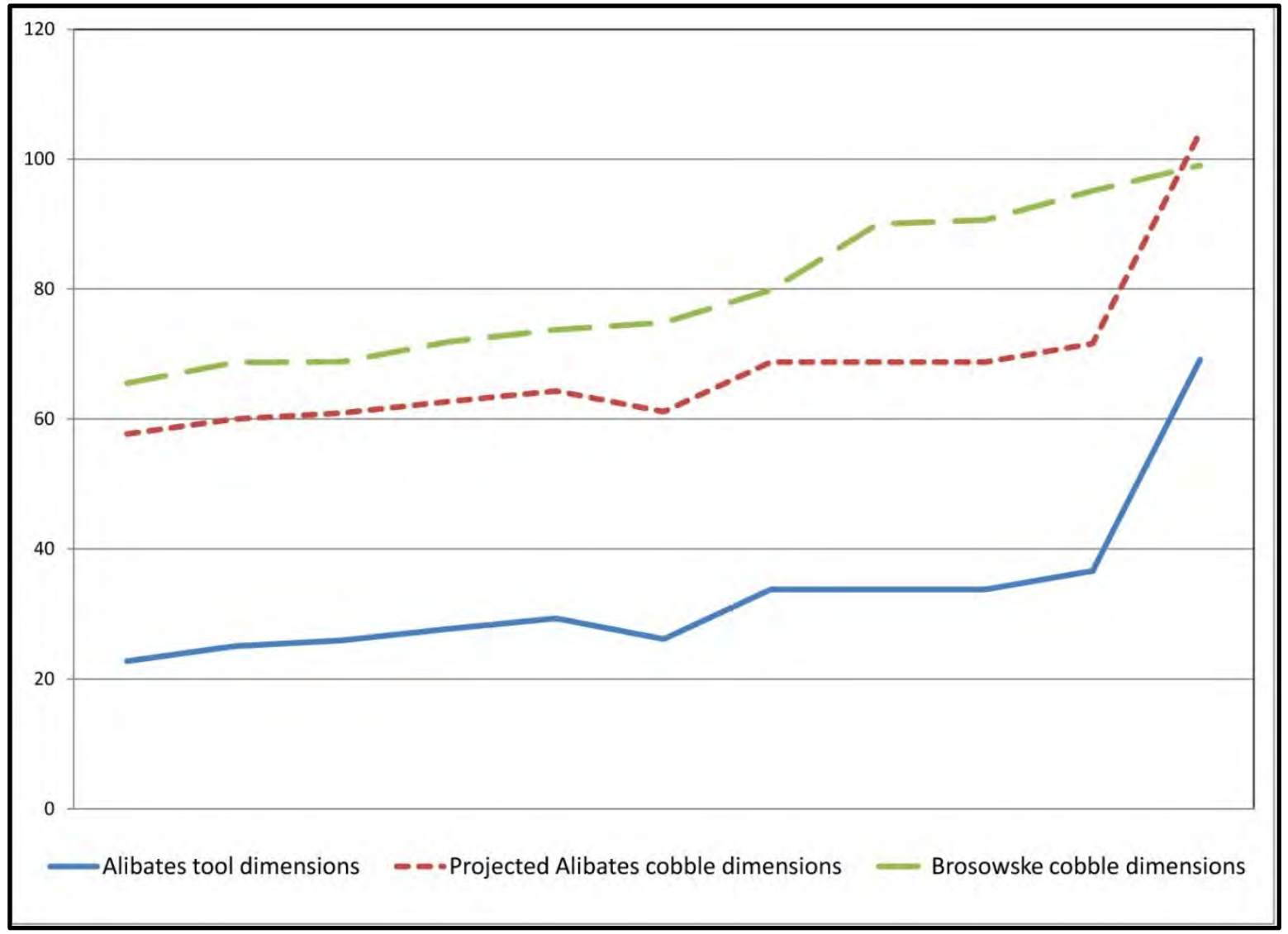

Figure 10-21. Line plots comparing maximum dimensions of Alibates tools in Component $C$ to documented cobbles (data from Brosowske 2012) and projected cobble size (data from Ringstaff 2012).

Two separate eolian deposits were recognized through examinations of deposits on- and off-site, and were informally termed Eolian Sand I and Eolian Sand II (Figure 10-22). These two deposits are discussed below.

\subsubsection{Eolian Sand I (ESI)}

The oldest eolian deposit, Eolian Sand I or (ESI), was present only within site context, and comprised the lower eolian deposits where a relatively thick eolian mantle was present. Profiles C-2 and C-4, each examined within the site, revealed an ESI deposit. These two profiles were collected from the southern end of the site where the eolian sands were between 70 and $120-\mathrm{cm}$-thick. In the field, ESI sediments were light yellowish brown (10YR 6/4, d; 10YR 5/4, m) to very pale brown (10YR 7/4, d; 10YR 6/6, m) loamy sand. In one exposure, these sands were observed directly resting upon the Ogallala Formation (see profile descriptions). Neither of the exposures of ESI in these profiles exhibited significant pedogenic alteration which would normally show that they were much older than the overlying late Holocene eolian sands. One of the exposures contained 1 to 3 percent of widely dispersed calcium carbonate nodules eroded from the Ogallala Formation, implying this deposit experienced a greater amount of post-depositional pedoturbation.

Luminescence dating indicated that ESI was most likely deposited between 37,000 and 64,000 years ago, and has experienced a complex post-depositional history. In Profile C-2, an OSL sample collected at a depth of $90 \mathrm{~cm}$ (Shfd-10175) yielded a single grain 


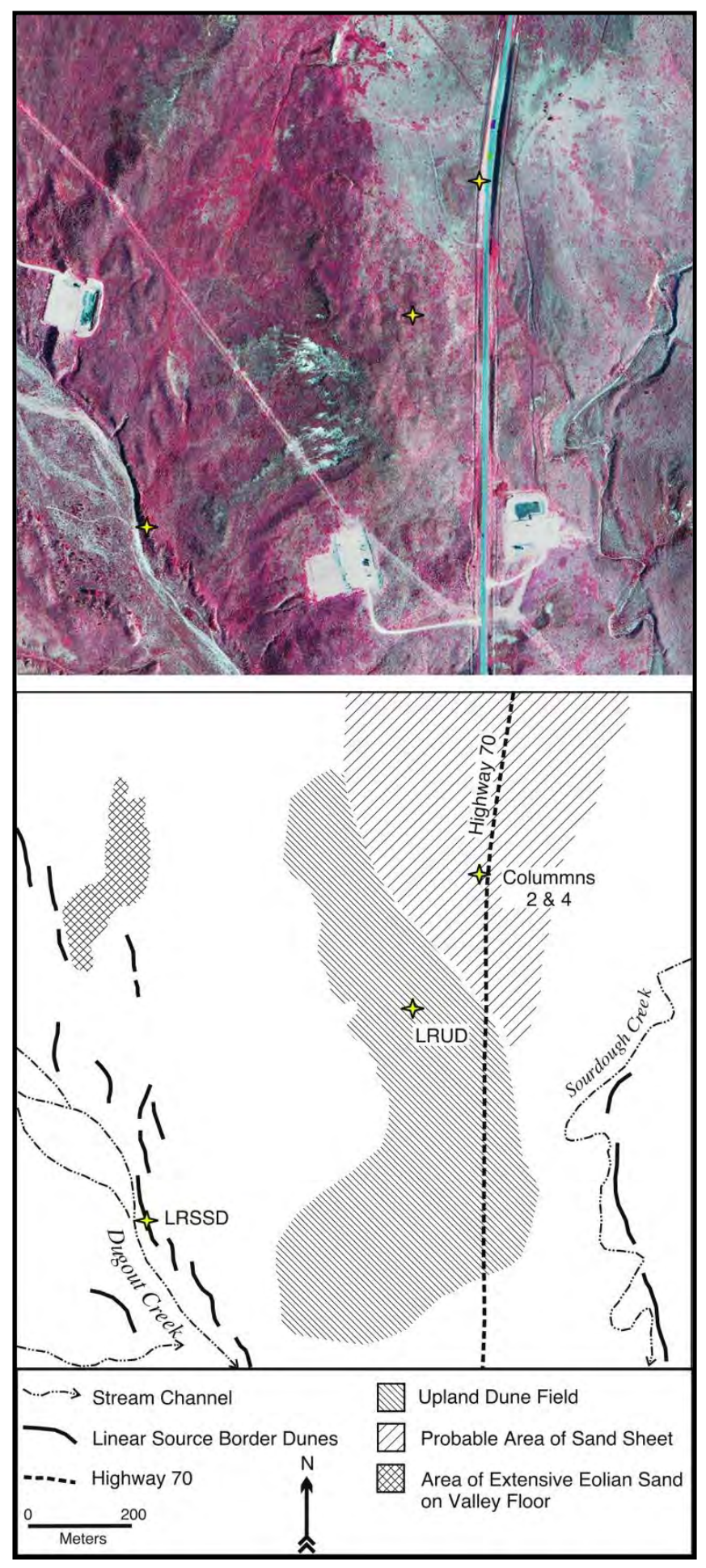

Figure 10-22. Top panel: A $1.72 \mathrm{~km}^{2}$ false color aerial photograph of the Long View site and vicinity taken on July 1, 2004, obtained from Terraserver. Lower Panel: Map compiled of selected Eolian geomorphic features in vicinity of the Long View Site compiled from the aerial image shown in the upper panel.

Stars show the locations of the profiles discussed in the text. 
OSL age distribution that was polymodal and had four different age components identified by finite mixture modeling. The majority (59 percent) of dated grains were associated with two components that dated 37,780 \pm 4660 years B.P. (24 percent) and $64,710 \pm 5450$ years B.P. (35 percent). The oldest is thought to represent the depositional age of this portion of the deposit. However, the polymodal age distribution yielded by the OSL single grain dating clearly demonstrates that this deposit has had a complex post-depositional history and has been adversely affected by pedoturbation.

The basal eolian sand in Profile C-4 was sampled for OSL dating at a depth of $80 \mathrm{~cm}$ (Shfd-10177) and the single grain age distribution of this sample was less complex than in Profile C-2, with finite mixture modeling identifying only two age components: $38,750 \pm 2400$ years B.P. (81 percent of the grains) and 530 years B.P. (10 percent). As in Profile C-2, the old grain age component in this sample (a total of 41 grains) exhibits a wide range of grain ages (4047 to 86,776 years B.P.). The young age component identified in this sample is consistent with the age of the Eolian Sand II (ESII) discussed below.

Although it is tempting to explain these old OSL ages away by citing pedoturbation of the Ogallala Formation, the granulometric attributes of ESI deposits are nearly identical to the late Holocene ESII sediments and are consistent with deposition in a sand sheet environment. In Profile C-4, where ESII was observed resting upon the Ogallala Formation, the deposit exhibits significantly different granulometric attributes from the Ogallala Formation deposits immediately beneath it. The fact that both profiles yielded similar grain age ranges implies that a significant amount of eolian deposition most likely occurred around 38,000 years ago. These broad age distributions could also indicate a long period of very incremental eolian sedimentation during the last glaciation. However, one would expect a significant soil to have formed in such a deposit and that is lacking here, suggesting that such a soil must have completely eroded prior to the deposition of ESII.

\subsubsection{Eolian Sand II (ESII)}

The majority of eolian sand examined and dated is attributable to a phase of deposition that began by A.D. 1500, and perhaps as early as A.D. 1150 and continues to this day. These sands, referred to as Eolian Sand II or ESII, were identified in three different eolian depositional environments, the source border dunes, an upland dune field, and in the sand sheet environment around the site.

\subsubsection{Riverine Source Border Dunes}

One of the more conspicuous features of the tributaries to the Canadian River in this region is the prominent linear source border dunes adjacent to the present stream channels. Slightly older source border dunes delineate now-abandoned stream channels. Dunes that form adjacent to river channels have been noted as distinct stratigraphic elements for nearly a century (cf. Haltenberger 1913). They are now recognized as a species of dune that forms adjacent to its sediment sources (in contrast to dunes found in lacustrine environments (lunettes) and marginal marine environments (coastal foredunes); cf. Page et al. 2001:187). Figure 10-22 depicts the spatial distribution of several source border dunes adjacent to Dugout Creek and Sourdough Creek. They are generally found on the northeast side of the stream channels. In the field these dunes are generally well-vegetated, less than 4-m-tall, about 10-m-wide and up to 150-m-long.

A single source border dune (Lipps Ranch Stream Side Dune or LRSSD) located immediately adjacent to Dugout Creek was examined by a series of handexcavated stair-step exposures cut into the west side of the dune. This excavation revealed about $3.2 \mathrm{~m}$ of eolian sand resting unconformably upon late Holocene alluvium (Figure 10-23; Table 1021). The dune lies about $10 \mathrm{~m}$ from the channel of Dugout Creek and about $900 \mathrm{~m}$ from the Long View site. Another, presumably older (no longer bordering an active stream channel) source border dune was observed immediately to the west of this dune, but this was not sampled.

The alluvium beneath the dune is Late Holocene, based on radiocarbon dating of a bulk sediment sample collected from near the top of the alluvium, within a Bk horizon at a depth of 344 to $349 \mathrm{~cm}$. The sample yielded an age of cal B.P. 3300 to 3260 (3110 \pm 30 years B.P.; Beta-297506). These alluvial deposits were of significantly finer texture 
(primarily silt loam and loam), and contained greater amounts of calcium carbonate and organic carbon than the overlying eolian sands. The upper portion of the alluvium was a calcic (Bk) horizon, and contained significantly more calcium carbonate than the underlying sediments.

The eolian sediments in this profile appear to have been deposited in two phases. The first phase started around 370 years B.P. and continued until sometime shortly after 270 years B.P., after which the dune briefly stabilized, and a very incipient A horizon formed. About $2 \mathrm{~m}$ of sand was deposited during this period. Sedimentation resumed around 100 years ago and deposition during this phase added about 1.2 $\mathrm{m}$ of sand to the dune crest. The deposits associated with this dune are generally very pale brown (10YR $7 / 4$, d) to pale brown $(10 \mathrm{YR} 6 / 3$, d) sand which is often laminated. The dune sand contains between 3 and 5 percent calcium carbonate, significantly less than the underlying alluvium (20 to 33 percent) and the Ogallala Formation (generally 10 to 20 percent). The paleosol separating the two phases of deposition is very faintly melanized pale brown (10YR 6/3, d, distinctly darker than the bounding deposits), and exhibits slightly greater amounts of organic carbon and a slight magnetic susceptibility enhancement.

\subsubsection{Upland Dune Field}

The western slopes of the interfluvial ridge do not exhibit any obvious eolian features. The crest of the ridge west and south of the site is occupied by a dune field. On some aerial photos thick stands of sagebrush are apparent, although today no sage is present, as it burned sometime in the recent past. Charred stems and branches are still readily found throughout this area.

The dunes are generally less than 1.5-m-tall, roughly oriented northwest to southeast, and are separated by relatively broad, irregularly shaped blowout depressions. The dunes are generally rather flat topped and none retain clear slip faces. Today the dunes are densely vegetated by grass, and are not active.

A single pit was hand-excavated into the crest of one dune about 700 m northeast of the channel of Dugout Creek and about $200 \mathrm{~m}$ southwest of the Long View site (see Figure 10-22). This 2-m-deep pit revealed $1.3 \mathrm{~m}$ of eolian sand that rested unconformably upon the Ogallala Formation. Like the streamside dune (LRSSD), the eolian sands exposed here were generally light yellowish brown (10YR 6/3, d), and were prominently laminated in most places (Table 10-22). An incipient, 24-cm-thick brown (10YR $4 / 3$, d) loamy sand A horizon had formed and exhibited weak subangular blocky structure. Three OSL samples were collected from this deposit. Two were dated using the single aliquot method and one was dated using the single grain method. The lowest sample (Shfd-10164), recovered from 1.2-m-depth near the base of the eolian sediments, had polymodal single aliquot age distribution, which suggests it has been disturbed since deposition or the grains were inadequately reset during transportation. Finite mixture modeling of the distribution identified five components. The youngest of these, at $800 \pm$ 60 years B.P. (36 percent of the dated aliquots), is representative of the age of transportation.

A sample collected from $60 \mathrm{~cm}$ depth (Shfd-10165) was also dated using the single aliquot method and yielded an age of $390 \pm 20$ years B.P. This sample exhibited a bimodal age structure where 91 percent of the aliquots comprised the dominant, younger age mode. Only two aliquots were rejected from the age calculation, both close in age (885 to 907 years B.P.).

A third OSL sample collected from a depth of $30 \mathrm{~cm}$ (Shfd-10166) was dated by the single grain method. This sample yielded two modes, one of which represented the transportation of the sand and dated $450 \pm 50$ years B.P. and a second that consisted of 16 percent zero dose grains (grains that have been reset so recently that they have no measureable age). This suggests that there is significant pedoturbation of this deposit. Although this age is older than the sample collected from $60 \mathrm{~cm}$ depth, the two ages overlap at both one and two standard deviations and should be considered statistically similar.

The dune was deposited on the former ground surface formed within the Ogallala Formation and exhibited an A-Bk soil profile. A bulk sample collected from the top of this buried soil yielded an age of $1230 \pm 30$ years B.P. (Beta-297507; $\delta^{13} \mathrm{C}=$ -24.0\%; cal B.P. 1300 to 1180; cal A.D. 650 to 770) 


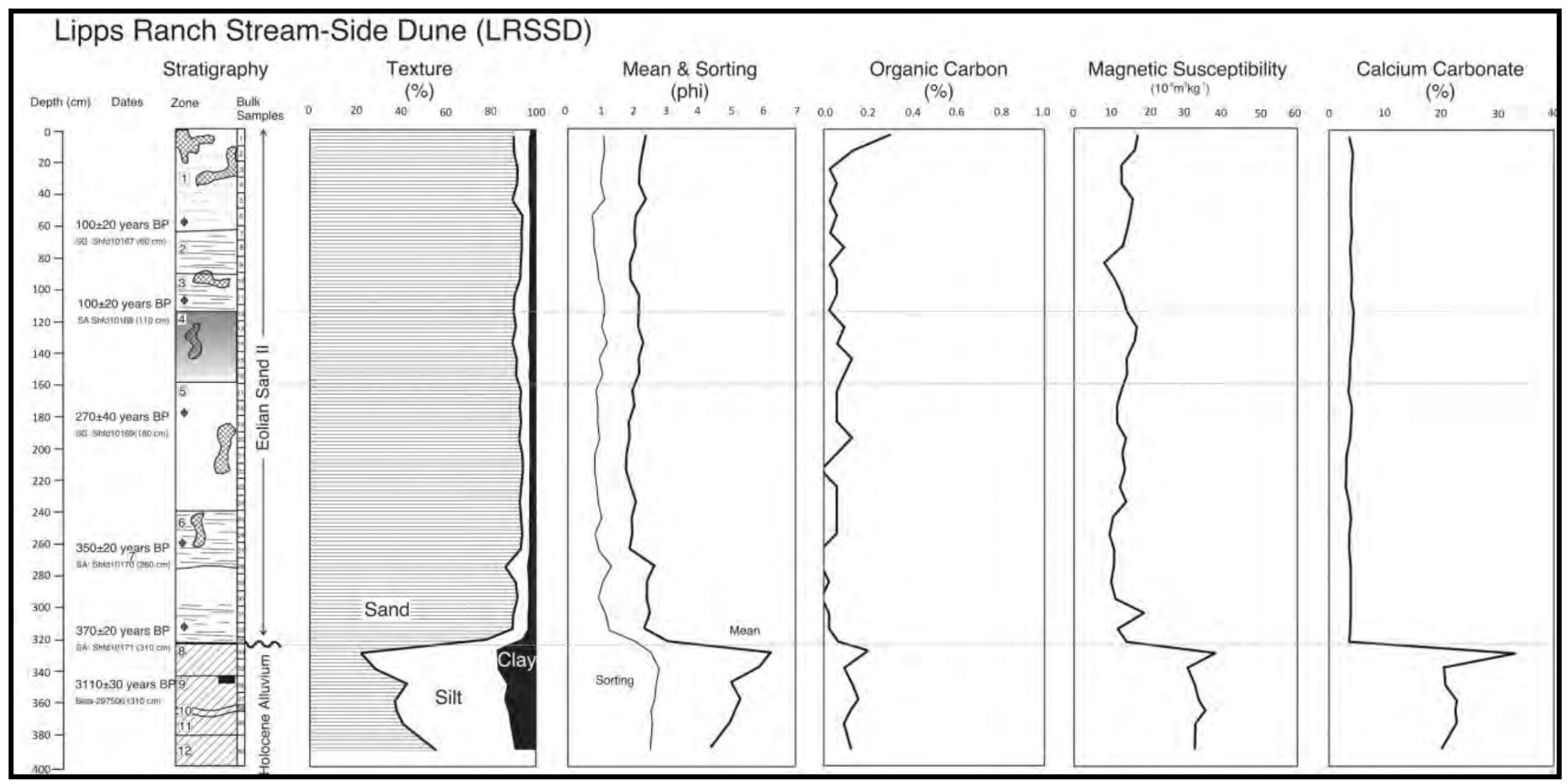

Figure 10-23. Stratigraphy, age, and depth variation in basic physical properties observed at the Lipps Ranch Stream Side Dune (LRSSD) locality. 
Table 10-21. Lipps Ranch Stream Side Dune (LRSSD) Profile from Hand-Excavated Stair Step Profile Through 3-to-4-m-Tall Dune Situated Adjacent to the Active Channel of Dugout Creek about $900 \mathrm{~m}$ Southwest of the Southern End of 41RB112.

\begin{tabular}{|c|c|c|c|c|}
\hline Zone & Horizon & $\begin{array}{l}\text { Depth } \\
\text { (cmbs) }\end{array}$ & Description & Interpretation \\
\hline 1 & $\mathrm{C}$ & $0-67$ & $\begin{array}{l}\text { Very pale brown (10YR } 7 / 4, \mathrm{~d}) \text { sand, loose, single grain, abrupt smooth boundary, } \\
\text { many krotovina, few faint discontinuous horizontal bedding planes; a single grain } \\
\text { OSL sample collected from } 60 \mathrm{~cm} \text { depth yielded finite mixture model ages of } 100 \\
\pm 20 \text { years B.P. ( } 20 \% \text { of the grains) and } 440 \pm 60 \text { years B.P. ( } 76 \% \text { of the grains). } \\
\text { The younger age mode is considered most likely depositional age (Shfd-10167). }\end{array}$ & Eolian Sand II \\
\hline 2 & $\mathrm{C}$ & $67-92$ & $\begin{array}{l}\text { Light yellowish brown-very pale brown (10YR 6.5/4, d) sand, loose, single } \\
\text { grain, abrupt smooth boundary, few ( } 1 \% \text { ) calcium carbonate filaments, prominent } \\
\text { horizontal laminations, few krotovina. }\end{array}$ & Eolian Sand II \\
\hline 3 & $\mathrm{C}$ & $92-115$ & $\begin{array}{l}\text { Pale brown }(10 \mathrm{YR} 6 / 3, \mathrm{~d}) \text { sand, loose to slightly hard, single grain, abrupt smooth } \\
\text { boundary, prominent low angle foresets dipping } 10^{\circ} \text { to the northeast, few of the } \\
\text { laminae are distinctly darker color (reworked sand from Zone } 4) \text {; a single aliquot } \\
\text { OSL age of } 100 \pm 20 \text { years B.P. obtained at a depth of } 110 \mathrm{~cm} \text { (Shfd-10168). }\end{array}$ & Eolian Sand II \\
\hline 4 & Akb & $115-160$ & $\begin{array}{l}\text { Pale brown (10YR 6/3, d) sand, loose to slightly hard, single grain, abrupt } \\
\text { smooth boundary, appears slightly darker than bounding zones, inferred in field } \\
\text { to be a weak A-horizon, lab work confirmed very slight increase in organic matter } \\
\text { and magnetic susceptibility; OSL dates suggest this surface may have been stable } \\
\text { for almost } 200 \text { years. }\end{array}$ & Eolian Sand II \\
\hline 5 & $\mathrm{C}$ & $160-240$ & $\begin{array}{l}\text { Very pale brown (10YR } 7 / 4, d) \text { sand, loose, single grain, abrupt smooth boundary, } \\
\text { appears massive; a single grain OSL sample collected from a depth of } 180 \mathrm{~cm} \\
\text { yielded two finite mixture model ages }(270 \pm 40 \text { years B.P. ( } 80 \% \text { of grains) and } \\
740 \pm 210 \text { years B.P. ( } 19 \% \text { of grains), the younger is considered to represent the } \\
\text { age at time of transportation (Shfd-10169). }\end{array}$ & Eolian Sand II \\
\hline 6 & $\mathrm{C}$ & $240-275$ & $\begin{array}{l}\text { Very pale brown }(10 Y \mathrm{Y} \text { 7/4, d) sand, loose, single grain, abrupt smooth boundary, } \\
\text { few }(1-3 \%) \text { calcium carbonate filaments, prominent low angle foresets dipping } \\
1-3^{\circ} \text { to the east; a single aliquot OSL age of } 350 \pm 20 \text { years B.P. obtained at a } \\
\text { depth of } 260 \mathrm{~cm}(\text { Shfd-10170). }\end{array}$ & Eolian Sand II \\
\hline 6 & $\mathrm{C}$ & $240-275$ & $\begin{array}{l}\text { Very pale brown }(10 Y \mathrm{Y} \text { } 7 / 4, \mathrm{~d}) \text { sand, loose, single grain, abrupt smooth boundary, } \\
\text { few }(1-3 \%) \text { calcium carbonate filaments, prominent low angle foresets dipping } \\
1-3^{\circ} \text { to the east; a single aliquot OSL age of } 350 \pm 20 \text { years B.P. obtained from a } \\
\text { depth of } 260 \mathrm{~cm} \text { (Shfd-10170). }\end{array}$ & Eolian Sand II \\
\hline 7 & $\mathrm{C}$ & $275-324$ & $\begin{array}{l}\text { Very pale brown (10YR 7/4, d; } 10 \text { YR } 6 / 4, \mathrm{~m}) \text { sand to loamy sand, very friable } \\
\text { to loose, single grain, abrupt wavy boundary, few }(1-3 \%) \text { calcium carbonate } \\
\text { filaments, top half of zone is slightly coarser textured, lower half of zone exhibits } \\
\text { several medium beds; a single aliquot OSL age of } 370 \pm 20 \text { years B.P. obtained at } \\
\text { a depth of } 310 \mathrm{~cm} \text { (Shfd-10171). }\end{array}$ & Eolian Sand II \\
\hline 8 & 2Bk1 & $324-344$ & $\begin{array}{l}\text { Very pale brown (10YR 7/3, d; } 7.5 Y R \text { R } 5 / 4, \mathrm{~m}) \text { silt loam, friable, moderate } \\
\text { medium to coarse subangular blocky structure, abrupt smooth boundary, common } \\
\text { (5-7\%) calcium carbonate filaments, few thin discontinuous coats of calcium } \\
\text { carbonate on ped faces, traces of a thin bed of sand within the middle of this } \\
\text { zone. }\end{array}$ & $\begin{array}{l}\text { Late Holocene } \\
\text { Alluvium }\end{array}$ \\
\hline 9 & 2Bk2 & $344-364$ & $\begin{array}{l}\text { Light yellowish brown (10YR 6/4, d; } 7.5 Y R \text { 5/4, m) loam, very friable, } \\
\text { moderate medium prismatic structure parting to moderate medium } \\
\text { subangular blocky structure, abrupt wavy boundary, common (5\%) } \\
\text { calcium carbonate filaments, few thin discontinuous coats of calcium } \\
\text { carbonate on ped faces and lining channels and pores; a bulk sediment } \\
\text { sample collected from } 344-349 \text { cm yielded an age of cal B.P. 3300-3260 } \\
(3110 \pm 30 \text { years B.P., Beta-297506). }\end{array}$ & $\begin{array}{l}\text { Late } \\
\text { Holocene } \\
\text { Alluvium }\end{array}$ \\
\hline
\end{tabular}


Table 10-21. Lipps Ranch Stream Side Dune (LRSSD) Profile from Hand-Excavated Stair Step Profile Through 3-to-4-m-Tall Dune Situated Adjacent to the Active Channel of Dugout Creek about $900 \mathrm{~m}$ Southwest of the Southern End of 41RB112. (cont.)

\begin{tabular}{|c|c|c|l|l|}
\hline Zone & Horizon & $\begin{array}{c}\text { Depth } \\
\text { (cmbs) }\end{array}$ & \multicolumn{1}{|c|}{ Description } & Interpretation \\
\hline 10 & BC & $364-367$ & $\begin{array}{l}\text { Reddish yellow (7.5YR 6/6, m) silt loam, very friable, massive, abrupt } \\
\text { wavy boundary, few (1-3\%) calcium carbonate filaments, a single very } \\
\text { thin wavy bed. }\end{array}$ & $\begin{array}{l}\text { Hate } \\
\text { Aolocene } \\
\text { Alluvium }\end{array}$ \\
\hline 11 & BC & $367-380$ & $\begin{array}{l}\text { Strong brown (7.5YR 5/6, m) loam, very friable, moderate coarse } \\
\text { subangular blocky structure, abrupt smooth boundary, few (3\%) calcium } \\
\text { carbonate filaments. }\end{array}$ & $\begin{array}{l}\text { Late } \\
\text { Holocene } \\
\text { Alluvium }\end{array}$ \\
\hline 12 & BC & $380-400$ & $\begin{array}{l}\text { Strong brown (7.5YR 5/6, m) sandy loam, very friable, moderate } \\
\text { medium prismatic structure parting to moderate medium subangular } \\
\text { blocky structure. }\end{array}$ & $\begin{array}{l}\text { Late } \\
\text { Holocene } \\
\text { Alluvium }\end{array}$ \\
\hline
\end{tabular}

Table 10-22. Column 2 (C-2) Collected from West Side of Fireguard, Adjacent to TxDOT Right-Of-Way Fence, Where Eolian Mantle Appeared Relatively Thick.

Note: stone alignment was in the top $20 \mathrm{~cm}$. Single grain OSL data, with all three ages exhibiting polymodal age distributions, showed this deposit was considerably disturbed at a granular level. Although no break in the profile was visibly obvious, the lower deposit (Zone 3) was older, as confirmed by OSL.

\begin{tabular}{|c|c|c|c|c|}
\hline Zone & Horizon & $\begin{array}{l}\text { Depth } \\
\text { (cmbs) }\end{array}$ & Description & Interpretation \\
\hline 1 & A & $0-22$ & $\begin{array}{l}\text { Very dark grayish brown }(10 \mathrm{YR} 3 / 2, \mathrm{~m}) \text { sandy loam, very friable, weak coarse } \\
\text { prismatic parting to weak medium subangular blocky structure, gradual smooth } \\
\text { boundary, slightly effervescent, many roots; OSL sample from near base of } \\
\text { zone at depth of } 20 \mathrm{~cm} \text { yielded a single grain age distribution that finite mixture } \\
\text { modeling identified three components } 410 \pm 50 \text { years B.P. ( } 63 \% \text { of the grains), } \\
1600 \pm 210 \text { years B.P. ( } 14 \% \text { of the grains), and } 9750 \pm 710 \text { years B.P. (24\% of } \\
\text { the grains), youngest thought to represent depositional age (Shfd-10174). }\end{array}$ & Eolian Sand II \\
\hline 2 & AC & $22-78$ & $\begin{array}{l}\text { Yellowish brown ( } 10 \text { YR } 5 / 4 \text {, d; } 10 \text { YR } 4 / 3, \mathrm{~m}) \text { sandy loam to loamy sand, very } \\
\text { friable, weak medium subangular blocky structure, strongly effervescent, few } \\
\text { krotovina; OSL sample from near the middle of zone at depth of } 50 \mathrm{~cm} \text { yielded } \\
\text { an single grain age distribution that finite mixture modeling identified three } \\
\text { components } 680 \pm 60 \text { years B.P. ( } 70 \% \text { of the grains), } 1530 \pm 200 \text { years B.P. ( } 19 \% \\
\text { of the grains), and } 6000 \pm 580 \text { years B.P. (11\% of the grains), youngest thought } \\
\text { to represent depositional age (Shfd-10173). }\end{array}$ & Eolian Sand II \\
\hline 3 & $\mathrm{C}$ & $78-120$ & $\begin{array}{l}\text { Light yellowish brown (10YR 6/4, d; } 10 \text { YR } 5 / 4, \mathrm{~m} \text { ) loamy sand to sandy loam, } \\
\text { very friable, massive to single grain, moderately effervescent, few krotovina; } \\
\text { OSL sample from near base of zone at depth of } 90 \mathrm{~cm} \text { yielded an single grain age } \\
\text { distribution that finite mixture modeling identified four components } 8190 \pm 1020 \\
\text { years B.P. ( } 11 \% \text { of the grains), } 15,770 \pm 1550 \text { years B.P. ( } 21 \% \text { of the grains), } \\
37,780 \pm 4660 \text { years B.P. ( } 24 \% \text { of the grains), and } 64,710 \pm 5450 \text { years B.P. (35\% } \\
\text { of the grains), oldest thought to represent depositional age (Shfd-10175). }\end{array}$ & Eolian Sand I \\
\hline
\end{tabular}


that provides a maximum age for dune formation. Surprisingly, the stable carbon isotope composition of this soil suggests that the upland at this time was vegetated by $\mathrm{C}_{3}$ grasses.

OSL samples from this dune suggest that sedimentation began around 800 years ago (A.D. 1146 to 1266) upon a surface with trees, and continued until sometime after 390 years B.P. (A.D. 1596 to 1636). The lack of evidence of soil development within the dune deposits except at the top of the profile suggests that deposition was more or less constant and too rapid for soil development to occur.

\subsubsection{Upland Sand Sheet}

An eolian sand sheet abuts the upland dune field on the northeast and is broad, relatively featureless, and lacks evidence of dunal topography normally associated with eolian sand sheets. This eolian depositional environment is represented at the site. Two profiles observed within the southern portion of the site were OSL dated for comparison with offsite profiles. Profile C-2 was collected from the area of the stone alignment adjacent to the fence that bounds the western edge of the TxDOT right-ofway. Profile C-4 was collected on the eastern side, immediately overlooking the highway road cut. The eolian mantle in this portion of the site appeared to thicken to the east. This trend may be due to the ground surface beginning to slope southeastward towards Sourdough Creek.

Unlike the dune sands, which exhibited minimal pedogenic alteration and often displayed bedding, the late Holocene ESII deposits in the sand sheet setting typically exhibit cumulic A horizons. Upon closer examination these A horizons show decreasing amounts of organic carbon with increasing depth, moderate magnetic susceptibility enhancement, and a very minor leaching of calcium carbonate at the very top of the profile (Figure 10-24; Tables 10-22 and 10-23). Profiles C-2 and C-4 also exhibit a slight fining upward texture defined by a gradual increase in silt throughout the deposition of the ESII. The reason for this shift in texture is unknown.

The A horizon formed at the top of the ESII deposits ranged from a very dark grayish brown (10YR 3/2, m) sandy loam in Profile C-2 to a brown (10YR 5/3, d; 10 YR $4 / 2, \mathrm{~m}$ ) sandy loam in Profile C-4. The core of this deposit ranged from a yellowish brown (10YR 5/4, d; 10YR 4/3, m) sandy loam to loamy sand in Profile C-2 to a brown (10YR 5/3, d; 10YR $4 / 3, \mathrm{~m})$ sandy loam in Profile C-4. Neither of these deposits exhibited evidence of bedding and graded almost imperceptibly to ESI at depth.

Two OSL samples were collected from the ESII in Profile C-2, one at a depth of $20 \mathrm{~cm}$ (Shfd-10174) and a second at $50 \mathrm{~cm}$ (Shfd-10173). The sample at 50 $\mathrm{cm}$ yielded a single grain age distribution with three different age components, the youngest of which is presumed to represent the age of transportation. These components dated $680 \pm 60$ years B.P. (70 percent of the grains), $1530 \pm 200$ years B.P. (19 percent of grains) and $6000 \pm 580$ (11 percent of grains). The sample collected from $20 \mathrm{~cm}$ also yielded a single grain age distribution from which finite mixture modeling identified three components: $410 \pm 50$ years B.P. (63 percent of the grains), 1600 \pm 210 years B.P. (14 percent of grains), and $9750 \pm$ 710 years B.P. (24 percent of grains). Like the lower sample, the youngest of these is thought to represent the depositional age of this portion of the deposit. A single OSL sample was collected from the ESII deposits in Profile C-4 from a depth of $30 \mathrm{~cm}$ (Shfd10176). Like the other samples within the sand sheet setting, the single grain age distribution exhibited significant scatter and finite mixture modeling was used to identify different age components within the data. Three such components were identified and the youngest of these, $400 \pm 110$ years B.P. is thought to represent the depositional age of the sediment and is represented by 64 percent of the dated sand grains. The next older component, $810 \pm 200$ years B.P. is represented by 25 percent of the dated grains, and the oldest, $2880 \pm 330$ years B.P. is represented by 11 percent of the dated grains.

Hence, the one sigma OSL data from the sand sheet environment indicate that deposition may have begun as early as A.D. 1260 and continued to aggrade beyond A.D. 1715. Sedimentation rates were much slower than in the dunes. At $0.5 \mathrm{~mm}$ to $1 \mathrm{~mm}$ per year, sedimentation would most likely have been fairly imperceptible unless the actual deposition was episodic. 


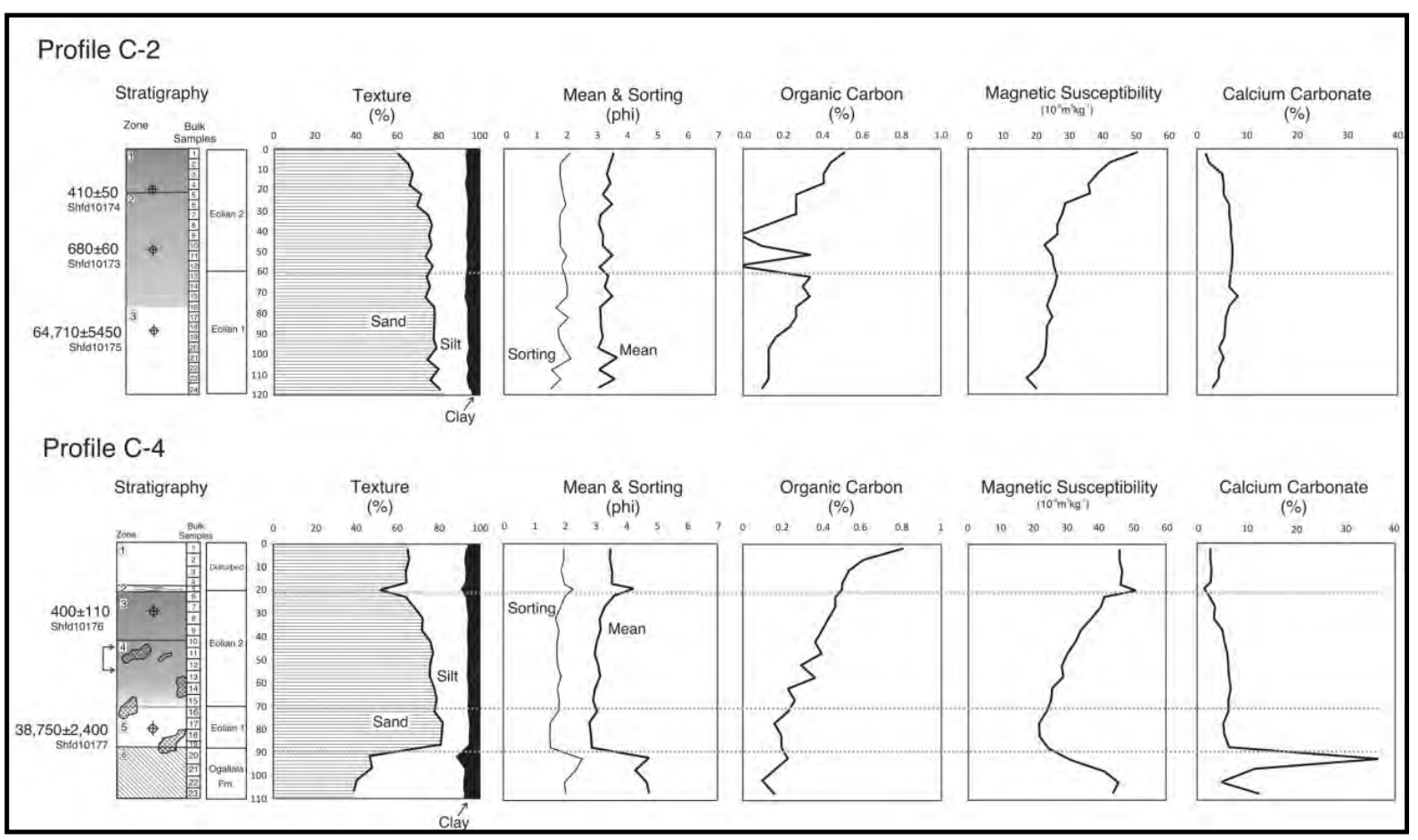

Figure 10-24. Stratigraphy, age, and depth variation in basic physical properties observed in column profiles $\mathrm{C}-2$ and $\mathrm{C}-4$, within Eolian sand sheet depositional environment on south side of the Long View site.

\subsubsection{Patterns of Deposition}

Our dating and documentation of the eolian deposits at the Long View site and surrounding area present a relatively clear image of recent eolian activity in the last millennium. These deposits appear to be the result of wind erosion of sand from the channel of Dugout Creek. They have been deposited in three distinct eolian facies within the Canadian River Valley; 1) riverine source border dunes, 2) upland dunes, and 3) sand sheets. No compositional work was performed to source the sand, but the spatial match between the three eolian suites is relatively direct, and indicates that southwesterly winds erode sand from the channel and transport it to higher landscapes to the northeast. The distinct tie to wind direction is the riverine source border dunes that lie on the eastern side of the stream channels.

The work performed here revealed trends that reflect the nature of this eolian system in terms of landforms and their textural composition and sedimentation rates. Generally, the eolian landforms become smaller and the deposits thinner away from the source. The riverine source border dunes ranged from less than $1 \mathrm{~m}$ to more than 4 -m-tall and were the largest dunal forms in the suite. The upland dunes were generally less than 1.5-m-tall and the deposits examined were about 1.3-m-thick. The sand sheet exhibits no obvious eolian landforms such as dunes and deposits range from less than $0.5 \mathrm{~m}$ to slightly less than a meter.

The eolian deposits become progressively finergrained and less well sorted with increasing distance from the sediment source, specifically the channel of Dugout Creek. Figure 10-25 shows a bivariate plot of mean particle size versus sorting (standard deviation of particle size distribution) and illustrates how the stream side dune is the coarsest and best sorted (moderately sorted medium sand to poorly sorted fine sand) deposit of the three present. These deposits exhibit no overlap with the sand sheet environment on the ridge crest (poorly to very poorly sorted very fine sand to very poorly sorted silt). Upland dune field sediments overlap 
Table 10-23. Column 4 (C-4) Collected from East of Fireguard, Next to the Road Cut at Feature 18.

\begin{tabular}{|c|c|c|c|c|}
\hline Zone & Horizon & $\begin{array}{l}\text { Depth } \\
\text { (cmbs) }\end{array}$ & Description & Interpretation \\
\hline 1 & $\mathrm{C}$ & $0-19$ & $\begin{array}{l}\text { Brown (10YR 5/3, d; } 10 \text { YR 3/2, m) sandy loam, very friable, moderate } \\
\text { medium subangular blocky structure, abrupt smooth boundary, strongly } \\
\text { effervescent, many roots, many worm casts. }\end{array}$ & $\begin{array}{l}\text { Disturbed fireguard } \\
\text { deposit }\end{array}$ \\
\hline 2 & $\mathrm{C}$ & $19-21$ & $\begin{array}{l}\text { Light yellowish brown (10YR 6/4, d; } 10 \mathrm{YR} 4 / 3, \mathrm{~m}) \text { sandy loam, very } \\
\text { friable, massive, abrupt discontinuous boundary, laminated in places. }\end{array}$ & $\begin{array}{l}\text { Sheetwash associated } \\
\text { with disturbed } \\
\text { Fireguard }\end{array}$ \\
\hline 3 & $2 \mathrm{Ab} 1$ & $21-42$ & $\begin{array}{l}\text { Brown (10YR 5/3, d; } 10 \text { YR 4/2, m) sandy loam, very friable, weak } \\
\text { extremely coarse prismatic structure, clear smooth boundary, strongly } \\
\text { effervescent, few krotovina, more massive than Zone } 4 \text {; OSL sample from } \\
\text { depth of } 30 \mathrm{~cm} \text { (Shfd-10176) yielded a single grain age distribution from } \\
\text { which finite mixture modeling identified three age components, } 400 \pm \\
110 \text { years B.P. ( } 64 \% \text { of the grains, considered the depositional age of the } \\
\text { deposit), } 810 \pm 200 \text { years B.P. ( } 25 \% \text { of the grains), and } 2880 \pm 330 \text { years } \\
\text { B.P. (11\% of the grains). }\end{array}$ & Eolian Sand II \\
\hline 4 & $2 \mathrm{Ab} 2$ & $42-71$ & $\begin{array}{l}\text { Brown (10YR 5/3, d; } 10 \text { YR 4/3, m) sandy loam, very friable, moderate } \\
\text { coarse prismatic structure, gradual smooth boundary, strongly effervescent, } \\
\text { many ant/worm passages, few larger krotovina, few charcoal fragments and } \\
\text { sherds in the top } 10 \mathrm{~cm} \text { of the zone. }\end{array}$ & Eolian Sand II \\
\hline 5 & $3 C$ & $71-88$ & $\begin{array}{l}\text { Very pale brown (10YR 7/4, d; } 10 \text { YR } 6 / 6, \mathrm{~m} \text { ) loamy sand, very friable, } \\
\text { massive, abrupt smooth to wavy boundary, strongly effervescent, few } \\
\text { krotovina, few (1-3\%) coarse fragments; OSL sample from a depth of } 80 \mathrm{~cm} \\
\text { yielded a single grain age distribution that finite mixture modeling identified } \\
\text { two age components, } 38,750 \pm 2400 \text { years B.P. ( } 81 \% \text { of the grains) and } 530 \\
\text { years B.P. (10\% of the grains), older of the two thought to represent the } \\
\text { depositional age. }\end{array}$ & $\begin{array}{l}\text { Eolian Sand I } \\
\text { the }\end{array}$ \\
\hline 6 & $4 \mathrm{Bk}$ & $88-110$ & $\begin{array}{l}\text { Light brown (7.5YR 6/4, d; 7.5YR 4/4, m) loam, sandy loam and silt } \\
\text { loam, very friable, weak to moderate columnar structure, strong to } \\
\text { violently effervescent, many (20-30\%) coarse } 3-7 \text { cm white irregular } \\
\text { calcium carbonate nodules. }\end{array}$ & Ogallala Formation \\
\hline
\end{tabular}

significantly with streamside dunes, but also include some samples that are texturally similar to the sand sheet (poorly sorted fine sand to poorly sorted very fine sand). Figure 10-26 shows how both silt and clay increase exponentially with increasing distance from the sediment source.

The sedimentation rates calculated from the OSL dates show an exponential decrease upslope, away from the sediment source (Figure 10-27). In particular, riverine source border dunes aggraded at rates around $1 \mathrm{~cm}$ per year, whereas upland dunes were deposited at a rate of $0.1 \mathrm{~cm}$ per year, and the sand sheet was deposited even more slowly, at a rate of around $0.05 \mathrm{~cm}$ per year. The slower sedimentation rate in the sand sheet setting resulted in greater opportunities for post-depositional mixing of different age sand grains, illustrated by the single grain OSL dates.

The chronology of eolian activity obtained from the OSL dates indicates that deposition of ESII may have started as early as A.D. 1250, but the majority of the deposits dated were transported after A.D. 1500. Figure 10-28 shows the two sigma radiocarbon ages obtained from Components $\mathrm{A}$ and $\mathrm{C}$ within the site (excluding four ages on wood charcoal that were unacceptable) compared with the one sigma OSL ages from ESII, in order from oldest to youngest. From these ages it is inferred that the eolian activity 


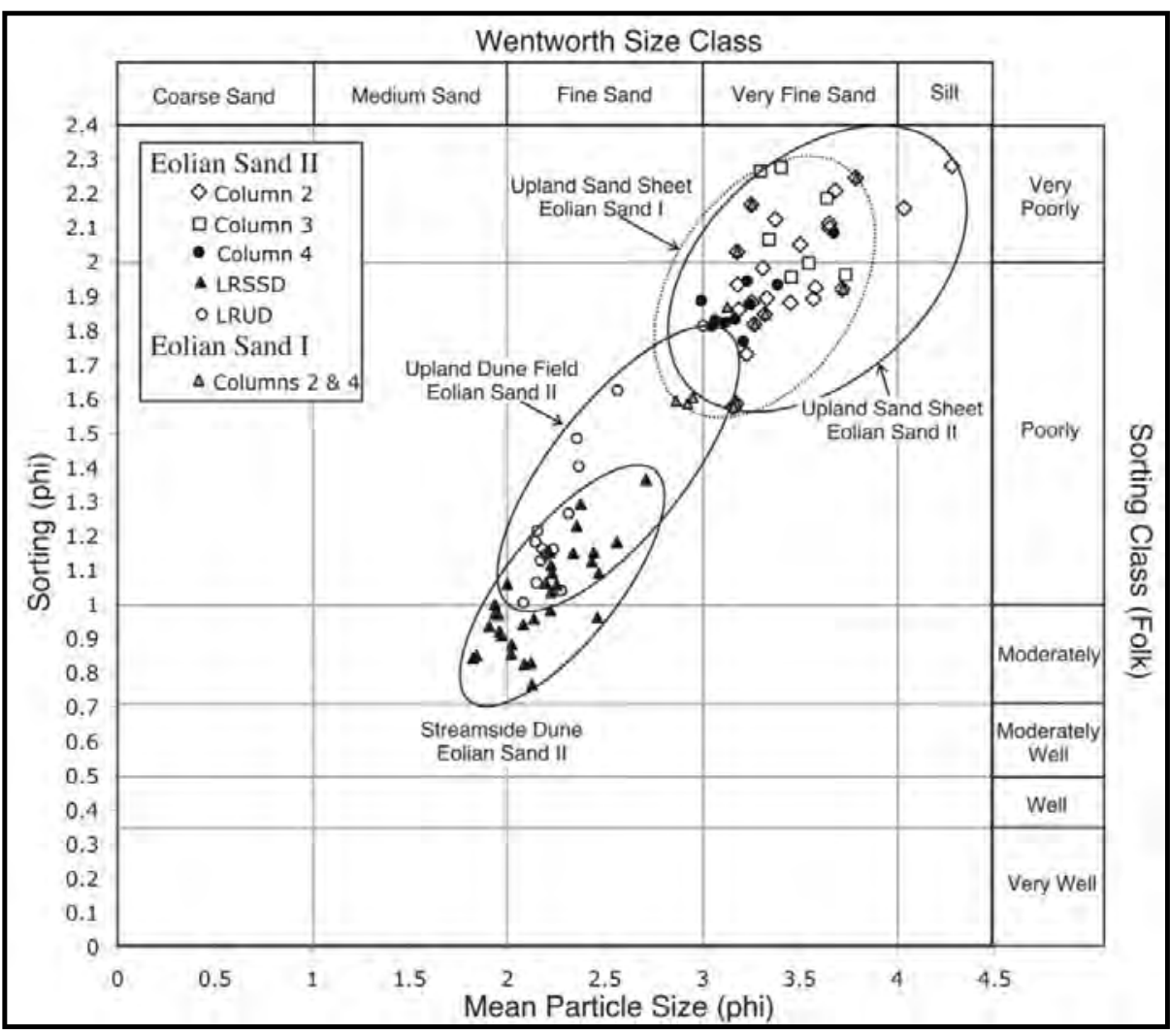

Figure 10-25. Plot of Folk and Ward mean particle size (in phi) versus sorting (standard deviation, in phi) for sediment samples collected from different Eolian depositional environments.

Note trend toward finer and more poorly sorted sediments as distance from sediment source increases. Ellipses delineate plotted area of samples from each depositional environment.

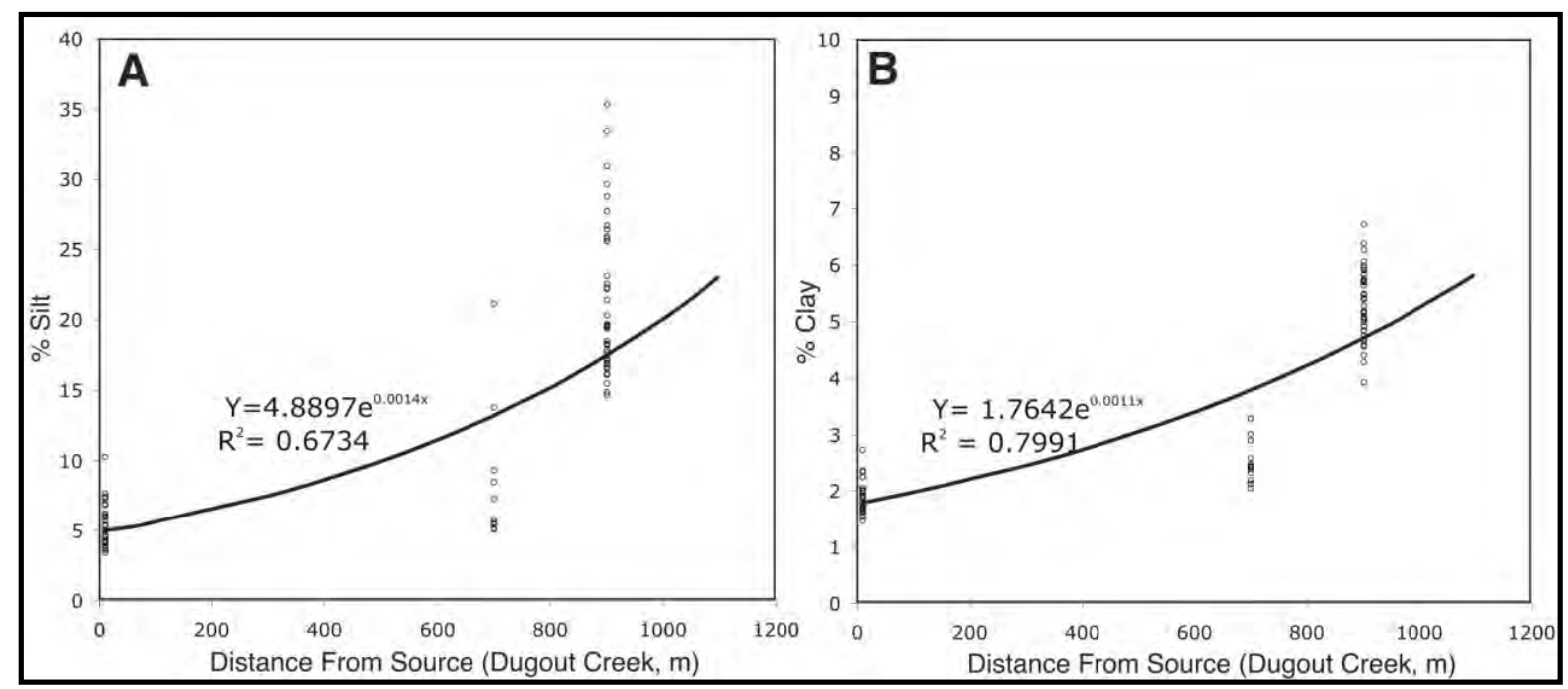

Figure 10-26. A. Change in percent silt with distance from sediment source for each Eolian depositional environment examined. B. Variation in percent clay in Eolian sediments with respect to distance from sediment source. 


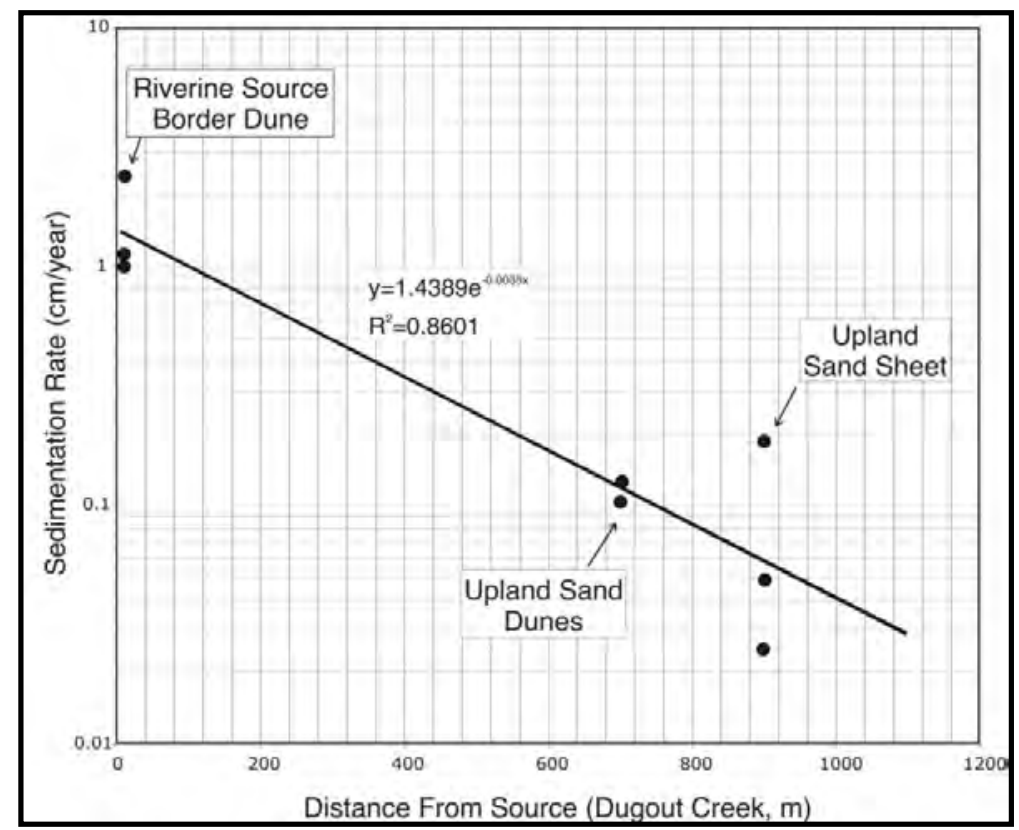

Figure 10-27. Plot of sedimentation rates obtained from OSL dates in each Eolian environment with respect to distance from sediment source (Dugout Creek).

Note exponential decrease in sedimentation rate with increasing distance from sediment source.

occurred in three pulses, the first from A.D. 1250 to 1400 , the second (the main phase) from A.D. 1500 to 1800 , and the third from around 1900 to the present. Field observation supports the latter two dates from the streamside dune, where a weak soil separated the two depositional events. There is no soil-geomorphic evidence to support a hiatus between the earliest phase of deposition and the main phase between A.D. 1500 and 1800. The most accurate age for the onset of eolian activity might be found in the base of the riverine source dune most distant from the modern channel, which presumably pre-dates the dune examined immediately adjacent to the channel of Dugout Creek.

The early phase of eolian sedimentation (ESI) is difficult to pinpoint conclusively. In the field, ESI was subtly different from ESII, and OSL dating confirmed the majority of its grains are significantly older. The ages obtained for this deposit are consistent with ages obtained by Rich and Stokes (2011) for the Blackwater Draw Formation on the Southern High Plains. Particle size analysis shows that this sediment is consistent with sand sheet deposits of late
Holocene age, and it is interpreted as a much older phase of sand sheet sedimentation. The absence of soil features associated with sediments of such antiquity suggests that the majority of this deposit had been eroded prior to deposition of the latest Holocene sand sheet. A prominent red color is typically associated with deposits of the Black Water Draw Formation, and is used in the field to discriminate between eolian deposits of different age. The absence of red in ESI is puzzling. Rich and Stokes (2011) dated one section of Blackwater Draw sediment of similar appearance, which was at the base of the eolian deposit, and as is inferred here, was below the level of significant pedogenic alteration.

\subsubsection{Regional and Climatic Implications}

Eolian activity on the Great Plains is often directly correlated with arid or drought conditions (cf. Forman et al. 1995, 2001, 2008; Hanson et al. 2010), but in the case of the system described here, the principal control on eolian sedimentation appears to be sediment supply. Eolian activity requires a sediment source and a wind source, and the lack of either will fail to result in eolian 


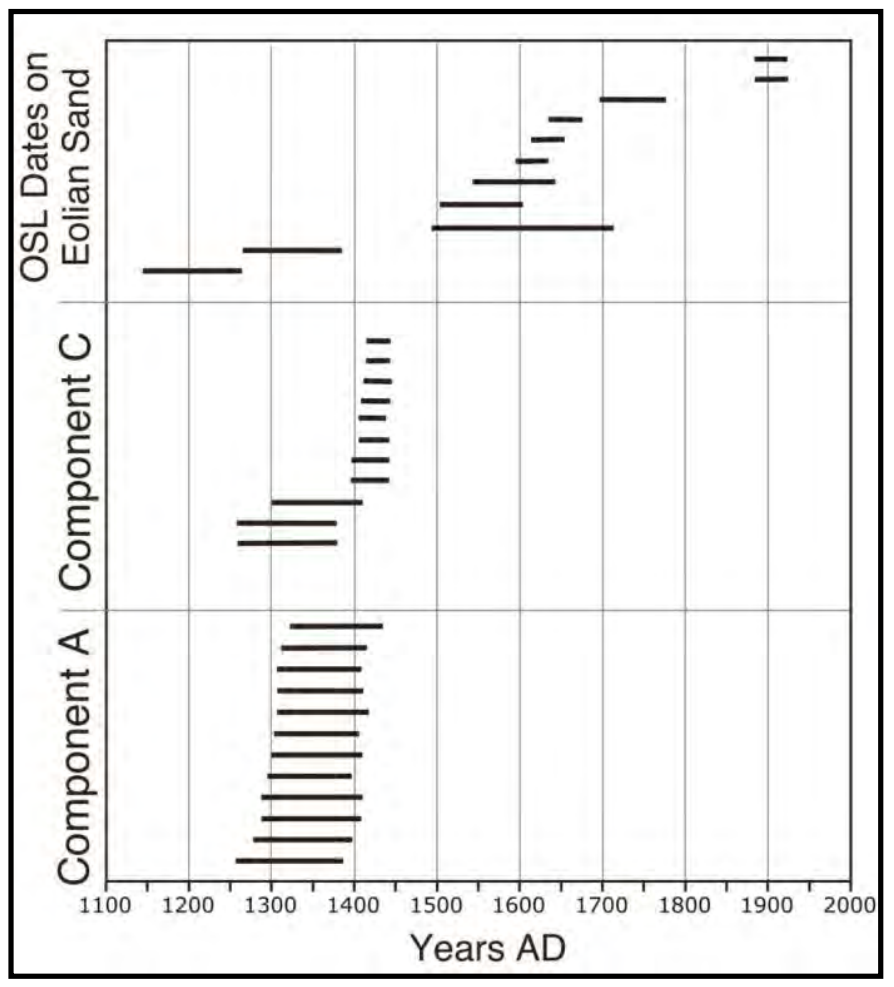

Figure 10-28. Two Sigma radiocarbon ages obtained from Long View Components A and $C$ with respect to one Sigma OSL ages obtained from riverine source border dune, upland sand dune, and upland sand sheet.

deflation, transport and sedimentation. A variety of factors may influence the availability of sediment for erosion and transport. For instance, Werner et al. (2011) cautions that the relationship between dune activity and climate is often nonlinear and can be influenced by other processes affecting the sediment supply, such as the long-term effect of pedogenesis. They argue that soil formation makes older dunes more resistant to remobilization than recent dunes, primarily through the addition of pedogenic clay to form argillic horizons, which have greater water holding capacity that supports more vegetation, leading to a greater resistance to eolian deflation.

In this system, the sediment source is the channel floor of Dugout Creek, which today is a broad, braided sandy plain that ranges from 100 to 200 -m-wide in the vicinity of the study area. Although it is tempting to assume that present conditions are similar to the past, the sandy sediment load and broad braided channel visible today is not necessarily representative of the nature of this channel during the late Pleistocene and Holocene. For instance, in a study of alluvial stratigraphy, Quigg et al. (2010) demonstrated that for much of the Holocene, West Amarillo Creek, on the south side of the Canadian River Valley, had a relatively fine-grained sediment load, and the coarse sand and gravel seen in the channel today is a recent phenomenon, begun about 800 to 1,000 years ago. The lack of earlier Holocene eolian deposits near the Long View site implies that there was insufficient sediment supply to form eolian deposits during the Holocene. Suggested testing includes examining the alluvial stratigraphy of Dugout Creek. Rolfe Mandel (personal communication, 2011) is conducting such a study.

Regardless of the causal linkage with drought, late Holocene eolian deposits are common in this region (the Southern Great Plains and Southern High Plains). In Texas, two studies summarize the dating results of numerous widely dispersed localities and 
report several localities with last millennium eolian deposits. Holliday (2001) prepared a compendium of eolian stratigraphy on the Southern High Plains. The majority of his examples were from the southern side of the Llano Estacado, where he identified several localities in the Muleshoe Dunes and a single locality in Terry County that were active in this period (e.g., Clovis, Tabosa Ranch and Plant X). Rich and Stokes (2011) examined eolian activity on the west and south sides of the region, focusing on Muleshoe valley and the Mescalero/ Monahans dunes on the southwestern margin. They confirmed the activity of the Muleshoe dunes in the last millennium.

To the north and east a number of studies, listed below, have documented widespread eolian activity in the last millennium, with sites to the east generally exhibiting a single period of sedimentation between 1100 and 500 years B.P., and sites to the west exhibiting multiple depositional events in this period. Lepper and Scott (2005) used OSL and radiocarbon dating to evaluate the age of a series of linear source-border dunes on the Qt2 terrace of the Cimarron River in Major and Kingfisher counties of Oklahoma. The majority of their dates indicate the last major phase of eolian activity was between A.D. 1100 and 1250. This activity coincides with Woodhouse and Overpeck's (1998) “Thirteenth Century Megadrought," also known as the Medieval Warm Period. Hanson et al. (2010) examined the age of the Abilene dunes in eastern Kansas, and 15 of their 20 OSL ages fell between 1060 and 460 years B.P. In contrast, Forman et al. (2008) examined dunes along the Arkansas River Valley in western Kansas and documented five periods of eolian sedimentation in the last 1,500 years, which they argue correlate well with tree-ring records of continental-scale drought. Werner et al. (2011) examined two dune localities between the Cimarron River in Western Kansas and the Beaver River in Western Oklahoma. They documented dune activity between 800 and 400 years B.P. at the Albright site, and between 630 and 520 years B.P. at the Banner site. Arbogast (1996) and Arbogast and Johnson (1998) examined the age of dunes and documented four periods of eolian sedimentation over the last 1,000 years in the Great Bend Sand Prairie on the south side of the Great Bend of the Arkansas River in south-central Kansas.

\subsubsection{Archeological Implications}

The possible onset of eolian sedimentation happening during and after Late Prehistoric occupations of the region hold significant implications for discovery and preservation of archeological sites of this age. If the eolian activity was dependent upon the rejuvenation of the stream network, this event may have adversely affected Late Prehistoric agricultural activities, which likely targeted water gathering slopes and small valley floors for passive irrigation (cf. Boyd 2008). The main phase of eolian activity appears to have completely buried Late Prehistoric period sites from the drainage divide all the way down onto the valley floor. Hank's House (41RB109; Boyd 2004), a Plains Village house a few kilometers east of Long View, was buried by about $4 \mathrm{~m}$ of eolian sand postabandonment, sometime after A.D. 1283 to 1398 (650 \pm 40 B.P., Beta-168385 radiocarbon age from charred maize collected from floor deposit). These results are consistent with the dates obtained here. Sites like Long View, situated in sand sheet settings on the drainage divide or valley slopes will not be as deeply buried, but will nonetheless have negligible archeological visibility. 
This page intentionally left blank. 


\section{0}

\section{SUMMARY, CONCLUSIONS, CRITIQUE OF METHODS AND RECOMMENDATIONS}

\author{
J. Michael Quigg and Paul M. Matchen
}

\subsection{Background}

Archeological investigations at the Long View site (41RB112) in Roberts County, in the northeastern panhandle of Texas, were necessitated by the proposed highway widening by Texas Department of Transportation (TxDOT). The proposed highway rehabilitation program will directly impact roughly a 10-m-wide by 270-m-long (north-south) section ( $0.0027 \mathrm{sq} \mathrm{km}$ or $0.67 \mathrm{ac}$ ) of this prehistoric site. This shallowly buried Plains Village site was in sandy eolian upland deposits on top of Ogallala Formation clays that occupy a broad, low-relief interfluvial north-south ridge that separates two ephemeral creek channels on the midslope of the deeply incised Canadian River valley west of the current highway. The area is referred to as the Canadian Breaks.

Following site discovery by TxDOT archeologist Dennis Price in June 2004, TRC was contracted to conduct the subsequent site investigations to assess eligibility for listing on the National Register of Historic Places under criterion d, as well as for designation as a State Archeological Landmark as per the requirements of Section 106 and 110 of the National Historic Preservation Act and other related legislation. This work was carried out under TxDOT Scientific Services Contract No. 573XXSA006 in May 2005 (see Appendix L). Following the Texas Historical Commission's determination that the Long View site was eligible for the National Register, data recovery fieldwork was conducted between August and November, 2006 by TRC under a new TxDOT Scientific Services Contract No. 575XXSA008.

Several stages of fieldwork were conducted; 1) initial archeological survey with two shovel tests by TxDOT archeologists, 2) site evaluation and assessment that included surface collection and mapping, and manual excavations of $16.8 \mathrm{~m}^{3}$ in 28 units, 32 linear meters of hand-excavated trenches, and cleaning $28 \mathrm{~m}$ of road cut by TRC archeologists, and 3 ) intensive data recovery excavation by TRC archeologists. The Long View site was determined to consist of the remains of two horizontally separate and distinct Plains Village period occupations (Components A and C). The nearly culturally sterile low swale, Area B, roughly $120 \mathrm{~m}$, separated the two components. The data recovery excavations were performed in two blocks consisted of $128 \mathrm{~m}^{2}$ in Component $\mathrm{A}$ and $93 \mathrm{~m}^{2}$ in Component $\mathrm{C}$, for a combined total of $221 \mathrm{~m}^{2}$ or $103.4 \mathrm{~m}^{3}$.

Immediately prior to the data recovery excavations, nondestructive geophysical investigations, using three different electronic detective devices, were carried out across Areas A and C. This work served to guide the subsequent hand-excavations. These techniques included ground penetrating radar, magnetic field gradient, and electrical resistance that detected multiple anomalies that might represent buried archeological features. Hand-excavations in, on, and around many of the detected anomalies yielded limited positive results that could be directly linked to the anomalies. The site setting was not ideal for electrical surveillance, because a fivestrand metal fence on the western edge, overhead power lines, a steep road cut on the eastern edge, extensive rodent burrows, the bladed fireguard, recent metal trash, all combined, along with very dry ground conditions and over $40^{\circ} \mathrm{C}$ temperatures during investigations, to produce mixed geophysical results.

Geoarcheological investigations were conducted during site assessment and data recovery. These were focused on defining the age and depositional characteristics of the natural Holocene sediments that contained the cultural materials. The geoarcheological field assessment included detailed stratigraphic documentation and sample collection within the two Long View components, including sampling of two pithouses, two storage pits, and near-site eolian deposits. Laboratory analyses of the sediment samples included texture characterization, soil thin sections, magnetic susceptibility, and multiple chemical analyses (organic, calcium, and phosphorus). Detailed stratigraphic data were also collected and analyzed in conjunction with other technical studies from the two pithouse features in order to identify construction and filling episodes of those structures. 
This final technical report incorporates the findings and results of previous fieldwork at Long View and documents the archeological and geoarcheological investigations through tables, figures, plus artifact and feature descriptions for each component. The report documents one of the few data recovery excavations of a Plains Village site within the broad Texas panhandle region, with augmentation from a suite of interdisciplinary technical analyses.

\subsection{Site Summary}

Two horizontally separated and diversified Plains Village period components, A and C, were documented. These components were about $120 \mathrm{~m}$ apart and were separated by basically the culturally sterile ground in the swale that was designated Area B. The cultural remains were in a shallowly buried, upland eolian sand sheet along an interfluvial ridge. The long narrow APE was bordered on the east by a 4- to 5-m-tall, steep road cut, whereas the western edge was bordered by the natural short-grass prairie. A fireguard, 4-m-wide by 30- to 50-cm-deep, had been mechanically bladed along the entire length of the APE, thus impacted the upper 20 to $50 \mathrm{~cm}$ of the deposits. Considerable pedoturbation and bioturbation occurred across the two areas, as evidenced throughout by many recent and old rodent animal burrows that had apparently displaced many smaller cultural items while leaving larger burned rocks and cultural features largely in their original positions between 25 and $35 \mathrm{~cm}$ beneath the current surface. The southern end of Component $C$ contained considerably more accumulated eolian sand because of a steep drop in bedrock at that end of the ridge, which increased the thickness of the deposits to roughly $110 \mathrm{~cm}$. The vertical displacement of smaller artifacts is not believed to pose a significant problem, as the two horizontally distinct components each reflect a single, multiple season occupation by a distinct group, meaning there has been no mixing of materials from different temporal or cultural contexts. Although some smaller pieces were vertically displaced, the entire cultural assemblage from each component, with the exception of the two burials and the rock alignment, is a culturally coherent package, a factor that optimizes the interpretive potential of the data. The two components yielded very similar cultural assemblages (Table 11-1). Each component is briefly summarized below.

\subsubsection{Component A}

Component A was investigated through the handexcavation of $128 \mathrm{~m}^{2}$ in a long, narrow block. The cultural remains were dated by 13 radiocarbon assays (with two yielding results deemed unacceptable) to 460 to 535 B.P. or cal A.D. 1398 to 1447. Eleven cultural features were excavated, and included the remaining one-half of a small pithouse, one small cylindrical storage pit outside the pithouse, five small heating elements, and four small discard/ dump features. The pithouse was unusual as it had multiple postholes both inside and outside the roughly 40-cm-deep pit, limited cultural items on an unprepared floor, no internal features, with no remnants of a supporting superstructure or covering.

The nearly 15,000 recovered cultural items include a Plains Village assemblage that consists of Washita and Fresno arrow points, small scrapers, beveled bifaces, drills, and edge-modified flakes (Table 111). A limited ground-stone tool inventory includes manos and metates, an edge-ground cobble, and a sandstone abrader. The lithic debitage is dominated by Alibates silicified dolomite with some nonlocal obsidian, Niobrara jasper, and local opalite. A total of 1,263 potsherds represent and estimated 14 ceramic vessels. A diverse suite of animal bones includes the remains of bison, deer, rabbits and turtles. Modified/worked bone items include awls, scapula hoes, and spatulas. The 14 pottery vessels mostly bear cordmarked exteriors, though there are some smoothed surfaces or surfaces with obliterated or smoothed-over cordmarkings, as well as at least one imported painted glazeware vessel, and one red-washed vessel of apparent local manufacture. Drilled and edge-ground sherd disks, or spindle whorls, are also relatively numerous. A few caliche and quartzite burned rocks were scattered across the occupation area, but did not occur as welldefined features. Macrobotanical remains were well-preserved and represent multiple wood types dominated by juniper, as well as maize and other very sparsely represented plant-food remains.

\subsubsection{Component C}

Component $\mathrm{C}$ was investigated through a handexcavated $93-\mathrm{m}^{2}$ block with dispersed lines of adjoining units. The cultural remains were 
The Long View Site (41RB112): Data Recovery of Two Late Prehistoric Plains Village Period Components in Roberts County, Texas -Texas Department of Transportation

Table 11-1. List of Artifacts and Features from Long View (41RB112).

\begin{tabular}{|c|c|c|c|}
\hline Artifact/Class & Component A & Component C & Totals \\
\hline Radiocarbon Age & $\begin{array}{l}460 \text { - } 535 \text { B.P. Cal } \\
\text { A.D. } 1398 \text { - } 1447\end{array}$ & $\begin{array}{c}530 \text { - } 700 \text { B.P. Cal } \\
\text { A.D. } 1280 \text { - } 1437\end{array}$ & \\
\hline Washita points & 7 & 8 & 15 \\
\hline Fresno points & 11 & 12 & 23 \\
\hline Harrell points & 1 & 4 & 5 \\
\hline Huffaker points & - & 1 & 1 \\
\hline Unidentifiable point fragments & 0 & 9 & 9 \\
\hline Bifaces & 17 & 8 & 25 \\
\hline Scrapers & 21 & 6 & 27 \\
\hline Drills & 4 & 5 & 9 \\
\hline Edge-modified flakes & 136 & 90 & 226 \\
\hline Manos & 1 & 6 & 7 \\
\hline Metates & 3 & 10 & 13 \\
\hline Abraders & 1 & 3 & 4 \\
\hline Hammerstones & 2 & 4 & 6 \\
\hline Unifaces & 7 & 4 & 11 \\
\hline Chopper & 1 & - & 1 \\
\hline Edge-ground cobble & 2 & - & 2 \\
\hline Bone tools & 10 & 15 & 25 \\
\hline Exotic sherds & 11 & - & 11 \\
\hline Cordmarked sherds & 1,249 & 262 & 1,511 \\
\hline Plain sherds & 3 & - & 3 \\
\hline Number of Vessels & 14 & 7 & 21 \\
\hline Spindle Whorls & 12 & - & 12 \\
\hline Clay Pipes & 4 & - & 4 \\
\hline Lithic Debitage, Total & & & $\mathbf{0}$ \\
\hline Alibates/chert & 1,663 & 779 & 2442 \\
\hline Opalite & 524 & - & 524 \\
\hline Ogallala quartzite & 144 & 36 & 180 \\
\hline Tecovas jasper & 36 & 3 & 39 \\
\hline Other & 116 & 24 & 140 \\
\hline Nonlocal - Niobrara & 24 & 16 & 40 \\
\hline Nonlocal - Obsidian & 49 & - & 49 \\
\hline Maize (corn cobs) & 7 & 15 & 16 \\
\hline Charcoal samples & 37 & 63 & 100 \\
\hline Bison bones & 52 & 475 & 527 \\
\hline Deer/antelope bones & 19 & 33 & 52 \\
\hline Turtle bones & 34 & 75 & 109 \\
\hline Rabbit bones & 4 & 48 & 52 \\
\hline Unidentifiable bones & 3,794 & 1928 & 5,722 \\
\hline Mussel shells & & & \\
\hline
\end{tabular}


Table 11-1. List of Artifacts and Features from Long View (41RB112) (cont.)

\begin{tabular}{|l|c|c|c|}
\hline Burned rocks & 356 & 1,434 & 1790 \\
\hline Daub/burned clay & 368 & 175 & 543 \\
\hline Shell beads & 1 partial & 1 partial & 0 \\
\hline \multicolumn{1}{|c|}{ Total per component } & $\mathbf{8 , 7 4 4}$ & $\mathbf{5 , 5 5 8}$ & $\mathbf{1 4 , 3 0 2}$ \\
\hline Feature Totals & $\mathbf{1 1}$ & $\mathbf{1 4}$ & $\mathbf{2 5}$ \\
\hline Basin hearths & 5 & 4 & 9 \\
\hline Rock alignment & - & 1, not associated & 1 \\
\hline Cairn burial & - & 1, not associated & 1 adult female \\
\hline Human cremation & - & 1, not associated & 1 adult, unknown sex \\
\hline Storage pit & 1 & 1 & 2 \\
\hline Post holes & 17 & 3 & 20 \\
\hline Pithouse & 1 partial & $1+1$ possible & 3 \\
\hline Discard/dumps & 4 & 4 & 8 \\
\hline Hand-excavated area $\mathrm{m}^{2}$ & 128 & 93 & 221 \\
\hline Artifact density per $\mathrm{m}^{2}$ & 68.4 & 59.8 & 64.8 \\
\hline
\end{tabular}

radiocarbon dated by means of 13 assayed samples (with one unacceptable) to 530 to 700 B.P. or cal A.D. 1280 to 1437 , indicating that Component $\mathrm{C}$ is, on average, some 60 to 70 years older than Component A. Fourteen cultural features were excavated and these included two human burials (1 secondary cremation and 1 cairn burial), a complete 3-m-long oval pithouse, one small cylindrical storage pit outside a second possible pithouse, four small heating elements, four small discard/dump features, and a 30-m-long rock alignment. The rock alignment was determined to be historic in age and to have been unassociated with the component. The two burials were not radiocarbon dated and appeared unassociated with Component C. The pithouse was again unusual and revealed two sets of small-diameter postholes - one inside and the second outside, but no large central supports or recognizable other distinguishing characteristics in the roughly 60- to 70 -cm-deep pit. The unprepared floor was littered with a diverse range of discarded cultural debris that was apparently tossed in following abandonment. Also found on the floor of this pithouse were illdefined internal ash concentrations and a thick earthen cover of a mixture of mud and sand. The structure had a sloping, east-facing entryway.
The nearly 5,600 cultural items recovered in Component $\mathrm{C}$ comprise a Plains Village assemblage that consists of nearly equal numbers of Washita and Fresno arrow points plus fewer Harrell and Huffaker arrow points, small end scrapers, drills, unifaces, hammerstones, and edge-modified flakes (see Table 11-1). The relatively limited quantity of lithic debitage is overwhelmingly of Alibates silicified dolomite, and there are only a few pieces of nonlocal Niobrara jasper. Fragmented metates, manos, and abraders constitute the ground stone assemblage. The faunal assemblage was diverse and includes bone elements that represent bison, deer, rabbit, and turtle. The inventory of worked bone is dominated by bison scapula hoe parts. The pottery includes sherds representing at least seven vessels, all with cordmarked exteriors. At least three thick-walled vessels are also represented within the ceramic assemblage. Burned rocks include small quartzite pebbles, many of which were not broken and some of which were in discard piles/dumps, or next to heating elements. The macrobotanical remains include quantities of charred maize parts including cobs, and very little else in the way of food products. The charcoal represents at least four species of wood, with juniper dominating. 
These datasets from the two components have been fully described and documented in chapters 8.0 and 9.0 respectively. Selected sets of artifacts and/ or samples from each component were subjected to multidisciplinary analyses to gain greater understanding of specific functions associated with each class of material, thus augmenting interpretations of prehistoric social behavior and community.

\subsubsection{Comparing Archeological Assemblages}

The two Plains Village period occupations yielded similar classes of material remains, with only slight differences in frequencies (see Table 11-1). Similarities might be expected as the occupations were by culturally similar and nearly contemporaneous groups at same position on the landscape and within essentially the same environment. Both components yielded similar cultural assemblages and features directly associated with oval pithouse habitation structures that lacked rock foundations and, lacked packed or prepared floors dug into the Ogallala Formation. Cultural features in both components were also similar, and that consist of small organic-rich heating elements that generally lacked burned rocks, as well as small, bucket-shaped storage pits. Both assemblages reveal a diversity of food/subsistence resources processed in same fashion, including a diversity of faunal remains (bison, deer, rabbits, turtles, and fish), cultigens (maize and squash), wild plants (i.e., little barley, cheno-ams, and mesquite), all reflecting a diversified subsistence economy relying on hunting, plant gathering, and horticulture. Both components yielded lithic debitage that reflects late stage tool finishing, resharpening, reworking with limited late-stage biface finishing and almost no primary knapping of large chert nodules. Overall, the lithic tool assemblages at Components A and C show little evidence of formal tool and/or blank production, but rather represent a focus on formal tool maintenance and the production of informal tools.

Additionally, both components show an extensive reliance on Alibates silicified dolomite. Alibates recovered during our investigations originated in bedrock quarries some $80.5 \mathrm{~km}$ upstream, judging from the dearth of sizeable river gravels of knappable quality in the area and the lack cobble cortex in the debitage assemblages. Evidence of controlled use of Alibates was all also present in the form of alternate edge beveling on bifacial knives, a strategy employed to extend the use-life of these tools as long as possible, thereby minimizing the labor investment needed to replenish the tool supply and conserve the Alibates raw material. Alibates was also used for expedient tool production, as were other available materials. The choices of the location of the two occupations were, therefore, apparently not influenced by a need to be in close proximity to a source of workable, high-quality stone such as Alibates.

Both components represent semisedentary residential bases occupied for multiple seasons. A spring through fall occupation is postulated for Component $\mathrm{A}$, whereas Component $\mathrm{C}$ is postulated to have been occupied from spring through summer and fall, and into winter. Multi-year, semipermanent occupations are not likely, judging from the limited quantities of debris left behind, the small size of the few storage facilities (pits) and the relatively informal characteristics of pit house constructions (e.g., the lack of prepared or packed floors). Therefore, it seems likely that these components were abandoned during residential moves that may have been prompted by a need to be in proximity to seasonally available resources at other localities.

Although both components share many similarities, there are a few minor aspects of each that serve as distinguishing characteristics. Such differences are expectable, given that the occupations are thought to reflect slightly different periods of time by different groups of people. The two pithouses exhibit distinct construction characteristics. The pithouse in Component A was a wood-framed structure that lacked an earthen cover, in contrast to the more substantial earth covering of the pithouse in Component C. Following abandonment of the structure, while still intact, the pithouse was used as a repository for trash. In terms of lithic raw materials, Component A yielded a more diverse debitage assemblage comprised of 20 visibly different materials that include 49 pieces of nonlocal obsidian and a moderate use of the poorer quality local opalite, both absent from Component C. A 
greater debitage-to-tool ratio, $7: 1$ is evident in Component A compared to Component C, which has a 4:1 ratio. Tool production was more prominent in Component A based on more crushed platforms, a greater diversity in platforms types, and more cortex present on local materials, indicating early-stage tool production.

The ceramics from Component A are similar to the Borger Cordmarked ware associated with Antelope Creek phase village sites, and were tempered primarily with crushed rock and minerals dominated by quartz and feldspar compared to the basalt with pyroxene temper common in Component $\mathrm{C}$ pottery. Both broad temper classes occur in Borger ware. A much greater use of pottery is evident in Component A with 14 individual vessels compared to 7 vessels in Component C. The Component C ceramic assemblage was also cordmarked, but yielded at least three thick-walled vessels reminiscent of the earlier Woodland/Middle Ceramic period occupations, which are absent from Component A. Thick Vessel 1 , consisting mostly of large sherds, was partially reconstructed and yielded 36 starch grains from maize, 51 lenticular starch grains of little barley, 5 possibly of lily bulb, and gelatinized starch grains indicative of cooking with heat and water (boiling). At least some of the maize starch is characteristic of popcorn.

Nonlocal artifacts, that includes at least one exotic painted vessel and 49 obsidian flakes, were recovered only from Component $\mathrm{A}$. Manos and metates are four times more abundant in Component C, which may indicate a greater degree of food processing, a particular discard pattern, or a longer occupation. The human remains (a rare cremation, a cairn burial, and the scattered deciduous teeth of a juvenile) were all from Component $C$, although their direct association with that component could not be firmly specifically established, except in the case of the child. Unfortunately, no radiocarbon dating or chemical analyses were approved by TxDOT for the human remains, consistent with NAGPRA and the expressed wishes of consulting tribes. Neither of the human burials yielded associated grave goods, except for a complete fresh water mussel shell valve with a worn edge found with the cremation. Minimal physical information was derived from the burials with only 10 percent of the skeleton present in the cremation, about 30 percent of the skeleton present in the cairn burial, and the skulls were absent in both cases. The cairn burial was an adult female with an amputated finger, whereas the cremation was an adult of indeterminate sex. Component $\mathrm{C}$ also yielded scattered deciduous teeth of a 2- to 5-yearold child in the "ghost" pithouse Feature 18, thought to be directly related to the occupation.

The two Long View cultural assemblages represent Plains Village period populations, with most artifacts being indistinguishable from those in Antelope Creek phase assemblages. Based on the presence of pithouse habitation structures, however, neither component can be assigned to the Antelope Creek phase as it is currently defined, given that it is characterized by vertical slab structure foundations, semisubterranean structures, and an absence of pithouses. The pithouses, although rarely recognized in the Texas panhandle, do not appear to represent intrusive population immigration. As revealed in Section 10.6 above and specifically shown in Figures 10-10 and 10-11, the emergence of pithouse architecture across the Texas and Oklahoma panhandles is not time-transgressive. Current analyses of pithouse structures indicates they primarily functioned as seasonal houses, but other functions (e.g., storage, social/ceremonial use) cannot be ruled out, as detailed information on most similar structures is lacking. Both Long View components likely represent one of the more recently named phases/complexes, such as the Buried City complex or the Odessa phase, which are currently undergoing revision and definition. Phase/complex assignment of the Long View assemblages will have to wait until the broader regional cultural history is better understood.

\subsection{Contributions and Critique of the Technical Analyses}

More detailed data from the Long View site and the two identified cultural assemblages was extracted through the integration of geoarcheological investigations and radiocarbon dating, plus employment of 11 different technical analyses that included: 1) high-powered use-wear analysis combined with residue identifications on 52 stone artifacts; 2) phytolith studies on 24 sediment 
samples; 3) diatom analysis on 12 burned rocks and 6 daub samples; 4) macrobotanical analyses on 34 float samples (566.7 liters) from 16 features plus identifications of 114 individual organic samples; 5) starch grain analysis on 104 specimens from multiple classes of artifacts; 6) instrumental neutron activation on 9 tempered clays, 7 daub, 111 pottery samples; 7) petrography on 11 tempered clays and 85 Plains Village pottery samples; 8) stable carbon and nitrogen isotope analysis on 10 bison bones; 9) obsidian sourcing on 49 pieces; 10) optical stimulated luminescence (OSL) dating on 14 sandy samples; and 11) physical anthropological analysis of human remains.

The employment of many of these analytical techniques stems in part from one of the key statements made by Michael Collins back in 1991, when he suggested that archeologists "escalate our application of specialized analytical techniques“ (Collins 1991:1). He goes on to stress that the microscale/fine fraction has been overlooked and the pursuit of those remains (i.e., microfossils) should receive greater effort. We totally agree and believe that our pursuit of microfossil data at Long View clearly confirms their importance. The results from these multidisciplinary analyses contribute new and significant information for a better understanding of the social, political and economic aspects of these two Plains Village period components and overall, a broader understanding of the Southern Plains Village populations and the immediate environment in which they lived. The highlights and/or significant contributions of each are briefly presented below.

\subsubsection{Geoarcheological Contributions}

The geoarcheological assessment was extremely important as it documented the stratigraphy and age of the sandy deposits on and off-site and placed the cultural materials in their geological context within an upland sand sheet. The sandy deposit ages were determined through 14 OSL dates and two bulk sediment dates, supplemented by 26 AMS dates derived from cultural materials. Here, the eolian activity started around A.D. 1250 with the majority of deposits having been transported after A.D. 1500, a process that continued until around A.D. 1800. Thus, eolian sedimentation occurred during and after the occupations at Long View. The source of these sediments was determined to have been the channel floor of Dugout Creek. The deposits were determined to be comprised of three distinct facies, namely, riverine source border dunes, upland dunes, and sand sheets. The investigations demonstrated that the eolian deposits became progressively finergrained and less well sorted with distance from the source. The main phase of deposition will have completely buried archeological sites within the Canadian River valley, resulting in an absence of surface visibility.

The geoarcheology was also crucial in documenting the internal stratigraphy of the two pithouses, especially Feature 6 with its more complex deposits. Through a series of chemical, textural, and detailed petrographic analyses, the sequences of depositional events within the two pithouses and across the components were securely documented. The detailed stratigraphic analysis of the Feature 6 pithouse clearly documented that this structure had an earthen roof comprised of a mixture of sand and alluvial creek muds (not Ogallala clays) over a wooden framework. The subsequent collapse of the earthen cover onto the floor below exposed the wooden framework, which was burned. A more detailed understanding of the construction of the earthen cover would have required that a greater number of micromorphological column samples had been extracted from various locations across the structure. In hindsight, the detailed geoarcheological documentation (collection of and analyses of micromorphological samples) could have been applied to heating elements and discard features to provide greater in-depth understanding of how those features functioned and how they were subsequently disturbed. Such thorough site and feature recording followed by diverse, multiple, and complex laboratory analyses should be incorporated at other sites, especially those with complex features and structural remains.

\subsubsection{Radiocarbon Dating}

A series of 26 radiocarbon dates (1 on bison bone collagen, 7 on wood charcoal, and 18 on charred maize kernels) document two distinct Plains Village period components occupied between uncalibrated 460 and 700 B.P. or cal A.D. 1280 and 1447, with Component A being roughly 65 years younger 
than Component C. The employment of numerous radiocarbon dates directed at both components enabled very narrow age range determinations for each component and allowed three outlier dates to be identified. The focus on maize was important to narrow the age range within the relatively short 400- to 500-year-long Plains Village period. The wood charcoal results are in most cases similar to the maize annuals, but the charred annuals are most appropriate when present. The one bison bone collagen date was statistically identical to the maize dates.

In addition to the 26 dates used to establish the age of the 2 cultural components, 8 additional AMS dates were obtained on 4 pairs of organic residues from pottery sherds. These included four dates on residues adhering to the sherd exteriors, and four on bulk sherds/residues from within the same sherds. The radiocarbon results on four organic residues that adhered to the exterior surfaces were statistically the same as the AMS dates derived from maize. However, the AMS dates on organic residues from within the same ceramic sherds were consistently earlier than dates derived from maize annuals except in one case, in which the sherd residue results were statistically identical. Radiocarbon dating the different materials from these two occupations allows direct comparisons between results obtained on different organic materials and assessment of the appropriateness of the different materials. The dating of annuals such as carbonized seeds, nuts, and maize parts appears to provide the most accurate and narrow time frame for the occupations in question and should be used whenever possible.

The significant findings of radiocarbon dating of organic residues both adhering to sherd surfaces and found within sherds from the Plains Village period components at Long View, clearly documents that thick-walled cordmarked sherds (i.e., Vessels 1, 3 and 7 from Component C) are present in Plains Village assemblages and do not necessarily represent the earlier Woodland/Early Ceramic period, as has been previously assumed to be the case. This demonstration cautions against assignments of ages to sites in this region based solely on ceramic types and attributes.

\subsubsection{Use-Wear and Residue Analysis}

The high-powered microscopic use-wear and residue identifications provide significant results from a diverse set of 52 stone tools that included 1 uniface, 1 edge-ground cobble, 2 points, 4 bifaces, 5 drills, 5 beveled knives, 11 scrapers, and 23 edge-modified flakes that represent both components nearly equally. The overall results reveal that 81 percent of the analyzed tools were used in ways that differed little between the components. Results also demonstrate that the analyzed tools were used in a variety of tasks and not solely for one function inferred on the basis of form. The use-wear analysis, combined with residue identifications, indicate use in scraping hides $(N=7)$, cutting wood/hard high silica plants $(N=8)$; cutting starchy plants $(N=1)$, hide working $(N=3)$, meat processing $(N=1)$; whittling of $\operatorname{wood}(N=1)$; boring of wood/hard high silica materials $(N=4)$, plus a residual class of indeterminate function $(N=$ 10). Haft wear was observed on at least two beveled bifaces, two scrapers, two edge-modified flakes, one drill, and one uniface. The highest percentage of use reflects woodworking and is in accord with the presence of wood-framed pithouses and, inferably, the manipulation of various other wooden items. Woodworking wear was revealed on drills, bifaces, beveled knives, scrapers, and edge-modified flakes. Surprisingly, three of five beveled knives showed evidence of use on wood. The documentation of specific tool use is quite informative and useful in identifying specific tasks, the kinds of materials that were worked, and on-site activities beyond the potentially simplistic assumptions of tool function based solely on morphology and typology. This kind of analysis is highly recommended for other assemblages for gaining a better understanding of specific tasks performed by specific stone tools and the range of materials those tasks were directed towards at a specific site. If certain tool types have unknown functions or the functions are in question, this combined use-wear-and-residue approach should be employed to gain clarification.

\subsubsection{Phytolith Analysis}

Phytolith studies were conducted on 24 sandy sediment samples from features split evenly between both components. Phytolith concentrations were generally low and this was exacerbated by moderate 
preservation issues resulting from a considerable degree of weathering in the sand-dominated matrix. The inclusion of two control samples, one on-site and one off-site, were excellent additions as they provided a means to compare and interpret cultural samples and the variations between cultural features. The dominance of short-cell Chloridoid phytoliths supports a general short-grassland environment for this location. The phytolith from the eolian sands that filled pithouse Feature 1 match the off-site control sample. Both have similar low Panicoid content and elevated Chloridoid content. The off-site control sample from the upland prairie on the south side of the Canadian River valley is very similar to the modern mixed-grass prairie control sample from the Dempsey Divide in western Oklahoma some $80 \mathrm{~km}$ to the east. The climatic conditions during Component A were hotter than those for the earlier Component C.

The phytolith results document the presence of maize cobs and leaves in both components, but poor preservation likely hindered full disclosure of other cultigens present, although phytoliths bearing some resemblance to squash (cucurbit) are present in 63 percent of the samples. No phytolith evidence of beans was identified. The on-site control sample yielded no evidence of cultigens or burned phytoliths, which supports the interpretation that the maize phytoliths were culturally derived. The discussions concerning feature usage benefited from the establishment of seasonal patterns reflected by the short-cell phytoliths and the presence of charred phytoliths. These provide clues about feature function, food processing, linkage with activity areas, and implied seasonality. The density of phytoliths in the Component A pithouse as compared to that in Component $\mathrm{C}$ pithouse may indicate a more intensive or longer use of the Component $\mathrm{C}$ pithouse.

Not sieving the samples in the initial processing of the phytolith samples, which is the standard process that most analysts use, helped to preserve materials/phytoliths that would not have otherwise been retained. Careful examination of the unsieved soil fractions eliminated during phytoliths isolation, yielded additional important data (i.e., fragments of maize, teeth, and mollusks). In the future, sample sizes of $50 \mathrm{~g}$ would enable soil pH to be determined, a critical factor in phytolith preservation and interpretations. Collection of one or two control samples is also necessary for comparisons with the cultural samples. As this discipline grows and matures and more phytoliths can be identified, the greater will be the resultant information return. Continued use of phytolith analysis is advocated for sites/components where cultigens are suspected. Also, understanding the presence and types of grass is an important factor in reconstructing past environments. Phytolith analysis is also significant at sites where wood charcoal preservation is limited and where paleoenvironmental questions are being asked.

\subsubsection{Diatom Analysis}

Diatom analysis, conducted on 12 burned rocks and 6 daub samples from the two components, was not as productive as had been anticipated, although 83 percent of the samples yielded 1,163 cells that represent 49 identifications at the level of species and 6 at the genus level. The frequency of diatoms scraped from the exteriors of burned rocks varied from 1 to 741 per sample, which likely reflects differences in use frequency and/or function. Identification of aquatic diatoms on burned rock surfaces is quite significant and is best explained by the transport of water to the site by people, and the combined use of hot rocks and water for cooking. The aquatic diatoms from the burned rocks are typically found in temperate, shallow, slightly too markedly alkaline, moderately high-conductivity, nutrient-rich, streams with sand, mud, pebble and/or rock bottoms and vegetated banklines as are found near the site.

The daub from each component yielded more diatoms $(N=889)$ than did the burned rocks $(N=$ 274). The diatoms in the daub were combined with clay, quartz, and other minerals and are distinct from those associated with the burned rocks. The daub contained two diatom associations that represent two distinct environments. One association is typical of a shallow, lacustrine-palustrine environment that contained cool, acidic, dilute, nutrient poor, low conductivity water unlike what would have existed in the streams near the site. In contrast, the second association includes diatoms that represent small, 
temperate, shallow, alkaline and nutrient-rich such waters as would have been present in the nearby streams. These results indicate that the daub was a mixture of clay dug from an ancient bog, reed swamp or shallow lake deposits (as represented by the Ogallala deposits), and muddy water along a stream. Therefore, the combination of two sets of diatoms allows the reconstruction of daub production, namely, that clays retrieved from the Ogallala were mixed with water from nearby streams. This is significant for understanding the daub production process and more about possible pithouse coverings. In the future, diatom analyses should be directed towards feature-specific sediments, burned rocks, and daub, if it is present, in order to help identify feature function as well as how daub was prepared. A number of modern diatom samples should also be collected from various localities (still ponds, flowing streams, and surface) at and around sites for comparison with intrasite findings. The diatom analysts also recommended experiments to determine how the heating and cooling of rocks affects coatings on the rocks since, where water is suspected to have been used in cooking and/or other functions at the site, diatom analysis is an effective way to address that question(s).

Assuming that the species of diatoms from the burned rocks are representative of local streams, it is apparent that moderate nutrient concentrations with a $\mathrm{pH}$ of seven and slightly elevated ion concentrations primarily from carbonate and sulfate indicate the water had a moderate to high conductivity and was shallow. The possibility exists that the water was enriched with nitrates and phosphate, possibly from associated decaying vegetation and/or human actions.

\subsubsection{Macrobotanical Analysis}

Macrobotanical analyses were extensive, with 34 flotation samples (11 from Component $\mathrm{A}$ and 23 from Component C) that involved a total of 566.7 liters of sediment, or an average of 15.1 liters-per sample, and resulted in the identification of 114 individual macrobotanical specimens from 16 features. Identified taxa include carbonized cultigens comprised of maize $(N=475), 1$ bean fragment, 5 squash rinds, together with limited carbonized wild plant parts $(N=16)$ that include 5 mesquite beans, 6 cheno-ams seeds, 1 juniper seed, 3 prickly pear seeds, 1 hackberry nutlet, and various wood species. Although 16 carbonized wild plant parts are documented in the macrobotanical remains, they were not abundant from either component, with only 6 in Component A and 12 in Component C. The botanical assemblages from the two components are very similar. The presence of maize from nearly all features also provides an indication of the abundant availability of this food resource, implying that it was more or less intensively cultivated. Both components yielded a high presence of maize, but only a low presence of beans and squash.

Juniper was the most abundantly used wood for fuel and construction. All other woods, mesquite, oak, willow/cottonwood, elm, and rose family, were present in more limited quantities in both components. These woods are also indicators of the nature of the arboreal vegetation along the stream valleys or sloping terrain in the local grassland environment. The identified wood types combined with the short-cell Chloridoid phytolith record reveals a broad short-grass local environment with diverse trees dominated by juniper at the time the site was occupied and also typical of the Canadian Breaks today.

The analyst's method of recording individual samples documents the types and frequencies of disturbance and reflects various physical and biological disturbances at the micoscale. Macrobotanical analyses have become a standard technique in analyzing sediment samples from archeological sites/features and should remain so with increased volumes floated from all parts of a site and from all features. This provides an excellent means to compare preservation and utilization of plants for food and fuel between sites. However, many sites reveal poor preservation and consequently macrobotanical analysis is not practical or at least may not be optimally informative. Therefore, phytolith and starch grain analyses should be used in attempts to identify the range of plant resources available and utilized.

\subsubsection{Starch Grain Analysis}

Starch grain analysis was conducted on a diverse suite of 104 artifacts, equally divided between the 
two components. These included 20 burned rocks, 27 chipped and 18 ground stone tools, 37 pottery sherds, and 2 sediment samples. The starch grains provide significant information in a number of ways. The two control sediment samples from cultural contexts contained no starch grains, which indicate that all starches were present as a result of prehistoric cultural activities. This analytical technique provides insights into the specific plant foods cooked in ceramic vessels, those processed with ground stone tools and with various chipped stone tools, and the plant foods cooked using heated rocks, all of which would otherwise have gone undetected.

In contrast to macrobotanical analysis that reveals maize was ubiquitous across all analyzed features, starch grain analysis documented the dominance of wild plant starches ( $N=456$ or 67 percent of the starch grains). Specifically, these include 421 little barley grains, cheno-ams, at least three distinct types within the unidentified starches, bulbs within the lily family, seeds of mesquite, and wild grass. Little barley starch is four times more frequent than maize starch, occuring on 25 of the 37 (or 68 percent) sherds, 12 of 20 (60 percent) of the burned rocks, 7 of 18 (39 percent) of the ground stone tools, and 10 of 27 (37 percent) of the chipped stone tools.

The 105 observed maize starch grains apparently were not processed by grinding, as only 6 grains (5.7 percent) were damaged. Altered wild plant starch grains document the specific processing techniques that were used. The damage to individual starch grains reveals grinding, heating with water, and parching. This evidence is significant as it indicates aspects of the food preparation that were only previously assumed or suspected.

The starch grain analysis provides direct evidence and documentation that wild plant foods were gathered, the species that were targeted, and how they were processed. This information is critical to understanding the full range of food resources procured, processed and consumed at Long View. As mentioned above, the findings from the ground stone tools (metates and manos) reveal that the majority of starch grains (84 percent) represent gathered wild plants rather than cultivated maize. This fact sharply contrasts with the macrobotanical findings, which reveal a relatively limited use of wild plants $(N=16)$ as compared to greater reliance on maize $(N=475)$. The starch record reveals harvesting and scraping of grains (seeds) with chipped stone tools, plus grinding with ground stone tools. In fact, the starches from pottery and burned rocks also reveal a heavy reliance on cooking of flour processed from wild plants (mostly little barley), as opposed to maize. Maize appears primarily as popcorn as evidenced by the repeated presence of hard endosperm types combined with the lack of floury morphologies, which makes sense in view of the absence of maize starch on the ground stone. Perhaps somewhat counterintuitively, then, maize at Long View may have been consumed primarily as popcorn, rather than ground into a flour.

Other interesting findings were that rim sherds are not only more likely to produce identifiable starchy residues as were body sherds, they also yielded over twice as many starch grains per sherd. Consequently, rim sherds should be targeted during starch analysis in the future. The ceramic pieces believed to be pipe fragments yielded multiple starches that indicate other functions. Although lenticular starches from little barley dominate the starch grain assemblage, this species is not represented in the macrobotanical record.

Starch grain analysis has made significant contributions here. It has enhanced our knowledge of the range of wild plants utilized, and provided insight into their relative dietary importance. Additionally, it has provided information on the different processing techniques that plants were subjected to, and how they were cooked. Without this technique, much of our understanding of the plant food resources used, especially wild species would not be possible, and our interpretations, if based solely on macrobotanical data, would likely be skewed toward an overestimation of the overall importance of maize. It is recommended that control samples from on- and off-site be collected and used to help better contextualize the findings on cultural items such as various tool types and burned rocks. Analysis directed towards diverse artifact classes is important for obtaining the broadest possible identification of the range of food resources obtained and how they were processed. 


\subsubsection{Instrumental Neutron Activation Analysis}

Instrumental neutron activation analysis (INAA) was conducted on 32 pottery sherds, 2 tempered clay samples, and 6 daub samples from Long View, plus 80 sherds and 7 tempered clay samples selected from 15 Plains Village sites in the surrounding region. This technique provides a broad understanding of the chemical composition of each specimen and through the use of principal component analysis, supported by statistical pattern recognition techniques (cluster analysis and discriminate analysis), permits inferences as to how individual specimens relate to each other in terms of chemical composition. This initial attempt at clustering was primarily focused on the large-scale identification of region-specific ceramic production patterns and on the small-scale examination of ceramic production in the two components at the Long View site. The overall goal has been to identify patterns of interaction among peoples in the region during the Plains Village period, as evidenced by the locational patterns of pottery production and the movements of pots originating in local areas within the wide region.

The 112 pottery samples submitted and analyzed were combined with the results from 81 previously analyzed pottery samples from Late Prehistoric sites in the panhandle region (total $N=193$ ) on file at the MURR laboratory to identify correlations between sherds and chemical compositional groups. This was done in order to potentially identify localized source and/or manufacturing areas, to investigate individual and/or community expressions by distinct social groups, and measure the patterns of movement of pottery and/or people across the landscape. The identification of clusterings of elements within sherds in the sampling universe $(N=193)$ resulted in the identification of 13 compositional groups, the baseline for identifying the spatial patterns of manufacturing, movement and exchange.

The compositional groups fall into three broad categories: 1) pairs of samples that consistently plot together; 2) small groups comprised of three to eight samples; and 3) larger groups containing ten or more samples. The distributional patterns of sherds across the 13 compositional groups strongly support the identification of numerous localized production localities/areas across the Texas panhandle region.

Only Compositional Group 2, comprised of 29 samples, has widespread distribution across multiple sites and areas. This group includes 15 sherds (52 percent of the total) from Long View, 12 sherds from Component $\mathrm{A}$ and 3 from Component C. Group 2 is comprised of 90 percent sherds from Longview or sites in the surrounding area but only 10 percent from the five Antelope Creek phase sites farther to the southwest. In Compositional Group 7, which has the highest number of samples of all the groups (56 assigned sherds or 34.8 percent of the total assigned sherds) 91.1 percent of the sherds are from the Antelope Creek phase core area sites and farther westward, and the remaining 8.9 percent are from two Antelope Creek phase sites (Stamper and Two Sisters) in the Oklahoma panhandle. The INAA results, in fact, support the close association of these two areas and accords with their assignment to the same phase.

Twelve (92 percent) of the compositional groups have more spatially restricted distributions. The INAA was able to distinguish the sherd assemblages from the two Long View components (Figure 11-1). None of the 42 clays, raw or experimentally tempered, were assigned to any of the thirteen compositional groups. However, the clays are generally similar to the ceramic samples and indicate a general regional commonality. Based on this lack of assignment, the analyzed clay resources from across the region exhibit similar ranges that could not be isolated or directly tied to the sherds.

The findings made by INAA can be listed, as follows:

1. The 193 Southern Plains ceramic samples are chemically unrelated to the Central Plains ceramic samples, as should be expected for these geographically separate regions.

2. The sherds analyzed from Antelope Creek phase sites in the core area and further west occur in some of the same compositional groups as do those from four Antelope Creek sites in the Oklahoma panhandle, indicating 


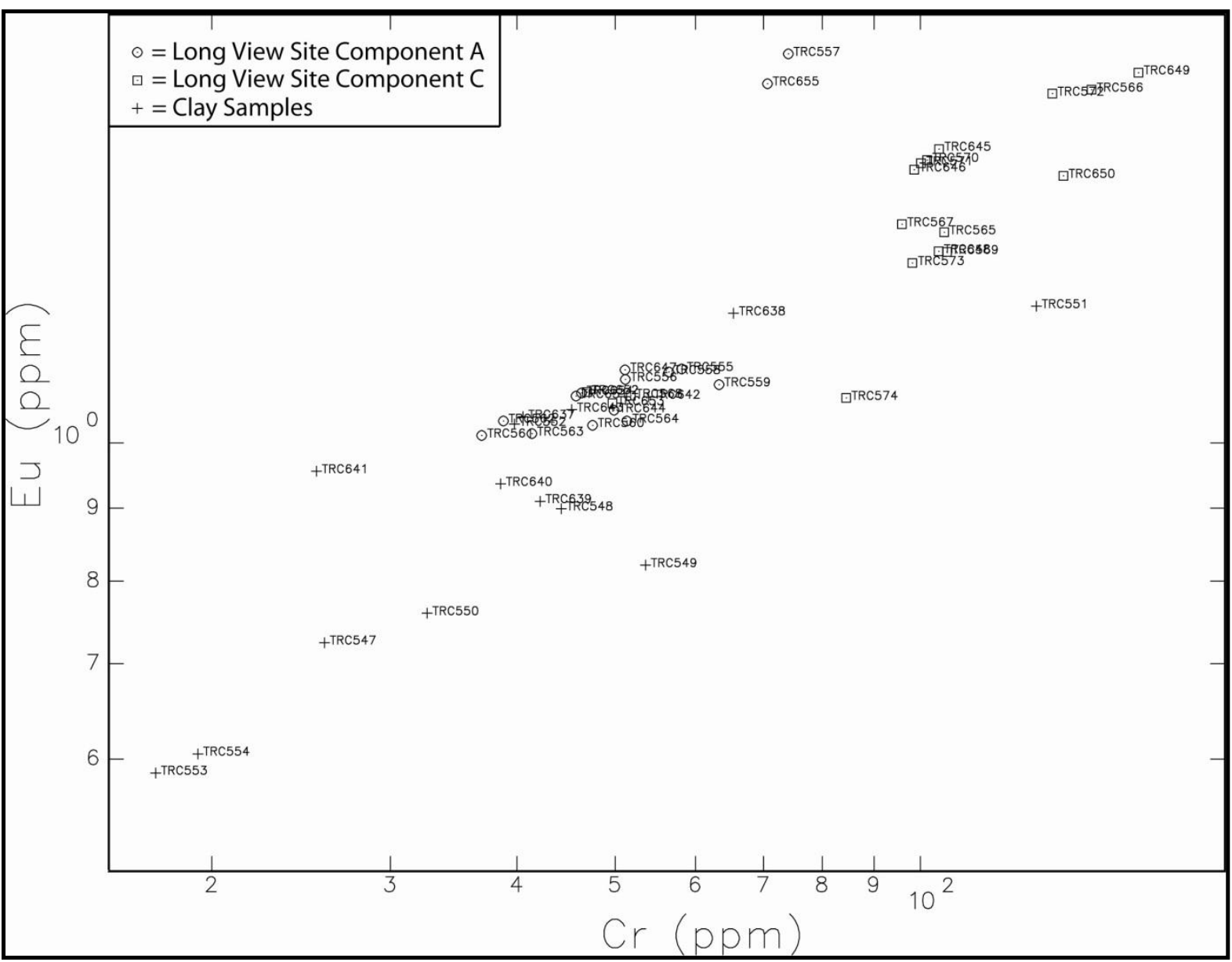

Figure 11-1. Bivariate plot of chromium (Cr) and europium (Eu) showing separation of Components $\mathrm{A}$ and $\mathrm{C}$ pottery and tempered natural clay samples from the region.

Note: The two clay samples in the middle of the clustered Component A sherds show little chemical pattern to the paste used in the pottery. No ellipses are depicted as ellipses are used to chemically define groups, which these are not chemically defined groups.

interconnectedness, perhaps via social and/or economic interactions, between these areas.

3. The Long View sherds are chemically more closely related to sherds from M-Cross Ranch and Wolf Creek/Buried City than they are to sherds from the Antelope Creek phase sites, indicating closer cultural ties to the former, as opposed to the latter, area.

4. The more northern sites outside the Antelope Creek phase core area contain the second most populous representation (90 percent) of Compositional Group 2 and indicates some movement/transport/exchange of pottery across the landscape by the data for Compositional Group 2, which appears in multiple sites.

5. The clays used in the production of the vessels reflect minimally two sources for Component $\mathrm{A}$ vessels and three sources for Component $\mathrm{C}$ vessels.

6. The homogeneity of the Component A assemblage may indicate residence there by a single, small and distinct, socially autonomous population. 
7. The rare and unusual red-washed Vessel C from Component A was assigned to the same chemical group as the thick cordmarked Vessel 3 from Component $\mathrm{C}$ indicating that it was likely manufactured within the region and was not an exotic import, as might have been inferred from its unusual surface treatment.

8. It is apparent that the clay resources across the region exhibit similar ranges of variation and do not group geographically with the pottery samples and show only limited relations to the pottery. It may be that the individual clay resources are too numerous to actually find the specific source or that the landscape has changed sufficiently over time so as not to enable to identify that original source.

9. This chemical analysis has clearly documented that the visibly and stylistic similarity within the cordmarked ceramic tradition of the Plains Village period has definite chemical variability that can help address questions of human behavior, social interactions, movements of people and/or goods, and related issues. Therefore, INAA has been confirmed as an effective analytical tool for characterizing the chemical composition of pottery and for making culturally relevant inferences therefrom.

These broad chemical groupings indicate that clay and temper resources used for the production of cordmarked pottery were procured either through short-distance logistical forays, exchange, or by a resource extraction strategy embedded in a residential mobility pattern. This likely indicates that most groups had localized territories and/or ranges. This has important implications for understanding group mobility and social interactions with adjacent groups and, potentially, trading networks. Further compositional analysis of ceramic artifacts from other sites, using INAA, is, therefore, highly recommended. Continued application to pottery from individual and multiple sites will enhance the database for this region and provide greater insight into the spatial-organization and mobility strategies of native groups. The laboratory analysts recommend that, in the future, more extensive sampling of currently under-sampled areas and/ or sites be undertaken to confirm these initial patterns. Submission of greater number of samples (preferably at least 20 sherds per individual site and/or component) should allow for more confident assignment of sherds to various compositional groups and thereby raise the level of interpretive confidence. Thirty-two percent of the 193 analyzed sherds were unassigned to a specific compositional group and this was thought to be partially the result of there being so few analyzed sherds from any single site. The two highest percentages of unassigned sherds (73.3 and 57 percent) were from two of the five areas, the Wolf Creek/Buried City area and sites near Long View at M-Cross Ranch, with only 15 and 18 sherds respectively. It is recommended that at least two natural clay samples be collected from different near-site localities be submitted with the pottery to help identify on-site production of ceramic vessels. The more Plains Village samples that are analyzed and incorporated into the MURR database, the greater will be our understanding of the individual ceramic assemblages at specific sites and of intraregional patterns of pottery production and transport/exchange.

There are numerous other techniques that may contribute to determining the sources of the clays and aplastic additives used in the making of pottery. Elemental compositional research through X-ray fluorescence spectroscopy (XRF), X-ray diffraction (XRD), proton/particle-induced X-ray emission (PIXE), and gamma ray emission (GIPG) have not been tried on the cordmarked pottery from this region. Induced coupled plasma emission spectroscopy (ICP) may also provide advantages over XRD and $\mathrm{XRF}$ as it can provide a more diverse set of major, minor, and trace elements. Its principal drawback is that it inherently contains poor sensitivity and spectral interferences to the trace elements such as lead, niobium, rubidium and others (Bentley 1995; Malainey 2011). One or more of these techniques may provide insights that other techniques cannot. As Malainey (2011) points out "most instrumental techniques measure multiple elements during an analysis, if potential sources can be successfully discriminated on the basis of a single element, any technique that can accurately assess that particular element can be selected". However, neither XRF 
nor ICP are capable of analyzing the large number of rare earth elements that can be identified using INAA. It is important to remember that different techniques measure different elements, which can make it difficult to compare data sets. Continued application of INAA on cordmarked sherds from this region is recommended, since this will add to this body of compositional data. As more sherd and clay samples from different sites and components are subjected to INAA, a greater understanding of the Plains Village pottery production and exchange will be realized. Ultimately this should contribute significantly to the study of regional interactions among the populations that occupied this region during this time period.

\subsubsection{Petrographic Analysis}

Petrography was conducted on 85 of the same potsherds and 10 mostly tempered clay samples on which INAA was performed, with a few exceptions. Petrography allowed identification of specific mineral types and quantities in the pastes, which facilitated grouping of similarly tempered sherds into four broad temper classes, which were then subdivided into 35 paste groups. Mixed and multiple tempers are common. The range of temper classes from across the panhandle region includes crushed rocks and minerals, crushed bone, crushed basalt with pyroxene, and crushed basalt combined with bone. A majority of sites revealed different tempers in the sherd assemblages and all tempering agents appear to be locally derived. The crushed rock and mineral class includes 40 sherds from 10 sites that are within 14 paste groups. The bone temper class includes nine sherds from three sites in four paste groups. The bone and basalt combination temper includes five sherds from four sites in three paste groups. The basalt with pyroxene temper class includes 31 sherds from 12 sites, suggesting group and/or vessel movement. Once paste groups were determined, the distribution of those groups across the landscape by site and region could be assessed. Sedimentological analysis of ten sediment samples from streams in the region and on-site soils matched characteristics of resident minerals in the ceramic pastes. In the case of the Blue Creek clay sample, its added basalt particles with pyroxene crystals match tempers in ceramic pastes from several sites. This petrographic analysis has begun to identify more detailed intersite connections among panhandle Plains Village sites. Paste groups of pottery wares common to two or more site clusters are a feature of the cultural network. Interactions among site clusters along the Canadian River valley are the strongest. Exclusive or restricted use of the localities is not suggested by these data.

Unfortunately the combined INAA and petrography provided no clear and definitive answers to the question of clay source locations, production areas, or typological correlations. These analyses did, however, reveal homogenous assemblages for the two Long View components that likely reflect occupations of both components by tightly knit social units. The results also reveal an intraregional diversity in tempering agents. The technology was a complex system that involved raw clay and temper selection, paste preparation, vessel construction, firing practices, and use applications. It appears likely that some variations in the system are related to geographical factors and also that specific technologies were localized and not employed throughout the entire Plains Village culture area.

This petrographic analysis was one of a few attempts conducted on Plains Village sherds from this region to identify specific minerals in the broad cordmarked vessels found across the Texas panhandle. The positive results need to be expanded with more sample submissions per site (ca. 20 items) to enhance the current understanding of regional pottery manufacturing localities and movement of peoples/vessels across the landscape. A combination of petrography and INAA will allow for strengthened interpretations concerning pottery manufacturing and possible movements of goods and/or people. Petrography has brought forth significant data on specific types and frequencies of pottery tempers, allowed sherd assignments, and augmented discussions considering pottery manufacturing, population movements and/or interactions.

One problem with the petrographic analysis was the inability of the analyst to specifically identify eolian particles in the thin section. This was not his fault, but is an inherent methodological problem deriving from the fact that the key indicator of wind transport is a frosted appearance on grain exteriors, which is something not visible in the thin sections, 
since only the interiors of grains are visible in cut/ ground thin sections. It is possible that wet mounts of samples may contribute to identification eolianweathered grain surfaces. Compared to digital image analysis (DIA), petrography provides more accurate numerical descriptions, more precise size and shape characteristics, and more in-depth descriptions of sample compositions (Livingood and Cordell (2009), and it is thus highly recommended on ceramic assemblages going forward.

\subsubsection{Stable Isotope Analyses on Bison Bones}

Stable carbon and nitrogen isotope analyses on 10 bison bones, 5 from each Long View component, provides insights into the general kinds of grass communities bison were consuming in the region. The percentage of $\mathrm{C}_{3}$ verses $\mathrm{C}_{4}$ plants reflected in the bison bone carbon isotopes provide proxy data that reveals the general composition of the regional grassland in which these generalized consumers were feeding. These carbon isotope results reveal the region surrounding the Long View site was clearly dominated by $\mathrm{C}_{4}$ grasslands, which is in accord with the phytoliths results. No differences are present in the carbon isotopes between Component A and $\mathrm{C}$, indicating that little change took place in the grasslands around the site during the decades that separated the respective site occupations, although a slight increase of $1.1 \%$ in nitrogen isotopes was detected in Component $\mathrm{C}$.

The documentation of carbon and nitrogen isotope values present in the Long View bison bones would theoretically allow for greater understanding of and comparisons with the same stable isotopes obtained from human skeletal remains contributing to the interpretation and understanding of Native population's diet. Unfortunately, stable isotope analyses were not permitted on the human remains recovered from Long View. However, this bison bone isotope data can be used to help interpret isotope results from other analyzed human remains recovered from Plains Village sites in this region. Going forward, it will be beneficial to determine the strontium isotope and zinc values in animal and human bones, preferably teeth, as these are good trace elements that might help in identifying aspects of the paleodiet (Malainey 2011).

\subsubsection{XRF Analysis}

The XRF trace element analyses on 49 obsidian flakes revealed that all came from a single geologic source, the Cerro Toledo Rhyolite, one of three obsidian flows in the Valles Caldera in the Jemez Mountains of northern New Mexico. This flow occurs along the northeastern and southern edges of the Caldera and is abundant and easily accessible, though it varies in the quality of obsidian (Shackley 2005). Away from the primary lava flows, the raw material in the adjacent stream valleys range in size between 10 and $20 \mathrm{~cm}$ in diameter. The rounded water worn exteriors on many Long View pieces indicate this obsidian was derived from cobbles and a secondary source. Having established the specific source for the obsidian that occurred in Component A indicates one direction and the distance over which the Long View populations had interactions and/or trade relations. However, the current site data does not allow the determination of how the obsidian arrived at the site, whether via downthe-line trading, direct acquisition, or through a regional distribution network. The identification of a single source is informative in view of the fact that the pieces appear macroscopically to fall into two varieties, one translucent and the other opaque black. Were it not for the XRF analysis, the obsidian from Long View would likely have been assumed to have come from two or more different source localities.

Trace element analysis was also used to detect the material from which two tiny white beads were manufactured. Both beads were identified as being made of shell, likely marine shell, again indicating long-distance interactions and movement of material. XRF trace element analysis is, then, quite useful in providing a means to specifically document material types and source areas (distance and direction) for nonlocal materials. Sourcing obsidian has also allowed discussions concerning broader issues of exchange between small-scale societies, social status among Plains populations, and intersocietal interactions (i.e., Brosowske 2005). XRF analysis is recommended for samples of unknown origin at every site where they are encountered to provide insight into population movements and/or trading networks. 


\subsubsection{Optical Stimulated Luminescence Dating}

Optical stimulated luminescence (OSL) dating on 14 sediment samples was the only means to date the sandy deposits on- and off-site, as the sandy eolian deposits contain insufficient organic matter to obtain reliable radiocarbon dates. Determining the timing of the eolian depositional processes and integrity in this area was critical for understanding the sequence of deposition at both the site and regional scales. This dating technique, at both the single aliquot and grain level, provided the general age of the deposits and allowed for interpretation of the sequence of natural stratigraphic superposition. Single-grain dating permitted a clearer understanding of the age structure of the eolian deposit and its integrity, especially where postdepositional mixing had occurred but was invisible to the naked eye. This approach was definitely necessary for obtaining usable absolute ages at the Long View site and the sandy deposits in the immediate area. This technique is broadly applicable for geoarcheological purposes at sites with sandy deposits and thus can be employed to help establish the timing and sequence of depositional events.

\subsubsection{Physical Anthropological Analyses}

Physical anthropologists conducted metric and nonmetric analyses on skeletal materials from two human burials, as well as the scattered dental remains of a juvenile from Long View. These analyses were successful in identifying the remains as Native Americans with age, sex and bone/body conditions revealed to the extent possible given the incomplete condition of the skeletons. While this documentation provides information about the specific individuals, the fact that we were not permitted to directly radiocarbon date and chemically analyzing (i.e., stable isotopes, DNA, strontium, zinc, etc.) the remains of each individual precluded any possibility to place these individuals within a specific time, assess their dietary patterns, determine group/tribal affiliations, or address other related questions. In the future, if archeologists are to obtain an understanding of past human populations, analyses to determine the specific ages of the burials, nondestructive heritable discrete or nonmetric dentral traits, and bone chemistry will need to be conducted.

\subsubsection{Summary of Technical Analyses}

In sum, the excellent geoarcheological work and intensive radiocarbon dating combined with multidisciplinary technical results have made significant contributions towards a greater understanding Plains Village period cultural behavior, specific aspects of the artifact assemblage, the environmental parameters of the site, and some of the human responses to that local environment. It is highly recommended that these and other technical analyses be employed at other excavated assemblages and sites so as to continue broadening our understanding aspects of the regional prehistoric culture such as subsistence patterns, food processing and cooking patterns, ceramic manufacturing techniques and clay sources, range and diversity of tool functions, population movements, patterns of exchange and other aspects of the lifeways of the aboriginal people who lived this and adjacent regions.

\subsection{Key Field Strategy Contributions}

One significant field method employed during the data recovery excavations of the pithouse in Component $\mathrm{C}$ was to leave two continuous linear baulks across the length of the pithouse. One 3+ m-long baulk was extremely helpful during the assessment of the fill deposits, allowing for intensive documentation and sampling the stratified fill across the length of the pithouse, Feature 6 . The two baulks allowed multiple views of deposits in different lighting conditions, selection and sampling at key positions, as well as the piece plotting individual charcoal samples horizontally and vertically across the deposits.

A second key strategy was the careful collection of many artifacts (chipped and ground stone tools plus pottery) without touching with bare hands, a tactic that helped to protect and preserve potential microfossils that might be adhering to these specimens. The artifacts recovered with this approach were carefully bagged without direct handling, and were left unwashed during laboratory processing. This facilitated the selection 
of specimens for high-power microscropic use-wear analysis and residue identification from a broad suite of samples. Additionally, some specimens were left untouched for curation in the event that further intensive analyses are possible in the future.

A third important strategy was the collection of large bulk sediment samples from nearly all identified features. These samples were not screened in the field, but returned to the laboratory for more intensive, controlled, and careful processing, either through fine-screening or flotation. This permitted greater recovery of macrobotanical remains that contributed to documentation of feature function, specific food remains, plus the recovery of two tiny, nonlocal marine shell beads that otherwise would have gone undetected.

A fourth key process was carried out in the field by geoarcheologist Charles Frederick who, with a critical eye, extensive background knowledge, devised and carried out an intensive strategic sampling of the pithouse deposits in Component $\mathrm{C}$ with the goal of addressing specific age and depositional questions. This was followed by a diverse employment of multiple laboratory analyses that permitted complete documentation and/or demonstration of the sequence of filling events that included the earthen roof in pithouse Feature 6 and the determination that this earthen cover was composed of sand and mud and not the Ogallala clays. He also had the foresight to sample a deep sand deposit just off-site in the adjacent creek margin to help clarify the on-site stratigraphy, document the broader depositional sequence for the surrounding area, and determine the age of the various sandy eolian deposits.

In contrast to the above-listed positive field strategies employed, a geophysical survey was conducted that yielded only very limited results. It was partially successful in that it identified several anomalies and/or anomalous patterns. However, the extensive disturbances in the APE significantly increased the uncertainty involved in interpreting these anomalies. The magnetic-field-gradient survey results were compromised by signal clutter from a variety of local metal interferences (i.e., fences lines, power lines, metal in the ground, etc.). The electrical resistance results were sensitive to the soil disturbances associated with the construction of the fireguard and other factors. The GPR survey results were also affected by modern soil disturbances and metal interferences. Although the targeted APE at the Long View site thus did not provide ideal conditions for geophysical investigations or yield particularly positive results, it does not follow that these strategies cannot yield satisfactory results at other sites. Previous work in the region at other buried sites has yielded not only many geophysical anomalies, but ground truthing those anomalies has documented cultural features such as, but not limited to, refuse or midden areas, storage/trash pits, hearths, house foundations, burial cairns, sheet middens, and pithouses (Brosowske 2008, 2009c; Brosowske and Maki 2002; Maki 2005). In support of the use of geophysical investigations at village sites, a cesium magnetometer survey at a pithouse site near Silver City, New Mexico yielded very positive results. This technique identified characteristic magnetic signatures of multiple pithouses and enabled differentiation of circular and rectilinear house shapes (Rogers et al. 2010). In attempting to locate and identify subsurface cultural features in possible village sites, this is a suitable strategy that should be employed more often to help guide hand excavations.

\subsection{Methods and Analytical Recommendations}

In combination, the employed field strategies and the many multidisciplinary technical analyses have provided significant and important data in which specific aspects of the two Plains Village components at Long View were brought forth, augmenting insights into the various dimensions of human behavior and culture of the site's inhabitants.

The specific field strategies just discussed provided excellent opportunities to increase the quantity and quality of information that could be gleaned from the deposits and as well as artifacts. Consequently, these procedures served to improve our interpretive capabilities, and are thus recommended for future excavations when and where possible. The combined application of various analytical techniques contributed significantly to maximize the information return and provide greater insight into 
past human behavior and TRC recommends their use in future archeological investigations.

One other technical analysis not performed here, the employment of lipid residue analysis using high temperature-gas chromatography (HT-GC) and high temperature gas chromatography/mass spectrometry HT-GC/MS) on the burned rocks and ceramic sherds would have provided information concerning the presence or absence of animal products cooked in the vessels or with hot rocks. Currently, no other technical analysis provides such information and it would be greatly beneficial to obtain direct information towards the cooking strategies employed on animal products, if they were cooked at all. That analysis can distinguish plant residues, animal residues, and plant/ animal residue combinations on burned rocks and ceramic vessels.

In the present case, our use of other techniques permitted the identification of only the plant residues present on burned rocks and pottery. To accomplish that determination, two analytical techniques (starch and macrobotanical) were required to bring to light the type and quantity of plants cooked by these means. If only one of these two techniques had been applied towards these materials, the results would have incorrectly skewed the interpretations, instead of documenting the entire range of plants processed. Each technique provided a special interpretive window.

This project incorporated multiple lines of data analyses directed towards the ceramic assemblage, two of which, INAA and petrography, targeted identification of the manufacturing constituents of vessels, and their source locations. The results are slanted towards the opposite ends of the interpretative spectrum in that the INAA generally appears to lump results, whereas the petrographic results tend to split the data. However, each technique made a significant contribution towards greater understanding of the ceramic industry. Although the information return was significant, there are still some aspects of the ceramics that went unattended and could be addressed with additional analytical techniques. For example, methods of vessel construction can be specified using the nondestructive technique of X-radiography, which provides an easy and unobstructive way of determining how a vessel was originally constructed (Parker 2002). This technique has been used successfully by a number of researchers, such as, Parker (2002) and Carr (1990), who were able to view the basic orientation or particles within the paste and by their orientation, determine whether the vessel was coil constructed, built with slabs, lump modeled or made using paddle and anvil construction. This is not widely used, but it should be at least investigated in more detail to determine its applicability in the study of Plains Village pottery.

TRC found that the sorting procedure outlined in the debitage analysis section of the TxDOT lithic analysis protocol (version 2.1) is designed for assemblages with large frequencies of material per individual provenience. Therefore, when applied to assemblages that contain few individual pieces per large number of proveniences, the procedure is time consuming and inefficient. In effect, the outcome, after tedious sorting and grouping of specimens by multiple attributes, is analogous to documenting the same attributes at the individual level (i.e., per flake) at the start. As such, TRC approached debitage analysis in a slightly different fashion, after size grading:

-within each size grade group, we sort platform-bearing pieces from nonplatform bearing pieces (or shatter),

- collect the shatter, count, weigh, and bag together, and then,

-assess each platform-bearing flake individually, documenting the prescribed attributes to be entered as a line item on the analysis form.

TRC demonstrated in at least one instance that the selection of a single sherd from an identified vessel or vessel group for technical analyses, petrographic and INAA, as directed in the TxDOT ceramic protocol, (Appendix N) was not sufficient to capture the variability within a single vessel. If identified within one vessel, the rim, body, and base sections should be sampled to help determine the construction process used in the making of that vessel and to adequately document the attribute variability for that vessel. 
Considerable time, effort, and public dollars were spent on this data recovery project. However, significant information was recovered, reported upon and extracted concerning the lifeways of the Plains Village populations at this site. The fact that not many professionally conducted excavations have occurred in this region over the last 30 years or so, the information return from Long View has made a tremendous contribution to the regional prehistoric. In all, this was a very successful project that satisfied the legal requirements and made significant contributions to the regional prehistory. The mitigation effort described in this report for
41RB112, a site determined eligible for nomination to the National Register of Historic Places by THC, and performed to off-set the adverse effects of the proposed road modifications to this highway modification, has effectively recovered, analyzed and disseminated the anthropological information of an archeological nature inherent in that part of site 41RB112 that will be compromised by the proposed undertaking. As such, this effort meets the requirements in Section 106 of the National Historic Preservation Act of 1966 as well as the Antiquities Code of Texas (Chapter 191, etc.) as set forth in TAC permit \#3721. 


\subsection{REFERENCES CITED}

Abbott, J. T.

1990 Geomorphic and Geoarcheological Investigations. In Phase II Investigations at Prehistoric and Rock Art Sites, Justiceburg Reservoir, Garza and Kent Counties, Texas, by D. K. Boyd, J. T. Abbott, W. A. Bryan, C. M. Garvey, S. A. Tomka, and R. C. Fields, pp. 23-62. Reports of Investigations No. 71, Vol. I. Prewitt and Associates, Inc., Austin.

Adkins, W. S.

1958 The Mesozoic Systems in Texas. In The Geology of Texas, Volume I: Stratigraphy, by E. H. Sellers, W. S. Adkins and F. B. Plummer, pp. 241-518. Bureau of Economic Geology, The University of Texas Bulletin No. 3232, Forth printing.

Allen, J. A.

1876 The American Bison, Living and Extinct. Geological Survey of Kentucky, Memoirs, $1(2)$.

Andrefsky, W. Jr.

1994 Raw Material Availability and the Organization of Technology. American Antiquity 59(1):21-34.

1998 Lithics: Macroscopic Approaches to Analysis. Cambridge University Press, Cambridge.

Andrefsky, W., Jr. and M. Bender (editors)

1988 The Pinon Canyon Maneuver Site Manual for the Conduct of Laboratory and Analytical Studies and Handling of Materials. Prepared for National Park Rocky Mountain Region and U.S. Department of Army, Fort Carson.

Arbogast, A. F.

1995 Paleoenvironments and Desertification on the Great Bend Sand Prairie in Kansas. Unpublished Ph.D. dissertation, University of Kansas, Lawrence.
1996 Stratigraphic evidence for late-Holocene aeolian sand mobilization and soil formation in south-central Kansas, U.S.A. Journal of Arid Environments 34:403-414.

Arbogast, A. F. and W. C. Johnson

1998 Late-Quaternary Landscape Response to Environmental Change in South-Central Kansas. Annals of the Association of American Geographers 88(1):126-145.

Arons, H. L. and E. F. Paschall

1975 Common Sugars and Starches. In Nutrients in Processed Foods: Fats-Carbohydrates, edited by P. L. White, D. C. Fletcher and M. Ellis, pp. 85-97. Publishing Sciences Group, Acton, Massachusetts.

Baerreis, D. A.

1954 The Huffaker Site, Delaware County, Oklahoma. Bulletin Oklahoma Anthropological Society 2:35-48.

Baerreis, D. A. and R. Bryson

1965 Historical Climatology and the Southern Plains: A Preliminary Statement. Bulletin of the Oklahoma Anthropological Society 13:69-75.

1966 Dating the Panhandle Aspect Cultures. Bulletin of the Oklahoma Anthropological Society 14:105-116.

Baker, E. M. and J. A. Baker

2000 Archaeological Excavations of Antelope Creek Ruins and Alibates Ruins Panhandle Aspect 1938-1941. Panhandle Archeological Society, Publication No. 8.

Bamforth, D. B.

1987 Historical Documents and Bison Ecology on the Great Plains. Plains Anthropologist 32(115):1-16.

Bandy, P.

1976 Lithic Technology: A Reconstruction of a North Texas Panhandle Archaeological Assemblage. Unpublished Master's thesis, Department of Anthropology, Texas Tech University, Lubbock. 
Banks, L. D.

1984 Lithic Resources and Quarries. In Prehistory of Oklahoma, edited by R. E. Bell, pp. 65-95.

1990 From Mountain Peaks to Alligator Stomachs: A Review of Lithic Sources in the Trans-Mississippi South, the Southern Plains, and Adjacent Southwest. Oklahoma Anthropological Society, Memoir \#4.

Barnes, V.

1968 Geological Atlas of Texas. Plainview Sheet (1:250,000 scale). Bureau of Economic Geology, The University of Texas at Austin, Austin.

1969 Geological Atlas of Texas. Amarillo Sheet (1:250,000 scale). Bureau of Economic Geology, The University of Texas at Austin, Austin.

1993 Geological Atlas of Texas. Perryton Sheet (1:250,000 scale). Charles Newton Gould Memorial Edition, Bureau of Economic Geology, The University of Texas at Austin, Austin.

Baugh, S. T.

1986 Late Prehistoric Bison Distribution in Oklahoma. In Current Trends in Southern Plains Archaeology, edited by T. G. Baugh, 31(114):83-96. Plains Anthropologist Memoir 21.

Baugh, T. G.

1982 Edwards I (34Bk2): Southern Plains Adaptations in the Protohistoric Period. Oklahoma Archaeological Survey, Studies in Oklahoma's Past 8 . University of Oklahoma, Norman.

Baugh, T. G. and F. W. Nelson, Jr.

1987 New Mexico Obsidian Sources and Exchange on the Southern High Plains. Journal of Field Archaeology 14(3):313-329.

Baumgardner, R. W., Jr.

1987 Morphometric Studies of Subhumid and Semiarid Drainage Basins, Texas
Panhandle and Northern New Mexico. Reports of Investigations No. 163. Bureau of Economic Geology, The University of Texas at Austin, Austin.

Beddington, N. L.

1986 The Effects of Mechanically-induced Stress in Plants-a Review. Plant Growth Regulation 4:103-123.

Bedord, J. N.

1974 Morphological Variation in Bison Metacarpals and Metatarsals. In The Casper Site, A Hell Gap Bison Kill on the High Plains, edited by G. C. Frison, pp. 199-240. Academic Press, New York.

1978 ATechnique for Sex Determination of Mature Bison Metapodials. In Bison Procurement and Utilization: A Symposium, edited by L. B. Davis and M. Wilson, pp. 40-43. Plains Anthropologist, Memoir 14.

Bell, R. E.

1958 Guide to the Identification of Certain American Indian Projectile Points. Special Bulletin No.1 of the Oklahoma Anthropological Society.

1960 Guide to the Identification of Certain American Indian Projectile Points. Special Bulletin No. 2 of the Oklahoma Anthropological Society.

1980 Oklahoma Indian Artifacts. Contributions from the Stovall Museum, University of Oklahoma, No. 4, Norman.

Bell, R. E. and D. A. Baerreis

1951 A Survey of Oklahoma Archeology. Bulletin of the Texas Archaeological and Paleontological Society 22:7-100.

Bell, W. H., and E. F. Castetter

1937 The Utilization of Mesquite and Screwbean by the Aborigines in the American Southwest. The University of New Mexico Bulletin, Ethnobiological Studies 
in the American Southwest, Volume V. The University of New Mexico Press, Albuquerque, New Mexico.

Bement, L., and S. D. Brosowske

2001 Streams in No Man's Land: A Cultural Resource Survey in Beaver and Texas Counties, Oklahoma. The University of Oklahoma, Oklahoma Archeological Survey, Archeological Resource Survey Report No. 43.

Bement, L. C. and S. Basmajim

1996 Epiphyseal Fusion in Bison antiquus. Current Research in the Pleistocene 13:9597.

Bentley, M.

1995 An INAA Study of Hot Well Village Clays and Affiliated Geological Clay Sources Used in the Production of El Paso Polychrome. In Hot Well Village and Reservoir National Register Site Investigations: Project 94-18. Vol. 1. Manuscript on file with Directorate of Environment, Conservation Division, Fort Bliss.

Benz, B. F.

1985 Maize in Paleoenvironmental Reconstruction: A Cautionary Note. Plains Anthropologist 30(108):145-147.

Bevitt, C. T.

1999 Life on the High Plains Border: Archeological Investigations of Three Late Prehistoric Habitation Sites in Southwest Kansas. Unpublished Master's thesis, Department of Anthropology, Wichita State University, Wichita.

Binford, L. R.

1978 Nunamiut Ethnoarchaeology. Academic Press, New York.

1979 Organization and Formation Processes: Looking at Curated Technologies. Journal of Anthropological Research 35:255-273.
1980 Willow Smoke and Dogs' Tails: Huntergatherer Settlement Systems and Archaeological Site Formation. American Antiquity 45(1):4-20.

1981 Bones: Ancient Men and Modern Myths. Academic Press, New York.

1984 Butchering, Sharing, and the Archaeological Record. Journal of Anthropological Archaeology 3:235-257.

Birkeland, P. W.

1984 Soils and Geomorphology. Oxford University Press, New York.

Blair, W. F.

1950 Biotic Provinces of Texas. The Texas Journal of Science 2(1):93-117.

Bleed, P.

1986 The Optimal Design of Hunting Weapons: Main-Tainability or Reliability. American Antiquity 51(4):737-747.

Boggs, S., Jr,

1987 Principles of Sedimentology and Stratigraphy. Merrill Publishing Company, Columbus.

Bohrer, V.

1987 The Plant Remains from La Ciudad, A Hohokam Site in Phoenix. In Specialized Studies in the Economy, Environment and Culture of La Ciudad, edited by J. A. E. Kisselburg, G. E. Rice, and B. Spears, pp. 67-202. Office of Cultural Resource Management, Department of Anthropology, Arizona State University, Tempe.

Bomar, G. W.

1983 Texas Weather. University of Texas Press, Austin.

Bonnischen, R.

1973 Some Operational Aspects of Human and Animal Bone Alteration. In Mammalian Osteo-Archaeology: North America, by B. M. Gilbert, pp. 9-24. 
Boulanger, M. T. and M. Glascock

2010 Appendix E, Chert Sourcing in the Texas Panhandle: Compositional Analyses of Chert and Jasper Sources and Artifacts, Landis Property Project. In Landis Property: Data Recovery at Three Prehistoric Sites (41PT185, 41PT186, and 41TP245) in Potter County, Texas, Volume II: Appendices, by J. M. Quigg, C. D. Frederick, P. M. Matchen, and K. G. DuBois, pp. 735-764. TRC Environmental Corporation, TRC Report No. 150832, Austin.

Boyd, D. K.

1995 The Palo Duro complex: Redefining the Early Ceramic period in the Caprock Canyonlands. Bulletin of the Texas Archeological Society 66:461-518.

1997 Caprock Canyonlands Archeology: A Synthesis of the Prehistory of Lake Allen Henry and the Texas Panhandle-Plains. Prewitt and Associates, Inc., Report of Investigations No. 110, Austin.

2004a Hank's House 1: Anatomy of a Burned Pithouse. Internet web exhibit on Texas Beyond History. Available at http://www. texasbeyondhistory.net/villagers/hank1/ index.html [Accessed April 24, 2005].

2004b The Palo Duro Complex: Redefining the Early Ceramic Period in the Caprock Canyonlands. In The Prehistory of Texas, edited by T. K. Perttula, pp. 296-330. Texas A\&M University Press, College Station.

2005 Prehistoric Agriculture on the Canadian River: Hank's Site and the M-Cross Ranch. Paper presented at the Society of Economic Botany Annual Meeting, Fort Worth.

2008 Prehistoric Agriculture on the Canadian River of the Texas Panhandle: New Insights from West Pasture Sites on the M-Cross Ranch. Plains Anthropologist 53(205):3357.
Boyd, D. K. and L. D. Wilkens

2001 Burnin' Down the House: Late Prehistoric Architecture, Abandonment, and Agriculture at Hank's Site, 41RB109, Roberts County, Texas. Current Archeology in Texas 3(2):17. Texas Historical Commission, Austin.

Boyd, D. K., J. Peck, S. A. Tomka, K. W. Kibler and M. D. Freeman

1994 Data Recovery at Lake Allen Henry (Justiceburg Reservoir), Garza and Kent Counties, Texas. Phase III, Season 3. Report of Investigations No. 93. Prewitt and Associates, Inc., Austin.

Bowers, R. L

1975 Petrography and Petrogenesis of the Alibates Dolomite and Chert (Permian), Northern Panhandle of Texas. Unpublished Master's thesis, The University of Texas at Arlington.

Bowers, R. L. and D. F. Reaser

1996 Replacement Chert in the Alibates Dolomite (Permian) of the Texas Panhandle. Texas Journal of Science 48(3):219-242.

Bowman, S.

1990 Radiocarbon Dating. Interpreting the Past. University of California Press/British Museum, Berkeley.

Bozarth, S.

2005 Assessment of Phytoliths Isolated from 41RB112. In Assessment of 41RB112, Roberts County, Texas: Interim Report, by J. M. Quigg and G. Smith, A-1 through A-2. TRC Interim Report No. 46557 Submitted to Texas Department of Transportation, Environmental Affairs Division, Austin.

Bozarth, S. And T. Woodburn

2010 Appendix D, Paleoenvironmental Reconstruction at West Amarillo Creek, Potter County, Texas, Based on Biosilicate Analysis and Palnology. In Landis Property: Data Recovery at Three Prehistoric Sites (41PT185, 41PT186, and 41PT245) in Potter County, Texas, by J. 
M. Quigg, C. D. Frederick, P. M. Matchen and K. G. DuBois, pp. 695-733. TRC Technical Report 150832. Manuscript on file with TRC in Austin and Bureau of Land Management, Santa Fe.

Brink, J. W.

1995 Fatty Acids in Leg Bones of Bison bison, and Applications to Archaeology. Paper presented at the 53rd Annual Plains Conference, Laramie.

Brink, J. W. and B. Dawe

1989 Final Report of the 1985 and 1986 Field Season at Head-Smashed-In Buffalo Jump Alberta. Archaeological Survey of Alberta, Manuscript Series No. 16, Alberta Culture and Multiculturalism, Edmonton.

Brooks, R. L.

1989 Village Farming Societies. In Clovis to Comanchero: Archeological Overview of the Southwestern Great Plains, by J. L. Hofman, R. L. Brooks, J. S. Hays, D. W. Owsley, R. L. Jantz, M. K. Marks, and M. H. Manhein, pp. 71-90. Arkansas Archeological Survey, Research Series No. 35. University of Arkansas, Fayetteville.

1994 Variability in Southern Plains Village Cultural Complexes: Archeological Investigations at the Lonker Site in the Oklahoma Panhandle. Bulletin of the Oklahoma Anthropological Society XLIII:1-27.

2004 From Stone Slab Architecture to Abandonment: A Revisionist View of the Antelope Creek Phase. In The Prehistory of Texas, edited by T. K. Perttula, pp. 331344. Texas A\&M University Press, College Station.

Brooks, R. L. and P. Flynn

1988 34Tx-71: A Late Prehistoric Bison Processing Station in the Oklahoma Panhandle. Plains Anthropologist 33(12):467-487.
Brooks, R. L. and R. R. Drass

2005 Ceramic Paint Cups and Lids Among the Southern Plains Villagers of Western and Central Oklahoma. Plains Anthropologist 50(194):143-157.

Brooks, R. L., M. C. Moore and D. Owsley

1992 New Smith, 34RM300: A Plains Village Mortuary Site in Western Oklahoma. Plains Anthropologist 37(138):59-78.

Brosowske, S. D.

2002a Obsidian Procurement and Distribution During the Middle Ceramic Period of the Southern High Plains: Evidence for the Emergence of Regional Trade Centers. Council of Texas Archeologists Newsletter 28(2):16-28.

2002b What Exactly is the Zimms Complex: A Review and Synthesis of Architectural and Assemblage Traits. Oklahoma Archeology 50(4):20-39.

2005 The Evolution of Exchange in Small-scale Societies of the Southern High Plains. Unpublished Ph.D. dissertation, University of Oklahoma, Norman.

2008 Archaeology in the Top of Texas: The 2008 and 2009 TAS Field Schools. Texas Archeology 52(1):6-10.

2009a High Plains Archaeology: The 2009 Summer Field School in the Texas Panhandle. Texas Archeology 53(1):6-7.

2009b Beyond the TAS Field School: A Look Behind the Scenes. Texas Archeology 53(2):1, 3-4.

2009c Test Excavations at the Archie King II: A Middle Ceramic Period Homestead in Roberts County, Texas. Texas Archeology 54(1):13-16.

2012 A Study of Alibates Silicified Dolomite from a Secondary Source. Pastimes, The Newletter of the Panhandle Archaeological 
Society 32(1):3-6.

Brosowske, S. D. and D. Maki

2002 Ground Truthing of Geophysical Anomalies at Area 1, Buried City Complex, Ochiltree County, Texas. Archaeo-Physics Report of Investigations \#40, Minneapolis.

Brosowske, S. D. and C. T. Bevitt

2006 Looking South: The Middle Ceramic Period in Southern Kansas and Beyond. In Kansas Archaeology, edited by R. J. Hoard and W. E. Banks, pp. 180-201. Kansas State Historical Society, University Press of Kansas.

Brune, G.

1981 Springs of Texas. Volume 1, Branch-smith, Inc., Fort Worth.

Bryson, R. A. and W. M. Wendland

1967 Tentative Climate Patterns for some Late Glacial and Post-Glacial Episodes in Central North America. In Life, Land and Water, edited by W. Mayer-Oakes, pp. 271298. University of Manitobia, Occasional Papers of the Department of Anthropology 1. University of Manitobia Press, Winnipeg.

Bureau of Economic Geology

1969 Geologic Atlas of Texas, Amarillo Sheet. The Bureau of Economic Geology, The University of Texas at Austin, Austin.

Butler, W. B.

1992 Bison Presence and Absence in Colorado, Southwestern Lore 58(3):1-14.

1997 Cultural and Climatic Patterns in the Faunal Record from Western Plains Archeological Sites. Southwestern Lore 63(4):1-36.

Butzer, K. W.

1982 Archaeology as Human Ecology: Method and Theory for a Contextual Approach. Cambridge University Press, Cambridge, UK.
Byrd, C. L.

1971 Origins and History of the Uvalde Gravel of Central Texas. Waco, Texas, Baylor University, Baylor Geological Studies Bulletin No. 20.

Cabeza de Vaca, A. N.

1961 Adventures in the Unknown Interior of America. Translated and edited by C. Covey. University of New Mexico Press, Albuquerque.

Callahan, E.

1979 The Basics of Biface Knapping in the Eastern Fluted Point Tradition: A Manual for Flintknappers and Lithic Analysts. Archeology of Eastern North America 7:1180.

Cambron, J. W. and D. C. Hulse

1964 Handbook of Alabama Archaeology: Part I, Point Types. Alabama Archaeological Society, Huntsville.

Campbell, R. G.

1969 Prehistoric Panhandle Culture on the Chaquaqua Plateau, Southeast Colorado. Unpublished Ph.D. dissertation, Department of Anthropology, University of Colorado, Boulder.

Campbell, T. J.

1983 The Greenbelt Site: An Example of Variation Among Prehistoric Plains Village Sites in the Texas Panhandle. Unpublished Master's thesis, Texas Tech University, Lubbock.

1996 The Green Belt Site: An Example of Variation Among Prehistoric Plains Village Sites in the Texas Panhandle. Aquamarine Publications, Canyon.

Cantu, R. and C. Richardson

1997 Mule Deer Management in Texas. Texas Parks and Wildlife, Austin. 
Caran, S. C.

1989 Geomorphic Analysis. In Prairie Hinterland: The Archaeology of Palo Duro Creek, Phase II Testing, edited by J. A. Peterson, pp. 367-406.

Caran, S. C. and R. W. Baumgardner , Jr.

1990 Quaternary Stratigraphy and Paleoenvironments of the Texas Rolling Plains. Geological Society of America Bulletin 102(6):768-785.

Carmichael, D. L.

1990 Patterns of Residential Mobility and Sedentism in the Jornada Mogollon Area. In Perspectives on Southern Prehistory, edited by P. E. Minnis and C. L. Redman, pp. 122134. Westview Press, Boulder.

Carr, C.

1990 Advances in Ceramic Radiography and Analysis: Applications and Potentials. Journal of Archaeological Sciences 17:1334.

Carter, F.

1934 Book \#1, Tx¹B \& Tx¹C Field Notebook on file at the Sam Noble Oklahoma Museum of Natural History, Norman.

Cassells, E. S.

1997 The Archaeology of Colorado, Revised edition. Johnson Books, Boulder.

Catlin, G.

1851 Letter and Notes on the North American Indians, 8th edition, 2 Volumes. London.

1857 Illustration of the Manners, Customs, and Conditions of the North American Indians. H. G. Bohn, London.

Center for Geospatial Technology

2007 USDA ARS Ogallala Aquifer Interactive Map. Texas Tech University and Kansas State University. http://mapserver.gis.ttu. edu/OgallalaOAP. Accessed on January 14, 2011.
Cepeda, J. C.

1996 Geology and Geological Setting of the Wildcat Bluff Preserve, Potter County, Texas. West Texas State University, Canyon.

Church, T.

2000 Distribution and Sources of Obsidian in the Rio Grande Gravels of New Mexico. Geoarchaeology 15:649-678.

Collins, M. B.

1991 Thoughts on Future Investigation of Burned Rock Middens. In the Burned rock Middens of Texas: An Archeological Symposium, edited by T. R. Hester, pp. 1-24. Studies in Archeology 13, Texas Archeological Research Laboratory, The University of Texas at Austin.

Cordell, L. S.

1984 Prehistory of the Southwest. Academic Press, Inc.

Couzzourt, J

1985 Preliminary Report: Testing at the Tascosa Creek Site, Oldham County, Texas. Transactions of the 20th Regional Archeological Symposium for Southeastern New Mexico and Western Texas, 20:65-141.

Couzzourt, J. and B. Schmidt-Couzzourt

1996 The 1969 Texas Archeological Society Field School at Blue Creek, Moore County, Texas. Bulletin of the Texas Archeological Society 67:1-114.

Creel, D.

1991 Bison Hides in Late Prehistoric Exchange in the Southern Plains. American Antiquity 56:40-49.

Cruse, J. B.

1989 Archeological Investigations at the Kent Creek Site (41HL66): Evidence of Mogollon Influence on the Southern Plains. Unpublished Master's thesis, Department of Anthropology, Texas A\&M University, Collage Station. 
1992 Archaeological Investigations at the Kent Creek Site (41HL66): Evidence of Mogollon Influence on the Southern Plains. Panhandle Archeological Society, Publication No. 6.

2007 Architecture Variability of the Late Woodland and Plains Village Occupations at the Indian Springs Site (41RB81), Roberts County, Texas. Current Archeology in Texas 9(1):11-18. Texas Historic Commission, Austin.

Culin, S.

1992 Games of the North American Indians, Volumes 1 and 2. The University of Nebraska Press, Lincoln and London.

Darton, N. H.

1899 Preliminary Report on the Geology and Water Resources of Nebraska West of the 103ed Meridian. U. S. Geological Survey, 19th Annual Report, Part 4, U. S. Government Printing Office, Washington, D. C.

Dary, D. A.

1974 The Buffalo Book, The Saga of an American Symbol. Avon Books, New York.

Davis, W. B.

1978 The Mammals of Texas. Texas Parks and Wildlife Department, Bulletin 41. Austin.

Deal, D. E.

1975 Geologic Environment of the Alamosa Creek Drainage. In Canadian Breaks: A Natural Area Survey part VII or VIII. pp. 20-45. Division of Natural Resources and Environment, The University of Texas at Austin.

Dean, G.

1986 The Archeobotany of Landergin Mesa. Manuscript on file at the Office of the State Archeologist, Texas Historical Commission, Austin.

Dello-Russo, R. D.

2004 Geochemical Comparisons of Silicified Rhyolites from Two Prehistoric Quarries and 11 Prehistoric Projectile Points, Socorro County, New Mexico, U.S.A. Geoarchaeology 19(3):237-64.

DeMarcay, G.

1986 Vertebrate Fauna at Landergin Mesa: An Antelope Creek Period Village Site. Unpublished Master's thesis, Texas A\&M University, College Station.

Dering, P.

1998 Carbonized Plant Remains. In WilsonLeonard: An 11,000-Year Archeological Record of Hunter-Gatherers in Central Texas, Volume V: Special Studies, assembled and edited by M. B. Collins, Studies in Archeology 31, Texas Archeological Research Laboratory, The University of Texas at Austin and Archeology Studies Program, Report 10, Texas Department of Transportation, Environmental Affairs Division, Austin.

2003 Appendix A: Plant Remains from U.S. Highway 277 Project, Val Verde County, Texas. In Archeological Data Recovery Investigations of Four Burned Rock Midden Sites (41VV1892, 41VV1893, 41VV1895, and 41VV1897) Val Verde County, Texas, by M. Cliff, pp. A1-A22. Texas Department of Transportation, Archeological Studies Program Report No. 51, and PBS\&J, Austin.

2005a Assessment of Marcobotanical Remains from 41RB112. In Assessment of 41RB112, Roberts County, Texas: Interim Report, by J. M. Quigg and G. Smith, B-1 through B-12. TRC Interim Report No. 46557. Report submitted to Texas Department of Transportation, Environmental Affairs Division, Austin.

2005b Appendix D, Plant Remains from 41PT109, Potter County, Texas. In Investigations at an Antelope Creek Phase Isolated Homestead (41PT109), by A. Weinstein, pp. 138-146. Unpublished Master's thesis, Department of Anthropology, Texas State University, San Marcos. 
2008 Plant Remains from the Varga Site(41ED28). In The Varga Site: A Multicomponent, stratified Campsite in the Canyonlands of Edwards County, Texas, by J. M. Quigg, J. D. Owens, P. M. Matchen, G. D. Smith, R. A. Ricklis, M. C. Cody, and C. D. Frederick, pp. 995-1018. Texas Department of Transportation, Environmental Affairs Division, Archeological Studies Program Report No. 110 and TRC Environmental Corporation, Technical Report No. 35319.

Dice, L. R.

1943 The Biotic Provinces of North America. University of Michigan Press, Ann Arbor.

Diehl, M. W.

1992 Architecture as a Material Correlate of Mobility Strategies: Some Implications for Archaeological Interpretation. Behaviour Science Research 26:1-35.

Diehl, M. W. and P. A. Gilman

1996 Implications from the Designs of Different Southwestern Architectural Forms. In Interpreting Southwestern Diversity: Underlying Principles and Overarching Patterns, edited by R. R. Fish and J. J. Reed. Arizona State University Anthropological Research Papers No. 48, Temple.

Dillehay, T.

1974 Late Quaternary Bison Population Changes on the Southern Plains. Plains Anthropologist 19(65):180-196.

Drass, R. R.

1989 Reexamination of the Hedding Site, 34WD2. Oklahoma Anthropological Society Newletter 37(8):2-6.

1997 Culture Change on the Eastern Margins of the Southern Plains. Studies in Oklahoma's Past No. 19. Oklahoma Anthropological Society Memoir No. $7 . \quad$ Oklahoma Archeological Survey, and Memoir 7, Oklahoma Anthropological Society, Norman.
1998 The Southern Plains Villagers. In Archaeology on the Great Plains, edited by W. R. Wood, pp. 415-455. The University Press of Kansas, Lawrence.

1999 Redefining Plains Village Complexes in Oklahoma: The Paoli Phase and the Redbud Plains Variant. Plains Anthropologist 44(168):121-140.

2008 Corn, Beans and Bison: Cultivated Plants and Changing Economies of the Late Prehistoric Villagers on the Plains of Oklahoma and Northwest Texas. Plains Anthropologist 53(205):7-31.

Drass, R. R. and C. L. Turner

1989 An Archeological Reconnaissance of the Wolf Creek Drainage Basin, Ellis County, Oklahoma. The University of Oklahoma, Oklahoma Archeological Survey, Archeological Resource Survey Report No. 35.

Drass, R. R. and P. Flynn

1990 Temporal and Geographic Variations in Subsistence Practices for Plains Villagers in the Southern Plains. Plains Anthropologist 35(128):175-190.

Drass, R. R., T. G. Baugh and P. Flynn

1987 The Heerwald Site and Early Plains Village Adaptation in the Southern Plains. North American Archaeologist 8:151-190.

Dreimani, A.

1962 Quantitative gasometric determination of calcite and dolomite by using a Chittick apparatus. Journal of Sedimentary Petrography 32(3):520-529.

Driesch, A. v. d.

1976 A Guide to the Measurement of Animal Bones from Archaeological Sites. Peabody Museum Bulletin 1, Harvard University, Cambridge, Massachusetts.

Duffield, L. F.

1964 Three Panhandle Aspect Sites at Sanford Reservoir, Hutchinson County, Texas. 
Bulletin of the Texas Archeological Society 35:19-81.

1970 Some Panhandle Aspects Sites in Texas: Their Vertebrates and Paleoecology. Unpublished Ph.D. dissertation, Department of Anthropology, University of Wisconsin, Madison.

1973 Aging and Sexing the Post-Cranial Skelton of Bison. Plains Anthropologist 18(60):132139.

Dunbar, J.

1918 Letters from John Dunbar. In Letters Concerning the Presbyterian Mission in the Pawnee Country, near Bellevue, Nebraska, 1983-1849. Collections of the Kansas State Historical Society 14:570-689.

Duncan, M. A.

2002 Adaptation During the Antelope Creek Phase: A Diet Breath and Site Catchment Analysis of the Subsistence Strategy at the Two Sisters Site. Unpublished Ph.D. dissertation, Department of Anthropology, University of Oklahoma, Norman.

2006 Adaption During the Antelope Creek Phase: Subsistence Strategies at the Two Sisters Site. Studies in Oklahoma's Past 20. Oklahoma Archeological Survey, The University of Oklahoma, Norman.

Eickmeier, W. G. and M. M. Bender

1976 Carbon Isotope Ratios of Crassulacean Acid Metabolism Species in Relation to Climate and Phytosociology. Oecologia 25:341347.

Ellwood, P. B.

1995 Pottery of Eastern Colorado's Early and Middle Ceramic Periods. In Archeological Pottery of Colorado: Ceramic Clues to the Prehistoric and Protohistoric Lives of the State's Native Peoples, R. H. Brunswig, Jr., General and Eastern Slope editor, and B. Bradley and S. M. Chandler Western Slope Editors. Colorado Council of Professional
Archeologist, CCPA Occasional Papers No.2.

2002 Native American Ceramics of Eastern Colorado. Natural History Inventory of Colorado, Number 21, University of Colorado Museum, Boulder.

Ellwood, P. B. and D. R. Parker

1994 Clays and Ceramics form the Prehistoric Front Range. Paper Presented at the Annual Meeting of the Colorado Council of Professional Archaeologists. Montrose.

Ellzey, T. S.

1966 A Panhandle Aspect Site (preliminary report). Midland Archaeological Society, Special Bulletin 1:59-65, Midland.

Emerson, A. M.

1990 Archaeological Implications of Variability in the Economic Anatomy of Bison Bison. Washington State University, UMI dissertation Services, Ann Arbor.

Erickson, J. R.

2004 Hank's House 2: A Puzzle Wrapped in a Mystery. Internet web exhibit on Texas Beyond History. Available at: http://www. texasbeyondhistory.net/villagers/hank1/ index.html [Accessed April 24, 2005].

Erickson, J. E and D. Boyd

2011 Hank's House 1: Anatomy of a Burned Pit House, and Hank's House 2, A Puzzle Wrapped in a Mystery. Texas Beyond History (www.texasbeyondhistory.net/ villagers/hank1/index.html and www. texasbeyondhistory.net/villagers/hank2/ index.html).

Etchieson, G. M.

1978 Archeological Investigations in the Truscot Reservoir Area, King and Knox Counties, Texas. Archeological Research Laboratory, Killgore Research Center, West Texas State University, Canyon. 
1979a Field Notes, December 1979. On file, Kilgore Research Center, West Texas State University, Canyon.

1979b Archeological Testing at the South Ridge Site, Lake Meredith Recreation Area, Hutchinson County, Texas. Archeological Research Laboratory, Killgore Research Center, West Texas State University, Canyon.

1981 Archaeological Survey at Lake Meredith Recreation Area, Moore and Potter Counties, Texas. Archaeological Research Laboratory, Kilgore Research Center, West Texas State University, Canyon.

Etchieson, G. M. and J. E. Couzzourt

1987 Shoreline Survey at Lake Meredith Recreation Area in the Texas Panhandle. U. S. Department of the Interior, Bureau of Reclamation, Southwest Region, Amarillo, Texas.

Ewers, J. C.

1955 The Horse in Blackfoot Indian Culture. Smithsonian Institution, Bureau of American Ethnology, Bulletin 159.

1958 The Blackfeet. University of Oklahoma Press, Norman.

Eyerly, T. L.

1907 Archaeological Work in the Texas Panhandle. Bulletin of the Canadian Academy. Canadian,Texas.

1908 The Buried City of the Panhandle. Transactions of the Kansas Academy of Science 21(1):219-228.

1910 The Indian Remains of the Canadian River Valley. The Archaeological Bulletin 1(3):77-80. Hico, Texas.

1912 The Buried City on the Panhandle. The Archaeological Bulletin 3(1):1-5.

Fawcett, W. B.

1987 Communal Hunts, Human Aggregation,
Social Variation, and Climate Change: Bison Utilization by Prehistoric Inhabitants of the Great Plains. Unpublished Ph.D. dissertation, University of Massachusetts.

Fenneman, N. M.

1931 Physiography of Western United States. McGraw-Hill Book Company, Inc., New York.

Ferring, C. R.

1982 The Late Holocene Prehistory of Delaware Canyon Oklahoma. Institute of Applied Sciences, Contributions to Archaeology 1. North Texas State University, Denton.

1986 Late Holocene Cultural Ecology in the Southern Plains; Perspectives from Delaware Canyon, Oklahoma. In Current Trends in Southern Plains Archaeology, pp. 55-82. Plains Anthropologist Memoir 21.

Fisher, J. W., Jr.

1995 Bone Surface Modifications in Zooarchaeology. Journal of Archaeological Methods and Theory 2(1):7-68.

Flynn, P.

1984 An Analysis of the 1973 Test Excavations at the Zimms Site (34RM72), Western Oklahoma. In Archaeology of the Mixed Grass Prairie Phase I: Quartermaster Creek, edited by T. G. Baugh, pp. 215-290. Archeological Resource Survey Report No. 20, Oklahoma Archeological Survey, Norman.

1986 Analysis of the Test Excavations at the Zimms Site (34RM72), Western Oklahoma. Plains Anthropologist 31(114):129140.

Folk, R. L. and W. C. Ward

1957 Brazos River Bar: A Study in the Significance of Grain Size Parameters. Journal of Sediment Petrology 27:514-529.

Fontana, B. L., W. J. Robinson, C. W. Cormack and E. E. Leavitt, Jr.

1962 Papago Indian Pottery. University of 
Washington Press, Seattle.

Forman, S. L., R. Oglesby and R. S. Webb

2001 Temporal and spatial patterns of Holocene dune activity on the Great Plains of North America: megadroughts and climate links. Global and Planetary Change 29 (1-2):129.

Forman, S. L., R. Oglesby, V. Markgraf and T. Stafford

1995 Paleoclimatic significance of late Quaternary eolian deposition on the Piedmont and High Plains, central United States. Global and Planetary Change 11:35-55.

Forman, S. L., L. Marín, J. Gomez and J. Pierson

2008 Late Quaternary eolian sand depositional record for southwestern Kansas: Landscape sensitivity to droughts. Palaeogeography, Palaeoclimatology, Palaeoecology 265:107-120.

Frederick, C. D.

1993 Geomorphology. In Historic and Prehistoric Data Recovery at Palo Duro Reservoir, Hansford County, Texas, by J. M. Quigg, C. Lintz, W. N. Trierweiler, D. Owsley, and K. W. Kibler, pp. 75-116. Mariah and Associates, Inc., Mariah Technical Report 485, Austin.

1998 Late Quaternary Clay Dune Sedimentation on the Llano Estacado, Texas. Plains Anthropologist 43:137-155.

2010 Stratigraphic Overview of Upper West Amarillo Creek Valley. In Landis Property: Data Recovery at Three Prehistoric Sites (41PT185, 41PT186, and 41TP245) in Potter County, Texas, Volumes I and II, by J. M. Quigg, C. D. Frederick, and K. G. Luedecke, pp. 151-163. TRC Environmental Corporation, TRC Report No. 150832, Austin.

Fredlund, G. G. and L. L. Tieszen

1994 Modern Phytolith Assemblages from the North American Great Plains. Journal of
Biogeography 21:321-335.

Frison, G. C.

1970 The Glenrock Buffalo Jump, 48 CO304. Plains Anthropologist Memoir 7.

1973 The Wardell Buffalo Trap 48CO304: Communal Procurement in the Upper Green River Basin, Wyoming. Anthropological Papers of the Museum of Anthropology 48. University of Michigan, Ann Arbor.

1974 The Archaeology of the Casper Site, In The Casper Site, A Hell Gap Bison Kill on the High Plains, edited by G. C. Frison, pp. 1-122. Academic Press, New York.

1978a Prehistoric Hunters of the High Plains. Academic Press, New York.

1978b Animal Population Studies and Cultural Inference. In Bison Procurement and Utilization: A Symposium, edited by L. B. Davis and M. Wilson, pp. 44-52. Plains Anthropologist, Memoir 14.

Frison, G. C. and C. A. Reher

1970 Age Determination of Buffalo by Teeth Eruption and Wear. In The Glenrock Buffalo Jump, 48CO304, edited by G. C. Frison, pp. 46-50. Plains Anthropologist Memoir 7

Frison, G. C., M. Wilson, and D. J. Wilson

1976 Fossil Bison and Artifacts from an Early Altithermal Period Arroyo Trap in Wyoming. American Antiquity 41(1):2857.

Gale, S. J. and P. G. Hoare

1991 Quaternary Sediments: Petrographic Methods for the Study of Unlithified Rocks. London: Belhaven Press.

Galm, J. R.

1979 The Uncas Site: A Late Prehistoric Manifestation in the Southern Plains. Archaeological Research and Management Center, The University of Oklahoma. Research Series No. 5 
Gilman, P. A.

1983 Changing Architectural Forms in the Prehistoric Southwest. Unpublished Ph.D. dissertation, Department of Anthropology, University of New Mexico, Albuquerque.

1987 Architecture as Artifact: Pit Structures and Pueblos in the American Southwest. American Antiquity 52(3):538-564.

1997 Wandering Villagers: Pit Structures, Mobility and Agriculture in South eastern Arizona. Arizona State University, Anthropological Research Papers No. 49.

Gilmore, E. L.

1963 Minerals of Oklahoma: A Rockhound's Guide to the Gems and Minerals of Oklahoma. E. L. Gilmore Press, Tulsa.

Gould, C. N.

1907 Geology and Water Resources of the Western Portion of the Panhandle of Texas. U. S. Geological Survey, Water Supply Paper No. 191, Washington, D. C.

Graves, J.

2002 Texas Rivers. Texas Parks and Wildlife Press, Austin, Texas.

Grayson, D. K.

1978 Minimum Numbers and Sample Size in Vertebrate Faunal Analysis. American Antiquity 43(1):53-65.

1979 On the Quantification of Vertebrate Archaeofaunas. Advances in Archaeological Methods and Theory, edited by M. B. Schiffer, pp. 199-237. Academic Press, New York.

1984 Quantitative Zooarchaeology Topics in the Analysis of Archaeological Faunas. Academic Press, Orlando.

Green, F. E.

1967 Archaeological Salvage in the Sanford Reservoir Area. National Park Service Report \#14-10-0333-1126. Texas Tech
University, Lubbock.

1986 Report on the Archeological Salvage in the Sanford Reservoir Area. Publication 4. Panhandle Archeological Society, Amarillo.

Green, F. E. and J. H. Kelley

1960 Comments on Alibates Flint. American Antiquity 25(3):413-414.

Griffith, G., S. Bryce, J. Omernick and A. Rogers

2007 Ecoregions of Texas. Report prepared for Texas Commission on Environmental Quality, December 27, 2007.

Grinnel, G. B.

1961 Pawnee Hero Stories and Folk-Tails. University of Nebraska Press, Lincoln.

Grissino-Mayer, H. D., C. H. Baisan and T. W. Swetnam

1997 A 1,373 Year Reconstruction of Annual Precipitation for the Southern Rio Grande Basin. Manuscript on file with the Directorate of Environments, Natural Resources Division, Fort Bliss, Texas.

Gustavson, T. C.

1986 Geomorphic Development of the Canadian River Valley, Texas Panhandle: An Example of Regional Salt Dissolution and Subsidence. Geological Society of America Bulletin 97(4):459-472

1996 Fluvial and Eolian Depositional Systems, Paleosols, and Paleoclimate of the Upper Cenozoic Ogallala and Blackwater Draw Formations, Southern High Plains, Texas and New Mexico. Bureau of Economic Geology, Report of Investigations No. 239, The University of Texas at Austin, Austin.

Gustavson, T. C., R. J. Finley, R. W. Baumgardner, Jr.

1980 Preliminary Rates of Slope Retreat and Salt Dissolution along the Eastern Caprock Escarpment of the Southern High Plains and in the Canadian River Valley. In Geology and Geohydrology of the Palo Duro Basin, 
Texas Panhandle: A Report on the Progress of Nuclear Waste Isolation Feasibility Studies (1979), edited by T. C. Gustavson, M. W. Presley, C. R. Handford, R. J. Finley, S. P. Dutton, R. W. Baumgardner, Jr, K. A. McGillis, and W. W. Simpkins, pp. 7687. Bureau of Economic Geology, The University of Texas at Austin, Austin.

Habicht-Mauche, J., A. A. Levendosky and M. J. Schoeninger

1994 Antelope Creek Phase Subsistence: The Bone Chemistry Evidence. In Skeletal Biology in the Great Plains, Migration, Warfare, Health, and Subsistence, edited by D. W. Owsley and R. L. Jantz, pp. 291-304. Smithsonian Institution Press, Washington.

Hafez, E. S. E.

1969 Prenatal Growth. In Animal Growth and Nutrition, edited by E. S. E. Hafez and I. A. Dyer, pp. 21-39. Lee and Febiger, Philadelphia.

Haines, F.

1970 The Buffalo: The Story of American Bison and Their Hunters from Prehistoric Times to the Present. Thomas Y. Crowell, New York.

Hall, S. A.

1982 Late Holocene Paleoecology of the Southern Plains. Quaternary Research 17:391-407.

1988 Environment and Archaeology of the Central Osage Plains. Plains Anthropologist 33(120):203-218.

1990 Channel Trenching and Climate Change in the Southern U. S. Great Plains. Geology 18:342-346.

Hall, S. A. and C. Lintz

1984 Buried Trees, Water Table Fluctuations, and 3000 years of Changing Environment in West-Central Oklahoma. Quaternary Research 22:129-133.
Halloran, A. F.

1961 American Bison Weights and Measurements from the Wichita Mountains Wildlife Refuge. Proceedings of the Oklahoma Academy of Science 41:211-218.

1968 Bison (Bovidae) Productivity on the Wichita Mountains Wildlife Refuge, Oklahoma. The Southwestern Naturalist 13(1):23-26.

Haltenberger, M.

1913 On a Genetic System of Sand Dunes, Including Two New Types. Bulletin of the American Geographical Society 45(7):513515.

Hanson, P. R., A. F. Arbogast, W. C. Johnson, R. M. Joeckel and A. R. Young

2010 Megadroughts and Late Holocene Dune Activation at the Eastern Margin of the Great Plains, North-central Kansas, USA. Aeolian Research 1:101-110.

Haragan, D. R

1978 Precipitation climatology for the Texas High Plains. Texas Journal of Science 30:107-124.

Hard, R. J., R. P. Mauldin and G. R. Raymond

1996 Mano size, Stable Isotope Ratios, and Macrobotanical Remains as Multiple Lines of Evidence of Maize Dependence in the American Southwest. Journal of Archeological Methods and Theory 3(4):253-318.

Harrison, B. R.

1983 Field notes on file at Panhandle-Plains Historical Museum, Canyon.

Haugen, A. O.

1974 Reproduction in the Plains Bison. Iowa State Journal of Research 49(1):1-8

Haynes, G. H.

1932 A Report of the Excavations at Saddleback Ruin. Unpublished Master's thesis, Texas Technological Collage, Lubbock. 
Haynes, G.

1983 Frequencies of Spiral and Green-Bone Fractures on Ungulate Limb Bones in Modern Surface Assemblages. American Antiquity 48(1):102-114.

Hedges, R. E. M., C. Tiemei and R. A. Housley

1992 Results and Methods in the Radiocarbon Dating of Pottery. Radiocarbon 34(3):906915.

Hobbs, H. R.

1941 Texas Panhandle Ruins. El Palacio 48(6):121-128)

Hofman, J. L.

1978 The Development and Northern Relationships of Two Archeological Phases in the Southern Plains Subarea. In The Central Plains Tradition: Internal and External Relationships, edited by D. J. Blakeslee, pp. 6-35. Office of the State Archeologist, University of Iowa, Iowa City.

Hofman, J., L, L. C. Todd, and M. B. Collins

1991 Identification of Central Edwards Chert at the Folsom and Lindenmeier Sites. Plains Anthropologist 36(137):297-322.

Holden, W. C.

1929 Some Recent Explorations and Excavations in Northwestern Texas. Bulletin of the Texas Archeological and Paleontological Society 1:23-35.

1930 The Canadian Valley Expedition, Summer of 1930. Bulletin of the Texas Archeological and Paleontological Society 2:21-32.

1932 Recent Archeological Discoveries in the Texas Panhandle. Southwestern Social Sciences Quarterly 13(3):289-293.

1933 Expeditions at Saddleback Ruins. Bulletin of the Texas Archeological and Paleontological Society 5:39-52.
Holliday, V. T.

1985 Holocene Soil-geomorphological Relations in a Semi-arid Environment: The Southern High Plains of Texas. In Soils and Quaternary Landscape Evolution, edited by J. Boardman, pp. 325-357.

1995 Stratigraphy and Paleoenvironments of Late Quaternary Valley Fills on the Southern High Plains. Geological Society of America. Memoir 186.

2001 Stratigraphy and Geochronology of Upper Quaternary Eolian Sand on the Southern High Plains of Texas and New Mexico, United States. Geological Society of America Bulletin 113:88-108.

Holliday, V. T. and C. M. Welty

1981 Lithic Tool Resources of the Eastern Llano Estacado. Bulletin of the Texas Archeological Society 52:201-214.

Holliday, V. T. and B. L. Allen

1987 Geology and Soils. In Lubbock Lake: Late Quaternary Studies on the Southern High Plains, edited by E. Johnson, pp. 1421. Texas A\&M University Press, College Station.

Hornaday, W. T.

1971 The Extermination of the American Bison, with a Sketch of its Discovery and Life History, Smithsonian Report, United States National Museum, 1887:367-548. Shorey Book Store, Seattle.

Howells, R. G., R. W. Neck and H. D. Murray

1996 Freshwater Mussels of Texas. Texas Parks and Wildlife Department, Austin.

Huebner, J. A.

1991 Late Prehistoric Bison Populations in Central and Southern Texas. Plains Anthropologist 36(137):343-358.

Hughes, D. T.

1991 Investigations of the Buried City, Ochiltree County, Texas: With an Emphasis on the 
Texas Archeological Society Field Schools of 1987 and 1988. Bulletin of the Texas Archeological Society 60:107-148.

2001 Buried City Architecture and Settlement. Paper presented at the 67th Annual Meeting of the Society of American Archaeology, Denver.

2002 Buried City Ceramics, Ochiltree County, Texas. Paper presented at the 2002 Plains Anthropological Conference in Oklahoma City.

Hughes, D. T. and A. A. Hughes-Jones

1987 The Courson Archeological Projects, 1985 and 1986: A Final Report of the 1985 Investigations and Preliminary Report of the 1986 Work. Innovative Publishing, Inc., Perryton.

Hughes, J. T.

1962 Lake Creek: A Woodland Site in the Texas Panhandle. Bulletin of the Texas Archeological and Paleontological Society 32:65-84.

1969 Field Trip Record on file at PanhandlePlains Historical Museum, Canyon.

1977 Final Report on an Archaeological Survey of the Red Deer Creek Watershed in Gray, Roberts, and Hemphill Counties, Texas. Killgore Research Center, West Texas State University, Canyon.

1983 Field Trip Notes on File with PanhandlePlains Historical Museum, Canyon.

1991 Prehistoric Cultural Developments on the Texas High Plains. Bulletin of the Texas Archeological Society 60:1-57.

Hughes, J. T., H. C. Hood and B. P. Newman

1978 Archaeological Testing in the Red Deer Creek Watershed in Gray, Roberts, and Hemphill Counties, Texas. Archaeological Research Laboratory, Killgore Research Center, West Texas State University, Canyon.
Hughes, J. T., H. C. Hood, B. P. Newman and P. B. Hughes

1977 Final Report on an Archaeological Survey of the Red Deer Creek Watershed in Gray, Roberts, and Hemphill Counties, Texas. Archaeological Research Laboratory, Killgore Research Center, West Texas State University, Canyon.

Huhnke, M. H.

2001 Form and Function: The Bone Tools from Alibates Ruin \#28. Unpublished Master's thesis, Department of Anthropology, Wichita State University, Wichita.

Johnson, A. M. and A. E. Johnson

1998 The Plains Woodland. In Archaeology on the Great Plains, edited by W. R. Wood, pp. 201-234. The University Press of Kansas.

Johnston, C. S.

2003 Report to the Anthropology Department of The University of Oklahoma Concerning the Field Work carried on in the SlabHouse Site on the Stamper Ranch, South of Optima, Oklahoma in the Summer of 1934. Oklahoma Archeology 51(2):38-45.

Johnston, C. Stuart

1933 Slab House Sites in Texas County, Anthropology Field Notes. Journal on file at the Sam Noble Oklahoma Museum of Natural History, Norman.

1934 Filed Notes, Optima, Oklahoma, Archaeology-Book I, C. S. Johnston--July 1st, 1934-August 30, 1934 (Typed Version). On file at the Sam Noble Oklahoma Museum of Natural History, Norman.

1939 A Report on the Antelope Creek Ruin. Bulletin of the Texas Archeological and Paleontological Society 11:190-202.

Johnson, E. (editor)

1987 Lubbock Lake: Late Quaternary Studies on the Southern High Plains. Texas A\&M University Press, College Station. 
Katz, S. R. and P. Katz

1976 Archeological Investigations in Lower Tule Canyon, Briscoe County, Texas. Office of the State Archeologist Survey Report No. 16. Texas Historical Commission, Austin.

2004 A Mine of Information. Paper presented at the 40th Annual Meeting of the Southwestern Federation of Archeological Societies, Canyon.

2005 A Mine of Information. Abstract in Transactions of the 40th Regional Archeological Symposium for Southeastern New Mexico and Western Texas, pp. 9-10. Midland Archeological Society.

Keener, B.

1991 Plant Remains form Prehistoric Village Sites. Manuscript on file, Oklahoma Archeological Survey, University of Oklahoma, Norman

Kehoe, T. F and A. B. Kehoe

1960 Observations on the Butchering Technique at a Prehistoric Bison-Kill in Montana. American Antiquity 25(3):420-423.

Keller, J. E.

1975 The Black Dog Village Site: A Panhandle Aspect Manifestation in Hutchinson County, Texas. Texas Highway Department, Publication in Archeology, Highway Design Division, Report No. 5, Austin.

Kibler, K. W.

1998 Late Holocene Environmental Effects on Sandstone Rockshelter Formation and Sedimentation on the Southern Plains. Plains Anthropologist 43(164):173-186.

Kirk, D. R.

1970 Wild Edible Plants. Naturegraph Publishers, Healdsburg, CA.

Klein, R. G. and K. Cruz-Uribe

1984 The Analysis of Animal Bones from Archaeological Sites. University of Chicago Press, Chicago.
Kraft, K. C.

1997 The Distribution of Alibates Silicified Dolomite Clasts along the Canadian River. Current Research in the Pleistocene. 14:106-109.

Koch, W.

1935 The Age Order of Epiphyseal Union in the Skelton of the European Bison (Bos bonasus L.). The Anatomical Record 61:371-376.

Krieger, A. D.

1946 Cultural Complexes and Chronology in Northern Texas with Extension of Puebloan Dating to the Mississippi Valley. University of Texas Publication, No. 4640.

Krunze, H. L. and J. N. Lee

1968 Reconnaissance of the chemical quality of surface waters of the Canadian River Basin, Texas. Texas Water Development Board Report 86.

Kuchler, A. W.

1975 Potential Natural Vegetation in the Coterminous United States. American Geographical Society, New York.

Kuo, S.

1996 Phosphorus. In Methods of Soil Analysis, Part 3, Chemical Methods, pp. 869-919. Soil Science Society of America Book Series No. 5, Madison.

Kwiatkowski, S.

1992 The Rye Creek Flotation and Macrobotanical Analyses. In The Rye Creek Project: Archaeology in the Upper Tonto Basin. Volume 2: Artifact and Specific Analyses, pp. 325-375. Anthropological Papers No. 11. Center for Desert Archeology, Tucson, Arizona.

Larson, M. L.

1997 Housepits and Mobile Hunter-Gatherers: A Consideration of the Wyoming Evidence. Plains Anthropologist 42(161):353-369. 
Leechman, D

1951 Bone Grease. American Antiquity 16:355356.

Lehmer, D. J.

1948 The Jornada Branch of the Mogollon. University of Arizona, Social Science Bulletin No. 17. University of Arizona Press, Tucson.

1954 Archeological Investigations in the Oahe Dam Area, South Dakota, 1950-51. Bureau of American Ethnology, Bulletin No. 158. River Basin Surveys Papers No. 7. U.S. Government Printing Office, Washington.

Lepper, K. and G. F. Scott,

2005 Late Holocene aeolian activity in the Cimarron River valley of west-central Oklahoma. Geomorphology 70(1-2):42-52.

Lepper, K., N. Agersnap-Larsen and S. W. S. McKeever

2000 Equivalent dose distribution analysis of Holocene eolian and fluvial quartz sands from Central Oklahoma. Radiation Measurements 32:603-608.

Levendosky, A. A.

1987 A Dietary Analysis of Antelope Creek Phase Using Bone Chemistry Analyses to Test Dietary Models Based on Archeological Evidence and Environmental Reconstruction. Honors Paper for Bachelor of Arts, Harvard College, Cambridge.

Lewis, R.

1998 Nutritional Inference from PaleoPathological Comparison of the Footprint and Bonnell Skeletal Populations. Unpublished Master's thesis, Texas Tech University, Lubbock.

Lintz, C.

1976 The McGrath Site of the Panhandle Aspect. Bulletin of the Oklahoma Anthropological Society XXV:1-110.

1978a The Panhandle Aspect and Its Early
Relationship with Upper Republican. In The Central Plains Tradition: Internal Development and External Relationships, edited by D. Blakeslee, pp. 36-55. Office of the State Archaeologist of Iowa, Report 11, University of Iowa.

1978b Architecture and Radiocarbon Dating of the Antelope Creek Focus: A Test of Campbell's Model. Plains Anthropologist 23(82):319-328.

1979 Radiocarbon and Archaeomagnetic Dates from the Two Sisters Site, 34Tx-32, Texas County, Oklahoma. Oklahoma Anthropological Society Newsletter 27(6):19.

1982 An Overview of the Antelope Creek Focus. Transactions of the 17th Regional Archaeological Symposium for Southeastern New Mexico and Western Texas, pp. 37-56.

1984 The Plains Villagers: Antelope Creek. In The Prehistory of Oklahoma, edited by R. E. Bell, pp. 325-346. Academic Press, Orlando.

1986 Architecture and Community Variability within the Antelope Creek Phase of the Texas Panhandle. Studies in Oklahoma's Past Number 14. Oklahoma Archeological Survey, Norman.

1989 The Upper Canark Regional Variant: Comparison and Contrast of the Antelope Creek and Apishapa Phases of the Southwestern Plains. In In Light of the Past Experience: Papers in Honor of Jack T. Hughes, compiled and edited by B. C. Roper, pp. 271-294. Panhandle Archeological Society Publication No. 5. Aquamarine Publications, Clarendon.

1990 Landergin Mesa: The 1984 Phase II Field Results. Manuscript on file at the Texas Historical Commission, Austin. 
1991 Texas Panhandle-Pueblo Interactions from the Thirteenth through the Sixteenth Century. In Farmers, Hunters, and Colonists, edited by K. A. Spielmann, pp. 89-106. University of Arizona Press, Tucson.

1997 The 1959 Norpan Excavations at the Cottonwood Creek Ruins, 41HC141 (A119), Hutchinson County, Texas. Transactions of the 32nd Regional Archeological Symposium for Southeastern New Mexico and Western Texas, 32:27-74.

1998 The Occurrence and Prehistoric Aboriginal Utilization of Opalite in the Palo Duro Creek Vicinity of the Texas Panhandle. Bulletin of the Oklahoma Anthropological Society KLVI:107-126.

2001 Architecture and Chronology at Landergin Mesa, Oldham County, Texas. La Tierra 28(2):10-39.

2003a The Stamper Site, 34TX1, Texas County Oklahoma. Part I: The Historical Context and Excavators. Oklahoma Archeology: Journal of the Oklahoma Anthropological Society 51(2):13-35.

2003b The Stamper Site, 34TX1, Texas County Oklahoma. Part II: Archaeological Contribution to the Plains. Oklahoma Archeology: Journal of the Oklahoma Anthropological Society 51(3):14-38.

2003c The Stamper Site, 34TX1, Texas County Oklahoma. Part III: The Architecture and Features Excavated by C. Stuart Johnston. Oklahoma Archeology: Journal of the Oklahoma Anthropological Society 51(4):14-46.

2004 The Stamper Site, 34TX1, Texas County Oklahoma. Part IV: The Architecture and Features Excavated by Fred Carder Jr. Oklahoma Archeology: Journal of the Oklahoma Anthropological Society 52(1):16-52.
2005 Appendix B, Prehistoric Ceramic Assemblage from 41PT109, Potter County, Texas. In Investigations at an Antelope Creek Phase Isolated Homestead (41PT109), by A. Weinstein, pp. 108-130. Unpublished Master's thesis, Department of Anthropology, Texas State University, San Marcos.

2009 Avian Procurement and Use by Middle Ceramic Period People on the Southern High Plains: A Design for Investigations. Bulletin of the Texas Archeological Society 80:85-131.

2010 Prehistoric Ceramic Assemblage from 41PT109, Potter County, Texas: The 2004 and 2005 Field School Seasons. Manuscript on file with author.

2011 A Preliminary Report on the 1960 Excavations at the Franklin Ranch Site, 41GY80, Gray County, Texas. Oklahoma Anthropological Society Bulletin 58:47-60.

Lintz C. and K. Reese-Taylor

1997 Migrations, Trade, or Replicated Ceramics: Petrographic Study of Collard Rim Sherds from the Texas Panhandle. Bulletin of the Texas Archeological Society 68:273-300.

Livingood, P. C. and A. S. Cordell

2009 Point/Counter Point: the accuracy and feasibility of sample composition and analysis of ceramic thin sections. Journal of Archeological Science 36:867-872.

Loetterle, G. J.

1937 The Micropaleontology of the Niobrara Formation in Kansas, Nebraska, and South Dakota. Nebraska Geological Survey, Bulletin 12, Second Series, Lincoln.

Lorrain, D.

1968 Analysis of the Bison Bones from Bonfire Shelter. In Bonfire Shelter: A Stratified Bison Kill Site, Val Verde County, Texas, by D. S. Dibble and D. Lorrain, pp. 77132. Miscellaneous Papers No. 1, Texas 
Memorial Museum, The University of Texas at Austin.

Lott, D. F.

1974 Sexual and Aggressive Behavior of Adult Male American Bison (Bison bison). In The Behavior of Ungulates and its Relation to Management, Vol. 1, edited by V. Giest and F. Walther, pp. 382-394. Publication 24. Morges, Switzerland: International Union for Conservation of Nature and Natural Resources.

Lowery, E. J.

1932 The Archaeology of the Antelope Creek Ruin. Unpublished Master's thesis, Texas Technological Collage, Lubbock.

Lowie, R. H.

1954 Indians of the Plains. American Museum Science Books, The American Museum of Natural History, The Natural History Press, New York.

Loy, T. H.

1994 Residue Analysis of Artifacts and Burned rocks from the Mustang Branch and Barton Sites (41HY209 and 41HY202). In Archaic and Late Prehistoric Human Ecology in the Middle Onion Creek valley, Hays County, Texas, Volume 2 by R. A. Ricklis and M. B. Collins, pp. 607-627. Studies in Archeology 19, Texas Archeological Research Laboratory, The University of Texas at Austin.

Lyman, R. L.

1982 The Taphonomy of Vertebrate Archaeofaunas: Bone Density and Differential Survivorship of Fossil Classes. Unpublished Ph.D. dissertation, Department of Anthropology, University of Washington.

1984 Bone Density and Differential Survivalship of FossilClasses. JournalofAnthropological Archaeology 3:259-299.

1985 Bone Frequencies: Differential Transportation, In Situ Destruction, and the
MGUI. Journal of Archaeological Science 12:221-236.

1987 Archaeolofaunns and Butchery Studies: A Taphonomic Perspective. In Advances in Archaeological Method and Theory, Vol. 10, edited by M. B. Schiffer, pp. 249-337. Academic Press, New York.

1992 Anatomical Considerations of Utility Curves in Zooarchaeology. Journal of Archaeological Science 19:7-22.

Lynn, A. R.

1982 Replication of Borger Cordmarked Pottery, Paper for Archaeological Reporting, West Texas State University, Manuscript in possession of the author.

1986 Tecovas Lithic Resources in the Texas Panhandle. Manuscript on file at West Texas State University, Canyon and author.

2004 Making Cordmarked Pottery. Texas Beyond History website (http:// www.texasbeyondhistory.net/village/ cordmarked/index.html)

Machette, M.

1986 Calcium and Magnesium Carbonates. In Field and Laboratory Procedures Used in Soil Chronosequence Studies, edited by M. J. Singer and P. Janitzky, pp. 30-33. U.S. Geological Survey Bulletin 1648, United States Government Printing Office, Washington D.C.

MacNeish, R. S., G. Cunnar, G. Jessop and P. Wilner 1993 A Summary of the Paleo-Indian Discoveries in Pendejo Cave near Orogrande, New Mexico. Annual Report of AFAR for 1993. Andover Foundation for Archaeological Research, Andover.

Magdoff, F. R., M. A. Tabatabai and E. D. Hanlon 1996 Soil Organic Matter: Analysis and Interpretation. Soil Science Special Publication. No. 46:21-31. 
Magne, M. P.

1989 Lithic Reduction Stages and Assemblage Formation Processes. In Experiments in Lithic Technology, edited by D. S. Amick and R. P. Mauldin, pp.15-31. BAR International Series 528, Oxford.

Maki, D.

2005 A Geophysical Investigation of Two Prehistoric Archeological Sites Located in the West Pasture of John Erickson's Canadian River Ranch. Letter Report, Archaeo-Physics Report of Investigations \#91, Minneapolis.

Malainey, M. E.

2011 A Consumer's Guide to Archaeological Science: Analytical Techniques. Springer Science+Business Media, New York.

Mallouf, R. J.

1989 Quarry Hunting with Jack Hughes: Tecovas Jasper in the South Basin of the Canadian River, Oldham County, Texas. In In Light of Past Experience: Papers in Honor of Jack T. Hughes, edited by B. C. Roper, pp. 307-326. Panhandle Archeological Society, Publication No. 5.

Mandelbaum, D. G.

1940 The Plains Cree. Anthropological Papers of the American Museum of Natural History, Vol. 37, Pt. II, pp. 154-316. American Museum of Natural History, New York.

Marlow, C. B., L. R. Irby and J. E. Norland

1984 Optimum Carrying Capacity for Bison in Theodore Roosevelt National Park. Montana State University, Bozeman.

Marmaduke W. S. and H. Witsett 1975

1975 Reconnaissance and Archeological Studies in the Canadian River Valley. In Canadian Breaks: A Natural Area Survey Part VII of VIII, pp. 68-126. Division of Natural Resources and Environment, The University of Texas at Austin, Austin.
Martin, A. C., H. S. Zim and A. L. Nelson

1951 American Wildlife and Plants: A Guide to Wildlife Food Habits. Dover Publications, Inc., New York.

Mason, A. J.

1929 The Texas Expedition. University of Pennsylvania Museum Journal 22:318-338.

Matchen, P. M.

2002a Mobility and the Organization of Stone Tool Technology: a Comparison of Tucker Blowout (34TX71) and the Little Deer Site (34CU10) in Western Oklahoma. Unpublished Master's thesis, Department of Anthropology, University of Oklahoma, Norman.

2002b Mobility and the Organization of Stone Tool Technology: a Comparison of Tucker Blowout (34TX71) and the Little Deer Site (34CU10) in Western Oklahoma. Bulletin of the Oklahoma Anthropological Society 50:31-100.

Matthews, W. H. III

1969 The Geologic Story of Palo Duro Canyon. Guidebook 8. Bureau of Economic Geology, The University of Texas at Austin, Austin.

Mauldin, R. P.

1983 An Inquiry into the Past: Basketmaker II Settlement on Northeastern Black Mesa, Arizona. Unpublished Master's thesis, Department of Anthropology, University of Texas, Austin.

McDonald, J. N.

1981 North American Bison: Their Classification and Evolution. University of California Press, Berkeley.

McHugh, T.

1958 Social Behavior of the American Buffalo (Bison bison bison). Zoologica 43(1):1-40.

1972 The Time of the Buffalo. Alfred A. Knopf, New York. 
Medsger, O. P.

1974 Edible Wild Plants. Collier Macmillan Publishing Company, New York.

Mehlich, A.

1978 New extractant for soil test evaluation of phosphorus, potassium, magnesium, calcium, sodium, manganese, and zinc. Communications in Soil Science and Plant Analysis 9:477-492.

Meier, H. A.

2007 An Evaluation of Antelope Creek Phase Interaction Using INAA. Unpublished Master's thesis, Texas State University, San Marcos.

Meisser, B.

2005 Appendix C: Vertebrate Faunal Remains from Cross Bar Ranch (41PT109). In Investigations at an Antelope Creek Phase Isolated Homestead (41PT109), by A. Weistein, pp. 132-137. Unpublished Master's thesis, Department of Anthropology, Texas State University, San Marcos.

Moorehead, W. K.

1920 The Origin and Development of the Pueblo Cliff Dweller Cultural: A Preliminary Paper on Explorations Recently Conducted. Andover.

1931 Archaeology of the Arkansas River Valley. Phillips Academy, Andover.

Morlan, R. E.

1991 Bison Carpal and Tarsal Measurements: Bull verses Cows and Calves. Plains Anthropologist 36(136):215-227.

Mosby, H. S.

1960 Manual of Game Investigational Techniques. The Wildlife Society, Ann Arbor, Michigan.

Munsell

1988 Munsell Soil Color Charts. Macbeth Division of Kollmorgen Instruments Corporation, Baltimore.
Munson, P. J., P. W. Parmalee and R. A. Yarnell

1971 The Subsistence Ecology of Scovill, a Terminal Middle Woodland Village. American Antiquity 36(4):410-431.

Nabokov, P. and R. Easton

1990 Native American Architecture. Oxford University Press, Inc.

Natural Resources Conservation Service

n.d. Common Rangeland Plants of the Texas Panhandle.

Newcomb, Jr., W. W.

1961 The Wichita and Affiliated Tribes of Kansas, Oklahoma, and Texas.

Nicholson, R. A.

1993 A Morphological Investigation of Burnt Animal Bone and an Evaluation of its Utility in Archaeology. Journal of Archaeological Science 20:411-428.

Norland, J. E.

1984 Habitat Use and Distribution of Bison in Theodore Roosevelt National Park. Unpublished Master's thesis, Montana State University, Bozeman.

Northcutt, J. D.

1981 Test Excavations at the Job Corps Site 34-CM-2B: Quartz Tools from the Wichita Mountains in Southwestern Oklahoma. Report prepared for the U. S. Fish and Wildlife Service, Albuquerque, New Mexico. Museum of the Great Plains, Lawton.

Olson, C. G. and D. A. Porter

2002 Isotopic and Geomorphic Evidence for Holocene Climate, Southwestern Kansas. Quaternary International 87:29-44.

O’Malley, N.

1981 A Petrographic Analysis of Late Woodland Ceramics from the Sperry Site, Jackson County, Missouri. Plains Anthropologist 26-93:241-249. 
Owsley, D. W.

1989 Human Skeletal Samples in the Southern Great Plains. In From Clovis to Comanchero: Archaeological Overview of the Southern Great Plains, by J. L. Hofman, R. L. Brooks, J. S. Hays, D. W. Owsley, R. L. Jantz, M. K. Marks, and M. H. Manheim, pp.111-122. Arkansas Archaeological Survey Research Series 35, Fayetteville.

Owsley, D. W. and R. W. Mann

1990 An American Indian Skeleton with Clubfoot from the Cabin Burial Site (A1184), Hemphill County, Texas. Plains Anthropologist 35(128):93-101.

Page, K. J., A. J. Dare-Edwards, J. W. Owens, P. S. Frazier, J. Kellett, and D. M. Price

2001 TL chronology and stratigraphy of riverine source-bordering sand dunes near Wagga Wagga, New South Wales, Australia. Quaternary International 83-85:187-193.

Parker, D. G.

2002 Results of X-Radiographic Analysis. In Native American Ceramics of Eastern Colorado by P. B. Ellwood, pp. 111-113. Natural History Inventory of Colorado, Number 21, University of Colorado Museum.

Parry, W. J. and R. L. Kelly

1987 Expedient Core Technology and Sedentism. In The Organization of Core Technology, edited by J. K. Johnson and C. A. Morrow, pp. 285-304. Westview Press, Boulder.

Patton, L. T.

1923 Geology of Potter County, Texas. Bureau of Economic Geology, Bulletin 2330, University of Texas, Austin.

Penden, D. G.

1976 Botanical Composition of Bison Diets on Short-Grass Plains. The American Midland Naturalist 96(1):225-229.

Penden, D. G., G. M. Van Dyne, R. W. Rive and R. M. Hansen

1974 The Tropic Ecological of Bison bison L. on Shortgrass Plains. Journal of Applied Ecology 11:489-498.

Perry, L. and J. M. Quigg

2011 Starch Remains and Stone Boiling in the Texas Panhandle, Part I: The Pipeline, Corral, and Pavilion Sites. Plains Anthropologist 56(218):95-107.

Perry, L., D. Sandweiss, D. R. Piperno, K. Rademaker, M. Malpass, A. Umire and P. de la Vera

2006 Early Maize Agriculture and Interzonal Interaction in Southern Peru. Nature 440(2):76-78.

Perttula, T. K. and C. Lintz

1995 Prehistoric and Protohistoric Ceramics from the Lower Plains, Caprock Canyonlands, and Texas Panhandle. In Prehistoric and Historic Aboriginal Ceramics in Texas. Bulletin of the Texas Archeological Society 66:203-210.

Perttula, T. K., S. A. Iruegas and H. Neff

2003 Caddoan Pottery in Central Texas: Chemical Analyses of Ceramics from Fort Hood and Vicinity. United States Army Fort Hood, Archeological Resource Management Series, Research Report No. 51.

Peter, D. E., R. S. Procter and M. M. Green (editors) 1997 Adaptations within the Lower Rolling Plains of Northcentral Texas, Crowell Reservoir, Foard County, Texas. Miscellaneous Report of Investigations, Number 122, GeoMarine, Inc., Plano.

Philips, W.

2000 Appendix A, Botanical Inventory. In Phase II Archeological Testing: Landis Property, Potter County, Texas, by C. M. Haecker. National Park Service, Intermountain Support Office, Anthropology Program, Santa Fe, New Mexico for the Bureau of Land Management, Helium Operations Unit, Amarillo, Texas. 
Piperno D. R. and I. Holst

1998 The Presence of Starch Grains on Prehistoric Stone Tools from the Humid Neotropics: Indications of Early Tuber Use and Agricultural in Panama. Journal of Archeological Science 25:765-776.

Piperno, D. R., A. J. Ranere, I. Holst and P. Hansell. 2000 Starch Grains Reveal Early Root Crop Horticulture in the Panamanian Tropical Forest. Nature 407:894-897.

Quigg, J. M.

1997 The Sanders Site (41HF128): A Single Event Late Archaic Camp/Bison Processing Site Hansford County, Texas. TRC Mariah Associates Inc., Technical Report No. 19751.

Quigg, J. M. and G. Smith

2005 Assessment of 41RB112, Roberts County, Texas: Testing Phase Interim Report. Technical Report No. 3721. TRC Environmental Corporation, Austin. Submitted to Texas Department of Transportation, Environmental Affairs Division, Austin.

Quigg, J. M., M. T. Boulanger and M. Glascock 2011b Geochemical Characterization of Tecovas and Alibates Source Samples. Plains Anthropologist 56(219):121-141).

Quigg, J. M., P. M. Matchen, C. Frederick and D. Maki

2007 Final Data Recovery at the Long View Site (41RB112), Roberts County, Texas: Interim Report. TRC Environmental Corporation, TRC Project No. 46557, Austin. Submitted to Texas Department of Transportation, Environmental Affairs Division, Austin.

Quigg, J. M., P. M. Matchen, R. A. Ricklis and C. D. Frederick

2007 Preliminary Final Research Design: Research Questions for the Long View Site (41RB112). TRC Environmental Corporation, Austin. Submitted to Texas Department of Transportation, Environmental Affairs Division, Austin.
Quigg, J. M., C. D. Frederick, P. M. Matchen and K. G. DuBois

2010 Landis Property: Data Recovery at Three Prehistoric Sites (41PT185, 41PT186, and 41TP245) in Potter County, Texas, Volumes $I$ and II. TRC Environmental Corporation, TRC Report No. 150832, Austin.

Quigg, J. Michael, P. M. Matchen, C. D. Frederick, and R. A. Ricklis

2011a Root-Be-Gone(41YN452): DataRecovery of Late Archaic Components in Young County, Texas. Two Volumes. Texas Department of Transportation, Environmental Affairs Division, Archeological Studies Program, Report No. 135 and TRC Environmental Corporation, TRC Technical Report No. 171219, Austin.

Quigg, J. M., C. Lintz, F. M. Oglesby, A. C. Earls, C. D. Frederick, W. N. Trierweiler, D. Owsley and K. W. Kibler

1993 Historic and Prehistoric Data Recovery at Palo Duro Reservoir, Hansford County, Texas. Mariah Associates, Technical Report 485, Austin.

Raab, H. A.

2005 Archaeological Survey in the Mullinaw Burn Unit, Lake Meredith National Recreation Area, Potter County, Texas. Draft Report on file with the National Parks Service.

Raisz, E.

1957 Landforms of the United States. Sixth edition of privately printed map. Cambridge, Massachusetts.

Ralph, E. K., H. N. Michaels and M. C. Han

1974 Radiocarbon Dates and Reality. Archaeology of Eastern North America 2(1):1-20.

Reece-Taylor, K.

1993a Petrographic Analysis. In Historic and Prehistoric Data Recovery at Palo Duro Reservoir, Hansford County, Texas, by J. M. Quigg, C. Lintz, F. M. Oglesby, A. C. Earls, C. D. Frederick, W. N. Trierweiler, D. Owsley and K. W. Kibler, pp. H-1 through 
H-13. Mariah Associates, Technical Report 485, Austin.

1993b Appendix I, Petrographic Studies of Ceramic Pastes. In Cultural Resource Investigations in the O. H. Ivie Reservoir, Concho, Coleman, and Runnels Counties, Texas, by A. C. Treece, C. Lintz, W. N. Trierweiler, J. M. Quigg and K. A. Miller, pp. I-1 through I-11. Volume IV Data Recovery Results from Ceramic Sites. Mariah Associates, Inc., Technical Report 346-IV, Austin.

1995a Petrographic Analysis of a Toyah Phase Ceramic Assemblage. In The Rush Site (41TG346): A Stratified Late Prehistoric Local in Tom Green County, Texas, by J. M. Quigg and J. Peck, pp. F-1through F-16. Mariah Associates, Inc., Technical Report No. 816C, Austin.

1995b Petrographic Analysis of Ceramic ThinSections. In NRHP Significance Testing of 57 Prehistoric Archeological Sites on Fort Hood, Texas, edited by J. T. Abbott and W. N. Trierweiler, pp. E-1 through E-11. 2 Vols. Archeological Resource Management Series, Research Report No. 34. United States Army, Fort Hood, Texas.

Reece-Taylor, K., J. Hageman and Robert A. Ricklis 1994 Preliminary Paste Analyses of Ceramic Samples from the Mustang Branch Site (41HY209) and Barton Site (41HY202). In Archaic and Late Prehistoric Human Ecology in the Middle Onion Creek Valley, Hays County, Texas, by R. A. Ricklis and M. B. Collins, pp. 549-568. 2 Vols. Studies in Archeology 19. Texas Archeological Research Laboratory, The University of Texas at Austin.

Reeves, C. C.

1976 Quaternary Stratigraphy and Geological History of the Southern High Plains, Texas and New Mexico. In Quaternary Stratigraphy of North America, edited by W. C. Mahaney pp. 213-234. Stroudsburg,
Pennsylvania, Dowden, Hutchinson and Ross, Inc.

Reher, C. A.

1970 Population Dynamics of the Glenrock Bison Bison Population. In The Glenrock Bufalo Jump, 48 CO 304, by G. Frison, pp. 51-55. Plains Anthropologist Memoir 7.

1973 The Wardell Bison bison Sample: Population Dynamics and Archaeological Interpretation. In The Wardell Buffalo Trap 48SU301: Communal Procurement in the Upper Green River Basin, Wyoming, by G. C. Frison, pp. 89-105. Anthropological Papers No. 48 Museum of Anthropology, University of Michigan, Ann Arbor.

1974 Population Study of the Casper Site Bison. In The Casper Site: A Hell Gap Bison Kill on the High Plains, edited by G. C. Frison, pp. 113-124. Academic Press, Inc., New York.

Reher, C. A. and G. C. Frison

1980 The Vore Site, 48CK302, A Stratified Buffalo Jump in the Wyoming Black Hills. Plains Anthropologist Memoir 16.

Retuerto, R. and F. I. Woodward

1992 Effects of windspeed on the growth of and biomass allocation of white mustard Sinapis alba L. Oecologia 92:113-123.

Rice, P. M.

1987 Macanche Island, El Peten, Guatemala: Excavation, Pottery, and Artifacts. University of Florida Press, Gainesville, Florida.

Rich, J. and S. Stokes

2011 A 200,000-year record of late Quaternary Aeolian Sedimentation on the Southern High Plains and nearby Pecos River Valley, USA. Aeolian Research 2:221-240.

Ricklis, R. A.

2011 Measurements of prehistoric archeological specimens of Gahagan Bifaces, Friday 
Bifaces, and Harahey Knives curated at TARL, and TxDOT replicated examples of those three types, with an assessment of the analytical suitability of the replicated specimens: Deliverable for WA 57104SA003, Task A. Letter Report submitted to Jason W. Barrett, PhD., TxDOT Lead Archeologist, dated December 13, 2011.

Robbins, C. T. and B. L. Robbins

1979 Fetal and Neonatal Growth Patterns and Material Reproductive Effort in Ungulates and Subungulates. The American Naturalist 101-114.

Robinson, R. C.

2001 Investigating Agricultural Dependence at Landergin Mesa (41OC2). Unpublished Master's thesis, Division of Behavioral and Cultural Sciences, University of Texas at San Antonio.

Roe, F. G.

1972 The North American Bison. David and Charles, Newton Abbot.

Rogers, M. B., K. Faehndrich, B. Roth, and G. Shear 2010 Cesium magnetometer surveys at a Pithouse Site near Silver City, New Mexico. Journal of Archaeological Science 37:1102-1109.

Roper, D. C. and M. J. Adair

2011 Interpreting AMS Radiocarbon Age Determinations from Selected Central Plains Tradition Sites. Plains Anthropologist 56(217):3-22.

Sala, O. E., W. J. Parton, L. A. Joyce, and W. K. Lauenroth

1988 Primary Production of the Central Grassland Region on the United States. Ecology 69(1):40-45.

Saunders, R.

1973 The Zimms Site, A Late Prehistoric House Site in Western Oklahoma. Oklahoma Anthropological Society Newsletter 21(6):78.
Schiffer, M. B.

1986 Radiocarbon Dates and the "Old Wood" Problem: The Case of the Hohokam Chronology. Journal of Archeological Science 13:13-30.

Schmidt-Couzzourt, B.

1983 The Chicken Creek Site: Archeological Testing in the Lake Meredith Recreation Area, Pottery County, Texas. United States Department of the Interior, Bureau of Reclamation, Southwest Region, Amarillo.

Schneider, F.

1969 The Roy Smith Site, Bv-14, Beaver County, Oklahoma. Bulletin of the Oklahoma Anthropological Society 18:119-179.

Schoeneberger, P. J., D. A. Wysocki, E. C. Benham, and W. D. Broderson, (editors)

2002 Field Book for Describing and Sampling Soils. Version 2.0. Natural Resources Conservation Service, National Soil Survey Center, Lincoln.

Schoolcraft, H. R.

1854 Historical and Statistical Information Respecting the History, Condition, and Prospects of Indian Tribes of the United States, Vol. 4. Lippencott and Co., Philadelphia.

Schwartz, C. C. and J. E. Ellis

1981 Feeding Ecology and Niche Separation in some Native and Domestic Ungulates on the Shortgrass Prairie. Journal of Applied Ecology 18:343-353.

Scudday, J. F. and L. F. Scudday

1975 A Preliminary Survey of the Vertebrate Fauna of the Upper Canadian Breaks Area. In Canadian Breaks: A Natural Area Survey Part VII of VIII, pp. 59-67. Division of Natural Resources and Environment, The University of Texas at Austin.

Sellers, E. H., W. S. Adkins and F. B. Plummer

1932 The Geology of Texas, Volume I. Bureau of Economic Geology. The University of 
Texas, Austin.

Selva, S. B.

1976 A biostratigraphic study of late Tertiary freshwater diatoms from the Ogallala of western Kansas. Unpublished Ph.D. dissertation, Department of Botany and Plant Pathology, Iowa State University, Ames.

Seni, S. J.

1980 Sandy-Body Geometry and Depositional Systems, Ogallala Formation, Texas. Bureau of Economic Geology, The University of Texas at Austin, Austin.

Seyffert, K.

2000 Birds of the Texas Panhandle. Texas A\&M University Press, College Station.

2001 Birds of the High Plains and Rolling Plains of Texas: A Field Checklist. Texas Parks and Wildlife Department, Austin.

Shackley

2005 Obsidian: Geology and Archaeology in the North American Southwest. University of Arizona Press, Tucson.

Shaeffer, J. B.

1958 The Alibates Flint Quarry, Texas. American Antiquity 24:189-191.

Shaw, J. H. and T. S. Carter

1989 Calving Patterns Among American Bison. Journal of Wildlife Management 53(4):896898.

Shepard, A. O.

1971 Ceramics for the Archaeologist. Publication No. 609. Carnegie Institution of Washington, Washington D.C.

Sikes, S. and J. Smith

1975 A Vegetation Study of the Canadian Breaks. In Canadian Breaks: A Natural Area Survey Part VII of VIII, pp. 46-67. Division of Natural Resources and Environment, The University of Texas at Austin.
Smiley, F. E.

1985 The Chronometrics of Early Agricultural Sites in Northeastern Arizona: Approaches to the Interpretations of Radiocarbon Dates. Unpublished Ph.D. dissertation, University of Michigan.

Smith, R. L.

1989 Post Holes are for Posts. In Light of the Past Experience: Papers in Honor of Jack T. Hughes, compiled and edited by B. C. Roper, pp. 359-365. Panhandle Archeological Society Publication No. 5. Aquamarine Publications, Clarendon.

Smith, B. N. and W. V. Brown

1973 The Kranz Syndrome in the Gramineae as Indicated by Carbon Isotopic Ratios. American Journal of Botany 60(6):505-513.

Smith, C. S. and W. Martin

2001 Sego Lilies and Prehistoric Foragers: Return Rates, Pit Ovens, and Carbohydrates. Journal of Archaeological Science 28:169183.

Sollberger, J. B.

1971 A Technological Study of Bevelled Knives. Plains Anthropologist 16:209-18.

Speth, J. D.

1983 Bison Kills and Bone Counts: Decision Making by Ancient Hunters. University of Chicago Press, Chicago.

1991 Some Unexplored Aspects of Mutualistic Plains-Pueblo Food Exchange. In Farmer, Hunters, and Colonists: Interaction between the Southwest and the Southern Plains, edited by K. A. Spielmann, pp. 18-35. The University of Arizona Press, Tucson.

Spielmann, K. A.

1991 Interactions among Nonhierarchical Societies. In Farmers, Hunters, and Colonists, edited by K. A. Spielmann, pp. 1-17. University of Arizona Press, Tucson. 
Stien, C. M.

2006 Kansas Lithic Resources. In Kansas Archaeology, edited by R. J. Hoard and W. E. Banks, pp. 265-282. The University Press of Kansas.

Stiger, M.

1998 The Role of Grass Seed in Southwestern Archaic Subsistence. Southwestern Lore Journal of Colorado Archaeology 64(1):2238.

Studer, F.

n.d. Chimney Rock Ruin, No. 51. Preliminary Report. Manuscript on file at the National Park Service Office, Late Meredith. Studer files no. 208.

1931 Archaeological Survey and of the North Panhandle of Texas. Bulletin of the Texas Archeological and Paleontological Society 3:70-75.

1934 Texas Panhandle Culture Ruin No. 55. Bulletin of the Texas Archeological and Paleontological Society 6:80-96.

Suhm, D. A. and E. B. Jelks

1962 Handbook of Texas Archeology: A Cumulative Compendium of Type Descriptions. The Texas Archeological Society, Special Publication, Number One and The Texas Memorial Museum, Bulletin Number Four, Austin.

Suhm, D. A., A. Krieger and E.B. Jelks

1954 An Introductory Handbook of Texas Archaeology. Bulletin of the Texas Archaeological Society, Vol. 25.

Summers, D.

1977 Native American Burials: The Texas Panhandle. Unpublished Master's thesis, Texas Tech University, Lubbock.

Texas Department of Transportation

2010a TxDOT Lithic Protocol Version 2.1, Chipped Stone Analytical Protocol, TxDOT Archeological Studies Program, On File with Environmental Affairs Division, Texas Department of Transportation, Austin.

2010b TxDOT Ceramic Standards and Guidelines, Version 2.0 (3/11/10). On File with Environmental Affairs Division, Texas Department of Transportation, Austin.

Thurmond, J. P. and D. G. Wyckoff

1994 Some surprising dune dates on the Washita. Newsletter of the Oklahoma Anthropological Society 42(6):4-5.

1996 A dated eolian sequence on the Dempsey Divide. Newsletter of the Oklahoma Anthropological Society 44(2):6-8.

1999 Paleoclimate and Archeology in far Western Oklahoma: Intermittent Habitation of a Climatological Marginal Region, and the Evidence for a 400 Year Rainfall Cycle Operating at least Since the Last Glacial Maximum. Paper presented at the 70th annual meeting of the Texas Archeological Society, Fort Worth, Texas.

2008 Prehistory and Past Environments of the Dempsey Divide. http://www.geocities. com/dempseydiv/Text.htm.

Tieszen, L. L., L. Stretch, and J. V. Kooi

1998 Stable Isotopic Determination of Seasonal Dietary Patterns in Bison at Four Preserves Across the Great Plains. In International Symposium on Bison Ecology and Management, edited by L. R. Irby and J. E. Knight, pp. 130-140. Bozeman.

Todd, L. C.

1986 Determination of Sex of Bison Upper Forelimb Bones: The Humerus and Radius. The Wyoming Archaeologist 29(1-2):109124.

1987a Analysis of Kill-Butchery Bonebeds and Interpretations of Paleoindian Hunting. In The Evolution of Human Hunting, edited by M. H. Nitecki and D. V. Nitecki, pp. 225266. Plenum Press, New York. 
1987b Taphonomy of the Horner II Bone Bed. In The Horner Site, Type Site of the Cody Complex, edited by G. C. Frison and L. C. Todd, pp. 107-198. Academic Press, Orlando.

Todd, L. C. and D. J. Rapson

1988 Long Bone Fragmentation and Interpretation of Faunal Assemblages: Approaches to Comparative Analysis. Journal of Archaeological Science 15:307-325.

Tunnell, C. D.

2006 Child of the Caprock. In Plains Archaeology's Past: A Collection of Personal Narratives, compiled and edited by M. F. Hawley and V. A. Wulfkuhle, Plains Anthropologist 51(200):733-744. Special Issue.

Turner, E. S., and T. R. Hester

1999 A Field Guide to Stone Artifacts of Texas Indians. 3rd edition. Houston: Gulf Publishing Company.

Valastro, S., E. M. Davis and A. Varela

1977 University of Texas at Austin Radiocarbon Dates XI. Radiocarbon 19(2):280-325.

Vehik, S. C.

1977 Bone Fragments and Bone Grease Manufacturing: A review of Their Archaeological Use and Potential. Plains Anthropologist 22(77):169-182.

2007 To Decorate of Not To Decorate: Ceramics in the Little River Focus of Central Kansas. In Plains Village Archaeology: Bison Hunting Farmers in the Central and Northern Plains, edited by S. A. Ahler and M. Kay, pp. 193-209. The University of Utah Press, Salt Lake City.

Vehik, S. C. and T. G. Baugh

1994 Prehistoric Plains Trade. In Prehistoric Exchange Systems in North America, edited by T. G. Baugh and J. E. Erickson, pp. 249274. Plenum Press, New York
Verbicky-Todd, E.

1984 Communal Buffalo Hunting Among the Plains Indians. Occasional Paper No. 24. Archaeological Survey of Alberta, Edmonton.

Virta, R. L.

1992 Clays. Annual Report 1990, U. S. Department of the Interior, Bureau of Mines.

Vsyakikh, A. S.

1969 Principles of Livestock Breeding (Teoretickheskie osnovy pleminnogo delo). Izdael'stvo "Kolos," Mooska 1964. Translated from Russian, 1969, Israel Program for Scientific Translations, Jerusalem.

Walkley, A. and I. A. Black

1934 An examination of the Degtjareff method for determining soil organic matter, and a proposed modification of the chromic acid titration method. Soil Science 37:29-38.

Wandsnider, L.

1997 The Roasted and the Boiled: Food Composition and Heat Treatment with Special Emphasis on Pit-Hearth Cooking. Journal of Anthropological Archaeology 16:1-48.

Watson, V.

1950 The Optima Focus of the Panhandle Aspect: Description and Analysis. Texas Archeological and Paleonotological Society Bulletin 21:7-68.

Weakly, H. E.

1965 Recurrence of Drought in the Great Plains During the last 700 years. Agricultural Engineering 46.

Weinstein, A.

2005 Investigations at an Antelope Creek Phase Isolated Homestead (41PT109). Unpublished Master's thesis, Department of Anthropology, Texas State University, San Marcos. 
Weltfish, G.

1965 The Lost Universe: Pawnee Life and Culture. University of Nebraska Press, Lincoln.

Werner, C. M., J. A. Mason and P. R. Hanson

2011 Non-linear connections between dune activity and climate in the High Plains of Kansas and Oklahoma, USA. Quaternary Research 73:267-277.

Whalen, M. E.

1981 Cultural-Ecological Aspects of the Pithouseto-Pueblo Transition in a Portion of the Southwest. American Antiquity 46(1):7592.

Wheat, J. B.

1972 The Olsen-Chubbuck Site: A Paleo-Indian Bison Kill. Society for American Archaeology Memoir 26.

White, T. E.

1952 Observations on the Butchering Technique of Some Aboriginal Peoples: No. 1. American Antiquity 17(4):337-338.

1953a A Method of Calculating the Dietary Percentage of Various Food Animals Utilized by Aboriginal Peoples. American Antiquity 18(4):396-398.

1953b Observations on the Butchering Technique of Some Aboriginal Peoples No. 2. American Antiquity 19(2):160-164.

1954 Observations on the Butchering Technique of Some Aboriginal Peoples Nos. 3, 4, 5, and 6. American Antiquity 19(3):254-264.

Whittaker, J. C. and E. J. Kaldahl

2001 Where the Waste Went: A Knapper's Dump at Grasshopper Pueblo in Lithic Debitage: Context, Form, and Meaning, edited by W. Andrefsky Jr., pp. 32-60. University of Utah, Salt Lake City.

Wilkens, L. D., 2005 The Dykema Canyon Burial (41RB106): A
Violent Death in the Texas Panhandle, ca. A.D. 660. Transactions of the 40th Regional Archeological Symposium for Southeastern New Mexico and Western Texas, pp. 23-31. Midland.

Wilkens, L. D., B. R. Harrison and J. R. Erickson 2005 The Erickson Caprock Site (41RB102): A Secondary Cremation Burial in Roberts County, Texas. Transactions of the 40th Regional Archeological Symposium for Southeastern New Mexico and Western Texas, pp. 79-98. Midland.

Willey, G.

1966 An Introduction to American Archaeology, Volume 1: North and Middle America. Prentice Hall, Englewood, New Jersey.

Wilson, G. L.

1924 The Horse and the Dog in the Hidatsa Culture. The American Museum of Natural History, Anthropological Paper 15(2):123311.

1934 The Hidatsa Earthlodge, arranged by and edited by B. Weitzner. Anthropological Papers of the American Museum of Natural History XXXIII (V):343-420. American Museum of Natural History, New York.

Wilson, M. C.

1974 The Casper Local Fauna and its Fossil Bison. In The Casper Site: A Hell Gap Bison Kill on the High Plains, edited by G. C. Frison, pp. 125-171. Academic Press, New York.

1978 Archaeological Kill Site Populations and Holocene Evolution of the Genus Bison. In Bison Procurement and Utilization: A Symposium, edited by L. B. Davis and M. C. Wilson, pp. 9-22. Plains Anthropologist Memoir 14, 23(82, Part 2).

1980 Population Dynamics of the Garnsey Site Bison. In Late Prehistoric Bison Procurement in Southeastern New Mexico: The 1978 Season at the Garnsey Site (LA-18399), 
by J. D. Speth and W. Parry, pp. 88-129. Museum of Anthropology Technical Report 12, University of Michigan, Ann Arbor.

Wisniewski, P. A. and F. J. Pazzaglia

2002 Epeirogenic Controls on Canadian River Incision and Landscape Evolution, Great Plains of Northeastern New Mexico. The Journal of Geology 110:437-456.

Wissler, C.

1910 Material Culture of the Blackfoot Indians, Reprinted 1976. AMS Press Inc., New York.

Withers, A. M.

1954 Reports of Archaeological Fieldwork in Colorado, Wyoming, New Mexico, Arizona, and Utah in 1952 and 1953: University of Denver Archaeological Fieldwork. Southwestern Lore 19(4):1-3.

Wood, W. R.

1969 Two House Sites in the Central Plains: An Experiment in Archaeology. Plains Anthropologist 14(4), Part 2.

Woodhouse, C. A. and J. T. Overpeck

19892000 Years of Drought Variability in the Central United States. Bulletin of the American Meteorological Society 79(12):2693-2714.

Wooster, L. D.

1935 Notes on the Effects of Drought on Animal Populations in Western Kansas. Kansas Academy of Science 38:351-353.

Wulfkuhle, V. A.

1984 Analysis of a Sample of the Surface Collected Ceramics from Landergin Mesa, Oldham County, Texas, Phase I Investigations, Fall 1981. Unpublished manuscript on file with the Texas Historical Commission, Austin.

Wyckoff, D. G.

1989 An Introductory Study of Alibates Gravel Occurrences Along Western Oklahoma's Candian River. In In the Light of Past
Experiences: Papers in Honor of Jack T. Hughes, compiled and edited by B. C. Roper, pp. 405-454. Panhandle Archeological Society, Publication No. 5. Aquamarine Publications, Clarendon.

1993 Gravel Sources of Knappable Alibates Silicified Dolomite. Geoarchaeology 8:3558.

Wynn, T., T. Huber, R. McDonald and L. S. Cummings

1993 Late Holocene Climate History in Eastern Colorado. Southwestern Lore 59(1):6-15.

Wyrick, J. C.

1981 Soil Survey of Roberts County, Texas. United States Department of Agriculture, Soil Conservation Service, in cooperation with the Texas Agricultural Experimental Station, Collage Station.

Yanovsky, E. and R. M. Kingsbury

1938 Analysis of Some Indian Food Plants. Association of Official Agricultural Chemists 21:648-665.

Zier, C. J. and S. M. Kalasz

1999 Colorado Prehistory: A Context for the Arkansas River Basin. Colorado Council of Professional Archaeologists, Denver. 
This page intentionally left blank. 


\subsection{GLOSSARY OF TECHNICAL TERMS}

A Horizon: The near surface horizon of a natural soil. This is a carbon rich soil horizon characterized by an accumulation of partially decomposed to decomposed organic matter and eluvial loss of constituents such as clays and carbonates, which tend to accumulate in the deeper B horizon. The A horizon represents the upper solum of a soil. Lower case letters with the upper case letter A indicate specific characteristics of that A horizon. An $\mathrm{Ab}$ designation indicates the A horizon is buried. An Ap designation indicates a disturbed or anthropically modified soil such as in a plow zone.

\section{Accelerated Mass Spectrometry (AMS):} Laboratory technique that separates and identifies ions based on their mass to charge ratios. This technique is used in radiocarbon dating tiny particles of carbon in organic remains and residues.

Acryloid B-72: This is a conservation material used to stabilize or glue the ceramic shreds together. It is an ethyl methacrylate copolymer.

A.D.: Anno domini in Latin. "In the year of our Lord." For example, A.D. 1000 is 1,000 years after Christ. This is generally used when a B.P. radiocarbon date is calibrated to the tree ring results with one of the calibration formulas.

Aerophilous Habitats: An environment that has free oxygen or air. These can include damp soils, wet plants and rocks, marshes, wetlands and mud lands. This term is used in the discussion of phytoliths and diatoms. Aerophilic diatoms live exposed to air and are adapted to damp or dry habitats.

Agavaceae: A plant family name that refers to fiber, vascular bundle, or the central stem sections that cannot be specifically identified as agave (Agave), yucca (Yucca) or sotol (Dasylirion).

Allostratigraphic Unit: Depositional unit made up of sediments dating to a similar period of deposition.
Alluvium: Clastic sediments, such as sand, silt, or clay deposited by a flowing stream, either in the channel or material deposited outside the channel during overbank flooding.

Anisotropic: The action of cross-polarization of light under a microscope as it passes through material. If the material causes any deviation in the transmission of light then the material will have illumination in the microscope in a pattern characteristic of the material and its properties. Anisotropic minerals inhibit or obstruct the passage of light. This term is used in the petrographic analysis of ceramic sherds.

Appendages: These are additions of clay to a vessel and include such items as handles, lugs (small attachments of clay to the upper exterior surface that may be used as handles), and nodes (these are horizontal protrusions on the lip, rim, shoulder, or body). Handles and lugs on pottery are usually related to the Central Plains groups or from the Southwest.

Applique: This is also an addition of clay to a vessel and involves a narrow coil of clay around the rim or even a design applied to the surface.

Argillic Horizon: A soil horizon (Bt horizon) that exhibits significant enrichment in illuvial clay minerals or clay-sized particles. Such clays typically form grain coats, grain bridges, and ped-face coats of oriented clay that are visible in thin sections, and usually can be identified with a hand lens.

Argilliturbation: Mixing of soil or sediment, and materials contained therein, due to expansion and contraction of clay minerals with wetting and drying.

Autecology: The older term, autecology refers to the study of individual species in relation to the environment or, essentially, species ecology.

Basalt: An extrusive igneous/volcanic rock that has crystals too small to see visually.

B.C.: The abbreviation for Before Christ, as in contrast to A.D. 
Benthic Diatoms: Those species of diatoms that live in sediment, microbial mats and vegetation at or near the floor of a stream or lake.

Biface or Bifacial: A stone tool that has two distinct sides or faces, both of which have been worked and flaked. This may take the form of many shapes and sizes.

B Horizon: The lower solum of a natural soil. A $\mathrm{B}$ horizon is a mineral soil horizon characterized by an accumulation of constituents such as clays, carbonates or salts, or organic complexes that have been translocated from the A horizon. Common subordinates include lowercase letters such as $t$ as $\mathrm{Bt}$, which indicates accumulation of illuvial clays. The lowercase $\mathrm{k}(\mathrm{Bk})$ indicates accumulation of carbonate. The lower case $\mathrm{w}$ indicates structural or color changes with no significant accumulations of alluvial material.

Biosilicates: This is a general term to include various tiny hard bodies that contain silicon and are developed in plants such as phytoliths, diatoms, algal statospores and sponge spicules.

Biotite: A specific black or dark green igneous rock consisting of potassium magnesium and iron aluminum. It occurs in granites, gabbros, and lavas.

Bioturbation: The churning and mixing of sediments by living organisms, including burrowing rodents, insects, worms, and plant roots.

Biplot: A biplot is a special type of graph following from principal component analysis on which both the samples and elements are displayed. Examination of biplot from the principal component analysis of ceramic specimens often leads to identification of the analyzed elements responsible for differentiating groups of specimens from one another.

Bivariate Plot (Scatter Plot): A two-dimensional graph where the $\mathrm{x}$-axis and $\mathrm{y}$-axis symbolize a pair of measured or calculated variables. The points on a bivariate plot represent the position of individual samples and show the concentration of one element compared to another. These graphs are used to recognize possible structure in a data set.
B.P.: An abbreviation for before present, which in radiocarbon dating is referenced to the standard year A.D. 1950, which is considered "present”. Generally B.P. dates have not been tree ring corrected using one of the calibration formulas.

$\boldsymbol{\beta}$-sitosterol and Stigmasterol: These are associated with plant products.

Brushing: This can occur on a wet clay surface of a vessel. Brushing leaves a group of fine parallel lines and is considered a decoration. This occurs most often near the rim or on the neck and shoulder of the vessel.

Burned Rock Dump: A loose cluster of previously heated rocks that exhibits no horizontal patterning to the positions of the rocks and lacks indications of in situ heating/burning, such as a prepared basin, lenses of charcoal or ash, and/or the absence of an oxidation rim. Scattered charcoal or other cultural items may be present between or around the burned rocks.

$\mathbf{C}_{3}$ : A photosynthetic pathway that most trees and flowering bushes use to assimilate carbon dioxide into their systems. The average carbon isotope of $\mathrm{C}_{3}$ matter is $-26.5 \%$ with a range from about $-19.0 \%$ o to $-34.0 \%$.

$\mathrm{C}_{4}$ : A photosynthetic pathway used by most arid (xeric) grasses and maize (corn) to assimilate carbon dioxide into their systems. The average carbon isotope of $C_{4}$ matter is $-12.5 \%$ with a range of $-6 \%$ o to $-19 \%$. These plants are more resistant to stress due to lack of water, but more susceptible to cold temperatures.

Cache: The deliberate placement or storage of artifacts in a tight grouping such as tools or pottery purposely placed for storage, generally in the ground. Caches are thought to represent storage with the intention of subsequently returning to retrieve the stored objects.

C Horizon: Weathered, but relatively unaltered parent material at the base of a soil profile. This term is roughly synonymous with subsoil, although the latter term is often used to encompass the lower B horizon. 
Calcareous: Rocks, minerals, or sediment containing calcium carbonates.

Calcite: A mineral consisting only or mainly of calcium, the principal mineral of limestone and marble.

Calcium: A chemical element with the symbol Ca and atomic number 20. Calcium is a soft gray alkaline earth metal, and is the fifth most abundant element by mass in the Earth's crust. Calcium is also the fifth most abundant dissolved ion in seawater by both molarity and mass, after sodium, chloride, magnesium, and sulfate.

Caliche: A more or less cemented deposit of calcium carbonate in soils of warm-temperate, subhumid to arid areas. Caliche, normally white, occurs as soft, thin layers in the soil or as hard, thick beds just beneath the solum, or it is exposed at the surface by erosion.

CAM: A photosynthetic pathway for assimilating carbon dioxide into plants that can change from $\mathrm{C}_{3}$ like to $\mathrm{C}_{4}$-like pathways depending on the diurnal (day or night) cycle. Most succulent plants such as cactus have crassulacean acid metabolism (CAM) pathways. The carbon isotope values of most CAM plants in Texas such as Agave lechuguilla and Opuntia englmannii, are similar to the values in $\mathrm{C}_{4}$ plants (see Eickmeier and Bender 1976).

Canonical Discriminant Analysis (CDA): This procedure finds axes (the number of categories -1 $=\mathrm{k}-1$ canonical coordinates) that best separate the categories. These linear functions are uncorrelated and define, in effect, an optimal k-1 space through the n-dimensional cloud of data that best separates (the projections in that space of) the k groups.

Carbonates: These are rock or mineral classes that include limestone, calcite, ooids, and bioclasts, and used in the petrographic analysis of the pottery sherds. The calcite staining in the thin-section preparation marked all these bodies with a carmine red color.

Cerro Toledo Rhyolite: Aspecific source of obsidian glass in the Jemez Mountains of north-central New
Mexico. Cerro Toledo Rhyolite is grouped with the Valle Grande Member obsidians within the Tewa Group due to similar magmatic origins. This obsidian comes from both the northern domes and from Rabbit Mountain, sometimes referred to as "Obsidian Ridge". Size ranges from pea gravel to $16 \mathrm{~cm}$ in diameter. Cerro Toledo Rhyolite occurs throughout the Rio Grande alluvium all the way to Chihuahua, Mexico (Shackley 2005).

Chalcedony: A cryptocrystalline variety of quartz or chert. Chalcedony is often a component of other cherts. It may be translucent or semitranslucent, has a wax-like luster, and generally are white, pale blue, gray, blown, or black in color.

Cheno-am: A term used in botanical classification that includes the plant family of Chenopodiaceae (goosefoot) and the genus Amaranthus (pigweed), with tiny charred seeds that are indistinguishable from each other.

Clast: Any detrital particle of sediment created by the weathering and disintegration of a larger rock mass and transported by water, wind, or ice. Clasts also include discrete particulates created and deposited by volcanic action.

Clay: This is mineral sediment particles less than 0.002 millimeters in diameter. As a soil textural class, soil mineral that is 40 percent or more clay, less than 45 percent sand, and less than 40 percent silt.

Cluster Analysis (CA): A type of numerical classification that uses the value of attributes to cluster data. Clustering is the classification of objects into groups so that objects from the same cluster are more similar to each other than to objects from different clusters. Often similarity is defined according to a distance measure. Clustering is a common technique for statistical data analysis, which is used in many fields, including data mining, pattern recognition, image analysis and bioinformatics.

Coil Construction: This is a ceramic vessel construction technique. This is the building up of vessel walls with superimposed rolls of clay placed on top of one another. Often the coil is referred to as a rope of clay. This rope of clay is formed by 
rolling clay between the hands or sometimes on a flat surface. Bonding of the coils is through pressing or pinching the coils together with the fingers. Subsequent smoothing or paddling the exterior often obliterates the coils (see Lynn 2004 for information on making coiled potter).

Collagen: The organic (protein) component of bone. It is this component that is usually radiocarbon dated by most laboratories, and decays over time.

Collared Rim: This is a rim that has been thickened, generally by the addition of extra clay to have facilitated vessel suspension (Wood 1969). This creates a bulging rim, a domed surface, an angular or overhanging ridge, or thick lip. It is currently believed that collared rims are not common in the Antelope Creek sites in the core area, but are more common in the Buried City complex. Collared rims are a characteristic of the Upper Republican and Loup River/Itskari phase ceramic assemblages (Lintz and Reese-Taylor 1997).

Colluvium: Soil material, rock fragments, or both, moved by creep, slide, or local wash that is deposited at the base of steep slopes.

Complex: A group of sites dating from the same time period and that contain similar artifacts. This term expresses a relationship of common cultural or technological traits in assemblages within widespread geographic area.

Component: A site or portion of a site that is spatially and chronologically discrete from other accumulations of artifacts. These can be horizontally or vertically differentiated.

Context: The association and position of artifacts, materials, and cultural features that are used by archeologists to interpret space, time, and culture.

Criterion of Abundance: If a large group of the specimens in a ceramic assemblage is represented by a single, homogenous, compositional fingerprint and the actual source of clay is unknown, then the criterion of abundance indicates that there is a high probability the group was produced locally or very near the site where it is most heavily represented.
Cord-Impressed: This is a decoration to the exterior of a vessel and occurs when a cord is pressed into the wet clay to leave a mark. This is a purposeful addition to the vessel surface and is not considered a surface treatment (see cordmarked below).

Cordmarked: This is the result of use of a cord wrapped paddle during the forming and shaping the wet vessel with the cords on the paddle leaving impressions in the wet clay. This occurs most often on the exterior of the vessel and is considered a surface treatment or manufacturing technique and not a decoration (see Lynn 2004 for information on making coiled pottery).

Cumulic Soil: Asoil formed in a setting experiencing relatively slow deposition, so that freshly introduced sediment is incorporated into the A horizon, leading to overthickening of the surface horizon. Cumulic soils are common in alluvial overbank and colluvial settings.

Curie Temperature: The temperature at which the magnetic properties of a substance change from ferromagnetic to paramagnetic. Magnetite has a Curie point of 580 degrees Celsius.

Deposition: The accumulation of sediments or gravels laid down by natural agencies such as moving water, or artificial agencies such as dumping.

Detrital: Loose rock fragments or grains that have been worn away from the parent rock.

Diagenesis: This is the alteration of the original constituents into new products.

Diatoms: These are single-celled algae whose cellular contents are enclosed between two valves of silica that are preserved when the organism dies. Often diatoms are preserved in ponds and streams and important to stream ecology. Different taxa have different tolerances for extremes of temperature, salinity, water depth, water clarity, and nutrient concentrations and respond rapidly to changes in the environment. These are useful in reconstructing aquatic paleoenvironments. 
Discriminant Analysis (DA): This is a statistical technique. This is used to predict group membership based on a linear combination of the interval variables. The procedure begins with a set of observations where both group membership and the values of the interval variables are known. The end result of the procedure is a model that allows prediction of group membership when only the interval variables are known. A second purpose of discriminant function analysis is an understanding of the data set, as a careful examination of the prediction model that results from the procedure can give insight into the relationship between group membership and the variables used to predict group membership.

Dolomite: A carbonate sedimentary rock consisting of more than 50 percent by weight of by areal percentage under the microscope of the mineral dolomite. Occurs in crystalline and noncrystalline forms, is clearly associated, and often interbedded, with limestone.

Effluent: This is the outflowing of water from a natural body of water, or from a man-made structure. Effluent is generally considered to be water pollution, such as the outflow from a sewage treatment facility or the wastewater discharge from industrial facilities.

Eluvial: The movement of materials such as clay or organic matter from a soil horizon by percolating water.

Eocene Epoch: The period of time between 37 and 58 million years ago, and a subdivision of the Tertiary Period of the Cenozoic era.

Eolian: Earthly particles moved by wind action that include sandy dunes, sand sheets, or loess deposits.

Eraillure Scar: An enigmatic flake formed between the bulb of force and the bulbar scar.

Erosional Unconformity: A significant break or gap in the geological or depositional record, indicative of erosion of the older unit prior to renewed deposition.
Euclidean Distance: In mathematics, the Euclidean distance or Euclidean metric is the "ordinary" distance between two points that one would measure with a ruler, which can be proven by repeated application of the Pythagorean theorem. By using this formula as distance, Euclidean space becomes a metric space. The associated norm is called the Euclidean norm.

Eutrophic: Having waters rich in mineral and organic nutrients that promote a proliferation of plant life, especially algae, which reduces the dissolved oxygen content and often causes the extinction of other organisms. This is used in the discussion of diatoms.

Fabric-Impressed: This refers to a textile or woven impression on the exterior of a vessel. The textiles generally include basketry, net, or other woven materials.

Facies: A definable subdivision of a formal or informal stratigraphic unit.

Ferric Iron: This is the type of iron often found in pottery fired in an oxidizing (oxygen rich) atmosphere.

Ferrous Iron: This is the type of iron often found in pottery fired in a reducing (oxygen poor) atmosphere.

Fetal Bone: This is the boney skeleton of a growing fetus inside the worm of a female. As the fetus grows so does the boney structure of that animal. These bones are developed in layers of tissue that once the animal places weight on the skeleton structure the layers fuse together to form the cortical walls of the various elements.

Firing Atmosphere: This generally refers to the balance of fuel and oxygen in the firing of a ceramic vessel before it is used. A reduction atmosphere reflects short firing indicted by black surfaces (sooting) indicating more fuel (carbon) than oxygen. An oxidation atmosphere indicates a longer firing reflected by orange, brown, and resurfaces caused by an overabundance of oxygen. 
Floodplain: A nearly level alluvial plain that borders a stream or river and is subject to periodic flooding.

Fractionation: This is the result of a reaction that preferentially favors one isotope of an element over another so the isotope ratio of the end product differs from the original material.

Gelatinization: In regards to starch grains this is a morphological change (distortion of the original shape) in the grain caused by the exposure to heat and water when starches are cooked.

Geomorphology: That part of geography concerned with the form and development of the landscape.

Geophytes: These are plants with underground storage organ such as bulbs (i.e., onions, camas, and false garlic), tubers, roots, and rhizomes that are a reserve of carbohydrates, nutrients, and water. These storage organs can be collected, cooked, and eaten as part of the human diet. The study of these geophytes from an archaeological site aids in determining the diet of the past occupants.

Glume: Pertains to small dry membranous chaffy bract found at the base of a grass spikelet or each flower in a sedge or related plant.

Graticule: A device used in the microscope to measure the size of items under magnification.

Grit Temper: This is a term used early on to describe visible particles in the clay of a pottery sherd. The pieces of temper in sherds were generally not identified and therefore a generic term like grit was used, and most often the term grit was not specifically defined. It is currently out of favor with most ceramicists and should not be used.

Hard/High Silica Polish: This is a residue that comes from the material that a stone tool comes in contact with. This type of polish is produced when processing soft plants with high silica content in the plant tissues such as grasses, wood, reeds, and potentially soil. This polish was detected during high-powered use-wear studies conducted during stone tools analysis.
HCL: Hydrochloric acid, which is the solution of hydrogen chloride $(\mathrm{HCl})$ in water. It is a highly corrosive, strong mineral acid and has major industrial uses.

Hematite: A blackish-red to brick-red mineral, Fe2O3, the chief ore of iron. This mineral is found naturally in the Trujillo Formation and is considered locally available.

Heating Element: This is an intentional, intact and localized spot were a human created a fire in an archeological site or component. This is generally evidenced by quantities of wood charcoal, prepared basin, lenses of charcoal or ash, and possibly an oxidation rim often accompanied by intentionally placed rocks, either lining the margins or directly amongst the charcoal. The function of this fire may reflect many different things, such as for heat to warm a person, to cook on, or to heat rocks for other uses. The specific contents may provide clues as to a more specific function or length of use.

Holocene: Geological time period spanning roughly the last 10,000-years before present. The Holocene is roughly equivalent to the Post-glacial period, and often referred to as the "Recent" period in geology. Many investigations consider the Holocene to be an interstadial in the ongoing Pleistocene epoch.

Horizon: A discrete, relatively uniform layer in a soil profile that is typically parallel with the surface and formed as the result of pedogenic process.

Humates: These are substances formed from the biological and chemical breakdown of animal and plant life over time. Humates are made up of compounds and materials that plant life on earth absolutely needs for growth. The humates contain a mixture of organic acids, including humic acids, fulvic acids, macromolecules of amino acids, amino sugars, and peptides. The chemistry of humate is so complex it can't really be broken down.

Humus: Adark, organic-rich substance consisting of decomposed organic material (animal or vegetable) and is found in the soil. 
Igneous: Rocks that are formed by the solidification of magma from volcanic activity or from molten magma, such as obsidian, rhyolite, basalt, and granite. These rocks are nonlocal to the area, although small pieces may be in the gravels that have washed downstream from New Mexico.

Illuvium: Material in a sediment profile that has moved downward into another soil horizon by water.

In Situ: An artifact in its original position that was placed or deposited within the landscape.

Integrity: This refers to the degree of intactness of archeological deposits, components, features, or artifacts.

Instrumental Neutron Activation Analysis (INAA): This is a method to determine the elemental composition of a sample (pottery or lithic) through the exposure of samples to a neutron flux from a nuclear reactor without the use of chemical separation. The exposure to neutrons produces several short- and long-lived radioactive isotopes that emit characteristic gamma rays. The energy of the emitted gamma rays provides information to identify the constituent elements, while the intensity of the emitted radiation is proportional to the amount of the element present in the sample. Gamma-ray spectroscopy is performed at different levels after irradiation to measure isotopes with different halflives. The method is particularly sensitive to a large number of trace elements, including the rare-earth elements, transition metals and others.

Iron Stain: These resemble a blood-red smear or splash on the matrix when using a cross polarized light in viewing a petrographic slide of a pottery sherd. The stained zone has irregular rounded shapes and commonly there are discontinuous zones or strips of several rounded iron stain smears. The source of the iron stain in the ceramic fabric is problematic.

Inulin: This is a carbohydrate, a fructan is not digestible via acid hydrolysis, the typical way we digest carbohydrates such as starch.
Isotope: An atom of an element. One of two or more forms of a chemical element, differentiated by the number of neutrons contained in the nucleus.

Isotropic: The behavior of cross-polarization of light as it passes through material, especially crystalline material. Having physical properties, as conductivity, elasticity, etc., that are the same regardless of the direction of measurement. This term is used in the petrographic analysis of ceramic sherds.

Jacal Structure: This is a type of an adobe house structure historically found throughout parts of the south-western United States and Mexico. This structure was built of slim close-set vertical poles tied together and filled out with either mud, clay and grasses or a combination of these materials. Jacal construction is similar to wattle and daub, although the "wattle" portion of jacal structures consists mainly of vertical poles lashed together with cordage and sometimes supported by a pole framework, as in the pit-houses. This is overlain with a layer of mud/adobe (the "daub"), sometimes applied over a middle layer of dry grasses or brush which functions as insulation.

Jasper: A dense, cryptocrystalline, opaque to slightly translucent variety of chert associated with iron oxide impurities that give the rock various colors. Most often red, but can be yellow, green, grayish-blue, brown or black.

Knapping: A term used to describe the manufacturing of prehistoric chipped stone tools using different techniques, such as pressure and/or percussion methods, to chip/flake a target mass of material to form a useful tool.

Krotovina: A discrete, anomalous area visible in plan or profile in a soil resulting from the infilling of a void (e.g. a burrow or root) with dissimilar sediment. Some investigators prefer to limit the term to animal burrows, preferring the term "root trace" for filling related to decayed roots. Some krotovina are obvious, whereas others are tiny and may only be identified in thin sections. 
Legume: A plant that produces a bean or seedpod in various forms consisting of one cell and/or two valves. Common legume plants across Texas include such plants as; mesquite, Texas ebony, various acacia, retama, Dalea sp., mimosa, and rattlebush.

Lithic: Means "of stone". This term is used by archeologists to refer to stone artifacts and the debris that results from the manufacture of stone artifacts.

Lithology: The scientific study and description of rocks, especially at the macroscopic level, in terms of their color, texture, and composition. The gross physical character of a rock or rock formation.

Little Barley: This is a short winter annual bunch grass with a scientific name of Hordeum pusillum in the Poaceae grass family. It has a rapid growth period with a brown seed that develops after spring and is available in the early summer. The seed head consists of flattened spikes. It is considered low in protein and is intolerant to shade. This grass has a low drought tolerance but can grow with only 10 inches of rain per year. It is considered a $\mathrm{C}_{3}$ grass (-26.7\%o; Smith and Brown 1973) adapted to fine and medium soil (http://plants.usda.gov 2011).

Logarithm: This is used in mathematics in which the exponent (or power) to which a base must be raised to give a particular number. This is used in compositional analysis. It is to allow the data transformation when comparing major, minor, and trace elements to prevent variables with higher concentrations form having excess weight in calculations of many coefficients of similarity.

Lug: This is an added lump of clay to the exterior of a ceramic vessel, usually on or near the rim.

Macrobotanical: These are remains of plant tissues, such as wood, charcoal, and seeds that one can see with the naked eye.

Magnetic Susceptibility: The degree of magnetization of a material in response to a magnetic field. Often this is used in identifying buried soils or humanly altered soils.

Magnetometer: An archeomagnetism, a nondestructive devise used to measure the magnetization of a sample or the ground. Used to detect subsurface anomalies in the ground.

Mahalanobis Distance: In statistics, Mahalanobis distance is a distance measure introduced by P. C. Mahalanobis in 1936. It is based on correlations between variables by which different patterns can be identified and analyzed. It is a useful way of determining similarity of an unknown sample set to a known one. It differs from Euclidean distance in that it takes into account the correlations of the data set and is scale-invariant, i.e., not dependent on the scale of measurements.

Maize or Zea Mays: The scientific name for corn, which is a water-efficient $\mathrm{C}_{4}$ plant with a shallow root system. The corn cob is also known as a rachis, which have alignments of cupules that are weakly jointed. The cupules are the sockets that hold the kernels. The kernels are attached with the cupule by a germ on which the kernel develops. Two kernels are attached via the germ in a side by side manner inside each cupule. The number of rows on a cob refers to the number of aligned kernels. Most prehistoric corn cobs have from 8 to 14 rows of kernels. Benz $(1985: 145)$ states that the "broad generalized "race" is taxonomically ill-defined grouping that has yet to be described in detail. We do not yet understand the racial diversity that exists in the prehistoric periods of what is now the United States.” The term Indian corn now generally refers specifically to multicolored "field corn" (flint corn) cultivars. There are many forms of maize, such as flint corn, popcorn, Dent corn, sweet corn (modern) and others.

Major Element: One of fewer than 10 elements that typically occur in systems at levels greater that $1 \mathrm{wt}$. percent. This is a category of elements that includes silicon $(\mathrm{Si})$, Aluminum ( $\mathrm{Al})$, sodium $(\mathrm{Na})$, Magnesium $(\mathrm{Mg})$, calcium $(\mathrm{Ca})$, iron $(\mathrm{Fe})$, and oxygen $(\mathrm{O})$.

Mano: This is a stone, usually sandstone or quartzite, used to grind plants such as corn, nuts, seeds, or other vegetable matter and sometimes other rocks. It is used in conjunction with a stone metate that plants are placed on to perform the grinding. 
M.A.S.C.A.: Museum of Applied Science Center for Archaeology, University Museum, University of Pennsylvania. One institution that has studied treering calibrations of radiocarbon dates.

Manuport: An object, usually a rock, that was transported by humans to the place it was recovered, but its macroscopic appearance does not indicate it had been artificially altered to form a specific tool or other kind of artifact.

Mass Modeling: This is another ceramic vessel construction technique using the hands. It begins with a lump or ball of paste (clay and temper) that is then formed into a pocket or small bowl like structure with the clay then pulled upward to form the base or lower sides of the vessel.

Mastic: This is a resin obtained from a plant, often a tree. It is a gum like substance that is often used to bind/glue a chipped stone tool to the haft. Mastic was observed on some stone tools during highpower use-wear analysis.

Matrix: Refers to the sediments in which the artifacts at an archeological site are encased, or surrounds.

Mesic Condition: A relatively moist interval of time generally used in the context of climatic conditions.

Metate: A slab of rock in which vegetable matter is placed for the purpose of grinding. The natural surface becomes polished and a concave depression forms on the metate surface from use. The grinding stone used with the metate is called a mano.

Microdebitage: Any stone or lithic material from the manufacture of stone tools that is less than 4.0 $\mathrm{mm}$ in diameter.

Micro: In the metric system this is $1 / 1000$ th of the base unit of measurement (i.e., meter, gram, liter). In sample analysis and instrumentation, a prefix commonly used for processes or instruments able to handle very small objects.

Microfossils: These include a variety of very tiny residues including such things starch grains, diatoms, phytoliths, pollen, and organic remains that are only detectable and visible under high-powered microscopes.

Micromorphology: The fine-level structures or shapes of an organism, mineral, or soil component visible through a microscope.

Midden: This is somewhat of a catch-all term. It generally refers to an accumulation of cultural material such as a zone of burned rocks, and it is often used to refer to a thick accumulation of mixed cultural material in a vertical zone.

Minor Element: One of about seven elements that typically occur in all systems at level between 0.1 and $1 \mathrm{wt}$ percent. This includes hydrogen $(\mathrm{H})$, potassium (K), sulfur (S), carbon $(\mathrm{C}$, phosphorus (P), titanium Ti), and Manganese (Mn).

MNI: The abbreviation for the minimum number of individuals represented in a given faunal or human osteological collection. This is determined by the largest number of any particular bone element representing a given species in a sample of bones.

Molar Solutions: A Molar (M) is a solution that contains one mole of solute in each liter of solution. A mole is the molecular weight expressed as grams. Therefore, $1 \mathrm{M}=1 \mathrm{~g}$ of molecular weight of solution per liter of solution.

Mussel Shells: This is the outer shell that protects a meaty soft mussel on the interior. The shell is composed of inorganic and organic components. Three major layers combine to make up the shell and include the thin outermost layer that is called the periostracum or epidermis. Underlying the epidermis is the prismatic layer made of calcium carbonate (calcite). The third layer is the innermost and is the nacre or mother-of-pearl layer, which is also composed of calcium carbonate in the form of calcite, aragonite, or both in alternating layers.

Neutron: This is an electrically neutral subatomic particle that occurs in the nucleus of an atom. It is also a subatomic particle that is slightly larger than a proton. 
Obsidian: A black or very dark-colored volcanic glass that forms from volcanic activity. It has very sharp edges when fractured. Obsidian is usually of rhyolite composition characterized by conchoidal fracture. It is sometimes banded, and may contain microlites. It is considered nonlocal to the Texas panhandle region.

Opalite: An impure, colored variety of common opal that ranges from white, creamy white, or pale white.

\section{Optically Stimulated Luminescence (OSL):} This is a relatively dating technique that measures the luminescence produced when electrons are evicted from sand particles by exposing them to monochromatic visible light. This is typically used to date unburned sediment, especially sand. The sand traps sunlight at the time of the event and then becomes buried electrons begin to accumulate.

Organic: Compounds that contain carbon and are associated with living organisms.

Orifice: This is the opening at the top of the vessel and would be measured on the inside of the rim. Orifice diameters are generally measured based of a section of a rim sherd set against a series of concentric circles.

Orthoclase: A colorless, white, creamy yellow, flesh-colored, reddish or grayish mineral of the alkali feldspar group. Common orthoclase is one of the most abundant rock-forming minerals and occurs in granites, acidic igneous rocks, and crystalline schists, and is usually perthitic.

Oxidation: A chemical process wherein oxygen is added to minerals or other compounds; weathering oxidizes minerals; burning wood and rusting metal are types of oxidation. Firing pottery in an oxidizing atmosphere produces a clear color reflecting a uniform firing.

Paleoenvironment: Ancient or past environments.

Paleogeography: The physical nature of the past landforms.
Paleomagnetic: The past magnetic properties used here in the properties in and around fires.

Paleosol: Generally refers to a soil that developed an A horizon and was subsequently buried.

Palimpsest: Archeologically, refers to the inability to distinguish and separate material remains from repeated occupations by a succession of cultural events of different ages due to their deposition and intermixing over time on relatively stable surfaces. Some palimpsest assemblages are buried following a long period of exposure.

Palynology: The study of fossil palynomorphs (pollens and spores) that are produced by plants. Commonly used to reconstruct the floral communities in paleoenvironments.

Parenchyma Residues: The functional parts of an organ or the thin-walled cells of the ground plant. These can be detected during phytolith analysis.

Paddle and Anvil Technique: This is a technique used to shape and form a ceramic vessel. The paddle is often a flat stick or bone that is sometimes wrapped with a cord and held in one hand. The anvil is held in the opposite hand, which is often a small round pebble. The paddle is used to pat the exterior of the vessel with the anvil held on the interior side opposite the paddle to prevent pushing the clay too far in.

Paste: The clay mixed with the temper that is used in the construction of a ceramic vessel. Sometimes this is also referred to as the fabric.

Patch Modeling: This is another ceramic construction technique. This involves adding flat pieces or patches of clay to one another to build the vessel or section of vessel. This is in contrast to coil building a vessel with long, rolled coils.

Pedogenesis: The dynamic process of soil formation and development, which typically leads to the formation of a darkened, organic-rich A-horizon at or near the surface, and the downward movement of fine clays into, and/or the formation of carbonate nodules within, the underlying $\mathrm{B}$ horizons. 
Pedoturbation: A general term used to describe soil that has been mixed.

Pee Dee Belmnite: A limestone found in Southern Carolina used as the international standard for various compositional (carbon and oxygen isotopic and elemental) analyses.

Permian: The seventh and last period of the Paleozoic Era in geologic time and before the Triassic period. A period of rock formation, specifically Alibates of the Quartermaster Formation.

Petrographic Analysis: The detailed descriptions and analyses of rocks at the microscopic level. Generally a thin section is cut from a lump of soil or ceramic sherd and that thin section is mounted on a glass slide, ground to a specified thickness, then viewed under a stereographic microscope to see and identify the properties present. The principal method of analysis is the identification and point counting of the minerals and ceramic structures in the sample. The point counting, generally 200, allows for replication and comparison to other samples.

pH: This is shorthand for the standard numerical designation of acidity and alkalinity commonly used in reference to soils. A neutral $\mathrm{pH}$ value (as in distilled water) is 7.0. Lower and higher values are acidic and base, respectively.

Phase: A group of related archeological traits (e.g., artifacts, features) that contain similar cultural material and date to one relatively narrow time period within a limited region.

Phosphorus: Achemical element that has the symbol $\mathrm{P}$ and atomic number 15 . A multivalent nonmetal of the nitrogen group, phosphorus is commonly found in inorganic phosphate rocks.

Photosynthesis: This is the process used by green plants and certain microorganisms to transform carbon dioxide and water into sugar and oxygen.

Phytoliths: Tiny microscopic silica particles (plant stones) that develop within the cells of most plants. Dissolved silica is transported into growing plants through water intake and then deposited along cell walls as silica particles. Different kinds of plants and different parts of a plant develop phytoliths of distinctive shapes. After the plants die, the silica bodies become part of the mineral component of soils left in the ground. The study of the phytoliths allows for specific plants or plant groups to be identified.

Pleistocene: The first epoch, which along with the Holocene Epoch constitutes the Quaternary period, spanning the time between roughly 2.0 or 1.65 million years ago and 10,000-years ago. Characterized by repeated continental glaciations, the Pleistocene witnessed the evolution of modern humans.

Plagioclase Feldspar: These are found in all igneous rocks with a distinctive striated cleavage.

Planktonic Diatoms: Those species that live suspended in the water column.

Pleistocene: The first epoch, which along with the Holocene Epoch constitutes the Quaternary period, spanning the time between roughly 2.0 or 1.65 million years ago and 10,000-years ago. Characterized by repeated continental glaciations, the Pleistocene witnessed the evolution of modern humans.

Pressure Flaking: A method used to shape stone tools through the application of force applied by pushing rather than striking.

Principal Component Analysis (PCA): This is a pattern recognition technique used for reducing the dimensionality of multivariate data, similar to factor analysis. It uses all of the variables measured in a sample and calculates the variation among those variables.

Profile: A cross-sectional exposure of the sequence of horizons that make up a soil or a sequence of sedimentary deposits. It can be the result of either natural erosional down cutting or an artificial excavation.

Provenience: The specific vertical and horizontal location of where an object is found. 
Provenance Postulate: This states that chemical analysis can successfully trace artifacts to their source if the differences in chemical composition between different natural sources exceed, in some recognizable way, the differences observed within a given source.

Punctation: This term applies to an intentional decoration technique on a ceramic vessel. It is created by pushing an object/tool into the soft clay that then leaves an indentation. This decoration may leave a positive and negative mark on the vessel. Most often the tip of the finger is used to push the clay which leaves a shallow indentation on the outside but no counter mark on the inside.

Quarry: The location where lithic raw material is obtained from the earth or a bedrock exposure.

Quaternary: The second period, which along with the Tertiary Period, make up the Cenozoic Era, encompassing the Pleistocene and Holocene epochs; roughly the last 2.0 or 1.65 million years.

Radiocarbon Dating: The process of determining the age of a sample based on the amount of radioactive carbon (carbon 14) retained in that object.

Raphides: Needle-shaped crystals in a plant cell, typically of calcium oxalate. These are small (30 to $500 \mu \mathrm{m})$ crystals, generally with points on the ends and of similar lengths. They are often found in plants of the Agavaceae family such as sotol, yucca, agave, and lechuguilla. They are not diagnostic of any particular plant. Bohrer (1987) and Kwiatkowski (1992) believe that only agave contain these crystals. In contrast, Dering (2003) believes raphides occur in a variety of Agavaceae including sotol, yucca, agave, and beargrass.

Rare Earth Elements (REE): Any one of a group of 17 elements that includes scandium (Sc), yttrium (Y), and those from atomic number 57 to 71 .

Reducing Atmosphere: A reducing environment in pottery analysis refers to firing completed vessels in the absence of oxygen.
Retouch: A technique of chipped stone artifact manufacture in which pressure flaking is used to detach small flakes to sharpen or otherwise modify the edge of a tool.

Rhyolite: A very fine-grained, extrusive igneous rock, same composition as granite. This is considered a nonlocal material.

Riparian Zone: The generally well-watered area along a stream course with trees, bushes, and grasses in contrast to the open prairies.

Root Etching: Thin, shallow lines, troughs, or pits that are etched into the surfaces of bones by acids associated with plant roots that grow against the bone after the bone is deposited in the ground.

Sand: Rock or mineral fragments from 0.05 to 2.0 millimeters in diameter. Most sand grains consist of quartz. As a soil/sediment textural class, a soil that is 85 percent or more sand and not more than 10 percent clay.

Salinity: This is the saltiness or dissolved salt content of a body of water. It is a general term used to describe the levels of different salts such as sodium chloride, magnesium and calcium sulfates, and bicarbonates. Salinity may also refer to the salt content of soil.

Saprobity: This refers to the presence of biodegradable organic matter and low oxygen concentrations.

Seasonality: The season of death of animals killed at a campsite. This is often determined by the presence of fetal or neonatal bones of bison and deer, linked to a specific birthing period or the age of the animal determined by tooth eruption and wear patters. The growth rings detected in the cross-section of fish otoliths provide clues as to the season of death as well.

Silt: A particle size that has a range from $0.06 \mathrm{~mm}$ to $0.002 \mathrm{~mm}$. These are smaller than sand grains and larger than clay particles. 
Siliceous: Pertaining to silica, as in silicon dioxide, the most common chemical constituent on earth, and the dominant component of chert and quartz.

Single Aliquot: Used in reference to OSL dating and is a fractional portion of a larger amount of material. This generally refers to a single grain analysis.

Site Structure: The spatial distribution of features, artifacts, and debris across a single occupation (or within a component) of an archeological site that is used to reconstruct manufacturing, maintenance, processing, production, and disposal activities at specific loci, and the spatial ways prehistoric groups organized their space at a site.

Sodium Hydroxide (NaOH): Also known as lye and caustic soda, sodium hydroxide forms a strong alkaline solution when dissolved in a solvent such as water. However, only the hydroxide ion is basic. It is used in many industries, mostly as a strong chemical base. Pure sodium hydroxide is white.

Soil Horizon: A layer of soil, approximately parallel to the surface, having distinct characteristics produced by soil-forming processes. In the identification of soil horizons an upper case letter (i.e., A, B, C, R, and O) represents the major horizon. Lower case letters that follow the upper case letters represent subdivisions of the major horizons.

Soluble Inorganic Residues: These are silica gel residues that build up with moisture availability on the utilized edges of stone tools, and that form discrete microplates as tool use progresses. Impervious to most acids and strong bases, they were are quite commonly found during use-wear analysis of stone tools and are valuable indicators of tool use due to their long term stability, and affects on the microgemometry of a tool edge that indicate kinds of motion during use. They exhibit flow characteristics of a viscous liquid and desiccation cracks as they harden.

Spindle Whorl: This is a small ceramic disc, often referred to as pottery disks, that has a hole drilled through it (Bell 1980:95). The function of this artifact has not been adequately studies and thus its true function is not established.
Stable Isotope: An isotope is not subjected to radioactive decay, it is stable. This contrasts with radioactive isotopes such as carbon (C13), oxygen $\mathrm{O} 18$, or nitrogen $(\mathrm{N} 15)$ isotopes that decay over time.

Starch: Starch is produced by all green plants for energy storage and is a major food source for humans. Pure starch is a white, tasteless and odorless powder that is insoluble in cold water or alcohol. tarch can be used as a thickening, stiffening or gluing agent when dissolved in warm water, giving, for example, wheat paste. In photosynthesis, plants use light energy to produce glucose from carbon dioxide. The glucose is stored mainly in the form of starch granules. Toward the end of the growing season, starch accumulates in twigs of trees near the buds. Fruit, seeds, rhizomes, and tubers store starch to prepare for the next growing season.

Stratigraphy: The study of layering in rocks and/or sediments, and how the layers correlate to each other.

Striae: These are tiny, thin, narrow grooves, channels, or lines, often called striations. Here, they were observed during high-powered use-wear analysis and are an indication of the direction of the movement of the tools during their use. They were observed under high magnification in the residues left on the tools.

Temper: This is the additives mixed with natural clays to form the paste/fabric used in the manufacturing of ceramic vessels. The temper can be a wide variety of materials, but most often includes at least one of the following; sand, crushed rock (i.e., granite, quartzite, sandstone), scoria, basalt, crushed shell (modern and fossil), crushed ceramic sherds (called grog), and crushed and burned bone. The temper helps to prevent cracking and provides strength. Mica maybe observed in many of the pastes, but the mica probably came from decomposed granite and gneiss and may be naturally present in many of the local formations such as the Trujillo Formation found throughout the Canadian River valley. Besides temper presence in sherds, it is often identified, and measured for size, and its shape recorded and percentage of the paste documented. 
Terrace: In geologic terms this is an old alluvial plain that is generally flat and borders a river, stream, lake, or sea.

Trace Elements: Chemical elements, such as zinc, manganese, and iron that typically occur in soils and other materials, when present in extremely small amounts.

Trophic State Index: This refers to the presence of inorganic nutrients such as nitrogen, phosphorus, silica and carbon or in organic forms. This is a measure of the ecological potential of the aquatic environment to sustain species at different levels in the food chain. Terms used to describe the trophic state; oligotrophic is nutrient poor, mesotrophic indicates moderate nutrient concentrations, eutrophic is nutrient rich, and eurytrophic is indifferent to nutrients.

Turbation: Disturbance to the natural matrix deposits generally caused by biological agents (burrowing rodents, insects, worms, and plant roots) and natural (soil creep, desiccation crack displacement, frost heaving, landslides, etc.) processes.

Type: This is a group of similar items (ceramic sherds or projectile points) all of which are more or less the same.

Ultraviolet Light: The wave length of light above that usually detected by the human eye that fluoresces various kinds of minerals and emits distinctive colors. Here, a multiband light source (UV light 254/366 nm Model UVGI-58) was used to investigate the visual fluorescence of culturally modified stones to help in identifying their source.

$\mu \mathrm{m}$ : This is the short-hand for a micron that is one millionth of a meter, or equivalently one thousandth of a millimeter. It can be written in scientific notation as $1 \times 10-6 \mathrm{~m}$, meaning $1 / 1000000 \mathrm{~m}$.

Unconformity: Stratigraphic term for a boundary or break created by a depositional hiatus. This boundary separates younger strata from older strata. An unconformity is usually caused by erosion and therefore deposits are missing.
Use-wear: The high-powered microscopic evidence on a stone tool that was created from sustained use. The wear may appear as striations, tiny nicks, abrasive particles, polish, rounding, soluble inorganic residues, etc. The accompanying use-wear study used magnification between 100x and 500x to observe wear and edge-modification on selected artifacts. This detailed analysis contributes to our understanding of the function of the tools and potentially the substances that tool were used on.

Uvalde Gravel: A gravel deposit throughout much of south and east Texas attributed to the late Miocene to early Pleistocene. The deposits are composed of pebbles, cobbles, and boulders of vein quartz, quartzite, chert, jasper, silicified wood, and limestone. The ultimate source of the lithology indicates the Llano Uplift, likely the Ogallala Formation (see Byrd 1971 for more details).

Valle Grande Rhyolite: Obsidian from the Jemez Mountains in north-central New Mexico. Along with Cerro Toledo Rhyolite, it is grouped within the Tewa Group due to similar magmatic origins. It is similar in appearance to the Cerro Toledo Rhyolite in that it is more vitreous and not granular. This material resulted from the most recent eruption in the caldera and does not erode out of the caldera (Shackley 2005).

Variance-covariance Matrix: This is the matrix of covariances between all pairs of measured variables in a study.

Varieties: These are subdivisions of types and often used in discussing ceramic assemblages.

Vector: This is a quantity that has both direction and magnitude and used in INAA analysis.

Voids: These are gaps, holes, pores, or spaces observed in pottery matrix when viewed under a microscope during petrographic analysis. They are often used as an indirect measure of vessel porosity.

Wares: Wares are groups of types which share a majority of basic characteristics including fabric of the pottery itself, the general vessel form, the surface finish, and rim form (Lehmer 1954:41) 
Wildrye (Elymus sp.): A common grass throughout the Plains of the United States, from Mexico to Canada and is all across Texas. The seeds of this genus are large and it possesses a large starch grain as well. This is a cool season $\mathrm{C}_{3}$ grass that produces short cell phytoliths.

Xeric Condition: A dry or relatively arid condition often in reference to climatic conditions.
X-Ray Diffraction: This is a technique used to identify crystalline solids on the basis of the constructive and deconstructive interference of $\mathrm{X}$-rays scattered by the parallel planes of atoms within a crystal. 
This page intentionally left blank. 